\title{
Latein als Medium sprachlichen Handelns in Ciceros Briefen an Terentia
}

Erweiterte Sprechaktanalyse mit Interpretation

\author{
Dissertation \\ zur Erlangung des philosophischen Doktorgrades \\ an der
}

Philosophischen Fakultät der Georg-August-Universität Göttingen

vorgelegt von

Silke Nickel

aus Bremerhaven 

Meinen Eltern

Alfred Martin und Eva-Johanna Nickel 



\section{Danksagung}

Mein großer Dank gilt zuallererst Herrn Prof. Dr. Peter Kuhlmann, der mir nicht nur die Chance, mein Forschungsprojekt überhaupt in Angriff nehmen zu können, gegeben, sondern dieses auch wohlwollend und konstruktiv begleitet hat. Zu ihm gefunden habe ich im Übrigen (auf Umwegen) durch den 2018 leider verstorbenen Herrn Dr. Rolf Heine, der mir schon während meines Erststudiums mit Rat und Tat zur Seite gestanden hat.

Dank gebührt außerdem meinem Zweitgutachter, Herrn Prof. Dr. Michael Job, von dem ich ebenfalls einige hilfreiche Tipps erhalten habe. Dies trifft auch auf Herrn Prof. Dr. Dieter Cherubim zu, der mir darüber hinaus Kontakt zu Frau Prof. Dr. Nina Janich und damit Zugang verschafft hat zu einigen (zu der Zeit) noch nicht veröffentlichten Aufsätzen aus dem „Handbuch Text und Gespräch“. Des Weiteren möchte ich mich bei Herrn Priv.-Doz. Dr. Christian Zgoll für seine Bereitschaft bedanken, den Prüfungsvorsitz bei der Disputation zu übernehmen.

Nicht zuletzt danke ich meiner Familie und meinen Freunden für ihre große Geduld, besonders in den letzten sehr arbeitsintensiven Monaten - v. a. meinem Bruder Arndt Nickel und meiner Schwester Birte Nickel. Hervorzuheben ist zudem der Einsatz von Frau Elisabeth Patak und Herrn Laurence Finston, die mich bei der englischen Übersetzung des Abstracts zu dieser Arbeit beraten haben, sowie von Frau Ilka Schmidt, die mir - zusammen mit Herrn Christian Löhr - bei der Vorbereitung der Disputation mit ihren unerwarteten technischen Herausforderungen geholfen und mir auch sonst gelegentlich ihr Ohr geliehen hat. Ein spezieller Dank geht zudem an Frau Sybille Jodar und Herrn Heinz Riemann für ihre praktische Unterstützung bei meinen Aufenthalten in Göttingen.

Welchen Beitrag Herr Uwe Ladwig zu dieser Dissertation geleistet hat, wird er selbst am besten wissen. Ich bin auf jeden Fall glücklich, dass sie trotz aller Widrigkeiten erfolgreich zum Abschluss gebracht werden konnte.

Göttingen im November 2020

Silke Nickel 



\section{Kurze Inhaltsübersicht}

ABBILDUNGSVERZEICHNIS .....................................................................................................

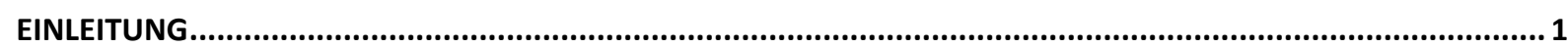

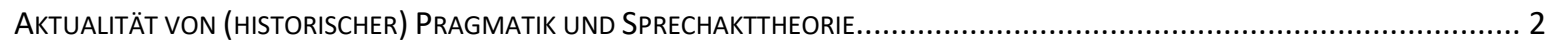

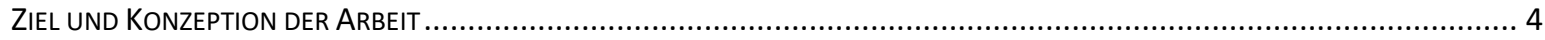

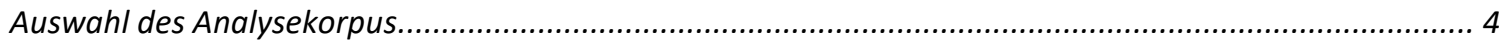

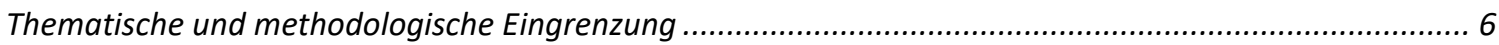

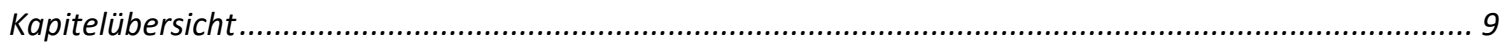

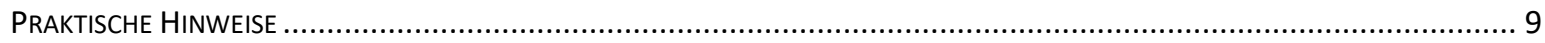

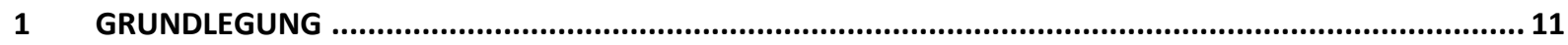

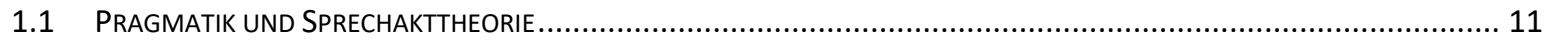

1.1.1 Grundzüge der Sprechakttheorie und Textpragmatik ...................................................... 11

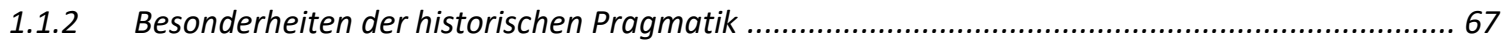

1.1.3 Pragmatik in der Lateinischen Philologie: Forschungsüberblick............................................... 77

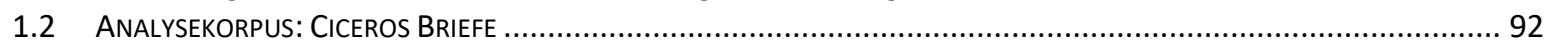

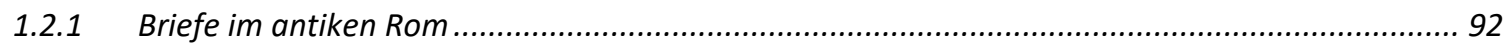

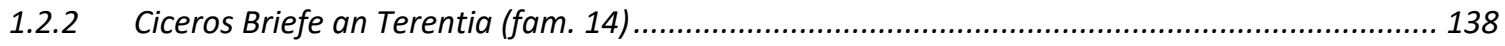

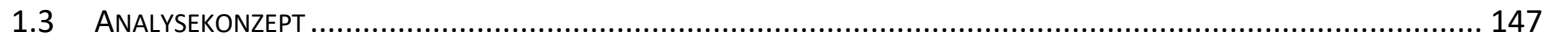

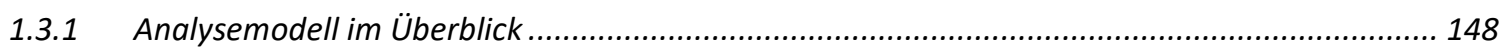

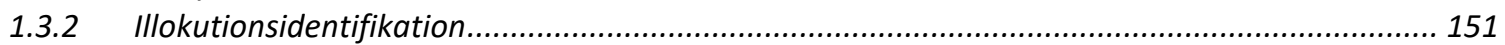

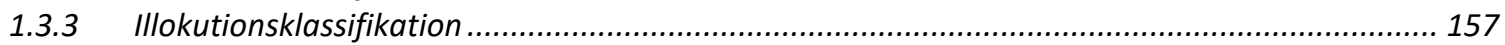

1.3.4 Sequenzierung und Hierarchisierung der Handlungsfunktionen ........................................... 169

1.3.5 Bestimmung der Textfunktion ........................................................................................ 174

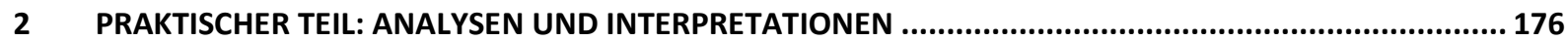

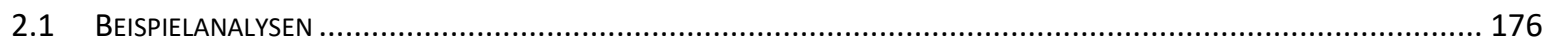

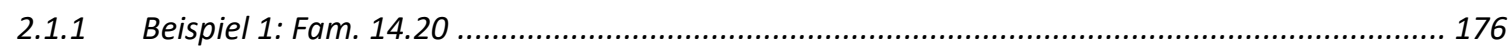

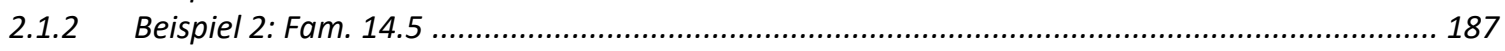

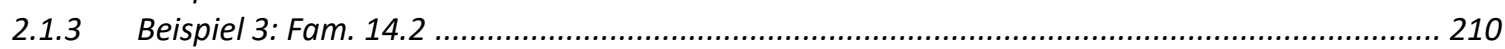

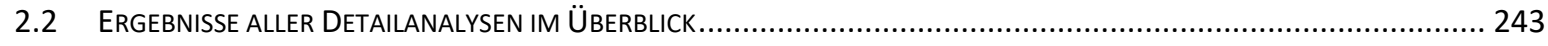

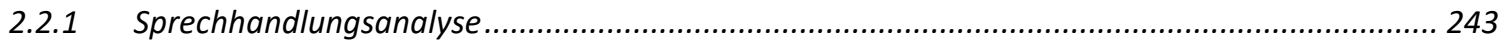

2.2.2 Beziehungs- und Identitätskonstitution: Das Verhältnis zwischen Cicero und Terentia .............. 396

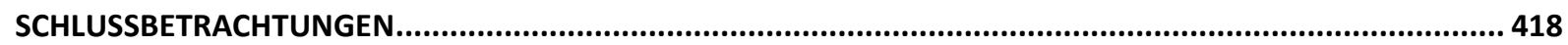

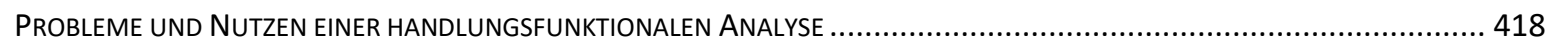

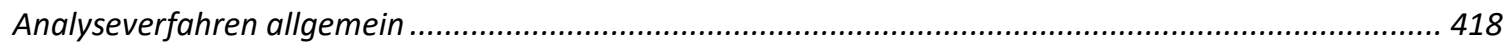

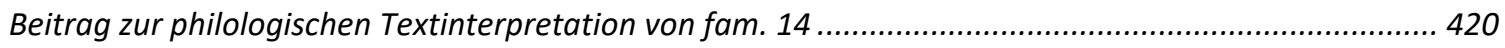

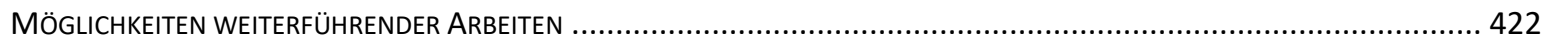

ANHANG 1 - ÜBERBLICK ÜBER DIE EINZELILLOKUTIONEN ALLER BRIEFE IN FAM. 14...............................426

ANHANG 2 - DEFINITIONEN DER SPRECHAKTUNTERMUSTER (GEM. MÜNSTERANER SCHULE) .....................441

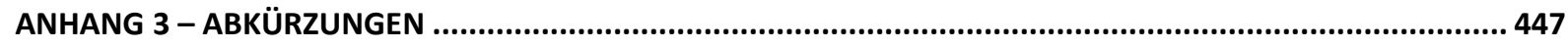

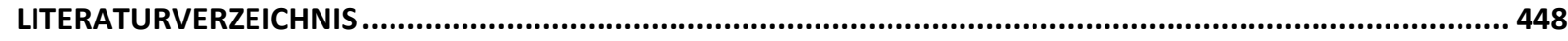




\title{
Ausführliches Inhaltsverzeichnis
}

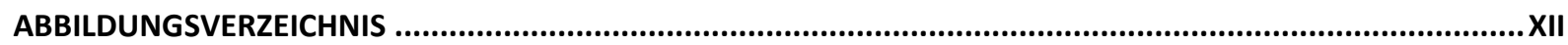

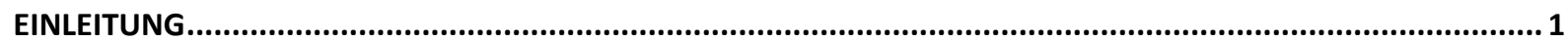

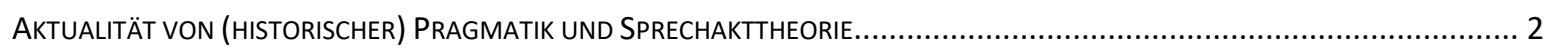

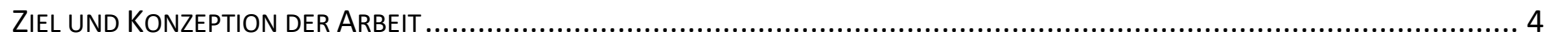

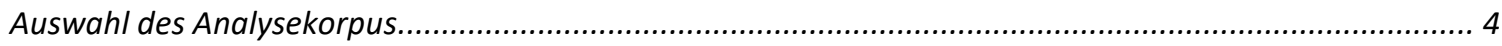

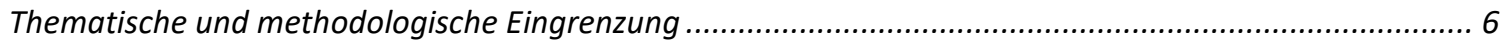

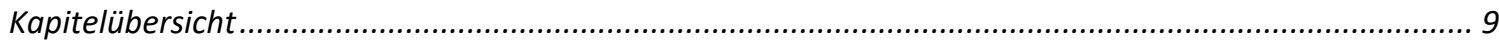

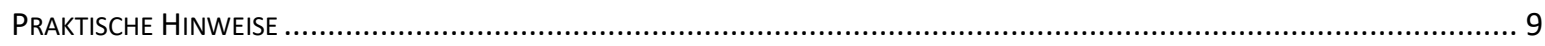

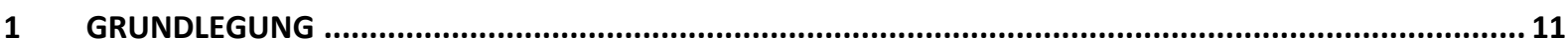

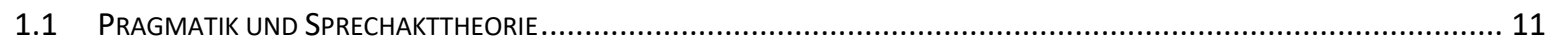

1.1.1 Grundzüge der Sprechakttheorie und Textpragmatik ................................................... 11

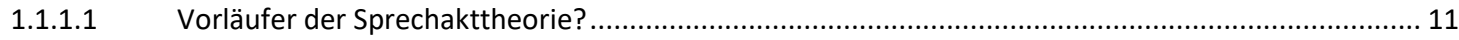

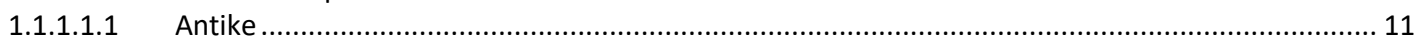

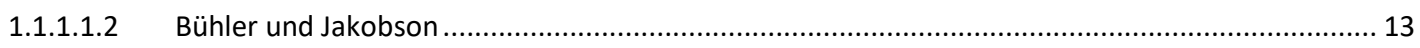

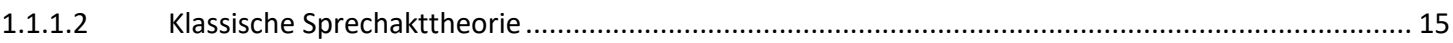

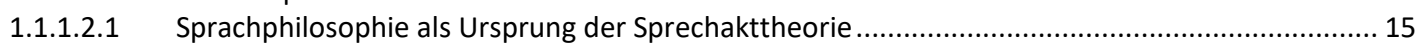

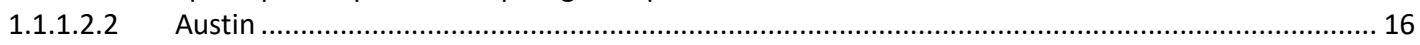

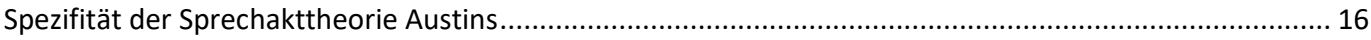

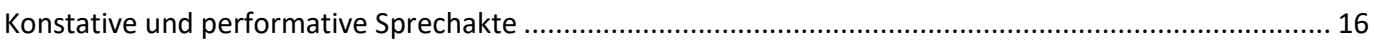

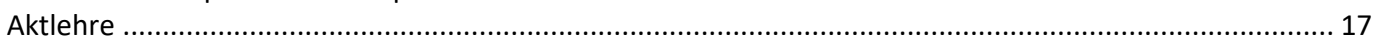

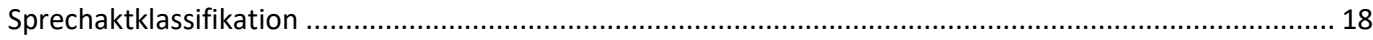

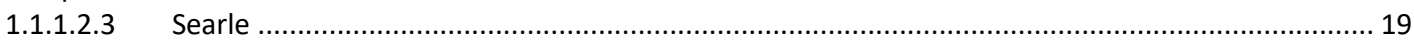

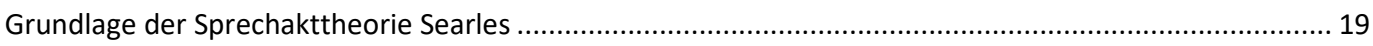

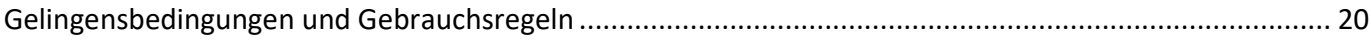

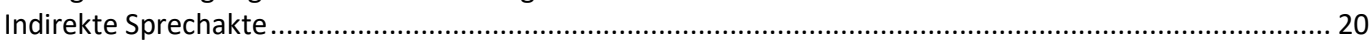

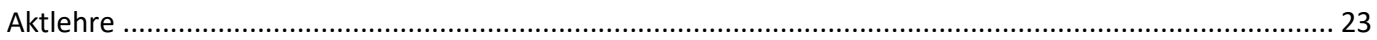

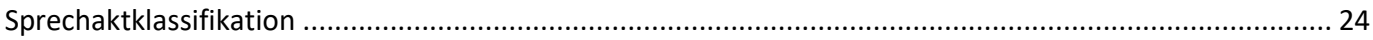

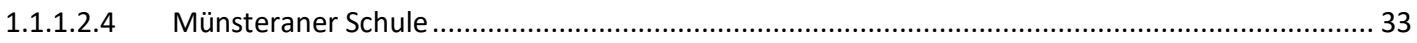

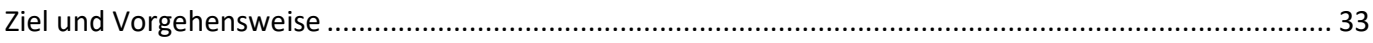

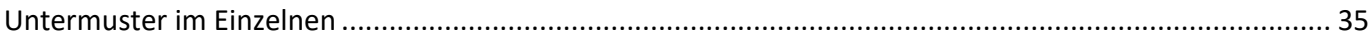

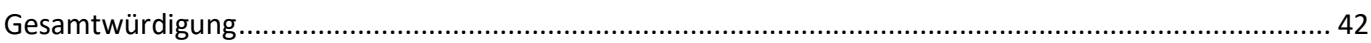

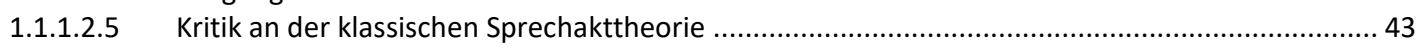

1.1.1.3 Textlinguistische Weiterentwicklung der Sprechakttheorie ......................................................... 44

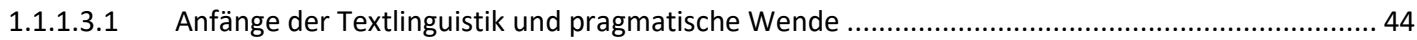

1.1.1.3.2 Grundlagen textpragmatischer Analyseansätze ....................................................................... 44

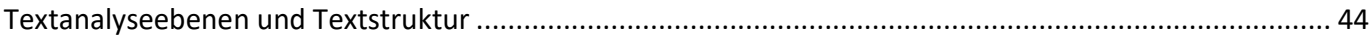

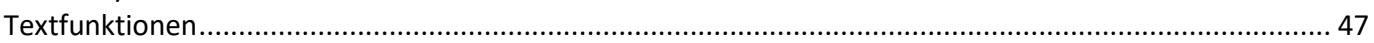

Die pragmatische Struktur von Texten: Hierarchisierung von textuellen Handlungseinheiten ..................... 52

Textaufbau und -gliederung: Identifizierung von textuellen (Handlungs-)Einheiten ...................................5 58

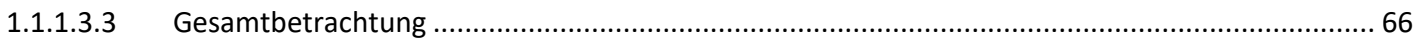

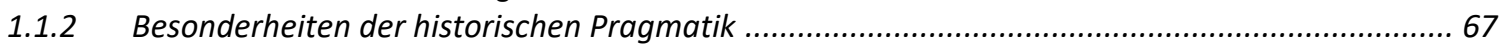

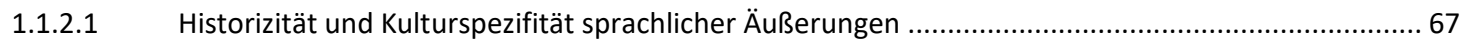

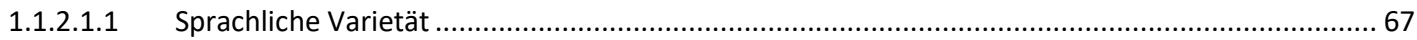

1.1.2.1.2 Beispiele für den Einfluss historischer und kultureller Faktoren...............................................6 68

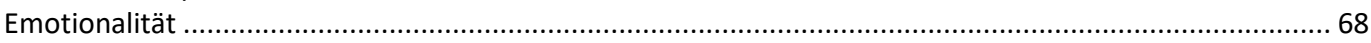

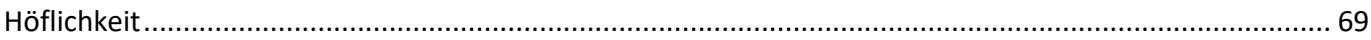

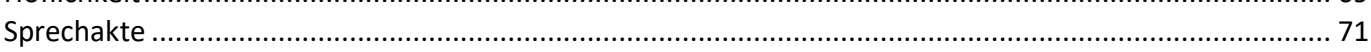

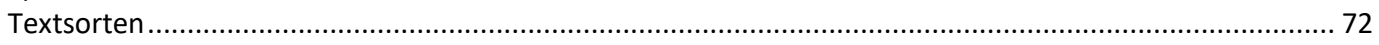

1.1.2.2 Historische Pragmatik als eigener Forschungszweig ............................................................ 73

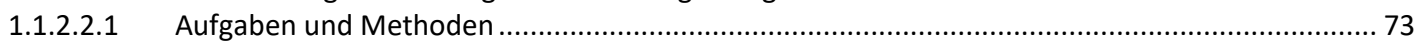

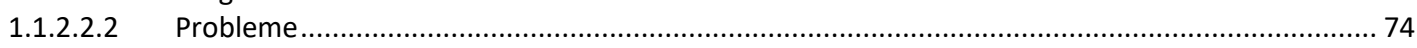

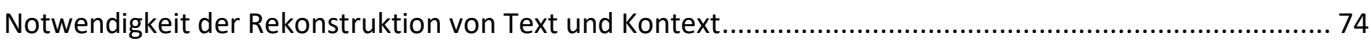

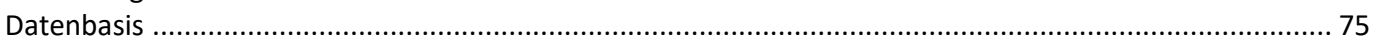

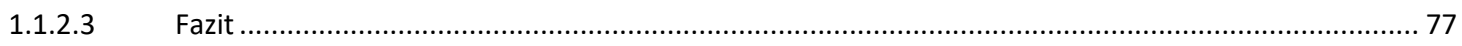

1.1.3 Pragmatik in der Lateinischen Philologie: Forschungsüberblick .......................................... 77

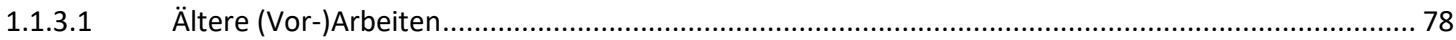

1.1.3.2 Fachdidaktik: Schullektüre und Schul- bzw. Studiengrammatiken ............................................... 79

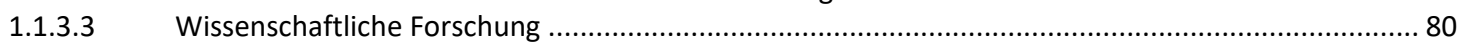




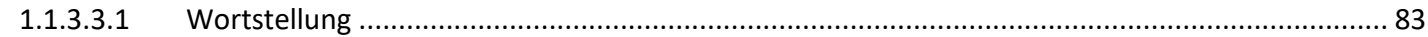

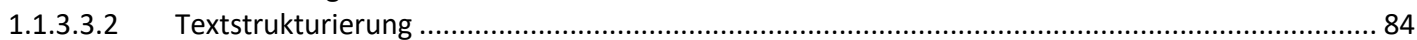

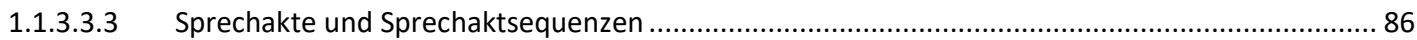

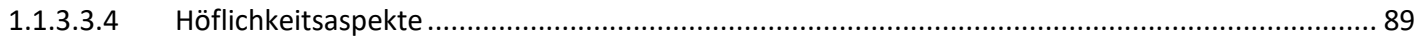

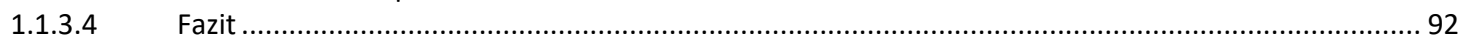

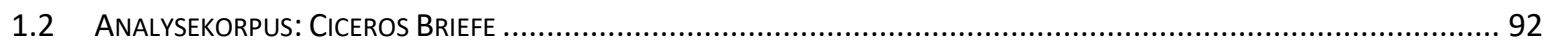

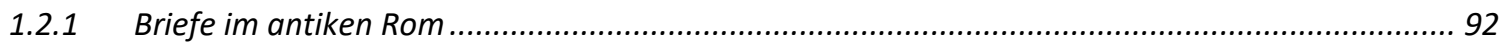

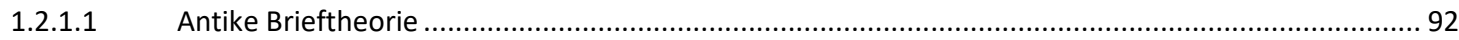

1.2.1.1.1 Überblick über die antiken Quellen zur Brieftheorie ........................................................... 93

1.2.1.1.2 Bedeutung der antiken Brieftheorie ................................................................................ 94

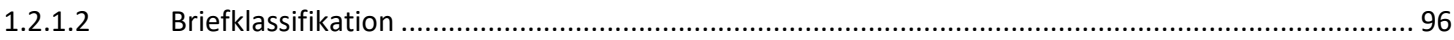

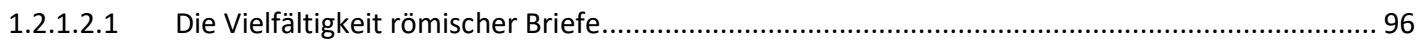

1.2.1.2.2 Möglichkeiten der (wissenschaftlichen) Klassifikation von Briefsorten und Brieftypen ............... 97

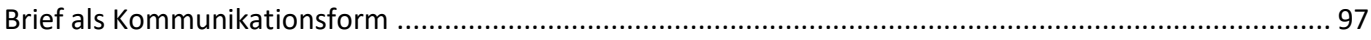

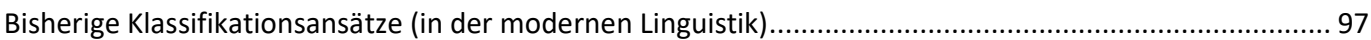

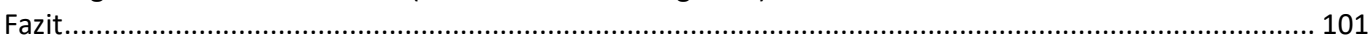

1.2.1.2.3 Briefarten in der (römischen) Antike............................................................................ 101

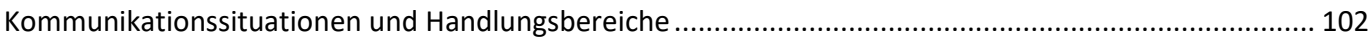

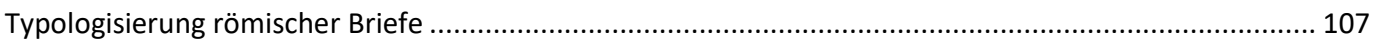

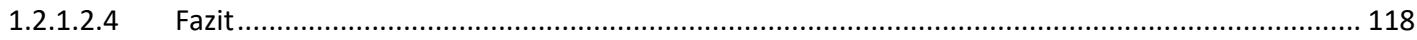

1.2.1.3 Wesensbestimmung des römischen (Privat-)Briefes.............................................................. 120

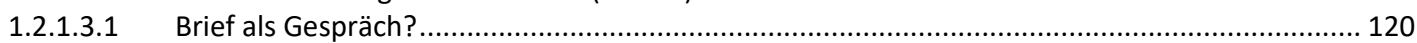

1.2.1.3.2 Klarheit: Explizierung, Präzisierung und Strukturierung ........................................................ 123

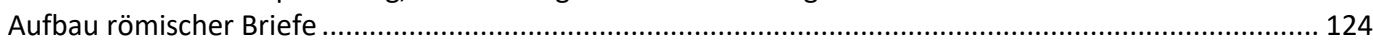

1.2.1.3.3 Partnerbezug: Angemessenheit, Allokution und Interaktion ................................................. 130

1.2.1.3.4 Konventionalität und Formelhaftigkeit vs. Unkonventionalität und Zwanglosigkeit .................. 132

Kennzeichen der lateinischen Umgangssprache bzw. des Briefstils (Ciceros) allgemein .......................... 134

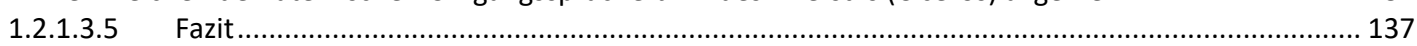

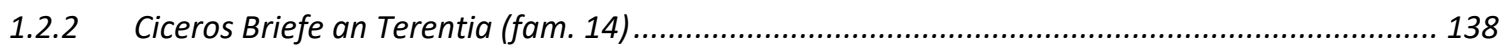

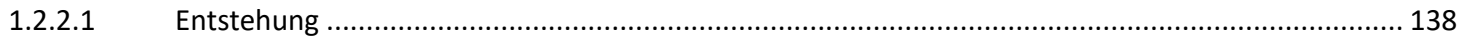

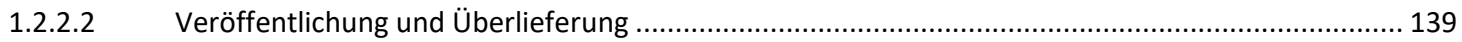

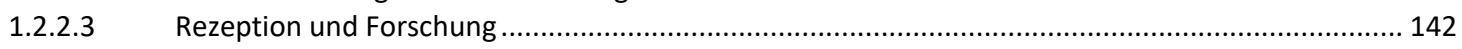

1.2.2.3.1 Ciceros Briefe im Urteil der Nachwelt: Vorbild oder negatives Beispiel?................................... 142

1.2.2.3.2 Forschungsschwerpunkte der Moderne .......................................................................... 143

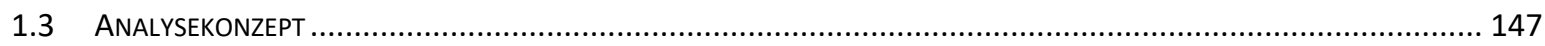

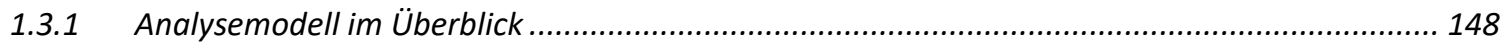

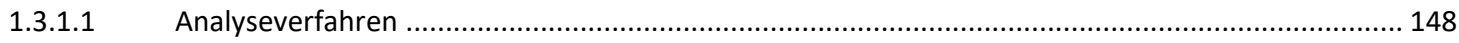

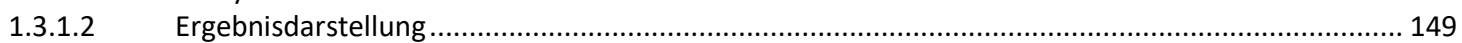

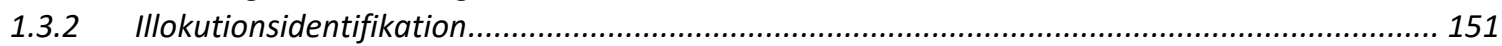

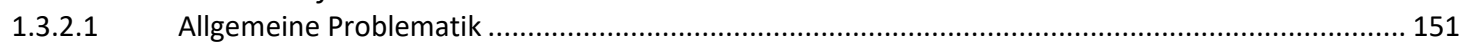

1.3.2.2 Propositionsanalyse als Verfahren zur strukturellen Abgrenzung von Illokutionen ......................... 152

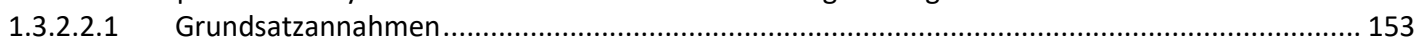

1.3.2.2.2 Hilfsmittel zur Lösung von Problemfällen ........................................................................ 154

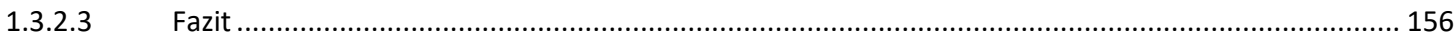

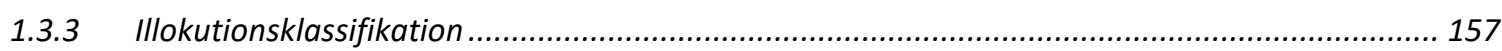

1.3.3.1 Sprechaktoberklassen und -untermuster im Überblick .......................................................... 157

1.3.3.2 Vorgehensweise bei der Zuordnung von Illokutionen zu Sprechaktoberklassen und

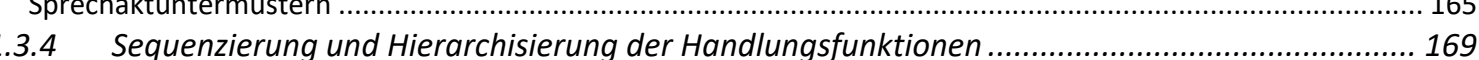

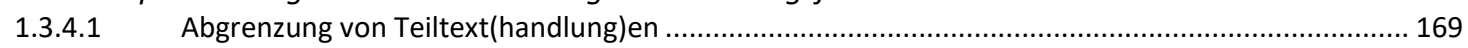

1.3.4.2 Funktionale Beziehungen zwischen den verschiedenen Handlungsebenen .................................. 170

1.3.4.2.1 Grundsätzliches zur Analyse der pragmatischen Briefstruktur .............................................. 170

1.3.4.2.2 Bestimmung der Handlungsfunktionen auf den untergeordneten Ebenen ............................... 171

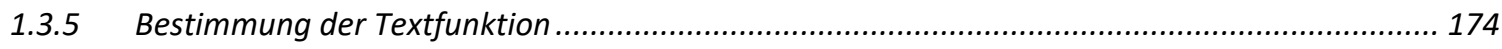

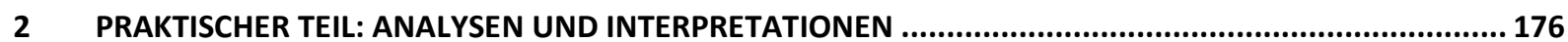

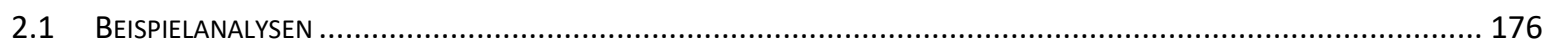

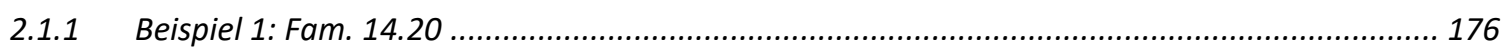

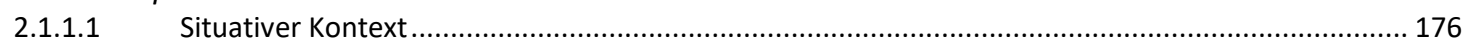

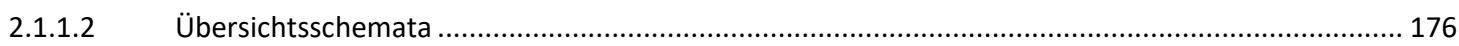

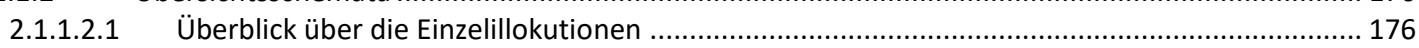

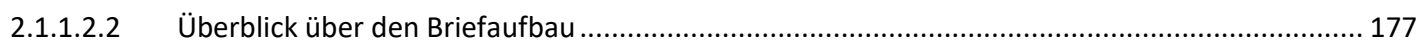




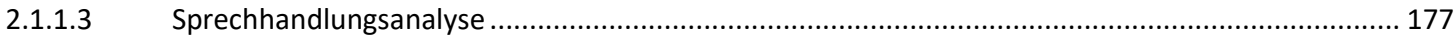

2.1.1.3.1 Einzelhandlungen: Illokutionsidentifikation und -klassifikation .............................................. 177

2.1.1.3.2 Teiltexthandlungen: Sequenzierung und Hierarchisierung .................................................... 183

2.1.1.3.3 Gesamttexthandlung: Bestimmung der Textfunktion ........................................................... 184

2.1.1.4 Beziehungs- und Identitätskonstitution: Das Verhältnis zwischen Cicero und Terentia ................... 185

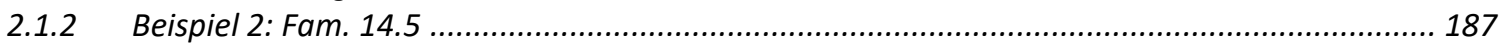

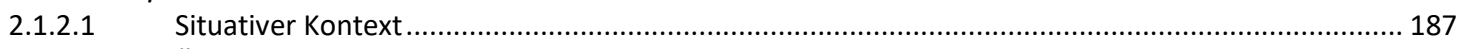

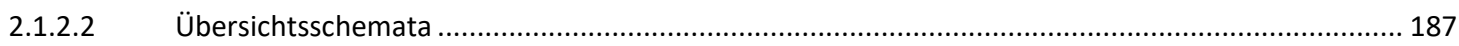

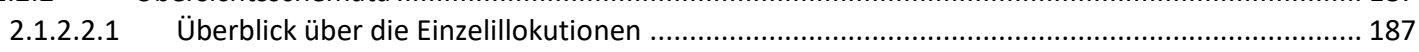

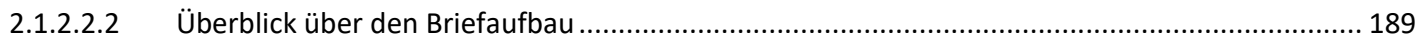

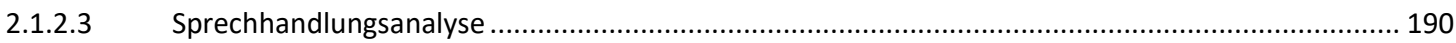

2.1.2.3.1 Einzelhandlungen: Illokutionsidentifikation und -klassifikation ............................................. 190

2.1.2.3.2 Teiltexthandlungen: Sequenzierung und Hierarchisierung ................................................... 200

2.1.2.3.3 Gesamttexthandlung: Bestimmung der Textfunktion ........................................................... 205

2.1.2.4 Beziehungs- und Identitätskonstitution: Das Verhältnis zwischen Cicero und Terentia ................... 207

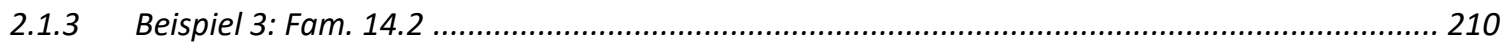

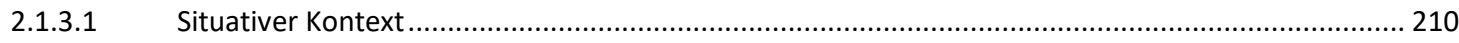

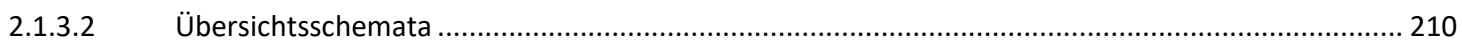

2.1.3.2.1 Überblick über die Einzelillokutionen ............................................................................. 210

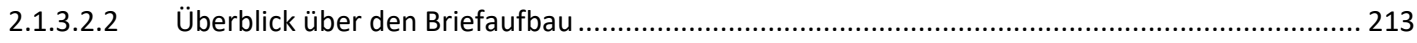

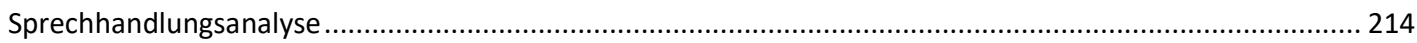

2.1.3.2.3 Einzelhandlungen: Illokutionsidentifikation und -klassifikation............................................ 214

2.1.3.2.4 Teiltexthandlungen: Sequenzierung und Hierarchisierung .................................................... 229

2.1.3.2.5 Gesamttexthandlung: Bestimmung der Textfunktion ............................................................... 237

2.1.3.3 Beziehungs- und Identitätskonstitution: Das Verhältnis zwischen Cicero und Terentia .................. 239

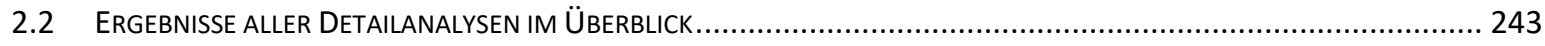

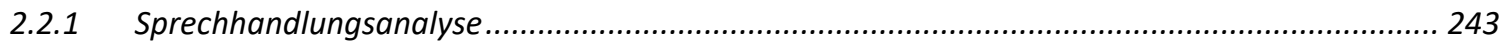

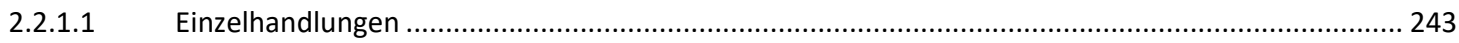

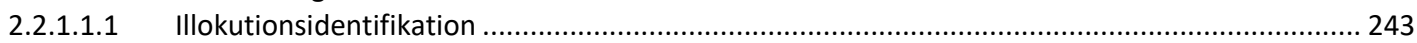

Unabhängigkeit des Illokutionsstatus von der grammatischen Einheit ,Satz' .......................................... 243

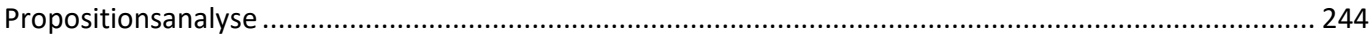

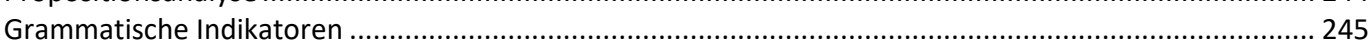

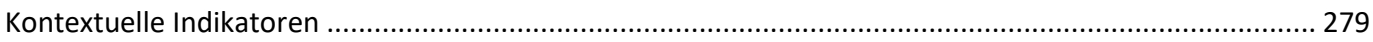

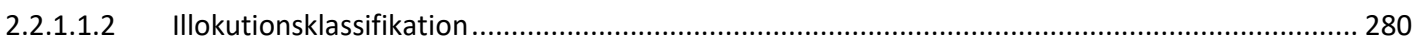

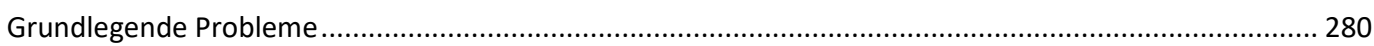

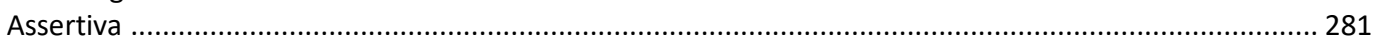

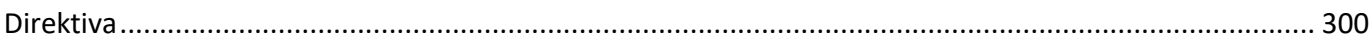

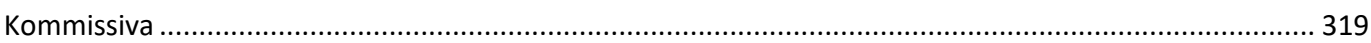

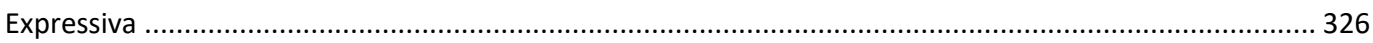

2.2.1.2 Teiltexthandlungen: Sequenzierung und Hierarchisierung ........................................................... 378

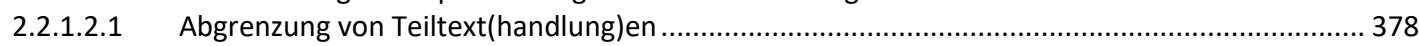

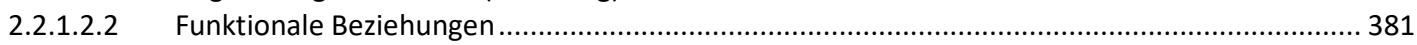

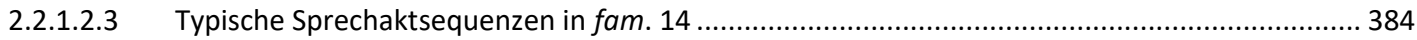

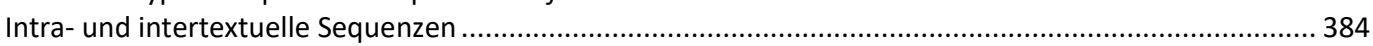

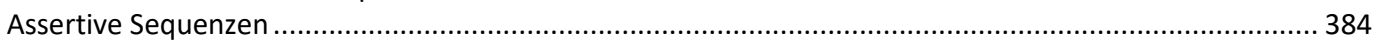

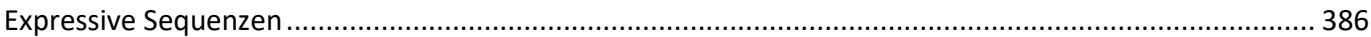

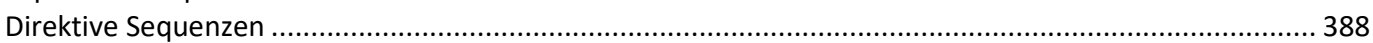

2.2.1.3 Gesamttexthandlungen: Bestimmung der Textfunktionen ........................................................ 389

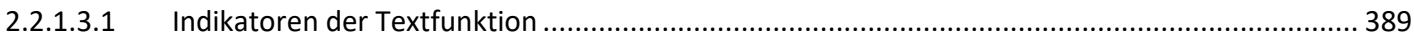

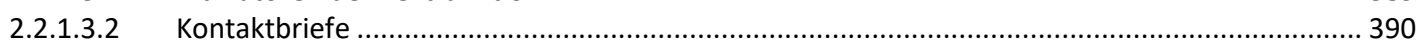

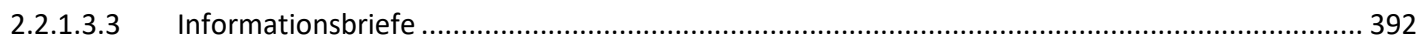

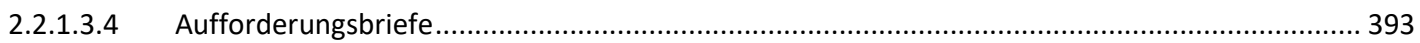

2.2.2 Beziehungs- und Identitätskonstitution: Das Verhältnis zwischen Cicero und Terentia .............. 396

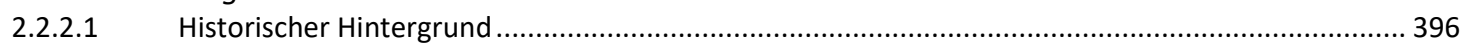

2.2.2.2 Die Briefe Ciceros an Terentia als Spiegel ihrer Ehe ................................................................ 399

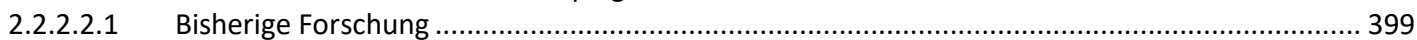

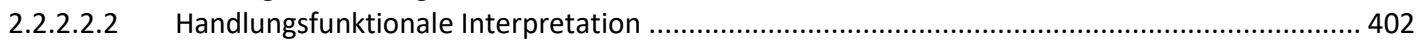

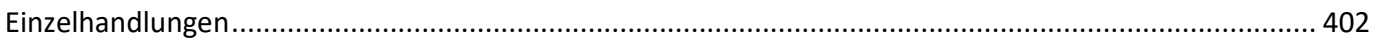

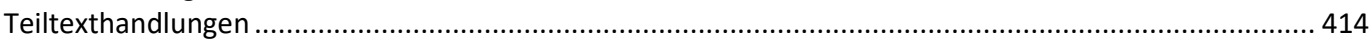

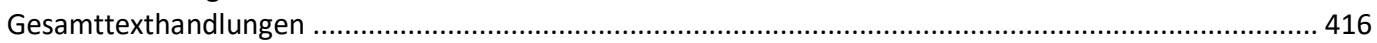

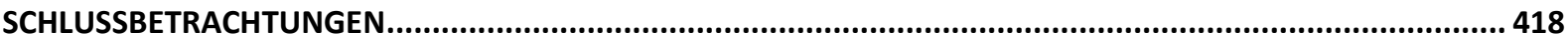

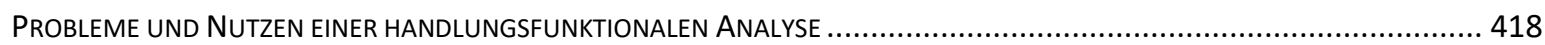


Analyseverfahren allgemein

Beitrag zur philologischen Textinterpretation von fam. 14 ............................................................. 420

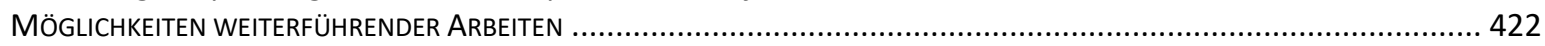

ANHANG 1 - ÜBERBLICK ÜBER DIE EINZELILLOKUTIONEN ALLER BRIEFE IN FAM. 14...............................426

ANHANG 2 - DEFINITIONEN DER SPRECHAKTUNTERMUSTER (GEM. MÜNSTERANER SCHULE) .................... 441

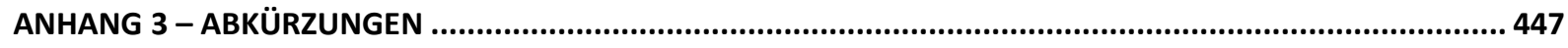

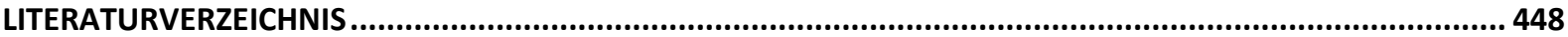




\section{Abbildungsverzeichnis}

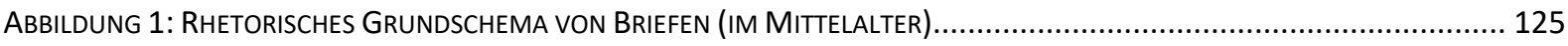

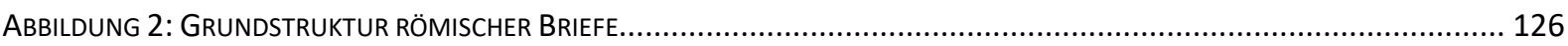

ABBILDUNG 3: VoRGEHENSWEISE BEI DER (HANDLUNGSSEMANTISCHEN) BRIEFANALYSE ............................................... 149

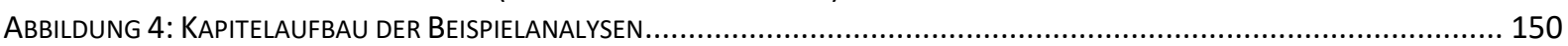

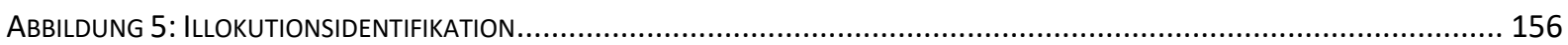

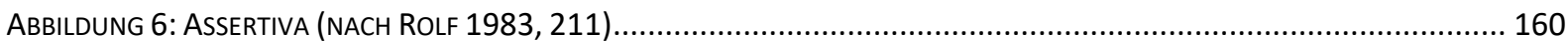

ABbildung 7: DiREKTIVA - AufFORDERUngShANDLUNGEN (NACH HINDELANG 1978, 131 BZW. EBD., 141 UND HINDELANG 2010,

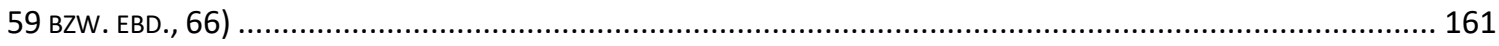

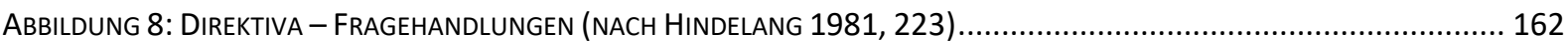

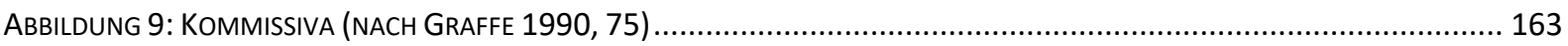

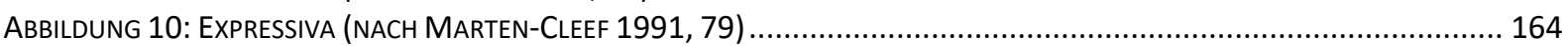

ABBILDUNG 11: ILLOKUTIONSKLASSIFIKATION: METHODOLOGISCHER ZIRKEL (NACH STAFFELDT 2014, 112)........................... 168

AbBildung 12: SCHACHTELSTRUKTUR deR HANDLUNGSEBENEN IN RÖMISCHEN BRIEFEN (IN ANLEHNUNG AN SCHRÖDER 2003, 36)

169

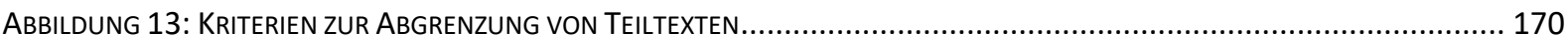

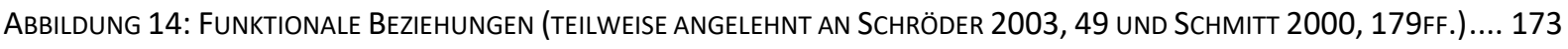

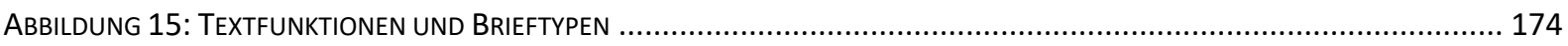

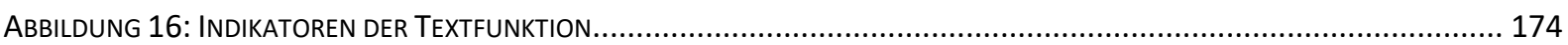

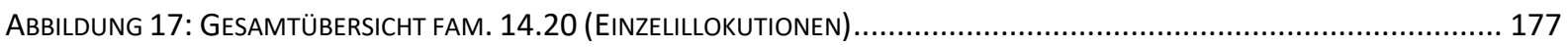

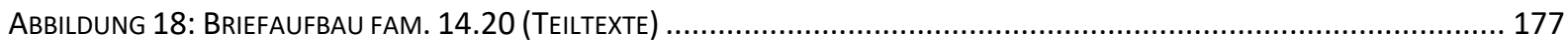

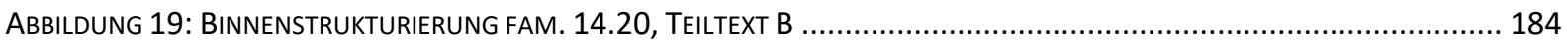

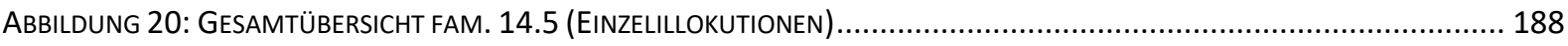

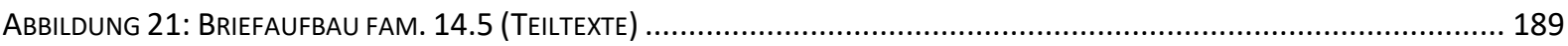

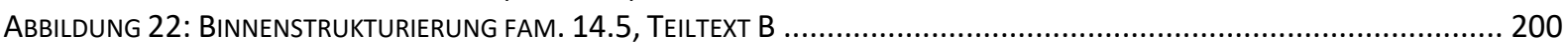

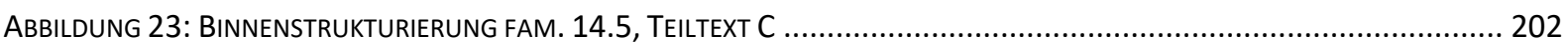

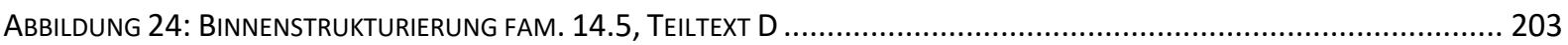

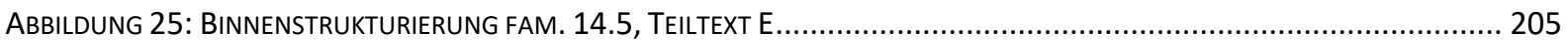

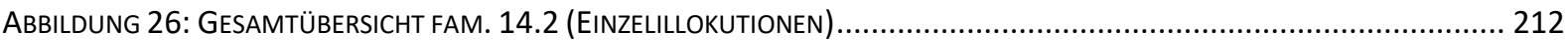

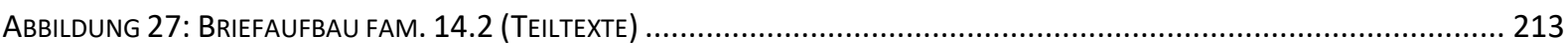

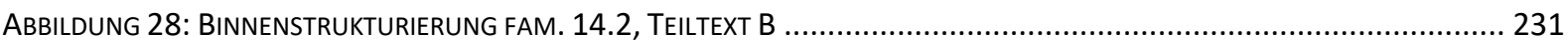

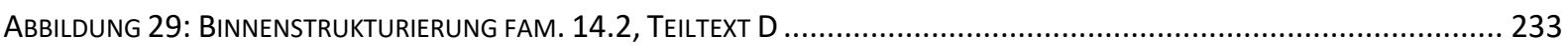

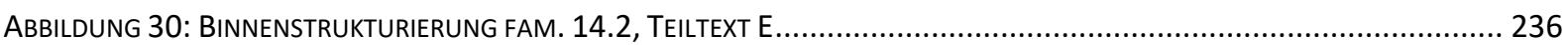

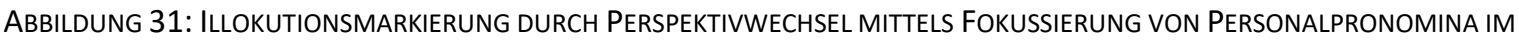

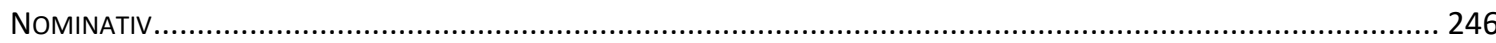

AbBILDUNG 32 ILLOKUTIONSMARKIERUNG DURCH PERSPEKTIVWECHSEL MITTELS FOKUSSIERUNG VON PERSONALPRONOMINA IM

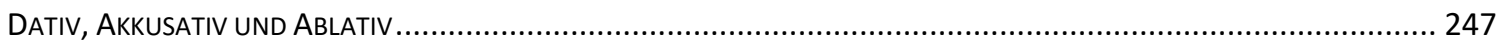

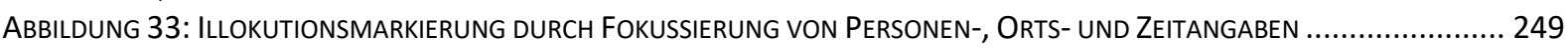

ABbildUNG 34: ILLOKUTIONSMARKIERUNG DURCH FoKUSSIERUNG BESTIMMTER GEGENSTÄNDE UND SACHVERHALTE ................ 251

ABBILDUNG 35: ILLOKUTIONSMARKIERUNG DURCH FOKUSSIERUNG UNBESTIMMTER SACHVERHALTE ....................................... 253

ABBILDUNG 36: ILLOKUTIONSMARKIERUNG DURCH KURZE THEMENANGABEN MIT DE + ABLATIV ..........................................253

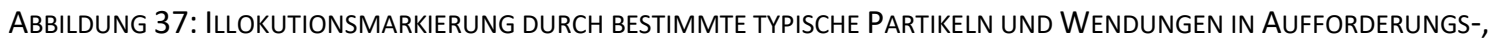

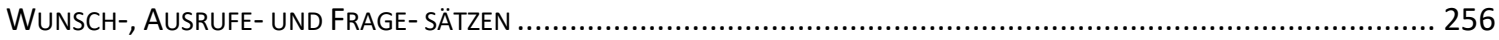

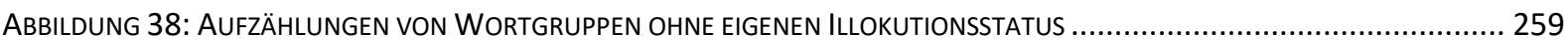

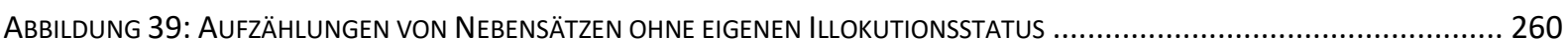

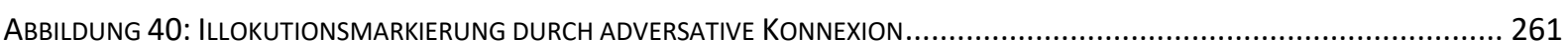

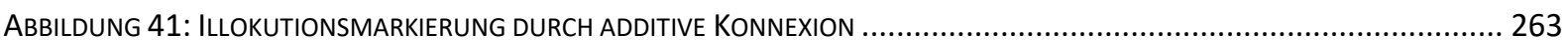

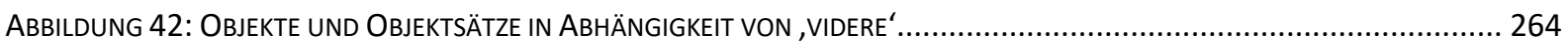

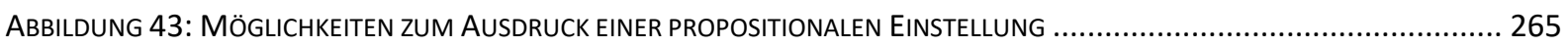

ABbILDUNG 44: KAUSALE BeStIMMUNGEN UND KAUSALSÄTZE MIT EIGENEM UND OHNE EIGENEN ILLOKUTIONSSTATUS .............. 270

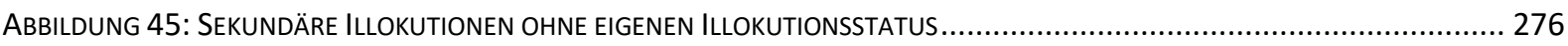

ABbILDUNG 46: BEZUgNAHME AUf VORANGEHENDE ÄUßERUNGEN (VON BRIEFADRESSAT ODER -AUTOR) ................................277

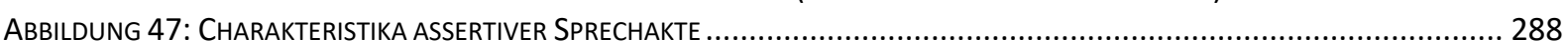

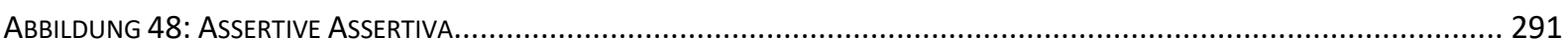

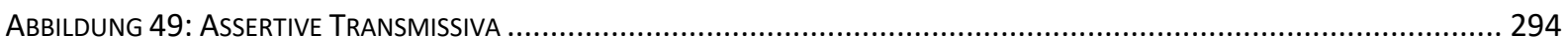

ABbILdUNG 50: ASSERTIVE TRANSMISSIVA: ORTS- UND DATUMSANGABEN IN DEN POSTSKRIPTA .......................................... 296 


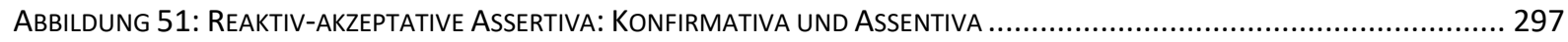

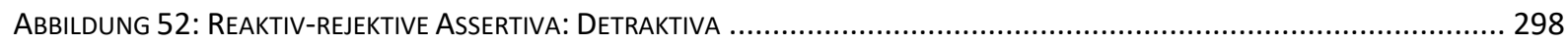

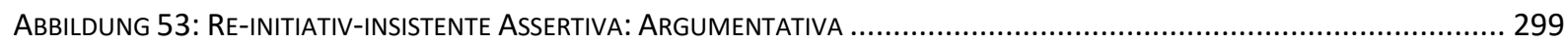

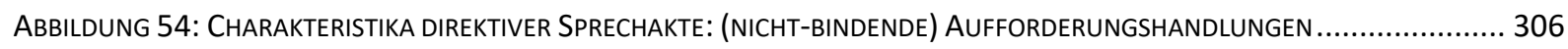

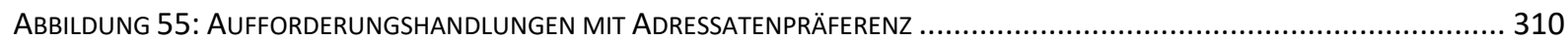

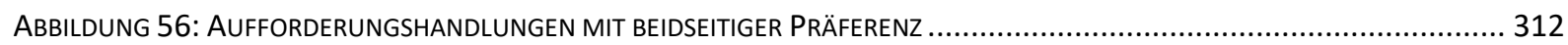

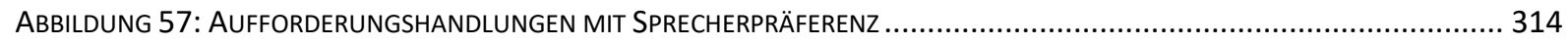

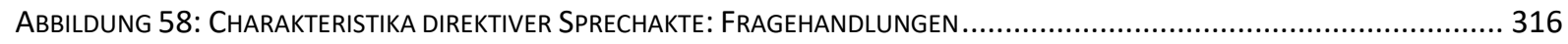

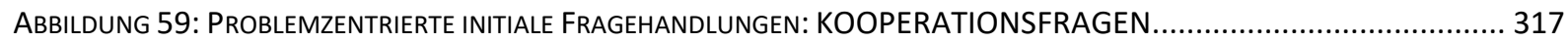

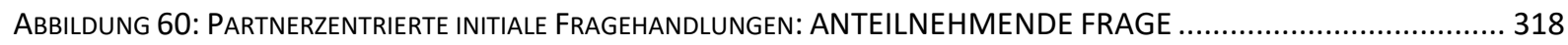

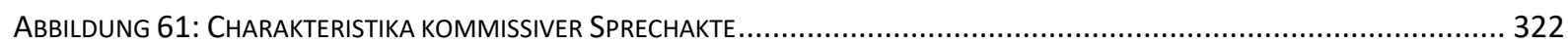

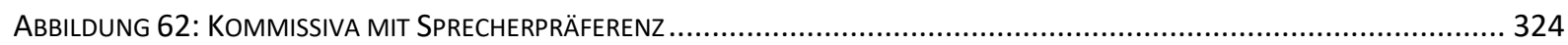

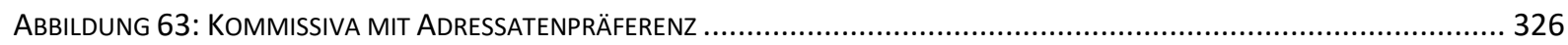

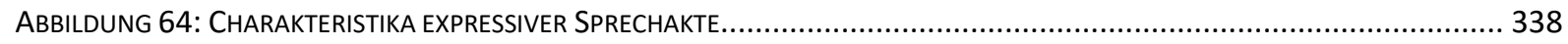

ABBILDUNG 65: EXPRESSIVE UNTERMUSTER UND EMOTIONSDIFFERENZIERUNG ........................................................ 341

ABBILDUNG 66: BEGRÜßUNGSFORMELN (DEKLARATIVES BRIEF ERÖFFNEN VS. EXPRESSIVES GUNST ERWEISEN) ................ 347

ABBILDUNG 67: VERABSCHIEDUNGSFORMELN (DEKLARATIVES BRIEF BEENDEN VS. EXPRESSIVES WOHLERGEHEN WÜNSCHEN)

348

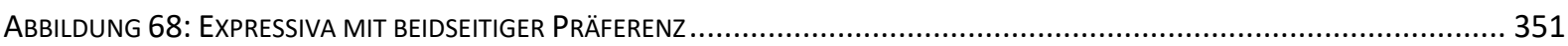

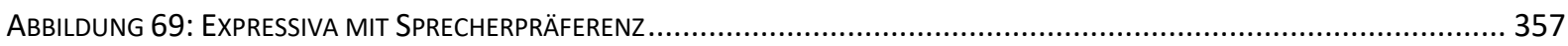

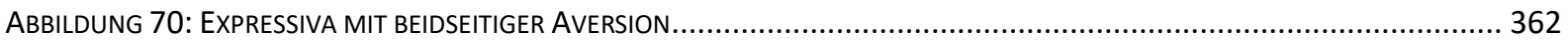

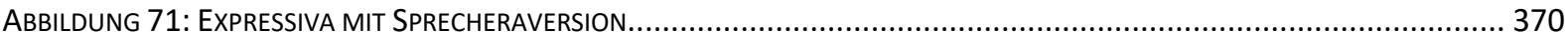

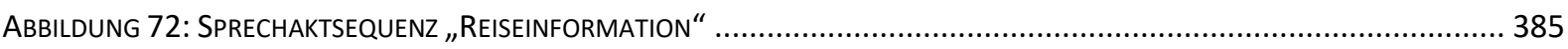

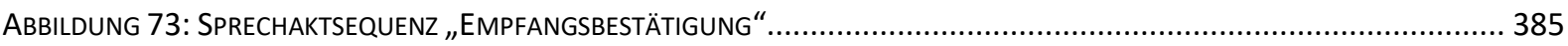

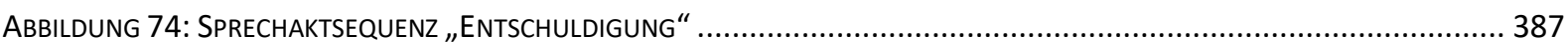

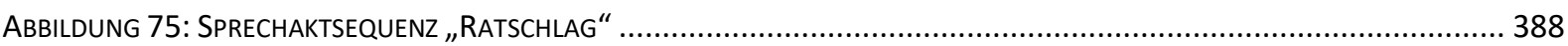

ABBILDUNG 76: DISTRIBUTION DER EINZELILLOKUTIONEN IN FAM. 14 IM HINBLICK AUF DIE FÜNF SPRECHAKTOBERKLASSEN .......... 389

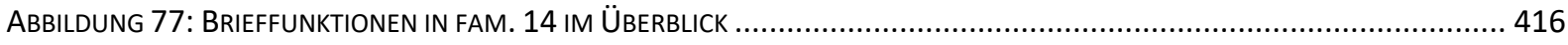

ABBILDUNG 78: ÜBERBLICK ÜBER DIE EINZELILLOKUTIONEN ALLER BRIEFE IN FAM. 14 ................................................. 440 



\section{Einleitung}

Etsi eius modi tempora nostra sunt ut nihil habeam quod aut a te litterarum exspectem aut ipse ad te scribam, tamen nescio quo modo et ipse vestras litteras exspecto et scribo ad vos cum habeo qui ferat.

(CIC. fam. 14.16)

Etwas umständlich zwar, aber sehr eindrücklich formuliert Cicero hier seinen Wunsch an Terentia nach einem gegenseitigen Austausch von Briefen, ohne dass es dazu einen konkreten Anlass gäbe. Warum scheint er dennoch das Verlangen zu haben, von ihr zu lesen und ihr zu schreiben? An dieser Stelle bleibt er sehr vage (nescio quo modo); betrachtet man jedoch eine entsprechende Äußerung Ciceros gegenüber Atticus in Att. 14.12.3, wird ein möglicher Grund deutlicher. Dort gesteht er seinem Freund nämlich, dass er ihm nur schreibe, um ihm einen Antwortbrief „zu entlocken”: Quam dudum nihil habeo quod ad te scribam! scribo tamen, non ut delectem meis litteris sed ut eliciam tuas. Es geht also v. a. darum, über eine räumliche Distanz hinweg mit einem anderen Menschen in enger Verbindung zu bleiben. Die Briefe kommen ähnlich wie ein persönliches Gespräch dem menschlichen Bedürfnis nach Kommunikation und Nähe entgegen. In Att. 12.1.2 spricht er in diesem Zusammenhang von der „Freude am Gespräch an sich" (collocutione ipsa suavitas). Lt. fam. 2.4 ermöglichen Briefe einen vertraulichen Gedankenaustausch, und zwar nicht nur in Form des scherzhaften Plauderns (genus familiare et iocosum), sondern auch - wie im Fall der eingangs zitierten Stelle aus einem Brief Ciceros an seine Frau - in Bezug auf ernstere Themen (genus severum et grave). ${ }^{1}$

Die Aussagen Ciceros erinnern an das, was in der modernen Sprechakttheorie bzw. ihrer Weiterentwicklung im Rahmen der Gesprächs- und Textlinguistik als, expressive Funktion' oder ,Kontaktfunktion' bezeichnet wird. Die von Cicero in fam. 2.4 außerdem genannte ursprüngliche ,Nachrichtenfunktion' von Briefen (certiorem facere) entspricht in gewisser Weise der ,assertiven Funktion' bzw. ,Informationsfunktion'. Wenn er wie in Att. 1.17 Briefen die Aufgabe zuspricht, Rat und Zuspruch (consilium) zu geben, erkennt man Anklänge an die ,direktive Funktion' bzw. ,Aufforderungsfunktion'.2 Die Römer waren sich also ganz offensichtlich der Handlungsfunktion sprachlicher Äußerungen bewusst. Mehr noch als auf Briefe trifft dies natürlich auf die Rede zu, über deren Wirkungsweise in der antiken Rhetorik ausführlich reflektiert wurde. Obschon man sich hüten sollte, Konzepte der Moderne unbedacht auf die Antike

\footnotetext{
${ }^{1}$ Vgl. SCHRÖDER 2004 - 2005, 209.

${ }^{2}$ Vgl. ebd., $206 f$.
} 
zu übertragen - dies gilt für theoretische Parallelisierungen ebenso wie für die praktische Anwendung linguistischer Methoden $-^{3}$, liegt es folglich doch nahe, auch altsprachliche Texte unter dem Blickwinkel der Handlungssemantik zu analysieren. ${ }^{4}$

\section{AKTUALITÄT VON (HISTORISCHER) PRAGMATIK UND SPRECHAKTTHEORIE}

Die (klassische) Sprechakttheorie gilt einigen zwar als überwunden und ist weitgehend „aus der Mode gekommen “5; ein Rückgriff auf ihre Theorien und Methoden erscheint nichtsdestotrotz überaus lohnend und vielversprechend. Während ihrer Hochphase wurden sehr umfangreiche Forschungen auf diesem Feld betrieben, sodass auf den ersten Blick alle Themen erschöpfend behandelt worden zu sein scheinen. ${ }^{6}$ Seither hat sie sich jedoch in vielfältiger Weise weiterentwickelt. ${ }^{7}$ So werden z. B. auch die Phasen vor und nach der eigentlichen Äußerung eines Sprechaktes (Planungs- bzw. Rezeptionsphase) analysiert. Neben Gesprächen werden schriftsprachliche Äußerungen berücksichtigt. Literarische bzw. fiktionale Sprechakte werden in den Blick genommen. In kontrastiven und historischen Studien wird u. a. untersucht, wieweit Sprechakte als universell oder sprach- und kulturspezifisch aufzufassen sind. V. a. aber wird der Gegenstandsbereich über die Satzebene hinaus erweitert. Schon recht früh wurde nämlich erkannt, dass es notwendig ist, diese Grenze zu überschreiten - hin zu größeren Einheiten wie Sprechaktsequenzen und ganzen Texten. ${ }^{8}$ In welchem Zusammenhang die untergeordneten Einheiten mit den übergeordneten stehen, inwieweit sie sich gegenseitig beeinflussen, ob man von Sprechakthierarchien sprechen kann usw., wurde und wird dabei z. T. äußerst kontrovers diskutiert.

Mit der Erweiterung der Sprechakttheorie sind also neue Probleme entstanden. Dabei sind nicht einmal alle grundlegenden Fragen im Rahmen der ursprünglichen Sprechakttheorie geklärt worden. ${ }^{9}$ Dies ist nun aber kein Grund, die Sprechakttheorie ganz aufzugeben, sondern im Gegenteil: Hier besteht dringender Handlungs- bzw. Forschungsbedarf. Auch eine weitere Beschäftigung mit der Analyse einzelner Sprechakte hat dabei durchaus noch seine Berechtigung und ist als notwendige Grundlagenarbeit zu betrachten, die die Basis für weitergehende

\footnotetext{
${ }^{3}$ Vgl. z. B. den Hinweis von Ax 2006b, 214 „auf eine grundsätzliche Gefahr [...], die jeder kennt, der schon von einer modernen zu einer antiken Theorie gegangen ist: die Gefahr der Hineininterpretation ex eventu, die nicht selten dazu führt, etwa Aristoteles als strukturalistischen Linguisten oder die Stoiker als generative Grammatiker oder Valenzsyntaktiker zu verstehen. Daß hier größte Vorsicht geboten ist, versteht sich von selbst." Zu einer möglichen definitorischen Unterscheidung der in dieser Arbeit weitgehend synonym gebrauchten Begriffe ,Sprachwissenschaft' und (moderne) ,Linguistik' vgl. z. B. HoffMANn 2018, 3.

${ }^{4}$ Vgl. z. B. RICOTTILLI 2010, 374: „In generale, l'applicazione della pragmatica della comunicazione ai testi classici appare realizzabile perché alcuni aspetti dell'impostazione pragmatica sono già presenti nelle teorizzazioni degli antichi relative alla retorica o alla critica letteraria." Vgl. a. ebd., 375; RIcotTILLI 2009, 147 und ebd., 158 sowie BICKMANN 1998, 45.

${ }^{5}$ Vgl. z. B. LEVINSON 2017, 200 und KISSINE 2012, 169.

${ }^{6}$ Vgl. ebd., 169.

${ }^{7}$ Vgl. z. B. die Übersicht bei RoLf 2006, $2531 \mathrm{ff}$.

${ }^{8}$ Vgl. z. B. SCHLIEBEN-LANGE 1979, 110, die auch auf die gegenseitige Beeinflussung von Pragmatik und Textlinguistik hinweist (s. N. 272). Ergänzt sei noch, dass Texte selbst wiederum in größeren, intertextuellen Zusammenhängen stehen, Teil sogenannter Diskurse sind. Diese sind Gegenstand der Diskurslinguistik, welche die Textlinguistik zwar nicht abgelöst hat, aber mittlerweile „als ein übergeordnetes methodisches Instrumentarium“ (SCHIEWE $2009,101)$ einen großen Einfluss gewonnen hat. Zur Weiterentwicklung bzw. Beziehung zwischen Text- und Diskurslinguistik vgI. z. B. NIEHR 2014, 29ff. Zum Verhältnis von Pragmatik und Diskurslinguistik vgI. z. B. REISIGL 2018. ${ }^{9}$ Vgl. z. B. LEVINSON 2011, $282 \mathrm{f}$.
} 
Forschungen schafft. ${ }^{10}$ Um mit Levinson zu sprechen: „[...] speech acts are a fundamentally important area of study in the language sciences. Work in this domain has been relatively, and inexplicably, neglected since the 1970s and 1980s, and it is time for a renaissance of work on speech acts [...]. “11

Gerade im Bereich der historischen Pragmatik eröffnen sich dabei spannende Perspektiven; und die bereits vorliegenden Studien zu altsprachlichen Texten zeigen, dass moderne Textzugänge, die über das Althergebrachte hinausgehen, die traditionellen Ansätze in vielfältiger Weise bereichern können. Diese werden damit nicht überflüssig, sondern vielmehr um zusätzliche Facetten erweitert und vertieft. Umgekehrt profitieren auch die (historische) Pragmatik und die Sprachwissenschaft insgesamt von den neu gewonnenen Einsichten. ${ }^{12}$

Gleichwohl finden sich solche Arbeiten in der Klassischen Philologie bislang recht selten. Zumindest im deutschsprachigen Raum lässt sich generell eine gewisse Zurückhaltung gegenüber den Erkenntnissen und Methoden der modernen Sprachwissenschaft feststellen. ${ }^{13}$ Von einem „gestörten Verhältnis der Klassischen Philologie zur Linguistik“"14 zu sprechen, erscheint mittlerweile übertrieben; es lässt sich jedoch kaum abstreiten, dass die moderne Sprachwissenschaft in der Altphilologie im Vergleich zu den neusprachlichen Philologien immer noch ein Schattendasein führt, was sich z. B. auch in der universitären Ausbildung bemerkbar macht. ${ }^{15}$

\footnotetext{
${ }^{10}$ Vgl. z. B. WAGNER 1997, 77.

11 LEVINSON 2017, 216.

12 Vgl. z. B. DenizOT UND SPEVAK 2017b, 10: „Pragmatics proves to be a useful instrument that provides a better understanding of linguistic phenomena in Latin and Ancient Greek. Thanks to pragmatics we have gained new insights into old matters as well as a number of new topics that deserve attention. Conversely, Latin and Ancient Greek as languages with quite a complex structure offer phenomena that are of interest to general linguistics." und RICOTTILLI 2009, 148: „Va precisato che la pragmatica della comunicazione non si sostituisce, ma si integra con le fondamentali metodologie utilizzate per l'analisi dei testi antichi (storico-letteraria, filologica, grammaticale-linguistica, ecc.) [...]." Vgl. a. ebd., 158 und RIcotrılıı 2010, 375 sowie (mit Bezug auf die Höflichkeitsforschung, teilw. unter Einschluss der Sprechakttheorie) UNCETA GóMEZ 2018, 11 und ebd., 26.

${ }^{13}$ Vgl. BeYer UND Cherubim 1973, 252, deren Einschätzung m. E. bis zu einem gewissen Punkt auch heute noch Geltung beanspruchen kann. Die beiden verweisen im Übrigen darauf, dass dies einmal anders war: „Ein Blick ins 19. Jahrhundert zeigt, daß die Klassische Philologie nicht immer eine solche isolationistische Haltung bewies. Die grammatische Forschung dieser Wissenschaft wurde nicht nur lange Zeit als Muster sprachwissenschaftlicher Forschung überhaupt angesehen, sondern sie war gegenüber wissenschaftlichen Ansätzen, die von anderen Fächern ausgingen, bemerkenswert aufgeschlossen. So fanden z. B. die historisch-vergleichende Sprachwissenschaft J. Grimms und die logisch fundierte Grammatik, wie sie von den Schulmännern des Frankfurtischen Gelehrtenvereins vertreten wurde, nicht nur Berücksichtigung, sondern auch Eingang in die griechischen und lateinischen Grammatiken der Zeit [...].“ (ebd., 252). Vgl. a. LATACZ 1974, 67. Einen (nicht auf den deutschsprachigen Raum beschränkten) Überblick über das Verhältnis zwischen Linguistik und Philologie von den Alexandrinern im alten Griechenland bis zum 21. Jahrhundert findet man bspw. bei SUÁREZ MARTínEZ 2012, 3ff.

${ }^{14}$ BEYER UND CHERUBIM 1973, 268. VgI. LATACZ 1974, 68, der - selbst ein großer Skeptiker hinsichtlich der modernen Linguistik und Literaturtheorie - von „Attacken gegen die angebliche sprachwissenschaftliche Agonie der Klassischen Philologie" spricht.

${ }^{15}$ Vgl. z. B. Stefan Kipf in seinen Vorbemerkungen („Zum Geleit“) zu TOURATIER 2013, 15: „Während Studierende der Germanistik, Romanistik oder Anglistik intensiv mit moderner Sprachwissenschaft bekannt gemacht werden, geschieht dies in den universitären Curricula der Klassischen Philologie in der Regel nicht." Vgl. a. BURKARD UND SChauer 2012, XVII; LATACZ 1974, 67 und BeYer Und Cherubim 1973, 251. Hoffmann 2018, 9f. sieht die Autonomie der lateinischen Linguistik von zwei Seiten gefährdet: durch eine Reduzierung auf die Diachronie und durch eine Übermacht der Literaturwissenschaft.
} 
Eine zunehmende Annäherung der beiden Disziplinen lässt sich immerhin erkennen ${ }^{16}$, gestaltet sich aber eher als langer, zäher Prozess. In den Niederlanden, im anglophonen und romanischen Sprachraum hat sich hingegen in den letzten Jahren die historische Pragmatik zunehmend als anerkannter und fruchtbringender Wissenschaftszweig innerhalb der Klassischen Philologie etabliert. Das Hauptaugenmerk gilt dabei der Funktionsweise von Partikeln, den Einflussfaktoren auf die Wortstellung und Höflichkeitsaspekten. ${ }^{17}$ Letztere betreffen insbesondere auch die Ausgestaltung bestimmter Sprechakte wie BITTEN, ABLEHNEN, SICH ENTSCHULDIGEN, DANKEN oder GRATULIEREN. ${ }^{18}$

\section{ZiEL und KONZEPTION DER ARBEIT}

Diese Arbeit knüpft an die genannten Studien an, verfolgt aber in verschiedener Hinsicht ein anderes Ziel. Sie beschränkt sich nicht auf einzelne Sprechakte oder Sprechaktklassen, sondern ein eng umgrenztes Textkorpus soll umfassend und systematisch in seiner Gesamtheit analysiert und bezüglich der Beziehung zwischen Schreiber und Adressat interpretiert werden. Höflichkeitsaspekte werden zwar berücksichtigt, stehen aber nicht im Zentrum.

\section{Auswahl des Analysekorpus}

Die Grundlage bilden Ciceros Briefe an seine Frau Terentia (fam. 14). Diese sind bereits intensiv erforscht worden, jedoch vornehmlich auf traditionelle Weise philologisch-textkritisch und -kommentierend. In jüngster Zeit sind allerdings mehrere Arbeiten erschienen, die auch kommunikativ-pragmatische Aspekte berücksichtigen. Eine detaillierte handlungssemantische Einzelanalyse in der hier intendierten Form gibt es aber noch nicht.

Briefe und insbesondere auch Ciceros Briefe bieten sich deshalb ganz besonders für einen pragmatischen bzw. sprechakttheoretischen Textzugang an, weil man in ihnen - aufgrund ihres (bis zu einem gewissen Grad) interaktionalen Charakters - sehr verschiedene Sprechakte vorfinden kann. ${ }^{19}$ Als besonderer Vorteil kann zudem gesehen werden, dass Sprechakte in Briefen im Vergleich zu einem persönlichen Gespräch wegen der fehlenden unmittelbaren Situationalität expliziter ausgedrückt werden müssen. ${ }^{20}$ Dass schriftsprachliche Äußerungen nicht Gegenstand der traditionellen Sprechakttheorie waren, sollte angesichts der bereits beschriebenen Weiterentwicklung kein Problem darstellen. ${ }^{21}$

\footnotetext{
${ }^{16}$ Vgl. z. B. LANDFESTER UND KUHN 2006, 2, die behaupten, dass die altsprachliche Sprachwissenschaft „sich nach anfänglicher Abkapselung vom modernen sprachwissenschaftlichen Diskurs [...] den modernen Theorien und Methoden der Sprachwissenschaften geöffnet" habe.

${ }^{17}$ Vgl. z. B. DenIZOT UND SPEVAK 2017b, 2.

${ }^{18}$ Entsprechend den üblichen Konventionen werden sprechhandlungsbezeichnende Ausdrücke (SB-Ausdrücke) in ihrer Funktion als Bezeichnungen für einzelne illokutionäre Typen (Sprechhandlungsmuster) durch Versalien gekennzeichnet.

${ }^{19}$ Vgl. z. B. KeRBRAT-ORECCHIONI 1998, 33 und GARCEA 2005, 113ff. Zur allgemeinen Eignung von (Privat-)Briefen als Untersuchungsgegenstand für historische Pragmatikstudien vgl. außerdem JUCKER 2018, 134 und (mit Bezug auf englische Briefe) PALANDER-COLLIN 2010.

${ }^{20}$ RisSELADA 1993, 15f. Vgl. a. CORREA 2010, 191f. und DiCKEY 2016, 205.

${ }^{21} \mathrm{Vgl}$. z. B. JACOBS UND JUCKER 1995, 10. Etwas kritischer: WAGNER 1997, 80, der eine Analyse schriftsprachlicher Texte am Ende aber mit gewissen Einschränkungen für durchaus praktikabel und erfolgversprechend hält. JUCKER 2018, 134 merkt an, in der Schriftlichkeit der Daten werde nach anfänglichen Bedenken mittlerweile überhaupt kein Problem mehr gesehen: „Die frühen Jahre der historischen Pragmatik waren [...] noch sehr stark durch Diskussionen zur Legitimität der schriftlichen Daten geprägt. Lange galten schriftliche Daten mit einer besonderen
} 
Andere lateinische Texte bzw. Textstellen mit mehr oder weniger stark ausgeprägtem Gesprächscharakter finden sich bspw. in den philosophischen und rhetorischen Schriften Ciceros und im Dialogus de oratoribus von Tacitus, in einigen Unterweisungstexten (zu Themen wie Landwirtschaft, Medizin, Kochkunst) und Gesetzestexten. ${ }^{22}$ Eine größere Nähe zu realen Gesprächen im alten Rom weisen - trotz ihrer Fiktivität - allerdings eher die Dialoge in den Romanen von Petron und Apuleius und v. a. in den römischen Komödien auf. ${ }^{23}$ Obwohl die sprechakttheoretische Methodologie grundsätzlich auch auf literarische Texte übertragbar ist, bietet sich für die umfassenden Analysen in der vorliegenden Arbeit aber ein eher authentischer Text an, weil mit literarisch-fiktionalen Sprechakten ganz spezielle Probleme verbunden sind, deren Berücksichtigung an dieser Stelle zu weit führen würde. ${ }^{24}$ Aus den gleichen Gründen scheiden poetische Briefe (wie z. B. Ovids Heroides) aus. Besser geeignet erscheinen dokumentarische „echte“ Briefe wie die Bloomberg- und Vindolanda-Tafeln, von denen letztere tatsächlich auch schon Gegenstand umfangreicher pragmatischer Analysen waren. ${ }^{25}$

Ciceros Briefe kann man ebenfalls als weitgehend authentisch ansehen, wenngleich einige von ihnen wohl bereits im Hinblick auf eine eventuelle Veröffentlichung teilweise bearbeitet worden sind. Zudem macht sich in ihnen immer wieder die rhetorische Vorbildung Ciceros bemerkbar. In fam. 14 sind diese beiden Phänomene aber nicht so stark ausgeprägt bzw. gar nicht festzustellen. Dass die Briefe von Ciceros Frau nicht erhalten sind, schmälert den möglichen Erkenntniswert kaum, weil der interaktionale Charakter auch so erkennbar ist. ${ }^{26}$ Und was den für das Verständnis notwendigen Kontext betrifft, so kann dieser oft aus anderen Briefen (v. a. denen an Atticus) erschlossen werden. ${ }^{27}$ Ein weiterer großer Vorteil von fam. 14 ist der relativ begrenzte Textumfang, sowohl, was die Anzahl der Briefe insgesamt, als auch, was den Textumfang der Briefe im Einzelnen angeht. Eine ausführliche Analyse wird selbst hier an ihre Grenzen stoßen, insbesondere bei den vergleichsweise langen Briefen aus dem Exil.

Nähe zur gesprochenen Sprache als besonders geeignet für historisch-pragmatische Analysen. [...] Heute ist der Umgang mit schriftlichen Daten in der historischen Pragmatik deutlich weniger apologetisch als noch vor zehn oder zwanzig Jahren. Überlieferte Texte, seien das Gerichtsprotokolle, Briefe oder Theaterstücke, werden nicht länger als mehr oder weniger geeignete Annäherungen an gesprochene Interaktion angesehen, sondern sie werden in ihren ursprünglichen kommunikativen Zusammenhängen als das untersucht, was sie tatsächlich sind, ohne voreilige Schlussfolgerungen auf andere kommunikative Zusammenhänge [...]."

22 Vgl. RISSELADA 1993, $13 f$.

${ }^{23}$ Vgl. ebd., 17f. und MonSERRAT RoIg 2004, 288. Vgl. a. JUCKER 2018, 134: „Bei Dramentexten handelt es sich um fiktive Interaktionen zwischen Gesprächspartnern, deren Verwendbarkeit für die historische Pragmatik aber gerade wegen ihrer Fiktionalität und wegen ihrer literarischen Ansprüche immer wieder kontrovers diskutiert wurde. Ihre Verwendung wurde mit der Begründung gerechtfertigt, dass sie zwar nicht ideal sei, aber als einzig vorliegende Annäherung an die gesprochene Sprache trotzdem in Frage kommt [...]. "Zu den Vorteilen z. B. der Komödien von Terenz (und Plautus) zählt neben der unmittelbaren Interaktion u. a. auch die große Spannbreite sprachlicher Varietäten im Hinblick auf verschiedene (soziolinguistische) Parameter (jung - alt, männlich - weiblich, hoher sozialer Rang - niedriger sozialer Rang): KRUSCHWITZ UND CLEARY-VENABLES 2013, 58. VgI. a. UNCETA GÓMEZ 2018, 14.

${ }^{24}$ Damit soll nicht gesagt sein, dass eine Beschäftigung mit (fiktionalen) Sprechakten in literarischen Texten nicht ebenfalls möglich und sinnvoll ist. Vgl. z. B. ARWEILER 2010 und WeRnER 2016. Vgl. a. MONSERRAT ROIG 2004, 289ff. ${ }^{25}$ Vgl. z. B. HALLA-AHO 2009. Vgl. a. die Untersuchung römischer Soldatenbriefe in BIVILLE 2014. Zur Authentizität bzw. Literarizität von Briefen vgl. außerdem Kap. 1.2.1.2.3.

${ }^{26}$ Interessanter noch wäre unter diesem Aspekt die Analyse eines vollständig erhaltenen Briefwechsels. Dem kommt bspw. der Schriftverkehr zwischen Cicero und M. Caelius Rufus recht nahe, den RüHL 2019, 31ff. ihrer kommunikativen Analyse zugrunde legt.

${ }^{27}$ Vgl. RISSELADA 1993, 15. Vgl. a. WHITE 2010, VIIIf. 


\section{Thematische und methodologische Eingrenzung}

In meiner Studie wird in erster Linie der (funktionale) Handlungsaspekt sprachlicher Äußerungen untersucht. Es geht also um eine handlungsfunktionale bzw. pragmatische Analyse. Weil die Bedeutung von Sprachhandlungen ${ }^{28}$ im Mittelpunkt stehen wird, könnte man auch von einer handlungssemantischen Analyse sprechen. Eine Bezeichnung als ,sprechakttheoretische Analyse' bzw. ,(erweiterte) Sprechaktanalyse' ist insofern möglich, als die Sprechakttheorie, die ein wichtiger Teil der Pragmatik ist und manchmal sogar weitgehend gleichgesetzt wird mit ihr, die Hauptgrundlage meiner Untersuchung darstellt. ${ }^{29}$

Allerdings will diese Arbeit zumindest ansatzweise über das, was der Begriff der traditionellen Sprechakttheorie umfasst, hinausgehen. So soll der handlungssemantische Zugang durch Erkenntnisse und Methoden vonseiten angrenzender, nicht nur sprachwissenschaftlicher Fachdisziplinen ergänzt werden. ${ }^{30}$ Dazu zählen z. B. Literaturwissenschaft, Stilistik und Rhetorik. Wo es notwendig und sinnvoll erscheint, wird $u$. a. auf Konzepte der Soziologie, Psychologie und Kommunikationswissenschaft Bezug genommen. Zurückgegriffen wird dabei i. d. R. auf die Forschungsliteratur der entsprechenden (v. a. soziolinguistischen) Sprachwissenschaftszweige (wie z. B. Emotionslinguistik), und zwar - genauso wie bei anderen relevanten sprachwissenschaftlichen Themen - meist aus dem Bereich der germanistischen Linguistik.

Weil anders eine sinnvolle handlungssemantische Analyse nicht möglich scheint, sollen über die Ebene der Einzelillokutionen hinausreichende funktionale Zusammenhänge sowie (sequenzielle und hierarchische) Strukturen auf Text- und Teiltextebene ebenfalls in die Überlegungen miteinbezogen werden, womit eine Ausweitung auf den Bereich der Textlinguistik

\footnotetext{
${ }^{28}$ Der Begriff ,Sprachhandlung' wird hier als Oberbegriff verstanden, der sowohl einzelne Äußerungen (Sprechhandlungen bzw. Sprechakte) als auch größere Einheiten wie Texthandlungen umfasst. Damit entspricht er weitgehend dem, was WAGNER 2001, 87 als ,Sprechhandlung' definiert, die für ihn ein Oberbegriff ist „für alles, was ein Sprecher mit Sprache tun kann. "In der vorliegenden Arbeit wird der Begriff ,Sprechhandlung' hingegen (im Einklang mit der klassischen Sprechakttheorie) gleichbedeutend mit ,Sprechakt' benutzt. ,Sprechakte' bzw. ,Sprechhandlungen“ werden dabei als „die kleinsten sprachlichen Einheiten mit einer kommunikativen Funktion“ (Staffeldt 2009, 14) bestimmt. Vgl. Searle 1971, 39. In SeArle Und VANDerVeKen 1985, 1 wird diese Definition speziell auf die illokutionären Akte bezogen. Bühler dagegen differenziert zwischen ,Sprechhandlung' und ,Sprechakt' folgendermaßen: „Während die Sprechhandlung etwas von konkreten Sprechern Vollzogenes repräsentiert, ist der Sprechakt das Produkt der Hervorbringung von Sprache, das die sprachliche Handlung der jeweiligen Situation enthebt und deren Zuordnung zu einer Sprechaktklasse ermöglicht." (PRASALSKI 2010, 16). Vgl. BüHLER $1999,48 \mathrm{ff}$.

${ }^{29}$ Dagegen aber z. B.: WUNDERLICH 1976, 119f. Von mir wird ein recht allgemeiner Begriff der Pragmatik zugrunde gelegt, wie er sich z. B. bei CHERUBIM 1980, 7 findet: „Sprachpragmatik analysiert, beschreibt und erklärt Sprache als Form sozialen Handelns in den dieses Handeln konstituierenden und durch dieses Handeln konstituierten kommunikativen Zusammenhängen.” Vgl. a. HUANG 2014, 2: „Pragmatics is the systematic study of meaning by virtue of, or dependent on, the use of language." Zum Unterschied zwischen dem umfassenden kontinentaleuropäischen und dem eher begrenzten angloamerikanischen Verständnis von Pragmatik und zu anderen Definitionen vgl. z. B. BARRON U. A. 2017 und LEVINSON 2011, 5ff. Vgl. a. SCHLIEBEN-LANGE 1979, 11ff. Zu weiteren Aspekten der Begriffsbestimmung, wie z. B. der Abgrenzung von ,Pragmatik' und ,Soziolinguistik' und v. a. ,Pragmatik' und ,Semantik' vgl. z. B. LeVINSON 2011, 27ff.; LEECH 1983, 10f. und SCHLIEBEN-LANGE 1979, 112ff. bzW. BUSSE 2015, 91ff.; LeVINSON 2011, 11ff.; MeIBAUer 2008, 4ff.; WeIGAND 2003, 60ff.; LeECH 1983, 5ff. und ebd., 19ff. sowie SCHLIEBEN-LANGE 1979, $108 \mathrm{f}$.
}

${ }^{30}$ Vgl. a. STAFFELDT 2014, 144 und WAGNER 1997, 231. 
stattfindet. Um den Rahmen dieser Arbeit nicht zu sprengen, kann das aber nur in einem bestimmten Ausmaß (am Beispiel einzelner Briefe) geschehen. ${ }^{31}$ Dies gilt insbesondere auch für intertextuelle Verbindungen, die nur insofern Berücksichtigung finden, als bspw. an der einen oder anderen Stelle Bezug auf einige Briefe von Atticus genommen wird. Gelegentlich wird zudem auf interaktionale Zusammenhänge mit den zwar nicht überlieferten, aber z. T. rekonstruierbaren Briefen Terentias ${ }^{32}$ verwiesen. Die der Textlinguistik eng verwandte Gesprächslinguistik ${ }^{33}$, die sich u. a. bei der Analyse römischer Komödien als nützlich erweist, wird dabei eher weniger Beachtung finden, weil die Briefe Ciceros im Wesentlichen als eigenständige monologische Texte zu betrachten sind und trotz vorhandener interaktionaler Elemente viele gesprächstypische Spezifika (Stichwort, turn-taking') fehlen.

Obwohl die Ursprünge der Sprechakttheorie in der Sprachphilosophie liegen, werden abstrakte illokutionslogische Betrachtungen bei den Analysen in dieser Arbeit keine Rolle spielen. ${ }^{34}$ Fragen, die die linguistische Sprechakttheorie beantworten soll, sind v. a. folgende: Inwiefern sind Sprechakte universell bzw. kulturell und historisch bedingt? Wie viele und welche Sprechakte gibt es in einer spezifischen Sprache? Wie können die einzelnen Sprechakte identifiziert und (nach übergeordneten Funktionen und einzelnen Untermustern) klassifiziert werden? Welche Hinweise liefert die Lexik einer Sprache zur Bezeichnung von Sprechhandlungen? Mit welchen sprachlichen und nicht-sprachlichen Mitteln wird eine Illokution signalisiert? Geschieht dies eher explizit oder implizit? Welche komplexen Sprechakte, Sprechaktsequenzen und -hierarchien gibt es? Lassen sich hier bestimmte Muster erkennen?

In dieser Arbeit können selbstverständlich nicht alle genannten Fragen (erschöpfend) beantwortet werden. Eine komplette Inventarisierung im Lateinischen existenter Sprechhandlungen, SB-Verben, sprachlicher Indikatoren usw. ist schon allein wegen des begrenzten Textkorpus unmöglich. ${ }^{35}$ Die Analysen werden aber einen ersten Befund liefern, indem exemplarisch

\footnotetext{
${ }^{31}$ Zum Problem einer sprechakttheoretischen Analyse umfangreicherer Texte vgl. z. B. SZWED 2014, 160 und WAGNER 1997, 321.

32 Vgl. RICHLIN 2013.

${ }^{33}$ Zum Unterschied zwischen geschriebenen und gesprochenen „Texten“ bzw. Text- und Gesprächslinguistik vgl. z. B. KoCh UND OesterReicher 2008 und das Vorwort zu Brinker 2000 - 2001a. Zum Unterschied zwischen Dialoganalyse und Gesprächsanalyse vgl. z. B. STAFFELDT 2009, 98 N. 66. In den letzten Jahren wird (v. a. angesichts der Entwicklungen im Bereich der neuen Medien) verstärkt diskutiert, inwieweit eine Abgrenzung von Text und Gespräch überhaupt sinnvoll möglich ist und welcher Stellenwert den Aspekten der Mündlichkeit und Schriftlichkeit dabei zukommt: Vgl. BIRKNER UND JANICH 2018, darin insbesondere STEIN 2018, ADAMZIK 2018b und SCHWITALLA 2018. Vgl. außerdem die Unterscheidung von medialer und konzeptueller Mündlichkeit bzw. Schriftlichkeit bei KOCH UND OESTERREICHER 2008.

${ }^{34}$ Im Unterschied zur Illokutionslogik geht es in der linguistischen Sprechakttheorie um den konkreten Sprachgebrauch in konkreten Handlungszusammenhängen mit Berücksichtigung nicht nur der jeweiligen Handlungsintention, sondern genauso der jeweiligen sprachlichen Ausgestaltung. Vgl. z. B. SEARLE UND VANDERVEKEN 1985, 1: „IIlocutionary forces are realized in the syntax of actual natural languages in a variety of ways, e.g. mood, punctuation, word-order, intonation contour, and stress, among others; and it is a task for empirical linguistics to study such devices as they function in actual languages. The task of illocutionary logic, on the other hand, is to study the entire range of possible illocutionary forces however these may be realized in particular natural languages." Vgl. a. Rolf 2006, 2520; Rolf 1997, 7ff.; WeIGAND 2003, 26 und SCHLIEBEN-LANGE 1979, $120 f$.

${ }^{35}$ Alternativ wäre eine Konzentration auf eng begrenzte Teilbereiche (z. B. einzelne Sprechakttypen oder sprachliche Indikatoren wie Diskurspartikeln) unter Zugrundelegung einer sehr viel größeren Textbasis denkbar: Vgl. WAGNER 1997, 73. Zu entsprechenden pragmatischen Arbeiten im Bereich der Klassischen Philologie vgl. Kap. 1.1.3.
} 
dargestellt wird, welche Sprechhandlungen sich in fam. 14 finden, wie sich diese voneinander abgrenzen und kategorisieren sowie hierarchisieren und ggf. zu funktionalen Sequenzen zusammenfassen lassen und wie eine übergeordnete Textfunktion ermittelt werden kann. Dabei wird untersucht, welche spezifischen sprachlichen Mittel zur Indizierung der einzelnen Handlungseinheiten zur Verfügung stehen und welche weiteren Indikatoren zu deren Bestimmung notwendig sind. Eine ausgefeilte eigene Klassifikation von Sprechakttypen und Textfunktionen kann hier nicht entwickelt werden, sondern es wird auf die bereits vorliegenden Klassifizierungen Searles und der sog. Münsteraner Schule bzw. Klaus Brinkers zurückgegriffen. Das Verfahren bei der Bestimmung der Handlungseinheiten ist dabei eher deduktiv (von den Funktionsklassen hin zur konkreten sprachlichen Realisierung) als induktiv, obwohl auch immer wieder der umgekehrte Blickwinkel eingenommen wird. STAFFELDT 2014 spricht in diesem Zusammenhang von einem „methodologischen Zirkel“. ${ }^{36}$

Die Wirkung der sprachlichen Äußerungen Ciceros auf Terentia ${ }^{37}(\approx$ perlokutionäre Effekte) ist i. d. R. kaum überprüfbar, weshalb entsprechende Betrachtungen weitgehend außen vor bleiben müssen. Im Vordergrund wird der funktionale Aspekt, d. h. die kommunikativ-pragmatische Ebene sprachlicher Äußerungen ( $\approx$ illokutionäre Akte) stehen, wobei zu beachten ist, dass auch die von Cicero tatsächlich (explizit und implizit) verfolgte Intention nur eingeschränkt rekonstruiert werden kann und es eher um eine Interpretation aus der Sicht des Textrezipienten geht. Eng damit verbunden und nur analytisch davon zu trennen sind die inhaltlich-semantische Ebene $(\approx$ propositionale Akte) und die sprachlich-grammatische Ebene ( $\approx$ lokutionäre Akte bzw. Äußerungsakte), die deshalb immer mitberücksichtigt werden. ${ }^{38}$ Am Ende der Analysen steht eine handlungssemantische Interpretation, d. h., die potenzielle Aussagekraft funktionaler Handlungseinheiten hinsichtlich der Beziehung zwischen Cicero und Terentia wird bewertet.

Der Schwerpunkt der Arbeit liegt auf einer qualitativen Analyse; quantitative Aspekte werden nur ergänzend und unter großem Vorbehalt in die Betrachtungen miteinbezogen. Wegen der Unmöglichkeit wirklich eindeutiger und unangreifbarer Funktionszuordnungen und aufgrund der schmalen Textbasis sind die quantitativ-statistischen Auswertungen, wie sie besonders im Zusammenhang mit der handlungssemantischen Interpretation von Ciceros Briefen in Bezug auf sein Verhältnis zu Terentia durchgeführt werden, zwar überaus interessant, aber letztlich nur begrenzt aussagekräftig. ${ }^{39}$

\footnotetext{
${ }^{36}$ StAFFELDT 2014, 111ff. Vgl. a. SCHMITT 2000, 14. Vgl. außerdem die Unterscheidung von (semasiologischem) form-to-function und (onomasiologischem) function-to-form mapping in der historischen Pragmatik, z. B. bei JUCKER UND TAAVITSAINEN 2010, 16ff. und JUCKER 2018, 135.

${ }^{37}$ Mit ,Cicero' und ,Terentia' sind in dieser Arbeit i. d. R. der aus den uns erhaltenen Briefen erschließbare Adressant (= Brief-Ich) bzw. Adressat (= Brief-Du) gemeint, wobei aber statt ,Adressant' meist die Termini ,(Brief-) Schreiber' oder (auch mit Bezug auf den Autor eines schriftlichen Textes, wie z. B. Cicero in seinen Briefen) ,Sprecher' verwendet werden. Die realen historischen Personen bleiben - selbst unter Heranziehung ergänzender historischer Quellen - immer nur schemenhaft greifbar.

${ }^{38}$ Vgl. z. B. BRINKER 2002, 41; ORTNER 2014b, 327f. und 414 sowie WAGNER 1997, 36.

${ }^{39}$ Vgl. a. ADAMZIK 2016, 234: „Der Vorstellung, dass exakte Quantifizierung ein besonderes Qualitätsmerkmal darstellt, steht natürlich die Annahme gegenüber, dass die inhaltliche Analyse von Texten grundsätzlich nicht objektivierbar ist [...]. “ Vgl. außerdem UNCETA GómeZ 2018, 14 und ebd., 24; UNCETA GÓmEZ 2016a, 274; FeRRI 2008,26 sowie die umfassenden statistischen Analysen zur Interaktion in der römischen Komödie in BARRIOS-LECH 2016. Auf die Verwendung spezieller quantifizierender Computerprogramme wurde in dieser Arbeit verzichtet, da im
} 


\section{Kapitelübersicht}

Die vorliegende Arbeit lässt sich grob in zwei Teile gliedern: eine theoretisch-methodologische Grundlegung und einen Praxisteil mit den konkreten Textanalysen und -interpretationen.

\section{Teil 1: Grundlegung}

Zunächst werden „Grundzüge der Sprechakttheorie und Textpragmatik“ (mit Schwerpunkt auf dem deutschsprachigen Raum) dargelegt (Kap. 1.1.1). Im Folgenden werden einige Besonderheiten der historischen und kulturwissenschaftlichen Pragmatik beleuchtet (Kap. 1.1.2) und eine Übersicht über die bisherigen Studien in der Lateinischen Philologie gegeben (Kap. 1.1.3). Es folgen Betrachtungen zu den Charakteristika der Kommunikationsform ,(römischer) Brief ${ }^{\prime}$ insgesamt (Kap. 1.2.1) sowie Informationen über wichtige Einzelheiten zum Analysekorpus fam. $14 \mathrm{im}$ Besonderen (Kap. 1.2.2). Das anschließend vorgestellte Analysekonzept erläutert nach einem allgemeinen Überblick (Kap. 1.3.1) die vier wesentlichen Untersuchungsphasen genauer: "Illokutionsidentifikation“ (Kap. 1.3.2), "Illokutionsklassifikation“ (Kap. 1.3.3), "Sequenzierung und Hierarchisierung der Handlungsfunktionen“ (Kap. 1.3.4) und „Bestimmung der Textfunktion“ (Kap. 1.3.5).

\section{Teil 2: Praktischer Teil - Analysen und Interpretationen}

Der Praxisteil beginnt mit einer detaillierten Analyse von drei exemplarischen Briefen aus fam. 14 (Kap. 2.1.1: fam. 14.20, Kap. 2.1.2: fam. 14.5, Kap. 2.1.3: fam. 14.2). Danach werden die Ergebnisse der Detailanalysen aller Briefe des Analysekorpus zusammenfassend dargestellt. In einem ersten Schritt geht es dabei um eine Sprechhandlungsanalyse auf den verschiedenen Handlungsebenen i. e. S. (Kap. 2.2.1), aus der sich weitreichende Einsichten in die formale und inhaltliche Ausgestaltung, Kategorisierung und Funktionsweise sprachlicher Handlungen im Lateinischen ergeben, schließlich dann um eine Interpretation im Hinblick auf die Beziehung zwischen Cicero und seiner Frau Terentia (Kap. 2.2.2), welche die Möglichkeiten einer handlungssemantischen Analyse und ihren Beitrag zur philologischen Bearbeitung antiker Texte aufzeigt.

\section{PRAKTISCHE HINWEISE}

Der Anhang enthält neben Übersichten über die Einzelillokutionen aller Briefe in fam. 14 und über die für diese Arbeit relevanten Definitionen der Sprechaktuntermuster (gem. Münsteraner Schule) auch ein Abkürzungsverzeichnis. Ein Abbildungsverzeichnis folgt direkt im Anschluss an die beiden Inhaltsübersichten am Anfang der Arbeit.

vorliegenden Fall kein zusätzlicher Nutzen zu erwarten ist, sondern eher zusätzliche Probleme entstehen. Für weitergehende Untersuchungen (nicht nur) mit größeren Textkorpora können diese aber sicherlich eine große Hilfe darstellen. Vgl. z. B. die ausführliche semiotisch-kommunikationstheoretische Analyse der Josefsgeschichte in SCHWEIZER 1995 mithilfe von TUSTEP (Tübinger System von Textverarbeitungs-Programmen): https://www.tustep.uni-tuebingen.de/ (zuletzt geprüft am 12.11.2020). Zur computergestützten Textanalyse vgl. a. NÜNNING UND NüNNING 2010, 109ff. Zu den damit verbundenen Problemen (in Bezug auf die Diskursanalyse) vgl. außerdem NIEHR 2014, 72f. und BENDEL LARCHER 2015, 47. 
Für Zitate aus den Cicero-Briefen sind die Teubner-Editionen Shackleton Baileys (CICERO 1987 und CICERO 1988) ausschlaggebend, auch was die Zählung betrifft. Abkürzungen von Autorennamen und Werktiteln erfolgen entsprechend den üblichen Konventionen. ${ }^{40}$ Buch, Brief und Paragraf (bzw. entsprechende Einteilungen in anderen Werken) werden allerdings jeweils durch einen Punkt voneinander getrennt. Die von mir ermittelten Illokutionen werden durch in runde Klammern gesetzte Ziffern angeschlossen, also z. B. CIc. fam. 14.4.5 (43). Übersetzungen bzw. Paraphrasierungen, soweit nicht anders angegeben, stammen von mir.

Nicht zu vergessen: Verbum hoc , si quis' tam masculos quam feminas complectitur. (VLP. dig. 50.16.1).

$40 \mathrm{Vgl}$ z. B. http://www.thesaurus.badw-muenchen.de/tll-digital/index.html und http://www.pegasusonlinezeitschrift.de/subsidia_autoren.html (zuletzt geprüft am 12.11.2020). 


\section{Grundlegung}

\subsection{PRAGMATIK UND SPRECHAKTTHEORIE}

\subsubsection{Grundzüge der Sprechakttheorie und Textpragmatik}

Die Sprechakttheorie wurde von verschiedensten Seiten vielfältig beeinflusst, und seit ihrer Entstehung haben sich sehr unterschiedliche Ansätze und Strömungen entwickelt. Hier wird davon lediglich ein kleiner Ausschnitt dargestellt, und selbst dies nur in stark komprimierter Form mit Fokus auf den für die vorliegende Untersuchung besonders interessanten und wichtigen Aspekten. ${ }^{41}$

\subsubsection{Vorläufer der Sprechakttheorie? \\ 1.1.1.1.1 Antike}

Die Rhetorik kann zwar nicht als Vorläufer der Sprechakttheorie i. e. S. gelten, da diese sich nicht direkt aus ihr heraus entwickelt hat. Trotzdem findet man in der antiken Rhetorik und auch in der antiken Sprachphilosophie bemerkenswerte Ähnlichkeiten mit der modernen Pragmatik.

So wurden tatsächlich bereits, Sprechakte' als besonderes Phänomen wahrgenommen. Lt. Diogenes Laertius (DIOG. LAERT. 9.8.53-54) soll schon Protagoras vier Formen des Logos unter-

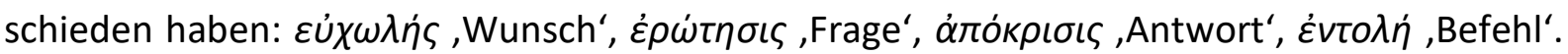

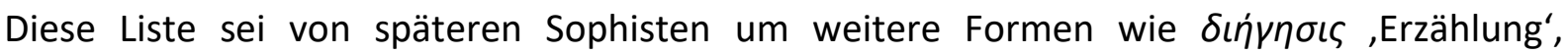
$\dot{\alpha} \pi \alpha \gamma \gamma \varepsilon \lambda i \alpha$,Nachricht' und $\kappa \lambda \tilde{\eta} \sigma \iota \varsigma$, Aufruf' ergänzt worden. Aristoteles (int. 17.a.1-7) differen-

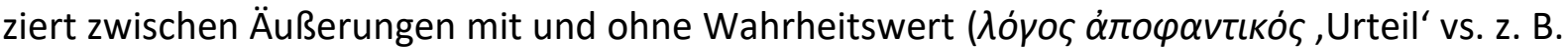
$\varepsilon \dot{x} \dot{\eta}^{\prime}$, Bitte'). An einer anderen Stelle (poet. 1456.b.8-19) benennt er im Einzelnen Ausdrucks-

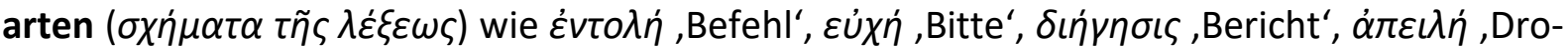

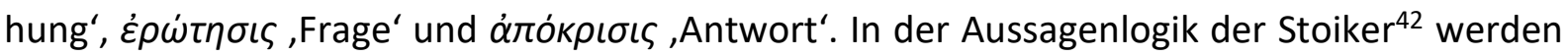
u. a. folgende (vollständige) Lekta aufgezählt: $\alpha \xi \iota \omega \dot{\alpha} \mu \alpha \tau \alpha$,Aussagen', $\sigma u \lambda \lambda o \gamma \iota \sigma \mu o i$, ,Syllogis-

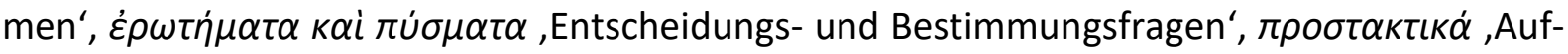
forderungen', $\dot{\rho} \kappa \iota \kappa \dot{\alpha}$, Eide'. $^{43}$

In der Rhetorik trifft man auf eine Vielzahl von modi des Sprechens, die es in den genera causarum zu berücksichtigen gelte. Quintilian (inst. 3.4.1-3) zählt einige dieser modi auf, um welche die ursprünglichen drei genera (genus iudiciale, genus deliberativum, genus demonstrativum bzw. laudativum) ergänzt wurden: „Insbesondere das epideiktische genus, mit seinen Formen des Lobens und Tadelns, verleitete die Rhetoriker dazu, sich zu überlegen, dass es dann auch für das Bedauern, das Trösten, das Besänftigen, das Aufstacheln, das Erschrecken, das Beweisen, das Vorschreiben, die Formen des Interpretierens von dunkel Gesagtem, für die Erzählung, für die Abbitte, für den Dank, für das Beglückwünschen, für das

\footnotetext{
${ }^{41}$ Ein kurzer Überblick über Grundlagen und zentrale Werke findet sich z. B. in LIEDTKE 2018. Zu Entstehung und Entwicklung der Sprechakttheorie bzw. Pragmatik vgl. a. LEVINSON 2017, 200ff.; HUANG 2014, 1ff.; JUCKER 2012; SCHMitT 2000, 17ff.; VerSCHUEREN 1995, 2ff.; SBISÀ 1995, 495ff.; LEECH 1983, 1ff. und SCHLIEBEN-LANGE 1979, 23ff. Für weitere Informationen sei auf die einschlägige umfangreiche Fachliteratur verwiesen.

42 Überliefert durch Diogenes Laertius und Sextus Empiricus. Hier zitiert nach HÜLSER 1992, 26.

${ }^{43}$ Vgl. z. B. SBISÀ 1995, 496; SCHIRREN 2010, 79ff. (zu Protagoras); HÜLSER 1992, 26 (zu den Stoikern) und SCHENKEVELD 1984 (zu Stoikern und Peripatetikern).
} 
Beschwören, für das Beschimpfen, für das Beschreiben, für das Empfehlen, für das Aufkündigen, für das Wünschen und das Meinen, usw. jeweils eigene genera geben müsse. "44 Allerdings ist hier weniger eine Abgrenzung von einzelnen mit Sprache möglichen Sprechhandlungen intendiert, sondern die Unterscheidung ist sehr eng mit der praktischen Gestaltung von Reden als Ganzes verbunden. ${ }^{45}$

Zu einigen Sprechakten gibt es aber durchaus differenzierte theoretische Überlegungen, wie bspw. die Ausführungen von Aristoteles zu ,Frage' und ,Antwort' im Bereich der Dialektik (top. 8) und die von Quintilian (inst. 9.2.6) zum Unterschied von, rhetorischen Fragen' (interrogare) und ,informativen Fragen' (percontari) zeigen. ${ }^{46}$ Eine vollständige, deskriptive und präzise systematisierende Erfassung von Sprechakten fehlt jedoch weitgehend (trotz einzelner Bemühungen v. a. der Stoiker) und wurde auch, was speziell die Rhetorik betrifft, gar nicht angestrebt. $^{47}$

Im Unterschied zur Sprechakttheorie geht es in der Rhetorik darum, was man mit Sprache subjektiv ,bewirken' kann, nicht darum, was man objektiv mit ihr ,tun' kann. ${ }^{48}$ Sie ist deshalb schon vom Grundsatz her eher bewertend und auf Sprachproduktion ausgerichtet. ${ }^{49}$ Die Sprechakttheorie erhebt im Gegensatz dazu den Anspruch auf neutrale und umfassende Beschreibung eines Sprachzustandes und bezieht z. B. neben der (öffentlichen) Rede stärker auch andere Textsorten und Kommunikationsformen mit ein. ${ }^{50}$ Da die Sprechakttheorie ihren Untersuchungsbereich irgendwann auf ganze Texte erweitert hat, besteht in dieser Hinsicht hingegen kein Unterschied mehr zur Rhetorik, wie man ihn im Vergleich zur ursprünglichen satzzentrierten Sprechakttheorie noch feststellen konnte. ${ }^{51}$ Sowohl in der Rhetorik als auch in der Sprechakttheorie geht es nicht nur um die sprachlich-stilistische Ausgestaltung von Einzeläußerungen, sondern auch um den Gesamtaufbau von ganzen Texten (unter rezeptionsorientierten Gesichtspunkten). Dabei werden in beiden Disziplinen zudem umfangreiche Überlegungen zur Kommunikationssituation angestellt. ${ }^{52}$ Trotz aller grundlegenden Unterschiede gibt es also durchaus einiges, was Rhetorik und Sprechakttheorie verbindet. Festzuhalten bleibt insbesondere, dass man sich in der Antike der Wirkungsmacht und des Handlungscharakters von Sprache sehr bewusst war.

\footnotetext{
${ }^{44}$ SCHIRREN 2010, 82. Der genaue Wortlaut bei Quintilian lautet: Sed tria an plura sint ambigitur. Nec dubie prope omnes utique summae apud antiquos auctoritatis scriptores Aristotelen secuti, qui nomine tantum alio contionalem pro deliberatiua appellat, hac partitione contenti fuerunt. Verum et tum leuiter est temptatum, cum apud Graecos quosdam tum apud Ciceronem in libris de oratore, et nunc maximo temporum nostrorum auctore prope inpulsum, ut non modo plura haec genera sed paene innumerabilia uideantur. Nam si laudandi ac uituperandi officium in parte tertia ponimus, in quo genere versari uidebimur cum querimur consolamur mitigamus concitamus terremus confirmamus praecipimus, obscure dicta interpretamur, narramus deprecamur, gratias agimus, gratulamur obiurgamus maledicimus describimus mandamus renuntiamus optamus opinamur, plurima alia?

${ }^{45}$ Ebd., 82ff.

${ }^{46} \mathrm{Vgl}$. Ax 1992, 252 bzw. PINKSTER 1996, 246.

47 Vgl. SCHIRREN 2010, 83 und Ax 1992, 252.

${ }^{48}$ LUPPOLD 2015, 343.

${ }^{49}$ Vgl. z. B. AdAMZIK 2016, 10ff.; BRINKER 2006, 2540; AX 2006a, 241 und BLACK 1995, 21.

${ }^{50}$ Vgl. z. B. BICKMANN 1998, 44f. Vgl. a. LEECH 1983, der sein „rhetorical model of pragmatics“ entgegen der klassischen Rhetorik vornehmlich auf Alltagsgespräche („everyday conversation“) ausrichtet „and only secondarily to more prepared and public uses of language" (ebd., 15).

${ }^{51} \mathrm{VgI}$. LUPPOLD 2015, 344.

52 Vgl. z. B. AdAMzIK 2016, 12; ARWEILER 2010, 203; Ax 2006a, 241 und KALVERKÄMPER 2000 - 2001, 4.
} 


\subsection{Bühler und Jakobson}

Daran knüpft auch Karl Bühler mit seinem Organon-Modell an, das sich auf Platons Kratylos beruft, wo die Sprache als öpyavov ,Werkzeug' bezeichnet wird, also als etwas, womit Menschen ,handeln' können. ${ }^{53}$ In Bühlers kommunikativen Modell kommen einem sprachlichen Zeichen bzw. einer sprachlichen Äußerung drei Funktionen zu: Darstellung (Bezug auf "Gegenstände und Sachverhalte“), Ausdruck (Bezug auf den "Sender") und Appell (Bezug auf den „Empfänger“). ${ }^{54}$

Roman Jakobson, Vertreter der funktional-strukturalistischen Prager Schule, baut mit seinem eigenen Modell darauf auf und ergänzt es um weitere drei Funktionen. ${ }^{55}$ Die referenzielle Funktion (Bühlers Darstellungsfunktion) ist gekennzeichnet durch eine „Orientierung auf den KONTEXT hin“, die konative Funktion (Bühlers Appellfunktion) durch ihre "Ausrichtung auf den EMPFÄNGER", die emotive oder expressive Funktion (Bühlers Ausdrucksfunktion) dadurch, dass sie "sich an den SENDER richtet“. Neu hinzu kommen die metasprachliche Funktion mit ihrer Orientierung „am KODE“, die phatische Funktion mit einer „Einstellung auf den KONTAKT“ und die (nicht auf die Dichtung beschränkte) poetische Funktion mit einer „Einstellung auf die BOTSCHAFT". ${ }^{66}$

Obwohl Jakobson allgemein zugestanden wird, die in Bühlers Modell angeführten Grundfunktionen der Sprache um ein paar wichtige Facetten bereichert zu haben ${ }^{57}$, werden seine Ergänzungen zum Teil sehr kritisch gesehen. Im Fokus steht häufig die poetische Funktion, der in Jakobsons Betrachtungen ein besonderer Stellenwert zukommt. ${ }^{58}$ So erscheine der Begriff ,poetisch' im Zusammenhang mit z. B. Werbe- und Nachrichtentexten unangemessen. ${ }^{59}$ Das von Jakobson selbst genannte Beispiel eines politischen Wahlslogans sei zudem letztlich eher als konativ bewerten. ${ }^{60}$ Einige sehen in der poetischen Funktion nur eine Variante der Ausdrucksfunktion. ${ }^{61}$ Die phatische und die metasprachliche Funktion werden manchmal ebenfalls lediglich als Unterfälle der Bühler'schen Funktionen betrachtet. ${ }^{62}$ Die konkrete Zuordnung sprachlicher Äußerungen gestaltet sich z. T. ziemlich schwierig, was bspw. daran deutlich wird, dass sowohl eigentlich referenzielle und expressive als auch konative Äußerungen unter die

\footnotetext{
53 BÜHLER 1999, 1 und ebd., 24f. Die Werkzeugmetapher hat z. T. heftige Kritik hervorgerufen, wie z. B. bei REISIGL 1999, 30, der sie als „extrem misanthropisch“ empfindet, da durch sie der Mensch zu einem zu bearbeitenden Material herabwürdigt werde. VgI. a. ORTNER 1992, 280, der meint, dass die Metapher deshalb unangemessen sei, weil sprachliche Äußerungen kein festes Gebilde seien, sodass höchstens von „Werkzeugbauplänen“ gesprochen werden könne, und dies auch nur mit Bezug auf die langue.

${ }^{54}$ Eine genauere Beschreibung des Organon-Modells findet sich u. a. bei COȘERIU 1994, 71ff.; REISIGL 1999, $29 \mathrm{ff}$. und natürlich bei Bühler selbst: BüHLER 1999, $28 \mathrm{ff}$.

55 Details zu Jakobsons Modell kann man u. a. nachlesen in JAKOBSON 1979; COȘERIU 1994, 76ff.; REISIGL 1999, 53ff. und KUßE 2012, $72 \mathrm{f}$.

56 JAKOBSON 1979, 88ff.

${ }^{57}$ Das geben selbst seine Kritiker zu, wie z. B. REISIGL 1999, 64f. und CoȘERIU 1994, 87.

${ }^{58}$ Bemerkenswert ist dabei auch Jakobsons Ansicht, die Poetik sei Teil der Linguistik: JAKOBSON 1979, 84f.

${ }^{59}$ COȘERIU 1994, 79ff.

60 COȘERIU 1994, $79 f$.

${ }^{61}$ Vgl. z. B. REISIGL 1999, 59.

${ }^{62}$ Vgl. z. B. ebd., 65, der jedoch auch bemerkt: „Die phatische und die metasprachliche Funktion als Unterfälle der Appell- und Darstellungsfunktion anzusehen, dafür dürfte vieles sprechen. Sie aber einfach wieder in der Versenkung verschwinden zu lassen, wo sie sich nun einmal als begriffliche Destillationen bereits gut bewährt haben, erscheint mir wenig sinnvoll."
} 
phatische Funktion fallen können. ${ }^{63}$ Das Problem liegt $u$. a. in den heterogenen Unterscheidungskriterien begründet. Entscheidend müssten eigentlich kommunikativ-handlungsfunktionale Aspekte sein. Der phatischen und auch der metasprachlichen Funktion liegen aber bspw. inhaltliche Merkmale zugrunde. Erstere ist v. a. durch den Bezug auf das Kontaktmedium definiert, letztere unterscheidet sich im Grunde nur durch ihre Referenz auf die Sprache selbst (den Kode) von der Darstellungsfunktion. ${ }^{64}$ Die Definition der poetischen Funktion wiederum wird auf eher formale Kriterien reduziert. ${ }^{65}$

Auch Bühlers Modell ist hinsichtlich der Differenzierungskriterien nicht konsistent, insofern die Darstellungsfunktion einem sprachlichen Zeichen - im Gegensatz zur Ausdrucks- und Appellfunktion - unabhängig vom tatsächlichen kommunikativen Gebrauch zukommt. ${ }^{66}$ Diese Kritik betrifft dann natürlich ebenso Jakobsons referenzielle Funktion. Außerdem ist bei Bühler genau wie bei Jakobson die Zuweisung der Funktionen zu einzelnen Kommunikationsfaktoren nicht in jeder Hinsicht überzeugend und stark vereinfachend. Die konative bzw. Appellfunktion wird in den Modellen z. B. dem Empfänger zugeordnet, obwohl letztlich die Art der Verwendung einer sprachlichen Äußerung durch den Sender entscheidend ist. Allgemein ist bei beiden eine Überbetonung der Senderseite unter Vernachlässigung der Empfängerseite und insgesamt der Interaktionalität menschlicher Kommunikation festzustellen. ${ }^{67}$

Die Modelle von Bühler und Jakobson gelten aus heutiger Sicht teilweise als überholt. ${ }^{68}$ In gewisser Weise können sie jedoch sogar als recht fortschrittlich bezeichnet werden, da sie z. B. - trotz aller bemängelten Einschränkungen - bereits soziale Komponenten und eine relativ umfassende Kommunikationssituation mitberücksichtigen. ${ }^{69}$ Entsprechend haben sie einen sehr weitreichenden Einfluss gehabt und wurden vielfach aufgegriffen. Sehr populär ist bspw. das in ihrer Tradition stehende Vier-Seiten-Modell von Schulz von Thun. ${ }^{70}$

Inwieweit gibt es nun aber Bezüge zur Sprechakttheorie ${ }^{71}$ Hierzu ist festzustellen, dass die beschriebenen Modelle Sprachfunktionen beschreiben, während es in der Sprechakttheorie

\footnotetext{
${ }^{63}$ Vgl. z. B. WEIGAND 2003, 46. Natürlich ist immer zu berücksichtigen, wie die einzelnen Funktionen genau definiert werden. Gerade in Bezug auf die ,expressive' Funktion gibt es dabei einige Schwierigkeiten, auf die (im Kap. „Besonderheiten der Expressiva“ ab S. 28) noch genauer eingegangen werden wird.

${ }^{64}$ Vgl. ebd., 46; KUßE 2012, 72f. und COȘERIU 1994, 85ff.

${ }^{65}$ Vgl. z. B. ebd., 79ff. und WEIGAND 2003, 46.

${ }^{66}$ COȘERIU 1994, 90. Vgl. a. Rolf 2006, 2523. Vgl. außerdem PrASALSKI 2010, $20 f$.

${ }^{67}$ VgI. REISIGL 1999, 61f.; ORTNER 1992, 279f. und WEIGAND 2003, 46.

${ }^{68}$ Vgl. z. B. ebd., 46 (zur in bestimmter Hinsicht fortschrittlicheren Denkweise der späteren Sprechakttheorie) und die Kritik von SPITZMÜLLER UND WARNKE 2011, 54 bezüglich des dem diskurslinguistischen Konstruktivismus widersprechenden „ontologischen Realismus“ der Modelle.

${ }^{69}$ Zur sozialen Komponente vgl. PRASALSKI 2010, 17 (mit Bezug auf BüHLER 1999, 68f.): „Auch Bühler macht darauf aufmerksam, dass bei der Erschließung der Sinneinheiten (Sprechakte) die ,intersubjektiv geregelten Konventionen' [...] und ,das soziale Moment der Sprache [...]' [...] zu berücksichtigen sind.“ Zu Jakobson vgl. z. B. REISIGL 1999, 58. Zur kommunikativen Komponente: HEINEMANN UND HEINEMANN 2002, 34; HARTUNG 2000 - 2001,83 (mit Bezug auf Bühler) und REISIGL 1999, 53 (mit Bezug auf Jakobson).

70 Dieses Vier-Seiten-Modell wird u. a. dargelegt in SCHULz VON Thun 2010. Vgl. a. die Erweiterungen und Ergänzungen in späteren Publikationen und auf seiner Website: www.schulz-von-thun.de/die-modelle bzw. www.schulz-von-thun.de/die-modelle/das-kommunikationsquadrat (zuletzt geprüft am 12.11.2020).

${ }^{71}$ Ausführlicher zu „Bühler als Vorläufer der Sprechakttheorie“: PRASALSKI 2010.
} 
um Sprechhandlungsfunktionen geht. ${ }^{72}$ Letzteren liegen vom Sprecher beabsichtigte Handlungen zugrunde. Sprachfunktionen im Sinne Bühlers und Jakobsons machen dagegen keinen Unterschied zwischen intendierten und nicht intendierten Funktionen. ${ }^{73}$ Ihre Sprachfunktionen beziehen sich zudem auf konkrete sprachliche Äußerungen im Gebrauch („Zeichengebrauchsaspekte"), die Sprechhandlungsfunktionen dagegen mehr auf abstrahierte Einheiten („Zeichenverwendungstypen“), die in Sprechaktklassen eingeordnet werden können. ${ }^{74}$

Dies verweist auch auf den fundamentalsten Unterschied zwischen den Modellen von Bühler und Jakobson (wie auch von Schulz von Thun) auf der einen Seite und den Klassifikationen der Sprechakttheorie (wie z. B. von Searle) auf der anderen Seite. Sowohl in Bühlers Modell als auch der ergänzten Version von Jakobson wird davon ausgegangen, dass einer sprachlichen Äußerung mehrere Funktionen zukommen, von denen i. d. R. aber eine dominiert, wobei Jakobson von einer Hierarchisierung der Funktionen ausgeht, während bei Bühler auch ein Gleichgewicht der Funktionen möglich ist. ${ }^{75}$ Damit unterscheiden sich ihre multifunktionalen Modelle grundlegend von den sprechakttheoretischen unifunktionalen Modellen, in denen mit einer sprachlichen Äußerung nur jeweils eine Illokution verbunden ist. ${ }^{76}$ Sollten mehrere Sprechhandlungen zu erkennen sein, werden i. d. R. (untergeordnete) direkte und (übergeordnete) indirekte Sprechakte differenziert. ${ }^{77}$ In anderen Fällen wird gar kein Sprechakt angenommen, weil eine Proposition als Basis fehlt, z. B. im Zusammenhang mit paraverbalen Phänomenen. ${ }^{78}$ Zum Teil wird von perlokutionären Effekten ausgegangen, wie im Falle einer Beleidigung, die bei Bühler als Ausdruck gleichzeitig mit einem Appell in einer sprachlichen Äußerung enthalten sein kann. ${ }^{79}$

\subsubsection{Klassische Sprechakttheorie}

\subsection{Sprachphilosophie als Ursprung der Sprechakttheorie}

Der Ursprung der klassischen Sprechakttheorie liegt also weder in der Antike noch in den Sprachfunktionsmodellen von Bühler und Jakobson. Vielmehr entsteht sie aus der analytischen Sprachphilosophie heraus. Als ein Wegbereiter wird oft Ludwig Wittgenstein ${ }^{80}$ genannt, auch wenn umstritten ist, wie weitreichend sein Einfluss tatsächlich war. Während er im „Tractatus Logico-Philosophicus“ (1921) noch der Idee des logischen Empirismus von einer idealen Sprache anhängt und versucht, eine formale Beschreibungssprache zur exakten Abbildung der Realität zu entwerfen, leitet er mit seinen „Philosophischen Untersuchungen“ (1953) eine Kehrtwende ein, indem er sich nun der Alltagssprache zuwendet, die nicht mehr als defizitär, sondern sogar als hilfreich bei der Suche nach philosophischer Erkenntnis betrachtet wird. ${ }^{81}$ Hiermit findet ein Übergang zur "Ordinary Language Philosophy" statt, die allerdings

\footnotetext{
72 Vgl. z. B. WAGNER 1997, 23 und ROLF 2000 - 2001, 423.

${ }^{73} \mathrm{Vgl}$. z. B. ORTNER 2014b, 57 und ORTNER 1992, $279 \mathrm{f}$.

${ }^{74}$ Rolf 2000 - 2001, 425. Vgl. COȘERIU 1994, 87; Rolf 2006, 2523 und PRASALSKI 2010, 19.

75 JAKOBSON 1979, 88 bzw. BüHLER 1999, 32. Vgl. ReISIGL 1999, 61 und WAGNER 1997, 214.

${ }^{76}$ Vgl. z. B. PrasalskI 2010, 20 und Rolf 2000 - 2001, 425. Vgl. a. N. 319.

77 Vgl. PRASALSKI 2010, 20.

${ }^{78} \mathrm{Vgl}$. ebd., 21. Vgl. aber auch S. 20 und 28.

${ }^{79}$ Vgl. PRASALSKI 2010, 21.

${ }^{80}$ Genaueres findet man z. B. bei HARRAS 2004, $96 \mathrm{ff}$.

${ }^{81} \mathrm{Vgl}$. SCHLIEBEN-LANGE 1979, 32: „In seinem Frühwerk, dem ,Tractatus Logico-Philosophicus‘ [1921] hat er - ein Hauptanliegen des ,Wiener Kreises', dem er nahestand - versucht, eine Beschreibungssprache zu konstruieren,
} 
nicht im näheren Umkreis von Wittgenstein in Cambridge, sondern (unter wohl noch größerem Einfluss von George E. Moore) in Oxford ihre Blüte erlebt. ${ }^{82}$ Zu den Hauptvertretern zählen Gilbert Ryle, Peter F. Strawson, Herbert P. Grice - und John L. Austin, dessen Sprechakttheorie von seinem amerikanischen Studenten John R. Searle systematisiert und weiterentwickelt wird.

\subsection{Austin \\ Spezifität der Sprechakttheorie Austins}

Austins Einfluss auf die Sprechakttheorie äußert sich weniger durch eigene Publikationen als durch seine Lehrtätigkeit. ${ }^{83}$ Bedeutsam geworden sind v. a. die Mitschriften aus einer von ihm 1955 in Harvard gehaltenen Vorlesung, die 1962 unter dem Titel „How to do things with words" veröffentlicht wurden. Damit hinterlässt er keine geschlossene Theorie, sondern eher eine lose Aufeinanderfolge von Betrachtungen, die weder den Anspruch auf Vollständigkeit erheben können noch in sich immer widerspruchsfrei sind. ${ }^{84}$

\section{Konstative und performative Sprechakte}

Im Einklang mit Wittgenstein bzw. der "Ordinary Language Philosophy” will Austin sich nicht mehr auf die Beschäftigung mit deskriptiven Aussagen beschränken: Neben konstativen Sprechakten, die wahr oder falsch sein können, gebe es performative Sprechakte ohne Wahrheitswert, die im Gegensatz zu ersteren dadurch gekennzeichnet seien, dass sie glücken oder nicht glücken können. ${ }^{85}$ Austin stellt in seinen Vorlesungen ausführlich sowohl die Glückensbedingungen als auch insbesondere mögliche Unglücksfälle dar, die z. B. darin bestehen, dass sich ein Sprecher undeutlich ausdrückt („misfire“) oder dass er unaufrichtig ist („abuse“).

Performative Sprechakte können nach Austin explizit performativ oder implizit (primär) performativ sein. In explizit performativen Äußerungen wird mit Hilfe von performativ gebrauchten SB-Verben explizit gesagt, was man tut, z. B. in Sätzen wie „Ich verspreche dir (hiermit), dass ich das Buch mitbringen werde.“ oder "Die Anwesenden werden (hiermit) aufgefordert, den Raum zu verlassen.", in denen ,versprechen' bzw. ,auffordern' performativ verwendet werden. ${ }^{86}$ Weniger deutlich, dafür aber ökonomischer sind implizit performative Äußerungen

die die Sachverhalte der Welt widerspiegelt. Dabei würde die logische Form der Sätze die Sachverhalte genau abbilden. In den ,Philosophischen Untersuchungen' [1953], mehr als 20 Jahre später, hat er dann die radikale Wende zur Sprachanalyse vollzogen, wobei er aufzuzeigen versucht, daß viele der Probleme beim Entwurf einer logischen Beschreibungssprache Scheinprobleme sind, die die Alltagssprache suggeriert. “

82 Vgl. SCHLIEBEN-LANGE 1979, 33.

${ }^{83}$ Es gibt nur wenige Aufsätze von Austin, die Themen der Sprechakttheorie betreffen, wie z. B. AUSTIN 1956 1957 und AUSTIN 1971. Genaueres zu Austins Sprechakttheorie kann man u. a. nachlesen bei STAFFELDT 2009, 37ff.; HARRAS 2004, 114ff. und SCHLIEBEN-LANGE 1979, $33 \mathrm{ff}$.

${ }^{84}$ Die folgende Darstellung von Austins Sprechakttheorie bezieht sich, soweit nicht anders angegeben, auf AUSTIN 2009 bzw. AUSTIN 2002.

${ }^{85}$ Vgl. a. AUSTIN 1971. Auf die Performativität bzw. den Handlungsaspekt von Sprache hat bereits Erich Koschmieder (KOSCHMIEDER 1945) im Zusammenhang mit einer besonderen Verwendungsweise des hebräischen Perfekts („Koinzidenzfall“) hingewiesen. Zum Vergleich mit Austin vgl. a. WAGNER 1997, 51ff.

${ }^{86}$ SB-Ausdrücke werden also nicht nur zur Bezeichnung von Sprechakttypen (z. B. BITTEN) genutzt, sondern können oft auch performativ (z. B.: „Wir bitten Sie, sich umgehend in die Empfangshalle zu begeben. “) verwendet werden. Außerdem ist eine referierende Gebrauchsweise (z. B. „Er bat sie telefonisch mehrfach um Hilfe.“) möglich. Was die performative Verwendung betrifft, so zeigen bereits die hier genannten Beispiele, dass sie in sehr verschiedener (grammatischer) Form auftreten. Ausführlicher dazu (in Bezug auf das Deutsche): WEIGAND 2003, 181ff., die i. E. zahlreiche Varianten solcher „lexikalisch ausgedrückter direkter Sprechakte“ differenziert, wie 
wie „Ich werde das Buch mitbringen. “87 Implizit performative Äußerungen können explizit gemacht werden, wobei verschiedene Indikatoren (wie z. B. Verbmodus, Betonung, Adverbien und adverbiale Bestimmungen, Konjunktionen, begleitendes Verhalten des Sprechers und die Umstände der Äußerungssituation) die Art der vorliegenden Handlung signalisieren. ${ }^{88}$

Im Laufe der Vorlesungsreihe kommt es zu einer Wende, als Austin zur Überzeugung gelangt, dass es rein deskriptive Aussagen gar nicht gibt, sondern Menschen letztlich mit allen sprachlichen Äußerungen handeln und entsprechend alle sprachlichen Äußerungen performativ sind. ${ }^{89}$ Auch konstative Äußerungen können glücken oder missglücken. Und die von ihm ursprünglich als performativ bezeichneten Äußerungen können durchaus auch nach dem Kriterium ,wahr oder falsch' beurteilt werden.

\section{Aktlehre}

An die Stelle der Trennung von konstativen und performativen Sprechhandlungen setzt Austin seine Aktlehre. Er geht davon aus, dass jeder Sprechakt drei verschiedene Dimensionen hat: Eine Sprechhandlung besteht zum einen darin, dass man mittels eines lokutionären Aktes etwas sagt, z. B.: „Ich werde das Buch mitbringen. “ Zum anderen vollzieht man, indem man dies tut, durch einen illokutionären Akt eine Handlung mit einer bestimmten kommunikativen Funktion (,illocutionary force" = illokutive Kraft oder auch Rolle), z. B. verspricht man etwas. Und außerdem kann man dadurch, dass man etwas sagt, mit einem perlokutionären Akt eine bestimmte Folgewirkung (,consequential effects upon the feelings, thoughts, or actions of the audience, or of the speaker, or of other persons") hervorrufen, z. B. eine freudige Reaktion des Angesprochenen.

Der lokutionäre Akt besteht i. E. aus einem phonetischen Akt („uttering certain noises“), einem phatischen Akt („uttering of certain vocables or words, i.e. noises of certain types, belonging to and as belonging to, a certain vocabulary, conforming to and as conforming to a certain grammar“) und einem rhetischen Akt („performance of an act of using those vocables with a certain more-or-less definite sense and reference"). Die Bedeutung des lokutionären Aktes kann wahr oder falsch sein. Ein illokutionärer Akt dagegen kann (wie die ursprünglichen performativen Sprechakte) glücken oder nicht glücken. Die zur Beurteilung des Glückens entscheidenden illokutionären Effekte (,illocutionary effects“) bestehen gemäß Austin dabei darin, dass der Adressat eine Äußerung überhaupt versteht (,securing of uptake “) ${ }^{90}$, dass die Äußerung (z. B. im Zusammenhang mit deklarativen Sprechakten wie bei einer Taufe) wirksam wird (,taking effect“) und dass sie eine (standardmäßige) Antwort oder eine andere Reaktion hervorruft (,inviting a response or sequel“), die sowohl vonseiten des Sprechers selbst (z. B. das Erfüllen eines Versprechens) als auch von einer anderen Person kommen kann. Alle diese illokutionären Effekte sind konventionell mit der Illokution verbunden. Dies unterscheidet sie

\footnotetext{
z. B. einfach performative und modifiziert performative Sprechakte. Vgl. a. Polenz 2008, 196f. Vgl. außerdem SÖKELAND 1980, 49f.

${ }^{87} \mathrm{VgI}$. WAGNER 1997, 138.

${ }^{88} \mathrm{Vgl}$. dagegen z. B. LEECH 1983, 174ff., der bezweifelt, dass jede Sprechhandlung performativ ausgedrückt werden kann. Vgl. im Übrigen das Kap. „Indirekte Sprechakte“ ab S. 20.

${ }^{89}$ Inwieweit die bis dahin gemachten Aussagen zu den performativen Äußerungen sich auf die illokutionären Akte übertragen lassen, ist nicht ganz klar. Vgl. LuPPOLD 2015, 349 N. 726 und HARRAS 2004, 143ff.

${ }^{90}$ Searle erkennt sogar nur den Aspekt des Verstehens als Teil des illokutionären Aktes bzw. Effektes an: Vgl. z. B. RoLF 1993, 77f.
} 
It. Austin von den perlokutionären Effekten („perlocutionary effects“), die konventionell nicht festgelegt sind. ${ }^{91}$ Diese Differenzierung von illokutionären und perlokutionären Effekten bzw. Akten hat viel Kritik hervorgerufen. So sieht z. B. Strawson den Unterschied zwischen beiden eher in der Sprecherintention begründet, die bei den illokutionären Akten im Unterschied zu den perlokutionären deutlich zu erkennen gegeben werde und entsprechend ohne Weiteres zugegeben werden könne. ${ }^{92}$ Von anderen wird darauf hingewiesen, dass perlokutionäre Akte durchaus konventionale Kennzeichen aufweisen können, wie es bspw. der Fall ist bei justiziablen Beleidigungen und Verleumdungen. ${ }^{93}$ Wie auch immer, die Unterscheidung beider Teilakte ist nicht leicht, und das mag einer der Gründe sein, weshalb man den perlokutionären Akt lange in der sprechakttheoretischen Forschung vernachlässigt hat. ${ }^{94}$

\section{Sprechaktklassifikation}

Abschließend noch ein paar Worte zu Austins Sprechaktklassifikation ${ }^{95}$ : Er unterscheidet verdiktive (urteilende), exerzitive (Macht ausübende), kommissive (den Sprecher zu etwas verpflichtende), konduktive (sich auf Einstellungen oder das Verhalten in der Gesellschaft beziehende) und expositive (feststellende) Sprechakte. ${ }^{96}$ Diese Einteilung und die Zuordnung der zugehörigen Verben erscheinen eher intuitiv, obgleich eine lexikographische Methode mit einer Art Cluster-Verfahren zugrunde liegt, mit der Netze von (verbalen) Ausdrücken durch Querverweise im Wörterbuch ermittelt werden. ${ }^{97}$ An der Klassifikation wird u. a. bemängelt, dass Austin SB-Verben mit Sprechakten bzw. Sprechakttypen verwechsle, dass nicht alle von ihm angeführten Beispielverben (explizit) performativ gebraucht werden könnten, dass die Sprechaktklassen nicht überzeugend definiert würden und die Unterscheidungskriterien für die einzelnen Klassen zu heterogen seien, dass es aus den genannten Gründen zu zahlreichen Überschneidungen der Kategorien komme, dass es auch innerhalb der Kategorien Unstimmigkeiten gebe, weil z. B. die genannten Verben nicht der Definition der zugeordneten Kategorie

\footnotetext{
${ }^{91}$ Genaueres zur Unterscheidung von illokutionären und perlokutionären Akten: LUPPOLD 2015, 359ff. Zu den perlokutionären Akten bzw. Effekten vgl. a. MelBAUER 2008, 86 und v. a. ORTNER 2014b, 266 (mit Bezug auf WEIGAND 2003, 12f.): „Manche Linguistinnen und Linguisten lehnen die Perlokution als Teil des Sprechakts gänzlich ab: Es gebe nur perlokutionäre Effekte, aber keine perlokutionären Akte [...]. Als Kompromiss kann Weigand (2003: 12f.) folgend vorgeschlagen werden, perlokutionäre Effekte als nicht-konventionelle, psychische Prozesse bei Hörerinnen und Hörern zu definieren, während perlokutionäre Akte an bestimmte Erwartungen und Konventionen gebundene reaktive Sprechakte sind (z.B. Versprechen oder Zurückweisungen nach Drohungen). Allerdings sind weder Perlokutionen noch perlokutionäre Effekte vollkommen beliebig - es gibt zumindest üblichere/erwartbare und weniger übliche/nicht erwartbare Möglichkeiten der Reaktion [...]."

92 StraWson 1971. Vgl. SCHLIEBEN-LANGe 1979, 37.

${ }^{93}$ Vgl. StAFFELDT 2009, 44 N. 34. Vgl. a. N. 91.

${ }^{94}$ Vgl. z. B. LUPPOLD 2015, 372; ARWEILER 2010, 202f. und SCHLIEBEN-LANGE 1979, 87ff. Andererseits sind sogar eigene Klassifikationen von perlokutionären Sprechakten entstanden: Vgl. z. B. STAFFELDT 2009, 106f. und WEIGAND 2003, 81ff. Vgl. a. ORTNER 2014b, 266f. und ROLF 2006, $2524 \mathrm{f}$.

${ }^{95}$ Die Begriffe (Sprechakt-)Klassifikation und Taxonomie werden in der vorliegenden Arbeit synonym verwendet. Vgl. aber WEIGAND 2003, 72ff., die zwischen induktiver Klassifikation und deduktiver Taxonomie unterscheidet.

96 Die englischen Begriffe lauten: „verdictives“, „exercitives“, „commissives“, „,behabitives“ und „expositives“.

${ }^{97}$ Austin erläutert dieses Verfahren in AUSTIN 1956 - 1957. Es wird auch als Vish!-Methode bezeichnet. Vgl. STAFFELDT 2009, 44f. Vgl. außerdem z. B. BALLMER UND BRENNENSTUHL 1981, 54, die für ihre Klassifikation eine ähnliche Methode anwenden.
} 
entsprächen und sehr verschiedenartige Verben in einer Klasse zusammengefasst würden, allgemein also, dass sie unsystematisch und theoretisch nicht genügend durchdacht sei. ${ }^{98}$ Austins Klassifikation konnte sich aufgrund all ihrer Unzulänglichkeiten zwar nicht durchsetzen, hat jedoch zu vielen anderen, in sich stimmigeren Klassifikationsversuchen angeregt. ${ }^{99}$

\subsection{Searle \\ Grundlage der Sprechakttheorie Searles}

Grundlegend für Searles Sprechakttheorie sind die Annahme vom „Sprechen als regelgeleiteter Tätigkeit“ und das „Prinzip der Ausdrückbarkeit“, nach dem alles gesagt werden kann, was man meint. ${ }^{100}$ Für Searle besteht eine enge Verbindung zwischen Handlungsfunktion und sprachlicher Äußerungsform. Ausgehend von den sprachlichen Äußerungen und einer Untersuchung, nach welchen Regeln diese erfolgen, müsste es also möglich sein, zu den Regeln für den Vollzug von Sprechakten und damit zur Bedeutung der einzelnen Sprechhandlungen vorzudringen bzw. umgekehrt. ${ }^{101}$

\footnotetext{
${ }^{98} \mathrm{Vgl}$. z. B. Searle 1976, 7ff. bzW. Searle 1980, 89ff.; Ballmer und BrenNenstuhl 1981, 53ff.; SChmitt 2000, 114 und WEIGAND 2003, 42. Zur (auch bei Searle) anzutreffenden Vermischung von SB-Ausdrücken mit Sprechakten bzW. Sprechakttypen ist Folgendes anzumerken: Sie geben zwar wichtige Hinweise auf mögliche Sprechakttypen, sind jedoch nicht mit ihnen gleichzusetzen. So kann mit demselben SB-Ausdruck auf verschiedene Sprechakte Bezug genommen werden (z. B. ,versprechen' zum Ausdruck eines VERSPRECHENS, aber auch einer DROHUNG), und umgekehrt gibt es für einen Sprechakt z. T. mehrere SB-Ausdrücke. Diese betonen i. E. meist verschiedene Aspekte der Sprechhandlung und stehen teilweise im Verhältnis der Hyperonymie oder Hyponymie zueinander. Vgl. (u. a. auch zu SB-Ausdrücken, die nicht explizit performativ verwendet werden können) STAFFELDT 2009, 91ff. und ebd., 98ff. sowie SCHMITT 2000, 120ff. Vgl. des Weiteren MAAS UND WUNDERLICH 1974, 131; LEECH 1983, 174ff. und ebd., 198ff. Die Frage, wieweit die Existenz von (nicht unbedingt performativ verwendbaren) SB-Ausdrücken notwendige Voraussetzung für die Existenz entsprechender Sprechakte ist, wurde z. T. kontrovers diskutiert. Vgl. z. B. SCHLIEBEN-LANGE 1976, 114: „Ein Korollar meiner These ist, daß es nur dann Sprechakte gibt, wenn es auch Bezeichnungen (nicht notwendigerweise Performativa) dafür gibt. Es scheint so, daß Bezeichnungen für sprachliche Handlungen erst relativ spät entstanden sind. Andererseits setzt für mich das Verständnis von Sprechakten als ,sozialen Handlungen' [...] voraus, daß es möglich ist, sie zu identifizieren und sich über ihren Sinn zu verständigen. “ Dagegen Weydt in SCHLIEBEN-LANGE U. A. 1979, 67: „,[...] ich meine, daß man doch eigentlich jeden Sprechakt in jeder beliebigen Sprache vollziehen kann, unabhängig davon, ob es ein Verb gibt, das gerade diesen Sprechakt in der entsprechenden Sprache nun auch wirklich definiert. " Vgl. a. Coșeriu in ebd., 74f. sowie (zur recht späten Entstehung explizit performativer Sprechakte) AUSTIN 2009, 71 bzw. AUSTIN 2002, 92.

${ }^{99} \mathrm{Vgl}$. SCHMITT 2000, 114.

${ }^{100}$ Vgl. STAFFELDT 2009, 49ff. Zum „Sprechen als regelgeleiteter Tätigkeit“ vgl. z. B. SEARLE 1969, 22: „The hypothesis then of this work is that speaking a language is engaging in a rule-governed form of behaviour." Zu Searles Unterscheidung von regulativen und konstitutiven Regeln, auf die hier nicht näher eingegangen werden kann: SEARLE 1969, 33ff. und SeARLE 1971, 40ff. Vgl. a. STAFFeLDT 2009, 56f. und HARRAS 2004, 211ff. Zum „Prinzip der Ausdrückbarkeit“ vgl. z. B. SEARLE 1969, 17: „I take it to be an analytic truth about language that whatever can be meant can be said." und ebd., 19: "The principle that whatever can be meant can be said, which I shall refer to as the ,principle of expressibility', is important for the subsequent argument of this book [...]".

${ }^{101} \mathrm{Vgl}$. ebd., 20f.: „But most important for present purposes it [= das Prinzip der Ausdrückbarkeit] enables us to equate rules for performing speech acts with rules for uttering certain linguistic elements, since for any possible speech act there is a possible linguistic element the meaning of which (given the context of the utterance) is sufficient to determine that its literal utterance is a performance of precisely that speech act. "Vgl. dagegen LEECH 1983, 171f. (mit Bezug auf G. A. Millers und P. N. Johnson-Lairds 1976 in Cambridge erschienener Arbeit Language and Perception), der solche Regeln zur Illokutionsbestimmung für überflüssig hält: „Conditions such as Searle's essential conditions, preparatory conditions, and sincerity conditions of illocutions do not have to be independently stated, since comparable (though probabilistic) conditions can in any case be arrived at by virtue of the sense of the utterance and the maxims of the CP [= Kooperationsprinzip]. As Miller and Johnson-Laird put it (1976: 636), , given a set of conversational maxims, a literal interpretation of the utterance, and a specification of its context of use, it is in principle possible to infer its illocutionary force'."
} 


\section{Gelingensbedingungen und Gebrauchsregeln}

Wie Austin formuliert auch Searle Bedingungen („,felicity conditions" = Gelingensbedingungen) ${ }^{102}$, die erfüllt sein müssen, damit Sprechhandlungen gelingen. Neben einigen sehr allgemeinen und grundlegenden Bedingungen zur Kommunikation, Semantik und Intentionalität gehören dazu sieben spezielle Typen von Bedingungen, aus denen Searle vier Typen von semantischen „Regeln für den Gebrauch des Illokutionsindikators“ („rules for the use of the illocutionary force indicating device") ableitet - womit dann die Rückbindung der Handlungsbedingungen an die sprachliche Realisierung erfolgt. ${ }^{103}$ Die Regel des propositionalen Gehalts („propositional-content rule“) bezieht sich auf den Inhalt einer Äußerung. Ein VERSPRECHEN kann bspw. nur in Bezug auf eine zukünftige, DANKEN nur in Bezug auf eine vergangene Handlung realisiert werden. Die Einleitungs- oder Vorbereitungsregeln („preparatory rules“) legen z. B. hinsichtlich eines VERSPRECHENs fest, dass der Adressat an der Ausführung des Versprochenen tatsächlich Interesse hat, der Sprecher dies weiß und es nicht um eine selbstverständliche Handlung geht. Dem liegen eine entsprechende Präferenz- bzw. Relevanzbedingung zugrunde. Die Aufrichtigkeitsregel (,sincerity rule“) verlangt, dass der Sprecher z. B. tatsächlich beabsichtigt, ein gegebenes VERSPRECHEN zu erfüllen. Die wesentliche Regel („essential rule") schließlich beinhaltet den Kern der illokutionären Handlung, also z. B. die Übernahme der Verpflichtung zur Erfüllung eines VERSPRECHENs durch die entsprechende sprachliche Äußerung.

Die von Searle formulierten Bedingungen und Regeln sind u. a. deshalb kritisiert worden, weil nicht unterschieden wird zwischen Bedingungen, die unbedingt notwendig sind, und solchen, die es nicht sind. So gibt es durchaus Sprechakte, die erfolgreich sein können, ohne die Bedingung des propositionalen Gehalts oder die Aufrichtigkeitsbedingung zu erfüllen, wie z. B. das GRÜSSEN. ${ }^{104}$ Wirklich notwendig sind wohl nur die Einleitungsbedingungen und v. a. die wesentliche Bedingung. Problematisch ist außerdem die mit der Zuordnung von Gelingensbedingungen und Regeln für den Gebrauch des Illokutionsindikators verbundene „Literal Force Hypothesis“. Diese ist nicht so eindeutig wie von Searle dargestellt. Das gilt insbesondere für Sprechakte, die nicht mittels performativ gebrauchter Verben explizit ausgedrückt werden, sondern durch andere Illokutionsindikatoren, wie z. B. Wortstellung, Intonation und Verbmodus. ${ }^{105}$

\section{Indirekte Sprechakte}

Noch schwieriger sind diesbezüglich die indirekten Sprechakte zu bewerten. Während es sich bei den (nach Austins Terminologie) implizit performativen Akten letztlich auch um direkte

\footnotetext{
102 Die Begriffe ,Glückensbedingungen', wie ich ihn im Kapitel zu Austin verwendet habe, und ,Gelingensbedingungen', wie ich ihn im Folgenden im Zusammenhang mit Searles Sprechakttheorie verwenden werde, sind im Prinzip synonym, wobei letzterer in der Fachliteratur gebräuchlicher zu sein scheint.

103 In SEARLE 1969, 66f. finden sich mehrere Beispiele dafür, wie die Regeln für einzelne Sprechakte aussehen können. In SEARLE 1971, 46ff. erläutert er die Bedingungen bzw. Regeln außerdem ausführlich am Beispiel des VERSPRECHENs. Im Folgenden beziehe ich mich auf die dort gemachten Ausführungen.

104 Vgl. Meibauer 2008, 94. Vgl. a. SeARLE 1971, 43, wo Interjektionen wie „Hurrah!“ und „Ouch!“ trotz fehlender propositionaler Basis ein Sprechaktstatus zugesprochen wird, und ORTNER 2014b, 229. Vgl. außerdem S. 28.

105 Vgl. z. B. HUANG 2014, 137f.; LEVINSON 2011, 263ff. und MEIBAUER 2008, 93f. Zu den verschiedenen Illokutionsindikatoren vgl. z. B. SEARLE 1971, 44.
} 
Sprechakte handelt ${ }^{106}$, sind bei Searle mit indirekten Sprechakten solche gemeint, bei denen es einen Gegensatz zwischen einer primären (auf die tatsächliche Intention des Sprechers bezogenen) Illokution und einer sekundären (durch die Art der sprachlichen Formulierung wörtlich ausgedrückten) Illokution gibt. ${ }^{107}$ Mit einer Äußerung wie „Can you reach the salt?" wird z. B. direkt (sekundär) eine FRAGE ausgedrückt, indirekt (primär) hingegen eine BITTE. ${ }^{108}$

Die Annahme einer doppelten Illokution muss dabei eher als ein theoretisches Konstrukt betrachtet werden, das nicht immer sinnvoll anwendbar ist. Bei rhetorischen Fragen scheint es zumindest zweifelhaft, dass der Sprecher tatsächlich zwei Sprechakte, die völlig konträren Bedingungen unterliegen (wie z. B. FRAGEN und BEHAUPTEN), gleichzeitig vollzieht. Manchmal ist zwar ein - meist scherzhafter - Bezug auf den direkten Akt möglich, wie z. B. bei der oben zitierten Frage nach dem Salz; oft ist eine derartige Reaktion aber unangemessen und wirkt eher albern. Dieses „Absurditätskriterium “109 kann als ein Kennzeichen indirekter Sprechakte gelten. Der Angesprochene reagiert in solchen Fällen entsprechend i. d. R. auch nur auf den indirekten Sprechakt, und dies z. T. genauso schnell wie bei direkten Sprechakten, da viele indirekte Sprechakte bereits weitgehend konventionalisiert sind. ${ }^{110}$

Zum Vollzug konventionaler indirekter Sprechakte können die Gelingensbedingungen in unterschiedlicher Weise thematisiert werden. Im Falle einer Aufforderung ist es bspw. möglich, unter Bezug auf die Einleitungsregeln eine Frage zu stellen wie „Könntet ihr etwas leiser sein?“ oder unter Bezug auf die Aufrichtigkeitsregel zu sagen: „Ich möchte, dass du jetzt gehst. “ In beiden Fällen wird zugleich auf die Regel des propositionalen Gehalts referiert (Zukunftsbezug der Handlung). ${ }^{111}$ Um solche und insbesondere auch andere, nicht-konventionale indirekte Sprechakte zu erschließen, benötigt der Adressat ein entsprechendes sprachliches Wissen, wie z. B. ein allgemeines Bewusstsein des Kooperationsprinzips von Grice und der damit verbundenen Konversationsmaximen, nach denen ein Sprecher eine sprachliche Äußerung so informativ wie eben notwendig gestaltet (Maxime der Quantität), sich so wahrheitsgetreu wie möglich äußert (Maxime der Qualität), sich auf Relevantes beschränkt (Maxime der Re-

\footnotetext{
${ }^{106}$ Searle unterscheidet nicht mehr wie Austin zwischen ,explizit performativ' und ,implizit performativ', sondern verwendet nur noch den Begriff ,performativ' (vs. ,nicht performativ'), der das Austin'sche ,explizit performativ` meint. Vgl. S. 16.

107 Vgl. z. B. SEARLE 1975, 60 und ebd., 62.

108 Zu berücksichtigen ist hierbei aber auch die zugrunde liegende Sprechaktklassifikation. FRAGEN werden z. B. in vielen Klassifikationen (wie auch bei Searle) ebenso unter die Direktiva subsumiert wie BITTEN. VgI. SCHMITT 2000, 165.

${ }^{109}$ Vgl. z. B. SÖKELAND 1980, 44.

110 Vgl. z. B. ebd., 41ff.; SCHMItT 2000, 162ff. und STAFFELDT 2009, 66ff. Zur Verarbeitungszeit bei der Rezeption direkter und indirekter Sprechakte vgl. zudem WüEST 2011, 43: „Wenn man [...] die Bedeutung der indirekten Sprechakte nur über Umwege erschließen könnte, so wäre anzunehmen, dass die Verarbeitungszeit eines indirekten Sprechaktes länger dauerte als die eines direkten Sprechakts. Eine Reihe von psycholinguistischen Untersuchungen ist jedoch zum Ergebnis gelangt, dass dies nicht der Fall ist, sofern die indirekten Sprechakte in einem sinnvollen Kontext präsentiert werden [...].“

${ }^{111}$ Vgl. SEARLE 1975, 64ff. und ebd., 71ff. Dort werden die hier angeführten und noch zahlreiche weitere Beispiele dafür genannt, wie Aufforderungen konventional indirekt realisiert werden können, und mittels Generalisierungen auf die Gelingensbedingungen bezogen. Vgl. a. HARRAS 2004, 265ff. sowie STAFFELDT 2009, 69: „Dieser indirekte Vollzug ist konventional, weil die sekundäre Illokution jeweils auf Regeln für den Vollzug der primären IIlokution bezogen ist und diese Regeln zum Sprachsystem gehören."
} 
Iation) und sich klar ausdrückt (Maxime der Modalität). Darüber hinaus sind noch verschiedene andere Kenntnisse und Fähigkeiten von Nutzen, wie z. B. ein (gemeinsames) Vorwissen hinsichtlich bestimmter Sachverhalte und die Berücksichtigung des Kontextes einer Äußerung (Beziehungskonstellation, konkrete Situation usw.). ${ }^{112}$

Ob der Adressat einer Äußerung am Ende tatsächlich in jedem Fall so umfangreiche Schlussprozesse anstellt, wie Searle sie anhand eines Beispiels darlegt, scheint fraglich. Auf der anderen Seite ist zu überlegen, ob nicht sogar auch direkte Sprechakte auf irgendeine Weise erschlossen werden müssen. In der Realität drücken sich Sprecher meistens eher indirekt aus ${ }^{113}$; und letztlich muss wohl bei allen sprachlichen Äußerungen zum richtigen Verständnis immer der Kontext berücksichtigt werden. ${ }^{114}$ Andererseits scheinen viele indirekte Sprechakte unmittelbar (direkt) von den Adressaten verstanden zu werden, weshalb man zumindest bei konventionalisierten indirekten Sprechakten manchmal gar nicht mehr von indirekten Sprechakten sprechen will. ${ }^{115}$

Macht es also überhaupt Sinn, direkte und indirekte Sprechakte zu unterscheiden? Man sollte sich der mit dem Konzept der indirekten Sprechakte verbundenen Probleme auf jeden Fall bewusst sein und es mehr als analytisches Instrument zum besseren Verständnis und zur Erklärung bestimmter Phänomene betrachten. In diesem Sinne hat es durchaus seine Berechtigung. ${ }^{116}$ Damit ist es u. a. möglich, bestimmte Sprecherstrategien aufzudecken, indem man nach den einer eher direkten oder eher indirekten Ausdrucksweise zugrunde liegenden Absichten forscht, wobei von einer „indirectness scale“117 auszugehen ist, d. h. einem Kontinuum mit mehreren Zwischenstufen, beginnend bei sehr explizit formulierten direkten Sprechakten hin zu sehr implizit formulierten indirekten Sprechakten. ${ }^{118}$

Als einen Hauptgrund für indirekte Formulierungen nennt Searle das Bemühen um Höflichkeit, um z. B. eine Aufforderung abzumildern. ${ }^{119}$ Es gibt aber auch andere Gründe: Kennzeichnend für indirekte Sprechakte sind ihre Mehrdeutigkeit und Unverbindlichkeit und die damit zusammenhängenden vielfältigeren „Reaktions- und Rückzugsmöglichkeiten“ für Adressat bzw.

\footnotetext{
112 Vgl. Searle 1975, 60ff. Vgl. außerdem SÖKeLAND 1980, 46ff.; WeIgAND 2003, 211ff. und ebd., 243f. sowie MeIBAUER 2008, 103. Auf die Implikaturentheorie von Grice kann hier nicht weiter eingegangen werden. Zum Unterschied von Implikaturentheorie und Theorie der indirekten Sprechakte vgl. z. B. ebd., 103 und RoLF 2013, 61ff. Zur „Theorie des illokutionären Schließens“ (in Bezug auf direkte und indirekte Sprechakte) vgl. z. B. MEIBAUER 2008, 106 bzW. BACH UND HARNISH 1979.

113 Vgl. z. B. HuANg 2014, 138; LeVInSON 2011, 264; HARRAS 2004, 228 und SCHLIEBEN-LANGe 1979, 91. Eindeutig direkte Sprechakte sind relativ selten. Zu ihnen kann man aber bspw. explizit performative Handlungsanweisungen wie „Hiermit wird angeordnet, dass ab sofort in allen öffentlichen Gebäuden Mund-Nasen-Schutzmasken getragen werden müssen. “ zählen, die unmittelbar, d. h. „direkt“ handlungswirksam werden.

${ }^{114}$ Vgl. z. B. LEVINSON 2011, 274.

115 Vgl. z. B. SöKELAND 1980, 44. Vgl. a. HINDELANG 2010, 96, der die Bezeichnung, semantisches Muster' statt, sekundärer illokutionärer Akt' bevorzugt.

${ }^{116}$ Vgl. SÖKELAND 1980, 44.

117 LEECH 1983, 123.

${ }^{118}$ Vgl. ebd., 123ff., der u. a. auch anmerkt, dass zwei (korrelierende) „indirectness scales“ unterschieden werden können, eine aus der Perspektive des Sprechers und eine aus der des Adressaten. Vgl. außerdem SBISÀ 1995, 501 SOwie ARNDT UND JANNEY 1987, 195ff. („The interpretation of variations in verbal directness“), die zwischen „direct", „less direct" sowie „,indirect" unterscheiden und ausführlich die entsprechenden sprachlichen Gestaltungsmöglichkeiten (im Englischen) untersuchen.

119 SEARLE 1975, 74f.
} 
Sprecher. ${ }^{120}$ Dies ist v. a. im Rahmen einer durch Distanz geprägten Kommunikation wichtig. Andererseits sind gerade dort manchmal umständlichere explizite Formulierungen (durch performative Formeln) erforderlich, während eine größere Nähe zwischen zwei Personen (aufgrund des gemeinsamen Vorwissens) indirektere Formulierungen zulässt, die durch Verkürzungen und Weglassen von Details charakterisiert sind. Dass mit dem Satz "Morgen ist Donnerstag." eine Aufforderung verbunden sein kann, die Sportsachen vorzubereiten, erschließt sich bspw. nur jemandem, der weiß, dass donnerstags regelmäßig das Fußballtraining stattfindet. ${ }^{121}$ Hiermit geht eine "Ökonomisierung der Kommunikation "122 einher, v. a. aber wird Vertrautheit signalisiert. ${ }^{123}$ Insgesamt ist die abschwächende Wirkung von indirekten Sprechakten Kennzeichen eines konsensorientierten Sprachstils. ${ }^{124}$ Es gibt allerdings auch Fälle, in denen indirekte Sprechakte eine verstärkende Wirkung haben und z. T. besonders unhöflich und verletzend sind, wie z. B. die Frage „Wollt ihr wohl ruhig sein?“ (im Vergleich zu „Ich bitte euch, ruhig zu sein. “) ${ }^{125}$ oder gar ironische Äußerungen wie ein DROHENDES „Ich verspreche dir, morgen zu kommen."126

\section{Aktlehre}

Searle hat Austins Aktlehre aufgegriffen, jedoch z. T. abgewandelt. ${ }^{127}$ Er löst Austins lokutionären Akt auf, indem er den phonetischen und phatischen Akt als Äußerungsakt (,utterance act") zusammenfasst und den rhetischen Akt als propositionalen Akt separiert, der wiederum aus einem Prädikations- und einem Referenzakt zusammengesetzt ist. ${ }^{128}$ Im Zentrum steht bei Searle der illokutionäre Akt, den er von Austin übernimmt. Eine eindeutige Definition findet sich bei ihm allerdings nicht; der Begriff der Illokution wird weitgehend identifiziert mit dem des Sprechaktes an sich. ${ }^{129}$ Den perlokutionären Akt erwähnt er zwar, betrachtet ihn aber mehr als zusätzliches Element denn als tatsächlichen Bestandteil des Sprechaktes. ${ }^{130}$

\footnotetext{
120 SÖKELAND 1980, 150ff. Vgl. WAGNER 1997, 43 und SCHMITT 2000, 162f. Zu Phänomenen wie Täuschung und Verschleierung, die eine gewisse Nähe zu den indirekten Sprechakten aufweisen, vgl. SöKELAND 1980, 147ff.

121 Vgl. ebd., 153f. und HINDELANG 2010, 97.

122 Vgl. SCHMITT 2000, 163.

123 SÖKELAND 1980, 154.

124 WÜEST 2011, 45f. Vgl. SÖKELAND 1980, 155.

125 WÜEST 2011, 45.

${ }^{126}$ Vgl. z. B. HARRAS 2004, 265 und WüEST 2011, 45. Vgl. außerdem SÖKELAND 1980, 155f., der solche Sprechakte, „bei denen tatsächliche und durch Basisindikatoren indizierte Illokution in einem Gegensatz zueinander stehen“, nicht zu den indirekten Sprechakten zählt.

${ }^{127}$ Vgl. z. B. SEARLE 1969, 22ff. Es gibt auch andere Aktlehren mit einer Ausdifferenzierung weiterer Teilakte, die aber z. T. Ausmaße annimmt, die kein sinnvolles Arbeiten damit mehr zulassen, wie z. B. in BURKHARDT 1986, der 20 (!) verschiedene Teilakte unterscheidet. Vgl. STAFFELDT 2009, 59ff.

${ }^{128}$ Zu den Gründen für diese Änderungen, durch die u. a. das Problem der Referenzpotentiale sprachlicher Ausdrücke angemessen berücksichtigt werden soll, vgl. z. B. ebd., 58f. Zu den sprachphilosophischen Implikationen vgl. SEARLE 1969, 72ff. und ebd., 157ff. (zum Referenzakt) bzw. ebd., 97ff. (zum Prädikationsakt).

${ }^{129} \mathrm{Vgl}$. z. B. SEARLE 1971, 39: ,[...] the production of the sentence token under certain conditions is the illocutionary act, and the illocutionary act is the minimal unit of linguistic communication." und SEARLE UND VANDERVEKEN 1985, 1: „The minimal units of human communication are speech acts of a type called illocutionary acts. “ Vgl. a. SBISÀ 1995, 499: „In this view, widely adopted by other philosophers and linguists, the illocutionary act coincides with the complete speech act [...], and its characteristic linguistic form is the complete sentence." und WEIGAND 2003, 48f.: „Für Searle bleibt das Konzept, auf dem seine Theorie begründet ist, die Illokution, ein undefinierter, nur tautologisch als ,das, was bei der Lokution geschieht' aufgeschlüsselter Begriff. “ Vgl. a. S. 26.

130 Vgl. z. B. SBISÀ 1995, 500: „Perlocution, however, is not considered by him [d. h. Searle] as an aspect of the complete speech act, but as an additional element."
} 
Alle Teilakte sind eng miteinander verbunden und nur analytisch voneinander zu trennen. Dies trifft insbesondere auf den illokutionären und propositionalen Akt zu. ${ }^{131}$ Für Searle besteht ein Sprechakt aus der Verbindung einer Handlungsfunktion, der illokutionären Kraft („force“ = F), und dem propositionalen Gehalt (,proposition“ = p) einer Äußerung und wird entsprechend visualisiert durch $F(p)$.

\section{Sprechaktklassifikation}

\section{Sprechaktkategorien und Klassifikationskriterien}

Während Wittgenstein mit seinem Sprachspielkonzept von unendlich vielen Möglichkeiten, mit Sprache zu handeln, ausgeht ${ }^{132}$, ist für Searle die Menge potenzieller Sprechakte begrenzt, insofern es nur eine bestimmte Anzahl von Basishandlungen gebe, die Menschen mit Sprache vollziehen können. ${ }^{133}$ Er unterscheidet entsprechend fünf (deduktiv hergeleitete) Kategorien von Handlungen. ${ }^{134}$ Diese definiert er durch ihren illokutionären Zweck (,illocutionary point “) ${ }^{135}$, die Anpassungsrichtung (,direction of fit“) von Welt und Worten und den zum Ausdruck gebrachten psychischen Zustand („psychological state“) des Sprechers.

Mit Assertiva ${ }^{136}$ sagen wir, wie sich eine Sache verhält („we tell people how things are“). Die Worte referieren also auf (nicht nur materielle) Gegebenheiten der Welt („words-to-world“). Der Sprecher legt sich mehr oder weniger dezidiert auf den Wahrheitsgehalt der ausgedrückten Proposition fest, je nachdem wie ausgeprägt der eigene Glaube („,belief“) hinsichtlich des betreffenden Sachverhalts ist.

\footnotetext{
${ }^{131} \mathrm{Vgl}$. SEARLE 1971, 43. Searle weist dort auch auf die durchaus vorhandene Möglichkeit von illokutionären Akten ohne propositionalen Gehalt hin. VgI. N. 78 sowie WEIGAND 2003, 76. Zu den unterschiedlichen Dimensionen von (semantischer und pragmatischer) ,Bedeutung' in diesem Zusammenhang vgl. ebd., 57. Vgl. a. SBISÀ 1995, 499. 132 Vgl. WiTTGENSTEIN 2001.

133 SEARLE 1976, 22f. StAFFELDT 2009, 72 bezieht die von Searle präsentierten Oberklassen auf „die großen Dinge des menschlich soziobiologischen Lebens“: Denken (Assertiva), Fühlen (Expressiva), Handeln (Direktiva und Kommissiva) und Sein (Deklarativa). Vgl. a. WEIGAND 2003, 74, die versucht, die Konzepte von Wittgenstein und Searle miteinander in Einklang zu bringen: „Als Form der Unterteilung von Komplexität sind prinzipiell zwei Möglichkeiten denkbar: Zum einen die induktive additive Unterscheidung relevanter Einheiten in Form einer offenen Liste, die etwa nach Wittgenstein durchaus unbegrenzte Möglichkeiten oder Überschneidungen zulässt [...]; zum anderen die durch explizite Kriterien begründete deduktive Unterscheidung der Einheiten, die von der Annahme ausgeht, dass die Zahl grundlegender quasi-universeller Funktionen begrenzt ist. Diese Annahme ist nach meinem Verständnis durchaus mit einer unbegrenzten individuellen Variation in der Wahrnehmung der Funktionen vereinbar, d.h., die unterschiedlichen Positionen von Wittgenstein und Searle beziehen sich auf unterschiedliche Sichtweisen, zugrunde liegende Funktionen versus Performanz des Handelns, und sind durchaus miteinander verträglich."

${ }^{134}$ Im Folgenden werden wesentliche Aspekte der Sprechaktklassifikation Searles gemäß SEARLE 1976 dargelegt und dadurch wichtige Grundlagen expliziert, auf die im weiteren Verlauf dieser Arbeit verschiedentlich zurückgegriffen wird. Eine Auseinandersetzung mit der (illokutionslogischen) Weiterentwicklung in SEARLE UND VANDERVEKEN 1985 würde im Rahmen des hier angestrebten sprachwissenschaftlichen Zugangs zu weit führen (vgl. S. 8), weshalb sie nur gelegentlich kurze Erwähnung findet.

135 Der illokutionäre Zweck ist Teil der illokutionären Kraft, die innerhalb der durch einen gemeinsamen Zweck verbundenen Oberklassen (z. B. Direktiva) bei den verschiedenen Untermustern (z. B. BITTEN vs. BEFEHLEN) differiert. Vgl. STAFFELDT 2009, $71 \mathrm{f}$.

${ }^{136}$ In SEARLE 1976 werden Sprechakte dieser Kategorie noch als ,Repräsentativa“ („representatives“) bezeichnet, später (in SEARLE 1979) entscheidet sich Searle jedoch für den passenderen Begriff ,Assertiva'. Zu den Gründen vgl. a. STAFFELDT 2009, 130: „Der Name Repräsentativa ist deshalb irreführend, weil nicht nur diese Klasse, sondern auch die der Kommissiva, der Direktiva, der Deklarativa und eingeschränkt sogar die der Expressiva etwas mit Repräsentationen zu tun haben."
} 
Mit Direktiva wollen wir jemanden dazu bringen, etwas zu tun („,we try to get them to do things"). Gegebenheiten der Welt sollen also den Worten entsprechend geändert werden („world-to-words“). Der Wille des Sprechers („want", „,wish" oder „desire“) in Bezug auf diese Änderung wird dabei mit jeweils variierender Intensität zum Ausdruck gebracht.

Mit Kommissiva verpflichten wir uns zu einer zukünftigen Handlung („we commit ourselves to doing things"). Wie bei den Direktiva sollen Gegebenheiten der Welt dadurch geändert werden („,world-to-words“). Die Absicht (,intention“) zur Umsetzung der betreffenden Handlung kann dabei unterschiedlich stark ausgeprägt sein.

Mit Expressiva drücken wir unsere Gefühle und Einstellungen aus („we express our feelings and attitudes"). Es gibt keine Entsprechungsrichtung von Wort zu Welt bzw. umgekehrt. Der Sprecher befindet sich angesichts eines bestimmten Ereignisses oder Anlasses in einem besonderen emotionalen Zustand, z. B. empfindet er Bedauern. ${ }^{137}$

Mit Deklarativa bewirken wir eine Veränderung der Wirklichkeit entsprechend des propositionalen Gehalts (,we bring about changes through our utterances“). Die psychologische Einstellung des Sprechers ist für das Gelingen des Sprechakts unerheblich.

Neben den genannten drei Klassifikationskriterien, von denen das letztlich entscheidende der illokutionäre Zweck ist, führt Searle noch weitere neun an, die der Unterklassifizierung innerhalb der fünf Oberklassen dienen. ${ }^{138}$ Anhand des vierten Kriteriums („,differences in the force or strength with which the illocutionary point is presented") kann bspw. zwischen VORSCHLAGEN und (auf etwas) BESTEHEN unterschieden werden, mithilfe des fünften Kriteriums („differences in the status or position of the speaker and hearer as these bear on the illocutionary force of the utterance“) zwischen BEFEHLEN und BITTEN. Durch das sechste Kriterium („differences in the way the utterance relates to the interests of the speaker and the hearer") werden z. B. GRATULIEREN und MITLEID BEKUNDEN voneinander abgegrenzt. Mit dem siebten Kriterium („differences in relations to the rest of the discourse“) können Äußerungen in Bezug auf den Kontext spezifiziert werden, wie z. B. bei ANTWORTEN und EINWENDEN. Das achte Kriterium („,differences in propositional content that are determined by illocutionary forceindicating devices") ermöglicht die Abgrenzung u. a. von BERICHTEN (Vergangenheits- oder

\footnotetext{
${ }^{137}$ Mit dem Substantiv ,Expressiva' (Sg. ,Expressivum') wird im Folgenden ebenso wie mit der Wendung ,expressiver Sprechakt' auf die entsprechende Sprechaktkategorie referiert. Allein für sich wird das Adjektiv, expressiv` auch in allgemeinerer Weise verwendet. Davon wiederum können nach ORTNER 2014a, 68 die verwandten Begriffe ,emotional' und ,emotiv' wie folgt abgegrenzt werden: „Nimmt man eine definitorische Trennung vor, kann ,emotional' dem psychischen Phänomen vorbehalten bleiben, während ,emotiv' als allgemeiner Terminus für die Kategorie des Emotionalen in der Sprache dient und ,expressiv' spezifisch die Intensität eines emotiven Gefühlsausdrucks betrifft [...]."

138 Vgl. z. B. LUPPOLD 2015, 353 N. 748, die meint, in SEARLE UND VANDERVEKEN 1985 zeige sich deutlich, "dass es genau ein Kriterium der Klassifikation illokutionärer Akte gibt: den illokutionären Zweck, der sich aus der WortWelt-Ausrichtung ableiten lässt. Weitere Spezifika illokutionärer Akttypen, wie die Aufrichtigkeitsbedingung oder Bedingungen des propositionalen Gehalts, lassen sich wiederum aus dem illokutionären Zweck ableiten, sind folglich nicht selbst als Klassifikationskriterien zu verstehen. “ bzw. STAFFELDT 2009, 79: „Sie [das vierte bis zwölfte Klassifikationskriterium] dienen nicht zur Aufstellung der Oberklassen, sondern zur Beschreibung und Abgrenzung einzelner Illokutionen. Zudem ist es so, dass mit der Weiterentwicklung der Sprechakttheorie zur Theorie illokutionärer und perlokutionärer Kräfte eine systematische Beschreibungsmöglichkeit gegeben ist, die diese Kriterien integriert hat. "Vgl. SeARLE UND VANDERVEKEN 1985, aber auch SEARLE 1976, 22, wo der illokutionäre Zweck bereits als „the basic notion on which to classify uses of language“ anerkannt wird.
} 
Gegenwartsbezug) und VORHERSAGEN (Zukunftsbezug). Das neunte Kriterium („differences between those acts that must always be speech acts, and those that can be, but need not be performed as speech acts") unterscheidet zwischen Handlungen, die nur als Sprechakt, und solchen, die auch anders realisiert werden können, wie z. B. DIAGNOSTIZIEREN und SCHLUSSFOLGERN. Das zehnte Kriterium („differences between those acts that require extra-linguistic institutions for their performance and those that do not") betrifft $u$. a. die Eigenart vieler deklarativer Sprechakte, die häufig institutionell gebunden sind. So ist es nur während einer kirchlichen Zeremonie möglich, einen Menschen zu TAUFEN, und nur bei einem Gerichtsverfahren, jemanden SCHULDIG zu SPRECHEN, wohingegen Sprechakte wie VERSPRECHEN und FESTSTELLEN ohne einen solchen Rahmen stattfinden. Mit dem elften Kriterium („differences between those acts where the corresponding illocutionary verb has a performative use and those where it does not") kann man illokutionäre Verben bzw. Sprechakte wie BEHAUPTEN, VERSPRECHEN und BEFEHLEN, die auch einen performativen Gebrauch zulassen, von solchen ohne performativen Gebrauch abgrenzen, wie z. B. BEDROHEN. Anhand des zwölften Kriteriums („differences in the style of performance of the illocutionary act“) werden Sprechakte hinsichtlich ihres Vollzugsstils differenziert, wie z. B. BEKANNT GEBEN vs. ANVERTRAUEN.

Die insgesamt zwölf Klassifikationskriterien lassen sich z. T. auf die Gelingensbedingungen ${ }^{139}$ beziehen: Dem ersten Kriterium (,illocutionary point“) liegt die wesentliche Bedingung zugrunde, dem dritten („psychological state“) die Aufrichtigkeitsbedingung, das fünfte und sechste Kriterium sind auf die Einleitungsbedingungen und das achte ist auf die Bedingung des propositionalen Gehalts bezogen. ${ }^{140}$

Kritik

\section{Grundsätzliches}

Die Vielzahl von Differenzierungskriterien und deren unterschiedliche Gewichtung werden mitunter kritisch gesehen. ${ }^{141}$ Als gravierende Schwachpunkte der Sprechaktklassifikation gelten aber (wie bei Austin) v. a. die unzureichende Differenzierung von Sprechakttypen und SBVerben sowie die (von Searle selbst kritisierte) Heterogenität der Klassifikationskriterien. ${ }^{142}$ Diese werden zudem nicht einmal klar und nachvollziehbar definiert, was insbesondere in Bezug auf den doch so zentralen illokutionären Zweck zu denken gibt. ${ }^{143} \mathrm{Es}$ ist also nicht verwunderlich, wenn konkrete Äußerungen z. T. nur sehr schwer den theoretischen Kategorien eindeutig zugewiesen werden können. Eine solche Zuordnung wird dadurch, dass Searle die

\footnotetext{
${ }^{139}$ Vgl. S. 20.

140 Vgl. StAFFELDT 2009, 71ff. und WAGNER 1997, 16f. Es gibt Versuche, die fünf Sprechaktklassen stringent nach den Gelingensbedingungen zu definieren, um so eine Einheitlichkeit der Klassifikationskriterien zu erreichen: Vgl. ROLF 1997 und STAFFELDT 2009, 86ff. Vgl. außerdem SEARLE UND VANDERVEKEN 1985.

141 Vgl. z. B. LUPPOLD 2015, 353 N. 748. SCHMITT 2000, 119 sieht allerdings in der Hierarchisierung von „entscheidenden und weniger wichtigen Kriterien" sogar einen Vorteil gegenüber Austins Klassifikation.

${ }^{142}$ Zur Gleichsetzung von Sprechakt(typ)en und SB-Verben vgl. BALLMER UND BRENNENSTUHL 1981, 57 und außerdem S. 18, v. a. N. 98. Zur Heterogenität der Klassifikationskriterien vgl. z. B. ebd., 57; WAGNER 1995, 269; WAGNER 1997, 22; WEIGAND 2003, 55f. und LEVINSON 2011, 240. Vgl. aber auch RoLF 2006, 2523: „Ein vergleichbarer Niveauunterschied zwischen den unterschiedenen Größen ist bei Searle nicht zu beobachten. Die fünf Sprechaktkategorien Searles beziehen sich allesamt, wenn man so will, auf Funktionen sprachlicher Zeichen in der Verwendung, auf Funktionen von Redeakten." Vgl. außerdem N. 140.

143 Vgl. z. B. BALLMER Und BRENNENSTUHL 1981, 57f.; ULKAN 1992, 76ff.; Rolf 1993, 72; WüESt 2011, 35 und bes. WEIGAND 2003, 48ff.
} 
Sprechaktklassen nur mit wenigen Beispielen veranschaulicht, nicht eben erleichtert. ${ }^{144}$ Teilweise wirken diese außerdem nicht ganz authentisch ${ }^{145}$, was mit Searles Arbeitsweise zusammenhängt: Er geht (im Unterschied zu Austin) tatsächlich vollkommen intuitiv und introspektiv vor, indem er allein auf seine eigene Sprachkompetenz setzt. ${ }^{146}$

Von einigen wird bemängelt, dass sich die Sprechakte (z. B. im Englischen und Deutschen) sehr ungleich auf die fünf Klassen verteilen: Mit Abstand die meisten lassen sich den Assertiva zuordnen, während Kommissiva und Deklarativa kaum vertreten sind. ${ }^{147}$ Auch sonst werden die einzelnen Kategorien und die ihnen zugrunde liegenden Definitionen aus verschiedenen Gründen kritisiert und in unterschiedlicher Weise ergänzt und abgewandelt. So scheint es zweifelhaft, dass der illokutionäre Zweck der Assertiva darin besteht, sich auf die Wahrheit der Proposition zu verpflichten. ${ }^{148}$ Dies sei eher eine Voraussetzung, während der Zweck vielmehr darin liege, „auf die Vorstellungen, die sich A [= der Adressat] von der Welt macht, einzuwirken”. Dabei könne es auch um die bloße Reaktivierung bereits bekannter Vorstellungen gehen. ${ }^{149}$ Hinsichtlich der Direktiva wird u. a. bezweifelt, dass Fragehandlungen darunter subsumiert werden können. Entsprechend werden sie manchmal als eigene Klasse (vgl. z. B. die Erotetika

\footnotetext{
144 Vgl. SCHMItT 2000, 120. Vgl. a. BALLMER UND BRENNENSTUHL 1981, 58.

145 Vgl. z. B. SCHMITT 2000, 120.

146 Vgl. z. B. SeARLE 1969, 13: „The ,justification“ I have for my linguistic intuitions as expressed in my linguistic characterizations is simply that I am a native speaker of a certain dialect of English and consequently have mastered the rules of that dialect, which mastery is both partially described by and manifested in my linguistic characterizations of elements of that dialect." Vgl. a. STAFFELDT 2009, 56 und WEIGAND 2003, 48ff. Vgl. außerdem TUCHEN 2018, 13f., der ausführlicher auf die Vor- und v. a. Nachteile von Intuition und Introspektion als pragmatischer Arbeitsmethode und die von verschiedenen Seiten geäußerte (positive und negative) Kritik daran eingeht. Zu Austin vgl. S. 18.

147 SCHMITT 2000, 122f. Schmitt entwirft aus diesem Grund eine alternative Klassifikation, in der die Assertiva weiter ausdifferenziert werden (vgl. N. 355). Vgl. außerdem BALLMER UND BRENNENSTUHL 1981, 59.

$148 \mathrm{Vgl}$. SEARLE 1976, 10: "The point or purpose of the members of the representative class is to commit the speaker (in varying degrees) to something's being the case, to the truth of the expressed proposition." Vgl. a. BALLMER UND BRENNENSTUHL 1981, 57, wo unter Verweis auf die Verwendung des Verbs ,commit' eine problematische Überschneidung mit den Kommissiva gesehen wird. Vgl. dazu auch S. 25 bzw. SEARLE 1976, 23 und ebd., 11: "Commissives then are those illocutionary acts whose point is to commit the speaker (again in varying degrees) to some future course of action."

149 WÜEST 2011, 35f. Er weist darauf hin, dass es hier um die intendierte, nicht um die tatsächlich erzielte Wirkung geht. Vgl. a. die Definition der Assertiva in KISSINE 2009, 130. LIEDTKE 2018, 33 meint dazu: „Mit dieser Definition gelingt es Kissine, Probleme der traditionellen Definition von Behauptungssprechakten zu vermeiden, die darauf beruhen, dass A der Intention von S [= Sprecher] zufolge tatsächlich zu dem Glauben gebracht werden soll, dass p. Seiner Auffassung gemäß stellt ein assertiver Sprechakt lediglich ein Angebot an A dar, aus dem gemeinsamen Hintergrund und der Behauptung auf die Wahrheit von p zu schließen."
} 
Wunderlichs) separiert und (als „Informationsgesuche“) zusammen mit den Assertiva als informative Akte gezählt. ${ }^{150}$ Einige Sprechakte (wie z. B. BEFEHLEN und ANORDNEN) haben institutionellen Charakter und stehen damit den Deklarativa nahe. ${ }^{151}$ Wünsche hingegen werden häufig eher den Expressiva als den Direktiva zugerechnet. ${ }^{152}$ Insgesamt sind die Direktiva v. a. den Kommissiva eng verbunden. Die zwei Klassen unterscheiden sich ja in erster Linie danach, ob der Sprecher oder der Adressat zum Handeln aufgefordert ist. ${ }^{153}$ Man kann beide zur Gruppe der obligativen Akte rechnen. ${ }^{154}$ Teilweise wird den Kommissiva ihr spezifischer Status als eigene Kategorie aber auch abgesprochen. ${ }^{155}$ Dies gilt im Übrigen ebenso für die Deklarativa und auch die Expressiva. ${ }^{156}$

\section{Besonderheiten der Expressiva}

Die Expressiva stellen in mehrfacher Hinsicht eine besondere Kategorie dar. Ihnen liegen zwar Anlässe oder Ereignisse zugrunde, von denen die Kommunikationspartner betroffen bzw. für die sie in irgendeiner Weise verantwortlich sind, aber ein propositionaler Gehalt i. e. S. ist nicht zwingend notwendig. ${ }^{157}$ Die mit ihnen vermittelten Gefühle und Einstellungen sind sehr

\footnotetext{
150 VgI. STAFFELDT 2009, 85f. (mit Bezug auf PöRINGS UNd SCHMITZ 2003 und WUNDERLICH 1976). Vgl. a. RISSELADA 1993, 38ff., die Fragen und Assertiva als „speech acts about facts“ betrachtet. Liedtke fasst die von ihm als Quaesitiva bezeichneten Fragehandlungen mit den Aufforderungshandlungen, den Direktiva i. e. S., zur Gruppe der Petitiva zusammen: „Sie besteht aus Sprechakttypen, mit denen auf unterschiedliche Weise Personen zu einer Handlung veranlasst werden." (LIEDTKE 2018, 32). Vgl. LIEDTKE 1998, 166f. Fragehandlungen als eigene Kategorie werden v. a. angenommen, wenn die zugrunde liegende Klassifikation (induktiv) von den grammatischen Strukturen ausgeht, wie es z. B. bei Wunderlich der Fall ist. Vgl. a. ZAEFFERER 2001 und HINDELANG 1981. Rhetorische Fragen können hingegen als assertive BEHAUPTUNGEN gelten. Vgl. KIENPOINTNER 1998, 67ff. Der z. T. stark emotionale Aspekt weist allerdings auch auf eine Nähe zu den Expressiva hin. Vgl. S. 21.

151 Vgl. z. B. WÜEST 2011, 38f.

152 Der Unterschied zwischen Formulierungen wie „Ich wünsche mir, dass du herkommst.“ und „Ich bitte dich, dass du herkommst." scheint in der Tat auf den ersten Blick marginal. Er kann in einem etwas stärkeren Appellcharakter der ersten Äußerung gesehen werden. Dadurch ergibt sich eine Skala, an deren anderem Ende bindende Aufforderungen wie „Ich befehle dir herzukommen." stehen. VgI. RISSELADA 1993, 40f. und NúÑEZ ROMEROBALMAS 1991a, 360, die bspw. (impressive) Direktiva und (expressive) Optativa differenziert. Vgl. a. die Ausführungen zur „optionality scale“ bei LEECH 1983, 123 und ebd., $126 f$.

153 Vgl. a. WÜEST 2011, 37f., der einzelne Sprechakte anders als Searle bewertet und u. a. auf Rolf 1993, $226 \mathrm{ff}$. und RoLF 1997, 170f. verweist, wo ERLAUBEN nicht zu den Direktiva, sondern zu den Kommissiva gezählt wird. Außerdem hält er die Definition der Kommissiva für zu eng, da man dazu durchaus auch Sprechakte rechnen könne, mit denen sich der Sprecher nicht (wie beim VERSPRECHEN) bindend auf etwas festlegt, sondern (wie z. B. beim DROHEN) nur die Absicht bekundet, etwas zu tun oder nicht zu tun, ohne sich zu dieser Handlung zu verpflichten, oder bei denen die Verpflichtung (wie z. B. beim VORSCHLAGEN) nur unter bestimmten Bedingungen gilt.

154 Vgl. STAFFELDT 2009, 85f. (mit Bezug auf PöRINGS UND SCHMITZ 2003).

155 Vgl. z. B. SCHMITT 2000, 123: „Die Existenzberechtigung dieser Klasse ist aus philosophischen Gründen mehrfach in Frage gestellt worden. "Vgl. a. ZAEFFERER 2001, 209, der auf die fehlenden Strukturmerkmale der Kommissiva hinweist.

156 Zu den Deklarativa vgl. z. B. BALLMER UND BRENNENSTUHL 1981, 56f. und auch ZAEFFERER 2001, 209. Zu den Expressiva vgl. z. B. ORTNER 2014b, 58f. und v. a. S. 30.

157 Vgl. Rolf 1997, 134ff. und LuPPOLD 2015, 386f. Vgl. außerdem S. 20. STAFFELDT 2009, 74 weist darauf hin, dass sich auch Expressiva mit unvollständigen Propositionen finden, wie z. B. LIEBEN, bei denen es zwar einen Referenz-, aber keinen Prädikationsakt gibt. Durch die fehlende bzw. unvollständige Proposition ergibt sich ein Problem mit dem Intentionalitätsbegriff von Searle, der eigentlich eine Referenz und eine Repräsentationsabsicht voraussetzt. Entsprechend werden die Expressiva (wie auch die Deklarativa) in diesem Zusammenhang von Searle unberücksichtigt gelassen: Vgl. ebd., 82ff. und SEARLE 1999.
} 
vielfältig, d. h., es werden mit den einzelnen Expressiva ganz unterschiedliche psychische Zustände zum Ausdruck gebracht. ${ }^{158}$

Man sollte Searles Definition insoweit ergänzen, als Expressiva neben dem Ausdruck von Gefühlen und Einstellungen auch dem Herstellen bzw. Aufrechterhalten sozialer Beziehungen dienen. ${ }^{159}$ Dies trifft insbesondere auf die von Searle selbst genannten Beispiele (wie z. B. KONDOLIEREN, DANKEN und GRATULIEREN) zu. Die Definition von Austins Konduktiva ist in dieser Hinsicht weiter gefasst, bezieht sich letztlich jedoch ebenfalls eher auf rituelle Sprechakte $^{160}$; Emotionen i. e. S. werden von ihm mehr dem paralinguistischen und perlokutionären Bereich zugewiesen. ${ }^{161}$ Was Ähnlichkeiten mit der emotiven (oder expressiven) und phatischen Funktion Jakobsons angeht, ist zum einen auf dessen anderes (sprach- und multifunktionales) Konzept hinzuweisen, zum anderen darauf, dass die phatische Funktion auch auf nicht-soziale Aspekte der Kommunikation (z. B. gestörter Kommunikationskanal) zielt. ${ }^{162}$

Die Expressiva weisen z. T. eine große Nähe zu den Deklarativa auf. ${ }^{163}$ So ist die Aufrichtigkeitsbedingung bei einigen Expressiva ähnlich wie bei den Deklarativa nicht sonderlich relevant. ${ }^{164}$ Sowohl bei den Expressiva als auch den Deklarativa „geht es darum, eine soziale Realität zu schaffen. Im Falle der Deklarativa um soziale Tatsachen, im Falle der Expressiva um soziale Beziehungen. Beide haben die doppelte Ausrichtung, das Schaffen sozialer Beziehungen ähnelt dem Schaffen sozialer Tatsachen. " ${ }^{165}$ Man könnte beide Sprechaktklassen folglich zu einer Gruppe der konstitutiven Sprechakte zusammenfassen. ${ }^{166}$ Bei einigen Expressiva ist allerdings auch eine gewisse Nähe zu den Assertiva festzustellen. ${ }^{167}$ Eine reine Emotionsbeschreibung ist aber nur in wenigen Situationen denkbar. ${ }^{168}$ Obwohl z. B. bei vielen Gesprächsritualen die Mitteilung eines bestimmten Gefühlszustands wichtiger ist als die tatsächlich

\footnotetext{
158 Vgl. RoLF 1997, 217 und LUPPOLD 2015, 386f.

159 Einige Klassifikationen legen den Schwerpunkt auf jeweils nur einen der beiden Aspekte, d. $h$., entweder Expressiva gelten als soziale Akte zur Beziehungsgestaltung oder als Akte zum Ausdruck von Emotionen. Manchmal werden hingegen (wie auch in der vorliegenden Arbeit) beide Aspekte in die Definition der Expressiva einbezogen. Dabei ist eine Bildung von Unterkategorien (z. B. phatische Akte als Teilklasse der Expressiva) möglich; oder man trennt beide Aspekte komplett voneinander, wie z. B. Weigand, die (zu den Deklarativa gehörende) Konstative und (den Assertiva nahestehende) Expressive unterscheidet. Vgl. u. a. ebd., 384ff.; OrTNER 2014b, 265f.; WÜESt 2011, 36; WeIGAND 2003, 40ff.; ebd., 112f. und ebd., 153ff.; WAGNER 1997, 214 sowie MARTEN-CLEEF 1991, $6 \mathrm{ff} . \mathrm{Vgl}$. außerdem das Kap. zu den (abreagierenden, sympathisierenden und opponierenden) Untermustern der „Expressiva“ nach Marten-Cleef ab S. 39.

160 AUSTIN 2009, 152: „The fourth [class of illocutionary force], behabitives, are a very miscellaneous group, and have to do with attitudes and social behaviour. Examples are apologizing, congratulating, commending, condoling, cursing, and challenging."

161 Vgl. z. B. ORTNER 2014b, 258f. und ebd., 263f. Vgl. a. S. 31.

162 Vgl. S. 15.

${ }^{163}$ Vgl. z. B. WeIGAND 2003, 40ff.; ebd., 112f. und ebd., 153ff. sowie ORTNER 2014b, $264 f f$.

164 Vgl. z. B. LUPPOLD 2015, 387f. und WÜESt 2011, 36. Vgl. a. ORTNER 2014b, 261. Vgl. außerdem S. 20.

165 STAFFELDT 2009, 85. Die (doppelte) Entsprechungsrichtung besteht nach ebd., 81 bei den Expressiva nicht wie bei den Deklarativa zwischen Worten und Welt, sondern zwischen Geist (des Sprechers) und Geist (des Adressaten).

${ }^{166}$ Vgl. ebd., 85f. (mit Bezug auf PöRINGS UND SCHMITZ 2003).

167 Vgl. z. B. ORTNER 2014b, 58f. und ebd., 261ff.; SCHWARZ-FrieSEL 2013, 27 sowie WeIGAND 2003, 49f.

168 Eine solche könnte evtl. vorliegen, wenn ein Patient im Rahmen einer psychotherapeutischen Anamnese über seine aktuelle Gefühlslage spricht. Allerdings geht es dabei meist mehr um die Beschreibung von chronischen
} 
empfundene Emotion, liegt der (illokutionäre) Zweck weniger in der Information des Gegenübers als in einer sozialen und emotionalen Regulation. ${ }^{169}$

Am Ende geht es bei den Expressiva - ob nun der Ausdruck von Gefühlen oder die Beziehungsgestaltung im Vordergrund steht - ganz allgemein immer darum, „auf bestimmte, beim Adressaten vorhandene oder nichtvorhandene oder als vorhanden bzw. nichtvorhanden unterstellte Emotionen einzuwirken“. ${ }^{170}$ Selbst stark ritualisierte Sprechakte lassen z. B. Rücksichtnahme auf die Gefühle anderer erkennen, wohingegen eine Normverletzung einen Affront darstellt. Auch Sprechakte, die auf den ersten Blick nur der persönlichen Gefühlsentladung dienen, sollen häufig auf die Gefühlslage des Adressaten Einfluss nehmen. Ob es tatsächlich rein „kathartische“ Sprechakte gibt, sei dahingestellt. ${ }^{171}$

In irgendeiner Weise spielen natürlich in allen sprachlichen Äußerungen Beziehungs- und emotionale Aspekte eine Rolle, weshalb zuweilen angezweifelt wird, ob Expressiva überhaupt als eigene Sprechaktkategorie gezählt werden sollten ${ }^{172}$ :

Beziehungsgestaltung findet hauptsächlich - in unterschiedlichem Umfang und in sehr unterschiedlicher Weise - indirekt und oft sogar unbewusst statt. ${ }^{173}$ Da hier keine einfachen schematischen Regeln gelten und unbewusste Prozesse zudem nicht primärer Gegenstand der Sprechakttheorie sind, ist zu deren genauerer Erfassung eine weitergehende, differenzierte Analyse notwendig. ${ }^{174}$ Der spezifische Beziehungsaspekt von Expressiva betrifft eher nur konventionelle "rituelle Kontaktmuster“. ${ }^{175}$

und umfassenderen psychischen Stimmungslagen als um die normalerweise mit Expressiva ausgedrückten emotionalen Momentaufnahmen. Außerdem ist der Übergang von einer objektiven Information hin zu einer subjektiven Entlastung fließend.

169 Vgl. aber auch ORTNER 2014b, 263f.: „Eine Abgrenzung gegenüber den repräsentativen Sprechakten ist teilweise schwierig, etwa bei Emotionsthematisierungen: Die Sprecherin bzw. der Sprecher macht eine Aussage über die Welt (repräsentativ), aber sie bezieht sich auf das Innenleben. Die Illokution besteht erstens darin, die psychische Einstellung (z.B. Dankbarkeit) darzustellen, und zweitens darin, die psychische Einstellung dem anderen zu erkennen zu geben [...]. Dieser zweite Aspekt ist der wichtigere bzw. dem anderen übergeordnete: Für das Gelingen des Sprechakts ist nicht die entsprechende psychische Einstellung erforderlich, sehr wohl aber, dass die psychische Einstellung für die Hörerin bzw. den Hörer ersichtlich wird."

170 Rolf 1997, 219. Vgl. ebd., 222f.; STAFFELDT 2009, 74; WüEST 2011, 36 und LUPPOLD 2015, 388f. ROLF 1997, $219 f f$. unterscheidet „Emotions-induzierende Situationen“ mit „Emotions-,therapeutischer ' oder -prophylaktischer" Vorgehensweise auf der einen Seite und „Emotions-erfordernde Situationen“ mit „Emotions-,intoxikativer“" Vorgehensweise auf der anderen Seite. Expressiva können nach Rolf stabilisierend oder destabilisierend wirken. Vgl. aber auch LUPPOLD 2015, 205: „Expressive Sprechakte sind als soziale Akte oder Beziehungsakte oft stark emotionsbehaftet; umgekehrt sind sie als ebensolche sozialen Akte bzw. Beziehungsakte in besonderer Weise auch geeignet, beim Adressaten verschiedenste Emotionen auszulösen - obgleich ihre primäre illokutionäre Aufgabe nicht im Ausdruck oder in der Regulation von Emotionen besteht. “

${ }^{171}$ Vgl. ORTNER 1992, 271ff., der „,kathartische Sprechakte“ als eigene, zusätzliche Sprechaktkategorie betrachtet.

172 Vgl. z. B. ORTNER 2014b, 264.

${ }^{173}$ Vgl. z. B. AdAMzIK 1984, 109; ebd., 180 und bes. ebd., 344ff. Adamzik weist auch auf die Gefahr „einer Entleerung des Begriffs Beziehungsaspekt“ hin, die entsteht, wenn jeder Kommunikation beziehungsrelevante Aspekte zugesprochen werden, wie dies im Anschluss an das entsprechende Postulat von Watzlawick/Beavin/Jackson häufig praktiziert worden sei. Vgl. WATZLAWICK U. A. 2011 und auch SCHULZ VON THUN 2010.

${ }^{174}$ Vgl. z. B. ADAMZIK 1984, 342 und ebd., $346 f$.

175 Ebd., 342 und ebd., 344. 
Gefühle können auch mit anderen Sprechakttypen ausgedrückt und beeinflusst bzw. hervorgerufen werden, was dann aber im Unterschied zu den Expressiva nicht als deren Hauptintention zu betrachten ist. ${ }^{176}$ Manchmal werden emotionale Effekte generell dem Bereich der Perlokution zugeordnet. ${ }^{177}$ Emotionalität kann außerdem als spezifische Modalität berücksichtigt werden, mit der eine bestimmte Einstellung zum Inhalt einer Äußerung ausgedrückt wird. ${ }^{178}$ So wird bisweilen neben einer epistemischen, motivationalen und evaluativen auch eine emotive Einstellung angenommen, was aber nur möglich ist, wenn der Begriff der Modalität weiter gefasst und nicht darauf beschränkt wird, Hinweise auf den „Realitätsgrad des Ausgesagten“, also die Faktizität oder (Un-)Möglichkeit des betreffenden Inhalts zu geben. ${ }^{179}$ Alternativ kann man (genau wie für den Beziehungsaspekt) eine eigene, spezifische Kategorie annehmen. ${ }^{180}$

Dies gilt entsprechend für Bewertungen, da die evaluative Einstellung ebenfalls nicht allgemein als Modalität akzeptiert wird. ${ }^{181}$ Auf der anderen Seite gibt es Versuche, Sprechakten mit evaluativer Modalität als bewertenden oder axiologischen Sprechakten sogar eine eigene Sprechaktklasse zuzuweisen - entsprechend den Assertiva mit epistemischer Modalität und den Direktiva und Kommissiva mit motivationaler Modalität (sowie den Expressiva mit emotiver Modalität). ${ }^{182}$ Das Verhältnis der bewertenden Sprechakte zu den Expressiva wird dabei

\footnotetext{
176 Bei insistierenden Direktiva wie FLEHEN schwingt z. B. oft auch Angst mit. Vgl. LUPPOLD 2015, 205; ORTNER 2014b, 262; SCHWARZ-FRIESEL 2013, 27 und StAFFELDT 2009, 74.

177 Vgl. z. B. LUPPOLD 2015, 389 und ORTNER 2014b, 258ff. GILBERT 2001, 245ff. versucht, auch den anderen Teilakten jeweils entsprechende emotive Aspekte zuzuweisen. Vgl. a. S. 29 (zu Austin).

${ }^{178} \mathrm{Vgl}$. z. B. ORTNER 2014b, 258. Der Terminus, Modalität' wird in dieser Arbeit synonym mit den Begriffen, propositionale Einstellung' und ,Sprechereinstellung' verwendet.

179 Ebd., 239. Die emotive Einstellung wird bspw. bei BRINKER 1994, 37 genannt. Dort und bei WUNDERLICH 1976, 73ff. und POLENZ 2008, 212ff. finden sich auch weitere Bezeichnungen für die epistemische und motivationale Einstellung, die z. T. synonym oder auch zur weiteren Differenzierung gebraucht werden (z. B. doxastisch bzw. präferentiell, intentional, expektativ, normativ, deontisch, volitiv, kommissiv). Wunderlich spricht in diesem Zusammenhang von Funktoren, von Polenz von Sprechereinstellungen. Vgl. a. ROSENGREN 1979a, 202ff. und ROSENGREN 1987, 30f., wo Sprechakte mit bestimmten Einstellungen zueinander in Beziehung gesetzt werden (z. B. kognitiv-assertive Illokutionen und doxastisch-epistemische Modalität oder interaktional-direktive Illokutionen und motivationale Modalität). Vgl. außerdem KoCH U. A. 1981, 162.

180 WÜEST 2011, 214 (mit Bezug auf JAHR 2000): „Silke Jahr [...] hat vorgeschlagen für die Emotionalität in der Sprache eine besondere, zusätzliche Ebene anzusetzen. Angesichts der Tatsache, dass sich die Emotionalität anderen Kommunikationsabsichten überlagern kann, wird man nicht umhinkommen, ihr eine Sonderstellung einzuräumen."

${ }^{181} \mathrm{Vgl}$. Z. B. ORTNER 2014b, $239 \mathrm{f}$.

182 Vgl. z. B. WÜEST 2011, 31; ZILLIG 1992 und KOHL UND KRANZ 1992, 42.
} 
unterschiedlich beurteilt. Manchmal werden sie als Unterkategorie der Expressiva betrachtet. ${ }^{183}$ Bisweilen wird jedoch darauf hingewiesen, dass zwar alle expressiven Sprechakte bewertend seien, aber nicht alle Bewertungen expressiv. ${ }^{184}$ Neben expressiv-emotiven Bewertungen, die Gefühle ausdrücken, gebe es informative Bewertungen, die eher zu den Assertiva gehören. ${ }^{185}$

\section{Alternative Klassifikationen und Gesamtwürdigung}

Auch anderweitig sind sehr zahlreiche Alternativvorschläge zu Searles Sprechaktklassifikation gemacht worden, weil einige Sprechakte nur schwer oder gar nicht den fünf Sprechaktklassen zugeordnet werden können und die Klassifikation deshalb häufig als unvollständig empfunden wird oder weil die Kriterien an sich nicht überzeugend erscheinen, da wichtige Aspekte vernachlässigt würden. ${ }^{186}$ So gibt es z. B. Versuche, die Dialogizität bzw. Perlokutivität von Sprechakten miteinzubeziehen. ${ }^{187}$ Außerdem finden sich Bemühungen, die Vielzahl und Heterogenität der Klassifikationskriterien Searles zu reduzieren und diese auf eine einheitliche Typisierungsbasis zu stellen, z. B. unter Zugrundelegung der Gelingensbedingungen. ${ }^{188}$ Andere Ansätze gehen von den Modi Indikativ, Konjunktiv und Imperativ bzw. den drei Satzarten Aussage-, Aufforderungs- und Fragesatz aus und bewerten entsprechend z. B. Fragehandlungen als eigene Sprechaktklasse. ${ }^{189}$ Problematisch erscheinen dabei v. a. die Gleichsetzung von Sprechakt und Satz und die Annahme, dass ein „direkter Zusammenhang zwischen Satzart und

\footnotetext{
183 Vgl. KOHL UND KRANZ 1992, 32 und ebd., 42: „In der vorliegenden Darstellung wurden diese [d. h., die bewertenden Sprechakttypen] aus Gründen der Übersichtlichkeit den Expressiva zugerechnet. Eine solche Zuweisung ist jedoch äußerst problematisch.“

${ }^{184}$ Vgl. z. B. Rolf 1997, 225: „Generell läßt sich sagen, daß Expressiva Bewertungen zum Ausdruck bringen: entweder explizit, was beispielsweise beim Kompliment und beim Selbstlob der Fall ist, oder implizit, über die zum Ausdruck gebrachte Emotion. Einer Emotion liegt aufgrund bestimmter Ziele, bestimmter Verhaltensstandards oder bestimmter Vorlieben oder Abneigungen, grundsätzlich eine Bewertung zugrunde. “ Dagegen ORTNER 2014b, 239: „Emotionen werden häufig mit Bewertungen gleichgesetzt, doch viele Bewertungen können völlig emotionslos erfolgen und nicht alle Emotionen sind Resultat einer Bewertung [...].” Vgl. a. MARTEN-CLeEf 1991, 90: „Zu betonen ist, daß alle EXPRESSIVA eine Bewertung zwar beinhalten, das mit ihnen verfolgte Kommunikationsziel aber nicht im Ausdrücken dieser Bewertung besteht." und WüEST 2011, 220 (mit Bezug auf ARNDT UND JANNEY 1987 und CAFFI UND JANNEY 1994): „Die axiologischen Sprechakte dienen dagegen nicht in erster Linie der Darstellung von Emotionen, sondern von Werten. Arndt/Janney (1987) und Janney/Caffi (1994) betrachten allerdings gestützt auf die Meinung verschiedener Psychologen die Axiologie als einen der fundamentalen Parameter der Emotionalität. Auch sprachlich besteht eine enge Verbindung zwischen expressiven und axiologischen Sprechakten."

${ }^{185}$ Neutrale Bewertungen, die auf rein objektiven Kriterien beruhen, sind durchaus denkbar, meist sind Bewertungen aber in irgendeiner Weise subjektiv und basieren (auch) auf Emotionen des Bewertenden. Vgl. z. B. ORtNer 2014b, 63f.; ebd., 239 und ebd., 243 (mit Verweis auf ZiLlig 1992, 306) sowie KOHL Und KRANZ 1992, 42.

${ }^{186}$ Vgl. z. B. Ballmer UNd BRENNENSTUHL 1981, 58 und LeVINSON 2011, 240. Vgl. a. SCHMITT 2000, 120 und dessen eigenen Klassifikationsversuch (s. N. 147 und 355). Übersichten zu verschiedenen Klassifikationsversuchen finden sich z. B. in WeigAND 2003, 42ff. sowie Rolf 2006, 2521ff.; Rolf 2000 - 2001, 425ff. und Rolf 1997, 112ff. Zur Klassifikation von Sprachfunktionen: ORTNER 1992, 274f. und ORTNER 2014b, 57f. Zur „Klassifikation von Textfunktionen" vgl. das entsprechende Kapitel (ab S. 48) in dieser Arbeit.

187 WeIGAND 2003, 72ff. und StAFFELDT 2009, 146ff. bzw. STAFFELDT 2014, 106f. ergänzen bspw. zu den an Searle angelehnten, z. T. aber abgewandelten sprecherbezogenen Illokutionen adressatenbezogene perlokutionäre Sprechakte. Ein Überblick bisheriger Klassifikationen unter Berücksichtigung der Dialogizität findet sich z. B. bei WEIGAND 2003, 53ff.

188 Vgl. z. B. ROLF 1997 und STAFFELDT 2009, 86ff. Ein mögliches Problem bei solchen Klassifikationen ist It. ebd., 87, dass Expressiva ohne propositionalen Gehalt unberücksichtigt bleiben. Vgl. a. S. 20 und 28.

${ }^{189} \mathrm{Vgl}$. S. 27. Eine kurze Übersicht solcher Klassifikationen findet sich z. B. bei WEIGAND 2003, 45.
} 
Illokution" bestehe. ${ }^{190}$ Dass sich insgesamt nur drei Sprechaktklassen ergeben, ist dagegen nicht per se zu kritisieren, was aber nicht bedeutet, dass für eine empirische Analyse nicht eine weitergehende Differenzierung notwendig ist. ${ }^{191}$

Tendenziell ist ohnehin zu bemerken, dass empirisch ausgerichtete Klassifikationen häufig eine (z. T. erheblich) größere Anzahl von Klassen zugrunde legen als abstrakt-funktionale. Mit empirischen Klassifikationen sind dabei solche gemeint, die eher induktiv von Sprechakten in konkreten Situationen ausgehen, was auch die lexikographische Erfassung von SB-Ausdrücken umfassen kann. ${ }^{192}$ Abstrakt-theoretische Klassifikationen ordnen hingegen umgekehrt die konkreten Sprechakte bzw. Sprechakttypen (deduktiv) gesetzten Kategorien zu. Austins Klassifikation wäre demnach als empirisch zu betrachten, Searles als abstrakt-funktional. ${ }^{193}$ Der Vorteil von Searles Klassifikation gegenüber Austins wird dabei oft darin gesehen, dass sie rationaler begründet, theoretisch fundierter und systematischer sei; andererseits wird an ihr aber eine zu große Rigidität kritisiert. ${ }^{194}$

Insgesamt bleibt festzuhalten, dass die alternativen Klassifikationen zwar möglicherweise in Teilen gewisse Verbesserungen gegenüber der Taxonomie Searles präsentieren, aber ihrerseits andere Schwächen aufweisen. Trotz aller Kritik kann Searles Sprechaktklassifikation immer noch als anerkannteste und am weitesten verbreitete gelten. Sie bietet eine gute, wenn auch ggf. anzupassende Grundlage für eigene sprechakttheoretische Arbeiten. ${ }^{195}$

\subsection{Münsteraner Schule}

\section{Ziel und Vorgehensweise}

Die fünf Sprechaktklassen Searles bezeichnen allgemeine Handlungstypen, denen jeweils recht verschiedene Sprechakte zugeordnet sind. Durch Abstraktion von einzelnen SB-Ausdrücken können diese Sprechakte innerhalb der Sprechakt(ober)klassen zu Subklassen bzw.

\footnotetext{
190 SCHMItT 2000, 125. Vgl. a. ROLF 2006, 2522f.; PINKSTER 1988, 285ff. und PINKSTER 2015, 306ff. bzW. ebd., $379 f f$. Vgl. außerdem Kap. 1.3.2.1.

191 Dagegen SCHMITT 2000, 125: „Eine Aufteilung aller Sprechakte in lediglich drei Klassen wäre für eine empirische Analyse viel zu grob, zumal wiederum die überwiegende Mehrzahl aller Sätze im Indikativ geäußert werden [...].“ Die sehr ungleiche Distribution ist also eher als ungünstig zu betrachten und müsste entsprechend sorgfältig begründet werden.

192 Vgl. WEIGAND 2003, 42ff. bzw. ebd., 45ff. Zu den empirischen Klassifikationen zählt Weigand neben der von Austin u. a. auch die von Ballmer / Brennenstuhl, die (auf der Grundlage von 4800 Sprechaktverben) insgesamt 600 (!) Kategorien („categories“) unterscheiden, die 24 Modellen („models“) und 8 Modellgruppen („model groups“) zugeordnet sind (BALLMER UND BRENNENSTUHL 1981, 48ff.). Zu den abstrakten Klassifikationen rechnet Weigand neben der von Searle u. a. die Taxonomien von Wunderlich, Hindelang und von Polenz. VgI. a. SCHMITT 2000, $124 f$.

193 Vgl. aber auch WEIGAND 2003, 49: „Bereits jetzt [...] lässt sich sagen, dass auch Searles Taxonomie nicht auf einem konsistenten deduktiven Prinzip beruhen kann [...]. Searle selbst bezeichnet sein Vorgehen als empirisch; die Deduktion aus der Natur des Geistes stehe noch aus [...]. Sie wird (1983) durch sein Buch über Intentionalität nachgeliefert."

194 Vgl. z. B. EhrhaRdt UND HeRINGer 2011, 59; LeVINSON 2011, 238 und SCHMITT 2000, 119. Vgl. a. WeIGAND 2003, 48ff., die Searle einerseits mangelnde theoretische Fundierung vorwirft, andererseits aber doch in seinem Bemühen um größere Rationalität einen Fortschritt gegenüber früheren Sprechaktklassifikationen sieht. Vgl. außerdem das Kap. zur „Sprechaktklassifikation“ Austins (ab S. 18), aus dem sich erhellt, dass dessen Vorgehen durchaus nicht als unsystematisch angesehen werden kann.

195 Vgl. z. B. SCHMItT 2000, 115 und ebd., 119; ZAEFFERER 2001, 209; WeIGAND 2003, 50 und ebd., 55f.; STAFFELDT 2009, 87f.; WÜEST 2011, 31; BRINKER U. A. 2014, 102 sowie LUPPOLD 2015, 353 N. 748.
} 
Untertypen oder -mustern zusammengefasst werden. ${ }^{196}$ Während solche Subklassen sonst häufig weitgehend intuitiv gebildet und benannt werden, hat die Münsteraner Schule versucht, sie für das Deutsche systematisch und objektiv nachvollziehbar zu erfassen und zu definieren. ${ }^{197}$

Dazu werden die vorhandenen SB-Ausdrücke gesammelt und analysiert, um dann nach den jeweiligen Handlungsqualitäten (Zielen, Bedingungen) verschiedene Untertypen festzulegen. ${ }^{198}$ In einem weiteren Schritt werden auch die zugehörigen sprachlichen Äußerungsformen untersucht, die wichtige Hinweise auf das vorliegende Untermuster geben können, insgesamt aber als entscheidendes Klassifikationskriterium zu unspezifisch sind. ${ }^{199}$

Um dem Phänomen der indirekten Sprechakte gerecht zu werden, wird eine semantische Zwischenebene angesetzt, die in gewisser Weise den sekundären Akten Searles entspricht. ${ }^{200}$ So benennt Hindelang bei seiner Untersuchung der Direktiva folgende semantische Muster, die mit entsprechenden Hinweisen bzw. Fragen korrelieren: deontisches Muster, Präferenzmuster, Kompetenzmuster und Befolgungsmuster. Eine WEISUNG kann bspw. durch Formulierungen wie „Dieser Brief muss schnell abgeschrieben werden!“ oder "Ich will, dass dieser Brief schnell abgeschrieben wird." ausgedrückt werden. ${ }^{201}$ Im ersten Fall liegt ein deontisches Muster mit deontischem Hinweis vor, im zweiten Fall ein Präferenzmuster mit Präferenzhinweis. Es sind noch viele alternative Äußerungsformen denkbar, darunter auch Fragen (z. B. eine Präferenzfrage wie: „Wollen Sie nicht den Brief abschreiben?“) und außerdem direktere Äußerungen in Gestalt von imperativischen („Schreiben Sie den Brief ab!“) und performativen

\footnotetext{
196 Vgl. Kohl und KRANZ 1992, 2; WAGNer 1997, 22 und StAFFeldt 2009, 95.

197 Vgl. z. B. HindeLANG 2010, 39. Zum Begriff ,Münsteraner Schule‘ vgl. STAFFELDT 2009, 98: „An der Universität Münster sind in den letzten drei Jahrzehnten einige Arbeiten zur Subklassifikation der Illokutionen entstanden. Da es sich dabei neben einer Reihe von Aufsätzen auch insbesondere um Dissertationen handelt, die von ein und derselben Person betreut wurden (Franz Hundsnurscher), kann man von einer Schule sprechen. Und da sie an der WWU Münster entstanden sind, lässt sich von ihr als Münsteraner Schule reden." Untersucht wurden die Assertiva („Informationshandlungen“: RolF 1983), Direktiva („Aufforderungshandlungen“: HINDELANG 1978 und HINDELANG 2010, 53ff.; „Fragehandlungen“: HINDELANG 1981; „Insistieren“: FranKE 1983), Kommissiva („Sich festlegen und verpflichten“: GrAfFe 1990) und Expressiva („Gefühle ausdrücken“: MARTEN-CLEEF 1991; „Bewerten“: ZILLIG 1992), während zu den Deklarativa keine entsprechende Abhandlung vorliegt. Übersichten zu den Arbeiten der Münsteraner Schule finden sich z. B. bei STAFFELDT 2009, 106ff. und (mit ausführlicheren Erläuterungen) bei KOHL UND KRANZ 1992.

198 Die den Arbeiten der Münsteraner Schule zugrunde gelegten Definitionen der Oberklassen entsprechen weitgehend denen Searles. Auf evtl. Abweichungen wird ggf. hingewiesen. Vgl. das Kap. zur "Sprechaktklassifikation“ Searles (ab S. 24). Vgl. außerdem das Kap. zu „Gelingensbedingungen und Gebrauchsregeln“ bei Searle (ab S. 20). ${ }^{199}$ Vgl. ebd., 40: „Auf diesem Hintergrund bleibt beispielsweise eine Aufforderung, die von einem Vorgesetzten an seine Untergebenen ergeht und sich auf einen arbeitsvertraglich geregelten Bereich bezieht - wie höflich sie auch immer formuliert sein mag - eine WEISUNG; sie wird nicht etwa aufgrund bestimmter Kennzeichen der Äußerungsform (z. B . des Gebrauchs der explizit performativen Formel ,Ich bitte Sie, ...') zur BITTE. Dies hat zur Konsequenz, daß bei der Zuordnung von Äußerungen zu Handlungsmustern nicht nur auf rein sprachliche Kennzeichen der Äußerungsform, sondern vor allem auf Kennzeichen des Handlungszusammenhangs, in dem die Äußerungsform verwendet wird, zurückgegriffen werden muß." Vgl. ebd., 2 und außerdem STAFFELDT 2009, 91ff. und ebd., 119ff. sowie HINDELANG 2010, 54f. und ebd., 69ff.

200 Ebd., 71ff. und STAFFELDT 2009, 119ff., bes. ebd., 124ff. Vgl. a. S. 21 (Bezug der Gelingensbedingungen auf indirekte Sprechakte)!

${ }^{201}$ Die Beispiele hier wie auch im Folgenden sind (z. T. leicht abgewandelt) größtenteils den entsprechenden Arbeiten von Hindelang entnommen.
} 
Handlungsanweisungen („Hiermit weise ich Sie an, den Brief abzuschreiben. “) sowie Kommandoausdrücken (z. B. die ANLEITUNG „Nun das Mehl hinzufügen!“ in einem Backrezept). ${ }^{202}$

\section{Untermuster im Einzelnen}

In den nächsten Abschnitten werden die Ergebnisse der Untersuchungen der Münsteraner Schule im Überblick vorgestellt, soweit sie für die Analysen im praktischen Teil dieser Arbeit relevant erscheinen. ${ }^{203}$ Feindifferenzierungen und evtl. notwendige Abänderungen werden ggf. an späterer Stelle erfolgen. In Kap. 1.3.3.1 finden sich (leicht angepasste) ausführliche schematische Übersichten der Untermuster. ${ }^{204}$

\section{Assertiva}

Die Studie von Rolf zu den Informationshandlungen ${ }^{205}$ bezieht im Gegensatz zu Hindelangs Arbeiten zu den Direktiva und Marten-Cleefs Analyse der Expressiva die Sequenzabhängigkeit bzw. Interaktionalität von Sprechhandlungen konsequent in die Klassifikation mit ein und unterscheidet nach ihrer jeweiligen „Handlungsvalenz" präsentative, reaktive und re-initiative Informationshandlungen. Diese werden nach ihrem „generellen Handlungssinn“ und ihrem „speziellen Handlungssinn“ weiter ausdifferenziert. ${ }^{206}$

Der spezielle Handlungssinn präsentativer Informationshandlungen besteht bei assertiven 207 Sprechhandlungen (z. B. BEHAUPTEN) darin, „S $\mathrm{Sp}_{2}$ davon zu überzeugen, daß eine Herleitung der jeweils ausgedrückten Proposition möglich ist" ${ }^{\prime 208}$, bei transmissiven Sprechhandlungen (z. B. HINWEISEN) dagegen darin, dass „Sp $\mathrm{S}_{2}$ glauben soll, daß die von $\mathrm{Sp}_{1}$ ausgedrückte Proposition wahr ist ${ }^{\prime 209}$. Die Sprechhandlungen innerhalb dieser beiden Gruppen werden anhand

\footnotetext{
202 Vgl. a. das Kap. zu den Expressiva im Praxisteil ab. S. 326.

203 Die Ausführungen lehnen sich sehr stark an KOHL UND KRANZ 1992 an, denen auch die meisten der folgenden Zitate entnommen sind, weil sie die Ergebnisse sehr gut auf den Punkt bringen, und das zudem noch ohne Verwendung einer speziellen (illokutionslogischen) Notation, die im Rahmen der vorliegenden Arbeit nicht notwendig erscheint. Gleichwohl wird i. d. R. auch auf die entsprechenden Passagen in den zugrunde liegenden Arbeiten der Münsteraner Schule verwiesen.

${ }^{204} \mathrm{Vgl}$. außerdem die Einzeldefinitionen der Sprechaktuntermuster im Anhang und im Zusammenhang mit den Detailanalysen von fam. 14 in Kap. 2.

205 Rolf beschränkt sich in seiner Arbeit auf „Handlungen, deren Ziel allgemein die Vermittlung einer propositionalen Einstellung hinsichtlich des Bestehens oder Nichtbestehens eines bestimmten Sachverhalts ist" (ebd., 6; vgl. RoLF 1983, 32), die abzugrenzen sind von Handlungen (wie z. B. PRÄZISIEREN), die dadurch gekennzeichnet sind, „daß Wirklichkeitserkenntnisse für den Handlungsadressaten zum Zwecke einer adäquaten kognitiven Verarbeitung aufbereitet werden" (ebd., 56).

${ }^{206}$ Ebd., 84ff. Vgl. KOHL UND KRANZ 1992, 7ff. Die „Handlungsvalenz“ wird dadurch bestimmt, „ob eine Informationshandlung die Realisierung einer oder mehrerer Handlungen logisch voraussetzt“ (ebd., 7). Der „generelle Handlungssinn“ von Informationshandlungen bezieht sich auf die „Frage, ob mit ihnen auf einen in einem vorhergehenden Sprechakt ausgedrückten propositionalen Gehalt z. B. akzeptierend oder zurückweisend reagiert wird“ (ebd., 9), der „spezielle Handlungssinn“ auf das mit ihnen „konventionellerweise verfolgte Kommunikationsziel“ (ebd., 9).

${ }^{207}$ Der Begriff , assertiv` ist insofern unglücklich, als er auch die Kategorie der Informationshandlungen insgesamt bezeichnet. Im Folgenden wird deshalb auf die Sprechaktoberklasse nach Searle mit ,Assertiva i. w. S.', auf die Subklasse nach Rolf mit ,Assertiva i. e. S.' referiert, wenn sich dies nicht automatisch aus dem Kontext ergeben sollte. Vgl. a. N. 136 (zum ursprünglichen Terminus ,Repräsentativa' bei Searle).

208 KOHL UND KRANZ 1992, 9. Vgl. ROLF 1983, 97f.

${ }^{209}$ KOHL UND KRANZ 1992, 9. Vgl. Rolf 1983, $99 f$.
} 
verschiedener Kriterien voneinander abgegrenzt. So unterscheiden sich die Transmissiva MITTEILEN, HINWEISEN und BENACHRICHTIGEN nach ihrer (in diesem Fall steigenden) „Relevanz des thematisierten Sachverhalts für den Adressaten“210.

Die reaktiven Informationshandlungen werden nach ihrem generellen Handlungssinn in einem ersten Schritt danach unterschieden, ob der Adressat dem ausgedrückten Inhalt positiv (akzeptativ), indefinit (problematisierend) oder negativ (rejektiv) gegenübersteht. Die akzeptativen Sprechhandlungen kann man dann weiter nach ihrem speziellen Handlungssinn differenzieren: Mit konfirmativen Sprechhandlungen (z. B. BESTÄTIGEN) „versucht $\mathrm{Sp}_{2}, \mathrm{Sp}_{1}$ davon zu überzeugen, daß er von der Wahrheit der durch $\mathrm{Sp}_{1}$ ausgedrückten Proposition überzeugt ist“ ${ }^{211}$. Bei assentiven Sprechhandlungen (z. B. ZUSTIMMEN) „ist $\mathrm{Sp}_{2}$ dagegen lediglich bestrebt, $\mathrm{Sp}_{1}$ davon in Kenntnis zu setzen, daß er $\left(\mathrm{Sp}_{2}\right)$ im schwachen Sinne glaubt, daß die Proposition wahr ist“212. Mit konzessiven Sprechhandlungen (z. B. EINRÄUMEN) „,ist konventionellerweise das Ziel verknüpft, $\mathrm{Sp}_{1}$ zu signalisieren, daß $\mathrm{Sp}_{2}$ den thematisierten Sachverhalt für möglich hält" ${ }^{\prime 213}$. Ähnlich werden die problematisierenden Sprechhandlungen voneinander abgegrenzt: Das Ziel disputativer Sprechhandlungen (z. B. WIDERSPRECHEN) besteht darin, „S $\mathrm{S}_{1}$ davon in Kenntnis zu setzen, daß $\mathrm{Sp}_{2}$ es für möglich hält, daß der von $\mathrm{Sp}_{1}$ in der Proposition ausgedrückte Sachverhalt nicht besteht “214, während mit dissentiven Sprechhandlungen (z. B. BESTREITEN) „Sp $p_{2}$ die Annahme bei $\mathrm{Sp}_{1}$ bewirken möchte, er $\left(\mathrm{Sp}_{2}\right)$ würde glauben, daß der thematisierte Sachverhalt nicht bestehe ${ }^{\prime 215}$. Was die rejektiven Sprechhandlungen betrifft, unterscheidet Rolf detraktive Sprechhandlungen (z. B. ABSTREITEN), mit denen "Sp glaubhaft gemacht werden [soll], daß $\mathrm{Sp}_{2}$ davon überzeugt ist, daß die ausgedrückte Proposition nicht wahr ist "216, und refutative Sprechhandlungen (z. B. WIDERLEGEN), deren Ziel es ist, „Sp$p_{1}$ die Erkenntnis zu vermitteln, daß $\mathrm{Sp}_{2}$ der Ansicht ist, das Nichtbestehen des Sachverhalts sei bereits hergeleitet" ${ }^{\prime 217}$.

Die re-initiativen Informationshandlungen lassen sich zunächst (nach ihrem generellen Handlungssinn) danach unterscheiden, ob $\mathrm{Sp}_{1}$ sein ursprüngliches Ziel weiterverfolgt (insistent) oder aufgibt (resignativ). Mit einer insistenten Sprechhandlung "wird das Ziel verfolgt, $\mathrm{Sp}_{2}$ glaubhaft zu machen, daß die zur Debatte stehende Proposition $p$ hergeleitet sei "218 (argumentative Sprechhandlungen: z. B. BEGRÜNDEN), oder „Sp $\mathrm{S}_{2}$ soll glauben, daß $\mathrm{Sp}_{1}$ davon überzeugt ist, daß p hergeleitet ist "219 (affirmative Sprechhandlungen: z. B. BEKRÄFTIGEN). Zu den resignativen Sprechhandlungen gehören Informationshandlungen, mit denen „zum Ausdruck gebracht werden soll, daß $\mathrm{Sp}_{1}$ sich seiner eigenen initialen Handlung gegenüber negativ verhält und $\mathrm{Sp}_{2}$ nunmehr glauben soll, daß die im ersten Zug der Sequenz von $\mathrm{Sp}_{1}$ zum Ausdruck

\footnotetext{
210 KoHL UND KRANZ 1992, 10.

${ }^{211}$ Ebd., 10. Vgl. Rolf 1983, 100.

212 Kohl und KRANz 1992, 10. Vgl. Rolf 1983, 101.

${ }^{213}$ Kohl Und KRANZ 1992, 10. Vgl. Rolf 1983, 101.

214 KOHL UND KRANZ 1992, 10. Vgl. Rolf 1983, $101 \mathrm{f}$.

215 Kohl und KRANZ 1992, 10. Vgl. Rolf 1983, 102.

${ }^{216}$ KOHL UND KRANZ 1992, 11. Vgl. Rolf 1983, $102 f$.

217 KOHL UND KRANZ 1992, 11. Vgl. Rolf 1983, 103.

${ }^{218}$ KOHL UND KRANZ 1992, 11. Vgl. Rolf 1983, $104 f$.

${ }^{219}$ KOHL Und KRANZ 1992, 11. Vgl. Rolf 1983, 105.
} 
gebrachte Proposition nicht mehr als zutreffend erachtet wird "220 (retraktive Sprechhandlungen: z. B. WIDERRUFEN).

\section{Direktiva}

Die Direktiva lassen sich grob in drei Gruppen einteilen 221 : Aufforderungen i. e. S. beziehen sich auf eine aktive Handlung des Adressaten. Bei Verboten handelt es sich um negative Handlungen, d. h. Handlungen, die in einer Unterlassung des Adressaten bestehen. ${ }^{222}$ Das Ziel von Fragehandlungen ,,besteht [darin], den Adressaten zu einer Auskunft zu bewegen, die ein kognitives Defizit beim Sprecher behebt. " ${ }^{223}$

\section{Aufforderungshandlungen}

Bei Hindelangs Analyse von Aufforderungshandlungen ${ }^{224}$ sind folgende spezifische Handlungsbedingungen für die Klassifikation ausschlaggebend: Verpflichtungsgrad, Sanktionspotential, Rollen- und Beziehungsstruktur, Bedürfnisse und Präferenzen.

Danach unterscheidet er auf einer übergeordneten Ebene bindende und nicht-bindende Aufforderungen. ${ }^{225}$ Bindende Aufforderungen können berechtigt oder nicht berechtigt sein. Weiterhin wird danach differenziert, ob eine berechtigte Aufforderung aufgrund eines freiwillig eingegangenen Vertrages (z. B. AUFTRAG und WEISUNG) oder aufgrund staatlicher Rechtsvorschriften (z. B. ANORDNUNG) erfolgt. Die genannten Untertypen werden je nach Rolle des Auffordernden (z. B. Kunde bei einem AUFTRAG, Arbeitgeber bei einer WEISUNG) voneinander abgegrenzt. Unberechtigt bindende Aufforderungen, bei denen „Sp $\mathrm{p}_{2}$ weder durch eine vertragliche Grundlage noch durch eine bestehende Rechtsvorschrift zur Befolgung der Aufforderung verpflichtet ist "226, können illegal sein (ERPRESSUNG, z. B. unter Androhung der Ermordung eines Angehörigen), oder die Sanktionshandlung ist legal (NÖTIGUNG, z. B. durch Androhung der Kündigung), oder der Adressat ist rechtlos (DESPOTISCHER BEFEHL, z. B. eines Sklavenhalters an seinen Sklaven). Nicht bindende Aufforderungen, die „dadurch charakterisiert [sind], daß $\mathrm{Sp}_{2}$ nicht dazu verpflichtet ist, der Aufforderung nachzukommen, und $\mathrm{Sp}_{1}$ auch über keine Sanktionsmittel bei einer Nichtbefolgung verfügt “227, unterscheidet Hindelang danach, ob eine reine Adressatenpräferenz (z. B. RATSCHLAG), eine beidseitige Präferenz (z. B. VORSCHLAG) oder eine reine Sprecherpräferenz (SYMMETRISCHE und ASYMMETRISCHE BITTE) vorliegt. Die Untermuster werden z. T. noch weiter ausdifferenziert.

\footnotetext{
${ }^{220}$ Kohl und KRANZ 1992, 11f. Vgl. Rolf 1983, 106.

${ }^{221}$ Vgl. dazu HINDELANG 2010, 54 und STAFFELDT 2009, 105.

222 Zu den direktiven Verbotshandlungen liegt $\mathrm{m}$. W. bislang keine entsprechende Analyse vor.

223 HiNDELANG 1981, 215.

${ }^{224}$ Hindelang 1978. Vgl. Hindelang 2010, 53ff.; KoHL Und KRANZ 1992, 12ff. und STAfFeldT 2009, 106ff. Berücksichtigt werden dabei nur solche Sprechakte, die verbal und nicht primär schriftlich zu einer „praktischen“ (also nicht rein geistigen oder kommunikativen) Handlung auffordern. Nicht in die Untersuchung eingeschlossen werden zudem institutionell gebundene und sequenzabhängige Sprechhandlungen. Vgl. HINDELANG 1978, 54; KOHL UND KRANZ 1992, 12 sowie StAFFELDT 2009, 101. Als Ergänzung zu den Arbeiten Hindelangs kann die Untersuchung Frankes (FRANKE 1983) betrachtet werden, der das Sequenzmuster INSISTIEREN (mit den Untermustern INTERROGIEREN, FLEHEN, DRÄNGEN, NÖTIGEN, BEKRÄFTIGEN und BETEUERN) erarbeitet und dabei neben dem Stärkegrad auch die Sequenzabhängigkeit der Sprechhandlungen berücksichtigt.

${ }^{225}$ Eine Einteilung der Direktiva nach ihrem Verbindlichkeitsgrad ist auch sonst weit verbreitet. Vgl. z. B. Leechs „optionality scale“ (LEECH 1983, 123ff.) sowie die entsprechenden Ansätze in der Latinistik (s. Kap. 1.1.3.3.3).

${ }^{226}$ KOHL UND KRANZ 1992, 15. Vgl. HINDELANG 1978, $124 \mathrm{ff}$.

227 KOHL UND KRANZ 1992, 15. VgI. HINDELANG 1978, $121 \mathrm{ff}$.
} 
Fragehandlungen

Hindelang unterscheidet nach ihrer Sequenzabhängigkeit initiale, reaktive und insistierende Fragehandlungen, behandelt in seiner Analyse ${ }^{228}$ jedoch nur die initialen Akte. Diese werden nach ihren Zwecken und Inhalten in problem- und partnerzentrierte Fragen eingeteilt.

Die problemzentrierten Fragen, die dadurch gekennzeichnet sind, „daß $\mathrm{Sp}_{1}$ zur Lösung eines Problems Informationen benötigt, die er sich durch eine FRAGE zu beschaffen versucht “229, werden danach unterschieden, ob eine einseitige oder gemeinsame Problemlage vorliegt, wobei jeweils zudem danach differenziert wird, ob es um theoretische oder praktische Probleme geht (z. B. INFORMATIONSFRAGE vs. RATFRAGE bzw. KOOPERATIONSFRAGE vs. PROBLEMATISIERUNGSFRAGE). Erstere werden bei einer passenden Antwort gelöst, während letztere außerdem eine entsprechende praktische Umsetzung erfordern. ${ }^{230}$ Die einzelnen Fragetypen werden z. T. noch weiter (z. B. nach der Art der Information) aufgegliedert.

Partnerzentrierte Fragen „entspringen [...] dem teilnehmenden Interesse an der Person des Adressaten, dem Wunsch, eine kommunikative Beziehung zum Adressaten herzustellen oder aufrechtzuerhalten, oder der Absicht, $\mathrm{Sp}_{2}$ zu überprüfen und zu kontrollieren. “231 Solche Fragen sind hinsichtlich ihres Beziehungsaspektes also eigentlich eher den Expressiva als den Direktiva zuzurechnen, zumindest die ANTEILNEHMENDEN FRAGEN, die „darauf gerichtet [sind], Informationen über Stimmungen, Empfindungen, Gefühle etc. des Adressaten zu erhalten mit dem Ziel, ihm eine Möglichkeit zur Aussprache zu geben und zu signalisieren, daß er dem Sprecher nicht gleichgültig ist. “232, und die ERKUNDIGUNGSFRAGEN, die mehr als Vorwand dienen, um mit jemandem ins Gespräch zu kommen und so die soziale Interaktion zu befördern. KONTROLLFRAGEN hingegen dienen „als Mittel zur Ausübung und Stabilisierung von Kontrolle und Macht “233. Voraussetzung dabei ist, „daß $\mathrm{Sp}_{1}$ gegenüber $\mathrm{Sp}_{2}$ hinsichtlich der erfragten Thematik weisungsbefugt ist. “234 (z. B. als Lehrer in einer Prüfung).

Kommissiva

Graffe legt seiner Untersuchung der Kommissiva die Kategorien „Erwartung“ und „Verpflichtung“ zur Typisierung der Untermuster zugrunde. ${ }^{235}$ Relevante Handlungsbedingungen sind außerdem „die Interessenlagen von $\mathrm{Sp}_{1}$ und $\mathrm{Sp}_{2}$ hinsichtlich der zu vollziehenden Handlung $\mathrm{H}$ [= Sprecher- bzw. Adressatenpräferenz], die Frage der Verläßlichkeit von $\mathrm{Sp}_{1}$ und schließlich die Art und Weise des Zustandekommens einer Verpflichtungsbeziehung. "236

Auf einer ersten Ebene werden einfache Typen kommissiver Sprechhandlungen, „bei denen jeweils von einer einzelnen Handlung die Rede ist, die allein im Kontroll- und Ermessensbereich von $\mathrm{Sp}_{1}$ liegt “237, und komplexe Typen unterschieden, „die dadurch gekennzeichnet

\footnotetext{
${ }^{228}$ Im Unterschied zu den Aufforderungshandlungen sind Hindelangs Fragehandlungen nicht ausschließlich auf praktische Handlungen ausgerichtet. Vgl. N. 224.

${ }^{229}$ KOHL UND KRANZ 1992, 17.

230 Ebd., 19.

${ }^{231}$ HINDELANG 1981, 216. Vgl. KoHL UND KRANZ 1992, 19.

232 KOHL UND KRANZ 1992, 19f. Vgl. HINDELANG 1981, $219 f$.

233 Ebd., 221. Vgl. KOHL Und KRANZ 1992, 20.

234 Ebd., 20. Vgl. HINDELANG 1981, 221.

${ }^{235} \mathrm{Vgl}$. KoHL UND KRANz 1992, 21 bzw. Graffe 1990, 51ff., bes. ebd., $56 \mathrm{ff}$.

${ }^{236}$ KoHL und KRANZ 1992, 21. Vgl. Graffe 1990, $51 \mathrm{ff}$.

${ }^{237}$ KoHL UND KRANZ 1992, 21. Vgl. GRAFFe 1990, 69.
} 
[sind], daß neben der von $\mathrm{Sp}_{1}$ auszuführenden Handlung noch weitere Ergebnisse oder Handlungen eine Rolle spielen, auf die $\mathrm{Sp}_{1}$ keinen Einfluß hat. “238

Bei den einfachen Typen mit Sprecherpräferenz (z. B. ABSICHT BEKUNDEN), besteht keine Verpflichtung des Sprechers zur Ausführung einer Handlung, die der Adressat nur mehr oder weniger zuverlässig erwarten kann. Die im Gegensatz dazu verpflichtenden Typen mit Adressatenpräferenz können obligationsvorbereitend sein (z. B. ANBIETEN), sofern der Sprecher ein mögliches Interesse des Adressaten an einer Handlung lediglich annimmt und die tatsächliche Realisierung dessen positive Rückmeldung erfordert. Obligationskonstituierende Sprechhandlungen (z. B. VERSPRECHEN), mit denen sich der Sprecher direkt zu einer Handlung verpflichtet, setzen hingegen voraus, dass der Adressat ein entsprechendes Interesse bereits im Vorfeld signalisiert hat. Bei obligationskonzedierenden Sprechhandlungen (NACHGEBEN) geht $\mathrm{Sp}_{2}$ eher unfreiwillig eine Handlungsverpflichtung ein, nachdem er diese zuvor abgelehnt, $\mathrm{Sp}_{1}$ aber insistiert hat. Auch die obligationsassertierenden Sprechhandlungen (ZUSICHERN) stehen erst am Ende einer Gesprächssequenz, in deren Verlauf $\mathrm{Sp}_{2}$ eine von $\mathrm{Sp}_{1}$ geäußerte Handlungsverpflichtung in Zweifel gezogen hat. Eine weitere Differenzierung erfolgt danach, ob eine voluntative Sprechhandlung vorliegt, bei der $\mathrm{Sp}_{1}$ die entsprechende Handlung ausführen wird (z. B. ZUSAGEN), oder eine permissive Sprechhandlung, bei der $\mathrm{Sp}_{2}$ dies übernimmt (z. B. ERLAUBEN).

Zu den komplexen Typen gehören $u$. a. die Untermuster DROHEN, GARANTIEREN und BÜRGEN. Für sie gilt als „obligatorischer Bestandteil des Musters, daß $\mathrm{Sp}_{1}$ die angekündigte Handlung nur unter einer bestimmten Bedingung vollziehen will. “239 Im Falle einer BÜRGSCHAFT übernimmt z. B. Sp $p_{1}$ eine Zahlungsverpflichtung einer dritten Person, wenn diese dazu nicht mehr in der Lage ist. Während man in solchen Fällen i. d. R. von unterschiedlichen Präferenzen ausgehen kann, stimmen die Präferenzen im Falle von VORSCHLAGEN ${ }^{240}$ und EINWILLIGEN, die Teil des Sequenzmusters VERABREDEN sind, überein.

\section{Expressiva}

Marten-Cleef bestimmt Expressiva als „sprachliche Handlungen, mit denen ein Sprecher zu erkennen gibt, wie ihm zumute ist, oder anders ausgedrückt, Sprechakte, die vollzogen werden, um ein Gefühl des Sprechers auszudrücken “241, vernachlässigt in ihrer Definition also den Beziehungsaspekt, obgleich sie in ihrer Untersuchung ${ }^{242}$ auch Sprechhandlungen berücksichtigt, die im Bereich sozialer Rituale anzusiedeln sind, wie z. B. GRATULIEREN, DANKEN und

\footnotetext{
238 Kohl und Kranz 1992, 21. Vgl. GrafFe 1990, $69 \mathrm{ff}$.

${ }^{239}$ KoHL und KRANZ 1992, 24. Vgl. Graffe 1990, $267 \mathrm{ff}$.

240 Das Untermuster VORSCHLAGEN findet sich auch in der Klassifikation der Aufforderungshandlungen von Hindelang und stellt eine Art Zwischenform der Kommissiva und Direktiva dar. Vgl. KoHL UND KRANZ 1992, 42.

${ }^{241}$ MARTEN-CLEEF 1991, 6.

242 Ebd. Vgl. KOHL UND KRANZ 1992, 26ff. Für Marten-Cleefs Untersuchung gelten ähnliche Einschränkungen wie für die meisten anderen Arbeiten der Münsteraner Schule: „Eine Eingrenzung des Untersuchungsbereichs ergibt sich durch die Beschränkung auf elementare expressive Sprechakte in initialer Position (die also weder sequentiell noch institutionell gebunden sind), wobei die Bekanntheit des Sachverhalts, der die Emotion auslöst, vorausgesetzt wird. Dabei werden vornehmlich Expressiva der mündlichen Kommunikation betrachtet." (ebd., 27).
} 
SICH ENTSCHULDIGEN. Der Fokus der Klassifikation liegt aber auf der emotionalen Komponente, genauer gesagt auf der Wahrnehmung und Bewertung einer Situation und dem Ausdruck der entsprechenden Gefühle. ${ }^{243}$

Auf der Ebene des generellen Handlungssinns grenzt Marten-Cleef Expressiva mit SprecherPräferenz von Expressiva mit Sprecher-Aversion ab, die wiederum danach unterschieden werden, ob sich Präferenz bzw. Aversion nur auf den Sprecher oder (auch) auf den Adressaten beziehen.

Weiterhin werden die Sprechhandlungen nach ihrem speziellen Handlungssinn unterteilt: Das konventionelle Kommunikationsziel von sympathisierenden Sprechakten besteht darin, „daß der Adressat glaubt, daß der Sprecher ein seiner Einstellung korrespondierendes Gefühl empfindet “244, das von opponierenden Sprechakten hingegen darin, „daß der Adressat glaubt, daß der Sprecher ein von seinen Einstellungen divergierendes Gefühl empfindet “245, und das von abreagierenden Sprechakten darin, „,bestimmte Gefühle zu äußern, um dadurch intrasubjektive Spannungen abzureagieren“246.

Eine Abgrenzung der einzelnen Untermuster erfolgt unter einem erneuten (spezielleren) Rückgriff auf die „Bedingung der Präferenz“, d. h. die Bewertung des zugrunde liegenden Sachverhalts im Hinblick auf die Interessen von Sprecher bzw. Adressat, und außerdem mit Bezug auf die „Bedingung des Sachverhalts“, „die einerseits spezifiziert, ob es um einen vergangenen, gegenwärtigen oder zukünftigen (und damit antizipierten) Sachverhalt (bzw. um eine entsprechende Handlung) geht, und die andererseits den Sprecher als Verantwortlichen, Betroffenen oder als Beobachter dieses Sachverhalts charakterisiert "247 (= Wahrnehmung des Sachverhalts), sowie auf die „Bedingung der psychischen Basis“, die „spezifiziert, welche Art von Gefühl angesichts des Sachverhalts empfunden wird“ (= Reaktion auf den Sachverhalt). ${ }^{248}$ Auf dieser Basis werden folgende Untermuster unterschieden:

Zu den sympathisierenden Expressiva mit beidseitiger Präferenz zählen zum einen die Untermuster KOMPLIMENT („Ausdruck der Sympathie angesichts eines Sachverhalts, für den $\mathrm{Sp}_{2}$ verantwortlich bzw. von dem er betroffen ist“), GRATULIEREN („Ausdruck der teilnehmenden Freude angesichts eines Ereignisses, von dem $\mathrm{Sp}_{2}$ betroffen ist“) und GUTER WUNSCH („Ausdruck der Hoffnung auf ein zukünftiges Ereignis, von dem $\mathrm{Sp}_{2}$ betroffen sein könnte"), bei denen die Präferenz eher aufseiten des Adressaten zu verorten ist, andererseits WILLKOMMEN

\footnotetext{
243 Vgl. Kohl und Kranz 1992, 27 bzw. Marten-Cleef 1991, 2 und ebd., 23. Obwohl die Differenzierung von interpersonalen sympathisierenden und opponierenden Expressiva auf der einen sowie intrapersonalen abreagierenden Expressiva auf der anderen Seite (vgl. ebd., 76ff.) Anklänge an Jakobsons Unterscheidung von phatischer und emotiver (oder expressiver) Sprachfunktion erkennen lässt, bezieht sich Marten-Cleef in ihrer Untersuchung nicht auf sein Modell. Sie erwähnt lediglich (ebd., 39 N. 52) dessen emotive (expressive) Funktion. Vgl. a. ebd., 38f. zu Bühlers „Kundgabe-“ bzw. „Ausdrucksfunktion“ (BüHLER 1918 bzw. BüHLER 1999), dessen „Hauptinteresse [...] der erstgenannten, kommunikativ bestimmten Expressivität“, d.h. deren „dialogischintersubjektivem“ und nicht dem „monologisch-intrasubjektiven“ Aspekt gegolten habe.

244 MARTEN-CleEF 1991, 76.

245 Ebd., 77.

246 Ebd., 77.

247 KOHL UND KRANZ 1992, 29.

248 Ebd., 29.
} 
HEISSEN („Ausdruck der Freude“), (SPRACHLICHER) GUNSTERWEIS („Ausdruck der Zuneigung“) und DANKEN („Ausdruck der Dankbarkeit“), bei denen sie eher sprecherseitig ist. ${ }^{249} \mathrm{Zu}$ den opponierenden Expressiva mit Sprecher-Präferenz gehören SPOTTEN („Ausdruck von Schadenfreude“), TRIUMPHIEREN („Ausdruck der Freude über den eigenen Erfolg“) und ANTIPATHISCHER WUNSCH („Ausdruck der Hoffnung auf ein zukünftiges Missgeschick des Adressaten“). ${ }^{250}$ Abreagierende Expressiva mit Sprecher-Präferenz sind FROHLOCKEN („Ausdruck der Freude über eine eigene Handlung“), JUBELN („Ausdruck der Freude über ein eigenes Erlebnis“) und HOFFNUNG ÄUSSERN („Ausdruck der - zu erwartenden - Freude über einen möglicherweise eintretenden, für $\mathrm{Sp}_{1}$ positiven Sachverhalt"). ${ }^{251}$

Zur Gruppe der sympathisierenden Expressiva mit beidseitiger Aversion gehören MITLEID BEKUNDEN („Ausdruck von Traurigkeit über einen - primär - für $\mathrm{Sp}_{2}$ negativen Sachverhalt“), SORGE BEKUNDEN („Ausdruck von Sorge über einen möglicherweise eintretenden, - primär für $\mathrm{Sp}_{2}$ negativen Sachverhalt") und SICH ENTSCHULDIGEN (,Ausdruck der Reue über ein von $\mathrm{Sp}_{1}$ verursachtes, - primär - für $\mathrm{Sp}_{2}$ negatives Ereignis“). ${ }^{252}$ Opponierende Expressiva mit Sprecher-Aversion sind KLAGEN („Ausdruck von Traurigkeit über eine für $\mathrm{Sp}_{1}$ negative Handlung von $\mathrm{Sp}_{2}{ }^{\prime \prime}$ ), SCHIMPFEN (,Ausdruck des Zorns über eine für $\mathrm{Sp}_{1}$ negative Handlung von $\mathrm{Sp}_{2}{ }^{\prime \prime}$ ) und KRITTELN („Ausdruck des Neides hinsichtlich eines $\mathrm{Sp}_{2}$ betreffenden Sachverhaltes“). ${ }^{253}$ JAMMERN („Ausdruck der Traurigkeit“), FLUCHEN („Ausdruck des Ärgers“) und ANGST ÄUSSERN („,Ausdruck der Angst bzw. Aversion gegenüber einer möglicherweise eintretenden unerwünschten Situation") schließlich werden zu den abreagierenden Expressiva mit Sprecher-Aversion gerechnet. ${ }^{254}$

Einige der von Marten-Cleef genannten Sprechhandlungsmuster werden von anderen nicht als eigene Illokutionen gewertet. ${ }^{255}$ Auf der anderen Seite gibt es Sprechhandlungen, die manchmal zu den Expressiva gezählt, aber von ihr nicht oder nur eingeschränkt berücksichtigt werden, wie z. B. axiologische Sprechhandlungen (vgl. aber Untermuster wie KOMPLIMENT und SPRACHLICHER GUNSTERWEIS oder auch KLAGEN und SCHIMPFEN). ${ }^{256}$ Eine ausführliche Analyse der bewertenden Sprechakte, findet sich bei Zillig. ${ }^{257}$ Sie ist allerdings auf solche Sprechhandlungen beschränkt, „die von einem individuellen und privaten Subjekt gegenüber einem individuellen und privaten Adressaten mittels einer Äußerung gemacht werden, wenn

\footnotetext{
249 MARTEN-Cleef 1991, 123ff. Vgl. Kohl und Kranz 1992, 30f. Die Definitionen (in Anführungszeichen) hier und im Folgenden lehnen sich mehr oder weniger stark an die bei Marten-Cleef bzw. Kohl und Kranz gemachten Ausführungen an, die insgesamt noch viel differenzierter sind. Vgl. a. die Definitionen (unter Einschluss aller Handlungsbedingungen) im Praxisteil und die Übersicht im Anhang (ab S. 441).

250 Marten-Cleef 1991, 220ff. Vgl. Kohl und Kranz 1992, 31.

251 Marten-CleEF 1991, 244ff. Vgl. KoHL und Kranz 1992, 31.

252 Marten-Cleef 1991, 267ff. Vgl. Kohl und Kranz 1992, 31.

253 Marten-CleEF 1991, 303ff. Vgl. Kohl und KRANZ 1992, $31 \mathrm{f}$.

${ }^{254}$ Marten-Cleef 1991, 327ff. Vgl. Kohl und KRANZ 1992, 32.

${ }^{255}$ Vgl. z. B. ORTNER 2014b, 264: „Während z.B. DANKEN und GRATULIEREN manchmal zu den Deklarativa gezählt werden, werden JAMMERN und KLAGEN teilweise als konventionell betrachtet, von Austin beispielsweise aber nicht als eigenständige Illokution anerkannt [...].“

${ }^{256}$ Vgl. MARTEN-CleEf 1991, 49ff. und ebd., 88ff. Vgl. a. KoHL und KRANZ 1992, 42, die als Beispiel das Untermuster JAMMERN nennen.

257 ZILLIG 1992. VgI. KOHL UND KRANZ 1992, 32ff.
} 
das Objekt der BEWERTUNG einzelne oder mehrere sprachliche Handlungen eines individuellen Sprechers oder aber sprachliche Gewohnheiten und Eigenheiten dieses Sprechers sind. “258

\section{Gesamtwürdigung}

Die Arbeiten der Münsteraner Schule leisten einen wichtigen Beitrag zu einer systematischen und differenzierten Subklassifikation der übergeordneten Sprechaktkategorien und zur Erfassung der Spezifik der jeweiligen Äußerungsformen im Deutschen. ${ }^{259}$ Dabei ergeben sich u. a. auch „Aufschlüsse über die Begründetheit und Plausibilität der Gesamttaxonomie “260 Searles, wenn z. B. deren Unvollständigkeit und Überschneidungen von Untertypen deutlich werden. ${ }^{261}$

Ein Problem könnte man allerdings darin sehen, dass keine einheitliche Methode angewandt wird, da den Typologisierungen neben einer empirischen lexikographischen Analyse auch sprachphilosophische Überlegungen und Reflexionen aufgrund der eigenen Sprachkompetenz zugrunde liegen. ${ }^{262}$ Außerdem ist die Terminologie zur Bezeichnung der einzelnen Untermuster teilweise gewöhnungsbedürftig. Insbesondere im Zusammenhang mit den Expressiva finden sich Begriffe, die zunächst eher unwissenschaftlich wirken, obwohl sie ja unter Zugrundelegung von klar formulierten Handlungsbedingungen fachsprachlich definiert werden. Dabei entsprechen die Begriffsbestimmungen trotz Bezugnahme auf die konkrete Sprachverwendung im Deutschen auch nicht immer der in der Alltagssprache gängigen Auffassung. Bspw. werden Verben wie ,benachrichtigen' und ,mitteilen', die umgangssprachlich oft synonym verwendet werden, zur Bezeichnung verschiedener Untermuster gebraucht. ${ }^{263}$

Letztlich entscheidend sollte sein, dass eine Klassifikation insgesamt nachvollziehbar und überzeugend ist - was auf die Kategorisierungen der Münsteraner Schule im Großen und Ganzen zutrifft. Auch wenn ihre Untersuchungen eher theoretischer Natur sind, können sie sicherlich als fundierte Basis für weiterführende praktische Arbeiten dienen, müssen nur ggf. den eigenen spezifischen Bedürfnissen angepasst werden. ${ }^{264}$

\footnotetext{
258 ZILLIG 1992, 28.

${ }^{259}$ Vgl. Hindelang 2010, 39 und ebd., 45; Diegritz Und FürSt 1999, 29 sowie KoHL UND KRANZ 1992, $40 \mathrm{ff}$.

260 Ebd., 2.

261 KOHL UND KRANZ 1992, $40 \mathrm{ff}$.

262 StAfFeldt 2009, 99f. (mit Bezug auf HindelANG 1978). Vgl. a. ebd., 73ff. und ebd., 119. STAFfeldt 2009, $102 \mathrm{ff}$. schlägt demgegenüber ein (einheitliches) Verfahren zur Ermittlung der Untermuster vor, das die lexikographische Vish!-Methode (vgl. N. 97) und Korpusanalysen miteinander verbindet. Vgl. a. ebd., 94ff.

263 KOHL UND KRANZ 1992, 16f.: „Es ist wichtig, zusammenfassend hervorzuheben, daß die Konstruktion der Untermuster an den für sie jeweils spezifischen Handlungsbedingungen und nicht etwa am umgangssprachlichen Gebrauch der sie bezeichnenden Ausdrücke orientiert ist." Vgl. ebd., 12; HINDELANG 2010, 39 und ebd., 45 sowie STAFFELDT 2009, 100f., der z. B. auf den im Vergleich zum alltagssprachlichen Verständnis stark eingeschränkten Bedeutungsumfang von BEFEHLEN hinweist.

${ }^{264}$ Vgl. ebd., 104 und DIEGRITZ UND FüRST 1999, 29ff., welche die Arbeiten der Münsteraner Schule zwar durchaus positiv beurteilen, aber eben auch kritisieren, dass sie „sehr stark hypothetisch und wenig praxisorientiert“ (ebd., 31) seien. Vgl. a. ebd., 29: „Die Münsteraner Musterlösungen können [...] keineswegs als endgültige Lösung für alle spezifischen Handlungsfelder der Alltagssprache und der Fachsprachen gelten. Dies wird spätestens dann deutlich, wenn man innerhalb eines spezifischen Bereiches (z.B. Unterrichtssprache) empirisch forscht und genötigt ist, konkrete authentische Äußerungen mit allen ihren Unvollkommenheiten und situativen Besonderheiten, möglichst exakt treffenden Sprechakttypen zuzuordnen." Vgl. aber auch die erfolgreiche Anwendung auf das Transkript einer Bundespressekonferenz in STAFFELDT 2014.
} 


\subsection{Kritik an der klassischen Sprechakttheorie}

Einige Kritikpunkte an der klassischen Sprechakttheorie wie die teilweise Gleichsetzung von SB-Ausdrücken und Sprechakten und die Uneinheitlichkeit der Kriterien bei der Klassifikation sowohl der Oberklassen als auch der Untermuster wurden bereits erläutert. Auf andere wie den „universalistischen Charakter der angenommenen Sprechaktkategorien “265 wird noch an späterer Stelle einzugehen sein.

Manches wirkt auf den ersten Blick erstaunlich: Obwohl die Untersuchungen sich eigentlich am mündlichen Sprachgebrauch orientieren, vernachlässigen sie die Dialogizität von Sprechakten, sind sprecherzentriert und damit einhergehend stark intentional geprägt. ${ }^{266}$ Der Grund ist v. a. darin zu sehen, dass in den meist ja eher theoretisch-abstrakten Arbeiten von einer idealisierten Kommunikationssituation mit idealisierten Sprechern und Adressaten ausgegangen wird. ${ }^{267}$ Der intratextuelle Kotext und der extratextuelle Kontext der Äußerungen werden kaum beachtet; stattdessen stehen isolierte Einzelsätze im Mittelpunkt. ${ }^{268}$ Eine solche Vorgehensweise erscheint deshalb problematisch und realitätsfern, weil zum einen Sätze und Illokutionen nicht immer deckungsgleich sind ${ }^{269}$; zum anderen stehen Sätze bzw. Illokutionen i. d. R. in einem bestimmten Zusammenhang und sind Teil größerer Gesprächssequenzen. Diese Eingebundenheit von Einzelsprechakten ist bereits Searle bewusst, wird aber erst von seinen Nachfolgern mehr oder minder angemessen berücksichtigt. ${ }^{270}$ Eine entsprechende Erweiterung des Untersuchungsgegenstandes findet v. a. im Rahmen gesprächs- und textlinguistischer Modelle statt, wobei außerdem verstärkt schriftsprachliche Texte in den Fokus geraten.

\footnotetext{
265 LIEDTKE 2018, 39. Vgl. dazu auch den Abschnitt „Sprechakte“ (ab S. 71) in Kap. 1.1.2.1.2.

${ }^{266}$ Vgl. z. B. SZWEd 2014, 154ff.; Rolf 2006, 2532; WeIGAND 2003, 67; HeINEMANN UND HEINEMANN 2002, 42 und BURKHARDT 1986, 99. Vgl. aber auch LIEDTKE 2018, 38: „, Der [...] Vorwurf lässt sich mit dem Schlagwort der Sprecherorientierung kennzeichnen; es werde die Tatsache ausgeblendet, dass sprachlicher Austausch eine Interaktion zwischen Sprecher/in S und Adressat/in A ist, innerhalb derer Bedeutungen und damit auch illokutionäre Kräfte nicht vorgängig und souverän von S festgelegt werden, sondern Teil eines Aushandlungsprozesses zwischen S und $A$ sein können. Dem lässt sich entgegnen, dass auch bei Vorliegen eines solchen Aushandlungsprozesses $S$ gestattet werden sollte - und dies in der Regel auch wird - die letztliche Entscheidung darüber zu treffen, was er/sie intendiert und damit gemeint hat. Gegen die eigene Überzeugung, was gemeint war, wird man $\mathrm{S}$ nicht auf eine Lesart festlegen, die er/sie nicht ratifizieren kann und will.“

${ }^{267}$ Vgl. z. B. SZWED 2014, 156: „In der Sprechakttheorie wird ein einsam und zweckrational handelndes Individuum vorausgesetzt [...]. Sprecher und Hörer erscheinen demnach als idealisierte Partner. [...] Damit hängt auch die Idealisierung der Glückensbedingungen zusammen. “ Vgl. außerdem WÜEST 2011, 35; HARRAS 2004, 227; WEIGAND 2003, 51; HeINEMANN UNd HeINEMANN 2002, 42; ULKAN 1992, 13 und CherubiM 1980, 16.

268 Vgl. z. B. SZWEd 2014, 156; Rolf 2006, 2532; WeIGAND 2003, 67; WüESt 2002, 183; HeINEMANN UND HEINEMANN 2002, 42 und WAGNER 1997, $318 \mathrm{f}$.

${ }^{269}$ Zur Problematik einer Gleichsetzung von Satz und Sprechakt bzw. Illokution vgl. Kap. 1.3.2.1.

270 Vgl. WEIGAND 2003, 53: „Searle selbst ist sich der Fragestellung des Zusammenhangs der Sprechakte in der Sequenz bewusst, gelangt aber nicht zu einer zufriedenstellenden Beschreibung, da er sich zu sehr an seiner regelhaften Beschreibung der Einzelsprechakte orientiert und dann notgedrungen feststellen muss, dass, conversation' nicht dieser Regelbeschreibung folgt." Vgl. a. STAfFeLDT 2009, 54 N. 40. Bereits SCHLIEBEN-LANGE 1979, 100 macht auf die zur Überwindung der Satzzentriertheit notwendigen Aufgaben aufmerksam. VgI. a. RoLF 2006, 2532, der u. a. auf erste Arbeiten mit Berücksichtigung dieses Aspekts (HENNE 1975 und BURKHARDT 1986) verweist. Natürlich war man sich aber auch schon früher satzübergreifender Phänomene bewusst, und zwar nicht nur im Rahmen der Stilistik: VgI. z. B. AdAMzIK 2016, 28 und ebd., 31 oder auch (zu textlinguistischen Ansätzen in der Antike) Ax 2006b.
} 
Durch diese Weiterentwicklung wird die traditionelle Sprechakttheorie in gewisser Weise überwunden. ${ }^{271}$

\subsubsection{Textlinguistische Weiterentwicklung der Sprechakttheorie}

\subsection{Anfänge der Textlinguistik und pragmatische Wende}

In den Anfängen der Textlinguistik werden satzübergreifende (transphrastische) Äußerungen zunächst v. a. nach strukturell-grammatischen Gesichtspunkten (z. B. Referenz, Substitution, Pronominalisierung) untersucht; es gibt aber auch semantische Ansätze (z. B. Analysen von Isotopie-Ebenen). Nach dieser eher systemlinguistisch orientierten Phase wendet man sich im Rahmen der pragmatischen Wende verstärkt dem Handlungsaspekt von Texten zu. Umgekehrt wird in der Pragmatik bald die Notwendigkeit der Berücksichtigung satzübergreifender Zusammenhänge erkannt, sodass beide Disziplinen zunehmend ineinander übergehen. ${ }^{272}$ Auf die pragmatische folgt eine kognitive Wende (mit genauerem Blick $u$. a. auf den Textverstehensprozess); das „,kognitive Paradigma“ wiederum wird von einem „kulturellen Paradigma“ und einem „(multi)medialem Paradigma“ abgelöst. ${ }^{273}$

\subsection{Grundlagen textpragmatischer Analyseansätze}

\section{Textanalyseebenen und Textstruktur}

Bei einer sprechakttheoretischen Textbetrachtung ist es wichtig, nicht einfach die Ergebnisse der Untersuchung von Einzelsätzen bzw. -illokutionen auf (Teil-)Texte zu übertragen, sondern die speziellen Eigenheiten von Texten zu beachten. ${ }^{274}$ Dafür wurden unterschiedliche Textanalyse- bzw. Textbeschreibungsansätze entwickelt. ${ }^{275}$ Eines der bekanntesten im deutsch-

\footnotetext{
${ }^{271}$ Vgl. HEINEMANN 2008, 128: „Als Repräsentationen oder Weiterführungen der Sprechakttheorie verstehen sich die meisten linguistischen Arbeiten, die im Rahmen der pragmatischen Wende in Deutschland entstanden sind. Doch werden dabei unterschiedliche Akzente gesetzt: Teils wird das Searle'sche Modell direkt (oder leicht modifiziert) übernommen, teils rücken ganzheitliche Texte (und nicht nur Sätze) ins Zentrum der Darstellung und bedingen dadurch eine Art Aufhebung des sprechakttheoretischen Grundmodells." Vgl. a. ebd., 131f.; ADAMZIK 2018a, 53 und CHERUBIM 1980, 16.

272 Vgl. SCHLIEBEN-LANGE 1979, 110 zur Annäherung von Textlinguistik und Pragmatik: „So konvergieren Textlinguistik und linguistische Pragmatik, die die Ebene des Satzes anfänglich in je verschiedener Weise überschritten hatten, zum gegenwärtigen Zeitpunkt fast völlig. " Sie weist auch darauf hin, dass es bereits vor der pragmatischen Wende - sowohl in der systemlinguistischen Phase der Textlinguistik als auch insbesondere in der älteren Linguistik - vereinzelte pragmatische Ansätze gab (ebd., 57f.).

${ }^{273}$ ADAMZIK 2018a, 53. Als Weiterentwicklung kann außerdem die Textgrenzen überschreitende Diskurslinguistik betrachtet werden (vgl. N. 8). Integrative Ansätze und Überschneidungen der verschiedenen textlinguistischen Konzepte gab es im Übrigen schon länger. Die einzelnen Perspektiven lassen sich ohnehin nicht trennscharf voneinander abgrenzen und bestehen z. T. gleichzeitig nebeneinander. Zur Entwicklung der Textlinguistik insgesamt vgl. z. B. ADAMZIK 2016, 1ff. bzw. (zu den neueren Tendenzen im 21. Jahrhundert) ebd., 350ff.; GANSEL UND JÜRGENS 2009, 35ff.; FIX 2008; BRINKER 2006 und BEAUGRANDE UND DRESSLER 1981, $15 \mathrm{ff}$.

274 Vgl. z. B. BRINKER 2002, 42: „Texte stellen [...] in der Regel komplexe sprachliche Handlungen dar, die nicht additiv aus elementaren Sprechhandlungen aufgebaut sind. Ihre Beschreibung macht deshalb auch Analysekategorien erforderlich, die das einfache Sprechaktmodell Searles nicht enthält." Vgl. a. HEINEMANN UND VIEHWEGER 1991, 56f. und WüEST 2011, 81. Zur Definition von ,Text' vgl. z. B. ADAMZIK 2018a, 55ff.; ADAMZIK 2016, 40ff.; KRIEGHOLZ UND BÜLOW 2015, 1ff.; BRINKER U. A. 2014, 11ff.; FIX 2008, 17ff. und Rolf 1993, 1ff. In der vorliegenden Arbeit wird folgende recht allgemeine und umfassende Bestimmung nach GANSEL UND JÜRGENS 2009, 51 zugrunde gelegt: „Ein Text ist eine in sich kohärente Einheit der sprachlichen Kommunikation mit einer erkennbaren kommunikativen Funktion und einer in spezifischer Weise organisierten Struktur."

275 In dieser Arbeit wird nicht genauer zwischen den Begriffen ,Textanalyse‘ und ,Textbeschreibung' unterschieden. Teilweise werden sie danach differenziert, ob ein Bottom-up-Verfahren (Textanalyse) und oder ein Top-
} 
sprachigen Raum ist das textfunktionale Modell (auch: Indikatorenkonzept) von Klaus Brinker. ${ }^{276}$ Er unterscheidet drei Textbeschreibungsebenen: die grammatische Ebene (Äußerungsebene), die thematische Ebene (Inhaltsebene) und die kommunikativ-pragmatische Ebene (Handlungsebene), wobei die ersten beiden Ebenen die Textstruktur betreffen, die dritte die Textfunktion. Ähnliche Unterscheidungen finden sich auch in anderen Modellen, wie z. B. dem Illokutionsstrukturkonzept (ISK) ${ }^{277}$, wo ebenfalls eine grammatische Ebene (Textkonstitutionsstruktur) und eine pragmatische Ebene differenziert werden, die thematische Ebene bzw. Informationsstruktur allerdings neben der Illokutionsstruktur als Teil der pragmatischen Ebene betrachtet wird. ${ }^{278}$ In jedem Fall wird aber davon ausgegangen, dass vielfältige und komplexe Verflechtungen der verschiedenen Ebenen untereinander bestehen, deren Trennung nur aus praktisch-analytischen Gründen erfolgt. ${ }^{279}$ Es gibt jedoch einen grundlegenden Unterschied zwischen den beiden genannten Ansätzen. ${ }^{280}$ Im ISK werden auch einzelnen Äußerungen bzw. Illokutionen in einem (Teil-)Text Funktionen zugeordnet, die in ihren Verbindungen zueinander innerhalb der ,Illokutionsstruktur' genauer analysiert werden (analytisches Konzept). Nach Brinker dagegen ist es zwar möglich, grammatische und thematische Strukturen von Texten zu untersuchen, eine textinterne pragmatische Struktur gebe es aber nicht, sondern der Text wird als „pragmatischer Monolith“281 betrachtet. Unmittelbare Handlungsqualität komme nur dem Text als Ganzem zu (holistisches Konzept). ${ }^{282}$ Auch dieser An-

down-Modell (Textbeschreibung) zugrunde liegt: VgI. z. B. HEINEMANN 2008, 140ff. und HEINEMANN UND HEINEMANN 2002, $195 \mathrm{ff}$.

${ }^{276}$ Vgl. z. B. WeEKE 2011, 56; HeINEMANn 2008, 139 und RoLf 2003, 199. Brinkers zuerst 1985 erschienenes Grundlagenwerk zur „Linguistischen Textanalyse“ wurde vor einigen Jahren überarbeitet von Hermann Cölfen und Steffen Pappert: BRINKER U. A. 2014 (9., durchges. Aufl. 2018). Vgl. a. Brinkers andere Arbeiten zu dem Thema. Dadurch, dass Brinker bzw. seine Nachfolger ihr Konzept ständig weiterentwickelt haben, liegt kein eindeutig fassbares, einheitliches Modell vor, was - neben den ohnehin teilweise vorhandenen Unklarheiten - eine gut nachvollziehbare Darstellung in der vorliegenden Arbeit erschwert. Vgl. a. RoLf 1993, 41.

277 Vgl. dazu z. B. HARTUNG 2000 - 2001, 88: „Am weitesten entwickelt und in Einzeluntersuchungen exemplifiziert wurde diese textlinguistische Erweiterung der Sprechakttheorie in Arbeiten von Motsch und Viehweger sowie der Gruppe um Rosengren, die teilweise auch in einem Projekt miteinander verbunden waren. "In ebd. wird u. a. die Entwicklung des ISK in seinen Anfängen anhand der Ansätze von MOTSCH UND VIEHWEGER 1981, KOCH U. A. 1981 und ROSENGREN 1983 beschrieben. Vgl. a. die von Rosengren im Rahmen des Forschungsprogramms „Sprache und Pragmatik" herausgegebenen Bände, z. B. ROSENGREN 1979b, ROSENGREN 1981 und ROSENGREN 1983. Vgl. außerdem die Darstellungen z. B. bei HeINEMANN UND VIeHWEGER 1991, 58ff.; SCHRÖDER 2003, 8ff. und SZWED 2014, $163 \mathrm{ff}$. Insgesamt handelt es sich beim ISK ebenfalls um kein einheitliches Modell, sondern eher um ein „Nebeneinander autonomer ,Module““ (HEINEMANN UND HEINEMANN 2002, 86).

278 Vgl. z. B. BRINKER 2006, 2545f.; KOTSCHI 1996, 241ff.; MotSCH 1996, 3ff. und KoCH U. A. 1981, 159ff. Zum Begriff ,Illokutionsstruktur' vgl. a. MOTSCH UND PASCH 1987, $13 \mathrm{f}$.

${ }^{279}$ Vgl. z. B. BRINKeR U. A. 2014, 10 und ebd., 125 bzw. ROSENGReN 1987, 29 und KoCH U. A. 1981, 159ff.

${ }^{280}$ Zum Unterschied zwischen ISK und Brinkers Ansatz insgesamt vgl. z. B. ROLF 2000 - 2001, 423f.; BRINKER 2006, 2544ff.; SZWED 2014, 116ff. und LUPPOLD 2015, 394ff.

281 Ebd., 397.

282 Vgl. z. B. BRINKER 1994, 36: „Mein Haupteinwand besteht darin, daß man Sätzen im Grunde nur bei einer isolierten Betrachtung eine illokutive Rolle zuordnen kann. Sind sie in die Ganzheit ,Text' integriert, besitzen sie in der Regel keine unmittelbare Handlungsqualität; sie erfüllen vielmehr bestimmte textinterne Funktionen, vor allem im Hinblick auf den thematischen Aufbau des Textes (Situierungs- oder Spezifizierungsfunktion oder Begründungsfunktion usw.). Der Handlungscharakter kommt dem Text als Ganzem zu und wird durch die Textfunktion bezeichnet." Vgl. a. BRINKER 2000 - 2001c, 172 und BRINKER U. A. 2014, 96f. sowie die Kritik am ISK in LUPPOLD 2015, 395f.; ORTAK 2004, 92ff., bes. ebd., 95ff. („Defizite der isolierten Illokutionsbestimmung“); HEINEMANN UND HEINEMANN 2002, 86 und HARTUNG 2000 - 2001, 89. Vgl. außerdem den Versuch in BRINKER 2000 - 2001b, 177, am 
satz wird aus verschiedenen Gründen stark kritisiert. U. a. wird auf den Widerspruch hingewiesen, dass Brinker zwar keine funktionalen Untereinheiten innerhalb einer pragmatischen Struktur mit Bezug auf eine übergeordnete Textfunktion, aber sehr wohl thematische Untereinheiten innerhalb der thematischen Struktur mit Bezug auf ein übergeordnetes Textthema annimmt. ${ }^{283}$ Brinkers Aussagen sind auch anderweitig z. T. logisch nicht stringent. So schließt eine übergeordnete Textfunktion das Vorhandensein von untergeordneten illokutiven Funktionen z. B. gar nicht aus. ${ }^{284}$

Die Diskussion zwischen Vertretern des analytischen Konzepts auf der einen und denen des holistischen Konzepts auf der anderen Seite wurde z. T. äußerst heftig geführt, was manchmal kaum mehr nachvollziehbar ist, zumal die Konzepte letztlich gar nicht so unterschiedlich und unvereinbar miteinander sind, wie es die Auseinandersetzungen vermuten lassen würden. ${ }^{285}$ Dies zeigt sich auch an verschiedenen Versuchen, sie miteinander in Einklang zu bringen. ${ }^{286}$ So vereint z. B. Schröders Modell der Konstituentenstruktur ${ }^{287}$ die Betrachtung der verschiede-

Beispiel eines Werbetextes die fehlende Praktikabilität und Unangemessenheit eines solchen Zugangs zu erweisen (s. S. 54). Vgl. darüber hinaus Leechs allgemeine Kritik an der „overgrammaticization“ in der Pragmatik, die zu einer „tendency to compartmentalize and hierarchize units of discourse, as if they were constituents in an immediate constituent analysis" geführt habe (LEECH 1983, 232).

${ }^{283}$ Vgl. z. B. LUPPOLD 2015, 398 N. 882: „Die Schlussregel Brinkers lautet hier offensichtlich: Wenn etwas als komplexe Ganzheit mehr ist als die Summe seiner Teile, dann dürfen die einzelnen Teile, die funktional auf das Ganze bezogen sind, nicht mehr als eigenständige Einheiten betrachtet werden. Wenn die einzelnen Teile nicht mehr als eigenständige Einheiten betrachtet werden dürfen, dann ist eine Analyse der Struktur dieser Teile obsolet. Abgesehen davon, dass der zweite Teil dieser Argumentation schwer begründbar sein dürfte, dürften auf der Grundlage dieser Regel auch thematische Strukturen im Text nicht mehr untersucht werden, denn auch einzelne thematische Einheiten lassen sich funktional auf ein übergeordnetes Textthema beziehen.“

${ }^{284}$ Vgl. z. B. Rolf 1993, 41f.: „Der Annahme, daß der durch die Textfunktion bezeichnete Handlungscharakter dem Text als Ganzem zukommt, kann man beipflichten, ohne die illokutive Qualität der einzelnen, in einem Text enthaltenen Äußerungseinheiten verleugnen zu müssen. [...] Der Handlungscharakter eines Textes kann bereits mit der dominierenden Illokution, die selbst in Form eines einzigen Satzes verwirklicht sein kann, gegeben sein. Die Textfunktion, der eigentliche Zweck, dem der Text dienen soll, wird durch weitere, unter- oder nebengeordnete Funktionsträger lediglich unterstützt, ergänzt oder erweitert. Daß aber die Textfunktion aus solchen unterstützenden oder ergänzenden Funktionen zusammengesetzt, aufgebaut wäre, muß damit nicht gesagt sein. Daß die Äußerungseinheiten, aus denen sich ein Text zusammensetzt, Träger einer illokutiven Funktion sind, gesteht Brinker durch den Hinweis auf die Begründungs- und Spezifizierungsfunktion [vgl. N. 282] übrigens selbst zu. Denn auch wenn die Begründungs- und die Spezifizierungsfunktion als textinterne Funktionen aufzufassen sind, so werden diese Funktionen doch durch Begründungen und Spezifizierungen erfüllt, und das sind Beispiele für Illokutionen. "Was die Einordnung von Begründungen, Spezifizierungen usw. angeht, liege der Unterschied zwischen beiden Konzepten letztlich v. a. darin begründet, ob sie „als semantische oder pragmatische Gegebenheiten anzusehen sind." (Rolf 2000 - 2001, 424). Vgl. SZWED 2014, 166. Vgl. a. Rolf 2003, 201f., wo u. a. auf den Widerspruch zwischen Brinkers sprechakttheoretischer Fundierung der Textfunktion und der Ablehnung einer entsprechenden Vorgehensweise bei den Vertretern des ISK hingewiesen wird. VgI. außerdem ARTMANN 1996, 90 und das Kap. „Textfunktionen“ ab S. 47. Rolf 1993, 41 macht im Übrigen darauf aufmerksam, dass Brinkers Ansichten sich im Laufe der Zeit z. T. gewandelt haben und er anfangs durchaus vom Vorhandensein dominierender Illokutionen ausgegangen ist, wobei er u. a. auf BRINKER 1983, 136 und ebd., 141 verweist.

285 Vgl. z. B. GANSEL UND JÜRGENS 2009, 82.

286 Vgl. z. B. Rolf 1993; ARtMANn 1996; SCHRÖDER 2003 und SZWEd 2014. Vgl. a. BrinKer 2000 - 2001c, 172 und BRINKER 2006, 2545. Diese Integrationsversuche werden erwartungsgemäß unterschiedlich beurteilt, häufig auch sehr negativ, insbesondere natürlich von den Vertretern des analytischen bzw. holistischen Konzepts selbst. Hier ist u. a. auf die heftige Kritik Brinkers an Artmanns Analyse von Erpresserbriefen in BRINKER 2002 zu verweisen. 287 SCHRÖDER 2003. Ein Überblick über Schröders Modell findet sich auch bei ORTNER 2014b, 326f. und LUPPOLD 2015, 399ff. 
nen Textebenen zu einem Gesamtkonzept und nimmt dabei insbesondere die enge Verbindung zwischen thematischer Struktur und Handlungsstruktur in den Blick, die im ISK nur unzureichend, von Brinker i. e. S. gar nicht berücksichtigt wird, da er ja das Vorhandensein einer pragmatischen Struktur leugnet. ${ }^{288}$ Obgleich mit Schröders Ansatz ebenfalls nicht alle Probleme, z. B. im Zusammenhang mit der Verbindung von thematischer und pragmatischer Ebene $^{289}$, gelöst werden, kann man ihn doch zumindest in folgender Hinsicht als Fortschritt betrachten: „Er [= Schröder] entkommt der scheinbaren Zwickmühle, Texte entweder auf Kosten ihrer Ganzheitlichkeit als Netz verknüpfter Einzelteile beschreiben zu müssen, oder sie auf Kosten einer Beschreibung textinterner Handlungsstrukturen als monolithischen Textakt mit komplexem propositionalem Gehalt erfassen zu müssen. Entsprechend kommt der Textanalyst bei Schröder nicht in die Bedrängnis, die Textfunktion nur analytisch unter weitestgehender Ausklammerung textexterner Faktoren oder nur holistisch unter weitestgehender Ausklammerung textinterner pragmatischer Strukturen beschreiben zu müssen. “290

\section{Textfunktionen}

\section{Definition und Bestimmung der Textfunktion}

Brinker definiert die Textfunktion ${ }^{291}$ in Anlehnung an die klassische Sprechakttheorie als „die im Text mit bestimmten, konventionell geltenden, $\mathrm{d}$. h. in der Kommunikationsgemeinschaft verbindlich festgelegten Mitteln ausgedrückte Kommunikationsabsicht des Emittenten“292.

\footnotetext{
288 Vgl. z. B. SCHRÖDER 2003, 83f.: „Demgegenüber sind Thema, thematische Struktur und Handlungsstruktur bei einer Anbindung des Textthemas an den Begriff der komplexen Handlung Beschreibungskategorien, die bereits im Ansatz eng aufeinander bezogen sind. Dabei wird die Kategorie des Themas verwendet, um die thematische Einheit von komplexen Handlungen zu beschreiben. Das Thema wird also als Gegenstand gesehen, auf den mit einer komplexen Handlung Bezug genommen wird. Auf diesen gemeinsamen Gegenstand beziehen sich alle zugehörigen Teil-Handlungen. Genauso wie die komplexe Handlung vollzogen wird, indem eine Folge von TeilHandlungen vollzogen wird, wird also das Thema behandelt, indem eine Folge von Teilthemen behandelt wird. Auch thematisch besteht zwischen Texthandlung und Teil-Handlungen ein Zerlegungszusammenhang. [...] Anders als in anderen Ansätzen ist die thematische Struktur von Texten damit keine eigenständige Strukturebene, die im Nachhinein mit einer ebenfalls eigenständigen Handlungsstruktur synchronisiert werden muß; das Verstehen der thematischen Bezüge und Zusammenhänge wird vielmehr als integraler Bestandteil des Textstrukturverstehens aufgefaßt; die thematische Struktur ist ein Teil der Handlungsstruktur. “ Vgl. a. LUPPOLD 2015, 401.

${ }^{289}$ Vgl. z. B. LÖTSCHER 2008, 109 (nicht nur) mit Bezug auf Schröders Ansatz: „In der Frage, ob und inwiefern die thematische und die illokutive Ebene etwas miteinander zu tun haben, bleibt jedoch noch vieles offen. Eine Fortsetzung der texttheoretischen und empirischen Diskussion wäre jedenfalls wünschenswert.“

290 LUPPOLD 2015, 401f.

${ }^{291}$ Neben ,Textfunktion' finden sich zahlreiche weitere Termini, die mit gleicher oder ähnlicher Bedeutung verwendet werden. Eher neutral und unabhängig von weiteren Implikationen wird der Begriff, textuelle Grundfunktion' gebraucht. Begriffe wie ,Gesamtfunktion', ,Texthandlung', ,Textakt' und ,Textillokution', aber auch die bereits genannte ,Textfunktion' werden abgesetzt von Untereinheiten wie bspw. ,Teilhandlung' und ,Einzelhandlung', fokussieren also die Textganzheit. Dagegen sind Ausdrücke wie ,Haupthandlung' und entsprechend ,Unterhandlung' bzw. ,Nebenhandlung' - so wie auch das Gegensatzpaar ,dominierender Sprechakt' und ,subsidiärer Sprechakt' - hierarchiebezogen. Will man (wie im ISK) die zugrunde liegende Textstrategie betonen, wird eher von ,Globalziel' (im Gegensatz zu den ,Teilzielen') bzw. ,Hauptziel' oder ,übergeordnetem Ziel' (im Gegensatz zu den ,untergeordneten Zielen') gesprochen. Im Einzelnen können die Definitionen stark voneinander abweichen. ,Textillokution' kann bspw. ein Synonym für ,Textfunktion' sein; es können mit ,Textillokutionen' aber auch sämtliche in einem Text ermittelbaren (Einzel-)Illokutionen gemeint sein. Vgl. a. das Kap. „Textfunktion und dominierende Illokution“ ab S. 53.

292 BRINKER U. A. 2014, 97. Vgl. a. BRINKER 2000 - 2001b, 175f. Dieser Arbeit liegt die Bestimmung Brinkers zugrunde. Vgl. aber auch die Definitionen bei DIMTER 1981, 52f. und HEINEMANN UND VIEHWEGER 1991, 148 sowie HAUSENDORF UND KESSELHEIM 2008 (s. S. 50). Zum Verhältnis zur Sprechakttheorie (Searles) vgl. z. B. BRINKER 2000 - 2001b, 176: „Diese [= Brinkers] Definition der Textfunktion entspricht weitgehend dem sprechakttheoretischen Begriff des
} 
Dabei geht es weder um die tatsächlich erzielte Textwirkung noch um die (i. d. R. kaum sicher ermittelbare) „wahre“ Autorabsicht, sondern „um die Absicht des Emittenten, die der Rezipient erkennen soll, sozusagen um die Anweisung des Emittenten an den Adressaten, als was dieser den Text insgesamt auffassen soll. “ 293

Sie wird durch sog. Indikatoren der Textfunktion signalisiert. ${ }^{294}$ Die textuellen Indikatoren betreffen die sprachliche Ausgestaltung (Grammatik, Stil), die thematische und - je nach konzeptioneller Ausrichtung des Analysierenden - pragmatische Struktur eines Textes. Hinzu kommen ggf. nicht-sprachliche Indikatoren (z. B. das Layout). Dabei wird die Textfunktion selten direkt, wie z. B. durch eine entsprechende explizit performative Überschrift, signalisiert, sondern i. d. R. indirekt, v. a. durch die thematische Einstellung, d. h. die „Einstellung des Emittenten zum Textinhalt, insbesondere zum Textthema““. ${ }^{295}$ Diese ist allerdings häufig nicht eindeutig; ausschlaggebend sind meist die inhaltlichen Kernaussagen und v. a. kontextuelle Indikatoren. ${ }^{296}$

Klassifikation von Textfunktionen

Zur Klassifikation von Textfunktionen gibt es ähnlich wie für die (Einzel-)Sprechakte eine Vielzahl von Vorschlägen, von denen im Folgenden einige besonders bekannte, die zudem recht verschiedene mögliche Herangehensweisen demonstrieren, vorgestellt werden sollen.

illokutiven Akts, indem sie den intentionalen und den konventionellen Aspekt sprachlicher Handlungen in ähnlicher Weise miteinander verknüpft. Wie der illokutive Akt den Handlungscharakter einer Äußerung festlegt, so bestimmt die Textfunktion den Kommunikationsmodus des Textes." Vgl. a. SANDIG 1978, 81 und LUPPOLD 2015, $397 f$.

293 BRINKER U. A. 2014, 97. Vgl. a. die weiteren Ausführungen in ebd., 97f. sowie BRINKER 1994, 37 und BRINKER 2000 - 2001b, 176. Vgl. außerdem GroßE 1976, 26. Die Textfunktion wird also aus der Perspektive des Textrezipienten erfasst, wobei zu klären wäre, wieweit dieser mit dem intendierten Adressaten identisch ist. Vgl. a. WüEST 2011, 183, der (mit Bezug auf SAGER 1994, 70) darauf aufmerksam macht, „dass ein gegebener Text für verschiedene Leser verschiedene Funktionen haben kann. So hätten [nach Sager] Gesetzestexte einen informativen Zweck für den allgemeinen Leser, einen direktiven dagegen ,for the specific group of people listed', d. h. für diejenigen Personen, die direkt von einer Anordnung betroffen sind.“

${ }^{294}$ Eine Übersicht über die verschiedenen Indikatoren der Textfunktion findet sich z. B. bei BRINKER U. A. 2014, 98ff.; BRINKER 2000 - 2001b, 179ff. und BRINKER 1994, 39f. Vgl. a. GrOßE 1976, 72ff. Hinsichtlich des Bezugs auf die Illokutionsindikatoren in der klassischen Sprechakttheorie vgI. BRINKER 2000 - 2001b, 179: „Eine Übertragung dieses für einfache sprachliche Handlungen geltenden Indikatorenkonzepts auf Texte führt zwar zu komplexeren Bestimmungen, ist aber grundsätzlich möglich, so daß in Analogie zu den Illokutionsindikatoren der Sprechakttheorie von Indikatoren der Textfunktion gesprochen werden kann. “ Vgl. a. BRINKER U. A. 2014, 98f.

295 BRINKER 1994, 37. VgI. ORTAK 2004, 121. Die, thematische Einstellung' entspricht der ,propositionalen Einstellung' (oder auch ,Modalität') auf der Textebene (vgl. S. 31).

${ }^{296}$ Vgl. ebd., 121 bzW. BRINKER 1994, 37f. Vgl. a. BRINKER U. A. 2014, 99f.: „WWas nun den Zusammenhang von Textfunktion und thematischer Einstellung betrifft, nehmen wir an, dass Textfunktionen und thematische Einstellungen insofern aufeinander bezogen sind, als sich bestimmte Einstellungen mit bestimmten Textfunktionen leichter (oder schwerer) verbinden lassen als mit anderen. [...] Wir betrachten die thematischen Einstellungen [...] nicht als eindeutige Indikatoren der Textfunktion. Sie zeigen zumeist nur in Verbindung mit bestimmten Kontextindikatoren eine bestimmte Textfunktion an. "Vgl. außerdem BURKHARDT 1986, 406 und ebd., 408 sowie ERMERT 1979, 74. Bei der Bestimmung kontextueller Indikatoren bleibt Brinker recht unkonkret. Dies und die Verbindung von textinternen und textexternen Indikatoren werden z. B. in GANSEL 2011, 63ff. kritisiert. Dort wird stattdessen eine Unterscheidung von textintern erschließbarer, struktural-funktionaler Textfunktion (Mitteilungsselektion) und textextern erschließbarer, funktions-strukturaler Bereichs- bzw. Bewirkungsfunktion (Informations- bzw. Verstehensselektion) vorgeschlagen. Vgl. HAUSENDORF UND KESSELHEIM 2008 bzw. S. 50. 
In Anlehnung an Searles Sprechakttaxonomie unterscheidet Brinker fünf textuelle Grundfunktionen. ${ }^{297}$ Im Gegensatz zu ihm bezieht er dabei die Rezipientenseite konsequent in seine Klassifikation mit ein und verwendet zur Unterscheidung der Textfunktionen ein einheitliches Kriterium, nämlich die „Art des kommunikativen Kontakts“298: Die Informationsfunktion ist dadurch gekennzeichnet, dass „der Emittent [...] dem Rezipienten zu verstehen [gibt], dass er ihm ein Wissen vermitteln, ihn über etwas informieren will. “299 Bei der Appellfunktion geht es darum, „dem Rezipienten zu verstehen [zu geben], dass er ihn dazu bewegen will, eine bestimmte Einstellung einer Sache gegenüber einzunehmen (Meinungsbeeinflussung) und/oder eine bestimmte Handlung zu vollziehen (Verhaltensbeeinflussung). ${ }^{\text {"300, }}$, bei der Obligationsfunktion darum, „dem Rezipienten zu verstehen [zu geben], dass er sich ihm gegenüber dazu verpflichtet, eine bestimmte Handlung zu vollziehen. “" ${ }^{301}$ In einem Text mit Kontaktfunktion „[gibt] der Emittent [...] dem Rezipienten zu verstehen, dass es inm um die personale Beziehung zum Rezipienten geht (insbesondere um die Herstellung und Erhaltung des persönlichen Kontakts). “302 Die Deklarationsfunktion schließlich ist dadurch charakterisiert, dass „der Emittent [...] dem Rezipienten zu verstehen [gibt], dass der Text eine neue Realität schafft, dass die (erfolgreiche) Äußerung des Textes die Einführung eines bestimmten Faktums bedeutet." ${ }^{\text {303 }}$

Brinker geht davon aus, dass Texte i. d. R. nur eine dominierende Kommunikationsfunktion besitzen, gesteht jedoch gleichwohl zu, dass es neben dieser Grundfunktion verschiedene, z. T. sogar obligatorische Zusatzfunktionen geben kann. ${ }^{304}$ Eine Zusatzfunktion wird dabei definiert als „eine Funktionseinheit [...], die der Grundfunktion (Textfunktion) untergeordnet und

\footnotetext{
${ }^{297}$ Rolf 2000 - 2001, 429 findet die Terminologie Brinkers z. T. problematisch. So merkt er in Bezug auf die Appellfunktion an: „,Appelle' sind in puncto ,Durchsetzungsmodus des verfolgten Anliegens' vergleichsweise schwach [...]. “ Was die Obligationsfunktion betrifft, meint er, dass der Begriff „nicht den bei Brinker intendierten interaktiven Sinn auf[weist]“ und „zu sehr den Sprecher-seitigen Aspekt der (Selbst-)Verpflichtung betont. “ Hinsichtlich der Kontaktfunktion äußert er sich folgendermaßen: „Diese Gruppe [...] ist erstens nicht sehr umfangreich, zweitens ist sie einer größeren Gruppe von Textsorten zuzuordnen: und zwar den expressiven Textsorten [...].“ Vgl. a. Rolf 1993, 313: „[...] der Begriff ,Kontaktfunktion“ gilt bestenfalls für zehn Prozent der expressiven Gebrauchstextsorten, denn nur zehn Prozent von diesen haben etwas mit dem Kontakt zwischen Personen, genauer gesagt, mit der Aufnahme, der Aufhebung oder der Pflege von Kontakt zu tun. “Vgl. die Diskussion zu den Expressiva im Hinblick auf Emotionalität und Beziehungsgestaltung im Kap. „Besonderheiten der Expressiva“ ab S. 28. Zum Bezug auf Searles Sprechaktklassifikation vgl. z. B. LUPPOLD 2015, 397f.: „Brinkers fünf textuelle Grundfunktionen orientieren sich an Searles fünf Illokutionsklassen, sodass Brinkers textuelle Grundfunktionen im Prinzip nichts anderes sind als illokutionäre Zwecke ganzer Texte."

298 Brinker U. A. 2014, 105. Vgl. Brinker 2000 - 2001b, 176 und BRINKer 1994, 36. Vgl. a. Rolf 2000 - 2001,429 und SZWED 2014, 120.

299 BRINKER U. A. 2014, 106.

300 Ebd., 109.

301 Ebd., 117.

302 Ebd., 118.

${ }^{303}$ Ebd., 120.

${ }^{304}$ Vgl. z. B. BRINKER 2000 - 2001b, 176f.: „Das textfunktionale Konzept beruht auf der Annahme, daß der Kommunikationsmodus des Textes insgesamt in der Regel nur durch eine Funktion bestimmt wird (dominierende Kommunikationsfunktion oder Textfunktion), wenn auch für einen Text durchaus mehrere Funktionen (sog. Zusatzfunktionen) charakteristisch sein können [...]. “Vgl. BRINKER 1994, 37; BRINKER U. A. 2014, 88 und ebd., 123. Als Beispiel für eine obligatorische Zusatzfunktion wird in BRINKER 2002, 49ff. eine mit der Appellfunktion (= Aufforderung an den Adressaten zur Durchführung einer Handlung, z. B. Zahlung einer bestimmten Geldsumme) verbundene Obligationsfunktion (= Selbstverpflichtung des Autors zur angedrohten Handlung) in Erpresserbriefen genannt. Fakultative Zusatzfunktionen seien dagegen z. B. eine (informative) „Zuschreibung der Verantwortung“
} 
oft aus ihr ableitbar ist. “" ${ }^{305}$ Dies lässt sich nur schwer in Einklang bringen mit der Aussage, dass ausschließlich dem Text als Ganzen und nicht seinen einzelnen Bestandteilen unmittelbare Handlungsqualität zukomme, obwohl Brinker deutlich betont, dass die Zusatzfunktionen keinesfalls als pragmatische Untereinheiten (wie z. B. die illokutiven Handlungen im ISK) aufzufassen seien. ${ }^{306}$ Sie könnten sich z. B. „auch auf situative und soziale Umstände beziehen, die mit der Textsorte und dem übergeordneten Kommunikations- bzw. Handlungsbereich verbunden sind. “" ${ }^{307}$ Hinweise auf die Zusatzfunktionen würden ebenso wie bei den textuellen Grundfunktionen bestimmte Indikatoren liefern. Es sei zudem möglich, dass sie eher implizit ausgedrückt werden. ${ }^{308}$

\section{Hausendorf / Kesselheim}

Brinkers Klassifikation der Textfunktionen hat weite Verbreitung gefunden und wurde dabei in verschiedener Form abgewandelt und weiterentwickelt. ${ }^{309}$ So werden von Hausendorf und Kesselheim ${ }^{310}$ sechs textuelle Grundfunktionen angeführt, die z. T. denen Brinkers entsprechen, wie die Darstellungsfunktion ( $\approx$ Informationsfunktion), die Steuerungsfunktion ( $\approx$ Appellfunktion) und die Kontaktfunktion. Die Belegfunktion korrespondiert in weiten Teilen mit der Obligations- und Deklarationsfunktion Brinkers. Hinzu kommen eine Unterhaltungs- und eine Reflexionsfunktion. ${ }^{311}$ Von solchen textuellen Grundfunktionen, die „immer wiederkehrende Ausprägungen von Textnützlichkeit [bezeichnen], die jeweils durch eine Vielfalt von Sprachhandlungen realisiert werden können und die sich häufig auf textuelle Untereinheiten beziehen lassen“"12, seien Texthandlungen als „spezifische Ausprägungen der textuellen Grundfunktionen, für die sich eigene Textsorten herausgebildet haben (so z. B. das Bewerbungsschreiben oder die Gebrauchsanweisung als Ausprägungen der Steuerungsfunktion)“313, zu unterscheiden. Zu ergänzen seien außerdem die gesellschaftlichen Funktionsbereiche von Texten, „die übergreifende Funktionszusammenhänge von Texthandlungen und Textsorten [bezeichnen], in denen sich die funktionale Differenzierung der modernen Gesellschaft in unterschiedliche Funktionssysteme (wie Politik, Wirtschaft, Recht, Religion, Kunst oder Wissenschaft) manifestiert." ${ }^{1314}$

\footnotetext{
für die Konsequenzen an den Briefempfänger im Falle einer Nichterfüllung der vom Erpresser verlangten Handlung und die Versicherung der Ernsthaftigkeit der entsprechenden Aufforderung. Vgl. a. Rolf 1993, 41f. (s. N. 284) zu Brinkers Annahme von (textinternen) Begründungs- und Spezifizierungsfunktionen bzw. BRINKER 2000 2001c, 172 (s. N. 282).

305 BRINKER 2002, 49.

${ }^{306}$ Vgl. z. B. ebd., 49 N. 20. Vgl. a. BRINKER 2006, 2545.

307 BRINKER 2002, 49.

308 Vgl. ebd., 49.

309 BRINKER U. A. 2014, 121. Vgl. a. ADAMZIK 2004, 108.

310 HAUSENDORF UND KESSELHEIM 2008.

${ }^{311}$ Damit wird auch auf Jakobsons poetische und metasprachliche Funktion referiert. Brinker erkennt zwar ebenfalls an, dass es Texte mit poetischer bzw. ästhetischer Funktion gebe, bemerkt aber, dass diese vornehmlich Gegenstand der Literaturwissenschaft seien. Als Zusatzfunktion werde eine solche Unterhaltungsfunktion aber durchaus in seinem Modell erfasst: BRINKER U. A. 2014, 106 N. 68 und ebd., 122 N. 105.

312 HAUSENDORF UND KESSELHEIM 2008, 142.

313 Ebd., 142.

${ }^{314}$ Ebd., 142. Vgl. a. GANSEL 2011, 63ff. bzw. N. 296.
} 
Adamzik

Adamziks Ertragsmodell ${ }^{315}$ liegt eine grundsätzlich andere, weitere Konzeption zugrunde, insofern neben den mehr oder weniger eindeutig zu bestimmenden, im Text angelegten Kommunikationsabsichten, d. h. den Textfunktionen i. e. S., auch implizite, nicht direkt erschließbare Intentionen und sogar nicht intendierte Erträge Eingang darin finden, wobei „unter Ertrag [...] alles verstanden werden [soll], was Produzenten und Rezipienten (potenziell) aus dem Text gewinnen können. " 316 Adamzik bezieht zudem ausdrücklich literarische Texte und außerdem automatische Texte in ihr Modell mit ein. Des Weiteren wird auch nicht-kommunikative Sprachverwendung („innere Sprache“, z. B. in Tagebüchern) berücksichtigt. ${ }^{317}$ Adamzik zählt beispielhaft neun Typen von Erträgen auf, nämlich die intellektuellen / kognitiven, praktischen, handlungsorientierten, emotional-psychischen, sozialen, geistig-moralischen, formbezogenen, metasprachlichen / -kommunikativen und die unterhaltenden. Sie weist darauf hin, dass „die Liste [...] nur einen Überblick über besonders geläufige Ertragsdimensionen geben [soll] und [...] prinzipiell als offen zu verstehen [ist]. “318

Für die praktische textanalytische Arbeit ist Adamziks Modell nur bedingt brauchbar, da z. B. individuelle Textverstehensweisen kaum wissenschaftlich zu erfassen und zu belegen sind. Auch der multifunktionale Ansatz, nach dem aus einem Text mehrere Erträge gleichzeitig gewonnen werden können, die zudem nicht festgelegt, sondern variabel sind, erschwert eine Textanalyse, wird komplexen Texten allerdings eher gerecht als die in der Tradition der klassischen Sprechakttheorie stehenden Modelle textueller Grundfunktionen (wie das von Brinker), die i. d. R. unifunktional ausgerichtet sind..$^{319}$

\footnotetext{
315 Vgl. z. B. ADAMzIK 2016, $192 \mathrm{ff}$.

${ }^{316}$ Ebd., 192. Vgl. ebd., 196: „Während Ansätze, die Texten eine konventionelle Grundfunktion direkt zuschreiben, Indikatoren dafür in diesen selbst aufsuchen wollen, geht es hier vielmehr darum, die kreativen und interpretatorischen Spielräume beim Umgang mit Texten zu fokussieren, auch nicht-konventionelle Gebrauchsweisen einzubeziehen und damit der eigentlich inzwischen allgemein akzeptierten These Rechnung zu tragen, dass der Umgang mit Texten als konstruktive Leistung zu verstehen ist." Es liegt also ein in der Tradition der kognitiven Textlinguistik stehender prozeduraler Ansatz vor.

${ }^{317}$ Allerdings kann man häufig auch in solchen Fällen durchaus von einem, wenn auch nur fiktiven Ansprechpartner ausgehen. In vielen Tagebüchern wird dieser ja sogar explizit benannt, wie z. B. bei Anne Frank (,Liebe Kitty, ..."). Vgl. SZWED 2014, 124.

${ }^{318}$ ADAMZIK 2016, 195.

${ }^{319}$ Vgl. ADAMZIK 2016, 196: „Ich stimme natürlich auch den Annahmen der an der Sprechakttheorie orientierten Autoren zu, dass bei Gebrauchstexten die (beiderseitige) Realisierung einer konventionellen Grundfunktion den (unproblematischen) Normalfall darstellt. Für anspruchsvollere und längere Sachtexte, erst recht aber für philosophische, literarische Texte usw., also für alle die Texte, die eine echte hermeneutische Herausforderung darstellen, gilt dies aber gerade nicht.“ und ebd., 194: „Der Vorteil dieses Modells [d. h. ihres Ertragsmodells] besteht darin, dass es mit konventionellen Mitteln ausgedrückte Absichten erfassen kann, aber gleichzeitig in der Lage ist, ein eventuelles Scheitern kommunikativer Interaktionen zu beschreiben und insgesamt der Vielfalt möglichen Umgangs mit Texten und unterschiedlichen Perspektiven der Beteiligten gerecht zu werden. "Zur strikteren Auffassung Brinkers vgl. z. B. S. 49. Im Übrigen wird in BRINKER U. A. 2014, 123 aber auf die Notwendigkeit hingewiesen, den jeweils zugrunde liegenden Funktionsbegriff zu berücksichtigen. Vgl. dazu auch ADAMzIK 2016, 181 und ROLF 2000 - 2001, 423. Letzterer meint, dass multifunktionale Modelle „grundsätzlich ungeeignet [sind] für eine an verschiedenen, einander ausschließenden Funktionen interessierte Typologie, wie sie hinsichtlich der textuellen Grundfunktionen erforderlich ist." (ebd., 425). Vgl. a. SzWED 2014, 116 und ebd., 121.
} 
Heinemann / Viehweger

Eine zwischen uni- und multifunktionalen Ansätzen vermittelnde Position nimmt das Text-Interaktionskonzept von Heinemann und Viehweger ein. ${ }^{320}$ Es geht von vier Primärfunktionen des Kommunizierens aus, nämlich Sich Ausdrücken / selbst Darstellen, Kontaktieren, Informieren und Steuern. Hinzu kommt die ästhetische Funktion, der eine Sonderstellung zukommt, insoweit sie alle anderen Funktionen überlagern kann. Die übrigen Funktionen stehen in einem Inklusionsverhältnis zueinander, d. h., sie lassen sich nicht strikt voneinander abgrenzen, sondern können fließend ineinander übergehen. ${ }^{321}$ Je nachdem, welche Funktion dominiert, werden unterschiedliche Texttypen und z. T. weitere Subklassen differenziert. Dabei ist aber durchaus auch ein Nebeneinanderbestehen verschiedener Funktionen denkbar. Ein solches ist bspw. bei Gesetzestexten (Informieren und Steuern) und vielen Privatbriefen anzunehmen. ${ }^{322}$

\section{Die pragmatische Struktur von Texten: Hierarchisierung von textuellen Handlungseinheiten}

Texte als komplexe Sprechakte

Wenn man - entgegen dem holistischen Ansatz - davon ausgeht, dass Texte eine pragmatische Struktur besitzen und auch einzelnen Textelementen eine eigene Handlungsqualität bzw. eine illokutive Funktion zuzuschreiben ist, stellt sich die Frage, wie sich diese i. E. analysieren lässt. Das ISK möchte z. B. die „erfolgsorientiert-strategische“, Schröders Konstituentenmodell „die regelorientiert-normative Ordnung von Texten auf pragmatischer Ebene“ erfassen. ${ }^{323}$ Beiden liegt die Auffassung zugrunde, dass durch eine einfache Illokution das mit einem Text verfolgte Globalziel oft nicht erreicht bzw. die Gesamtfunktion nicht erfüllt werden kann, sondern weitere Illokutionen zur Stützung notwendig sind, wobei sich verschiedene untergeordnete Teilziele bzw. zusätzliche Funktionen ergeben können. ${ }^{324}$ Diese sind auf vielfältige Weise

\footnotetext{
${ }^{320}$ Heinemann und Viehweger 1991, 148ff. Vgl. Adamzik 2016, 179f. und SzWed 2014, 122. Von einem geschlossenen Modell kann man It. HEINEMANN 2008, 140 nicht sprechen: „Das kommunikativ orientierte Text-Interaktionskonzept ist heute noch kein in sich geschlossenes, stringentes theoretisches Modell. Noch sind die praktischen Ziele (auch die Intentionen) der Partner zu wenig spezifiziert, sind die Konnexionen zwischen den Zielen und Intentionen der Handelnden einerseits mit den Textstrukturen und Formulierungen andererseits nur in ersten Umrissen fassbar, wurden vor allem die praktischen Wirkungen der Kommunikationsakte, auch für die Veränderung oder Stützung sozialer Beziehungen, in den Untersuchungen kaum berücksichtigt. “

${ }^{321}$ Vgl. Heinemann Und ViehWEger 1991, 149: „Diese 4 Primärfunktionen des Kommunizierens stehen untereinander in einem Inklusionsverhältnis: Steuernde Texte vermitteln (zumindest mittelbar) auch Informationen, informierende Texte setzen den Kontakt zwischen Partnern voraus, und für die Kontakt-Herstellung oder KontaktErhaltung ist normalerweise eine ,Entäußerung' des handelnden Individuums notwendig. Zwischen diesen Grundtypen bestehen daher auch fließende Übergänge, so daß die Abgrenzung der Funktionstypen [=Texttypen] voneinander nur mit Hilfe des Dominanzkriteriums möglich zu sein scheint: Aus einem bloßen Kontakttext (BEGRÜSSEN) kann sich $u$. U. schnell ein Informationskontakt entwickeln, wenn es einem der Interagierenden einfällt, beiläufig noch bestimmte Informationen zu vermitteln. Spielt dagegen die Kontaktfunktion nur noch eine untergeordnete Rolle (ist also das INFORMIEREN dominant), haben wir es mit ,Kontakt-Informationen' zu tun." 322 Vgl. ebd., 150ff. Vgl. a. N. 293. Vgl. außerdem SzWED 2014, 123 sowie N. 319.

${ }^{323}$ LUPPOLD 2015, 402. Vgl. a. ebd., 396: „So beschreibt das Modell der Illokutionshierarchien [im Unterschied zum Konstituentenmodell] nicht, wie einzelne Illokutionen aufgrund konventioneller Regelzusammenhänge zu komplexeren Handlungen integriert werden können. Stattdessen wird die strategische Ordnung der Illokutionen im Text sichtbar gemacht, die auf dem individuellen Erfolgskalkül eines Kommunikators basiert. “ Vgl. außerdem (zUM ISK) ROSENGREN 1987, 37.

${ }^{324}$ Vgl. RolF 2000 - 2001, 423: „Normalerweise hat ein Textproduzent (er ist mit dem Textemittenten gewöhnlich personalidentisch) nur ein Anliegen; das Problem aber, vor dem er steht, ist prinzipiell komplexer Art. Das Problem, vor dem ein Textproduzent steht, läßt sich zunächst einmal negativ bestimmen: Durch die bloße Äußerung
} 
miteinander verbunden: „Der Text läßt sich damit als komplexer Sprechakt und als gegliedertes Gefüge von Sprechakten beschreiben [...]. “325

\section{Funktionale Beziehungen innerhalb von Texten}

\section{Textfunktion und dominierende Illokution}

Die Textfunktion wird meist durch eine im Text dominierende Illokution bestimmt, ist aber nicht unbedingt identisch mit ihr und lässt sich nicht einfach aus ihr ableiten. ${ }^{326}$ Häufig wird die dominierende Illokution durch subsidiäre Illokutionen gestützt und die Textfunktion dadurch möglicherweise modifiziert. ${ }^{327}$ Zudem kann ein Text von mehreren dominierenden IIlokutionen geprägt sein, von denen allerdings i. d. R. nur eine die Hauptillokution darstellt. ${ }^{328}$ Ein „konjunktiver Illokutionsstrukturtyp“329 mit nicht eindeutig zu bestimmender Textfunktion bzw. mehreren Textfunktionen ist aber durchaus denkbar. So bestehen bspw. viele (private) Briefe und Gespräche aus sehr unterschiedlichen (Teil-)Texthandlungen, ohne dass eine einheitliche Gesamthandlung mit übergeordneter Text- bzw. Gesprächsfunktion auszumachen wäre. ${ }^{330}$ Zumindest ist diese häufig nicht auf den ersten Blick erkennbar. In Beschrei-

eines einzelnen Satzes läßt sich das Ziel, welches er verfolgt, nicht erreichen. Man könnte auch sagen, daß sich das von einem Textproduzenten verfolgte Ziel durch den alleinigen Vollzug eines einzelnen Sprechakts grundsätzlich nicht erreichen läßt. [...] In handlungstheoretisch ausgerichteten Textbetrachtungen hat sich dafür die Auffassung etabliert, daß von seiten des Textproduzenten Teilziele verfolgt werden müssen, damit sein eigentliches Ziel erreicht werden kann." Vgl. Rolf 2006, 2534.

325 BICKMANN 1998, 43. Vgl. a. (zUm ISK) BRINKER 2006, 2545; Rolf 1993, 42f. und Rolf 2006, 2534 SOWie SZWED 2014, 163.

${ }^{326}$ Vgl. SCHRÖDER 2003, 8ff., bes. ebd., 10ff. (mit Bezug auf das ISK): „Grundlegend ist die Annahme, daß es in jedem Text mindestens eine übergeordnete Illokution [= dominierende oder auch dominante Illokution] gibt, in der die Textillokution greifbar ist.“ (ebd., 8) und: „Die Annahme, daß jede Textillokution [...] auf eine klar identifizierbare dominierende Einzelillokution zurückzuführen sei, ist [...] nicht ganz unproblematisch." (ebd., 11). Vgl. a. Rolf 1993, 42f. und ARTMANN 1996, 90. VgI. außerdem BRINKER U. A. 2014, 97: „Der Illokutionsstrukturanalyse liegt die Auffassung zugrunde, dass die dominierende illokutive Handlung auf das Globalziel des Textes, also auf seine kommunikative Gesamtfunktion verweist. Ein solcher Zusammenhang darf aber nicht grundsätzlich unterstellt werden [...]. " Zur entsprechenden Kritik Brinkers am ISK vgl. a. LUPPOLD 2015, 395 N. 872 und ebd., 396: „Zur Verteidigung muss an dieser Stelle allerdings auch in aller Deutlichkeit angemerkt werden, dass das Modell der Illokutionshierarchien den Begriff ,Textfunktion“ nicht zufällig überhaupt nicht kennt.“

327 Vgl. z. B. SCHRÖDER 2003, 10 und LUPPOLD 2015, 395 N. 872. Vgl. a. das Kap. „Subsidiäre Illokutionen“ ab S. 54. ${ }^{328}$ Vgl. z. B. Rolf 1993, 42f.: „Es [= ein Illokutionsprofil] gibt Auskunft über die dominierende und die subsidiäre(n) Illokution(en) einer textuellen Ganzheit, und es enthält mehrere solcher Auskünfte, wenn ein Text in mehrere Illokutionsgruppen unterteilt werden kann, die sich untereinander in dominierende und subsidiäre Einheiten zerlegen lassen. In einem solchen Fall ist dann allerdings [...] davon auszugehen, daß die dominierenden Illokutionen selbst hierarchisch geordnet sind, kurz: daß es auch dann eine dominierende Hauptillokution gibt, wenn ein Text insgesamt mehrere dominierende Illokutionen aufweist. Die letzteren sind dann der Hauptillokution unter-, allerhöchstens neben-, nie jedoch übergeordnet."

${ }^{329}$ SZWED 2014, 174.

${ }^{330}$ Vgl. z. B. ebd., 156; VIEHWEGER 1983, 230 und DIMTER 1981, 84f. sowie SCHRÖDER 2003, 11 und ebd., 34f.: „Ein anderes Problem könnte darin gesehen werden, daß es offensichtlich auch Texte gibt, die sich nicht als Handlungseinheit beschreiben lassen, weil mit ihnen unterschiedliche, nicht über indem-Zusammenhänge in Beziehung stehende Texthandlungen vollzogen werden. Zwei Fälle sind dabei zu unterscheiden. Im ersten Fall handelt es sich um Texte, die sich aus mehreren Texten zusammensetzen. [...] Der Dialogzusammenhang ist dabei ein besonders wichtiger, aber nicht der einzige Zusammenhang. Der kommunikationsgeschichtliche Zusammenhang von Texten erweist sich beispielsweise im Fall der Pressekommunikation als besonders wichtig. [...] Im zweiten Fall handelt es sich um ein Problem, das im Zusammenhang mit der Qualitätsfrage zu sehen ist. Noch stärker als 
bungen und Schilderungen lässt sich die Textfunktion ebenfalls kaum auf eine einzelne (dominierende) Illokution zurückführen, sondern sie ergibt sich üblicherweise aus dem Zusammenspiel mehrerer (gleichrangiger) Illokutionen. ${ }^{331}$ Während es teilweise gar keine dominierenden Illokutionen zu geben scheint ${ }^{332}$, stehen sie in anderen Texten wiederum im Widerspruch zur Textfunktion, wie z. B. in einigen Werbetexten, die von assertiven Sprechakten beherrscht werden, textfunktional jedoch als Appelle zu betrachten sind. ${ }^{333}$ Auch sonst wird die Textfunktion oft nur indirekt signalisiert und muss vom Textrezipienten entsprechend erschlossen werden. Dies kann mithilfe von Brinkers Indikatoren geschehen; die zugrunde liegende pragmatische Struktur mit ihrem Geflecht aus verschiedenen Illokutionen sollte dabei aber nicht unberücksichtigt bleiben. ${ }^{334}$ Insgesamt lässt sich sagen, dass noch vieles unklar ist hinsichtlich einer genauen, eindeutigen und systematischen Erfassung von dominierender Illokution und Textfunktion sowie ihrem Verhältnis zueinander. ${ }^{335}$

\section{Subsidiäre Illokutionen}

Subsidiäre Illokutionen dienen dazu, die übergeordnete dominierende Illokution in verschiedener Weise zu stützen, und tragen damit dazu bei, den Erfolg der betreffenden Handlung zu sichern bzw. das verfolgte Globalziel zu erreichen. ${ }^{336}$ Voraussetzung für den Erfolg ist v. a., dass der Adressat das Anliegen des Sprechers versteht und akzeptiert. ${ }^{337}$ Danach können zwei große Gruppen von subsidiären Sprechakten unterschieden werden, wobei eine abschließende Aufzählung möglicher Funktionen und Untermuster kaum möglich scheint und es sich

\footnotetext{
für einfache sprachliche Handlungen gilt für Texthandlungen, daß das Befolgen von Mustern Kompetenz voraussetzt und daß Mißerfolge oder Abweichungen immer im Bereich der Möglichkeiten liegen [...]. “ Vgl. a. S. 52 und Kap. 1.1.3.3.4

${ }^{331}$ Vgl. z. B. SCHRÖDER 2003, 10 und LUPPOLD 2015, 395 N. 872.

332 Vgl. z. B. SCHRÖDER 2003, 11.

333 Vgl. BRINKER 2000 - 2001b, 177 und ORTNer 2014b, 324. Vgl. a. LUPPold 2015, 395 N. 872 und ORTNER 2014b, 324. Vgl. außerdem Rolf 1993, 147f. zum Zusammenhang zwischen der Frequenz bestimmter Illokutionen und der Textfunktion, der zwar häufig gegeben sei, aber eben nicht immer. Vgl. des Weiteren BURKHARDT 1986, 397f. ${ }^{334}$ Vgl. z. B. Rolf 1993, 42f. bzw. N. 328. Vgl. a. S. 48.

335 Vgl. z. B. Heinemann und Heinemann 2002, 86; ORTAK 2004, 104f.; SCHRÖder 2003, 11 und LUPPOLD 2015, 395 N. 872.

${ }^{336}$ Vgl. z. B. SCHMITT 2000, 181: „Bei der Frage nach den Beziehungen der Illokutionen untereinander geht es [...] um die Identifikation von funktionalen Beziehungen mehrerer auf bestimmte Ziele ausgerichteter Sprachhandlungen. Dabei werden die hierarchisch übergeordneten Illokutionen als dominant, solche, die das Erreichen des Zieles einer dominanten Illokution sicherstellen sollen, als subsidiär bezeichnet. "Im Gegensatz zu den untergeordneten subsidiären Sprechakten finden sich kaum Ansätze für eine Typologie nebengeordneter Sprechakte. Zu Schröders rudimentärem Ansatz (SCHRÖDER 2003, 46ff.) vgl. z. B. LUPPOLD 2015, 402f.: „Im Bereich der funktionalen Nebenordnung kann festgestellt werden, dass Schröders drei Typen der Nebenordnung - Ergänzung, Reihung, Fortsetzung - primär am Modell der Nachrichtentexte, also am Modell von Texten mit Informationsfunktion nach Brinker, entwickelt wurden. Diese bestehen fast ausschließlich aus nebengeordneten Sprechakten desselben Typs (meist Assertiva). Über Nebenordnungsbeziehungen zwischen unterschiedlichen Illokutionstypen müsste entsprechend noch genauer nachgedacht werden."

${ }^{337}$ Vgl. BRANDT UND ROSENGREN 1992, 18, die es als grundlegend für die Funktion der stützenden Illokutionen betrachten, „daß der Adressat versteht, was der Sender von ihm will, daß der Adressat die dominierende Illokution (als angemessen) akzeptiert, daß er zu der erwünschten Reaktion bereit ist oder aber zu der Ausführung der erwünschten Reaktionshandlung fähig ist. "Hier ist außerdem auf die Konversationsmaximen von Grice sowie die Glückens- bzw. Gelingensbedingungen von Austin und Searle zu verweisen.
} 
hier ebenso wie bei anderswo zu findenden Klassifikationsvorschlägen bzw. Aufzählungen also um offene Listen handelt. ${ }^{338}$

Sprechakte, die das Verstehen sichern sollen, werden u. a. verstehenssichernde, verstehensstützende, sachverhaltsklärende und informationserweiternde Sprechakte genannt. ${ }^{339}$ Wenn der Fokus mehr auf den konkreten Details liegt, deren Kenntnis für eine korrekte Ausführung der Handlung erforderlich ist, spricht man $u$. a. von ausführungsstützenden oder -sichernden Illokutionen. ${ }^{340}$ Zu dieser Gruppe gehören z. B. Erklärungen, Spezifizierungen und Zusammenfassungen. ${ }^{341}$

Sprechakte, welche die Akzeptanz des Adressaten und seine Bereitschaft zur Ausführung der Handlung fördern sollen, werden u. a. als akzeptanzstützende und glaubensstützende bzw. kooperationssichernde und motivationsstützende Sprechakte bezeichnet. ${ }^{342}$ Geht es mehr um logisch-rationales Überzeugen, wird u. a. auch von kausalen und argumentativen Sprechakten gesprochen. Zu dieser (Unter-)Gruppe gehören z. B. Begründungen und Belege. ${ }^{343}$ Dagegen wird bei verständnissichernden und emotionsunterstützenden Sprechakten auf die emotionale Ebene referiert. ${ }^{344}$ Hierbei spielen der Beziehungsaspekt und Höflichkeitskonventionen eine große Rolle. ${ }^{345}$ So werden i. d. R. gesichtsbedrohende Handlungen („,face threatening acts" = FTAs) vermieden, zumindest aber (z. B. durch die Verwendung indirekter Sprechakte) abgeschwächt oder (z. B. durch „face flattering acts“ = FFAs) „,kompensiert", damit das Gesicht

\footnotetext{
${ }^{338}$ Vgl. z. B. SCHMITT 2000, 191f.: „Grundsätzlich kann die Klasse der mittelbar und unmittelbar stützenden Illokutionen als eine offene Klasse angesehen werden. Prinzipiell sind auch andere Stützungsziele denkbar.“

${ }^{339}$ Der Begriff, sachverhaltsklärend' ist nach Ansicht von WüEST 2011, 99 zu eng gefasst, weil er z. B. für fiktionale Texte nicht passend ist, und wird von ihm deshalb durch den Terminus, informationserweiternd' ersetzt. Vgl. a. ebd., 197ff. Vgl. außerdem allgemein SCHMITT 2000, $182 f$.

${ }^{340} \mathrm{Vgl}$. ebd., $182 \mathrm{f}$.

${ }^{341} \mathrm{Vgl}$. z. B. SCHRÖDER 2003, 42ff. Es sei an dieser Stelle auch hingewiesen auf die schwierige Abgrenzung bzw. enge Zusammengehörigkeit von semantischen und pragmatischen Kategorien. Vgl. z. B. Polenz 2008, 268ff., der im Bereich der semantischen Verknüpfungen u. a. kopulatives Summieren, Ergänzen und Nachtragen sowie adversatives Korrigieren und Entgegensetzen unterscheidet. Vgl. außerdem SCHRÖDER 2003, 85ff. zu thematischen Beziehungen in Texten. Man beachte im Übrigen, dass zur Unterscheidung von den durch die Münsteraner Schule genau definierten Sprechaktuntermustern subsidiäre Sprechakte nicht durch Versalien gekennzeichnet werden (vgl. N. 18 und S. 172).

${ }^{342}$ Vgl. SCHMITT 2000, $182 \mathrm{f}$.

${ }^{343}$ Zur Unterscheidung von argumentativen und kausalen Sprechakten: WÜEST 2011, 123. Vgl. a. SCHRÖDER 2003, 43.

${ }^{344}$ Nach WÜEST 2011, 99 ist der Begriff, emotionsunterstützend ' angemessener als ,kooperationssichernd'. Vgl. a. ebd., 217ff. Vgl. außerdem allgemein SCHMITT 2000, 182f. und ebd., 187.

${ }^{345}$ Zum Beziehungsaspekt vgl. a. das Kapitel „Besonderheiten der Expressiva“ ab S. 28, zum Thema Höflichkeit das entsprechende Kapitel ab S. 69.
} 
(„face“) des anderen gewahrt bleibt. ${ }^{346}$ Dabei besteht kein strikter Gegensatz zwischen höflichen und unhöflichen Äußerungen, sondern es ist von einer „facework scale“ auszugehen. ${ }^{347}$ Zu dieser (Unter-)Gruppe gehören z. B. Begrüßungs- und Verabschiedungsrituale, Danksagungen und Komplimente. ${ }^{348}$

Im ISK werden die subsidiären Sprechakte z. T. noch danach differenziert, ob die erfolgssichernde Stützung eher direkt oder indirekt erfolgt. ${ }^{349}$ Nur Sprechhandlungen der ersten Kategorie, zu denen die ausführungs- und akzeptanzstützenden, z. T. auch die verstehensstützenden Akte zählen, werden mit dem Begriff der subsidiären Sprechakte i. e. S. bezeichnet, während Sprechhandlungen der zweiten Kategorie, zu denen die sachverhaltsklärenden und kooperationssichernden Sprechakte gerechnet werden, den komplementären Sprechakten zugeordnet sind. ${ }^{350}$

Abgrenzungen sind z. T. schwierig bzw. gar nicht möglich - sowohl, was die Zuordnung zu einer der beiden Kategorien (subsidiär vs. komplementär) als auch die Zuordnungen und Begrifflichkeiten innerhalb der Kategorien bzw. ganz allgemein betrifft. ${ }^{351}$ Dies gilt bspw. für die Einord-

${ }^{346}$ Vgl. z. B. WÜEST 2011, 44: „Nach ihrer Theorie [d. h. der von Brown und Levinson: s. das Kap. „Höflichkeit“ ab S. 69] gibt es Sprechakte, welche das Gesicht einer Gesprächsteilnehmerin oder eines Gesprächsteilnehmers bedrohen, die so genannten face threatening acts. Dabei ist zwischen dem positiven und dem negativen Gesicht einer Person zu unterscheiden. Das positive Gesicht betrifft das Ansehen, das jedermann in der Gesellschaft genießt oder genießen möchte; das negative Gesicht dagegen die Autonomie des Individuums, die Möglichkeit, über sich selbst bestimmen zu können. Da sowohl S [= Sprecher] wie A [= Adressat] diese beiden Gesichter haben, gibt es insgesamt vier Arten von face threatening acts: a) Geständnisse, Selbstkritik oder Entschuldigungen bedrohen das positive Gesicht von S; b) Kritik, Vorwürfe oder Beleidigungen bedrohen das positive Gesicht von A; c) die kommissiven Sprechakte bedrohen das negative Gesicht von S und d) die direktiven Sprechakte bedrohen das negative Gesicht von A. Der Zweck der Höflichkeit bestünde nun darin, diese Bedrohungen abzuschwächen.“ und ebd., 220f. (mit Bezug u. a. auf KeRBRAT-ORECCHIONI 1992, 59): „Nun gibt es [...] Sprechakte, die eigentlich eher negative Gefühle hervorbringen. Dazu gehören die face threatening acts (FTA) der Höflichkeitstheorie. Diese können abgeschwächt [...] oder durch jene Sprechakte kompensiert werden, die Catherine Kerbrat-Orecchioni [...] antiFTAs oder face flattering acts nennt." Zur Unterscheidung von positiver und negativer Höflichkeit, gesichtsbedrohenden und gesichtsbeschützenden Akten vgl. a. MEIBAUER 2008, 114ff. Zur Funktion indirekter Sprechakte vgl. außerdem das Kapitel „Indirekte Sprechakte“ ab S. 20, bes. S. 22.

${ }^{347}$ ARCHER 2017, 392: „The facework scale is based on the assumption that face enhancement represents the positive end of a pragmatic space relating to $S^{\prime} s$ [= speakers] evaluation of the addressee, and face aggravation, the negative end."

348 Vgl. z. B. WÜEST 2011, 221 und KIESENDAHL 2011, 84f.

349 BRANDT UND RosengRen 1992, 18. Vgl. a. z. B. ebd., 28ff. und ebd., 32ff. Vgl. außerdem WüEst 2011, 96, der zu den komplementären Sprechakten im Sinne des ISK bemerkt, dass sie „sich mehr auf das Umfeld des Textes beziehen“. Ausführlicher zu der Unterscheidung von subsidiären und komplementären Sprechakten: Ebd., $197 \mathrm{ff}$. und SCHRÖDER 2003, 12ff. Vgl. a. SZWED 2014, $167 f$.

${ }^{350}$ Vgl. z. B. MotsCH 1996, 21ff., der die seiner Ansicht nach z. T. etwas unklare Darstellung von BRANDT UND RoSENGREN 1992 präzisiert. Vgl. aber auch die Kritik an Motsch und den Alternativvorschlag bei WüEST 2011, 98f. und ebd., $149 f$.

351 Vgl. z. B. SCHRÖDER 2003, 14, der die Unterscheidung von subsidiären und komplementären Sprechakten insgesamt für problematisch hält: „Ein [...] Problem, das unmittelbar ins Auge fällt, betrifft die Abgrenzung zwischen subsidiären und komplementären Funktionen. Mit der Unterscheidung zwischen direkter bzw. indirekter Bezugnahme bleibt diese Grenze unscharf. Da beide Typen sich offensichtlich auf die gleichen Erfolgsbedingungen beziehen, scheint es sich zunächst nur um einen graduellen Unterschied zu handeln. Darüber hinaus scheint es aber auch so, daß eine direkte Bezugnahme auf die Illokution selber zielt [...], während eine indirekte Bezugnahme eher auf der Ebene der ,Informationseinheiten' angesiedelt ist [...]. Unklar ist aber, ob eine solche Trennlinie wirklich generelle Gültigkeit haben soll oder ob sie möglicherweise nur für bestimmte Illokutionstypen relevant ist. Festzuhalten ist jedenfalls, daß die vorgeschlagene Trennung zwar bei Direktiva, wie Brandt und Rosengren 
nung der verstehensstützenden Sprechakte und für die Unterscheidung von sachverhaltsklärenden und kooperationssichernden Sprechakten. ${ }^{352}$ Die Aufgabe von Beispielen in einem Text kann gleichermaßen darin liegen, ein Sprecheranliegen zu spezifizieren, zu präzisieren und zu belegen. ${ }^{353}$ Eine Begründung dient häufig in erster Linie der logisch-rationalen Akzeptanzstützung, kann aber gleichzeitig auch kooperationssichernd bzw. emotionsunterstützend wirken. ${ }^{354}$

\section{Primäre und sekundäre Illokutionen}

Eine alternative oder vielmehr ergänzende Typologie von Sprechakten innerhalb der Handlungsstruktur von Texten findet sich bei Holger Schmitt, der primäre Illokutionen, die auch isoliert für sich allein stehen können, und sekundäre Illokutionen, bei denen dies nicht möglich ist, unterscheidet. ${ }^{355}$ Sekundäre Illokutionen haben zwar letztlich wie auch einige subsidiäre Sprechakte eine verstehensstützende Funktion, sind aber im Gegensatz zu diesen nicht hierarchie- und funktionsbezogen, sondern referieren auf die Sequenzierungs- und Äußerungsebene. ${ }^{356}$ Die Aufgabe von sekundären Illokutionen besteht „in der Verständlichmachung des Status einer Äußerung, der Gliederung eines Textes oder auch in der Verdeutlichung des Gültigkeitsraums einer Aussage “357. Zu ihnen zählen i. E. Metasprechakte, „die im weitesten Sinne einen Kommentar zu dem eben Gesagten oder auch zu dem zu Sagenden “358 geben,

sie untersuchen, zu brauchbaren Ergebnissen führen mag; in Mitteilungstexten bilden subsidiäre Illokutionen nach diesem Kriterium bestimmt - jedoch eine seltene Ausnahme." Er sieht die Klassifikation untergeordneter Sprechakte im ISK auch sonst kritisch, bemängelt bspw. die fehlende Ausdifferenzierung und zu starke Vereinfachung, bietet aber andererseits selbst nur eine fragmentarische Einteilung an: „Seine eigene Typologie ist [...] sehr viel weniger umfangreich [als die von ihm in dieser Hinsicht bemängelte Typologie des ISK]. So findet sich bei Schröder keine systematische Typologie funktionaler Unterordnungsbeziehungen [...].“ (LUPPOLD 2015, 402). Vgl. a. ebd., 395 N. 873. Vgl. außerdem N. 336.

352 Vgl. z. B. WÜEST 2011, 149f. bzw. BRANDT UND ROSENGREN 1992, 29.

353 SCHRÖDER 2003, 114.

354 Vgl. a. WÜEST 2011, 123.

355 Vgl. SCHMITT 2000, 140ff. (zu den primären Illokutionen) bzw. ebd., 158ff. (zu den sekundären Illokutionen). Die primären Illokutionen unterteilt Schmitt in Reportiva, Estimativa, Evaluativa, Identifikativa, Relationata und Direktiva. Obwohl der Ansatz, die im Vergleich zu den anderen Oberklassen Searles ungleich häufiger auftretenden Assertiva weiter auszudifferenzieren, durchaus überlegenswert ist, konnte sich Schmitts Klassifikation nicht durchsetzen. Solche primären Illokutionen sind zu unterscheiden von den primären (= implizit performativen) Akten Austins und den primären Illokutionen im Zusammenhang mit den indirekten Sprechakten bei Searle. Vgl. das Kap. zu „Austin“ ab S. 16 und insbes. das Kap. „Indirekte Sprechakte“ ab S. 20.

${ }^{356}$ Vgl. SCHMITT 2000, 161f.: „Sekundäre Illokutionen dürfen nicht mit subsidiären Illokutionen, also jenen Sprechakten, die zur Erreichung des Ziels eines anderen Sprechaktes dienen und somit in einem hierarchischen Gefälle zu diesem stehen [...], verwechselt werden. Sekundäre Illokutionen sind zwar in gewissem Sinne immer auch verstehensfördernd [...], beziehen sich jedoch auf andere Ebenen der Kommunikation [d. h. die Sequenzierungsund Äußerungsebene] als subsidiäre Illokutionen. Zudem können subsidiäre Illokutionen zumindest potentiell (d. h. in anderen Kontexten) isoliert auftreten, was bei sekundären Illokutionen nicht der Fall ist." Vgl. BRANDT UND ROSENGREN 1992, 26, die solche („formulierungsexplizierenden“) Illokutionen einer anderen Ebene als der Illokutionsstruktur zuordnen und von „Suprastrukturen als [...] Ergebnis rezeptionsstrategischer Überlegungen des Senders“ ausgehen, und WÜEST 2011, 118 (mit Bezug auf die „strukturindizierenden Illokutionen“ bei MOTSCH 1996, 24): „Metatextuelle Hinweise sind keine eigentlichen Peritexte, da sie formal völlig in den Text integriert sind. Inhaltlich gehören sie jedoch nicht zur Illokutionshierarchie, da sie vielmehr Aussagen über diese machen." 357 SCHMITT 2000, 158. Vgl. a. die „formulierungsexplizierenden“ Illokutionen bei BRANDT UND ROSENGREN 1992, 26 und die „strukturindizierenden Illokutionen“ bei MOTSCH 1996, 24 (vgl. N. 356).

${ }^{358}$ SCHMITT 2000, 159. 
Textillokutionen, die „zur Kennzeichnung der Eröffnung, Gliederung, der momentanen Position oder des Schlusses eines Textes“359 dienen, bekanntheitsreportierende Illokutionen, in denen darauf hingewiesen wird, „dass die im Skopus befindliche Information eigentlich schon bekannt ist oder bekannt sein könnte ${ }^{\prime 360}$, quellenreportierende / einbettende Illokutionen, die „die Herkunft der geäußerten Informationen“361 belegen, und Konditionalia, die „eine Bedingung für den Geltungsraum einer Äußerung "362 auslagern.

\section{Untergeordnete Sprechakte und illokutionäre Grundfunktionen}

Die sekundären Illokutionen haben mehrheitlich eine metasprachliche bzw. assertive Funktion. Auch die subsidiären Sprechakte können letztlich immer auf die illokutionären Oberklassen zurückgeführt werden. Die meisten sind ebenfalls assertiver Natur, es finden sich aber außerdem einige Expressiva, wie im Zusammenhang mit den Ausführungen zu den kooperationssichernden bzw. emotionsstützenden Illokutionen deutlich geworden sein dürfte. Viele kooperations- und einige ausführungssichernde Sprechakte gehören zur Klasse der Direktiva, die (abgesehen evtl. von Fragen) insgesamt jedoch relativ selten unter den subsidiären Akten anzutreffen sind. Davon unterschieden werden müssen Direktiva, die implizit eigentlich als Expressiva zu verstehen sind, wie es der Fall bei einigen Begrüßungs- und Wohlergehensformeln (z. B. „Sei gegrüßt!“, „Bleib gesund!“) ist. ${ }^{363}$

\section{Textaufbau und -gliederung: Identifizierung von textuellen (Handlungs-)Einheiten}

Schachtelstruktur komplexer Texte

Die einzelnen Bestandteile eines Textes lassen sich meist zu größeren Einheiten zusammenfassen: So ergeben sich aus Einzeläußerungen (Lokutionen) Teiltexte, aus denen sich wiederum Texte als Ganzes konstituieren. In bestimmten Fällen sind auch Textfolgen denkbar, z. B. in der Presse oder in der Briefkorrespondenz. Auf der thematischen Ebene wird zwischen Einzelthemen (Propositionen), Teilthemen, Textthemen und Themafolgen, auf der Handlungsebene zwischen Einzelhandlungen (Illokutionen), Teilhandlungen, Texthandlungen und Handlungsfolgen differenziert. ${ }^{364}$

\footnotetext{
${ }^{359}$ SCHMITT 2000, 159.

${ }^{360}$ Ebd., 160.

${ }^{361}$ Ebd., 161.

362 Ebd., 161.

${ }^{363}$ Vgl. z. B. ebd., 186: „[...] die vier Klassen von subsidiären Illokutionen [scheinen] eng mit bestimmten Klassen von dominierenden Illokutionen assoziiert zu sein. Glaubensstützende Illokutionen sind hauptsächlich mit externen Repräsentativa, vornehmlich mit Estimativa, zu erwarten. Motivationsstützende Sprechakte dürften tendenziell mit fakultativen Direktiva und mit Interrogativa, ausführungssichernde Illokutionen mit Direktiva jeglicher Art verbunden sein. Allein verstehenssichernde Illokutionen können potentiell mit allen Sprechakten in Verbindung treten, dürften empirisch jedoch hauptsächlich zur Stützung von Reportiva dienen. " und RISSELADA 1993, 55: „[...] directives can be either main acts or subsidiary acts. [...] the former, i.e. directive main acts, are far more usual than the latter; subsidiary acts usually are assertives or questions, not directives. " Zu den Gruß- und Wohlergehensformeln vgl. z. B. ebd., 57f. und das Kap. „Grußformeln“ ab S. 346.

${ }^{364} \mathrm{Vgl}$. die entsprechende Differenzierung in SCHRÖDER 2003, bes. ebd., 32ff., ebd., 77ff. und ebd., $90 \mathrm{ff}$. Vgl. a. ORTNER 2014b, 327. Zur Problematik, dass Schröder von ,Sätzen', ,Satzthemen“ und ,Satzhandlungen' (statt von ,Einzeläußerungen' usw.) spricht und diese wider besseren Wissens mit Lokutionen, Propositionen und Illokutionen gleichsetzt, vgl. z. B. SCHRÖDER 2003, 36: „Die möglichen Probleme, die mit einer solchen Parallelsetzung von Sätzen und einfachen Handlungen verbunden sind, werden an dieser Stelle bewusst ausgeklammert. Beide Kategorien, erst recht aber ihr Verhältnis, sind heftig umstritten. Diese Diskussion hier aufzunehmen, würde allzu weit vom Hauptgegenstand der Untersuchung wegführen. ,Satzhandlungen' werden deshalb im folgenden ohne weitere Problematisierung als kleinste Bausteine der Handlungsstruktur aufgefaßt [...]. " und LUPPOLD 2015, 402:
} 
Unter den Textkonstituenten bestehen vielfältige Beziehungen (Konstituentenstruktur). So haben Einzelhandlungen neben ihrer von der hierarchischen Handlungsstruktur unabhängigen Bedeutung eine Funktion zunächst innerhalb der jeweiligen Teilhandlung, z. T. aber auch teilhandlungsübergreifend und in Bezug auf die Texthandlung insgesamt. ${ }^{365}$ Dies gilt entsprechend für alle Zwischenebenen. Die Haupthandlungen eines Textes stehen in einem sequenziellen Und dann-Zusammenhang. Innerhalb von Haupthandlungen sind nebenordnende Wobei-Zusammenhänge (Nebenhandlungen) und unterordnende Indem-Zusammenhänge (Unterhandlungen) denkbar. Auf diese Weise entsteht am Ende eine Art Schachtelstruktur. ${ }^{366}$ Damit korrespondiert auf thematischer Ebene in Abhängigkeit von der Komplexität eines Textes eine mehr oder minder umfassende Themenhierarchie mit Hauptthemen, Nebenthemen und Unterthemen. ${ }^{367}$ Auch auf der Äußerungsebene werden mit verschiedenen Mitteln hierarchische und nicht-hierarchische Bezüge (grammatische Subordination und Koordination) hergestellt.

\section{Prinzipien der Gliederung}

Bei der Gliederung eines Textes in Teiltexte kann man sich an der linear-sequenziellen Abfolge, den inhaltlich-thematischen und den logisch-funktionalen Zusammenhängen orientieren. Diese drei Prinzipien stehen i. d. R. im Einklang miteinander, können sich aber auch widersprechen. So ist es durchaus möglich, dass inhaltliche und funktionale Zusammenhänge in

\footnotetext{
„Im Bereich der Verbindung von grammatischer Struktur und Handlungsstruktur weist das Modell [von Schröder] allerdings eine Schwäche auf: Die grammatische Größe ,Satz' wird - vermutlich aus praktischen Gründen im Hinblick auf die Textanalyse - mit der sprechakttheoretischen Größe, Illokution' faktisch gleichgesetzt. “ Vgl. a. N. 269 bzw. Kap. 1.3.2.1. Was Ähnlichkeiten mit verwandten Begriffen wie ,(funktionaler) Teiltext' (z. B. in GüLICH U. A. 1979), ,diktive Handlung' (KOCH U. A. 1981) sowie den ,Zügen' bzw. ,moves' in der move analysis betrifft, sei auf die entsprechende Fachliteratur verwiesen.

${ }^{365}$ Eine klare Abgrenzung zwischen der Funktion einer Illokution, die sie innerhalb der Handlungsstruktur erfüllt, und der Funktion, wie sie sich unabhängig davon ergibt, ist nicht immer möglich und eine Funktionsbestimmung völlig losgelöst vom Kontext entsprechend kaum praktikabel und sinnvoll. Vgl. z. B. HINDELANG UND YANG 2014, 155: „Bei der Beschreibung der Illokution einer Äußerung muss man unterscheiden zwischen der Illokution [bzw. Funktion], die sie isoliert für sich betrachtet hat, und der Handlungsqualität, die ihr in der Sequenz zukommt." Vgl. a. WÜEST 2011, 94 und LUPPOLD 2015, 399 (s. N. 366).

366 Zur Konstituentenstruktur vgl. v. a. SCHRÖDER 2003, 35ff. Dort wird zum „Begriff der komplexen Handlung“ bemerkt: „Seine Grundkomponenten, also einerseits die komplexe Handlung, andererseits die Teil-Handlungen, stehen untereinander in einer Teil-Ganzes-Beziehung. Ein Beschreibungsmodell, das auf diesem Begriff von Texthandlung basiert, wird die Handlungsstruktur von Texten also primär im Sinne einer Konstituentenstruktur auffassen. Im Mittelpunkt der Handlungsstrukturbeschreibung steht somit der Zerlegungszusammenhang, der zwischen der Texthandlung und ihren Bestandteilen, den Teil-Handlungen, besteht. Als kleinste Einheiten werden dabei die einfachen sprachlichen Handlungen gesehen.“ (ebd., 35). Vgl. a. LUPPOLD 2015, 399: „Eine komplexe Texthandlung wird damit vollzogen, indem einzelne Teil-Text-Handlungen entsprechend eines komplexen pragmatischen Musters bzw. einer komplexen pragmatischen Regel vollzogen werden. Die einzelnen Teil-Text-Handlungen sind dabei einerseits für sich jeweils illokutionär charakterisierbar; die Gesamttexthandlung setzt sich jedoch andererseits aus ihnen zusammen, d.h.: Die Textfunktion hängt nicht allein an einer einzelnen ,dominierenden' Illokution, sondern an dem gesamten Bündel der Teil-Texthandlungen." und ebd., 400: „Einzelne Teiltexthandlungen können sich rekursiv wiederum sozusagen aus ,Teil-Teilhandlungen' zusammensetzen, sodass eine Schachtelstruktur entsteht. Die einzelnen Teiltexthandlungen stehen untereinander in einer Und-dann-Beziehung; sie werden nacheinander und zusammenhängend vollzogen. Darüber hinaus stehen sie aber auch in funktionalen Beziehungen zueinander. "Ähnliche Auffassungen hinsichtlich der intratextuellen Zusammenhänge finden sich schon in GÜLICH U. A. 1979. Vgl. a. BICKMANN 1998, 43. Vgl. außerdem die Unterscheidungen von Haupt-, Neben- und Unterhandlungen bei Polenz 2008, 329f. und HAUSENDORF UND KESSELHEIM 2008, 165f. sowie N. 291. Vgl. des Weiteren Kap. 1.3.4.1.

${ }^{367}$ Vgl. z. B. SCHRÖDER 2003, 85ff. Genaueres zur Definition von ,Thema': N. 391.
} 
der linearen Abfolge eines Textes durchbrochen werden, sei es aufgrund mangelnder Kompetenz des Autors oder aber aus künstlerischen oder anderen Gründen. ${ }^{368}$ Dann stellt sich die Frage, inwieweit solche „diskontinuierlich realisierten Einheiten “369 bei der Gliederung und der Analyse berücksichtigt werden sollen. Das ISK orientiert sich z. B. bei der Erstellung von Illokutionshierarchien in erster Linie an funktionalen Aspekten und sieht entsprechend solche diskontinuierlichen Einheiten vor. In Schröders Modell der Konstituentenstruktur hingegen bestehen Teiltexte aus Sequenzen, die funktionale Struktur ist fest mit der sequenziellen Struktur verwoben. ${ }^{370}$ Zudem wird ein intensiver Zusammenhang von funktionaler und thematischer Struktur angenommen, bei dem Teilhandlungen und Teilthemen im Normalfall parallel laufen. ${ }^{371}$ Nach Schröder bestehen also insgesamt enge Verbindungen aller drei Gliederungsebenen. ${ }^{372}$

\section{Abgrenzungs- und Gliederungskriterien}

Der Aufbau eines Textes spiegelt sich meist auf der Textoberfläche ${ }^{373}$, wo mit verschiedenen Mitteln der Text als Ganzes und seine verschiedenen Bestandteile (z. B. Kapitel, Teilkapitel, einzelne Textabschnitte) voneinander abgegrenzt und intern gegliedert werden. ${ }^{374}$ Textbeginn

${ }^{368}$ Vgl. z. B. SCHRÖDER 2003, 34f. bzw. N. 330.
${ }^{669}$ Ebd., 37.
${ }^{370}$ Vgl. z. B. ebd., 37: „Diskontinuierlich realisierte Textkonstituenten [...] sind in diesem [Schröders] Modell [...] ${ }^{370}$ Vgl. z. B. ebd., 37: „Diskontinuierlich realisierte Textkonstituenten [...] sind in diesem [Schröders] Modell [...]
nicht vorgesehen. Anders als in der Illokutionshierarchie, deren Bäume prinzipiell unabhängig von der im Text gegebenen Abfolge der Einzelillokutionen sind, weil die Sequenzierung auf einer nachgeordneten Ebene analysiert wird, kann und muß für die Beschreibung der Konstituentenstruktur also auch die Sequenzierung im Text mit einbezogen werden." Vgl. a. ebd., 20f.; ebd., 33 und ebd., 35. Zum Begriff der ,Sequenz' in diesem Zusammenhang, welcher nicht identisch ist mit dem der Gesprächssequenz, vgl. z. B. ebd., 32: „Eine Texthandlung ist einerseits eine Sequenz aus Einzelhandlungen, sie ist aber andererseits - anders als im Fall einer dialogischen Sequenz - nicht nur ein Produkt ihrer Bestandteile, sondern auch selber eine Handlung. "Vgl. a. ebd., 34 und RoLF 2006, 2531ff.

${ }^{371}$ Vgl. z. B. LUPPOLD 2015, 401: „War der Zusammenhang zwischen thematischer/inhaltlicher Struktur und Handlungsstruktur im Modell der Illokutionshierarchien etwas vage geblieben, versucht nun Schröder, den Themenbegriff an den Handlungsbegriff bzw. die thematische Struktur eines Textes an die Handlungsstruktur rückzubinden. So vertritt er die nachvollziehbare Auffassung, einzelne Teiltexthandlungen stünden nicht nur in sequentiellen und funktionalen, sondern parallel dazu auch in thematischen Beziehungen zueinander. [...] Thematische Progression geht somit immer mit einer parallelen Progression der Handlungsstruktur einher." Vgl. aber auch LÖTSCHER 2008, 109: „Die Arbeiten von Lötscher (1987) [= LÖTSCHER 1987] und Schröder (2003) [= SCHRÖDER 2003] diskutieren das Verhältnis zwischen thematischer Struktur und illokutiver Struktur einerseits grundsätzlich und andererseits eher einzelfallbezogen. In der Frage, ob und inwiefern die thematische und die illokutive Ebene etwas miteinander zu tun haben, bleibt jedoch noch vieles offen.“ Vgl. außerdem das Kap. „Textanalyseebenen und Textstruktur" ab S. 44.

372 Vgl. z. B. ebd., 92.

${ }^{373}$ Mit ,Textoberfläche' sind hier im Wesentlichen das Layout und weitere vom Textinhalt i. e. S. weitgehend unabhängige (nonverbale) Mittel gemeint.

${ }^{374}$ Zur antiken Schreibpraxis vgl. z. B. SARRI 2017; BERNARD 2013, 33ff.; KLAUCK 1998, 55ff.; TYRRELL 1966, IXff. und Peter 1965, 29ff. Speziell zur Textgliederung vgl. a. DeNIzOT UND SPEVAK 2017b, 2 : „Only a small number of documents were directly transmitted (inscriptions, papyri, etc.); these provide valuable information about writing practices in the period in which they were produced. The formal presentation of a text in Antiquity was very different from our modern conventions in text segmentation and punctuation; as a result, the subdivision and segmentation of a Greek or Latin text can pose serious problems. “ Zur Unterscheidung von ,Abgrenzungskriterien bzw. -hinweisen“ und ,Gliederungskriterien bzw. -hinweisen“ vgl. HAUSENDORF UND KESSELHEIM 2008, 41: „Abgrenzungshinweise dienen der Auszeichnung textueller Obereinheiten. Oftmals fällt der Hinweis auf eine Obereinheit mit dem Hinweis auf eine (scheinbar) absolute textuelle Einheit zusammen: [...].“ bzw. ebd., 51: „Gliederungshinweise verstehen sich immer relativ zu einem Textganzen (also z. B. zu einem Buch, einer Zeitung, einem Artikel 
und -ende (i. e. S.) können nicht nur durch das Layout (z. B. künstlerische Gestaltung des ersten Buchstabens in vielen älteren Schriften), sondern ebenso durch metakommunikative Druckvermerke wie „Ende“, explizite Formulierungen wie „Hiermit endet die Geschichte.“ oder bestimmte Einleitungs- und Abschlussformeln (z. B.: „Es war einmal ...") bzw. BegrüBungs- und Abschiedsformeln (in Briefen) gekennzeichnet sein. ${ }^{375}$ Die Abgrenzung von Texten i. w. S. als geschlossenes Ganzes kann außerdem mittels eines Titels bzw. einer Titelei, eines Anhangs usw. und letztlich auch durch die Materialität eines Textes erreicht werden. ${ }^{376}$ Innerhalb der Texte kann man durch Zeilenumbruch, Texteinzug und Leerzeilen Absätze bzw. (z. B. in Gesetzestexten, aber auch in Editionen antiker Texte) Paragraphen bilden und ggf. mit (nummerierten) Paragraphenzeichen oder - vornehmlich in älteren Texten - Absatzzeichen (Alinea) markieren. ${ }^{377}$ Aufgrund solcher und anderer (typo)graphischer ${ }^{378}$ Gestaltungsmöglichkeiten (wie Interpunktion, Schriftart, -größe, und -format, Zeilenabstand, Platzierung von Text und Bildern) ergeben sich (weitere) Hinweise auf den Textaufbau. So werden Fließtext und Überschriften i. d. R. unterschiedlich formatiert und die betreffenden Textteile dadurch üblicherweise zugleich hierarchisiert, oft unterstützt durch entsprechende Nummerierungen, manchmal auch durch metasprachliche Hinweise (vgl. z. B. Überschriften wie „Kapitel 3“ oder „Liber quartus decimus“). In vielen Fällen sind mit den Überschriften zudem thematische Hinweise verbunden. Gliederungs- bzw. Inhaltsübersichten werden den Texten häufig zusätzlich (in Tabellen-, aber auch - z. B. in der Einleitung - in Textform) voran- oder (seltener) nachgestellt.

Die (mehr oder weniger ausdifferenzierte) Einteilung durch den Autor bzw. Schreiber, Kopisten oder Herausgeber kann wertvolle Anhaltspunkte liefern, entspricht aber nicht unbedingt

oder einer Erzählung), dessen Innenwelt dann weiter ausdifferenziert wird (im Hinblick z. B. auf Kapitel, Abschnitte, Paragrafen, Absätze, ...). “ Die folgende Darstellung einzelner Aspekte der Abgrenzung und Gliederung und die genannten Beispiele orientieren sich hauptsächlich an ebd., 39ff. Vgl. aber auch N. 379.

${ }^{375}$ Die Texteröffnungs- und Textbeendigungsformeln kann man als eine Art Zwischenbereich zwischen Textoberfläche, Text(inhalt) i. e. S. und funktionaler Ebene betrachten. Dies trifft teilweise auch auf andere der genannten Indikatoren zu, wie z. B. die Überschriften. Zu den metakommunikativen Äußerungen vgl. a. S. 65, zu den Briefformeln Kap. 1.2.1 (ab S. 92) sowie das Kap. „Grußformeln“ (ab S. 346).

${ }^{376}$ Zur Materialität zählen die Besonderheiten des jeweiligen Textträgers (Papyrus, Pergament, Papier) und der Art der Textsammlung (Schriftrolle, Kodex, Buch).

${ }^{377}$ Absatz- und Paragraphenzeichen sind nicht immer deutlich voneinander zu trennen (vgl. z. B. RINAS 2015, 143). Zu den Besonderheiten der Textstrukturierung in antiken und mittelalterlichen Schriften (scriptio continua, scriptio per cola et commata) sei auf die einschlägige Fachliteratur verwiesen. Vgl. a. ebd., 141 zur Periodenlehre der Antike: „Dieser Lehre zufolge kann man Texte sukzessive in die Einheiten Perioden, Cola und Commata gliedern, welche nach rhythmisch-semantischen Kriterien definiert sind [...]. " Dabei stehe die Periode in einem engen Verhältnis zum Satz, werde manchmal sogar mit ihm gleichgesetzt. Dies entspreche aber keineswegs dem antiken Verständnis, nach dem das Verhältnis zwischen beiden komplexer sei. Vgl. außerdem N. 374.

${ }^{378} \mathrm{Hier}$ ist zu unterscheiden zwischen modernen drucktechnischen (typographischen) Verfahren und den handschriftlichen (chirographischen) Gestaltungsmöglichkeiten (vor der Erfindung des Buchdrucks). 
dem Ergebnis einer fundierten Analyse der Textstruktur, die auf jeden Fall noch weitere Kriterien berücksichtigen muss. ${ }^{379}$ Solche liegen jener zwar oft (bewusst oder unbewusst) zugrunde ${ }^{380}$, werden teilweise aber von anderen, z. B. stilistisch-künstlerischen Aspekten überlagert, die i. d. R. eher Gegenstand rhetorischer oder literaturwissenschaftlicher als textlinguistischer Analysen sind.

Die Verfahren zur Herstellung von Kohärenz bzw. zur Delimitation auf verbaler Ebene sind z. T. eng miteinander verbunden. ${ }^{381}$ Beides wird $u$. a. durch Rekurrenz erreicht, indem bspw. einzelne Wörter und Wortgruppen oder Sätze und Satzgruppen, aber auch bestimmte phonetische, graphische, morphologische und semantische Merkmale wiederholt werden. ${ }^{382}$ Wiederaufnahmen dienen der (Ko-)Referenz innerhalb eines Textes. Eine solche Verkettung mittels Vor- und Rückverweisen (Anaphern, Kataphern), die nicht auf den unmittelbaren Kotext beschränkt ist, findet, von Wiederholungen abgesehen, auch durch metakommunikative Formulierungen, Ellipse des Subjekts und verschiedene Arten der Substitution statt, wie z. B. die Verwendung von sog. Proformen (Pronomina, Pronominaladverbien sowie bestimmte Substantive und Verben) ${ }^{383}$, (Quasi-)Synonymen, Hyperonymen und weiteren Arten der Umschreibung. ${ }^{384}$ Man kann dabei sowohl auf einzelne Wörter als auch auf größere Einheiten (bis hin zu ganzen Texten) Bezug nehmen. ${ }^{385}$

\footnotetext{
${ }^{379}$ Ausführlicher zu den verschiedenen Abgrenzungs- und Gliederungskriterien: ADAMZIK 2016, 276ff.; HAUSENDORF UND KESSELHEIM 2008, 39ff.; SCHRÖDER 2003, 114ff. und BICKMANN 1998, 58ff. Häufig wird dabei auf die grundlegenden Arbeiten von Gülich und Raible (z. B. GÜLıCH U. A. 1979) zurückgegriffen. Vgl. dazu u. a. BICKMANN 1998, 60ff. und SCHRÖDER 2003, 103ff. Einen anderen Ansatz verfolgt das ,Modell der referenziellen Bewegung (oder Progression)', bei dem u. a. auch Topik- und Fokuskomponenten eine Rolle spielen: Vgl. z. B. ebd., 107ff. und STUTTERHEIM UND KLEIN 2008. Vgl. a. N. 391 und die Ausführungen zur Themenentfaltung ab S. 64. Zu Möglichkeiten der Textgliederung speziell von lateinischen Texten: SCHERER 1975, 104ff. und (mit Bezug auf Ciceros Briefe) KISS 2001.

$380 \mathrm{VgI}$. z. B. ADAMZIK 2016, 232. Zur inzwischen wissenschaftlich widerlegten scheinbaren „großen Schwankung und Willkürlichkeit bei der Absatzgliederung“: RinAs 2015, 144f. und ebd., 152.

${ }^{381}$ In der vorliegenden Arbeit wird der Begriff ,Kohärenz' (Textzusammenhang) als Oberbegriff gebraucht, der (auf die Äußerungsform bezogene) ,Kohäsion' und (inhaltsbezogene) ,Kohärenz' i. e. S. mit einschließt. Vgl. dazu z. B. ADAMZIK 2016, 263: „Die Durchmusterung von verschieden engen Vorstellung[en] von Kohäsion führt zu dem Schluss, dass die Trennung von grammatischen und semantisch-lexikalischen Aspekten mindestens einigermaßen arbiträr ist." Vgl. a. ebd., 266ff. Ausführlicher zu verschiedenen Möglichkeiten der Kohärenzbildung: Ebd., 251ff.; HeRINGer 2015, 16ff.; BRINKER U. A. 2014, 29ff. bzw. 44ff.; SCHWARZ-FrIESEL UND CONSTEN 2014, 74ff.; HAUSENDORF UND KESSELHEIM 2008, 59ff.; LÖTSCHER 2008, 85ff. sOwie BEAUGRANDE UND DRESSLER 1981, 50ff. bzw. ebd., $88 \mathrm{ff}$. Vgl. a. (mit Bezug auf das ISK): PASCH 1987. Zu verschiedenen Möglichkeiten der grammatischen Kohärenz im Lateinischen: LANDFESTER UND KUHN 2006, 146ff. und PINKSTER 1988, 369ff. Zur Interdependenz von Kohärenz und Delimitation (mit Bezug auf die Verwendung von Pronomina) vgl. z. B. KIss 2001, 386. Mit ,Delimitation' oder auch ,Demarkation' wird auf die Abgrenzung von Texten und Textteilen referiert. Zu anderen, mit der Kohärenz von Texten im Zusammenhang stehenden Termini und deren i. E. stark differierender Verwendungsweise vgl. z. B. ADAMZIK 2016, 251.

$382 \mathrm{Vgl}$. z. B. HAUSENDORF UND KESSELHEIM 2008, 61ff. und (zu den verschiedenen Dimensionen der Rekurrenz) ADAMZIK 2016, 264f. Zur semantischen Rekurrenz vgl. a. das Isotopiekonzept (von Greimas), das sich im Unterschied zur lexikalischen Semantik auf die (ko)textabhängige Bedeutung bezieht.

${ }^{383} \mathrm{Vgl}$. z. B. ebd., 262.

384 Ausführlicher zur (Ko-)Referenz und den damit verbundenen Aspekten Phorik und Deixis: HAUSENDORF UND KESSELHEIM 2008, 69ff. und HERINGER 2015, 31ff. Speziell zu „Discourse Organization and anaphora in Latin“: BOLKESTEIN 2001. Vgl. außerdem S. 65.

${ }^{385}$ ADAMZIK 2016, 262.
} 
Konnexion innerhalb von Texten erfolgt asyndetisch oder durch Konnektoren, also z. B. Konjunktionen, Satzadverbien und Relativpronomina. ${ }^{386}$ Die Grenze zwischen satzinternen und satzübergreifenden Verknüpfungen ist dabei z. T. fließend. Manchmal werden (insbesondere in Bezug auf die Satzkonjunktionen) zusätzlich noch Koordinatoren (Parataxe) und Subordinatoren (Hypotaxe) unterschieden. ${ }^{387}$ Die Aufgabe von Konnektoren liegt nicht nur in der grammatischen Aneinanderreihung, sondern v. a. darin, semantische und pragmatische Beziehungen explizit zu machen, die bei Asyndese häufig nur impliziert sind und entsprechend (durch Inferenz) erschlossen werden müssen: Dazu gehören konjunktive (kopulative oder additive), disjunktive (alternative), adversative, konzessive, temporale, kausale, konsekutive, finale, konditionale, komparative, restriktive, explikative und spezifizierende Relationen. ${ }^{388}$ Solche Beziehungen können allerdings auch auf anderem Wege hergestellt werden, z. B. durch entsprechende Inhaltswörter in Formulierungen wie den folgenden: „Der Brand wurde durch einen technischen Defekt verursacht.“ oder „Die Folge seiner Nachlässigkeit war eine Überschwemmung des Kellers. “389

Außerdem kann mittels der Wortstellung (grammatisch und semantisch) an das Vorangehende angeknüpft werden, z. B. durch die (betonte) Spitzenstellung eines Textelementes. Sie kann (im Lateinischen) aber ebenso durch andere Faktoren begründet sein. ${ }^{390}$ So spielen - abgesehen von den grammatisch-syntaktischen Gegebenheiten - evtl. prosodische oder stilistische,

\footnotetext{
386 In der vorliegenden Arbeit werden die Termini ,Konnexion` und ,Konnektor` in einer umfassenderen Weise als sonst oft üblich verwendet und beziehen sich auf die grammatische, semantische und pragmatische Verknüpfung von Textelementen, die sich von der Einzelwort- bis hin zur Textebene erstrecken kann. Zu möglichen (anderen) Definitionen von Begriffen wie ,Konnektor' oder ,Diskurspartikel', ,Koordinator' und ,Partikel' vgl. z. B. DENIZOT UND SPEVAK 2017b, 8f. Vgl. a. AdAMZIK 2016, 261; GHEZZI 2014, 15; Brinton 2010; KROON 2007, 149; KRYLOVÁ 2007, 159 und PINKSTER 1988, 383ff. sowie N. 388. Allgemein anerkannte Definitionen gibt es in diesem Bereich nicht (vgl. ADAMZIK 2016, 262); und eine strikte Abgrenzung der verschiedenen Termini ist m. E. auch kaum möglich. ${ }^{387}$ Vgl. z. B. PINKSTER 1988, 383.

388 Vgl. z. B. HAUSENDORF UND KESSELHEIM 2008, 81ff. zu „Relationshinweisen“ und LÖTSCHER 2008, 93ff. zu „Kontiguitätsbeziehungen und propositionalen Beziehungen zwischen Sätzen“. Vgl. a. PASCH 1987. Die hierbei angesprochenen Ebenen und Arten von Beziehungen sind vielfältiger Natur und manchmal nur schwer voneinander abzugrenzen. Vgl. z. B. LÖTSCHER 2008, 95: „Die hier erwähnten Beziehungen sind allerdings auf recht unterschiedlichen Inhaltsebenen anzusiedeln. Viele davon sind [...] Beziehungen zwischen den Denotaten der Sätze, also den bezeichneten Sachverhalten, so die konjunktionale oder die kausale Relation. Andere sind eher logisch-satzsemantischer Art; sie werden nicht von einzelnen Situationen ausgesagt, sondern über die Wahrheitsbedingungen der einzelnen Sätze, etwa im Falle der konditionalen Relation oder der spezifizierenden Relation. Andere Relationen betreffen weniger die sachliche Bedeutung der verknüpften Sätze als die Aussageabsichten der Sprecherin oder des Sprechers, also die illokutive Ebene, so im Falle der explizierenden Relation. Und wieder andere Verknüpfungen beziehen sich auf die Erwartungen des Lesers oder der Leserin, so bei der konzessiven und bei der adversativen Relation [...]. Die zuletzt genannten textuellen Relationen zwischen Sätzen in einer Textfolge können also kaum als Prädikate zwischen Propositionen verstanden werden, sondern sind Verknüpfungen auf anderen Ebenen, der Pragmatik oder der Illokution. “ Vgl. a. ScHMITT 2000, 179f.: „[...] syntaktische Abhängigkeitsverhältnisse innerhalb eines Satzes [dürfen] nicht gleichgesetzt werden mit hierarchischen illokutionären Beziehungen. [...] Während diese relative Unabhängigkeit von syntaktischen und pragmatischen Gegebenheiten noch recht leicht nachvollziehbar ist, scheint die Gefahr einer Verwechslung von pragmatischen und semantischen Beziehungen ungleich größer." Vgl. außerdem N. 386.

389 Vgl. z. B. ADAMZIK 2016, $262 f$.

390 KIENPOINTNER 2010, 359f. nennt z. B. pragmatische, syntaktische, semantische, morphologische, prosodische und stilistische Aspekte als Einflussfaktoren auf die Wortstellung. Vgl. a. BLÄNSDORF 2015, 52 sowie die im Kap. „Wortstellung“ (ab S. 83) genannten Arbeiten. Trotz i. E. unterschiedlicher Auffassungen wird i. A. besonders die Bedeutung pragmatischer Faktoren hervorgehoben, während die grammatischen z. T. für eher unwesentlich erachtet werden: Vgl. z. B. Denizot und SPEVAK 2017b, 6; SPEVAK 2010, 27 und ebd., 285; DeVINE UND STEPHENS 2006,
} 
v. a. jedoch pragmatische Aspekte eine Rolle, die (kognitive) Bedeutsamkeit (,salience') soll hervorgehoben werden, oder die betreffende Information ist neu bzw. ein neues Thema wird eingeführt. ${ }^{391}$

Eine Themeneinführung bzw. ein Themenwechsel ist kennzeichnend für den Beginn eines Textes oder Teiltextes und hat i. d. R. eine demarkative Funktion. Dies gilt ebenso für den Themenabschluss am Ende eines Textes. Eine Themenwiedereinführung wirkt dagegen (auch) kohäsiv. Dies gilt erst recht für einen Themenerhalt und die verschiedenen Formen der Themenentwicklung, die deskriptiv, narrativ, explikativ oder argumentativ sein kann. ${ }^{392}$ Neben der Wortstellung gibt es noch zahlreiche andere mögliche Themen- und Themenstrukturierungshinweise, wie z. B. Wechsel bzw. Kontinuität im Hinblick auf (zeitliche und örtliche) Situation, Handlungsträger, Adressat oder Perspektive. ${ }^{393}$ Dabei stehen sprachliche und inhaltliche, aber auch funktionale Aspekte häufig in Wechselwirkung zueinander. So bedeutet ein Themenwechsel meist gleichzeitig einen funktionalen Wechsel, Themenerhalt ist i. d. R. mit einem funktionalen Zusammenhang verbunden. ${ }^{394}$

114 sowie den Überblick bei HOFFMANN 2018, 111ff. Insgesamt scheint mittlerweile auch weitgehend Konsens darüber zu herrschen, dass es eine „normale“ Wortstellung nicht gibt: „In all, these findings show that it would be inappropriate to speak of an unmarked word order. Each word order is influenced by pragmatic functions, among other things. There is no position that is privileged to be the basic word order." (HoffMANn 2010, 274). Vgl. JONGE 2007, 224.

${ }^{391}$ Hier ist u. a. auf das Thema-Rhema-Konzept der Prager Schule zu verweisen, das ursprünglich satzbezogen war (funktionale Satzperspektive), von Daneš zwar hinsichtlich der Analyse von Textstrukturen weiterentwickelt wurde, für textthematische Analysen aber dennoch kaum sinnvoll anwendbar ist: Vgl. z. B. ADAMzIK 2016, 209; BRINKER U. A. 2014, 47ff. und LÖTSCHER 2008, 103ff. VgI. a. N. 392. Vgl. außerdem SCHRÖDER 2003, 152ff., der u. a. auch spätere Entwicklungen mit der Unterscheidung verschiedener Gliederungsebenen (z. B. Fokus-Hintergrundund Topik-Kommentar-Gliederung) ausführlich berücksichtigt, sowie WULF 2018. Zur Terminologie (Thema vs. Rhema bzw. topic vs. comment, Hintergrund vs. Fokus, bekannt vs. neu) vgl. z. B. LÖTSCHER 2008, 103f. Zu verschiedenen textbezogenen Themenbegriffen vgl. z. B. ADAMZIK 2016, 209ff.; LUPPOLD 2015, 94ff.; BRINKER U. A. 2014, 44ff. und SCHRÖDER 2003, 50ff. sowie LÖTSCHER 1987. In der vorliegenden Arbeit wird das Thema unter Zugrundelegung der Definition bei SCHRÖDER 2003, 92 als Bezugsgegenstand betrachtet: „Thema eines Textes ist [...] der Gegenstand, auf den mit einer Texthandlung Bezug genommen wird, auf den sich die Teil-Handlungen gemeinsam beziehen und dessen Teilaspekte in den zugehörigen Teil-Handlungen behandelt werden." Zur Frage, wie das Thema ermittelt werden kann, vgl. z. B. BRINKER U. A. 2014, 53f.: „Man muss sich [...] darüber im Klaren sein, dass die textanalytische Bestimmung des Themas primär auf interpretativen Verfahren beruht; es kann hier keine ,mechanische‘ Prozedur geben, die nach endlich vielen Schritten automatisch zur ,richtigen“ Themenformulierung führt." und LÖTSCHER 2008, 105: „Überhaupt ist kaum je systematisch untersucht worden, wie man zu einem gegebenen Text das Thema finden kann. Es ist anzunehmen, dass hier viel Intuition im Spiel ist, was eine für alle gültige Identifikation des Textthemas erschweren dürfte."

${ }^{392}$ Vgl. z. B. BRINKER U. A. 2014, 60ff. („Grundformen thematischer Entfaltung “); LÖTSCHER 2008, 106ff. („Themenstruktur und Handlungsstruktur“) und SCHRÖDER 2003, 85ff. („Thematische Beziehungen“). Vgl. a. SANDIG 2006, 357ff. Vgl. außerdem das Konzept der thematischen Progression von Daneš, der "einfache lineare Progression“, „Progression mit einem durchlaufenden Thema“, „Progression mit abgeleiteten Themen“, „Entwickeln eines gespaltenen Rhemas“ und „Progression mit einem thematischen Sprung“ unterscheidet. Dazu ausführlicher: SCHRÖDER 2003, 64ff. Vgl. a. N. 391. Vgl. des Weiteren das Modell der referenziellen Bewegung (s. N. 379): Bei Referenzkonstanz wird von ,statischer Kohärenz' gesprochen, bei regelhafter Veränderung von ,dynamischer Kohärenz'. Zum Lateinischen vgl. z. B. LANDFESTER UND KUHN 2006, 154ff. („Textkohärenz durch Formen des Themaverlaufs/Themaaufbaus“. Vgl. a. SOMERS 1994.

393 Vgl. z. B. HAUSENDORF UND KESSELHEIM 2008, 103ff. (zu „Themahinweisen“) bzw. ebd., 90ff. (zu „Strukturhinweisen“) und SCHRÖDER 2003, 120ff. (zu „Zeit- und Ortsbezug“) bzw. ebd., 133ff. (zu „Personenbezug“). Zum Lateinischen vgl. z. B. SCHERER 1975, $104 \mathrm{ff}$.

${ }^{394}$ Vgl. z. B. SCHRÖDER 2003, 48 und ebd., 93 sowie OrtNER 2014b, 327. Vgl. a. SZWEd 2014, 173. 
Zur Textstrukturierung auf pragmatischer Ebene dienen v. a. subsidiäre und sekundäre Illokutionen mit assertiver (metakommunikativer) Funktion. Durch intratextuelle und intertextuelle Bezugnahmen wird Kohärenz hergestellt, z. B. mittels expliziter Formulierungen wie „Um auf ... zurückzukommen." oder „Wie ich bereits oben bemerkt habe ...". Beginn und Schluss eines Textes werden ebenfalls manchmal durch entsprechende Formulierungen markiert. Es ist möglich, einen (Teil-)Text einzuleiten, indem man an Äußerungen anderer Personen anknüpft, sie ggf. sogar direkt oder indirekt zitiert. Eine Zusammenfassung kann das Ende eines Teiltextes signalisieren. Demarkative Funktion haben insbesondere bestimmte Einleitungs- und Schlussformeln, die damit auch als deklarative Sprechakte zu betrachten sind. ${ }^{395}$

Nicht zu unterschätzen sind schließlich die kognitiven Verfahren zur Herstellung von Kohärenz und zur Delimitation. So hat ein Rezipient aufgrund seines Vorwissens (z. B. Textsortenwissen, Kenntnisse über den Autor, bestimmte historische und kulturelle Besonderheiten) gewisse Erwartungen an einen Text hinsichtlich der Funktion, des Inhalts sowie der stilistischen Gestaltung und Strukturierung. ${ }^{396}$ Da das Vorwissen individuell unterschiedlich ausgeprägt und sein Einfluss auch nicht jedem in vollem Ausmaß bewusst ist, besteht immer die Gefahr der Subjektivität bei der Analyse eines Textes. Es sollte deshalb zumindest möglichst deutlich offengelegt werden, welche Kriterien man einer Gliederung zugrunde legt. Dabei scheint angesichts der Vielzahl von Indikatoren eine Auswahl und v. a. eine Hierarchisierung notwendig. ${ }^{397}$ Letztlich ist (in Zweifelsfällen) jedoch trotzdem oft die Intuition entscheidend. Außerdem sollte man sich klarmachen, dass jeder Text anders ist und es ein wirklich durchgehend konsequentes, einheitliches Verfahren gar nicht geben kann. ${ }^{398}$

\footnotetext{
395 Zur Bedeutung funktionaler Indikatoren vgl. z. B. BICKMANN 1998, 58: „Der hier vertretene sprechakttheoretische Ansatz legt es [...] nahe, Explizierungen oder deutliche Indikatoren der illokutionären und der perlokutionären Rolle als wichtige Signale der Gliederung anzusehen. Es erscheint dabei als wahrscheinlich, daß die dominierenden Sprechakte an strategisch wichtigen Textstellen eher expliziert oder zumindest indiziert werden als die Sprechakte, denen im Gefüge des Textes eine stützende Funktion zukommt." Vgl. a. SCHRÖDER 2003, 114ff. zu „textbezüglichen Ausdrücken“ und ebd., 146f. zu „metakommunikativen Handlungen“. Zum Lateinischen vgl. a. SCHERER 1975, 101ff. Vgl. außerdem S. 61 (zur Markierung von Textbeginn und -ende), S. 62 (zur Koreferenz) sowie Kap. 1.2.1.3.2 und das Kap. „Grußformeln“ ab S. 346 (zu den Briefformeln).

${ }^{396}$ Vgl. z. B. WEIGAND 2003, 4: „Kohärenz ist keine Eigenschaft des Textes, sondern wird von den Kommunikationsteilnehmern in ihrem kognitiven Bestreben gestiftet, empirische Signale soweit möglich als sinnvoll und zusammenhängend zu verstehen [...]. “ Vgl. AdAMZIK 2016, 20ff. und ebd., 230; FIX 2008, 25f.; HAUSENDORF UND KESSELHEIM 2008, 27 und ebd., 132ff.; SCHRÖDER 2003, 99ff. sowie BEAUGRANDE UND DRESSLER 1981, 19f. und ebd., $88 f f$. In den genannten Arbeiten wird auch ausführlicher auf die entsprechenden kognitionspsychologischen bzw. -linguistischen Konzepte wie ,Schema', ,frame' (Rahmen), ,Skript', ,slot' und ,filler' eingegangen.

${ }^{397}$ Was bisherige Vorschläge zur Textgliederung angeht, dominierten v. a. inhaltlich-thematische Faktoren (vgl. z. B. BICKMANN 1998, 58). Im Modell von Gülich / Raible (z. B. GüLICH U. A. 1979, 73ff.) sind die Gliederungssignale auf der Textoberfläche („Merkmale mit einem textexternen Analogon“) entscheidend; es kommen aber weitere (unterschiedlich hierarchisierte) Gliederungssignale hinzu (vgl. ebd., 86f.). Bei BICKMANN 1998 hingegen sind funktionale (illokutionäre und perlokutionäre) Kriterien wichtiger als inhaltliche (propositionale) Kriterien, denen wiederum syntaktische (lokutionäre) Kriterien untergeordnet werden (vgl. z. B. ebd., 62).

${ }^{398}$ Vgl. z. B. BLÄNSDORF 2015, 65: „Es erweist sich, dass die Methoden der Autoren, Textkohärenz herzustellen, nicht nur außerordentlich verschieden sind, sondern dass einige Phänomene bei den einen Autoren die Textkohärenz weitgehend herstellen, während sie auf die anderen Autoren gar nicht anwendbar sind. Dieser Befund rechtfertigt zugleich die niemals gleichartig-schematisch, sondern immer textadäquat anzuwendende Methode der hier vorgelegten Analysen. “ VgI. a. GüLICH U. A. 1979, IX. VgI. außerdem N. 379.
} 


\subsection{Gesamtbetrachtung}

Die Bedeutung eines Textes bzw. einer Texthandlung ergibt sich aus dem vielschichtigen Gesamtgeflecht aller Textkonstituenten, von den Einzelelementen bis hin zum Textganzen, und zwar auf funktionaler, thematischer und grammatischer Ebene. Damit interdependent verbunden sind noch viele weitere (z. B. stilistische und kognitive) Faktoren. Ziel einer umfassenden (pragmatischen) Textanalyse sollte es sein, sowohl die textinternen Strukturen als auch den Text in seiner Gesamtheit zu erfassen, also einen Kompromiss zwischen analytischem und holistischem Konzept zu finden.

In Bezug auf die Frage nach der Uni- bzw. Multifunktionalität von Texten scheint eine zu rigide Auffassung ebenfalls unangemessen bzw. kaum praktikabel zu sein, insbesondere deshalb, weil sich die unterschiedlichen Funktionsbegriffe oft nur sehr schwer voneinander abgrenzen lassen. ${ }^{399}$ Auf verwirrende Begrifflichkeiten trifft man aber auch an anderer Stelle: So findet sich die Problematik einer Vielzahl unterschiedlicher, sich mehr oder weniger überschneidender und z. T. unzureichend definierter Termini bei der Bezeichnung von Sprechaktoberklassen und -untermustern in ähnlicher Weise bei den Textfunktionen und erst recht bei den verschiedenen Arten untergeordneter (und nebengeordneter) Sprechakte innerhalb von Texten.

Auch andere bereits in Bezug auf die klassische Sprechakttheorie geäußerte Kritikpunkte bleiben im Rahmen der textlinguistischen Erweiterung (v. a., aber nicht nur im ISK) z. T. weiterhin bestehen: Satz und Illokution werden immer noch meistens gleichgesetzt, der Kontext wird bisweilen nur unzureichend berücksichtigt, die Kommunikationssituation häufig idealisiert, die Vorgehensweise bleibt oft intentionalistisch und sprecherbezogen, Dialogizität und Prozeduralität bei Textproduktion und -rezeption werden vielfach vernachlässigt. ${ }^{400}$ Als Grund wird u. a. auf die Zuständigkeit anderer Disziplinen verwiesen. ${ }^{401}$ Eine wesentliche Ursache - auch für die sich darüber hinaus ergebenden, textspezifischen Probleme - ist aber wohl v. a. darin zu sehen, dass es äußerst schwer ist, die entsprechenden Analyseprozesse, die notwendigerweise sehr komplex ausfallen müssen, angemessen und ohne zu starke Vereinfachungen zu operationalisieren. Entsprechende Verfahren finden sich bspw. für die Identifikation von IIlokutionen, aber ebenso von größeren Texteinheiten nur selten. Das Gleiche gilt für die genaue Vorgehensweise bei der Ermittlung von Textfunktion, dominierender Illokution, den weiteren Sprechakten sowie den (hierarchischen und nicht-hierarchischen) Beziehungen aller Textkonstituenten zueinander. Zudem stellt sich die Frage, wie das Verhältnis von direkten

\footnotetext{
399 Vgl. a. N. 319.

400 Vgl. z. B. (zum ISK): LUPPold 2015, 395f.; BRINKER U. A. 2014, 96; SzWEd 2014, 40; HeINEMANN 2008, 131; HeINE-

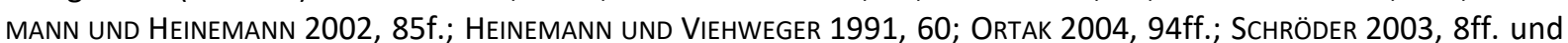
HARTUNG 2000 - 2001, 89f. Zur Gleichsetzung von Satz und Illokution vgl. a. ROSENGREN 1987, 29 sowie (zu Schröders Konstituentenmodell) LUPPOLD 2015, 402 und SCHRÖDER 2003, 36 bzw. N. 364. Vgl. außerdem das Kap. „Kritik an der klassischen Sprechakttheorie" ab S. 43.

${ }^{401}$ Vgl. z. B. BRINKER U. A. 2014, 10: „Dabei [d. h. bei der linguistischen Analyse von Textfunktion und -struktur] stehen die regulären, vom sprachlichen Handlungssystem bestimmten Beziehungen im Vordergrund, nicht die aktuellen mentalen Abläufe bei der Produktion und Rezeption von Texten; mit ihnen befasst sich die Psycholinguistik, die Textlinguistik beschreibt aber wichtige systembedingte Voraussetzungen solcher Prozesse."
} 
und indirekten Sprechakten (auch im Zusammenhang mit dem Gesamttext und den Teiltexten) zu bewerten ist. ${ }^{402}$

Bisherige empirische Textanalysen beziehen sich insgesamt auf ein recht eng umgrenztes Textkorpus: Zum einen handelt es sich i. d. R. um ziemlich kurze und überschaubare Texte, was allerdings angesichts der Komplexität einer umfassenden Analyse kaum anders möglich ist. Zum anderen stehen häufig nur ganz spezifische Textsorten, in denen bestimmte Arten von Sprechakten dominieren, im Mittelpunkt der Analyse, z. B. von Direktiva geprägte Geschäftsbriefe oder von Assertiva bestimmte Nachrichtentexte. ${ }^{403}$ Dies ist ein weiterer Grund dafür, dass Aussagen zur Praxistauglichkeit der zugrunde liegenden Analysekonzepte und ihrer potenziellen Anwendbarkeit auf Texte anderer Art und größeren Umfangs nur eingeschränkt möglich sind. ${ }^{404}$

\subsubsection{Besonderheiten der historischen Pragmatik}

\subsubsection{Historizität und Kulturspezifität sprachlicher Äußerungen \\ 1.1.2.1.1 Sprachliche Varietät}

Inwieweit sind nun die Erkenntnisse und Methoden, die im vorangegangenen Kapitel beschrieben wurden, auf eine Analyse von fam. 14 übertragbar? Schließlich beziehen sie sich (zumindest zum größten Teil) auf sprachliche Kommunikation in unserem heutigen Kulturkreis $^{405}$, während die Cicero-Briefe einer weit entfernten Epoche angehören, geprägt von einer ganz anderen Kultur. Dies betrifft nicht nur Sprache und Literatur, sondern ebenso soziokulturelle Verhältnisse wie Geschlechterrollen, Alters- und Berufsgruppen, Familienbeziehungen und Gesellschaftsschichten, die - neben eher individuellen, regionalen, medialen und situativen Faktoren - Einfluss auf die sprachliche Ausgestaltung, den Inhalt, aber auch die Funktion sprachlicher Äußerungen nehmen können. Außerdem ist ihre spezifische Historizität zu beachten. ${ }^{406}$

\footnotetext{
402 Vgl. z. B. SZWEd 2014, 40; Heinemann 2008, 131; OrtaK 2004, 104 und Heinemann und Heinemann 2002, 86. Zur Illokutionsidentifikation vgl. a. das entsprechende Kap. ab S. 148.

${ }^{403}$ Zum ISK vgl. z. B. BRINKER U. A. 2014, 95 N. 31 (u. a. mit Bezug auf MotSCH 1987 und BRANDT U. A. 1983): „Bisher wurden im Rahmen dieses Ansatzes nur wenige konkrete Analysen zu komplexen Texten vorgelegt; es gibt $z$. B. Analysen zu einzelnen Texten aus dem Bereich der Feststellungstexte [...], der Anordnungstexte [...], der produktbegleitenden Texte [...] und des Geschäftsbriefs [...]. “ HeINEMANN Und HeINEMANN 2002, 86 weisen auf die „Reduzierung der Handlungsziele auf eine beschränkte Zahl von Handlungstypen“ hin, SzWED 2014, 40 spricht mit Bezug auf HARTUNG 2000 - 2001, 89 von einer „Einschränkung der funktionalen Erklärung von Texten durch die Festlegung auf eine kleine Zahl von Handlungstypen (Illokutionen)“. Vgl. a. SCHRÖDER 2003, 21.

${ }^{404}$ Vgl. z. B. ORTAK 2004, 104: „Einige Ergebnisse - etwa zur globalstrukturellen Sequenzierung von Illokutionen sind durch die Spezifik des Textcorpus vorgezeichnet und nicht generalisierbar."

${ }^{405}$ Allerdings ist zu bemerken, dass dabei ein ziemlich weiter Zeitraum im 20. und 21. Jahrhundert erfasst wird und sich die betreffenden Arbeiten durchaus auf unterschiedliche Sprachen (v. a. Englisch und Deutsch) beziehen. Zum Kulturbegriff vgl. z. B. KUßE 2012, $25 \mathrm{ff}$.

406 Vgl. JUCKER UND LANDERT 2017, 84ff., z. B. ebd., 87: „In principle, it would be important to explore all of the established levels of sociolinguistic variation - social class, gender, age, region and genre - to all sorts of pragmatic entities - speech acts, discourse markers, conversational styles and so on - in order to determine the interrelationship between synchronic variation at a given point in time and diachronic change. In reality many of these dimensions will remain very difficult to investigate because of the limited survival of relevant material and the impossibility of carrying out historical experiments.“ Vgl. a. BARRON 2017 („Variational Pragmatics“). Vgl. außerdem FöGEN 2001 über Cicero und dessen Einstellung zu den Varietäten im Lateinischen.
} 


\subsection{Beispiele für den Einfluss historischer und kultureller Faktoren}

\section{Emotionalität}

Verschiedene Kulturen gehen z. T. unterschiedlich mit Emotionen um, bewerten diese anders und drücken sie v. a. anders aus. ${ }^{407}$ Die Unterschiede können sich dabei i. E. auf folgende Aspekte beziehen:

„Individualismus: Wird die Bedürfnisbefriedigung des Individuums oder die Rücksichtnahme auf die soziale Umgebung positiver bewertet? [...]

Gefühlskomponente: Werden Emotionen eher als ein privates Phänomen oder als eine hauptsächlich sozial relevante Erfahrung aufgefasst?

Moralische Wertigkeit einzelner Emotionen und situative Einbettung: Welche Emotionen gelten als angemessen in welchen Situationen?

Emotionsregulation: Welche Strategien im Umgang mit Emotionen werden für effektiv und zulässig erachtet?

Emotionsentwicklung und Emotionsausdruck: Wie unterstützt die Bezugsperson, die sehr stark durch ihre kulturelle Herkunft geprägt wird, die Emotionsentwicklung? Welche Formen des Emotionsausdrucks sind üblich?"408

Emotionalität ist wohl zu einem großen Teil gesellschaftlich geprägt (konstruiert) und unterliegt zudem einem historischen Wandel. Einige grundlegende (universale) Komponenten ähneln sich jedoch in den verschiedenen Kulturen und Epochen und sind anscheinend biologisch determiniert. ${ }^{409}$ Selbst hinsichtlich des sprachlichen Ausdrucks scheint es gewisse Universalien zu geben, z. B. bei der Verwendung von Interjektionen und Reduplikationen. ${ }^{410}$

407 Zur Definition von ,Emotion' und verwandten Begriffen wie ,Gefühl', ,Empfindung' und ,Affekt', die in dieser Arbeit weitgehend synonym verwendet werden, vgl. z. B. ORTNER 2014b, 5ff. bzw. ebd., 13ff.; SCHWARz-FRIESEL 2013, 43ff. und VAŇKOVÁ 2014, 11ff. Dort (z. B. ebd., 13) wird u. a. auch zwischen ,Emotionsausdruck' (Zeigen von Emotionen), ,Emotionsbeschreibung' (Sprechen über Emotionen) und ,Emotionserregung' (Emotionalisierung) unterschieden. Ein Überblick über die Forschung zum Thema „Sprache und Emotion“ (mit Berücksichtigung u. a. von Sprechakttheorie / Pragmatik und Sprachfunktionsforschung) findet sich z. B. in ORTNER 2014b, 45ff. Vgl. a. SCHWARZ-FRIESEL 2013, 12ff. Zu Emotionen im antiken Rom (und Griechenland) vgl. z. B. KAZANTZIDIS UND SPATHARAS 2018a (Hoffnung); HARRIS 2018 (Schmerz und Freude); HARRIS 2004 (Wut); CHANIOTIS UND DUCREY 2013 (darin u. a. MUSTAKALLIO 2013 zum Gefühl der Trauer); FULKERSON 2013 (Reue und Schuldgefühl); GRISWOLD UND KONSTAN 2012 (Vergebung); LACOURSE MUNTEANU 2011a (Emotionen in der Literatur mit besonderem Blick auf die Geschlechtsspezifik) und KASTER 2005 (zu den Grundemotionen verecundia, pudor, paenitentia, invidia, fastidium).

408 ORTNER 2014b, 151f. (mit Bezug auf HOLODYNSKI 2006 und HELFRICH 2003). ORTNER 2014b, 152 weist auch auf die Interdependenzen der Faktoren hin: „Teilweise korrelieren diese Faktoren miteinander, z.B. ist in kollektivistischen Kulturen oft auch eine höhere Machtdistanz zu beobachten [...]. " Allgemein bemerkt sie (ebd., 150): „So, wie das Farbspektrum von Sprache zu Sprache höchst unterschiedlich mit Wörtern belegt wird, sind auch die Abstufungen der Emotionalität unterschiedlich fein und von verschiedenen Kategorien geprägt."

${ }^{409}$ Vgl. z. B. ebd., 41 und ebd., 153. Zur Historizität vgl. a. ebd., 160: „Die Regeln [der Emotionalität] unterliegen historischem Wandel und zeigen rollen-, geschlechts-, schicht- und (sub-)kulturspezifische Variation, in denen sich gesellschaftliche Bewertungen von Emotionen ausdrücken. Verstöße, Abweichungen und Abschwächungen sind möglich."

${ }^{410}$ Vgl. z. B. ebd., 188. Zu den Unterschieden beim sprachlichen Ausdruck von Emotionen in verschiedenen Sprachen vgl. a. ebd., 158 (mit Bezug auf PAVLENKo 2005, 117f.). Vgl. außerdem ORTNER 2014b, 164 zu den sozialen und kulturellen Einflüssen: „Interpretationen von Sätzen, Äußerungen und Texten hängen ganz wesentlich an lexikalischen Entscheidungen und semantischen Beziehungen zwischen den einzelnen sprachlichen Elementen. Emotionale Kommunikation ist somit nicht völlig idiosynkratisch, sondern durch soziale und kulturelle Schemata 


\section{Höflichkeit}

Der Umgang mit Emotionen wird auch durch Höflichkeitskonventionen geregelt, die allerdings noch andere Aspekte des gesellschaftlichen Miteinanders betreffen. ${ }^{411}$ Wieweit Höflichkeitsregeln kulturspezifisch sind, ist dabei umstritten. Das bekannte Modell von Brown / Levinson beansprucht bspw., weitgehend universelle Regeln der Höflichkeit bzw. des Face-Managements zu beschreiben. Menschen seien im Rahmen eines allgemeinen Kooperationsprinzips generell bemüht, das Gesicht anderer zu wahren. ${ }^{412}$ Als entscheidende Faktoren werden dabei „degrees of social distance“, „degrees of (vertical) social hierarchy“ und „degrees of impositions" genannt: Je unbekannter man einer anderen Person, je höher deren (gesellschaftlicher) Rang und je größer ein evtl. erbetener Gefallen seien, umso höflicher verhalte man sich tendenziell. ${ }^{413}$ Dieser Universalitätsanspruch wird vielfach in Frage gestellt, indem z. B. darauf hingewiesen wird, dass Höflichkeit durch bestimmte, für eine Gesellschaft spezifische Wertvorstellungen geprägt sei, die mit den ihr jeweils eigenen sprachlichen Mitteln zum Ausdruck gebracht würden. ${ }^{414}$ Brown / Levinson gehen selbst durchaus von sozialen und kulturspezifischen Eigenheiten aus, stellen aber insgesamt fest: „,[...] while the content of face will differ in different cultures (what exact limits are to personal territories, and what the publicly relevant content of personality consists in), we are assuming that the mutual knowledge of members' public self-image or face, and the social necessity to orient oneself to it in interaction, are universal. “415

Davon abgesehen werden noch zahlreiche weitere Kritikpunkte gegen Brown / Levinson vorgebracht - was jedoch genauso für alternative Ansätze gilt. ${ }^{416}$ Ein allgemein anerkanntes Mo-

mitbestimmt. "Zu den Unterschieden beim sprachlichen Ausdruck von Emotionen in verschiedenen historischen Epochen vgl. z. B. ebd., 180: „Historische Texte weisen auch historische Emotionskonzepte, Grammatik, Semantik und Pragmatik auf, was in der Analyse eines Textes, der nicht aus der Gegenwart stammt, berücksichtigt werden muss."

411 Zur Definition von ,Höflichkeit' vgl. z. B. HUANG 2014, 142: „Politeness can be defined as any behaviour including verbal behaviour of an interlocutor to maintain his or her face and that of the individuals he or she is interacting with." Vgl. a. BROWN 2017, 383ff.; NeVALA 2010, 421f. und RoEsCH 2004, 141f. In Bezug auf Höflichkeit als wissenschaftlichem Konzept spricht man von ,second order politeness', die vom alltagssprachlichen Verständnis von Höflichkeit (,first order politeness') unterschieden wird: Vgl. z. B. HUANG 2014, 143 und TERKOURAFI 2012, 618. Zur Höflichkeitsforschung insgesamt vgl. z. B. EHRHARDT 2018; UNCETA GÓMEZ 2018, 10ff. und UNCETA GÓMEZ 2014a, 3ff.; ARCHER 2017; BROWN 2017, 384ff.; DiCKEY 2012b, 313ff.; KUßE 2012, 86f.; NeVAla 2010; Hall 2009, 5ff. und HOPPMANN 2008, 530ff.

412 BROWN UND LEVINSON 2006, 311. Vgl. a. das Kap. „Subsidiäre Illokutionen“ ab S. 54, bes. N. 346.

${ }^{413}$ Vgl. BROWn 2017, 386 bzw. ebd., 387f. Vgl. a. BROWN UND LEVINSON 2006, 319ff.

${ }^{414}$ CATRAMBOne 2016, 174. Vgl. a. ebd., 175 und DiCKEY 2012b, 315. Dazu und zu weiteren Kritikpunkten vgl. außerdem N. 416.

415 BROWN UND LEVINSON 2006, 312. Vgl. a. BROWN 2017, 386ff., bes. ebd., 387f.: „Cross-cultural variability in politeness is attributable to facts of social structure, cultural meaning and cultural value (how hierarchical/egalitarian is the society, how much value do people place on respect and social distance vs brotherhood and conviviality, what kinds of social relationships do they have, how do they define situations and activities and what kinds do they find especially threatening, etc.), but across diverse societies, the same principles are at work producing analogous ways of putting things - communicative styles - in relatively analogous situations (e.g. intimate vs formal)."

${ }^{416}$ Zur Kritik an Brown / Levinson vgl. z. B. EHRHARDT 2018, 287f.; UNCETA GÓMEZ 2018, 18; ARCHER 2017, 386ff.; BROWN 2017, 388ff. und DICKEY 2012b, 313ff. Weitere bedeutsame Vertreter der Höflichkeitsforschung sind u. a. Erving Goffman, Robin Lakoff, Geoffrey Leech, Marina Terkourafi und Richard Watts. In der neueren Forschung stehen u. a. Unhöflichkeit, alltagssprachliche Höflichkeitskonzepte, Beziehungsaspekte sowie die Kulturspezifik 
dell gibt es bislang nicht; alle Theorien haben ihre Stärken und Schwächen. Am weitesten verbreitet, insbesondere auch in der historischen Pragmatik und speziell in der Latinistik, ist nach wie vor das Modell von Brown / Levinson: Es bietet eine umfassende und einfach anzuwendende Grundlage für Höflichkeitsanalysen - zwar nicht für alle, aber doch sehr viele (v. a. westlich geprägte) Kulturen, und das sogar für Sprachen, die man nicht perfekt beherrscht. ${ }^{417}$ So hat z. B. auch Jon Hall ${ }^{418}$ den Ansatz aufgegriffen, allerdings mit Blick auf die Besonderheiten der römischen Gesellschaft modifiziert. In Anlehnung an die Unterscheidung von positiver und negativer Höflichkeit differenziert er eine „affiliative politeness“ zur Herstellung von Nähe und Verbundenheit (z. B. durch Zuneigungsbekundungen) und eine "redressive politeness" zur Abmilderung und Kompensation von FTAs (z. B. durch Begründungen). Ergänzt wird eine dritte Kategorie: die zeremonielle „politeness of respect“ (lat. verecundia), mit der (z. B. durch respektvolle Anredeformen) die soziale Distanz der Kommunikationspartner betont wird. ${ }^{419}$ Gerade den (in Abhängigkeit vom Adressaten variierenden) formellen Höflichkeitsritualen, wie sie für die ,politeness of respect' typisch sind, kommt in der stark hierarchisch geprägten römischen Gesellschaft ein hoher Stellenwert zu. ${ }^{420}$ Höflichkeit gilt dabei nicht nur als Zeichen

und Historizität von Höflichkeit im Mittelpunkt: Vgl. z. B. EHRHARDT 2018, 288ff.; UNCETA GóMEZ 2018, 18; ARCHER 2017, 384f. und ebd., 394f. sowie HUANG 2014, $142 \mathrm{ff}$.

417 Vgl. z. B. UNCETA GÓMEZ 2016a, 268 und RIDEALGH 2016, 150 sowie DICKEY 2016, 201 und ebd., 197f. Vgl. aber auch ebd., 207: „Despite all its drawbacks, Brown and Levinson's framework has some real advantages that allow one to attain genuine insight into particular polite usages, though it did not in this trial [d. h. bei ihrem eigenen Anwendungsversuch] provide the easy shortcut that it is often thought to offer, since extensive scrutiny of data was required in order to employ the theory usefully."

${ }^{418}$ HALL 2009.

${ }^{419}$ Ebd., 8ff. Vgl. a. DICKEY 2016, 204 und DICKEY 2012b, 317f. sowie UNCETA GÓMEZ 2016a, 268f. Zur Unterscheidung von ,redressive politeness' und ,politeness of respect' vgl. z. B. HALL 2009, 15: „[...] the Roman material is best analysed ( $\mathrm{b}$ believe) by drawing a distinction between the more ceremonial politeness of respect, which derives from a broader cultural ethos (that is, the respect owed to individuals according to their age, gender, wealth, political position, and so on), and redressive politeness, which occurs in response to specific face-threatening acts. “ Vgl. a. UNCETA GÓMEZ 2016a, 269: „The division of negative politeness into two categories is similar to the one proposed by Andreas Jucker in various publications [...]. The names given to these two categories are, deference politeness', which Jucker explicitly connects with Watts' [...] , politic behaviour', and , non-imposition politeness'.“ Vgl. außerdem DICKEY 2016, 204 (mit Bezug auf KASTER 2005): „,[...] this category [= politeness of respect bzw. verecundia] draws heavily on the work of Kaster (2005). Although Hall does not explicitly make this comparison, his uerecundia is very similar to Watts's politic behaviour."

${ }^{420}$ Vgl. z. B. HALL 2009, 4. Vgl. a. RIDEALGH 2016, 149f., dessen Ausführungen die besondere Bedeutung der, politeness of respect' als eigene Kategorie für die Analyse von Höflichkeitsaspekten in der Antike unterstreichen: „,...] the modern concept of ,politeness' needs to be better defined when it is applied to the ancient world, especially if the culture or language system under study has no direct terminology or understanding of ,politeness' as it is defined today. This is primarily due to the ancient world having a fixed hierarchical structure, where social power and distance supported interpersonal relationships and were maintained by set linguistic structures. The assessment of such relationships and communicative acts in the ancient world is not fully compatible with modern frameworks of politeness, and so one of the difficulties faced is that when politeness frameworks are too theoretical or reliant on modern concepts and technology, it is not always possible to utilize them in the same way as if a modern language was under review. "Zum (fehlenden) Höflichkeitsbegriff bei den Römern bzw. verwandten Konzepten wie humanitas, urbanitas, dignitas, observantia und verecundia vgl. außerdem HALL 2009, 4 bzw. ebd., 191 sowie UNCETA GómEZ 2019a und UNCETA GóMEZ 2014a, 11, der (unter Verweis auf Watts) auch auf deren Einfluss auf die moderne Höflichkeitstheorie aufmerksam macht (vgl. N. 436). Vgl. des Weiteren GIORGIO 2015, 106 zur Vereinbarkeit von Face-Konzept und (weniger „aggressiver“) antiker sermo-Theorie. 
gegenseitiger Achtung, sondern auch von Bildung und dient v. a. dem Herstellen und Aufrechterhalten von Kontakten. ${ }^{421}$ Hinsichtlich der sprachlichen Realisierung von höflichen Sprechakten sind dabei durchaus Ähnlichkeiten mit unseren modernen Sprachen festzustellen. ${ }^{422}$

\section{Sprechakte}

Jede Kultur bzw. Sprache hat ihre eigenen Ausdrucksmöglichkeiten, sowohl was die grammatische und semantische als auch die pragmatische Ebene betrifft. Im Zusammenhang mit der vorliegenden Arbeit stellt sich dabei insbesondere die Frage, wieweit Sprechhandlungen universell oder historisch und kulturspezifisch geprägt sind. Dies wird durchaus kontrovers diskutiert. $^{423}$

Tendenziell wird den übergeordneten Sprechaktkategorien eher eine universelle Bedeutung zugemessen ${ }^{424}$, jedenfalls sofern diese deduktiv abgeleitet sind und Handlungsfunktionen der menschlichen Kommunikation allgemein zu erfassen versuchen, wie z. B. bei der Klassifikation Searles, also nicht induktiv erschlossen worden sind, wie z. B. bei der Klassifikation Wunderlichs, die nicht so leicht auf andere Sprachen übertragbar ist, weil sie von den syntaktischen Gegebenheiten der deutschen Sprache ausgeht. ${ }^{425}$

In Bezug auf die einzelnen Untermuster wird dagegen häufiger auf kulturspezifische Besonderheiten hingewiesen. Manche Sprechakte seien bspw. nicht in allen Kulturen anzutreffen, einige würden nur in wenigen oder sogar nur einer einzigen Kultur existieren. Insgesamt

\footnotetext{
${ }^{421}$ Zur Funktion von Höflichkeit im antiken Rom vgl. z. B. HALL 2009, 25 und (mit besonderem Bezug auf die politeness of respect) ebd., $191 \mathrm{f}$.

422 Vgl. z. B. ROESCH 2004, 143ff. und DICKEY 2012a, 731.

${ }^{423} \mathrm{Vgl}$. z. B. die ziemlich extreme Auffassung hinsichtlich der Universalität von Sprechakten von Schlieben-Lange: „Meine (zugegebenermaßen starke) These ist: Es gibt keine universellen sprachlichen Handlungen, sondern nur je historisch bestimmte, unterschiedene, konventionalisierte sprachliche Handlungen. [...]." (SCHLIEBEN-LANGE 1976, 114). Sie gesteht eine universalistische Perspektive nur einer allgemeinen (eher sprachphilosophischen) Kommunikationstheorie zu: „Trotzdem ist die universalistische Fragestellung sinnvoll, aber nicht als Beschreibungsmöglichkeit für sprachliche Handlungen, sondern als Frage nach den normativen Sätzen, die Kommunikation regeln, als Fundament für eine Ethik des Sprechens. “ (ebd., 118) und stellt sich damit u. a. gegen die Auffassung von Wunderlich, der „gelegentlich von ,naturwüchsigen“ Sprechakten [rede], ohne daß deren Status genauer erklärt würde." (ebd., 114), und Harald Weydt (vgl. SCHLIEBEN-LANGE U. A. 1979). Vgl. dazu auch JACOBS UND JUCKER 1995, 20. Vgl. außerdem den Verweis in ebd., 19 auf die ebenfalls rigide Position von Wierzbicka (vgl. WIERZBICKA 2003): „[...] different cultures, or one culture at two different points in history, may very well encode a different range of speaker intentions. Wierzbicka [...] goes even further and advocates a kind of neo-Whorfianism, i.e. she believes that speech acts are so culture-specific that we cannot compare them across cultures." Vgl. des Weiteren HUANG 2014, 152ff. (zu „Speech acts and culture“).

${ }^{424}$ Vgl. a. LIEDTKE 2018, 39: „Bei der Diskussion im Spannungsfeld zwischen Universalismus und Kulturspezifik ist es [...] wichtig, die argumentativen Ebenen zu beachten, auf denen sich die Diskussion abspielt. So spricht die Tatsache, dass es kulturspezifische Realisierungen von Sprechakttypen gibt, nicht gegen den universellen Charakter der Typen selbst - sondern setzt diesen mit der Redeweise von ,Ausprägungen' geradezu voraus. Eine radikal kulturrelativistische Sicht würde dann die Universalität der Kategorien selbst bestreiten müssen, etwa derart, dass sich in einer spezifischen Kultur keine Sprechakte des einen oder anderen Typs nachweisen lassen, oder eben in dieser Kultur Sprechakte vorkommen, die es in keiner anderen gibt. Ob dies sich allerdings auf der allgemeinen Ebene der Sprechakttaxonomie mit (mehr oder weniger) fünf Sprechaktklassen zeigen lässt, erscheint zweifelhaft. Kulturspezifische Vorkommnisse (oder Abwesenheiten) von Sprechakttypen lassen sich in der Regel auf einer feinkörnigeren Ebene aufzeigen, unterhalb der Taxonomie, wie sie beispielsweise von J. R. Searle vertreten wurde."

${ }^{425}$ Vgl. z. B. WAGNER 1995, 270 und WAGNER 1997, 24. Zu Wunderlich vgl. a. ebd., 51 sowie WUNDERLICH 1976, 77ff. und ebd., 148ff. Zu Searle bzw. den sprachphilosophischen Klassifikationen allgemein vgl. a. WAGNER 1997, 48ff. Vgl. außerdem PRASALSKI 2010, 18 und SBISÀ 1995, 503.
} 
scheint es aber so zu sein, dass es einen Kern universeller Handlungsmuster (z. B. GRÜSSEN, ERZÄHLEN und ZUSTIMMEN) gibt. ${ }^{426}$ Allerdings können diese sich im Laufe der Zeit verändern, was z. B. ihre Ritualität und die genaue Interpretation betrifft. So haben sich Begrüßungsrituale, die sich ja (in synchroner Sicht) interkulturell häufig ebenfalls stark unterscheiden, (intrakulturell) historisch i. d. R. gewandelt. Einige Handlungsmuster verlieren oder gewinnen an Bedeutung, eine evtl. vorhandene institutionelle Einbindung entfällt oder entsteht neu. Entsprechend können sich auch die Folgen bei der Be- bzw. Missachtung von Regeln im Zusammenhang mit bestimmten Sprechhandlungen ändern, $d$. h. die (zu erwartenden und tatsächlichen) Reaktionen der Adressaten und ggf. weiterreichende Handlungskonsequenzen bzw. Sanktionen. ${ }^{427}$ Am augenfälligsten zeigen sich Unterschiede in der konkreten (sprachlichen) Ausgestaltung von Sprechakten, z. B. im Hinblick auf das Ausmaß an Direktheit bzw. Indirektheit, das in einer bestimmten Kultur üblich ist. Teilweise wird aber auch hier von sprachlichen Universalien ausgegangen. ${ }^{428}$

\section{Textsorten}

Textsorten sind ebenfalls mehr oder weniger stark kulturspezifisch bestimmt: „Besonders ausgeprägt ist das überkulturelle Moment in Texten, die nicht an die Kultur eines Landes gebunden, nicht aus ihr hervorgegangen sind, sondern ,jenseits' von Sprach- und Kulturgrenzen eine eigene Kultur konstituieren [...]. Textsorten, deren Schwerpunkt auf der einzelkulturellen Spezifik liegt, können sich in sehr verschiedenen Einzelaspekten unterscheiden: z. B. Unterschiede in Textlokution oder Textproposition, in Themenentfaltung und Argumentationsweise, Unterschiede in textsortentypischen Sprachhandlungen und schließlich sogar in der Frage, wer die Textsorte realisieren (,benutzen') darf [...]. ${ }^{\text {“429 }}$ Klar ist zudem, dass Textsorten einem historischen Wandel unterliegen, was z. B. ihren allgemeinen Stellenwert, ihre konkrete sprachliche und inhaltliche Ausgestaltung sowie die Häufigkeit bestimmter Formelemente betrifft. ${ }^{430}$ In diachroner Perspektive können zudem jeweils andere Funktionen mehr zum Tragen kommen,

\footnotetext{
${ }^{426}$ Vgl. z. B. LEVINSON 2017, 206: „Is there a finite set of speech act types, and if so how big is it? The answers are that we really don't know. Is the set universal in character? Not in the sense that all speech acts are pan-cultural [...], but it is an open question as to whether there is a pan-cultural core with such plausibly general functions as telling, questioning, greeting, agreeing, or initiating repair. “ Vgl. a. SCHLIEBEN-LANGE U. A. 1979, 73 und WAGNER 1997, 49. Vgl. außerdem LIEDTKE 2018, 39 bzw. N. 424 sowie das Kap. „Antike“ ab S. 11 zu einigen bereits von den alten Griechen und Römern benannten Sprechhandlungsmustern (wie z. B. ERZÄHLEN).

${ }^{427}$ Vgl. z. B. die Ergebnisse der Analyse mittelalterlicher Wörterbücher bei SCHLIEBEN-LANGE 1976, 115ff. und die diachrone Untersuchung der Sprechakte GRÜSSEN und KOMPLIMENT sowie des Nachrichtendiskurses bei JUCKER 2017, 557ff. Vgl. a. WAGNER 1997, 313.

${ }^{428}$ Vgl. z. B. WÜEST 2011, 42 (mit Bezug auf WIERZBICKA 2003 und BLUM-KULKA U. A. 1989) zur größeren Direktheit des Polnischen im Vergleich zum (australischen) Englisch sowie WAGNER 1997, 49: „Alle Sprachen besitzen ein bestimmtes Repertoire an sprachlichen Hinweisen auf Sprechaktkategorien [...]. Auch wenn es in jeder Sprache verschieden sein dürfte, ist aber die Annahme, da ß es in jeder Sprache ein solches Repertoire gibt, wohl universal. [...] Auch die [...] Grundmöglichkeiten der sprachlichen Formung von Sprechakten gehören zu den universalen Annahmen."

${ }^{429}$ FIX 2014, 32f. Vgl. a. HeINEMANN 2000 - 2001c, 515: „Da Textsorten kondensierte Reflexe kommunikativer Aufgaben darstellen, darf man auch von der universellen Geltung zahlreicher Basistextsorten ausgehen, variiert und modifiziert in der praktischen Ausgestaltung durch gesellschaftliche und kulturelle Spezifika einzelner Regionen oder Kulturen [...]." Vgl. außerdem FIX 2014, 31f.; ZHAO 2011 und SANDIG 2006, 481f.

${ }^{430}$ Vgl. z. B. AdAM 1998, 44f. (zu Briefen). Zur Bedeutung von Textsorten für die historische Pragmatik vgl. a. ZHAO 2011, 139; CHeRubim 1980, 16ff. und (mit Bezug auf die pragmatische Briefanalyse) LANGeHEINE 1983b, $204 \mathrm{f}$. Vgl. außerdem Kap. 1.2.1.
} 
wohingegen die übergeordnete Textfunktion häufig bestehen bleibt. Viele Textsorten halten sich auch über einen längeren Zeitraum stabil. Insgesamt kann man eine zunehmende Standardisierung der Textsorten feststellen. ${ }^{431}$

\subsubsection{Historische Pragmatik als eigener Forschungszweig \\ 1.1.2.2.1 Aufgaben und Methoden}

Die im vorangegangenen Kapitel thematisierten sprachlichen Varietäten sind Gegenstand historischer, kulturwissenschaftlicher und kontrastiver Studien, wobei eine eindeutige Zuordnung zu einem bestimmten Wissenschaftsbereich oft nicht möglich ist. Man denke z. B. an eine vergleichende Untersuchung von Höflichkeitsritualen im Griechischen und Lateinischen. Handlungssemantische Arbeiten mit Bezug auf die alten Sprachen werden aber i. d. R. der historischen Pragmatik zugerechnet.

Bei der historischen Pragmatik handelt es sich um einen noch relativ jungen Forschungszweig, der sich in den 1990er Jahren als Subdisziplin der Pragmatik ausgebildet und in den letzten Jahren zunehmend auch in der Klassischen Philologie etabliert hat. ${ }^{432}$ Als übergreifendes Ziel kann „die Erforschung von vergangenen Sprachzuständen und -prozessen [...] in pragmatischer Hinsicht ${ }^{\prime 433}$ gelten. Hauptuntersuchungsgebiet ist neben der pragmatischen Sprachgeschichte die historische Sprachpragmatik, in der grundsätzlich drei Ansätze unterschieden werden können: eine synchrone historische Sprachpragmatik, in welcher der Sprachzustand in einer bestimmten historischen Epoche analysiert wird, eine kontrastive historische Sprachpragmatik, in der verschiedene Sprachstufen einander gegenübergestellt werden, und eine diachrone historische Sprachpragmatik, in der sprachliche Entwicklungen nachgezeichnet werden. ${ }^{434}$

In sprechakttheoretischen und textpragmatischen Arbeiten steht bspw. die Frage nach der Universalität bzw. kulturellen und historischen Bedingtheit von Sprechakten, Sprechaktsequenzen und Textfunktionen im Fokus. Der Wandel und das Verschwinden von bestehenden Sprechakten und Textsorten sowie das Entstehen von neuen werden beschrieben. So können (nur) durch historische Analysen u. a. die Sinnentleerung und Ritualisierung von Sprechakten

\footnotetext{
431 Vgl. z. B. RÜTTEN 2011, $26 f$.

432 Vgl. JUCKER 2018, z. B. ebd., 138: „Als eigenständige Subdisziplin der Pragmatik konstituierte sich die historische Pragmatik in den 1990er Jahren. Einige Philologien, so zum Beispiel die Germanistik, die Romanistik aber auch die Anglistik, verfügen über eine lange Tradition vereinzelter Arbeiten, die man aus heutiger Sicht der historischen Pragmatik zurechnen kann. Andere Philologien, zumal die Altphilologien haben die historische Pragmatik erst in den letzten Jahren für sich entdeckt." Vgl. a. HofFMANN 2018, der in Bezug auf die Latinistik bemerkt, dass es sich bei der Pragmatik um „,,eine Beschreibungsebene [handelt], die relativ spät als autonomer Bereich erkannt wurde“ (ebd., 11), und dass „die Pragmatik erst wenig über Anfänge hinausgelangt ist“ (ebd., 35f.). Einzelne (Vor)Arbeiten finden sich in der Klassischen Philologie allerdings schon vor den 1990er Jahren: VgI. z. B. IURESCIA 2019, 20, die auf erste Untersuchungen bereits Anfang der 1980er Jahre hinweist, sowie den Überblick in Kap. 1.1.3. Vgl. außerdem DenIzOT UND SPEVAK 2017b, 2; JUCKER 2012, 510; RÜTTEN 2011, 13 und MARTíneZ-INSUA $2010,174$.

${ }^{433}$ WAGNER 1997, 91. Vgl. a. die Definitionen in JUCKER 2018, 132 und MARTínEZ-INSUA 2010, 174f. Ausführlicher zum Gegenstandsbereich bzw. den Aufgaben der historischen Pragmatik: JUCKER 2018; JACOBS UND JUCKER 1995, 10ff.; PRESCH 1981, 222ff. und CHERUBIM 1980, 11ff.

${ }^{434}$ Genaueres zu Definition und Gegenstandsbestimmung der genannten Zweige der historischen Pragmatik: JuCKER 2018, 132f. Häufig wird auch zwischen (synchroner) ,pragmaphilology' (oder , historical discourse analysis proper') und ,diachronic pragmatics' unterschieden. Vgl. z. B. JUCKER UND LANDERT 2017, 82ff.; JUCKER UND TAAVITSAINEN 2010, 12ff.; JACOBS UND JUCKER 1995, 4ff. und ebd., 10ff. sowie BRINTON 2010, 285.
} 
und die Standardisierung von Textsorten erklärt werden. ${ }^{435}$ Sie leisten damit einen wichtigen Beitrag zur Sprechakttheorie allgemein und zum linguistischen Verstehen von Texten (in ihrer kommunikativen Funktion) insgesamt, verhelfen aber ebenso zum besseren Verständnis älterer Sprachen bzw. Sprachstufen an und für sich. ${ }^{436}$

Studien im Bereich der historischen Pragmatik bedeuten aufgrund der fehlenden Muttersprachler naturgemäß immer Textarbeit. Diese kann aus traditioneller Textanalyse und -interpretation bestehen, welche sich insbesondere für detaillierte qualitative Untersuchungen einzelner Texte bzw. Textgruppen eignet, oder aus umfassenderen korpuspragmatischen Analysen, mit denen unter Zuhilfenahme computerlinguistischer Programme eine (quantitative) Bearbeitung größerer (elektronischer) Textkorpora möglich ist. ${ }^{437}$ Je nach Art der Daten können außerdem noch weitere Methoden unterstützend zur Anwendung kommen, wie z. B. lexikographische Methoden zur Auswertung von antiken Glossaren oder auch eines modernen Wörterbuchs wie des TLL und soziolinguistische Methoden zur Beurteilung der Mündlichkeit bzw. Schriftlichkeit sprachlicher Äußerungen. ${ }^{438}$

\subsection{Probleme}

Notwendigkeit der Rekonstruktion von Text und Kontext

Bei älteren Texten ist (aufgrund der großen zeitlichen Distanz) - mehr noch als i. A. ohnehin schon - darauf zu achten, sich bei der Analyse nicht von seinem (unzureichend) vorhandenen Vorwissen und eigenen vorgefertigten Sichtweisen unzulässig beeinflussen und zu vorschnellen (Fehl-)Interpretationen verleiten zu lassen. ${ }^{439}$ Was ein Autor ursprünglich mit seinem Text bewirken wollte, wie ihn der eigentliche (intendierte) Adressat auffassen sollte und tatsächlich aufgefasst hat, lässt sich normalerweise nicht einmal für neuere Texte mit Bestimmtheit sagen, wenngleich hier immerhin zuverlässigere Aussagen möglich sind als bei antiken Texten,

\footnotetext{
435 Vgl. z. B. SCHLIEBEN-LANGE 1976, 118.

436 Dagegen Denizot Und SPEVAK 2017b, 3 (mit Verweis auf TRAUGotT 2004): „Unlike historical pragmatics, pragmatic studies of the classical languages aim at describing Greek and Latin phenomena for their own sake: they are not considered part of contrastive studies (comparison with modern varieties of languages [...]), nor of a ,usage-based approach to language change' (Traugott 2004: 538). A comparison is theoretically possible for Ancient Greek but the timespan separating Ancient Greek from its Modern variant makes it difficult from a methodological point of view. The same holds true for a comparison between Latin and the Romance languages." Vgl. aber z. B. GHEZZI UND MolineLLI 2014b und GHEZZI 2016 Zur Höflichkeitsforschung in der Klassischen Philologie vgl. a. RIDEALGH 2016, 152: „Better understanding politeness or behavioural norms of the past is essential to fully understand politeness systems of the modern world; after all, the roots of many modern politeness systems can be found in the ancient world. “ Vgl. außerdem UNCETA GÓMEZ 2014a, 11 bzw. N. 420.

${ }^{437}$ Vgl. z. B. JUCKER 2018, 134f.: „Die Einschränkung auf schriftliche Daten in der historischen Pragmatik hat offenkundige Konsequenzen für die Wahl der Methoden. Experimentelle Methoden der Datengenerierung wie Befragungen, Diskursergänzungsaufgaben oder Rollenspiele stehen selbstredend nicht zur Verfügung. Die historische Pragmatik stützt sich deshalb notwendigerweise auf die Methoden der Textanalyse und -interpretation. Das können qualitative Methoden sein, die der philologischen Tradition folgend auf einer sorgfältigen Lektüre und Analyse einer überschaubaren Textmenge basieren, oder es können quantitative Methoden sein, die auf der computergestützten Auswertung großer Textkorpora beruhen [...].“ Vgl. a. ebd., 138 und JUCKER 2012, 509ff. Zur „Methodologie der Pragmatik" allgemein vgl. außerdem TUCHEN 2018, der u. a. auch den Begriff ,Korpuspragmatik' erläutert und auf die Vorteile moderner Textkorpora aufmerksam macht, die mit vielfältigen kontextuellen Informationen versehen werden, welche eine fundierte pragmatische Analyse erst ermöglichen (ebd., 21). Vgl. dazu auch ARCHER 2010, 385f.

438 Vgl. z. B. JACOBS UND JUCKER 1995, 10.

${ }^{439}$ Vgl. z. B. Grolimund 1995, 124 und (zu historischen Höflichkeitsstudien) ARCHER 2010, 402. Vgl. a. S. 1 f. bzw. N. 3 (zur „Gefahr der Hineininterpretation ex eventu“).
} 
deren Deutung oft nicht sehr weit über „educated guesses “440 hinausgeht. Umso mehr muss man darum bemüht sein, sich möglichst umfassende Kenntnisse über die genauen Entstehens- und originären Rezeptionsbedingungen zu verschaffen. ${ }^{441}$ Auch hinsichtlich einer gesicherten Textgrundlage i. e. S. ist große Sorgfalt geboten. Nur so ist eine angemessene Beurteilung von Äußerungs-, Inhalts- und Handlungsebene möglich.

\section{Datenbasis}

\section{Art der vorhandenen Quellen}

Mangels eines Korrektivs durch native speakers wird eine linguistische Bewertung älterer Texte erschwert. ${ }^{422}$ Zur Rekonstruktion von Text und Kontext muss - neben anderen, archäologischen Zeugnissen - v. a. auf schriftliche Quellen zurückgegriffen werden. ${ }^{443}$ In Frage kommen dabei wissenschaftliche und literarische Werke sowie private Schriften (z. B. Briefe). Die Grenzen zwischen diesen Bereichen sind in der Antike allerdings fließend. So galten bspw. in der vielfach stark literarisch geprägten Geschichtsschreibung ganz andere Standards als in der modernen Geschichtswissenschaft, z. B. bei „direkten Zitaten“, die insbesondere, was den genauen Wortlaut betrifft, nicht unbedingt dem Original entsprechen, v. a. bei mündlichen Zitaten, ganz zu schweigen von erfundenen Reden. Die indirekte Überlieferung antiker Texte ist $u$. a. deshalb unter besonders großem Vorbehalt zu betrachten. Des Weiteren sind auch (metasprachliche) Arbeiten aus dem Bereich der Philologie (Textkritik und -kommentar, Gram-

\footnotetext{
${ }^{440}$ Vgl. z. B. NeVAlA 2010, 440 (mit Bezug auf KASPER 2007 und die Höflichkeitsforschung).

441 Zum Problem des fehlenden Kontextes historischer Äußerungen vgl. z. B. IURESCIA 2019, 21; UNCETA GÓMEZ 2014a, 12 (Höflichkeitsstudien); JUCKER UND TAAVITSAINEN 2010, 20f.; JACOBS UND JUCKER 1995, 19f. (Sprechaktanalysen) und LANGEHEINE 1983b, 204f. (Briefanalysen). HeRRING U. A. 2001a, 3 äußern sich dazu (mit Bezug auf JACOBS UND JUCKER 1995) folgendermaßen: „[...] historical texts tend to come down to us through the ages stripped of their social context. Information about the text producers and intended receivers, their social roles and personal relationships, the physical and social setting of text production and reception, and the goals of the text is notoriously sparse for older texts, making pragmatic and sociolinguistic analyses based on such texts difficult. This leads Jacobs and Jucker (1995:7) to conclude that ,except for the very immediate past, historical pragmatic hypotheses can never be empirically supported'." Vgl. a. STETTER 1991, welcher der Sprechakttheorie eine historische Dimension sogar vollkommen abspricht (ebd., 74 und ebd., 79). Vgl. dazu JACOBS UND JUCKER 1995, 19 und ARCHER 2010, 379, der Stetters Auffassung die etwas optimistischere Sicht von BERTUCCELLI PAPI 2000 entgegensetzt. Zur (unmöglichen) Rekonstruktion von Autorintention und Adressatenrezeption (nicht nur) in historischen Untersuchungen vgl. a. RüTTEN 2011, 24 und PALANDER-ColuIN 2010, 665 sowie NeVALA 2010, 440 (Höflichkeitsstudien). Vgl. außerdem RüHL 2019, 28f., die mit Bezug auf die Interpretation von Ciceros Briefen vom unumgänglichen „Dilemma eines Zirkelschlusses“ spricht: „Die Situation, in der beispielsweise Cicero einen Brief schreibt, muss bekannt sein, damit die Kommunikation analysiert werden kann; allerdings kann die Situation im Prinzip nur aus diesem Brief abgeleitet werden. Freilich ist die Vorgehensweise insofern doch zu rechtfertigen, als Cicero durch seine Äußerungen den Kontext ja gerade auch generiert. Ob dieser der absoluten Wirklichkeit entspricht oder nur der produzierten sozialen Wirklichkeit des Briefes, braucht nicht entschieden zu werden; wichtig allein ist, wie der Gesprächs- resp. Briefpartner diese interpretiert."

442 Vgl. z. B. IURESCIA 2019, 21; Denizot und SPEVAK 2017b, 2; HeRring U. A. 2001a, 3; WAgner 1997, 90 und RISSELAdA 1993, 12.

443 Vgl. a. WAGNeR 1997, 83 (mit Bezug auf das Alte Testament): „Wir können im AT wie in jeder historischen Disziplin den Kontext nur rekonstruieren; die Rekonstruktion erfolgt dabei auf zwei Ebenen: über die Analyse des erzählten Textes und über die Analyse sämtlicher relevanter Daten, die für die Interpretation alttestamentlicher Texte und Traditionen beigezogen werden können (Archäologie, außeralttestamentliche Berichte, Inschriften, Ikonographie u. ä.); beide Wege ergänzen sich in der Forschung. " Für lateinische Texte gelten ähnliche Bedingungen.
} 
matik, Lexikografie), Sprachphilosophie und Rhetorik nicht nach heutigen Maßstäben zu messen, können aber - mit entsprechender Vorsicht gebraucht - durchaus Aufschlüsse über die (sprachlichen) Gegebenheiten der Antike geben.

Repräsentativität und Authentizität der Quellen

Die Datenbasis ist in der Klassischen Philologie zwar um einiges größer und vielfältiger als bei anderen alten Sprachen, im Vergleich zu modernen Sprachen dennoch recht schmal und lückenhaft. ${ }^{444}$ Manchmal sind nicht einmal genauer Autor, Ort oder Zeit der Entstehung eines Textes bekannt. Repräsentativität und Authentizität alter Quellen müssen in jedem Fall kritisch analysiert und bewertet werden.

Die inhaltliche Aussagekraft ist bisweilen dadurch eingeschränkt, dass bestimmte Informationen verloren gegangen oder als nicht überlieferungswürdig eingestuft und unterdrückt worden sind. Im Falle von fam. 14 erfahren wir bspw. nicht, welche Sicht der Dinge Terentia vertritt, da ihre Briefe nicht erhalten sind. Sie zu rekonstruieren ist nur bedingt möglich, nämlich anhand von Textzitaten oder -anspielungen in Ciceros Briefen an sie und andere. ${ }^{455} \mathrm{Hinzu}$ kommen ggf. (bewusste und unbewusste) Darstellungsverzerrungen. So muss bedacht werden, dass unsere Quellen im Wesentlichen nur die (subjektive) Männerperspektive wiedergeben, da kaum Äußerungen antiker Frauen überliefert sind.

Auch die Sprache ist nicht unbedingt repräsentativ für das Lateinische insgesamt. Sie spiegelt vornehmlich den offiziellen Schriftstil einer gebildeten männlichen Oberschicht, und selbst dies nur eingeschränkt, insofern lediglich die Texte einzelner Autoren erhalten geblieben sind. ${ }^{446}$ Es gibt nur wenige Quellen, die eine Beurteilung anderer Varietäten der lateinischen Sprache erlauben. ${ }^{447}$ Zudem sind hier ebenfalls die Unwägbarkeiten der Überlieferungsgeschichte zu berücksichtigen, während derer es i. d. R. zu zahlreichen Textfehlern und -verfälschungen gekommen ist, sodass der erhaltene Text nur bedingt die Originalsprache reflektiert, sondern beeinflusst ist von der Sprache der Kopisten späterer Epochen. ${ }^{448}$

\footnotetext{
${ }^{444}$ So haben Arbeiten bspw. zum Hebräischen (z. B. WAGNER 1997) oder Altbabylonischen (z. B. SALLABERGER 1999) in dieser Hinsicht mit größeren Problemen zu kämpfen. Zum Lateinischen und Altgriechischen vgl. z. B. DENIzOT UND SPEVAK 2017b, 2: „Latin and Greek provide us with substantial texts encompassing various text types from various periods (comedies, tragedies, historical narratives, speeches delivered on various occasions, technical treatises, letters, didactic poetry, etc.). Different text types are linked with various communicative purposes (narrative, argumentative, didactic) and they involve participation of the addressee to a different extent. [...] The extant Latin literary texts date form c. 240 BC to 600 AD."

${ }^{445}$ Vgl. z. B. RICHLIN 2013.

${ }^{446}$ Zu möglichen Problemen durch die Beschränkung auf schriftliche Daten vgl. a. die Einleitung (ab S. 4: „Auswahl des Analysekorpus“). Vgl. außerdem IURESCIA 2019, 21ff.; JUCKER UND LANDERT 2017, 80f.; JUCKER UND TAAVITSAINEN 2010, 7ff.; HERRING U. A. 2001a, 3 sowie DENIZOT UND SPEVAK 2017b, 2f., die u. a. anmerken: „The Latin and Greek texts that came down to us are mainly highly stylized literary texts, which implies considerations about stylistic arrangements (rhythmical or metrical prose, metrics in poetry, etc.). These aspects, text types and literariness, may have some influence on constituent ordering but also on the use of particles or pragmatic markers. Furthermore, our corpora are lacunar in the sense that individual text types are not equally attested for each period; for example, the only substantial Latin dialogical texts are Plautus' and Terence's comedies from the 2nd century BC." (ebd., 3).

${ }^{447}$ Vgl. S. 5, wo z. B. auf die die Bloomberg- und Vindolanda-Tafeln hingewiesen wird.

448 Vgl. z. B. HeRRING U. A. 2001a, 2f.: „,'Text languages' [...] are limited in comparison with modern spoken languages in several respects. [...] Some texts may effectively have been written by multiple authors, e.g. in cases where older manuscripts were copied and modified by later hands [...]. The language of the documents may thus reflect a mix of different linguistic systems, the sources of which remain largely unrecoverable to the analyst."
} 


\subsubsection{Fazit}

Es scheint einige grundlegende pragmatische Universalien zu geben; dennoch sollte man sich bei einer handlungssemantischen Analyse lateinischer Texte gewisser sprach- und kulturspezifischer Varietäten bewusst sein. Unter dem Vorbehalt möglicherweise notwendiger Anpassungen kann man aber wohl ohne allzu große Bedenken von den modernen Pragmatiktheorien ausgehen, zumal unsere moderne Kultur stark von der antiken (römischen) Kultur geprägt ist und uns das Lateinische (als indogermanische Sprache) wohl auch sprachlich näher steht als bspw. der asiatische oder afrikanische Raum.

Die vorliegende Arbeit ist der synchronen historischen Sprachpragmatik zuzuordnen, also auf eine bestimmte vergangene Epoche (die späte römische Republik) bezogen. Auch in anderer Hinsicht ist die sprachliche Varietät beschränkt, insofern die Briefe in fam. 14 einem einzigen Autor entspringen und sich (abgesehen vom gelegentlichen Miteinbezug der Kinder Ciceros) an einen einzigen Adressaten richten. Die Texte sind also, wenn überhaupt, nur sehr begrenzt repräsentativ - für in klassischem Latein formulierte private Familienbriefe eines gebildeten Mannes der römischen Oberschicht in seiner Eigenschaft als Ehemann (und Vater) und als Individuum.

\subsubsection{Pragmatik in der Lateinischen Philologie: Forschungsüberblick}

Je nach Betrachtungsweise divergieren die Meinungen darüber, wie groß die Anzahl pragmatischer Arbeiten in der Klassischen Philologie tatsächlich ist ${ }^{449}$ : Bei welchen Studien handelt es sich überhaupt um pragmatische Arbeiten? Bei welchen nur um Vorarbeiten? Welche sind zwar wichtig für den Bereich der Pragmatik, ihm aber nicht i. e. S. zuzuordnen? Wie sind Arbeiten zu bewerten, die nur unbewusst oder zumindest recht unreflektiert, theoretisch bzw. empirisch wenig fundiert oder nur sehr allgemein pragmatische Phänomene behandeln? Welcher Stellenwert kommt der Pragmatik in einer Untersuchung überhaupt zu? Ist sie entsprechend nicht evtl. eher einer anderen wissenschaftlichen Disziplin zuzuordnen? ${ }^{450}$ Außerdem spielt es eine Rolle, auf welche Forschungsregion man sich bezieht. Der folgende - notwendigerweise unvollständige - Überblick soll einen ersten Eindruck von der Vielfalt und den Möglichkeiten dieses spannenden Forschungsfeldes vermitteln. ${ }^{451}$

\footnotetext{
${ }^{449}$ Vgl. z. B. RICOTTILLI 2009, 123 (mit dem Schwerpunkt Italien): „,[...] la bibliografia sulla pragmatica linguistica o ,pragmalinguistica‘ applicata al latino è ormai estremamente ricca.“ und ebd., 134: „Esiste un ricco filone di studi in cui la linguistica pragmatica (e la linguistica del testo) viene applicata allo studio della lingua latina [...]. " Vgl. a. ALBRECHT 2003, 5. Dagegen z. B. ARWEILER 2010, 199f.: „Latinists engage in the study of sentences and the production of sentences about the sentences they have studied. They work on and with words, meaning, reference, predication, representation, and a whole lot of other notions regarding the use of words and symbols. Given this obsession, it is astonishing to note that the efforts of various disciplines in the 20th century to understand and to analyse language have left comparatively few traces in Latin scholarship. Especially in the different branches of philosophy of language, including speech act analysis, but also linguistics, logic and epistemology, people are studying what are at the same time objects of Latin scholarship and its means of communication. "Vgl. a. FUHRER UND NELIS 2010, 1 und ebd., 6.

450 Vgl. z. B. RICOTTILLI 2009, 134: „[...] va rilevato che negli studi latini in cui viene applicata la considerazione pragmatica non di rado è difficile distinguere in modo netto fra ambito linguistico, ed analisi letteraria e stilistica del testo."

${ }^{451} \mathrm{Vgl}$. a. die Übersichten in ebd. (bes. ebd., 135ff.) und QUETGLAs 2005 (bes. ebd., 581ff.) sowie (zu Höflichkeitsstudien) in UNCETA GÓMEZ 2014a; UNCETA GómEZ 2018 und auf der Internetseite https://www.historicalpoliteness.net/bibliography/index.html (zuletzt geprüft am 12.11.2020). Vgl. außerdem
} 


\subsubsection{1 Ältere (Vor-)Arbeiten}

Bereits lange vor Entstehung der modernen Pragmatik gab es handlungsorientierte Reflexionen und Zugangsweisen zu sprachlichen Äußerungen, wie bereits an anderer Stelle mit Bezug auf das klassische Altertum deutlich geworden ist. Solche finden sich auch in der älteren Philologie bzw. Linguistik der Neuzeit. ${ }^{452}$ In Kommentaren zu antiken Texten, die aktuellen Lesern irgendwie erklärt werden mussten, v. a. aber in (grammatischen) Arbeiten zu Sprache und Stil wird - obschon unbewusst - z. T. eine pragmatische Sichtweise eingenommen. Sogar gewisse Ähnlichkeiten zu Konzepten wie ,Präsupposition' und, indirekter Sprechakt' begegnen einem (z. B. in Hofmanns Werk zur lateinischen Umgangssprache). ${ }^{453}$ Häufig werden pragmatische Phänomene im Zusammenhang mit Stilistik, Syntax (v. a. Satzarten) und Deixis in den Blick genommen, dabei mitunter als eine Art Agrammatikalität oder Inkorrektheit angeführt (z. B. bei Hofmann und in Kühner-Stegmanns Satzlehre). ${ }^{454}$ Einer Arbeit wie bspw. MILlER 1914 („Roman etiquette of the late Republic as revealed by the correspondence of Cicero"), in der Höflichkeitsaspekte und die (bewusste und unbewusste) Berücksichtigung sozialer Faktoren (wie Alter, Beruf, Rang usw.) durch die römischen Briefeschreiber thematisiert werden, liegen letztlich ebenfalls pragmatische und soziolinguistische Erkenntnisse zugrunde. ${ }^{455}$

Kap. 1.2.2.3.2, wo einige Arbeiten zu Ciceros Briefen genannt werden, die auch pragmatische Aspekte berücksichtigen.

452 Vgl. z. B. RICOTTILLI 2009, 122: „Possiamo individuare anche nei contributi relativi alla lingua ed alla letteratura latina studiosi che operavano con strumenti tipicamente pragmatici prima ancora che apparissero teorizzazioni sulla pragmatica linguistica: del resto, la stessa retorica antica aveva un'impostazione che oggi potremmo definire pragmatica." Vgl. a. (in allgemeinerer Sichtweise) CHERUBIM 1980, 12 (mit Bezug auf WUNDERLICH 1970): „In einem Aufsatz von 1970 hat D. Wunderlich zu Recht darauf hingewiesen, daß außer in der Stilistik und in der Rhetorik auch in der historischen Sprachwissenschaft immer schon pragmatische Perspektiven verfolgt wurden [...]." Vgl. außerdem das Kap. „Antike“ (ab S. 11).

453 Vgl. z. B. RicotTILLI 2009, 133 (mit Bezug auf die Erstausgabe 1926 von HofMANN 1978): „[...] già orientata in ottica pragmatica è l'attenzione di Hofmann alle,comunanza di presupposti' fra parlante e ascoltatore (che non sembra molto lontana dal moderno concetto di ,presupposizioni'), nonché l'importanza che egli conferisce, nell'interazione fra parlante e ascoltatore, alla necessità da parte del primo di influire sul secondo (ad es. di persuaderlo a fare qualcosa: si veda a questo riguardo l'analisi delle forme di persuasione e dei performativi come quaeso, oro, rogo, obsecro $\S \S 113-125)$, e l'attenzione agli atti linguistici indiretti (come le frasi esclamative e interrogative in funzione di un'affermazione - $\S \S 65-66-$, le frasi interrogative in funzione di un comando $-\S$ 67 -, le frasi imperative in sostituzione di proibizioni - $\S 68$ ); in questo ambito H. sembra anticipare anche le trattazioni di Austin e di J. R. Searle sugli atti linguistici.“

${ }^{454}$ Vgl. z. B. Quetglas 2005, 575ff. Vgl. a. RISSELADA 1993, 24: „It is interesting to note that most linguists, in describing such properties [= expressive properties of utterances or certain properties of non-declarative sentences], make use of notions that belong to an action perspective, even if they are not explicitly committed to such a perspective. If we take as a random example Kühner-Stegmann's characterization of the imperative mood in Latin, we can find that they repeatedly refer to elements that relate to the performance of a speech act: ,Der Imperativ ist der Modus des unmittelbar ausgesprochenen Willens oder Gewollten, der als Befehl an eine Person gerichtet wird.' $(I, 195)$ Thus unmittelbar ausgesprochenen refers to the way in which the speech act is actually performed, des (...) Willens oder Gewollten refers to the intentions of the speaker, der (...) an eine Person gerichtet wird involves the addressee, and als Befehl is a speech act label." Vgl. außerdem PINKSTER 1996, 247, der von einem nur begrenzten Interesse an pragmatischen Phänomenen in den älteren lateinischen Grammatiken spricht und dazu bemerkt: „[...] ces phénomènes sont souvent présentés comme des écarts (incorrects) de l'expression correcte, en somme, au même titre que des agrammaticalités." Er veranschaulicht seine Aussage anhand von Beispielen aus KüHNER UND STEGMANN 1966 (§ 118) und HofMANN 1978 (in der Ausgabe von 1951).

${ }^{455}$ Vgl. UNCETA GÓMEZ 2014a, 9. 


\subsubsection{Fachdidaktik: Schullektüre und Schul- bzw. Studiengrammatiken}

In die (deutsche) fachdidaktische Literatur bzw. Schullektüre finden pragmatische und sprechakttheoretische Überlegungen bislang nur vereinzelt Eingang. So regt KUHLMANN 2014b in seiner Schulausgabe „Römische Briefliteratur - Plinius und Cicero“ zu einer Interpretation kommunikativer Äußerungen durch Zuordnung zu verschiedenen Funktionstypen an. ${ }^{456}$ Deutlicheren Einfluss hat hingegen eine eher strukturell ausgerichtete Textlinguistik ausgeübt, wie sich in der ausführlichen Theoretisierung und, wie es scheint, erfolgreichen Anwendung entsprechender Methoden zur Texterschließung im Lateinunterricht zeigt. Gelegentlich sind aber auch hier stärker funktionale Herangehensweisen anzutreffen, wie z. B. bei HöHN 1979, die u. a. Textfunktionen und Illokutionspotenziale von den Schülern analysieren lassen will. ${ }^{457}$

Ähnlich sieht die Situation bei den Schul- und Studiengrammatiken aus. Zwar gibt es mit „Interpretatio - Neue Lateinische Textgrammatik" von GLÜCKLICH U. A. 1980 ein frühes Beispiel für eine Grammatik, die konsequent und in großem Umfang die Text- und dabei explizit auch die pragmatische Ebene mit einbezieht. Sie stellt mit ihrem Konzept allerdings eine Ausnahmeerscheinung dar, obgleich Stefan Kipf zur neueren Entwicklung meint: „Insgesamt ist die Text-

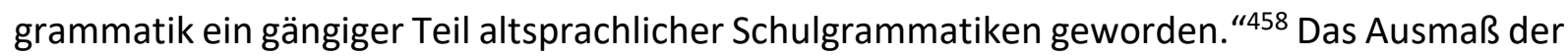
Berücksichtigung textgrammatischer und insbesondere funktionaler bzw. pragmatischer Aspekte ist tatsächlich aber immer noch oft recht begrenzt, und sie ist eher in Grammatiken aus dem nicht-deutschsprachigen Raum festzustellen, die dann in ihrer übersetzten Version weitere Verbreitung auch hier finden. In der (urspr. in Frankreich erschienenen) „Lateinischen

\footnotetext{
${ }^{456} \mathrm{Vgl}$. a. den zugehörigen Erwartungshorizont in KUHLMANN 2014a, 62 bzw. ebd., 65.

457 NICKEL 2014, 2 hält die Anwendung moderner Textanalyseverfahren im Lateinunterricht für mittlerweile üblich. Vgl. a. Touratier 2013, 14. Im „Altsprachlichen Unterricht“ und verschiedenen Sammelbänden sind zu diesem Thema zahlreiche Aufsätze erschienen, wie z. B. „Lineares Dekodieren, Textlinguistik und typisch lateinische Satzelemente“ (GLÜCKLICH 1976), „Zur Anwendung textlinguistischer Verfahren im Lateinunterricht der Sekundarstufe II“ (HÖHN 1979), „Latein und Textlinguistik“ (CONTI UND PROVERBIO 1990) und „Interpretieren heißt Verknüpfen“ (NICKEL 2014). Die praktische Anwendbarkeit auf konkrete Textbeispiele wurde z. B. demonstriert in "Textwissenschaftliche Aspekte der unterrichtlichen Behandlung von Plinius ep. X 96 und 97“ (TöcHTERLE 1980) und ",Ovids ,Weltalter' - Eine textlinguistische Interpretation“ (TÖCHTERLE 1985). Vgl. außerdem neuere Fachdidaktiken wie z. B. KEIP UND DOEPNER 2014 (bes. ebd., 81ff. zu „,̈bersetzung und Texterschließung“). Der Nutzen textlinguistischer Methoden für den Lateinunterricht wurde früh erkannt, wenn auch bisweilen etwas skeptisch beurteilt. Vgl. z. B. TÖCHTERLE 1985, 4: „Der große Tübinger Sprachwissenschaftler E. Coșeriu stellt in seiner Einführung zur Textlinguistik fest, daß sie in der einen Weise Interpretation im guten alten Sinn, in der anderen eigentlich nur Ausweitung grammatikalischer Beschreibung über die Satzgrenze hinaus sei. Dies mag den Altphilologen trösten, der beim Betrachten der Publikationsflut zur Textwissenschaft sich vielleicht die bange Frage stellt, ob er sein Geschäft bisher nur sehr unzulänglich, auf einem ungenügenden theoretischen Fundament betrieben habe. In der Tat hat die Altphilologie sowohl in der wissenschaftlichen Beschreibung ihrer Sprachen ganz allgemein und speziell in textrelevanten Disziplinen wie Rhetorik und Stilistik, als auch in der schulischen Übersetzungsarbeit viele Verfahrensweisen der Textlinguistik bereits vorweggenommen. Zur verstärkten und bewußten Hereinnahme textexterner Gesichtspunkte in die Texterklärung war der Lehrer der alten Sprachen schon durch die Distanz von antiker und moderner Welt gezwungen, die Beachtung mancher transphrastischer Phänomene wurde durch die Schwierigkeit der antiken Sprache gefordert und durch das langsame Lesetempo, als deren Folge, ermöglicht. Dennoch läßt sich die Didaktik des altsprachlichen Unterrichts zurecht anregen von neuen Ergebnissen der Textlinguistik, die sich außerhalb unserer altphilologischen Disziplin entwickelt hat, und baut einiges von ihren teilweise doch neuen Methoden in die Unterrichtsarbeit ein." Vgl. a. BLÄNSDORF 2007, 106.

${ }^{458}$ TOURATIER 2013, 14. Insgesamt kommt er aber zu dem Schluss: „Gleichwohl kann nicht die Rede davon sein, dass die altsprachliche Grammatik konzeptionell grundsätzlich geändert wurde: Man kann wohl am ehesten von einer strukturalistischen Anreicherung eines nach wie vor diachron ausgerichteten Systems sprechen." (ebd., 14).
} 
Grammatik“ von Touratier 2013 (Untertitel „Linguistische Einführung in die lateinische Sprache) wird z. B. im Zusammenhang mit der Syntax das Thema-Rhema-Konzept angewendet. In der (urspr. in den Niederlanden erschienenen) „Lateinischen Grammatik“ von PANHUIS 2015 gibt es sogar ein eigenes Kapitel zur „Textlinguistik“, in dem ebenfalls das Thema-Rhema-Konzept Anwendung findet, aber auch der „Text im Kontext “ unter Einbeziehung des „Sprechakts" und die „Funktionen im Text" behandelt werden. ${ }^{459}$ Außerdem werden die „kommunikative Perspektive“ im Zusammenhang mit der Wortstellung und "die emotive und die spezielle Wortstellung" thematisiert. ${ }^{460}$ Die Neubearbeitung von Menges „Lehrbuch der lateinischen Syntax und Semantik“ durch BURKARD UND SCHAUER 2012 wiederum wird ihrem Anspruch, moderne linguistische Erkenntnisse zu berücksichtigen, nur eingeschränkt gerecht, insbesondere was die Pragmatik betrifft. ${ }^{461}$

\subsubsection{Wissenschaftliche Forschung}

Bereits in den 1970er Jahren versuchte Heinz Happ (z. B. HAPP 1976: „Grundfragen einer Dependenz-Grammatik des Lateinischen“), die Valenz- und Dependenzgrammatik in systematischer Weise für die deutsche Latinistik fruchtbar zu machen. Gleichwohl hat die moderne Linguistik in der Wissenschaft des deutschsprachigen Raums bis heute einen schweren Stand. ${ }^{462}$ Entsprechende Forschungsimpulse kommen eher aus dem Ausland. Sie entspringen v. a. dem „Internationalen Kolloquium zur Lateinischen Linguistik“ (ICLL), das zum ersten Mal 1981 in Amsterdam stattfand und seither im zweijährlichen Wechsel in verschiedenen Städten organisiert wird, und dem von Gualtiero Calboli und Pierluigi Cuzzolin herausgegebenen „Journal

\footnotetext{
459 PANHUIS 2015, 239ff. bzw. ebd., 243f. Dabei ist allerdings zu berücksichtigen, dass die Begriffe ,Sprechakt‘ und ,Funktion im Text' hier in einem weiteren Sinne gebraucht werden als in der vorliegenden Arbeit.

460 Ebd., $245 \mathrm{ff}$.

${ }^{461}$ Vgl. z. B. BURKARD UND SCHAUER 2012, XVII: „Diese Orientierung an neueren Forschungsansätzen (die inzwischen gar nicht mehr so neu sind) ist keine Verneigung vor einer Mode, sondern entspringt der Überzeugung, dass mithilfe neuerer Tendenzen der Sprachwissenschaft die lateinische Grammatik einfacher und adäquater zu beschreiben und zu erklären ist. Dadurch wird der Entwicklung in der Linguistik (auch der alten Sprachen) Rechnung getragen und eine Brücke zu den Neuphilologien geschlagen, wo die betreffende Begrifflichkeit längst auch außerhalb der sprachwissenschaftlichen Disziplinen bekannt ist.“ Dagegen HeBERLEIN 2001, 155 (zur Erstausgabe 2000): „Insgesamt ergibt sich nicht der Eindruck, daß der neue Menge mit seinem Anspruch, eine moderne wissenschaftliche Grammatik zu sein, gegen die existierenden (Touratier) und im Erscheinen begriffenen (Pinkster, Reference Grammar) modernen Grammatiken synchroner Ausrichtung einen leichten Stand haben wird. Sein künftiger Platz in der grammatischen Literatur dürfte vielmehr der traditionelle bleiben: Er ist das modernste Glied in der Traditionskette der ,stilistischen Grammatik' und damit das umfassendste Referenzwerk für alle Fragen der deutsch-lateinischen Übersetzung."

462 Vgl. a. HAPP 1976, 333ff. zu Vorarbeiten z. B. von Dressler, Pape-Zifonun, Pinkster, Schmitt-Brandt, Barié, und Zielinski. HofFMANN 2018 nennt außerdem Anton Scherers „Handbuch der lateinischen Syntax“ (SCHERER 1975), „das zwar einen traditionellen Rahmen wahrte, aber erstmals im deutschsprachigen Raum neuere Theorien in größeren Umfang einbezog“ (HOFFMANN 2018, 16), u. a. „sogar ein Kapitel zur Textsyntax“ (ebd., 16) enthält. Er bezeichnet die Arbeit insgesamt als „,konzeptionell eher eine Mischsyntax, die versucht, Altes mit Neuem zu verbinden“ (ebd., 16f.), kommt allerdings immerhin zu dem Schluss: „[...] das Verdienst dieses Buches [liegt] darin, dass hier, kurz vor dem Erscheinen von Happs ,Grundfragen` (1976) zum ersten Mal innerhalb der lateinischen Grammatik die Tesnièrsche Valenztheorie zum Angelpunkt der Syntax gemacht wurde.“ (ebd., 17). Vgl. a. N. 482. Darüber hinaus weist Hoffmann auf noch frühere Studien (zur generativen Grammatik) außerhalb Deutschlands hin, nämlich LAKOFF 1968 und CALBOLI 1972.
} 
of Latin Linguistics“ (JOLL, vorher: „Papers on Grammar“). ${ }^{463}$ Das ICLL wurde von Harm Pinkster initiiert, einem der Hauptvertreter der sog. Amsterdamer Latinistenschule, die insbesondere funktionale Ansätze (in der Tradition Simon C. Diks) verfolgt und zu der u. a. noch Alide Machtelt Bolkestein, Caroline Kroon und Rodie Risselada gehören. In ihren Arbeiten kommt ebenso wie in den Beiträgen zum ICLL und zum JOLL pragmatischen Themen ein großer Stellenwert zu. Auffällig dabei ist jedoch, dass deutsche Wissenschaftler in den betreffenden Gremien kaum vertreten sind und auch sonst offensichtlich nur recht wenige Studien zur Linguistik allgemein und zur Pragmatik im Besonderen aus dem deutschsprachigen Raum stammen. ${ }^{464}$ Die überwiegende Mehrzahl der Arbeiten ist in den Niederlanden, den anglophonen und romanischen Ländern entstanden, wobei einzelne Autoren häufig in verschiedenen Sprachen publizieren, besonders natürlich auf Englisch.

Bei den meisten Arbeiten aus dem Bereich der historischen Pragmatik handelt es sich eher um Resümees und empirische Erprobungen des Bisherigen. Viele weisen zwar durchaus einen hohen Grad an theoretischer Reflexion auf, eigene theoretische Ansätze (wie z. B. in HALL 2009) werden aber nur selten entwickelt. ${ }^{465}$ Die Sprechakttheorie findet ihren Niederschlag v. a. in Höflichkeitsstudien, welche sich zu einem bedeutsamen Schwerpunkt der historischen Pragmatik innerhalb der Klassischen Philologie entwickelt haben. ${ }^{466}$ In dem kürzlich erschienenen Sammelband Denizot Und SPEVAK 2017a („Pragmatic approaches to Latin and Ancient Greek“) sind sprechakttheoretische Untersuchungen und Höflichkeitsstudien folgerichtig zusammengefasst $^{467}$, wobei allerdings zu bemerken ist, dass die Sprechakttheorie mehr als die Analyse von Höflichkeitsaspekten umfasst, ebenso wie die Höflichkeitsforschung nicht nur Sprechaktanalysen beinhaltet. Weitere Schwerpunkte sind der Einfluss pragmatischer Faktoren auf die Wortstellung und die pragmatische Strukturierung von Texten. Demgemäß ist dieses Kapitel nachfolgend in vier Teilabschnitte gegliedert:

\footnotetext{
${ }^{463}$ Vgl. HoffMANN 2018, 12ff., der außerdem den seit 1985 stattfindenden Kongress zum Spät- und Vulgärlatein (,Latin vulgaire - latin tardif“) anführt.

${ }^{464}$ Vgl. z. B. ebd., 14 zum JOLL: „Dass in den beiden 19 Personen umfassenden [die beiden Herausgeber aus Bologna und Bergamo unterstützenden internationalen] Gremien keine einzige Person aus Deutschland ist, ist wohl ein anderes Thema, das eine längere Vorgeschichte hat und hier nicht vertieft werden sollte. " Vgl. a. S. 3f. Außerhalb der Klassischen Philologie sieht die Situation z. T. anders aus. Interessanterweise hat z. B. die Sprechakttheorie in der deutschen Theologie recht früh größere Beachtung gefunden. Vgl. z. B. (zum Alten Testament) WAGNER 1997 sowie (zum Neuen Testament) BICKMANN 1998 und KLEINE 2002.

465 Vgl. a. Denizot und SPEVAK 2017b, 1, die auf HeRRING U. A. 2001b (Ausgabe 2000) verweisen. In der historischen Pragmatik hat es allgemein eine gewisse Zeit bis zum Entstehen umfassenderer Theoretisierungen (vgl. v. a. die Arbeiten von Jucker) gedauert. Die Notwendigkeit historischer Analysen im Bereich der Pragmatik wurde zwar schon recht früh erkannt; es fanden sich allerdings nur wenige weitergehende theoretische Beiträge (v. a. in der Romanistik und Germanistik, aber auch der Geschichtswissenschaft), die zudem recht allgemein und insgesamt unzureichend blieben: Vgl. z. B. PRESCH 1981, 222ff. und JACOBS UND JUCKER 1995, 3ff., wo (neben PRESCH 1981) u. a. (die Erstausgabe 1975 von) SChlieben-LANGe 1979; SCHLIeben-LANGe 1983; WunderliCh 1976 und CheruBim 1980 genannt werden. Vgl. außerdem SCHLIEBEN-LANGE 1976 und SCHLIEBEN-LANGE U. A. 1979 sowie LANGEHEINE 1983b, 204f., der betont, wie wichtig der „Einbezug der historischen Dimension“ bei einer pragmatisch orientierten Briefanalyse" sei. Zu empirischen Studien im Bereich der historischen Pragmatik vgl. z. B. RüTTEN 2011, $13 f$.

${ }^{466} \mathrm{Vgl}$. z. B. ARCHER 2010, 402, der (u. a.) „the utilisation of (im)politeness approaches" als „a recent trend among speech-act analysts" bezeichnet und dazu bemerkt: „That speech acts and facework should overlap is not surprising, of course, given speech acts primarily help us to ,do' things with language and when we ,do' those things we impact upon our interlocutors' and/or our own actions or environment in some way. “ Vgl. a. Kap. 1.1.3.3.4. ${ }^{467}$ Der Band ist in drei Teile unterteilt: „Speech acts“ (einschl. Höflichkeit und Pragmatikalisierung), „New insights into word order" und „Pragmatic interfaces“ (zur Funktion verschiedener Arten von Partikeln).
} 
- Wortstellung (Kap. 1.1.3.3.1)

- Textstrukturierung (Kap. 1.1.3.3.2)

- Sprechakte und Sprechaktsequenzen (Kap.1.1.3.3.3)

- Höflichkeitsaspekte (Kap. 1.1.3.3.4).

Mit dieser Einteilung lassen sich m. E. die zugehörigen Arbeiten am übersichtlichsten zusammenstellen, obwohl klar ist, dass sich die vier Themen in vielerlei Hinsicht überschneiden und die Zuordnungen nur nach den angenommenen Schwerpunkten erfolgen können. Die Wortstellung ist bspw. auch ein Mittel der Textstrukturierung, Sprechaktsequenzen können quasi als das Ergebnis der Textstrukturierung betrachtet werden. Modalität, Abmilderung und Verstärkung wiederum, die unter Kap. 1.1.3.3.4 subsumiert werden, sind eng mit einzelnen Sprechakten verbunden und nicht unbedingt durch Höflichkeitserwägungen beeinflusst.

Zu ergänzen sind noch weitere Themen(aspekte), welche in Zusammenhang mit Pragmatik und Höflichkeitsforschung stehen (können) und die von dieser Systematik nur unzureichend erfasst werden. Dazu gehört u. a. der Einfluss sozialer Faktoren auf die sprachliche Ausgestaltung lateinischer Texte, der bspw. in ADAMS 1984 („Female speech in Latin comedy“) und ADAMS 2013 (,Social variation and the Latin language“), FöGEN 2001 („Spracheinstellungen und Sprachnormbewußtsein bei Cicero“) und BIVILLE 2014 („Lettres de soldats romains") thematisiert wird. ${ }^{468}$ Mit ,Emotionalität bzw. Selbstausdruck und Selbstdarstellung' kann ein weiteres, in jüngerer Zeit florierendes Themengebiet umrissen werden, zu dem u. a. einige umfangreichere Arbeiten über Ciceros Briefe erschienen sind, die pragmatischen Betrachtungen einen mehr oder minder großen Platz einräumen. ${ }^{469}$ Teilweise stehen dabei ebenfalls soziolinguistische Aspekte mit im Fokus, wie z. B. in LACOURSE MUNTEANU 2011a („Emotion, genre and gender in classical antiquity"), die darüber hinaus die Textsortenspezifität von Emotionalität untersucht. ${ }^{470}$

Die genannten Inhaltsbereiche sind also nur schwer voneinander zu trennen und werden entsprechend auch in vielen anderen Arbeiten miteinander verbunden, wie z. B. in HALLA-AHO 2009 („The non-literacy Latin letters - A study of their syntax and pragmatics“), die einen übergreifenden syntaktisch-pragmatischen Ansatz verfolgt, der $u$. a. eine Analyse von Wortstellung, Textkohärenz und Textsorte umfasst, und BARRIOS-LECH 2016 („,Linguistic interaction in Roman comedy"), der die Direktiva und die Rituale bei Eröffnung, Unterbrechung und Beendigung von Gesprächen in der römischen Komödie untersucht und dabei auch Höflichkeitsaspekte und soziale Faktoren berücksichtigt. Erwähnt werden sollten außerdem oder vielmehr ganz besonders einige allgemeinere Werke zur lateinischen Sprache und Grammatik wie auch speziell zur Syntax, z. B. KienPOINTNER 2010 („,Latein-Deutsch kontrastiv - Vom Phonem zum Text“) und ONIGA UND SCHIFANO 2014 (,'Latin - A linguistic introduction) bzW. BAÑOs BAÑOs 2009 („Sintaxis del latín clásico“) und v. a. die Arbeiten von Pinkster, in denen pragmatisch-

\footnotetext{
${ }^{468} \mathrm{Vgl}$. a. die in Kap. 1.1.3.1 erwähnte Studie von Anna Bertha Miller (MILler 1914).

${ }^{469} \mathrm{Vgl}$. Kap. 1.2.2.3.2. Vgl. a. NeVAlA 2010, 419 und LaCourSE Munteanu 2011b, 1: „Studies of ancient emotions have flourished in recent years. In these, expressions of emotion in literature have been seen as reflections of social interactions and values."

$470 \mathrm{Vgl}$. ebd., 1, wo als Untersuchungsthemen „connections between genres and emotions“ und „gender-based peculiarities of emotions" genannt werden.
} 
funktionalen Aspekten ausgiebig Raum gewährt wird, wie z. B. PINKSTER 1988 („Lateinische Syntax und Semantik") und das aktuellere umfassende Grundlagenwerk "The Oxford Latin syntax" (PINKSTER 2015 = OLS), das Kühner-Stegmanns Satzlehre (mit einem anderen Konzept) ersetzen soll, von dem bislang aber nur der erste Band („The simple clause“) erschienen ist, der zweite allerdings kurz vor der Fertigstellung steht. ${ }^{471}$

Arbeiten wie z. B. LAIRD 1999 („Powers of expression, expressions of power - Speech presentation and Latin literature“) und die Aufsätze im Sammelband von FUHRER UND NELIS 2010 („Acting with words - Communication, rhetorical performance and performative acts in Latin literature") lassen sich hingegen deshalb so schwer in eine der drei Kategorien einordnen, weil sie eher rhetorisch-literarisch bzw. narratologisch als linguistisch orientiert sind - was im Übrigen auch für einige weitere der gerade genannten Werke (wie die Studien zu Emotionalität und Selbstdarstellung in der römischen Literatur) gilt.

\subsection{Wortstellung}

Die immense Bedeutung pragmatischer Faktoren für die Wortstellung ist mittlerweile unbestritten. ${ }^{472}$ Als "the first systematic study of Latin word order using a pragmatic approach" kann wohl PANHUIS 1982 („The communicative perspective in the sentence - A study of Latin word order") gelten, der zunächst allerdings keinen weitergehenden Einfluss ausübte. ${ }^{473} \mathrm{Ir}$ gendwann setzte aber doch eine größere Forschungswelle ein, und in den nachfolgenden Jahrzehnten sind zahlreiche umfangreichere Arbeiten und Aufsätze zu dem Thema entstanden, wie z. B. DEVINE UND STEPHENS 2006 („Latin word order - Structured meaning and information“) und SPEVAK 2010 („CConstituent order in classical Latin prose“) bzw. JONES 1992 („Subject, topic, given and salient - Sentence-beginnings in Latin“), SOMERS 1994 („Theme and topic - The relation between discourse and constituent fronting in Latin), BOLKESTEIN 1998b (,What to do with topic and focus? - Evaluating pragmatic information“), JONGE 2007 („From Demetrius to Dik Ancient and modern views on Greek and Latin word order“), HofFMANN 2010 (,Latin word order revisited - Information structure of topic and focus“), BAMMANN 2015 („A treebank-based study on Latin word order“), CABRILLANA 2017 („Constituent order in directives with stative

\footnotetext{
${ }^{471}$ Ausführlicher zu BAÑOS BAÑOS 2009 und v. a. PINKSTER 2015 sowie zu weiteren modernen Satzlehren wie der strukturalistisch geprägten „Syntaxe latine“ (TOURATIER 1994), der unvollständigen „Grammaire fondamentale du langue Latin“ (SERBAT 1994-2003) und den diachron ausgerichteten „New Perspectives on Historical Latin Syntax“ (BALDI UNd CuZZolin 2009 - 2011): HoffMANn 2018, 15ff. Vgl. a. Denizot und SPEVAK 2017b, 5f. Zum Verhältnis von PINKSTER 2015 zu Kühner-Stegmanns Satzlehre vgl. HoffMAnN 2018, 35f., der seine Darlegungen wie folgt zusammenfasst: „Nicht nur die Unterschiede zum Kühner-Stegmann (wie etwa die stärker funktionale Ausrichtung oder die konsequentere Einbeziehung von Semantik und Pragmatik in der OLS), sondern auch die Gemeinsamkeiten (großes Belegmaterial, synchrone Konzeption, Aufteilung in eine Syntax des einfachen Satzes und in eine Syntax des komplexen Satzes, weitgehender Verzicht auf die Einbeziehung außerlateinischen Sprachmaterials) wurden deutlich." Im Übrigen kommt er in Bezug auf die aktuellen Arbeiten zur lateinischen Syntax insgesamt zu dem Schluss: „Eine auf moderne linguistische Theorien gestützte lateinische Syntax ist also weit fortgeschritten, während die Pragmatik erst wenig über Anfänge hinausgelangt ist [...].“

472 Vgl. S. 63.

473 Denizot Und SPeVAK 2017b, 6. Sie verweisen auch auf WeIL 1844 („De l'ordre des mots dans les langues anciennes comparées aux langues modernes - Question de grammaire générale“).
} 
verbs in Latin“) und ToRRego SALCEdo 2017 („Res gestae divi Augusti - Word order and pragmatics of the Latin original“). Hinzu kommen die entsprechenden Kapitel in umfassenderen Arbeiten zur Grammatik und Syntax des Lateinischen. ${ }^{474}$

\subsection{Textstrukturierung}

Das große pragmatische Interesse in neuerer Zeit und die daraus resultierende umfangreiche Forschungsarbeit haben u. a. dazu geführt, dass auch traditionell eher dem Bereich der Syntax und Semantik bzw. Stilistik zugehörige Themen einer Revision unterzogen wurden. ${ }^{475}$ Dazu zählt neben der Wortstellung die Strukturierung von Texten durch bestimmte Partikeln (Konnektoren) sowie (deiktisch und phorisch gebrauchte) Proformen, deren Verwendung in hohem Maße pragmatisch bestimmt ist. ${ }^{476}$ Namentlich Caroline Kroon hat viele Aufsätze zu diesem Themenkomplex verfasst, z. B. KROON 1989 („Causal connectors in Latin - The discourse function of nam, enim, igitur and ergo“), KROON 1994 („Discourse connectives and discourse type - The case of Latin $a t^{\prime \prime}$ ), KROON 2007 („Latin linguistics between grammar and discourse - Units of analysis, levels of analysis“) und KROON 2017 („Textual deixis and the ,anchoring' use of the Latin pronoun hic"). ${ }^{477}$ Weitere Beispiele stammen von Bolkestein ${ }^{478}$, wie z. B. BOLKESTEIN 1994 („Participant tracking in Latin discourse“) und BOLKESTEIN 2001 („Discourse organization and anaphora in Latin"), und anderen Autoren, wie z. B. ORLANDINI UND POCCETTI 2007 („Semantisch-pragmatische Beziehungen zwischen koordinierenden adversativen Strukturen im Lateinischen und in den Sprachen Altitaliens“) sowie GIORDANO 1989 („La deissi personale nella comunicazione drammatica - Analisi del Miles gloriosus di Plauto"), QUETGLAS 1997 („Aplicaciones de la pragmática al estudio del latín - Los discursos de Cicerón“), JoNG 1998 („Deictic and (pseudo)anaphoric functions of the pronoun iste“) und EDMUNDS 2008 („Deixis in ancient Greek and Latin literature - Historical introduction and state of the question“).

Garceas Aufsatz „Représentation et reproduction du discours dans la correspondance de Cicéron" (GARCEA 2001) liegt ebenfalls ein pragmatischer Ansatz zugrunde, bezieht sich aber mehr auf intertextuelle Verweise. Andere Arbeiten wie z. B. die Beiträge zu den Sammelbänden SHARROCK UND MORALES 2000 (,Intratextuality - Greek and Roman textual relations“) und HARRISON U. A. 2018 (,Intratextuality and Latin literature“) konzentrieren sich zwar hauptsächlich auf intratextuelle Beziehungen, verfolgen aber einen anderen, in diesem Fall eher kognitiven Ansatz und stellen oft zudem weniger einzelne sprachliche Mittel als vielmehr die zugrunde liegenden literarischen Werke (bzw. Teile davon) als geschlossenes Ganzes in den Mittelpunkt. ${ }^{479}$ In den zuvor genannten Arbeiten findet sich eine solche Vorgehensweise meist

\footnotetext{
${ }^{474}$ Vgl. S. 82. Auch der zweite Band der OLS wird ein eigenes Kapitel zur Wortstellung (Kap. 23) und darüber hinaus eines zur „pragmatic structure of clauses and sentences“ (Kap. 22) enthalten (HofFMANN 2018, 34).

475 DeNIZOT UND SPEVAK 2017b, 2.

${ }^{476}$ Vgl. S. 62 (zu Proformen) und S. 63 (zu Konnektoren). Vgl. a. das Kapitel zu „Diskurszusammenhang und Diskursstruktur“ (Kap. 24) in dem bald erscheinenden zweiten Band der OLS (HOFFMANN 2018, 34).

${ }^{477} \mathrm{Zu}$ weiteren Arbeiten von Kroon (nicht nur zu diesem Thema) vgl. http://www.uva.nl/profiel/k/r/c.h.m.kroon/ c.h.m.kroon.html (zuletzt geprüft am 12.11.2020).

478 Eine vollständige Bibliographie der Werke Bolkesteins findet sich in BOLKESTEIN 2002, 7ff.

${ }^{479} \mathrm{Vgl}$. a. folgende Arbeiten (mit Schwerpunkt auf der grammatischen Kohärenz): WüLFING-VON MARTITZ 1993 („,Textlinguistics applied to the Metamorphoses of Ovid“ mit einer Analyse der narrativen Struktur der Metamorphosen); CAMPBELL 2001 („Performing and processing The Aeneid“ mit einer Analyse der syntaktischen Struktur der Aeneis) und BLÄNSDORF 2015 (mit einer textlinguistischen Analyse von kurzen Textausschnitten verschiedener
} 
nur exemplarisch, wie z. B. in KROON 2007, wo die „move structure" einer Passage aus Sallusts Bellum lugurthinum analysiert wird.

Ausführlicher mit übergreifenden rhetorischen Textstrategien in Reden bzw. Predigten setzen sich z. B. Bernaus 2004 („Els ,Sermones ad populum ' de Sant Agustí - Noves perspectives“) und FERRI 2014 („Witness and lawyer in the Roman courts - Linguistic strategies of evasiveness and intimidation in Roman trial debates") auseinander. Die funktionale Textstruktur von Briefen ergründen (mit verschiedenen Schwerpunkten) u. a. MuÑOz MARTín 1991 („El sector central del cuerpo epistolar en Cicerón“) und MUÑOz MARTín 1994 („Estructura de la carta en Cicerón“), FERNÁNDEZ LóPEZ 1994 („Sidonio Apolinar, humanista de la antigüedad tardía - Su correspondencia“), RüHL 2019 („Ciceros Korrespondenz als Medium literarischen und gesellschaftlichen Handelns") sowie HALLA-AHO 2009 (s. o.). Mitunter liegt der Fokus dabei mehr auf der übergeordneten Text- bzw. Brieffunktion als auf der Ebene der Einzeläußerungen, wie dies bspw. auch in THRAEDE 1980 („Zwischen Gebrauchstext und Poesie - Zur Spannweite der antiken Gattung ,Brief') und LUDOLPH 1997 („Epistolographie und Selbstdarstellung“) festzustellen ist.

Die interaktive Struktur von Dramen, d. h. die Verfahren beim turn-taking und bestimmte Sprecherstrategien bzw. Gesprächsmuster, werden z. B. in der gleichfalls schon erwähnten Arbeit von BARRIOS-LECH 2016, aber auch in MüLLER 1997 („Sprechen und Sprache - Dialoglinguistische Studien zu Terenz“), SPEYER 2003 („Kommunikationsstrukturen in Senecas Dramen - Eine pragmatisch-linguistische Analyse mit statistischer Auswertung als Grundlage neuer Ansätze zur Interpretation“) und RICOTTILLI 2010 („Teatro latino e pragmatica della comunicazione") genauer untersucht. Besonders in den Blick genommen werden dabei oft Eröffnung und Beendigung sowie Unterbrechung von Gesprächen. ${ }^{480}$ Den ersten beiden Punkten widmen sich u. a. auch HofFMANN 1983 („Conversation openings in the comedies of Plautus"), ROESCH 2002a („Les stratégies de clôture du dialogue dans les comédies de Plaute“), RoESCH 2005 („L'échec des clôtures du dialogue dans les comédies de Plaute“) und RoESCH 2008 (,Les débuts des dialogues dans la comédie et la tragédie latines“) sowie FerRI 2008 („Politeness in Latin comedy - Some preliminary thoughts“) und BERGER 2017b („Estrategias de la cortesía positiva en la apertura dialógica en Plauto y Terencio“). Nicht auf die Dramatik beschränkt ist bspw. ORLANDINI UND POCCETTI 2008 („Pour une pragmatique du début et de la fin - Stratégies de l'organisation textuelle et argumentative").

Ebenso wenig auf eine bestimmte Textsorte festgelegt sind viele Studien zu den Anredeformen, dem deutlichsten Kennzeichen interaktionaler Texte. ${ }^{481}$ Hier hat sich besonders Eleanor Dickey hervorgetan, von deren Arbeiten für die Latinistik DICKEY 2002 („,Latin forms of address - From Plautus to Apuleius") hervorzuheben ist. Weitere Arbeiten zu dem Thema stammen u. a. von ORLANDINI UND POCCETTI 2010 („Stratégies discursives de non-interpellation et échecs de l'interpellation dans des dialogues latin“), ROESCH 2010 (,Interpellation et enjeux de pouvoir

\footnotetext{
Autoren: Auctor ad Herennium, Horaz, Cicero, Cäsar, Tacitus, Catull, Horaz, Vergil, Persius). Vgl. außerdem N. 457 zu solchen textlinguistischen Analysen im Bereich der Fachdidaktik.

${ }^{480} \mathrm{Vgl}$. a. die Übersicht über Arbeiten zur ",struttura della conversazione“ (,apertura“, „gestione dei turni“, „,cambio di tema“ und „chiusura“) in UNCETA GóMEZ 2018, 18.

${ }^{481}$ Vgl. a. die Übersicht über Arbeiten zu „marcatori allocutivi“ und „address system“ in ebd., 17.
} 
dans les comédies et tragédies latines“), GhezzI UND Molinelu 2015 („Segnali allocutivi di richiamo - Percorsi pragmatici e sviluppi diacronici tra latino e italiano“), MolinelL 2015 („Plural pronouns and social deixis in Latin - A pragmatic development") und MoLINELLI 2018 („SOCiocultural and linguistic constraints in address choice from Latin to Italian"). Die pragmatische Funktion des Vokativs beleuchten z. B. CTIBOR 2017 („Pragmatic functions of the Latin vocative“) sowie - mit besonderem Fokus auf Beleidigungen - MonSERRAT RoIG 2013a („Los vocativos despectivos en Plauto - Análisis de los insultos en la reacción interaccional"), MONSERRAT RoIG 2013b („LOs vocativos plautinos en la impostura de las identidades“), MONSERRAT ROIG 2015a („Insultarse en Roma y en Madrid - Los vocativos despectivos en Plauto y en Alonso de Santos“) und MonSERRAT RoIg 2015b („Otras perspectivas para el análisis lingüístico de Plauto - Los vocativos insultantes en la reacción conversacional“). WATT 1963 („Heus“) und BERGER 2015 (,(Meta)discursive uses of Latin HEUS“) analysieren die Verwendung der Partikel heus. Ricottilli behandelt in ihrem Aufsatz „Tra filologia e semiotica - Ripristino e interpretazione di una formula allocutiva (quid tu? quid uos?)" (RICOTTILLI 1982) die interrogative Wendung quid tu? bzw. quid vos?.

\subsection{Sprechakte und Sprechaktsequenzen}

Sprechakttheoretische Aspekte i. e. S. hat wohl als Erste Bolkestein in ihren Arbeiten zur lateinischen Linguistik behandelt. In BOLKESTEIN 1976a („,Acl and ut-clauses with verba dicendi in Latin“), BOLKESTEIN 1976b („The relation between form and meaning of Latin subordinate clauses governed by verba dicendi“), BOLKESTEIN 1977 („De herkenbaarheid van illocutieve functies in het Latijn“) und BOLKESTEIN 1980 („Problems in the description of modal verbs - An investigation of Latin“) diskutiert sie diese in eher allgemeintheoretischer Weise. ${ }^{482}$

Mittlerweile sind aber auch zahlreiche Arbeiten entstanden, die sich konkret mit einzelnen Sprechakten auseinandersetzen, v. a. Höflichkeitsstudien, in denen sie als FTAs bzw. FFAs für den Sprecher oder für den Adressaten analysiert werden. ${ }^{483}$ In recht prägnanter Weise geschieht dies z. B. in ROESCH 2004 (s. u.) und HALL 2009 (s. u.). Nicht nur bei ihnen ist dabei eine starke Konzentration auf die Expressiva und Direktiva festzustellen. Assertiva spielen nur eine untergeordnete, Kommissiva nahezu gar keine Rolle. Deklarativa werden insofern berücksichtigt, als Eröffnung, Unterbrechung und Beendigung von kommunikativen Kontakten als deklarative Akte zu betrachten sind. Entsprechende Abhandlungen wurden bereits in Kap. 1.1.3.3.2 aufgeführt.

\footnotetext{
${ }^{482}$ VgI. z. B. RISSELADA 1993, 2. Zu ersten (quasi-)sprechakttheoretischen Ansätzen in anderen Arbeiten vgl. a. ebd., 1: „Observations on the communicative functions of utterances are not new in the tradition of Latin linguistics. Studies of particular expression forms often contain useful observations with respect to their use in particular speech acts.“ und ebd., 2 (mit Bezug auf SCHERER 1975 und die englische Ausgabe 1990 von PINKSTER 1988): „Two recent grammars, finally, viz. Scherer (1975) and Pinkster (1990), make a systematic distinction between sentence type, verbal mood, and speech act type, thus providing a framework to discuss the complexity of the relationships that hold between these three concepts." Vgl. a. Kap. 1.1.3.1.

${ }^{483} \mathrm{Vgl}$. die Tabelle in UNCETA GómEZ 2018, 12, in der Arbeiten aus der Latinistik zu FTAs (bzw. FFAs) wie z. B. „,ordini e richieste“, "consigli“, "congratulazioni“, „elogi“, „espressioni di disaccordo o disapprovazione ", "critiche“ und „scuse“ zusammengestellt sind. Vgl. a. die Zuordnung verschiedener Sprechakte zu bestimmten Arten von FTAs in WüEST 2011, 44 (s. N. 346).
} 
Hier wie überhaupt erweist sich, dass Sprechakte oft als Teil umfassenderer Sequenzen in den Blick genommen werden. BERGER 2016, 68 identifiziert in seiner Untersuchung zu Willkommensritualen bei Plautus („Escenas de bienvenida en las comedias de Plauto“) bspw. folgende typische Phasen der Begrüßung nach einer langen Reise (ebd., 68):

a) establecimiento del contacto (llamada) e identificación,

b) saludo bipartito,

c) invitación a cenar,

d) intercambio tipo small talk.

Neben dem eigentlichen Akt des GRÜSSENS ${ }^{484}$ gehört zum Willkommensritual also u. a. das EINLADEN zum gemeinsamen Essen.

Mit Begrüßungen beschäftigt sich auch LETESSIER 1999 („La ,salutatio' chez Plaute - Adaptation ludique d'un rituel social“). Darüber hinaus existieren zahlreiche Studien speziell zu den Grußformeln, wie z. B. LANHAM 1975 („Salutatio formulas in Latin letters to 1200 - Syntax, style, and theory“), POCCETTI 2010 („Greeting and farewell expressions as evidence for colloquial language") und Torrego SALCEDo 2013 („lubeo saluere - una forma de saludo con directivo léxico“). ${ }^{485}$ In Berger 2017a („Bendecir para saludar en Plauto - Redistribución de la función pragmática") wird die Entwicklung bzw. (Re-)Pragmatikalisierung von Formeln wie di tibi dent quae velis! und di te ament! nachgezeichnet, die zum GRÜSSEN, aber auch zum DANKEN verwendet werden konnten. Die Möglichkeiten, Dank auszudrücken, untersucht außerdem UNCETA GÓMEZ 2010 („La expresión del agradecimiento en la comedia Latina“).

In KOCHOVSKA 2013 („Expressing congratulations in Latin - The case of Cicero's correspondence“) und UNCETA GÓMEZ 2016a („Congratulations in Latin comedy - Types and functions“) geht es dagegen um dem Akt des GRATULIERENS. Lobende Sprechhandlungen wie SCHMEICHELN und KOMPLIMENT ÄUSSERN analysieren z. B. LÓPEZ LóPEZ 2012 („El preludio de la risa o el llanto (I) - Expresiones de halago y requiebro en los tragediógrafos y comediógrafos fragmentarios latinos“), LATEINER 2013 („Gendered and gendering insults and compliments in the Latin novels“) und UNCETA GómEz 2019b („I complimenti e il loro contributo all'espressione della cortesia linguistica nelle commedie di Plauto“). Lateiner bezieht zudem den entgegengesetzten Sprechakt BELEIDIGEN in seinen Aufsatz mit ein. BELEIDIGEN und verwandte Sprechakte wie SCHIMPFEN und FLUCHEN bzw. übergreifende Sprechaktsequenzen wie ,Streiten" haben sich überhaupt als beliebter Forschungsgegenstand entpuppt ${ }^{486}$, wie $u$. a. auch URíA 2007 („The semantics and pragmatics of Ciceronian invective“), Hummel 2008 (,Mala dictaEssai sur la malédiction et la calomnie dans l'Antiquité classique“), KRUSCHWITZ 2012 („How to avoid profanity in Latin - An exploratory study“), DUBREUIL 2013 (,Le marché aux injures à Rome - Injures et insultes dans la littérature latine“), PASETTI 2015 („L'arte di ingiuriare - Stili-

\footnotetext{
${ }^{484}$ Vgl. S. 178, wo begründet wird, warum BEGRÜSSEN und SICH VERABSCHIEDEN nicht als Sprechakte i. e. S. gezählt werden können.

${ }^{485}$ Vgl. a. das Kap. „Briefe im antiken Rom“ ab S. 92.

${ }^{486}$ Vgl. UNCETA GÓMEZ 2018, 15. Er nennt u. a. auch die bereits ältere Arbeit von LILA 1965 („Terms of abuse in Roman comedy“). JUCKER 2018, 133 weist außerdem auf MONTAGU 1967 („The anatomy of swearing“) hin, deren Untersuchung sich auch auf Antike erstreckt.
} 
stica e retorica dell'insulto in Apuleio“), MENCACCI 2016 („Praeter consuetudinem - (Im)politeness e stili comunicativi a Roma“), BORK 2018 („A rough guide to insult in Plautus“) und IURESCIA 2019 („Credo iam ut solet iurgabit - Pragmatica della lite a Roma“) zeigen. Montserrat Roig stellt dabei besonders auf den Vokativ ab (s. Kap. 1.1.3.3.2).

Allgemeiner mit Entschuldigungen befassen sich KRUSCHWITZ UND CLEARY-VENABLES 2013 („How to apologise in Latin - A case study“) and UNCETA GómEz 2014b („Pedir perdón en latín - El acto de habla de la disculpa en las obras de Plauto y Terencio“). Hier geht es meist ebenfalls um mehr als den Akt des SICH ENTSCHULDIGENS an sich, sondern um umfassendere Sequenzen, zu denen u. a. assertive Begründungen und Sprechakte wie ZUGEBEN gehören. Die Bedeutung von Begründungen beim „Konfliktmanagement“ wird u. a. auch durch KRYLOVÁ 2006 („Consensus suggested and demanded - The use and role of enim and ergo in conflict management") verdeutlicht, welche die Rolle von kausalen Partikeln in diesem Zusammenhang beleuchtet. In ähnlicher Weise verbinden sich Assertiva und Expressiva in FERRI 2012 („,How to say no in Latin - Negative turns, politeness and pragmatic variation“), der darlegt, wie Ablehnungen im Lateinischen formuliert werden können.

Grundlegend für die Direktiva schließlich ist in erster Linie die Untersuchung von Risselada zu „Imperatives and other directive expressions in Latin“ (RISSELADA 1993). ${ }^{487}$ Sie behandelt diese Sprechaktkategorie sehr ausführlich und umfassend, wenngleich ihr Ansatz nur bedingt pragmatisch ist. Letztlich konzentriert sie sich v. a. auf lexikalisch-semantische und syntaktische Aspekte der Äußerungsebene direktiver Sprechakte. ${ }^{488}$ Sie stellt sogar Überlegungen zu einer Klassifikation direktiver Sprechakte ${ }^{489}{ }^{48}$, wie sie sich zumindest in Ansätzen aber ebenso in einigen anderen Arbeiten finden, z. B. in NúÑEZ ROMERO-BALMAS 1991a („Hacia una tipología de los actos de habla directiva en latín“) und UNCETA GóMEZ 2014a („La politesse linguistique en latin - Bilan d'une étude en cours": Ebd., 29ff.). ${ }^{490}$ Mit Direktiva beschäftigen sich außerdem RISSELADA 2004 („Actes de langage et rapports sociaux - Les directifs dans Plaute“) und CABRILLANA 2016 („Directives in Latin comedy - Pragmatics, dramatic role and social status“). Bei UNCETA GÓMEZ 2009b („La petición verbal en latín - Estudio léxico, semántico y pragmático“)

\footnotetext{
${ }^{487}$ Vgl. z. B. die Bewertung von DICKEY 2016, 206: „Significant previous work on Latin requests includes that of Rodie Risselada (1993), who analysed Latin directives from the perspective of speech act theory. Her results were based on a corpus of selections from Plautus, Terence, Cicero, and Pliny [...]; although the selections are relatively short and therefore the corpus of data not as large as one might have hoped, her analysis is rigorous and her conclusions generally respected."

${ }^{488} \mathrm{Vgl}$. z. B. RISSELADA 1993, 329: „Although the present study is based on insights revealed by pragmatic theories (such as speech act theory, politeness theory, and discourse analysis) and takes a pragmatic functional category (viz. directive speech acts) as its starting point, it focuses first of all on the various syntactic, semantic, and lexical properties of the expression forms involved that underly their ability to be used in directive utterances. [...] The contribution of the present study to pragmatics is best characterized, therefore, as ,instrumental'."

${ }^{489}$ RISSELADA 1993, 45ff. Vgl. a. RISSELADA 1989, 372. Vgl. außerdem CABRILLANA 2016, 186ff. Risselada unterscheidet „on a descending scale of obligation of compliance, what the speaker says, between ,order,' ,advice,' ,supplication, ',proposal,' ,request, ', invitation,' ,suggestion“ and ,permission. '” (ebd., 186), wobei „it is not always easy to practice a clear cut between the different subtypes of speech act considered“ (ebd., 186). Vgl. N. 1235.

490 Unceta Gómez differenziert die Direktiva nach folgenden Kriterien: „le bénéficiaire de l'action suscitée“ (Unterscheidung von „actes impositifs“ wie „ordres, demandes, prières“ und „actes non-impositifs“ wie "avertissements, conseils, recommandations“), "la possibilité pour le récepteur de refuser“ (Unterscheidung der impositiven Sprechakte nach dem Grad der Optionalität, z. B. „ordre“ vs. „demande“) und „le degré de contrainte“ (z. B. „prières“ bzw. „suppliques“ vs. „demandes“), wobei eine eindeutige Zuordnung von bestimmten Sprechakten nicht immer möglich ist: Vgl. UNCETA GómEZ 2014a, 29ff. Vgl. außerdem UNCETA GóMEZ 2017b, 145.
} 
und in einigen - allerdings mehr auf Einzelaspekte (der Äußerungsebene) bezogenen - Arbeiten wie der von HALLA-AHO 2010 (,Requesting in a letter - Context, syntax and the choice between complements in the letters of Cicero and Pliny the Younger") steht das direktive Untermuster BITTEN im Mittelpunkt. In den Aufsätzen im Sammelband von GAVOILLE UND GUILLAUMONT 2017a („Conseiller, diriger par lettre“) werden verschiedene Handlungstypen nicht-bindender Aufforderungen (wie RATSCHLAG und VORSCHLAG) analysiert. KIENPOINTNER 1998 („Speech act sequences in Latin prose - Questions and answers) studiert Frage-Antwort-Sequenzen im Lateinischen. ${ }^{491}$ In STEPHENS 1985 („Indirect questions in old Latin - Syntactic and pragmatic factors conditioning modal shift") werden indirekte Fragen untersucht. ${ }^{492}$ SCHRICKX 2017 („Polar questions in Latin with and without the enclitic particle -ne“) nimmt die pragmatische Funktion der Fragepartikel -ne genauer unter die Lupe.

\subsection{Höflichkeitsaspekte}

Die große Bedeutung der Höflichkeitsforschung in der Klassischen Philologie wurde bereits mehrfach hervorgehoben. ${ }^{493}$ Sie schlägt sich bspw. in zwei jüngst erschienenen Sonderheften des „Journal of Historical Pragmatics“ (2019: Band 20, Heft 2) bzw. des „Journal of Politeness Research - Language, Behaviour, Culture" (2016: Band 12, Heft 2) nieder, in denen Aufsätze aus ganz verschiedenen altertumswissenschaftlichen Disziplinen zusammengetragen werden, darunter auch der Latinistik. Sogar eine eigene Internetseite („The Historical Politeness Network for Ancient Languages") ist eingerichtet worden, welche "information about the community of academics studying politeness in the ancient world and bibliographical resources for those interested in research in this field" zur Verfügung stellt. ${ }^{494}$

Als Pioniere (in der Latinistik) gelten Eleanor Dickey und Jon Hall, deren Arbeiten teilweise schon an anderer Stelle erwähnt wurden. ${ }^{495}$ Das in HALL 2009 („,Politeness and politics in Cicero's letters") dargelegte Höflichkeitskonzept wurde in Kap. 1.1.2.1.2 im Abschnitt zum Einfluss historischer und kultureller Faktoren auf die „Höflichkeit“ etwas ausführlicher vorgestellt. Hall hat es in mehreren Aufsätzen anhand einiger Cicero-Briefe selbst erprobt, z. B. in HALL 1996

\footnotetext{
${ }^{491}$ Kienpointner bietet u. a. auch eine Typologie möglicher Fragearten, die teilweise Ähnlichkeiten zur Klassifikation von Fragehandlungen in HINDELANG 1981 aufweist: Er unterscheidet „information questions“, „examination and leading questions“, "questions requesting action“, „rhetorical questions“ und „phatic questions“ (vgl. KIENPOINTNER 1998, 67). Vgl. a. PINKSTER 2015, 315ff. und RISSELADA 1993, $36 \mathrm{f}$.

492 Ebd., 1 N. 1 verweist außerdem auf MORRIS 1889; MORRIS 1890a; MORRIS 1890b und HOFF 1979 „on interrogative sentences“; BECKER 1972 (ursprünglich 1873 erschienen); STEPHENS 1985; BODELOT 1987; BODELOT 1990 und BOLKESTEIN 1995 „on indirect questions“ sowie ORLANDINI 1980 „on rhetorical questions“.

${ }^{493}$ Vgl. dazu auch IURESCIA 2019, 25f.; UNCETA GómEZ 2018, 25f. und CATRAMBONE 2016, 173f. Zum allgemeinen Nutzen der Analyse von Höflichkeitsstrategien im Lateinischen vgl. z. B. FERRI 2012, 116: „Firstly, attention to politeness issues is useful to clarify the literal meaning of some passages. Secondly, the study of polite language enhances our understanding of characterization, in dramatic and narrative texts. Thirdly, politeness is important to determine register variation in Latin, that is the need to adapt one's language and style of expression in response to contextual variants, typically social [...], but also pragmatic [...]."

${ }^{494} \mathrm{https://thehistoricalpolitenessnetworkforancientlanguages.wordpress.com/} \mathrm{(zuletzt} \mathrm{geprüft} \mathrm{am} \mathrm{12.11.2020).}$ $495 \mathrm{Vgl}$. z. B. RIDEALGH 2016, 149: „[...] it is only in the past few years that studies focusing on politeness research in the ancient world have become more numerous, further developing the discussion of politeness, facework, and interpersonal relations. However, none of this would have been possible without the pioneering work by scholars such as Deborah Sweeney [...], Jon Hall [...], Eleanor Dickey [...] and Michael Lloyd [...], who were the first in their fields to conduct studies on historical politeness, introducing the concept of politeness studies for the first time into their respective disciplines." Vgl. a. UNCETA GóMEZ 2018, 9, wo außerdem SCHRIJVERS 1993 (ebd., 75ff.) und OLIENSIS 1998 sowie (als weiter zurückliegende Vorarbeit) MILLER 1914 genannt werden.
} 
("Cicero Fam. 5.8 and Fam. 15.5 in the light of modern politeness theory“), HALL 1998 („The deference-greeting in Roman society“), HALL 2005a („Cicero Fam. 16.21 - Roman politeness, and the socialization of Marcus Cicero the Younger“) und HALL 2005b („Politeness and formality in Cicero's letter to Matius (Fam. 11.27)“). Es findet außerdem in Arbeiten anderer Autoren Anwendung, wie z. B. in UNCETA Gómez 2016a (s. o.).

Halls Ansatz liegt das Modell von Brown / Levinson zugrunde, von dem auch die meisten anderen Studien zur Höflichkeit in der Latinistik beeinflusst sind, ohne dass in ihnen jedoch eigene Theorien entwickeln würden, wie z. B. der Aufsatz „La politesse dans la correspondance de Cicéron" von Roesch (ROESCH 2004) oder die Passage zu den Höflichkeitsstrategien in Ciceros Briefen in GIORGIO 2015 („Face contre face“: Ebd., 87ff.). Vereinzelt werden aber durchaus davon abweichende Höflichkeitskonzepte verwendet, wie z. B. das von Leech in BROoKINS 2010 („A politeness analysis of Catullus' polymetric poems - Can Leech's GSP cross the ancientmodern divide?") oder das von Terkourafi in DICKEY 2012b („The rules of politeness and Latin request formulae“). ${ }^{496}$ Hervorzuheben ist darüber hinaus DICKEY 2016 („Politeness in ancient Rome - Can it help us evaluate modern politeness theories?"), die verschiedene theoretische Ansätze (Brown / Levinson, Terkourafi, Watts und Hall) auf ihre Anwendbarkeit für lateinische Texte (Bitten in Ciceros Briefen) hin überprüft hat und zu dem Schluss kommt, dass „the best results are achieved by applying several different frameworks to the same question ". ${ }^{497}$ Eine zielgerechte Auswahl und Anpassung der Konzepte erscheint demnach am erfolgversprechendsten. ${ }^{498}$

Wie hoch der Grad der Gesichtsbedrohung durch einen Sprechakt ist, hängt davon ab, wie stark er abgemildert oder verstärkt wird, wobei aber nicht jede Abmilderung mit größerer Höflichkeit und nicht jede Verstärkung mit größerer Unhöflichkeit verbunden sein muss. ${ }^{499}$ Mit diesem Thema befasst sich z. B. BARRIOS-LECH 2016 (s. o.): „Fac amabo - How to soften a command“ (ebd., 115ff.) bzw. „Quin fac! - How to strengthen a command“ (ebd., 134ff.). Mit Abschwächungen von Direktiva (v. a. Bittformeln) beschäftigen sich außerdem u. a. CARNEY 1964 („The words sodes and quaeso in Terentian usage“), RISSELADA 1989 („Latin illocutionary parentheticals“), NúÑEZ ROMERO-BALMAS 1995 („Materiales para una sociología de la lengua latina - Terencio y los modificadores de imperativo“), UNCETA GÓMEZ 2008 („Incidencia de

\footnotetext{
496 Vgl. UNCETA GÓMEZ 2016a, 268 und UNCETA GÓMEZ 2018, 15 sowie KÁDÁr 2016, 292.

497 DICKEY 2016, 218: „In fact, the specific results for the four politeness theories are much less reliable than the more general finding that none of them can be simply applied as a template to tell us, without further effort on our part, how Latin politeness worked. Yet several of the theories have particular strengths that allow them, if judiciously applied in the context of careful examination of evidence, to enhance our understanding. As a result, the best results are achieved by applying several different frameworks to the same question. The idea of using multiple frameworks seems to run counter to the very concept of a theory: on a theoretical level only one of these frameworks can actually be right. But since we cannot actually know for sure which one is right, there is something to be said for following the method that can be empirically demonstrated to be most useful, namely applying multiple frameworks."

${ }^{498} \mathrm{Vgl}$. a. RIDEALGH 2016, 152: „The future for politeness research in ancient languages is to further collaborate across historical disciplines, assessing which framework, or rather frameworks, are most suitable for such a study. It may well be the case that the hindrances of ancient languages, such as incomplete and fragmentary data sets, mean that a new, more robust, framework needs to be developed; one which can accommodate so many different historical, social and cultural variables."

${ }^{499}$ Vgl. a. das Kap. „Indirekte Sprechakte“ ab S. 20 und die Analysen im zweiten Teil dieser Arbeit. Eine Übersicht entsprechender Arbeiten in der Latinistik findet sich bei UNCETA GómEZ 2018, $16 f$.
} 
factores pragmáticos en la evolución semántica del verbo rogare“), DICKEY 2012a („How to say ,please' in classical Latin“), RosÉn 2009 („Coherence, sentence modification, and sentencepart-modification - The contribution of particles“), MoLINELL 2010 („From verbs to interactional discourse markers - The pragmaticalization of Latin rogo, quaeso"), GHEZZI UND MOLINELLI 2014a („Deverbal pragmatic markers from Latin to Italian (Lat. quaeso and It. prego) - The cyclic nature of functional developments“), GHeZZI UND Molinelu 2016 („Politeness markers from Latin to Italian - Periphery, discourse structure and cyclicity“), GHEZZI 2016 („Marcatori interazionali di cortesia dal latino alle lingue romanze - Nomi e verbi tra morfosintassi e contesto discorsivo“) und FEDRIANI 2017 („Quapropter, quaeso? ,Why, for pity's sake?' - Questions and the pragmatic functions of quaeso, obsecro, and amabo in Plautus"). In UNCETA GómEZ 2009a („Elementos parentéticos en la organización discursiva de la oratoria de Cicerón“) stehen Parenthesen wie si me amas, si tibi placet und si tibi videtur im Fokus. Erwähnenswert sind zudem der Abschnitt zum sprachlichen Ausdruck von Bitten in Ciceros Briefen in GARCEA 2004 (ebd., 162ff.) und das Teilkapitel „Bitt- und Überredungsformeln“ in HOFMANN 1978 (ebd., 127ff.). Nur wenige Arbeiten beziehen sich auf andere Sprechaktkategorien, wie z. B. ScHRIJVERS 1993 („Amicus liber et dulcis - Horace moraliste“: Ebd., 77f.), REINHARDT 2010 („Syntactic colloquialism in Lucretius“: Ebd., 224) und FEDRIANI UND MolINELLI 2013 („Ut ita dicam and cognates - A pragmatic account"), welche die Abschwächung von Assertiva behandeln. Interjektionen werden z. B. in UNCETA GÓMEZ 2012 („Cuando los sentimientos irrumpen - Valores expresivos de las interjecciones primarias en las comedias de Plauto“), UNCETA GóMEZ 2016b („Cuando los sentimientos irrumpen (2) - Análisis de las interjecciones secundarias en las comedias de Plauto“) und UNCETA GómEZ 2017a („Cuando las emociones irrumpen - Análisis comparativo del empleo de las interjecciones en las comedias de Terencio y las tragedias de Séneca“) untersucht. Hinzu kommen einige bereits genannte Arbeiten bzw. einzelne Passagen darin, wie z. B. (zu den Direktiva) AdAMs 1984, RisSELADA 1993, FERRI 2008, UnCETA Gómez 2009b (ebd., 67ff.), Dickey 2012b und CABRILlanA 2016 bzw. (zu den Assertiva) Müller 1997 (ebd., 177ff.) und BARRIOS-LECH 2016 (,,,Pluet cras, ut opinor - How to soften a statement in Latin“: Ebd., 142ff.) sowie (zu Interjektionen) HOFMANn 1978 (ebd., 9ff.) und MülleR 1997. Auf Arbeiten zu den verschiedenen Formen der Anrede, mit der sprachliche Äußerungen ebenfalls intensiviert werden können, wurde bereits in Kap. 1.1.3.3.2 hingewiesen.

Schließlich kann auch der Verbmodus bzw. Modalität allgemein den Höflichkeitsgrad einer Äußerung beeinflussen, wenngleich zu bemerken ist, dass der Gebrauch oft eher durch andere Faktoren bestimmt wird. ${ }^{500}$ Mit Modalität im Lateinischen beschäftigen sich z. B. NúÑEZ ROMERO-BALMAS 1991b („Semántica de la modalidad en latín“) und FRUYT UND Moussy 2002 („,Les modalités en latin“). BOLKESTEIN 1980 (s. o.) geht speziell auf die mit den direktiven Sprechakten verbundene deontische Modalität ein. Weitergehende Diskussionen dazu finden sich außerdem in LÖFSTEDT 1966 („Les expressions du commandement et de la défense en latin et leur survie dans les langues romanes“), VAIREL-CARRON 1975 („Exclamation, ordre et défense Analyse de deux systèmes syntaxiques en latin“) und VAIREL-CARRON 1981 („Les énoncés prohibitifs au subjonctif“). ${ }^{501}$ Der Zusammenhang von Optativ und (zwischen Direktiva und

\footnotetext{
500 Vgl. N. 1228 (zum Gebrauch des Imperativs in den Direktiva).

501 Vgl. RISSELADA 1993, 1f. Sie verweist außerdem auf MORRIS 1897a; MORRIS 1897b und MoRRIS 1897c "on the subjunctive in independent sentences" (RISSELADA 1993, 1 N. 1).
} 
Expressiva anzusiedelnden) ${ }^{502}$ Wünschen ist Thema in MESA SANZ 1998 („El deseo y el subjuntivo - Análisis de los actos de habla y el valor ,optativo' en lengua latina.").

\subsubsection{Fazit}

Viele der angeführten Arbeiten fokussieren sich auf sehr spezielle Teilbereiche der historischen Pragmatik, sei es, dass einzelne sprachliche Mittel oder bestimmte Texte genauer in den Blick genommen werden. Unabhängig von der jeweiligen Zugangsweise zeigen sich dabei immer wieder die vielfältigen Querverbindungen. Dies trifft auf die vorliegende Arbeit ebenfalls zu, die entsprechend zahlreiche Anknüpfungspunkte zu ihnen, aber auch einige Besonderheiten aufweist. Die genannten Studien konzentrieren sich nämlich zumeist nur auf einzelne Sprechaktkategorien oder sogar -untermuster, streben also keine übergreifende Darstellung unter Einbeziehung aller Sprechaktkategorien an. Klassifikationen gibt es nur vereinzelt zu den Direktiva, wobei eine wirklich stringente Definition der Untermuster nur ansatzweise erkennbar ist. Auch sonst werden Sprechakttypen eher intuitiv bestimmt, ohne sie genau von anderen, ähnlichen Typen abzugrenzen. Eine umfassende Typologisierung wie in den Arbeiten der Münsteraner Schule gibt es nicht. Sprechakte und Sprechaktsequenzen werden manchmal nicht genau voneinander getrennt. Ausführlichere Reflexionen zum Verfahren bei der Identifikation einzelner Handlungseinheiten (Sprechakte) finden sich - wie ja auch in den meisten sprechakttheoretischen Arbeiten außerhalb der Klassischen Philologie - erst recht kaum, und wenn, dann eher mit anderer Zielrichtung (vgl. z. B. die Ausführungen zur Linksdislokation in KROON 2007). Nichtsdestotrotz sind die gemachten Vorgaben für den jeweiligen Untersuchungszweck offensichtlich meist ausreichend und die bis jetzt erzielten Ergebnisse in der latinistischen Pragmatik in jedem Fall beeindruckend.

\subsection{Analysekorpus: Ciceros Briefe}

\subsubsection{Briefe im antiken Rom}

\subsubsection{Antike Brieftheorie}

Eine geschlossene Brieftheorie gab es in der Antike nicht, „da man dieser Gattung keine besondere Eigenwertigkeit zubilligte [...]. “503 Eine solche kann nur aus diesbezüglichen Überlegungen in verschiedenen rhetorischen und grammatischen Werken sowie in den Briefen selbst rekonstruiert werden. ${ }^{504}$

\footnotetext{
502 Vgl. S. 28.

503 ManuWald 2009, 13 N. 8. Vgl. a. CAVARZere 1998, 11: „Il fatto è che nel mondo antico non esiste un ,genere“ epistolare. Neppure l'età ellenistica [...] giunse mai a formulare una compiuta teoria del genere epistolare, limitandosi tutt'al più a proporre classificazioni tipologiche basate sul contenuto.“ und GARCíA 1974, 428: „Frente al abundante material de que disponemos para definir la función y la tipología de los discursos retóricos, son escasísimas las indicaciones que los antiguos nos proporcionan respecto al arte de escribir epístolas, de forma que no puede hablarse de un cuerpo coherente de doctrina referida específicamente a esta esfera del quehacer literario." Vgl. außerdem BeRNARDI PERINI 1985, 17f. Zum Stellenwert des Briefes in der antiken Rhetorik vgl. a. MALHERBE 1988, 3: „It is thus clear that letter writing was of interest to rhetoricians, but it appears only gradually to have attached itself to their rhetorical systems. The discussion in Demetrius is an excursus, Cicero makes no room for a systematic discussion of it in his works on rhetoric, and the references in Quintilian and Theon are casual." 504 Vgl. z. B. Manuwald 2009, 13 N. 8; Antón 1996, 111ff.; PenNaCINI 1985, 12f. und García 1974, 428. Vgl. außerdem N. 503. Ausführlich zur antiken Brieftheorie: GIORGIO 2015, 108ff.; CORREA 2013, 21ff.; CORBINELLI 2008 , bes. ebd., 21ff.; WULFRAM 2008, 16ff.; SCHRÖDER 2007, 140ff.; Trapp in Div. 2003, 42ff.; CONRING 2001, 7ff.; KLAUCK 1998, 148ff.; ANTÓN 1996; CUgUSI 1989 - 1991 und CUGUSI 1983, bes. ebd., 27ff.; MALHERBE 1988, bes. ebd., 2ff.; STOWERS
} 


\subsubsection{1 Überblick über die antiken Quellen zur Brieftheorie}

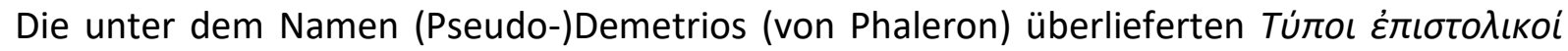
sind ursprünglich wohl bereits in vorchristlicher Zeit in Ägypten entstanden, aber bis ungefähr ins 3. Jh. n. Chr. mehrfach überarbeitet worden. Darin werden (nach rhetorisch-stilistischen Gesichtspunkten) 21 verschiedene Brieftypen unterschieden und durch Beispielbriefe veran-

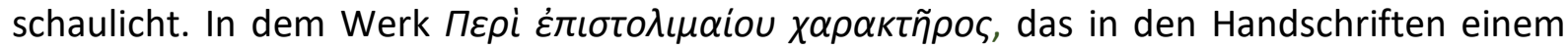
(Pseudo-)Libanios bzw. (Pseudo-)Proklos zugeschrieben wird und etwa aus der Zeit zwischen dem 4. und 6. Jh. n. Chr. stammt, wird diese Liste auf 41 Brieftypen erweitert. Ähnliche Briefsteller gibt es für römische Briefe nicht, wenn man vom Bologna Papyrus 5 aus dem 3. oder 4. Jh. n. Chr. absieht, in dem ungefähr 10 (unvollständig erhaltene) griechisch-lateinische Beispielbriefe gesammelt sind, die sich allerdings auf einem sehr viel niedrigeren Niveau bewegen und bei denen es sich wahrscheinlich um Übungsbriefe eines Schülers handelt. ${ }^{505}$

Auf griechische Briefe beziehen sich auch die zahlreichen Hinweise zur stilistischen Ausgestal-

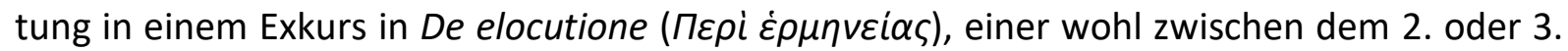
Jh. v. Chr. und dem 1. Jh. n. Chr. verfassten Schrift, welche (ebenfalls fälschlicherweise) Demetrios von Phaleron zugeordnet wurde. Darin wird u. a. auf entsprechende Ausführungen des Artemon von Kassandreia (2. Jh. v. Chr.) referiert, um die dieser eine Ausgabe von Aristoteles-

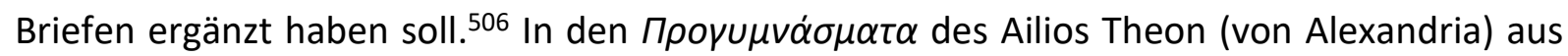
dem 1. Jh. n. Chr. wird das Schreiben von Briefen zum Einüben von Charakterisierungen genutzt. ${ }^{507}$ Was die lateinische Rhetorik betrifft, so ist zum einen hinzuweisen auf ein paar knappe Bemerkungen zum Briefstil bzw. allgemeinen brieftheoretischen Prinzipien bei Theons Zeitgenossen Quintilian, bei Aquila Romanus (3. Jh. n. Chr.) und in einem Abriss De epistolis eines anonymen Verfassers, v. a. aber auf die ausführlicheren Anmerkungen bei lulius Victor (4. Jh. n. Chr.), der den Brief in zwei Anhängen (De sermocinatione und De epistulis) zu seinem Handbuch Ars rhetorica behandelt. ${ }^{508}$

\footnotetext{
1986, bes. ebd., 32ff.; MuÑoz MARTín 1985, bes. ebd., 31ff.; Thraede 1970; Peter 1965, bes. ebd., 13ff.; KoSkENNIEMI 1956 , bes. ebd., $18 \mathrm{ff}$.

505 Genaueres zu den Briefstellern: CoRbinelu 2008, 68f.; KLAUCK 1998, 157ff.; MALherbe 1988, 4 bzw. ebd., $30 \mathrm{ff}$. und ebd., 66ff. (Text); StOWERS 1986, 52ff. und StOWERS 1988; MUÑOz MARTín 1985, 49ff. und KOSKENNIEMI 1956, 54ff. Speziell zu den Túroı દ́rı herbe 1988, 4f. bzw. ebd., 44ff. (Text); CUgusı 1983, 106 und KoskenNIEMI 1956, 59. Die im Pariser Papyrus 63 enthaltenen griechischen Übungsbriefe aus den Jahren 164 / 163 v. Chr. dienten wohl ebenfalls rhetorischen Übungszwecken: Vgl. z. B. ebd., 57ff. MuÑOz MARTín 1985, 54 verweist (mit Bezug auf RABE 1909, 285) im Übrigen darauf, dass in mittelalterlichen Briefstellern möglicherweise durchaus auch antikes Material lateinischer Schriftsteller mitüberliefert ist.

506 Genaueres zu De elocutione: RÜHL 2019, 15f.; GIORGIO 2015, 108ff.; BERNARD 2006, 69f.; KLAUCK 1998, 149ff.; MuÑOz MARTín 1985, 37ff.; THRAEDE 1970, $17 \mathrm{ff}$.

507 Vgl. z. B. MALheRBe 1988, 3 und Muñoz MARTín 1985, 44f. Vgl. a. KoSKENNIEMI 1956, 19, der im Zusammenhang mit der Behandlung von Briefen in rhetorischen Handbüchern außerdem auf entsprechende Bemerkungen bei Nikolaus von Myra (5. Jh. n. Chr.) und späteren Rhetorikern aufmerksam macht.

508 Vgl. z. B. Corbinelli 2008, 22ff.; Malherbe 1988, 3; Muñoz Martín 1985, 43ff.; Cugusi 1983, 27ff.; Peter 1965, 22f. bzw. ebd., 27f. Die beiden Anhänge im rhetorischen Handbuch von lulius Victor gehen möglicherweise auf den Rhetor Titianus (2. Jh. n. Chr.) zurück, wie z. B. MuÑoz MARTín 1985, 45 anmerkt. Der anonyme Abschnitt De epistolis, der in einer Handschrift im Anschluss an die Ars Rhetorica des Fortunacianus überliefert wurde, findet sich (ebenso wie der Text von Iulius Victor) in Div. 1964 (Excerpta rhetorica).
} 


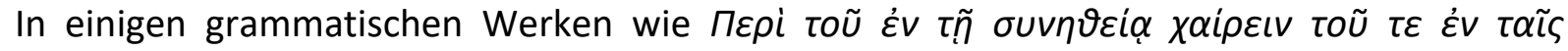

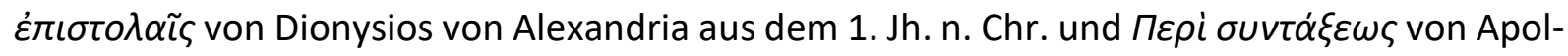
Ionios Dyskolos aus dem 2. Jh. n. Chr. fanden sich wohl bzw. finden sich ebenfalls Bemerkungen zum Briefstil. ${ }^{509}$ Aufschlussreich sind des Weiteren die zahlreichen Exkurse innerhalb der antiken Briefe selbst. Besonders hervorgetan haben sich in dieser Hinsicht bezüglich der griechischen Briefe Philostratos von Lemnos (3. Jh. n. Chr.) und Gregor von Nazianz (4. Jh. n. Chr.). Für die römischen Briefe interessant sind in erster Linie Cicero, Seneca, Plinius, Fronto und Symmachus. ${ }^{510}$

\subsection{Bedeutung der antiken Brieftheorie}

Briefe wurden in der Antike (in eher unsystematischer Weise) v. a. in der Rhetorik in den Blick genommen, da sie aufgrund ihrer Nähe zum Gespräch (vgl. Kap. 1.2.1.3) als eine „rhetorische Form" betrachtet wurden. ${ }^{511}$ Zum einen diente das Schreiben von Briefen im Rahmen rhetorischer Übungen (Progymnasmata) dem Erlernen bestimmter, für das Halten von Reden notwendiger Techniken und Fähigkeiten. Zum anderen wurden Erkenntnisse der Rhetorik (Stillehre) auf die Gestaltung von Briefen übertragen. Es gab also eine wechselseitige Beeinflussung. Bezeichnend ist, dass viele große Briefeschreiber auch professionelle Redner waren. ${ }^{512}$

Allerdings fällt auf, dass die uns erhaltenen Briefe den Bestimmungen und Musterbeispielen der Brieftheorie nicht immer ganz entsprechen. Seneca hält sich z. B. nicht an die in De elocutione festgelegten thematischen Beschränkungen, nach denen in Briefen wissenschaftliche Inhalte und logische Auseinandersetzungen keinen Platz haben. ${ }^{513}$ Auch Cicero geht in seinen Briefen sehr frei mit den brieftheoretischen Vorgaben um und orientiert sich mehr an seinen individuellen Zielen und Bedürfnissen. ${ }^{514}$

Die große Divergenz, die manchen modernen Brieftheoretiker irritiert ${ }^{515}$, lässt sich auf verschiedene Faktoren zurückführen. So sind die inhaltlichen Schwerpunkte der antiken Theoretiker anders gelagert. Ihnen geht es vornehmlich um die sprachlich-stilistische Gestaltung von

${ }^{509}$ CUGUSI 1983, 28 verweist zudem auf PRISC. gramm. 3.149.14. Zu Dionysios von Alexandria und Apollonios Dyskolos vgl. z. B. KoSKENNIEMI 1956, 19 und MuÑoz MARTín 1985, 45. Vgl. außerdem Ax 2006b, 225 (zu Apollonios Dyskolos). Vom Werk des Dionysios von Alexandria erfahren wir in SCHOL. ARISTOPH. Plut. 322.

${ }^{510}$ Vgl. z. B. KOSKENNIEMI 1956, 20: „Die bedeutendsten ,Praktiker' der Brieftheorie sind Philostratos von Lemnos in der ersten Hälfte des 3. Jahrh. n. Chr., der in seinem Brief an Aspasios [...] Richtlinien für den Briefstil gibt, und Gregor von Nazianz, dessen Brief an Nikobulos [...] ein ähnlich konzises Programm des Briefstils enthält." Vgl. ergänzend ebd., 21: „Von den späteren setzen diese Reihe fort Isidoros Pelusiota mit seinem kurzen Brief an Ophelios [...] und der Patriarch Photios mit seinem Brief an den Metropoliten Amphilochios [...]." Vgl. a. MuÑOz MARTín 1985, 44, die außerdem auf Apollonios von Tyana (Brief an den Sophisten Skopelianus) hinweist. Zu den römischen Briefautoren vgl. ebd., 70ff. (Cicero) bzw. ebd., 87ff. (Seneca), ebd., 93ff. (Plinius), ebd., 98ff. (Fronto) und ebd., 104ff. (Symmachus). Neben einigen ausführlicheren Bemerkungen finden sich bei den genannten und anderen Autoren an weiteren Stellen außerdem gelegentliche kürzere Hinweise, v. a. bei Gregor von Nazianz, Cicero und Seneca. KoskENNIEMI 1956, 21 verweist noch auf Basileios d. Gr. und Synesios. Des Weiteren gibt es Hinweise in den verschiedensten anderen Werken (vgl. die Übersicht bei CUGUSI 1983, 27ff.) und in Kommentaren, z. B. zu den Briefen von Aristoteles (vgl. KOSKENNIEMI 1956, 19).

${ }^{511}$ Vgl. z. B. MANUWALD 2009, 13 N. 8 und BERNARD 2006, 68.

512 Vgl. ANTÓN 1996, 106 sowie auch KLAUCK 1998, 127.

513 Vgl. z. B. Ebbeler 2010, 469 bzw. Peter 1965, 20. Natürlich ist dabei zu beachten, dass es sich bei Senecas Briefen nicht um „normale“ Gebrauchsbriefe handelt. Genaueres dazu in Kap. 1.2.1.2.3.

514 Vgl. z. B. BERNARD 2013, 83.

${ }^{515} \mathrm{Vgl}$. z. B. (zum Unterschied zwischen den in den Briefstellern überlieferten Musterbriefen und den erhaltenen realen Briefen) STOWERS 1988, 84f.: „Scholars of ancient epistolography have been impressed by the disparity 
Briefen, um deren funktionale und inhaltliche Typologisierung und (abgesehen von gelegentlichen Hinweisen zu den Grußformeln) eher weniger um strukturelle Aspekte, die hingegen für einige Briefforscher der Neuzeit gerade die Essenz eines Briefes ausmachen. ${ }^{516}$ Andere Wissenschaftler konzentrieren sich zu sehr auf Freundschaftsbriefe und werden damit nicht der viel umfassenderen realen Briefpraxis gerecht. ${ }^{517}$ Dabei ist außerdem zu berücksichtigen, dass auch in der antiken Brieftheorie einige Briefarten eher vernachlässigt werden, wie z. B. amtliche Briefe oder Briefe mit persönlichen Ratschlägen, während andere Brieftypen, wie z. B. scherzhafte Briefe und Informationsbriefe, nicht so häufig vertreten sind, wie ihre Thematisierung in der Brieftheorie vermuten lassen würde. ${ }^{518}$ Des Weiteren muss beachtet werden, dass die antike Brieftheorie (im Gegensatz zur modernen deskriptiven Brieftheorie) je nach Art der Quelle zwar mehr oder weniger präskriptiv-normativ ausgerichtet ${ }^{519}$, letztlich aber sehr allgemeiner Natur ist und lediglich stark vereinfachende und idealisierende Grundlagen und Beispiele liefert, die von den Autoren entsprechend ihren jeweiligen Erfordernissen und stilistisch-rhetorischen Fähigkeiten variiert wurden. ${ }^{520} \mathrm{Im}$ Übrigen ist davon auszugehen, dass das Schreiben von Briefen gemäß üblicher antiker Praxis hauptsächlich durch die Nachahmung $(\mu i \mu \eta \sigma \iota \varsigma)$ von Vorbildern wie z. B. Aristoteles gelernt wurde. ${ }^{521}$

Cicero repräsentiert in diesem Zusammenhang „una specie di ,crocevia' cronologico e stilistico"522: Auf der einen Seite wurde er (direkt oder indirekt) von den rhetorischen Handbüchern, aber auch von allgemeinen Briefkonventionen (mos epistularum) beeinflusst, auf der anderen Seite entwickelt er sich bald zum Ideal eines Briefeschreibers, der eine große Wirkung auf die nachfolgende römische Briefpraxis und Brieftheorie ausübt. ${ }^{523} \mathrm{Nach}$ ihm kommt es zu

between the papyri and the literarily transmitted letters. Some have even denied that the types of the handbooks reflect the reality of practice at all.“ Vgl. a. KOSKENNIEMI 1956, 61ff. („Die Handbücher und die Praxis“). Vgl. außerdem KLAUCK 1998, 162.

516 Vgl. z. B. StOWERS 1988, 85 und Muñoz MARTín 1994, 11. Vgl. außerdem CaVARzere 1998, 11.

517 Vgl. z. B. STOWERS 1988, 85.

518 Vgl. z. B. SCHWITTER 2018, 85; WHITE 2010, 23 und KOSKENNIEMI 1956, $48 f f$.

519 Vgl. z. B. ANTÓN 1996, 108.

${ }^{520}$ Vgl. z. B. STOWERS 1986, 56: „In sum, then, the concept of epistolary types provided the ancient writer with a taxonomy of letters according to typical actions performed in corresponding social contexts and occasions. The types in the handbooks give a sample, in barest outline, of form and language that is appropriate to the logic of the social code in a particular instance. The author, then, could elaborate, combine, and adapt this ideal according to the occasion in view, his purpose and his literary abilities. Rhetorical training provided the letter writer with techniques for the endless elaboration and development of the basic ideal captured in the handbook descriptions. " Vgl. a. StOWERS 1988, 86 und BeRnARDI PeRINI 1985, 18. Vgl. außerdem KosKenNiemI 1956, 53, der den „sehr allgemeinen Charakter“ der griechischen Brieftheorie zu erklären versucht. Des Weiteren ist zu bedenken, dass die antiken Briefsteller sich im Gegensatz zu den anderen Quellen der antiken Brieftheorie häufig eher an Menschen mit geringerer Bildung wandten: Vgl. MALHERBE 1988, 6, aber auch CORBINELLI 2008, 68f. Speziell zu Cicero vgl. außerdem BERNARD 2006, 79.

521 Vgl. STOWERS 1986, 32ff. („Education, art, and professional letter writing“). Zum Vorbildcharakter der Briefe des Aristoteles vgl. z. B. Bernard 2006, 70. Vgl. a. Bernardi PeRINI 1985, $19 \mathrm{f}$.

522 CUGUSI 1998, 188.

${ }^{523}$ Vgl. CUGUSI 1998, 188f. sowie GUGLIELMI 2013, 18. Zum Einfluss der rhetorischen Handbücher und zu den allgemeinen Briefkonventionen, die sich in einigen Briefen Ciceros in Form von „colloquialismi e topoi epistolari di umile livello" bemerkbar machen würden, vgl. a. die weiteren Ausführungen Cugusis (CUGUSI 1998, passim). Vgl. außerdem MALHERBE 1988, 2f.: „The exact degree of Cicero's indebtedness to Greek epistolary theorists is difficult to determine. [...]. Cicero did know rhetorical prescriptions on letters and was probably familiar with handbooks on letter writing. To that extent he does show many points of contact with Greek letter theory [...]. Cicero is an important secondary source for the illumination of epistolary theory. "Vgl. des Weiteren PETER 1965, 21f.; THRAEDE 
einer verstärkten Literarisierung des Briefes, und seiner doch recht freien Textgestaltung wird später zunächst eine zunehmend strengere Brieflehre entgegengesetzt, im Humanismus die Vielfältigkeit des Briefes, wie sie sich in seinen Briefen manifestiert, jedoch wiederentdeckt. ${ }^{524}$ Die antike Brieftheorie wirkt in ihren verschiedenen Erscheinungsformen (als ars dictaminis oder dictandi) jedenfalls bis in die Spätantike und ins Mittelalter fort und beeinflusst sogar noch die (lateinischen und volkssprachlichen) Briefsteller der Renaissance und der frühen Neuzeit. ${ }^{525}$

\subsubsection{Briefklassifikation}

\subsection{Die Vielfältigkeit römischer Briefe}

Erasmus von Rotterdam spricht mit Blick auf die antiken Briefe (insbes. Ciceros) von einer res tam multiplex propeque ad infinitum varia. ${ }^{526}$ Diese Vielfalt äußert sich bereits in den verschiedenen Bezeichnungen für das Phänomen ,Brief' im Lateinischen (epistula, tabella / tabula / codicillus, libellus, scriptum, missum, litterae), welche jeweils andere Aspekte betonen und z. B. auf die Kommunikationsweise (verbal, schriftlich, nicht persönlich bzw. postalisch) hinweisen. ${ }^{527}$ Gleichwohl ist das dabei entstehende Bild unvollständig. In der Realität gab es bspw. neben Wachstafeln noch andere, sogar häufigere Arten der Materialität. ${ }^{528}$ Briefe mögen kürzer als ein ganzes Buch sein, allerdings differieren sie i. E. im Textumfang ganz erheblich. Auch in sonstiger Hinsicht umfassen die römischen Briefe ein sehr breites Spektrum: Verfasser waren u. a. Politiker, Philosophen und Dichter. Sie entstammen zwar meist der männli-

1970, 27f. und Malherbe 1988, 6. Vgl. a. BeRnARD 2006, 68ff. zum Einfluss von Elternhaus, Lehrern, literarischen Vorbildern (Dichtern, Rednern) und anderen Briefschreibern (Plato, Demosthenes, Poseidonius, Panaitios, Philipp von Makedonien, Epikur, Aristoteles, Theopomp). Er macht dort u. a. auf den besonderen Einfluss von De elocutione aufmerksam, wobei er darüber spekuliert, ob der Verfasser einer der Rhetoriklehrer des jungen Ciceros während seines Aufenthaltes in Athen 80 v. Chr. gewesen sein könnte. Neben Cicero entwickelte sich v. a. Plinius d. J. zum Modellautor. Später gesellten sich spätantike Briefeschreiber hinzu: Vgl. z. B. MüLLER 2018,13 bzw. ebd., 15. Zum Modellcharakter der Briefe Ciceros vgl. a. DICKEY 2016, 206 sowie N. 574 und das Kap. 1.2.2.3. Zu Plinius vgl. z. B. GIBSON UND ReES 2013.

${ }^{524}$ Vgl. z. B. GIORGIO 2015, 61. Vgl. a. das Kap. „Grundschema und allgemeine Prinzipien“ ab S. 124 (zum aus dem Mittelalter stammenden rigiden Aufbauschema eines Briefes). Vgl. außerdem THRAEDE 1980, 197ff. (zur Literarisierung des antiken Briefs seit Cicero).

525 Vgl. z. B. MANUWALD 2009, 8.

526 Das vollständige Zitat in De epistolis conscribendis (1502) lautet: Qui in epistolis vnum aliquem characterem vel requirunt, vel praescribunt, id quod ab eruditioribus etiam quibusdam video factum: ii mihi nimirum de re tam multiplici, propeque in infinitum varia nimis anguste atque arcte videntur agere. (ROTTERDAM 1971, 209, 5ff.). Vgl. a. GIORGIO 2015, 61. Vgl. außerdem Müller 2018, 10; CORREA 2013, 64; SCHRÖDER 2007, 136ff.; FERNÁNDEZ LóPEZ 1994, 234 und GARCíA 1974, 429.

${ }^{527}$ Vgl. MANUWALD 2009, 3f. Zur Unterscheidung der Termini epistula (= „lettre comme objet envoyé") und litterae (= „texte“ bzw. „produit d'une énonciation“) vgl. a. BernaRD 2013, 33. Vgl. außerdem SARRI 2017, 22ff. (zu den griechischen Bezeichnungen).

${ }^{528}$ Vgl. z. B. ebd., 74ff. (zu verschiedenen Schreibmaterialien antiker Briefe). Vgl. a. WULfRAM 2008, 19. 
chen gebildeten Oberschicht, es gibt aber ebenso Autoren anderer sozialer Herkunft, und vereinzelt finden sich sogar Briefe von Frauen. ${ }^{529} \mathrm{~V}$. a. aber unterscheiden sich die Briefe nach ihren Handlungsbereichen, Inhalten, Funktionen und ihrer Form (Aufbau und Sprachstil). ${ }^{530}$

\subsection{Möglichkeiten der (wissenschaftlichen) Klassifikation von Briefsorten und Brief- typen}

\section{Brief als Kommunikationsform}

Aufgrund der genannten Unterschiede lassen sich z. B. Briefarten wie privater und öffentlicher Brief, Empfehlungsbrief, Trostbrief oder Liebesbrief voneinander abgrenzen. ${ }^{531}$ Erst auf dieser Ebene kann man i. A. auch von Text- bzw. Briefsorten oder -typen sprechen. ${ }^{532}$ Der Begriff ,Brief' bezeichnet nämlich zunächst einmal nur eine (medial bzw. situativ bestimmte) Kommunikationsform, alternativ zu ,(persönlichem oder telefonischem) Gespräch', ,Fax', ,E-Mail ‘ usw. ${ }^{533}$

\section{Bisherige Klassifikationsansätze (in der modernen Linguistik)}

Es gibt zahlreiche Bemühungen, die als unzureichend empfundenen alltagssprachlichen Kategorisierungen von Briefen bzw. Gebrauchstexten ${ }^{534}$ allgemein, durch wissenschaftlichen An529 Einen Überblick über die Zeugnisse der antiken bzw. römischen Briefkultur findet man z. B. bei MANUWALD
$2009,5 f$. („Historische Entwicklung der ,realen“ Briefkultur“) bzw. ebd., 8ff. („Zeugnisse lateinischer Briefkultur“);
CUGUSI 1983, 151ff. („L'epistolografia latina prima di Cicerone“), ebd., 159ff. („L'epistolografia tardo-repubbli-
cana“) und ebd., 187ff. („Dall'epistolografia tardo-repubblicana all’epistolografia dell'età imperiale“) sowie
GARCÍA 1974, 429ff. („,La epistolografía en la antigüedad“). Vgl. a. PETER 1965. Zu den dokumentarischen Briefen
vgl. außerdem SARRI 2017, 59ff.

530 Vgl. z. B. EbBeler 2010, 465; GARCíA 1974, 436; CORREA 2013, 64 sowie (mit Bezug auf den Brief allgemein bzw. den deutschen Brief) ERMERT 1979, 12 und ebd., 63.

531 Vgl. z. B. BRINKER U. A. 2014, 142.

532 Zur Definition des Begriffs ,Textsorte‘ vgl. z. B. BRINKER 2002, 42: „Auf der Grundlage des sprechakttheoretisch begründeten Textbegriffs können Textsorten als konventionalisierte Muster für komplexe sprachliche Handlungen definiert werden. “ und ebd., 45: „Vor dem Hintergrund des skizzierten Ebenenmodells [vgl. S. 45] lassen sich Textsorten als jeweils typische Verbindungen von kontextuellen (situativen), kommunikativ-funktionalen, thematischen und sprachlichen Merkmalen beschreiben." Insgesamt herrscht ein verwirrendes terminologisches Neben- bzw. Durcheinander: So existieren zahlreiche verwandte Begriffe wie ,Texttyp', ,Textklasse', ,Textmuster' und ,Gattung'. Zu einer möglichen Abgrenzung der Termini vgl. z. B. HEINEMANN 2000 - 2001c, 515. VgI. a. KRIEGHolz UND BÜLOW 2015, 220ff.; GANSEl 2011, 11ff.; WüEST 2011, 89 und ebd., 237; HeINEMANN UND HeINEMANN 2002, 143; HeINEMANN 2000 - 2001c, 519; AdAMZIK 2008, 149f.; Rolf 1993, 43ff. sowie ERMERT 1979, 42 und ebd., $174 \mathrm{ff}$. Vgl. außerdem ORTNER 2014b, 299ff. (zu „emotiven Textsortenspezifika“). In der vorliegenden Arbeit wird der Begriff ,Textart' bzw. ,Briefart' als allgemeiner, unspezifischer Begriff verwendet. ,Textsorten' bzw. ,Briefsorten“ gelten als übergeordnete Begriffe im Sinne der Definition Brinkers, während ,Texttypen' bzw. ,Brieftypen`Varianten innerhalb einer Text- bzw. Briefsortengruppe bezeichnen.

533 Zur Definition des Begriffs ,Kommunikationsform‘ vgl. z. B. BRINKER 2002, 43: „Kommunikationsformen [...] werden durch die besonderen situativen Merkmale der einzelnen Medien begründet, die zur Übermittlung von Texten eingesetzt werden. Für sie ist kennzeichnend, dass sie - im Unterschied zu den Textsorten - in kommunikativ-funktionaler Hinsicht nicht festgelegt sind. "VgI. a. BRINKER U. A. 2014, 140ff., u. a. ebd., 142, wo die Kommunikationsform ,Brief' (zusammen mit ,Mail' und im Unterschied zu ,direktem Gespräch', ,Telefongespräch', ,Rundfunksendung', ,Fernsehsendung' und ,Zeitungsartikel/Buch') folgendermaßen bestimmt wird: „KR [Kommunikationsrichtung]: monologisch - KO [Kontakt]: zeitlich und räumlich getrennt - S [Sprache]: geschrieben“. Vgl. außerdem BICKMANN 1998, 5 und ORTNER 2014b, 303f. sowie (mit speziellem Bezug auf den Brief) BICKMANN 1998, 67; THRAEDE 1980, 183 und ERMERT 1979, 59.

534 Zum Begriff ,Gebrauchstext' bzw. ,Gebrauchsform‘ vgl. z. B. BELKE 1973, 7: „In der bisherigen Diskussion wird der Begriff ,Gebrauchs-' bzw. ,Zweckformen` recht unscharf als Sammelbegriff benutzt, unter dem vor allem Texte subsumiert werden, die mit der herkömmlichen Trias von Epik, Lyrik und Dramatik nicht zu erfassen sind. Dabei 
sprüchen genügende Typologisierungen zu ersetzen. Diese berücksichtigen allerdings durchaus - mehr oder weniger - das Textsortenverständnis der Alltagswelt, da ja am Ende die Wirklichkeit, die durch die konventionellen Bezeichnungen widergespiegelt wird, angemessen beschrieben werden soll. ${ }^{535}$ Die Klassifikation erfolgt meist nach den gleichen Kriterien, jedoch nicht in unsystematischer und bloß intuitiver Weise, sondern strukturiert und objektiv nachvollziehbar. ${ }^{536}$

Den Klassifikationsversuchen liegen z. T. sehr unterschiedliche Konzepte zugrunde. So gibt es z. B. semiotische, kommunikationstheoretische und linguistische Klassifikationen i. e. S. Einige gehen empirisch-induktiv von einer begrenzten Menge ausgewählter Texte bzw. Textsorten aus, andere sind theoretisch-deduktiv bzw. typologisch-ganzheitlich ausgerichtet. Man kann merkmalsorientierte Klassifikationen mit vielen verschiedenen (gleichrangigen) Klassifikationskriterien und Klassifikationen mit übergeordnetem Basiskriterium unterscheiden. Die Kriterien können textintern oder textextern sein. Strukturell-grammatischen und semantisch-inhaltlichen Ansätzen stehen kontextuell-situative und funktional-kommunikative gegenüber. ${ }^{537}$

Dazu ist freilich zu bemerken, dass die einzelnen Kriterien eng miteinander verbunden und für sich genommen z. T. problematisch sind. ${ }^{538}$ Brieftypen lassen sich z. B. kaum sinnvoll nur nach

werden, dem jeweiligen Verständnis von ,literarisch', von ,Gebrauch' bzw. ,Zweck' und ,Form' entsprechend, verschiedenartigste Texte potpourrihaft zusammengebracht." BELKE 1986, 320 schlägt folgende Definition vor: „Unter Gebrauchstexten werden [...] solche Texte verstanden, die nicht, wie poetische Texte, ihren Gegenstand selbst konstituieren, sondern die primär durch außerhalb ihrer selbst liegende Zwecke bestimmt werden." Gebrauchstexte kann man folgendermaßen weiter differenzieren: „1. Als reine Gebrauchsformen, als Gebrauchstexte bzw. expositorische Texte, sind solche Texte anzusehen, die ohne literarische Ansprüche und Zielsetzungen ausschließlich praktisch-okkasionellen Zwecken dienen, z. B. Geschäftsbrief, Protokoll, Rundfunknachricht, Wetterbericht, Bulletin, Gebrauchsanweisung, Gesetzestext, Tagebuch als Faktenjournal. 2. Als literarisierte Gebrauchsformen gelten solche Texte, die literarische Elemente zur Erreichung praktischer Zwecke gezielt einsetzen und ein gewisses Maß literarischer Formung anstreben. [...] 3. Als literarische Gebrauchsformen werden solche Texte bezeichnet, die sich die Möglichkeiten reiner bzw. literarisierter Gebrauchsformen zunutze machen, sie fiktional einsetzen und dadurch ihren Gegenstand erst konstituieren, z. B. Briefroman, Tagebuchroman, fingiertes Tagebuch, fingierter Brief.“ (BELKE 1973, 8). Speziell zu Briefen vgl. a. NICKISCH 1991, $101 \mathrm{ff}$.

${ }^{535} \mathrm{Vgl}$. z. B. BRINKER U. A. 2014, 135: „Wenn sich [...] die ,theoretischen' Textsorten der Wissenschaft zu weit von den ,intuitiven' Textsorten der Alltagswelt entfernen, besteht die Gefahr, dass die linguistische Forschung in diesem Bereich inadäquat wird. “Vgl. a. die Erläuterung der eigenen Ansätze in ebd., 146 und ERMERT 1979, 187. Vgl. außerdem DIMTER 1981 (,Textklassenkonzepte heutiger Alltagssprache) und HEINEMANN 2000 - 2001c, 513ff. bzw. HEINEMANN UND VIEHWEGER 1991, $129 \mathrm{ff}$.

${ }^{536}$ Vgl. z. B. GROLIMUND 1995, 101ff.; AdAMZIK 2008, 146ff. und BRINKER U. A. 2014, 136ff. Vgl. a. ISENBERG 1978 bzW. GANSEL 2011, 10 und ADAMZIK 2008, 150f. Zu den alltagssprachlichen Kategorisierungen vgl. außerdem BRINKER U. A. 2014, 136 (mit Bezug auf DIMTER 1981, 35, ebd., 38ff., ebd., $52 \mathrm{ff}$. und ebd., 94ff.): „Hinsichtlich der zentralen Merkmale, die den alltagssprachlichen Textsortenbegriffen zugrunde liegen, kommt Dimter zu dem Ergebnis, dass die entscheidenden Kriterien im Wesentlichen drei Kategorien angehören, der Kommunikationssituation, der Textfunktion und dem Textinhalt." Zu einer (in dieser Arbeit nicht getroffenen) möglichen Unterscheidung von (hierarchischer) ,Textklassifikation“ (mit der „Dominante des Kommunikationsbereichs") und (nicht-hierarchischer) ,Texttypologisierung' (nach linguistischen Kriterien) vgl. z. B. GANSEL 2011, 11ff.

${ }^{537}$ Ein Überblick über bisherige Klassifikationsvorschläge findet sich z. B. bei HERINGER 2015, 127ff.; KRIEG-HOLz UND BÜLOW 2015, 211ff.; ADAMZIK 2008, 161ff.; WüEST 2011, 2ff.; HEINEMANN 2000 - 2001c, 509ff.; ROLF 1993, 81ff.; ERMERT 1979, 27ff. und BELKE 1973, 37ff. Zu möglichen Klassifikationskriterien allgemein vgl. z. B. KRIEG-HOLz UND BÜLOW 2015, 222ff. und GANSEL 2011.

538 Vgl. Z. B. (allgemein) ORTNER 2014b, 299: „Hingewiesen sei nur darauf, dass die wesentlichen Richtungen der Textsortenlinguistik - formale/sprachstrukturelle, kognitive und pragmatische/funktionale Ansätze - in Wahrheit nicht zu trennen sind. Textgestalt, Formulierungsmuster, Textthema, Textfunktion und situative Aspekte sind 
inhaltlichen Gesichtspunkten einteilen, da von unendlich vielen möglichen Themen auszugehen ist. ${ }^{539} \mathrm{Ob}$ im Gegensatz dazu die Anzahl potenzieller Funktionen begrenzt ist und wieweit sie sich bspw. auf die fünf Sprechaktklassen Searles zurückführen lassen, ist umstritten. ${ }^{540}$ Große Schwierigkeiten bei einer Klassifikation bereiten außerdem die insbesondere für Briefe aus dem persönlichen Bereich charakteristische Multithematizität und Multifunktionalität, weshalb teilweise sogar in Zweifel gezogen wird, dass sich solche Briefe (ähnlich wie auch einige andere Gebrauchstextsorten des Alltags) überhaupt Textsorten i. e. S. zuordnen lassen. ${ }^{541}$ In einigen Briefen werden ganz unterschiedliche Themen behandelt, und es treten z. T. verschiedene Funktionen mehr oder weniger gleichrangig auf. Es mag durchaus Briefe geben, die eindeutig assertiv, direktiv oder expressiv sind und damit als Informations-, Aufforderungsbzw. Kontaktbriefe kategorisiert werden können; meist vermischen sich die Funktionen jedoch. ${ }^{542}$ Elementar für Privatbriefe ist dabei die expressive Funktion (mit Schwerpunkt auf dem Beziehungsaspekt), die sich manchmal auf einzelne Briefbestandteile (wie die Wohlergehensformeln) beschränkt, manchmal aber Hauptfunktion oder sogar einzige Funktion eines Briefes zu sein scheint. ${ }^{543}$

gleichermaßen textsortenkonstituierend, und zwar je nach Textsorte oder sogar Einzeltext in unterschiedlichen Dominanzverhältnissen [...]. “ Vgl. a. GANSEL UND JÜRGENS 2009, 92 und VATER 2001, 180 sowie (speziell zum Brief) ERMERT 1979, 80.

${ }^{539}$ Vgl. z. B. Grolimund 1995, 175: „Man ist sich einig, dass eine Thementypologie problematisch ist, und dass die potentiellen Themen einer beliebigen Textsorte sich nicht auflisten lassen, es sei denn, die Textsorte wird durch ein einzelnes Thema determiniert (z. B. Wetterbericht). "Vgl. a. (zum Brief) ERMERT 1979, 196. Vgl. dagegen ADAMZIK 2008, 164: „Erstaunlich erscheint es mir allerdings, dass beim Thema nur der Themenentfaltungstyp regelmäßig behandelt wird. Dabei ist es durchaus möglich, auch Thementypen selbst auf einem hohen Abstraktionsniveau zu typologisieren [...].“ und ADAMzIK 2016, 212ff. (zu verschiedenen „Thementypen“).

540 Vgl. z. B. Rolf 1993, 166: „[...] bezüglich der Gebrauchstextsorten ist die Annahme der Grenzenlosigkeit ihrer Verwendungen illusionär. Wählt man die Textfunktion, das Pendant zum, illocutionary point' bei den Sprechakttypen, zum Basiskriterium der Textsortenklassifikation, dann zeigt sich, daß wir auch mit Texten nur eine begrenzte Anzahl grundlegender Dinge tun bzw. zu erreichen versuchen. “ Dagegen WüEST 2011, 237f.: „Tatsächlich ist es nicht immer leicht, Kommunikationsabsichten zu bestimmen. Wir glauben auch nicht, dass sich diese immer in einer der fünf Sprechaktkategorien Searles ausdrücken lassen. Für fiktionale Texte, mit denen sich Rolf nicht beschäftigt, kann man dies sogar ausschließen [...].“ Vgl. außerdem die Darlegungen in Kap. 1.1.

${ }^{541}$ Vgl. z. B. HEINEMANN 2000 - 2001a, 610: „Küchenzettel (Zettel mit einer privaten Information auf den Küchentisch gelegt, am Kühlschrank befestigt ...), Leserbriefe, Flyers [!], Zeitungsanzeigen, Testamente, Entschuldigungsbriefe, Spickzettel, z. T. Telegramme, z. T. Privatbriefe sind ebenfalls Textsorten, die zwar vordergründig Informationen vermitteln, gewöhnlich aber auch eine emotive Komponente (z. B. über Anreden) und zusätzlich eine Steuerungsabsicht verfolgen. Es bleibt die Frage offen, ob man solche Textexemplare in feste Textsortenschemata einfügen kann, oder ob nicht vielmehr im Alltagsbereich individuelle und auch aktuelle Aspekte zusätzliche Differenzierungskriterien abgeben sollten."

542 Vgl. z. B. NICKISCH 1991, 13: „Da der Brief als Redesubstitut zum Zwecke eines dialogischen Austausches fungiert, weist er wie jeder kommunikative Akt ein diesem entsprechendes Merkmal als dominant auf: Er informiert (sach-orientiert), appelliert (partner-orientiert) oder manifestiert (selbst-orientiert). [...] Die Grundfunktionen der Informationsübermittlung, des Appellierens und der Selbst-Äußerung machen die genuinen und historisch quasi-invarianten kommunikativen Möglichkeiten des Briefes aus. Sie kommen in praxi natürlich kaum je rein vor, vielmehr meist miteinander vermischt; doch dominiert in der Regel eine dieser Funktionen, bedingt durch den jeweiligen Hauptzweck, um den es einem Briefeschreiber geht.“ VgI. a. BELKE 1973, 142ff. und DIMTER 1981, $84 \mathrm{f}$.

543 Vgl. z. B. HARTUNG 1983, 225: „Vordergründiges Anliegen persönlicher Briefe ist der Austausch von Informationen über persönliche Erlebnisse, Eindrücke, Meinungen, Neigungen, über persönliches Wohlergehen und beabsichtigte Unternehmungen. Dieser Austausch kann Bestandteil eines Interaktionsrahmens sein (Fragen und ihre Beantwortung zu einem ganz bestimmten Zweck, Vorbereitung von Besuchen usw.), er kann aber auch Teil der 
Insgesamt wird klar, dass „man bei einer Klassifikation von Texten mit einer einzigen Typologisierungsbasis nicht auskommt. “" ${ }^{444}$ Die meisten Ansätze kombinieren folgerichtig verschiedene Kriterien miteinander und hierarchisieren diese in irgendeiner Form. ${ }^{545}$ Besonders interessant im Zusammenhang mit der vorliegenden Arbeit ist die Briefklassifikation von ERMERT 1979, der sich zu den Klassifikationskriterien und ihrer Rangfolge folgendermaßen äußert:

\begin{abstract}
Briefsorten werden konstituiert (a) durch die Zugehörigkeit zur Kommunikationsform ,Brief', (b) durch die Intention[en] des Briefschreibers, die in ihnen realisiert werden [...], (c) durch die Zugehörigkeit zu bestimmten Handlungsbereichen (die durch den jeweiligen Status und die soziale Rolle der Kommunikationspartner bezüglich der jeweiligen kommunikativen Handlung und den Status der jeweiligen kommunikativen Handlung definiert werden), (d) durch je spezifische textinterne Strukturen und (e) durch die äußeren Formalien. (d) und (e) variieren mit (b) und (c). Die Zuordnung konkreter Briefexemplare zu Briefsorten erfolgt zunächst durch die Zuweisung zu einer bestimmten Intention [Kontaktintention, Darstellungsintention, Wertungsintention, Aufforderungsintention] und zu einem bestimmten Handlungsbereich, sodann durch die Analyse der Texte hinsichtlich weiterer Merkmale unter kommunikativem, textstrukturellem, thematischem und formalem Aspekt. ${ }^{546}$
\end{abstract}

\begin{abstract}
kommunikativen Bestätigung einer Beziehung sein, wie sie zwischen Verwandten, Freunden oder guten Bekannten besteht, sich also außerhalb eines aktuellen Interaktionsrahmens vollziehen." Vgl. a. WüEST 2011, 88.

${ }^{544}$ ADAMZIK 2008, 151. Vgl. a. ADAMZIK 2018a, 56f. und SCHRÖDER 2003, 254.

${ }^{545}$ Eher eine Ausnahme bildet der Ansatz von Rolf 1993, der eine einheitlich funktionale Klassifikationsweise unter Zugrundelegung "des mit den jeweiligen Textsorten verknüpften Handlungsziels, des mode of achievement, d. h. des Durchsetzungsmodus respektive der Zielerreichungsweise, sowie charakteristischer vorbereitender Bedingungen“ (ebd., 119) anstrebt. Vgl. dazu auch die Kritik bei KRIEG-Holz UND BüLOW 2015, 220: „Was die verwendeten Klassifikationsmerkmale anbelangt, so ist in der Regel ab der vierten, zum Teil auch schon auf der dritten Ebene eine Art Beliebigkeit festzustellen. Offensichtlich zwingt die völlige Vernachlässigung formaler, sprachlicher oder stilistischer Aspekte zu einer Wahl von Klassifikationskriterien, die sehr heterogen sind." Zu den hierarchisch angelegten Textklassifikationen insgesamt vgl. z. B. GROLIMUND 1995, 103ff.; SCHRÖDER 2003, 254ff. und ADAMZIK 2008, 161ff. Dort wird u. a. auf die Klassifikationen von Ermert (s. u.), Brinker und Heinemann / Viehweger eingegangen. Zu Brinker, der zu seinen funktionalen Textsortenklassen unter Heranziehung weiterer Kriterien Subklassen (= Textsorten) bildet vgl. a. BRINKER U. A. 2014, 133ff. Zum flexiblen Mehr-Ebenen-Modell von Heinemann / Viehweger vgl. a. HeINEMANN UND VIEHWEGER 1991, 129ff.; HeINEMANn 2000 - 2001b und die Zusammenfassung bei HEINEMANN 2000 - 2001c, 513ff.

${ }^{546}$ ERMERT 1979, 67. Vgl. a. die weiteren Erläuterungen zu Ermerts Briefklassifikation in ebd. (z. B. ebd., 176ff.), deren Ergebnis ein „Raster" darstellt, „in das prinzipiell alle konkreten Briefe (bis auf eventuell die thematische Ebene eindeutig) typologisch eingeordnet werden können." (ebd., 186). Denkbar seien immerhin 1.325.308 (!) potenzielle Brieftypen, deren Anzahl jedoch durch das Alltagswissen der Kommunikationsteilnehmer eingegrenzt werden könne (vgl. ebd., 176 und ebd., 187). Letztlich geht es Ermert erst mal nur um die Demonstration des methodischen Prinzips für eine mögliche Klassifikation. Vgl. a. ebd., 186: „Letzte Stimmigkeit der Zuordnungen von Einzelmerkmalen oder Merkmalgruppen zu den einzelnen typologischen Ebenen kann freilich in der gegenwärtigen Forschungssituation nicht erreicht werden. Und auch wenn die angenommenen Vorkommensrelationen zwischen außersprachlichen Determinationsfaktoren und sprachlich strukturellen und formalen Eigenschaften von Briefen sehr viel weiter untersucht wären, als es jetzt der Fall ist, bliebe immer noch ein nicht zu unterschätzender (und unter erkenntnistheoretischem Aspekt selbstverständlicher) Interpretationsspielraum."
\end{abstract}


Letztlich gibt es bis heute keine in jeder Hinsicht befriedigende Textsortentypologie, da auch Mehr-Ebenen-Klassifikationen nicht frei von Problemen sind. ${ }^{547}$ Angesichts der unüberschaubaren Vielzahl mehr oder weniger relevanter Klassifikationsmerkmale muss man zu dem Schluss kommen, dass eine solche wohl überhaupt nicht möglich, aber auch gar nicht notwendig ist: „Der Versuch einer exhaustiven, universellen und absoluten Erfassung irgendeines ,Gesamtsystems' von Textsorten erscheint [...] weder sinnvoll noch erreichbar. ${ }^{4548}$ Als ausschlaggebend erweist sich vielmehr die „pragmatische Effizienz von Klassifikationen, die Frage also, ob und in welchem Grade eine Typologie/Teiltypologie potentielle reale Aspekte kognitiver und kommunikativer Prozesse und Zusammenhänge abbildet oder nicht. "549 Textklassifikationen sollen lediglich helfen, bereits existierende Texte bzw. ihre Texteigenschaften zu beschreiben. ${ }^{550}$ Dabei ist zu berücksichtigen, dass es sich bei ihnen je nach Vorgehensweise im Ergebnis eher um theoretische Konstrukte handelt, an deren „Regeln“ reale Autoren sich bei der konkreten Textgestaltung nur bedingt halten, wenngleich bestehende Konventionen bewusst oder unbewusst i. A. durchaus keinen geringen Einfluss ausüben. ${ }^{551}$ Eine Klassifikation sollte also am besten "dynamisch-verwendungsorientiert" sein und jeweils an die spezifischen Erfordernisse angepasst werden, wobei Teilklassifikationen durchaus möglich oder sogar vorzuziehen sind. ${ }^{552}$

\subsection{Briefarten in der (römischen) Antike}

Trotz i. E. veränderter Bedingungen (z. B. hinsichtlich der Materialität und der Beförderungsmöglichkeiten) kann man durchaus davon ausgehen, dass antike (römische) und moderne

\footnotetext{
${ }^{547}$ Vgl. z. B. BRINKER U. A. 2014, 134: „Von der Aufstellung einer geschlossenen und in sich stimmigen allgemeinen Texttypologie ist die Textlinguistik noch weit entfernt.“ und GANSEL UND JÜRGENS 2009, 53: „Zwar haben Klassifikation und Typologisierung von Texten in der textlinguistischen Diskussion innerhalb der vergangenen 30 Jahre eine herausragende Rolle gespielt und zahlreiche korpusbasierte empirische Forschungen konnten das Konzept ,Textsorte' theoretisch vertiefen. Dennoch scheint sich eine gewisse Ermüdung in der Erforschung von Textsorten eingestellt zu haben, die zudem in terminologischer Uneinheitlichkeit und unklarer Systematik offensichtlich wird."

548 HeINEMANn 2000 - 2001b, 543. Vgl. a. AdAMZIK 2008, 167.

549 HeINEMANN 2000 - 2001b, 543.

550 Vgl. z. B. ADAMZIK 2008, 175 (s. N. 552).

551 Vgl. z. B. HeINEMANN 2000 - 2001c, 514: „Auch wenn Texte immer individuell gebildet werden, so ist doch die Art ihrer Konstitution nicht arbiträr, sondern gebunden an Konventionen bestimmter Sprachgemeinschaften." Vgl. a. WÜEST 2011, 237.

${ }^{552}$ ADAMZIK 2008, 175: „Mein zentrales Anliegen bestand [...] darin aufzuzeigen dass Klassifikationen auf verschiedenen Abstraktionsebenen und unter verschiedenen Kriterien (,Typologisierungsbasen') möglich und sinnvoll sind, dass deren Auswahl an die jeweilige Fragestellung und das Untersuchungsmaterial angepasst und teilweise erst induktiv daraus zu entwickeln ist, dass sich Typologien weniger als Sortier- denn als Beschreibungswerkzeug eignen und nicht Texte, sondern Texteigenschaften betreffen, dass die statisch-produktorientierte Sicht auf Texte und Textsorten dringend durch eine dynamisch-verwendungsorientierte Sicht ersetzt oder mindestens ergänzt werden muss, und schließlich dass die Suche nach einer begrenzten Menge standardisiert abzuarbeitender Analyseprozeduren die Gefahr mit sich bringt, eine Vielzahl relevanter(er) Fragestellungen auszublenden und die Textsortenlinguistik zu einer einigermaßen sterilen Beschäftigung zu machen." Zu einer möglichen Teiltypologisierung vgl. a. ebd., 167, wo sie „der von [Horst] Isenberg (und anderen) zumindest implizit unterstellten Annahme “ widerspricht, „dass ad hoc gebildete bzw. ausgewählte Klassen für die Analyse ungeeignet wären. “, und der dahingehend geäußerten Kritik entgegensetzt: „Bei allen empirischen, an irgendwelchen Korpora ansetzenden Studien ist [...] die Auswahl von Merkmalen normalerweise nicht willkürlich, sondern eben induktiv, durch das Beschreibungsobjekt geleitet." Vgl. a. HeInEMANn 2000 - 2001b, 541.
} 
Briefe sich grundsätzlich ähneln und damit auch bis zu einem gewissen Grad vergleichbar sind. ${ }^{553}$ Dies gilt insbesondere für Privatbriefe, wobei im Hinblick auf die aktuellen Entwicklungen zu bemerken ist, dass persönliche Briefe im Alltagsleben der Gegenwart nur noch eine geringe Rolle spielen und weitgehend von anderen Kommunikationsformen (wie E-Mail und Chat) abgelöst wurden und damit eher als historisches Relikt zu betrachten sind. Im Übrigen ist auf die Ausführungen zur Universalität bzw. Kulturspezifität von Textsorten zu verweisen. ${ }^{554}$

Im Folgenden werden - mit Bezug auf die modernen linguistischen Konzepte - die Versuche zur Klassifikation antiker Briefe erläutert, wie sie sich im Altertum selbst und der Klassischen Philologie der Neuzeit finden. ${ }^{555}$ Dabei werden einige grundlegende Überlegungen zu einer sinnvollen Typologisierung römischer Briefe angestellt, eine fundierte eigene Klassifikation ist an dieser Stelle jedoch nicht möglich.

\section{Kommunikationssituationen und Handlungsbereiche}

\section{Litterae publicae et privatae}

Cicero differenziert in Flacc. 23 und 37 zwischen litterae publicae und litterae privatae. Eine ähnliche Unterscheidung findet sich bei lulius Victor: Epistolarum species duplex est; sunt enim aut negotiales aut familiares. Eine eindeutige Definition dessen, was unter publicae und privatae bzw. negotiales und familiares zu verstehen ist, gibt es aber nicht. ${ }^{556}$ Es wird lediglich darauf hingewiesen, dass erstere inhaltlich und formal von größerer Ernsthaftigkeit (severitas), Würde (dignitas) und Bedeutsamkeit (gravitas) geprägt seien. Iulius Victor merkt z. B. im Hinblick auf die litterae negotiales an: illarum [...] severitas maior est. bzw. ausführlicher: Negotiales sunt argumento negotioso et gravi. In hoc genere et sententiarum pondera et verborum lumina et figurarum insignia conpendii opera requiruntur atque omnia denique oratoria praecepta, una modo exceptione, ut aliquid de summis copiis detrahamus et orationem proprius sermo explicet. In einer anonymen rhetorischen Schrift heißt es zudem: In re de qua scribemus videndum est, privata an publica, sacra an extra religionem, nostra an aliena, magna an modica: sic enim non solum sensus temperandi et adfectiones adfectandae sunt, sed etiam dignitas elocutionis ipsius moderanda. ${ }^{557}$

\footnotetext{
${ }^{553}$ Vgl. Kap. 1.2.1.3 („Wesensbestimmung des römischen (Privat-)Briefes“).

554 Vgl. das Kap. „Textsorten“ ab S. 72.

${ }^{555}$ Vgl. insbesondere die Klassifikationsansätze bei CUGUSI 1983, 105ff. („Classificazione delle lettere“) und CUGUSI 1989 - 1991; STOWERS 1986, 49ff. („Types of Letters“) und STOWERS 1988, aber auch die Übersichten z. B. bei PETER 1965, 13ff. („Die Anfänge der Brieflitteratur bei den Alten und die Gattungen der Briefe nach ihren Vorstellungen und Lehren“); ANTÓN 1996, 113f. („Clasificación de las cartas“) und BERNARD 2013, 117ff. („Typologie des lettres“). Vgl. außerdem CORBINELLI 2008, 56ff.

${ }^{556}$ Auch eine explizite Unterscheidung von amtlichen Briefen und anderen öffentlichen bzw. offiziellen Briefen findet sich nicht. Vgl. z. B. SCHWITTER 2018, 85f. N. 4 (mit Bezug auf die beiden griech. Briefsteller).

${ }^{557}$ Die betreffenden Textstellen in CIC. Flacc. lauten: privatae litterae nullae proferuntur, publicae retentae sunt in accusatorum potestate (23) bzw. Haec [...] laudatio obsignata erat creta illa Asiatica [...] qua utuntur omnes non modo in publicis sed etiam in privatis litteris quas cotidie videmus mitti. (37). Die Zitate aus lulius Victor sind in Div. 1964, 447, 37ff. bzw. ebd., 448, 34f. zu finden. Vgl. a. MALHERBE 1988, 62ff. Die anonyme Textstelle ist den Excerpta Rhetorica in Div. 1964, 589, 8ff. entnommen. Zu den privaten Briefen vgl. außerdem QUINT. inst. 1.1.29. Vgl. im Übrigen z. B. Cugusı 1983, 30ff. und ebd., 105ff.; CAVARZERE 1998, 12f. und Muñoz MARTín 1985, 82. In den beiden griechischen Briefstellern gibt es dagegen keine entsprechende Differenzierung. Vgl. dazu z. B. SCHWITTER
} 
Nach CIc. fam. 15.21.4 berücksichtigt ein Autor beim Schreiben, ob ein Brief an mehrere oder einzelne Adressaten gerichtet ist: aliter [...] scribimus quod eos solos quibus mittimus, aliter quod multos lecturos putamus. Plinius (epist. 6.16.22) macht ebenfalls auf die Bedeutung des Adressatenkreises aufmerksam: aliud est enim epistulam aliud historiam, aliud amico aliud omnibus scribere. Danach kann man also persönliche Briefe unterscheiden von Briefen, die sich an ein größeres Publikum richten. ${ }^{558}$

Die Termini ,öffentlich' bzw. ,offiziell‘ und ,privat' können allerdings auch auf Handlungsbereiche bezogen werden, also auf „,bestimmte gesellschaftliche Bereiche, für die jeweils spezifische Handlungs- und Bewertungsnormen gelten“, welche durch „die Art des Rollenverhältnisses zwischen den Kommunikationspartnern" bestimmt sind. ${ }^{559}$ Die Begriffe negotiales (,geschäftlich') und familiares (,bekannt', ,vertraut') referieren sogar deutlich auf solche Rollenverhältnisse; und die Art der Beziehung zwischen Verfasser und Adressat eines Briefes war in der römischen Antike in der Tat sehr wichtig: Ist diese offizieller oder persönlicher Natur? Sind beide Parteien (im Falle einer persönlichen Beziehung) freundschaftlich miteinander verbunden (amici), pflegen sie regelmäßigen Umgang miteinander (familiares), bestehen Verpflichtungen zwischen ihnen (necessarii)? Handelt es sich um Familienangehörige, sozial Gleichgestellte, Höhergestellte oder Untergebene? ${ }^{560}$

Abgesehen davon, dass die Verhältnisse nicht immer mit denen unserer modernen Gesellschaft vergleichbar sind, z. B. was die Bedeutung von amicitia oder familia betrifft ${ }^{561}$, ist damit jedoch noch nicht unbedingt eine Zuordnung zum privaten oder öffentlichen Bereich verbunden. Eine genaue Abgrenzung zwischen beiden Bereichen existiert im alten Rom auch gar nicht. ${ }^{562}$ Vielmehr könnte man unter Berücksichtigung sowohl der Größe des anvisierten Rezipientenkreises als auch des (sozialen und persönlichen) Verhältnisses zwischen Adressat und

2018, 85f.: „Die brieftypologische Klassifizierung wird allein anhand adressatenorientierter sowie inhaltlicher Gesichtspunkte vorgenommen, während der für die moderne Brieftheorie so wichtige Aspekt der Öffentlichkeit keinerlei Beachtung findet."

558 Vgl. die Definitionen bei CUGUSI 1983, 105: „Lettere private sono quelle in cui si stabilisce un commercio epistolare tra due interlocutori, al di fuori di possibili intromissioni di terzi [...]; lettere pubbliche sono tutte le altre, che possono capitare nelle mani di terzi senza che venga violato il segreto epistolare. "Vgl. a. PENNACINI 1985, 11f. und MUÑOZ MARTín 1985, 82.

559 BRINKER 2002, 43 bzw. BRINKER U. A. 2014, 143. Ausführlicher dazu: Ebd., 142ff. Dort wird auch auf eine mögliche inhaltliche Differenzierung von gesellschaftlichen Bereichen hingewiesen: „Die Kommunikationssituationen, die den Rahmen für Textsorten bilden, sind bestimmten gesellschaftlichen Bereichen zugeordnet, für die jeweils spezifische Handlungs- und Bewertungsnormen gelten. Alltagswelt, Welt der Wissenschaft, des Rechts, der Kunst, der Religion, der Wirtschaft, der Verwaltung, der Presse, der Politik sind z. B. solche Bereiche. Sie müssten allerdings in inhaltlicher Hinsicht noch weiter differenziert werden (insbesondere im Hinblick auf die Regeln und sozialen Normen, die für sie jeweils konstitutiv sind).“ (ebd., 142f.). Vgl. a. die Unterscheidung „gesellschaftlicher Funktionsbereiche" bei HAUSENDORF UND KESSELHEIM 2008, 142 (s. S. 50).

560 Vgl. z. B. Bernard 2010, 419. Vgl. a. BeRnARd 2013, 112ff. und Stowers 1986, $27 \mathrm{ff}$.

${ }^{561}$ Zur Bedeutung von römischer amicitia und familia vgl. z. B. ebd., 28ff. Speziell zur Freundschaft in der (griechischen und v. a. römischen) Antike vgl. a. GIORGIO 2015, 65ff.; ROLLINGER 2014; WILLIAMS 2012; WILCOX 2005; ROESCH 2004, 139ff.; KONSTAN 1997; FüRST 1996 und PIZZOLATO 1993.

562 Zur Abgrenzung von privatem und öffentlichen Bereich vgl. bes. CAVARZERE 1998. Vgl. a. BURCKHARDT 2003, 112, der sich nicht auf den „Öffentlichen“, sondern den (weitgehend identischen) „politischen“ Bereich bezieht,: „Im römischen Recht sind die Bereiche des Privaten und des Politischen strikt voneinander geschieden, und auch die meisten republikanischen Autoren sehen eine scharfe Trennung zwischen beiden Lebenssphären. Lange Zeit hat auch die Forschung einen modernistischen Begriff des Privaten an die römische Gesellschaft herangetragen, 
Absender und des Status der jeweiligen kommunikativen Handlung bzw. der mit ihr verbundenen Funktionen und Inhalte offizielle und semi-offizielle Briefe, persönliche Briefe mit öffentlichem oder halb-öffentlichem Charakter und persönliche Briefe mit privatem Charakter unterscheiden, wobei eine eindeutige Zuordnung nicht immer möglich ist. ${ }^{563}$ Vor allem ist zu bedenken, dass es - nicht nur wegen des sehr eingeschränkten Briefgeheimnisses - reine Privatbriefe in der Antike kaum gab und meistens eine wie auch immer geartete Veröffentlichungsabsicht hinter den Briefen stand. Cavarzere kommt zu dem Schluss: „[...] potremmo credo - concludere che in tutti i grandi epistolari dell'antichità, i quali presentano sempre un duplice piano di destinazione, viene sostanzialmente vanificata la differenza, che sembrava così ovvia e chiara, tra lettera pubblica e lettera privata. “564

\section{Brief zwischen Gebrauchstext und Literatur}

Durch eine Publikation wechseln Briefe nicht nur vom privaten oder offiziellen in den öffentlichen Bereich, sondern sie werden auch anderweitig in einen neuen Handlungsbereich transferiert. ${ }^{565}$ Aus ursprünglich persönlichen Briefen der Alltagswelt oder amtlichen Briefen der Verwaltung können historiografische und (auto-)biografische Dokumente werden, denen politische oder wissenschaftliche Bedeutung zukommt. ${ }^{566}$ Neben der besonderen Persönlichkeit des Adressaten oder Autors sind häufig v. a. die besondere Form und der besondere Inhalt von Briefen für eine Veröffentlichung ausschlaggebend. Als Gebrauchstexte konzipierte „gewöhnliche“ Briefe werden so zur Kunst bzw. Literatur „erhoben“. Andere, von vornherein öffentliche Briefe, z. B. philosophische Briefe und Lehrbriefe, können neben ihrem Ursprungsbereich (wie Philosophie oder Wissenschaft) ebenfalls in einem mehr oder minder großen Ausmaß dem literarischen Gebiet zugewiesen werden. ${ }^{567}$

ohne sich über die historischen Voraussetzungen einer solchen Begrifflichkeit Gedanken zu machen. Neuere Ansätze wie z. B. derjenige der Geschlechtergeschichte machen neuerdings auf eine vielfältige Durchmischung beider Sphären aufmerksam, zumindest was einen senatorischen Haushalt angeht. Ciceros Briefcorpus bietet reichhaltiges Material für die These, daß das Private für einen nobilis politisch geladen und die Grenze zwischen den Bereichen für ihn fließend war [...]. “ Burckhardt belegt dies in seinem Aufsatz „an den aus der Korrespondenz entnommenen Beispielen der Funktion der domus, dem Umgang mit Geld, der Stellung der matrona und der Heiratspolitik sowie dem geselligen Verkehr" (ebd., 112f.).

${ }^{563}$ Vgl. BeRnARD 2013, 118. Vgl. a. ebd., 117ff.; SCHWITTER 2018, 90 und ebd., 98ff. sowie (speziell zu Cicero) THRAEDE 1980, 192 und ebd., 195. Vgl. außerdem (zur Unterscheidung von privaten und offiziellen bzw. administrativen Briefen und von persönlichen und öffentlichen Briefen) CAVARZERE 1998; CORBINELLI 2008, 132ff. und MANUWALD 2009, 4f. sowie (mit Bezug auf antike dokumentarische Briefe) SARRI 2017, 15. Eine weitergehende Einteilung der „weniger privaten“ Briefe findet man bei DOTY 1969, 196ff. Vgl. dazu auch ROSENMEYER 2001, 8f.

${ }^{564}$ CAVARZERE 1998, 20. Vgl. a. ebd., 13: „Ma in realtà sono i concetti stessi di ,pubblico' e ,privato' a prestarsi a una certa dose di ambiguità. Se guardiamo bene, tutti i grandi epistolari dell'antichità, con l'importante ma al tempo stesso involontaria eccezione di quello ciceroniano, e forse proprio a causa di quest'ultima, furono composti fin dall'inizio in vista di una pubblicazione futura, e dunque tenendo conto non solo del destinatario immediato, ma anche di un pubblico più vasto di lettori. " und ebd., passim. Vgl. außerdem Correa 2013, 25f. (mit Bezug auf das fehlende Briefgeheimnis) und BERNARDI PERINI 1985, 23f. (zum besonderen Status der Briefe Ciceros).

565 Vgl. S. 103 sowie N. 559.

${ }^{566}$ Zur Veröffentlichung von Briefen lateinischer Autoren wie Cicero als (auto-)biografischen oder historiografischen Zeugnissen vgl. a. Kap. 1.2.2.

567 Vgl. z. B. SYKUTRIS 1931, 187. Entscheidend dafür, ob ein Text als Literatur gelten kann, ist in der Klassischen Philologie allerdings v. a. die Materialität bzw. Art der Überlieferung (vgl. z. B. SCHWITTER 2018, 93f.). Es ist nun zwar nicht zu bestreiten, dass die Materialität eine große Rolle bei der Rezeption eines Textes spielt. Vgl. z. B. ebd., 99: „Die in einer Rolle oder einem Codex präsentierte Epistel eröffnet dem Leser ein weitaus größeres Interpretationspotential als der zirkulierende Einzelbrief. Der durch die Buchrolle beziehungsweise den Codex 
Die zeitweilig diskutierte strikte Trennung von „echten“ Briefen und (literarischen) Episteln ist bald wieder verworfen worden. ${ }^{568}$ Eine solche Differenzierung ist nicht möglich und entspricht zudem auch gar nicht dem antiken Verständnis von Briefen. ${ }^{569}$ Vielmehr ist eine Skala anzunehmen, ausgehend von eindeutig authentischen Briefen wie den Vindolanda-Täfelchen, die als reine Gebrauchstexte (i. e. S.) gelten können, bis hin zu eindeutig literarischen Briefen wie den fiktiven Heroides von Ovid, die keinen praktischen Nutzen (i. e. S.) haben bzw. hatten..$^{570}$

implizierte wirkungsästhetische Anspruch konditioniert die Lesererwartung und beeinflusst entsprechend auch die Interpretation. " Vgl. a. GRoss 2006. Allerdings erweist sich dieses Kriterium als nicht immer ganz nachvollziehbar oder gar willkürlich. Vgl. außerdem das Teilkap. „Ästhetische Briefe“ ab S. 111.

568 Zur Diskussion zwischen Adolf Deißmann und seinen (zeitgenössischen) Kontrahenten (z. B. Franz Overbeck, Paul Wendland), ob Privatbriefe und Epistel eindeutig voneinander abzugrenzen seien, vgl. DEIBMANN 1895, 187ff. und DeIßMANN 1908, 117ff. bzw. OVERBECK 1882, 429ff. und WENDLAND 1907. Vgl. a. SCHWITTER 2018, 86 N. 6; WHITE 2010, 90; WULfRAM 2008, 39ff.; SCHRÖDER 2007, 144; CONRING 2001, 17ff.; ROSENMEYER 2001, 5ff.; KLAUCK 1998, 73; ANTÓN 1996, 109; STOWERS 1986, 17ff.; GARCíA 1974, 436f.; THRAEDE 1970, 1ff.; DOTY 1969 und SYKUTRIS 1931, 187. Zur Unterscheidung von (echten) Privatbriefen und literarischen Briefen allgemein vgl. außerdem WHITE 2010, 90ff.; MANUWALD 2009, 6f.; KLAUCK 1998, 72f.; ANTÓN 1996, 109ff.; CUGUSI 1989 - 1991; KOSKENNIEMI 1956, 50f.; SYKUTRIS 1931, 187 und v. a. THRAEDE 1980. Vgl. a. CUGUSI 1983, 187ff. (mit Schwerpunkt auf den Briefen der Kaiserzeit) und JÄGER 1986, 14ff. (zu Briefen als Literatur). Vgl. darüber hinaus die Unterscheidung von reinen, literarisierten und literarischen Gebrauchsformen bei Belke (s. N. 534). SCHWITTER 2018, 88f. fasst die Diskussion (mit Blick auf die Spätantike) folgendermaßen zusammen: „Als besonders problematisch für die Beurteilung des Privatbriefs wirkte sich im Nachhinein die grundlegende Differenzierung zwischen, literarischen' und ,unliterarischen' Briefen aus, die sich aus der Applikation eines Literaturbegriff ergab, der wesentlich an die Dichotomie privat-öffentlich bzw. authentisch-künstlerisch gebunden ist. Die Unzulänglichkeit dieser Herangehensweise ist bekannt, doch fehlt es an praktikablen Alternativen, die den spezifischen spätantiken Gegebenheiten gerecht werden. Die Aporie ergibt sich vor allem aus der Tatsache, dass das Verhältnis von realer Kommunikation, Literatur und Brief bislang nicht eindeutig geklärt werden konnte." So ist nicht nur eine Bewertung der Literarizität von Briefen aufgrund der Art der Überlieferung problematisch (vgl. N. 567), sondern auch vage ästhetische Konzepte sind $-u$. a. wegen ihrer oft stark subjektiven Prägung (sowohl auf Produzenten- als auch auf Rezipientenseite) - kritisch zu bewerten. Vgl. z. B. ebd., 95f., wo Schwitter auf die seines Erachtens unbefriedigenden Brieftypologien bei LUDOLPH 1997, 23ff. und WULFRAM 2008, 36ff. verweist, welche die Autorintention als entscheidend für eine Kategorisierung als ,echter Gebrauchsbrief' bzw. ,literarischer Privatbrief' betrachten. Zur rezeptiv gesteuerten Literarizität vgl. a. SCHWITTER 2018, 100ff. und FISH 1980, 322ff.

569 Vgl. z. B. KOSKEnNIEMI 1956, 50 und GARCíA 1974, 436f. Vgl. a. SARRI 2017, 29ff. sowie SCHWITTER 2018, 86 und ebd., 88 N. 22: „Die Unterscheidung von ,literarischen' und ,unliterarischen' Briefen ist eine moderne Projektion." Vgl. außerdem THRAEDE 1970, 3 zu den Freundschaftsbriefen (nicht nur) Ciceros: „,...] ausgerechnet jene Machart, die Deißmann als ,Mischgattung', ja als ,Entartung des Briefes' schmähte, galt der Anschauung des griechischrömischen Altertums, jedenfalls spätestens seit augusteischer Zeit, als Brief schlechthin: die Gebildeten kannten aus Theorie und Praxis als Inbegriff der Epistolographie den Typus des kultivierten Freundschaftsbriefes, weder ,rein' literarische Form noch ,rein' sprudelnde Natürlichkeit, sondern persönlich gefärbte Konvention und gesellschaftlich stilisierte Individualität."

570 Vgl. z. B. MANUWALD 2009, 6 und SYKUTRIS 1931, 187 sowie MülLeR 2018, 11 (mit Bezug auf SCHWITTER 2018) und WULFRAM 2008, 45. Vgl. a. den Ansatz von RüHL 2019, aus dem sich u. a. ergibt, „dass die Literarizität eines Textes sich an der Intensität der Integration des situativen Kontextes ablesen lässt. Eine Unterscheidung zwischen literarischem und nichtliterarischem bzw. öffentlichem und privatem Brief wird damit hinfällig, da sich alle Briefe auf einer stufenlosen Skala ansiedeln lassen, deren äußerste Enden sich lediglich zwischen den Antagonismen nichtliterarisch-real und literarisch-fiktional bewegen." (ebd., 308). Ausführlicher dazu: Ebd., 23ff. Vgl. außerdem das flexible "historisch-deskriptive Klassifizierungsmodell“ in SCHWITTER 2018, 96ff., das „auf drei Grundannahmen [basiert]": [...]: 1.Der Öffentlichkeitsgrad eines Briefs ist variabel und historisch veränderbar. 2. Jeder Brief verfügt über literarisches Potential. 3. Der Öffentlichkeitsgrad eines Briefs entscheidet über die Aktualisierung seines literarischen Potentials." Die Begriffe ,literarisch' und ,öffentlich' werden von Schwitter quasi synonym verwendet. Er rechtfertigt dies mit zwei Argumenten: „Erstens ist die Wirkungsweise eines Briefes abhängig vom jeweiligen Kommunikationsraum, in welchen er von einem beliebigen Akteur zu einem beliebigen Zeitpunkt gestellt wird.“ (ebd., 101) und „Zweitens erscheint der Öffentlichkeitsgrad auch daher für die Aktualisierung 
Als kennzeichnend für authentische Briefe wird häufig $u$. a. der Umstand betrachtet, dass sie in einer konkreten Situation begründet, an einen bestimmten Adressaten gerichtet und durch eine größere Spontaneität charakterisiert seien. Literarische Briefe dagegen seien unpersönlicher und allgemeiner, an ein größeres Publikum, ja vielleicht die (gesamte) Mit- und Nachwelt gerichtet, inhaltlich und funktional (im Gegensatz zur Multithematizität und Multifunktionalität vieler echter Privatbriefe) in sich kohärenter, rhetorisch ausgefeilter, geprägt von einer gehobeneren Ausdrucksweise, ggf. sogar in Versform verfasst. ${ }^{571}$

In der Praxis bewegen sich viele Briefe zwischen diesen beiden Polen. Es gibt sogar „echte“ Briefe, in denen sich metrisch ausgearbeitete Passagen finden, und zwar nicht nur in der Gestalt von Klauseln und in Zitaten, sondern auch als normaler Fließtext (z. B. bei Ausonius und Paulinus von Nola). ${ }^{572}$ Selbst in Alltagsbriefen einfacher Leute werden gewisse Formalia (z. B. Briefformular) beachtet und oft stereotype Wendungen und Topoi benutzt. Die Briefe rhetorisch und literarisch gebildeter Schreiber enthalten andererseits neben formal sehr elaborierten Passagen häufig auch solche, die eine ungezwungene Spontaneität widerspiegeln. ${ }^{573}$

Ein gutes Beispiel für die Verbindung von Authentizität bzw. praktischer Funktionalität und Literarizität sind die Briefe Ciceros, die allerdings eine große Spannbreite abdecken und sich je nach Adressat, Situation und Ziel - z. T. inhaltlich und formal sehr stark voneinander unterscheiden. ${ }^{574}$ Viele von ihnen weisen eine inhärente literarische Qualität ${ }^{575}$ auf, die ja auch im rein privaten Rahmen zwischen gebildeten Menschen geschätzt wurde, $v$. a. aber bedingt ist

literarischen Potentials als maßgebend, da eine steigende Anzahl von Rezipienten tendenziell auch eine steigende Anzahl (variabler) literarischer Aktualisierungen mit sich bringt." (ebd., 102). Dennoch erscheint mir diese Gleichsetzung nicht ganz überzeugend, und es stellt sich die Frage, wozu man dann noch den Begriff der Literarizität benötigt. Eher sollte man $m$. E. bei der Unterscheidung von eigentlicher und uneigentlicher Verwendung von Gebrauchstexten (s. N. 600) bleiben, wie sie ja auch bei Schwitter selbst (z. B. ebd., 101) durchaus zu finden ist. Vgl. a. NICKISCH 1991, 93ff. Vgl. außerdem das Teilkap. „Ästhetische Briefe“ ab S. 111.

${ }^{571} \mathrm{Vgl}$. die in N. 568 genannte Literatur, z. B. SYKUTRIS 1931, 187 und THRAEDE 1980, 192.

572 Vgl. z. B. SCHRÖDER 2007, 136f. Vgl. a. SCHWITTER 2018, 101 N. 77: „Die Versform ist per se [...] kein Hinweis auf einen erhöhten Öffentlichkeitsgrad eines Briefs. Sie kann in der Spätantike auch in rein privater Korrespondenz als Bildungsauszeichnung oder Freundschaftserweis Verwendung finden, vgl. u.a. Ruric. Epist. 2,19; Epist. Austri. 13; Desid. Card. epist. 2,1.“ Vgl. außerdem FernÁNDEZ LóPEZ 1994, 235ff. THRAEDE 1980, 190ff. schließt dagegen eine metrische Gestaltung in „echten“ Briefen aus. In klassischer und nachklassischer Zeit beschränkte sich diese ja auch tatsächlich auf Zitate und Klauseln. Zum Prosarhythmus in Ciceros Briefen (in Relation zu Adressat und Briefanlass) vgl. z. B. BeRnARD 2013, 101f. Vgl. a. ALBRECHT 2003, 66f. und HUTCHINSON 1998, 9ff.

${ }^{573}$ Zur Briefgestaltung von Menschen mit nur einfacher Bildung und (im Vergleich dazu) der von solchen mit höherer Bildung vgl. v. a. CUGUSI 1989 - 1991, bes. ebd., 391ff. und ebd., 400ff. Vgl. a. KLAUCK 1998, 71ff. Vgl. außerdem THRAEDE 1970, 2f. und MANUWALD 2009, $4 \mathrm{ff}$.

574 Vgl. z. B. CUGUSI 1998, 186f. zur „non forzata convivenza di spontaneità da un lato, dall'altro di abbellimento letterario" in der Briefkorrespondenz Ciceros. VgI. a. GUGLIELMI 2013, 19 zur „relazione tra spontaneità linguistica e controllo stilistico" bei Cicero (mit besonderem Bezug auf fam.), zwischen denen ein „armonioso equilibrio” bestehe. Ausführlicher zu den (z. T. sehr konkreten) Gemeinsamkeiten der Briefe Ciceros mit den dokumentarischen Briefen (einfacher Leute): CUGUSI 1998, passim und GUGLIELMI 2013, 17f. Vgl. a. ebd., 355; BERNARD 2013, 407 und BERNARD 2006, 78; SCHRÖDER 2004 - 2005, 210 sowie N. 523. Vgl. außerdem Müller 2018, 11, der (mit Bezug auf SCHWITTER 2018) meint, dass „der antike Brief [sich] komplementär zu dem Befund, dass nicht zuletzt Ciceros Korrespondenz bereits auf der Ebene des Gebrauchsbriefs zahlreiche aufwändig gestaltete Beispiele enthält, als eine höchst flexible Textsorte [erweist], die je nach Anspruch des Verfassers, Verwendungskontext und Rezeptionsverständnis zwischen den Polen Alltagstextualität und Literatur changieren kann. “

575 Vgl. N. 568. 
durch die tief verwurzelte und kaum abzulegende rhetorische Prägung Ciceros. ${ }^{576}$ Dies gilt unabhängig von einer potenziellen Veröffentlichungsabsicht, die im Übrigen aber immer zu berücksichtigen ist. ${ }^{577}$ Je nachdem, ob ein Autor eine Publikation seiner Briefe (von Anfang an oder erst zu einem späteren Zeitpunkt) im Sinn hatte, sind diese entsprechend mehr oder weniger stark bearbeitet worden. Ihren ursprünglichen Charakter haben - wenn man von einem evtl. Redigieren durch die Herausgeber und verschiedenen Unwägbarkeiten der Überlieferungsgeschichte absieht - am ehesten Briefe erhalten, die ohne oder sogar gegen den ausdrücklichen Willen des Verfassers veröffentlicht worden sind. ${ }^{578}$

\section{Typologisierung römischer Briefe}

Klassifikationsansätze in antiker und moderner Brieftheorie

In der Antike wurden nur wenige Versuche einer systematischen Klassifikation von Briefen unternommen. ${ }^{579} \mathrm{Zu}$ nennen sind in erster Linie die beiden griechischen Briefsteller Túroı

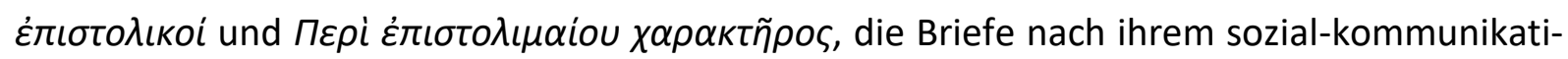
ven Kontext typologisieren und entsprechend den jeweils damit verbundenen Stilen benennen, womit in gewissem Sinne eine durchaus pragmatisch zu nennende Herangehensweise vorliegt. ${ }^{580}$ Trotz ihres rhetorischen Hintergrundes lassen sich die einzelnen Typen nur bedingt

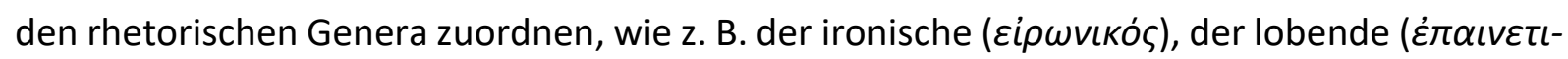
кóৎ) und der tadelnde (

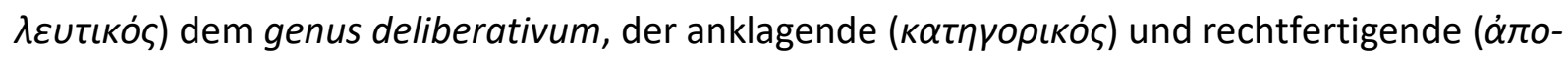
$\lambda о \gamma \eta \tau$ ¿ós) dem genus iudiciale. Viele der in den Briefstellern angeführten Typen sind als ermahnend zu charakterisieren und der Paränese zuzurechnen, die im Grunde genommen kein wesentlicher Gegenstand der Rhetorik i. e. S. war. ${ }^{581}$

Überlegungen zu einer römischen Brieftypologie, die allerdings kaum Ähnlichkeiten mit den Systemen der griechischen Briefsteller aufweist, finden sich schon bei Cicero. So differenziert er nicht nur litterae publicae und litterae privatae, sondern auch Briefe mit ernstem Inhalt (genus severum et grave), worunter bspw. politische Themen zu verstehen sind, und solche mit heiterem Inhalt (genus familiare et iocosum). Gerade letztere werden häufig verfasst, wenn es nichts Besonderes (nihil novi bzw. certa res nulla) zu berichten gibt, und bestehen in eher zwanglosem Plaudern (iocari) über verschiedene Themen. Derartige Schreiben entsprechen eigentlich nicht dem ursprünglichen Zweck von Briefen, der nach Cicero darin besteht, die abwesenden Adressaten über alles Wichtige auf dem Laufenden zu halten (certiores facere absentes). Es gibt noch weitere Brieftypen, die andere Aufgaben erfüllen. Ihr Anlass kann glücklich (secundae res) oder traurig (triste et miserum) sein. Es geht dann z. B. darum, dem

\footnotetext{
576 Vgl. z. B. BURKARD Und SCHAUER 2012, XX und Trapp in Div. 2003, 14 sowie SCHRÖDER 2004 - 2005, 213. Vgl. a. SCHWITTER 2018, 93, ebd., 95 und ebd., 101; SARRI 2017, 37 und außerdem ALBRECHT 2003, 66.

${ }^{577}$ Vgl. a. SCHWITTER 2018, 96: „Weder stellen [...] formalästhetische Gestaltung und inhaltliche Intimität einander ausschließende Kategorien dar, noch bedeutet eine entsprechende Stilisierung immer auch den autorintendierten Blick auf die Öffentlichkeit."

${ }^{578} \mathrm{Vgl}$. a. Kap. 1.2.2.

${ }^{579}$ Vgl. z. B. CORBINELLI 2008, 68. Vgl. a. den Überblick in SCHRÖDER 2007, 204ff. zu den epistolographischen Bemerkungen über „Funktionen und Inhalte von Briefen“ bei Cicero, Plinius, Symmachus, Hieronymus, Ambrosius und v. a. Ennodius.

580 Vgl. z. B. StOWers 1988, 78 und ebd., 80f. bzw. CORBINELLI 2008, 68 sowie SCHWITTER 2018, 85 N. 4.

${ }^{581} \mathrm{Vgl}$. STOWERS 1988, 84 bzw. STOWERS 1986, 51ff. Vgl. a. STOWERS 1988, 82, wo darauf hingewiesen wird, dass die Klassifikationsmethode an sich durchaus der rhetorischen Tradition entspricht.
} 
Empfänger Trost zu spenden (consolari) und ihm Unterstützung anzubieten (promissio auxilii bzw. polliceri). ${ }^{582}$ An verschiedenen Stellen erwähnt Cicero zudem Empfehlungsbriefe (litterae commendaticiae), die in seinen allgemeinen Typologisierungen nicht erfasst werden. ${ }^{53}$ Aus Att. 5.5.1 kann sogar eine konzis auf den Punkt gebrachte Differenzierung in direktive, assertive und expressive Brieffunktionen abgeleitet werden: Plane nil est quod scribam; nam nec quid mandem habeo (nihil enim pratermissum est) $[\rightarrow$ direktiv] nec quid narrem (novi enim nihil est) [ $\rightarrow$ assertiv] nec iocandi locus est; ita me multa sollicitant [ $\rightarrow$ expressiv]. " ${ }^{584}$ Cicero bietet zwar keine methodisch stringente Brieftypologie, lässt aber zumindest ein grundsätzliches Bewusstsein für die Möglichkeiten einer solchen erkennen. ${ }^{585}$

Einen - überdies nur rudimentären Ansatz - zu einer systematischen Klassifizierung von Briefen in der römischen Rhetorik findet man nur bei lulius Victor. ${ }^{586}$ Als Beispiele für die epistulae negotiales nennt er Briefe mit historischem Gegenstand (quid historicum) und Briefe, die gelehrte Themen anderer Art (quid eruditius) behandeln ${ }^{587}$, wobei nicht ganz klar wird, was genau darunter zu verstehen ist und worin sie sich von den historischen Briefen unterscheiden. ${ }^{588}$ Aufgabe der epistulae familiares sei es hingegen, zu beglückwünschen (gratulari), zu trösten (consolari) und zu scherzen (ludere), nicht jedoch zu streiten (iurgari). ${ }^{589}$ Einige Parallelen zu Cicero sind augenfällig: Trostbriefe kennt auch Cicero, ludere entspricht iocari, und Glückwunschbriefe gehören zu den Briefen aus glücklichem Anlass. Empfehlungsbriefe werden von Iulius Victor ebenfalls thematisiert. ${ }^{590}$

582 Der Darstellung liegen folgende Textstellen zugrunde: CIC. Att. 6.5.4- CIC. Att. 7.5.4f. - CIC. Att. 7.15.1 - CIC. Att. 9.4.1 - Cic. fam. 2.4 (an Curio) - Cic. fam. 4.13.1ff. (an Figulus) - Cic. fam. 6.10.4ff. (an Trebianus) - Cic. ad Q. fr. 1.1.37.

${ }^{583}$ Zu den Empfehlungsbriefen vgl. z. B. CIc. fam. 5.5.1 (an C. Antonius), Cıc. fam. 13.15.1ff. (an Cäsar) und CıC. fam. 13.27.1 (an Servius).

${ }^{584}$ Vgl. a. WULFRAM 2008, 17 (mit Bezug auf Bühler und spätere brieftheoretische Adaptionen in der Germanistik und Klassischen Philologie).

585 Vgl. CORBINELLI 2008, 69. Vgl. a. WHITE 2010, 23 sowie KOSKENNIEMI 1954, 101f.: „Es scheint also, als ob die hier [bei Cicero] genannten Briefarten nicht den Grund eines festen Briefsystems oder auch nur einen Teil eines solchen vertreten können. Sie bilden eher eine durchaus konventionelle, praktische Disposition der Spezialfälle, ein Mittel[,] um die geeignete Form für gewisse wichtige Situationen zu finden. Bemerkenswert ist auch ihr allgemeiner Charakter. Sie enthalten nicht an und für sich besonders Brieftheoretisches, sondern sind sozusagen allgemein rhetorischer Natur." Trotz ihres besonderen Charakters gibt es verschiedene Versuche, Ciceros verstreute und eher spontane Bemerkungen zu einzelnen Brieftypen zu systematisieren: Vgl. z. B. ebd. und THRAEDE 1970, 30ff. sowie CORBINELLI 2008, 72f. Vgl. außerdem MuÑoz MARTín 1985, 77ff.; SCHRÖDER 2004 - 2005, 206ff. und BERNARD 2013, 81ff.

${ }^{586}$ Vgl. CORBINELLI 2008, 69 und ebd., 73.

587 Die betreffende Textstelle, die im Zusammenhang mit den Empfehlungen zur stilistischen Gestaltung der epistulae negotiales steht, findet sich in Div. 1964, 447, 37ff. Vgl. a. MALHERBE 1988, 62.

588 Vgl. CORBINELLI 2008, 74: „Per quanto riguarda l'oggetto historicum, si può certo ritenere che l'espressione indichi la lettera che tratta di argomenti storici. Più difficile è invece capire a cosa il retore si riferisca con eruditius (un'espressione il cui significato è certamente più indefinito rispetto a quello di historicum), ma si può immaginare che sotto questa definizione si debbano classificare tutti quegli argomenti che sono tipicamente oggetto di studio e di insegnamento: filosofia, medicina, diritto etc. “

${ }^{589}$ Vgl. Div. 1964, 447, 37ff. bzw. MALHERBE 1988, 64. Was iurgari betrifft, könnte man eine Verbindung zu einigen

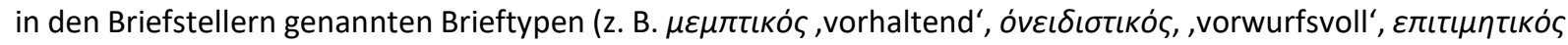

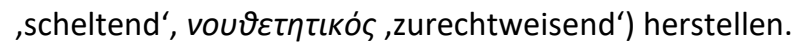

${ }^{590} \mathrm{VgI}$. CORBINELLI 2008, 80. Zu Trostbriefen vgl. a. SEN. epist. 16.99.1 und den entsprechenden Brieftyp ( $\pi \alpha \rho \alpha-$ $\mu$ der erhaltenen Trostbriefe legt nahe, dass die betreffenden Briefkonventionen recht strikt gewesen sein müssen: 
Moderne Brieftheoretiker wie Paolo Cugusi und Stanley Kent Stowers haben versucht, auf der Grundlage der antiken Brieftheorie und -praxis eine umfassendere Klassifikation zu erstellen. ${ }^{591}$ Cugusi konzentriert sich bei seiner Übersicht über römische Briefarten auf die Typen, die in dem uns überlieferten Korpus lateinischer Briefe aus der Zeit der späten Republik und v. a. des römischen Kaiserreichs am stärksten repräsentiert sind. Grundlegend ist für ihn dabei die Unterscheidung von privaten und öffentlichen Briefen. ${ }^{592}$ Stowers greift bei seiner Typologisierung neutestamentlicher Briefe v. a. auf die griechischen Briefsteller zurück. Er teilt die Briefe grob ein in „letters of friendship“, "family letters", „letters of praise and blame“, „letters of exhortation and advice", "letters of mediation" und "accusing, apologetic, and accounting letters".

Maria Concepción Fernandez López legt ihrer Analyse von Briefen des Sidonius Apollinaris dagegen eine Klassifikation zugrunde, die sich durchgehend an den Handlungsfunktionen im Sinne moderner pragmatischer Theorien orientiert, und unterscheidet Briefe mit metalinguistischer Funktion („,cartas de función metalingüística“), Briefe mit phatischer Funktion („cartas de función fática“), Briefe mit expressiver Funktion („cartas de función expresiva“), Briefe mit direktiver Funktion („,cartas de función impresiva“) sowie Briefe mit assertiver und poetischer Funktion („,cartas de función declarativa y poética“). ${ }^{593}$

Etwas komplexer ist der auf die Briefe von Ennodius ausgerichtete Ansatz von Bianca-Jeanette Schröder. ${ }^{594}$ Sie teilt die Briefe bzw. deren Bestandteile in vier Kategorien ein, wobei folgende Faktoren entscheidend sind: 1. „die Situation bzw. der Kenntnisstand des Verfassers (der entweder eine Reaktion erwartet, die ihn selbst betrifft [a], oder nicht [b])“, 2. „die Situation des

Vgl. ebd., 72. Zu Empfehlungsbriefen vgl. neben den Bemerkungen bei Cicero und lulius Victor (s. Div. 1964, 448, 28f.) außerdem Fronto epist. (ad amicos) 1.1 (an Claudius Severus), SYMm. epist. 2.9 und den entsprechenden

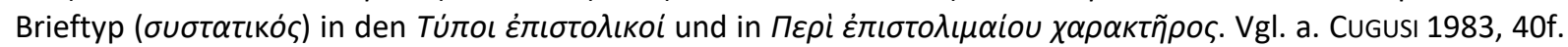
bzw. ebd., 111ff.; BERNARD 2013, 78 und ebd., 83f.

${ }^{591}$ CUgUSI 1983 und CUgUSI 1989 - 1991 bzW. StOWERS 1986. Vgl. a. SCHRÖDER 2007, 143ff., die darüber hinaus auf Klassifikationen in verschiedenen anderen neuzeitlichen Arbeiten zur antiken Epistolographie eingeht.

592 Vgl. z. B. Cugusı 1983, 7 und ebd., 106. Er bezieht auch dokumentarische Briefe mit ein: „Una [...] - credo importante - novità è costituita dal fatto che per la prima volta vengono presi sistematicamente in esame $i$ testi papiracei ed epigrafici, che sono inseriti nel quadro complessivo dell'epistolografia latina sia per quanto riguarda il loro aspetto formale, sia ai fini della ricostruzione letteraria." (ebd., 5). Die Übersichten in ebd. und CUGUSI 1989 - 1991 unterscheiden sich teilweise. So werden die ursprünglich mit den philosophisch-moralischen Briefen zusammengefassten christlichen Briefe später als eigene Kategorie angeführt, während gefälschte Briefe als eigene Kategorie entfallen. Zu gefälschten Briefen, die sich bei allen Brieftypen finden, wenngleich einige besonders prädestiniert dafür sind, wie z. B. politische Briefe, aber auch Widmungs- und Vorwortbriefe, vgl. a. PETER 1965, 168ff. Vgl. außerdem Wulframs „Entwurf einer kommunikativ-medialen Brieftypologie“ (WULFRAM 2008, 36ff.), in der Briefe nach „autorintentional-produktionsästhetischen“ Gesichtspunkten als kommunizierende oder fingierte Briefe eingeordnet werden, wobei noch weiter danach unterschieden wird, ob es sich um private oder öffentliche (halbliterarische oder literarische) Briefe handelt. Kritisch zur Differenzierung von „öffentlichen“ und „privaten“ Briefen äußert sich z. B. SCHRÖDER 2007, 148: „, [...] diese Kriterien werden zum einen in der Forschung nicht einheitlich verwendet und zum anderen mit der Frage vermengt, ob es sich um, echte' oder ,zu veröffentlichende' Briefe handelt. Da sich aber häufig weder die Grenze zwischen ,privat' und ,öffentlich' eindeutig ziehen lässt noch erkennbar ist, welche Briefe in der überlieferten Gestalt auch versandt wurden, sollte man diese Unterscheidung lieber nicht zum übergeordneten Kriterium machen.“ Vgl. a. das Kap. „Kommunikationssituationen und Handlungsbereiche" (ab S. 102).

593 FERNÁNDEZ LÓPEZ 1994. Eine Übersicht über die von ihr unterschiedenen Brieftypen findet sich ebd., 31. Vgl. a. die funktionale Typologisierung in ZELZER 1997 und die kommunikationspragmatischen Ansätze in CONRING 2001 und CAIN 2009.

${ }^{594}$ Vgl. SCHRÖDER 2007, 148ff. 
Adressaten“, 3. „die Situation eines Dritten“, 4. „die Beziehung zwischen Adressat und Verfasser“. Während Brief(teil)e der zweiten Kategorie generell du-orientiert sind (z. B. Glückwünsche, Trostschreiben), die der dritten er-/sie-orientiert (z. B. Empfehlungsschreiben) und die der vierten beziehungsorientiert (z. B. Grüße, Danksagungen, Entschuldigungen), können solche der ersten sowohl ich-orientiert (z. B. Bitten bzw. Informationen über den Gesundheitszustand des Schreibers) als auch sachorientiert (z. B. Anfragen bzw. Auskünfte und Mitteilungen) oder beziehungsorientiert (z. B. Einladungen) sein.

\section{Brieftypen und Brieffunktionen}

Die Brieftheoretiker des klassischen Altertums liefern keine Taxonomie, die mit den differenzierteren Textsortenklassifikationen der modernen Linguistik vergleichbar wäre. Immerhin orientieren sich die griechischen Briefsteller, wenn sie Briefarten nach ihrer sozialen Situation bestimmen, in gewisser Weise an Handlungsbereichen. Die rhetorischen Genera sind letztlich den Bereichen Politik, Gericht und Privatleben zugeordnet. Cicero und lulius Victor differenzieren Briefarten nach inhaltlichen und funktionalen Kriterien. Die antiken Brieftypen entsprechen damit oft bestimmten Sprechaktuntermustern, womit sich durchaus Ansatzpunkte für eine weitergehende Klassifikation ergeben, die aber von den modernen Theoretikern nur teilweise aufgegriffen werden. ${ }^{595}$

Dem dieser Arbeit zugrunde liegenden sprechakttheoretischen Konzept kommt der Ansatz von Fernandez López am nächsten, wenngleich auch die anderen Klassifikationen mehr oder weniger stark pragmatisch geprägt sind. ${ }^{596}$ Die Sortierung in den nächsten Abschnitten erfolgt nach der übergeordneten Textfunktion (weitgehend in Anlehnung an Brinker). ${ }^{597}$ Phatische und i. e. S. expressive Briefe werden dabei zur Gruppe der Kontaktbriefe zusammengefasst, assertive und poetische Briefe hingegen voneinander getrennt ( $\rightarrow$ Informationsbriefe bzw. ästhetische Briefe). Metalinguistische Briefe bilden keine eigene Kategorie, sondern sind unter die Informations- oder Deklarationsbriefe subsumiert. Hinzu kommen multifunktionale Briefe, bei denen die übergeordnete Funktion nur schwer oder gar nicht bestimmt werden kann. Innerhalb der Teilkapitel wird auf Cugusis Zusammenstellung von Brieftypen zurückgegriffen, die auch anderweitig eine gute Übersicht liefert, obgleich die Einteilung nach privaten und öffentlichen Briefen problematisch scheint und zudem zu berücksichtigen ist, dass er keine distinkte Klassifikation anstrebt und die von ihm angeführten Brieftypen sich teilweise überschneiden, bei einigen zudem fraglich ist, ob man sie überhaupt als eigene Brieftypen bezeichnen sollte. ${ }^{598}$ Weitere Aspekte wie Handlungsbereiche sowie inhaltliche und formale Kriterien

\footnotetext{
${ }^{595}$ Zur grundsätzlichen Vereinbarkeit moderner Sprachfunktionsbegriffe mit den antiken Vorstellungen vgl. z. B. ANTÓN 1996, 114. Vgl. a. WULFRAM 2008, 17. Zur Beurteilung der Brieftypologisierungen in den antiken Briefstellern aus moderner Sicht vgl. außerdem STOWERS 1988, 80f. und ebd., 84.

${ }^{596}$ Zu Stowers vgl. z. B. BICKMANN 1998, 32, zur spätantiken Briefforschung SCHWITTER 2018, 96. Vgl. a. ebd., 103; SCHRÖDER 2007, 146f. und KLAUCK 1998, 72 zur allgemeinen Notwendigkeit pragmatischer Ansätze bei der Klassifikation antiker Briefe.

597 Den Begriffen ,Appellfunktion‘ bzw. ,Appellbrief‘ ziehe ich allerdings aufgrund ihrer m. E. größeren Neutralität die Termini ,Aufforderungsfunktion' bzw. ,Aufforderungsbrief' vor. Deklarationsbriefe und Obligationsbriefe werden im Folgenden nicht eigens erfasst, da sie insbes. im Zusammenhang mit dieser Arbeit nur von untergeordneter Bedeutung sind. Vgl. a. Kap. 1.2.1.2.4.

${ }^{598} \mathrm{Vgl}$. dazu und zu den anderen genannten Punkten die entsprechenden Passagen in der folgenden Übersicht bzw. im Kap. „Litterae publicae et privatae“ ab S. 102. Vgl. a. N. 592.
} 
können der Subklassifizierung dienen, worauf gelegentlich anhand einzelner Beispiele hingewiesen wird. Eine sinnvolle Hierarchisierung der Klassifikationskriterien wäre zu diskutieren. Hier geht es nur um einen ersten Überblick und allgemeine Anregungen zu einer weitergehenden Klassifikation. ${ }^{599}$

\section{Ästhetische Briefe}

Werden gewöhnliche Briefe zu literarischen Briefen, ändert sich nicht nur der Handlungsbereich und (durch die einer Veröffentlichung vorangehende Bearbeitung) ggf. die sprachliche und inhaltliche Ausformung, sondern v. a. auch die Verwendungsweise bzw. Funktion. ${ }^{600}$ Die Bestimmung eines reinen Gebrauchstextes liegt darin, gelesen und dann vernichtet zu werden, sofern er nicht als Beleg bzw. Beweismittel oder schlicht als Erinnerung aufbewahrt wird. ${ }^{601} \mathrm{Er}$ soll dem Empfänger also in irgendeiner Weise nützen (prodesse). Ein literarischer Text hingegen ist prinzipiell der Zeitlichkeit enthoben. Die zunächst in der konkreten Situation begründete Funktion wird abgelöst oder zumindest ergänzt durch eine ästhetische Funktion, die darin besteht, den Leser zu erfreuen (delectare) bzw. ihm Genuss zu verschaffen, sei es durch Bewunderung der ansprechenden Gestaltung eines Textes, sei es schlicht durch kurzweilige Unterhaltung. ${ }^{602}$ Diese läuft i. d. R. gewissermaßen quer zu den anderen Funktionen nicht nur, aber besonders in öffentlichen Briefen. In den meisten poetischen Briefen und Kunstbriefen steht sie sogar im Vordergrund. In einigen Fällen ist dies allerdings nicht so eindeutig zu entscheiden. So kommt in Ovids Exilbriefen (trist. und Pont.) der (expressiven) Gefühlsentladung, in den Episteln des Horaz der (direktiven) philosophisch-moralischen Anleitung zu einem guten Leben, und in vielen Briefen von Plinius (epist. 1-9) der (assertiven oder

\footnotetext{
${ }^{599}$ Vgl. S. 102.

600 Oft wird in diesem Zusammenhang zwischen eigentlicher und uneigentlicher Verwendung von Gebrauchstexten unterschieden. VgI. z. B. NICKISCH 1991, 107: „Die Trennlinie zwischen eigentlicher und uneigentlicher Verwendung der Gebrauchstextsorte Brief ist dann überschritten, wenn ein wirklicher Brief in den Dienst nicht-pragmatischer Intentionen gestellt wird, wenn er also seine Qualität als Träger einer aktuellen schriftlich realisierten Sprechhandlung im Rahmen einer individuellen realen Beziehung zwischen räumlich getrennten Partnern verliert." Vgl. a. THRAEDE 1980, 191. Eine uneigentliche Verwendung ist allerdings nicht gleichbedeutend mit einer besonderen literarästhetischen Qualität: VgI. z. B. SCHWITTER 2018, 98 N. 68 und NICKISCH 1991, 100 Vgl. a. N. 570. ${ }^{601}$ Zu Briefen als Gebrauchstexten vgl. z. B. THRAEDE 1980, 180f. Dort heißt es u. a.: „Die Wissenschaft stuft Briefe zunächst als Gebrauchstexte ein wie Leitartikel oder Annoncen. Ein Brief wandert von einer benennbaren Person oder Gruppe zur andern, er verfolgt einen bestimmten Zweck, will mitteilen oder grüssen. Ein Brief ist auch zeitgebunden: er wird obsolet, erledigt sich, sobald entweder Antwort kommt oder Sender und Empfänger einander wiedersehen. Mündlichkeit annulliert dann Geschriebenes; es sollte ja ein Gespräch notdürftig ersetzen." (ebd., 180). Zu den Gebrauchstexten, die i. d. R. aufbewahrt wurden, kann man z. B. Empfangsbriefe bzw. Quittungen zählen, die (informativ) den Erhalt einer Geldsumme oder eines anderen Gutes bestätigen und zugleich eine (kommissive) Zahlungsverpflichtung enthalten (vgl. CUGUSI 1983, 114f.). Freundschaftsbriefe sind hingegen im Sinne ihres "Geschenkcharakters" und der normalerweise damit verbundenen besonderen Gestaltung als bleibende Erinnerungen gedacht: Vgl. z. B. MüLleR 2018, 8. Vgl. a. das Kap. „Multifunktionale Briefe“ ab S. 116. Interessant in diesem Zusammenhang ist zudem die römische Praxis der Anfertigung von Briefkopien und des Aufhebens von Briefen in Hausarchiven (vgl. PETER 1965, 29ff.). Zur „Belegfunktion“ von Briefen vgl. a. HAUSENDORF UND KESSELHEIM 2008 (s. das Kap. „Hausendorf / Kesselheim“ ab S. 50).

602 Der Begriff, ästhetische Funktion“ wird hier in umfassenderer Weise verwendet, als es die Bedeutung i. e. S. nahe legt, die mehr auf den erstgenannten Aspekt (literarischer Genuss aufgrund einer besonderen formalen oder inhaltlichen Gestaltung) fokussiert. Er erscheint mir aber immerhin geeigneter als die noch enger gefassten Begriffe ,poetische Funktion' oder ,Unterhaltungsfunktion', die oft alternativ verwendet werden. Denkbar wäre auch ein neuer Begriff wie ,delektative Funktion“ - in Abgrenzung zu den anderen, „nützlichen“ (utilitaristischen) Gebrauchsfunktionen. Vgl. a. die Verwendung des Begriffs, delektativ' im Zusammenhang mit Funktionalstilen, z. B. bei BUSCH-LAUER 2008, 1724 bzw. LÖFFLER 2016, 98.
} 
auch expressiv-bewertenden) Darstellung von bestimmten Ereignissen und Sachverhalten ein hoher Stellenwert zu. ${ }^{603}$

\section{Informationsbriefe}

Die Nachrichtenfunktion gilt in der Antike „als die eigentliche, ursprüngliche Funktion von Briefen", konstituiert jedoch keinen eigenen Brieftyp. ${ }^{604}$ Es gibt aber durchaus Briefe, in denen die Information eindeutig im Vordergrund steht, und dies sowohl im privaten als auch im offiziellen und öffentlichen Bereich. ${ }^{605}$ Meistens sind solche (assertiven) Informationsbriefe eher zweckmäßig und schmucklos gehalten. ${ }^{606}$ Dies gilt bspw. für amtliche Briefe mit reiner Berichtsfunktion, Vollzugsmeldungen u. Ä. ${ }^{607}$ (Wissenschaftliche) Lehrbriefe erfüllen ebenfalls v. a. den Zweck, bestimmte (z. B. grammatische, juristische und medizinische Themen) informativ darzustellen. ${ }^{608}$ In einigen (poetischen) Lehrbriefen wie der Ars poetica von Horaz spielt aber außerdem die ästhetische Funktion eine bedeutsame Rolle. ${ }^{609}$

Autobiografische Briefe haben vordergründig zwar eine Informationsfunktion, dienen häufig allerdings weniger der objektiven Sachverhalts- als der subjektiven Selbstdarstellung oder der (expressiven) Selbstreflexion. ${ }^{610}$ Noch eindeutiger sind in dieser Hinsicht einige propagandistische politische Briefe mit stark persuasiver Färbung, in denen (einseitige) Informationen nur ein Mittel zur Durchsetzung eigener Sichtweisen und Ziele sind. ${ }^{611}$

Auch in den von Cugusi tatsächlich als Informationsbriefe bezeichneten persönlichen Privatbriefen geht es häufig gar nicht primär darum, den Briefempfänger, der oft bereits durch andere Kanäle unterrichtet war, über bestimmte Ereignisse zu informieren, sondern mehr um

${ }^{603}$ Zu den poetischen Briefen (= „lettere poetiche“) und Kunstbriefen (= „lettere d'arte): CUGUSI 1983, $127 \mathrm{ff}$. bzw. ebd., 129ff. Zur Problematik des Begriffs, lettere d'arte' vgl. a. SCHWITTER 2018, 94f. Vgl. außerdem PETER 1965, 101ff. bzw. ebd., 178ff.

${ }^{604}$ DRECOLL 2006, 43: „Diese Funktion [d. h. die Nachrichtenfunktion] ist zwar nicht ein genus/typos in der antiken Brieftheorie gewesen, aber sie ist thematisiert worden und wurde sogar als die eigentliche, ursprüngliche Funktion von Briefen angesehen. Daraus erklärt sich auch, dass die Brieftheorie diese Funktion nicht berücksichtigt. Denn ihre Einteilung in unterschiedliche genera/typoi erfolgt auf der Ebene der stilistischen, rhetorischen Gestaltung." Entsprechend findet sich weder in den griechischen Briefstellern noch bei lulius Victor ein informativer Brieftyp. Cugusi führt den (privaten) Informationsbrief hingegen als eigene Kategorie auf. Vgl. a. CUGUSI 1983, 106 und CUGUSI 1989 - 1991, 383 sowie BERNARD 2004, 150f. Vgl. außerdem MülLeR 2018, 7. Ausführlicher zu Briefen als Mittel des Informations- bzw. Nachrichtenaustauschs: DRECOLL 2006, 33ff. und CORBINELLI 2008, $57 \mathrm{ff}$.

${ }^{605}$ Vgl. z. B. BERNARD 2013, 101.

${ }^{606}$ Vgl. z. B. ebd., 97.

${ }^{607}$ Ausführlicher zu amtlichen Briefen (= „lettere ufficiali“): CUGUSI 1983, 116ff. und PETER 1965, 198ff. Zur entsprechenden funktionalen Subklassifizierung (Vollzugsmeldung und verschiedene Arten von Berichten) vgl. a. RoLF 1993, 177 bzw. ebd., $185 f$.

${ }^{608}$ Ausführlicher zu Lehrbriefen (= „lettere erudite o scientifiche“): CUGUSI 1983, 123ff. und PETER 1965, $216 \mathrm{ff}$. Vgl. a. S. 108 bzw. N. 588. Zur entsprechenden funktionalen Subklassifizierung vgl. außerdem RoLf 1993, 197.

${ }^{609}$ Vgl. z. B. Peter 1965, $221 \mathrm{ff}$.

${ }^{610}$ Ausführlicher zu den autobiografischen Briefen [= „lettere di tipo autobiografico“): CUGUSI 1983, 121f. Vgl. a. GIORGIO 2015, 23ff. („,La correspondance ou l'impossible histoire de l'autobiographie dans l'antiquité“). Dort wird auf die Möglichkeiten der autobiografischen Selbstkonstruktion in der Antike eingegangen. Vgl. außerdem CORREA 2013; CORREA 2011 und CORREA 2010. Zur entsprechenden funktionalen Subklassifizierung vgl. a. ROLF 1993, 186 bzw. ebd., 284 (zu „lobenden“ Textsorten wie dem Selbstlob).

${ }^{611}$ Zu den politischen Briefen (= „lettere politiche“ bzw. „lettere propagandistico-politiche“) vgl. z. B. CUGUSI 1983, 122f. : „[...] Pompeio ed i pompeiani, Cesare ed i cesariani, Antonio, Ottaviano ed altri cercavano di imporre e far accettare le proprie vedute politiche [...]. Caratteristiche le lettere con cui i condottieri ricordavano ufficialmente quanto avevano compiuto a vantaggio della collettività per ottenere la dovuta ricompensa [...]." Vgl. PETER 1965, 213ff. Zur entsprechenden funktionalen Subklassifizierung vgl. a. RoLf 1993, $190 \mathrm{ff}$. 
eine (bewertende) Einordnung und Deutung oder sogar Beeinflussung sowie um (kontaktorientierten) Meinungsaustausch, z. B. hinsichtlich politischer Geschehnisse, aber ebenso verschiedenster anderer Themen. Briefe über literarische Gegenstände zählt Cugusi dabei als eigene Kategorie. Grundsätzlich können sich in einzelnen Briefen - im Gegensatz zu den (entsprechend bearbeiteten) monothematischen Kunstbriefen - die Themen vermischen, wie auch die Funktion sich selten auf die reine Information beschränkt. ${ }^{612}$

\section{Aufforderungsbriefe}

Aufforderungsbriefe werden von Cicero und lulius Victor nicht in ihren Basisklassifikationen, sondern anderweitig erfasst. So wird an mehreren Stellen klar, dass Cicero es als wichtige Aufgabe von Briefen betrachtet, den Empfänger auf verschiedene Art und Weise zu beraten (consilium dare, suadere, monere). ${ }^{613}$ Eine solche direktive Komponente kann in einem persönlichen Brief zentral sein, verbindet sich aber häufig mit anderen, neben- oder sogar übergeordneten Funktionen. In vielen Trostbriefen ist bspw. die expressive Funktion gegenüber der direktiven und einer evtl. ebenfalls vorhandenen kommissiven Funktion dominant: Der Verfasser versucht, den Adressaten u. a. damit zu trösten, dass er ihm (praktische) Unterstützung verspricht und Rat gibt. ${ }^{614}$

Beratende Briefe finden sich nicht nur im privaten, sondern auch im öffentlichen Bereich. Philosophisch-moralische und religiöse (christliche) Briefe dienen im Rahmen einer allgemeinen Lebensberatung ebenfalls der Ermunterung, der Ermahnung und ggf. dem Trost. Im Gegensatz zu den privaten Briefen kann man solche Briefe meistens recht eindeutig als Aufforderungsbriefe (mit dominanter direktiver Funktion) identifizieren. ${ }^{615}$

\footnotetext{
612 Zum Informationsbrief (= „lettera d'informazione“) vgl. z. B. CUGUSI 1983, $106 f .:$ „Può vertere sugli argomenti più disparati: stato di salute degli interlocutori o di terzi [...]; informazioni su affari in corso; notizie su cose politiche [...], e via dicendo.“ Zum Brief über literarische Gegenstände (= „lettera su fatti letterari“) vgl. ebd., 110f.: „In questo genere di lettere si possono esprimere giudizi su opere letterarie [...], o si può avvisare il corrispondente dell'invio o del ricevimento di libri, o si possono esporre ,sistemi' letterari [...]. “ Zu den alternativen Informationswegen vgl. z. B. WHITE 2010, 23 sowie auch CIC. fam. 2.4.1 (an Curio). Zur über die reine Information hinausgehenden Funktionen bei der Übermittlung politischer Nachrichten (in CIC. Att. bzw. fam.) vgl. z. B. SCHRÖDER 2004 - 2005, 206 und DRECOLl 2006, 196. Vgl. a. ebd., 191ff. (zu „politischen Nachrichten in Ciceros Briefen“). Insgesamt sind vielfältige funktionale Subklassifizierungen der Informationsbriefe möglich, z. B. als Schilderung, Kommentar, Kunst- oder Literaturkritik: RoLf 1993, $172 \mathrm{ff}$.

${ }^{613}$ Vgl. z. B. BeRnARd 2013, 79 und GAVOILle Und GUILLAUMONT 2017b, 17ff. Dort wird beispielhaft u. a. auf folgende Textstellen hingewiesen: Att. 11.25 - fam. 6.22.1 (an Cn. Domitius Ahenobarbus) - fam. 4.8.1 (an M. Marcellus). Vgl. a. die Einleitung, S. 1 (mit Verweis auf Att. 1.17) sowie S. 95 und 107. In den griechischen Briefstellern werden hingegen durchaus verschiedenen Brieftypen aufgezählt, die man zu den Aufforderungsbriefen rechnen kann. Vgl. a. die Klassifikation in STOWERS 1986, 91ff., der zu den "letters of exhortation and advice“ folgende Untergruppen bildet: „parenetic letters (exhortation and dissuasion)“, „letters of advice“, ,protreptic letters (exhortation to a Way of Life)“, „letters of admonition“, „letters of rebuke“, „letters of reproach“, „letters of consolation“. Vgl. S. 109.

${ }^{614}$ Kurz hingewiesen sei außerdem darauf, dass in vielen anderen Briefen ebenfalls eine unterschwellige direktive Komponente enthalten ist, die aber nicht auf den ersten Blick zu erkennen ist und auch nicht unbedingt erkannt werden soll, wie z. B. in den Exilbriefen Ciceros und Ovids, die mit ihren Briefen letztlich auf eine Rückkehr nach Rom hinwirken wollten.

${ }^{615}$ Zu den philosophisch-moralischen Briefen („lettere filosofico-morali“) bzw. christlich-religiösen Briefen („lettere dottrinali cristiane“) vgl. Cugusı 1983, 127 bzw. CUgusı 1989 - 1991, 399. Vgl. a. Peter 1965, 225ff. Zur entsprechenden funktionalen Subklassifizierung (Hirtenbriefe) vgl. a. RoLf 1993, $245 \mathrm{ff}$.
} 
Beratend sind außerdem die in der antiken Brieftheorie in besonderer Weise thematisierten Empfehlungsbriefe ${ }^{616}$, und einige (symbuleutische) politische Briefe ${ }^{617}$, wie z. B. Ciceros Brief an seinen Bruder über die richtige Verwaltung ( $a d$ Q. fr. 1.1), die zwischen öffentlichen und privaten Briefen angesiedelt werden können. Außerdem gibt es amtliche Briefe mit direktiver Textfunktion, z. B. Anweisungen, Erlasse, Verfügungen sowie offizielle (An-)Fragen und Bittgesuche. ${ }^{618}$ Des Weiteren kann man Einladungsbriefe zu den Aufforderungsbriefen zählen. ${ }^{619}$

Nicht immer ist die Grenze zwischen den verschiedenen Brieftypen bzw. Handlungsbereichen leicht zu ziehen. So liegt der Unterschied zwischen einigen politischen, amtlichen und rein privaten Briefen bei z. T. sehr ähnlichem Inhalt im Wesentlichen in der Rolle, die Absender und Adressat jeweils einnehmen, also z. B. Politiker, Beamter, Vorgesetzter, Freund oder Familienangehöriger, womit dann in Bezug auf die geäußerten Aufforderungen (Empfehlungen, Ratschläge, Bitten, Befehle, Fragen usw.) unterschiedliche Grade der Verbindlichkeit korrelieren.

\section{Kontaktbriefe}

Die expressive Funktion bzw. Kontaktfunktion ist in öffentlichen Briefen naturgemäß nicht so stark ausgeprägt wie in privaten, da das Verhältnis zwischen Schreiber und Empfänger eher von unpersönlicher bzw. unbestimmter Natur ist, spielt in einigen Brieftypen aber durchaus eine wichtige Rolle. So haben Widmungs- oder Eröffnungsbriefe neben ihrer deklarativen Funktion zumindest vordergründig v. a. das Ziel, dem Adressaten als (potenziellem) Förderer zu danken. ${ }^{620}$ Politische Angriffs- und Verteidigungsbriefe stellen Anklage- oder Schmähschriften bzw. Apologien dar, die Tadel und (negative) Abwertung des Gegners mit (Selbst-)Lob und positiver Selbstdarstellung verbinden. ${ }^{621}$ Auch amtliche Briefe können solche

\footnotetext{
${ }^{616}$ Zu den Empfehlungsbriefen („commendatizie“) vgl. N. 590. Zur entsprechenden funktionalen Subklassifizierung vgl. a. Rolf 1993, 246ff.

${ }^{617}$ Zu den beratenden politischen Briefen („lettere simbuleutiche“) vgl. CUGUSI 1983, 122. Zu CIC. ad Q. fr. 1.1 vgl. a. KLAUCK 1998, 128f., der zudem auf das Commentariolum petitionis hinweist, das Ciceros Brief vorangegangen sein soll, bei dem aber die Urheberschaft von Quintus zweifelhaft scheint, und MüLLER 2018, 8, der ad Q. fr. 1.1 als „politischen Lehrbrief“ bezeichnet. Vgl. außerdem KLAUCK 1998, 119 zu zwei - auch bei CUGUSI 1983, 122 erwähnten - Sallust zugeschriebenen Briefen an Cäsar „mit Vorschlägen für eine politische und moralische Reform des Staatswesens".

${ }^{618} \mathrm{Zu}$ den amtlichen Briefen vgl. N. 607. Zur entsprechenden funktionalen Subklassifizierung vgl. a. RoLF 1993, 224ff., bes. ebd., 239ff., wo direktive Textsorten behandelt werden, die als bindend (mit Exekutionspflicht) zu charakterisieren sind. Ein bekanntes Beispiel ist die Korrespondenz zwischen Plinius d. J. und Kaiser Trajan. Vgl. a. KLAUCK 1998, 119.

${ }^{619}$ Vgl. MANUWALD 2009, 5. Zur entsprechenden funktionalen Subklassifizierung vgl. a. Rolf 1993, 250.

${ }^{620}$ Zu den Widmungs- und Eröffnungsbriefen („lettere prefatorie-dedicatorie“) vgl. CUGUSI 1983, 131ff. und PETER 1965, 242ff. Solche Briefe, die ursprünglich zusammen mit dem betreffenden Werk als echte Briefe verschickt wurden, erfüllen oft auch eine assertive Funktion, indem sie über das Werk informieren, und weisen außerdem meist eine recht starke direktive Komponente auf, insofern der Adressat nicht nur zur Lektüre angeregt, sondern mehr oder minder indirekt außerdem um (finanzielle) Unterstützung gebeten wird. Darauf, dass fast alle Briefe eine implizite direktive Komponente enthalten, wurde bereits eingegangen. Im Übrigen konnte einem Werk mit einem Widmungsbrief ein besonderes Gewicht verliehen werden, weshalb dieser Brieftyp besonders anfällig für Fälschungen war: Vgl. CUGUSı 1983, 132. Zur entsprechenden funktionalen Subklassifizierung vgl. RoLF 1993, 283. ${ }^{621}$ Zu den politischen Angriffs- und Verteidigungsbriefen („lettere di attacco e difesa personale“): CUGUSI 1983, 123 und PETER 1965, 213ff. Dort wird u. a. der Briefwechsel zwischen Antonius und Octavian als Beispiel genannt. Vgl. a. STOWERS 1986, 77ff. („Letters of praise and blame“) und ebd., 166ff. („Accusing, apologetic, and accounting letters") mit Verweis auf die zugehörigen Brieftypen in den Briefstellern. Zur entsprechenden funktionalen Subklassifizierung (z. B. Schmähbriefe) vgl. Rolf 1993, 277ff. Vgl. a. N. 622 und 623.
} 
expressiven Funktionen haben. Möglich sind z. B. offizielle Danksagungen und Belobigungsschreiben bzw. ihre negativen Entsprechungen, aber ebenso Briefe, die gute Wünsche an den Adressaten richten oder ihm gratulieren. ${ }^{622}$

Dankes- und Entschuldigungsbriefe sowie Gratulations- und Glückwunschbriefe finden sich auch oder vielmehr sogar hauptsächlich im privaten Bereich. ${ }^{623}$ Hinzu kommen Trostbriefe, auf die bereits im Zusammenhang mit den Aufforderungsbriefen kurz eingegangen wurde, die insgesamt jedoch als Kontaktbriefe zu charakterisieren sind, deren Hauptaufgabe darin besteht, dem Adressaten seelischen Beistand zu leisten. ${ }^{624}$ Umgekehrt kann das Schreiben von Briefen aber ebenfalls tröstlich und beruhigend auf den Textproduzenten wirken. ${ }^{625}$

Die eben genannten Brieftypen erfüllen häufig in erster Linie eine den (Höflichkeits-)Konventionen entsprechende beziehungsgestalterische Funktion und bewegen sich dabei - je nach Intensität der Beziehung - zwischen Konventionalität und echter emotionaler Anteilnahme. ${ }^{626}$ Dass Briefe auch ohne besonderen Anlass geschrieben werden, macht ebenfalls klar, dass bereits in der Antike ein Bewusstsein für den mit Briefen verbundenen Beziehungsaspekt vorhanden ist. Briefe werden zum Ersatz für das persönliche Gespräch. ${ }^{627}$ In scherzhaften Briefen genauso wie in Briefen ernsterer Natur werden durch „zweckfreies Plaudern“ Intimität und Nähe signalisiert. ${ }^{628}$ Besonders intensiv wirken die Briefe, wenn in ihnen sehr persönliche Gefühle ausgedrückt werden, wie z. B. in Liebesbriefen oder erotischen Briefen. Authentische Liebesbriefe aus der römischen Antike sind nicht erhalten, aber PLIN. epist. 7.5 kommt diesem Brieftyp recht nahe. Einige Passagen in Ciceros Briefen an Terentia aus der Zeit seines Exils könnten ebenfalls einem Liebesbrief entstammen, wobei die Exilbriefe überhaupt stark expressiv geprägt sind, wie es ja allgemein eher in Briefen an eng vertraute als an nicht so vertraute Personen zu erwarten ist. ${ }^{629}$

${ }^{622}$ Vgl. z. B. PLIN. epist. 10.1, wo Plinius Trajan zu seinem Amtsantritt gratuliert und ihm alles Gute wünscht. Zur entsprechenden funktionalen Subklassifizierung (z. B. Belobigungsschreiben, Dank-, Gratulations- und Glückwunschbriefe) vgl. RoLf 1993, 277ff. Vgl. a. N. 621 und 623.

${ }^{623}$ Zum (privaten) Gratulations- und Glückwunschbrief (,lettera gratulatoria“ bzw. „lettera augurale“) vgl. CUGUSI 1983, 107f. Vgl. a. die Ausführungen von lulius Victor zu den epistulae familiares (s. S. 108). Zur entsprechenden funktionalen Subklassifizierung vgl. RoLf 1993, 277ff. bzw. N. 621 und 622.

${ }^{624}$ Zum Trostbrief („lettera consolatoria“) vgl. CUGUSI 1983, 108f. und N. 590. Zur entsprechenden funktionalen Subklassifizierung (Beileids- und Kondolenzbriefe) vgl. RoLF 1993, 282.

${ }^{625} \mathrm{Vgl}$. z. B. SCHRÖDER 2004 - 2005, 210.

${ }^{626} \mathrm{Vgl}$. Kap. 1.2.1.2.4.

${ }^{627} \mathrm{Vgl}$. z. B. Att. 9.10.1 und 8.14.1 sowie fam. 1.7.1. Vgl. a. die Einleitung (S. 1), wo außerdem Att. 12.1 .2 und 14.12.3 zitiert werden. Ausführlicher zum „Brief als Gespräch“: Kap. 1.2.1.2.4. Zum Beziehungsaspekt antiker Briefe vgl. z. B. WHITE 2010, 29: „Cicero and his friends were not familiar with Jakobson's helpful analysis of communicative functions. But they did perceive that the officium litterarum or , work of letters' [...] figured significantly in the exchange of performances by which their relationships were formed and maintained. "Vgl. a. MüLLER 2018, 11; CorRea 2010, 190; CorbinelLI 2008, 56ff., bes. ebd., 63ff.; Bernard 2004, 153; CAVARzere 1998, 29; MuÑoz MARTín 1985, 76f. und THRAEDE 1970, 34. Zu Freundschaftsbriefen vgl. außerdem das Kapitel „Multifunktionale Briefe" ab S. 116.

${ }^{628}$ THRAEDE 1980, 194 (mit Bezug auf die scherzhaften Briefe): „[...] Inhalt findet Ersatz im zweckfreien, unterhaltsamen Plaudern.“ Zum scherzhaften Brief („lettera scherzosa“) vgl. im Übrigen CUGUsI 1983, 107 und S. 107 bzw. 108 in der vorliegenden Arbeit. Es ist nicht immer einfach zu unterscheiden zwischen iocari als (heiterem) Inhalt und als (Kommunikations-)Form (= Gespräch): Vgl. z. B. THRAEDE 1970, 34f. WHITE 2010, 23 weist außerdem darauf hin, dass es nur wenige Vertreter des Brieftyps „scherzhafter Brief“ in Reinform gibt. Vgl. a. S. 95.

${ }^{629}$ Zum Liebesbrief oder erotischen Brief (,lettera erotica“) vgl. CUGUSI 1983, 110. Dort wird auch auf antike Hinweise zu entsprechenden Schreiben von Servilia an Cäsar bzw. von Antonius an Fulvia aufmerksam gemacht. Zu 


\section{Multifunktionale Briefe}

Einige Brieftypen tauchen in den vorangegangenen Teilkapiteln mehrfach auf. So begegnen politische und amtliche Briefe sowohl als Informations- als auch als Aufforderungs- und Kontaktbriefe. Sie sind weder funktional noch inhaltlich festgelegt, sondern lediglich durch die Zugehörigkeit zu einem bestimmten Handlungsbereich definiert, sodass entsprechende (funktionale und inhaltliche) Untertypen gebildet werden können. Dies trifft ganz besonders auch auf private Briefe zu. ${ }^{630}$ Hier sind aufgrund der Art des Verhältnisses zwischen Briefschreiber und -empfänger, das durch Freundschaft (amicitia) oder Haushaltszugehörigkeit bzw. Verwandtschaft (familia) charakterisiert sein kann, Freundschafts- und Familienbriefe zu differenzieren. ${ }^{631}$

Freundschaftsbriefe werden in der antiken Brieftheorie ausführlich thematisiert und erweisen sich quasi als Paradebeispiele des Briefes überhaupt. ${ }^{632}$ Briefeschreiben gehört zu den Pflichten (officia) eines Freundes. Schon der Brief an sich gilt als (konventioneller) Freundschaftsbeweis, ebenso jedoch konkret auch die Erfüllung der mehr oder weniger direkt mit einzelnen Brieftypen verbundenen Aufgaben wie Benachrichtigung, Empfehlung, (praktischer und moralischer) Rat, Ermunterung, Trost und Glückwunsch. Mit Freundschaftsbriefen bezeugt man dem Empfänger seine Sympathie. Zugleich demonstrieren sie die höhere Bildung des Briefschreibers, dienen also der Etablierung und Festigung eines positiven Selbstbildes. V. a. sind sie freilich ein Mittel, sich den anderen zu verpflichten. ${ }^{633}$

den Briefen Ciceros an Terentia vgl. den Praxisteil (Kap. 2). RoLf 1993 versteht „Liebesbriefe“ (ebenso wie „Liebesanträge") entgegen der hier vertretenen Auffassung als Aufforderungstexte. Daneben finden sich in seiner Klassifikation assertive „Liebesgeständnisse“.

${ }^{630}$ Zur Problematik des Terminus ,Privatbrief' in Bezug auf antike Briefe vgl. z. B. SCHWITTER 2018, 89f.

${ }^{631}$ Angesichts des antiken Freundschaftsverständnisses können auch einige nach modernen Begriffen eher unpersönliche Briefe als Freundschaftsbriefe gelten. Vgl. z. B. BERNARD 2010, 416 und MANUWALD 2009, 8 sowie N. 632 und das Kap. „Litterae publicae et privatae“ ab S. 102, bes. S. 103.

632 Vgl. z. B. Thraede 1970, 3 und KosKenNiEMI 1956, 49f. Vgl. a. SCHWITTER 2018, 90 N. 26: „Die rhetorische Briefthe-

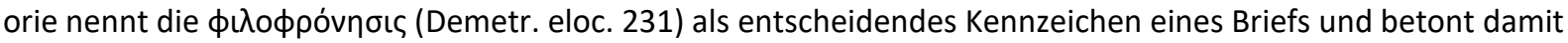
- ohne Verweis auf die Intimität des Inhalts - die freundschaftliche Verbundenheit, die prinzipiell allen Brieftypen zugrunde liegen soll.“ Freundschaftsbriefe („lettere del typos philikós“) werden zwar nicht in CUGUSI 1983, aber - wenn auch ohne weitergehende Erläuterung - in CUGUSI 1989 - 1991, 396 als eigener Brieftyp erfasst. Ausführlicher zu Freundschaftsbriefen: THRAEDE 1970, 125ff.; STOWERS 1986, 58ff. sowie WILCOX 2012, bes. ebd., 23ff. und BERNARD 2013, 71ff. Speziell zu griechischen Freundschaftsbriefen vgl. a. KoSKENNIEMI 1956, 88ff., bes. ebd., $115 \mathrm{ff}$. ${ }^{633}$ Zum Brief als Geschenk bzw. Freundschaftsbeweis in der antiken Brieftheorie vgl. z. B. CIC. fam. 6.6.1 (an A. Caecina). Vgl. a. De elocutione 225, 229 und 231f. sowie den entsprechenden Brieftyp ( $\varphi$ ıاкós) in den Túroı

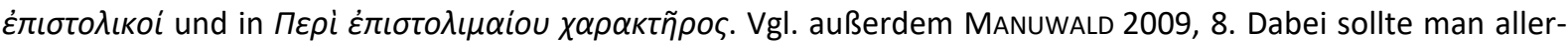
dings gewöhnliche Alltagsbriefe von sorgfältig ausgearbeiteten Freundschaftsbriefen i. e. S. unterscheiden. Vgl. a. SCHWITTER 2018, 89f. und THRAEDE 1970, 3 sowie WILCOX 2012. Zum Brief als Mittel zur Erfüllung der Freundschaftspflichten vgl. z. B. BERnARD 2013, 71ff.; BERnARD 2010, 416 und BERnARD 2004, 148. Speziell zum consilium vgl. a. GAVOILlE UND GUILLAUMONT 2017b, 17ff. und GIORGIO 2015, 180ff. Vgl. außerdem Müller 2018, 10ff.; SARRI 2017, 33ff.; GIORGIO 2015, 65ff.; Correa 2013, 65ff.; SCHRÖDER 2007, 150ff.; ROESCH 2002b, 104ff. und THRAEDE 1970, 36f. sowie das Kap. „Kontaktbriefe“ ab S. 114. Zum Brief als Zeichen der Bildung vgl. a. HutCHINSON 1998, $16 \mathrm{f}$. Vgl. des Weiteren (mit Bezug auf die Gegenwart) KERBRAT-ORECCHIONI 1998, 27f., wo das Briefeschreiben an sich als Akt der Höflichkeit bezeichnet wird: „Nos observations ont fait apparaître que dans notre société, l'envoi d'une lettre est généralement considéré comme une ,action bienfaisante' ou ,FFA' [...], alors que son non-envoi ou son envoi trop tardif, ainsi d'ailleurs que le fait d'avoir à y mettre un terme, sont plutôt considérés comme ,des actions menaçantes' ou ,FTAs' [...].“", bzw. (mit Bezug auf die Antike) GARCEA 2005, 134. 
Familienbriefe werden in der antiken Brieftheorie nicht als eigener Typ erfasst ${ }^{634}$, zeigen aber gewisse Parallelen zu den Freundschaftsbriefen. Gerade in der neueren Forschung wird z. B. auf eine teilweise starke Ähnlichkeit von römischer Ehe und Freundschaft hingewiesen. Als Beispiel dienen häufig die Exilbriefe Ciceros an Terentia bzw. Atticus, die sich allerdings nur bis zu einem bestimmen Grad tatsächlich ähneln. Dabei muss zum einen die mit dem Exil verbundene Extremsituation bedacht werden, die zu einer Verschiebung der traditionellen Rollenverhältnisse führen konnte, zum anderen der nicht unbedeutende Einfluss anderer Faktoren (wie z. B. Geschlecht und Bildungsgrad) auf die individuelle Ausgestaltung der Briefe. ${ }^{635}$

Die Exilbriefe sind im Übrigen auch Beispiele für eher unspezifische Privatbriefe, in denen sich verschiedene Funktionen so vermischen, dass nicht immer leicht zu entscheiden ist, wieweit eine bestimmte Funktion dominiert. Multifunktionalität (und Multithematizität), insbesondere die Verbindung von Kontakt- und Informationsfunktion, sind zwar typisch für Freundschafts- und Familienbriefe, in vielen Briefen steht indessen eine Funktion deutlich im Mittelpunkt, wie z. B. bei einigen der bereits (unter den entsprechenden Funktionskategorien) aufgeführten Brieftypen. Zu nennen wären bspw. assertive Informationsbriefe und expressive Glückwunsch- und Trostbriefe, aber ebenso direktive Bittbriefe, in denen der Briefschreiber den Adressaten um Hilfe, Rat oder schlicht Informationen ersucht. ${ }^{636}$

Dass die Kontaktfunktion zwar in einigen Fällen nicht dominant, in Freundschafts- und Familienbriefen allgemein aber besonders wichtig ist, scheint klar. Letztlich dienen ja sogar Informations- und Aufforderungsbriefe der Beziehungspflege. Man muss jedoch unterscheiden zwi-

\footnotetext{
${ }^{634} \mathrm{VgI}$. STOWERS 1986, 71: „The family or household letter was never recognized as a type by the ancient theorists. In fact, very many of the types were customarily employed in correspondence between members of the household. Yet the epistolary theorists could have isolated the family letter as a type analogous to the friendly letter: A letter for maintaining the affection and social relationships of the household. The Greek epistolographic tradition was too closely tied to the traditionally segregated literate culture of free adult males, i.e., friendship, for that to happen. The papyri from Egypt have shown the enormous lacunae that would be left in our picture of letter writing if we were to follow the epistolary theorists at this point."

${ }^{635}$ Ausführlicher zu den Familienbriefen: STOWERS 1986, 71ff. Speziell zu griechischen Familienbriefen: KOSKENNIEMI 1956, 88ff., bes. ebd., 104ff. Zur Ähnlichkeit von römischer Ehe und Freundschaft vgl. bes. JEPPESEN-WIGELSWORTH 2013. Zum Vergleich der Exilbriefe Ciceros an Terentia, Atticus und Quintus vgl. die Analysen in JÄGER 1986 und HUTCHINSON 1998. Vgl. außerdem Kap. 2.1.3 und 2.2.2.

${ }^{636}$ Vgl. z. B. GIORGIO 2015, 57: „Certaines lettres privilégient un seul type d'acte de langage (la requête ou l'exhortation, qui deviennent alors de véritables ,macro-actes' de langage): c'est la caractéristique des genres très codifiés. D’autres, au contraire, laissent des énoncés à valeurs illocutoires très différentes se juxtaposer et caractérisent les lettres les plus familières. “ und WHITE 2010, 23: „Often a writer does confront some limited practical objective: to canvass a vote, to introduce a protégé, to negotiate a purchase or sale, or to discharge an obligation of congratulation or condolence, for example. But it can be deceptive to approach the letters of the Ciceronian corpus simply in terms of their immediate goals. For one thing, they often pursue more than one at a time. But more important is that practical objectives are usually subordinate to, or at least, accompanied by, a larger purpose." Zur Multifunktionalität und -thematizität vieler Privatbriefe insgesamt vgl. S. 99. Speziell zu römischen Briefen vgl. a. THRAEDE 1980, 183 und ebd., 193f. Vgl. außerdem KOSKENNIEMI 1956, 92, der drei Arten von Briefen unterscheidet: Briefe als reine Benachrichtigung, Briefe als Verbindung von praktischen Zwecken und Beziehungspflege und schließlich Briefe, in denen der persönliche Kontakt im Vordergrund steht. Vgl. des Weiteren N. 637. Im Übrigen bleibt festzustellen, dass teilweise, wenngleich nicht so stark ausgeprägt, auch amtliche Briefe multifunktionale und multithematische Tendenzen aufweisen und bspw. neben einem assertiven Bericht direktive Fragen oder Bitten enthalten können.
} 
schen den unmittelbaren kurzfristigen Zielen bzw. Funktionen eines Briefes und der langfristigen Pflege einer Beziehung. ${ }^{637}$ In Anbetracht der Tatsache, dass Briefe immer auch phatisch sind und eine Informationsfunktion ebenfalls notwendigerweise fast immer vorliegt, könnte man bei der Bestimmung des Brieftyps der Aufforderungsfunktion einen Vorrang vor der Informationsfunktion einräumen und dieser wiederum einen höheren Stellenwert beimessen als der Kontaktfunktion. ${ }^{638}$ Allerdings erscheint eine solche Vorgehensweise nicht in jedem Fall sinnvoll, da zu bezweifeln ist, dass sich Brieffunktionen tatsächlich so pauschal hierarchisieren lassen.

\subsection{Fazit}

Im Wesentlichen begegnen uns in der römischen Antike Briefe mit übergeordneter Informations-, Aufforderungs- und Kontaktfunktion sowie Mischformen, in denen keine Funktion eindeutig vorherrschend ist. Natürlich sind auch Obligationsbriefe denkbar, z. B. persönliche Briefe, in denen ein Versprechen im Mittelpunkt steht, oder amtliche Briefe mit deklarativer Textfunktion, die bspw. eine Freilassung, eine Ernennung, eine Vollmacht, einen Beschluss oder ein Urteil beinhalten. ${ }^{639}$ Insgesamt spielen solche Brieftypen aber eine untergeordnete Rolle und können im Hinblick auf den Gegenstand dieser Arbeit weitgehend vernachlässigt werden. Einen Sonderstatus nimmt die ästhetische Funktion ein, die nur in wenigen, v. a. öffentlichen Briefen dominiert und im Übrigen auch in vielen anderen Brieftypen mehr oder minder bedeutsam sein kann, wobei sie quasi quer zu den weiteren Funktionen läuft. ${ }^{640}$

Die Bestimmung der Textfunktion gestaltet sich ebenso schwierig wie die des zugehörigen Handlungsbereichs. Probleme bereitet zum einen die Multifunktionalität vieler Briefe, zum anderen die unklare Grenze zwischen öffentlicher und privater Sphäre in der römischen Gesellschaft. Bei einigen Brieftypen, wie z. B. den politischen Briefen, verbinden sich zudem Handlungsbereich und Inhalt, wobei Ersterer entscheidend ist. Es kommt also für die Typologisierung weniger auf ein politisches Thema an als auf die Tatsache, dass die Korrespondenten als Politiker (und nicht als Privatpersonen) agieren. ${ }^{641}$ Auch in anderen Fällen sind die Kriterien, aus denen sich Bezeichnungen der Brieftypen, wie sie u. a. bei Cugusi zu finden sind, herleiten, nicht immer klar voneinander abzugrenzen. So referieren scherzhafte (ebenso wie ernsthafte) Briefe sowohl auf einen bestimmten Inhalt als auch auf den Ton, also die Form der Briefe.

Abgesehen von der Mehrdeutigkeit einiger Termini besteht die Krux hauptsächlich darin, dass den Definitionen der einzelnen Brieftypen keine einheitliche Basis zugrunde liegt. Mit einigen

\footnotetext{
${ }^{637}$ Vgl. z. B. WHITE 2010, 28. Vgl. a. ebd., 23 bzw. N. 636. Zur (herausragenden) Bedeutung der Beziehungspflege in Verbindung mit anderen (assertiven oder direktiven) Funktionen vgl. außerdem ebd., 137 und THRAEDE 1980, 182 SOWie CORBINELLI 2008, 67.

${ }^{638}$ Vgl. z. B. SALLABeRger 1999, 142, aus dessen Äußerungen man ableiten kann, dass er zumindest der Informationsfunktion anscheinend einen Vorrang gegenüber dem Kontaktfunktion einräumt: „Ein Brief muß [...] nicht alle Teile aufweisen. Hier ergibt sich dann weitgehend eine direkte Relation zwischen Textstruktur und Textfunktion: fehlt etwa der Aufforderungsteil, handelt es sich üblicherweise um eine Information, fehlt auch der Informationsteil, um einen Kontaktbrief [...]."

${ }^{639}$ Als Deklarationsbriefe können außerdem Widmungs- oder Eröffnungsbriefe gelten. Im Grunde steht dort allerdings eher die Kontaktfunktion im Vordergrund. Vgl. den Abschnitt „Kontaktbriefe“ ab S. 114.

${ }^{640}$ Vgl. die Kap. „Brief zwischen Gebrauchstext und Literatur“ ab S. 104 und „Textfunktionen“ ab S. 47.

${ }^{641}$ Vgl. das Kap. „Kommunikationssituationen und Handlungsbereiche“ ab S. 102, bes. N. 559.
} 
Bezeichnungen wird auf spezielle Funktionen (z. B. Informationsbriefe) bzw. funktionale Untermuster (z. B. Gratulations- und Trostbriefe) referiert. Andere beziehen sich auf den Handlungsbereich (amtliche und politische Briefe sowie Freundschafts- und Familienbriefe), wieder andere auf den Inhalt (z. B. autobiografische Briefe und Briefe über literarische Gegenstände) oder die Form (z. B. poetische Briefe). Auch dadurch kommt es zu Überschneidungen. Handelt es sich z. B. bei der Ars poetica von Horaz um einen poetischen Brief mit dominanter ästhetischer Funktion oder um einen Lehrbrief mit dominanter Informationsfunktion? Ähnlich verhält es sich mit Kunstbriefen zu bestimmten, z. B. literarischen Themen. ${ }^{642}$

Für eine überzeugendere Klassifikation römischer Briefe müssten die Bezeichnungen für einige Brieftypen angepasst und verschiedene Untertypen ausdifferenziert werden. Ein einziges Klassifikationskriterium scheint dabei nicht ausreichend zu sein, hat bislang wenigstens noch nicht zu gänzlich befriedigenden Resultaten geführt, wie z. B. der grundsätzlich durchaus interessante funktionale Ansatz von Rolf zeigt. ${ }^{643}$ Nicht nur die Textfunktion, auch andere mögliche Klassifikationskriterien sind jeweils mit eigenen Problemen verbunden. Möglich wäre eine Brieftypologie in Anlehnung an Ermert, in der Handlungsbereich und Funktion als übergeordnete Kriterien dienen. ${ }^{644}$ Dabei wäre zu überlegen, ob man Briefe des öffentlichen Bereichs wie poetische Briefe, Kunstbriefe und philosophische Briefe, die nur begrenzt als Briefe i. e. S. gelten können, aus der Klassifikation ganz herausnimmt und sich stattdessen auf eine Unterscheidung von privaten und offiziellen (amtlichen) Briefen beschränkt, obgleich auch so viele Abgrenzungsprobleme bestehen bleiben. Man könnte also bspw. offizielle und private Informations-, Aufforderungs- und Kontaktbriefe differenzieren. Hinzu kämen als gesonderte Kategorie unspezifische multifunktionale (und -thematische) Briefe. Eine Subklassifikation würde aufgrund verschiedener Themen erfolgen. Die Form schließlich eignet sich eher weniger als Klassifikationskriterium, kann aber zur genaueren Charakterisierung von Brieftypen dienen, mit denen sie ja eng verbunden ist. Amtliche Briefe sind bspw. i. d. R. formeller gehalten als private Briefe. Ein Gratulationsbrief wäre somit z. B. ein Kontaktbrief privater oder offizieller Natur, dessen Inhalt durch den konkreten Anlass (wie Geburtstag oder Amtsantritt) bestimmt ist. Die zu den Familienbriefen zählenden Briefe Ciceros an Terentia in fam. 14 gehören dagegen tendenziell eher zu den unspezifischen Privatbriefen, in denen verschiedene Funktionen (und Inhalte) mehr oder weniger gleichberechtigt nebeneinanderstehen. Wieweit in einzelnen Fällen eine dominante Textfunktion identifiziert werden kann, sodass

\footnotetext{
642 Zur Heterogenität und den Überschneidungen der Kriterien zur Typologisierung antiker Briefe vgl. a. MANUWALD 2009, 4.

${ }^{643} \mathrm{Vgl}$. die entsprechenden Anmerkungen zu einzelnen Brieftypen in den Fußnoten der vorangegangenen Teilkapitel. Zur Kritik an Rolfs Klassifikation vgl. N. 545.

${ }^{644}$ Eine Einteilung nach Handlungsbereichen, d. h. die Unterscheidung privater und öffentlicher Briefe, findet sich in modernen Untersuchungen zur Klassifikation antiker Briefe häufiger. Cugusi zählt bspw. Informationsbriefe, Freundschaftsbriefe, scherzhafte Briefe, Gratulations- und Glückwunschbriefe, Trostbriefe, erotische Briefe bzw. Liebesbriefe und Briefe über literarische Themen zu den litterae privatae, amtliche Briefe, autobiografische Briefe, politische Briefe, gelehrte oder wissenschaftliche Briefe, philosophisch-moralische und religiöse Briefe, Kunstbriefe, poetische Briefe und Widmungsbriefe zu den litterae publicae. Als Zwischenformen gelten bei ihm Empfehlungsbriefe und Empfangsbriefe: VgI. CUGUSI 1983, 106ff.; ebd., 111ff. und ebd., 115ff. sowie CUGUSI 1989 - 1991, 395ff. Vgl. außerdem BERNARD 2013, 101, wonach Informationsbriefe auch im öffentlichen Bereich möglich sind.
} 
eine Kategorisierung als Informations-, Aufforderungs- oder Kontaktbrief möglich ist, wird im zweiten Teil dieser Arbeit untersucht.

\subsubsection{Wesensbestimmung des römischen (Privat-)Briefes \\ 1.2.1.3.1 Brief als Gespräch?}

Das dieser Arbeit zugrunde liegende Textkorpus (CIC. fam. 14) wird zu den privaten Briefen gerechnet, welche auch - allerdings mit Fokus auf den Freundschaftsbriefen - im Mittelpunkt der antiken Brieftheorie standen. ${ }^{645}$ Zur Erfassung ihrer Wesensart bietet ein Vergleich mit dem Gespräch eine gute Ausgangsbasis. Dabei handelt es sich um einen gängigen Topos der

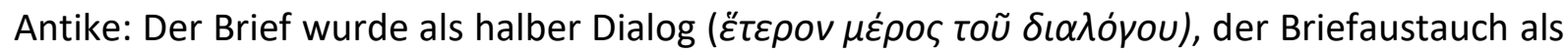
Gespräch (ouliia bzw. colloquium) betrachtet. Cicero spricht bspw. von amicorum colloquia absentium. Häufig findet sich außerdem die Vorstellung, man sehe den anderen quasi coram $(=\dot{\omega} \varsigma \pi \alpha \rho \dot{\omega} v$ bzw. $\pi \alpha \rho o v \sigma i \alpha) .646$

Allerdings besteht tatsächlich ja eine räumliche Trennung der Briefpartner. ${ }^{647}$ Ebendiese ist ursächlich und - neben weiteren allgemeinen Rahmenbedingungen des Briefeschreibens und den besonderen Bedingungen der antiken Briefpraxis ${ }^{648}$ - kennzeichnend für die briefliche Kommunikation im Unterschied zum persönlichen Gespräch.

In einigen Fällen konnten Nachrichten durch Boten mündlich übermittelt werden, aber oft reichte dies nicht aus, und die mündliche Mitteilung wurde durch eine schriftliche ergänzt

\footnotetext{
${ }^{645}$ Vgl. S. 116.

${ }^{646}$ Vgl. z. B. ThRAEDE 1970, 38, der meint, dass „sich aus diesem Gedanken - Brief als Gespräch zwischen Abwesenden, d.h. Gespräch trotz räumlicher Trennung (die Kehrseite zur Als-ob-Unmittelbarkeit) - so etwas wie eine Definition des Briefwechsels im allgemeinen entwickelt zu haben scheint [...]. "Vgl. a. ebd., 45. Ausführlicher zum Brief(wechsel) als Gespräch in der Antike: CORREA 2010, 189ff.; WHITE 2010, 18ff.; WULfRAM 2008, 17f.; GARCEA 2005, 97ff.; SCHRÖDER 2004 - 2005, 210ff.; GAVOILle 2004; GARCEA 2002, 209ff.; ANTÓN 1996, 116f.; PENNACINI 1985, 14f.; CUgusi 1983, 43ff.; KOSKENNIEMI 1956, 42ff. und bes. ThRAEDE 1970, passim, speziell zu Cicero ebd., 27ff. („,Brief als Gespräch“) und ebd., 39ff. („Die Idee der Anwesenheit“). Vgl. a. RANDALl 2018, 17ff. (bes. ebd., 27ff.) sowie die Briefanalysen in RÜHL 2019. Bei CUGUSI 1983, 32f. werden im vorliegenden Zusammenhang CIC. Phil. 2.7.44

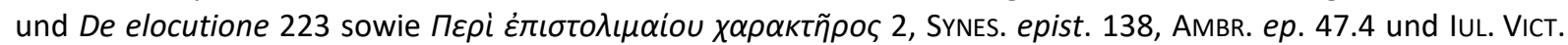
rhet. (Div. 1964, 448, 32) zitiert. Vgl. des Weiteren CIC. fam. 2.9.2, 3.11.2 und 15.19.1, Att. 6.1.24 und 12.53, ad Q. fr. 1.1.45 sowie darüber hinaus Ov. epist. (her.) 21.20, trist. 4.4.23, Pont. 1.2.6 und 49, 2.4.1 und 3.5.50. THRAEDE 1970, 46f. fasst (mit Bezug auf Ciceros Briefe) folgendermaßen zusammen: „[...] in Ciceros Briefwechsel stoßen wir auf die nachweislich ältesten Belege für die briefgebundenen Motive 1 . Brief als $\lambda \alpha \lambda \varepsilon \tilde{v}$ (iocari: Inhalt, colloqui: Situation), 2. Briefpartner als $\dot{\omega} \varsigma \pi \alpha \rho \omega \dot{v}$-quasi coram (auch als quasi colloqui), 3. Schreiben (Lesen) als Erlebnis geistigen ,Sehens'. Davon wird 1) durch den Brief selbst konstituiert, während 2) und 3) wohl eher als Anwendung populärer Maximen über ,Freundschaft' auf den Freundschaftsbrief aufgefaßt werden müssen, so daß man, zumindest für die frühe Zeit, gern primäre von sekundärer Brieftopik wird unterscheiden wollen." Zu den Unterschieden zwischen Brief und oratio bzw. sermocinatio vgl. außerdem IUL. VICT. rhet. (Div. 1964, 448, 10ff.; vgl. CORBINELLI 2008, 82). Allgemein zu den Unterschieden und Gemeinsamkeiten der beiden Kommunikationsformen Brief und Gespräch: KERBRAT-ORECCHIONI 1998, 16ff. und LANGEHEINE 1983b, 193ff. Vgl. a. (zur Textualität von Gesprächen) ROLF 1993, 27ff.

${ }^{647}$ Natürlich ist dies auch den antiken Briefschreibern bewusst und wird entsprechend thematisiert, wobei mal die (Quasi-)Anwesenheit, mal die Trennung hervorgehoben wird: Vgl. z. B. SCHRÖDER 2018, 85 (mit Bezug auf die Atticus-Briefe) und ALtMAN 1982, 13. Vgl. a. ebd., 42f. und CLAASSEN 1999, 103ff. („Bridging the divide“). Ausführlicher zur räumlichen Trennung und ihrem Einfluss auf die Briefe Ciceros: RÜHL 2019.

${ }^{648}$ Ausführlicher zur antiken Briefpraxis allgemein: BERNARD 2013, 33ff.; CORREA 2013, 65ff.; WHITE 2010, 3ff. und ebd., 63ff.; KLAUCK 1998, 55ff.; BernARDI PerinI 1985, 22f.; TYrRell 1966, LXff. und Peter 1965, 29ff. Zur Spätantike vgl. a. SCHRÖDER 2007, $138 \mathrm{ff}$.
} 
oder ganz ersetzt. ${ }^{649}$ Dies konnte z. B. bei vertraulicheren Informationen sinnvoll erscheinen, die nicht für die Ohren des Boten (und anderer Personen) gedacht waren. Aus dem gleichen Grund verzichtete man bisweilen auf das Diktieren von Briefen und schrieb diese selbst (Autographie), wodurch man ihnen zugleich eine persönlichere Note verlieh. ${ }^{650}$ Ein zusätzlicher Schutz, wenn auch keine Garantie für die Wahrung der Privatsphäre, war die Versiegelung von Briefen. Die Unwägbarkeiten des Transportwesens stellten eine Gefahr dar, durch die Briefe nicht nur bei absichtlicher Unterschlagung, sondern ebenso aus den verschiedensten anderen Gründen verloren gehen konnten, weshalb z. B. einige Briefe mehrfach verschickt wurden. ${ }^{651}$

Der Brieftransport und der Vorgang des Schreibens an sich bewirken eine stark verlangsamte Kommunikation. Durch die raum-zeitliche Distanz wird eine spontane Reaktion verhindert; andererseits ergibt sich dadurch, dass kein unmittelbarer Handlungsdruck besteht, die Möglichkeit zu größerer Überlegtheit und Strukturiertheit bei der Antwort. ${ }^{652}$ Besondere Klarheit bei der Ausgestaltung eines Briefes ist v. a. deshalb notwendig, weil die Briefkommunikation nicht in einer konkreten gemeinsamen Situation stattfindet und damit gewisse Informationen

${ }^{649}$ Zu Briefboten in der (Spät-)Antike vgl. z. B. SCIOR 2018, 368: „Die Spannbreite der Funktionen, die Boten in brieflichen Kommunikationsprozessen innehaben konnten, war groß. Sie reichte vom sprichwörtlichen Tragen schriftlicher Botschaften über die mündliche Ergänzung von Briefen und das Ausrichten oraler Botschaften bis hin zur Übermittlung komplizierter mündlicher Sachverhalte, die vor Ort erläutert oder überzeugend vermittelt werden mussten." Zur Rolle von Boten allgemein vgl. z. B. ebd., 369 und ebd., 377. Vgl. a. SCHRÖDER 2018 (mit besonderem Bezug auf Ciceros Briefe an Atticus), die als Ziel ihrer Arbeit angibt: „This chapter will consider the fundamental influence of the courier on both the conception and the actual content of letters [...]." (ebd., 82). Vgl. außerdem SCHRÖDER 2007, 149f. und WULFRAM 2008, 20 sowie (auf allgemein-abstrakter Ebene) KRÄMER 2008a und KRÄMER 2008b. Vgl. des Weiteren N. 651.

${ }^{650}$ Auf der anderen Seite bestand die Möglichkeit, das Schreiben eines Briefes in besonderen Situationen auch ganz an andere zu delegieren: Vgl. z. B. WHITE 2010, 66.

${ }^{651}$ Zum Briefgeheimnis vgl. z. B. SCHWITTER 2018, 90; GARCEA 2002, 209; KLAUCK 1998, 131f. und PENNACINI 1985, 13 sowie ausführlicher (auch zum Brieftransport) NICHOLSON 1994. CUGUSI 1989 - 1991, 380 macht darauf aufmerksam, dass die Privatheit persönlicher Briefe von den antiken Autoren zwar immer wieder betont wurde (vgl. z. B. CIC. Phil. 2.7, APUL. apol. 84, AMM. 20.8.18), sie sich aber nicht unbedingt selbst daran gehalten haben (vgl. z. B. Att. 4.6.4 und 5.11.7, fam. 5.12, 10.31.2 und 10.31.6). Vgl. a. SCHWITTER 2018, 90: „Die unberechtigte Einsichtnahme in einen Privatbrief war zivilrechtlich zwar nicht belangbar, doch zeigen Stellen bei Cicero, Apuleius oder Ammianus Marcellinus, dass insbesondere die weitere Verbreitung oder Veröffentlichung vertraulicher Briefe als Ehrverbrechen galt.“ und ebd., 92: „Dass antike Briefautoren mit einer (kleinräumigen) Zirkulation gewisser Privatbriefe rechneten, zeigt insbesondere Cicero, doch liegt für die moderne Briefforschung die Schwierigkeit darin festzustellen, aufgrund welcher Kriterien die primären Rezipienten ersahen, wann das Briefgeheimnis beachtet werden musste und wann nicht. “ Als Hinweise können z. B. Vertraulichkeit signalisierende Anredeformeln, „eine persönlich verfasste subscriptio oder die Anbringung eines Siegels“ (ebd., 92 N. 38) gelten. Zur „authentication“ im Zusammenhang mit antiken Briefen vgl. a. SARRI 2017, 120ff. Zur fidelitas (bzw. infidelitas) und veritas der (spät)antiken Briefboten vgl. SCIOR 2018, 371ff. Vgl. a. SCHRÖDER 2018, 84. Zur Autographie von Briefen als Zeichen der Intimität und Verbundenheit: CORBINELLI 2008, 30f.; GARCEA 2002, 213; CUGUSI 1983, 69f.; THRAEDE 1980, 192. Vgl. a. IUL. VICT. rhet. (s. Div. 1964, 448, 27).

652 Vgl. z. B. KERBRAT-ORECCHIONI 1998, 35f.: „Par rapport à la conversation orale, la principale caractéristique de la communication épistolaire est sa lenteur: les mots se forment lentement, ils s'acheminent lentement, et l'on peut prendre son temps pour y répondre. Lenteur qui peut être vue comme un inconvénient, mais aussi comme un avantage [...]. Risques réduits, liberté accrue: ce sont les avantages de la communication par lettres [...]." In ebd., 16 hebt sie zudem den „caractère improvisé“ von persönlichen Gesprächen im Unterschied zum „caractère prémédité“ brieflicher Kommunikation hervor. Vgl. a. NICKISCH 1991, 11 bzw. BÜRGEL 1976, 286 sowie KLAUCK 1998, 132, der mit Bezug auf CIC. fam. 8.6.5 darauf hinweist, dass sich das Schreiben eines (längeren) Briefes über einen größeren Zeitraum erstrecken konnte. Vgl. außerdem WüEST 2011, 48. 
fehlen, die im persönlichen Gespräch unmittelbar - verbal oder non- und paraverbal - übermittelt werden können. ${ }^{653}$

Die Ähnlichkeit von Briefen mit Gesprächen zeigt sich dagegen durch den Partnerbezug und eine scheinbare Zwanglosigkeit bzw. Unkonventionalität, welche sich z. B. in einer Tendenz zur Multithematizität und -funktionalität äußert, die im Übrigen aber auch mit verschiedenen anderen Mitteln suggeriert werden soll, obschon Briefe im Übrigen stark von Formelhaftigkeit bzw. Konventionalität geprägt sind. Diese Dialogizität ist nicht gleichzusetzen mit Mündlichkeit, ebenso wenig wie Monologizität mit Schriftlichkeit. Manchmal wird deshalb mediale und konzeptionelle Mündlichkeit bzw. Schriftlichkeit unterschieden, wonach bspw. Briefe medial schriftlich sind, konzeptionell aber vielfach eher als mündlich gelten können. ${ }^{654}$ In neuerer Zeit wird - v. a. in Anbetracht der jüngsten medialen Entwicklungen - sogar grundsätzlich in Frage gestellt, ob eine Unterscheidung von Mündlichkeit und Schriftlichkeit (noch) sinnvoll ist. ${ }^{655}$ Festzuhalten bleibt jedenfalls, dass viele Besonderheiten schriftlicher Texte nur z. T. direkt durch das Medium Schrift bedingt sind, obgleich Schriftlichkeit häufig mit bestimmten Merkmalen eher korreliert als mit anderen. Letztlich ist die konkrete Ausgestaltung von Briefen mehr durch die spezifische Kommunikationssituation und andere Faktoren (wie z. B. den räumlich-zeitlichen Phasenverzug, den Grad der Vertrautheit der Partner miteinander, ihre emotionale Beteiligung und Kooperationsbereitschaft) beeinflusst. ${ }^{656}$

653 Vgl. z. B. WÜEST 2011, 48; ROESCH 2002b, 111; BICKMANn 1998, 69ff.; StOWERS 1988, 79 und BeRNARDI PERINI 1985, 17. KERBRAT-ORECCHIONI 1998, 16f. unterscheidet eine „situation partagée“ bei persönlichen Gesprächen von einer „situation non partagée“ in der brieflichen Kommunikation. Vgl. dagegen THRAEDE 1980, 182, der von einem anderen (allgemeineren) Situationsbegriff ausgeht: „Gespräch und Brief sind verwandt, [...]. Situationsgebundenheit und Partnerbezug prägen hier wie dort die Art der ,Botschaft' [...].“

${ }^{654}$ Zur Unterscheidung von medialer und konzeptueller Mündlichkeit bzw. Schriftlichkeit: KOCH UND OESTERREICHER 2008, 199ff. (vgl. N. 656). Kritisch zu Koch / Oesterreicher äußern sich z. B. STEIN 2018, 23 (vgl. N. 655) und SCHNEIDER 2018, 276, der u. a. auf die Problematik des dort verwendeten Medienbegriffs hinweist. Vgl. a. die weiteren Ausführungen in ebd. zu den Termini ,Medium' und ,Medialität' sowie verwandten Begriffen wie ,Kommunikationsform' bzw. ,Modalität'. Vgl. außerdem die Darlegungen zum Einfluss des Mediums auf die Bedeutung einer Äußerung, z. B. ebd., 277: „Ein Medium ist [...] konstitutiv für das darin Mediatisierte; es ist intrinsisch mit diesem verbunden. Genau dies ist es, was ein Medium von einem Mittel unterscheidet: [...] Medium und Mediatisiertes bilden [...] eine untrennbare Einheit. [...] Das Medium hinterlässt seine Spuren an der jeweiligen Botschaft: Wenn meine Stimme zittert, werde ich kommunikativ anders wahrgenommen, als wenn ich ruhig und gelassen rede." Er verweist u. a. auf die Arbeiten des Klassischen Philologen Havelock, in denen die „Medienabhängigkeit des Denkens“ (ebd., 272) dargelegt werde. Vgl. des Weiteren ADAMzIK 2018a, 57ff. Allgemein zu Mündlichkeit und Schriftlichkeit: AdAMZIK 2018b; SCHWITALLA 2018; STEIN 2018 sowie HeINEMANN UND VIEHWEGER 1991, 176ff. bzW. ebd., 209ff. Speziell zum Lateinischen vgl. z. B. RüHL 2019, 19ff.; GARCEA 2002, 209ff.; MüLLER 1997, 8f.; RISSELADA 1993, 16 und bes. BIVILLE 2003.

${ }^{655}$ Abgesehen von der verstärkten Interaktivität moderner Kommunikation ist zudem zu bemerken, dass Schriftlichkeit nicht unbedingt mit einer größeren Zeitverzögerung einhergeht (z. B. bei SMS, Chat, E-Mail) und dass es auch Möglichkeiten zu einer mündlichen Kommunikation mit Phasenverzug (z. B. beim Chat mittels Audiobotschaften) gibt. Vgl. a. ADAMZIK 2018b, 50, die u. a. auf die zahlreichen Leserforen im Internet aufmerksam macht, sowie STEIN 2018, 23, der unter Verweis auf die Gemeinsamkeiten der bislang oft „begrifflich wie methodisch stark isolierten Konzepte von Textsorten und Gesprächssorten bzw. kommunikativen Gattungen “ die Möglichkeit und Notwendigkeit betont, sie „so weit wie möglich und bei aller Verschiedenheit ihrer methodisch-analytischen Verfahrensweisen in ihren Grundgedanken zusammenzuführen."

${ }^{656}$ Vgl. z. B. ebd., 23f.: „Differenzen zwischen Textsorten- oder Textmusterwissen und Gesprächssorten- bzw. Gattungswissen sind nicht prinzipieller Natur, sondern resultieren vor allem aus den unterschiedlichen kommunikativen Rahmenbedingungen. Aufgabe muss es daher sein, in empirischen Studien diejenigen Äußerungseigenschaften zu bestimmen, die auf Grundbedingungen mündlicher bzw. schriftlicher Verständigung zurückzu- 
Briefe können durchaus als Ersatz für ein persönliches Gespräch dienen, wodurch es auch möglich ist, ein unterbrochenes Gespräch fortzuführen und umgekehrt. Dabei sind Briefe und Gespräche allerdings nicht wirklich gleichwertig, ,insofern [...] der Brief bzw. der Briefwechsel nicht nur eine Fortsetzung des direkten Gesprächs mit anderen Mitteln [ist], zu denen der Schreiber durch die Ungunst der Verhältnisse gezwungen ist, sondern er schafft durch die ihm eignende räumliche und zeitliche Indirektheit der kommunikativen Interaktion auch eigene Bedingungen und Möglichkeiten, die zugleich weniger und mehr bieten als die Situation der mündlichen und direkten Kommunikation [...]. “657

\subsection{Klarheit: Explizierung, Präzisierung und Strukturierung}

Es kann gute (und weniger gute) Gründe für den Verfasser eines Briefes geben, seinen Text so zu gestalten, dass er (für Außenstehende) nicht ohne Weiteres verständlich ist. So werden manchmal bestimmte Passagen aus Angst vor der Verletzung des Briefgeheimnisses verschlüsselt. Ziel kann aber ebenso die Abgrenzung von anderen (weniger gebildeten) Gruppen sein. Es ist außerdem ein Zeichen besonderer Vertrautheit zwischen den Korrespondenten, wenn nicht alles ausdrücklich expliziert werden muss. Möglicherweise sind einem Autor auch andere Dinge wichtiger, wie z. B. der Eindruck von Zwanglosigkeit, oder es handelt sich schlicht um Nachlässigkeit. ${ }^{658}$

führen sind, und sie von jenen abzuheben, die spezifisch sind für und verursacht werden durch bestimmte kommunikative Praktiken.“ In KOCH UND OESTERREICHER 2008, 201 werden verschiedene „Parameter” der „Kommunikationsbedingungen mit Einfluss auf Medium und Konzeption” aufgezählt, aus denen sich ein „Nähe-DistanzKontinuum“ (ebd., 202) ergebe. Dazu gehören neben dem Gegensatz von „raum-zeitlicher Nähe (face-to-face)“ und „raum-zeitlicher Distanz" v. a. folgende (skalare) Faktoren: „Privatheit“ vs. „Öffentlichkeit“, „Vertrautheit der Kommunikationspartner“ vs. „Fremdheit der Kommunikationspartner“, "starke emotionale Beteiligung " vs. „geringe emotionale Beteiligung", „Situations- und Handlungseinbindung“ vs. „Situations- und Handlungsentbindung“, „referenzielle Nähe“ vs. „referenzielle Distanz“, „,kommunikative Kooperation“ vs. „keine kommunikative Kooperation“, „Dialogizität vs. Monologizität“, „Spontaneität“ vs. „Reflektiertheit“, „freie Themenentwicklung“ vs. „Themenfixierung“. Vgl. a. PoWELL 2013, 53. Dabei gibt es aber nur wenige Texteigenschaften, die tatsächlich auf das Medium Schrift zurückzuführen sind. So stellt selbst „die relative Dauerhaftigkeit der Schriftform gegenüber der größeren Flüchtigkeit des gesprochenen Wortes“ (HARTUNG 1983, 223) nur eine Tendenz dar, da zum einen Gespräche sehr leicht aufgezeichnet, Schriftstücke hinwiederum schnell vernichtet werden können. Andererseits ist heutzutage das komplette Löschen von Informationen nahezu unmöglich geworden, was aber sowohl schriftliche als auch mündliche Aufzeichnungen betrifft.

${ }^{657}$ ERMERT 1979, 5. Zum Brief als Gesprächsersatz und Mittel der Kontaktpflege vgl. a. S. 115. Vgl. außerdem Bernard 2013, 91 und Thraede 1970, 39. Im Übrigen sei auf den Topos der $\pi \alpha \rho o u \sigma i \alpha$ verwiesen (vgl. N. 646). Vgl. des Weiteren ROESCH 2002b, 103 (mit Bezug auf verschiedene Textstellen in CIC. fam.). Dagegen GavolLLe 2004, 50: „Il apparaît donc que tout rapproche lettre et sermo: structure dialogale, fonctions et style semblables. [...] Si l'on donne à sermo ce sens fondamental de ,texte', alors on peut dire que la lettre (ou la correspondance) relève du sermo, est du sermo - et non pas seulement qu'elle est comme le sermo. À partir de là, il n'est pas étonnant que leurs fonctions et leur style soient identiques. “Vgl. darüber hinaus SALLABERGER 1999, 17ff. („Briefliche und mündliche Kommunikation im Wechsel“).

658 Vgl. z. B. ThRAEDE 1980, 197 und CHESSA 1999, 243. Zur Kryptographie in Briefen vgl. a. CUGUSI 1983,70 und CUGUSI 1998, 172. Dort wird u. a. auf IUL. VICT. rhet. (s. Div. 1964, 448, 6ff.) verwiesen. Die entsprechenden brieftheoretischen Quellen (Iulius Victor und Quintilian) werden in CUGUSI 1983, 29f. zitiert. Zur obscuritas als Mittel der Abgrenzung einer Bildungselite von „illiteraten Barbaren“: MüLlER 2018, 14. Zum Aspekt der Vertrautheit vgl. a. THRAEDE 1980, 195 und (ausführlicher) CORBINELLI 2008, 125ff. Vgl. außerdem AltMAN 1982, 47ff. sowie Kap. 1.2.1.3.4. 
Im Allgemeinen wird jedoch perspicuitas ${ }^{659}$ angestrebt. Das durch die räumliche Getrenntheit entstehende Informationsdefizit beim Adressaten soll ausgeglichen werden und Unklarheiten, die im persönlichen Gespräch sofort beseitigt werden könnten, möglichst gar nicht erst entstehen. Inhalt und Ziel eines Briefes sind entsprechend meist besonders präzise formuliert. Vieles, was face to face (ganz oder nur unterstützend) mit non- und paraverbalen Mitteln ausgedrückt werden kann, muss verbalisiert werden, insbesondere Emotionen. In der brieflichen Kommunikation ist es bspw. nicht möglich, mit einem strahlenden Lächeln seine Freude zu äußern, dem Gegenüber die Hand zu geben, um ihm zu gratulieren, oder einer Aufforderung durch das Anheben der Stimme größeren Nachdruck zu verleihen. Auch eine zweckmäßige und nachvollziehbare Struktur dient dem leichteren und besseren Verständnis. ${ }^{660}$

\section{Aufbau römischer Briefe}

Grundschema und allgemeine Prinzipien

Römische Autoren waren zwar insgesamt recht frei bei der strukturellen Ausgestaltung v. a. persönlicher Briefe. Es gab aber durchaus gewisse formale Konventionen, aus denen sich im Laufe der Jahrhunderte ein festes Grundschema in Anlehnung an die klassische Rede entwickelte. ${ }^{661} \mathrm{Im}$ Mittelalter wurden folgende Briefbestandteile unterschieden:

${ }^{659}$ Klarheit (griech. $\sigma \alpha \varphi \eta ́ v \varepsilon \iota \alpha$ ) gehört zu den von Aristoteles (rhet. 3.2.1404b1-8) genannten - an die virtutes narrationis der Isokrateer anknüpfenden - $\dot{\rho} \rho \varepsilon \tau \alpha i$ ז̃̄ $\Lambda \dot{\varepsilon} \xi \varepsilon \omega \varsigma$ und wird auch von Theophrast (in seinem verloren gegangenen Werk $\Pi \varepsilon \rho i \lambda \varepsilon \dot{\varepsilon} \varepsilon \omega \varsigma)$ als eine der virtutes dicendi bzw. virtutes elocutionis genannt. Während $\sigma \alpha \varphi \dot{\eta}-$ $v \varepsilon \iota \alpha$ bei Aristoteles allerdings die sprachliche Korrektheit ( $\dot{\varepsilon} \lambda \lambda \eta \dot{\zeta} \zeta \varepsilon \iota v$ bzw. $\dot{\varepsilon} \lambda \lambda \varepsilon v \iota \sigma \mu o ́ \varsigma)$ miteinschließt, erfasst Theophrast diese als eigene Stilqualität. Die Entsprechungen in der römischen Rhetorik lauten perspicuitas bzw. latinitas (oder allgemeiner puritas bzw. sermo purus). Neben perspicuitas finden sich u. a. auch die (nur teilweise synonymen) Begriffe claritas und explanatio. Vgl. z. B. STYKA 2017; ZIMMERMANN UND RENKAKOS 2014, 862ff. und ASMUTH 1992, 585. Vgl. a. SCHRÖTER 2011, 142f. (mit Bezug auf ASMUTH 2003 und GARDT 1993): „In der antiken Rhetorik ist Deutlichkeit als eine von vier Stiltugenden bekannt - neben Angemessenheit (lateinisch ,aptum'), Schmuck (lateinisch ,ornatus') und Sprachrichtigkeit oder -reinheit (lateinisch ,puritas'). [...] Seiner langen Geschichte und seiner Zugehörigkeit zu verschiedenen kommunikativen Kulturen entsprechend lassen sich mehrere Ausprägungen des Deutlichkeitsideals unterscheiden. Nach Bernhard Asmuth umfasst der Begriff der ,perspicuitas' im Laufe seiner historischen Entwicklung folgende ,Elemente' bzw. - wie ich sagen würde Facetten: ,1. Eindeutigkeit', ,2. gute Anordnung' der Wörter, Sätze sowie größeren Textbausteine, ,3. hinreichende Ausführlichkeit bzw. Detailgenauigkeit', ,4. Anschaulichkeit', ,5. Ungewöhnlichkeit bzw. ästhetischen Glanz', einen Aspekt, der in der als ,claritas' bezeichneten antiken Ausprägung des Begriffs eine Rolle spielt, sowie ,6. Verständlichkeit‘. Andreas Gardt macht darauf aufmerksam, dass mit Deutlichkeit (,perspicuitas') in der Antike zumindest bei Quintilian sowie später in der humanistischen Tradition primär die Verständlichkeit für den Rezipienten gemeint ist, weniger aber die ,Eindeutigkeit der Relation zwischen sprachlichem Ausdruck und außersprachlichem Gegenstand'. "Während im vorliegenden Teilkapitel vornehmlich die Punkte 1 bis 3 sowie 6 angesprochen sind, umfasst Kap. 1.2.1.3.4 auch die Punkte 4 und 5 sowie die Stilqualität des ornatus. Auf die Kategorie des aptum wird insbesondere in Kap. 1.2.1.3.3 eingegangen. Letztlich sind die genannten Stileigenschaften aber alle eng miteinander verbunden. Zur Klarheit als epistolographischer Tradition vgl. a. die entsprechenden antiken Quellen, wie sie bei CUGUSI 1983, 34f. zitiert werden. Zu den virtutes elocutionis insgesamt vgl. außerdem SCHIRREN 2009a.

660 Vgl. z. B. CORREA 2010, 191f. und RISSELADA 1993, 16. KERBRAT-ORECCHIONI 1998, 16 weist darauf hin, dass fehlende para- und nonverbale Informationen in der schriftlichen Kommunikation (wenn auch eingeschränkt) mittels Interpunktion ausgedrückt werden können. In neuerer Zeit bestehen noch zahlreiche weitere (multimediale) Möglichkeiten, z. B. die Verwendung von Emoticons und die Einbindung von Bildern, Audio- und Videodateien.

${ }^{661}$ Vgl. z. B. GIORGIO 2015, 61. Vgl. a. PLETT 2001, 17; AdAM 1998, 41 und BICKMANn 1998, 46 (s. N.662). Ausführlicher zum Aufbau antiker bzw. römischer Briefe: CUGUSI 1983, 43ff. und (speziell zu Ciceros Briefen) MUÑOz MARTín 1994 und MuÑoz MARTín 1991. Vgl. a. SARRI 2017, 110ff.; CORBInelLI 2008, 31ff.; BICKMANn 1998, 80ff. und ANTÓN 1996, 114ff. Eine gute Zusammenfassung findet sich bei MANUWALD 2009, 4. Zu den antiken Quellen, in denen 
salutatio - captatio benevolentiae - narratio - petitio - peroratio (auch: conclusio)

Abbildung 1: Rhetorisches Grundschema von Briefen (im Mittelalter)

Wenngleich zur Zeit Ciceros noch keine so strengen Vorgaben galten, lassen sich dennoch teilweise entsprechende Tendenzen hinsichtlich des Aufbaus und Inhalts der Briefe erkennen. Das rhetorische Schema kann also eine hilfreiche Grundlage sein, um sich bewusst zu machen, welche Intentionen hinter einer bestimmten Briefstruktur stehen - auch oder vielmehr ganz besonders bei einem handlungssemantischen Ansatz, wie er in dieser Arbeit verfolgt wird. Geeigneter als Grundlage erscheint aber gleichwohl ein spezifischeres - i. E. natürlich trotzdem ggf. abzuwandelndes - Gliederungsschema, das ungefähr folgendermaßen aussehen könnte ${ }^{662}$ :

\section{Briefbeginn}

\section{Präskript}

Begrüßungsformel: intitulatio (superscriptio) + inscriptio (adscriptio) + salutatio

Bsp.: Tullius Terentiae suae salutem dicit.

\section{Wohlergehensformel (formula valetudinis)}

Bsp.: s(i) v(ales), b(ene) e(st), e(go) q(uidem) v(aleo). bzw. SVBEEQV.

\section{Briefkorpus}

\section{Einleitungssequenz/en (exordium)}

Bsp.: Empfangsbestätigung, Entschuldigung für eine längere Schreibpause, Freundschaftsversicherung

\section{Hauptteil des Briefes}

\section{Schlusssequenz/en (peroratio)}

Bsp.: Bitte um einen Antwortbrief, Äußerung eines Wiedersehenswunsches, Entschuldigung für die Beendigung des Briefes

\section{Briefschluss}

\section{Wohlergehensformel (formula valetudinis)}

Bsp.: cura ut valeas!

sich Anmerkungen zum Aufbau von Briefen finden, vgl. z. B. CugusI 1989 - 1991, 384 N. 22, wo in diesem Zusam-

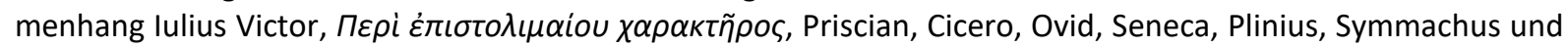
Prokopius genannt werden. Das in Abbildung 1 wiedergegebene rhetorische Grundschema findet sich in dieser Form zum ersten Mal in den 1135 in Bologna entstandenen anonymen Rationes dictandi (vgl. z. B. FERNÁNDEZ LóPEZ 1994, 26 N. 23 und CALENDRILLO 2009, 433).

662 Das hier präsentierte Schema ist angelehnt an KLAUCK 1998, 54 und ADAM 1998, 41ff. Letztere bezieht sich zwar auf moderne (französische) Briefe, liefert aber eine sehr allgemeine Übersicht, die weitgehend auch auf die Briefe anderer Kultur(epoch)en übertragbar ist. Zur sprechakttheoretischen Gliederung von Briefen vgl. z. B. BICKMANN 1998, 46: „Ein Brief kann das Gliederungsschema einer antiken Rede aufweisen - er muß es aber nicht. Statt einer unbedingten Schematisierung des Textes als Rede ist bei der Analyse eines Briefes der Text als gegliederte Abfolge von Sprechakten zu beschreiben, aus deren Zusammenspiel der Hörer/Leser den Gesamtsprechakt, den der Brief bildet, erschließen, den Hörverstehensakt vollziehen und somit Sinn konstituieren kann. " Vgl. a. (mit Bezug auf die deutsche Briefliteratur) LANGEHEINE 1983a, 312 sowie LANGEHEINE 1983b, $198 \mathrm{ff}$. 


\section{Verabschiedungsformel}

Bsp.: vale!

\section{Postskript}

- Vermerk zu Ort und Zeit der Briefentstehung

- weitere Nachträge

Abbildung 2: Grundstruktur römischer Briefe

Eine grundsätzliche Beachtung dieses Schemas, unterstützt u. a. durch metakommunikative Sprechakte und strukturierende Konnektoren, dient dazu, die Gliederung eines Briefes klar und nachvollziehbar zu gestalten. Dies scheint umso dringlicher geboten, je weniger das traditionelle Prinzip der brevitas beachtet wird, mit dem eine Beschränkung auf das Wichtigste und damit von vornherein eine gewisse Überschaubarkeit gewährleistet oder zumindest befördert wird. ${ }^{663}$ Autoren wie Cicero hielten sich nämlich nicht unbedingt daran und schrieben bisweilen eher kleine Büchlein (libelli) als kurze Briefe. ${ }^{664}$ Die Themen sind dabei oft vielfältig, was die Notwendigkeit einer transparenten Strukturierung noch weiter erhöht. ${ }^{665}$ Insbesondere für den Hauptteil kann dabei eine Anordnung nach dem Grad der Wichtigkeit sinnvoll sein. ${ }^{666}$ Ein anderes Ordnungsprinzip, das nicht ganz im Einklang mit dem Anspruch einer klaren Briefstruktur, aber ebenso wenig automatisch im Widerspruch dazu steht, ist das Bestreben nach variatio. ${ }^{667}$ Häufig orientiert sich die Abfolge auch am Bezugsbrief. ${ }^{668}$ Damit wird

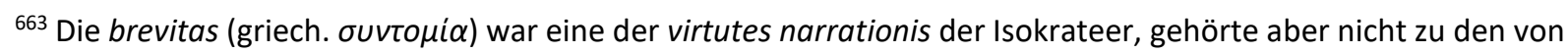
Aristoteles bzw. Theophrast angeführten virtutes dicendi: Vgl. z. B. ASMUTH 1992, 585. Von den Stoikern wurde sie dagegen wieder eingeführt: Vgl. z. B. Ax in QuINTILIANUs 2011, 149. Vgl. a. KALLENDORF 1994 sowie N. 659. Zur brevitas in der Brieftradition vgl. z. B. BERNARD 2004, 142ff. sowie CUGUSI 1983, 69 und ebd., 74f. Die entsprechenden brieftheoretischen Quellen werden in ebd., 34f. angeführt. Zur Beschränkung auf wichtige Nachrichten vgl. a. ebd., 68. Zur Explizierung der Briefstruktur (z. B. durch Konnektoren) vgl. z. B. MUÑOz MARTín 1994, passim und MuÑOz MARTín 1991, passim. Vgl. a. (zur Explizitmachung des Themenverlaufs in Ciceros Briefen) GARCEA 2002, 211f. und ebd., 219.

${ }^{664}$ Vgl. dazu bes. BERNARD 2004, der als Hauptgrund den Vorrang des Prinzips des aptum nennt. Zur Verwendung des Topos vom Brief als Gespräch zur Entschuldigung für die Länge eines Briefes vgl. a. THRAEDE 1970, 37: „[ [...] die Als-ob-Unterhaltung bewirkt, daß der Schreiber, der diesmal sehr viel zu erzählen hat, gar nicht mehr auf den Umfang des Briefes achtet." Vgl. a. Bernard 2004, 152f. Als mögliche Gründe für die Beachtung des Prinzips der brevitas können hingegen u. a. die Begrenztheit des Materials und das (mangelnde) Briefgeheimnis gelten.

${ }^{665}$ Die Themenvielfalt ist dabei ähnlich groß wie in Gesprächen, z. T. sogar noch größer (vgl. Kap. 1.2.1.3.4 zu den Topoi „epistula non rubescit“ und „Brief als Spiegel der Seele“), aber es gibt auch Themeneinschränkungen bzw. üblichere und eher unangemessene Themen. Übliche Themen wären z. B. Gesundheit, Wetter und Landschaftliches, während wissenschaftliche Inhalte und logische Auseinandersetzungen als eher unangemessener Briefinhalt galten: Vgl. z. B. White 2010, 3ff. bzw. S. 94 in dieser Arbeit. Vgl. außerdem ThRAEDe 1980, 182.

666 Zur Anordnung nach dem Grad der Wichtigkeit vgl. z. B. CuguSI 1983, 68 und ebd., 29 (mit Anführung der entsprechenden brieftheoretischen Quellen der Antike).

667 Vgl. z. B. PENNACINI 1985, 15, wo u. a. auf SEN. epist. 7.64 .2 verwiesen wird: Varius nobis fuit sermo, ut in convivio, nullam rem usque ad exitum adducens sed aliunde alio transiliens. Vgl. a. HARTUNG 1983, 225f. und ADAM 1998, 43 sowie insbes. FEKADU 2009.

${ }^{668}$ Vgl. z. B. GARCEA 2002, 218f. Er verweist auf IUL. VICT. rhet. (Div. 1964, 448, 25f.), wo allerdings eher nur die Bezugnahme auf die Themen im Vorgängerbrief allgemein und weniger deren Reihenfolge angesprochen wird: Rescribere sic oportet, ut litterae, quibus respondes, prae manu sint, ne quid, cui responsio opus sit, de memoria effluat. Vgl. aber auch CIc. Att. 6.1.1: Accepi tuas litteras [...]. iis igitur respondebo, *** (sic enim postulas), nec оікоvонiav meam instituam sed ordinem conservabo tuum. Vgl. außerdem GARCEA 2005, 106ff., bes. ebd., 109 und ebd., 140 sowie CORREA 2010, 192. Vgl. des Weiteren AlBRECHT 2003, 55 sowie Muñoz MARTín 1991, 348f. und ebd., 354. Vgl. darüber hinaus Kap. 1.2.1.3.3., bes. N. 689. 
eine größere Nähe zum persönlichen Gespräch suggeriert. ${ }^{669}$ Eigentlich wäre ein durchgehender monologischer Aufbau ohne Wiederholungen und Überschneidungen möglich, da bei einem Brief keine Unterbrechungen zu befürchten sind. Manchmal ist es dem Autor allerdings wichtiger, den Eindruck des Improvisierten und Unmittelbaren zu erwecken. Aber auch mangelnde Sorgfalt, wie sie sich bspw. in Form von irregulären Postskripta äußert, kann einer konsequent durchdachten Struktur entgegenstehen. ${ }^{670}$

\section{Besonderheiten einzelner Briefbestandteile}

\section{Briefbeginn und -schluss}

Römische Briefe beginnen i. d. R. mit einer aus intitulatio (auch superscriptio $=$ Name des Briefschreibers), inscriptio (auch adscriptio = Name des Briefempfängers) und salutatio i. e. S. bestehenden Begrüßungsformel, wie z. B. Tullius Terentiae suae salutem dicit. Es gibt zahlreiche Möglichkeiten zur individuellen Anpassung der an sich stark rituellen und stereotypisierten, sich im Laufe der Zeit aber auch immer wieder wandelnden Formel, z. B. durch Abkürzungen, veränderte Wortstellung, Variation bei der Verwendung der tria nomina und zusätzliche Possessivpronomina oder Adjektive. ${ }^{671}$ Gelegentlich folgt eine formula valetudinis wie $s$ (i) v(ales), b(ene) e(st), e(go) q(uidem) v(aleo) bzw. SVBEEQV. ${ }^{672}$ Sie ist im Gegensatz zur salutatio (als Präskript) bereits Bestandteil des eigentlichen Brieftextes. Dies gilt ebenso für den Abschiedsgruß, sofern ein solcher überhaupt vorhanden sein sollte, was eher selten der Fall ist. Dieser besteht aus einem einfachen oder wiederholten vale(te)!, das manchmal in einen längeren und persönlicher formulierten Satz eingebettet ist. Voran geht bisweilen noch eine zusätzliche Wohlergehensformel wie cura(te) ut valeas bzw. valeatis!, die aber auch für sich allein stehen kann. Die Abgrenzung zur Schlusssequenz des Hauptteils ist oft unklar, v. a., wenn weitere Elemente wie z. B. Grüße an andere und von anderen hinzukommen. Ab und zu finden sich außerdem am Ende des Briefes - wieder außerhalb des Brieftextes i. e. S. (als Postskript) Angaben zu Ort und Zeit der Entstehung sowie evtl. weitere Nachträge. ${ }^{673}$

\footnotetext{
${ }^{669}$ VgI. z. B. CORBINELLI 2008, 142.

670 Vgl. z. B. ALBRECHT 2003, 69 (zu Cicero): „Many private letters are not carefully structured, they proceed by leaps and bound and contain postscripts and enclosures [...]." Vgl. a. GIORGIO 2015, 115ff.; GARCEA 2005, 121ff. und GARCEA 2002, 210ff. Zum Postskriptum vgl. außerdem CUGUSI 1983, $71 \mathrm{f}$.

${ }^{671}$ Zur Terminologie vgl. z. B. LANHAM 1975, 7 und KLAUCK 1998, 54. Zur historischen Entwicklung der Begrüßungsformeln in lateinischen Briefen vgl. z. B. CUGUSI 1989 - 1991, 385f. und LANHAM 1975, 13ff. Manchmal wird mit ,inscriptio' (ebenso wie mit ,salutatio') auch die gesamte Grußformel bezeichnet. Zu den Variationsmöglichkeiten der Begrüßungsformel allgemein vgl. z. B. BERNARD 2013, 133ff.; WHITE 2010, 67ff.; MANUWALD 2009, 4; CORBINELLI 2008, 36ff. sowie (speziell zu Cicero) ebd., 101ff.; GIORGIO 2008b, 352 und GARCEA 2005, 106ff. Vgl. a. N. 676 und (zur Allokution) Kap. 1.2.1.3.3. Die entsprechenden brieftheoretischen antiken Quellen werden z. B. in CUGUSI 1983, 28f. zitiert. Zum Unterschied zwischen den Begrüßungs- bzw. Verabschiedungsformeln in Brief und persönlichem Gespräch vgl. z. B. POCCETTI 2010, 105. Zur bei den Grußformeln (salutatio) besonders stark ausgeprägten Unzuverlässigkeit der Überlieferung vgl. z. B. LANHAM 1975, 6f. und ebd., 17.

672 Diese sehr formelle Wohlergehensformel, die verschiedenartig variiert werden kann, wird nur recht selten verwendet. Seit dem 1. Jh. n. Chr. verschwindet sie allmählich ganz und wird durch andere Formeln ersetzt: Vgl. z. B. CUgusi 1989 - 1991, 386. Vgl. a. BeRNARD 2013, 138f.; WHITE 2010, 71ff.; CORBINELLI 2008, 48f. und CUGUSI 1983, 48 (mit Verweis auf weiterführende Literatur).

${ }^{673}$ Der Abschiedsgruß wird häufig auch als subscriptio bezeichnet, womit also nicht die ,Unterschrift' im heutigen Sinne gemeint ist, die es in der Antike so gar nicht gab. Zur historischen Entwicklung der Verabschiedungsformeln in lateinischen Briefen vgl. z. B. CUGUSI 1989 - 1991, 386ff. und LANHAM 1975, 69ff. Zu den Verabschiedungsformeln und der Angabe von Zeit und Ort der Briefentstehung allgemein vgl. z. B. WHITE 2010, 73ff.; CORBINELLI 2008, 49ff. sowie (speziell zu Cicero) ebd., 113ff.; GARCEA 2005, 112f. und ALBRECHT 2003, 63.
} 
Prä- bzw. Postskript, Gruß- und Wohlergehensformeln wirken zunächst einmal deklarativ, indem sie die Briefkommunikation eröffnen bzw. beenden. ${ }^{674}$ Darüber hinaus werden die Rahmenbedingungen wie Ort, Zeit, beteiligte Personen und ihr Verhältnis zueinander expliziert (assertive Funktion). ${ }^{675}$ Der zuletzt genannte Punkt korreliert eng mit der kontaktbezogenen bzw. expressiven Funktion von Briefbeginn und -schluss, die durch Individualisierung noch verstärkt werden kann. ${ }^{676}$ Das Fehlen der Grußformeln bzw. einzelner Bestandteile kann sowohl einen Affront bedeuten als auch Zeichen besonderer Vertrautheit sein, sollte aber allgemein nicht überbewertet werden, da auch verschiedene anderer Gründe ursächlich dafür sein können. ${ }^{677}$

\section{Übergangssequenzen}

Der Einstieg in den Hauptteil eines Briefes kann medias in res erfolgen. Häufig finden sich aber zur Überleitung mehr oder weniger konventionelle Einleitungssequenzen, in denen z. B. ausführlicher als mit der rituellen Wohlergehensformel auf das (körperliche und seelische) Befinden des Autors oder des Adressaten eingegangen und generelle Wertschätzung für Letzteren ausgedrückt wird. Ein schlechter Gesundheitszustand des Briefschreibers wird manchmal auch - neben anderen Gründen - zur Rechtfertigung für eine längere Schreibpause angeführt. Umgekehrt kommt es des Öfteren vor, dass der Autor seine Enttäuschung über das Ausbleiben von Briefen des Adressaten äußert oder auch den Empfang von Briefen dankend bestätigt, die

${ }^{674}$ Vgl. z. B. BICKMANN 1998, 80ff. Vgl. a. MuÑOz MARTín 1994, 74f. (mit Bezug auf den gesamten Eingangs- und Schlussteil). Vgl. außerdem CORBINELLI 2008, 31ff. Vgl. des Weiteren - zur metalinguistischen Signalisierung von Textanfang und -ende durch Grußformeln (in lateinischen Grabinschriften und in der römischen Komödie) - PocCETTI 2010, 110ff.

${ }^{675}$ Vgl. z. B. GIORGIO 2015, 73f. Zu den Grußformeln als Mittel der (Selbst-)Vorstellung und der Adressierung vgl. a. POCCETTI 2010, 113. Vgl. außerdem CORBINELLI 2008, 36ff., die u. a. auf entsprechende Ausführungen in der antiken Brieftheorie hinweist. Vgl. dazu auch LANHAM 1975, 89ff. Vgl. des Weiteren GARCEA 2005, 108 und CUGUSI 1998, 166 sowie (in allgemeiner Perspektive) RoLF 1993, 213.

${ }^{676}$ Mit der konkreten Ausgestaltung der Formel wird die Art des Kontakts genauer festgelegt, insbesondere hinsichtlich der hierarchischen und affektiven Beziehung zwischen den Briefpartnern: Vgl. z. B. GIORGIO $2008 \mathrm{~b}, 352$ bzw. DÉniaux 1993, 75ff. Vgl. a. Bernard 2013, 133; Corbinelli 2008, 101; RoesCh 2004, 143f. und GarCEA 2002, 216. Vgl. außerdem KRATOCHVILOVA 2014, 478 (in allgemeinerer Perspektive) zur „Anredeformel als Indikator für die Beziehungen [...], die der Briefschreiber zu dem Empfänger hat oder zu haben glaubt“. Vgl. im Übrigen Kap. 1.2.1.3.3 zur Allokution bzw. den Anredeformen und Kap. 1.2.1.3.4 zur Formelhaftigkeit. Vgl. darüber hinaus GIORGIO 2015, 76, der darauf aufmerksam macht, dass sich hinter der Verwendung bestimmter Gruß- bzw. Anredeformeln eine bestimmte persuasive Strategie verbergen kann.

677 Zur Begrüßungsformel vgl. z. B. GIORGIO 2015, 77: „Lorsque l'ami est très intime, ne pas mettre d'inscriptio du tout apparaît dès lors comme une marque d'affection et de confiance, car cela signifie que les correspondants dépassent l'obstacle de l'intervalle spatio-temporel: l'épistolier engage son discours sans se présenter, certain d'être reconnu. "Zum (Nicht-)Gebrauch der Abschiedsgrußformel vgl. z. B. JEPPESEN-WIGELSWORTH 2013, 353 N. 14: „However, the usage was not common and seems only a courteous addition to a letter with little true emotional value. The lack of it does not seem indicative of a lack or loss of emotional attachment." und ebd., 354: „[...] the inclusion of this phrase might indicate concern or worry, the lack of it [...] is not indicative of the opposite." Vgl. dagegen CORBINELLI 2008, 51: „II modo in cui vengono riferiti i casi in cui la lettera era priva di subscriptio non lascia infatti dubbi riguardo al fatto che l'assenza dei saluti finali fosse solitamente interpretata come l'attestazione della mancanza di una benevola disposizione di chi scriveva nei confronti del destinatario del massaggio [...]. La mancanza dei saluti finali non limitava certamente l'efficacia della trasmissione del messaggio, ma costituiva comunque un chiaro affronto alla dignità del destinatario.“, aber auch ebd., 113f.: „Nella maggior parte delle lettere di Cicerone manca infatti una delle canoniche espressioni di congedo; ciò non significa comunque che esse terminino solitamente in modo brusco, [...]. Di frequente, infatti, l'oratore chiude le sue missive con vere e proprie frasi conclusive [...]. “ Vgl. außerdem N. 671 (zur unzuverlässigen Überlieferung). 
dann ebenso wie die eigenen in den übergeordneten Konversationsdiskurs eingeordnet werden können. Bisweilen geht der Verfasser dabei ziemlich detailliert auf die Umstände der Briefabfassung ein - bis hin zu allgemeinen Exkursen zur Kommunikationsform Brief. ${ }^{678}$

Die Schlusssequenzen beginnen oft mit der Formulierung verschiedener Bitten. Ggf. wird auf Aussagen der Einleitungssequenzen oder des Briefkorpus Bezug genommen und das Hauptanliegen noch einmal deutlich in den Vordergrund gerückt. Damit wird zum eigentlichen Schlussteil übergeleitet, der sich aber selten klar vom vorangehenden Teil abgrenzen lässt, z. B., wenn der Autor seiner Hoffnung auf ein persönliches Wiedersehen oder zumindest einen baldigen Antwortbrief Ausdruck verleiht. Häufig erinnert der Briefschreiber noch einmal an die freundschaftliche Verbundenheit mit dem Adressaten, bedankt sich für ihm erwiesene Dienste und stellt eigene (z. B. die umgehende Weitergabe neuer Informationen) in Aussicht. Er entschuldigt sich dafür, dass er den Brief beenden muss, indem er bspw. auf die späte Stunde oder einen eintreffenden Besucher verweist, und lässt gelegentlich Grüße an Dritte ausrichten. Zuweilen werden am Ende recht ausführlich Wünsche für die gute Gesundheit des Adressaten geäußert, die kaum von der rituellen Abschiedsgrußformel zu trennen sind und sie manchmal ganz ersetzen. ${ }^{679}$

Einleitungs- und Schlusssequenzen erfüllen oft in erster Linie eine expressiv-kontaktbezogene Funktion. Insbesondere in der Einleitung geht es i. d. R. darum, den Adressaten (im Sinne der klassisch-rhetorischen captatio benevolentiae) auf verschiedene Art und Weise zu umschmeicheln und ihn so wohlwollend zu stimmen (benevolum parare). Im Schlussteil wird versucht, das Wohlwollen zu erhalten, z. B. durch (erneutes) Signalisieren von Interesse am Wohlergehen des Adressaten und durch Abmilderung des Kontaktabbruchs. ${ }^{680}$ Eindeutig direktiv sind v. a. die Bitten am Ende eines Briefes. Die Einleitung hingegen kann meist nur als direktiv gewertet werden, insofern mit besonderen Mitteln das Interesse des Adressaten geweckt wird (attentum parare), um ihn zum Weiterlesen anzuregen. Mitunter findet man (v. a. im Schlussteil) außerdem eine kommissive Komponente, z. B. das Versprechen von bestimmten Gefälligkeiten. Schließlich besitzen die Übergangssequenzen i. A. eine assertiv-metakommunikative Funktion: In der Einleitung soll der Inhalt des Hauptteils vorbereitet werden (docilem parare), am Schluss wird er ggf. noch einmal zusammengefasst. Insgesamt erfüllen die Einleitungs- und Schlusssequenzen zumindest tendenziell die Funktionen von exordium bzw. peroratio (oder conclusio) der klassischen Rede. Die Übergänge zum Hauptteil sind dabei oft

\footnotetext{
${ }^{678}$ Zu den verschiedenen Einstiegstechniken vgl. z. B. GIORGIO 2015, 90ff.; GIORGIO 2008b, 353ff.; BERNARD 2013, 139 und GARCEA 2005, 108f. Vgl. a. CUGUSI 1989 - 1991, 389 zur „,tecnica‘ proemiale“ in Briefen (der Spätantike) und MUÑOZ MARTín 1994, $11 \mathrm{ff}$.

${ }^{679}$ Zu den verschiedenen Ausgestaltungsmöglichkeiten der Schlusssequenzen vgl. z. B. GIORGIO 2015, 102ff. und GIORGIO 2008b, 358ff.; WHITE 2010, 74; CORBINELLI 2008, 113ff. sowie MUÑOZ MARTín 1994, 55ff.

${ }^{680}$ Zum expressiv-kontaktbezogenen Aspekt der Einleitungs- und Schlusssequenzen vgl. u. a. GIORGIO 2015, 87ff.; GIORGIO 2008b, 350ff.; GARCEA 2002, 216ff. und MuÑOz MARTín 1991, 351f. Vgl. a. (mit Bezug auf das Deutsche) WÜEST 2011, 219f. Zum Einleitungsteil (in allgemeiner Perspektive) vgl. außerdem KERBRAT-ORECCHIONI 1990, $221 \mathrm{f}$. und LANGEHEINE 1983a, 310. Zum Schlussteil vgl. darüber hinaus BICKMANN 1998, 82 und (hinsichtlich der Abmilderung des Kontaktabbruchs) KeRBRAT-ORECCHIONI 1998, 29.
} 
fließend, d. h., die Themen überschneiden sich teilweise, und es ist nicht immer genau zu bestimmen, wo der Hauptteil eigentlich beginnt bzw. endet. ${ }^{681}$

\subsection{Partnerbezug: Angemessenheit, Allokution und Interaktion}

Als gemeinsames Merkmal von Briefen und Gesprächen wird oft v. a. ihr mehr oder minder stark ausgeprägter Partnerbezug genannt. Dieser zeigt sich zunächst einmal ganz allgemein darin, dass die konkrete Ausgestaltung dem jeweiligen Empfänger angepasst wird. Es gilt das übergeordnete Prinzip des aptum, das im Übrigen aber noch weitere Faktoren der Kommunikationssituation berücksichtigt. ${ }^{682}$ Der Einfluss des Adressaten erstreckt sich dabei sowohl auf Inhalte und Funktionen eines Briefes als auch insbesondere die Form, darunter z. B. die Verwendung bestimmter (Brief-)Tempora und deiktischer Ausdrücke. ${ }^{683}$ Der Grad der Klarheit (s. Kap. 1.2.1.3.2) und der (Un-)Konventionalität (s. Kap. 1.2.1.3.4) sind ebenfalls abhängig von der Art des Verhältnisses der Briefpartner zueinander.

Kennzeichnend für Briefe und Gespräche ist außerdem die Allokution, d. h. die direkte Ansprache des Gegenübers, die sich in der Verwendung der 2. Person (Verben, Pronomina) und des Vokativs äußert. ${ }^{684}$ In Abhängigkeit von der Beziehung zwischen den Korrespondenten können die Anredeformen in Briefen vielfältig variiert werden, wobei u. a. auch Aspekte wie Alter und Geschlecht eine Rolle spielen. Die Nennung aller Titel im Präskript kann bspw. Distanz signalisieren. Durch Diminutive, Possessivpronomina, bestimmte (affektive) Adjektive und Substantive sowie Spitz- und Kosenamen können dagegen besondere Vertrautheit und emotionale Verbundenheit ausgedrückt werden. ${ }^{685}$

\footnotetext{
${ }^{681}$ Zum Verhältnis von Einleitungs- und Schlusssequenzen zu den Redeteilen exordium und peroratio vgl. z. B. AdAM 1998, 42 und MuÑoz MARTín 1994, 30 (zur Briefeinleitung) bzw. ebd., 74 (zum Briefschluss). Speziell zu den Einleitungssequenzen vgl. a. (in allgemeiner Perspektive) LANGEHEINE 1983a, 310. Zu den Verbindungen zwischen Hauptteil und Einleitungs- bzw. Schlusssequenzen vgl. z. B. MUÑOz MARTín 1991, 352ff. und MuÑOz MARTín 1994, 52f. sowie (unter Einbeziehung des Präskripts) ebd., 32f. Vgl. außerdem BICKMANN 1998, 83.

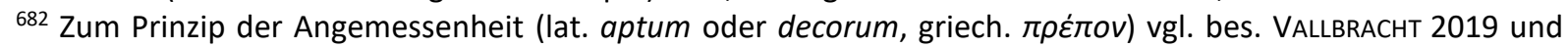
ASMUTH 1992. Vgl. a. (neben vielen anderen) SCHWITTER 2018, 100; BERNARD 2013, 111ff., ebd., 123ff. und ebd., 408; Bernard 2010, 416; Morello 2013 (z. B. ebd., 202 und ebd., 214); White 2010, 77ff.; MANUWALD 2009, 8; SCHRÖDER 2009, 17; CORBINELLI 2008, 125ff.; AlBRECHT 2003, 6 und ebd., 54ff.; FÖGEN 2001, 7 und ebd., 17; WenSKUS 2001 (zur Rolle des Geschlechts); ANTÓn 1996, 119; FERNÁNDEZ LóPEZ 1994, 237ff.; CUGUsi 1983, 45f.; ALLEN JR. 1957 - 1959, 59f. sowie BAILlEUX 1933, 66. Zur Korrelation des Prinzips des aptum mit der Selbstdarstellung Ciceros vgl. z. B. GIORGIO 2015, 84. Vgl. a. MüLLER 2018, 8. Ausführlichere Vergleichsanalysen finden sich u. a. in JÄGER 1986 (vgl. z. B. ebd., 108 und ebd., 111f.) und HUTCHINSON 1998. Zu den betreffenden brieftheoretischen (Stil-)Vorgaben in der Antike vgl. z. B. Cugus 1983, 38f. und MALHERBE 1988, 13. Als Quellen werden u. a. die entsprechenden (anonymen) Ausführungen in De epistolis (Div. 1964, 589, 4ff. und ebd., 589, 25ff.), IUL. VICT. rhet. (ebd., 448) sowie THEON prog. 10.2 genannt.

683 Zum „Aufbau einer spezifischen Raum-Zeit-Deixis“ (BICKMANN 1998, 79), insbesondere den Brieftempora, in lateinischen Briefen vgl. z. B. CORREA 2013, 65; WHITE 2010, 78; GARCEA 2005, 97ff.; GARCEA 2002, 213ff. und ROESCH 2002b, $97 f$.

${ }^{684}$ Zur Terminologie vgl. z. B. KeRBRAT-ORECCHIONI 1998, 16. Vgl. a. N. 686. Zu den grammatischen Äußerungsformen vgl. z. B. CORBINELLI 2008, 132. Zum Vokativ vgl. a. Kap. 1.2.1.3.4.

${ }^{685}$ Vgl. bes. DICKEY 2002. Vgl. a. GIORGIO 2015, 76; BERNARD 2013, 133ff.; JEPPESEN-WIGELSWORTH 2013, 352ff.; CORBINELLI 2008, 31ff. und ebd., 89ff.; GARCEA 2005, 126ff.; CHESSA 1999, 229 sowie AdAMS 1978. Vgl. außerdem das Kap. „Briefbeginn und -schluss“ ab S. 127. Speziell zur Verwendung der tria nomina und von zusätzlichen Titeln vgl. a. SCHWITTER 2018, 92 N. 38 und WHITE 2010, 69. Vgl. außerdem CORBINELLI 2008, 101f. Zu den Possessivpronomina vgl. darüber hinaus BIVILLE 2006, zu Spitz- bzw. Kosenamen CUGUSI 1998, 172 und KLAUCK 1998, 162.
} 
Im Fokus eines Vergleichs von Brief und Gespräch hinsichtlich des Partnerbezugs steht meist die Interaktivität. ${ }^{686}$ Briefschreiber nutzen verschiedene Möglichkeiten, mit dem Adressaten in Kontakt zu treten. So finden sich relativ viele Sprechakte, die sich sehr direkt an den Briefpartner richten und eine Antwort verlangen, wie BITTEN und verschiedene Arten von Fragen. ${ }^{687}$ Letztere werden auch gerne zur Inszenierung fiktiver Dialoge genutzt, oft in Form rhetorischer Fragen. ${ }^{688}$ Häufig anzutreffen sind außerdem reaktive Sprechakte, wie z. B. ZUSTIMMEN oder WIDERSPRECHEN, mit denen der Autor sich auf eine Äußerung des Adressaten bezieht, die dieser ihm gegenüber zuvor (in einem früheren Brief oder Gespräch) gemacht hat. Die inhaltlich-funktionale und strukturelle Orientierung an der vorangehenden Kommunikation zeigt sich u. a. in Gestalt von Zitaten, Zusammenfassungen und Kommentaren. ${ }^{689}$ Die Interaktivität in Briefen ist allerdings insofern eingeschränkt, als die Korrespondenten nicht unmittelbar von Angesicht zu Angesicht miteinander interagieren. ${ }^{690}$ Man sollte überhaupt in Bezug auf die menschliche Kommunikation von verschiedenen Graden der Interaktivität ausgehen. ${ }^{691}$ Briefe sind dabei irgendwo zwischen Dialog und Monolog anzusiedeln. Sie sind beides: einerseits (unvollständiger) Dialog, also Teil einer umfassenderen Kommunikation, der im Rahmen intertextueller Analysen zu untersuchen ist, andererseits (vollständiger) Monolog, der für sich betrachtet werden kann. ${ }^{692}$

${ }^{686}$ Der Begriff ,Interaktivität' (oder auch ,Interaktionalität') wird häufig (nahezu) gleichgesetzt mit ,Dialogizität', soll hier jedoch enger gefasst werden, insofern letzterer auch andere, durch die Gesprächssituation mit einem (oder mehreren) Partner(n) bedingte Parameter miteinbezieht, wie z. B. Allokution und Interlokution (s. u.) oder die Zwanglosigkeit der Kommunikation (vgl. Kap. 1.2.1.3.4). Sehr umfassend hat sich Kerbrat-Orecchioni in ihrem mehrbändigen Grundlagenwerk Les interactions verbales (KERBRAT-ORECCHIONI 1990; KERBRAT-ORECCHIONI 1992; KERBRAT-ORECCHIONI 1994) mit dem Thema beschäftigt. Speziell zum Brief vgl. a. KERBRAT-OrECCHIONI 1998. Nach ebd., 16 ist ,interaction' dadurch gekennzeichnet: „,[...] que tout au long de l'échange communicatif, les différents participants exercent les uns sur les autres un réseau d'influences mutuelles - parler, c'est échanger, et c'est changer en échangeant." "Davon abgegrenzt werden die Termini ,allocution' (Ansprache eines bestimmten Adressaten) und ,interlocution' (,alternance des rôles d'émetteur et de récepteur").

687 VgI. WEIGAND 2003, $35 f$.

688 Zu fiktiven Dialogen vgl. z. B. GARCEA 2002, 218f. und (mit Bezug auf einige Atticusbriefe) HofMANN 1978, 2 f.

${ }^{689}$ Zur (funktionalen und strukturellen) Dialogizität von römischen Briefen vgl. z. B. GARCEA 2005, 106ff.; CHESSA 1999, 228ff. und MUÑoz MARTíN 1994, 52f. Zur (grammatischen) Wiederaufnahmestruktur i. E. vgl. z. B. MuÑOZ MARTín 1991, 348f. und ebd., 352f. sowie ROESCH 2002b, 90ff. und GARCEA 2002, 218f. Vgl. außerdem ALBRECHT 2003, 55f., der u. a. darauf aufmerksam macht, dass ein vorangehender Brief nicht nur Einfluss auf die Briefstruktur, sondern auch auf die Lexik nimmt. Vgl. des Weiteren Kap. 1.2.1.3.2 und das Kap. „Extrapositionen“ ab S. 274. 690 Vgl. z. B. RISSELADA 1993, 15f. Vgl. a. RÜHL 2019, 29, die auf die Unregelmäßigkeiten beim Brieftransport und die daraus bisweilen resultierende Durchbrechung der chronologischen Reihenfolge beim Lesen hinweist, durch welche die Interaktivität noch weiter eingeschränkt wurde. Bei brieflicher Kommunikation handelt es sich letztlich also nur um einen Quasi-Dialog: Vgl. z. B. ROESCH 2002b, 103 sowie außerdem Kap. 1.2.1.3.1.

${ }^{691} \mathrm{Zu}$ den verschiedenen Interaktivitätsgraden menschlicher Kommunikation vgl. z. B. KERBRAT-ORECCHIONI 1998, 35: „L'existence de formes discursives telles que la lettre (formes intermédiaires entre le dialogal et le monologal) prouve la nécessité d'admettre des degrés d'interactivité, représentables selon un axe graduel où l'on trouverait, du plus fortement au plus faiblement interactif: [...] les conversations familières en face à face; [...] d'autres situations de discours oral où l'alternance est plus réduite (communication en classe), voire exclue (conférence magistrale); [...] les échanges par courrier électronique [...]; les échanges épistolaires ,classiques'; [...] les autres formes de discours écrit, sans adressage précis ni réponse prévue." Dazu ist anzumerken, dass die Kommunikation der Gegenwart insgesamt immer stärker von Interaktivität geprägt wird, auch in Bezug auf viele „traditionelle" Gattungen wie z. B. Zeitungsberichte und sogar Romane.

${ }^{692}$ Wieweit Briefe allgemein als monologisch oder dialogisch zu betrachten sind, wird unterschiedlich gesehen. Meist gelten sie aber als Zwischenform zwischen Monolog und Dialog: Vgl. z. B. WEIGAND 2003, 29 und ebd., 35f.; GROBE 1976, 12 und BRINKER U. A. 2014, 142 N. 33 sowie KERBRAT-ORECCHIONI 1998, 31ff. Vgl. a. KOCH U. A. 1981, 159: 
keit

Ziel der gestalterischen Bemühungen eines Briefautors sind urbanitas und elegantia. ${ }^{693}$ Für den prototypischen Freundschaftsbrief, der durch geistreiches und heiteres iocari charakterisiert ist, wird dabei eine Art „Plauderton“ oder „idealisierter Unterhaltungston“694 bzw. ein mittlerer oder gemischter Stil bevorzugt. Als kennzeichnend hierfür gilt die Verwendung von Umgangssprache (sermo cotidianus), mit der die Ungezwungenheit eines persönlichen Gesprächs simuliert werden kann. Gleichwohl soll gemäß antiker Brieftheorie ein Brief sorgfältiger als ein spontaner Dialog ausgearbeitet sein, wenn man inn im Rahmen der Freundschaftspflichten als Geschenk übersenden möchte. Dies kann nicht nur auf den Redeschmuck, sondern auch auf die Beachtung allgemeiner Brief- und Höflichkeitskonventionen bezogen werden. Selbst in ganz alltäglichen Briefen, die rein zweckmäßig ausgerichtet sind und nicht un-

\footnotetext{
„Jeder Brief ist im Prinzip einem Gesprächsschritt in einem Gespräch zu vergleichen. Eine adäquate Analyse der kommunikativen Struktur der brieflichen Kommunikation müßte deshalb - so könnte man argumentieren - nicht einzelne Briefe [...] beschreiben, sondern den ganzen Dialog, der sich zuweilen über Jahre hinzieht, mit einbegreifen. Ganz abgesehen davon, daß eine empirische Analyse, die sich ein solches Ziel setzen würde, beim heutigen Stand der theoretischen und methodischen Entwicklung der texttheoretischen Forschung und durch die sich daraus ergebende Materialmenge wahrscheinlich nicht zum Abschluß gebracht werden könnte, scheint es uns nicht nur erlaubt, sondern auch theoretisch begründbar, daß man mit einer Beschreibung der einzelnen Dialogschritte innerhalb eines solchen Dialogs anfängt. "Vgl. außerdem SALLABERGER 1999, 14 und ARTMANN 1996, 47 sowie (speziell zu römischen Briefen) GIORGIO 2015, 55ff.; CORBINELLI 2008, 132ff.; GARCEA 2005, 100ff. und ROESCH 2002b (z. B. ebd., 111f.). Vgl. des Weiteren S. 123 und N. 691.

${ }^{693}$ Vgl. z. B. LeIDL 2012 bzw. AlBERTINI 1994. Zur urbanitas vgl. a. RüHL 2019, 200ff., bes. ebd., 232ff. und FÖGEN 2001, 19f. sowie N. 709.

${ }^{694}$ Peter 1965, 20.
} 
bedingt einer besonders akkuraten Bearbeitung bedürfen, werden diese grundsätzlich eingehalten. ${ }^{695}$ Ob die zum Ausdruck gebrachten Gefühle ehrlich gemeint sind, ist eher zweitrangig, obwohl Aufrichtigkeit und Integrität im Prinzip wertgeschätzt wurden. ${ }^{696}$

Den Briefautoren steht ein großer Fundus an Topoi und Formeln zur Verfügung, auf die sie dabei zurückgreifen und die sie entsprechend ihren Erfordernissen und Fähigkeiten variieren können. Zu den schon genannten loci communes gehören z. B. der Freundschaftstopos und die Vorstellung vom Brief als Gespräch und der Quasi-Anwesenheit des Briefpartners. Besonders hervorzuheben sind außerdem die Idee vom „Brief als Spiegel der Seele“ und die Vorstellung, dass die Kommunikationsform Brief eine (im Vergleich zum persönlichen Gespräch) stärkere Emotionalität und Offenheit begünstigt (epistula non erubescit). Zu den auf die sprachlich-strukturelle Gestaltung zielenden Topoi zählen z. B. die Verwendung des sermo cotidianus und bereits erwähnte Briefcharakteristika wie die brevitas. Auf einigen Gebieten hat sich im Laufe der Zeit überdies ein ausgefeiltes Repertoire an mehr oder weniger festen Formeln und Wendungen entwickelt, z. B. was (Selbst-)Trost (consolatio) und Klage (miseratio) betrifft. Aber auch im Zusammenhang mit Entschuldigungen, Danksagungen, Glückwünschen, Ratschlägen, Bitten und natürlich Begrüßungen finden sich viele stereotype und rituelle Formeln. ${ }^{697}$

\footnotetext{
${ }^{695}$ In der antiken Brieftheorie finden sich nur recht unspezifische und nicht immer ganz eindeutige Hinweise zum Briefstil, der oft im Zusammenhang mit der Kunst der Rede (oratio) oder des Gesprächs (sermo) abgehandelt wird. MALHERBE 1988, 13f. fasst sie folgendermaßen zusammen: „They [= Briefe] should be written in the style of the dialogue (Dem. 223; Quint. 9,4,19), but should be natural (Greg. Naz. 51,5,7). Letters should be written as artistically as possible (Ps. Dem., proem.; Jul. Vict.). According to some theorists they should be written in everyday speech (Cic. Ad Fam. 9,21,1; Sen. Ep. 75,1), while to others they should be written in a style between the vernacular and Atticism (Philostr.; Ps. Lib. 47; cf. Greg. Naz. 51,4). [...] While the epistolary style is plain (Dem. 223), from the standpoint of expression it is actually a compound of the graceful and plain styles (Dem. 235). It should therefore be characterized by ornamentation (Philostrat.; Greg. Naz. 51, 5-7; Ps. Lib. 48; Jul. Vict.), the main characteristic of which is charm." Vgl. a. CUGUSI 1983, 32ff. und CUGUSI 1989 - 1991, 383f. sowie außerdem SARRI 2017, 50ff.; GIORGIO 2015, 107ff.; BERNARD 2013, 91ff. und ebd., 242; SCHRÖDER 2004 - 2005, 210ff.; GAVOILLE 2004; AlBRECHT 2003, 52ff.; ROESCH 2002b, 103; PENNACINI 1985, 15 und PETER 1965, 13ff. Zur rhetorischen Dreistillehre, nach der (recht grob und pauschalisierend) genus humile oder subtile, genus grande oder sublime und genus medium oder mixtum unterschieden werden, vgl. z. B. SCHIRREN 2009b. Die zum großen Teil bereits erwähnten Briefkonventionen (vgl. Kap. 1.2.1.3.2 und 1.2.1.3.3 sowie N. 693) gelten prinzipiell für alle Stilarten. Dazu zählen perspicuitas, brevitas, variatio, aptum und elegantia sowie außerdem gratia und dignitas. Unterschiede bestehen v. a. hinsichtlich der Verwendung von Redeschmuck. Vgl. a. BERNARDI PERINI 1985, 17 und BICKMANN 1998, 79ff. sowie N. 698. Vgl. außerdem LANDFESTER 2008, 318ff. zu den verschiedenen Stilprogrammen (Attizismus, Asianismus, Archaismus), denen sich einzelne Autoren verpflichtet fühlten und die - neben idiolektischen Eigenheiten - bei der stilistischen Beurteilung eines Textes berücksichtigt werden müssen, sowie die Ausführungen zu "défauts" und „qualités" von Briefautor und -adressat bei BERNARD 2013, 165ff. Vgl. des Weiteren GIORGIO 2015, 65ff. und bes. ebd., 107ff. Die Brief- bzw. Stilkonventionen sind im Übrigen eng verbunden oder vielmehr nahezu gleichzusetzen mit allgemeinen Höflichkeitskonventionen. Vgl. a. HALL 2009, 24. Zum besonderen Stellenwert der Höflichkeit in Briefen (im Vergleich zum persönlichen Gespräch) vgl. z. B. White 2010, 79. Vgl. außerdem die Höflichkeitskonzepte von Terkourafi und Watts, für welche die (geringe) Gebrauchsfrequenz bzw. Konventionalisierung sprachlicher Ausdrücke ein wichtiger Faktor zur Beurteilung der Höflichkeit einer Aussage ist: DICKEY 2016, 202ff. Vgl. a. das Kap. „Höflichkeit“ ab S. 69.

${ }^{696} \mathrm{Vgl}$. z. B. ebd., 204.

${ }^{697}$ Zur Topik allgemein vgl. z. B. SCHIRREN 2009c. Speziell zu den Brieftopoi: BICKMANN 1998, 85ff.; ANTÓN 1996, 116ff.; CUGUSI 1983, 32ff. (brieftheoretische Quellen der Antike) bzw. ebd., 73ff.; GARCíA 1974, 438ff. und THRAEDE 1970. Vgl. a. (zu „allgemein-philophrenetischen Phrasen und Formeln“ in griechischen Briefen) KOSKENNIEMI 1956, 128ff. Speziell zu Cicero: GIORGIO 2015, 112ff. Thraede (z. B. THRAEDE 1970, 46f.: s. N. 646) differenziert primäre und sekundäre Topoi. Cugusi unterscheidet „topica di idee“ (CUGusI 1983, 73ff.) und „topica di lingua" (ebd.,
} 
Briefe bewegen sich also immer im Spannungsfeld zwischen subtilitas und ornatus, (rhetorischer) Schlichtheit und Elaboriertheit. Der Grad der Formelhaftigkeit und Konventionalität bzw. der (scheinbaren) Zwanglosigkeit und Unkonventionalität hängt von verschiedenen Faktoren ab. So spielen u. a. die individuellen Ansprüche und Vorlieben des jeweiligen Adressaten eine Rolle, bei ernsten Briefen bietet sich oft eher ein gehobenerer Stil, bei (neutralen) Informationsbriefen ein einfacherer Stil an. Um dem Ideal eines Briefschreibers gerecht zu werden, muss in jedem Fall eine spezifische Anpassung gemäß dem Prinzip des aptum erfolgen. Damit kann auch eher phrasenhaften Wendungen und Topoi Individualität, Ausdruckskraft und in gewissem Sinne sogar Authentizität verliehen werden. ${ }^{698}$

\section{Kennzeichen der lateinischen Umgangssprache bzw. des Briefstils (Ciceros) allgemein}

Die lateinische Umgangssprache (sermo cotidianus bzw. sermo familiaris, sermo vulgaris oder sermo plebeius) stellt kein homogenes Gebilde dar. Sie umfasst sowohl die gewöhnliche Alltagssprache des "einfachen Volkes" als auch die gehobene Umgangssprache der höheren Bildungsschichten. ${ }^{699}$ In der römischen Briefliteratur wird sie wohl am ehesten in Ciceros Briefen an Atticus fassbar, und zwar - je nach Kontext - in verschiedenartiger Ausprägung. ${ }^{700}$ Dabei

78ff.). Die sprachlichen Topoi reichen bis hin zu einzelnen Formulierungen. Vgl. a. CUGUSI 1989 - 1991, $383 \mathrm{ff}$.; ebd., 400ff. und ebd., 405ff. sowie AlBRECHT 2003, 62f. Vgl. außerdem MuÑOz MARTín 1994, 33f. und MuÑOz MARTín 1991, 351f. sowie (zu den Briefeinleitungs- und Briefbeendigungssequenzen, in denen sich besonders viele topische Äußerungen finden) das Kap. „Besonderheiten einzelner Briefbestandteile“ ab S. 127. Zu deren formelhaftrituellem Charakter vgl. a. GIORGIO 2008b, 351 und (allgemein) KERBRAT-ORECCHIONI 1998, 27. Zum Topos „Brief als Spiegel der Seele" vgl. a. CugusI 1983, 33 und MALHERBE 1988, 12 bzw. De elocutione 227, NiKOL. prog. 11.3, CIC. fam. 16.16.2, SEN. epist. 40.1, SIDON. epist. 7.18.2 und PHILOSTR. VgI. außerdem MANUWALD 2009, 8 und BERNARD 2013, 166ff. Zum Topos „epistula non erubescit“ vgl. a. CugusI 1983, 34 bzw. CIc. fam. 5.12.1. Vgl. außerdem GarCeA 2005, 148; GARCEA 2002; CAVARzere 1998, 14 und ebd., 28; Cugusi 1983, 44ff. sowie PenNaCini 1985, 14. Vgl. des Weiteren das Kap. „Emotionalität“ ab S. 68. Zur Formelhaftigkeit römischer Briefe allgemein vgl. z. B. SARRI 2017, 51. Zur rhetorischen Strategie im Zusammenhang mit (Selbst)Trost bzw. consolatio vgl. z. B. WILCOX 2005. Vgl. a. NDIAYE 2010, 197f. Zur miseratio vgl. z. B. Bernard 2013, 218; NDIAYE 2010, 196f.; GARCEA 2005, 207ff. und GARCEA 2004, 158ff. Zu Entschuldigungen vgl. z. B. ROESCH 2004, 150ff. Zu Danksagungen vgl. z. B. HALL 2009, 198 sowie ROESCH 2004, 147 und ebd., 149. Zu Glückwünschen vgl. z. B. HALL 2009, 202f. sowie ROESCH 2004, 149f. Zu Ratschlägen vgl. z. B. WHITE 2010, 117ff. Zu Bitten vgl. z. B. HALL 2009, 204f. und ALBRECHT 2003, 63 bzw. (ausführlicher) UNCETA GÓMEZ 2009b und RISSELADA 1993. Vgl. a. HOFMANN 1978, $125 \mathrm{ff}$.

698 Vgl. z. B. BernaRd 2013, 103f. (zu Ciceros Briefen): „Nombre de lettres mélangent [...] les tons, passant du sérieux au plaisant, de la gravité au badinage. [...] C'est pourquoi, s'il fallait déterminer une typologie des styles épistolaires chez Cicéron, il conviendrait d'en énumérer non pas trois, mais des centaines. [...] Son caractère fonctionnel [d. h. das Wesen der ,épistolarité cicéronienne'] explique que Cicéron ne cherche pas à l'enserrer dans des catégories rhétoriques prédéterminées, comme la théorie des trois styles, mais le subordonne aux officia qu'elle remplit, tantôt privés, tantôt publics, avec des nuances intermédiaires selon les contextes particuliers. "Vgl. a. Powell 2013, 53 und Thraede 1970, 30 sowie Bernard 2013, 97; KLAUCK 1998, 130 und StOWERS 1986, 55. Zur Formelhaftigkeit bzw. Individualisierung in Briefen allgemein vgl. a. HARTUNG 1983, 224. Vgl. im Übrigen Kap. 1.2.1.3.3 und die Analysen im Praxisteil.

${ }^{699}$ Zur lateinischen Umgangssprache insgesamt vgl. v. a. HOFMANN 1978. Vgl. aber auch DICKEY UND CHAHOUD 2010 und HAPP 1967 sowie BAUM 2009. Zum Briefstil allgemein vgl. außerdem GIORGIO 2015, 113f.; GARCEA 2005, 135ff.; AlbreCht 2003, 52ff.; CAVArZere 1998, 29ff.; Antón 1996, 119ff. sowie Cugusı 1983, 45 und ebd., 78ff. Zur Problematik des Begriffs ,Umgangssprache' (bei Hofmann) vgl. S. 135.

700 Vgl. die Einleitung zu HOFMANN 1978, z. B. ebd., 2f.: „Nicht so rein und unvermischt sind die umgangssprachlichen Elemente im Briefstil zu fassen; am ehesten noch dort, wo der Brief an eine sozial gleichstehende, eng befreundete Persönlichkeit gerichtet ist und vorzüglich Dinge des Alltagslebens behandelt [...]. Für uns kommen namentlich Ciceros Briefe an seinen Freund Atticus in Betracht, deren sermo familiaris er selbst $($ Att. 1, 9, 1) bezeugt. Aber auch hier scheiden alle Stellen, an denen er z. B. über hohe Staatsaktionen wie Senatsverhandlungen berichtet und in denen er ganz von selbst in den rhetorischen Ton der Staats- und Gerichtsreden verfällt, seine Mitteilungen über Schauspielaufführungen mit eingestreuten Dichterzitaten und manches andere auf 
muss allerdings bedacht werden, dass sich die im persönlichen Gespräch tatsächlich verwendete Umgangssprache nur eingeschränkt darin widerspiegelt. Vielmehr wird sie überwiegend als Stilmittel zur Herstellung einer ungezwungenen, vertraulichen Atmosphäre und zur Demonstration von urbanitas genutzt. Es handelt sich hier also bis zu einem gewissen Grad um eine Art Kunstsprache und letztlich nur einen gängigen Topos. ${ }^{701}$ Wie authentisch das „zwanglose Plaudern" und der damit verbundene Ausdruck von Emotionalität einerseits, wie groß das Ausmaß an Zielgerichtetheit und (manipulativer) Selbstdarstellung andererseits i. E. zu bewerten sind, kann nicht immer leicht entschieden werden, zumal sich beides ja nicht unbedingt ausschließt. ${ }^{702}$

Hofmann nennt in seinem Grundlagenwerk ${ }^{703}$ vier Hauptkennzeichen der lateinischen Umgangssprache: Einfachheit („Der triviale und sparsame Zug der Umgangssprache“), Anschaulichkeit („Der sinnlich-anschauliche Zug der Umgangssprache“), Partnerbezug („Die Rolle des Partners in der Äußerung des persönlichen Gedankens“ bzw. „Rücksichtnahme und Einwirkung auf den Hörer“) und Affektivität („Die subjektiv-affektische Seite der Umgangssprache“). Ein besonderer Stellenwert kommt der Affektivität zu, da sie die übrigen drei Punkte mehr oder weniger mit einschließt. ${ }^{704}$ (Nicht nur) Hofmann bezieht den Begriff ,Umgangssprache also auf eine psychologische Gefühlsebene - ebenso wie auf eine mediale und eine stilistische Ebene, da er sie außerdem mit Mündlichkeit assoziiert und als Substandardsprache versteht. ${ }^{705}$ Die im Folgenden genannten sprachlichen Merkmale orientieren sich nur grob an seiner Darstellung und nehmen letztlich eher den lateinischen Briefstil (Ciceros) als Ganzes in den Blick, indem sie die Ausprägungen von ,Anschaulichkeit' und ,Einfachheit' im Lateinischen sowie deren affektive Komponenten beschreiben. ${ }^{706}$

Anschaulichkeit wird v. a. durch die Verwendung einer konkreten, weitgehend auf Abstrakta verzichtenden Lexik und Phraseologie erreicht. Kennzeichnend für affektiv-emotionale Passagen sind dabei Wörter aus dem (semantischen) Feld der Gefühlswelt und Psychologie. Wäh-

einen feierlichen oder pathetischen Ton Gestimmte für uns ohne weiteres aus." Vgl. a. CUGUSI 1983, 163 und RISSELADA 1993, 15ff. Vgl. außerdem AlBRECHT 2003, 68 (zum Prinzip des aptum in diesem Zusammenhang). Als Vergleichsquellen zur Beschreibung der lateinischen Umgangssprache in den Briefen gelten v. a. Komödien und Satiren: Vgl. z. B. CuguSI 1998, 173.

701 Vgl. S. 133 bzw. Bernardi Perini 1985, 22: „Ma io sarei tentato di forzare il confronto fino ad asserire che appunto l'epistola, anche l'epistola familiare, non diversamente dalla satira fa del sermo familiaris una lingua in qualche modo d'arte, in cui la spontaneità e la quotidianità risultano da un precisa volontà di stile piuttosto che da un esercizio naïf della lingua di tutti i giorni.“

702 Vgl. z. B. MANUWALD 2009, 5 sowie GIORGIO 2015, 30ff.; BernARD 2013, 165ff.; CORREA 2013, 23ff. und HUTCHINSON 1998, 20ff. Vgl. außerdem die Kapitel zur „Beziehungs- und Identitätskonstitution“ im Praxisteil.

703 HOFMANN 1978.

704 Zur Affektivität bzw. Expressivität in Ciceros Briefen insgesamt vgl. z. B. NDIAYE 2010; GARCEA 2002 und CHESSA 1999. Vgl. a. HOFMANN 1978, 9ff. und GIORGIO 2015, 77ff. Vgl. außerdem PoWELL 2013, 53 (zur „emotional temperature" als Stilvariable).

${ }^{705}$ Vgl. MüLLER 1997, 1f., der nicht nur die Vermischung der drei Ebenen, sondern auch noch weitere Abgrenzungsschwächen und Unklarheiten bei Hofmann bemängelt.

${ }^{706}$ Zum Partnerbezug vgl. Kap. 1.2.1.3.3. 
rend (eher nüchterne und farblose) Partikel und Präpositionen meist nur relativ selten eingesetzt werden, sind bspw. (primäre und sekundäre) Interjektionen und Adjektive (z. B. als Epitheta) i. d. R. häufiger als in der Standardsprache anzutreffen. ${ }^{707}$

Die Ausdruckskraft wird oft mit verschiedenen Mitteln noch intensiviert: Statt Verbalabstrakta werden z. B. substantivierte Verben gebraucht. Eine gewissermaßen verminderte Expressivität bzw. Passivität (z. B. als Symptom der Ratlosigkeit) wird durch Zustandsverben und passive Verbformen nachgezeichnet. Abschwächungen durch Diminutive können Zärtlichkeit oder aber Verachtung vermitteln. Auf der anderen Seite finden sich Verstärkungen und Übertreibungen (Hyperbeln), z. B. durch Wiederholung und Komparation mittels Superlativen, Adverbien oder Präfixen. ${ }^{708}$

Fremdwörter (Gräzismen) und andere ungewohnte Wörter wie Archaismen oder Neologismen können ebenfalls veranschaulichend wirken, wenngleich sie weniger Kennzeichen einer normalen Alltagssprache als der Umgangssprache (i. w. S.) höherer Bildungsschichten sind. Außerdem leisten Stilmittel wie Klang- und Wortspiele, Metaphern, Vergleiche, Periphrasen u. Ä. einen Beitrag zur Bildlichkeit. Auch durch Scherz und Ironie, (rhetorische) Fragen und fiktive Dialoge, Zitate und Sprichwörter wird eine lebendige Eindrücklichkeit befördert. Zugleich ist es möglich, Bildung oder (z. B. im Falle der Sprichwörter) Volkstümlichkeit und - insofern der gemeinsame (Bildungs-)Hintergrund betont wird - Vertrautheit zu demonstrieren. $^{709}$

Eine größere Anschaulichkeit kann, insbesondere im Zusammenhang mit der Präzisierung von Begrifflichkeiten (z. B. griechische Wörter), einen Beitrag zum besseren Verständnis leisten, ist aber nicht mit Klarheit gleichzusetzen. Sie hat ggf. sogar den gegenteiligen Effekt, sei es aufgrund einer Fehleinschätzung des Adressaten, der möglicherweise einen Ausdruck nicht kennt und einzelne Aussagen nicht (sofort) zu erschließen vermag, sei es, weil der Autor die sprachlichen Mittel ungeschickt einsetzt. Dies zeigt sich auch im Bereich der Syntax. Einerseits dient eine bestimmte Satzstruktur der Veranschaulichung und Verdeutlichung, z. B. wenn einzelne Ausdrücke durch die Wortstellung (v. a. am Anfang und Ende von Sätzen) stärker betont und Inhalte ikonisch (durch Parallelismus, Chiasmus u. Ä.) nachgebildet werden. Andererseits kann ein Durchbrechen der üblichen Satzstruktur - durch Hyperbata, Tmesis, Inkonzinnität,

\footnotetext{
707 Zur Lexik allgemein vgl. z. B. HofMANN 1978, 153ff. Zur emotionalen Komponente vgl. a. GIORGIO 2015, 78; JEPPESEN-WIGELSWORTH 2013, 352ff. (besonders zur Verwendung von Adjektiven); NDIAYE 2010, 194ff.; GARCEA 2005, 150ff.; GARCEA 2004, 157f.; CHESSA 1999, 234ff. und BAILlEUX 1933.

708 Vgl. z. B. NDIAYE 2010, 194 (mit Bezug auf Garcea 2005); GARCEA 2002, 215f.; CHESSA 1999, 237f. bzW. HALL 2009, 200ff. und ALBRECHT 2003, 53.

${ }^{709}$ Zur urbanitas in diesem Zusammenhang vgl. z. B. GIORGIO 2015, 108ff. und THRAEDE 1980, 195. Zu den Gründen für die Verwendung von (griechischen) Fremdwörtern (als Zeichen der Vertrautheit bzw. Distanz) vgl. a. BERNARD 2013, 102 sowie SARRI 2017, 50 und ALBRECHT 2003, 54. Dass sich in den Briefen Ciceros an Terentia (von einer Ausnahme abgesehen) keine Gräzismen finden, ist nach WENSKUS 2001, 218 kein Zeichen mangelnder Nähe; eine Verwendung von Gräzismen sei wohl einfach nicht notwendig oder passend gewesen. Dass Terentia eine Abneigung gegen Gräzismen hatte oder des Griechischen nicht mächtig war, hält sie für unwahrscheinlich (ebd., $218 \mathrm{f}$.). Genaueres zu Fremdwörtern bzw. Gräzismen in römischen Briefen: RolLINGER 2015; ALBRECHT 2003, 53ff. und (zur Syntax) ebd., 60f.; CHESSA 1999, 250ff.; HUTCHINSON 1998, 13ff.; ANTÓn 1996, 121; CUGUSI 1989 - 1991, 390f.; CUGUSI 1983, 83ff. und Thraede 1980, 195f. Zu Neologismen und Archaismen: ALBRECHT 2003, 53 und GARCEA $2005,136$. Zu Zitaten und Sprichwörtern: ALBRECHT 2003, 64; CHESSA 1999, 251ff.; ANTÓN 1996, 121f.; CUGUSI 1989 - 1991 , 389ff. und CUGUSı 1983, 91ff. Zu Scherzen, Witzen, Wortspielen usW.: ALBRECHT 2003, 64f.; CHESSA 1999, 246ff. und THRAEDE 1980, 194f. Zu (fiktiven) Dialogen: CHESSA 1999, 229ff. Zur Bildlichkeit: ebd., $239 \mathrm{ff}$.
} 
satzinterne Korrekturen, Parenthesen, Anakoluth usw. - zu Verwirrung führen. Solche Irregularitäten drücken i. d. R. eine große Emotionalität aus. ${ }^{710}$

Ähnliches gilt für die Tendenz zur Vereinfachung und Verkürzung, die im Kontrast steht zum gelegentlich anzutreffenden und wenig zielführenden Übermaß an Explizierung, zu (überflüssigen) Wiederholungen und zusätzlichen Erklärungen, Pleonasmen und Interferenzen. Mit der Verwendung einer sehr einfachen Lexik (z. B. generalisierende Ausdrücke in Verbindung mit Allerweltsverben wie esse und facere) und Syntax (z. B. Parataxe, wenige Partizipialkonstruktionen) und einem insgesamt eher zurückhaltenden Einsatz von Redeschmuck werden Nähe zum normalen Volk und Intimität signalisiert. Die Ausführungen werden nicht unnötig verkompliziert. Durch das Weglassen von (nicht notwendigen) Einzelheiten wird die Übersichtlichkeit erhöht. Simplifizierungen und Verkürzungen (z. B. Brachylogie, Ellipse, Apokope, Synkope) korrespondieren allerdings letztlich auch nicht unbedingt mit einer besseren Verständlichkeit und wirken ebenfalls oft sehr emotional und expressiv. Man denke nur an abrupte Satzabbrüche (Aposiopesen), Exklamativsätze in Gestalt eines Akkusativs oder Infinitivs des Ausrufs und andere Formen affektischer Kurzsätze. ${ }^{711}$

\subsection{Fazit}

Trotz ihrer enormen Vielfältigkeit gab es immer ein recht stabiles Grundverständnis der Kommunikationsform Brief, das über die Jahrhunderte hin erstaunlich konstant geblieben ist, wenngleich sie i. E. natürlich dem jeweiligen Zweck und Bedürfnis entsprechend abgewandelt wurde. ${ }^{712}$ Die wesentlichen Kennzeichen sind dabei weniger inhaltlicher als vielmehr formaler und funktionaler Natur. ${ }^{713}$ Sehr reduziert ist z. B. die Bestimmung bei Ermert: „Der Brief ist zunächst nichts als ein durch bestimmte formale Merkmale gekennzeichnetes Mittel, mit dem ein Mensch mit einem anderen kommunizieren kann, der räumlich von ihm getrennt ist. " Noch schlichter nimmt sich die Definition in den Retractiones (2.20) des Augustinus aus: Epistula est, habet quippe in capite quis ad quem scribat. ${ }^{715}$ Als zentrales Charakteristikum von Briefen wird in der Antike zudem sehr häufig die Nähe zum Gespräch angeführt, die jedoch nur teilweise tatsächlich gegeben ist, wie dieses Teilkapitel gezeigt hat. ${ }^{716}$

\footnotetext{
710 Vgl. z. B. GIORGIO 2015, 78; AlbreCHT 2003, 59 sowie GARCEA 2002, 119ff. und ebd., 211.

711 Zur Vereinfachung und Verkürzung allgemein vgl. z. B. HoFMANN 1978, 165ff. Zu generalisierenden Verbkonstruktionen vgl. a. GARCEA 2005, 138f. Zur Verkürzung (bes. Ellipsen und Anakoluth, Brachylogie) vgl. a. CHESSA 1999, 225ff. und CUGUSI 1983, 104. Zur (affektischen) Syntax in Briefen allgemein vgl. z. B. HofMANN 1978, 46ff. und ebd., 102ff. sowie GARCEA 2005, 124ff. und ebd., 136ff.; AlBRECHT 2003, 56ff. und CUGUSI 1983, 98ff. Speziell zu Ausrufe(sätze)n und Interjektionen vgl. a. CHESSA 1999, $206 \mathrm{ff}$.

712 Vgl. z. B. EbBeler 2010, 466. Vgl. a. Antón 1996, 148 und LeJEUne 1975, 315f. sowie außerdem BernARD 2013, 17; White 2010, 21 und THRAEDE 1970, 9 N. 17.

713 Vgl. z. B. MANUWALD 2009, 3 und CAVARZERE 1998, 11.

${ }^{714}$ ERMERT 1979, 9.

715 Vgl. dazu auch SCHWITTER 2018, 85: „Augustinus' vielzitierte Gattungsbestimmung ist erstaunlich offen und schließt mit der exklusiven Beschränkung auf einen formalen Aspekt prinzipiell ein breites Spektrum weiterer Gattungen mit ein, die offenkundig über dasselbe Distinktionsmerkmal verfügen. Als singulärer gattungskonstituierender Faktor ist die textinterne Nennung von Absender und Adressat aus moderner Perspektive kaum tauglich, um die mannigfache Variationsbreite der Textsorte Brief in Antike und Spätantike ausreichend zu definieren und von anderen Textsorten beziehungsweise Gattungen befriedigend abzugrenzen."

${ }^{716}$ Eine häufig aufgegriffene, ausführlichere Definition (mit Bezug auf die Antike) schlägt Michael Trapp in Div. 2003, 1 vor: „A letter is a written message from one person (or set of people) to another, requiring to be set down in a tangible medium, which itself is to be physically conveyed from sender(s) to recipient(s). Formally, it
} 
Insgesamt sind die genannten Merkmale nicht sehr spezifisch. So ist es auch bezeichnend, dass sich andere Kommunikationsformen bzw. Textsorten (wie z. B. philosophische Abhandlungen, Romane und Gedichte) zur Einkleidung ihrer Inhalte gerne der Briefform bedienen. ${ }^{717}$ Derrida betrachtet den Brief sogar als Verbindung aller Textsorten: „Mixture is the letter, the epistle, which is not a genre, but all genres, literature itself." ${ }^{118}$ Klar ist jedenfalls, dass es keine absolut stringente Definition des Begriffs ,Brief' geben kann. Gleichwohl ist das Konzept vor dem Hintergrund der gemachten Ausführungen und der „normativen Kraft des Faktischen“ beizubehalten. ${ }^{719}$

\subsubsection{Ciceros Briefe an Terentia (fam. 14)}

\subsubsection{Entstehung}

Ciceros Briefe an Terentia sind auf die Zeit vom 29. April 58 bis zum 1. Oktober 47 v. Chr. zu datieren. ${ }^{720}$ Fam. 14.1 bis 14.4 hat Cicero 58 v. Chr. geschrieben, im ersten Jahr seines bis 57 v. Chr. währenden Exils. Fam. 14.5 ist 50 v. Chr. entstanden, zweieinhalb Monate vor seiner

is a piece of writing that is overtly addressed from sender(s) to recipient(s), by the use at beginning and end of one of a limited set of conventional formulae of salutation (or some allusive variation of them) which specify both parties to the transaction. One might also add, by way of a further explanation, that the need for a letter as a medium of communication normally arises because the two parties are physically distant (separated) from each other, and so unable to communicate by unmediated voice or gesture; and that a letter is normally expected to be of relatively limited length." Vgl. dazu auch GIBSON UND MORRISON 2007, 3, die (wie Trapp selbst) darauf hinweisen, dass nicht einmal diese allgemeine Definition alle Briefe angemessen erfassen kann. Weitere Definitionen finden sich z. B. in SARRI 2017, 15 und MANUWALD 2009, 3. Vgl. außerdem (mit besonderem Bezug auf Ähnlichkeiten und Unterschiede mit bzw. zu Gesprächen) GAVOILLE 2004, 45ff. und (allgemeiner) ORTNER 2014b, $303 \mathrm{f}$. Vgl. des Weiteren BÜRGEL 1976, 296 und NICKISCH 1991, 6f.

${ }^{717}$ Ebd., 19ff. unterscheidet eigentliche (primäre) und uneigentliche (sekundäre) Verwendung der Briefform. Zu den Gründen für eine (auch sekundäre) Verwendung der Briefform vgl. z. B. MANUWALD 2009, 7: „Die Briefform, sei es bei der Publikation von Kollektionen realer Briefe, sei es bei der fiktiver Briefe, erlaubt es dem Verfasser, die einem Brief inhärente Subjektivität beizubehalten bzw. sie bewusst einzusetzen, durch Hinwendung an einen Adressaten die Darstellung aufzulockern und die formale Offenheit der Form für Ponderierung und Gliederung des Werks zu nutzen [...]. Bei den Rezipienten wiederum kann sich das Gefühl einstellen, in das Privatleben und die persönlichen Gedanken des Verfassers Einblick zu bekommen und ihm oder auch dem Adressaten nahe zu sein." Zur (sekundären) Verwendung der Briefform in wissenschaftlichen und philosophischen Abhandlungen vgl. z. B. CORBINELLI 2008, 74; BERNARD 2006, 74 und GARCíA 1974, 437. Vgl. a. (zu - theologischen - Brieftraktaten) SCHWITTER 2018, 86ff. Zur Briefform in der Lyrik vgl. z. B. ebd., 85 N. 2 und (zu poetischer Epistel bzw. Briefgedicht) THRAEDE 1980, 190ff. Vgl. a. SCHWITTER 2018, 85 zur Definition von Augustinus (s. N. 715).

718 DERRIDA 1987, 48. Vgl. dagegen GIBSON UND MORRISON 2007, 14f.: „It is [...] important to see that the letter, even though it is a distinct type of text, with recognizable features such as those listed by Trapp, is also connected by some family-resemblances to other, non-epistolary types of text. This is not to say, however, that all literature is really or metaphorically epistolary [vgl. Derrida], but to note that several texts can display characteristics similar to or reminiscent of letters. [...] We should approach and interpret letters with full awareness both of the importance of their epistolary character, and their connections to other non-epistolary texts." Vgl. a. GAVOILLE UND GUILLAUMONT 2017b, 44 und EBbeler 2010, 465.

719 Vgl. z. B. ebd., 465 und GIBSON UND MORRISON 2007, 13. Vgl. a. ebd., 15: „If [...] a definition is meant to divide off the letter, to make it a hermetically sealed conceptual category, clearly and definitively delineated from nonepistolary texts, then the futility of such a definition should be obvious. Letters cannot be separated in this manner from other texts, as the borderline cases [...] show - a network of family resemblances, albeit less strong than those within the category of the letter, connect letters to texts and types of text ,outside' the letter. Such a definition, for example in the form of a set of necessary and sufficient conditions, is also problematic in that it may be used to exclude individual examples from the category of the letter and hence from the canon of texts to be read or criticized."

${ }^{720}$ Eine Übersicht über die genauen Daten findet sich bspw. in Abbildung 77 (S. 416). Vgl. a. N. 723. 
Rückkehr aus Kilikien, wo Cicero von 51 bis 50 v. Chr. Prokonsul war. Fam. 14.14, 14.18 und 14.7 sind 49 v. Chr. verfasst worden, die ersten beiden Briefe Anfang des Jahres, kurz nach Ausbruch des Bürgerkrieges zwischen Cäsar und Pompejus bzw. dessen Anhängern (49 bis 45 v. Chr.), der dritte am Ende des Jahres. Die übrigen Briefe (fam. 14.6, 14.8 - 14.13, 14.15 14.17 und 14.19 - 14.24) stammen aus den Jahren 48 und 47 v. Chr., wobei außer fam. 14.6 alle in die Zeit nach dem Sieg Cäsars in der Schlacht von Pharsalus fallen. ${ }^{721}$

\subsubsection{Veröffentlichung und Überlieferung}

Cicero hat durchaus Überlegungen zu einer späteren Publikation seiner Korrespondenz angestellt, auch wenn er sie nicht mehr selbst in die Tat umsetzen konnte. Diese beziehen sich allerdings nur auf einige besondere Schreiben, die er zuvor noch entsprechend bearbeiten wollte. ${ }^{722}$ Was seine Briefe an Terentia betrifft, dürfte er wohl kaum beabsichtigt haben, sie irgendwann zu veröffentlichen. Zwar weisen v. a. die Exilbriefe eine recht stark elaborierte Form auf, doch diese lässt sich eher erklären durch die mit ihnen verfolgten Absichten und die tiefsitzende rhetorische Prägung Ciceros. Insgesamt erweisen sich insbesondere die späteren Schreiben als wenig spektakulär hinsichtlich Inhalt und Form. Dies wird erst recht für die nicht erhaltenen Briefe gelten, also für die Briefe Terentias und weitere Briefe Ciceros an seine Frau, obwohl es - neben den allgemeinen Widrigkeiten der Überlieferung - auch andere Gründe für deren (bewusste oder unbewusste) Unterdrückung geben mag. ${ }^{723}$

Wie die Veröffentlichung von fam. 14 bzw. der Epistulae ad familiares insgesamt erfolgte, ist i. E. nicht mehr nachvollziehbar. Man weiß also nicht, inwieweit z. B. Tiro dafür verantwortlich war und ob die Epistulae ad familiares von Anfang an als ein zusammengehöriges Werk oder zunächst nur - was wahrscheinlicher ist - in einzelnen Büchern veröffentlicht wurden. Möglicherweise sind zudem einige Bücher, die eigentlich Bestandteil dieser - in ihrer heutigen Form 16 Bücher umfassenden - Sammlung sein könnten, verloren gegangen. ${ }^{724}$

\footnotetext{
${ }^{721}$ Zu Einzelheiten der genannten Lebensphasen bzw. zur Biografie Ciceros insgesamt sei auf die einschlägige Fachliteratur verwiesen (vgl. a. N. 742). Sofern es notwendig erscheint, wird außerdem im Zusammenhang mit den Einzelanalysen im Praxisteil auf Details eingegangen.

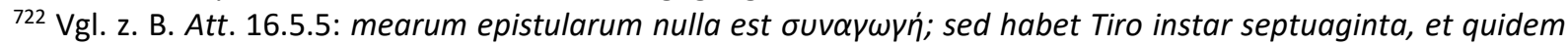
sunt a te quaedam sumendae. eas ego oportet perspiciam, corrigam; tum denique edentur. Vgl. a. fam. 16.17.1 Sowie Müller 2018, 8f. Vgl. außerdem Bernardi PeRINI 1985, 20 und CAVARZERE 1998, 14. Zur Veröffentlichung von Ciceros Briefen insgesamt vgl. darüber hinaus CORREA 2013, 76ff.; WHITE 2010, 31ff.; HUTCHINSON 1998, 3ff.; KLAUCK 1998, 127f.; NICHOLSON 1998, 63ff.; JÄGER 1986, 19ff. (bes. ebd., 20f.) und TYRRELL 1966, LXIIff. sowie CUGUSI 1989 1991, 415f.; CUGUSI 1983, 139ff. und PETER 1965, $29 \mathrm{ff}$.

${ }^{723}$ Vgl. a. Kap. 1.1.2.2.2. Zu den Briefen Terentias und dazu, dass Cicero sicherlich sehr viel mehr Briefe an seine Frau geschrieben hat, als uns überliefert worden sind, vgl. z. B. CLAASSEN 1996, 214. Vgl. a. das „thought experiment" zur Rekonstruktion der Briefe Terentias bei RICHLIN 2013.

${ }^{724}$ Vgl. z. B. GIBSON 2012, 59f. und Kasten in CICERO 2004, 938. Genaueres zur Textüberlieferung: CICERO 1988, IIIff. (Praefatio); Shackleton Bailey in CICERO 1977, 3ff. und (unter Vorbehalt) TYRRELL 1966, XCIVff. Vgl. a. BINDER 2007, 149f. Vgl. außerdem (zur Überlieferung während der Zeit der Antike) NICHOLSON 1998. Zu den ersten Druckausgaben vgl. z. B. BINDER 2007, 148. Bedeutende textkritische Ausgaben in neuerer Zeit wurden von L. C. Purser (Oxford Classical Texts: CICERo 1952, 1. Aufl. 1901) und D. R. Shackleton Bailey (Bibliotheca scriptorum Graecorum et Romanorum Teubneriana: CICERo 1988) herausgegeben. Hinzu kommen Ausgaben, die das Gesamtwerk Ciceros bzw. sämtliche Briefe umfassen, wie z. B. die von W. S. Watt und D. R. Shackleton Bailey (CICERo 1958 - 1982): Vgl. BINDER 2007, 151. Weit verbreitete Übersetzungen haben u. a. W. G. Williams (CICERO 1927) und D. R. Shackleton Bailey (CICERO 2001) für das Englische sowie H. Kasten (CICERO 2004, 1. Aufl. 1964) für das Deutsche erstellt. Zu erwähnen ist außerdem die Edition sämtlicher Briefe Ciceros mit französischer Übersetzung von J. Bayet, J. Beaujeu und L.-A. Constans (CICERO 2002, 1. Aufl. 1934-1996): Vgl. BINDER 2007, 151f. Der ausführliche
} 
Der Titel Epistulae ad familiares hat sich seit der Ausgabe von H. Stephanus (1577) eingebürgert. Frühere Bezeichnungen sind Epistulae familiares und Epistulae ad diversos. ${ }^{725}$ Die Briefsammlung enthält im Wesentlichen Briefe von und an Cicero aus den Jahren 62 bis 43 v. Chr., die sich im Gegensatz zu den anderen Briefsammlungen (Att., ad Q. fr., ad Brut.) nicht einem bestimmten Adressaten- bzw. Autorenkreis zuordnen lassen. So sind z. B. neben Cicero tatsächlich nahestehenden Personen bzw. Familienangehörigen wie seiner Frau Terentia (fam. 14) und seinem Freigelassenen Tiro (fam. 16) auch eher weitläufig bekannte politische „Freunde" vertreten. ${ }^{726}$

Die Epistulae ad familiares sind z. T. nach der Art der Briefe (fam. 13: Empfehlungsschreiben), hauptsächlich aber nach Adressaten zu Büchern zusammengefasst. Die Reihenfolge der Schreiben (innerhalb der einzelnen Bücher) variiert je nach Herausgeber. In der Antike wurde bei solchen Briefsammlungen - ähnlich wie bspw. bei Sammlungen von Autobiografien oder Gedichten - einerseits oft eine Anordnung nach Adressat und Inhalt bevorzugt, diese aber andererseits gerne im Streben nach variatio durchbrochen. ${ }^{727}$ Ergebnis sind sorgfältig durchkomponierte "Gesamtkunstwerke“ ${ }^{728}$ In der (klassisch-)literarischen Welt der Römer wurden offensichtlich Anordnungsprinzipien hoch geschätzt, die nicht unbedingt narrativ-chronologisch ausgerichtet waren. ${ }^{729}$ Somit handelt es sich um einen bewussten Akt und nicht, wie z. T. unterstellt wurde, um Inkompetenz der antiken Editoren, wenn die Briefe abweichend von ihrer zeitlichen Reihenfolge arrangiert werden, wie dies später üblich ist, d. h., etwa ab dem

Kommentar von Tyrrell / Purser (CICERO 1904 - 1933, 1. Aufl. 1885-1901) wurde von dem D. R. Shackleton Baileys (CICERO 1977) als Standardkommentar abgelöst bzw. ergänzt. Daneben finden sich auch in vielen anderen Textausgaben und Übersetzungen oft ergänzende Kommentare.

725 Vgl. z. B. BINDER 2007, 149 und Kasten in CICERO 2004, 938.

${ }^{726}$ Einige Briefe haben sogar überhaupt keinen Bezug zu Cicero: Vgl. z. B. Kasten in ebd., 938 und KLAUCK 1998, $127 f$.

${ }^{727}$ Zu den Anordnungsprinzipien in antiken Briefsammlungen allgemein vgl. GIBSON 2013 und GIBSON 2012 sowie Wulfram 2008, 30ff., bes. ebd., 32. Speziell zu fam. vgl. z. B. GiBSON 2012, 64f. Zur variatio, wie sie sich bspw. bei Plinius d. J. findet, vgl. u. a. ebd., 67ff. Anzumerken bleibt, dass sich die verschiedenen Kriterien (wie Inhalt und Adressat) nicht immer klar voneinander unterscheiden lassen und dass im Übrigen oft verschiedene Anordnungsprinzipien miteinander kombiniert werden: Vgl. z. B. ebd., 64 und GIBSON 2013, 391.

${ }^{728} \mathrm{Vgl}$. z. B. ebd., 392f.: „The sixteen books which make up the collection which we now know as Cicero's ad Familiares reveal a number of different principles of ordering. [...] Put together by an editor or editors other than Cicero at some point in the early imperial period, each of these books in its original format shows evidence of intelligent selection and design, and can be read as satisfying artistic units in their own right (not unlike ancient poetry books)." VgI. a. (allgemeiner) GIBSON 2012, 65, der darüber hinaus auf BEARD 2002 hinweist, die dies am Beispiel von fam. 16 aufgezeigt habe.

${ }^{729} \mathrm{Vgl}$. z. B. GiBson 2012, 72: „Rather, it is enough to say that classic poetry books are evidence for a broad literary environment in which a narrative-chronological ordering of one's material was not a necessary or even a ,natural' choice. Indeed, it could be argued that greater cultural prestige accrued to methods of arrangement other than the chronological." 
16. Jahrhundert und verstärkt seit dem 19. Jahrhundert. ${ }^{730}$ Auch in neueren Textausgaben dominiert das chronologische Prinzip, wenngleich sich in jüngster Zeit eine zunehmende Rückbesinnung auf die alten Handschriften feststellen lässt. ${ }^{731}$

Klar ist, dass der Reihenfolge große Bedeutung für die (intertextuelle) Interpretation zukommt: So können z. B. die Verdienste und das hohe Ansehen des Autors ins Zentrum gerückt werden (Enkomion), indem man Briefe hinzufügt, die er an bedeutende Persönlichkeiten geschrieben bzw. von ihnen erhalten hat. ${ }^{732}$ Durch die Zusammenstellung von Briefen an bestimmte Personengruppen (wie z. B. die Ehefrau in fam. 14) wird der Charakter bzw. die Rollenidentität des Autors im Verhältnis zu seinen Mitmenschen genauer beleuchtet. ${ }^{733}$ Dabei können auch gewissermaßen didaktische Absichten verfolgt werden, insofern sich aus seinem Umgang mit anderen Handlungsvorbilder für die betreffenden Situationen ableiten lassen. ${ }^{734}$ Während also in der antiken Tradition das (in den Briefen dargestellte) Leben des Autors quasi zur „Kunstform“ erhoben werden kann ${ }^{735}$, rücken durch die korrekte zeitliche Abfolge (Auto-)Biografie und Historiografie stärker in den Blickpunkt. ${ }^{736}$

\footnotetext{
730 Vgl. z. B. GIBSON 2013, 391 bzw. ebd., 407. In ebd., 394ff. bzw. ebd., 405ff. findet sich ein Überblick über einzelne Editionen der Briefe Ciceros (bes. fam.) in der frühen bzw. späteren Neuzeit, die dem chronologischen Prinzip folgen, beginnend mit der Ausgabe der Epistulae ad familiares von Girolamo Ragazzoni (1555). Dieser Arbeit liegt CICERO 1988 zugrunde, da es sich um die jüngste und am weitesten verbreitete textkritische Edition von fam. handelt. Wie sinnvoll die Reihenfolge der Briefe in dieser Ausgabe ist, müsste sicherlich diskutiert werden. Letztlich spielt sie für die vorliegende Arbeit jedoch keine Rolle, wäre aber für weitergehende Analysen durchaus wichtig. Vgl. a. CORREA 2013, 80f. bzw. N. 737.

${ }^{731} \mathrm{VgI}$. GIBSON 2012, 64 bzW. MCCUTCHEON 2016, 59.

732 Vgl. z. B. GIBSON 2012, $74 f$.

733 Vgl. z. B. ebd., 67 und ebd., 75, wo u. a. Parallelen zu den Biografien Suetons gezogen werden.

$734 \mathrm{Vgl}$. z. B. ebd., 74: „[...] ancient letter collections may be understood as a field of ,significant performance', where the writer's skill in managing social and familiar relationships (dealing with others right, and comporting oneself right in such dealings) is put on public display and held up for imitation. The reader's interest is assumed to lie more in observing the ability of the letter-writer to conduct social relations with his family and the most powerful men of the time in an appropriate manner, and to lie less in following his life story. [...] At any rate, the organization of correspondence by (type of) addressee or by theme allows these social abilities to emerge with particular clarity."

735 Ebd., $72 f .:$ „,[...] the parallel between letters and books of poetry has one potential consequence for understanding the nature and purpose of ancient letters. For books of letters created by editors - where these exist in an author's manuscript tradition - might often have as their broad purpose the elevation of the ,life' of the writer into an art form (rather than a merely documentary one). This art form requires interpretive techniques not formally dissimilar from those applied to the decipherment of first-person poetry books familiar from the early Empire and later." Vgl. a. N. 728.

${ }^{736}$ Vgl. z. B. GIBSON 2013, 389. Vgl. a. GIBSON 2012, 58, der darauf aufmerksam macht, dass die Herausgeber nur selten explizit Rechenschaft ablegen über ihre Beweggründe für eine chronologische Anordnung. Vgl. außerdem GIBSON 2013, 407f. In der Antike selbst war die Vorstellung von Briefen als (auto)biografischen oder historiografischen Zeugnissen eher gering ausgeprägt, ist aber in Ansätzen durchaus erkennbar, wie GIBSON 2012, 57 mit Verweis auf NEP. Att. 16.3f. ([...] undecim volumina epistularum ab consulatu eius usque ad extremum tempus ad Atticum missarum; quae qui legat, non multum desideret historiam contextam eorum temporum. Sic enim omnia de studiis principum, vitiis ducum, mutationibus rei publicae perscripta sunt [...].) verdeutlicht, wobei er auch auf einige Ungereimtheiten (z. B. in Bezug auf die Anzahl der Bücher der Briefsammlung Cıc. Att.) hinweist.
} 
Textanalysen müssen demnach nicht nur unter Vorbehalt von Unsicherheiten bei der konkreten Textgestalt, sondern ebenso bei der Anordnung der einzelnen Briefe erfolgen. ${ }^{737}$ Man sollte auf jeden Fall nicht von einer unverrückbaren, festen Reihenfolge ausgehen, sondern die Briefsammlungen vielmehr als "fluid, malleable textual object “738 betrachten.

\subsubsection{Rezeption und Forschung}

\subsection{Ciceros Briefe im Urteil der Nachwelt: Vorbild oder negatives Beispiel?}

So wie für Cicero die Briefe anderer Autoren Modellcharakter hatten, wurde er selbst zum Vorbild für nachfolgende Briefschreiber. ${ }^{739}$ Allerdings ist umstritten, wie weitreichend Ciceros Einfluss tatsächlich war. Sicher ist jedenfalls, dass seine Briefe häufig als Vergleichspunkt dienten und im Allgemeinen große Wertschätzung erfuhren. ${ }^{740}$ Insbesondere Ciceros emotionale Exilbriefe haben allerdings $z$. T. auch sehr heftige negative Reaktionen bei der Nachwelt hervorgerufen, zumal sie im völligen Widerspruch zu Ciceros philosophischen Grundsätzen zu stehen scheinen. Bereits in der Antike finden sich wenig schmeichelhafte Kommentare, z. B. bei PLUT. Cic. 32 und CASS. DIO 38.18-29. ${ }^{741}$ Bekannt sind außerdem das Entsetzen Petrarcas angesichts der von ihm (wieder-)entdeckten Briefe Ciceros und die - wesentlich durch die Briefe beeinflusste - kritische Bewertung seiner Persönlichkeit durch die Historiker Mommsen und Drumann. ${ }^{72}$ Diese wurde jedoch bald von objektiveren Urteilen abgelöst. Oft wird versucht,

737 Vgl. z. B. White 2010, 169f. und MCCUTCHEON 2016, 59 (s. N. 738). Vgl. aber auch CORREA 2013, 80f., die eine Analyse von Einzelbriefen trotz solcher Unsicherheiten für möglich und sinnvoll hält, da deren Auswahl bzw. Anordnung „no parece haber afectado en modo sustantivo el texto de las cartas en sí “, sondern lediglich „parece haber reforzado [...] cuestiones ya presentes en las cartas".

738 MCCUTCHEON 2016, 59: „With their perspectives on textuality influenced, as they were, by the epistemological and ideological constraints of print culture, scholars have failed to observe that his [= Ciceros] corpus was never a stable, fixed artefact - not in the way that other texts in modern print culture are (which are still unstable) and not even in the way that other texts from antiquity were (which were generally quite unstable). What we know as Cicero's Letters likely developed slowly and messily in antiquity, something that would explain its confused appearance in the literary record. In short, there was no original or true form of this corpus to which we should return or which we should favour to the exclusion to others. Cicero's epistolary corpus has always been a fluid, malleable textual object and one that is prone to reconfiguration. Accordingly, my recommendation is that we must similarly read Cicero's epistolary corpus fluidly: in the manuscript book forms; within the larger manuscript collections; with and without spurious materials; with and without other texts transmitted in the manuscript traditions; and in chronological order, by addressee or cumulatively. In short, there is no definitive, singular form to this corpus; therefore, nor can there be a singular way of reading it."

${ }^{739}$ CugusI 1998, 164. Vgl. a. ebd., 170 und ebd., 187 sowie GuglielmI 2013, 18 und außerdem ThraEdE 1980, 199. Vorbild war Cicero u. a. für Plinius. MüLLER 2018, 10 meint z. B., dass „[...] Plinius im wertschätzenden Wettbewerb mit Cicero, welcher sich nicht nur ganz allgemein auf dessen stilistisches Können bezieht, sondern dezidiert auch seine Briefkunst miteinschließt, ein Verständnis seines epistolographischen Schaffens [artikuliert], das sich entschieden als Teil einer Traditionslinie begreift und aus dieser seine Bewertungsmaßstäbe bezieht. " Vgl. a. RüHL 2019, 2. Darüber hinaus bildeten Ciceros Briefe - neben denen anderer Autoren wie Cäsars und Augustus' - die Grundlage für die brieftheoretischen Vorgaben in IUL. VICT. rhet.: Vgl. CORBINELLI 2008, 23. Zum Modellcharakter der Briefe Ciceros vgl. im Übrigen auch S. $95 \mathrm{f}$.

740 Vgl. z. B. BeRnARDI PeRINI 1985, 20 (mit bes. Bezug auf fam.). Ausführlicher zur Thematik: CORREA 2013, 70ff. („Cicerón - ¿,Padre' del género epistolar?“) und CUGUSI 1998 („L'epistola ciceroniana - Strumento di comunicazione quotidiana e modello letterario“).

741 Vgl. z. B. CORREA 2011, 18 N. 54 und Jäger $121 \mathrm{f}$.

742 Vgl. Petrarcas zweiten Brief an Cicero (Epistolae familiares 24.3) bzw. Theodor Mommsens „Römische Geschichte“ sowie die "Geschichte Roms“ von Wilhelm Drumann und Paul Groebe. Vgl. a. CARCoPINO 1947, welcher in der gegen den Willen Ciceros erfolgten Veröffentlichung der Briefe einen Demontageversuch durch seine Gegner vermutet. Positivere bzw. neutrale Darstellungen finden sich z. B. in den Biografien von O. Seel (1953= SEEL 1967); K. Büchner (1962 = BüCHNER 1962); M. Gelzer (1969 = GELZER 2014); D. R. Shackleton Bailey (1971 = 
die in den Briefen zum Ausdruck kommende desolate Verfassung Ciceros psychologisch zu erklären. ${ }^{73}$ Teilweise werden aber auch sehr rationale strategische Überlegungen hinter der Darstellung vermutet. ${ }^{744}$

\subsection{Forschungsschwerpunkte der Moderne}

Ciceros Briefe sind in der bisherigen Forschung ausgiebig und unter recht verschiedenen Blickwinkeln analysiert worden. ${ }^{745} \mathrm{Im}$ Folgenden soll ein kurzer Überblick über wesentliche Schwerpunkte gegeben werden, wobei der Fokus auf (v. a. neueren) Arbeiten liegt, die für die vorliegende Untersuchung besonders relevant erscheinen. Dabei wird auch deutlich werden, dass in einer wissenschaftlichen Arbeit klare methodologische Bestimmungen und Eingrenzungen zwar wünschenswert, aber offensichtlich nicht immer möglich bzw. nicht notwendig sind.

Neben Textkommentaren ${ }^{746}$ und spezielleren Arbeiten, z. B. aus dem Bereich Textkritik und Überlieferung, sind zunächst einmal die lange Zeit in der Forschung vorherrschenden historisch-biografischen Untersuchungen der Cicero-Briefe zu nennen. ${ }^{747}$ Die Schreiben liefern u. a. literarhistorische Informationen und können Hinweise geben für die Interpretation der Werke Ciceros (und anderer Autoren). ${ }^{748}$ Cicero war aber nicht nur Schriftsteller, sondern außerdem ein einflussreicher Politiker und allgemein ein Mensch mit vielfältigen sozialen und familiären Beziehungen, die sich in seiner Korrespondenz widerspiegeln, welche somit interessante Einblicke vermittelt in die römische Politik und Sozialgeschichte sowie das Leben einzelner bedeutender und weniger bedeutender Personen. Und natürlich tritt uns Cicero selbst mit seiner individuellen Lebensgeschichte, seinen Ansichten und Gefühlen gegenüber. Seine Briefe sind deshalb essenziell für die Rekonstruktion seiner Vita. ${ }^{749}$ So gibt es zahlreiche Biografien Ciceros. ${ }^{750}$ Beispielhaft angeführt seien hier zudem CARCOPINO 1947 (, Les secrets de la correspondance de Cicéron“), WISTRAND 1979 ( "Cicero imperator - Studies in Cicero's correspondence 51-47 B.C.“), TRISOGLIO 1984 („La quotidianità dei rapporti sociali in Cicerone epi-

SHACKLETON BAILEY 1971); E. Rawson (1975 = RAWSON 2001); M. Giebel (1977 = GIeBeL 2013); M. Fuhrmann (1989 = Fuhrmann 2011); K. Bringmann (2010 = Bringmann und Clauss 2014); F. Pina Polo (= PINA Polo 2010); W. Schuller $(2013=$ SCHULLER 2013 und 2018 = SCHULLER 2018) sowie Z. Lowery und F. Forsyth (2016 = LOWERY UND FORSYTH 2016). VgI. a. NARDUCCI 2012, 302ff. („Das Cicero-Bild im 19. und 20. Jahrhundert“) und NARDUCCI 2004 sowie JÄGER 1986, 2ff. und ebd., 121f. Vgl. außerdem GARCEA 2005, 143 N. 1 und GIORGIO 2015, $16 f$.

${ }^{743}$ Vgl. z. B. CORREA 2011, 18f. N. 54. JÄGER 1986, 120ff. erkennt in den Briefen sogar alle Anzeichen einer „reaktiven Depression".

744 Vgl. z. B. Correa 2011; LI CAUSI 2008 und GARCEA 2005. VgI. a. S. 135.

${ }^{745}$ Ciceros Briefe sind v. a. seit der Mitte des 20. Jahrhunderts zu einem beliebten Forschungsobjekt geworden. Gerade auch in den letzten Jahren ist eine Reihe umfassenderer Arbeiten entstanden. Einen Überblick findet man z. B. bei RÜHL 2019, 3ff.; GIORGIO 2015, 16ff. und BERNARD 2013, 13ff. Für die Literatur bis 1982 vgl. a. JäGER 1986, 1ff. Vgl. außerdem WHITE 2010, IX und SCHRÖDER 2004 - 2005, 193.

${ }^{746} \mathrm{Vgl}$. N. 724 (Kommentare zu fam.).

747 Vgl. z. B. RüHL 2019, 2 und VALETTE-CAGNAC 2017, 21 sowie CORREA 2013, 17 und SCHRÖDER 2004 - 2005, 194ff. Vgl. außerdem BERNARD 2013, 14ff., der Ciceros Briefe als Informationsquelle für folgende Bereiche sieht, zu denen er jeweils entsprechende Forschungsarbeiten nennt: „I'histoire et la civilisation romaines“, „la personnalité de Cicéron et son environnement socioculturel“, „la langue latine et grecque“ (vgl. S. 147), „les œuvres de l'Arpinate".

748 Ebd., 17 verweist z. B. auf die Arbeiten von Carlos Lévy.

${ }^{749}$ Vgl. CugusI 1983, $161 \mathrm{ff}$.

750 Vgl. N. 742. 
stolografo“), TRISOGLIO 1985 („La lettera ciceroniana come specchio di umanità“), CITRONI MARCHETTI 2000 („Amicizia e potere nelle lettere di Cicerone e nelle elegie ovidiane dall'esilio“), BURCKHARDT 2003 ( ,,,Zu Hause geht alles, wie wir wünschen ...' - Privates und Politisches in den Briefen Ciceros“) und LeHMANN 2015 („Historiographie et autobiographie dans la Correspondance de Cicéron des années 58-56"). ${ }^{751}$

Zu Terentia sind mittlerweile ebenfalls einige Biografien und weitergehende Untersuchungen erschienen. Zu nennen sind z. B. ERMETE 2003 („,Terentia und Tullia - Frauen der senatorischen Oberschicht") und TREGGIARI 2007 („Terentia, Tullia and Publilia - The women of Cicero's family“) sowie DIXON 1984 („Family finances - Tullia and Terentia“), BRENNAN 2012 („Perceptions of women's power in the late republic - Terentia, Fulvia, and the generation of 63 BCE") und BUONOPANE 2016 („,Terenzia, una matrona in domo et in re publica agens“). Mit dem Verhältnis zwischen Cicero und Terentia beschäftigen sich zudem SCHMIDT 1898 („Cicero und Terentia“), AlLen JR. 1960 („Cicero's last letter to Terentia [fam. 14.20]“), CLAASSEN 1996 („Documents of a crumbling marriage - The case of Cicero and Terentia“), Grebe 2003 („Marriage and exile Cicero's letters to Terentia“) und JEPPESEN-WIGELSWORTH 2013 („Amici and coniuges in Cicero's letters - Atticus and Terentia“). ${ }^{752}$

Die (Selbst-)Darstellung Ciceros ist subjektiv geprägt und darüber hinaus durch Eingriffe der Herausgeber und letztlich auch die Art der Rezeption des Lesers beeinflusst. ${ }^{753}$ Dies wird in den meisten der genannten Arbeiten angemessen berücksichtigt, besonders deutlich z. B. in LEHMANN 2015. Um Untersuchungen zur Selbst(- und Fremd)darstellung bzw. Selbstkonstruktion i. e. S. handelt es sich z. B. bei ERNSTBERGER 1956 („,Studien zur Selbstdarstellung Ciceros in seinen Briefen“), STEEL 2005 („Reading Cicero - Genre and performance in late republican Rome“), GIORGIO 2015 („L'écriture de soi à Rome. Autour de la correspondance de Cicéron“) sowie verschiedenen Arbeiten von S. Correa wie CORREA 2010 (,Scribo me ita dolere ut [...] a mente non deserar - Escritura y estrategias retórico-pragmáticas de autofiguración en Att., III, 15“), CORREA 2011 („Autofiguración epistolar y construcción del destinatario en la correspondencia ciceroniana del exilio - La imagen de Terencia en Fam. 14. 1 - 4") und CORREA 2013 („Omnis peregrinatio (...) obscura et sordida est - Estrategias de autofiguración de un nouus homo en Epistulae ad Atticum y Epistulae ad Familiares de M. T. Cicerón“).

Historisch-biografische und literaturwissenschaftliche Interpretation lassen sich nicht klar voneinander abgrenzen, weshalb Correa bspw. die verschiedenen Ansätze explizit miteinander verbindet: „Si bien en la bibliografía es posible discernir que la correspondencia ciceroniana ha sido leída ya como documento, ya como literatura, en el presente trabajo intentaremos ofrecer una lectura alternativa a estos abordajes disyuntivos [...]." ${ }^{1754}$ Ähnlich äußert sich

\footnotetext{
${ }^{751}$ Insofern sozialhistorische Aspekte zentral für eine Arbeit sind, wie z. B. in CITRONI MARCHETTI 2000, ergeben sich teilweise mehr oder weniger deutliche Querverbindungen zu eher sprachwissenschaftlich-pragmatisch ausgerichteten Untersuchungen, in denen der Beziehungsaspekt der Korrespondenz Ciceros besonders in den Blick genommen wird, der überhaupt in vielen (auch anders ausgerichteten) Arbeiten eine wichtige Rolle spielt.

752 Vgl. a. Kap. 2.2.2.

753 Vgl. z. B. CORREA 2013, 12; TRAPP 2006, 342 und (mit Bezug auf die Exilbriefe Ciceros) HutCHINSON $1993,442$.

754 CORREA 2011, 4. Außerdem berücksichtigt Correa noch weitere (soziologische, rhetorische und linguistische) Aspekte und Verfahren: Vgl. z. B. CORREA 2013, 24.
} 
Guglielmi zu ihrer umfassenden Analyse der Terentia-Briefe Ciceros (GugLIELMI 2013: „Cicerone e Terenzia - Un ritratto di coppia nell'epistolario ciceroniano“): „Il carattere peculiare di questa ricerca consiste nel tentativo, non sempre perseguito nella critica, di prendere in considerazione le lettere sia dal punto di vista contenutistico, e quindi storico-biografico, sia sotto l'aspetto formale, quello più propriamente letterario, e di mettere in relazione le deduzioni tratte nell'uno e nell'altro caso, trovando possibili collegamenti tra lingua e stile delle epistole e il contesto in cui esse sono state prodotte, in riferimento particolare ad alcune tematiche specifiche, in questo caso il rapporto tra i coniugi e il ruolo della donna all'interno della famiglia e della società romana. “755 In anderen Werken wie HUTCHINSON 1993 („Ciceros Briefe als Literatur - Ad Att. 1,16“), HUTCHINSON 1998 („Cicero's correspondence - A literary study“) und GUNDERSON 2007 (,S. V. B. E.; E. V.“) wird dagegen ein vornehmlich literarischer Ansatz verfolgt. ${ }^{756}$

Literarische Studien sind häufig zugleich rhetorische Studien, die wiederum oft verbunden sind mit epistolographischen Analysen. Dies zeigen z. B. BERNARD 2006 (,Art et tradition épistolaires dans la correspondance de Cicéron“), BERNARD 2013 („La sociabilité épistolaire chez Cicéron“) sowie die bereits genannte Arbeit von GIORGIO 2015 (s. o.), deren Ansatz u. a. auch von VALETTE-CAGNAC 2017 („Cura ut valeas - Santé et épistolarité dans la correspondance de Cicéron") aufgegriffen wird.

In erster Linie brieftheoretisch ausgerichtet sind u. a. BERNARDI PERINI 1985 („Alle origini della lettera familiare“), CUGUSI 1998 („L'epistola ciceroniana - Strumento di comunicazione quotidiana e modello letterario“), SCHRÖDER 2004 - 2005 („Ciceros Briefe als Briefe“) und SCHRÖDER 2009 („Brief als multifunktionales Medium - Beispiele aus Ciceros Briefen“). Daneben existieren zahlreiche weitere, z. T. sehr spezielle Untersuchungen. So beschäftigen sich COTTON 1984 („Greek and Latin epistolary formulae - Some light on Cicero's letter writing“), MUÑOZ MARTín 1991 („El sector central del cuerpo epistolar en Cicerón“), MUÑOz MARTín 1994 („Estructura de la carta en Cicerón“) und GIORGIO 2008b („Savoir commencer une lettre et savoir la finir -Étude des interactions dans les séquences d'ouverture et de clôture des lettres de Cicéron") mit ein-

\footnotetext{
755 GUGLIELMI 2013, 9.

756 Zu Hutchinson vgl. z. B. die Ausführungen in HUTCHINSON 1998, 1ff., wo darlegt wird, inwieweit Ciceros Briefe (auch) als literarische Werke betrachtet werden müssen. Vgl. a. GIORGIO 2015, 19: „[...] G. O. Hutchinson, à la fin des années 90, avait proposé une approche résolument littéraire, en adoptant les outils de la rhétorique, mais aussi de la narratologie structuraliste ou encore ceux développés dans le domaine de la pragmatique. "Vgl. außerdem BeRNARD 2013, 18 und GugLIELMI 2013, 15. SCHWITTER 2018, 94 äußert sich eher kritisch zu HUTCHINSON 1998 und HUTCHINSON 1993 bzw. zu Hutchinsons „Berufung auf formalästhetische Qualitäten“. Vgl. a. CORREA 2013, 17ff. Zum sehr umfassenden, u. a. auf Derrida und Foucault fußenden literarischen Ansatz Gundersons vgl. z. B. GuNDERSON 2007, 6f.: ,[...] a non-literary approach to the letters is inadequate. The letters are not mere documents. [...] by literature I mean to indicate not just a text that is ,intended' to be rich, a text that feeds its readers a feast to which they have been cordially invited [...]. Cicero does offer that as well. But I wish to look instead for the movement of key signifiers, and the working of the text against its own manifest meaning. Here we should imagine, then, a richness that comes from the resources of language itself and one which is drawn from the reservoir of the letter's trans-individual agency. What the letter means [...] and what the letter wants to say [...] ought not to be confused even if the same expression should be used twice to express two notions that both diverge and converge." Ein literarischer Ansatz liegt im Übrigen letztlich z. B. auch bei BEARD 2002 vor, welche die (literarischen) Kriterien untersucht, nach denen die Epistulae ad familiares zusammengestellt wurden. VgI. a. GIORGIO 2015, 20.
} 
zelnen Briefbestandteilen, in WILCOx 2005 („Sympathetic rivals - Consolation in Cicero's letters“) geht es um einen bestimmten Brieftyp (Trostbriefe), in BERNARD 2004 („Vie sociale et norme épistolaire - Les lettres de Cicéron et la ,brevitas' ")) um ein epistolographisches Stilprinzip (brevitas). GIORGIO 2008a („,Je t'ai vu tout entier dans la lettre' - Humanitas, ,portrait d'âme' et persuasion dans la Correspondance de Cicéron“), Bernard 2008 („Le langage de I'amicitia dans les lettres de Cicéron à Appius Claudius - La société des amis à Rome") und WILCOX 2012 („The gift of correspondence in classical Rome - Friendship in Cicero's Ad Familiares and Seneca's Moral Epistles") setzen sich mit der Konkretisierung von einzelnen Brieftopoi („Brief als Spiegel der Seele“ bzw. amicitia), ROESCH 2002b („L'interaction auteur / destinataire dans la correspondance de Cicéron“) und MORELLO 2013 („Writer and addressee in Cicero's letters") mit dem Adressatenbezug in Ciceros Briefen auseinander. ${ }^{757}$

Solche rhetorischen und epistolographischen Studien bewegen sich ebenso wie andere Arbeiten, die Sprache und Stil in Ciceros Briefen analysieren, oft im Übergangsbereich zwischen Literatur- und Sprachwissenschaft. Dies gilt auch für viele Untersuchungen zur Expressivität und Emotionalität, wie z. B. CHESSA 1999 („Aspetti di espressività nell'epistolario ciceroniano“) und NDIAYE 2010 („,Les souffrances de l'exil dans la correspondance de Cicéron“) sowie GARCEA 2002 („Dialogo ed emozioni nell’epistolario ciceroniano“), GARCEA 2004 („Le langage des émotions dans les lettres d'exil de Cicéron“) und GARCEA 2005 („Cicerone in esilio - L'epistolario e le passioni“). ${ }^{758}$

Häufig spielen dabei pragmatische Gesichtspunkte eine wichtige Rolle. Dies trifft z. B. auch auf die weiter oben genannten Arbeiten von Correa zu. Auf andere pragmatisch orientierte Studien wie HALL 2009 und ROESCH 2004 zum Thema Höflichkeit oder HALLA-AHO 2010 zu Bitten in Ciceros Briefen wurde bereits in Kap. 1.1.3 hingewiesen. Einen teilweise pragmatischen bzw. sozialkommunikativen Ansatz verfolgen zudem SCHURICHT 1994 („Cicero an Appius (Cic. fam. III) - Umgangsformen in einer politischen Freundschaft“), SCHNEIDER 1998 („Vom Handeln der Römer - Kommunikation und Interaktion der politischen Führungsschicht vor Ausbruch des Bürgerkriegs im Briefwechsel mit Cicero“), WHITE 2010 („Cicero in letters - Epistolary relations

\footnotetext{
757 SCHRÖDER 2004 - 2005, 193 betrachtet epistolographische Studien als grundlegend: „Wenn man [...] die brieftechnischen Realien und die Brieftheorie in die Interpretation der Briefe einbezieht, lassen sich die angedeuteten Widersprüche [zwischen verschiedenen Textherangehensweisen] erklären. Es wird zum einen deutlich, dass und warum bei der Verwendung der Briefe als Quelle eine gewisse Vorsicht geboten ist, und zum anderen lässt sich erklären, warum Briefe sowohl Elemente der Umgangssprache unter Gebildeten aufweisen als auch literarische Werke darstellen können."

${ }^{758} \mathrm{Vgl}$. a. den Überblick über (ältere) Arbeiten zur Expressivität in Ciceros Briefen in GARCEA 2005, 143ff. Dort werden u. a. die Studien von ERnStberger 1956, JÄGer 1986 und Citroni MARChetTI 2000 genannt, die hier an anderer Stelle angeführt werden. Beispiele für sehr frühe Untersuchungen zum sprachlichen Ausdruck von Gefühlen in Ciceros Briefen sind BAILlEux 1933 und MeNNA 1955. Zu Garceas rhetorisch-(pragma)linguistischem Ansatz vgl. z. B. GIORGIO 2015, 20: „[...] A. Garcea a montré, en s'appuyant [...] sur les acquis de la linguistique pragmatique, que les lettres d'exil, trop souvent lues comme manifestation de la détresse spontanée et incontrôlée de l'épistolier, visaient avant tout à influencer les destinataires, priés de s'activer pour aider Cicéron à revenir à Rome, s'appuyant sur une rhétorique de la miseratio [...]." Vgl. a. BERNARD 2013, 18f. Vgl. außerdem Garceas eigene Erläuterungen, der das Ziel seiner Arbeit folgendermaßen zusammenfasst: „Le ragioni che inducono un nuovo studio delle lettere [...] consistono anzitutto nella volontà di indagare il rapporto tra mezzi di comunicazione e opzioni espressive [...]." (GARCEA 2005, VI).
} 
of the late republic“) und RÜHL 2019 („Ciceros Korrespondenz als Medium literarischen und gesellschaftlichen Handelns"). ${ }^{759}$

Der Stil der Briefe Ciceros wird u. a. in einem eigenen Kapitel in ALBRECHT 2003 („Cicero's style - A synopsis“) und in BeRNARD 2004 („Pragmatisme et souci du style dans la correspondance de Cicéron (Septembre 45-6 août 44)“) untersucht. In BIVILLE 2003 („Échos de voix romaines dans la correspondance de Cicéron - Réflexions sur l'oralité") geht es um die Mündlichkeit in den Schreiben. Häufig werden die Briefe außerdem als Zeugnisse der lateinischen (und z. T. auch griechischen) Sprache herangezogen, z. B. zur Charakterisierung der lateinischen Umgangssprache. ${ }^{760}$

Linguistische Arbeiten i. e. S. sind (im deutschsprachigen Raum) allgemein eher selten, wie bereits in Kap. 1.1.3 ausgeführt wurde. Sprachwissenschaftlich geprägt sind aber z. B. die quantitativen und qualitativen Analysen in JÄGER 1986 („Briefanalysen - Zum Zusammenhang von Realitätserfahrung und Sprache in Briefen Ciceros"), bei denen zudem kommunikative und situative sowie psychologische Aspekte berücksichtigt werden. ${ }^{761}$ Hinzu kommen zahlreiche Arbeiten zu verschiedenen grammatischen Aspekten der Briefe Ciceros, von denen einige ebenfalls bereits in Kap. 1.1.3 genannt wurden. Es finden sich Untersuchungen zu einzelnen Wortarten, wie z. B. AdAMs 1978 („Conventions of naming in Cicero“) und BIVILLE 2006 („The qualification of personal names by possessive adjectives in Cicero's letters“), zur Syntax, wie z. B. BOLKESTEIN 1998a („Between brackets: (some properties of) parenthetical clauses in Latin - An investigation of the language of Cicero's letters"), und zu satz- bzw. textübergreifenden Phänomenen, wie z. B. KISs 2001 („Principes d'organisation textuelles dans les, Lettres' de Cicéron“), GARCEA 2001 („Représentation et reproduction du discours dans la correspondance de Cicéron“), RÜHL 2009 ( „,,Sed quid ago? paene orationem in epistulam inclusi“ - Das Selbstzitat in Ciceros Briefen“), BEHRENDT 2013 („Mit Zitaten kommunizieren - Untersuchungen zur Zitierweise in der Korrespondenz des Marcus Tullius Cicero“) und RolLINGER 2015 („Bilingualität, Codewechsel und Zitate im Briefverkehr Ciceros und der spätrepublikanischen Oberschicht"). Selbst hier sind aber die Grenzen zu einer literaturwissenschaftlichen Herangehensweise z. T. fließend.

\subsection{ANALYSEKONZEPT}

Im Folgenden sollen im Anschluss an die Grundlegungen in der Einleitung („Ziel und Konzeption der Arbeit") und den beiden vorangegangenen Kapiteln einige Festlegungen zur

\footnotetext{
${ }^{759}$ Zu White vgl. White 2010, VIIIff. Vgl. a. BernARD 2013, 20: „Prenant en compte les règles sociales qui déterminent les relations des hommes politiques romains, mais aussi les conditions dans lesquelles fut publiée la correspondance, l'auteur étudie dans une première partie les contraintes extérieures qui pèsent sur les lettres avant de voir, en une série d'études juxtaposées, les principaux thèmes des lettres cicéroniennes: les préoccupations littéraires, l'échange de conseils, l'exercice du pouvoir politique par le biais des lettres." Zu Rühl vgl. RüHL 2019, 2f.: „Die vorliegende Arbeit untersucht den Brief als Kommunikationsmedium sui generis. Ihr besonderes Interesse gilt dabei den Fragen, welche Folgen sich daraus ergeben, dass der Brief in besonderer Weise auf die räumlich getrennten Kommunikationspole Sender und Empfänger ausgerichtet ist, und inwiefern es gerade die unbestimmte Mittelstellung des Briefes zwischen ,Gebrauchstext' und ,Literatur' ist, die ihn zu einem Instrument literarischen und gesellschaftlichen Handelns werden lässt. "Zur methodologischen Einordnung vgl. ebd., 8ff.

760 Vgl. z. B. die Übersicht bei BERNARD 2013, 16. Ein bekanntes Beispiel für die Darstellung der lateinischen Umgangssprache unter Berücksichtigung auch der Briefe Ciceros ist HOFMANN 1978 (vgl. Kap. 1.2.1.3.4).

761 Vgl. JÄGER 1986, 25ff. Vgl. a. GARCEA 2005, 145.
} 
Konkretisierung der Vorgehensweise im praktischen Teil erfolgen. Dabei werden nur allgemeine Grundsätze dargelegt, während im Rahmen der Beispielanalysen in Kap. 2.1 und der Ergebnisinterpretation in Kap. 2.2 eine genauere Diskussion sprachlicher Einzelheiten stattfindet.

\subsubsection{Analysemodell im Überblick}

\subsubsection{Analyseverfahren}

Bislang gibt es kaum umfassende und methodisch fundierte Modelle zur sprechakttheoretischen Analyse von Texten, wenngleich durchaus einige Ansätze vorliegen, die meist im Zusammenhang mit der Untersuchung spezifischer Textkorpora entwickelt wurden. ${ }^{762}$ In der Regel wird dort in ähnlicher Weise vorgegangen wie in der vorliegenden Arbeit. Das hier angewandte Verfahren zur Briefanalyse kann wie folgt zusammengefasst werden:

\section{1. (intuitive) Vorerfassung}

- erste (vorläufige) Einordnung des Briefes mittels Explizierung des Kontextes (Handlungsvoraussetzungen, Hintergrundwissen)

- Grobgliederung des Briefes (in Teiltexte)

- (vorläufige) Bestimmung der Textfunktion und evtl. weiterer Handlungsfunktionen

\section{Illokutionsidentifikation}

- Bestimmung der Analyseeinheiten auf der untersten Hierarchieebene

\section{Illokutionsklassifikation}

- Zuordnung der Analyseeinheiten (der untersten Ebene) zu Sprechaktoberklassen und -untermustern

- Bestimmung des Grades der Direktheit bzw. Indirektheit in Bezug auf die Signalisierung der Handlungsfunktionen

- Problematisierung von evtl. vorhandenen Überschneidungen mit anderen Handlungsfunktionen

\footnotetext{
762 Vgl. z. B. STAFFELDT 2014, 107f.: „Von einer sprechakttheoretischen Analysemethode zu reden ist ein wenig gewagt, da neben der Entwicklung der Theorie selbst bisher eher Aspekte der Klassifikation der Sprechakte und/oder der sprechaktbezeichnenden Ausdrücke von Interesse gewesen sind. Größere, methodisch belastbare sprechakttheoretische Analysen des Sprachgebrauchs oder gar methodologische Arbeiten dazu liegen dagegen nur vereinzelt vor." Einen konkreten Anwendungsvorschlag für eine handlungssemantische Textanalyse findet man bei POLENZ 2008, 328ff. Vgl. a. SCHMITT 2000 und STAFFELDT 2014. Vgl. außerdem die entsprechenden Darlegungen in praktischen Untersuchungen wie z. B. SZWED 2014, 182f.; KIESENDAHL 2011, 53ff. sowie WAGNER 1997, $75 \mathrm{ff}$. und ebd., 253f. Pragmatische Aspekte werden mehr oder weniger ausgeprägt auch in den meisten anderen modernen (text- und diskurslinguistischen) Analysemodellen berücksichtigt. Vgl. z. B. BENDEL LARCHER 2015, 59ff.; BRINKER U. A. 2014, 154ff.; BUSSE 2013, 43ff.; WARNKE 2008, 44ff. bzw. WARNKE UND SPITZMÜller 2008, 121ff. sowie GARDT 2007, 277f. Speziell zur emotionslinguistischen Textanalyse vgl. a. ORTNER 2014b, 313ff. Zur Briefanalyse vgl. zudem LANGEHEINE 1983b, 199f., der drei Analyseebenen unterscheidet: „Ebene der Handlungs- und Bedeutungskonstitution, die in propositionaler und illokutiver Hinsicht differenziert werden kann“, „Ebene der Textorganisation (wie wird der Brief eingeleitet, durchgeführt, beendet?)“ und „Ebene der Beziehungs- und Identitätskonstitution".
} 
- Bewertung der Initialität bzw. Reaktivität der Sprechakte (durch Reflexion von evtl. vorhandenen intertextuellen Bezügen zu vorangehenden bzw. nachfolgenden Briefen)

- Reflexion der Relation zwischen Handlungsfunktionen und wahrer Intention des Briefschreibers (Cicero)

\section{Sequenzierung und Hierarchisierung der Handlungsfunktionen}

- Zusammenfassung von Einzelillokutionen zu Teiltexthandlungen (Sequenzen)

- weitergehende Reflexion und Problematisierung entsprechend der Klassifikation der Einzelillokutionen (s. 3.)

- Analyse der handlungsfunktionalen Beziehungen (z. B. Über- / Neben- / Unterordnung, Erklärung vs. Begründung, ...)

\section{5. (endgültige) Bestimmung der Textfunktion}

- verbunden u. a. mit einer Analyse der Distribution der einzelnen Funktionskategorien (Quantifizierung)

\section{Analyse der (handlungssemantischen) Beziehungs- und Identitätskonstitution ${ }^{763}$}

- Übertragung der Ergebnisse der Sprechhandlungsanalyse:

- Wie gestaltet Cicero seine Beziehung zu Terentia durch die Art der Verwendung verschiedener Sprechakte bzw. Sprechaktsequenzen?

- Inwieweit liegt der Fokus der Äußerungen eher auf Cicero selbst oder auf seiner Frau (und anderen Mitmenschen)?

- Wie stark ausgeprägt sind Expressivität und Emotionalität?

○ Welche Rolle spielen Abschwächungen und Verstärkungen?

- Vergleich mit den Ergebnissen der bisherigen Forschung zur Beziehung zwischen Cicero und Terentia

\section{Gesamtschau}

- zusammenfassende Bewertung und kritische Diskussion der Ergebnisse der Einzelanalysen

Abbildung 3: Vorgehensweise bei der (handlungssemantischen) Briefanalyse

Auf Details hinsichtlich der Begrifflichkeiten und der konkreten Vorgehensweise bei den Analyseschritten 2 bis 5 gehen die Kapitel 1.3.2 bis 1.3.5 ein.

\subsubsection{Ergebnisdarstellung}

Den Beispielanalysen im Praxisteil sind - nach einer kurzen Kontextbeschreibung (gem. Abbildung 3, Punkt 1) - jeweils zwei Übersichtsschemata vorangestellt, die einen Überblick über die Einzelillokutionen und den Gesamtaufbau des betreffenden Briefes, einschließlich einer Zusammenfassung der wichtigsten Ergebnisse der Analysen, beinhalten und neben der Lesefreundlichkeit v. a. als Diskussionsgrundlage für die genaueren Erläuterungen im Rahmen

${ }^{763}$ Vgl. LANGEHEINE 1983b, 199f. (s. a. N. 762). 
der Einzelanalysen dienen. ${ }^{764} \mathrm{Im}$ ersten Schema werden sämtliche Analyseeinheiten, die sich bei der Illokutionsidentifikation ergeben haben, in ihrem genauen Wortlaut und unter Angabe der zugehörigen Sprechaktoberklassen und -untermuster nummeriert aufgelistet. ${ }^{765} \mathrm{Im}$ zweiten Schema werden sie zu Teiltexten $([A],[B]$, ...) zusammengefasst, die ggf. (bei den längeren Briefen) noch weiter in Unterabschnitte ([B1], [B2], ...) aufgegliedert sind. Auch zu den größeren Analyseeinheiten (Teiltexte und Gesamttext) sind die Handlungsfunktionen mit angeführt. Außerdem gibt es jeweils eine kurze Themenangabe. Eine weitergehende Differenzierung erfolgt erst im betreffenden Unterkapitel zur Sequenzierung und Hierarchisierung, da das Aufbauschema ansonsten zu unübersichtlich würde. Die der Überblicksdarstellung folgenden Teilkapitel widmen sich der Analyse der Sprechhandlungen, fortschreitend von der (untersten) Ebene der Einzelillokutionen (gem. Abbildung 3, Punkt 2 und 3) über die Ebene der Teiltexthandlungen (gem. Abbildung 3, Punkt 4) hin zur Gesamttextebene (gem. Abbildung 3, Punkt $5)$, sowie der Beziehungs- und Identitätskonstitution mit Bezug auf das Verhältnis zwischen Cicero und Terentia (gem. Abbildung 3, Punkt 6). Daraus ergibt sich folgender Grundaufbau:

1. Situativer Kontext (Beschreibung der Handlungsvoraussetzungen)

\section{2. Übersichtsschemata}

2.1 Überblick über die Einzelillokutionen

2.2 Überblick über den Briefaufbau (Teiltexte)

\section{Sprechhandlungsanalyse}

3.1 Einzelhandlungen (unterste Hierarchieebene)

$\rightarrow$ Illokutionsidentifikation und -klassifikation

3.2 Teiltexthandlungen (mittlere Hierarchieebenen)

$\rightarrow$ Sequenzierung und Hierarchisierung

3.3 Gesamttexthandlung (oberste Hierarchieebene)

$\rightarrow$ Bestimmung der Textfunktion

\section{Beziehungs- und Identitätskonstitution}

$\rightarrow$ Analyse des Verhältnisses zwischen Cicero und Terentia (alle Hierarchieebenen)

Abbildung 4: Kapitelaufbau der Beispielanalysen

Identifikation und Klassifikation der Handlungseinheiten werden demnach innerhalb eines Kapitels (Abbildung 4: 3.1 und 3.2) miteinander verbunden. Aufgrund ihres engen Zusammenhangs entstehen notwendigerweise häufig Überschneidungen, und so können Wiederholungen in der Darstellung besser eingegrenzt werden. Ein zusammenfassender Überblick (gem.

\footnotetext{
${ }^{764}$ Hier wie auch allgemein steht man immer im Konflikt zwischen dem Anspruch, der Komplexität eines Sachverhalts in differenzierter und möglichst nicht anfechtbarer Weise gerecht zu werden, auf der einen Seite und dem Bemühen um Klarheit und Verständlichkeit mithilfe eines praxistauglichen Verfahrens auf der anderen Seite: VgI. ORTNER 2014b, 313.

765 Ein „Überblick über die Einzelillokutionen aller Briefe in fam. 14“ findet sich im Anhang (ab S. 426).
} 
Abbildung 3, Punkt 7) über die Ergebnisse der drei Detailanalysen, ergänzt um Beispiele aus den übrigen 21 Briefen des Analysekorpus, findet sich in Kap. 2.2.

\subsubsection{Illokutionsidentifikation}

\subsubsection{Allgemeine Problematik}

In sprechakttheoretischen Studien wird nur selten explizit thematisiert, wie genau Sprechakte bzw. Illokutionen zu bestimmen und von anderen abzugrenzen sind, obwohl dies eigentlich die Grundvoraussetzung für die Untersuchung der Handlungsebene eines Textes ist. ${ }^{766} \mathrm{Oft}$ werden Illokutionen einfach mit Sätzen gleichgesetzt. Eine solche Vorgehensweise, die ja bereits bei Austin und Searle angelegt ist, erleichtert die Arbeit zwar ungemein, kann aber im Hinblick auf die damit verbundenen Schwierigkeiten kaum befriedigen. Illokution und Satz fallen nämlich nicht immer zusammen: Ein Satz kann aus mehreren Illokutionen bestehen, und umgekehrt kann sich eine Illokution über mehrere Sätze erstrecken. Offensichtlich wird die Problematik beispielsweise, wenn man den Satz „Ich bitte dich, das Fenster zu schließen, denn (oder auch: weil) es zieht.“ mit der Äußerung „Ich bitte dich, das Fenster zu schließen. Es zieht." vergleicht. Es scheint kaum überzeugend, in dem einen Fall eine Illokution, im anderen zwei Illokutionen anzunehmen. Dabei stellt sich nicht zuletzt - v. a. (aufgrund der Besonderheiten der Überlieferung, z. B. im Zusammenhang mit der Interpunktion) auch bei antiken Texten - die Frage, was ein Satz überhaupt ist. ${ }^{767}$

Das Problem liegt darin begründet, dass es sich bei Illokutionen nicht um syntaktische, sondern um pragmatische Einheiten handelt. Entscheidend ist also die kommunikative Funktion und nicht die grammatische Ausgestaltung, die lediglich Anhaltspunkte für deren Bestimmung

\footnotetext{
766 Vgl. SCHMITT 2000, 37 und ebd., 51: „Wie groß ist die Einheit Sprechakt? Wie kann determiniert werden, wo die Grenze zwischen zwei Illokutionen anzusetzen ist? Wohl kein anderes Gebiet der Pragmatik liegt so im Dunkeln wie die Frage nach der Illokutionsidentifikation; häufig wird es sogar noch nicht einmal als Problem erkannt." ${ }^{767}$ Vgl. z. B. ebd., 52, wo folgende Probleme einer Gleichsetzung von Satz und Illokution (im Englischen und Deutschen) genannt werden: „1. Es gibt keine allgemein anerkannte Definition des Konzeptes ,Satz', vielmehr sind zahlreiche Begriffsbestimmungen denkbar, von denen jede ihre eigenen Schwierigkeiten aufweist [...]. 2. Mehrere eigenständige Sätze können zu einem komplexen Satz zusammengezogen werden, eventuell unter Verwendung von Konjunktionen, oder ein komplexer Satz kann in mehrere Einzelsätze aufgelöst werden, ohne dass sich in der pragmatischen Leistung der Äußerung etwas ändert [...]. 3. Die Annahme einer Möglichkeit mehrerer Sprechakte innerhalb eines Satzes darf nicht auf syntaktisch komplexe Sätze beschränkt sein. Semantisch komplexe, syntaktisch jedoch nicht hierarchisch durch Hypo- oder Parataxe gegliederte Sätze erscheinen intuitiv ebenso als aus mehreren verknüpften Sprechakten bestehend. "Vgl. a. HERINGER 2015, 29; BRINKER U. A. 2014, 28; SZWED 2014, 156; WÜEST 2011, 58; GANSEL UND JÜRGENS 2008, 66ff.; KROON 2007, 145; SCHRÖDER 2003, 36; BICKMANN 1998, 43; RISSELADA 1993, 50; Rosengren 1987, 29; VIEHWEGER 1983, 231; DIMTER 1981, 86 und SCHLIEBEN-LANGE 1979, 110. Zur ,Tradition' der Gleichsetzung von Sprechakt und Satz von den Anfängen bis in neuere Zeit vgl. z. B. SCHMITT 2000, 51: „Wissenschaftsgeschichtlich ist hier früh eine zweifelhafte Weichenstellung aus den Anfangstagen der Sprechakttheorie in die Forschung übernommen worden, der erst in den letzten etwa eineinhalb Jahrzehnten widersprochen wird. Sowohl Austin als auch Searle setzten in ihren Grundlagenwerken Sprechakt und Satz vom Umfang her gleich. " Vgl. aber auch SzWED 2014, 156 zu frühen Ansätzen mit einer (teilweisen) Aufbrechung dieser Gleichsetzung (z. B. bei KoCH U. A. 1981). Vgl. außerdem SCHMITT 2000, 37. Zu den Gründen für die Gleichsetzung vgl. z. B. ebd., 53 N. 3: „Warum immer wieder auf den Satz zurückgegriffen wird, ist offensichtlich: Zum einen existiert einfach kein wirkliches Alternativkonzept, zum anderen ist die Gleichsetzung, zumindest wenn man sich auf eine bestimmte Satzdefinition festlegt, sehr bequem. "Vgl. a. LupPold 2015, 402 (zu Schröders Konstituentenmodell: s. N. 364). Zu den Besonderheiten der Überlieferung antiker Schriften vgl. z. B. N. 377.
} 
liefern kann. ${ }^{768}$ Mehr noch zählt bei der Bewertung des Illokutionsstatus der Kontext, in den eine Äußerung eingebettet ist. Am Ende muss man, um die (mutmaßliche) Intention eines Autors zu erfassen, auf das eigene (Welt- und Sprach-)Wissen und somit auf die Intuition zurückgreifen, wobei eher psychologische als linguistische Aspekte eine Rolle spielen. ${ }^{769}$ Zur genaueren strukturellen Abgrenzung einer Illokution wäre jedoch (zusätzlich) ein besser zu operationalisierendes Verfahren wünschenswert. Die wenigen Versuche, Sprechakte unabhängig von den Satzgrenzen zu bestimmen, nehmen meist die Proposition als Ausgangsbasis, wie z. B. SCHMITT 2000 und STAFFELDT 2014. Denn jede Illokution ist (nach Searle) untrennbar mit einer Proposition verbunden. Hat man die Proposition erfasst, ist demnach zugleich der Sprechakt als (abgegrenzte) Handlungseinheit festgelegt. ${ }^{770}$ Die Proposition dient also als „struktureller Anker ${ }^{\text {“771 }}$. Schmitt fasst die Bedeutung seiner Vorgehensweise folgendermaßen zusammen: „Damit erhält die Illokution, die bisher lediglich von ihrem psychologischen Ursprung her bekannt war, eine Form, wird greifbar. Die Intention wird durch einen festen Körper realisiert, also ist es jetzt die Aufgabe, mittels dieses festen Körpers und unter Einbindung des Weltwissens und mit Hilfe der die situativen Bedingungen erfassenden Intuition die Intention des Sprechers zu rekonstruieren. ${ }^{\text {"772 }}$

\subsubsection{Propositionsanalyse als Verfahren zur strukturellen Abgrenzung von II- lokutionen}

StAFFeldT 2014 versucht die Proposition bzw. Referenz und Prädikation durch eine ThemaRhema-Analyse im Anschluss an die Duden-Grammatik zu ermitteln. ${ }^{773}$ Die Referenz entspricht dabei dem Thema, die Prädikation dem Rhema. Er ergänzt das Verfahren durch eine grammatische Bestimmung von Subjekt und Prädikat, die er weitgehend mit Referenz bzw. Prädikation gleichsetzt. Ihm ist klar, dass diese Methode eine Vereinfachung darstellt, „mitunter zu seltsamen Ergebnissen “774 führt und insgesamt noch verfeinert werden müsste, meint

\footnotetext{
${ }^{768}$ Vgl. z. B. SCHMITT 2000, 53 N. 3: „Beim Satz handelt es sich um eine grammatische Entität; die Illokution hingegen ist eine pragmatische, aus der Intention des Sprechers geborene, teleologische Einheit. “ und ebd., 105f.: „[...] die Grammatik [steht] zur Pragmatik in einem, wenn auch nicht willkürlichen, so doch in einem flexiblen Verhältnis [...], sodass jede starre grammatische Definition der pragmatischen Basiseinheit Illokution zum Scheitern verurteilt ist. [...] Grammatische Merkmale sind für die Analyse zwar nicht bedeutungslos, sie erhalten jedoch den Status eines dienenden Hilfsmittels." Vgl. a. WEIGAND 2003, 26f. Vgl. außerdem GANSEL UND JüRGENS 2008, 66ff. und (speziell zum Brief) LANGeHEINE 1983b, 198 sowie WeIGAND 2003, 56f.; ERMERT 1979, 196 und (zur „Literal Force Hypothesis" Searles) S. 20.

${ }^{769} \mathrm{Vgl}$. z. B. SCHMITT 2000, 42f.: „Mit der Ausrufung der Intention als entscheidendem Kriterium ergeben sich [...] zwei Probleme: Zum einen ist die Intention als solches nicht greifbar, sie besitzt, im Unterschied zur Lokution, keinen messbaren, physischen Körper. Sie ist ein psychischer Zustand, der erst durch den Vollzug des Sprechakts Körper und Kontur gewinnt. Hinzu kommt, dass die Intention und die Form der Illokution, die Lokution, in keinem festen Verhältnis zueinander stehen. [...] Zum Zweiten kann die Intention, die ein Sprecher mit einem Sprechakt hegt, äußerst vielschichtig und -fältig sein. [...] Die Fülle [...] und der Facettenreichtum eines Sprechaktes hinsichtlich seiner Intentionen ist [!] unermesslich und mit linguistischen Mitteln allein nicht greifbar. Um der Intention eines Sprechers auch nur entfernt nahekommen zu können, bedarf es also zunächst eines Werkzeugs, das weit über das durch strukturelle Kriterien Erfassbare hinausgeht: die (kommunikative und außerkommunikative) Erfahrung, das Weltwissen, die Intuition."

770 Vgl. z. B. STAFFELDT 2014, 113 sowie WeIGAND 2003, 76. Vgl. a. S. 24.

${ }^{771}$ Ebd., 46.

772 SCHMITT 2000, 45.

773 Vgl. STAFFELDT 2014, 113ff. Er bezieht sich auf S. 1122 der 8. Auflage der Duden-Grammatik (KUnKEL-RAZUm UND EISENBERG 2009). Vgl. a. N. 391.
}

774 STAFFELDT 2014, 115. 
aber aufgrund seiner eigenen Textanalysen, dass damit durchaus ein sinnvolles und erfolgreiches Arbeiten möglich sei. ${ }^{775}$

SCHMITT 2000, dessen Ansatz mit dem Staffeldts grundsätzlich im Einklang steht, jedoch viel umfassender ist, hat ein recht ausgefeiltes System entwickelt, das entsprechend weniger leicht zugänglich ist ${ }^{776}$, aber dennoch gut praktikabel scheint und trotzdem der Vielfältigkeit der meisten Texte gerecht wird, obwohl letztlich auch hier Vereinfachungen notwendig sind. Er strebt eine große Anwendungsbreite an und berücksichtigt zudem kontextuelle Faktoren. ${ }^{777}$ Außerdem ermöglicht sein Konzept die Erfassung von mehreren gleichartigen Illokutionen hintereinander, was bspw. das ISK nicht vorsieht. Dieses nimmt eine neue Illokution erst bei einem Wechsel der Sprecherabsicht an ${ }^{778}$ - ein Vorgehen, das in meinen Augen nicht überzeugend ist und das Gesamtbild einer sprechakttheoretischen Analyse verzerrt.

Sowohl Staffeldt als auch Schmitt machen im Gegensatz zu vielen anderen Wissenschaftlern ihr Vorgehen transparent und vermeiden eine einfache Gleichsetzung von Sätzen und Sprechakten. Der Ansatz Staffeldts hat den Vorteil, dass man dennoch relativ schnell zu Ergebnissen kommt, scheint für meine Zwecke aber nicht ausreichend zu sein, weshalb ich mich im Folgenden bei der Darstellung meiner eigenen Vorgehensweise weitgehend an Schmitt orientiere. Obwohl eine Propositionsanalyse prinzipiell sehr sprachspezifisch ausgerichtet ist, steht einer Übertragung auf das Lateinische dabei zunächst nichts entgegen. Schmitt selbst legt seinen Analysen deutsche und englische Texte zugrunde. Insbesondere wenn Sprachen eng miteinander verwandt sind, wie es bei den genannten Sprachen der Fall ist, zeigen sich viele Gemeinsamkeiten. ${ }^{779}$ Einige trotzdem notwendige Anpassungen bleiben natürlich vorbehalten.

\subsection{Grundsatzannahmen}

Eine Propositionsanalyse ist sehr aufwendig und wird umso wahrscheinlicher an ihre Grenzen stoßen, je feinmaschiger sie erfolgt, insbesondere bei größeren Textmengen. Hier stellt sich dann irgendwann die Frage, bis zu welchem Grad überhaupt noch ein Erkenntnisgewinn zu erwarten ist. ${ }^{780}$ Allgemein ist aber davon auszugehen, dass in einem einfachen Satz i. d. R.

\footnotetext{
775 Vgl. z. B. STAFFELDT 2014, 115 und ebd., 143.

${ }^{776}$ Vgl. a. SCHMITT 2000, 110: „Möglicherweise erscheint das [!] so entstandene Entwurf zur Identifikation illokutionärer Einheiten dem einen oder anderen Leser als zu differenziert. Dies mag zwei verschiedene Gründe haben: Zum einen haben wir uns als Sprecher, zumal in monologischen Texten, daran gewöhnt, viele intentionale Akte innerhalb eines Satzes zu vollziehen; mit anderen Worten, die Handlungsdichte, mit der wir Sprache produzieren, fällt uns gar nicht mehr auf. Zum anderen ist das Verständnis von Sprechakten durch die Rezeption eher philosophisch ausgerichteter Literatur häufig in einseitige Bahnen gelenkt worden."

777 Vgl. z. B. ebd., 55f.: „Das Kriterium [zur Illokutionsidentifikation] muss kontextsensitiv sein. Es darf nicht auf die Analyse isolierter Äußerungen beschränkt sein, sondern muss für identische Äußerungen in unterschiedlichen Kontexten auch potentiell unterschiedliche Illokutionskompositionen annehmen können. [...] Dabei ist nicht nur der sprachliche Kotext, sondern auch der situationelle Kontext für die Interpretation von Bedeutung. So kann [!] in manchen Situationen bestimmtes Vorwissen der Hörerschaft, bestimmte Einstellungen etc. vorausgesetzt werden, in anderen nicht." Vgl. a. ebd., 106.

778 Vgl. z. B. ebd., 56 und SzWED 2014, 173 bzw. KOCH U. A. 1981, 161.

${ }^{779}$ Vgl. Kap. 1.1.2.3.

780 Vgl. z. B. ADAMzIK 2016, 231f.: „Die relevante Minimaleinheit [bei der Analyse von „Inhaltskomplexen“] sind [...] Propositionen. Diese können bereits durch einzelne Wörter (Wohnungsbrand) oder Wortgruppen (in der heimgesuchten Wohnung) repräsentiert sein; daher können in einem einzelnen Satz mehrere (bis viele) erscheinen. Eine vollständige Propositionsanalyse ist außerordentlich aufwendig und gerät schnell an die Grenzen kognitiv verarbeitbarer Darstellungsformen [...]. Sie ist daher nur bei sehr kurzen Texten oder Textpassagen möglich
} 
Subjekt (= Referenz) und Prädikat mit dazugehörigen Objekten (= Prädikation) eine Proposition bilden, während bei Attributen und adverbialen Bestimmungen der Illokutionsstatus jeweils genauer untersucht werden muss. Entsprechendes gilt dann auch für Subjekt- und Objektsätze auf der einen, Attribut- und Adverbialsätze auf der anderen Seite. ${ }^{781}$

Die vielfältigen Möglichkeiten, in einem einzigen Satz verschiedene (zusätzliche) Informationen einzubetten, können eine Illokutionsidentifikation sehr erschweren. ${ }^{782}$ Entscheidend im Hinblick auf die Propositionsermittlung ist, ob eine intentionale Weitergabe einer neuen Information vorliegt. Einem Element kommt ein eigener Illokutionsstatus nur dann zu, wenn es eine eigenständige Information enthält, nicht aber, wenn es zum Verständnis der Hauptinformation unbedingt erforderlich (informationstragend) oder lediglich informationsspezifizierend ist. Äußerungen, die einen bereits im Vorfeld formulierten Inhalt nur stilistisch variieren, ohne dass eine neue Information zu erkennen wäre, können demnach bspw. nicht als eigenständige Illokutionen gelten. ${ }^{783}$

\subsection{Hilfsmittel zur Lösung von Problemfällen}

In den meisten Texten findet man - aus sprachökonomischen und stilistischen Gründen - eine hohe Sprachverdichtung, die dazu führen kann, dass Illokutionen ohne vollständige Explizierung von Referenz und Prädikation formuliert werden. ${ }^{784}$ In solchen Fällen bietet sich zur IIlokutionsidentifikation eine Erweiterungsprobe an, die Schmitt folgendermaßen erläutert: „Eine Illokution ist dann anzunehmen, wenn ein gegebenes Äußerungsfragment so ergänzt oder umgeformt werden kann, dass es eine eigenständige (grammatisch unabhängige) und vollständige Proposition ergibt, wenn dabei die Restproposition ihre eigenständige illokutionäre Funktion unverändert beibehält. Hierbei ist weder nach einer syntaktischen noch nach einer semantischen (informationsstrukturellen) Erweiterungsfähigkeit des Äußerungsteils gefragt, sondern nach einer pragmatischen, die sich darin manifestiert, dass das erweiterte Fragment innerhalb desselben Kontextes die gleiche vom Sprecher intendierte Aufgabe erfüllt wie das Fragment selbst. “785

\footnotetext{
bzw. sinnvoll, z.B. wenn es darum geht, einen sehr komprimierten Aussagenkomplex in seine Einzelbestandteile zu zerlegen, um Hintergründiges oder nur Implizites aufzudecken."

${ }^{781}$ Bei den adverbialen Bestimmungen können zusätzliche Angaben, die eine eigenständige Illokution darstellen, und spezifizierende bzw. präzisierende Ergänzungen, die keinen eigenen Illokutionswert haben, unterschieden werden.

782 Vgl. z. B. SCHMITT 2000, 46: „Im tatsächlichen Sprachgebrauch werden zahlreiche, vielleicht sogar die meisten Illokutionen wesentlich subtiler realisiert, als dass sie allein durch die Identifikation der grammatischen Entitäten Subjekt und Prädikat erfasst werden könnten.“ Vgl. a. ebd., 63ff. zu den verschiedenen „Möglichkeiten der Weitergabe zusätzlicher Informationen“ i. E. Vgl. außerdem ebd., 171ff. zur „Einbettung von Illokutionen“ (im Zusammenhang mit der Illokutionsklassifikation).

${ }^{783}$ Vgl. ebd., 108f. (s. N. 789), wo „kommunikativ eigenständige“, „kommunikativ tragende“ und „,kommunikativ untergeordnete“ Elemente unterschieden werden. Die Differenzierung wird an dieser Stelle entsprechend angepasst, wobei es auch hier letztlich um die kommunikative Funktion geht, nur eben mit dem Fokus auf ihrer (sprachlichen) Realisierung als pragmatischer Information. Vgl. a. ebd., 59f. und ebd., 107f. (s. N. 789).

784 Vgl. z. B. ebd., 107. Vgl. a. HeRINGER 2015, 30.

${ }^{785}$ SCHMITT 2000, 59f. Vgl. a. ebd., 108. Vgl. außerdem ebd., 60: „Dieses Ergänzungs- bzw. Umformulierungskriterium ist das wichtigste Kriterium zur Illokutionsidentifikation. [...] Das Kriterium geht [...] im Gegensatz zu herkömmlichen Ansätzen, die sich in ihrer Betrachtung zumeist auf die tatsächliche grammatische Ausformung beschränken, von der Potenz einer intentional produzierten, jedoch innerhalb einer umfassenderen grammatischen
} 
In einigen Fällen führt die Erweiterungsprobe allerdings zu unbefriedigenden Ergebnissen. Schmitt nennt als Beispiele Konditionale und Metasprechakte, bei denen die Annahme von zwei getrennten Illokutionen unnatürlich erscheine. ${ }^{786}$ Mithin gibt es auch den umgekehrten Fall, dass trotz (potenziell oder tatsächlich) vorhandener Verbindung von Referenz und Prädikation keine separate Illokution vorliegt. Dies gilt z. B. auch für restringierende und spezifizierende Attributsätze, die im Gegensatz zu freien Attributsätzen keine eigenständige Information beinhalten, sondern informationstragend oder -spezifizierend sind, und die meisten Inhaltsbeziehungen. Letztere werden v. a. durch Objektsätze in Form von dass- bzw. quod- und Infinitiv(sätz)en, repräsentiert. ${ }^{787} \mathrm{Zu}$ nennen sind außerdem direkte und indirekte Redewiedergaben. ${ }^{788}$ Hinsichtlich der Textanalysen in dieser Arbeit sei im Übrigen darauf hingewiesen, dass Zitate von Äußerungen des Briefadressaten von vornherein keinen eigenen Informationswert besitzen. Ein solcher ist bei vielen stereotypen Formeln ebenfalls fraglich. Dabei zeigt sich allerdings der Unterschied zwischen semantischem und pragmatischem Informationswert bzw. kommunikativer Funktion, da sie trotz fehlenden Inhalts sehr häufig eine nicht zu unterschätzende expressive Funktion besitzen, abgesehen davon, dass sie oft individuell abgewandelt werden und dadurch ihren ursprünglichen Informationswert wiedererlangen können.

Zur Beantwortung der Frage, ob eine Information wirklich mit einer eigenständigen kommunikativen Funktion verbunden oder kommunikativ nur untergeordnet bzw. tragend ist, kann eine Weglassprobe (= Omissionsprobe) durchgeführt werden, zu der Schmitt anmerkt: „Hierbei werden in Frage kommende Äußerungsfragmente gestrichen, um zu sehen, in wieweit [!] sich die Äußerungsbedeutung verändert. Diese Methode kann als ein schnelles heuristisches Hilfsmittel zur Identifikation von Illokutionen angesehen werden, die dem primären Identifikationskriterium [= Erweiterungsprobe] jedoch immer untergeordnet ist. Sie eignet sich besonders für solche Illokutionen, die sich nur schwer in eine vollständige Proposition umformen lassen. "789

Struktur realisierten Illokution zur Bildung einer Proposition aus. Damit kann es als das primäre Identifikationskriterium, die entsprechende Probe als Erweiterungsprobe bezeichnet werden."

786 Vgl. SCHMITT 2000, 62: „Eine Erweiterung und die damit einhergehende Trennung in zwei verschiedene Aussagen ist zwar auch bei Konditionalen [...] und neutralen (d. h. für den jeweiligen Sprechakt ohnehin zu erwartenden) Metasprechakten [...] bzw. textuellen Markierungen grammatisch möglich, erscheint aber im Vergleich zu den ursprünglichen Äußerungen als zu künstlich, um noch als natürlicher Einzelsprechakt gelten zu können [...]." Vgl. a. ebd., $59 f$.

787 Vgl. ebd., 59.

788 Vgl. dazu auch ebd., 171ff. („Einbettung von Illokutionen“).

${ }^{789}$ Ebd., 61. Vgl. a. ebd., 108f.: „Bei der Anwendung der Omissionsprobe [...] lassen sich drei verschiedene kommunikative Funktionen des jeweiligen Fragments unterscheiden: I) Das Fragment ist kommunikativ tragend (intentional äußerungsmodifizierend). Hierzu gehören folgende Fälle: a) Die Aussage der Äußerung wird bei Omission des Fragments verfälscht. [...] b) Die Äußerung wäre so nicht getätigt worden. [...] c) Bei der Omission von Aufzählungsteilen geht ein für die wahrheitsgetreue Abbildung bedeutender Teil einer Gesamtheit verloren: [...] d) Es kommt zur (nicht-intendierten) Verletzung einer sozialen Norm: [...] e) Die Äußerung verliert bei Omission an (intendierter) Abbildungsgenauigkeit oder kommunikativer Ausrichtung. [...] f) Bei Omission des Fragments fallen zum vollständigen Verständnis der Äußerung notwendige Informationen weg: [...] g) Bei Omission käme es zu einem falschen Verständnis der Äußerung. Der Kontext erfordert das Fragment: [...]. II) Das Fragment ist kommunikativ untergeordnet. Hierzu können folgende Fälle gezählt werden: h) Im Verständnis der Äußerung ändert sich durch die Omission nichts. [...] i) Bei der Omission von Aufzählungsteilen geht ein eher unwichtiger Teil einer Gesamtheit verloren, z. B. bei der Aneinanderreihung von Beispielen. j) Das weggelassene Fragment hat zwar eine gewisse Unabhängigkeit von der kommunikativen Haupthandlung, ist jedoch für die Gesamtaussage der 
In Abhängigkeit von der (grammatischen) Form der Informationsübermittlung ist entweder die Erweiterungs- oder die Weglassprobe zu bevorzugen. ${ }^{790}$ Erstere eignet sich besonders für Ellipsen, Parenthesen, Fälle von (Ko-)Referenz und verschiedene Arten von Nebensätzen ${ }^{791}$, letztere kann „bei [fast] allen anderen grammatischen Entitäten [...] als der schnellere und direktere Weg angesehen werden “792. Manchmal kommen (je nach konkreter Realisierung) auch beide Methoden in Betracht, z. B. bei Aufzählungen. Erweiterungs- und Weglassprobe können prinzipiell nicht nur bei Assertiva, sondern genauso bei anderen Sprechaktklassen angewendet werden, obgleich solche Illokutionen oft weniger komplex gestaltet sind und eher isoliert auftreten. ${ }^{793}$

\subsubsection{Fazit}

Die Vorgehensweise bei der Illokutionsidentifikation kann wie folgt zusammengefasst werden $^{794}$ :

Eine Illokution (als kleinste funktionstragende Einheit) wird ermittelt

1. aufgrund des eigenen Sprach- und Weltwissens ( $\approx$ Intuition), und zwar unter Berücksichtigung des Kontextes

$\rightarrow$ allgemeine und endgültige Einordnung

2. durch Propositionsanalyse (unter Berücksichtigung der grammatischen Strukturen), wobei Folgendes gilt: (eigenständige) Information $\approx$ Proposition = Illokution

$\rightarrow$ „struktureller Anker"

Abbildung 5: Illokutionsidentifikation

Obschon am Ende doch auf die eigene Intuition zurückgegriffen werden muss, wird bei diesem Verfahren durch die Heranziehung substanzieller Kriterien eine - im Vergleich zu anderen Vorgehensweisen - weitergehende Objektivierung gewährleistet, die zugleich den konkreten textlichen Gegebenheiten gerechter wird. Allerdings ist auch damit nicht immer eine exakte Abgrenzung aller Illokutionen voneinander möglich - was einer handlungssemantischen Analyse aber nicht abträglich sein muss. ${ }^{795}$

\footnotetext{
Äußerung so bedeutungslos, dass eine Omission keine grundsätzliche Veränderung des Verständnisses mit sich bringen würde: [...] In allen diesen Fällen handelt es sich bei den ausgelassenen Fragmenten nicht um Illokutionen. Hingegen besitzt ein Fragment Illokutionsstatus, wenn es kommunikativ eigenständig ist (Fall III), d. h. bei seiner Omission eine eigenständige Sprachhandlung wie etwa die Weitergabe einer Information über die Welt, den Sprecher, den Text, eine Einschätzung, eine Wertung, ein Relationsakt oder ein Direktivum verlorengeht."

${ }^{790}$ Vgl. SCHMITT 2000, 107.

791 Vgl. ebd., 108.

792 Ebd., 108.

${ }^{793}$ Vgl. ebd., 110.

${ }^{794} \mathrm{Vgl}$. a. ebd., 105.

795 Dies beweist u. a. die Tatsache, dass in der Linguistik auch mit anderen Begriffen wie z. B. ,Sätzen' und ,Wörtern'seit Urzeiten durchaus erfolgreich gearbeitet wird, ohne dass sie jemals eine eindeutige und allgemein anerkannte Definition erhalten hätten: Vgl. ebd., 53.
} 


\subsubsection{Illokutionsklassifikation}

\subsubsection{Sprechaktoberklassen und -untermuster im Überblick}

Bei den Briefanalysen im Praxisteil dieser Arbeit wird auf die Kategorisierung der Sprechaktoberklassen Searles zurückgegriffen. In Kap. 1.1.1 ist deutlich geworden, dass bislang keine besseren Alternativen existieren und seine Klassifikation trotz aller Kritik noch immer die anerkannteste und am weitesten verbreitete ist. ${ }^{796}$ Gerade für lateinische Texte bietet sie - v. a. aufgrund der deduktiven Vorgehensweise unter Vernachlässigung konkreter (auch historischer) Sprachspezifika - eine angemessene und sinnvolle Grundlage. ${ }^{797}$ Die Differenzierung der Untermuster erfolgt in enger Anlehnung an die Münsteraner Schule, deren Arbeiten sich eigentlich auf das Deutsche beziehen, bis zu einem gewissen Grad jedoch ebenfalls einen (sprach-)übergreifenden Charakter haben, insofern in erster Linie allgemeingültige Handlungsbedingungen für die Typisierung entscheidend sind, die prinzipiell genauso für das Lateinische gelten. ${ }^{798}$ Zwar finden sich auch innerhalb der Latinistik vereinzelt (Teil-)Klassifikationen von Sprechakten, insbesondere zu den Direktiva, aber ein so umfassender Ansatz unter Berücksichtigung (fast) aller Sprechaktoberklassen mit stringenten Definitionen der zugehörigen Untermuster existiert bislang nicht. ${ }^{799}$ Bedacht und ggf. problematisiert werden muss allerdings zum einen, dass es in dieser Arbeit um (weitgehend) authentische und damit im Vergleich zu den Beispielen der Münsteraner Schule komplexere Äußerungen geht, zum anderen, dass diese schriftlich im Rahmen brieflicher Kommunikation und nicht mündlich im direkten persönlichen Austausch getätigt wurden.

Die Sprachfunktionsmodelle von Bühler, Jakobson und Schulz von Thun eignen sich eher dafür, einen bestimmten Text im konkreten Sprachgebrauch in seiner funktionalen Vielfalt zu interpretieren. Das geschieht zwar auch in der vorliegenden Untersuchung, wenn (v. a. im Rahmen der Beispielanalysen in Kap. 2.1) die Handlungsfunktion einzelner Äußerungen bestimmt werden soll, wobei immer wieder deutlich werden wird, wie schwierig dies im Einzelfall sein kann, weil Sprache eben selten eindeutig ist. Was dies angeht, sind die multifunktionalen Ansätze viel näher an der Sprachwirklichkeit als die grundsätzlich unifunktional ausgerichtete Sprechakttheorie. Ihr Fokus ist auch sonst weiter, insofern sie nicht-intendierte Sprachhandlungen und psychologische Aspekte teilweise ebenfalls berücksichtigen. ${ }^{800}$ Sie eignen sich hingegen weniger für eine strukturierte allgemeinere Darstellung der Möglichkeiten sprachlichen Handelns im Lateinischen, wie sie in dieser Arbeit angestrebt wird. Ciceros Briefe an Terentia sind nicht der eigentliche Ausgangspunkt der Studie, sondern nur ein Beispiel, anhand dessen diese Möglichkeiten (oder zumindest ein kleiner Ausschnitt davon) demonstriert werden sollen.

Die folgenden schematischen Übersichten (Abbildung 6 bis Abbildung 10) sind den betreffenden Studien der Münsteraner Schule entnommen, an einigen Stellen jedoch angepasst worden, um eine gewisse Einheitlichkeit herzustellen und die Übersichtlichkeit zu erhöhen. Neben

\footnotetext{
796 Vgl. das Teilkap. „Alternative Klassifikationen und Gesamtwürdigung“ ab S. 32.

797 Vgl. z. B. WAGNER 1995, 270. Vgl. a. LIEDTKE 2018, 39 (s. N. 424).

798 Dies schließt gelegentliche Abweichungen nicht aus, die ggf. an betreffender Stelle im Praxisteil diskutiert werden. Vgl. a. Kap. 1.1.2.1.2 sowie die „Schlussbetrachtungen“ ab S. 418. Vgl. außerdem LIEDTKE 2018, 39 (s. N. 424).

${ }^{799} \mathrm{Vgl.} \mathrm{Kap.} \mathrm{1.1.3.3.3.}$

${ }^{800}$ Vgl. a. S. 165 und 167.
} 
einem geänderten Layout und einer teilweisen Abweichung bei der Abfolge und Anzahl der Untermuster betrifft dies v. a. die Begrifflichkeiten: Die Kürzel ,Sp ${ }^{\prime}$ (oder ,Sp1 ${ }^{\prime}$ ) und , $\mathrm{Sp}_{2}{ }^{\prime}$ (oder ,Sp2') werden ggf. durch die Ausdrücke ,Sprecher ${ }^{\prime 801}$ bzw. ,Adressat' ersetzt, sofern diese nicht ohnehin gebraucht werden. Die Bezeichnungen der Oberklassen orientieren sich an Searle (z. B. ,Assertiva' statt ,Informationshandlungen'). ${ }^{802}$ Alle Untermuster werden in Verbform präsentiert (z. B. ,ANORDNEN' statt,ANORDNUNG'). Dadurch entstehen z. T. etwas sperrige Termini (z. B. ,DESPOTISCHEN BEFEHL ERTEILEN` oder ,PROBLEMATISIERUNGSFRAGE STELLEN'). Alternativ wäre eine durchgehende Bezeichnung mittels Substantiven denkbar, was jedoch oft keine wesentliche Verbesserung darstellen würde, zumal der aktive Handlungscharakter der Sprechakte dadurch weniger deutlich zum Ausdruck kommt.

Andere Begriffe wirken ebenfalls nicht besonders eingängig oder sogar auf den ersten Blick (für eine wissenschaftliche Analyse) etwas befremdlich, wie z. B. ,JAMMERN` ${ }^{803}$ Mit Sprechakten des Typs JAMMERN wird ein Gefühl der Traurigkeit ausgedrückt, was allerdings auch auf ,KLAGEN` und ,MITLEID BEKUNDEN`zutrifft. Sprechhandlungen des Typs MITLEID BEKUNDEN beziehen sich dabei auf das Schicksal des Adressaten, während solche des Typs KLAGEN und JAMMERN im Hinblick auf das eigene Schicksal geäußert werden. Im Falle des KLAGENs wird die Schuld beim Adressaten gesehen, beim JAMMERN dagegen beim Sprecher selbst, einer dritten Person, oder es liegt eine „nicht-personale Ursache“ vor. ${ }^{804}$,TRAURIGKEIT ÄUSSERN` oder ,KUMMER ÄUSSERN` wären also zu ungenau als Ersatz für ,JAMMERN', obgleich viele Verben ja durchaus einen gewissen Spielraum lassen und nach eigenem Ermessen per definitionem genauer festgelegt werden könnten. Ähnliche Schwierigkeiten ergeben sich bei anderen Untermustern. Oft ist es kaum möglich, angemessenere Begriffe zu finden, und letztlich habe ich mich entschieden, pauschal sämtliche Bezeichnungen (ggf. in Verbform transformiert) beizubehalten und nur manchmal auf von den Vertretern der Münsteraner Schule

\footnotetext{
${ }^{801}$ Da es sich bei CIC. fam. 14 um schriftliche Kommunikation handelt, könnte man alternativ den Begriff ,(Brief-) Schreiber' verwenden, was in der vorliegenden Arbeit gelegentlich auch getan wird. ,Sprecher' wird an dieser Stelle aber als allgemeinerer Ausdruck bevorzugt, zumal in Briefen manchmal tatsächlich mündliche Äußerungen sowohl der Briefkorrespondenten als auch von dritter Seite aufgegriffen werden. Eine Unterscheidung von $\mathrm{Sp}(\text { recher })_{1}$ und $\mathrm{Sp}$ (recher) $)_{2}$ erscheint nicht notwendig, weil es sich im vorliegenden Fall ja (aufgrund der Überlieferungslage) bei Cicero immer um den Sprecher und bei Terentia um den Adressaten handelt. Ein Sprecherwechsel kommt also nicht vor. Die Verwendung der Bezeichnung , $\mathrm{Sp}_{3}{ }^{\prime}$ in einigen Definitionen der Münsteraner Schule ist im Übrigen missverständlich, weil damit eher irgendeine dritte Person gemeint ist, die nicht unbedingt als „Sprecher" in Erscheinung tritt.

802 Als ungünstig erweist sich dabei allerdings, dass RoLf 1983 zu den Informationshandlungen u. a. eine Gruppe von Sprechakten zählt, die er als „Assertiva“ bezeichnet. Im Folgenden muss deshalb im Zweifelsfall immer deutlich gemacht werden, ob die Sprechaktoberklasse Searles („Assertiva i. w. S.“) oder das entsprechende Untermuster Rolfs („Assertiva i. e. S.“) gemeint ist.

${ }^{803}$ Vgl. S. 42.

804 Untermuster, die in fam. 14 begegnen, werden in der Übersicht „Definitionen der Sprechaktuntermuster (gem. Münsteraner Schule)“ im Anhang (ab S. 441) erklärt. Dies gilt z. B. für JAMMERN. MITLEID BEKUNDEN (vgl. MARTEN-CLEEF 1991, 267ff.) ist weitgehend identisch mit BEDAUERN BEKUNDEN, schließt aber auch den Spezialfall KONDOLIEREN (aus Anlass des Todes eines Angehörigen des Adressaten) mit ein, der aufgrund der besonderen Ritualität gesondert erfasst wird. Als zugrundeliegendes Gefühl ist dort nicht von Traurigkeit, sondern Mitleid die Rede. Zum KLAGEN vgl. ebd., 303ff.: „KLAGEN als opponierender expressiver Handlungstyp mit Sprecher-Aversion wird mit der Absicht vollzogen, dem Adressaten zu bekunden, daß dessen Verhalten oder Handlungsweise im Sprecher ein Gefühl von Traurigkeit ausgelöst hat.“ (ebd., 303). Folgende Handlungsbedingungen gelten: „B1: $S p_{1}$ ist von einem Sachverhalt $S$ betroffen, den $S p_{2}$ verursacht hat. B2: $S p_{1}$ bewertet $S$ negativ für sich. B3: $S p_{1}$ ist traurig über S." (ebd., 305).
} 
selbst alternativ verwendete Begriffe zurückzugreifen, wie z. B. ,VERMUTEN'statt ,KONJIZIEREN`oder ,FESTSTELLEN`statt, KONSTATIEREN`.

Abgesehen davon gibt es weitere Termini, die einer genaueren Erklärung bedürfen, weil sie uneindeutig sind, wie z. B. ,VORSCHLAGEN', das sowohl als direktiver wie auch als kommissiver Sprechakt begegnet ${ }^{805}$, oder weil sie sich nicht intuitiv erschließen und von anderen Bezeichnungen abgrenzen lassen. Die allgemeine Einteilung der Sprechaktuntermuster, wie sie sich in den Übersichten auf den folgenden Seiten widerspiegelt, wurde bereits in Kap. 1.1.1.2.4 beschrieben. Zu den weitergehenden Differenzierungen innerhalb der Untergruppen sei v. a. auf die betreffenden Untersuchungen der Münsteraner Schule selbst verwiesen. Ein Überblick über die Definitionen der für die vorliegende Untersuchung relevanten Untermuster findet sich im Anhang dieser Arbeit. Außerdem werden einzelne Untertypen im Rahmen der konkreten Briefanalysen im Praxisteil dieser Arbeit ausführlicher erläutert.

Im Übrigen bleiben deklarative Sprechakte und - abgesehen von den Assertiva und den Kommissiva - alle sequenzabhängigen Sprechakte in den Übersichten (sowie im Großen und Ganzen auch bei der Illokutionsanalyse im Praxisteil) unberücksichtigt. Dies gilt ebenso für eine detailliertere Klassifizierung insistierender und bewertender Sprechakte, obwohl dazu sogar eigene Untersuchungen vorliegen. Insistierende Sprechakte spielen in fam. 14 keine Rolle. Was die bewertenden Sprechakte angeht, reichen die von Marten-Cleef erfassten expressiven Sprechhandlungen (wie z. B. KOMPLIMENT MACHEN) für meinen Zweck vollkommen aus. Überhaupt ist ihre Klassifikation sehr umfassend und schließt - der in dieser Arbeit vertretenen weiten Auffassung der Expressiva gemäß - den Beziehungsaspekt („sympathisierende“ bzw. „opponierende“ Expressiva) und den Gefühlsausdruck („abreagierende Expressiva“) gleichermaßen mit ein. ${ }^{806}$ Auch sonst ist die folgende Darstellung hinsichtlich einiger Sprechakte (z. B. bei den Kommissiva) ein wenig verkürzt. Andererseits werden teilweise Sprechakte präsentiert, die in Ciceros Briefen an Terentia gar nicht verwendet werden (können) - wie z. B. bindende Aufforderungen ${ }^{807}$-, um das übergreifende Ordnungsprinzip bei der Typisierung der Untermuster begreiflich zu machen.

\footnotetext{
${ }^{805}$ Vgl. HINDELANG 1978, 464ff. bzw. GRAFFE 1990, 287ff. Mehrdeutig ist aber z. B. auch das kommissive Untermuster VERSPRECHEN, das bei Graffe als obligationskonstituierend, obligationskonzedierend (,,abgerungenes“ VERSPRECHEN) und obligationsassertierend („zusicherndes“ VERSPRECHEN) begegnet. Vgl. a. N. 153.

${ }^{806}$ Sie differenziert also die sonst oft als phatisch bezeichneten Expressiva danach, ob eine Sprecher- bzw. Adressatenpräferenz oder -aversion vorliegt.

${ }^{807}$ Vgl. S. 181.
} 


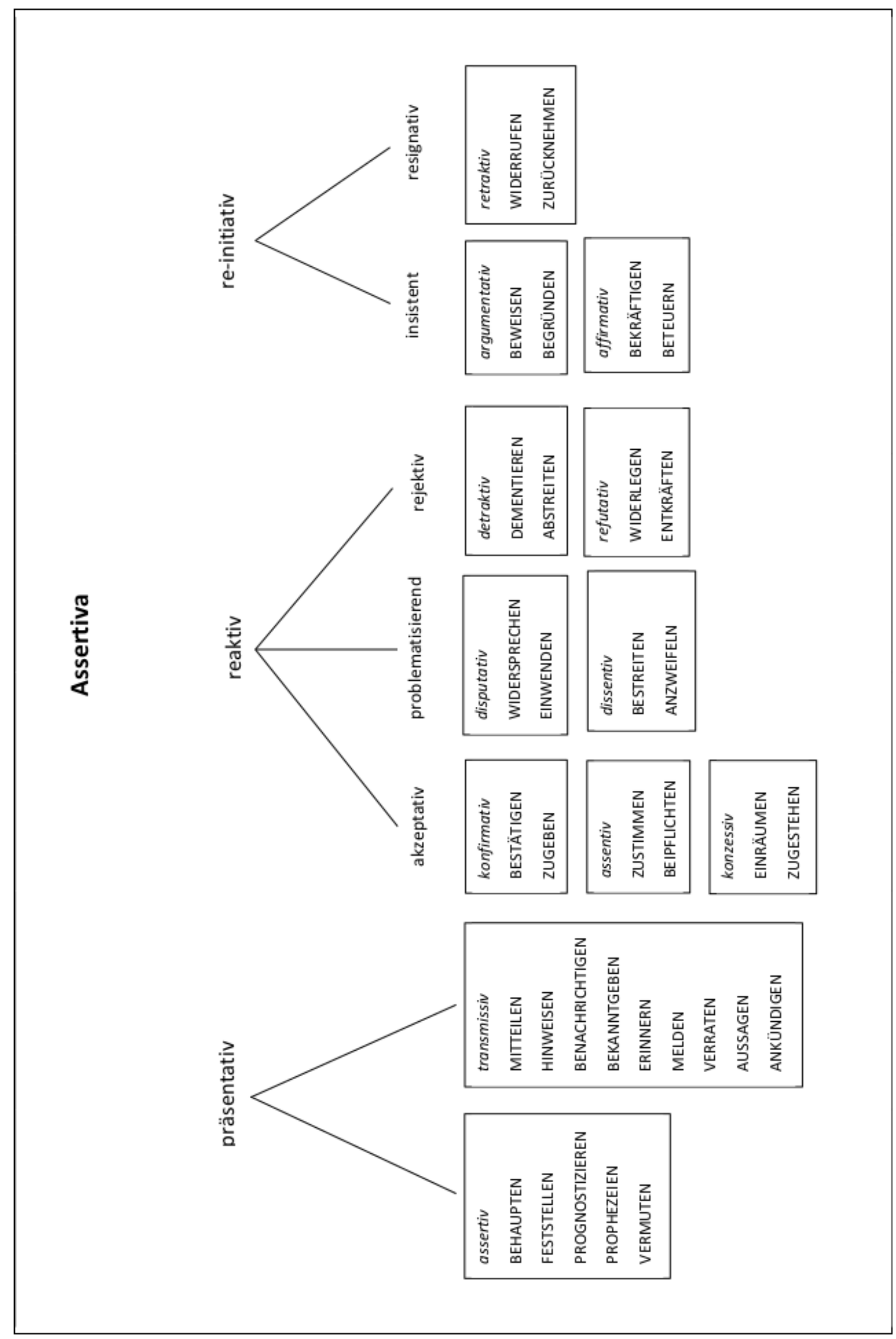

Abbildung 6: Assertiva (nach Rolf 1983, 211) 


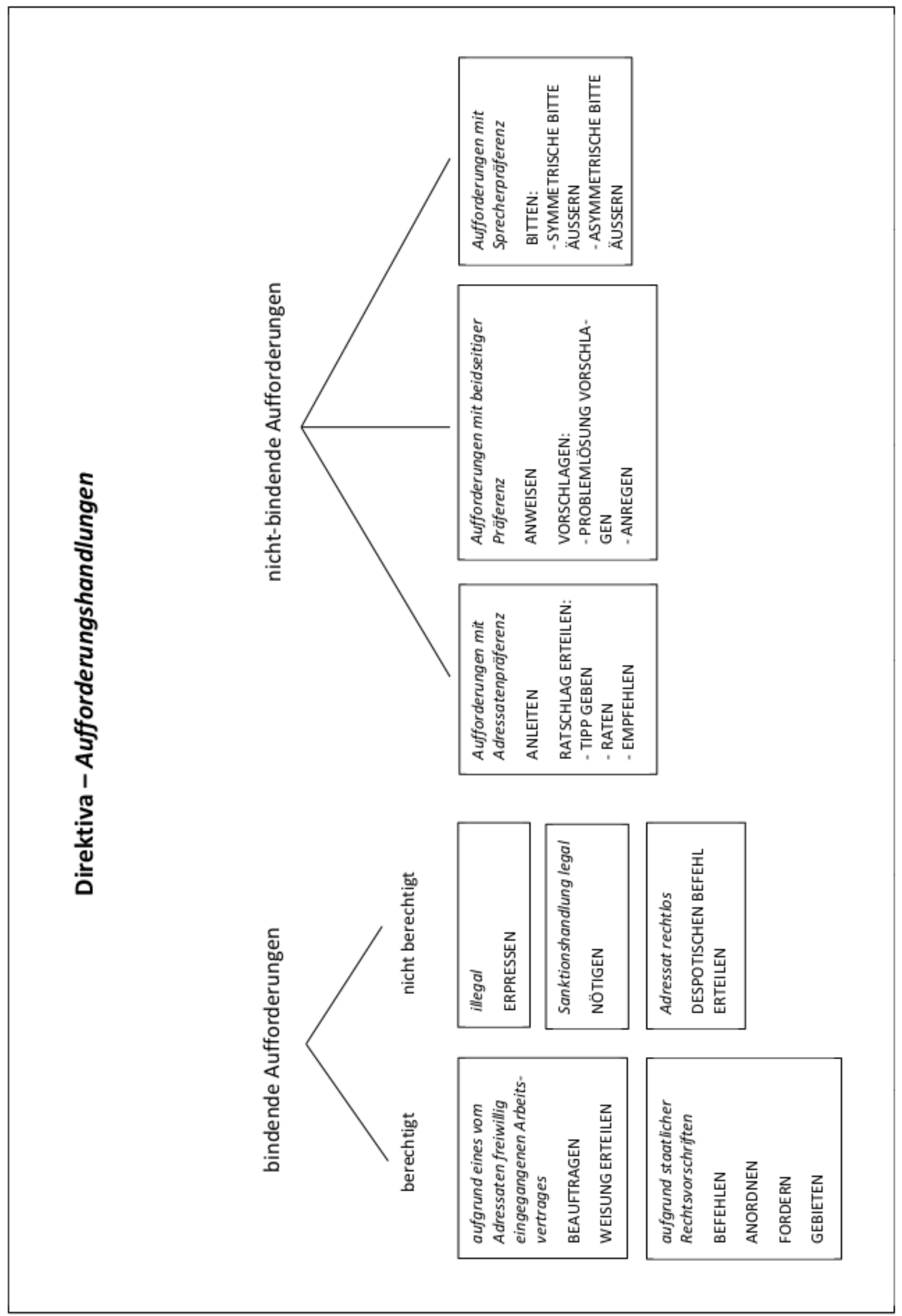

Abbildung 7: Direktiva - Aufforderungshandlungen (nach HINDELANG 1978, 131 bzw. ebd., 141 und HINDELANG 2010, 59 bzW. ebd., 66) 


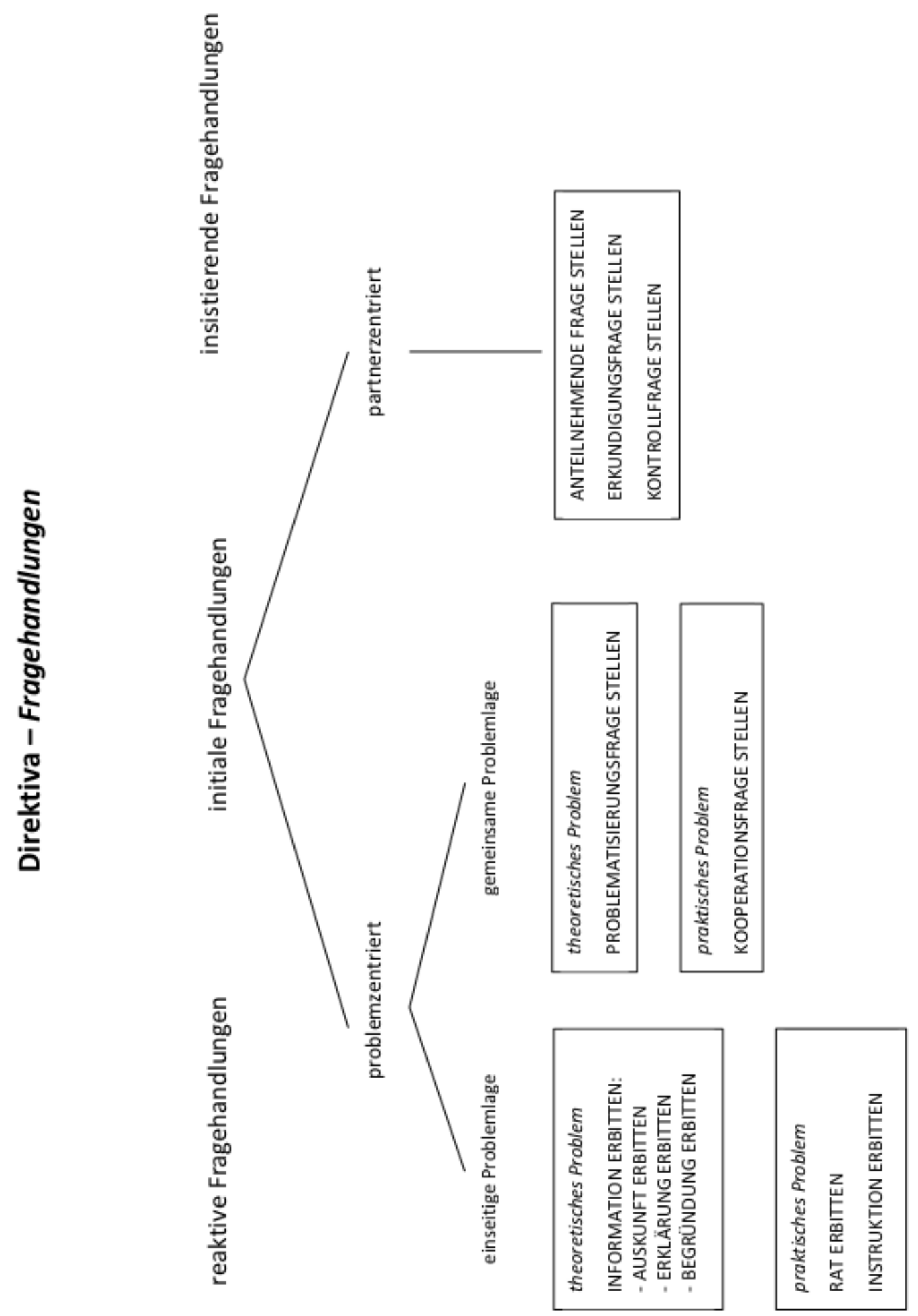

Abbildung 8: Direktiva - Fragehandlungen (nach HINDELANG 1981, 223) 

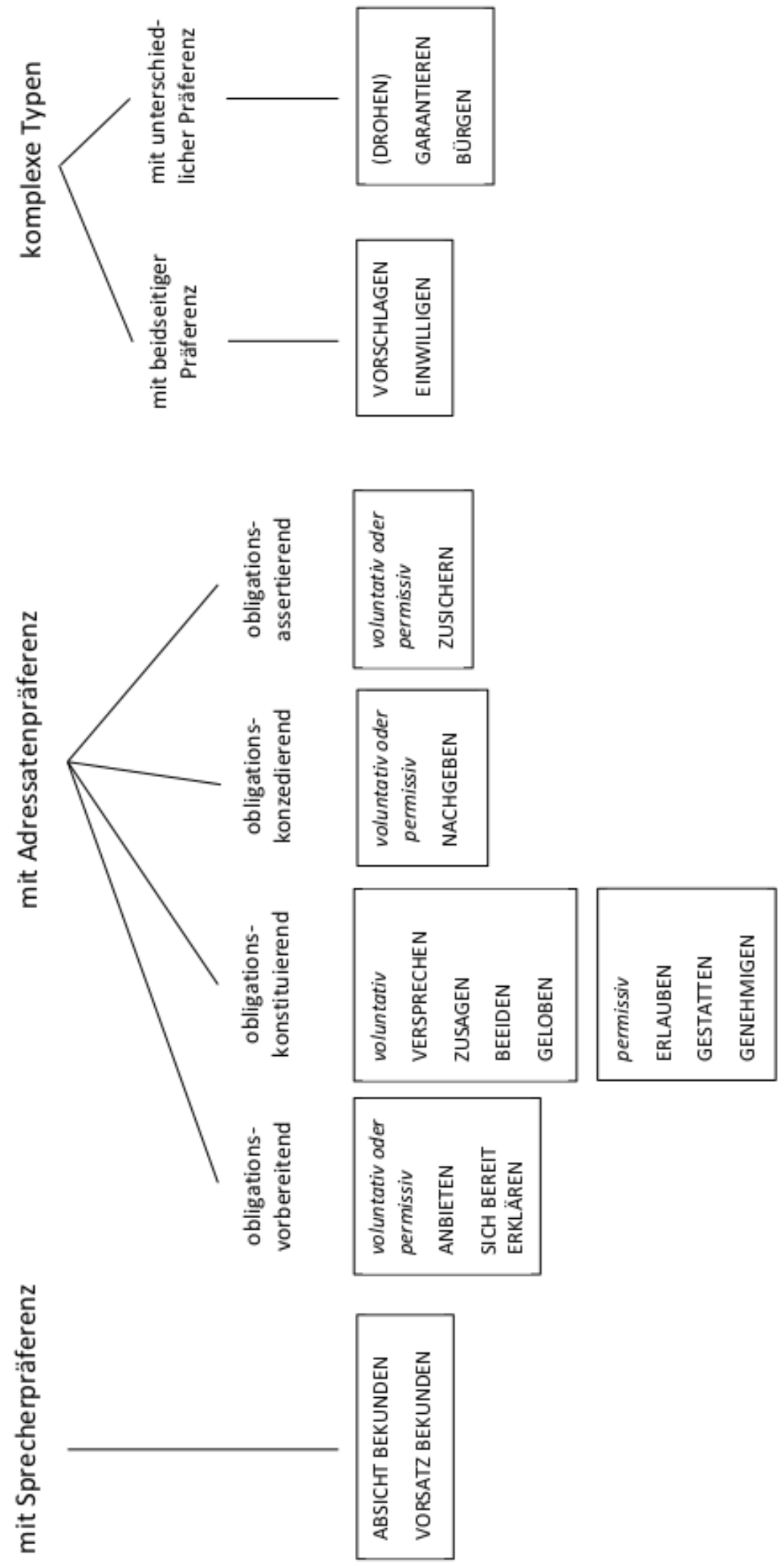

Abbildung 9: Kommissiva (nach GRAFFE 1990, 75) 


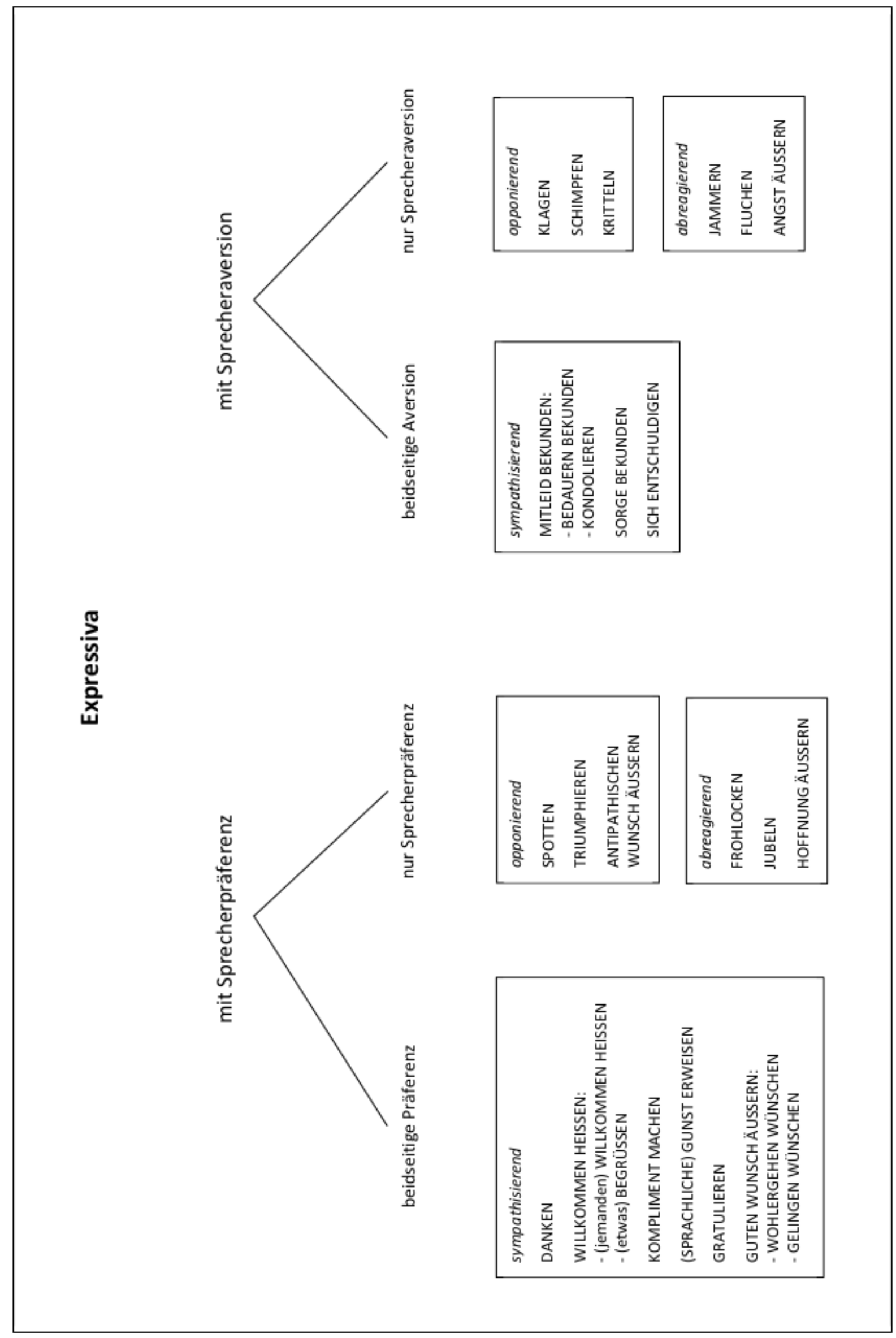

Abbildung 10: Expressiva (nach Marten-Cleef 1991, 79) 


\subsubsection{Vorgehensweise bei der Zuordnung von Illokutionen zu Sprechaktober- klassen und Sprechaktuntermustern}

Essenziell für eine sprechakttheoretische Untersuchung ist die Eruierung von mutmaßlichen Handlungsintentionen, von denen die (linguistisch) für besonders relevant erachteten mittels einer Sprechaktklassifikation erfasst werden. Weitergehende Intentionen können im Rahmen der vorliegenden Arbeit nur bedingt berücksichtigt werden. ${ }^{808}$

In der Taxonomie Searles sind drei Faktoren für die Differenzierung der Sprechaktoberklassen entscheidend: der illokutionäre Zweck, die Anpassungsrichtung von Welt und Worten und der zum Ausdruck gebrachte psychische Zustand des Sprechers. ${ }^{809}$ Auch die Münsteraner Schule hat zur Definition der einzelnen Sprechaktuntermuster jeweils bestimmte Handlungsbedingungen festgelegt. ${ }^{810}$ Insbesondere im Hinblick auf die Untermuster ist aber nicht immer leicht zu entscheiden, ob die betreffenden Kriterien erfüllt sind.

Hilfreich bei der Zuordnung können verschiedene sog. IFIDs (,illocutionary force indicating devices") sein. ${ }^{811}$ Zu den offensichtlichen sprachlichen Indikatoren gehören explizit performative Ausdrücke und die Satzart. Wie eindeutig sie bisweilen auch erscheinen mögen, wiegen allerdings andere Indikatoren schwerer, wenngleich diese ebenfalls selten einfache und klare Zuweisungen ermöglichen. ${ }^{812} \mathrm{Zu}$ ihnen gehören propositionaler Gehalt, bestimmte Partikeln und prosodische Merkmale, welche in Schrifttexten z. B. durch die Interpunktion oder die Wortstellung kenntlich gemacht werden können. Hinzu kommen weitere sprachlich-stilistische Aspekte. So gibt z. B. bei der Einordnung von Grußformeln die (entweder eher sachlich-

\footnotetext{
${ }^{808}$ Vgl. WEIGAND 2003, 58f.: „Bisweilen wird der Sprechakttheorie auch heute noch von Linguisten Skepsis entgegengebracht, die sich an den Vorwurf knüpft, die Linguistik drohe sich im Rahmen einer linguistischen Sprechakttheorie zu einer Humanwissenschaft auszuweiten, die Grenze, was noch bzw. nicht mehr linguistisch relevant sei, werde verwischt. [...] Diese Frage ist klar zu beantworten, indem man den großen Bereich möglicher Intentionen nach sprechakttheoretisch relevanten und anderen Intentionen unterteilt. Welche Intentionen sprechakttheoretisch relevant sind, wird in einer Sprechakttaxonomie festgelegt. Allerdings gehören auch die anderen Intentionen [...] zu dem komplexen Geschehen im Handlungsspiel, weshalb wir in der Tat uns von einem engen Konzept der Disziplin Linguistik verabschieden sollten [...]. “ Vgl. a. AdAMzIK 2016, 177 und WüEST 2011, 183, die deutlich machen, wie sehr sich Textfunktionsbestimmungen durch die (von verschiedenen Faktoren beeinflusste) jeweilige Perspektive (als Autor, intendierter oder nicht-intendierter Rezipient) unterscheiden können. Vgl. außerdem SzWED 2014, 155 (mit Bezug auf HARTUNG 2000 - 2001): „Bei der Frage nach der Intentionalität in der Sprechakttheorie taucht [...] das allgemeine Problem auf, dass nämlich ,im Grunde nicht Intentionen der Handelnden offengelegt werden, sondern dass die Analysierenden ihnen welche zuschreiben' (Hartung 2000: 89). Dieser Einwand kann m.E. mit der Bemerkung widerlegt werden, dass eigentlich die gesamte menschliche Kommunikation darin besteht, dass irgendwelche Intentionen dem Partner zugeschrieben werden, unter Rückgriff auf unterschiedliche Faktoren, u.a. auf die Konventionalität. " Vgl. a. SzWED 2014, 58. Zur Ermittlung der ,wahren" Autorabsicht und evtl. damit verbundener Manipulationsstrategien ist auf jeden Fall die Hinzuziehung ergänzender Methoden notwendig, v. a. aus dem Bereich der Psychologie. Vgl. z. B. ScHMITT 2000, 169f., der in diesem Zusammenhang u. a. auf die Nützlichkeit des Modells von Schulz von Thun (s. a. N. 70) hinweist.

${ }^{809}$ Vgl. Kap. 1.1.1.2.3, bes. das Kap. „Sprechaktkategorien und Klassifikationskriterien“ ab S. 24.

${ }^{810}$ Vgl. Kap. 1.1.1.2.4. und die Übersicht „Definitionen der Sprechaktuntermuster (gem. Münsteraner Schule)“ im Anhang (ab S. 441).

${ }^{811}$ Die Bezeichnung geht auf Searle zurück. Vgl. a. ebd., 46. Auf die einzelnen (sprachlichen und anderen) Indikatoren wird im Zusammenhang mit den konkreten Briefanalysen im Praxisteil näher eingegangen. Vgl. außerdem WeIGAND 2003, 172ff.; MOTSCH UND PASCH 1987, 34ff. und SöKELAND 1980, 46ff. sowie (zum Lateinischen) RISSELADA 1993, 63ff.

812 Vgl. z. B. BRINKER 2000 - 2001b, 179 und BRINKER 1994, 39.
} 
neutrale oder emotional-expressive) Lexik einen Hinweis darauf, inwieweit diese als rein deklarative oder expressive Sprechakte zu betrachten sind.

Ob ein indirekter Sprechakt vorliegt, kann außerdem durch die Beantwortung folgender Fragen entschieden werden: Wäre eine Interpretation als direkter Sprechakt abwegig (Absurditätskriterium) ? $^{813}$ Ist eine Konventionalisierung bzw. Phraseologisierung eingetreten? Liegen „sprachliche Besonderheiten [...], die von der wörtlichen Bedeutung her, nicht nötig wären" 814 , vor, wie z. B. eine spezifische Verwendung von Modalverben und Partikeln? Äußerungen wie „Musst du denn (wirklich schon) gehen?" und „Müsstest du nicht (langsam mal) losfahren?" (oder lat. Num bzw. Nonne tibi proficiscendum est?) sind z. B. kaum als Informationsfragen, sondern i. d. R. als BITTEN zu verstehen, noch etwas zu bleiben bzw. (endlich) aufzubrechen. ${ }^{815}$ Insgesamt ist dabei von einem Kontinuum von sehr direkten bis hin zu sehr indirekten Sprechakten auszugehen. ${ }^{816}$

In vielen Fällen reichen sprachliche Indikatoren nicht aus, um eine Handlungsfunktion zu identifizieren: Die Hinzuziehung kontextueller Indikatoren ist notwendig, welche bei der endgültigen Einordnung immer den Ausschlag geben ${ }^{817}$, wobei der Kontext insbesondere bei antiken Texten oft nur eingeschränkt rekonstruierbar ist. ${ }^{818}$ Dazu zählt zunächst einmal der äußere Kommunikationsrahmen, also örtliche und zeitliche Situation, aber auch Medialität und Materialität. Man sollte bei der Analyse also ggf. Fragen beantworten wie: Wo befinden sich die Korrespondenten? Seit wann und wie lange noch? Inwieweit stehen (zuverlässige) Boten zur Verfügung? Gibt es Probleme mit der Beschaffung oder Qualität des Schreibmaterials? Wichtig sind außerdem Kenntnisse zum allgemeinen politischen, sozialen und kulturellen Hintergrund und zur persönlichen Lage der Briefpartner, und zwar sowohl was Vergangenheit als auch Gegenwart und Zukunft betrifft. Dabei ist u. a. (historisches) Wissen über typische Handlungsabläufe (frames und scripts) sowie bestimmte Höflichkeits- und Gesprächskonventionen in der Antike nützlich. Eine sehr wichtige Rolle spielt zudem, wie groß der Grad der Vertrautheit zwischen Briefschreiber und -empfänger ist, welche Art von (z. B. familiärer, freundschaftlicher, geschäftlicher) Beziehung zwischen ihnen besteht, in welcher (z. B. sozialen oder beruflichen) Rolle sie auftreten. Je nachdem, welchem Handlungsbereich ein Brief zuzuordnen ist, muss z. B. eine Aufforderung als BEFEHL oder BITTE interpretiert werden. Auch die Anzahl der

\footnotetext{
${ }^{813} \mathrm{Vgl.} \mathrm{SCHMITT} 2000,164$. Vgl. a. S. 21.

814 WEIGAND 2003, 243.

${ }^{815} \mathrm{Vgl}$. dazu bes. ebd., 243f., woran auch die genannten Beispiele angelehnt sind.

${ }^{816}$ Vgl. S. 22 bzw. das Kap. „Indirekte Sprechakte“ (ab S. 20) insgesamt. Vgl. a. RISSELADA 1993, 88 und BoLKESTEIN 1980, 34f. zu verschiedenen Graden der Indirektheit.

817 Vgl. z. B. BRINKER 2000 - 2001b, 179. Vgl. a. STAFFELDT 2014, 110: „Für die postulierten Indikatoren gilt ganz allgemein, dass sie bei weitem nicht in allen Kontexten dieselbe Illokution oder Perlokution indizieren. Noch nicht einmal die eigentlich stärksten Indikatoren für Illokutionen, die performativ gebrauchten illokutionären Verben, sind voll verlässlich (z. B. ich verspreche dir bei VERSPRECHEN, aber auch bei VERSICHERUNGEN oder DROHUNGEN).“ Sogar rein "situativ ausgedrückte direkte Sprechakte" sind möglich, wie WEIGAND 2003, 208f. deutlich macht. Sie weist z. B. in Anlehnung an Austin (AUSTIN 1971, 16) darauf hin, dass das Wort ,dog' auf einem Schild am Eingang eines Gartens eine Warnung ausdrücken, unter einem (illustrativen) Bild jedoch eine rein beschreibende Funktion haben kann. SCHLUND 2014 hält dagegen (mit Verweis auf Konzept des „abstrakten Kontextes” in ESCANDELL-VIDAL 1996) einen „non-contextual approach” (in der pragmatischen Höflichkeitsforschung) für durchaus möglich.

${ }^{818}$ Vgl. Kap. 1.1.2.2.2. Vgl. a. UNCETA GÓMEZ 2014a, 12 (zu Höflichkeitsanalysen).
} 
Kommunikationsteilnehmer kann bedeutsam sein: Schreibt Cicero nur an Terentia, oder richtet er sich noch an andere Familienmitglieder?819

Bei der Zuordnung zu Sprechaktoberklassen und -untermustern interagieren i. d. R. mehrere Indikatoren miteinander. Probleme entstehen dadurch, dass sie oft nicht eindeutig sind oder sich sogar widersprechen. ${ }^{820}$ Dies gilt v. a. bei impliziten und indirekten Sprechakten. ${ }^{821} \mathrm{Je}$ nachdem, wie genau ein Sprechakt formuliert ist, können jeweils recht unterschiedliche Nuancen mitschwingen. ${ }^{822}$ Es ist manchmal sehr schwierig zu beurteilen, worin diese konkret bestehen, welche Aspekte dominieren, welche als eher untergeordnet anzusehen sind, worin also die hauptsächliche Handlungsfunktion besteht, die für die Klassifizierung einer Illokution ausschlaggebend ist. Innerhalb eines „pragmatic space“ gibt es verschiedene Abstufungen, wobei einige Äußerungen eher als protypisch für einen bestimmten Sprechakttyp anzusehen sind als andere. ${ }^{823}$ Obwohl die Sprechakttheorie eigentlich unifunktional ausgerichtet ist, wird man am Ende zugestehen müssen, dass trotz aller Bemühungen um eine gut begründete $\mathrm{Zu}$ weisung eine klare und distinkte Bestimmung oft nicht möglich ist. ${ }^{824}$

Ähnlich wie die Abgrenzung der einzelnen Handlungseinheiten (Illokutionsidentifikation) erfolgt ihre Qualifizierung (Illokutionsklassifikation) also letztendlich durch subjektive Interpretation (Intuition) aufgrund von Kontextinformation. Inhaltlich-grammatische Aspekte bzw. strukturelle Kriterien dienen lediglich als unterstützende Indikatoren bei der Beantwortung der Frage, ob die für die Klassifikation notwendigen Handlungsbedingungen erfüllt sind. Sie

\footnotetext{
${ }^{819}$ Was alles zum Kontext zählt, wird recht unterschiedlich gesehen und nicht immer klar definiert. Mancher spricht in diesem Zusammenhang von einem „conceptual garbage can“ (FABER UND LEóN-ARAúz 2017, 9). VgI. a. AIRENTI UND PLEBE 2017, 6: „Intuitively, context is the background for comprehension, what makes communication possible. This is a critical point. In fact, context both is an inescapable concept in the study of communication and eludes univocal definition. There is no one context but many. "Ausführlicher auf verschiedene kontextuelle Aspekte gehen die einzelnen Beiträge zu dem Sammelband AIRENTI U. A. 2017 ein. VgI. außerdem AdAMZIK 2016, 114ff.; KoCh und Oesterreicher 2008, 201 sowie Meibauer 2008, 9; SAllaberger 1999, 13f. und Rosengren 1987, 33. Speziell zur Briefanalyse vgl. darüber hinaus LANGEHEINE 1983b, 199f. Zu ,Handlungsbereichen` vgl. a. S. 103.

${ }^{820}$ Vgl. z. B. STAFFELDT 2014, 108.

821 In Anlehnung an Wagner (z. B. WAGNER 1997, 47) werde ich im Folgenden nicht nur zwischen direkten und indirekten Sprechakten, sondern bei den direkten Sprechakten zudem noch zwischen expliziten (Austins explizit performativen) Akten und impliziten bzw. primären (Austins implizit performativen) Akten unterscheiden. Vgl. a. WEIGAND 2003, 174ff., die lexikalisch (durch performative Verben), grammatisch und situativ ausgedrückte direkte Sprechakte differenziert. Vgl. außerdem BOLKESTEIN 1980, 26ff. zu den unterschiedlichen Konzepten in Bezug auf die Interdependenz von semantischer Struktur und illokutionärer Kraft (primäre vs. sekundäre illokutionäre Kraft - direkte vs. indirekte Sprechakte - implizite vs. explizite Sprechakte) sowie den Überschneidungen der Konzepte.

822 Vgl. z. B. HARRAS 2004, 267.

823 Vgl. z. B. ARCHER 2010, 380 (mit Bezug auf JUCKER UND TAAVITSAINEN 2008 ): „Taavitsainen and Jucker (2008a: 4) [...] prefer to think of speech acts as being, fuzzy concepts that show both diachronic and synchronic variation" [...]. What this means, in practice, is a rejection of the application of speech-act theory in its most conservative Searlean sense in favour of a view of speech acts as ,prototypes' linked by shared multidimensional ,pragmatic space' (analogous to a semantic field capturing word meanings in relation to neighbouring words)."

${ }^{824} \mathrm{Vgl}$. z. B. S. 15. Hier zeigt sich deutlich der Unterschied zwischen sprachphilosophischer Abstraktion und konkreter Sprachpraxis. Vgl. a. STAFFELDT 2014, 110f. (zu indirekten Sprechakten): „Selbst wenn Indikatoren eine Illokution relativ sicher anzeigen sollten und diese auch möglicherweise vorliegt, so kann es immer noch sein, dass damit zugleich ein weiterer anderer Sprechakt vollzogen wird. Wie kommt man methodisch auf diesen Sprechakt? Oder: Wie kann man ausschließen, dass damit nicht zugleich noch hundert weitere vollzogen wurden?"
} 
sind aber gleichwohl sehr bedeutsam, insofern sie das Ausmaß an Beliebigkeit beschränken. ${ }^{825}$ Konkrete Analyse und Zuordnung werden dabei mittels eines methodologischen Zirkels ${ }^{826}$ vollzogen:

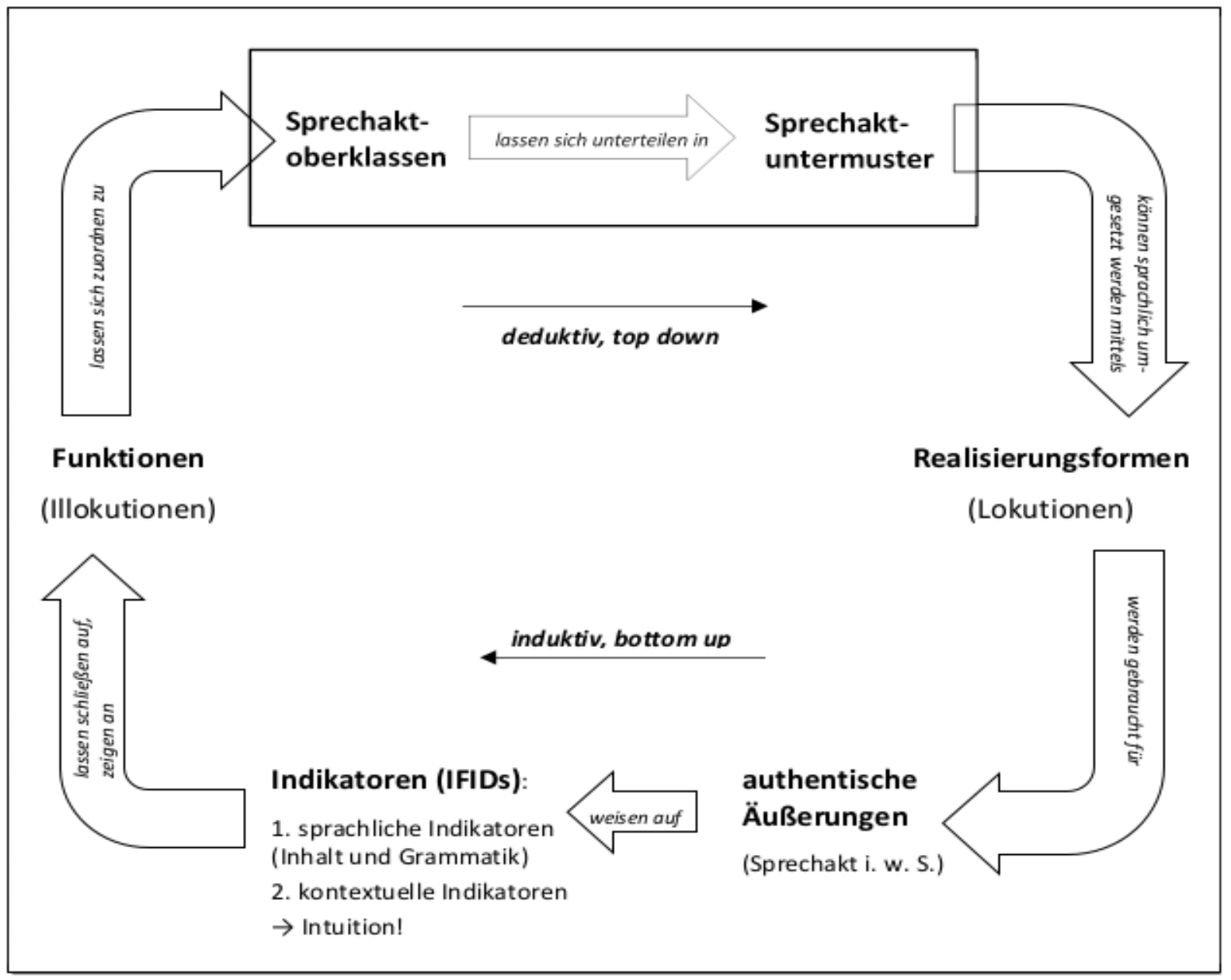

Abbildung 11: Illokutionsklassifikation: Methodologischer Zirkel (nach STAFFELDT 2014, 112)

${ }^{825}$ Vgl. z. B. SCHMITT 2000, 43f.: „In den meisten Arbeiten, die sich der Illokution aus theoretischer oder angewandter Sicht nähern, spielt die Intuition eine Rolle. Nur selten wird dies aber so explizit zugegeben wie bei Searle [...]. Gerade bei der Anwendung einer Theorie, die bislang eher von einem philosophischen Hintergrund aus erforscht worden ist, auf authentische Texte muss [...] einer ,intuitionsgestützten' Analyse der Vorzug vor einer rein auf strukturelle Merkmale ausgerichteten Methode gegeben werden. Eine Theorie, die sich mit der Erfassung intentional determinierter Sprachhandlungen befasst, wird kaum jemals so komplex sein können, dass sie alle möglichen Verwendungsweisen von Sprache allein durch die Strukturbeschreibung erfassen könnte. Zur Identifizierung einer Illokution als Folge einer Sprecherintention wird neben dem sprachlichen Wissen immer weit darüber hinausgehendes Weltwissen, etwa das Wissen um den Kontext der Äußerung erforderlich sein. " und ebd., 49f.: „Wie die Übersetzung eines Textes von einer Sprache in eine andere muss [...] auch die Illokutionsanalyse durch eine Kombination aus umfassend-intuitiver und struktureller Analyse bewerkstelligt werden; jede einseitige Auflösung wäre kontraproduktiv. Nur so kann ein wirklichkeitsnahes und begründet-legitimierbares Ergebnis gewährleistet werden. Dies bedeutet aber auch, dass man sich als Analysator freimachen muss von der Vorstellung, eine Illokutionsanalyse sei immer eindeutig durchzuführen [...]. Ebenso wenig, wie erwartet werden kann, dass verschiedene Übersetzer eines Textes zu ein und derselben Übersetzung gelangen, selbst wenn die internen Systeme sowohl der Ausgangs- als auch der Zielsprache als hinreichend bekannt vorausgesetzt werden können, kann erwartet werden, dass ein Text hinsichtlich seiner Illokutionskomposition von allen Analysatoren vollkommen identisch interpretiert wird. [...] Ziel muss es also sein, dem Analysator Hilfsmittel und Kriterien an die Hand zu geben, mit deren Hilfe eine theoretisch begründete Analyse möglich ist, ohne dabei diesen Kriterien und Methoden letzte Objektivität zuzuschreiben. "Vgl. a. WAGNER 1997, 73; ARTMANN 1996, 96 und BURKHARDT 1986, 400f. ${ }^{826}$ Vgl. a. S. 8. 


\subsubsection{Sequenzierung und Hierarchisierung der Handlungsfunktionen}

\subsubsection{Abgrenzung von Teiltext(handlung)en}

Komplexe Texthandlungen können und sollten in zusammenhängende Teileinheiten gegliedert werden - nicht nur als Beitrag zur Übersichtlichkeit, sondern auch zur Verdeutlichung der vielfältigen Verflechtungen innerhalb der Textstruktur: Der übergeordneten Texthandlung sind in einem (römischen) Brief üblicherweise mindestens drei Teil(text)handlungen untergeordnet, die evtl. noch in weitere Teilhandlungen (auf verschiedenen hierarchischen Ebenen) aufgegliedert werden können. Die unterste Ebene besteht aus den Einzelillokutionen bzw. Einzelhandlungen. Die jeweils übergeordneten Handlungen werden vollzogen, indem die jeweils untergeordneten Handlungen ausgeführt werden. Zwischen nebengeordneten Handlungen besteht eine und dann-Beziehung. Daraus ergibt sich eine Schachtelstruktur ${ }^{827}$, die zum Beispiel so aussehen könnte:

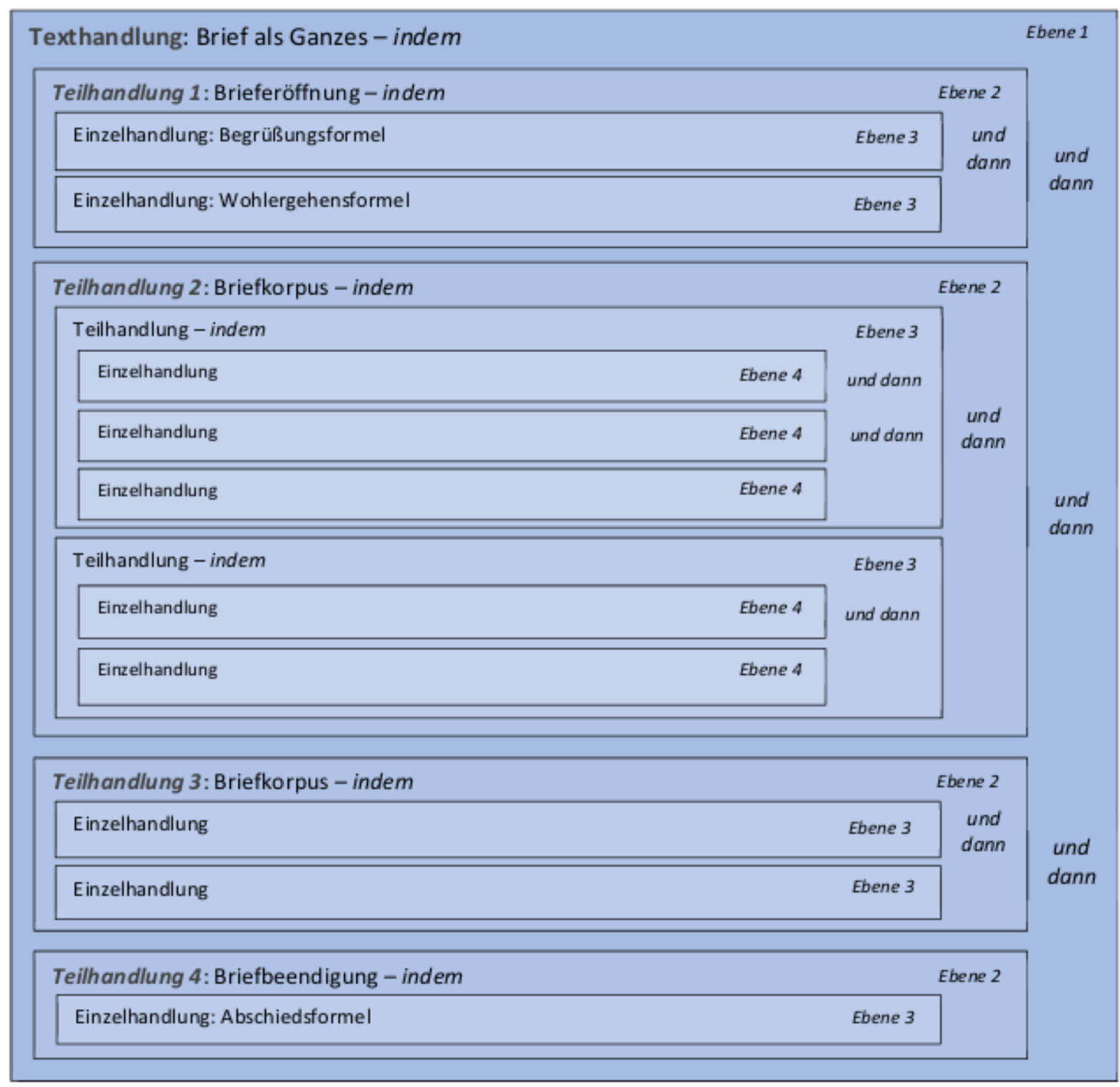

Abbildung 12: Schachtelstruktur der Handlungsebenen in römischen Briefen (in Anlehnung an SCHRÖDER 2003, 36)

${ }^{827}$ Vgl. das Kap. „Schachtelstruktur komplexer Texte“ ab S. 58. 
Die an dieses Schema angelehnten Übersichten im Praxisteil stellen selbstverständlich nur abstrahierende Vereinfachungen dar, welche die sprachliche Realität, in der es so klare Abgrenzungen gar nicht geben kann, nur eingeschränkt widerspiegeln. ${ }^{828} \mathrm{Zu}$ beachten ist bspw., dass die Handlungsebenen identisch mit einer Einzelhandlung sein können, z. T. aber auch zusätzliche virtuelle (Zwischen-)Ebenen angesetzt werden, die mehrere einander nebengeordnete Einheiten zusammenfassen. Dies betrifft die übergeordnete Gesamttextebene ebenso wie die untergeordneten Ebenen. So wird u. a. eine einheitliche, parallele Darstellung verschiedener Teiltexte ermöglicht. Die Anzahl von Hierarchieebenen sagt also nur bedingt etwas über die tatsächliche Komplexität eines Textes im Vergleich zu einem anderen aus.

Die Einteilung der Briefe in Teiltexte erfolgt auf Grundlage der ab S. 60 ausführlich dargelegten „Abgrenzungs- und Gliederungskriterien“. Da die ursprüngliche Gestaltung der Textoberfläche durch Cicero unbekannt ist und von dieser Seite keine Aufschlüsse über die (intendierte) Textstruktur, sondern lediglich Hinweise aus zweiter Hand (durch den jeweiligen Herausgeber) zu erwarten sind, bleibt dieser Punkt außen vor. Im Übrigen sind die Kriterien eng miteinander verwoben, weshalb in den meisten Fällen Teiltexte und Teil(text)handlungen einander entsprechen. Den im Folgenden genannten Aspekten kommt i. E. allerdings ein unterschiedlicher Stellenwert zu, wobei für die endgültige Gliederung letztlich wieder die Intuition entscheidend ist. Dementsprechend werden sie in dieser Reihenfolge (in absteigender Bedeutung) berücksichtigt:

1. (kognitives) Textsortenwissen (s. Abbildung 2: Grundstruktur römischer Briefe)

2. linear-sequenzieller Verlauf

3. logisch-funktionaler Zusammenhang

4. inhaltlich-thematischer Zusammenhang

5. grammatische Strukturierung:

- Rekurrenz

- (Ko-)Referenz

- Konnexion

- Wortstellung

Abbildung 13: Kriterien zur Abgrenzung von Teiltexten

\subsubsection{Funktionale Beziehungen zwischen den verschiedenen Handlungsebenen}

\subsection{Grundsätzliches zur Analyse der pragmatischen Briefstruktur}

Bei der Einteilung in Teiltexte wird der linear-sequenziellen Abfolge Vorrang vor logisch-funktionalen und inhaltlich-thematischen Zusammenhängen gegeben. ${ }^{829}$ Dadurch wird zum einen eine bessere Übersichtlichkeit gewährleistet. Zum anderen sollte ein Text ohnehin zunächst einmal in seiner gegebenen Form betrachtet werden. Obschon die drei Gliederungsprinzipien i. d. R. weitgehend miteinander korrelieren, kommen gleichwohl Brüche und Sprünge im

\footnotetext{
${ }^{828}$ Vgl. a. Kap. 1.3.4.2.1.

${ }^{829}$ Vgl. a. das Kap. „Prinzipien der Gliederung“ ab S. 59.
} 
Handlungsverlauf vor, und es bestehen auch sonst vielfältige Querverbindungen zwischen den einzelnen Handlungsebenen, welche in einem vereinfachten Aufbauschema (vgl. Abbildung 12) nicht angemessen repräsentiert werden können. Solche diskontinuierlich realisierten (hierarchischen) Beziehungen sollten ebenfalls in den Blick genommen werden, um die pragmatische Struktur eines Textes in seiner Gesamtheit zu erfassen. Eine umfassende Analyse gestaltet sich also äußerst komplex und ist im Rahmen dieser Arbeit nur eingeschränkt möglich. Im Wesentlichen wird sie sich auf eine Diskussion von Einzelfällen im Rahmen der Beispielanalysen beschränken, durch die der wechselseitige Einfluss der pragmatischen Einheiten auf den verschiedenen Handlungsebenen und ihre unterschiedliche Funktionalität in Abhängigkeit von der Stellung im Gesamtgefüge exemplarisch verdeutlicht werden können.

\subsection{Bestimmung der Handlungsfunktionen auf den untergeordneten Ebenen}

Da in dieser Arbeit keine umfassende Analyse der z. T. äußerst komplexen Handlungsstruktur der Briefe Ciceros angestrebt wird, reicht es aus, sich grob die wichtigsten Arten funktionaler Beziehungen zu vergegenwärtigen ${ }^{830}$ :

Die Handlungseinheiten eines Textes können im Verhältnis der funktionalen Nebenordnung oder Unterordnung zueinander stehen. Zu den untergeordneten Handlungseinheiten gehören zunächst einmal Einzel- und Teilhandlungen, welche die Akzeptanz des Autoranliegens erhöhen sollen, indem der Adressat durch sachliche Argumente überzeugt oder anderweitig (emotional) überredet wird, z. B. durch eine moralische Wertung („,Die Sache dient einem guten Zweck. “), die Würdigung der speziellen Fähigkeiten des Adressaten („Du machst das doch immer so schön!“) oder die Hervorhebung der persönlichen Bedeutsamkeit für den Autor („,Ich wäre glücklich, wenn ..."), für den Adressaten selbst („Du wärest bestimmt sehr froh, wenn...“) oder auch beide Seiten (,Wir würden uns sicherlich beide sehr freuen, wenn ..."). ${ }^{831}$ Indirekt wird die Erreichung des übergeordneten Ziels darüber hinaus durch kommunikative Klarheit gefördert. Grundvoraussetzung ist ja, dass der Adressat das Anliegen des Schreibers überhaupt versteht. Auf der Äußerungsebene können z. B. metasprachliche Einheiten den Textbzw. Handlungsaufbau verdeutlichen, auf semantischer Ebene zusätzliche Informationen und Erklärungen den Inhalt verständlicher machen. ${ }^{832}$

Ebenfalls indirekt unterstützend sind alle sprachlichen Handlungen zur allgemeinen Beziehungsgestaltung, die den Adressaten wohlgesonnen stimmen sollen - sowohl was das unmittelbar verfolgte Ziel als auch die langfristige Kontaktpflege betrifft. ${ }^{833}$ Dabei geht es v. a. um die Beachtung von (rituellen) Höflichkeitsregeln. Ob man solche pragmatischen Einheiten als

\footnotetext{
${ }^{830}$ Vgl. a. das Kap. „Subsidiäre Illokutionen“ ab S. 54.

${ }^{831}$ Hier wird nicht unterschieden zwischen „glaubensstützenden“ und „motivationsstützenden“ Illokutionen, weil diese Differenzierung für meine Zwecke nicht zielführend ist. In beiden Fällen geht es darum, dass der Adressat (v. a. durch verschiedene Arten der ,Begründung') davon überzeugt bzw. dazu überredet (oder motiviert) wird, das Anliegen des Autors zu erfüllen. Dieses Anliegen kann auch schlicht darin bestehen, dass der Adressat ihm Glauben schenkt. Zu Einzelheiten der Argumentationstheorie und den vielfältigen Arten von möglichen Argumenten sei im Übrigen auf die einschlägige Fachliteratur verwiesen. Hier geht es nur um die Verdeutlichung möglicher Prinzipien.

${ }^{832}$ Auch die manchmal separat angeführten ausführungssichernden Illokutionen können m. E. weitgehend hierunter subsumiert werden, da die Ausführung ja im Grunde dadurch gesichert wird, dass zusätzliche Informationen geliefert werden, die letzten Endes zum besseren Verstehen notwendig sind.

${ }^{833}$ Vgl. S. $117 f$.
} 
Teil der Handlungshierarchie betrachten sollte, ist allerdings umstritten, da sie häufig sehr unspezifisch und nur entfernt mit dem konkreten Anliegen des Textes verbunden sind. Schmitt spricht in diesem Zusammenhang von einer sekundären „spekulativen Hierarchie“, die zu unterscheiden sei von der primären „logischen Hierarchie“".834

Die Art der funktionalen Beziehungen ergibt sich meist intuitiv aus dem Kontext. ${ }^{835}$ Hilfreich bei der Bewertung können die Indikatoren sein, welche bereits im Zusammenhang mit der Abgrenzung von Teiltexten genannt wurden. ${ }^{836}$ Besonders interessant sind dabei die verschiedenen Verfahren zur Herstellung von Konnexion. ${ }^{837}$ Manchmal bleibt die Bestimmung dennoch schwierig, und nicht immer lassen sich die Hierarchie-Verhältnisse eindeutig nachvollziehen. ${ }^{838}$ Dies gilt umso eher, je komplexer die Handlungsstruktur eines Textes gestaltet ist, wenn also mehr als nur zwei oder drei Hierarchieebenen vorhanden sind. ${ }^{839}$ Probleme ergeben sich aber u. a. auch dadurch, dass „viele - vielleicht sogar alle - Sprechakte in außersprachliche Zielhierarchien eingebettet [sind], die z. T. weit über die in den Sprechakten verbalisierten Ziele hinausgehen. ${ }^{\text {} 840}$ Zudem kann die Art der funktionalen Beziehung bisweilen uneindeutig sein. So kann eine Äußerung wie „Du bist doch ein Experte auf dem Gebiet.“ (neben einer ironischen Interpretation) als reine Schmeichelei oder aber tatsächlich als objektives Argument gemeint sein.

Abbildung 14 soll die innerhalb der Handlungsstruktur möglichen funktionalen Beziehungen veranschaulichen. Die Übersicht erhebt keinen Anspruch auf Vollständigkeit, insbesondere was die dort aufgelisteten Untermuster betrifft. Diese sind im Gegensatz zu den Typisierungen der Münsteraner Schule nicht eindeutig (durch spezifische Handlungsbedingungen) definiert, weshalb $u$. a. einige Überschneidungen unvermeidlich sind. Bei den Bezeichnungen handelt es sich um keine festen Begriffe. Deshalb werden sie in Abgrenzung dazu nicht durch Versalien gekennzeichnet. Dies gilt auch für die Fälle, in denen sich Entsprechungen finden. Stellenweise werden dort nämlich durchaus (über die Einzelillokution hinausgehende) funktionale Beziehungen (z. B. BEGRÜNDEN) und sogar komplexe Typen bzw. übergreifende Sprechaktsequenzen (z. B. Begrüßungsrituale) berücksichtigt.

\footnotetext{
${ }^{834}$ Vgl. SCHMITT 2000, 188f. Zur Unterscheidung beider Formen führt er das sog. „Spekulationskriterium“ an: „Analog zu dem bei den indirekten Sprechakten eingeführten Absurditätskriterium lässt sich [...] ein Spekulationskriterium einführen, durch das eine logische (oder primäre) und eine spekulative (oder sekundäre) Hierarchie differenziert werden kann [!]. Trennkriterium ist die Frage, ob eine betreffende Struktur nur deshalb hierarchisch zu nennen sei, weil sie mit den für bestimmte Textsorten zu erwartenden Verhaltensmustern des Sprechers übereinstimmt (spekulative Hierarchie), oder ob sie erst durch eine hierarchische Ordnung Sinn ergibt (logische Hierarchie).“ (ebd., 189). Vgl. a. die Ausführungen in UNCETA GómEZ 2017b und UNCETA GómEZ 2014a zur „cortesía ritual“ bzw. „politesse rituelle“, die von der „cortesía estratégica“ bzw. „politesse stratégique“ abgegrenzt wird. ${ }^{835} \mathrm{Vgl}$. SCHMITT 2000, 182.

${ }^{836}$ Vgl. die Kap. „Abgrenzungs- und Gliederungskriterien“ ab S. 60 und „Abgrenzung von Teiltext(handlung)en“ ab S. 169. Vgl. a. Schmitt 185f., der im Zusammenhang mit der Hierarchisierung von Illokutionen in Anlehnung an die IFIDs (,illocutionary force indicating devices“) von HOIDs („,hierarchical order indicating devices“) spricht. ${ }^{837} \mathrm{Vgl}$. S. $63 \mathrm{ff}$.

838 Vgl. z. B. ebd., 182 und LANGEHEINE 1983b, 204 sowie auch BURKHARDT 1986, 407ff.

${ }^{839}$ Vgl. SCHMITT 2000, 188.

840 Ebd., 187.
} 


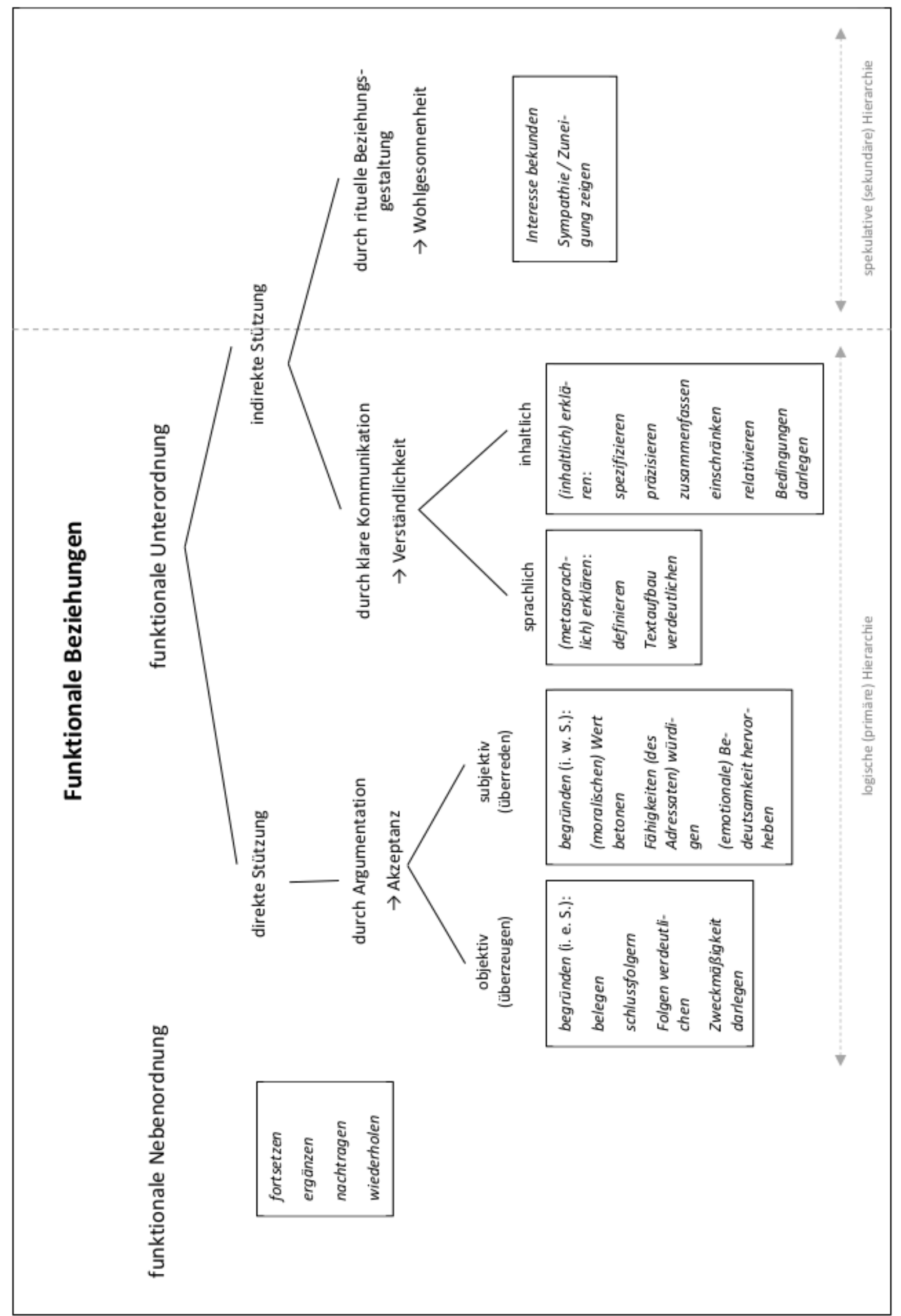

Abbildung 14: Funktionale Beziehungen (teilweise angelehnt an SCHRÖDER 2003, 49 und SCHMITT 2000, 179ff.) 


\subsubsection{Bestimmung der Textfunktion}

An oberster Stelle in der Handlungshierarchie stehen die Textfunktionen, welche den jeweiligen Brieftyp bestimmen. In grober Anlehnung an Brinker ergibt sich folgende Kategorisierung $^{841}$ :

\begin{tabular}{|lll|}
\hline Informationsfunktion & $\rightarrow$ & Informationsbrief \\
\hline Aufforderungsfunktion & $\rightarrow$ & Aufforderungsbrief \\
\hline Kontaktfunktion & $\rightarrow$ & Kontaktbrief \\
\hline keine dominante Textfunktion erkennbar & $\rightarrow$ & multifunktionaler Brief \\
\hline
\end{tabular}

Abbildung 15: Textfunktionen und Brieftypen

Sie entspricht im Wesentlichen der Sprechaktklassifikation Searles. Die anderen Bezeichnungen dienen v. a. der deutlicheren Abgrenzung von Textfunktion und untergeordneten Funktionen.

Die Textfunktion lässt sich i. d. R. nicht einfach aus den Funktionen der Einzel- und Teilhandlungen ableiten. Bei ihrer Erschließung müssen viele weitere Aspekte berücksichtigt werden. ${ }^{842}$ Die wichtigsten Indikatoren der Textfunktion sind:

- Kontext

- pragmatische Struktur: Art, Distribution und Hierarchie der Handlungsfunktionen

- inhaltlich-thematische Struktur (Kohärenz): Formen der Themenentfaltung, thematische Einstellung, ...

- grammatische Struktur (Kohäsion): Hierarchiehinweise (z. B. durch Konnektoren), ...

Abbildung 16: Indikatoren der Textfunktion

Insgesamt ist das Spektrum an möglichen Indikatoren der Textfunktion sehr vielfältig. ${ }^{843}$ Was fam. 14 angeht, entfallen jedoch einige Punkte. So gibt es zwar Musterhinweise (z. B. die rituellen Gruß- und Wohlergehensformeln), die deutlich anzeigen, dass es sich bei den Texten um Briefe handelt. Damit ist aber nur die Kommunikationsform festgelegt, die hinsichtlich der Textfunktion weitgehend indifferent ist. Titel i. e. S. gibt es ebenfalls nicht.

Insbesondere wenn die Textfunktion nur undeutlich signalisiert wird und verdeckt ist oder wenn sie durch konkurrierende Zusatzfunktionen „angereichert“ ist und mehrere Deutungen möglich sind ${ }^{844}$, was ja auf viele der meist multifunktionalen Familienbriefe ${ }^{845}$ im vorliegenden

${ }^{841}$ Vgl. die Kap. „Textfunktionen“ ab S. 47, bes. ab S. 49 (zu Brinker) sowie „Brieftypen und Brieffunktionen“ ab S. 110. Briefe mit dominanter Obligations- oder Deklarationsfunktion sind im Analysekorpus ebenso wenig vertreten wie ästhetische Briefe, weshalb sie hier unberücksichtigt bleiben. Dazu und zum Begriff ,Aufforderungsbrief' bzw. ,Aufforderungsfunktion' (statt ,Appellbrief' bzw. ,Appellfunktion') vgl. a. N. 597.

${ }^{842}$ Vgl. das Kap. „Definition und Bestimmung der Textfunktion“ ab S. 47, bes. S. $48 f$.

${ }^{843}$ Vgl. z. B. HAUSENDORF UND KESSELHEIM 2008, 139: „Alles, was dazu beiträgt, den Text als einen in spezielle Zwecksetzungen eingebetteten Zusammenhang von Sprachhandlungen erkennbar zu machen, kommt [...] prinzipiell als Hinweis auf Textfunktionen in Betracht."

${ }^{844} \mathrm{VgI}$. SANDIG 2006, 326ff. (zu „stilistischen Abwandlungen des Hinweisens auf die Textfunktion“) und BURKHARDT 1986, 398ff.

${ }^{845}$ Vgl. das Kap. „Multifunktionale Briefe“ ab S. 116. 
Analysekorpus zutrifft, entscheidet der Leser v. a. auf Grundlage des Kontextes, wie er den betreffenden Brief aufzufassen hat. ${ }^{846}$ Dies geschieht häufig sogar in schwierigen Fällen automatisch und intuitiv, d. h., der Adressat erkennt i. d. R. sofort, was der Briefschreiber ihm sagen will. ${ }^{847} \mathrm{Ob}$ eine wissenschaftlich exakte Kategorisierung allerdings genauso schnell und einfach möglich ist, steht auf einem anderen Blatt, zumal dabei auch noch offengelegt werden muss, wie genau die Entscheidung zustande kommt.

${ }^{846}$ Vgl. a. S. 118 zu einer möglichen allgemeinen Hierarchie der Brieffunktionen, bei welcher der Aufforderungsfunktion Vorrang vor der Informationsfunktion eingeräumt wird, die wiederum gegenüber der Kontaktfunktion dominant ist.

${ }^{847}$ Vgl. HAUSENDORF UND KeSSELHEIM 2008, 139. Vgl. a. BURKHARDT 1986, 398ff. und SZWEd 2014, 165 bzW. HARTUNG 2000 - 2001, 90. 


\section{Praktischer Teil: Analysen und Interpretationen}

\subsection{BEISPIELANALYSEN}

Für die Beispielanalysen wurden drei Briefe ausgewählt, die (nicht nur) in sprechakttheoretischer Hinsicht einen guten Eindruck von der Vielfalt des Analysekorpus vermitteln, indem sie ein großes Spektrum an verschiedenen Einzelillokutionen mit jeweils unterschiedlicher Dominanz und spezifisch ausgeprägten (Teil-)Textfunktionen abdecken. Dadurch, dass die Briefe vom kurzen „Billett“ bis hin zu einem vergleichsweise langen Schreiben reichen, können Unterschiede in der Komplexität der pragmatischen Struktur gut verdeutlicht werden. Die Tatsache, dass die Briefe verschiedenen Lebensphasen Ciceros (und damit unterschiedlichen Kontexten) entstammen, erweitert die Aussagekraft hinsichtlich der Analyse des Verhältnisses zwischen Cicero und Terentia.

Begonnen wird mit dem recht gut überschaubaren Brief fam. 14.20. Dabei werden quasi die Grundlagen gelegt für die beiden folgenden Analysen (fam. 14.5 und 14.2), die zunehmend weiter in die pragmatischen Untiefen eintauchen, mit anderen Worten immer umfassender und komplexer werden. Die Verfahren zur Illokutionsidentifikation werden zu Anfang anhand einzelner Beispiele etwas detaillierter expliziert, danach lediglich noch in komplizierteren Zweifelsfällen. Die Handlungsbedingungen eines Sprechaktuntermusters werden i. E. nur dann angeführt, wenn es zum ersten Mal in den Fokus einer ausführlicheren handlungsfunktionalen Analyse gerät. Im Übrigen wird auf die geordnete Zusammenschau in Kap. 2.2 („Ergebnisse aller Detailanalysen im Überblick“) sowie die Übersicht „Definitionen der Sprechaktuntermuster (gem. Münsteraner Schule)“ im Anhang verwiesen. Ähnliches gilt auch für alle weiteren Ausführungen.

\subsubsection{Beispiel 1: Fam. 14.20 \\ 2.1.1.1 Situativer Kontext}

Nach Ausbruch des Bürgerkriegs begibt sich Cicero (angesichts seiner erfolglosen Vermittlungsversuche zwischen den gegnerischen Parteien) im Juni 49 zu Pompejus nach Griechenland. In Folge von dessen Niederlage bei Pharsalus im August 48 reist er nach Brundisium, wo er auf die Begnadigung durch Cäsar wartet, die er im Jahre 47 nach einem (etwa am 25. September stattfindenden) gemeinsamen Treffen erlangt. Den Brief schreibt er am 1. Oktober auf seinem Weg zurück nach Rom - begleitet von seiner Tochter Tullia - während eines Zwischenstopps in der Gegend von Venusia. ${ }^{848}$

\subsubsection{2 Übersichtsschemata}

\subsubsection{1 Überblick über die Einzelillokutionen}

\begin{tabular}{|l|l|l|l|}
\hline Nr. & Text & Oberklasse & Untermuster \\
\hline$(1)$ & TULLIUS S. D. TERENTIAE SUAE & deklarativ & BRIEF ERÖFFNEN \\
\hline$(2)$ & In Tusculanum nos venturos putamus aut Nonis aut postridie. & assertiv & PROGNOSTIZIEREN \\
\hline$(3)$ & ibi ut sint omnia parata. & direktiv & BITTEN \\
\hline$(4)$ & plures enim fortasse nobiscum erunt & assertiv & PROGNOSTIZIEREN \\
\hline$(5)$ & et, ut arbitror, diutius ibi commorabimur. & assertiv & PROGNOSTIZIEREN \\
\hline
\end{tabular}

${ }^{848}$ Vgl. z. B. Shackleton Bailey in CICERO 1977, 594 und Tyrrell / Purser in CICERO 1904 - 1933, IV 347. 


\begin{tabular}{|l|l|l|l|}
\hline (6) & labrum si in balineo non est, ut sit; & direktiv & BITTEN \\
\hline (7) & item cetera quae sunt ad victum et ad valetudinem necessaria. & direktiv & BITTEN \\
\hline$(8)$ & Vale. & deklarativ & BRIEF BEENDEN \\
\hline$(9)$ & Kal. Oct. de Ven $\langle u\rangle$ sino. & assertiv & HINWEISEN \\
\hline
\end{tabular}

Abbildung 17: Gesamtübersicht fam. 14.20 (Einzelillokutionen)

2.1.1.2.2 Überblick über den Briefaufbau

Cicero fordert Terentia auf, die notwendigen Vorkehrungen für seine Ankunft auf dem Tusculanum zu treffen (Aufforderung) - indem

\begin{tabular}{|lc|}
\hline $\begin{array}{l}\text { [A] er den Brief eröffnet } \\
\rightarrow \text { deklarativ: BRIEF ERÖFFNEN, indem (1) }\end{array}$ & Ebene 2 \\
\begin{tabular}{|l|l|} 
und \\
dann
\end{tabular} \\
$\begin{array}{l}\text { [B] Terentia bittet, alles Notwendige vorzubereiten, } \\
\rightarrow \text { direktiv: BITTEN, indem (2) - (7) | vgl. Abbildung 19 }\end{array}$ & Ebene 2 \\
\hline $\begin{array}{l}\text { [C] den Brief beendet. } \\
\text { dann }\end{array}$ \\
\hline deklarativ: BRIEF BEENDEN, indem (8) - (9)
\end{tabular}

Abbildung 18: Briefaufbau fam. 14.20 (Teiltexte)

\subsubsection{Sprechhandlungsanalyse}

\subsection{Einzelhandlungen: Illokutionsidentifikation und -klassifikation}

Teiltext $[\mathrm{A}]$

(1): Der Status der rituellen Begrüßungsformel als Einzelillokution ergibt sich automatisch daraus, dass es sich hierbei um einen konventionell (auch handlungsfunktional) zusammengehörigen Briefbestandteil handelt. ${ }^{849}$ Der direkte Sprechakt ist assertiver Natur und benennt Absender (TULLIUS) sowie Empfänger (TERENTIAE SUAE). Denkbar wäre zudem eine Interpretation als metakommunikativer Sprechakt, mit dem auf den Beginn des Briefes hingewiesen und somit die Textstruktur verdeutlicht wird. Die Hauptfunktion der Äußerung ist aber in erster Linie darin zu sehen, den BRIEF zu ERÖFFNEN, weshalb sie als (indirekter) deklarativer Sprechakt klassifiziert wird. ${ }^{850}$ Hinzu kommen noch eine direktive Komponente („,Lies bitte den folgenden Text!“) und eine kommissive Komponente („Hiermit lege ich mich darauf fest, - mit den folgenden Zeilen - einen Brief zu schreiben."), die aber schwerlich als dominant erachtet werden können. Eine besondere expressive Komponente ist ebenso wenig festzustellen. Lediglich der Gebrauch des Vornamens Tullius und des Possessivpronomens suae sind Zeichen der Vertrautheit, die jedoch in Bezug auf nahestehende Personen im Grunde Standard sind. 851

\footnotetext{
${ }^{849}$ Zu den folgenden Ausführungen vgl. a. das Teilkap. „Briefbeginn und -schluss“ ab S. 127.

${ }^{850}$ Zwar fehlt die typische institutionelle Einbindung. Dies gilt aber auch für andere deklarative Sprechhandlungen wie BÜFFET ERÖFFNEN (z. B. auf einer privaten Geburtstagsfeier). Zu den Deklarativa ist bislang keine Studie der Münsteraner Schule erschienen. Eine eigene Definition der exakten Handlungsbedingungen für die Sprechakte BRIEF ERÖFFNEN und BRIEF BEENDEN kann in dieser Arbeit nicht geleistet werden, weil dazu ein Überblick über sämtliche (anderen) deklarativen Sprechaktuntermuster, die (im Lateinischen) existieren, notwendig ist, von denen jene i. E. abzugrenzen wären.

${ }^{851}$ Der Vorname Tullius findet sich sonst nur noch in den Grußformeln in fam. 16 (Briefe an Tiro). Zum Possessivpronomen vgl. z. B. GUGLIELMI 2013, 209f. und CUGUSI 1983, 48.
} 
Deshalb ist nicht, wie z. B. in fam. 14.2, vom Untermuster (SPRACHLICHE) GUNST ERWEISEN auszugehen, mit dem ein intensives (emotionales) Verhältnis zum Adressaten ausgedrückt wird. ${ }^{852}$

Ebenfalls kaum in Frage kommt das Untermuster (jemanden) WILLKOMMEN HEISSEN, welches durch folgende Handlungsbedingungen definiert ist:

„B1: Es geht eine Handlung H voraus, für die Sp2 verantwortlich und von der Sp1 betroffen ist.

B2: Sp1 bewertet $\mathrm{H}$ bzw. die Folgen von $\mathrm{H}$ positiv für sich selbst.

B3: Sp1 freut sich über H. “853

WILLKOMMEN HEISSEN bezieht sich demnach auf eine vorhergehende Handlung des Adressaten, wie z. B. das Erscheinen auf einer Geburtstagsfeier, über das der Sprecher (als Gastgeber) seine Freude äußert. ${ }^{854}$ Selbst wenn die Expressivität in der Begrüßungsformel stärker ausgeprägt wäre, bleibt fraglich, ob man die Definition auf Briefe übertragen kann (Ausdruck der Freude über das In-Kontakt-Treten?), da ja tatsächlich - abgesehen evtl. von einem früheren Brief, auf den der Sprecher Bezug nimmt - keine Handlung des Adressaten vorausgeht, wobei der Begriff ,WILLKOMMEN HEISSEN` im Zusammenhang mit schriftlicher Kommunikation ohnehin unglücklich gewählt wäre.

Auf die Annahme eines eigenen Sprechaktuntermusters (jemanden) ,BEGRÜSSEN` wird in dieser Arbeit verzichtet, jedenfalls soweit darin ein expressiver Sprechakt gesehen werden sollte. ${ }^{855}$ Geht man hingegen davon aus, dass (jemanden) ,BEGRÜSSEN` v. a. bedeutet, ein Gespräch zu beginnen, kann man auch von einem deklarativen Sprechakt sprechen und, BEGRÜSSEN`quasi als Synonym für, GESPRÄCH ERÖFFNEN` bzw. ,BRIEF ERÖFFNEN` betrachten. ${ }^{856}$

\footnotetext{
${ }^{852}$ Vgl. Kap. 2.1.3.2.3 (zu fam. 14.2 (1)).

853 MARTEN-CLEEF 1991, 177. Die genannten Handlungsbedingungen gelten für das übergeordnete Sprechaktmuster WILLKOMMEN HEISSEN, das Marten-Cleef unterteilt in die Untermuster, (jd.) WILLKOMMEN HEISSEN` und ,(etw.) BEGRÜSSEN`. Vgl. a. S. 192.

${ }^{854}$ Vgl. ebd., 177: „Situativer Kontext in WILLKOMMEN HEISSEN schlechthin ist, daß Sp2 als Gast in die Wohnung oder zu einer Veranstaltung von Sp1 kommt. Neben dem Anlaß ,Besuch` gibt es aber auch andere Handlungen, deren Erwünschtheit Sp1 durch WILLKOMMEN HEISSEN bekundet.“

${ }^{855}$ So werden GRÜSSEN und BEGRÜSSEN z. B. im „Lexikon der illokutiven Typen“ in WAGNER 2001 zu den expressiven Sprechakten gezählt (ebd., 234 bzw. ebd., 188). Vgl. a. N. 856. Das hier angesprochene Untermuster, jemanden BEGRÜSSEN` ist im Übrigen nicht zu verwechseln mit ,(etwas) BEGRÜSSEN`, einer Unterkategorie von ,WILLKOMMEN HEISSEN`. Vgl. a. N. 853 und Kap. 2.1.2.3.1 (zu fam. 14.5.1 (10)).

${ }^{856}$ Eine Begrüßung als übergeordnetes Begrüßungsritual besteht meist aus einer Sequenz mit mehreren Sprechakten, zu denen u. a. WILLKOMMEN HEISSEN zählt. Vgl. z. B. MARTEN-CLEef 1991, 178f. (mit Bezug auf SEARLE UND VANDERVEKEN 1985): „JEMANDEN WILLKOMMEN HEISSEN wird vollzogen im Zusammenhang eines BEGEGNUNGSRITUALS, der BEGRÜSSUNG oder des BEGRÜSSUNGSRITUALS. Für diese Grußhandlungen ist typisch, daß sie den Übergang von Nicht-Interaktion zu Interaktion regeln. Es empfiehlt sich, zwischen ,Initialgrüßen` oder ,Begegnungsgrüßen' (BEGRÜSSEN) und ,Abschieds- oder Terminalgrüßen` (VERABSCHIEDEN) zu differenzieren. Für Grußhandlungen ist allgemein [...] ein hoher Grad an Stereotypizität charakteristisch, der sich vor allem aus ihrer Stellung an den Interaktionsgrenzen ergibt. Aufgrund der Stellung am Beginn der Interaktion gehört JEMANDEN WILLKOMMEN HEISSEN zum Sprachspiel des BEGRÜSSENS. BEGRÜSSEN und WILLKOMMEN HEISSEN sind aber durchaus nicht gleichzusetzen, weil es sich bei BEGRÜSSEN nicht um eine expressive Sprechhandlung handelt. In SEARLE/VANDERVEKEN (1985: 215) wird greet nicht als echter illokutionärer Akt angesehen, weil es keinen propositionalen Gehalt habe. Um einen expressiven Sprechhandlungstyp handele es sich deshalb nicht, weil durch seinen Vollzug nicht ein Gefühl ausgedrückt werde, sondern das (Wieder-)Erkennen des anderen in höflicher Form. Demgegenüber könne welcoming als Sprechakt verstanden werden, mit dem der Sprecher Freude
} 
Teiltext [B]

(2): Die Hauptinformation (nos venturos putamus) wird lokal (in Tusculanum) und temporal (aut Nonis aut postridie) spezifiziert. Theoretisch könnte man drei Informationen unterscheiden und die Einheiten folgendermaßen erweitern: "Wir bzw. ich werde(n) kommen. ", „Ich werde mich auf das Tusculanum begeben." und "Ich werde wahrscheinlich am 7. (Oktober) oder am folgenden Tag eintreffen." Sie sind jedoch kaum sinnvoll voneinander zu trennen. Für Terentia ist wohl nur die Angabe des voraussichtlichen Zeitpunkts von Ciceros Ankunft neu und relevant, welche auch durch die Position am Ende des Satzes hervorgehoben wird. Disjunktive Verbindungen (aut ... aut) können nicht aufgelöst werden, da sich ihre Bedeutung ja gerade aus der Zusammensetzung der einzelnen Bestandteile ergibt. Eine untrennbare Einheit bilden grundsätzlich auch $\mathrm{Acl}$ (als erweitertes Akkusativobjekt) und übergeordnetes Prädikat. Im vorliegenden Fall drückt putamus - ähnlich einem Modalwort wie, vielleicht' oder ,voraussichtlich`- lediglich die Einstellung Ciceros hinsichtlich der Wahrscheinlichkeit der Proposition aus, vermittelt also keine unabhängige Information.

Cicero möchte Terentia mit (2) über seine bevorstehende Ankunft auf dem Tusculanum informieren (assertive Oberklasse). Der Sprechakt kann dem (i. e. S.) assertiven Untermuster PROGNOSTIZIEREN zugeordnet werden. ${ }^{857}$ Der Inhalt bezieht sich auf die Zukunft (venturos). Mit putamus wird Unsicherheit hinsichtlich der genauen Ankunftszeit zum Ausdruck gebracht. Damit wird deutlich, dass es sich nicht um das ebenfalls zukunftsbezogene transmissive Untermuster ANKÜNDIGEN ${ }^{858}$ handeln kann, obschon Ciceros Aussage im Übrigen recht bestimmt klingt. Genauso wenig kommt eine kommissive ABSICHTSBEKUNDUNG in Frage, die ja u. a. auch eine informative Komponente enthält und für die ebenfalls Aussagesatz und $\mathrm{Acl}$ sowie der Zukunftsbezug typisch sind. Die Handlungsbedingungen für das Sprechaktuntermuster ABSICHT BEKUNDEN lauten:

„B1: Sp1 glaubt, Sp2 habe am Vollzug der angekündigten Handlung $\mathrm{H}$ kein unmittelbares eigenes Interesse.

B2: Sp1 glaubt, Sp2 werde sich auf den Vollzug von $\mathrm{H}$ nicht verlassen.

B3: $\mathrm{H}$ ist nicht gegen die unmittelbaren eigenen Interessen von $\mathrm{Sp} 2$ gerichtet.

ausdrückt: [...]. “ Hieraus erhellt sich auch die Nähe zu den deklarativen Sprechakten, sowohl was einzelne Sprechakte als auch die Begrüßungsrituale als Ganzes betrifft. In römischen Briefen können Letztere z. B. aus der (wie auch immer klassifizierten) Begrüßungsformel, einer Wohlergehensformel und einer Einleitungssequenz als Übergang zum Hauptteil (vgl. Abbildung 2: Grundstruktur römischer Briefe) bestehen. Ähnliches gilt für den Briefschluss (Schlusssequenz + Wohlergehens- und Verabschiedungsformel), der als (deklaratives) Abschiedsritual verstanden werden kann. Vgl. a. Kap. 2.1.1.3.2.

${ }^{857}$ Zu den Assertiva (i. e. S.) allgemein vgl. Rolf 1983, 97: „Mit einer assertiven Informationshandlung [...] gibt S zu verstehen, daß die Herleitung der Proposition $\mathrm{p}$ möglich ist [...]. Das mit einer solchen Informationshandlung verfolgte Ziel ist dementsprechend, daß H (im starken Sinne) glaubt, daß die Herleitung von p möglich ist [...].“ Als spezifisches Merkmal des Untermusters PROGNOSTIZIEREN gilt: „p bezieht sich auf einen künftigen Sachverhalt." (ebd., 163). Vgl. a. S. 35 und die Definitionen im Anhang.

858 Zu den Transmissiva allgemein vgl. ebd., 164: „S [bringt] mit einer eine Handlung dieser Art realisierenden Äußerung zum Ausdruck, daß er um das tatsächliche Bestehen des durch $p$ bezeichneten Sachverhalts weiß. Dementsprechend soll auch $\mathrm{H}$ registrieren, daß p." Als spezifisches Merkmal des Untermusters ANKÜNDIGEN gilt: „p bezieht sich auf etwas Zukünftiges“ (ebd., 175). Vgl. a. S. 35 und die Definitionen im Anhang. 
B4: H ist eine zukünftige Handlung von Sp1, für deren Vollzug Sp1 unmittelbar selbst verantwortlich ist.

B5: $H$ ist keine auf Dauer und Kontinuität angelegte Handlung, deren Vollzug Sp1 subjektiv Schwierigkeiten bereitet.

B6: Sp1 ist nicht gegenüber Sp2 verpflichtet, $\mathrm{H}$ zu tun.

B7: Sp2 ist bezüglich H gegenüber Sp1 gleichgeordnet, er hat keine Sanktionsgewalt. Der Vollzug von $\mathrm{H}$ kann jedoch abhängig sein von einer Erlaubnis durch Sp3, die (i) bereits vorliegt oder (ii) noch von Sp1 einzuholen ist.

B8: Sp1 will Sp2 über die von ihm in Aussicht genommenen Handlungen ,informieren', ihm eine ,Orientierung' bezüglich seines eigenen, zukünftigen Verhaltens geben. " ${ }^{1859}$

Es bestehen also gewisse Parallelen zwischen den Sprechakttypen. Aber zunächst einmal kann Cicero wohl davon auszugehen, dass Terentia seine Ankündigung nicht in Frage stellen wird, womit die zweite Bedingung für das Untermuster ABSICHT BEKUNDEN nicht erfüllt ist. V. a. jedoch steht $\mathrm{m}$. E. der Aspekt der Informationsvermittlung und nicht eine irgendwie geartete (motivationale) Selbstverpflichtung im Vordergrund.

(3): Die Konstruktion begegnet eher selten im klassischen (und nachklassischen) Latein. Man könnte einen Imperativ wie fac oder cura ergänzen. ${ }^{860} \mathrm{Im}$ Vergleich zu einem einfachen Imperativsatz stellt der Finalsatz (mit evtl. übergeordnetem Imperativ) nur eine stilistische Variante dar und repräsentiert ebenso nur eine Illokution, bestehend aus dem Kernsatz (sint omnia parata) mit lokaler Spezifizierung (ibi). Grammatischer Indikator für den direktiven Charakter ist der Konjunktiv, der im vorliegenden Zusammenhang final aufzufassen ist. Die Aufforderung ist durch keinerlei Höflichkeitsformeln und -floskeln abgemildert, sondern sogar noch verstärkt durch das umfassende omnia. Sie entspricht mithin kaum dem, was wir konventionellerweise unter einer Bitte verstehen, erfüllt aber (zumindest teilweise) die Handlungsbedingungen für eine (SYMMETRISCHE) BITTE:

„B1: Sp1 hat ein direktes und persönliches Interesse daran, daß Sp2 Xt.

B2: Sp2 hat kein direktes oder persönliches Interesse an der Ausführung von X oder dem entsprechenden Handlungsergebnis.

B3: Sp2 ist nicht verpflichtet zu X-en. Sp1 verfügt nicht über die Sanktionsmöglichkeiten, durch die er AUF Nachdruck verleihen könnte.

B4: Aufgrund der Rollen- und Statusbeziehung zwischen Sp1 und Sp2 wäre es denkbar, daß sich auch Sp2 in einer analogen Situation mit einer Aufforderung zum X-en an Sp1 gewandt hätte. “861

\footnotetext{
859 GRAFFE 1990, $116 f$.

860 GUGLIELMI 2013, 328 meint, dass man diese Konstruktion entweder als einfache Ellipse oder als historisches Überbleibsel aus der Zeit des Übergangs von der Parataxe zur Hypotaxe erklären könne. Vgl. a. Shackleton Bailey in CICERO 1977, 504, der (mit Verweis auf KüHNER UND STEGMANN 1966, § 147) ebenfalls darauf aufmerksam macht, dass sie auf die Vorklassik beschränkt sei, als weitere Ausnahme aber eine Stelle aus Varros Res Rusticae (rust. 1.69.1) zitiert. Vgl. außerdem Tyrrell / Purser in CICERO 1904 - 1933, IV 347. Die Imperative fac und cura gehören im Übrigen zu den sog. Metadirektiva (mit Bezug auf die Perlokution): Vgl. dazu N. 959.

${ }^{861}$ HINDELANG 1978, 504, wobei AUF = Aufforderung, X = die entsprechende Sprechhandlung.
} 
Cicero hat im Gegensatz zu Terentia in der Tat „ein direktes und persönliches Interesse“ an den Vorbereitungen für seine Ankunft (B1 und B2). Schwieriger wird es bei der Beurteilung der Frage, ob Terentia dazu verpflichtet ist und ob sie sich umgekehrt genauso an Cicero hätte wenden können (B 3 und B4). Hier stößt die Klassifikation der Münsteraner Schule an ihre Grenzen, da sie den Besonderheiten der römischen Gesellschaft und Kultur nur bedingt gerecht wird. Doch auch wenn die rechtliche Stellung der Frau im alten Rom eine andere als bei uns war, möchte ich solche Äußerungen dennoch als nicht-bindende Aufforderungen klassifizieren. Das Verhältnis zwischen Cicero und Terentia ist z. B. kaum mit dem zwischen Feldherrn und untergebenen Soldaten vergleichbar und ähnelt in vielen Belangen tatsächlich einer durch Zuneigung geprägten gleichberechtigten Freundschaft ${ }^{862}$, sodass man durchaus von einer SYMMETRISCHEN BITTE sprechen und sich bspw. eher ein rogo te oder oro te als ein impero als Ergänzung denken kann. ${ }^{863}$

(4) und (5): (4) ist zwar parataktisch mit (5) verbunden, besitzt jedoch einen eigenständigen Informationswert, welcher in einer Angabe der Größe der Reisegruppe (plures erunt) besteht. Als weitere Information wird in (5) die Aufenthaltsdauer (diutius) genannt, die noch mal andere Auswirkungen auf die Art der notwendigen Vorbereitungen Terentias hat. Die Unabhängigkeit von (4) wird dadurch unterstrichen, dass (5) durch die Parenthese ut arbitror mit einer eigenen propositionalen Einstellung verbunden wird, wenngleich diese letztlich mit fortasse in (4) identisch ist. Der Fokus in (5) liegt auf diutius, das eng mit dem Prädikat (commorabimur) verbunden ist. Neben der temporalen findet sich erneut die lokale Spezifizierung $i b i$. Die Hauptinformation in (4) wird (abgesehen von fortasse) modal durch nobiscum ergänzt. (4) und (5) führen die in (2) gemachte allgemeine Aussage unter Angabe von Details weiter aus. Die Zuweisung zum Untermuster PROGNOSTIZIEREN erfolgt aufgrund der bereits beschriebenen Überlegungen.

(6) und (7): Konditionalsätze wie in (6) sind untrennbar mit dem übergeordneten Satz verbunden, indem sie die notwendigen Handlungsbedingungen bzw. -voraussetzungen festlegen, und besitzen demnach keinen eigenen Illokutionsstatus: (Nur) wenn keine Wanne vorhanden ist, muss eine beschafft werden. Mit der Ergänzung in balineo wird der örtliche Bezug präzisiert. Im Übrigen sei auf das bereits zu (3) Gesagte verwiesen. Die Aufforderung in (7), welche allgemein auf alle übrigen zu erledigenden Aufgaben (cetera) hinweist, ist noch stärker verkürzt als (3) und (6). Sie könnte in etwa wie folgt ausformuliert werden: Cura, ut item cetera parata sint. Mit dem restringierenden Attributsatz werden diese Aufgaben eingegrenzt. Die Aufzählung ad victum et ad valetudinem ist als - durch Rekurrenz (Wortwiederholung und Alliteration) unterstrichene - informationelle und illokutionäre Einheit (,leibliches Wohlergehen ") zu betrachten. Die beiden BITTEN stellen eine Fortsetzung bzw. Präzisierung von (3) dar. (6) ist dabei in Anlehnung an (3) konstruiert, während in (7) sogar das Prädikat im Konjunktiv

\footnotetext{
${ }^{862} \mathrm{Vgl}$. bes. Kap. 2.2.2. Hinzu kommt, dass unklar bleiben muss, welche Art von Ehe zwischen Cicero und seiner Frau geschlossen wurde, inwieweit Terentia also tatsächlich der potestas Ciceros unterstand.

$863 \mathrm{Im}$ Folgenden wird nur noch verkürzt von BITTEN die Rede sein. Hier wird also nicht weiter unterschieden zwischen SYMMETRISCHEN und ASYMMETRISCHEN BITTEN, wobei letztere nach Hindelang dadurch definiert sind, dass sich der Adressat (und nicht der Sprecher!) in einer superioren Position befindet.
} 
ausgelassen wird. Die Direktivität wird stattdessen durch necessaria unterstrichen und erschließt sich im Übrigen leicht aus einer Parallelisierung mit (3) und (6).

Teiltext [C]

(8): Wie bei (1) handelt es sich um eine übliche rituelle Grußformel ohne spezielle Erweiterung. Der Imperativ vale signalisiert zunächst (direkt) einen direktiven Sprechakt. Eigentlich wird damit aber ein Wohlergehenswunsch („Ich wünsche dir, dass du gesund bleibst!“) formuliert, weshalb die Zuordnung zum expressiven Sprechaktuntermuster GUTEN WUNSCH ÄUSSERN näher liegt, für das folgende Handlungsbedingungen gelten:

„B1: Der Sprecher Sp1 antizipiert einen zukünftigen Sachverhalt S, von dem der Adressat Sp2 betroffen ist. Sp1 ist nicht, Sp2 ist nicht bzw. nicht allein verantwortlich für das (So-)Eintreten von S.

B2: Sp1 bewertet S positiv für Sp2 und positiv im Rückbezug auf sich selbst.

B3: Sp1 erhofft S." 864

Ähnlich wie bei (1) liegt hier allerdings eine stark standardisierte (Abschieds-)Grußformel vor, die kaum mehr expressiven Charakter trägt, sondern in erster Linie als neutraler deklarativer Sprechakt BRIEF BEENDEN zu interpretieren ist. ${ }^{865}$

(9): Das (elliptische) Postskript enthält zwei verschiedene Angaben, nämlich Datum und Ort der Briefabfassung, die jedoch als konventionell zusammengehörig betrachtet werden können. Die Information ist insofern von Bedeutung, als Terentia so z. B. besser abschätzen kann, wie aussagekräftig Ciceros Angaben zu seiner voraussichtlichen Ankunftszeit sind. ${ }^{866}$ Es liegt ein transmissiver Sprechakt vor. Die Information ist dabei mehr als „interessant" und geht über eine bloße MITTEILUNG hinaus, für die gilt: „S ist zur Weitergabe von p nicht verpflichtet;

\footnotetext{
${ }^{864}$ MARTEN-CLEEF 1991, 167. Im vorliegenden Fall handelt es sich um einen WOHLERGEHENSWUNSCH, von dem GELINGENSWÜNSCHE abzugrenzen sind. Zu Ersterem vgl. a. ebd., 163: „WOHLERGEHEN WÜNSCHEN wird vollzogen anläßlich allgemeiner Festtage, zu Beginn neuer Zeitspannen und an individuellen Eckdaten im Leben eines Menschen (FESTTAGSWUNSCH) sowie bei Tisch (TISCHWUNSCH), wobei WÜNSCHE zum Essen und zum Trinken unterschieden werden können. Ebenfalls zum Untertyp WOHLERGEHEN WÜNSCHEN wird der GENESUNGSWUNSCH gezählt, der allerdings schon in der Nähe zu GELINGEN WÜNSCHEN steht (je nach Einschätzung des Gesundwerdens als Ergehen oder als Tätigkeit: vergleiche dazu die Äußerungsformen ,Gesundheit!' versus ,Gute Besserung!')." Außerdem merkt sie an, „daß sich der expressive WUNSCH von direktiven und kommissiven Sprechakten unterscheidet, daß mit ihm ein Gefühl wie Hoffnung oder Wohlwollen zum Ausdruck gebracht wird. Da der erhoffte Sachverhalt weder im Kompetenzbereich des Adressaten noch des Sprechers selbst liegt, sondern im wesentlichen von außerpersonalen Einflüssen abhängt, handelt es sich beim expressiven WUNSCH nicht um einen Versuch, den Adressaten zu einer Handlung zu veranlassen, und nicht um einen Sprechakt, mit dem der Sprecher sich selbst auf eine zukünftige Handlung festlegt.“ (ebd., 160). Vgl. des Weiteren N. 865.

${ }^{865}$ Vgl. a. ebd., 163ff. zum Unterschied zwischen GRÜSSEN und GUTEN WUNSCH ÄUSSERN. Nach ebd., 164f. ist es beim GRÜSSEN im Gegensatz zum GUTEN WUNSCH üblich, die entsprechende Formel (in einer Art Echo) zu wiederholen (z. B. „Guten Tag!“ - „Guten Tag!“), während umgekehrt auf einen GUTEN WUNSCH meist ein DANKEN folgt. Die Grenze vom stereotypen GRÜSSEN zum ÄUSSERN eines GUTEN WUNSCHes ist jedoch leicht überschritten. Bereits auf ein „Ich wünsche Ihnen noch einen guten Tag!“ oder „Lebe wohl!“ wird häufig mit einem Dank geantwortet, allerdings oft verbunden mit einer mehr oder weniger wörtlichen Wiederholung (,Das wünsche ich Ihnen auch!“). Außerdem ist zu bemerken, dass auch mit einer stereotypen Formel eine Wertschätzung des Adressaten ausgedrückt werden kann. Vgl. im Übrigen die Ausführungen weiter oben zu fam. 14.20 (1).

${ }^{866}$ Vgl. a. WHITE 2010, 76, der darauf hinweist, dass ein Postskript ggf. Aufschluss darüber geben kann, wohin ein potenzieller Antwortbrief gesendet und welche Transportdauer dafür in etwa veranschlagt werden musste.
} 
$z u$ wissen, $d a ß p$, könnte für $\mathrm{H}$ interessant sein. “867 Vielmehr ist sie durchaus „wichtig" für Terentia, weshalb man vom Untermuster HINWEISEN ausgehen sollte. ${ }^{868}$ Als unbedingt „notwendig“ wie bei einer BENACHRICHTIGUNG kann sie hingegen nicht angesehen werden. ${ }^{869}$ Auf einer übergeordneten (Teiltext-)Ebene hat (9) zwar auch eine deklarative Funktion, dominant ist hier aber die assertive Funktion.

\subsection{Teiltexthandlungen: Sequenzierung und Hierarchisierung}

\section{Teiltexte $[A]$ und $[C]$}

Die Teiltexte $[A]$ und $[C]$ ergeben sich aus dem konventionellen Aufbau römischer Briefe und sind durch die üblichen rituellen Briefformeln deutlich markiert: [A] stellt die Brieferöffnung und [C] die Briefbeendigung dar, wobei allerdings (8) und (9), abgesehen von ihrer gemeinsamen deklarativen Funktion ${ }^{870}$, weitgehend unverbunden nebeneinander stehen. Eine Verbindung zum Briefkorpus [B] besteht lediglich durch Personenkoreferenz hinsichtlich (1) und (8) sowie einen gemeinsamen lokalen und temporalen Bezug hinsichtlich (9).

\section{Teiltext [B]}

Der Hauptteil des Briefes beginnt mit einer kurzen Information über Ciceros Reiseverlauf, wie sie eigentlich typisch für die Brieferöffnungsphase ist. Der Einstieg wirkt dennoch etwas abrupt, wohl v. a. deshalb, weil er unmittelbar zusammenhängt mit dem in fam. 14.20 vorgebrachten Anliegen Ciceros, d. h. der Aufforderung, alles Notwendige für seine Ankunft vorzubereiten, welche die thematische und funktionale Einheit von [B] bestimmt. Auf grammatischer Ebene entsteht Kohärenz durch Koreferenz und Rekurrenz. Gemeinsamer Bezugspunkt ist zum einen das Tusculanum, das in (2) erwähnt und in (3) sowie (5) mit ibi, in (6) mit in balineo (hyponymisch) aufgenommen wird. Zum anderen gibt es durch entsprechende Verbformen, Pronomina und Adjektive, wie nos (2), putamus (2), plures (4), nobiscum (4) und commorabimur (5), einen durchgehenden Bezug auf Cicero (und seine Begleiter). Außerdem werden bestimmte Satzmuster, wie ut sint (3) bzw. ut sit (6), und morphologische Merkmale (Komparativ), wie in plures (4) bzw. diutius (5), wiederholt. Konnexion wird hergestellt mittels der Wortstellung, wie in (5), wo durch die betonte Anfangsstellung von ibi die Themenfortführung unterstrichen wird, und durch Konnektoren, wie enim in (4), et in (5) sowie item in (7).

Die Illokutionen in [B] stehen in einem Grund-Folge-Verhältnis zueinander, wobei einzelne IIlokutionen jeweils noch weiter spezifiziert werden: Die Anreise Ciceros begründet, v. a. angesichts der besonderen Umstände, welche durch die (verstärkende) Verwendung der Komparative betont werden, d. h. der höheren Anzahl von Personen und der längeren Aufenthaltsdauer, die Notwendigkeit spezieller Vorbereitungsmaßnahmen. Insgesamt ergibt sich für [B] in etwa folgende Binnenstrukturierung ${ }^{871}$ :

\footnotetext{
${ }^{867}$ RoLF 1983, 175.

${ }^{868} \mathrm{Vgl}$. ebd., 175 zum Untermuster HINWEISEN: „S ist zur Weitergabe von $\mathrm{p}$ nicht verpflichtet; zu wissen, daß $p$, könnte für H wichtig sein."

${ }^{869}$ Vgl. ebd., 175 zum Untermuster BENACHRICHTIGEN: „Es ist für H notwendig, zu wissen, daß p.“

${ }^{870}$ Der Vermerk zu Ort und Zeit der Briefentstehung im Postskript markiert - sofern vorhanden - sogar deutlicher als ein evtl. vale den Schluss eines Briefes, wenngleich selbst danach noch weitere Nachträge folgen können.

${ }^{871}$ Ebene 1 ist immer der Gesamtbrief, Ebene 2 der ihm direkt untergeordnete Teiltext.
} 
[B] Cicero bittet Terentia, alles Notwendige vorzubereiten,

indem er sie über seine bevorstehende Ankunft informiert (2),

Ebene 3

\begin{tabular}{|l} 
woraus er folgert, dass sie alles vorbereiten müsse (3), \\
\begin{tabular}{|l} 
was er es dadurch begründet, \\
dass vielleicht noch einige Begleiter mitkommen würden (4) und \\
dass sie wahrscheinlich länger bleiben würden (5),
\end{tabular} \\
$\begin{array}{l}\text { woraus er folgert, } \\
\text { dass sie ggf. eine Wanne organisieren mūsse (6) und } \\
\text { dass sie sich auch sonst um alles kūmmern mūsse, was zum Wohl der } \\
\text { Gäste erforderlich sei (7). }\end{array}$
\end{tabular}

Abbildung 19: Binnenstrukturierung fam. 14.20, Teiltext $B$

Die funktional-hierarchischen Beziehungen werden u. a. verdeutlicht durch die Konnektoren, wonach et und item eine nebenordnende (additive bzw. komparative) Beziehung zwischen (4) und (5) bzw. (6) und (7) indizieren. Durch enim wird allerdings eine kausale Beziehung zwischen (3) und (4) angezeigt, die dafür spricht, dass (3) untergeordnet ist in Bezug auf (4), was insofern logisch erscheint, als die Textfunktion bzw. die Teiltextfunktion eher in einer Aufforderung als in einer Information zu sehen ist. ${ }^{872}$ Vor diesem Hintergrund könnte man (gedanklich) auch in (2) ein enim ergänzen und die Illokution eine Ebene herabstufen, während (3) als dominante Illokution hochgestuft würde. Im Hinblick auf andere Illokutionen sind ähnliche Überlegungen möglich. So wird durch die parallelen Satzmuster ${ }^{873}$ eine Verbindung von (6) und (3) angezeigt. Funktional stellen sowohl (6) als auch (7) Spezifizierungen von (3) dar. Dies zeigt beispielhaft, dass die logische Hierarchie nicht unbedingt mit der sequenziellen Abfolge, der in der vorliegenden Arbeit bei der Briefstrukturierung der Vorrang eingeräumt wird, korreliert und dass vielfältige Querverbindungen bestehen. Ein generelles Problem ist dabei die Einordnung kausal-konsekutiver Beziehungen, d. h. die Frage, ob Grund oder Folge hierarchisch höher stehen oder beide gleichgewichtet sind, ob dies generell so zu sehen oder in jedem Einzelfall anders zu beurteilen ist. Auf der Äußerungsebene ist sowohl die eine wie auch die andere Reihenfolge möglich (vgl. z. B.: „Ich lobe dich, weil du so schöne Briefe geschrieben hast." vs. „Weil du so schöne Briefe geschrieben hast, lobe ich dich."), die nicht unbedingt mit einer entsprechenden Hierarchisierung verbunden ist. Ein Textelement kann z. B. sowohl durch eine betonte Anfangs- als auch Endposition hervorgehoben werden.

\subsection{Gesamttexthandlung: Bestimmung der Textfunktion}

Die Kontaktfunktion spielt in fam. 14.20 nur eine marginale Rolle. Keine einzige der Einzelillokutionen lässt sich einem expressiven Handlungsmuster zuordnen. Der Beziehungsaspekt beschränkt sich v. a. auf eine grobe Beachtung der allgemeinen Höflichkeitskonventionen, wie z. B. die Verwendung der üblichen Grußformeln. Diese können im Übrigen bei der Bestimmung

\footnotetext{
872 Vgl. Kap. 2.1.1.3.3.

873 Vgl. S. 183.
} 
der Textfunktion generell vernachlässigt werden, es sei denn, dass sie auf besondere Weise individuell abgewandelt werden. Geprägt ist der Brief von assertiven und direktiven Sprechakten, die sich von ihrer Anzahl her in etwa die Waage halten. Im vorliegenden Kontext ist das Gewicht der Direktiva letztlich höher zu bewerten, wie auch die Analyse der funktionalen Beziehungen innerhalb des Briefkorpus teilweise belegt: Das entscheidende Ziel Ciceros besteht darin, dass Terentia Vorkehrungen für seine Ankunft auf dem Tusculanum trifft. Die assertiven Sprechakte legen nur die Voraussetzungen dar, welche die Notwendigkeit der Vorbereitungsmaßnahmen begründen. Man kann fam. 14.20 also als Aufforderungsbrief klassifizieren.

\subsubsection{Beziehungs- und Identitätskonstitution: Das Verhältnis zwischen Cicero und Terentia}

Der letzte erhaltene Brief Ciceros an Terentia wird oft als Sinnbild der Entfremdung zwischen den beiden Eheleuten gesehen. In der Tat wirkt er ziemlich unterkühlt: keinerlei Zärtlichkeitsbekundungen, kein Ausdruck der Freude über das bevorstehende Wiedersehen und keine über das karge vale hinausgehenden Wohlergehenswünsche. Die Grußformeln erfüllen nur den minimalen Höflichkeitsstandard in Form der politeness of respect, wohingegen kein Versuch unternommen wird, emotionale Nähe herzustellen (affiliative politeness) oder FTAs wie die energischen BITTEN durch Höflichkeitsfloskeln (obsecro te, quaeso o. Ä.) wenigstens ein wenig abzumildern (redressive politeness). ${ }^{874}$ Cicero formuliert sein Anliegen sehr direkt und ohne Umschweife. Die rein sachlichen Assertiva beschränken sich auf das Unerlässliche. Cicero sagt nichts über sein Treffen mit Cäsar und erwähnt auch nicht, dass Tullia ihn wohl auf seiner Reise begleitet. ${ }^{875}$ Der Brief ist überhaupt sehr unpersönlich gehalten: Terentia wird (abgesehen von den Grußformeln) an keiner Stelle direkt angesprochen. ${ }^{876}$ Selbst die Bitten sind nur mehr oder weniger implizit auf Terentia bezogen, je nachdem, ob und wie man die Äußerungen in (3), (6) und (7) ggf. ergänzen möchte. ${ }^{877}$ Die beiden Ich- bzw. Wir-Aussagen in (2) und (5) wirken ebenfalls recht nüchtern, demonstrieren aber, dass Cicero in diesem Brief sich und seine persönlichen Bedürfnisse in den Vordergrund stellt, deren Erfüllung er von Terentia nachdrücklich einfordert. Überall zeigt sich, dass fam. 14.20 kein Kontakt-, sondern in höchstem Maße ein Aufforderungsbrief ist.

Der Eindruck, den der Leser von dem Brief erhält, ist auch durch seine einfache Struktur und die prägnante Kürze bestimmt, die ihn etwas brüsk erscheinen lassen. ${ }^{878}$ Gerade diese Eigenschaften lassen sich allerdings durch die Umstände seiner Entstehung erklären. Bei dem kurzen Zwischenstopp auf seiner Rückreise hat Cicero kaum Zeit für einen längeren Brief, und

\footnotetext{
${ }^{874}$ Vgl. z. B. TREgGIARI 2007, 128; CLAASSEN 1996, 222; JÄGER 1986, 281 und Tyrrell / Purser in CICERO 1904 - 1933, IV 347 sowie Kasten in CICERO 2004, 1005. Vgl. a. S. 70.

${ }^{875}$ Vgl. z. B. JÄGER 1986, 281 bzw. TREgGIARI 2007, 128f. GuglieLMI 2013, 329 N. 4 spekuliert, dass ein (vorangehender) Brief mit den entsprechenden Informationen möglicherweise verloren gegangen sei. Vgl. a. CLAASSEN 1996, 222 und Tyrrell / Purser in CICERO 1904 - 1933, IV 347.

${ }^{876}$ Vgl. z. B. GUGLIELMI 2013, 329.

877 Vgl. S. 180.

878 Vgl. a. BuONOPANE 2016, 60; CLAASSEN 1996, 222 und Tyrrell / Purser in CICERO 1904 - 1933, IV 347.
} 
zudem sind angesichts des unmittelbar bevorstehenden Wiedersehens mit Terentia alle weiteren Auslassungen im Grunde unnötig. ${ }^{879}$ Immerhin setzt Cicero seine Frau über das Wesentliche in Kenntnis. Durch die Begründung wirken seine Bitten weniger rüde. Mit seiner Vorankündigung erkennt er Terentias „Hoheitsrecht“ als Hausherrin an, denn sie hat ja nicht nur die Pflicht, sondern auch das Recht, sich um die häuslichen Angelegenheiten zu kümmern. ${ }^{880} \mathrm{Zu}$ gleich wird deutlich, dass Cicero ihr - zumindest in diesem Bereich - noch vertraut. Die Tatsache, dass Terentia inn auf dem Tusculanum erwartet, zeigt ebenfalls, dass noch kein endgültiger Bruch zwischen den beiden entstanden ist. 881

Der Anschein von Kälte beruht also eher auf der Art der Formulierung des Briefes als auf seinem Inhalt. ${ }^{82}$ Dabei muss Kürze an sich nicht Unhöflichkeit bedeuten, und auch die spezifische Ausprägung der Bitten steht durchaus nicht einmalig da im antiken Rom. ${ }^{883}$ Dennoch ist das Fehlen jeglichen Anzeichens emotionaler Nähe bemerkenswert, und dies umso mehr, als Cicero Terentia seit über zwei Jahren nicht mehr gesehen hat. ${ }^{884}$ Alles weist darauf hin, dass Cicero nicht eben an einer (positiven) Beziehungsgestaltung gelegen ist. ${ }^{885}$ Natürlich hat eine (manipulative) Verschleierung der eigenen Absicht ebenso wenig einen guten Einfluss auf das Verhältnis zu den Mitmenschen; ein gewisses Maß an Höflichkeit, das über die reinen Grußformeln hinausgeht, wäre dennoch ein Zeichen der Wertschätzung, das Cicero hier vermissen lässt. Der Brief reiht sich damit ein in die Gruppe der anderen Schreiben aus den Jahren 48 und 47, die allesamt durch auffällige Kürze gekennzeichnet sind. Inwieweit damit tatsächlich eine Verschlechterung im Verhältnis zwischen Cicero und Terentia einhergeht, ob sich einfach nur die - unabhängig von der ehelichen Beziehung bestehenden - situativen Umstände im Vergleich zu früheren Phasen der Briefkommunikation geändert haben, wie weitreichend der Einfluss der Überlieferungsgeschichte auf die Auswahl der erhaltenen Briefe ist ${ }^{886}$, all das lässt sich nicht abschließend beurteilen.

\footnotetext{
879 Vgl. z. B. JEPPESEN-WIGELSWORTH 2013, 356f. Vgl. a. fam. 14.5, wo Cicero - in (12) bzw. (13) - die Kürze eines Briefes von Terentia an ihn mit dem unmittelbar bevorstehenden Wiedersehen erklärt und entsprechend nicht verwunderlich findet. Vgl. aber auch CLAASSEN 1996, 222: „,[...] we may ascribe this curtness to mere haste, but the note did differ in format and tone quite considerably from even the briefest of earlier missives."

${ }^{880} \mathrm{VgI}$. z. B. AlLEN JR. 1960, 58: „,...] we must also conclude that, while Cicero's tone in his last letter to Terentia seems curt, the tasks which he asked Terentia to perform were within her province; he would have been doubly rude to her if he had asked anyone else to do them. And Plutarch (Cic. 20,2) reports the remark by Cicero that Terentia preferred to deal with domestic matters without his interference." Vgl. a. GUGLIELMI 2013, 329.

${ }^{881} \mathrm{VgI}$. z. B. TREGGIARI 2007, 129: „It is fair to see this note as evidence that Cicero had lost his old feelings for his wife. But he still trusted her to administer the staffing, supplying and maintenance of the Tusculan villa, and so presumably of the house and all the other villas. He did not doubt that she, in her usual capable way, would make the arrangements he vaguely specified. If Terentia was awaiting him at Tusculum, there was no open breach between them at this point."

882 Vgl. GUGLIELMI 2013, 329.

${ }^{883} \mathrm{Vgl}$. z. B. ebd., 329: „In realtà è stato osservato come richieste di questo tipo, in particolare riguardo la preparazione del bagno, non siano strane qualora ci si rivolga ad un amico che si sta per visitare: ve ne sono esempi nello stesso epistolario ciceroniano." Sie verweist (in N. 2) auf fam. 9.5.3 (an Varro) und fam. 9.16.9 (an Papirius Paetus). Vgl. a. JEPPESEN-WIGELSWORTH 2013, 356.

${ }^{884}$ Vgl. z. B. SHACKLETON BAILEY 1971, 177.

885 Vgl. a. JÄGER 1986, 281 und DICKEY 2012a, 743 N. 12.

${ }^{886}$ Vgl. a. TREGGIARI 2007, 196 N. 38: „I used to wonder if we might suppose that this was merely a quick message about practicalities of the, your dinner is in the oven' variety, and that other more loving letters had not survived $[\ldots] . "$
} 
Dies spiegelt sich auch in vielen (v. a. neueren) Ansichten zu fam. 14.20 wider: So wägen z. B. TREGGIARI 2007 und GUGLIELMI 2013 ihr Urteil unter Berücksichtigung verschiedener Aspekte ab, ohne zu einem eindeutigen Ergebnis zu kommen. Am Ende zieht Erstere ein eher positives oder vielmehr neutrales Fazit im Hinblick auf die Beziehung von Cicero und Terentia, während Letztere tendenziell den negativen Aspekten einen höheren Stellenwert beimisst. Die Auswertung der handlungssemantischen Analyse stützt die Position von Guglielmi. Nur der unmittelbare Kontext der Briefentstehung spricht für eine insgesamt neutrale Bewertung der ehelichen Verbindung Ciceros und Terentias zu diesem Zeitpunkt. Was den weitergehenden Kontext betrifft, bleibt festzustellen, dass kurze Zeit später (47 oder 46 v. Chr.) die Scheidung dieser langjährigen Ehe erfolgte. ${ }^{887}$

\subsubsection{Beispiel 2: Fam. 14.5}

\subsubsection{Situativer Kontext}

Nach Ende seines Prokonsulats in Kilikien begibt Cicero sich auf die Rückreise nach Italien. Er bricht am 3. August 50 in Begleitung seines Sohnes von dort auf und erreicht am 14. Oktober Piräus. Den Brief an Terentia verfasst er am 16. Oktober, zwei Tage nach seiner Ankunft in Athen. ${ }^{888}$

\subsubsection{2 Übersichtsschemata}

\subsubsection{1 Überblick über die Einzelillokutionen}

\begin{tabular}{|l|l|l|l|}
\hline Nr. & Text & Oberklasse & Untermuster \\
\hline$(1)$ & TULLIUS S. D. TERENTIAE SUAE & deklarativ & BRIEF ERÖFFNEN \\
\hline (2) & $\begin{array}{l}\text { Si tu et Tullia, lux nostra, valetis, ego et suavissimus Cicero } \\
\text { valemus. }\end{array}$ & expressiv & $\begin{array}{l}\text { WOHLERGEHEN } \\
\text { WÜNSCHEN }\end{array}$ \\
\hline (3) & Prid. Id. Oct. Athenas venimus, & assertiv & HINWEISEN \\
\hline (4) & $\begin{array}{l}\text { cum sane adversis ventis usi essemus tardeque et incommode } \\
\text { navigassemus. }\end{array}$ & assertiv & HINWEISEN \\
\hline (5) & de nave exeuntibus nobis Acastus cum litteris praesto fuit & assertiv & HINWEISEN \\
\hline (6) & uno et vice〈n〉simo die & assertiv & MITTEILEN \\
\hline (7) & sane strenue. & expressiv & JUBELN \\
\hline (8) & accepi tuas litteras, & assertiv & BESTÄTIGEN \\
\hline (9) & $\begin{array}{l}\text { quibus intellexi te vereri ne superiores mihi redditae non } \\
\text { essent. omnes sunt redditae }\end{array}$ & assertiv & BESTÄTIGEN \\
\hline
\end{tabular}

${ }^{887}$ Vgl. z. B. TREGGIARI 2007, 129

888 Zur Datierung des Briefes vgl. z. B. GugLIELMI 2013, 209 N. 1 (mit Bezug auf Shackleton Bailey in CICERO 1977 und Cavarzere in CICERO 2007): „Infatti Cicerone, come dice proprio in questa epistola, era arrivato ad Atene il 14 ottobre 50 (si veda anche Cic. Att. 7, 1, 1 scis me Athenas venisse pr. Idus Octobris). La datazione è congetturale, dal momento che i manoscritti riportano per questa missiva la data 18 ottobre (a. d. XV Kal. Nov.); l'epistola viene fatta risalire al 16 ottobre per confronto con CIc. Att. 6, 9, 4 (15 ottobre) ego tabellarios postero die ad vos eram missurus: i tabellarii in questione avrebbero portato a Roma Cic. fam. 14, 5 insieme a Cic. Att. 7, 1, che riporta anche un riferimento alla lettera a Terenzia (Cic. Att. 7, 1, 9 scripsi ad Terentiam). Sull'argomento, si veda SHACKLETON BAILEY 1977, vol. I, 461, che comunque non ritiene impossibile che i corrieri siano partiti due giorni più tardi del previsto, rendendo così superfluo correggere la datazione tràdita; Cavarzere, in CAVARZERE-NARDUCCI 2007, vol. II, 1528 n. ad loc. crede tuttavia che si possa far risalire questa lettera al 16 ottobre in modo pressoché certo." Vgl. a. Tyrrell / Purser in CICERO 1904 - 1933, III 279. 


\begin{tabular}{|c|c|c|c|}
\hline (10) & diligentissimeque a te perscripta sunt omnia, & expressiv & BEGRÜSSEN \\
\hline$(11)$ & idque mihi gratissimum fuit. & expressiv & DANKEN \\
\hline$(12)$ & $\begin{array}{l}\text { neque sum admiratus hanc epistulam quam Acastus attulit } \\
\text { brevem fuisse. }\end{array}$ & expressiv & BEGRÜSSEN \\
\hline (13) & iam enim me ipsum exspectas, sive nos ipsos, & assertiv & VERMUTEN \\
\hline (14) & qui quidem quam primum ad vos venire cupimus, & kommissiv & ABSICHT BEKUNDEN \\
\hline (15) & $\begin{array}{l}\text { etsi in quam rem publicam veni }\langle a\rangle \text { mus intellego. cognovi enim } \\
{[\ldots] \text { ad arma rem spectare, }}\end{array}$ & assertiv & PROGNOSTIZIEREN \\
\hline$(16)$ & [...] ex multorum amicorum litteris, quas attulit Acastus, $[. .]$. & assertiv & MITTEILEN \\
\hline (17) & ut mihi, cum venero, dissimulare non liceat quid sentiam. & assertiv & PROGNOSTIZIEREN \\
\hline$(18)$ & sed quoniam subeunda fortuna est, & assertiv & FESTSTELLEN \\
\hline (19) & $\begin{array}{l}\text { eo citius dabimus operam ut veniamus, quo facilius de tota re } \\
\text { deliberemus. }\end{array}$ & kommissiv & ABSICHT BEKUNDEN \\
\hline (20) & $\begin{array}{l}\text { tu velim, quod commodo valetudinis tuae fiat, quam longis- } \\
\text { sime poteris obviam nobis prodeas. }\end{array}$ & direktiv & BITTEN \\
\hline$(21)$ & $\begin{array}{l}\text { De hereditate Preciana, }[. . .]-\text { sed hoc velim cures, siauctio ante } \\
\text { meum adventum fiet, ut Pomponius aut, si is minus poterit, } \\
\text { Camillus nostrum negotium curet; }\end{array}$ & direktiv & BITTEN \\
\hline$(22)$ & $\begin{array}{l}\text { [...] quae quidem mihi magno dolori est (valde enim illum } \\
\text { amavi) [...] }\end{array}$ & expressiv & JAMMERN \\
\hline (23) & nos, cum [...] venerimus, reliqua per nos agemus. & kommissiv & ABSICHT BEKUNDEN \\
\hline (24) & {$[\ldots]$ salvi $[\ldots]$} & expressiv & HOFFNUNG ÄUSSERN \\
\hline$(25)$ & sin tu iam Roma profecta eris, tamen curabis ut hoc ita fiat. & direktiv & BITTEN \\
\hline$(26)$ & nos, si di adiuvabunt, circiter Id. Nov. in Italia speramus fore. & expressiv & HOFFNUNG ÄUSSERN \\
\hline (27) & $\begin{array}{l}\text { vos, mea suavissima et optatissima Terentia, si nos amatis, } \\
\text { curate ut valeatis. }\end{array}$ & expressiv & $\begin{array}{l}\text { WOHLERGEHEN } \\
\text { WÜNSCHEN }\end{array}$ \\
\hline (28) & Vale. & deklarativ & BRIEF BEENDEN \\
\hline (29) & Athenis a. d. XV 〈II $\rangle$ Kal. Nov. & assertiv & HINWEISEN \\
\hline
\end{tabular}

Abbildung 20: Gesamtübersicht fam. 14.5 (Einzelillokutionen) 


\subsubsection{2 Überblick über den Briefaufbau}

Cicero bekräftigt seinen Willen zur schnellen Rückkehr nach Italien (Obligation) und gibt Terentia diesbezüglich einige wichtige Hinweise (Information) - indem

[A] er den Brief eröffnet

Ebene 2

$\rightarrow$ deklarativ: BRIEF ERÖFFNEN, indem (1) - (2)

[B] Terentia den bisherigen Reiseverlauf beschreibt

Ebene 2

$\rightarrow$ assertiv: HINWEISEN, indem (3) - (4) | vgl. Abbildung 22

[C] den Empfang von Terentias Briefen bestätigt

$\rightarrow$ assertiv: BESTÄTIGEN, indem | vgl. Abbildung 23

[C1] er sie über den Erhalt ihrer (aktuellen und früheren) Briefe informiert Ebene 3

$\rightarrow$ assertiv: BESTÄTIGEN, indem (5) - (9)

[C2] ihre schreiberischen Fähigkeiten positiv würdigt,

$\rightarrow$ expressiv: BEGRÜSSEN, indem (10) - (13)

[D] seine Absicht bekundet, baldmöglichst zu Terentia zurückzukehren,

$\rightarrow$ kommissiv: ABSICHT BEKUNDEN, indem | vgl. Abbildung 24

[D1] er ihr seine Entscheidung darlegt, so schnell wie möglich zu ihr zu Ebene 3 reisen,

$\rightarrow$ kommissiv: ABSICHT BEKUNDEN, indem (14) - (19)

$\rightarrow$ direktiv: BITTEN, indem (20)

[E] Terentia um Unterstützung in der Erbschaftssache Precius bittet

$\rightarrow$ direktiv: BITTEN, indem (21) - (25) | vgl. Abbildung 25

$\rightarrow$ deklarativ: BRIEF BEENDEN, indem (27) - (29). 


\subsubsection{Sprechhandlungsanalyse}

\subsection{Einzelhandlungen: Illokutionsidentifikation und -klassifikation}

Teiltext $[\mathrm{A}]$

(1): Der BRIEF wird mit der gleichen Grußformel wie in fam. 14.20 ERÖFFNET. ${ }^{889}$ Auffällig dabei ist, dass Cicero - im Gegensatz zu den vier Exilbriefen - Tullia nicht miteinschließt, obwohl das Schreiben auch an sie gerichtet ist, wie (2) zeigt. Hauptadressat ist allerdings tatsächlich in allen Briefen seine Frau Terentia. ${ }^{890}$

(2): Die Wohlergehensformel Si tu et Tullia, lux nostra, valetis, ego et suavissimus Cicero valemus. kann als konventionell zusammengehörig betrachtet werden. Durch die Apposition lux nostra und das Attribut suavissimus, die sich allerdings nicht auf Terentia selbst, sondern auf die gemeinsamen Kinder beziehen, und dadurch, dass die formula valetudinis nicht, wie es sonst meistens der Fall ist, einfach abgekürzt wird, erhöht sich der Affektivitätsgrad der Aussage. ${ }^{891}$ Aufgrund dessen und in Anbetracht der Ritualität der Formel ist ihre Funktion am besten als expressives WOHLERGEHEN WÜNSCHEN ${ }^{892} \mathrm{zu}$ beschreiben, obwohl der direkte Sprechakt ja keinen Wunsch, sondern nur eine hypothetische Feststellung darstellt.

Teiltext [B]

(3): Da (3) lediglich aus der nüchternen Feststellung von Ankunftsort und -zeit besteht, kann der Sprechakt leicht als assertiv identifiziert werden. Nach dem Wichtigkeitsgrad der (gesicherten) Information ist am ehesten vom transmissiven Untermuster HINWEISEN auszugehen. ${ }^{893}$

(4): Der zweiteilige Kausalsatz cum sane adversis ventis usi essemus tardeque et incommode navigassemus beinhaltet eine von (3) zunächst einmal unabhängige zusätzliche Information. Obwohl die beiden Teile des Adverbialsatzes grammatisch einander nebengeordnet sind, kann man den ersten Teil als Begründung für den zweiten sehen, dem er logisch betrachtet also untergeordnet ist. ${ }^{894}$ Zusammengenommen soll mit der Äußerung die in (3) erwähnte (späte) Ankunftszeit, welche augenscheinlich nicht mit der ursprünglichen Planung übereinstimmt, erklärt werden: Cicero beschreibt die näheren Umstände der Schiffsreise nach Piräus, die aufgrund der ungünstigen Windverhältnisse langsam und beschwerlich war. Attribut (adversis) und adverbiale Bestimmungen (v. a incommode) enthalten eine leichte expressiv-wertende

\footnotetext{
${ }^{889}$ Vgl. S. 177.

${ }^{890}$ Vgl. S. 214.

${ }^{891}$ Vgl. z. B. GUGLIELMI 2013, 210: „Tale formula costituisce una variazione di quella, più consueta e distaccata, che recita si vales bene, ego valeo e che si trova comunemente abbreviata in s. v. b. e. v.; per quanto riguarda la corrispondenza ciceroniana, è stato osservato che la presenza di quest'elemento non è solitamente riscontrata nelle lettere più informali, ma la versione che si ritrova qui è tuttavia connotata da appellativi affettuosi nei confronti dei figli (Tullia, lux nostra; suavissimus Cicero). Questi elementi veicolano indubbiamente un sentimento di tenerezza, anche se non rivolto direttamente a Terenzia, e moderano la formalità del saluto." Zu suavissimus und lux nostra vgl. a. ebd., 210 N. 3 (mit Bezug auf DICKEY 2002): „Lux è un appellativo che esprime tenerezza o lode, spesso usato in riferimento ad un amante e normalmente accompagnato dal possessivo (DICKEY $2002,338)$, mentre suavissimus è un termine indicante affetto sincero, specialmente nei confronti di familiari ed amici (DICKEY 2002, 360). “ Vgl. außerdem GUNDERSON 2007, 19.

$892 \mathrm{Vgl}$. die Erläuterungen zu fam. 14.20 (8).

${ }^{893}$ Vgl. S. 182 zu fam. 14.20 (9).

${ }^{894} \mathrm{Vgl}$. aber auch die Ausführungen in Kap. 2.1.1.3.2 zur Einordnung kausal-konsekutiver Beziehungen.
} 
Komponente und damit Anklänge an das Untermuster FLUCHEN. ${ }^{895}$ Im Grunde wird aber m. E. nur eine weitgehend objektive Beschreibung der Gründe für die späte Ankunft intendiert. Der Sprechakt ist also als assertiv aufzufassen, das Untermuster wie in (3) als HINWEISEN zu interpretieren. ${ }^{896}$

Teiltext [C]

(5): Indem Cicero nun genauer auf die Ankunft im Hafen zu sprechen kommt, wo sie Acastus bereits mit Briefen erwartet habe, wird die Reisebeschreibung fortgesetzt. Im Anschluss an (3) und (4) kann auch (5) als assertives HINWEISEN klassifiziert werden. Zentrale Information ist die Briefübergabe (nobis Acastus cum litteris praesto fuit), während das (attributive) p. c. de nave exeuntibus nur den zeitlichen Handlungsrahmen absteckt.

(6): Mit der Apposition uno et vice $\langle n\rangle$ simo die macht Cicero auf die (erstaunlich kurze) Wegezeit des Briefboten von Rom nach Athen aufmerksam. Dass es sich hierbei um eine eigenwertige zusätzliche Angabe handelt, wird durch die Stellung als Nachtrag am Satzende unterstrichen. Sie kann (durch Ergänzung eines entsprechenden Prädikats wie z. B. spatium conficit) leicht zu einer vollständigen Aussage erweitert werden. Diese Information, welche im Grunde schon aus (3) erschlossen werden kann, ist nicht wirklich wichtig, in den Augen von Cicero aber wohl durchaus auch für Terentia so interessant, dass er sie ihr MITTEILEN will. ${ }^{897}$

(7): Während Cicero in (6) zunächst die Leistung von Acastus objektiv anhand der für den Weg bis zum Hafen benötigten Tage beziffert, drückt er in (8) mit der explizit positiven Bewertung sane strenue, dem expressiven Sprechaktuntermuster JUBELN entsprechend, seine Bewunderung bzw. Freude darüber aus. Die Handlungsbedingungen für das Untermuster JUBELN lauten:

„B1: Sp1 nimmt eine Handlung H wahr, für die Sp3 verantwortlich ist, oder einen Sachverhalt $\mathrm{S}$, dessen Ursache eine nicht-personale Quelle $\mathrm{Q}$ ist. (Bei Dialogsituation gilt zusätzlich: Sp1 nimmt an, daß Sp2 Kenntnis von H oder S hat.)

B2: Sp1 bewertet $\mathrm{H}$ bzw. S positiv im Rückbezug auf sich selbst.

B3: Sp1 freut sich über S oder H. “ 898

Wie in (6) kann auch hier die Aussage leicht passend erweitert werden, und auch hier wird die illokutionäre Eigenständigkeit durch die betonte Satzendstellung hervorgehoben, mit der (7) klar von den vorangehenden Illokutionen abgegrenzt wird.

(8) und (9): Mit litteras in (8) wird auf (5) referiert. Unter den dort erwähnten Schreiben befindet sich auch ein Brief Terentias (tuas). Dagegen bezieht sich (9) auf ihre früheren Schreiben (superiores). Der Attributsatz quibus intellexi te vereri ne superiores mihi redditae non essent. wirkt in Hinsicht auf (8) in gewisser Weise restringierend (im Sinne von: „Ich meine genau die Briefe, in denen du ...") oder zumindest spezifizierend, insofern er sich auf den Inhalt der Briefe

\footnotetext{
${ }^{895}$ Vgl. S. 218.

${ }^{896}$ Möglich wäre aber vielleicht eine Separierung von incommode als eigenem expressiven Sprechakt FLUCHEN in Ergänzung bzw. als Exkurs zur objektiven Reisebeschreibung.

897 Man könnte sie allerdings insofern für wichtig erachten, als sie allgemein Aufschluss gibt über die für den Transport eines Briefes anzusetzende Zeit. Vgl. a. S. 182 zum Postskript in fam. 14.20 (9).

898 MARTEN-CLEEF 1991, 255.
} 
bezieht. Seine Hauptfunktion besteht darin, den Bezugsrahmen für (9) zu liefern. Da er im Übrigen eine bloße Wiederholung ohne wirklichen Informationswert (für Terentia) darstellt, bleibt er bei der Sprechhandlungsanalyse i. e. S. unberücksichtigt. ${ }^{899}$

Sowohl in (8) als auch in (9) wird von einer reaktiven Informationshandlung ausgegangen, die genauer als akzeptativ und konfirmativ beschrieben werden kann und dadurch bestimmt ist, dass ${ }_{\text {, }} \mathrm{H}^{900}[$ [...] bezüglich einer zuvor (etwa im Rahmen einer Mitteilung, einer Frage oder auch einer Beschuldigung) thematisierten Proposition p zum Ausdruck [bringt], daß er weiß bzw. davon überzeugt ist, daß $p$ den Tatsachen entspricht. " ${ }^{\text {901 }}$ Rolf unterscheidet dabei u. a. zwischen den Untermustern BESTÄTIGEN und BEJAHEN, für die beide gilt, dass „H [...] in

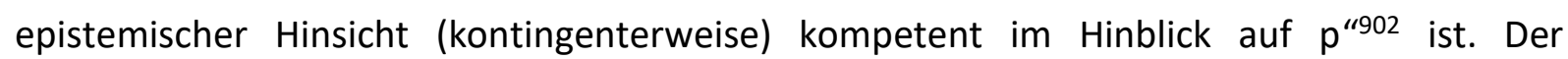
Unterschied besteht lediglich darin, dass bei BEJAHEN hinzukommt, dass „der Adressat [...] die Rolle eines auf eine Entscheidungsfrage Antwortenden [trägt]. “903 Diese Differenzierung erscheint in Bezug auf das Lateinische nicht ganz passend, da sie dort so gar nicht existiert. In der Regel wird wohl, wie auch im vorliegenden Fall, eine Zuordnung zum Untermuster BESTÄTIGEN am treffendsten sein.

Die Reaktivität von (9) ergibt sich ganz offensichtlich aus dem Attributsatz, der auf eine (zumindest indirekte) Frage Terentias verweist, außerdem aber deutlich macht, dass Terentia generell viel Wert auf eine Empfangsbestätigung ihrer Briefe legt, sodass im Fall von (8) ebenfalls eine reaktive Sprechhandlung anzunehmen ist, zumal es durchaus möglich ist, dass sie in der vorangegangenen Kommunikation tatsächlich einen entsprechenden Wunsch geäußert hat. Anzumerken ist jedoch, dass Cicero, wenn man dem genauen Wortlaut des Zitats in (9) folgt, gar nicht „zum Ausdruck bringt, daß er weiß, daß p den Tatsachen entspricht“ “ d. h., er BESTÄTIGT nicht Terentias Zweifel, ihre Briefe seien womöglich nicht angekommen, sondern entkräftet sie im Gegenteil sogar. Man kann ihre Äußerung wohl am besten als indirekte Aufforderung zu einer Empfangsbestätigung zu verstehen, auf die Cicero reagiert, indem er ihr mit (9) den Erhalt ihrer früheren Briefe BESTÄTIGT, mit (8) auch den ihres letzten Schreibens. Zugleich beruhigt er seine Frau hinsichtlich der von ihr gehegten Befürchtungen (vereri). Zumindest (9) enthält also auch eine recht deutliche expressive Komponente.

(10): Cicero würdigt die Schreibfertigkeiten seiner Frau, die er mit dem wertenden Adverb diligentissime beschreibt, das durch den Superlativ in seiner positiven Bedeutung noch verstärkt wird. Anscheinend hat ihm das Lesen ihrer Briefe große Freude bereitet. Da deren Ursache im vorliegenden Fall allerdings bei Terentia, also dem Briefempfänger, und nicht bei einer dritten Person wie z. B. Acastus in (7) liegt, handelt es sich bei (10) nicht um JUBELN, sondern um BEGRÜSSEN. ${ }^{904}$ Die Handlungsbedingungen für BEGRÜSSEN entsprechen denen

\footnotetext{
${ }^{899}$ Es wäre auch denkbar, den Attributsatz als HINWEIS aufzufassen, insofern man die Tatsache, dass Cicero Terentias Briefe gelesen und verstanden hat (intellexi) als zusätzliche Information auffasst. Vgl. a. die Erläuterungen zu fam. 14.2.2 (14) auf S. 218.

${ }_{900} \mathrm{Mit}, \mathrm{H}$ ‘ ist bei Rolf im Gegensatz z. B. zu Marten-Cleef nicht die Handlung gemeint, sondern der „Hörer“ oder vielmehr Adressat einer entsprechenden vorangehenden Äußerung.

901 ROLF 1983, 176.

902 Ebd., 178.

903 Ebd., 178.

${ }^{904}$ Vgl. S. 191.
} 
des übergeordneten Untermusters WILLKOMMEN HEISSEN. ${ }^{905}$ Im Unterschied zu ,jd. WILLKOMMEN HEISSEN` bezieht sich, etw. BEGRÜSSEN` aber nicht auf eine Person bzw. ihre Anwesenheit oder ihr Erscheinen an sich, sondern auf eine konkrete Handlung, von welcher der Sprecher in irgendeiner Weise profitiert - und die er mithin „BEGRÜSST“.

Es besteht eine gewisse Nähe zum Untermuster KOMPLIMENT MACHEN. ${ }^{906}$ Bei einem KOMPLIMENT ist der Sprecher jedoch persönlich nicht (direkt) von dem positiv bewerteten Sachverhalt bzw. einer entsprechenden Handlung des Adressaten betroffen. Ähnliche Gründe sprechen auch gegen das Untermuster GRATULIEREN, das durch folgende Handlungsbedingungen gekennzeichnet ist:

„B1: Der Sprecher Sp1 beobachtet einen gegenwärtigen Sachverhalt S, von dem der Adressat betroffen ist, bzw. eine abgeschlossene Handlung $\mathrm{H}$, für die Sp2 verantwortlich ist.

B2: Sp1 bewertet S oder H (aufgrund konventioneller Wertmaßstäbe) positiv für Sp2 und (aufgrund sozialer Gepflogenheiten) positiv im Rückbezug auf sich selbst.

B3: Sp1 freut sich über S oder H. “907

Im vorliegenden Zusammenhang wäre es zudem nicht wirklich passend, von „sozialen Gepflogenheiten“ und „konventionellen Wertmaßstäben“ zu sprechen, jedenfalls nicht im (von Marten-Cleef) intendierten Sinne, wonach sich GRATULIEREN eher auf bedeutendere Sachverhalte wie einen Geburtstag oder eine bestandene Prüfung bezieht und stark ritualisiert ist. Ebenso wenig handelt es sich bei (10) im Übrigen um ein LOB, mit dem Cicero Terentia (wie z. B. ein Lehrer seinen Schüler beim Schreibunterricht in der Schule) „,in bestimmte Handlungsweisen einführen“ wollte, oder um SCHMEICHELEI, mit der er (direkt) darauf abzielen würde, „persönliche Vorteile zu erreichen“. 908

(11): Häufig wird ein Akt des BEGRÜSSENS mit einer Sprechhandlung des Typs DANKEN verbunden. Dies trifft auch in diesem Fall zu. Während für (10) ein Gefühl der Freude zentral ist, wird mit (11) - explizit - ein Gefühl der Dankbarkeit zum Ausdruck gebracht: mihi gratissimum fuit. Gemeinsam ist (10) und (11) die Verwendung positiv wertender Adjektive im Superlativ (diligentissime bzw. gratissimum), welche den expressiven Wert der Illokutionen anzeigen, wobei in (11) durch mihi der persönliche Bezug deutlicher herausgestellt wird. Die Handlungsbedingungen für DANKEN lauten:

„B1: Sp2 hat eine Handlung H vollzogen, von der Sp1 betroffen ist.

\footnotetext{
${ }^{905} \mathrm{Vgl.S.} 178$.

${ }^{906} \mathrm{Vgl}$. S. 221.

907 MARTEN-CLeEF 1991, 145. Vgl. a. ebd., 127.

${ }^{908}$ Ebd., 128. Vgl. a. ebd., 133f. Vgl. außerdem die Ausführungen von UNCETA GóMEZ 2016a, 272f. (u. a. mit Verweis auf LEECH 2014) zu den Überschneidungen zwischen lobenden Sprechakten und Sprechakten des Typs GRATULIEREN (und DANKEN): „,...] it is not always easy to distinguish between congratulations and other communicative intentions, especially approval, praise and thanks, since these sometimes overlap both formally and pragmatically [...]. There are, nevertheless, some features that allow its acknowledgement. [...] The one speech event [= compliments and praises] focuses on high evaluation of something connected with the addressee; the other [= congratulations] focuses on the favorable emotion S[peaker] feels in sympathy with the addressee. In practice, the same example may illustrate both." Er verweist außerdem auf MAKRI-TSILIPAKOU 2001, 143, wonach Komplimente nicht auf einer persönlichen Leistung des Adressaten beruhen müssen und auch nicht unbedingt auf Sachverhalten, die günstig für den Sprecher sind. Vgl. a. N. 909.
} 
B2: Sp1 bewertet $\mathrm{H}$ bzw. die Folgen von $\mathrm{H}$ positiv für sich selbst.

B3: Sp1 ist Sp2 für H dankbar. "909

(12): In einem weiteren Schritt bemerkt Cicero, dass Terentia sich in ihrem aktuellen Brief offensichtlich etwas kurzgefasst hat, was er allerdings sehr gut nachvollziehen könne. Er wundert sich nicht darüber (neque sum admiratus), sondern BEGRÜSST dies vielmehr, da die Kürze, wie er nachfolgend in (13) darlegt, anscheinend recht gut begründet ist. Das expressive Untermuster ergibt sich mithin v. a. aus dem Kontext, wenn man von der leichten (emotionalen) Einfärbung des Prädikats (admiratus sum) absieht. Die in (12) geäußerte Freude wirkt dabei recht verhalten, sofern man überhaupt von Freude sprechen kann. Sie ist jedenfalls auf der unteren Stufe einer Skala anzusiedeln, die von bloßer Akzeptanz und leichter Zufriedenheit bis hin zu ekstatischer Begeisterung reichen kann. ${ }^{910}$

(13): Von (12) abzugrenzen ist die in (13) formulierte, mit enim (sachlich) eingeleitete Begründung für die Kürze des letzten Briefes von Terentia bzw. für das von Cicero dafür geäußerte Verständnis. Hier liegt ein selbständiger, nicht mehr expressiver, sondern (i. w. S.) assertiver Sprechakt vor. Cicero stellt die Vermutung an, Terentia sei wohl der Meinung, das bald bevorstehende persönliche Wiedersehen mache ausführlichere Darlegungen unnötig. Je nachdem, für wie überzeugend man die Begründung hält, ist das (i. e. S.) assertive Untermuster BEHAUPTEN oder VERMUTEN anzunehmen. BEHAUPTEN ist dadurch bestimmt, dass es „möglich [ist], daß $\mathrm{H}$ die Herleitung von $\mathrm{p}$ für unwahr hält. “, bei VERMUTEN kommt hinzu, dass „S [...] für die

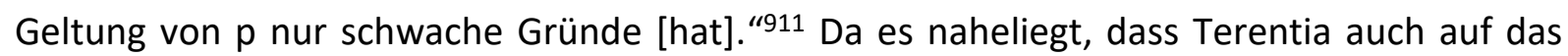

\footnotetext{
${ }^{909}$ MARTEN-CLEEF 1991, 203. Vgl. a. UNCETA GÓMEZ 2016a, 273 zur (auch etymologischen) Verwandtschaft von DANKEN und GRATULIEREN im Lateinischen: „Regarding concomitances [von Sprechakten des Typs GRATULIEREN] with the speech act of thanking, it must be emphasised that the joint conceptualisation in Latin of these two communicative intentions is evident in the polysemy of gratari and (con)gratulari. These two verbs, derivatives of gratus (,thankful, grateful; pleasant, charming') [...], mean both ,to congratulate' and ,to thank'. It is also remarkable that both praise and the expression of appreciation have a certain degree of conventionality as expressions of the speech act of thanking [...]. Nevertheless, [...] there are some differences between these two illocutionary forces: Congratulating and thanking share some common properties in general: the illocutionary point of both is to express a positive psychological state; the object of both may refer only to an act related to or performed by the hearer in the past; and they both protect the needs of the positive face of the hearer. The key difference is in the way they relate to the interests of the speaker and the hearer: congratulation is an expression of pleasure at something that is beneficial to the hearer and thanking is an expression of gratitude for something that has been done by the hearer and is beneficial to the speaker."

${ }^{910}$ Vgl. MARTEN-CLeEF 1991, 181: „Bei diesem Gefühl, bislang als Freude charakterisiert, kann es sich um wenig aktivierende Zufriedenheit und Fröhlichkeit, um Erleichterung, aber auch um die hoch aktivierenden Emotionen Glück und Begeisterung handeln." Vgl. a. ebd., 177, wo bemerkt wird, dass bei Sprechhandlungen des Typs WILLKOMMEN HEISSEN (und damit auch BEGRÜSSEN) „der Sprecher durch seinen Vollzug zu erkennen gibt, daß er eine vorausgehende Handlung akzeptiert [Hervorhebung durch S. N.]." Andere illokutionäre Typen, zu denen fam. 14.5.1 (12) zunächst eine gewisse Nähe aufzuweisen scheint, kommen m. E. noch weniger in Betracht als BEGRÜSSEN. Vgl. z. B. WAGNER 2001, 173 zu ANERKENNEN und ebd., 203 zu BILLIGEN. Vgl. a. ebd., 397 zum Sprechplan ,Beschönigen': „Der Sprecher bewertet etwas Negatives unaufrichtig positiver [...], als sachlich gerechtfertigt wäre. Er versucht dadurch, sich der Verantwortung, der Pflicht zur Rechenschaftsablegung und evtl. zur Haftung zu entziehen [...]. Beschönigen ist eine Sprechstrategie, die assertive Sprechakte (z.B. BEHAUPTEN $\nearrow$, FESTSTELLEN $\nearrow$ u.ä.) für ihre Zwecke einsetzt ( $\nearrow$ SP 102 Überreden). “Vgl. außerdem ZILLIG 1992, 101f. zu BESCHÖNIGEN (SCHÖNFÄRBEN, SCHMEICHELN), das er zu den POSITIV-NEGATIVBEWERTUNGEN (vgl. ebd., 212ff.) zählt. ${ }^{911}$ ROLF 1983, 163.
} 
lange Schweigen aufseiten Ciceros reagieren ${ }^{912}$ und es vielleicht noch andere Ursachen für den begrenzten Umfang der Briefe geben könnte, soll hier vom Untermuster VERMUTEN ausgegangen werden.

Teiltext [D]

(14): Cicero leitet mit dem freien Attributsatz (markiert durch quidem) zu einem neuen Thema über. Die entscheidende Information wird durch die temporale Ergänzung quam primum vermittelt, die in Verbindung mit cupimus die Art des Sprechakts indiziert. Cicero drückt seinen dezidierten Willen zu einer möglichst schnellen Heimreise aus, weshalb von einem kommissiven Sprechakt auszugehen ist. Zu überlegen wäre, ob nicht eine beidseitige Präferenz vorliegt, da man davon ausgehen kann, dass auch Terentia ein Interesse hat, Ehemann und Sohn bald wiederzusehen. Das zugehörige komplexe Untermuster VORSCHLAGEN wird von Graffe folgendermaßen definiert:

„B1: Sp1 und Sp2 befinden sich in einer Handlungskooperation, in der mindestens $\mathrm{H} 1$ und $\mathrm{H} 2$ koordiniert zu vollziehen sind, damit die Kooperation gelingt.

B2: Sp1 glaubt, $\mathrm{H} 1$ und $\mathrm{H} 2$ sind Handlungen, die das Gelingen der Kooperation sicherstellen. In dem Sinne präferiert Sp1 den Vollzug von $\mathrm{H} 1$ und $\mathrm{H} 2$.

B3: Sp1 glaubt, daß Sp2 den Vollzug von $\mathrm{H} 1$ und $\mathrm{H} 2$ präferiert, da er weiß, daß Sp2 ebenfalls das Kooperationsziel erreichen will.

B4: Sp1 will H1 vollziehen und glaubt, daß Sp2 H1 präferiert. (= ANBIETEN)

B5: Sp1 möchte, daß Sp2 H2 vollzieht. (= BITTEN)

B6: Die Realisierung des Musters gilt als (i) vorbereitendes, verpflichtendes Festlegen auf zukünftiges eigenes Handeln und (ii) der Versuch, Sp2 zum Vollzug einer Handlung in der Kooperation zu veranlassen. “913

Dies würde bedeuten, dass Cicero hier in einem ersten Schritt ANBIETET, sich (um Terentias willen) zu beeilen, um sie dann in einem zweiten Schritt in (21) (um seinetwillen) zu BITTEN, ihrerseits ihm so weit wie möglich entgegenzukommen. ${ }^{914}$ Gemeinsames Handlungsziel wäre ein baldiges Wiedersehen. Allerdings weist nichts oder zumindest kaum etwas direkt auf solche Überlegungen hin. Im Gegensatz z. B. zu fam. 14.3.5 (30), als es um seine Rückkehr aus dem Exil geht, erwähnt Cicero an keiner Stelle, dass Terentia einen entsprechenden Wunsch geäußert hätte ${ }^{915}$, sondern er scheint, wie der Textzusammenhang nahelegt, seine Äußerungen sowohl in (14) als auch in (20) ausschließlich aus dem eigenen Blickwinkel zu betrachten und eher nur seine eigenen Interessen zu verfolgen, weshalb ich diese Sprechhandlung als ABSICHT BEKUNDEN deute. ${ }^{916}$

\footnotetext{
${ }_{912} \mathrm{Vgl}$. z. B. JäGER 1986, 226: „Wie Cicero selbst indirekt zugibt, war er wohl nicht gerade schreibfreudig und ließ manchmal einen Brief Terentias, die befürchtet, die Briefe könnten ihn gar nicht erreicht haben, unbeantwortet [...]. Die Kürze des von Acastus überbrachten Briefes will er nicht als Terentias ,Reaktion' auf sein Schweigen verstehen, sondern meint in Erwartung seiner baldigen Heimkehr, dies sei nur natürlich [...]."

${ }^{913}$ GRAFFE 1990, 289. Vgl. a. HINDELANG 1978, 464ff. zum (direktiven) Sprechaktmuster VORSCHLAG.

${ }^{914}$ Zu ANBIETEN vgl. GRAFFE 1990, $139 \mathrm{ff}$.

${ }^{915} \mathrm{Vgl}$. a. JäGER 1986, 226. Natürlich ist nicht auszuschließen, dass nicht doch irgendwann vorher einmal entsprechende Bemerkungen Terentias gefallen sind.

${ }^{916}$ GRAFFE 1990, $116 f$.
} 
(15): Dem an (14) anknüpfenden Konzessivsatz etsi in quam rem publicam veni〈a〉mus intellego kommt (als allgemeiner Einleitung) zusammen mit der Spezifizierung cognovi enim [...] ad arma rem spectare ein eigener Illokutionsstatus zu: Cicero legt damit seine Sicht der aktuellen politischen Lage in Rom dar. Er erklärt, dass ihm durchaus bewusst sei (intellego), wie schwierig sich die Situation darstelle, und zeigt sich ziemlich sicher (cognovi), dass ein Krieg im Anzug ist. Die Formulierungen weisen recht deutlich auf einen (i. w. S.) assertiven Sprechakt hin, für den Aussagen in der vorliegenden Form (redeeinleitende Verben wie intellegere bzw. cognoscere in Verbindung mit einer Inhaltsaussage in Form eines indirekten Fragesatzes bzw. Ac/s) typisch sind. Er bezieht sich auf die Zukunft, was nicht grammatisch (durch das Tempus), sondern lexikalisch (spectare) deutlich gemacht wird, sich im Übrigen aber auch aus dem Kontext erhellt.

Man kann die Illokution am besten als (i. e. S.) assertives PROGNOSTIZIEREN klassifizieren. ${ }^{917}$ Es handelt sich weder um einen gesicherten Sachverhalt wie beim transmissiven ANKÜNDIGEN noch um eine PROPHEZEIUNG, für die gilt, dass „eine rationale Rechtfertigung für die Thematisierung von $p$ [...] von S nicht zu erwarten [ist]. ${ }^{\text {"918 }}$ Die Äußerung enthält allerdings auch eine deutliche expressive Komponente, die sich aus der eher schwammigen Formulierung in quam republicam, welche allerhand (negativen) Spekulationen Raum lässt, und v. a. aus dem Gesamtzusammenhang ergibt. Es wäre in der Tat zu überlegen, ob (15) nicht eher dem Untermuster ANGST ÄUSSERN ${ }^{919}$ zuzuordnen ist. Man kann leicht erahnen, welche Bedenken und Befürchtungen Cicero hegte. Gegenüber Atticus bringt er diese auch klar zum Ausdruck. In fam. 14.5 verbleiben sie dagegen weitgehend unter der Oberfläche. ${ }^{920}$

(16): In Ergänzung zu (15) benennt (16) rein sachlich Ciceros Informationsquelle. Er TEILT Terentia MIT, dass seine PROGNOSE hauptsächlich auf (brieflichen) Nachrichten gründe, die er (durch Acastus) von Freunden erhalten habe.

(17): Konsekutivsätze erhalten meist einen eigenen Illokutionsstatus. Sie können informationell bzw. funktional recht deutlich vom übergeordneten Satz abgegrenzt werden. Ähnlich wie in (15) schwankt die Sprechhandlung zwischen Assertivität und Expressivität. Cicero erwartet, dass sein Handlungsspielraum in Rom künftig eher begrenzt sein wird. Dies bereitet ihm große Sorge, da er nicht (mehr) den einfachen Weg des Schweigens wählen kann, sondern klar Stellung beziehen muss, was natürlich mit den entsprechenden Gefahren verbunden ist. Obwohl (17) einen persönlicheren Bezug auf Ciceros Situation hat und die expressive Note noch etwas stärker ausgeprägt ist als in (15), wird dennoch aus den dort genannten Gründen auch hier dem assertiven Untermuster PROGNOSTIZIEREN der Vorrang vor dem expressiven Untermuster ANGST ÄUSSERN eingeräumt.

(18) und (19): Der Fokus in (18) und (19) liegt nicht auf dabimus operam ut veniamus, womit lediglich (14) wiederholt wird. ${ }^{921}$ Die dortige ABSICHTSBEKUNDUNG wird nun vielmehr (kausal

\footnotetext{
917 Vgl. S. 179.

918 RoLF 1983, 163.

${ }^{919}$ Vgl. Kap. 2.1.3.2.3 zu fam. 14.2.2 (15).

920 Vgl. Kap. 2.1.2.4.

${ }^{921}$ Im Übrigen weist die Formulierung aber alle Kennzeichen einer ABSICHTSBEKUNDUNG auf: ein typisches Verb wie operam dare, das zudem im Futur verwendet wird, und einen (ebenfalls auf die Zukunft gerichteten) Finalsatz (ut veniamus).
} 
und final) begründet - und dadurch ebenso wie durch die Wiederholung verstärkt. Die Aussagen sind eng miteinander verwoben; dennoch erscheint eine Trennung in zwei Illokutionen mit jeweils eigenem inhaltlichem und funktionalem Schwerpunkt sinnvoll: 1. [sed] quoniam subeunda fortuna est, [eo citius dabimus operam ut veniamus,] (18) 2. quo facilius de tota re deliberemus. (19). Der Hauptsatz (mit untergeordnetem Finalsatz) wird dabei wechselweise auf beide Illokutionen bezogen.

In (18) schreibt Cicero, dass man seinem Schicksal ja ohnehin nicht entkommen könne. Solche allgemeinen Lebensweisheiten zählen zu den (i. e. S.) assertiven FESTSTELLUNGEN, für die gilt: „Obwohl (auch) H registriert hat, daß p, ist nicht ausgeschlossen, daß $\mathrm{H}$ die Herleitung (Geltung) von $\mathrm{p}$ (irgendwann) in Zweifel zieht. "922 Auch wenn die Berufung auf das Schicksal per se erst einmal expressiv erscheint, handelt es sich hier m. E. um eine sachliche Argumentation, denn er hat ja durchaus recht damit, dass es (rational) keinen Sinn macht, Rom einfach fernzubleiben, weil die Situation sich (früher oder später) auch auf die entfernteren Landesteile auswirken wird.

(19) dagegen enthält zwar ebenfalls eine Begründung dafür, warum Cicero so schnell nach Rom zurückkehren will, weil er so nämlich leichter mit Terentia über alles beratschlagen könne. Die hauptsächliche Funktion ist jedoch nicht assertiv, sondern kommissiv und besteht in einer - von (14) zu unterscheidenden - ABSICHTSBEKUNDUNG, die durch die beiden Komparative citius und facilius noch verstärkt wird. Während Cicero im Allgemeinen in fam. 14.5 mit ,wir' sich und seinen Sohn meinen wird, bezieht sich deliberemus in (19) allerdings wohl auf Cicero und Terentia ${ }^{923}$, womit eine beidseitige Präferenz angedeutet wird und sich die Frage stellt, ob hier tatsächlich das Untermuster ABSICHT BEKUNDEN vorliegt. Es ist schwer zu beurteilen, inwieweit Terentia im Vorfeld einen entsprechenden Gesprächsbedarf angemeldet hat und damit vielleicht eher von den Untermustern VERSPRECHEN, ANBIETEN oder (sequenzbezogen) VORSCHLAGEN ausgegangen werden sollte. ${ }^{924} \mathrm{Da}$ aber letztlich keine diesbezüglichen Hinweise zu finden sind, wird hier angenommen, dass es v. a. im Interesse Ciceros liegt, sich mit Terentia auszutauschen, womit eine Zuweisung von (19) zum Untermuster ABSICHT BEKUNDEN gerechtfertigt erscheint.

(20): Die Verbindung von velim mit dem Konjunktiv Präsens (prodeas) stellt eine typische Form der BITTE dar. Der einschränkende quod-Satz ist einem Konditionalsatz vergleichbar (,soweit bzw. wenn dies dein Gesundheitszustand zulässt") und besitzt entsprechend keinen eigenen Illokutionsstatus. Er mildert die BITTE ein wenig ab. Dagegen hat - neben dem exponierten tu am Satzanfang - der Komparativsatz durch den Superlativ longissime eine eher intensivierende Wirkung, obschon die Aussage durch poteris gleichzeitig abgeschwächt wird. Was die Frage der Sprecher- bzw. Adressatenpräferenz betrifft, sei auf die Diskussion im Zusammenhang mit (14) und (19) verwiesen.

\footnotetext{
${ }^{922}$ Rolf 1983, 163. Vgl. a. das Kap. „Assertiva (i. e. S.)“ ab S. 290.

${ }^{923}$ Vgl. a. GUGLIELMI 2013, 211.

${ }^{924} \mathrm{Vgl}$. die Erläuterungen zu fam. 14.5.1 (14).
} 


\section{Teiltext [E]}

(21): Die BITTE in (21) ist grammatisch ähnlich wie in (20) formuliert (velim + Konjunktiv Präsens). Sie umfasst zwei Alternativen im Hinblick auf die Erbschaft des Precius ${ }^{925}$ : Entweder Atticus oder Camillus, ein befreundeter Rechtsanwalt ${ }^{926}$, soll sich um die Angelegenheit kümmern, deren Regelung wohl vornehmlich im Interesse Ciceros liegt. Die Konditionalsätze nennen zwei einschränkende Bedingungen im Zusammenhang mit der BITTE, welche die sachlichen Voraussetzungen für das von Terentia erbetene Handeln vorgeben.

(22): Eingeschoben in (21) ist ein freier Attributsatz, in dem Cicero seine Trauer über den Tod von Precius ausdrückt. Diese Aussage wird begründet und damit auch verstärkt durch eine mit inm informationell und funktional eng verbundene Parenthese. Die Lexik hat eine eindeutig emotionale Färbung, die durch quantifizierende und teilweise umgangssprachliche Ausdrücke (valde) noch intensiviert wird: Cicero empfinde großen Schmerz (mihi magno dolore est), weil er Precius überaus geschätzt habe (valde illum amavi). ${ }^{927}$ Dies entspricht dem expressiven Untermuster JAMMERN, für welches folgende Bedingungen gelten:

„B1: Sp1 ist von einem Sachverhalt S betroffen. Die Verantwortlichkeit für S liegt bei Sp1, Sp3 oder der nicht-personalen Quelle Q. (Bei Dialogsituation gilt zusätzlich: Sp1 nimmt an, daß Sp2 Kenntnis von $\mathrm{S}$ hat.)

B2: Sp1 bewertet S negativ für sich selbst.

B3: Sp1 ist traurig über S. “928

(23): Die BITTE in (21) betrifft die notwendigen Vorkehrungen bis zur Ankunft Ciceros in Rom. In (23) BEKUNDET er die ABSICHT, sich danach um alles Übrige selbst kümmern zu wollen. Durch das aktionsorientierte Verb agere und dessen Verwendung im Futur wird die auf die Zukunft gerichtete kommissive Willensbekundung markiert, unterstützt durch den Temporalsatz im Futur II, der die Voraussetzung für die angekündigte Handlung vorgibt.

(24): Gesondert zu betrachten ist das im Temporalsatz von (23) enthaltene Prädikativum, mit dem Cicero (quasi nebenbei) die HOFFNUNG ÄUSSERT, er möge wohlbehalten in Rom ankommen. Das expressive Untermuster HOFFNUNG ÄUSSERN ist durch folgende Handlungsbedingungen bestimmt:

„B1: Der Sprecher Sp1 antizipiert einen künftigen Sachverhalt S, von dem er selbst betroffen ist. Sp1 ist nicht bzw. nicht allein verantwortlich für das (So-)Eintreten von S.

B2: Sp1 bewertet S positiv für sich selbst.

B3: Sp1 erhofft S. ${ }^{\text {"929 }}$

Diese Bedingungen sind im Fall von (24) erfüllt: Auf das Eintreten des erhofften Sachverhalts, der mit dem positiv wertenden Adjektiv salvi bezeichnet wird, hat Cicero tatsächlich kaum

\footnotetext{
925 Zur Frage der Schreibung (Precius oder Praecius) vgl. z. B. Shackleton Bailey in CICERO 1977, 462.

${ }^{926}$ Vgl. Tyrrell / Purser in CICERO 1904 - 1933, III 278.

927 Vgl. GUGLIELMI 2013, 211 bzw. HOFMANN 1978, $75 f$.

928 MARTEN-CLEEF 1991, $327 \mathrm{f}$.

929 Ebd., 261.
} 
Einfluss. Der Zukunftsbezug ergibt sich aus dem Futur (II) des aus dem übergeordneten Satz zu ergänzenden Prädikats venerimus.

(25): Die bereits in (21) formulierte BITTE wird noch einmal wiederholt, diesmal unter Verwendung des Futurs curabis, das eine forderndere Wirkung hat als der zudem noch durch die Höflichkeitsfloskel velim abgemilderte Konjunktiv cures. ${ }^{930}$ Weiter verstärkt wird die BITTE durch die Partikel tamen in Verbindung mit dem Konditionalsatz, in dem Cicero deutlich macht, dass er ihre Erfüllung selbst dann erwartet, wenn Terentia bereits aus Rom aufgebrochen sein sollte. Insofern ist (25) auch mehr als nur eine stilistische Variante von (21).

\section{Teiltext [F]}

(26): Cicero ÄUSSERT seine HOFFNUNG, ungefähr am 13. November in Italien einzutreffen. ${ }^{931}$ Die Illokution enthält eine deutliche assertive Komponente, da ein sehr genaues (voraussichtliches) Ankunftsdatum genannt wird, was für Terentia sicherlich eine wertvolle Information darstellt. Die mit circiter ausgedrückte Unsicherheit und der Zukunftsbezug (fore) könnten wie in fam. 14.20 auf das Untermuster PROGNOSTIZIEREN hinweisen. Das Verb sperare und die Berufung auf die Götter, welche verdeutlicht, dass der Zeitpunkt seiner Ankunft nicht (allein) in der Macht Ciceros steht, indizieren jedoch eher das Untermuster HOFFNUNG ÄUSSERN. Die floskelhafte Wendung si di adiuvabunt dient dabei v. a. der Verstärkung.

Teiltext $[\mathrm{G}]$

(27): Am Schluss sendet Cicero seiner Frau einen der üblichen WOHLERGEHENSWÜNSCHE, deren ursprünglich direktiver Charakter durch die Ritualität weitgehend verloren gegangen ist. ${ }^{932} \mathrm{Er}$ wandelt das konventionelle curate ut valeatis ${ }^{933}$ allerdings stark expressiv ab: durch markiertes vos am Satzanfang, durch eine Apposition mit direkter Anrede Terentias (mea suavissima et optatissima Terentia) und durch den Konditionalsatz si nos amatis. Mit Wörtern wie amare, suavis und optatus herrscht eine ausgesprochen affektive Lexik vor, die teilweise weiter verstärkt wird durch den Gebrauch des Superlativs (suavissima et optatissima). ${ }^{934}$ Die Verwendung der Pronomina vos, nos und v. a. mea unterstützt diese Wirkung noch. Mit vos zeigt Cicero, dass er, wie am Briefanfang, auch Tullia in seinen Wunsch miteinschließt. Die Zärtlichkeitsausdrücke sind dagegen diesmal auf Terentia bezogen.

\footnotetext{
930 Vgl. GUGLIELMI 2013, 211: „È anche doveroso considerare la forma in cui le esortazioni a Terenzia vengono formulate: nel primo caso compare la formula velim + congiuntivo (velim cures), tipica della convenzione epistolare, mentre nel secondo caso viene utilizzato l'indicativo futuro (tamen curabis ut ita hoc fiat), che indica che il mittente dà per scontata la realizzazione di quanto richiesto, e quindi non dà al destinatario altra possibilità. " Sie verweist auch auf RISSELADA 1993, 169ff. bzw. ebd., $285 \mathrm{ff}$.

931 Tatsächlich landete er erst am 24. November in Brundisium: Vgl. Shackleton Bailey in CICERO 1977, 462.

932 Vgl. die Erläuterungen zu fam. 14.20 (8).

933 Vgl. a. das Kap. „Expressiva mit beidseitiger Präferenz“ ab S. 346.

${ }^{934}$ Zu suavissima vgl. DICKEY 2002, 360 (s. N. 891), zu optatissima ebd., 346 bzw. GugLIELMI 2013, 210: „[...] optatissima è un termine che esprime un affetto piuttosto intenso, utilizzato per parenti e amici intimi [...]."
} 
(28): Der BRIEF wird BEENDET mit dem rituellen vale. ${ }^{935}$ Durch die Verdopplung der Wohlergehensformel erhält (27) gewissermaßen einen noch höheren Stellenwert ${ }^{936}$ und steht mehr für sich, während in (28) der deklarative Charakter noch deutlicher in den Vordergrund rückt. (29): Ganz am Ende des Briefes findet sich wie in fam. 14.20 der assertive Hinweis auf Ort und Zeitpunkt der Briefabfassung. ${ }^{937}$

\subsection{Teiltexthandlungen: Sequenzierung und Hierarchisierung \\ Teiltexte $[A]$ und $[G]$}

Brieferöffnung [A] und Briefbeendigung [G] sind im Vergleich zu fam. 14.20 jeweils um eine (zusätzliche) individuell abgewandelte rituelle Wohlergehensformel erweitert, die im Gesamtzusammenhang - aufgrund der allgemeinen Briefkonventionen - gemeinsam mit der Begrüßungs- bzw. Verabschiedungsformel eine deklarative Funktion haben, während für sich betrachtet die expressive Funktion dominant ist. Gruß- und Wohlergehensformeln stehen, abgesehen von der Personenkoreferenz, weitgehend unverbunden nebeneinander. Für das Postskript gilt das bereits zu fam. 14.20 (9) Gesagte.

\section{Teiltexte $[\mathrm{B}]$ und $[\mathrm{F}]$}

Cicero beginnt und beschließt den Hauptteil mit grundlegenden Informationen zum Reiseverlauf, wie es typisch für die Einleitungs- und Schlussphase römischer Briefe ist. Die wesentliche Information von [B], die Ankunftszeit in Athen, ist prominent an den Anfang gesetzt und markiert den Beginn des Teiltextes, in dem Cicero die Schifffahrt nach Piräus beschreibt. [B] ist geprägt von Ausdrücken, die mehr oder weniger dem Bereich „(Schiffs-)Reisen“ zugeordnet werden können: venimus, adversis ventis, tarde, incommode, navigassemus. Typisch sind außerdem die Orts- und Zeitangaben, wie sie sich auch in [F] finden, wo Cicero einen Ausblick auf die voraussichtliche Weiterreise nach Italien gibt.

Aufgrund der bereits in Kap. 2.1.2.3.1 dargelegten Überlegungen ergibt sich folgende Binnenstrukturierung von $[B]$, die durch eine wechselseitige Grund-Folge-Beziehung (cum) geprägt ist:

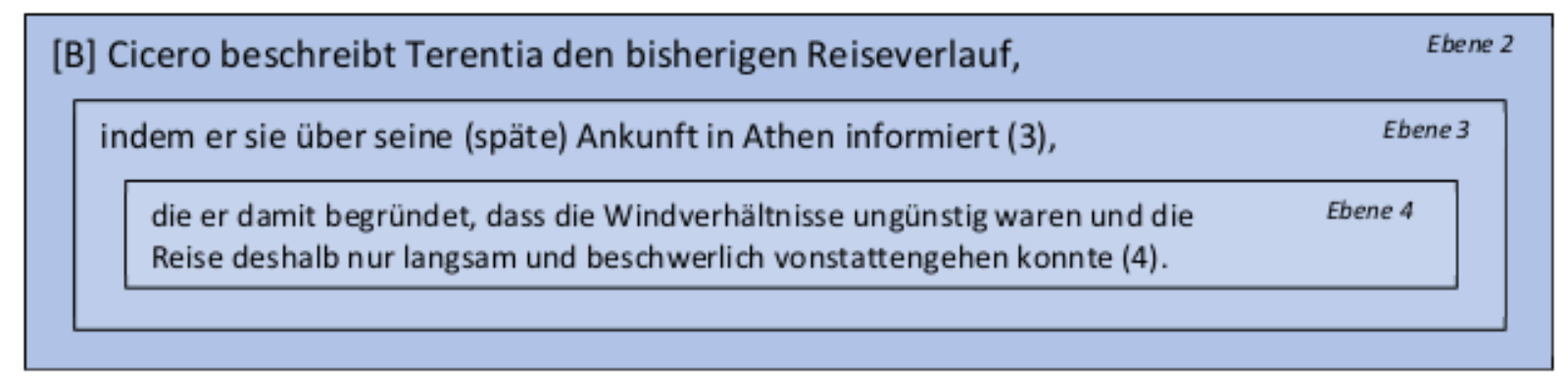

Abbildung 22: Binnenstrukturierung fam. 14.5, Teiltext $B$

\footnotetext{
935 Vgl. a. S. 182.

${ }^{936}$ Vgl. a. GUGLIELMI 2013, 210: „Inoltre, il fatto che le raccomandazioni per la salute, tipiche dei saluti finali, siano ripetute è segnale di coinvolgimento emotivo nei confronti del destinatario, accentuato dall'inserzione dell'inciso si nos amatis [...]." Vgl. a. CUGUSI 1983, 57.

937 Vgl. a. S. 182.
} 


\section{Teiltext [C]}

Teiltext [C] knüpft mit de nave exeuntibus an die Schiffsreise in $[\mathrm{B}]$ an, bevor mit der Einführung eines neuen Protagonisten, nämlich des Briefboten Acastus, in Verbindung mit der modalen Ergänzung cum litteris zu einem neuen Thema und der damit korrelierenden neuen Handlungsfunktion übergeleitet wird: Cicero BESTÄTIGT Terentia den Empfang ihrer Briefe - ebenfalls ein häufiges Thema in der Einleitungsphase. Kennzeichnend für [C] sind Ausdrücke aus dem Bereich „Briefe (schreiben, überbringen und erhalten)": cum litteris praesto fuit, accepi tuas litteras, redditae non essent, sunt redditae, perscripta sunt, hanc epistulam, quam attulit. Darüber hinaus wird auch mit quibus, superiores, omnes und omnia auf die Briefe Terentias bzw. deren Inhalt referiert.

Im ersten Teil [C1] informiert Cicero seine Frau zunächst rein assertiv über den Erhalt ihrer Briefe (BESTÄTIGEN). Der zweite Teil [C2], eingeleitet mit diligentissime in betonter (Teilsatz-) Anfangsposition, ist hingegen durch das expressive Untermuster BEGRÜSSEN geprägt. Zugleich DANKT Cicero Terentia für ihre Briefe und möglicherweise will er SICH durch das überschwängliche Lob ihrer Schreibkünste und das für die Kürze des letzten Briefes geäußerte Verständnis auch indirekt für seine Schreibfaulheit ENTSCHULDIGEN. Der kleine Exkurs zu Acastus in (7) und (8) wird durch die Endstellung (nach dem Prädikat) deutlich vom übrigen Teil des Satzes und damit von (6) abgegrenzt, wohingegen der Übergang zu (9) und damit die Rückkehr zum Hauptthema asyndetisch erfolgt. Die Bedeutung des Exkurses ist für die Bestimmung der Handlungsfunktion von [C] weitgehend unerheblich.

Der interne Aufbau von [C] wird nur teilweise durch die grammatischen Konnektoren indiziert. In [C1] werden die Aussagen asyndetisch aneinandergereiht, abgesehen von dem Attributsatz in (10), welcher den Übergang von Terentias aktuellem Brief zu den früheren Schreiben markiert, wobei innerhalb von (10) die Referenz durch Wiederholung (redditae non essent - sunt redditae) hergestellt wird. In [C2] sind die Illokutionen hingegen durchgehend mit Konnektoren verbunden. Der Anschluss an (10) in [C1] ist ebenso wie der zwischen (11) und (12) sowie (12) und (13) additiv (-que bzw. neque). (14) wird kausal mit enim angeknüpft, ist grammatisch nebengeordnet, sequenziell-hierarchisch aber untergeordnet.

Die Binnenstruktur von [C] kann wie folgt zusammengefasst werden: 
indem er sie über den Erhalt ihrer (aktuellen und früheren) Briefe informiert [C1], Ebene 3

indem er von der Briefübergabe durch Acastus bei seiner Ankunft in Athen Ebene 4
berichtet (5),

$\begin{aligned} & \text { wobei er erwähnt, dass Acastus nur 21 Tage für den Brieftransport benötigt } \\
& \text { habe (6), }\end{aligned}$
\begin{tabular}{|lr|}
\hline womit er begrūndet, dass er große Bewunderung fūr ihn empfinde (7), & $\begin{array}{r}\text { Ebene } 5 \\
\text { (Exkurs) }\end{array}$ \\
\hline $\begin{array}{l}\text { und was er dadurch prāzisiert, } \\
\text { (Exkurs) }\end{array}$ \\
\hline $\begin{array}{l}\text { dass er (auch) ihren Brief erhalten habe (8) und } \\
\text { dass ihm die früheren Briefe Terentias ebenfalls zugestellt worden seien (9), }\end{array}$ \\
\hline
\end{tabular}

und indem er ihre schreiberischen Fähigkeiten positiv würdigt [C2],

Ebene 3

indem er seine Freude über die Sorgfalt äußert, mit der sie ihre (früheren)

Ebene 4 Briefe geschrieben habe (10),

womit er begründet, dass er ihr sehr dankbar (dafür) sei (11),

Ebene 5

und indem er Verständnis für die Kürze ihres aktuellen Briefes äußert (12),

Ebene 4

was er damit begründet, dass sie ihn (und ihren Sohn) anscheinend bald persön- Ebene 5 lich erwarte (13).

Abbildung 23: Binnenstrukturierung fam. 14.5, Teiltext $C$

\section{Teiltext [D]}

Cicero greift in (14) mit dem demarkativen qui quidem die Pronomina me bzw. nos ipsos aus (13) auf, um zu seinen Rückreiseplänen überzugehen, die das Hauptthema von [D] sind. Im Mittelpunkt stehen hier Wörter aus dem Bereich „(möglichst schnell) kommen“. Dazu gehören verbale Ausdrücke wie (ad vos) venire, veni〈a〉mus, cum venero, (ut) veniamus, (obviam nobis) prodeas und letztlich auch das in übertragener Bedeutung gebrauchte subeunda. Die Dringlichkeit wird zum einen durch die grammatische Realisierung (finaler Konjunktiv, Futur, Gerundivum) und ergänzende Verben wie cupere und operam dare unterstrichen, zum anderen durch adverbiale Bestimmungen im Komparativ und Superlativ (quam primum, eo citius, quo facilius, quam longissime).

Während Cicero in [D1] seine ABSICHT BEKUNDET, so schnell wie möglich zu Terentia zu reisen, wird in [D2] die BITTE geäußert, dass sie ihm so weit wie möglich entgegenkommen solle. Der Übergang zwischen den beiden Teilen wird signalisiert durch den Perspektivwechsel von qui ( $\approx$ ego sive nos ipsi) quidem in (14) zu tu in (20), jeweils deutlich markiert durch die betonte Anfangsposition. [D1] und [D2] sind verbunden durch die übergreifende Intention Ciceros, 
baldmöglichst mit seiner Frau zusammenzukommen - um dann (mit ihr gemeinsam) nach Italien zurückzukehren.

In (15) bis (17) verweist Cicero auf mögliche Bedenken, die ihn von einer Rückreise abhalten könnten. Der Abschnitt wird entsprechend eingeleitet durch die konzessive Konjunktion etsi. Der Zusammenhang (von allgemeiner Einleitung und Konkretisierung) innerhalb von (15) wird durch das (grammatisch koordinierende) kausale enim hergestellt. Darin eingebettet ist (16), eine präpositionale Adverbiale mit restringierendem Attributsatz, welche die (Informations-) Grundlage der in (15) geäußerten Befürchtungen benennt. In (17), markiert durch konsekutives $u t$, wird die sich aus (15) ergebende Folgerung gezogen. In (18) und (19) führt Cicero die Gründe an, weshalb er dennoch schnell zurückreisen will. Dieser zweite Abschnitt ist vom ersten deutlich abgesetzt durch das adversative - zugleich trennende und verbindende - sed. Der begründende Charakter wird in (18) mit kausalem quoniam verdeutlicht, in (19) dagegen mit finalem (quo citius) eo facilius.

Daraus lässt sich folgende Binnenstrukturierung ableiten:

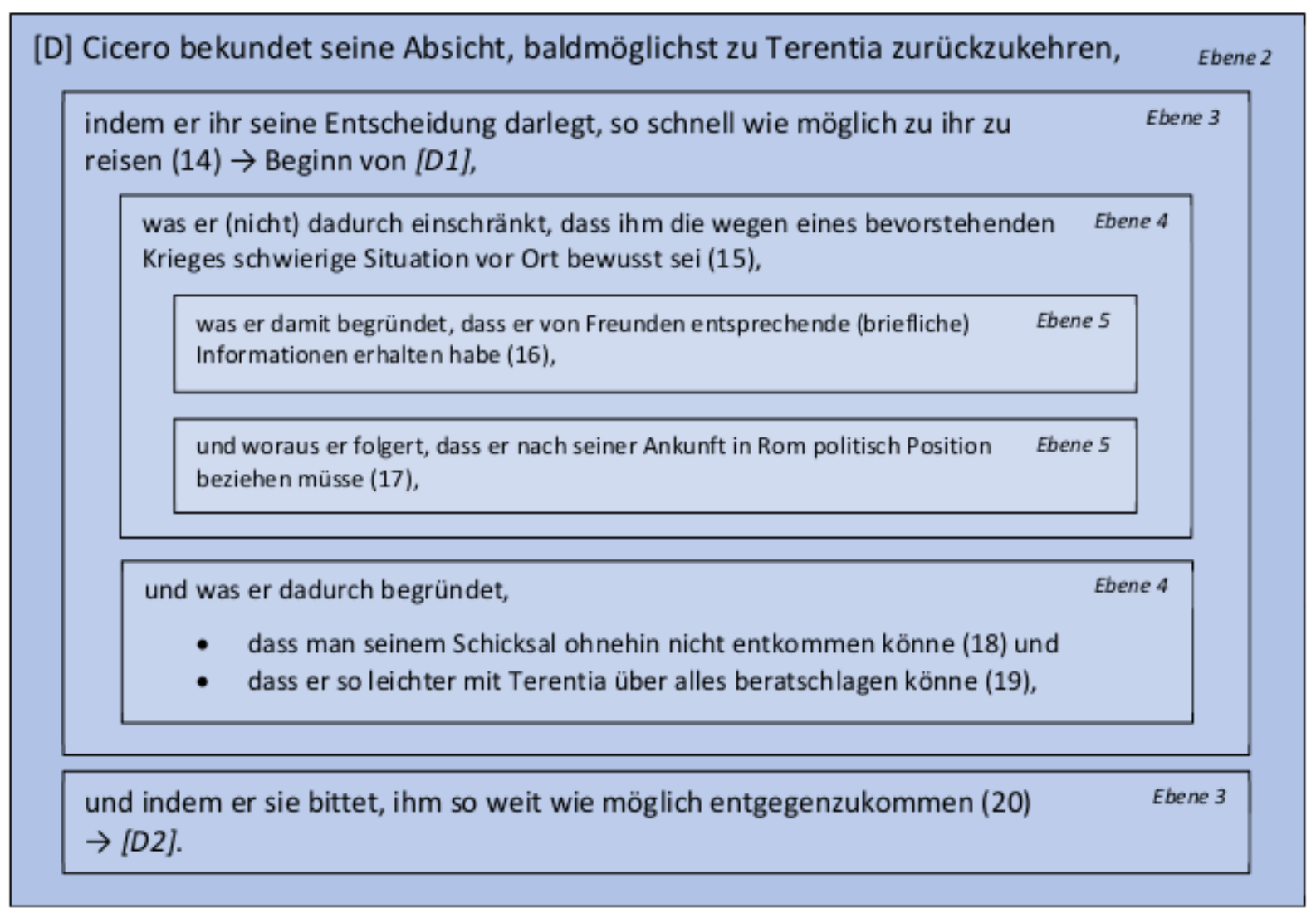

Abbildung 24: Binnenstrukturierung fam. 14.5, Teiltext $D$

Teiltext [E]

Durch die links versetzte explizite Themenangabe De hereditate Preciana in (21) wird der folgende Teiltext sehr deutlich von [D] getrennt. Es geht in [E] darum, dass Cicero alles Notwendige zur Wahrung seiner Interessen im Zusammenhang mit der Erbschaft des Precius regeln will, wozu er Terentias Unterstützung benötigt. Das Thema wird noch weiter spezifiziert durch auctio und nostrum negotium, wodurch bereits der insgesamt sehr aktionsorientierte (direktive und kommissive) Charakter von [E] vorgegeben ist, welcher im Übrigen durch entsprechende Verben im (finalen) Konjunktiv und Futur betont wird: velim cures, (ut) curet, (ut) fiat 
bzw. agemus und curabis. Kennzeichnend sind außerdem die disjunktive Konnexion mit aut sowie die temporalen Spezifizierungen (cum venerimus, ante meum adventum) und v. a. die vielen Konditionalsätze, welche die verschiedenen Handlungsmöglichkeiten verdeutlichen. Dabei wirkt sin in (25) zugleich demarkativ und verbindend. Außerdem hat es einen quasi zusammenfassenden und abschließenden Charakter, was noch unterstützt wird durch die Rückbezüge auf (21): Die Formulierung hoc velim cures ut mit anschließender Erläuterung wird mit sehr ähnlichem Wortlaut aufgegriffen durch das allgemeinere curabis ut hoc ita fiat. Außerdem wird in Verbindung mit tu erneut ein betonter Perspektivwechsel vollzogen wie schon von (21) zu (23) mit nos (in ebenfalls markierter Anfangsposition).

[E] ist unterbrochen von zwei kurzen Exkursen: In (22) bringt Cicero seine Trauer über den Tod des Precius zum Ausdruck, die nur bedingt in einem funktionalen Zusammenhang mit dem Teiltext steht. Die Parenthese kann vielleicht als indirekte Verstärkung seiner Bitte an Terentia gesehen werden, indem betont wird, wie wichtig Cicero die Angelegenheit insgesamt ist. Der Exkurs ist deutlich abgegrenzt vom umgebenden Text durch quae quidem (mit Bezug auf de hereditate Preciana) auf der einen und $\operatorname{sed}^{938}$ sowie hoc (mit Rückbezug auf de hereditate Preciana) auf der anderen Seite. Mit dem Prädikativum salvi in (24) äußert Cicero lediglich in einer knappen Nebenbemerkung seine Hoffnung, er möge wohlbehalten in Rom ankommen.

Der Übergang von [E] zu [F] ist nicht ganz klar. (26) stellt in gewissem Sinne eine Abwandlung und (temporal spezifizierende) Ergänzung zu (23) und (24) dar, insofern in beiden Fällen auf die baldige Rückkehr Ciceros verwiesen wird, beide Male leicht eingeschränkt durch cum salvi venerimus bzw. si di adiuvabunt und jeweils markiert durch nos in Satzspitzenstellung in deutlicher Abgrenzung zu tu in (25). Im Gesamtzusammenhang ist (26) aber im Anschluss an die Beschreibung des zeitlichen Reiseverlaufs in der Einleitungssequenz [B] bereits als Überleitungssequenz zum Schlussteil des Briefes zu betrachten.

Insgesamt ergibt sich folgende Binnenstrukturierung von $[\mathrm{E}]$ :

\footnotetext{
${ }_{938}$ Vgl. Tyrrell / Purser in CICERO 1904 - 1933, III 278, die darauf hinweisen, dass sed oft nach einer Parenthese gebraucht wird.
} 
[E] Cicero bittet Terentia um Unterstützung in der Erbschaftssache des Precius,

indem er sie auffordert, entweder Atticus oder Camillus mit der Angelegenheit zu Ebene 3 betrauen (21),

wobei er erwähnt, dass ihm der Tod des von ihm sehr geschätzten Precius über- Ebene 4 aus nahe gehe (22),

und was er insoweit einschränkt, dass er sich nach seiner Rückkehr um alles

Ebene 4 Übrige selbst kümmern wolle (23),

wobei er die Hoffnung auf seine wohlbehaltene Ankunft āußert (24),

(Exkurs)

und was er insoweit (verstärkend) präzisiert, dass sie seiner Bitte auch dann

Ebene 4 nachkommen solle, wenn sie bereits aus Rom aufgebrochen sei (25).

Abbildung 25: Binnenstrukturierung fam. 14.5, Teiltext $E$

\subsection{Gesamttexthandlung: Bestimmung der Textfunktion}

Das Hauptthema von fam. 14.5 ist unbestreitbar in der Rückkehr Ciceros aus Kilikien zu sehen. Abgesehen von $[B],[D]$ und $[F]$, wo es eindeutig dominant ist, wird anderweitig ebenfalls Bezug darauf genommen. In der Übergangspassage von [B] zu [C] greift (5) mit de nave exeuntibus das Prädikat navigassemus aus (4) auf, während beim Übergang von [C] zu [D] mit (14) bzw. qui quidem quam primum ad vos venire cupimus direkt Bezug auf me ipsum [...] sive nos ipsos in (13) genommen wird. Darüber hinaus wird in [E] zu Beginn mit ante meum adventum in (21) und am Ende mit cum salvi venerimus in (23) bzw. (24) sowie (i. w. S.) auch mit sin tu iam Roma profecta eris in (25) auf die Reise referiert.

Ist nun dementsprechend die Hauptfunktion des Briefes in der Weitergabe der wichtigsten Reisedaten zu sehen? Steht also die assertive Funktion im Vordergrund? [B] und - trotz der dominant expressiven Funktion (HOFFNUNG ÄUSSERN) von (26) - [F] dienen in der Tat vornehmlich der Information Terentias über den Reiseverlauf. Dies gilt ebenso für (29) in Teiltext [G]. Allgemeiner ist der Zusammenhang bei den Illokutionen (15), (17) und (18), die eine recht deutliche (Schicksalsergebenheit und Angst vor dem Krieg und den sich daraus für Cicero ergebenden politischen Konsequenzen ausdrückende) expressive Komponente beinhalten, v. a. aber als assertiv und im funktionalen Kontext als spezifizierend (im Hinblick auf mögliche Reisehindernisse) bzw. begründend zu verstehen sind. Die übrigen assertiven Illokutionen stehen hingegen mehr oder weniger in Verbindung mit der (konventionellen) Empfangsbestätigung der Briefe Terentias in [C], welche aber wohl kaum den Hauptanlass für Ciceros Schreiben darstellt, obwohl nicht nur in (5) und (12), sondern außerdem noch in (16) auf die Briefübergabe Bezug genommen wird.

Der Wille Ciceros, so schnell wie möglich nach Italien zurückzukehren, ist im gesamten Brief stark präsent: Nichts kann ihn davon abhalten, weder schlechtes Wetter noch ein heraufziehender Krieg. Die Gründe für eine baldige Rückkehr sind zu schwerwiegend. Nur so wird er 
seine eigenen und - wie er in [D] ebenfalls andeutet - die Interessen der römischen Republik angemessen vertreten und durchsetzen können. Neben der assertiven kommt also der kommissiven Funktion im Gesamtkontext ebenfalls ein hoher Stellenwert zu, wenngleich sie nur dreimal unter den Einzelillokutionen vertreten und nur für einen der Teiltexte bestimmend ist, nämlich für [D], wohingegen sie in [E] lediglich die BITTEN an Terentia ergänzt.

Die direktive Funktion ist zahlenmäßig ähnlich schwach repräsentiert. Sie begegnet im Wesentlichen nur in [E], wo Cicero zweimal um Unterstützung in der Erbschaftssache Precius BITTET. Es ist schwierig zu beurteilen, wie wichtig diese Angelegenheit für Cicero ist, aber sie wird nicht der primäre Grund für die Abfassung des Briefes gewesen sein. ${ }^{939}$ Die vielen Details zur konkreten Abwicklung deuten außerdem auf einen eher informativen Charakter von (21) und (25) hin. Die BITTE in (20) hat nur eine unterstützende Funktion in Bezug auf den Wiedersehenswunsch Ciceros.

Obwohl neun Illokutionen einem expressiven Sprechakttyp zuzuordnen sind, spielt die expressive Funktion ebenso wenig eine besonders bedeutende Rolle für die Gesamttexthandlung. Die WOHLERGEHENSWÜNSCHE in der Brieferöffnungsphase $[A]$ und Briefbeendigungsphase [G] sowie das Lob Terentias in [C2] dienen in erster Linie der allgemeinen Beziehungsgestaltung und damit nur indirekt der Erreichung konkreter Ziele, wie sie v. a. in [E] geäußert werden. Auch der Ausdruck von Betrübnis angesichts des Todes von Precius in (22) könnte in dieser Hinsicht möglicherweise verstärkend wirken, ist aber als Bestandteil eines nur locker mit dem Gesamttext in Zusammenhang stehenden Exkurses ebenso wie der Ausdruck von Bewunderung für die Schnelligkeit des Briefboten Acastus in (7) bei der Bestimmung Textfunktion zu vernachlässigen.

Es scheint also klar, dass weder Kontakt- noch Aufforderungsfunktion den Text als Ganzes bestimmen. Bei den Einzelillokutionen und Teiltexten sind expressive und direktive Funktion von untergeordneter Bedeutung und haben zudem teilweise sogar einen starken (zusätzlichen) informationellen Wert. Schwieriger zu entscheiden ist, ob es Cicero eher darum geht, seine ABSICHT zur raschen Rückreise zu BEKUNDEN (= Obligationsfunktion), oder ob mehr die HINWEISE im Zusammenhang mit der Reise im Vordergrund stehen (= Informationsfunktion). In der bisherigen Forschung wird fam. 14.5 meist als (wenig expressiver) Informationsbrief wahrgenommen, ${ }^{940}$ und rein quantitativ ist die Antwort auch recht eindeutig. Von den insgesamt 29 Illokutionen sind 12 als assertiv, aber nur drei als kommissiv zu bezeichnen. Allerdings beinhalten lediglich drei der assertiven Illokutionen tatsächlich konkrete Reiseinformationen, einige haben letztlich gar nichts mit der Reise zu tun. (13) hingegen verstärkt sogar eher den kommissiven Charakter des Briefes. Am Ende sind beide Handlungsfunktionen m. E. in etwa

\footnotetext{
939 In Att. 7.1.9 äußert er sich dazu folgendermaßen: reliqua expediamus, hoc primum, quae accessit cura dolori meo - sed tamen hoc, quicquid est, Precianum cum iis rationibus quas ille meas tractat admisceri nolo. Es scheint sich also um keine große Erbschaft zu handeln. Gleichwohl ist es Cicero offenbar sehr wichtig, dass Philotimus aus der Sache herausgehalten wird.

940 Vgl. z. B. JÄGER 1986, 227: „Der Brief hat lediglich die Funktion, kurz über die baldige Heimkehr zu berichten.“ und GugLIELMI 2013, 210: „Nel complesso, si può osservare come lo scopo fondamentale della lettera sia trasmettere informazioni (quali ad esempio l'arrivo del mittente ad Atene, la ricezione di alcune lettere, la questione dell'eredità di Precio) piuttosto che esprimere emozioni e stati d'animo [...].“
} 
gleich zu gewichten. Fam. 14.5 gehört also zu den multifunktionalen Briefen mit einer Dominanz von Obligations- und Informationsfunktion.

\subsubsection{Beziehungs- und Identitätskonstitution: Das Verhältnis zwischen Cicero und Terentia}

In fam. 14.5 kommt eine ausgesprochen starke Selbstfokussierung Ciceros zum Ausdruck, dessen ganzes Denken und Handeln auf seine Rückkehr nach Italien ausgerichtet ist. Das spiegelt sich in einer sehr hohen Anzahl von Ich- und Wir-Aussagen. Allerdings beziehen diese sich oft gar nicht auf Cicero selbst, sondern auf Terentia oder dritte Personen, wie in (8), im Attributsatz in (9), in (12) und (14) bzw. in (22). Andere Äußerungen dagegen, in erster Linie die Assertiva, beschreiben tatsächlich Ciceros eigene Erlebnisse. Vollkommen im Zentrum steht Cicero mit seinen Gefühlen und Gedanken in (15) und (17). Nur zweimal - in den Kommissiva (19) und (23) - scheint er von sich und Terentia als einer Einheit zu sprechen. ${ }^{941}$ Dort geht es aber ebenso wie bei den Direktiva in (20), (21) und (25) letztlich vornehmlich ebenfalls nur um die Wahrung seiner eigenen Interessen. Abgesehen von den drei Aufforderungen und den rituellen Wohlergehensformeln, die teilweise Tullia miteinschließen, wird Terentia lediglich in [C2] angesprochen, einmal direkt in (13) und einmal indirekt (im Passiv) in (10).

Das Verhältnis von (selbstbezogenen) abreagierenden zu (partnerorientierten) sympathisierenden Expressiva ist mit 4 zu 5 recht ausgeglichen. Beide betreffen keine existenziellen Probleme, vermitteln aber dennoch große Vertrautheit und Zuneigung ${ }^{942}$ und sollen zugleich auch die Wohlgesonnenheit Terentias befördern, die sich bis zu Ciceros Eintreffen um seine Angelegenheiten (wie die Erbschaftssache Precius) kümmern muss. Hervorzuheben ist das (für eine Frau) außergewöhnliche Lob der Schreibkünste Terentias ${ }^{943}$, das im Gesamtkontext zudem als indirekte Entschuldigung für die eigene Schreibfaulheit verstanden werden kann, wobei Cicero im Übrigen über eine daraus wohl resultierende leichte Verstimmtheit Terentias einfach hinweggeht. Brieferöffnung und -beendigung reichen über die konventionellen (deklarativen) Grußformeln nicht hinaus, sind indes ergänzt um zwei zusätzliche Wohlergehensformeln. Die Zärtlichkeitsausdrücke in (2) zielen zwar nicht explizit auf Terentia, aber immerhin doch auf

\footnotetext{
${ }^{941}$ Vgl. dagegen JäGER 1986, 226 N. 110: [...] für das ungetrübte Verhältnis zu Terentia sprechen [...] die zahlreichen Wir-Aussagen, die ein Verbundenheitsgefühl zu Terentia ausdrücken." Dem kann ich mich aus den genannten Gründen nicht so ganz anschließen. Vgl. a. GUGLIELMI 2013, 210f.: „Comunque, il frequente uso di pronomi di prima persona plurale in questa lettera potrebbe essere interpretato come la manifestazione, da parte di Cicerone, di un sentimento di unione con la moglie. Considerando, però, che l'oratore, durante il proconsolato in Cilicia, si fa accompagnare dal figlio, è più plausibile ritenere che con il plurale egli voglia riferirsi appunto a sé stesso e al giovane Marco; l'interpretazione come plurale sociativo potrebbe essere applicata solamente al verbo deliberemus (\$2): se così fosse, Cicerone manifesterebbe la volontà di collaborare con Terenzia nel prendere una decisione."

942 Vgl. a. ebd., 211.

${ }^{943} \mathrm{Vgl}$. ebd., 210: „,...] in quest'epistola [...] si possono rintracciare manifestazioni di stima, seppure non esplicite, nei confronti della donna, dal momento che Cicerone la loda per l'accuratezza con cui l'ha informato, e le esprime la propria gratitudine: ciò avviene per mezzo di due superlativi, diligentissime e gratissimum; per quanto riguarda in particolare il primo, si nota un riferimento alla virtù della diligentia, che [...] è normalmente tipica del vir Romanus, e viene applicata da Cicerone anche alla moglie, che egli considera dotata di qualità eccezionali per una donna."
} 
die gemeinsamen Kinder. Durch die Verwendung der Wohlergehensformel an sich, insbesondere jedoch durch ihre stark expressive Abwandlung wird in (2) und v. a. in (27) eine intensive emotionale Verbundenheit ausgedrückt. ${ }^{944}$

Ein natürliches Gemeinschaftsgefühl äußert sich trotz der gerade gemachten Einschränkung auch in den kommissiven ABSICHTSBEKUNDUNGEN (19) und (23). In (14) schwingt implizit sogar der Wunsch nach einem baldigen Wiedersehen mit, wobei die Wir-Form sich hier nicht auf Terentia, sondern - wie im übrigen Teil des Briefes - auf Cicero (und seinen Sohn) bezieht. ${ }^{945}$

Die drei BITTEN in fam. 14.5 sind alle sehr direkt formuliert. Nur (20) ist etwas höflicher gehalten: Die tatsächliche Entscheidung wird - unter Berücksichtigung ihres Gesundheitszustands - Terentia überlassen. ${ }^{946}$ Demgegenüber sind (21), wo zumindest - wie in (20) - die Floskel velim (mit Konjunktiv) verwendet wird, und besonders (25), wo die BITTE durch das Futur und die Partikel tamen noch verstärkt wird, sehr fordernd. Dass Cicero sich so vehement dafür einsetzt, die Vertretung seiner Interessen auf Atticus oder Camillus zu übertragen, lässt sich auf seine Vorbehalte gegen Terentias Vermögensverwalter, den Freigelassenen Philotimus, zurückführen, den er unbedingt aus der Erbschaftsangelegenheit heraushalten will. ${ }^{947}$

Cicero übermittelt Terentia in (3) und (4), (26) und (29) wichtige Reisedaten und erfüllt auch sonst, wie z. B. mit der Empfangsbestätigung der Briefe Terentias, die „Auskunftspflichten“ gegenüber seiner Ehefrau. Assertiva, zu denen außer (26) alle genannten Illokutionen zählen, spielen also, obwohl oder gerade weil sie direkt, sachlich und eher emotionslos formuliert sind, eine wichtige Rolle bei der Beziehungsgestaltung. Dies gilt auch für die expressiv gefärbten Illokutionen (15) und (18), die mit der Reiseinformation insofern im Zusammenhang stehen, als sie den unbedingten Rückkehrwillen Ciceros begründen.

Es ist überhaupt kennzeichnend für den Brief, dass vielen Illokutionen innerhalb der Handlungsstruktur eine begründende oder spezifizierende Funktion zukommt. ${ }^{948}$ So erklärt Cicero in [B] die späte Ankunft in Athen und beschreibt in [C1] die Briefübergabe genauer, ja er begründet und spezifiziert sogar das Lob von Terentias Schreibfertigkeiten in [C2]. Während es in den genannten Fällen v. a. darum geht, Terentia wohlgesonnen zu stimmen, präzisiert Cicero in [E] seine Anweisungen in erster Linie deshalb, um sicherzustellen, dass die Erbschaftssache ganz nach seinen Vorstellungen (ohne ein evtl. Eingreifen von Philotimus) geregelt wird.

\footnotetext{
${ }^{944}$ Vgl. GUGLIELMI 2013, 210. Vgl. a. GUNDERSON 2007, 19f., der den Briefbeginn jedoch etwas anders beurteilt (s. a. N. 946).

945 Vgl. GUGLIELMI 2013, 210 bzw. N. 941.

${ }^{946} \mathrm{Vgl}$. a. die diesbezüglich sehr weitgehende Interpretation bei GUNDERSON 2007, 20: „It is up to Terentia to choose whether or not to be the person Cicero would choose her to be. He leaves in her hands her own health and the health of the whole family as well as the health of the relationship between husband and wife. The opening is almost chilly, the closing almost warm. She can decide whether or not to meet him halfway both literally and figuratively."

${ }^{947}$ Vgl. Att. 6.9.2 und Att. 7.1.9. Vgl. a. GUGLIELMI 2013, 209 N. 3: „Le trattative riguardanti l'eredità sono affidate da Cicerone ad Attico e a Camillo perché evidentemente l'oratore non si fida di Filotimo, liberto e procuratore di Terenzia: egli teme che il lascito di Precio cada nelle mani di costui, ma non vuole manifestare alla moglie i propri dubbi sull'onestà del liberto di lei, e allo stesso tempo si rivolge anche ad Attico pregandolo di occuparsi della questione [...]." Vgl. außerdem ebd., 211 und ebd., 216f.; JÄGER 1986, 226 sowie Shackleton Bailey in CICERO 1977, $461 \mathrm{f}$.

948 Zur damit zusammenhängenden grammatischen Struktur vgl. z. B. JÄGER 1986, 227 N. 111. VgI. a. GUGLIELMI 2013, 211.
} 
Obligations- und Informationsfunktion konkurrieren in fam. 14.5 miteinander. Cicero steht unter massivem Druck, so schnell wie möglich nach Italien zurückzukehren, weshalb er wenig Sinn für andere(s) hat. Dass er angesichts der ungewissen aktuellen politischen Situation, die für ihn mit ganz individuellen und konkreten Problemen verbunden ist, sehr mit sich selbst beschäftigt ist und eher weniger auf Terentias Bedürfnisse und Interessen eingeht, kann nicht wirklich überraschen. Trotzdem deutet er ein gemeinsames Vorgehen bei der Regelung ihrer Angelegenheiten an und hält sie über alles Wichtige auf dem Laufenden. Nirgendwo schwingt wirklich ein gegen Terentia gerichteter negativer Unterton mit. Die recht ruppigen Bitten sind eher dem Misstrauen gegenüber Philotimus geschuldet. ${ }^{949}$ Für den Gesamttext ist die Aufforderungsfunktion im Vergleich zu fam. 14.20 ohnehin von eher untergeordneter Bedeutung. Dies gilt zwar auch für die Kontaktfunktion; dennoch ist nicht zu verkennen, wie sehr Cicero sich um eine positive Beziehungsgestaltung bemüht.

Dass Cicero sich Terentia im Gegensatz zu Atticus, an den er am 16. Oktober ebenfalls einen Brief (Att. 7.1) geschrieben hat, nicht mit seinen Ängsten und Nöten anvertraut, diese nur mehr oder weniger indirekt andeutet, kann daran liegen, dass er in ihr nicht den geeigneten Ansprechpartner für solche Themen sieht, muss aber keineswegs ein Zeichen für fehlendes Vertrauen sein. Eher wird es so sein, dass er seine Frau nicht allzu sehr beunruhigen will. Besonders am Schluss in (27) deutet sich an, dass er sich große Sorgen um sie (und Tullia) macht. Außerdem wird er davon ausgehen, sie ja bald wiederzusehen und dann vieles persönlich mit ihr besprechen zu können. ${ }^{950}$ Insgesamt weist jedenfalls nichts darauf hin, dass ihr Verhältnis in irgendeiner Weise - von kleinen Missstimmungen abgesehen ${ }^{951}$ - gestört ist. Somit ist es auch wahrscheinlich, dass Cicero während seines Prokonsulats neben fam. 14.5 weitere Briefe an seine Frau geschrieben hat, die aber verloren gegangen sind. ${ }^{952}$ Belegt ist hingegen, dass Terentia seinem Wunsch entsprochen hat und (am 24. November) zu ihm nach Brundisium gereist ist. $^{953}$

\footnotetext{
949 Vgl. GuglielMI 2013, 211: „Si osserva dunque un sostanziale contrasto tra il tono generale della lettera, improntato alla manifestazione dell'affetto dell'oratore per la moglie, e il modo in cui le richieste a lei dirette vengono espresse, non caratterizzato da elementi veicolanti cortesia: questo fatto può essere attribuito [...] all'esigenza di evitare a tutti i costi che Filotimo venga coinvolto nella questione, ma tuttavia ciò non compromette la fiducia e i sentimenti del mittente nei confronti della donna. "Vgl. a. ebd., 217.

950 Vgl. z. B. JÄGER 1986, 227: „Es überrascht, wie wenig Persönliches der Brief an Terentia enthält. Nichts von all den im Brief an Atticus geäußerten Ängsten und Zweifeln ist herauszuhören. Er vermeidet es, Terentia mit seinen Sorgen zu belasten. [...] Breitere Ausführungen sind nicht notwendig, zumal er hofft, die betreffenden Dinge bald selbst mit ihr besprechen zu können: [...]. Atticus gegenüber schreibt er mit ganz anderen Erwartungen und Intentionen. Im Gegensatz zu Atticus wird Terentia wohl auch nur bedingt in der Lage gewesen sein, Cicero mit Rat und Tat zur Seite zu stehen. In den beiden Briefen liegen also unterschiedliche Zweckabsichten zugrunde, an denen Inhalt, Form und Sprache ausgerichtet sind. “Vgl. a. GUGLIELMI 2013, 210.

${ }^{951}$ Auf eine leichte Verstimmtheit Terentias deutet z. B. die in (13) erwähnte Kürze ihres letzten Briefes hin. Vgl. dazu S. 194 und außerdem die Anmerkungen zur Kürze von fam. 14.20 auf S. 185 bzw. in N. 879 und N. 883.

952 Vgl. JÄGER 1986, 226: „Daß er in der gesamten Zeit seiner Abwesenheit von Rom während des Prokonsulats von Mai 51 bis 15. Oktober 50 nur einen einzigen Brief an die Familie geschrieben hat, ist ziemlich unwahrscheinlich, denn nichts deutet bisher auf eine ernsthafte Verstimmung oder Krise in der Ehe mit Terentia hin."

953 Vgl. Shackleton Bailey in CICERO 1977, 461 bzw. fam. 16.9.2. Vgl. a. GUGLIELMI 2013, 217: „Anche la rappresentazione dell'incontro avvenuto a Brindisi tra Cicerone, di ritorno dalla provincia, e la moglie lascia intendere che i rapporti tra i due continuino ad essere sereni."
} 


\subsubsection{Beispiel 3: Fam. 14.2}

\subsubsection{Situativer Kontext}

Nachdem es Ciceros Widersacher Clodius endlich gelungen ist, sich zum Volkstribunen wählen zu lassen, ergreift dieser sofort die Gelegenheit, gegen jenen mittels der auch rückwirkend geltenden lex Clodia de capite civis Romani vorzugehen, nach der jeder, der - wie Cicero nach der Aufdeckung der Catilinarischen Verschwörung - einen römischen Bürger ohne ordentliches Gerichtsverfahren zum Tode verurteilt, geächtet werden soll. Kurz vor der Beschlussfassung im März 58 v. Chr. flieht Cicero aus Rom. Während des Aufenthaltes bei seinem Freund Sicca auf Sizilien erfährt er, dass in einem zweiten Gesetz, der lex Clodia de exsilio Ciceronis, eine 500-Meilen-Bannzone gegen inn verhängt wurde. Deshalb eilt er nach Brundisium und fährt von dort am 29. April mit dem Schiff nach Dyrrachium, um dann nach Kyzikos weiterzureisen. Davon rät ihm der mazedonische Quästor Gnaeus Plancius aber ab. Stattdessen nimmt er ihn als Gast zu sich nach Thessaloniki, obwohl die Stadt in der Bannzone liegt, und sichert Cicero seinen Schutz zu. Am 5. Oktober, ungefähr viereinhalb Monate nach seiner Ankunft in Thessaloniki am 23. Mai, schreibt Cicero fam. 14.2, den zweiten (erhaltenen) Brief an seine Frau während der Exilzeit. ${ }^{954}$

\subsubsection{2 Übersichtsschemata}

\subsubsection{1 Überblick über die Einzelillokutionen}

\begin{tabular}{|l|l|l|l|}
\hline Nr. & Text & Oberklasse & Untermuster \\
\hline (1) & $\begin{array}{l}\text { TULLIUS S. D. TERENTIAE SUAE ET TULLIOLAE ET CICERONI } \\
\text { SUIS }\end{array}$ & expressiv & GUNST ERWEISEN \\
\hline (2) & Noli putare me ad quemquam longiores epistulas scribere, & assertiv & ABSTREITEN \\
\hline (3) & nisi si quis ad me plura scripsit, & assertiv & ZUGEBEN \\
\hline (4) & cui puto rescribi oportere. & assertiv & BEGRÜNDEN \\
\hline (5) & nec enim habeo quid scribam & assertiv & BEGRÜNDEN \\
\hline (6) & nec hoc tempore quicquam difficilius facio. & assertiv & BEGRÜNDEN \\
\hline (7) & $\begin{array}{l}\text { ad te vero et ad nostram Tulliolam non queo sine plurimis } \\
\text { lacrimis scribere. }\end{array}$ & expressiv & SICH ENTSCHULDIGEN \\
\hline (8) & $\begin{array}{l}\text { vos enim video esse miserrimas, quas ego beatissimas semper } \\
\text { esse volui }\end{array}$ & expressiv & SICH ENTSCHULDIGEN \\
\hline (9) & idque praestare debui, & expressiv & SICH ENTSCHULDIGEN \\
\hline (10) & et, nisi tam timidi fuissemus, praestitissem. & FLUCHEN \\
\hline
\end{tabular}

\footnotetext{
954 Vgl. z. B. CORREA 2013, 85ff. und GugLIELMI 2013, 97ff. Der Begriff ,Exil’ wird hier in einer sehr allgemeinen Weise gebraucht. Ausführlicher zu den genauen rechtlichen Implikationen: GRASMÜCK 1978, 62ff. Vgl. a. CORREA 2013, 85 N. 396 und CLAASSEN 1999, 50ff. Insgesamt sind 34 Briefe aus Ciceros Exilzeit erhalten: 27 an Atticus (Att. 3), vier an Terentia (fam. 14.1 bis 14.4), zwei an Quintus (ad Q. fr. 1.3 und 1.4) und einer an Q. Metellus (fam. 5.4). Den ersten Brief an Terentia (fam. 14.4) hat er Ende April vor seiner Abreise aus Brundisium verfasst, die letzten beiden (fam. 14.1 und 14.3) sind Ende November in Dyrrachium entstanden, wohin er sich in hoffnungsvoller Erwartung einer baldigen Rückberufung nach Rom erneut begeben hat, welche letztlich im August 57 v. Chr. erfolgt. Anfang September 57 ist er dann wieder zurück in Rom.
} 


\begin{tabular}{|c|c|c|c|}
\hline (11) & Pisonem nostrum merito eius amo plurimum. & expressiv & JUBELN \\
\hline (12) & eum, ut potui, per litteras cohortatus sum & assertiv & HINWEISEN \\
\hline (13) & gratiasque egi, ut debui. & assertiv & HINWEISEN \\
\hline (14) & $\begin{array}{l}\text { in novis tribunis pl. intellego spem te habere. id erit firmum, si } \\
\text { Pompei voluntas erit; }\end{array}$ & expressiv & HOFFNUNG ÄUSSERN \\
\hline$(15)$ & sed Crassum tamen metuo. & expressiv & ANGST ÄUSSERN \\
\hline (16) & $\begin{array}{l}\text { A te quidem omnia fieri fortissime et amantissime video, nec } \\
\text { miror, }\end{array}$ & expressiv & BEGRÜSSEN \\
\hline (17) & $\begin{array}{l}\text { sed maereo casum eius modi ut tantis tuis miseriis meae } \\
\text { miseriae subleventur. }\end{array}$ & expressiv & SICH ENTSCHULDIGEN \\
\hline (18) & $\begin{array}{l}\text { nam ad me P. Valerius [...] scripsit, [...] quem ad modum a } \\
\text { Vestae ad Tabulam Valeriam ducta esses. }\end{array}$ & assertiv & HINWEISEN \\
\hline (19) & {$[\ldots]$, homo officiosus, $[\ldots]$} & expressiv & JUBELN \\
\hline (20) & [...] id quod ego maximo cum fletu legi, $[. .]$. & expressiv & $\begin{array}{l}\text { BEDAUERN BEKUN- } \\
\text { DEN }\end{array}$ \\
\hline$(21)$ & $\begin{array}{l}\text { hem, }[. . .] \text { te nunc, mea Terentia, sic vexari, sic iacere in } \\
\text { lacrimis et sordibus, }\end{array}$ & expressiv & SICH ENTSCHULDIGEN \\
\hline$(22)$ & $\begin{array}{l}\text { [...] mea lux, meum desiderium, unde omnes opem petere } \\
\text { solebant, }[. . .]\end{array}$ & expressiv & $\begin{array}{l}\text { KOMPLIMENT MA- } \\
\text { CHEN }\end{array}$ \\
\hline$(23)$ & idque fieri mea culpa, & expressiv & SICH ENTSCHULDIGEN \\
\hline (24) & qui ceteros servavi ut nos periremus! & expressiv & FLUCHEN \\
\hline$(25)$ & $\begin{array}{l}\text { Quod de domo scribis, hoc est de area, ego vero tum denique } \\
\text { mihi videbor restitutus si illa nobis erit restituta. }\end{array}$ & expressiv & HOFFNUNG ÄUSSERN \\
\hline (26) & verum haec non sunt in nostra manu; & assertiv & FESTSTELLEN \\
\hline (27) & $\begin{array}{l}\text { illud doleo, quae impensa facienda est, in eius partem te } \\
\text { miseram et despoliatam venire. }\end{array}$ & expressiv & SICH ENTSCHULDIGEN \\
\hline (28) & quod si conficitur negotium, omnia consequemur; & expressiv & HOFFNUNG ÄUSSERN \\
\hline (29) & $\begin{array}{l}\text { sin eadem nos fortuna premet, etiamne reliquias tuas miseras } \\
\text { proicies? }\end{array}$ & expressiv & ANGST ÄUSSERN \\
\hline (30) & $\begin{array}{l}\text { obsecro te, mea vita, quod ad sumptum attinet, sine alios [...] } \\
\text { sustinere; }\end{array}$ & direktiv & ANWEISEN \\
\hline (31) & {$[\ldots]$, qui possunt si modo volunt, $[. .]$.} & assertiv & BEHAUPTEN \\
\hline (32) & et valetudinem istam infirmam, si me amas, noli vexare. & direktiv & ANWEISEN \\
\hline (33) & $\begin{array}{l}\text { nam mihi ante oculos dies noctesque versaris. omnis labores } \\
\text { te excipere video; }\end{array}$ & expressiv & SICH ENTSCHULDIGEN \\
\hline (34) & timeo ut sustineas, & expressiv & ANGST ÄUSSERN \\
\hline (35) & $\begin{array}{l}\text { sed video in te esse omnia. quare, ut id quod speras et quod } \\
\text { agis consequamur, servi valetudini. }\end{array}$ & direktiv & ANWEISEN \\
\hline (36) & $\begin{array}{l}\text { Ego ad quos scribam nescio, nisi ad eos qui ad me scribunt aut } \\
\text { ad eos de quibus ad me vos aliquid scribitis. }\end{array}$ & assertiv & MITTEILEN \\
\hline (37) & longius, quoniam ita vobis placet, non discedam; & kommissiv & VERSPRECHEN \\
\hline
\end{tabular}




\begin{tabular}{|l|l|l|l|}
\hline (38) & $\begin{array}{l}\text { sed velim quam saepissime litteras mittatis, praesertim si quid } \\
\text { est firmius quod speremus. }\end{array}$ & direktiv & BITTEN \\
\hline (39) & Valete, mea desideria, valete. & expressiv & $\begin{array}{l}\text { WOHLERGEHEN } \\
\text { WÜNSCHEN }\end{array}$ \\
\hline (40) & D. a. d. III Non. Oct. Thessalonica. & assertiv & HINWEISEN \\
\hline
\end{tabular}

Abbildung 26: Gesamtübersicht fam. 14.2 (Einzelillokutionen) 


\subsubsection{2 Überblick über den Briefaufbau}

Cicero drückt Terentia gegenüber seine Hoffnungen und Ängste angesichts der gegenwärtigen Exilsituation aus (Kontakt) - indem

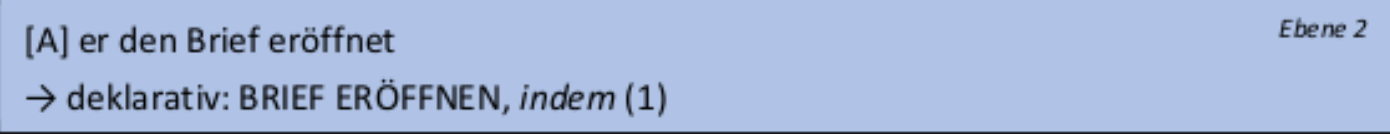

[B] sich für die Kürze seiner Briefe an Terentia entschuldigt

$\rightarrow$ expressiv: SICH ENTSCHULDIGEN, indem | vgl. Abbildung 28

\begin{tabular}{|lc|}
\hline $\begin{array}{l}\text { [B1] er einerseits die längeren Briefe an einige andere Personen begründet } \\
\rightarrow \text { assertiv: BEGRÜNDEN, indem (2) }-(4)\end{array}$ & Ebene 3 \\
\hline \hline $\begin{array}{l}\text { [B2] andererseits die kürzeren Briefe (an Terentia) rechtfertigt } \\
\rightarrow \text { expressiv: SICH ENTSCHULDIGEN, indem (5) - (10) }\end{array}$ & Ebene 3 \\
\hline $\begin{array}{l}\text { [B3] außerdem seine Briefe an Piso begründet, } \\
\rightarrow \text { assertiv: BEGRÜNDEN, indem (11) - (13) }\end{array}$ & Ebene 3 \\
\hline
\end{tabular}

[C] Terentia gegenüber seine Hoffnungen und Ängste bezüglich der neuen Volkstribune äußert

$\rightarrow$ expressiv: HOFFNUNG und ANGST ÄUSSERN, indem (14) - (15)

[D] sich für das Leid, das Terentia seinetwegen erdulden müsse, entschuldigt

Ebene 2 $\rightarrow$ expressiv: SICH ENTSCHULDIGEN, indem (16) - (24) | vgl. Abbildung 29

[E] Terentia gegenüber seine Hoffnungen und Ängste hinsichtlich seiner - und Ebene 2 bedingt auch ihrer - (v. a. finanziellen) Zukunft äußert

$\rightarrow$ expressiv: HOFFNUNG und ANGST ÄUSSERN, indem | vgl. Abbildung 30

[E1] er die Hoffnung auf Rückerhalt seines früheren Besitzes zum Ausdruck Ebene 3 bringt

$\rightarrow$ expressiv: HOFFNUNG ÄUSSERN, indem (25) - (26)

[E2] seine (nur schwach abgemilderte) Angst hinsichtlich Terentias schwieriger Ebene 3 finanzieller Situation zum Ausdruck bringt

$\rightarrow$ expressiv: ANGST ÄUSSERN, indem (27) - (31)

[E3] seine Angst hinsichtlich Terentias schwacher Gesundheit zum Ausdruck Ebene 3 bringt,

$\rightarrow$ expressiv: ANGST ÄUSSERN, indem (32) - (35)

$\rightarrow$ multifunktional: assertiv: MITTEILEN, indem (36) + kommissiv: VERSPRECHEN, indem (37) + direktiv: BITTEN, indem (38)

$\rightarrow$ deklarativ: BRIEF BEENDEN, indem (39) - (40). 


\subsection{Einzelhandlungen: Illokutionsidentifikation und -klassifikation \\ Teiltext $[\mathrm{A}]$}

(1): Im Unterschied zu fam. 14.5 und 14.20 schließt Cicero in 14.2-ebenso wie in den anderen drei Exilbriefen - seine beiden Kinder in die Grußformel mit ein, obwohl sich der Brief eigentlich nur an Terentia richtet. ${ }^{955}$ Abgesehen von den beiden Possessivpronomina wirkt auch die zärtliche Anrede Tulliolae emotional verstärkend. Mit der zusätzlichen Ansprache der Kinder und durch das Diminutiv geht (1) über die übliche rein deklarative Standardformel hinaus; und wenngleich die Abweichungen nur geringfügig sind, erscheinen sie angesichts der wenigen Variationsmöglichkeiten und im Gesamtkontext dennoch bezeichnend, weshalb hier das expressive Untermuster (SPRACHLICHE) GUNST ERWEISEN angenommen wird, das durch folgende Handlungsbedingungen definiert ist:

„B1: Sp1 beobachtet Sp2 und glaubt sich durch dessen Anblick positiv betroffen.

B2: Sp1 bewertet Sp2 als Person positiv.

B3: Sp1 empfindet Sympathie für Sp2.“956

B1 gilt im Rahmen der Briefkommunikation nur im übertragenen Sinn, d. h., der Sprecher ist nicht beim direkten Anblick, sondern beim Gedanken an den (ihm geistig vor Augen stehenden) Adressaten „positiv betroffen“. Es bestehen gewisse Ähnlichkeiten zum Untermuster WILLKOMMEN HEISSEN, aber "anders als bei WILLKOMMEN HEISSEN ist der Anlaß von

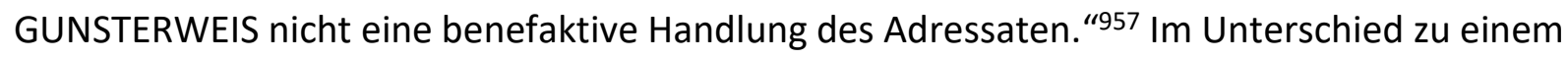
KOMPLIMENT werden nicht besondere Eigenschaften des Adressaten, wie z. B. seine Computerkenntnisse oder sein gutes Aussehen, gewürdigt, sondern die Person steht als Ganzes im Fokus. 958

\section{Teiltext [B]}

(2): Direkt wird eine Aufforderung formuliert, tatsächlich ist aber trotz des negierten Imperativs eine assertive Funktion anzunehmen. Die Wendung noli putare gehört zu den (negierten) Metadirektiva, mit denen (perlokutionär) das Ziel eines Sprechaktes signalisiert wird: „Du sollst nicht glauben, dass ... ${ }^{4959}$ Cicero STREITET mit seiner (detraktiven) Äußerung AB, dass er

\footnotetext{
955 Vgl. Prost 2015, 9: „Les enfants sont associés comme destinataires des lettres [= fam. 14.1 - 14.4] adressées à leur mère, en dépit du fait qu'ils ne pouvaient être directement concernés par nombre des considérations d'ordre politique ou financier adressées à Terentia (surtout Marcus, né en 65).“

${ }^{956}$ MARTEN-CLEEF 1991, 195f. Im Folgenden wird nur noch verkürzt von GUNST ERWEISEN die Rede sein.

957 Ebd., 193.

958 Vgl. ebd., 193: „Vom KOMPLIMENT unterscheidet GUNSTERWEIS, daß letzterer sich nicht auf spezielle Eigenschaften des Adressaten bezieht. Ein Sprecher vollzieht einen (SPRACHLICHEN) GUNSTERWEIS, um dem Adressaten als Person seine Zuneigung zu erkennen zu geben. "Als Beispiele für das Untermuster (SPRACHLICHER) GUNSTERWEIS nennt sie u. a. „Ich liebe dich!“ und „Meine sehr verehrten Damen und Herren!“ Die Beispiele für KOMPLIMENTE sind an ebd., 134ff. angelehnt. Vgl. a. S. 221. Vgl. außerdem S. 193 (zum verwandten Untermuster GRATULIEREN).

959 RISSELADA 1993, 258 definiert ,metadirectives' folgendermaßen: „Metadirectives are expressions by means of which the speaker explicitly mentions the perlocutionary effects that are systematically connected with the speech act that is being performed and ,directs' the addressee to realize these effects." Vgl. a. ebd., 272: „[...] the basic function of directive metadirective expressions is in all cases the same, viz. to emphasize the addressee's responsibility for the realization of a state of affairs."
} 
anderen längere Briefe ${ }^{960}$ schreibe als seiner Ehefrau. Für die Detraktiva „ist kennzeichnend: $\mathrm{da}$ von $\mathrm{H}$ gilt, er habe hinsichtlich der zuvor von $\mathrm{S}$ thematisierten Proposition $\mathrm{p}$ ein bestimmtes Wissen, und zwar, daß nicht-p. “961 Für das Untermuster ABSTREITEN kommt noch folgende Handlungsbedingung hinzu: „H gilt in epistemischer Hinsicht als notwendigerweise kompetent bezüglich $p$ und trägt die Rolle eines auf eine Unterstellung Antwortenden. " ${ }^{962}$ Da die Exilbriefe - im Gegensatz zu den späteren Briefen - allerdings nicht wirklich als kurz zu bezeichnen sind, handelt es sich wohl mehr um einen imaginären Vorwurf, auf den Cicero hier reagiert, obwohl nicht auszuschließen ist, dass es ein entsprechendes Schreiben Terentias im Vorfeld gegeben hat. Immerhin wird in späteren Briefen eine gewisse Trägheit Ciceros in dieser Hinsicht angedeutet, und in Anbetracht der prekären Situation erwartet seine Frau wohl verständlicherweise häufige und umfassende Lebenszeichen. Der letzte überlieferte Brief liegt fast ein halbes Jahr zurück, und wir wissen nicht, wie die Kommunikation in der Zwischenzeit verlaufen ist. Für die sprechakttheoretische Bewertung (als reaktiver Sprechakt) ist dies aber letztlich unerheblich. Implizit enthalten ist im Übrigen auch, wie in den folgenden vier Illokutionen, eine expressive Komponente, insofern Cicero SICH für die relative Kürze seiner Briefe ENTSCHULDIGT. ${ }^{963}$ Dieses Untermuster ist auf der Ebene der Einzelillokutionen jedoch nicht dominant, sondern entfaltet seine volle Wirkung vielmehr erst auf der Teiltextebene. ${ }^{964}$

(3): Dem Konditionalsatz wird entgegen dem allgemeinen Grundsatz ${ }^{965}$ ein eigenständiger Handlungswert zugemessen: Cicero schränkt seine Aussage in (2) ein, indem er ZUGIBT, dass es Ausnahmen gebe, nämlich in Bezug auf die Personen, die ihm selbst einen ausführlicheren Brief geschrieben hätten. ${ }^{966}$ Wie für ABSTREITEN gilt - neben den allgemeinen Handlungsbedingungen für die Konfirmativa ${ }^{967}$ - folgende spezielle Bedingung: „H ist in epistemischer Hinsicht notwendigerweise kompetent bezüglich $\mathrm{p}$ und trägt die Rolle eines auf eine Unterstellung Antwortenden. “968 Das Eingeständnis Ciceros ist nur indirekt formuliert: Damit dass er seine ursprüngliche Aussage in (2), er hätte niemandem längere Briefe geschrieben, einschränkt, GIBT er zugleich ZU, dass dies eben doch der Fall ist. Andererseits steht (3) aber ebenso wie (4) bis (6) im Gegensatz zu (2) entsprechend der assertiven Funktion im Indikativ. Textoberfläche und Handlungsebene korrespondieren also in dieser Hinsicht miteinander.

(4): Man könnte (4) als restringierenden Attributsatz sehen, dem entsprechend kein eigener Illokutionsstatus zukäme: Cicero will nur einigen der Absender, die ihm ausführlicher geschrieben haben, länger antworten, nämlich denjenigen, denen er meint zurückschreiben zu müssen. Einleuchtender erscheint es aber, die Aussage in dem Sinne zu interpretieren, dass Cicero sich allein deshalb, weil jemand ihm ausführlicher geschrieben hat, dazu verpflichtet fühlt,

\footnotetext{
960 Shackleton Bailey in CICERO 1977, 287 geht von einem absoluten Komparativ aus und versteht longiores litteras eher als „Briefe von beträchtlicher Länge“.

961 RoLf 1983, 195.

962 Ebd., 196.

963 Vgl. S. 216.

${ }^{964}$ Vgl. Kap. 2.1.3.2.4.

965 Vgl. S. 181.

${ }^{966}$ Zu nisi si vgl. Shackleton Bailey in CICERO 1977, 287, der bemerkt, dass diese Formulierung sowohl in literarischer Prosa als auch in der Komödie zu finden sei. Vgl. a. KüHNER 1879, 938 (§ 217).

967 Vgl. S. 192.

968 ROLF 1983, 178.
} 
ebenfalls einen längeren Brief zu verfassen. Die Ausnahme, von der Cicero in (3) spricht, wird also damit BEGRÜNDET, dass er glaube, es gehöre sich so, mit einem längeren Brief zu antworten, wenn ein ausführlicher Brief vorangegangen ist. Vorausgesetzt wird dabei ein (potenzieller) Einwand Terentias gegen die Aussage in (3), da BEGRÜNDEN zu den re-initiativen argumentativen Sprechaktuntermustern gehört. Das „Ziel [der argumentativen Sprechakte liegt], darin daß deren Adressat glaubt: $p$ ist hergeleitet. “969 Für BEGRÜNDEN gilt zudem (in Abgrenzung zum Untermuster BEWEISEN) folgende Handlungsbedingung: „S hat Anhaltspunkte (Gründe) für die Überzeugung, daß p; es ist jedoch nicht sicher, daß diese Gründe hinreichend sind für diese Überzeugung. “970 Mit oportere wird der Zwang zum Schreiben betont und damit die Überzeugungskraft der BEGRÜNDUNG erhöht.

(5) und (6): Während es in (4) darum geht, weshalb Cicero einigen anderen längere Briefe schreibt, BEGRÜNDET Cicero in (5) und (6), warum er Terentia nur relativ kurze Briefe schreibt. Da zwei verschiedene, voneinander unabhängige Gründe dafür benannt werden, wird von zwei separaten Illokutionen ausgegangen: (5) = Es gebe einfach nichts, worüber er schreiben könnte. ${ }^{971}(6)=$ Außerdem bereite ihm im Moment nichts größere Probleme. Das Untermuster BEGRÜNDEN wird indiziert durch das kausale enim in (5), das auch für die folgende Illokution (6) gilt, die nebenordnend mit nec angeschlossen ist. Der Komparativ difficilius in (5) intensiviert die Begründung.

(7): Terentia und Tullia werden hier und im Folgenden als eine Einheit betrachtet, die den Sohn Marcus ebenfalls einschließen wird, welchen Cicero wohl nur aufgrund seines jungen Alters von ca. sieben Jahren nicht explizit erwähnt. Die Konjunktion vero ist ein Hinweis darauf, dass die vorangehende BEGRÜNDUNG fortgesetzt und spezifiziert wird, und zwar insofern, als Cicero seiner Familie nicht ohne viele Tränen ${ }^{972}$ schreiben könne, ihm das Schreiben gerade an seine Liebsten also besonders schwer falle. Gleichzeitig erfolgt der Übergang zu einer ausgesprochen emotionalen Passage. In Anbetracht der affektiv-emotiven Lexik (Possessivpronomina, Diminutiv, non sine plurimis lacrimis) und des Gesamtkontextes sowie unter Anwendung des Absurditätskriteriums erscheint eine dominant assertive Handlungsfunktion wenig wahrscheinlich. Vielmehr ist ein Sprechakt des Typs SICH ENTSCHULDIGEN ${ }^{973}$ anzunehmen: Beim Gedanken an seine Familie wird Cicero offenbar von einer großen Traurigkeit erfasst, welche man als Folge eines überwältigenden Schuldgefühls deuten kann. Für das Untermuster SICH ENTSCHULDIGEN gelten folgende Handlungsbedingungen:

„B1: Sp1 ist verantwortlich für eine Handlung $\mathrm{H}$ oder eine Unterlassung $\mathrm{U}$, von der bzw. deren Folgen Sp2 betroffen ist.

B2: Sp1 bewertet $\mathrm{H}$ bzw. U negativ für Sp2 und negativ im Rückbezug auf sich selbst.

B3: Sp1 bedauert H bzw. U.“974

\footnotetext{
969 RolF 1983, 202.

970 Ebd., 203.

${ }^{971}$ Zu den Erwartungen an den Inhalt eines Briefes in der römischen Antike (certiorem facere vs. iocari) vgl. Kap. 1.2.1.2.

972 Zum Motiv der durch das Schicksal der Verbannung verursachten Tränen vgl. z. B. GUGLIELMI 2013, 141.

973 Vgl. S. 216.

974 MARTEN-CLEEF 1991, 290.
} 
(8): Der spezifizierende Attributsatz ist eng auf den Hauptsatz bezogen, mit dem er eine illokutionäre Einheit mit konzessiver Komponente bildet: „Obwohl ich wollte, dass ihr immer ein vollkommen glückerfülltes Leben führt, muss ich nun mit ansehen, wie zutiefst unglücklich ihr seid." Wie in (7) wird auch hier kaum die Übermittlung einer Information i. e. S. angestrebt. Zwar gibt es Hinweise auf eine mögliche assertive Handlungsfunktion: Es liegt ein Deklarativsatz mit Attributsatz im Indikativ und Acl vor. Die Konjunktion enim deutet auf das Untermuster BEGRÜNDEN hin, und tatsächlich geht es auch darum, zu begründen, warum Cicero ein schlechtes Gewissen hat und beim Schreiben so weinen muss, bzw. immer noch um die Frage, weshalb er keine längeren Briefe an die Familie schreibt. Der (inhaltliche) Kontext und intensivierende Ausdrücke wie semper sowie die superlativisch gebrauchten Adjektive beatissimas und miserrimas sprechen jedoch für die Dominanz einer expressiven Funktion. Zu verweisen ist an dieser Stelle zudem auf einen entsprechenden Topos der miseratio: die Gegenüberstellung von früherem Glück und aktuellem Unglück. ${ }^{975}$ Damit wird die Größe der Schuld betont, die Cicero am Schicksal seiner Familie trägt und die er ständig vor Augen hat. Wie in (7) liegt das Untermuster SICH ENTSCHULDIGEN vor. Wie dort schwingt aber auch Selbstmitleid mit, finden sich also Anklänge an das abreagierende Untermuster JAMMERN: „Ich Unglückseliger, der ich euch so bekümmert sehen muss, werde von Schmerz und Tränen überwältigt!“ Die (sympathisierende) ENTSCHULDIGUNG ist wohl dennoch aufrichtig gemeint. ${ }^{976}$

(9): Es gibt nichts, was auf den ersten Blick gegen eine Kategorisierung als assertive Illokution sprechen würde, sodass man vom Untermuster HINWEISEN oder auch - falls Terentia entsprechende Vorwürfe erhoben haben sollte - ZUGEBEN ${ }^{977}$ ausgehen müsste. Berücksichtigt man allerdings den Gesamtzusammenhang, scheint eher eine expressive Handlungsfunktion vorzuherrschen: Cicero macht sich Vorwürfe, weil er nicht für seine eigene Familie sorgen konnte, wie er es eigentlich hätte tun müssen. Hier wird ebenfalls an einen Topos der miseratio erinnert: Cicero war untätig in einer Situation, in der er hätte handeln müssen. ${ }^{978}$ Damit verweist er deutlich auf seine Verantwortung für das Unglück seiner Familie, wie es kennzeichnend für Sprechakte des Typs SICH ENTSCHULDIGEN ist. Wie in (7) und (8) ist auch ein Anflug von Selbstmitleid zu bemerken, etwas mehr noch aber zudem Ärger (über sich selbst), wie er dann in (10) dominant wird.

(10): Was eine mögliche Klassifizierung von (10) als assertiv angeht, gilt das bereits zu (9) Angemerkte, wobei hier jedoch ein Irrealis im Konjunktiv Plusquamperfekt vorliegt. Wie in den vorangehenden Illokutionen sind Anzeichen von Selbstmitleid (JAMMERN) und Schuldgefühl (SICH ENTSCHULDIGEN) zu erkennen, weil Cicero durch seine Ängstlichkeit das Unglück der eigenen Familie verursacht habe - was im Übrigen erneut auf einen Topos der miseratio weist $^{979}$ - ; im Vordergrund steht allerdings der Ärger, der sich in (9) bereits andeutet hat. Obwohl letztlich sehr schwer zu entscheiden ist, welche Handlungsfunktion tatsächlich dominiert, erscheint mir eine Zuordnung zum expressiven Untertyp FLUCHEN am überzeugendsten, das durch folgende Handlungsbedingungen definiert ist:

\footnotetext{
975 Vgl. Guglielmi 2013, 142 (mit Bezug auf GARCEA 2005, 160).

976 Vgl. JÄGER 1986, 105.

977 Vgl. S. 215.

978 Vgl. GugLIELMI 2013, 142f. (mit Bezug auf GARCEA 2005, 215 bzw. Cic. inv. 1.108).

979 Vgl. GUGLIELMI 2013, 142, die zudem auf GARCEA 2005, 219 verweist.
} 
„B1: Sp1 ist von einem Sachverhalt S betroffen. Die Verantwortlichkeit für S liegt bei Sp1, Sp3 oder der nicht-personalen Quelle Q. (Bei Dialogsituation gilt zusätzlich: Sp1 nimmt an, daß Sp2 Kenntnis von $\mathrm{S}$ hat.)

B2: Sp1 bewertet $\mathrm{S}$ negativ für sich selbst.

B3: Sp1 ist ärgerlich über S. “980

(11): Cicero drückt seine Wertschätzung und Dankbarkeit gegenüber Piso aus. ${ }^{981}$ Diese können als Grund für das bzw. die in (12) und (13) erwähnten Schreiben gelten. Je nachdem, wie man diese Illokution bewertet, könnte man hierin auch eine Fortsetzung des mit (3) einsetzenden BEGRÜNDENS sehen. Piso gehört vielleicht zu den in (3) und (4) genannten Ausnahmen. Allerdings äußert sich Cicero nicht zur Länge der Briefe an Piso. Und er muss ja nicht einen (potenziellen) Vorwurf Terentias entkräften, dass er anderen überhaupt Briefe schreibe, sondern dass er anderen ausführlicher schreibe. Der Deklarativsatz steht zwar im Indikativ Präsens; dass es sich aber nicht um einen rein assertiven Sprechakt handelt, wird durch die in Ausdrücken wie amo plurimum, (Pisonem) nostrum und merito enthaltene expressiv-evaluative Komponente betont. Ein weiterer Hinweis darauf, wie die Äußerung zu verstehen ist, findet sich in (13): gratias egi. Es geht Cicero wohl v. a. darum, seine Freude über den Schwiegersohn und dessen Verdienste zu äußern. Deshalb wird (11) dem Sprechaktuntermuster JUBELN ${ }^{982}$ zugeordnet.

(12) und (13): Die beiden kurzen Komparativsätze in (12) und (13) dienen lediglich der (kausalen bzw. modalen) Spezifizierung und haben keinen eigenen Handlungswert, auch wenn man dies gerade in Bezug auf ut debui in (13) anders sehen mag, wo eine gewisse Parallele zu cui puto rescribi oportere in (4) zu erkennen ist. Im Gegensatz zu (11) steht bei beiden Illokutionen deutlich die assertive Funktion im Zentrum. Cicero WEIST Terentia darauf HIN, dass er einen Brief (oder mehrere Briefe) an Piso geschrieben habe, in dem (bzw. denen) er ihn ermuntert (12) und ihm gedankt (13) habe. Dabei ist eher von HINWEISEN als MITTEILEN auszugehen: Die Information ist wichtig für die Gestaltung des Alltags in Rom. Terentia steht in persönlichem Kontakt zu Piso und sollte daher darüber Bescheid wissen, dass Cicero seiner moralischen Pflicht nachgekommen ist, dem Schwiegersohn gebührend zu danken. Wenn man den möglichen Bezug auf den ersten Teil von [B] berücksichtigt, käme auch eine Kategorisierung als ZUGEBEN in Betracht, wobei in (13) mit ut debui gleichzeitig eine BEGRÜNDUNG gegeben wird, nicht nur für die in (12) und (13) erwähnten Briefe, sondern auch in Bezug auf (2) bis (4).

Teiltext [C]

(14) und (15): Mit dem Satz in novis tribunis pl. intellego spem te habere wird ähnlich wie mit dem Attributsatz in fam. 14.5.1 (9) nur der Ausgangspunkt für die daran anschließenden Bemerkungen in (14) und (15) gesetzt, indem Cicero eine Äußerung Terentias aufgreift: „Was deine Hoffnung betrifft, die du in die neuen Tribunen setzt: Diese ..." Der Satz hat keinen weiteren Informationswert für Terentia, weshalb hier keine gesonderte Illokution anzunehmen ist. Im Folgenden äußert Cicero sich zu seinen eigenen Erwartungen: (14) beinhaltet einen

\footnotetext{
980 MARTEN-CLEEF 1991, 332.

981 Piso hat wegen Cicero sogar auf die Quästur verzichtet: Vgl. GugLIELMI 2013, 140.

982 Vgl. S. $191 f$.
} 
vorsichtigen Ausdruck von Hoffnung, dass Terentias Zuversicht hinsichtlich der neuen Volkstribune begründet sei ${ }^{983}$, eingeschränkt durch den Konditionalsatz. Indizien für die Annahme des Untermusters HOFFNUNG ÄUSSERN ${ }^{984}$ sind das Futur und auch das Pronomen id, das sich auf spem im vorangehenden Satz bezieht. Der Gegensatz (sed tamen) zu der in (15) GEÄUSSERTEN ANGST, dass Crassus ihrem Ziel im Wege stehen könnte ${ }^{985}$, spricht ebenfalls für die Annahme einer expressiven und gegen eine assertive Funktion (im Sinne von PROGNOSTIZIEREN $^{986}$ ). In (15) wird die expressive Funktion bzw. das Untermuster ANGST ÄUSSERN durch metuo recht deutlich angezeigt. ANGST ÄUSSERN ist durch folgende Handlungsbedingungen gekennzeichnet:

„B1: Sp1 antizipiert einen Sachverhalt S, von dem er betroffen ist. (Bei Dialogsituation gilt zusätzlich: Sp1 nimmt an, daß Sp2 Kenntnis von S hat.)

B2: Sp1 bewertet $S$ negativ für sich selbst.

B3: Sp1 hat Angst vor S. “987

Teiltext [D]

(16): Der Nachsatz nec miror spezifiziert lediglich evaluativ den ersten Teil des Satzes, sodass von einem gemeinsamen Handlungs- und Informationswert der gesamten Äußerung auszugehen ist: „Ich wundere mich nicht darüber, dass du alles so vorbildlich erledigst." oder noch kürzer: „Natürlich erledigst du alles ganz hervorragend!“ Da Cicero selbst von den Aktivitäten Terentias profitiert, ist vom Untermuster BEGRÜSSEN auszugehen. ${ }^{988}$ Indikatoren der expressiven Funktion und speziell des Untermusters BEGRÜSSEN sind die wertenden Adverbien im Superlativ (fortissime et amantissime), mit denen auf die römischen Tugenden fortitudo und amor verwiesen wird. ${ }^{989}$ Das Pronomen omnia und ganz besonders nec miror verstärken das Lob für Terentias Tapferkeit und ihren liebevollen Eifer.

(17): Der Konsekutivsatz spezifiziert eius modi und bildet mit dem Hauptsatz eine illokutionäre Einheit. ${ }^{990}$ Im Mittelpunkt steht dabei die missliche Lage Terentias, die durch ihr Bemühen, Ciceros Leid zu lindern, entstanden ist. Entsprechend finden sich Ausdrücke aus dem Sachfeld maeror und miseria. Das Unglück wird durch Alliterationen betont: miseriis - meae - miseriae bzw. tantis - tuis. Verstärkend wirkt auch die wiederholte (antithetische) Referenz auf Cicero

\footnotetext{
983 Fam. 14.2 entstand kurz nach den Wahlen für das Jahr 57. Die neuen Volkstribune traten am 10. Dezember ihr Amt an, unter ihnen Milo und Sestus, die Cicero zu einem früheren Zeitpunkt vor Gericht vertreten hatte. Trotz anfänglicher Zuversicht, dass alle auf Ciceros Seite stehen würden, haben sich zwei von ihnen später von ihm abgewandt: Vgl. Shackleton Bailey in CICERO 1977, 287.

${ }^{984} \mathrm{Vgl}$. S. 198.

985 Während Pompeius sich mittlerweile, nachdem er sich mit Clodius überworfen hatte, für eine Rückkehr Ciceros einsetzte, waren Crassus und Cicero einander hingegen weiterhin feindlich gesinnt: Vgl. Shackleton Bailey in ebd., 287.

${ }^{986}$ Vgl. S. 179.

987 MARTEN-CLEEF 1991, 338.

988 Vgl. S. 192 sowie die Erläuterungen zu (22) in diesem Teilkapitel.

989 Nach Guglielmi 2013, 143 bzw. MenNA 1955, 132 sind die Adverbien im Superlativ umgangssprachlich. Zu fortissime und amantissime bzw. zu den Begriffen fortitudo und amor vgl. a. GUGLIELMI 2013, 143 N. 3 (mit Verweis auf HellegouARC'H 1972 in der Ausgabe 1963).

${ }^{990} \mathrm{Vgl}$. Shackleton Bailey in CICERO 1977, 287: „These words [eius modi ut ... subleventur] function like an adjective qualifying casum. It does not seem necessary to add esse." Die Verbindung von eius modi mit dem Konsekutivsatz erhält also den Stellenwert eines bloß qualifizierenden Adjektivs.
} 
und Terentia (z. B. durch Possessivpronomina). ${ }^{991}$ Zudem finden sich erneut Topoi der miseratio wie das Mitgefühl mit Nahestehenden und die Selbstbeschuldigung. ${ }^{992}$ Die Art der Illokution wird ziemlich deutlich durch das einleitende maereo indiziert. Cicero drückt sein Bedauern über Terentias Situation aus, an der er sich selbst die Schuld gibt. Dies entspricht der Definition des expressiven Untermusters SICH ENTSCHULDIGEN. ${ }^{993}$

(18): Cicero WEIST Terentia darauf HIN, dass er von P. Valerius gehört habe, sie sei gewaltsam zur Tabula Valeria verschleppt worden. ${ }^{994}$ Die Information für Terentia besteht dabei nicht in den wiedergegebenen Geschehnissen an sich, sondern darin, dass Valerius Cicero davon unterrichtet hat. Sie bildet den erklärenden Hintergrund für die Aussagen in (17) und (19) bis (21).

(19): Das Lob des Valerius in der Apposition stellt einen "Mini-Exkurs" dar, in dem Cicero (assertiv) MITTEILT, Valerius sei ein pflichtbewusster Mann. Diese Äußerung hängt nur insoweit mit dem umgebenden Text zusammen, als Cicero seine Einschätzung wohl auch daraus ableitet, dass Valerius seiner freundschaftlichen Pflicht des certiorem facere nachgekommen ist, wie sich aus (18) ergibt. Indirekt drückt Cicero seine Dankbarkeit dafür bzw. seine Freude über die Verdienste des Freundes aus, was dem expressiven Sprechaktuntermuster JUBELN ${ }^{995}$ entspricht, welches auch durch das evaluative officiosus sowie v. a. den Gesamtzusammenhang indiziert wird und als dominant gelten kann.

(20): Während in (18) nur weitgehend sachlich der Bericht von Valerius wiedergeben wird, drückt Cicero in (20) seine Traurigkeit über die Geschehnisse aus. Dass es nicht um eine rein assertive Beschreibung seines Gefühlszustandes geht, ergibt sich aus dem Kontext. Die superlativische Wendung maximo cum fletu enthält eine starke expressive Note. Der Grund für Terentias Unglück liegt im vorliegenden Fall zumindest nicht direkt in Ciceros Verantwortungsbereich, wenngleich er sich in (23) letztlich doch die Schuld gibt. Gleichwohl ist an dieser Stelle zunächst einmal kein Sprechakt des Typs SICH ENTSCHULDIGEN, sondern BEDAUERN BEKUN$\mathrm{DEN}^{996}$ anzunehmen, wonach der „Sprecher lediglich in der Rolle des Beobachters [ist], da er weder Betroffener noch Urheber des Sachverhalts ist " ${ }^{\text {"997, }}$, wobei Cicero (nicht nur) im vorliegenden Fall kein Beobachter i. e. S. ist, sondern nur auf die Nachricht eines Dritten reagiert. Für das Untermuster BEDAUERN BEKUNDEN gelten folgende Handlungsbedingungen:

„B1: Sp1 beobachtet einen gegenwärtigen Sachverhalt S, von dem Sp2 betroffen ist.

B2: Sp1 bewertet S negativ für Sp2 und negativ im Rückbezug auf sich selbst.

\footnotetext{
991 Vgl. GUGLIELMI 2013, 143.

992 Vgl. ebd., 143 (mit Bezug auf GARCEA 2005, 219).

${ }^{993} \mathrm{Vgl}$. S. 216.

994 Terentia hatte zwischenzeitlich Zuflucht im Vestatempel bei ihrer Halbschwester Fabia, einer Vestalin, gesucht. Von dort wurde sie gewaltsam zur Tabula Valeria geschleppt. Warum genau Terentia dorthin verbracht wurde, ist nicht ganz klar, aber es ging wohl um finanzielle Angelegenheiten: Vgl. Shackleton Bailey in CICERO 1977, 287f. und GUGLIELMI 2013, 141. Vgl. a. BuONOPANE 2016, 56, der meint, es könnte sich evtl. um einen Einschüchterungsversuch von Clodius gehandelt haben, der Terentia von einem weiteren Einsatz für ihren Mann abhalten wollte.

995 Vgl. S. $191 \mathrm{f}$.

996 Vgl. S. 220.

997 MARTEN-CleEF 1991, 269.
} 
B3: Sp1 empfindet angesichts von S Mitleid mit Sp2." ${ }^{\text {"998 }}$

(21): Die Interjektion hem, die evtl. auch als eigene Illokution separiert werden könnte, bezieht sich als Einleitung schmerzvoller Einsichten ${ }^{999}$ auf die folgenden, eine Informations- und Handlungseinheit bildenden exklamativen Infinitive in (21) und auf (23), weniger hingegen auf die Würdigung Terentias in (22), in der ja kein Schmerz ausgedrückt wird, sondern eher Stolz. Durch hem sowie die beiden Infinitive ( $A c l$ des Ausrufs) wird sehr direkt und klar eine expressive Funktion angezeigt. ${ }^{1000}$ Intensivierend wirken dabei die Anrede mea Terentia, die asyndetische Wiederholung sic ... sic und Ausdrücke aus dem Sachfeld dolor wie vexari und iacere in lacrimis et sordibus. ${ }^{1001}$ Indirekt wird auf das Thema Tod Bezug genommen. ${ }^{1002}$ Da wie in (17) und im Unterschied zu (20) die (direkte) Schuld für das Unglück Terentias nicht bei einer anderen Person gesehen wird, sondern bei Cicero selbst, wie er in (23) zu verstehen gibt, ist vom Untermuster SICH ENTSCHULDIGEN auszugehen.

(22): Im Gegensatz zu mea Terentia in (21) handelt es sich bei (22) um mehr als eine bloße Anrede. Grundlage für diese Einschätzung ist nicht die verdoppelte und besonders expressive Anrede. Die Ausdrücke mea lux, meum desiderium sind typisch für die Sprache von Liebenden und normalerweise in der Liebeselegie zu finden. ${ }^{1003}$ Entscheidend ist vielmehr der (logische) Attributsatz, in dem Terentias Einsatz für andere positiv gewürdigt wird. Auf dieser Folie erscheint das in (21) beschriebene aktuelle Unglück umso bedauerlicher. Cicero hebt (hyperbolisch) hervor, dass alle (omnes) immer Hilfe bei ihr gesucht hätten (opem petere solebant), Hilfe, die sie jetzt selbst nicht erhält, wie man stillschweigend ergänzen kann. Damit wird abermals auf einen Topos der miseratio angespielt, der frühere Verdienste (22) und jetziges Unglück (21) einander entgegensetzt. ${ }^{1004}$ Da der Inhalt der Äußerung nicht auf Cicero selbst, sondern allgemein auf Terentias Hilfsbereitschaft (gegenüber Dritten) zielt, kann sie dem Untermuster KOMPLIMENT MACHEN ${ }^{1005}$ zugewiesen werden. Für KOMPLIMENT MACHEN gelten folgende Handlungsbedingungen:

„B1: Der Sprecher Sp1 beobachtet einen gegenwärtigen oder vergangenen Sachverhalt S, für den der Adressat Sp2 verantwortlich ist und/oder von dem Sp2 betroffen ist.

\footnotetext{
998 MARTEN-CLEEF 1991, 269.

999 Vgl. GUGLIELMI 2013, 143; MüLleR 1997, 121ff. (zur Verwendung von hem in der römischen Komödie) und HofMANN 1978, 21f. Nach Shackleton Bailey in CICERO 1977, 288 ist Cicero der einzige klassische Autor, der diese Interjektion verwendet. Zur allgemeinen handlungsfunktionalen und demarkativen Bedeutung von Interjektionen (in der römischen Komödie) vgl. a. UNCETA GómEZ 2012, 390.

1000 Zu den exklamativen Infinitiven (infinitivi indignantis, admirantis, paenitentis, ...) vgl. HoFMANN 1978, 49f. Vgl. a. GUGLIELMI 2013, $143 \mathrm{f}$.

1001 Vgl. GuglieLmi 2013, 143f. Zu iacere vgl. a. GARCEA 2005, 184.

1002 Vgl. GUGLIELMI 2013, 144 (mit Verweis auf GARCEA 2005, 195f. und Degl'Innocenti Pierini in CICERO 1996, 148 N. 225): Mit sordes wird auf die Trauerkleidung Hinterbliebener referiert und damit auf die Metapher des Verbannten als quasi Toten. Vgl. a. HoFMANN 1978, $49 \mathrm{f}$.

1003 Vgl. Guglielmi 2013, 143 und ebd., 210; RiCHLIN 2013, 98; GReBE 2003, 143 sowie DiCKEY 2002, 338. Vgl. a. MAmoojee 2001, 15, der die Anreden an dieser Stelle als Beispiel für „expression of deep feelings, emotional outbursts, pathetic lamentations“ sieht und (unter Einschluss von mea Terentia in (21)) bemerkt: „A case in point is this triple vocative in a tearful eruption of self-pity and spousal commiseration from the dumps of depression in exile [...]." Vgl. außerdem N. 891.

1004 Vgl. GUGLIELMI 2013, 143 und GARCEA 2005, 223.
}

1005 Vgl. S. 221. 
B2: Sp1 bewertet S positiv für Sp2 und positiv im Rückbezug auf sich selbst. (Anders ausgedrückt: S entspricht einem Wunsch von Sp1 und nach seiner Einschätzung auch dem Wunsch von Sp2).

B3: Sp1 empfindet angesichts von S Sympathie für Sp2. " 1006

(23): Die in (21) begonnene Reihe der stark expressiv wirkenden exklamativen Infinitive wird in (23) fortgesetzt. Cicero bezichtigt sich ganz unmittelbar selbst, schuld an Terentias unglücklicher Situation zu sein. ${ }^{1007}$ Die Verwendung des Begriffs (mea) culpa ist an dieser Stelle bezeichnend und indiziert deutlich das Untermuster SICH ENTSCHULDIGEN.

(24): Evtl. könnten (23) und (24) zu einer Handlungseinheit zusammengefasst werden, wenn man (24) als bloße Spezifikation oder Begründung der Schuld Ciceros betrachtet: "Ich entschuldige mich wegen meines Einsatzes für andere, der dein bzw. unser Leid verursacht hat.“ Es spricht allerdings viel dafür, die Illokutionen zu trennen. (24) enthält einen von (23) unabhängigen Aspekt: Die Selbstbeschuldigung wird eingeschränkt, die Schuld bei anderen gesucht. V. a. aber verschiebt sich der emotionale Fokus dahingehend, dass sich nun der Ärger über den Undank derjenigen, die er doch gerettet habe, Bahn bricht. Dieser ist gegenüber der ebenfalls vorhandenen Traurigkeit und dem Selbstmitleid, das in fam. 14.2 fast durchgehend mitschwingt, dominant, weshalb das Untermuster FLUCHEN anzunehmen ist (und nicht SICH ENTSCHULDIGEN oder JAMMERN). Verstärkend wirken ceteros und die Antithese servavi periremus, wobei mit perire erneut die Metapher vom Verbannten als Toten in den Blick gerückt wird. ${ }^{1008}$ Außerdem ist wieder auf den Topos der Gegenüberstellung vergangener Verdienste und aktuellen Unglücks zu verweisen. ${ }^{1009}$

Teiltext [E]

(25): Mit Quod de domo scribis, hoc est de area wird unter Rückgriff auf entsprechende Äußerungen Terentias nur der inhaltlich-thematische Ausgangspunkt für das Folgende gesetzt, ohne dass diesem Teilsatz ein eigener Informationswert zukäme. ${ }^{1010}$ Den Zukunftsbezug in (25) indiziert bereits das Futur I (videbor) bzw. Futur II (erit restituta). Mit tum denique wird zudem Gewissheit ausgedrückt, was dann bei Annahme einer assertiven Funktion eher für ANKÜNDIGEN ${ }^{1011}$ als für PROGNOSTIZIEREN ${ }^{1012}$ sprechen würde, da man bei Letzterem ja mehr von möglichen als von gesicherten Ereignissen ausgeht. Obschon die Lage insgesamt recht nüchtern betrachtet wird, handelt es sich in (25) letztlich aber doch um einen ungewissen Sachverhalt, den Cicero selbst kaum beeinflussen kann, wie er in (26) schreibt. Ihm bleibt nur die Hoffnung, seine verlorenen Güter und damit auch seine Ehre, um nicht zu sagen seine verlorene Identität wiederzuerlangen. ${ }^{1013}$ Somit liegt also ein expressiver Sprechakt des Typs

\footnotetext{
1006 MARTEN-CLEEF 1991, $129 f$.

1007 Vgl. GUGLIELMI 2013, 144; GARCEA 2005, 219 und JÄGER 1986, 105.

1008 Vgl. GUGLIELMI 2013, 144. Vgl. a. N. 1002.

${ }^{1009}$ Vgl. ebd., 144 mit Verweis auf GALASSO 1987, 87 N. 24, der die Besonderheit hervorhebt, dass im vorliegenden Fall ausgerechnet diejenigen, für deren Rettung sich Cicero eingesetzt habe, ihm Schaden zufügt hätten.

${ }^{1010}$ Das Haus Ciceros am Palatin hatte Clodius sofort nach dessen Abreise niederreißen lassen. Stattdessen wurde dort ein Libertas-Tempel errichtet: Vgl. Shackleton Bailey in CICERO 1977, 288.

1011 Vgl. N. 858.

1012 Vgl. S. 179.

${ }^{1013}$ VgI. z. B. GUGLIELMI 2013, 144: „Con questa tematica si combina il problema dell'identità dell'esule, già accennato in fam. 14, 4, 5 per quanto riguarda la costituzione della persona, che oltre all'anima comprende anche gli
} 
HOFFNUNG ÄUSSERN näher, welcher hier indirekt zum Ausdruck gebracht wird. Die Wiederholung restitutus - restituta wirkt dabei verstärkend.

(26): An (25) schließt die einschränkende, mit verum abgegrenzte FESTSTELLUNG ${ }^{1014}$ an, es liege nicht in ihrer Hand, ob Cicero irgendwann sein Grundstück auf dem Palatin zurückerhalten werde. Dies wird Terentia vielleicht ohnehin klar sein, aber trotzdem ist die Information, dass sie in dieser Angelegenheit nicht viel ausrichten könne, von Bedeutung, insofern es eine Bestätigung und v. a. eine indirekte Aufforderung für sie ist, nichts weiter zu unternehmen. Zugleich macht Cicero klar, dass er auch selbst in dieser Angelegenheit nichts weiter zu tun gedenke. Außerdem ist eine gewisse Angst impliziert. Dominant gegenüber den direktiven, kommissiven und expressiven Anklängen an die Untermuster ANWEISEN, ABSICHT BEKUNDEN bzw. ANGST ÄUSSERN ist jedoch am Ende die (direkt zum Ausdruck gebrachte) assertive Handlungsfunktion.

(27): Cicero ENTSCHULDIGT SICH dafür, dass Terentia trotz ihrer ohnehin prekären Lage so hohe Kosten seinetwegen zu tragen habe. Das Untermuster wird explizit durch das Verb doleo („es tut mir leid“) in Verbindung mit der Tatsache angezeigt, dass die Schuld bzw. der Grund für die ganzen Kosten bei Cicero zu verorten ist. Der Topos der miseratio vom Verlassensein von allen bezieht sich hier vor allem auf Terentia. ${ }^{1015}$ Intensivierend wirken das Gerundivum (facienda est) und expressive Ausdrücke wie miseram et despoliatam. ${ }^{1016}$

(28) und (29): Cicero entwirft mit den beiden Konditionalsatzgefügen zwei alternative Szenarien für die finanzielle Zukunft Terentias bzw. seine eigene, zunächst ein hoffnungsvolles in (28), in dem er in Aussicht stellt, dass sie alles zurückerhalten würden, dann eines, das ihm Sorge bereitet, weil Terentia gezwungen sein könnte, einen weiteren Teil ihres Vermögens zu opfern, in (29). Durch die Verbformen im Futur ${ }^{1017}$ wird der Zukunftsbezug der Aussagen verdeutlicht, durch die expressive "costruzione dilemmatica“ die Ungewissheit ihrer Lage ausgedrückt: Sie sind dem Handeln und den Entscheidungen anderer ausgeliefert. ${ }^{1018}$ Dabei stellt

ornamenta: colui che è colpito dall'esilio, insieme alla cittadinanza e agli averi, perde la sua stessa identità; così Cicerone, quando la casa gli sarà stata restituita, riterrà di aver recuperato anche sé stesso." Vgl. a. ebd., 144 N. 5 (mit Bezug auf CLAASSEN 1992, 28): „CLAASSEN 1992, 28 ricorda che questo tema contraddice il tóroৎ consolatorio secondo cui la perdita dei beni materiali non costituirebbe né un bene né un male [...]." Sie verweist dabei auf CIC. Att. 3.5, wo Cicero selbst auf diesen Topos referiert: inimici mei mea mihi, non me ipsum ademerunt. Vgl. außerdem NDIAYE 2010, 202; GARCEA 2005, 242ff. und Degl'INNOCENTI PIERINI 1998b, 52f. sowie Degl'Innocenti Pierini in CICERO 1996, 12 und ebd., 25 N. 27.

1014 Vgl. S. 197.

1015 VgI. Guglielmi 2013, 144 N. 7 (mit Bezug auf GARCEA 2005, 15): „Secondo GARCEA 2005a, 15 anche la preoccupazione di carattere economico rientra nel tóros della miseratio che prevede la rappresentazione dell'abbandono da parte di tutti della persona colpita da sfortuna; qui tale abbandono si estende anche alla moglie dell'esiliato, che [...] è pienamente partecipe del male toccato al marito."

1016 Nach Degl'Innocenti Pierini in CICERO 1996, 148 N. 228 handelt es sich bei despoliatum wohl um einen eher umgangssprachlich-expressiven Ausdruck. Vgl. a. GUGLIELMI 2013, 145 N. 2.

${ }^{1017}$ Auch conficitur ist bezogen auf die Zukunft. Nach Shackleton Bailey in CICERO 1977, 288 ist die Annahme eines Futurs conficietur unnötig.

1018 Vgl. GUGLIELMI 2013, 145: „La struttura della frase è [...] caratterizzata da una costruzione dilemmatica, costituita dalla presentazione, per mezzo di proposizioni ipotetiche, di due alternative contrapposte: ciò indica l'incertezza della condizione dell'esule." Sie verweist in diesem Zusammenhang auch auf GARCEA 2004, 161f. und GARCEA 2005, $115 f$. 
sich - wie im Übrigen für den gesamten Teiltext [E] - immer wieder die Frage, ob Cicero mehr an sein eigenes Schicksal oder das seiner Frau denkt. ${ }^{1019}$

Träfe Letzteres zu, wäre für (28) z. B. das Untermuster GELINGEN WÜNSCHEN in Betracht zu ziehen, für das dieselben Handlungsbedingungen wie für das Untermuster WOHLERGEHEN WÜNSCHEN gelten. Beide gehören zur übergeordneten Gruppe „GUTEN WUNSCH ÄUSSERN“. ${ }^{1020}$ Obwohl der Fall noch uneindeutiger ist als bei (25), legen die Verbform (1. PI.: consequemur) und der Gesamtzusammenhang nahe, dass Cicero an die ganze Familie oder sogar in erster Linie an sich selbst denkt und damit eher das Sprechaktuntermuster HOFFNUNG ÄUSSERN anzunehmen ist. Wie dort ist die Formulierung zwar ziemlich nüchtern, aber es ist genauso wenig von einem assertiven Sprechakt auszugehen, sondern von einem indirekt formulierten expressiven Sprechakt.

Bei (29) liegt ebenfalls ein indirekter Sprechakt vor. Explizit wird eine Aufforderung formuliert, genauer eine Frage, auf die Cicero allerdings wohl kaum ernsthaft eine Antwort erwartet. Wenn überhaupt, wäre von einer ANTEILNEMENDEN FRAGE auszugehen, die „darauf gerichtet [ist], Informationen über Stimmungen, Empfindungen, Gefühle etc. des Hörers [bzw. Adressaten] zu erhalten mit dem Ziel, ihm eine Möglichkeit zur Aussprache zu geben und zu signalisieren, daß er dem Sprecher nicht gleichgültig ist. “1021 Durch ausdrucksstarke Substantive (fortuna), Adjektive (miseras) ${ }^{1022}$ und v. a. Verben (premet, proicies) wird allerdings eher ein expressiver Sprechakt signalisiert. Verstärkend wirkt das Adverb etiam (,sogar'). Hinzu kommen die Personal- bzw. Possessivpronomina, durch die zudem verdeutlicht wird, dass es zwar um Terentias Vermögen (tuas) geht, letztlich aber auch Cicero und die anderen Familienmitglieder (nos) betroffen sind, welche ja ebenfalls bis zu einem gewisse Grad daran teilhaben. ${ }^{1023}$ In Anlehnung an (28) wird in Bezug auf (29) nicht das auf den Adressaten (also Terentia) bezogene sympathisierende Untermuster SORGE BEKUNDEN angenommen, welches durch folgende Handlungsbedingungen charakterisiert ist:

„B1: Sp1 antizipiert eine zukünftigen Sachverhalt S, von dem Sp2 betroffen ist. Sp1 ist nicht, $\mathrm{Sp2}$ ist nicht bzw. nicht allein für das (So-)Eintreten von $\mathrm{S}$ verantwortlich.

B2: Sp1 bewertet S negativ für Sp2 und negativ im Rückbezug auf sich selbst.

B3: Sp1 hat Sorge um Sp2 wegen S. “1024

Vielmehr ist davon auszugehen, dass Cicero hier ANGST ÄUSSERT ${ }^{1025}$, die eben nicht nur das Schicksal seiner Frau, sondern auch das eigene und das der gemeinsamen Kinder betrifft.

\footnotetext{
1019 Vgl. Kap. 2.1.3.3.

1020 Vgl. S. 182.

1021 KOHL UND KRANZ 1992, 19f. Vgl. HINDELANG 1981, $219 f$.

1022 In der Formulierung reliquias miseras wird das von Cicero empfundene Unglück auf die Güter übertragen, während sich misera(s) nach anderer Lesart auf Terentia bezieht. Nach Shackleton Bailey in CICERO 1977, 288 sei aber eine Änderung von miseras zu misera nicht notwendig. Vgl. a. GUGLIELMI 2013, 145.

${ }^{1023}$ So war das Vermögen auch für den Lebensunterhalt ihres Sohnes bestimmt. Vgl. ebd., 145 und Tyrrell / Purser in CICERO 1904 - 1933, I 402.

1024 MARTEN-CleEF 1991, 283.

1025 Vgl. S. $219 f$.
} 
(30): Es handelt sich hierbei um eine explizite Aufforderung im Imperativ mit abhängigem $\mathrm{Acl}$ (sine alios sustinere), wobei der Attributsatz (quod ad sumptum attinet) das (erweiterte) Objekt bildet. Da es um die Verbesserung der Situation Terentias geht, könnte man das Untermuster RATSCHLAG ERTEILEN annehmen, welches wie folgt definiert ist:

\section{„B1: Sp2 hat ein praktisches Problem T.}

B2: Sp1 hat kein unmittelbares persönliches Interesse an der Lösung von T.

B3: Sp1 glaubt, daß X-en die beste Lösung für T darstellt bzw. daß X-en ein optimaler Beitrag zur Bewältigung von $\mathrm{T}$ ist.

B4: Es bleibt Sp2 überlassen ob er AUF [= Aufforderung] berücksichtigt oder nicht. "1026

Bei einem einfachen (eher technischen) Problem würde es sich um den Untertyp TIPP GEBEN handeln, ansonsten wird von RATEN gesprochen. Beim EMPFEHLEN käme noch eine (positive) Bewertung hinzu. ${ }^{1027}$ Allerdings entspricht (30) m. E. letztlich keinem der drei Untertypen. B1 und B3 sind zwar durchaus erfüllt. Das praktische Problem besteht darin, dass Terentia ihre Lebenshaltungskosten ${ }^{1028}$ allein nicht mehr tragen kann. Dieses könnte dadurch gelöst werden, dass sie die Hilfe anderer annimmt. Allerdings weist die eindringliche Formulierung mit intensivierender Anrede (mea vita) und Parenthese (obsecro te) darauf hin, dass Cicero entgegen B4 Terentia kaum eine Wahl lässt. ${ }^{1029}$ Das Interesse Ciceros an der Lösung ist vielleicht nicht unmittelbar, aber es geht über das reine Betroffensein als Ehemann hinaus. Cicero will seine Rückberufung nach Rom erreichen („Zielzustand“), für die u. a. - als Teil einer „,komplexen Handlungssequenz" - das Wohlergehen Terentias Voraussetzung ist, wie aus dem Folgenden deutlich hervorgeht. Dieses wiederum hängt $u$. a. davon ab, dass sie sich von anderen (finanziell) unterstützen lässt. Es besteht also eine beidseitige Präferenz, wie sie beim Untermuster ANWEISEN gegeben ist, für das folgende Handlungsbedingungen gelten:

„B1: Sp1 und Sp2 kooperieren zur Erreichung eines Zielzustandes p.

B2: Sp1 und Sp2 sind beide gleich stark an der Erreichung von $\mathrm{p}$ interessiert.

B3: Sp1 und Sp2 sind gleichberechtigte Partner.

B4: Sp1 und Sp2 sind sich über den zur Erreichung von p notwendigen Lösungsweg einig. $p$ kann nur durch die Ausführung einer komplexen Handlungssequenz HS erreicht werden.

B5: X-en ist Teil von HS oder steht in direktem Zusammenhang mit der Erreichung von p. “1030

Sicherlich würde man Cicero unrecht tun, wenn man seine (implizit) mit (30) geäußerte Sorge um Terentia als rein „zweckgebunden“ bewertet. Sie wird durchaus aufrichtig gemeint sein, ist aber als expressive Handlungsfunktion SORGE BEKUNDEN an dieser Stelle ebenso wenig wie in (29) dominant.

\footnotetext{
1026 HINDELANG 1978, 413.

1027 Vgl. ebd., 416 bzw. ebd., 417.

1028 Nachdem zunächst von den impensa die Rede war, die Terentia wegen Cicero habe, geht es nun um Terentias persönliche Lebenshaltungskosten (sumptum).

1029 Zur affektiven Intensivierung vgI. GUGLIELMI 2013, 145. Zu obsecro te vgl. a. GARCEA 2005, 230 sowie RISSELADA 1993, 248 und ebd., 253. Ersterer verweist auf einen Zusammenhang mit der rhetorischen deprecatio.

1030 HINDELANG 1978, 450.
} 
(31): Dem freien Attributsatz kommt ein eigener Informations- und Handlungswert zu. Cicero BEHAUPTET, es gebe andere, die ohne Weiteres helfen könnten (und sollten). ${ }^{1031}$ Für das (i. e. S.) assertive Untermuster BEHAUPTEN gilt: „Es ist möglich, daß H die Herleitung von $\mathrm{p}$ für unwahr hält. "1032 Im Grunde wird sich Terentia allerdings auch selbst über die finanziellen Möglichkeiten ihrer Bekannten im Klaren sein. Die assertive Handlungsfunktion ist dominant; es klingt aber außerdem eine gewisse Ungehaltenheit über die mangelnde Hilfsbereitschaft der anderen an, die auf das expressive Untermuster FLUCHEN hinweist, das insgesamt jedoch nur von untergeordneter Bedeutung ist. ${ }^{1033}$

(32): Die Äußerung ähnelt den üblichen Wohlergehensformeln. Der verneinte Imperativ noli vexare signalisiert an dieser Stelle aber wohl tatsächlich eine Aufforderung zum Handeln, welche durch den affektiven (obgleich floskelhaften) Konditionalsatz si me amas noch verstärkt wird ${ }^{1034}$ : Terentia müsse unbedingt, „wenn sie Cicero liebt“, auf ihre Gesundheit achten, um das zu erreichen, was wirklich zähle, nämlich die Rückkehr Ciceros nach Rom. Es liegt in Anknüpfung an (30) eine ANWEISUNG vor, wobei es jedoch nicht mehr um die finanzielle, sondern um die gesundheitliche Situation von Ciceros Frau geht. Wie dort scheint neben der dominanten Direktivität deutlich auch (expressive) Sorge um Terentia durch, die sich - trotz aller Konventionalität - u. a. an der expressiven Lexik (valetudinem istam infirmam, vexare, amas) festmachen lässt.

(33): Beide Sätze stehen in einer engen (Inhalts-)Beziehung zueinander, wobei der erste Hauptsatz die allgemeine Einleitung darstellt, der kein eigener Informations- und Handlungswert im Vergleich zum zweiten Hauptsatz zukommt. Man könnte möglicherweise auch zwei Illokutionen annehmen: In der ersten würde eine allgemeine Sorge um Terentia ausgedrückt, in der zweiten mit einer Konkretisierung einzelner Gedanken begonnen, die in (34) und (35) fortgesetzt wird. Überzeugender erscheint aber die Auffassung, dass es sich nur um eine stilistische Variation des gleichen Inhalts handelt. Die Formulierungen mihi ante oculos versaris und video te sind ja quasi synonym.

\footnotetext{
1031 Damit ist z. B. auch Atticus angesprochen, der gerade eine größere Erbschaft erhalten hat. Vgl. GUGLIELMI 2013, 141.

1032 RoLF 1983, 163.

1033 Es finden sich in dieser Passage ((30) bis (32)) außerdem Anklänge an den Topos der miseratio vom Verlassensein von allen: Vgl. GugLIELMI 2013, 145 N. 5 (mit Bezug auf GARCEA 2005, 215).

1034 Oft wird auf die abmildernde Funktion von si me amas und ähnlichen Bittformeln hingewiesen, welche die emotionale Verbundenheit der Kommunikationspartner und die Entscheidungsfreiheit des Adressaten betonen würden: Vgl. z. B. ebd., 146 sowie (mit speziellem Bezug auf fam. 14.2.3 (32)) GUGLIELMI 2013, 145 bzw. GARCEA 2005, 129 und Monsuez 1953, 106. Vgl. außerdem GARCEA 2005, 232. Vgl. aber auch DiCKEY 2016, 202: „Terms with such a request-intensifying function are often described as , urgent', and urgency in this sense is often considered not to be polite at all; in fact it is essentially the opposite of negative politeness [...]. What all this means is that the term ,please' cannot be consistently classified as a marker of negative politeness: it can indeed be such a marker, but it can also have other functions, including one that is diametrically opposed to negative politeness." Vgl. darüber hinaus das Kap. „Aufforderungshandlungen“ ab S. 300.
} 
Hier wird einerseits auf den Topos vom Brief als Gespräch ${ }^{1035}$, andererseits aber auch auf die rhetorische miseratio bzw. evidentia ${ }^{1036}$ verwiesen, , secondo cui per suscitare la compassione dell'uditorio si descrive una situazione particolarmente penosa come se la si vedesse con $\mathrm{i}$ propri occhi“ ${ }^{\prime 1037}$. Damit veranschaulicht Cicero, wie sehr ihn Terentias Leid berühre, welche er in ihrer Bedrängnis ständig vor Augen habe. Da er sich (im vorliegenden Zusammenhang sehr direkt) die Schuld an ihrer Lage gibt, ist eher von SICH ENTSCHULDIGEN als von BEDAUERN BEKUNDEN auszugehen. Hinzu kommen Anklänge an das Untermuster JAMMERN, wie sie in fast allen Äußerungen des Briefes zu finden sind. Dass kein assertiver Sprechakt vorliegt, wie er auf der Textoberfläche signalisiert wird, ergibt sich v. a. aus dem (inhaltlichen, situativfunktionalen und intertextuellen) Zusammenhang in Verbindung mit der speziellen Lexik. Intensivierend wirkt dabei die Formulierung dies noctesque, die verdeutlichen soll, dass Cicero sich wirklich sehr große Sorgen mache und Tag und Nacht an die schwierige Lage Terentias denken müsse. Mit omnis labores excipere weist Cicero auf Terentias Leiden hin, wobei das hyperbolische omnis ebenfalls verstärkend wirkt.

(34): Das einleitende Prädikat timeo legt explizit das Untermuster ANGST ÄUSSERN nahe. Es schwingt zwar Sorge um Terentias Gesundheit mit, im Vordergrund steht jedoch die Angst, dass Terentia dem allseitigen Druck nicht standhalten werde und dies bei ihrem Einsatz für Cicero hinderlich sein könnte, wie sich auch aus dem Folgenden klar ergibt. ${ }^{1038}$

(35): Es besteht eine große Ähnlichkeit zu (32). Trotz ihrer Nähe zu den konventionellen Wohlergehensformeln und dem expressiven Untermuster WOHLERGEHEN WÜNSCHEN handelt es sich um eine dominant direktive Äußerung, die eng in den pragmatischen Zusammenhang eingebunden und final zu interpretieren ist: Es geht um mehr als allgemeine Gesundheitswünsche. Terentias Gesundheit ist äußerst wichtig zur Erreichung ihrer Ziele, kein Selbstzweck. Die Aufforderung wird explizit mittels eines Imperativsatzes ausgedrückt. Es liegt abermals eine ANWEISUNG in beiderseitigem Interesse vor, welches durch die Verwendung der 1. Person Plural (consequamur) unterstrichen wird. Verstärkt wird sie durch die Verbsemantik von servire und durch den Finalsatz, der die absolute Notwendigkeit von Terentias Gesundheit verdeutlicht, v. a. aber durch den einleitenden Hinweis, dass alles von Terentia abhänge, der die ANWEISUNG begründet, implizit aber auch eine (untergeordnete) expressive Komponente wie ANGST ÄUSSERN enthält. Die Zweiteilung des Attributsatzes mit doppeltem quod, der das gemeinsame Ziel allgemein und umfassend beschreibt, intensiviert die Aussage zusätzlich und verbindet den Aspekt der Hoffnung (quod speras) ${ }^{1039}$ mit dem der Aktion (quod agis), welche den Hintergrund von [E] bilden.

\footnotetext{
1035 Vgl. Guglielmi 2013, 145 (mit Verweis auf GaRCEA 2005, 234, Degl'INNOCENTI PIERINI 1998a, 99f., CUGUSI 1983, 73f. sowie Thraede 1970, 25ff. und ebd., 55ff.). Nach GUGLIELMI 2013, 145f. sei die Formulierung hier auch deshalb besonders bemerkenswert, weil sie bei Cicero selten und nur in den (Exil-)Briefen und Reden begegne. Vgl. außerdem Degl'INNOCENTI PIERINI 1998a, 100.

1036 Vgl. Guglielmi 2013, 145f. mit Verweis u. a. auf GARCEA 2005, 232, CALBOLI Montefusco 1988, 103f. und LAUSBERG 2008, 399ff. (1. Aufl. 1960).

1037 GUGLIELMI 2013, 145.

1038 Vgl. a. ebd., 146.

${ }^{1039}$ Vgl. a. ebd., 146, die auf die Verbindung zu speremus in (38) verweist und darauf, dass die Hoffnung v. a. auf der Hilfe von Fürsprechern in Rom beruht habe.
} 
Teiltext [F]

(36): Das Prädikat nescio macht klar, dass es um die Weitergabe von Wissen bzw. Nicht-Wissen geht. Da der Inhalt der Aussage nicht sonderlich wichtig wirkt, wird (37) nicht als HINWEISEN kategorisiert: Cicero TEILT Terentia lediglich MIT, er wisse nicht, wem er schreiben solle, außer denen, die ihm schrieben, und denen, von denen Terentia ihm schreibe. Möglicherweise könnte man in Anlehnung an (2) und (3) auch zwei Illokutionen annehmen, von denen die zweite die erste einschränkt und quasi wieder aufhebt. Im Unterschied zum Briefanfang erscheint der spezielle Handlungswert aber zu marginal. Beide Teile haben eine assertive Funktion. Die Aufgabe der Ergänzung besteht hier tatsächlich nur in der Spezifizierung des übergeordneten Satzes.

(37): Das Futur (non discedam) verweist auf ein künftiges Handeln. Dass es sich nicht um ein rein assertives ANKÜNDIGEN handelt, erhellt sich v. a. aus dem Kausalsatz, der im Gegensatz zu anderen Kausalsätzen eine enge Einheit mit dem übergeordneten Satz bildet. Beide Teilsätze sind direkt voneinander abhängig und als eine Illokution zu betrachten. Cicero nimmt offenkundig Bezug auf einen Wunsch, den Terentia im Vorfeld geäußert hat, und VERSPRICHT ihr, sich nicht noch weiter von seinem aktuellen Aufenthaltsort (bzw. von Italien) wegzubegeben. Das Untermuster VERSPRECHEN ist durch folgende Handlungsbedingungen definiert:

„B1: Sp2 hat durch eine Initialsprechhandlung vom Typ ,symmetrische BITTE' seine Interessen am Vollzug von $\mathrm{H}$ durch Sp1 zu erkennen gegeben.

B2: Demzufolge weiß Sp1, daß Sp2 den Vollzug von H durch ihn gegenüber dem Nicht-Vollzug präferiert.

B3: Sp1 glaubt, daß er in der Lage ist, $\mathrm{H}$ zu vollziehen.

B4: Sp1 ist nicht im Rahmen gesetzlicher bzw. institutioneller Vorschriften oder Vereinbarungen verpflichtet, $\mathrm{H}$ ohnehin zu tun.

B5: Sp1 und Sp2 sind gleichberechtigte Partner hinsichtlich der Entscheidung, die Handlungsverpflichtung einzugehen.

B6: Sp1 glaubt, Sp2 habe die Absicht, sich auf den Vollzug H durch Sp1 zu verlassen.

B7: $\mathrm{H}$ kann demzufolge die Voraussetzung zum Vollzug von $\mathrm{H}^{\prime}$, die $\mathrm{Sp} 2$ vollziehen will, darstellen.

B8: Sp1 verpflichtet sich beim Vollzug von VERSPRECHEN gegenüber Sp2, H zu tun. “1040

Indirekt klingt zudem eine gewisse Hoffnung Ciceros an, dass er bald zurückkehren könne, weshalb es nicht sinnvoll erscheine, sich weiter zu entfernen. Dieser kommt aber keine größere handlungsfunktionale Bedeutung zu.

(38): Mit dem Optativ formuliert Cicero eine BITTE an Terentia, die durch quam saepissime und den Konditionalsatz noch verstärkt wird. Es handelt sich explizit um einen direktiven Sprechakt. Dieser ist dominant gegenüber dem Untermuster HOFFNUNG ÄUSSERN, das nur sehr implizit im Nachsatz praesertim si quid est firmius quod speremus mitschwingt. ${ }^{1041}$

${ }^{1040}$ Graffe 1990, 189f.
${ }^{1041}$ Vgl. GuGLIELMI 2013, 146: „[...] qui il sentimento in questione [= Hoffnung] è riferito anche all'esiliato stesso,
oltre a chi opera per lui; un probabile motivo di ciò potrebbe risiedere nel fatto che speremus, essendo inserito 
Teiltext [G]

(39): Im Gegensatz zu fam. 14.5 geht keine weitere Wohlergehensformel unmittelbar voran. Es gibt zwar entsprechende Äußerungen in (32) und (35) ${ }^{1042}$, deren Handlungsfunktion allerdings überwiegend direktiv ist, wovon in (40) kaum die Rede sein kann. Von einer rein deklarativen Funktion ist ebenso wenig auszugehen, auch wenn diese durch die Einzelstellung zunächst verstärkt wird. Die expressive Abwandlung der Verabschiedungsformel durch die Wiederholung von valete und v. a. die zärtliche Anrede mea desideria signalisieren deutlich eine Dominanz des Untermusters WOHLERGEHEN WÜNSCHEN. ${ }^{1043}$

(40): Obwohl Orts- und Datumsangabe im Allgemeinen eher selten im Postskript der Briefe Ciceros zu finden sind, schließt auch fam. 14.2 mit einem solchen assertiven HINWEIS.

\subsection{Teiltexthandlungen: Sequenzierung und Hierarchisierung \\ Teiltexte $[A]$ und $[G]$}

Im Unterschied zu den beiden anderen Beispielbriefen ist in der Begrüßungs- und Verabschiedungsformel von fam. 14.2 die expressive Funktion (GUNST ERWEISEN bzw. WOHLERGEHEN WÜNSCHEN) dominant, wohingegen die deklarative Funktion (BRIEF ERÖFFNEN bzw. BEENDEN) wie auch beim eigentlich assertiven Postskript erst auf der (Teil-)Textebene zur Wirkung kommt.

Teiltext [B]

Bei $[B]$ handelt es sich um eine typische Einleitungssequenz, die von der Brieferöffnung zum eigentlichen Haupttext des Briefes überleitet: Cicero ENTSCHULDIGT SICH dafür, keine längeren Briefe an Terentia zu schreiben. Das übergeordnete Thema „Briefe schreiben“ wird lexikalisch verdeutlicht durch das Vorherrschen des zugehörigen Sachfeldes, welches in erster Linie durch das Verb scribere repräsentiert ist (epistulas scribere, scripsit, rescribi, scribam, scribere sowie außerdem per litteras). Im Übrigen finden sich aber auch Bezüge zu anderen Teiltexten, insbesondere was [B2] betrifft, wo es ähnlich wie in einigen Passagen von [D] und [E] um die leidvolle Situation der Familie Ciceros geht. Man vergleiche z. B. die Illokutionen (8) und (33): In beiden Fällen spricht Cicero davon, dass er mit ansehen müsse, wie unglücklich seine Familie sei.

Im ersten Unterabschnitt [B1] rechtfertigt sich Cicero dafür, einigen Personen (quemquam) ausführlichere Briefe (longiores, plura) zu schreiben. Cicero nimmt dabei möglicherweise Bezug auf ein vorangehendes Schreiben, in dem sich Terentia über die Kürze von Ciceros Briefen beschwert hat. Cicero streitet in (2) zunächst ab, dass er anderen längere Briefe schreibe, schränkt diese Aussage aber durch die mit nisi si angeschlossene Illokution (3) ein, welche er

in una frase ipotetica, indica che la conclusione positiva delle azioni che in questo momento vengono intraprese a Roma è limitata all'ambito della possibilità: per il presente, dunque, Cicerone non può ancora nutrire una speranza fondata su basi sicure." Vgl. a. N. 1039.

1042 Vgl. GUGLELMI 2013, 142: „L'assenza nella subscriptio di raccomandazioni specifiche riguardo la salute potrebbe essere dovuta al fatto che queste ultime si trovano, in modo particolarmente insistito, nel paragrafo immediatamente precedente: et valetudinem istam infirmam, si me amas, noli vexare ... timeo ut sustineas ... servi valetudini (§3)."

1043 Vgl. ebd., 141f.: „La subscriptio [...] è molto breve (valete, mea desideria, valete, §4), ma riesce comunque a veicolare affettività per mezzo della ripetizione del saluto valete e per la presenza dell'appellativo mea desideria, termine affettuoso e colloquiale[,] ma comunque legato al lessico della sofferenza tipico dell'esilio, e in particolare alla sensazione di perdita da esso provocata." Sie verweist auch auf DICKEY 2002, 319 und GARCEA 2005, 186. 
wiederum mit (4) begründet. Das Pronomen cui in (4) bezieht sich auf (ali)quis in (3), wodurch eine inhaltlich-thematische Einheit hergestellt wird. [B1] ist assertiv geprägt, wobei im Hinblick auf die Teiltextfunktion die BEGRÜNDUNGsfunktion dominiert.

Im zweiten Unterabschnitt [B2] versucht Cicero zu erklären, warum seine Briefe, von den genannten Ausnahmen abgesehen, eher kurz sind, und führt dazu mit (5) und (6) zwei allgemeine Gründe an, die sowohl grammatisch (nec) als auch handlungslogisch einander nebengeordnet sind. Mit nec enim in (5) wird zurückverwiesen auf (2) bzw. den entsprechenden Brief Terentias und zugleich der Übergang von [B1] zu [B2] signalisiert. (6) bildet den Ausgangspunkt für die anschließende stark expressive Rechtfertigung ab (7), die beherrscht wird von Selbstmitleid und Selbstvorwürfen, deutlich abgegrenzt vom Vorangehenden durch ad te vero et ad nostram Tulliolam, was auch als Gegensatz zu quemquam und quis in [B1] zu betrachten ist. (7) stellt dabei einen fließenden Übergang vom eher sachlichen BEGRÜNDEN zum subjektiven SICH ENTSCHULDIGEN dar. Zugleich verengt sich der Fokus nun auf Ciceros engste Familienangehörige, d. h. in erster Linie Terentia. Die Aussage in (6) wird demnach spezifiziert. Dass es in (8) um eine Begründung für (7) geht, wird u. a. durch die Konjunktion enim indiziert. ${ }^{1044}$ Die Aussage wird, anknüpfend mit id, in (9) weiter ausgeführt. Sowohl (9) als auch (10) sind jeweils nebenordnend (durch -que bzw. et) an die vorangehende Illokution angeschlossen, wobei aber (10) handlungslogisch der Aussage in (9) untergeordnet ist. Der Zusammenhang der assertiven Illokutionen (5) und (6) auf der einen und der expressiven Illokutionen (7) bis (10) auf der anderen Seite (längere Briefe an einige Personen vs. kürzere Briefe an andere Personen, insbesondere Terentia) sowie die Abgrenzung zu [B1] ist v. a. inhaltlich-kontextuell begründet. Insgesamt dominiert in [B2] das expressive Untermuster SICH ENTSCHULDIGEN.

Im dritten Unterabschnitt [B3] BEGRÜNDET Cicero seine(n) Brief(e) an Piso. ${ }^{1045}$ Er schließt inhaltlich an den ersten Abschnitt an, in dem es um Briefe an die Personen geht, denen Cicero seiner Meinung nach schreiben müsse (vgl. z. B. puto rescribi oportere und ut debui). Mit dem zweiten Unterabschnitt verbindet die Passage der gemeinsame Bezug auf die engere Familie. Außerdem wird auch in [B3] implizit auf Ciceros Unvermögen, (längere) Briefe zu schreiben, hingewiesen (vgl. z. B. non queo und ut potui). Der Name von Ciceros Schwiegersohn (Pisonem nostrum) steht in (11) in Spitzenstellung und zeigt den Übergang zum neuen (Unter-)Thema an. Das Pronomen eum in (12) verweist auf Pisonem in (11) und signalisiert, dass das Thema fortgesetzt wird, so wie auch -que in (13) die Fortsetzung von (12) verdeutlicht. Dass (12) und (13) auf einer Ebene anzusiedeln sind, wird außerdem klar durch die parallele Konstruktion ut potui - ut debui. (11) liefert den begründenden Hintergrund für (12) und (13), welche umgekehrt die Folge aus (11) darstellen. Im Hinblick auf die Teiltextfunktion kommt [B3] ebenso wie [B1] eine assertiv BEGRÜNDENDE Funktion zu. Allerdings ist der Zusammenhang von [B3] mit den beiden vorangehenden Teiltexten nicht ganz so eng und es muss offenbleiben, ob es Cicero hier tatsächlich immer noch um eine ENTSCHULDIGUNG geht oder [B3] nur ein ergän-

1044 Vgl. S. 217.

1045 Vgl. a. S. 218. 
zender HINWEIS für Terentia ist, der lediglich durch das gemeinsame Thema „Briefe schreiben" mit [B1] und [B2] verbunden ist. Da m. E. mehr für einen auch funktionalen Zusammenhang spricht, ergibt sich folgende Binnenstrukturierung für [B] insgesamt:
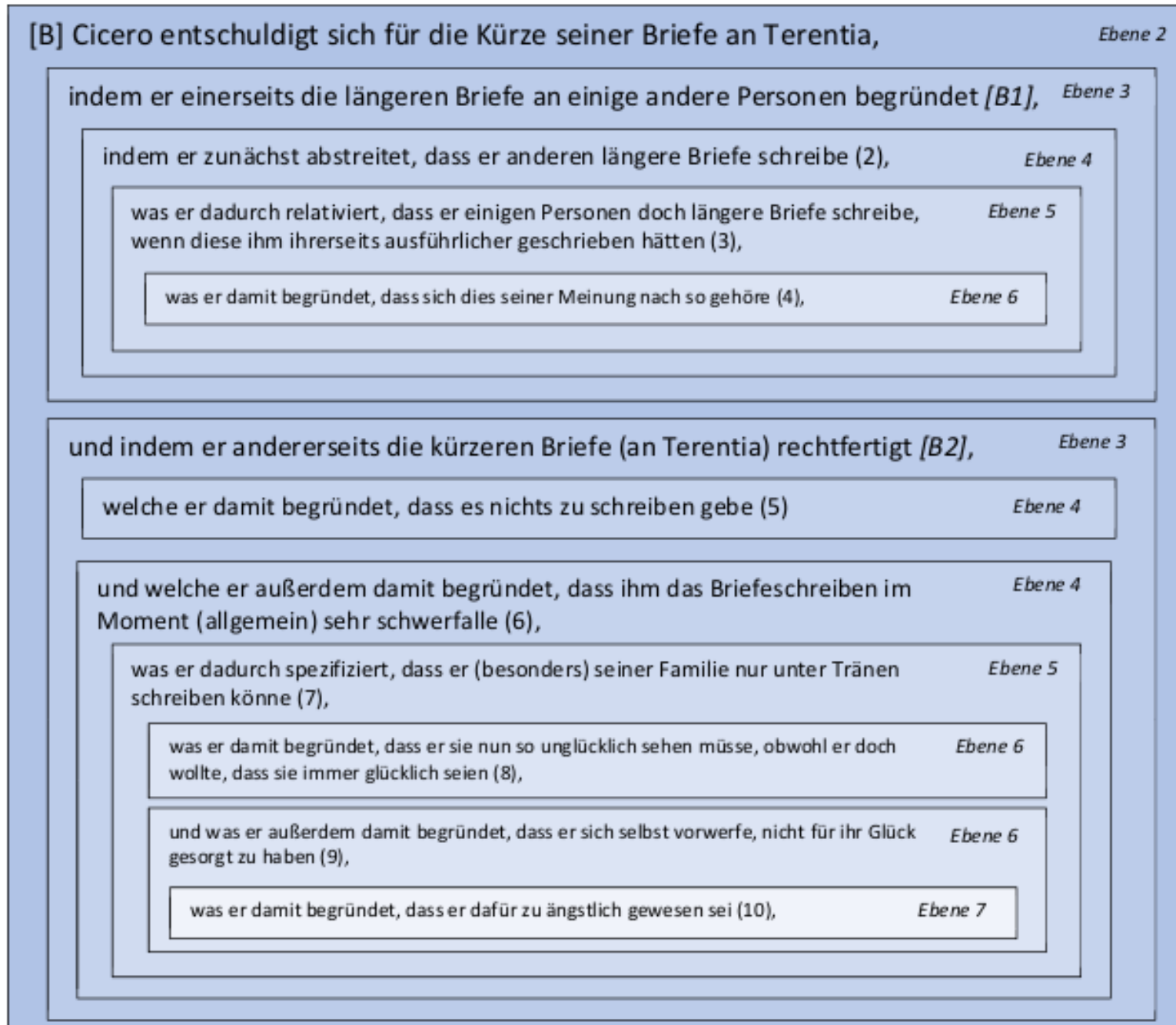

und indem er außerdem seine Briefe an Piso begründet [B3],

Ebene 3

indem er seiner Dankbarkeit gegenüber dem Schwiegersohn Ausdruck verleiht, Ebene 4 den er aufgrund seiner Verdienste sehr wertschätze (11),

womit er begründet,

Ebene 5

- dass er ihn, soweit möglich, per Brief ermuntert habe (12)

- und dass er ihm außerdem pflichtschuldigst gedankt habe (13).

Abbildung 28: Binnenstrukturierung fam. 14.2, Teiltext B

Teiltext [C]

[C] wird durch die Benennung des neuen Themas (in novis tribunis pl. intellego spem te habere) direkt zu Beginn von (14) sehr markant von [B] abgegrenzt. Die (schwache) Verbindung beider Teiltexte besteht darin, dass der Ausgangspunkt für die in [C] geäußerten Gefühle ein Brief Terentias ist, womit an das Thema „Briefe schreiben“ in [B] angeknüpft wird. Auch wenn [C] 
sehr kurz ist und auf den ersten Blick losgelöst vom übrigen Text erscheint, bildet er nicht nur den Beginn des eigentlichen Hauptteils, sondern quasi das Zentrum des gesamten Briefes, der insgesamt geprägt ist von dem in [C] formulierten Gegensatz zwischen HOFFNUNG bzw. ANGST ÄUSSERN hinsichtlich der neu gewählten Tribunen, von denen Ciceros weiteres Schicksal zu einem großen Teil abhängt. Die Konjunktion sed in (15) signalisiert die adversative Fortsetzung von (14). Beide Illokutionen sind handlungslogisch auf der gleichen Ebene einzuordnen.

\section{Teiltext [D]}

[D] beginnt mit einer positiven Würdigung des Einsatzes von Terentia für Cicero, der letztlich seine Rückkehr nach Rom zum Ziel hat, wodurch der Zusammenhang mit [C] gegeben ist. Mit a te quidem wird [D] aber zugleich klar von [C] abgegrenzt. Im Mittelpunkt von [D] steht Terentia, auf die innerhalb des Teiltextes noch weitere Male pronominal Bezug genommen wird (tuis miseriis, te nunc sic vexari ...) und die mehrfach direkt angesprochen wird (mea Terentia, mea lux, meum desiderium). ${ }^{1046}$ Dabei tritt sie an keiner Stelle als direkt handelndes Subjekt auf, nicht einmal, wenn über ihre Aktivitäten berichtet wird (vgl. a te ... omnia fieri, aber auch unde omnes opem petere solebant). Aktives Subjekt sind andere (video, nec miror, maereo, $P$. Valerius scripsit, legi, servavi). Sie selbst begegnet v. a. als betroffenes Objekt. Auf sie bezogene Verben sind Zustandsverben (iacere), oder sie stehen im Passiv (ducta esses, vexari). Manchmal ist die Formulierung sogar noch indirekter (tantis tuis miseriis meae miseriae subleventur, idque fieri mea culpa). Dies alles unterstreicht, dass es in [D] um das (passive) Leid geht, das Terentia erdulden müsse, was außerdem durch eine entsprechende lexikalische Semantik zum Ausdruck gebracht wird, z. B. mit Formulierungen wie tantis tuis miseriis, sic vexari, sic iacere in lacrimis et sordibus, periremus, aber auch quod ego maximo cum fletu legi und maereo. ${ }^{1047}$ Mit maereo gesteht Cicero zudem ebenso wie mit idque fieri mea culpa seine Schuld an Terentias traurigem Schicksal ein, wenngleich er diese in (24) relativiert, nie sein eigenes Unglück (meae miseriae) aus dem Auge verliert und am Ende von ihrem gemeinsamen Verderben spricht (nos periremus). Auf der anderen Seite wird der Ausdruck von Mitgefühl und Schuldbewusstsein dadurch intensiviert, dass er immer wieder, v. a. in (16) und (22), betont, dass sie, die durch so viele lobenswerte Eigenschaften ausgezeichnet sei, ein solches Schicksal nicht verdient habe. Diese Aussage überträgt er allerdings in (24) auch auf sich selbst. Als übergeordnete Teiltextfunktion ist dennoch deutlich das Untermuster SICH ENTSCHULDIGEN identifizierbar.

Nachdem Cicero in (16) seine Bewunderung für Terentias Tapferkeit und Eifer offenbart hat, entschuldigt er sich zunächst für eine (konkrete) leidvolle Erfahrung, die Terentia gerade habe machen müssen. In (17) wird mit sed ein Gegensatz und gleichzeitig eine Fortsetzung hinsichtlich (16) signalisiert. Der Bezug auf den Vorfall an der Tabula Valeria und die Erklärung für die in (17) ausgedrückte Traurigkeit ergibt sich aus der folgenden Illokution (18), welche durch nam kausal an (17) angeknüpft wird. Bei (19) handelt es sich um eine Apposition im direkten Anschluss an das Subjekt des vorangehenden Satzes: homo (officiosus) bezieht sich auf P. Valerius in (18). Die in (19) ausgedrückte Freude ist wohl im vorliegenden Zusammenhang v. a.

1046 Vgl. a. S. 240.

1047 Vgl. aber auch Kap. 2.1.3.3. 
durch den in (18) erwähnten Brief begründet, mit dem P. Valerius Cicero pflichtbewusst über alles informiert habe. Im Einklang mit dem Status als bloße Apposition ist nur eine untergeordnete Nebenhandlung in der Art eines Exkurses ohne engeren Bezug zur Teiltextfunktion anzunehmen. Mit dem betonten Subjektwechsel in (20) zu ego wird ein Perspektivwechsel signalisiert, während id quod Bezug auf den Inhalt von (18) nimmt, durch den der evaluativemotive Kommentar begründet ist. Mit (21) geht Cicero über zu einer allgemeinen Entschuldigung für Terentias unglückseliges Schicksal während seiner Exilzeit insgesamt. Die Interjektion hem leitet einen „plötzlichen“ Gefühlsausbruch ein, der durch den parenthetischen Einschub in (22) unterbrochen und dann in (23) fortgesetzt wird: idque schließt an die Reihe der exklamativen Infinitive in (21) an. Das Pronomen qui in (24) bezieht sich auf Cicero, der quasi auch das logische Subjekt (mea culpa) von (23) ist. Das in (21) ausgedrückte Schuldbewusstsein wird zunächst durch ein weiteres Lob Terentias in (22) und dann mit seiner Selbstbezichtigung in (23) begründet, welche allerdings in (24) gleich wieder eingeschränkt wird. Beides lässt das Schicksal Terentias besonders ungerecht erscheinen. Daraus ergibt sich folgende Binnenstrukturierung von [D]:

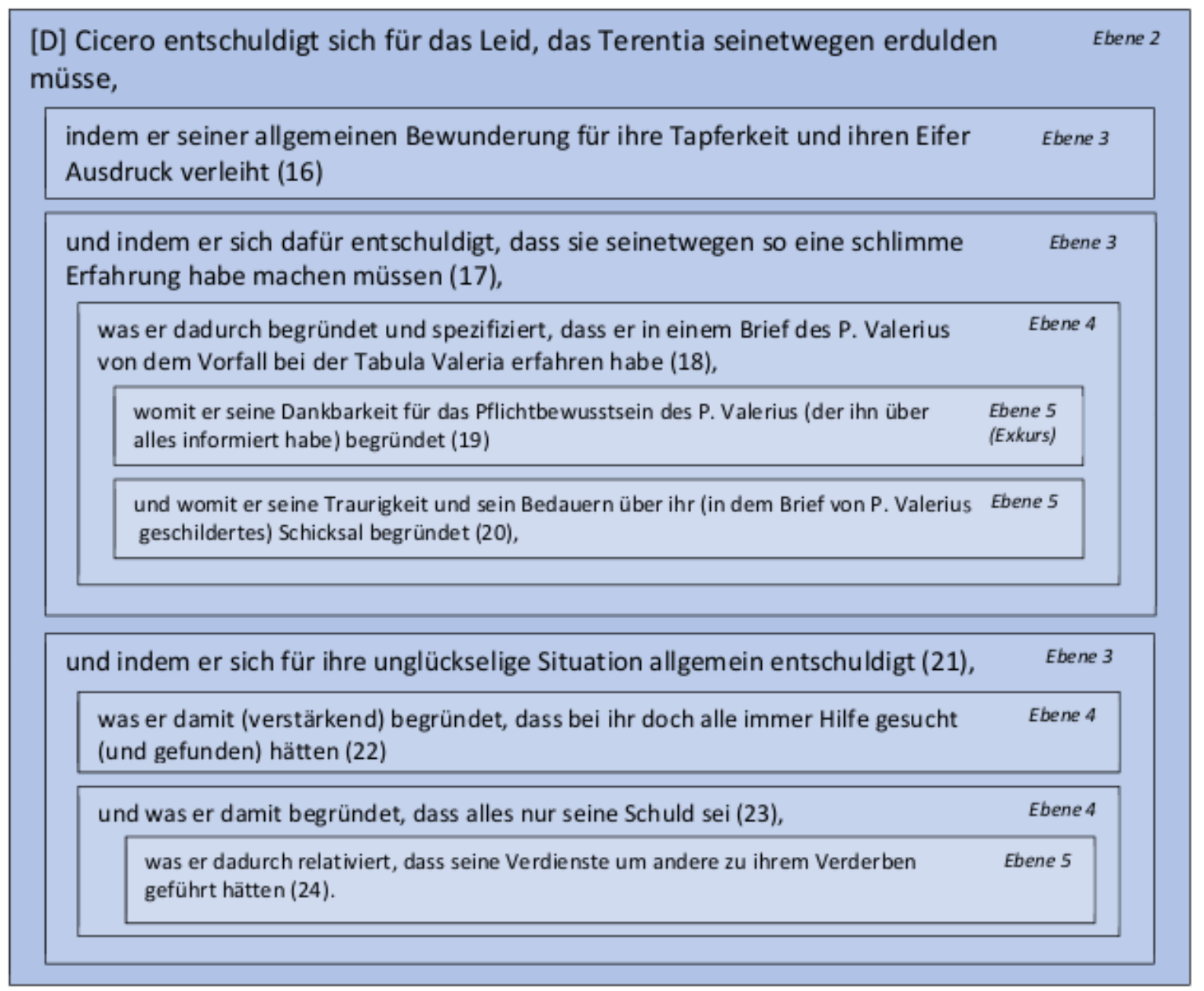

Abbildung 29: Binnenstrukturierung fam. 14.2, Teiltext $D$ 


\section{Teiltext [E]}

Der Beginn von [E] wird durch die explizite Einführung eines neuen Themas mittels eines indirekten Zitates aus einem der Briefe Terentias (quod de domo scribis, hoc est de area ...) deutlich signalisiert. ${ }^{1048}$ Mit ego vero grenzt Cicero seine nun folgenden Äußerungen von denen seiner Frau ab - und liefert zugleich einen Hinweis darauf, dass im Zentrum von [E] im Gegensatz zu [D] v. a. er selbst und nicht mehr so sehr Terentia steht, wobei die Fokusverschiebung am Ende von [D] mit (23) und v. a. (24) bereits einleitet wird.

[E] thematisiert Ciceros Zukunft und - soweit sie damit in Verbindung steht - die seiner Frau. Dabei geht es zunächst konkret um das persönliche Besitztum Ciceros, nämlich sein ehemaliges Haus bzw. Grundstück (domo, area) auf dem Palatin, dann um die finanzielle (vgl. impensa facienda est, despoliatam venire, reliquias tuas miseras proicies, sumptum, sustinere) und schließlich (auch) um die gesundheitliche (vgl. valetudinem istam infirmam noli vexare, omnis labores te excipere video, timeo ut sustineas, servi valetudini) Situation Terentias. Entsprechend kann man drei Unterabschnitte differenzieren: (25) und (26) $=$ [E1], (27) bis (31) $=$ [E2] sowie (32) bis (35) $=[E 3]$.

Das übergeordnete Ziel Ciceros wird in [E1] mit (25) vorgegeben: ego vero tum denique mihi videbor restitutus si illa nobis erit restituta. In den anderen Unterabschnitten wird die mit der Wiedererlangung seiner Güter eng verbundene Rehabilitierung Ciceros ebenfalls immer wieder thematisiert - in [E2] mit (28): si conficitur negotium, omnia consequemur und in [E3] mit (35): ut id quod speras et quod agis consequamur. In den gerade zitierten Illokutionen ÄUSSERT Cicero seine HOFFNUNG auf Erreichung seines Ziels, in (26) mit haec non sunt in nostra manu ([E1]), in (29) mit sin eadem nos fortuna premet ([E2]) und in (34) mit timeo ut sustineas ([E3]) dagegen ANGST vor dem Scheitern. Er schwankt zwischen diesen beiden Gefühlen. In [E1] überwiegt die Hoffnung, in [E2] und [E3] die Angst. Diese Angst bzw. Sorge gilt dabei nur mittelbar Terentia; ihre Finanzen und Gesundheit spielen in erster Linie deshalb eine Rolle, weil beides ihr Wohlbefinden beeinflusst, welches wiederum entscheidend dafür ist, dass sie sich mit voller Kraft für ihren Mann einsetzen kann. ${ }^{1049}$ Hinzu kommt, dass Cicero bzw. seine Kinder auch anderweitig mehr oder weniger direkt von ihren finanziellen Verhältnissen betroffen sind. ${ }^{1050}$ Der Zusammenhang von [E2] und [E3] wird sprachlich u. a. durch die Verwendung des Verbs sustinere verdeutlicht, das in (30) mit Bezug auf die Finanzen (noli sustinere), in (34) (zumindest auch) in Bezug auf ihre Gesundheit (timeo, ut sustineas) verwendet wird. Die Bereiche sind sonst ebenfalls nicht klar voneinander abzugrenzen. Insbesondere (33) und (34) beziehen sich wohl auf beide Aspekte.

In [E1] wird die Aussage in (26) durch die mit verum eingeleitete Illokution (25) eingeschränkt. Die Konjunktion wirkt abgrenzend und verleiht (25) zugleich einen zusammenfassenden Charakter, womit auch das Ende des ersten Unterabschnittes signalisiert wird.

Mit illud in (27) wird der zweite Unterabschnitt [E2] betont vom vorangehenden (vgl. haec am Ende von [E1]) abgesetzt. (28) wird mit quod si angeschlossen. Die Entschuldigung in (27) bzw. der Grund der Entschuldigung wird relativiert, indem Cicero (positiv) in Aussicht stellt, dass

\footnotetext{
1048 Vgl. S. 222.

1049 Vgl. S. $225 \mathrm{ff}$.

1050 Vgl. a. N. 1023.
} 
die finanziellen Einbußen Terentias im Zusammenhang mit ihrem Einsatz für Cicero bei einem erfolgreichen Handel (negotium = Rückberufung Ciceros?) wieder wettgemacht würden. (29) dagegen, angeschlossen mit der weiterführenden Konjunktion sin, verstärkt bzw. begründet die Entschuldigung durch die (negative) Aussicht eines ihnen weiterhin nicht gewogenen Schicksals. Die Wendung quod ad sumptum attinet in (30) zeigt den Übergang zu einem neuen inhaltlichen Teilaspekt an, und zwar von impensa zu sumptus. Beide stehen insofern in Beziehung zueinander, als Erstere (= Kosten, die Terentia durch ihren Einsatz für Cicero entstehen), zur Folge haben, dass Terentia (noch mehr) Mühe hat, Letztere (= ihre eigenen Lebenshaltungskosten) zu bestreiten. Deshalb ist sie gezwungen und wird von Cicero entsprechend dazu aufgefordert, sich von anderen unterstützen zu lassen. Mit der Formulierung obsecro te, mea vita zu Beginn von (30) wird der Fokus im Anschluss an (27) wieder mehr auf Terentia verschoben, während in (28), aber auch (29) eher das gemeinsame Schicksal im Blickpunkt steht (vgl. consequemur, nos). (31) wird mit qui direkt an alios in (30) angebunden. Cicero verstärkt bzw. begründet seine Aufforderung, sich an andere zu wenden, indem er auf deren finanzielle Möglichkeiten hinweist.

[E3] knüpft mit et in (32) additiv nebenordnend an (30) in [E2] an. Die Konjunktion nam in (33) stellt eine kausale Verbindung zu (30) bis (32) her: Die Aufforderung, auf sich zu achten, wird begründet. Mit labores excipere wird wahrscheinlich Bezug sowohl auf die finanziellen als auch gesundheitlichen Belastungen Terentias genommen. In (34) ist omnis labores als Objekt zu sustineas zu ergänzen, wodurch dann implizit eine inhaltlich-thematische Verbindung hergestellt ist. Mehr zusammenfassenden als adversativen Charakter hat sed in (35). Innerhalb der Illokution verdeutlicht quare den kausalen Zusammenhang. Mit valetudini wird noch einmal im Anschluss an (32) explizit auf das Thema Gesundheit referiert. Gleichzeitig wird ein Bezug hergestellt zum übergeordneten Ziel: Für die Rückberufung Ciceros ist Terentias Gesundheit (ebenso wie der entsprechende finanzielle Einsatz) Voraussetzung. Das in (35) gezogene Fazit lautet also: Terentia müsse einfach (trotz all der Belastungen) durchhalten, da alles von ihr abhänge.

Die Binnenstrukturierung von fam. 14.2 [E] kann entsprechend wie folgt dargestellt werden: 


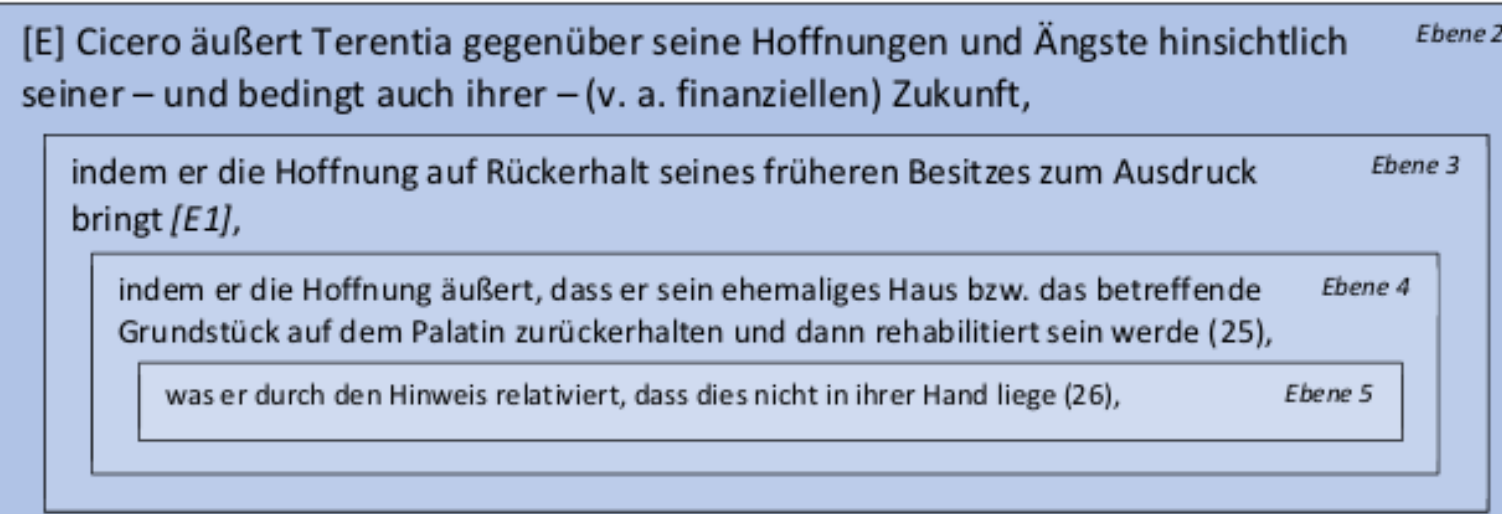

und indem er seine (nur schwach abgemilderte) Angst hinsichtlich Terentias Ebene 3 schwieriger finanzieller Situation zum Ausd ruck bringt [E2],

indem er sich dafür entschuldigt, dass Terentia trotz ihrer ohnehin prekären
Lage so hohe Kosten seinetwegen zu tragen habe (27),
\begin{tabular}{|ll|}
\hline $\begin{array}{l}\text { was er einerseits durch den Ausdruck von Hoffnung auf Wie derlangen (aller Güter) } \\
\text { abmildert (28) }\end{array}$ & Ebene 5 \\
\hline $\begin{array}{l}\text { und was er andererseits dadurch verstärkt, dass er seine Angst äußert, das Schicksal } \\
\text { könnte sie weiterhin beuteln und Terentia noch mehr von ihrem Vermögen ver- }\end{array}$ & Ebene \\
\hline lieren (29),
\end{tabular}
lieren (29),

und woraus er folgert, dass sie sich bei ihren (Lebenshaltungs-) Kosten von anderen Ebene 5 unterstützen lassen müsse (30),

was er dadurch begrūndet, dass die anderen ohne große Probleme dazu in der Lage Ebene 6 seien (31),

und indem er seine Angst hinsichtlich Terentias schwacher Gesundheit zum Ausdruck bringt [E3],

indem er Terentia auffordert, auf ihre ohnehin schwache Gesundheit Rücksicht Ebene 4 zu nehmen (32),

\begin{tabular}{|c|c|}
\hline was er damit begründet, dass sie ja so viele Mühen auf sich nehmen müsse (33), & Ebene 5 \\
\hline womit er seine Angst begrūndet, dass sie nicht standhalten werde (34), & Ebene 6 \\
\hline $\begin{array}{l}\text { woraus er folgert, dass sie, von der doch alles abhänge, unbedingt auf ihre Gesund- } \\
\text { heit achten mūsse, damit sie ihre Ziele erreichen können (35). }\end{array}$ & Ebene 7 \\
\hline
\end{tabular}

Abbildung 30: Binnenstrukturierung fam. 14.2, Teiltext $E$

Abweichend von der sequenziellen Hierarchie könnte man (25) und (28) sowie evtl. (35) auf der (logisch betrachtet) obersten Ebene anordnen, insofern sie sich auf das übergeordnete Ziel, d. h. Ciceros Hoffnung auf Rehabilitierung, beziehen. Die anderen Illokutionen dienen entsprechend der Spezifizierung oder Verstärkung und Intensivierung auf verschiedenen (handlungslogischen) Ebenen. 


\section{Teiltext [F]}

Der Übergang von [E] zu [F] wird durch das in betonter Anfangsstellung die Illokution (36) einleitende Pronomen ego signalisiert. Der Fokus verschiebt sich nun noch mehr von Terentia zu Cicero, der letztlich ja schon in [E] im Mittelpunkt steht, insofern es dort in erster Linie um seine Interessen geht. Im Übrigen erfolgt der Wechsel recht unvermittelt. Auch (37) wird ohne explizite Konnexion an das Vorangehende angeschlossen. Allerdings bezieht sich Cicero hier auf frühere Äußerungen Terentias (quoniam ita vobis placet). Die Bedeutung von sed, mit dem (38) an (37) anknüpft, ist unklar. Naheliegender als eine abgrenzende ist eine zusammenfassende Bedeutung ${ }^{1051}$ im Sinne von: Trotz allem solle Terentia bitte so oft wie möglich schreiben.

Der Zusammenhang der Illokutionen in [F] ist insgesamt recht locker. Es handelt sich um abschließende Bemerkungen, die alle mehr oder weniger in Verbindung mit dem Thema Briefeschreiben stehen, wobei diese in Bezug auf (37) nur indirekt gegeben ist: Der Aufenthaltsort Ciceros ist wichtig für die Organisation des Briefwechsels (Brieftransport). Somit knüpft [F] also an $[B]$ an, wie sich auch aus den ähnlichen Formulierungen nisi si quis ad me plura scripsit in (3) bzw. nisi ad eos qui ad me scribunt aut ad eos de quibus ad me vos aliquid scribitis in (36) erhellt. Im Unterschied zum Briefbeginn beziehen sich die Äußerungen am Briefende nicht mehr auf die Vergangenheit, sondern auf die Gegenwart und Zukunft. Es ist kaum eindeutig zu klären, welche Handlungsfunktion in [F] dominiert. Am wichtigsten im Hinblick auf die übergeordnete Textfunktion ist die abschließende Bitte an Terentia, welche eng mit Ciceros Hoffnungen hinsichtlich der ersehnten Rückkehr nach Rom verbunden ist. Sie steht in keinem direkten funktionalen Zusammenhang mit den beiden anderen Illokutionen. Letztlich handelt es sich eigentlich um drei nebeneinanderstehende Teiltexte mit jeweils eigener Teiltextfunktion. [F] ist also multifunktional (assertiv, kommissiv und direktiv).

\subsection{Gesamttexthandlung: Bestimmung der Textfunktion}

Thema und Funktion von fam. 14.2 sind durch das Ergebnis der Wahlen der neuen Volkstribune bestimmt, womit die Hoffnung Ciceros auf eine baldige Rückkehr nach Rom wächst, obschon seine Situation weiterhin schwierig bleibt und die Stimmung, die sich in dem Brief spiegelt, am ehesten als angstvolle Erwartung beschrieben werden kann. Als inhaltliches und funktionales Zentrum des Briefes kann dabei Teiltext [C] gesehen werden, in welchem die ständig zwischen HOFFNUNG und ANGST ÄUSSERN schwankende Balance auf ihren Kern reduziert zur Anschauung kommt. Daneben begegnen die beiden Sprechaktuntermuster noch jeweils zweimal in [E], wo sie sich oberflächlich auf die Wiedererlangung der materiellen Güter beziehen, darüber hinaus aber auch auf den personalen Status Ciceros insgesamt übertragen werden können. ${ }^{1052}$ In den übrigen Teiltexten scheinen beide Gefühle nur stellenweise etwas deutlicher durch, wie z. B. in [F], sind aber nicht dominant.

\footnotetext{
${ }^{1051}$ Vgl. S. $235 \mathrm{zu}$ (35) in [E3].

1052 Dies gilt insbesondere für das Sprechaktuntermuster HOFFNUNG ÄUSSERN in (25) und (28). Beim Untermuster ANGST ÄUSSERN ist der Zusammenhang eher indirekt. (29) und (34) beziehen sich auf Terentias Finanzen bzw. Gesundheit, die Voraussetzung für Ciceros Rehabilitation sind.
} 
Zahlenmäßig mit Abstand am stärksten vertreten ist in fam. 14.2 das Sprechaktuntermuster SICH ENTSCHULDIGEN, das in [B] und [D] sogar die Teiltexte als Ganzes bestimmt. Acht Einzelillokutionen sind ihm direkt zuzuordnen. Hinzu kommen assertive Äußerungen mit v. a. begründender Funktion als Teil einer übergeordneten Handlungssequenz SICH ENTSCHULDIGEN in [B]. Für den Gesamttext ist das Untermuster dennoch von eher untergeordneter Bedeutung. Zum Teil wird damit schlicht den üblichen Briefgepflogenheiten Genüge getan. Aber auch ansonsten kommt ihm ebenso wie den Untermustern BEDAUERN BEKUNDEN und FLUCHEN mehr eine mittelbare Funktion zu: Sie stehen alle im Zusammenhang mit der leidvollen Situation der Familie Ciceros. Seine Sorge, dass sie weiterhin andauern und sich ein so trauriger Vorfall wie der an der Tabula Valeria wiederholen könnte, vergrößert die Angst Ciceros vor einer Schwächung Terentias und vor einem Fehlschlagen seiner Rehabilitation insgesamt. Auf der anderen Seite versucht er, durch seine Selbstbezichtigungen, den Ausdruck von Mitgefühl usw. Terentia positiv zu beeinflussen. Dies gilt erst recht für die Untermuster BEGRÜSSEN und KOMPLIMENT MACHEN in (16) bzW. (22) sowie den brieferöffnenden GUNSTERWEIS in (1) und den abschließenden WOHLERGEHENSWUNSCH in (39). Damit befördert er letztlich seine Hoffnung auf Rückkehr, die ja u. a. vom Wirken Terentias abhängt. Ähnlich zu beurteilen ist das Untermuster JUBELN in (11) und (19), mit dem Cicero seine Freude über den Einsatz anderer Personen (P. Valerius und Piso) äußert.

Die assertiven Illokutionen in fam. 14.2 haben ebenfalls nur eine stützende Funktion. Bedeutsam ist dabei v. a. (26), welche die Abhängigkeit Ciceros von anderen Personen bei seinen Bemühungen um eine Rehabilitation verdeutlicht. Hier ebenso wie in den meisten anderen Assertiva schwingt eine mehr oder minder starke expressive Note mit, wie z. B. Angst in (26) oder Ratlosigkeit in (36). Bereits erwähnt wurden die Illokutionen in [B], die Teil einer übergreifenden Entschuldigungssequenz sind. Lediglich (18) und v. a. (40) haben einen klar informativen Charakter, liefern aber wie auch (31) im Grunde nur ergänzende Hinweise, die für die Textfunktion nicht von zentraler Bedeutung sind.

Im Vergleich zum bereits einige Monate zurückliegenden ersten Exilbrief fam. 14.4 sowie zu den späteren Schreiben fam. 14.1 und 14.3 enthält fam. 14.2 wesentlich weniger Informationen i. e. S. Diese beziehen sich überdies hauptsächlich auf das Thema Briefwechsel, d. h., es geht darum, wem Cicero schreibt, wie viel er schreibt, z. T. außerdem darum, was er schreibt, warum er (nicht bzw. nicht mehr) schreibt, oder darum, was ihm andere schreiben. Diese Abweichung kann jedoch kaum überraschen, da gerade am Anfang und am Ende der Verbannung aufgrund der kurz zuvor geschehenen bzw. bevorstehenden Ereignisse ein gröBerer Informationsaustausch notwendig ist - wenngleich selbst in diesen Briefen Gefühle am Ende wichtiger als Informationen sind und die Kontaktfunktion dominiert. ${ }^{1053}$

Dementsprechend finden sich in fam. 14.2 auch keine Informationsfragen und nur eine Informationsbitte, obwohl das Informationsbedürfnis Ciceros während seines Exils grundsätzlich sehr stark, um nicht zu sagen existenziell war. ${ }^{1054}$ Die BITTE in (38) sowie die ANWEISUNGEN in (30), (32) und (35) korrelieren im Übrigen eng mit dem übergeordneten Ziel bzw. der Text-

1053 Vgl. z. B. GARCEA 2005, 149. Vgl. a. NDIAYE 2010, 192 und JäGER 1986, 113.

1054 Vgl. z. B. BERNARD 2004, 151. 
funktion, wobei in (38) die Hoffnung auf positive Nachrichten in Bezug auf Ciceros Rehabilitierung anklingt, in den anderen Illokutionen hingegen die Angst, Terentia könnte (finanziell und gesundheitlich) der Lage nicht gewachsen sein. Ähnliches gilt für die einzige kommissive IIlokution in (37), die eng verbunden ist mit der Hoffnung auf eine baldige Rückkehr Ciceros nach Rom. ${ }^{1055}$

Auch wenn die quantitative Distribution der Untermuster nicht deren tatsächliche Bedeutung widerspiegelt, insofern die Sprechakttypen HOFFNUNG und ANGST ÄUSSERN gegenüber SICH ENTSCHULDIGEN im Hinblick auf die Textfunktion dominant sind, ist diese in Bezug auf die Bedeutung der Expressiva an sich ziemlich aufschlussreich: Während lediglich zwölf Illokutionen als assertiv gelten können, vier Illokutionen als direktiv kategorisiert und die Kommissiva sogar nur einmal vertreten sind, dominiert in 23 von 40 Einzelillokutionen und 4 von 7 Teiltexten die expressive Funktion. Sogar (1) am Briefanfang und (39) am Briefschluss sind auf der Ebene der Einzelillokutionen als expressiv einzuordnen. Hiermit wird unterstrichen, was sich bereits aus den vorherigen Ausführungen deutlich ergibt, dass es sich bei fam. 14.2 nämlich eindeutig um einen Kontaktbrief handelt.

\subsubsection{Beziehungs- und Identitätskonstitution: Das Verhältnis zwischen Cicero und Terentia}

Die Exilbriefe Ciceros bewegen sich deutlich im Spannungsfeld zwischen Authentizität und Rhetorizität. ${ }^{1056}$ Auf der einen Seite ist anzunehmen, dass Cicero durchaus echte Emotionen zum Ausdruck bringt. So entlädt er in fam. 14.2 Gefühle wie Traurigkeit, Ärger, Freude und v. a. Hoffnung und Angst. Die Selbstmitteilung und der Dialog mit anderen dienen dabei dem (letztlich unmöglichen) Selbsttrost und helfen, einen klaren Kopf zu bekommen, entfalten also kathartische Wirkung. ${ }^{1057}$ Andererseits trägt das Schreiben dazu bei, die durch die Verbannung angeschlagene oder sogar zerstörte eigene Identität ${ }^{1058} \mathrm{zu}$ bewahren bzw. wiederzufinden, indem - auch durch die Thematisierung bestimmter Emotionen - ein spezielles Selbstbild konstruiert wird. ${ }^{1059}$ Cicero stellt sich z. B. als Retter (der Republik) dar und sieht die Verantwortung für das eigene Unglück und das seiner Familie weniger bei sich selbst als bei anderen, die er als undankbar empfindet, wie z. B. in (24) deutlich wird. Zwar finden sich ebenso Selbstanklagen, wie z. B. in (23); es fällt aber auf, dass er - im Unterschied zu den Fällen, in denen er seine eigenen (z. T. virtuellen) Leistungen hervorhebt (z. B. servavi, praestitissem) - anscheinend nur ungern Ich-Aussagen verwendet, wenn er sich selbst beschuldigt, sondern dann lieber auf eine unpersönliche Formulierung wie einen exklamativen Infinitiv (idque fieri mea culpa) oder die umfassendere 1. Person Plural (nisi tam timidi fuissemus) zurückgreift.

\footnotetext{
1055 Vgl. S. 228.

${ }^{1056}$ Vgl. das Kap. „Brief zwischen Gebrauchstext und Literatur“ ab S. 104. Vgl. a. S. 134.

1057 Vgl. z. B. JÄGER 1986, 113: „In der Äußerung von inneren Erlebnissen und Gefühlen werden Denkprozesse, Reflexionen in Gang gesetzt. In der ersten Phase des Exils geschieht dies mehr monologisch, im weiteren Verlauf dialogisch insofern, als die Gefühlsregungen aus der Position Ciceros auf das Zuhören des Dialogpartners angewiesen ist [!], denn nur im Wissen um sie erfüllt sich die Erleichterung von seelischem Schmerz. " Vgl. a. ebd., 106 bzw. N. 1068. Zur Unmöglichkeit des Selbsttrostes und des (verbalen) Trostes durch andere vgl. z. B. NDIAYE 2010, 197f. Vgl. a. CLAASSEN 1999, 77ff. Vgl. außerdem N. 1061, 1062 und 1075.

1058 Vgl. S. 222.

${ }^{1059}$ Vgl. z. B. CORREA 2013, 85ff. sowie GARCEA 2004, 160 und ebd., 164.
} 
Durch seine Art der Darstellung will Cicero die Deutungshoheit über ihn betreffende umstrittene Tatsachen erlangen, die Legitimität seines Handelns und seine Glaubwürdigkeit fest im Bewusstsein der römischen Bürger verankern und seine (gewichtige) Position in Rom möglichst weitgehend aufrechterhalten. ${ }^{1060}$ Dies geschieht über die Einwirkung auf die Briefempfänger persönlich und darüber hinaus mittelbar, indem diese ihrerseits Einfluss auf andere nehmen. In diesem Sinne werden die Sprechakte in fam. 14.2 sehr gezielt eingesetzt, um psychologische, v. a. aber konkrete praktische Unterstützung zu erhalten. ${ }^{1061} \mathrm{Im}$ Vergleich zu fam. 14.20, wo er seine Bitten zwar ebenfalls (assertiv) begründet, insgesamt jedoch ziemlich vehement und explizit äußert, geht Cicero in fam. 14.2 sehr viel diffiziler vor. Am stärksten kommt der Aufforderungscharakter noch in (35) zum Tragen, und sogar hier wird er dadurch abgemildert, dass das Ziel hingestellt wird als etwas, worauf Terentia selbst hofft und wonach sie strebt. Die beiden anderen ANWEISUNGEN in (30) und (32) vermitteln vordergründig Sorge um Terentias Wohlergehen. Besonders jedoch mit den zahlreichen expressiven Sprechakten versucht Cicero, Mitgefühl und Wohlwollen zu wecken, wobei das Verhältnis zwischen selbstbezogenen abreagierenden zu partnerorientierten sympathisierenden Expressiva mit 10 zu 13 beinahe ausgewogen ist. Viele Assertiva und das kommissive VERSPRECHEN in (37) sind ebenfalls stark partnerbezogen und fördern die positive Beziehungsgestaltung. Unterstützend wirken zudem die vielfältigen Verflechtungen innerhalb des Gesamttextes und der Teiltexte, $d$. $h$. Spezifizierungen und v. a. (abmildernde und verstärkende) Relativierungen und Begründungen. Wie alle Exilbriefe hat fam. 14.2 demnach einen zwar latent, aber dennoch deutlich persuasiven Charakter, der sich - ähnlich wie die expressive Komponente - auf fast alle Illokutionen auswirkt. Dass fam. 14.2 als Kontaktbrief (mit Dominanz der Untermuster ANGST und HOFFNUNG ÄUSSERN) und nicht als Aufforderungsbrief klassifiziert wird, liegt darin begründet, dass für die textfunktionale Einordnung nur die tatsächlich fassbaren kommunikativen Absichten und nicht eventuell dahinterstehende Motive und Manipulationen entscheidend sind.

Cicero behält seine Interessen also immer genau im Blick, sogar am Briefanfang und -schluss, wo das Augenmerk noch am ehesten auf Terentia und ihr Wohlergehen gerichtet ist, während insgesamt eine starke Fokussierung auf Cicero festzustellen ist. Diese Selbstbezogenheit zeigt sich u. a. in der häufigen Verwendung der 1. Person Singular. ${ }^{1062}$ Die 1. Person Plural taucht dagegen nur fünfmal auf, wobei lediglich in vier Fällen (omnia consequemur, ut id consequamur, quod speremus, ut nos periremus) das, Wir' tatsächlich Terentia umfasst und ein gewisses

\footnotetext{
1060 Vgl. z. B. CORREA 2013, 85ff., bes. ebd., 88: „A nuestro juicio, lo que las cartas de este período evidencian es una necesidad doble: por una parte, la de controlar la interpretación de hechos controvertidos, a fin de otorgar legitimidad al remitente; por otra, la de continuar la performance de delante de otros, esta vez sobre la materialidad del texto epistolar." Vgl. a. ebd., 119.

1061 VgI. z. B. NDIAYE 2010, 197; GARCEA 2005, 121 und JÄGER 1986, 113. Vgl. aber auch ebd., 135: „Natürlich möchte Cicero in seinen Briefen auf sich und seine Situation aufmerksam machen, seine Freunde zu Hilfe und Mitleid bewegen. Die Sprache dient ihm aber nicht in erster Linie als rhetorisches Vehikel, in übertriebener und der psychischen Situation unangemessener Weise persuasiv-rational das Handeln anderer zu beeinflussen, wie man es in seinen Reden gewohnt ist, sondern vor allem dazu, innere Gefühlsregungen zu verbalisieren, um so das Erlebte wenigstens teilweise bewältigen zu können. “ Vgl. außerdem N. 1057, 1073 und 1075.

${ }^{1062} \mathrm{Ca} .30$ von insgesamt knapp 70 finiten Verbformen in fam. 14.2 stehen in der 1. Person Singular. Somit gilt für diesen Brief die Aussage „Die monologische Ich-Perspektive ist durch dialogische adressatenbezogene Aussagen zurückgenommen. “ in JÄGER 1986, 106 nicht oder zumindest nur sehr eingeschränkt. Vgl. a. N. 1057.
} 
Gemeinschaftsgefühl signalisiert wird, insofern Terentia an Ciceros Rehabilitation bzw. seiner unglücklichen Situation partizipiert; letztlich denkt Cicero aber wohl sogar dabei vorrangig an sein eigenes Schicksal.

In (7) und (8) kontrastiert ego mit vos (bzw. ad te et ad nostram Tulliolam). Terentia (und die übrigen Familienangehörigen) werden nicht nur hier als (von Leid) betroffenes Objekt dargestellt (vgl. z. B. te excipere video und auch mihi ante oculos versaris, quemadmodum ducta esses). Dies spiegelt sich in ähnlicher Weise in den Infinitivkonstruktionen (exklamativer Infinitiv, $A c l$ ), in denen Terentia als Subjekt(sakkusativ) auftaucht (te nunc sic vexari, sic iacere und te miseram et despoliatam venire). ${ }^{1063}$ Geht es um sie als handelndes Objekt wird eher auf ihren eng begrenztem Handlungsspielraum verwiesen (etiamne reliquias tuas miseras proicies und timeo, ut sustineas, i. w. S. aber auch ut tantis tuis miseriis meae miseriae subleventur). Auf der anderen Seite wird gerade durch unpersönlichere Formulierungen (z. B. im Passiv) verdeutlicht, dass Terentia durchaus sehr aktiv war und ist (a te quidem omnia fieri fortissime et amantissime video, unde omnes petere solebant, aber auch quae impensa facienda est). Im Übrigen begegnet die 2. Person v. a. dann, wenn Terentia (im Dienste Ciceros) zu etwas aufgefordert wird, sei es direkt (sine alios sustinere, noli vexare, servi valetudini, quam saepissime litteras mittatis und eingeschränkt auch noli putare) oder in verstärkenden Ergänzungen (si me amas), die jedoch teilweise treffendererweise in der 1. Person Plural stehen müssten (quod speras, quod agis).

Cicero erscheint - trotz der Vielzahl von Ich-Aussagen - letztlich passiver als seine Frau. Neben Floskeln wie ut debui, ut potui und obsecro te werden insbesondere seine (Gefühls-)Wahrnehmungen (amo, metuo, maereo, doleo, timeo bzw. nescio, puto, intellego und v. a. video) beschrieben. Lediglich bei der auf die fernere Vergangenheit bezogenen Wendung servavi kann man von aktivem Handeln i. e. S. sprechen. Ansonsten beschränken sich seine Tätigkeiten in erster Linie auf Briefeschreiben u. Ä. (vgl. cohortatus sum, gratias egi, legi); und selbst hier geht es wie auch in einigen anderen Fällen eher um Ciceros Nicht- oder Nur-beinahe-Handeln (z. B. nec enim habeo quid scribam nec hoc tempore quicquam difficilius facio, non queo scribere, non discedam, praestare debui, praestare volui, praestitissem).

Angesichts der Tatsache, dass Cicero kaum eine Möglichkeit zum wirklich aktiven Handeln hat, ist dies wenig verwunderlich. Er ist vielmehr (positiv wie negativ) auf andere Personen angewiesen. Zu diesen gehören (neben Terentia) z. B. Atticus, Piso, P. Valerius, Crassus und Pompejus. Gleichwohl wird in fam. 14.2 nur deren Informationstätigkeit explizit erwähnt ${ }^{1064}$ und im Übrigen recht allgemein und oft eher indirekt auf ihre Handlungsmöglichkeiten verwiesen (qui possunt si modo volunt, si Pompei voluntas erit, haec non sunt in nostra manu). Gerade mit den vielen hypothetischen Wendungen, die zudem häufig unpersönlich (in der 3. Person) und / oder passivisch formuliert sind, wird ein Gefühl des Ausgeliefertseins betont (vgl. a. sin fortuna premet, si quid est firmius, si conficitur negotium, tum denique mihi videbor restitutus, si illa nobis erit restituta). ${ }^{1065}$

\footnotetext{
1063 Vgl. S. 232.

1064 Wie bei Cicero selbst und teilweise auch bei Terentia (vgl.: scribis, scribitis) geht es meist um das Schreiben von Briefen (vgl.: quis scripsit, Valerius scripsit, qui ad me scribunt).

1065 Vgl. S. 223.
} 
Durch diese Situation kommt es zu einem Rollentausch zwischen Cicero und seiner Frau. ${ }^{1066}$ Terentia muss zwangsweise viele Aufgaben übernehmen, die sonst eigentlich zu Ciceros Pflichten gehören. Sie wird über die traditionelle Rolle einer (Ehe-)Frau hinausgehend zu einer gleichwertigen oder vielmehr sogar überlegenen Partnerin, deren Gunst (z. B. mittels handlungsfunktionaler Beziehungsgestaltung und Textstrukturierung) erhalten bzw. befördert werden muss. Die Beziehung zwischen den Eheleuten ähnelt während des Exils in gewisser Hinsicht einer Freundschaft. ${ }^{1067}$ Allerdings ergeben sich auch Unterschiede, wie z. B. ein Vergleich mit dem zur selben Zeit entstandenen Brief an Atticus (Att. 3.20) zeigt. ${ }^{1068}$ Fam. 14.2 erscheint expressiver und emotionaler. Terentia begegnet als geliebte Frau, der Cicero Zärtlichkeit und romantische Gefühle entgegenbringt, was sich z. B. in der expressiven Anrede mea lux, meum desiderium in (22) und der Verwendung einer Vielzahl anderer expressiver Sprechakte niederschlägt. 1069

Cicero empfindet aufgrund der (durch sein Schicksal verursachten) Erniedrigung und der Sorgen Terentias sicherlich - trotz aller strategischen Überlegungen - aufrichtigen Kummer, Mitgefühl und Schmerz. ${ }^{1070}$ Zugleich bringt er eine gerade dadurch noch verstärkte Sehnsucht nach ihr zum Ausdruck. ${ }^{1071}$ Terentia scheint ihm ebenfalls sehr verbunden zu sein: Sie hat (nach Ciceros Aussage) das gleiche Ziel wie ihr Mann und teilt die gleichen Hoffnungen (und Ängste). Es entsteht hier durchaus das Bild einer liebevollen, partnerschaftlichen und harmonischen Ehe.

Es ist schwer zu entscheiden und in der Forschung dementsprechend umstritten, wie authentisch die in fam. 14.2 ausgedrückten Gefühle tatsächlich sind. So macht Jäger bspw. darauf aufmerksam, dass in den Exilbriefen alle Anzeichen einer echten Depression zu erkennen

${ }^{1066}$ Vgl. z. B. GREBE 2003, 135ff. („Terentia's activities during Cicero's exile“) und ebd., 139ff. („The exceptionality of Terentia's praise for her public activities”). Sie verdeutlicht Ciceros „financial, business, and emotional dependence" von Terentia während seines Exils. Dabei verweist sie u. a. auch auf die vertauschten Geschlechterrollen: "Cicero described his wife as a tough woman, her life as a vita activa. In ancient Rome, the idea of a vita activa was traditionally associated with men. Cicero was keen to convey himself as a man of action in many of his writings, but in his exile, it was Terentia who played this role. The traditional gender roles were reversed." (ebd., 138). Vgl. außerdem PROST 2015, 12, der dazu aber auch bemerkt: „Mais cela n'implique aucune masculinisation de Terentia, encore moins dans son rapport à son mari par une quelconque fusion ou confusion des genres, d'autant que les vertus illustrées par l'action de Terentia sont tout aussi bien celles traditionnelles de l'épouse romaine." Gunderson sieht Cicero dabei in einem Zwiespalt, schwankend zwischen Ermunterung seiner über sich (und Cicero) hinauswachsenden und ihre körperliche Schwäche überwindenden Frau und Bitterkeit angesichts seiner eigenen Schwäche: Vgl. z. B. GUNDERSON 2007, 15 und ebd., 18. Vgl. im Übrigen Kap. 2.2.2.1.

1067 Vgl. z. B. GREBE 2003, 139.

1068 Allgemein zu den Exilbriefen und den Unterschieden in der Gestaltung in Abhängigkeit vom jeweiligen Adressaten vgl. z. B. JÄGER 1986, 105f.: „Zusammenfassend läßt sich [...] folgendes festhalten: Gegenüber Atticus hat sich mit der steigenden Hoffnung auf Rettung das Sprachverhalten geändert: Die Formulierungen liegen deutlich im Bereich einer sachlich orientierten, argumentativen, appellativ-rationalen Schreibweise. [...] In den Briefen an die Familie [fam. 14.1 - 14.3] hingegen bleiben die inneren Erlebnisse, Selbstreflexionen, das Schwanken zwischen Hoffnung und Verzweiflung Gegenstand der sprachlichen Äußerungen. Die Funktion dieser Briefe mag in der Kompensation der gegenüber Atticus geäußerten Sachlichkeit durch eine verstärkte Entladung emotionaler Regungen (Hoffnungen, Enttäuschung, Spannung, Selbstmitleid usw.) liegen. Auch aus der Stilanalyse ist dies hier klar ablesbar: [...]." Vgl. a. CORREA 2013, 93f.

${ }^{1069} \mathrm{VgI}$. z. B. Grebe 130ff. („The celebration of deep marital love“). Zur Anrede mea lux, meum desiderium vgl. a. S. 221.

1070 Vgl. z. B. HUTCHINSON 1998, 28 (s. N. 1075).

1071 Vgl. a. GUNDERSON 2007, 14. 
seien. ${ }^{1072}$ Auf der anderen Seite wird auf die Parallelen zu anderen Exilanten hingewiesen, die eher eine rhetorische Strategie nahelegen. ${ }^{1073}$ Insgesamt wirkt fam. 14.2 bei einer intensiven Analyse angesichts der psychischen Notlage Ciceros außerdem erstaunlich durchstrukturiert. Dies bedeutet nicht, dass sich einzelne Gedanken und Inhalte nicht wiederholen. Von „ungeordneten Gedankenabläufen" 1074 wie Jäger kann man m. E. aber nicht sprechen. Am Ende vereint der Brief beides: Cicero verfolgt mit (aus seiner Abhängigkeit resultierenden) verschiedenen rhetorischen Strategien ein bestimmtes Ziel. Zugleich bekundet er tiefgehende Gefühle und echte Zuneigung. Rhetorizität bzw. Persuasion und Authentizität müssen einander nicht ausschließen. ${ }^{1075}$

\subsection{ERgebnisse AlLer Detailanalysen Im ÜBBerblick}

Die folgende Darstellung gibt einen Überblick über die Ergebnisse einer Detailanalyse der 24 in fam. 14 enthaltenen Schreiben Ciceros an seine Frau. Lediglich Kap. 2.2.1.2 beschränkt sich auf die drei Beispielbriefe aus Kap. 2.1. Die übrigen Teilkapitel beziehen sich grundsätzlich auf die gesamte Briefsammlung, wobei aber Kap. 2.2.1.1.1 die besprochenen Phänomene lediglich exemplarisch zu verdeutlichen sucht.

\subsubsection{Sprechhandlungsanalyse}

\subsubsection{Einzelhandlungen \\ 2.2.1.1.1 Illokutionsidentifikation}

\section{Unabhängigkeit des Illokutionsstatus von der grammatischen Einheit ,Satz'}

Angesichts der hohen Sprachverdichtung im Lateinischen überrascht es nicht, dass viele Sätze in mehrere Illokutionen aufgeteilt werden können. Als hilfreich bei der Abgrenzung der (z. T. sehr kurzen) handlungsfunktionalen Einheiten erweist sich i. d. R. die Erweiterungsprobe. So kann in fam. 14.5.1 der Teilsatz (eo citius) dabimus operam ut veniamus sowohl auf den vorangehenden Kausalsatz quoniam subeunda fortuna est in (18) als auch den nachfolgenden Finalsatz quo facilius de tota re deliberemus in (19) bezogen werden. ${ }^{1076}$ Ein anderer Fall ist der Kausalsatz quoniam neque di, quos tu castissime coluisti, neque homines, quibus ego semper servivi, nobis gratiam rettulerunt in fam. 14.4.1. Hier kann man ebenfalls zwei inhaltliche

\footnotetext{
1072 Vgl. JÄGER 1986, 120ff. Vgl. a. NDIAYE 2010, $190 f$.

1073 Vgl. z. B. GUGLIELMI 2013, 356.

1074 JÄGER 1986, 105.

1075 Vgl. (zu Ciceros Exilbriefen allgemein) NDIAYE 2010, 198: „Il est donc aisé de voir que, si l'expression de la souffrance a une fonction expressive et cathartique évidente, elle a également une fonction impressive ou conative tout aussi patente [...]. Les sentiments, la souffrance, de la sincérité desquels il n'y a pas de raison de douter, les siens comme ceux que ses destinataires peuvent éprouver, sont mis au service de l'action en faveur de son retour." und HUTCHINSON 1998, 28: „In general the emotional passages in these letters respond to a particular situation between Cicero and the addressee, of whom Cicero is always acutely aware. This is not at all to suggest that the passages are insincere acting. Feeling is perfectly compatible with focused purpose and stylistic organization. A naive antithesis between rhetorical hypocrisy and thoughtless abandon would not be adequate to the interpretation of these forceful and articulate pieces of writing." sowie ebd., 47f.: „In general, crude divisions and antitheses, as between the formal and the informal, or between the rhetorical and the sincere, would do little justice to the whole phenomenon of Ciceronian writing. There the relations of emotion, persuasion, art, and the self are elaborate and entangled. These very letters, which appear on a superficial inspection so direct and straightforward, show on more careful analysis the complexity and organizing intelligence so characteristic of their author." Vgl. a. CORREA 2010, 203f. und MANUWALD 2009, 5. Vgl. außerdem N. 1061. ${ }^{1076}$ Vgl. S. $196 f$.
} 
und damit funktionale Aussagen voneinander trennen, wobei (auf grammatischer Ebene) neben der Erweiterung zwei kleine Abänderungen (non statt neque und tibi bzw. mihi statt nobis) notwendig sind. Die erste Aussage (quoniam di, quos tu castissime coluisti, tibi gratiam non rettulerunt $=(8)$ ) bezieht sich auf Terentia, die zweite (quoniam homines, quibus ego semper servivi, mihi gratiam non rettulerunt $=(9))$ auf Cicero. Noch komplexer gestaltet sich ein Satz wie Etsi eius modi tempora nostra sunt ut nihil habeam quod aut a te litterarum exspectem aut ipse ad te scribam, tamen nescio quo modo et ipse vestras litteras exspecto et scribo ad vos cum habeo qui ferat. in fam. 14.16, den man (unter Auslassung von aut ... aut und et ... et) folgendermaßen aufsplitten könnte:

1. Etsi eius modi tempora nostra sunt ut nihil habeam quod a te litterarum exspectem, tamen nescio quo modo ipse vestras litteras exspecto. $=(3)$

2. Etsi eius modi tempora nostra sunt ut nihil habeam quod ipse ad te scribam, tamen nescio quo modo scribo ad vos cum habeo qui ferat. $=(4)$

Solche Abgrenzungen gehen nicht unbedingt einher mit verschiedenen Handlungsfunktionen, wie die gerade genannten Beispiele belegen. Während man z. B. in fam. 14.5.1 (assertives) FESTSTELLEN und (kommissives) ABSICHT BEKUNDEN, in fam. 14.16 (expressives) HOFFNUNG ÄUSSERN und (assertives) HINWEISEN unterscheiden kann, sind in fam. 14.4.1 beide Illokutionen dem (expressiven) Untermuster FLUCHEN zuzuordnen.

Der umgekehrte Fall, dass eine Illokution aus mehreren Sätzen besteht, begegnet ungleich seltener, zumindest was parataktische Satzreihen betrifft, die aus grammatisch deutlich voneinander getrennten Sätzen bestehen. ${ }^{1077}$ Die handlungsfunktionale Zusammengehörigkeit kann meist mithilfe der Weglassprobe ermittelt werden. In fam. 14.2.3 (33) z. B. stellt der zweite Teil (omnis labores te excipere video) nur eine spezifizierende stilistische Variation des ersten Teils (nam mihi ante oculos dies noctesque versaris) dar. Ausgehend von der Annahme, dass mihi ante oculos versaris und te video quasi synonym sind, könnte man beide Sätze folgendermaßen zusammenfassen: nam dies noctesque omnis labores te excipere video. ${ }^{1078}$

\section{Propositionsanalyse}

Die endgültige Entscheidung darüber, ob eine eigenständige Illokution vorliegt oder nicht, erfolgt im Wesentlichen intuitiv, aber nicht willkürlich. Ihr liegen rationale Überlegungen zugrunde, wofür die Propositionsanalyse eine nachvollziehbare Basis liefert, wenngleich immer Interpretationsspielräume bleiben. In fam. 14.20 (2) kann man bspw. zunächst einmal drei verschiedene Informationseinheiten unterscheiden, nämlich 1., dass Cicero kommt, 2., wohin er kommt, und 3., wann er kommt. Aufgrund des historisch-biografischen und soziokulturellen Hintergrundes ist es wahrscheinlich, dass Terentia sich über Punkt 1 und 2 bereits im Klaren ist, weshalb also nur Punkt 3 tatsächlich eine Information für sie darstellt, woraus sich die illokutionäre Zusammengehörigkeit des gesamten Satzes gibt. ${ }^{1079}$ Die Zeitbestimmung ist in

\footnotetext{
1077 Somit liegt die Annahme, dass Parataxe automatisch auf zwei eigenständige Illokutionen hindeute, zunächst nahe, wird aber u. a. durch das angeführte Beispiel widerlegt. Dass Hypotaxe auf eine illokutionäre Zusammengehörigkeit schließen lasse, läuft den Ergebnissen der Sprechaktanalysen in dieser Arbeit erst recht vollkommen zuwider. Vgl. a. die folgenden Ausführungen zu den verschiedenen Arten von Nebensätzen in diesem Teilkapitel. 1078 Vgl. S. 226.

1079 Vgl. S. 179.
} 
diesem Fall also informationstragend. Die Angabe uno et vice $\langle n\rangle$ simo die in fam. 14.5.1 (6) ist dagegen sogar komplett als eigenständige Information (und damit Illokution) vom Rest des Satzes abzugrenzen, während es sich z. B. bei tum denique in fam. 14.2.3 (25) nur um eine (für das Textverständnis nicht unbedingt notwendige) informationsspezifizierende Ergänzung handelt. 1080

\section{Grammatische Indikatoren}

\section{Illokutionsdemarkation durch exponierte Wortstellung}

Entscheidend für die Wortstellung im Lateinischen sind pragmatische Faktoren. ${ }^{1081}$ Ebendeshalb liefert sie wichtige Hinweise in Bezug auf die Abgrenzung von Handlungseinheiten. Zwar gibt es keine „normale“ Wortstellung; dennoch sind einige Anordnungen ungewöhnlicher und auffälliger als andere. Das Durchbrechen der regulären Satzstruktur oder (selten und weniger deutlich) die parallele Konstruktion aufeinanderfolgender Äußerungen kann im Hinblick auf die Illokutionsidentifikation durchaus aufschlussreich sein. ${ }^{1082}$ Handlungsfunktional bedeutsame Wörter oder Wortgruppen werden oft durch Anfangs- oder Endposition in den Fokus gerückt. Bisweilen entsteht so eine Art Klammer, wie z. B. bei Valete, mea desideria, valete. (fam. 14.2.4 (39)) oder diligentissimeque a te perscripta sunt omnia (fam. 14.5.1 (10)). Insbesondere durch eine exponierte Anfangsstellung kann (einführend, wiederaufnehmend oder abschließend) ein Themen- oder Perspektivwechsel angekündigt werden, der häufig mit dem Beginn einer neuen Illokution einhergeht.

Augenfällig ist z. B. die Verwendung der prinzipiell fakultativen Personalpronomina im Nominativ:

\begin{tabular}{|c|c|}
\hline \multicolumn{2}{|l|}{ ego } \\
\hline fam. 14.2.2 (20): & id quod ego maximo cum fletu legi \\
\hline fam. 14.2.3 (25): & $\begin{array}{l}\text { [Quod de domo scribis, hoc est de area,] ego vero tum denique mihi } \\
\text { videbor restitutus si ... }\end{array}$ \\
\hline fam. 14.2.4 (36): & Ego ad quos scribam nescio, nisi ad eos ... \\
\hline fam. 14.3.3 (16): & ego tamen faciam quae praecipis. \\
\hline fam. 14.3 .4 (27): & nam ego eo nomine sum Dyrrachi hoc tempore ut ... \\
\hline fam. 14.4.1 (2): & Ego minus saepe do ad vos litteras quam possum \\
\hline fam. $14.17(5):$ & $\begin{array}{l}\text { ego autem quo modo sim affectus, ex Lepta et Trebatio poteris } \\
\text { cognoscere. }\end{array}$ \\
\hline \multicolumn{2}{|l|}{ nos } \\
\hline fam. 14.4.2 (10): & Nos Brundisi apud M. Laenium Flaccum dies XIII fuimus \\
\hline fam. 14.5 .2 (23): & nos, cum [...] venerimus, reliqua per nos agemus. \\
\hline
\end{tabular}

\footnotetext{
1080 Vgl. die entsprechenden Beispielanalysen und v. a. das Teilkapitel „Temporale Beziehungen“ ab S. 267. Vgl. außerdem das Kap. „Kontextuelle Indikatoren“ ab S. 279 zu den Zeit- und Ortsangaben in den Postskripta.

${ }^{1081}$ Zu den verschiedenen Faktoren, die Einfluss auf die Wortstellung nehmen, vgl. a. S. 63.

1082 Ein Beispiel für zwei parallel konstruierte Äußerungen, die jeweils illokutionär eigenständig sind, stellen fam. 14.2.2 (12) und (13) dar, während die (noch deutlichere) Parallelität bei inimici sunt multi, invidi paene omnes (fam. 14.3.2 (12)) eher verbindend wirkt. Zu (die Satzstruktur durchbrechenden) „Extrapositionen“ vgl. das betreffende Teilkapitel ab S. 274.
} 


\begin{tabular}{|c|c|}
\hline $\begin{array}{l}\text { fam. } 14.5 .2(26): \\
\text { fam. } 14.22(3): \\
\text { fam. } 14.24(3) \text { / (4): }\end{array}$ & $\begin{array}{l}\text { nos, si di adiuvabunt, circiter Id. Nov. in Italia speramus fore. } \\
\text { Nos cottidie tabellarios nostros exspectamus } \\
\text { Nos neque de Caesaris adventu neque de litteris quicquam adhuc certi } \\
\text { habemus. }\end{array}$ \\
\hline \multicolumn{2}{|l|}{ tu } \\
\hline fam. 14.3.5 (34): & tu modo ad me velim omnia diligentissime perscribas \\
\hline fam. 14.4.4 (30): & Tu quid egeris nescio, utrum aliquid teneas an [...] plane sis spoliata. \\
\hline fam. 14.5.1 (20): & $\begin{array}{l}\text { tu velim, quod commodo valetudinis tuae fiat, quam longissime pote- } \\
\text { ris obviam nobis prodeas. }\end{array}$ \\
\hline fam. 14.5.2 (25): & sin tu iam Roma profecta eris, tamen curabis ut hoc ita fiat. \\
\hline fam. 14.7.3 (14): & tu primum valetudinem tuam velim cures \\
\hline fam. $14.17(6):$ & tu fac ut tuam et Tulliae valetudinem cures. \\
\hline \multicolumn{2}{|l|}{ vos } \\
\hline fam. $14.4 .3(26):$ & iam id vos videte ... \\
\hline fam. 14.5.2 (27): & $\begin{array}{l}\text { vos, mea suavissima et optatissima Terentia, si nos amatis, curate ut } \\
\text { valeatis. }\end{array}$ \\
\hline fam. 14.14.2 (15): & Vos, meae carissimae animae, quam saepissime ad me scribite ... \\
\hline m. 14.18.2 (9): & vos videte quid aliae faciant isto loco feminae \\
\hline
\end{tabular}

Abbildung 31: Illokutionsmarkierung durch Perspektivwechsel mittels Fokussierung von Personalpronomina im Nominativ

Zu den Pronomina gesellen sich häufig zusätzlich abgrenzende Konnektoren wie satzeinleitende Konjunktionen und Adverbien. Als typische Ergänzung zu den Pronomina der 2. Person findet sich zudem gelegentlich eine appositive Anrede, wie z. B. mea suavissima et optatissima Terentia in fam. 14.5.2 (27) oder meae carissimae animae in 14.14.2 (15). ${ }^{1083}$ Manchmal kann sie auch für sich allein den Beginn einer Illokution signalisieren, wie z. B. mea lux, meum desiderium in fam. 14.2.2 (22). Die Possessivpronomina verstärken dabei die demarkative Wirkung noch, wie es stellenweise auch außerhalb von Anreden der Fall ist, z. B. in fam. 14.3.1 (6) und 14.14.1 (3).

Die deklinierten Formen der Personalpronomina begegnen ebenfalls teilweise an exponierter Stelle und können einen Perspektivwechsel signalisieren, wenngleich ihre Signalfunktion im Allgemeinen eher schwach ist:

\section{Person Singular}

fam. 14.1.6 (46): $\quad$ mihi omnino iam brevis exspectatio est.

fam. 14.2.2 (18): $\quad$ nam ad me P. Valerius [...] scripsit, [...] quem ad modum ...

fam. 14.2.3 (33): $\quad$ nam mihi ante oculos dies noctesque versaris ...

fam. 14.5 .1 (13): $\quad$ iam enim me ipsum exspectas, sive nos ipsos

fam. 14.5.1 (17): $\quad$ ut mihi, cum venero, dissimulare non liceat quid sentiam.

${ }^{1083}$ Vgl. a. das Kap. „Appositionen und Parenthesen“ ab S. 274. 


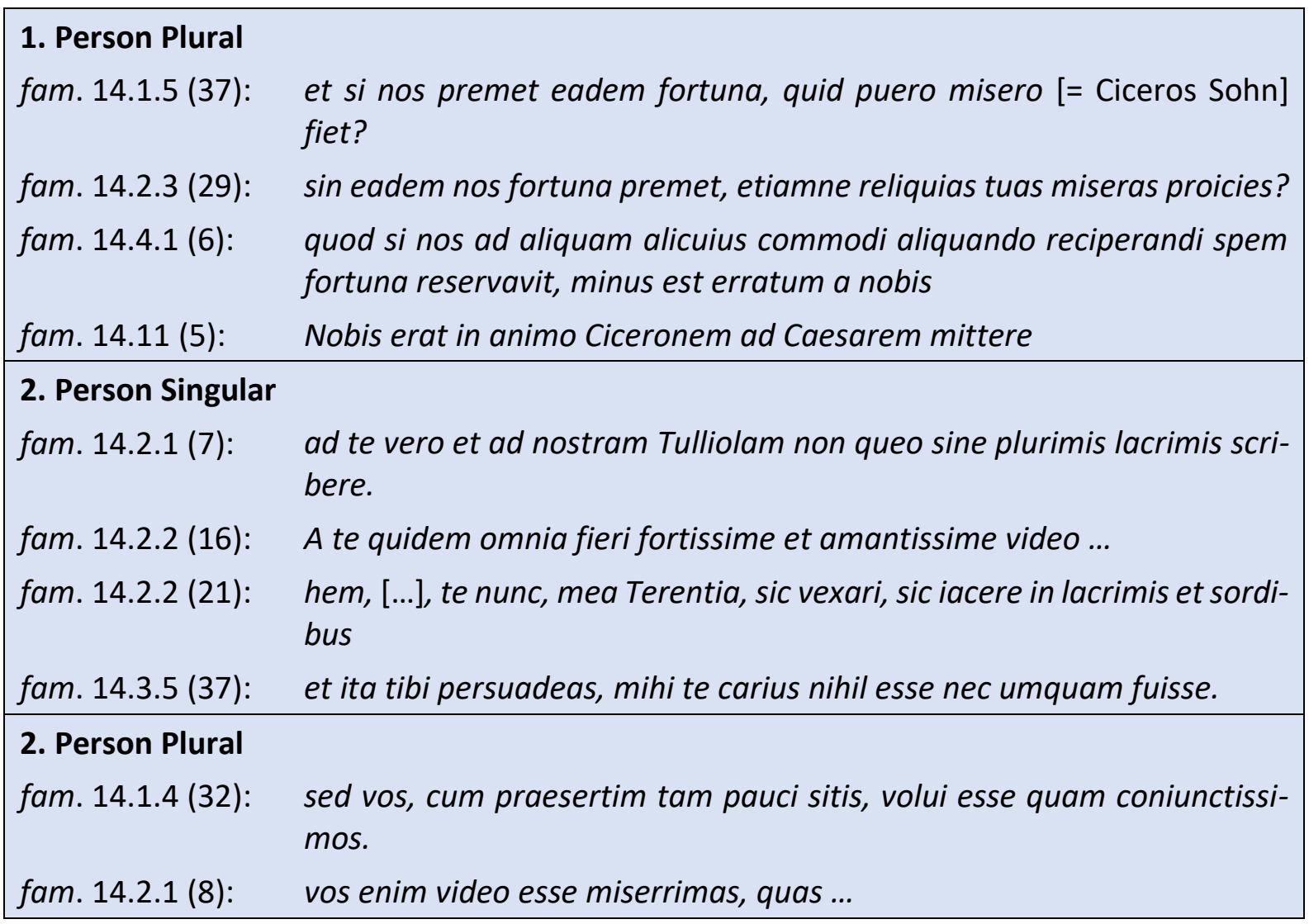

Abbildung 32 Illokutionsmarkierung durch Perspektivwechsel mittels Fokussierung von Personalpronomina im Dativ, Akkusativ und Ablativ

Die Pronomina an und für sich sind selten so deutlich demarkativ wie nobis in fam. 14.11 (5). Die Wirkung intensiviert sich allerdings durch die Verbindung mit anderen Indikatoren, $z$. B. in Wendungen wie sed vos in fam. 14.1.4 (32), ad te vero in 14.2.1 (7), vos enim in 14.2.1 (8) und a te quidem in 14.2.2 (16). Mitunter erhöht sie sich zudem durch (variierende) Wiederholung, wie z. B. in fam. 14.5.1 (13) mit me ipsum in Anfangs- und nos ipsos in Endposition oder nos und a nobis in fam. 14.4.1 (6).

In vielen Fällen verschwimmt die Grenze zur normalen, unmarkierten Verwendung, sodass kaum noch eine illokutionsabgrenzende Wirkung festzustellen ist, z. B. wenn 1. und 2. Person als Subjekt(sakkusativ) und Objekt innerhalb eines Satzes kombiniert werden wie in fam. 14.2.1 (8) oder 14.1.5 (34). Dies zeigt, dass die Personalpronomina, v. a. in deklinierter Form, nur bedingt als Indikatoren taugen. Bisweilen jedoch ist ihre Wirkung durchaus eindrucksvoll, wie z. B. in fam. 14.5.2 (23) bis (27), wo kurz aufeinanderfolgend zwischen verschiedenen Perspektiven (ego / nos - tu / vos) hin und her gewechselt wird.

Ein Perspektiv- oder Themenwechsel kann außerdem dritte Personen sowie Handlungsort und -zeit betreffen. Auf diese wird explizit durch Personen- oder Ortsnamen bzw. genaue Zeitangaben referiert oder durch entsprechende (v. a. pronominale und adverbiale) Ersatzformen:

\section{Person}

Namen

fam. 14.1.3 (20): Plancius [...] me cupit esse secum et adhuc retinet.

fam. 14.1.4 (28): Pisonis humanitas, virtus, amor in omnis nos tantus est ut nihil supra possit. 


\begin{tabular}{|c|c|}
\hline fam. 14.1.4 (31): & de Quinto fratre, nihil ego te accusavi \\
\hline fam. 14.1.6 (47): & Tulliolae et Ciceroni salutem dic. \\
\hline fam. 14.2.2 (11): & Pisonem nostrum merito eius amo plurimum. \\
\hline fam. 14.2.2 (15): & sed Crassum tamen metuo. \\
\hline fam. 14.19 (7): & sed a Pomponio exspecto litteras \\
\hline \multicolumn{2}{|l|}{ Pronomina } \\
\hline fam. 14.1.5 (33): & quibus me voluisti agere gratias egi \\
\hline fam. 14.2.1 (4): & cui puto rescribi oportere. \\
\hline fam. 14.2.2 (12): & eum, ut potui, per litteras cohortatus sum \\
\hline fam. $14.2 .3(31):$ & qui possunt si modo volunt \\
\hline fam. 14.4.2 (13): & huic [= M. Laenius Flaccus] utinam aliquando gratiam referre possimus! \\
\hline fam. 14.4 .3 (28): & iste vero [= Ciceros Sohn] sit in sinu semper et complexu meo. \\
\hline fam. 14.4.5 (41): & qui $[=$ nautae $]$ tempestatem praetermittere noluerunt. \\
\hline fam. 14.4.6 (53): & quem [= Pescennius] semper spero tui fore observantem \\
\hline fam. $14.10(4):$ & cum eo [= Pomponius] si locuta eris, intelleges quid fieri velim. \\
\hline fam. 14.11 (4): & $\begin{array}{l}\text { cuius [= Tullias] summa virtute et singulari humanitate graviore etiam } \\
\text { sum dolore adfectus nostra factum esse neglegentia ut ... }\end{array}$ \\
\hline fam. 14.14.1 (4): & $\begin{array}{l}\text { si ille [= Cäsar] Romam modeste venturus est, recte in praesentia domi } \\
\text { esse potestis }\end{array}$ \\
\hline fam. 14.15 (4): & quia de illius [= Cäsars] adventu nihil audiebamus. \\
\hline fam. $14.18 .1(5):$ & et eos [= omnes bonos] mulieres suas secum habere [erg. video]. \\
\hline fam. 14.23 (4): & et ipse [= Cäsar] opinione celerius venturus esse dicitur \\
\hline fam. $14.23(5):$ & $\begin{array}{l}\text { cui [= Cäsar] utrum obviam procedam an hic eum exspectem cum } \\
\text { constituero, faciam te certiorem }\end{array}$ \\
\hline \multicolumn{2}{|c|}{ andere Ersatzformen } \\
\hline fam. 14.1 .3 (17): & De familia, quo modo placuisse scribis amicis faciemus. \\
\hline fam. 14.3.3 (17): & amicis quibus voluisti egi gratias \\
\hline fam. 14.4.4 (37): & ceterorum servorum ea causa est ut ... \\
\hline fam. 14.14.1 (5): & sin homo amens diripiendam urbem daturus est, vereor ut ... \\
\hline fam. 14.20 (4): & plures enim fortasse nobiscum erunt \\
\hline fam. $14.23(6):$ & tabellarios mihi velim quam primum remittas \\
\hline \multicolumn{2}{|l|}{ Ort } \\
\hline \multicolumn{2}{|l|}{ Namen } \\
\hline fam. 14.1.7 (49): & Dyrrachium veni \\
\hline fam. 14.4.3 (15): & Brundisio profecti sumus a. d. II Kal. Mai. \\
\hline fam. 14.4.3 (16): & per Macedoniam Cyzicum petebamus. \\
\hline fam. 14.7.3 (16): & fundo Arpinati bene poteris uti cum familia urbana si ... \\
\hline fam. $14.20(2):$ & In Tusculanum nos venturos putamus aut Nonis aut postridie. \\
\hline
\end{tabular}




\begin{tabular}{|c|c|}
\hline \multicolumn{2}{|c|}{ Adverbien und Pronomina } \\
\hline fam. $14.1 .7(50):$ & quod [= Dyrrachium] et libera civitas est \\
\hline fam. 14.7.2 (9): & in eam [erg. navem] simul atque conscendi, haec scripsi. \\
\hline fam. 14.20 (3): & $i b i[=$ auf dem Tusculanum] ut sint omnia parata \\
\hline \multicolumn{2}{|c|}{ andere Ersatzformen } \\
\hline fam. 14.1.3 (18): & de loco, nunc quidem iam abiit pestilentia \\
\hline fam. $14.12(6):$ & in viam quod te des hoc tempore nihil est. \\
\hline fam.14.18.1 (6): & $\begin{array}{l}\text { haec autem regio in qua ego sum nostrorum est cum oppidorum tum } \\
\text { etiam praediorum }\end{array}$ \\
\hline fam. 14.18.2 (12): & domus ut propugnacula et prae〈si〉idium habeat Philotimo dicetis. \\
\hline \multicolumn{2}{|l|}{ Zeitpunkt } \\
\hline \multicolumn{2}{|c|}{ genaue Zeitangaben } \\
\hline fam. 14.5.1 (3): & Prid. Id. Oct. Athenas venimus \\
\hline \multicolumn{2}{|l|}{ Adverbien } \\
\hline fam. 14.3.3 (22): & nunc spes reliqua est in novis tribunis pl. et in primis quidem diebus. \\
\hline fam. $14.4 .5(40):$ & nunc miser quando tuas iam litteras accipiam? \\
\hline fam. 14.8 (7): & item posthac, si quid opus erit, si quid acciderit novi, facies ut sciam. \\
\hline fam. $14.17(4):$ & nunc, quae sint negotia, vides. \\
\hline fam. $14.19(5):$ & et iam ante fecissem, sed me multa impediverunt \\
\hline \multicolumn{2}{|c|}{ andere Ersatzformen } \\
\hline fam. 14.2.1 (6): & nec hoc tempore quicquam difficilius facio. \\
\hline
\end{tabular}

Abbildung 33: Illokutionsmarkierung durch Fokussierung von Personen-, Orts- und Zeitangaben

Eine weitere Möglichkeit für Orts- und Zeitangaben sind Adverbialsätze und Partizipialkonstruktionen, wie z. B. de nave exeuntibus in fam. 14.5.1 (5), die durch Linksherausstellung ebenfalls eine demarkative Funktion erhalten können. ${ }^{1084}$

Pronomina dienen naturgemäß eher der Themenfortführung als -einführung, was auf die Pronomina der dritten Person noch mehr als auf die der 1. und 2. Person zutrifft. Dies gilt ebenso für andere Ersatzformen, wie z. B. die Wendung homo amens in fam. 14.14.1 (5), die auf das vorangehende Pronomen ille referiert. Mit ille ist Cäsar gemeint, der an dieser Stelle zum ersten Mal im Text erwähnt wird, und zwar ohne Nennung des konkreten Namens. In einer solchen anonymisierenden Verwendungsweise kann ein Pronomen also in einigen Fällen doch themeneinführend fungieren. ${ }^{1085}$

Der Beginn einer neuen Illokution geht nicht zwingend mit einer Themeneinführung einher, sondern wird häufig einfach dadurch signalisiert, dass ein bereits eingeführtes Thema erneut in den Fokus gerückt wird. Bei den Relativpronomina ist dies z. B. regelmäßig der Fall, wenn ein sog. relativer Satzanschluss vorliegt, wie z. B. in fam. 14.23 (5) oder in fam. 14.1 .3 (25) und

\footnotetext{
${ }^{1084}$ Vgl. a. die Kap. „Temporale Beziehungen“ ab S. 267 und „Lokale Beziehungen“ ab S. 268.

1085 Vgl. a. fam. 14.13 (2), wo mit istius Dolabella gemeint ist, der im Text nicht namentlich erwähnt wird.
} 
14.7.1 (7), wo die Bezugswörter (diem bzw. deo) mit in den Satz hineingezogen sind. Relativpronomina können außerdem auch mit Bezug auf den Briefautor und -adressaten gebraucht werden und dabei ebenfalls oft eine illokutionsmarkierende Funktion haben, wie z. B. in fam. 14.2.3 (24) und 14.5.1 (14) bzw. fam. 14.3 .5 (39).

Die Signalwirkung der Pronomina ergibt sich meist am deutlichsten in der Kombination mit weiteren Indikatoren, wie z. B. bei iste vero in fam. 14.4.3 (28), oder aus einer besonders exponierten Wortstellung, wie z. B. von huic in fam. 14.4.2 (13), (cum) eo in fam. 14.10 (4) und cui in fam. 14.23 (5). Ähnliches ist bei Adjektiven und Adverbien festzustellen. So wird plures in fam. 14.20 (4) mit enim verbunden und ibi in fam. 14.20 (3) durch die Linksherausstellung betont.

Von vornherein stärker ist die demarkative Wirkung bei konkreten Namen und (Zeit-)Angaben, was hinsichtlich ihrer ersten Erwähnung im Text oft sogar weitgehend unabhängig von deren Position gilt. Diese kann z. B. auch durch eine betonte Endposition erzielt werden, wie z. B. von Orpheus in fam. 14.4.4 (35) oder Piso in fam. 14.14.2 (14), wo allerdings ein nachfolgender Kausalsatz mit der Äußerung illokutionär verbunden ist. Besonders markant wirken kurz aufeinanderfolgende Themenwechsel, wie z. B. in fam. 14.1.4: Pisonis ... (28) - de Quinto fratre ... (31) und in fam. 14.4.6: Clodium Philetaerum ... (48) - Sal〈I $\rangle$ ustius ... (51) - Pescennius ... (52) - Sicca ... (54).

Es ist darüber hinaus möglich, die verschiedensten (anderen) Gegenstände und Sachverhalte zu topikalisieren, welche sowohl konkreter als auch abstrakter Natur sein können. Dabei begegnen sehr unterschiedliche Äußerungsformen:

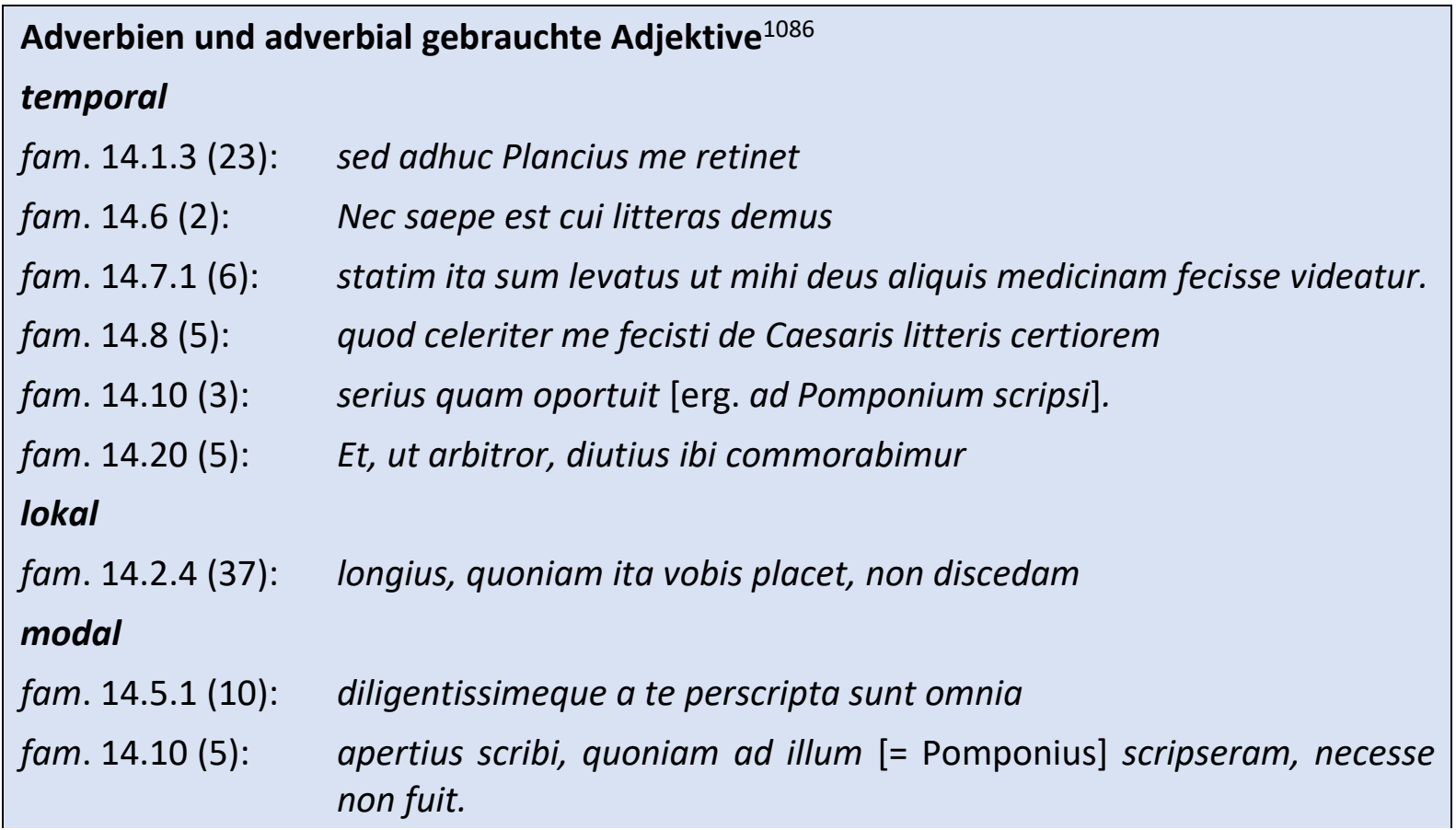

\footnotetext{
1086 Die hier angeführten temporalen Bestimmungen geben im Gegensatz zu den eben behandelten Zeitangaben keinen Zeitpunkt, sondern eine Zeitdauer an. Statt Adverbien und adverbial gebrauchten Adjektiven können auch Adverbialsätze und entsprechende Partizipialkonstruktionen verwendet werden. Vgl. a. das Kap. „Adverbiale Bestimmungen und Adverbialsätze" ab S. 267.
} 


\begin{tabular}{|c|c|}
\hline Verben & \\
\hline fam. $14.1 .3(24):$ & [erg. Plancius] sperat posse fieri ut mecum in Italiam decedat. \\
\hline fam. 14.2.2 (17): & $\begin{array}{l}\text { sed maereo casum eius modi ut tantis tuis miseriis meae miseriae } \\
\text { subleventur. }\end{array}$ \\
\hline fam. 14.2.3 (34): & timeo ut sustineas \\
\hline fam. 14.2.3 (35): & sed video in te esse omnia ... \\
\hline fam. 14.4.4 (35): & est autem in officio adhuc Orpheus \\
\hline fam. 14.5.1 (8): & accepi tuas litteras \\
\hline fam. 14.5.1 (12): & $\begin{array}{l}\text { neque sum admiratus hanc epistulam quam Acastus attulit brevem } \\
\text { fuisse. }\end{array}$ \\
\hline fam. 14.14.2 (14): & $\begin{array}{l}\text { adiuvat etiam Piso, quod ab urbe discedit et sceleris condemnat gene- } \\
\text { rum suum. }\end{array}$ \\
\hline fam. $14.22(5):$ & faciemusque te statim certiorem \\
\hline fam. $14.23(3):$ & Redditae mihi tandem sunt a Caesare litterae satis liberales \\
\hline Substantive & \\
\hline fam. 14.1.4 (30): & [erg. Pisoni ea res] gloriae quidem video fore. \\
\hline fam. 14.2.3 (32): & et valetudinem istam infirmam, si me amas, noli vexare. \\
\hline fam. 14.3.2 (11): & spes autem salutis pertenuis ostenditur \\
\hline fam. $14.4 .5(45):$ & peccatum est nullum, nisi quod ... \\
\hline fam. 14.7.2 (8): & Navem spero nos valde bonam habere. \\
\hline fam. 14.8 (3): & Valetudinem tuam velim cures diligentissime. \\
\hline fam. $14.20(6):$ & labrum si in balineo non est, ut sit \\
\hline Pronomina & \\
\hline fam. 14.3.1 (3): & quas [= epistulas] ego lacrimis prope delevi ... \\
\hline fam. 14.5.2 (22): & quae [= hereditas Preciana] quidem mihi magno dolori est ... \\
\hline fam. 14.7.1 (3): & quibus [= molestiis et sollicitudinibus] et te miserrimam habui ... \\
\hline fam. $14.19(3):$ & de qua [= valetudine Tulliae] nihil est quod ad te plura scribam ... \\
\hline fam. 14.19 (8): & quas [= litteras] ad me quam primum perferendas cures velim. \\
\hline
\end{tabular}

Abbildung 34: Illokutionsmarkierung durch Fokussierung bestimmter Gegenstände und Sachverhalte

Bei sehr kurzen (oft elliptischen) Satzkomponenten ${ }^{1087}$ ist die demarkative Wirkung naturgemäß weniger durch eine besondere Wortstellung bedingt als durch die Kürze an sich. Häufig sind solche Kurzeinheiten auch illokutionär eng miteinander verbunden, wie z. B. eicere nos magnum fuit, excludere facile est. in fam. 14.3.2 (13) oder viximus, floruimus in fam. 14.4 .5 (43), die sich aber gerade aufgrund ihrer Zusammengehörigkeit klar vom Kotext abheben. ${ }^{1088}$

Die Abgrenzungsfunktion tritt normalerweise offensichtlicher zutage, wenn keine Konnektoren vorgeschaltet sind. In zweiter Position können diese jedoch sogar verstärkend wirken, v. a. bei einer besonders ungewöhnlichen Wortstellung wie einer Sperrung (Hyperbaton), die

${ }^{1087}$ Vgl. a. das Kap. „Appositionen und Parenthesen“ ab S. 274.

1088 Vgl. a. das Kap. „Aufzählungen“ ab S. 257. 
ohnehin eine starke Exponierung der betreffenden Komponenten zur Folge hat. Das wird z. B. deutlich in fam. 14.3.2 (11), 14.4.4 (35) und 14.20 (6) bzw. 14.7.2 (8) und 14.23 (3). Durch die hervorgehobene Position (v. a. von Prädikaten) am Anfang einer Äußerung kann überdies gleichzeitig das Element am Satzende betont werden, wie z. B. litterae (satis liberales) in fam. 14.23 (3) und Orpheus in fam. 14.4.4 (35).

Viele grammatische Einheiten sind (zusätzlich zu den Konnektoren) durch ihre gemeinsame Satz(spitzen)position hinsichtlich ihrer demarkativen Wirkung miteinander verbunden. Dies betrifft u. a. Phraseologismen wie gratias agere in fam. 14.2.2 (13), die Kombination von adverbialer Bestimmung und zugehörigem Verb wie apertius scribi in fam. 14.10 (5) und insbesondere attributive Verbindungen von Substantiven mit Pronomina und Adjektiven wie z. B. (et) eas litteras in fam. 14.3.3 (18) bzw. ceterorum servorum in fam. 14.4.4 (37), omnis molestias et sollicitudines in fam. 14.7.1 (2) und (in) maximis meis doloribus in fam. 14.19 (2). ${ }^{1089}$

Um unbestimmtere und umfassendere Sachverhalte in den Fokus zu rücken, stehen ebenfalls verschiedene Ausdrucksmöglichkeiten zur Verfügung. Häufig wird ein neutrales Pronomen verwendet:

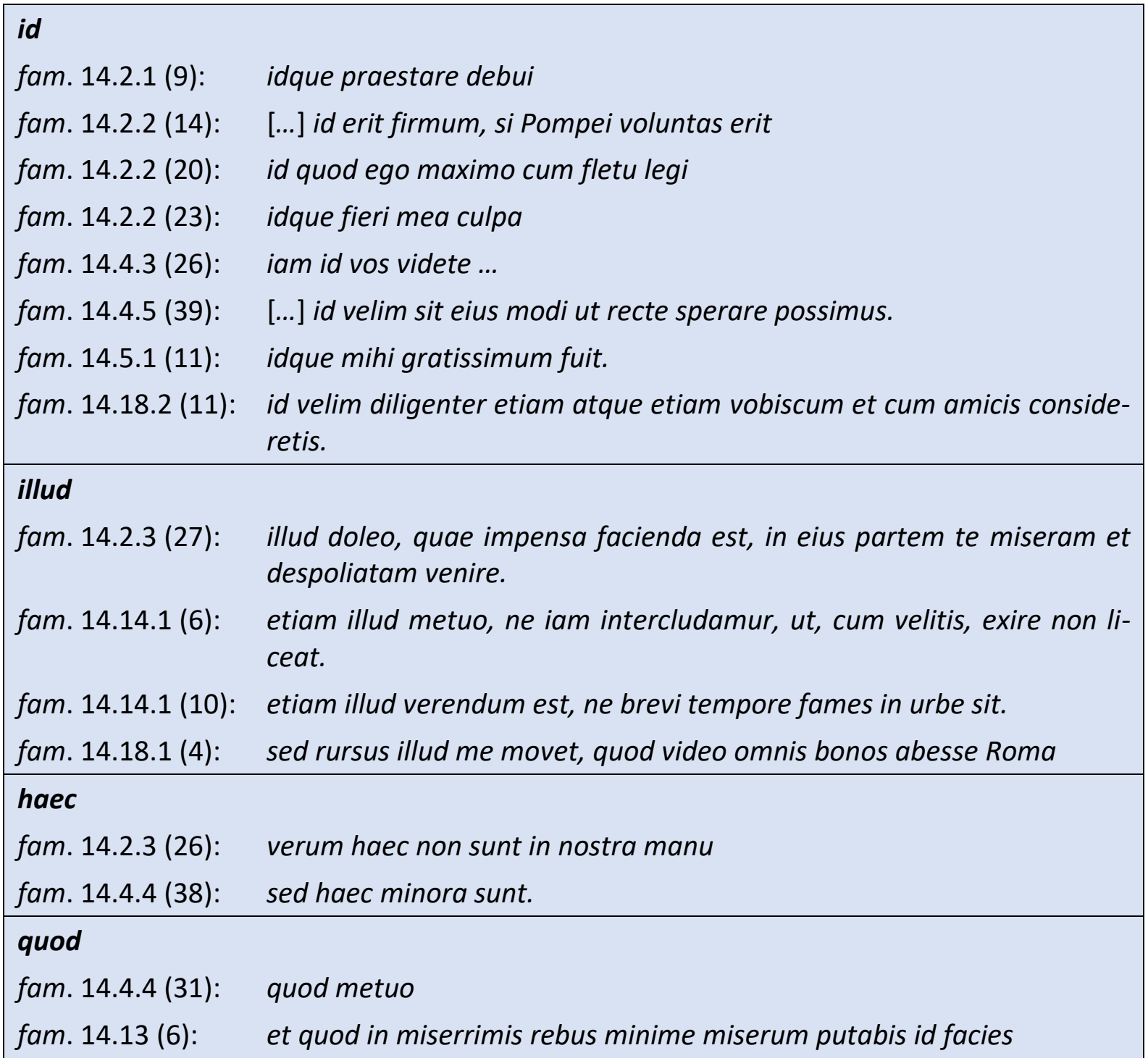

${ }^{1089}$ Vgl. a. das Kap. „Attribute und Attributsätze“ ab 273. 


\begin{tabular}{|ll|} 
fam. $14.21(4):$ & quod opus erit, ut res tempusque postulat, provideas atque administres \\
\hline quae & \\
fam. $14.1 .1(7):$ & quae si, tu ut scribis, fato facta putarem, ferrem paulo facilius ... \\
fam.14.16 (7): & quae [ $\approx$ alia] me ita conficiunt ut ii voluerunt qui ... \\
fam. $14.19(6):$ & quae [ $\approx$ multa] ne nunc quidem expedita sunt.
\end{tabular}

Abbildung 35: Illokutionsmarkierung durch Fokussierung unbestimmter Sachverhalte

In vorangestellten Konditionalsätzen findet man gelegentlich noch (ali)quid, wie in fam. 14.17 (3) oder 14.24 (6). ${ }^{1090}$ Die Pronomina illud und v. a. id korrelieren oft mit quod, wie z. B. in fam. 14.18.1 (4) bzw. 14.2.2 (20), 14.4.5 (39) und 14.13 (6). Ein neutrales Pronomen kann auch im Ablativ stehen, wie z. B. in fam. 14.3.1 (7): hoc miserius, turpius, indignius nobis nihil fuit. ${ }^{1091}$

Alternativ zu den Pronomina werden mitunter allgemeine Begriffe wie totum und nihil verwendet, z. B. in fam. 14.13 (5) bzw. 14.15 (6). Weit verbreitet ist der Gebrauch von res ${ }^{1092}$, wie z. B. in fam. 14.1 .2 (12) und 14.6 (3). Besonders markant wirkt die Verbindung von de mit res im Ablativ als kurze Themenangabe am Beginn einer Äußerung(ssequenz). Eine solche Wendung ist aber nicht auf res beschränkt:

\begin{tabular}{|ll|}
\hline fam. 14.1.3 (17): & De familia, quo modo placuisse scribis amicis faciemus. \\
fam. 14.1.4 (31): & de Quinto fratre, nihil ego te accusavi \\
fam. 14.4.4 (33): & de familia liberata, nihil est quod te moveat. \\
fam. 14.5.2 (21): & De hereditate Preciana, [...] - sed hoc velim cures ... \\
fam. 14.10 (6): & de ea re et de ceteris rebus quam primum velim nobis litteras mittas. \\
fam. 14.14.2 (11): & $\begin{array}{l}\text { his de rebus velim cum Pomponio, cum Camillo, cum quibus vobis vide- } \\
\text { bitur, consideretis }\end{array}$ \\
fam. $14.15(5):$ & $\begin{array}{l}\text { de ceteris rebus [...] quid velimus et quid hoc tempore putemus opus } \\
\text { esse ex Sicca poteris cognoscere. }\end{array}$ \\
\hline
\end{tabular}

Abbildung 36: Illokutionsmarkierung durch kurze Themenangaben mit de + Ablativ

Es gibt Fälle, in denen die Themenangabe weiter in den Satz hineingezogen wird, wodurch die illokutionsmarkierende Wirkung abgeschwächt wird, aber dennoch erhalten bleibt. So können in fam. 14.24 (3) / (4) dadurch zwei Illokutionen voneinander geschieden werden: Nos neque de Caesaris adventu [neque...] quicquam adhuc certi habemus. und Nos [neque ...] neque de litteris [...] quicquam adhuc certi habemus.

Eine andere Möglichkeit, das Thema vorzugeben, stellt die Formulierung quod ... attinet dar, wie sie sich in fam. 14.2.3 (30) - ebenso wenig direkt am Satzbeginn - findet. Außerdem macht Cicero wiederholt ausführlichere Themenangaben, bei denen es sich oft um Zitate aus einem vorangehenden Brief Terentias handelt. ${ }^{1093}$ Der Beginn der eigentlichen (neuen) Information wird dabei häufig mit zusätzlichen demarkativen Indikatoren, wie z. B. ego vero in fam. 14.2.3

\footnotetext{
1090 Vgl. a. fam. 14.1.5 (43), 14.2.4 (38) und 14.8 (7), wo der Konditionalsatz weiter in den Satz hineingezogen, z. T. ganz nachgestellt ist. Vgl. außerdem ORLANDINI 1995, $19 \mathrm{ff}$.

${ }^{1091}$ Manchmal findet sich außerdem eine ausführlichere Formulierung wie z. B. mihi veniunt in mentem haec: ... in fam. 14.18.1 (3). Vgl. a. das Kap. „Sekundäre Illokutionen“ ab S. 275.

1092 Vgl. a. ebd., 141ff.

${ }^{1093}$ Vgl. a. das Kap. „Zitate“ ab S. 276.
} 
(25) verdeutlicht. Bei kürzeren Themenangaben ist dies nur nach längeren Unterbrechungen üblich, wie z. B. in fam. 14.5.2 (21), wo die Äußerung mit sed hoc velim cures an De hereditate Preciana vom Satzanfang anschließt.

Letztlich können im Prinzip alle Äußerungskomponenten durch ihre Position im Satz besonders in den Fokus gerückt werden und eine illokutionsindizierende Funktion übernehmen, wobei die Entscheidung, inwieweit eine bestimmte Wortstellung tatsächlich markiert ist, oft eine ziemlich subjektive Interpretation darstellt. Sie wird aber dadurch eingegrenzt, dass meist darüber hinaus ein oder sogar mehrere Konnektoren zur Demarkation eingesetzt werden, die im Übrigen auch unabhängig von einer besonderen Wortstellung den Beginn einer neuen Illokution signalisieren können. Durch Kombination rücken zumindest die adverbialen Konnektoren (zusätzlich zu einer regulären Nachstellung) manchmal ziemlich weit nach rechts. So wird quidem oft über die zweite Position hinaus versetzt, wie in fam. 14.19 (6) und 14.1 .3 (18). Manchmal geht ein ganzer Nebensatz voran, wie in fam. 14.5 .2 (25) und 14.4.1 (7). Recht häufig ist eine längere Themenangabe vorgeschaltet, z. B. in fam. 14.2.3 (25). Die verschiedenen Konnektoren sind am Ende allerdings ebenfalls keine eindeutigen Indikatoren. ${ }^{1094}$

Überblick sprachlicher Einzelaspekte

Im Folgenden werden verschiedene grammatischen Einheiten im Lateinischen auf ihre Aussagekraft hin analysiert, die sie möglicherweise im Hinblick darauf haben können, ob eine eigenständige Illokution vorliegt oder nicht. Dabei gilt: „Nicht bestimmte grammatische Phänomene sind zu identifizieren und damit - mehr oder weniger automatisch - als Illokutionen zu bezeichnen. Vielmehr lassen sich Illokutionen als intentionale Handlungseinheiten mit Hilfe von verschiedenen grammatischen Entitäten realisieren, ohne dass damit zwangsläufig eine generelle Festlegung auf die grammatische Entität als Träger der Illokution erfolgen müsste. Es kann allenfalls gefragt werden, welcher grammatischen Einheit potentiell Illokutionsstatus zukommen kann und unter welchen Umständen dies so ist. “1095

Satzarten: Aufforderungs-, Wunsch-, Ausrufe- und Fragesätze

Satz und Illokution sind zwar nicht identisch, aber dennoch lässt sich eine gewisse Tendenz erkennen, dass viele Hauptsätze häufiger, wenngleich nicht immer mit Illokutionen zusammenfallen. Dies scheint für Aufforderungs-, Wunsch-, Ausrufe- und Fragesätze vielleicht noch etwas mehr als für Aussagesätze zu gelten ${ }^{1096}$, obwohl es auch dort Ausnahmen gibt. Somit

\footnotetext{
${ }^{1094}$ Vgl. a. die Kap. „Aufzählungen“ ab S. 257, „Adverbiale Bestimmungen und Adverbialsätze“ ab S. 267 sowie „Attribute und Attributsätze“ ab S. 273.

1095 SCHMITT 2000, 55.

1096 In dieser Arbeit werden sowohl Imperativsätze als auch mit velim + Konjunktiv eingeleitete Sätze als Aufforderungssätze aufgefasst. Davon zu unterscheiden sind Wunschsätze, die oft mit utinam, manchmal aber ebenfalls mit velim eingeleitet werden, wie z. B. fam. 14.4 .5 (39) und v. a. viele Wohlergehensformeln. Im Gegensatz zu Aufforderungssätzen liegt die Erfüllung der mit einem Wunschsatz geäußerten Wünsche nicht oder wenigstens kaum in der Macht des Adressaten. Oft sind sie auch gar nicht direkt an den Adressaten gerichtet: Vgl. z. B. PINKSTER 2015, 359. Vgl. a. N. 1354. Ausrufesätze wiederum bringen starke Gefühle des Sprechers zum Ausdruck, haben also von vornherein keinen direktiven Charakter. Im persönlichen Gespräch sind bzw. waren sie u. a. an einer besonderen Stimmführung und Lautstärke erkennbar. In schriftlichen Texten dagegen bleibt es oft der Interpretation des Lesers bzw. Editors überlassen, ob ein Ausrufesatz vorliegt und z. B. durch Ausrufezeichen markiert werden soll oder nicht. In Verbindung mit Interjektionen sowie Akkusativen und Infinitiven des Ausrufs mag die Entscheidung noch leichtfallen, wie sieht es aber z. B. mit den in fam. 14.2.1 (7) bis (10) formulierten Sprechakten aus?
} 
können Partikeln und Wendungen, die für solche Satzarten typisch sind, durchaus als (demarkative) Illokutionsindikatoren verstanden werden:

\begin{tabular}{|c|c|}
\hline $\begin{array}{l}\text { Aufforderungssätze } \\
\text { velim }\end{array}$ & \\
\hline fam. 14.2 .4 (38): & sed velim quam saepissime litteras mittatis ... \\
\hline fam. $14.5 .1(20):$ & $\begin{array}{l}\text { tu velim, quod commodo valetudinis tuae fiat, quam longissime pote- } \\
\text { ris obviam nobis prodeas. }\end{array}$ \\
\hline fam. 14.5.2 (21): & De hereditate Preciana, $[. .$.$] - sed hoc velim cures ...$ \\
\hline fam. 14.14.2 (11): & $\begin{array}{l}\text { his de rebus velim cum Pomponio, cum Camillo, cum quibus vobis } \\
\text { videbitur, consideretis }\end{array}$ \\
\hline fam. 14.18.2 (11): & $\begin{array}{l}\text { id velim diligenter etiam atque etiam vobiscum et cum amicis conside- } \\
\text { retis. }\end{array}$ \\
\hline fam. 14.18.2 (13): & et velim tabellarios instituatis certos ut ... \\
\hline fam. $14.23(6):$ & tabellarios mihi velim quam primum remittas \\
\hline Wunschsätze & \\
\hline utinam & \\
\hline fam. 14.1 .4 (29): & utinam ea res ei [= Piso] voluptati sit! \\
\hline fam. 14.4.1 (5): & quod utinam minus vitae cupidi fuissemus! ... \\
\hline fam. 14.4.2 (13): & $\begin{array}{l}\text { huic [= M. Laenius Flaccus] utinam aliquando gratiam referre possi- } \\
\text { mus! }\end{array}$ \\
\hline Sonstiges & \\
\hline fam. 14.3.3 (21): & $\begin{array}{l}\text { di faxint, ut tali genero mihi praesenti tecum simul et cum liberis } \\
\text { nostris frui liceat! }\end{array}$ \\
\hline fam. 14.4 .5 (39): & [...] id velim sit eius modi ut recte sperare possimus. \\
\hline fam. $14.5 .2(26):$ & nos, si di adiuvabunt, circiter Id. Nov. in Italia speramus fore. \\
\hline Ausrufesätze & \\
\hline Interjektionen & \\
\hline fam. 14.2.2 (21): & $\begin{array}{l}\text { hem, [...] te nunc, mea Terentia, sic vexari, sic iacere in lacrimis et sor- } \\
\text { dibus }\end{array}$ \\
\hline fam. 14.4 .3 (17): & O me perditum, o me adflictum! \\
\hline Fragesätze & \\
\hline$-n e$ & \\
\hline fam. 14.2.3 (29): & $\begin{array}{l}\text { sin eadem nos fortuna premet, etiamne reliquias tuas miseras pro- } \\
\text { icies? }\end{array}$ \\
\hline quid & \\
\hline fam. 14.1.1 (6): & nam quid ego de Cicerone dicam? qui ... \\
\hline fam. $14.1 .5(35):$ & {$[\ldots]$ quid, obsecro te, $[\ldots]$ quid futurum est? } \\
\hline fam. 14.1 .5 (37): & $\begin{array}{l}\text { et si nos premet eadem fortuna, quid puero misero [= Ciceros Sohn] } \\
\text { fiet? }\end{array}$ \\
\hline
\end{tabular}


fam. 14.4.3 (25): $\quad$ sed quid Tulliola mea fiet?

fam. 14.4.3 (27): $\quad$ quid? Cicero meus quid aget?

Abbildung 37: Illokutionsmarkierung durch bestimmte typische Partikeln und Wendungen in Aufforderungs-, Wunsch-, Ausrufe- und Fragesätzen

Neben dem Imperativ sind v. a. konjunktivische Wendungen weit verbreitet, um Aufforderungssätze zu formulieren. Diese werden häufig mit der Partikel velim eingeleitet, welche aber nicht nur in exponierter Stellung am Satzanfang begegnet, sondern zuweilen auch mehr oder weniger weit in den Satz hineingezogen wird, sodass sie nur eingeschränkt demarkativ wirkt. Dies gilt im Grunde schon für fam. 14.23 (5), noch viel mehr jedoch für Äußerungen wie fam. 14.3.5 (34), 14.6 (4), 14.10 (6) und 14.19 (8). I. d. R. wird velim durch weitere demarkative Indikatoren (z. B. Konjunktionen, Wortstellung) ergänzt. Das trifft ebenso auf Partikeln und Wendungen wie utinam bzw. si di adiuvabunt und di faxint zu, die Wunschsätze einleiten, obwohl diese eher als velim bereits für sich allein eine deutliche Abgrenzungsfunktion haben.

Typisch für Ausrufesätze sind exklamative Infinitive und Akkusative, denen manchmal eine Interjektion vorangestellt ist, wie z. B. hem in fam. 14.2.2 (21) oder o in fam. 14.4.3 (17), manchmal hingegen nicht, wie z. B. in fam. 14.1.1 (3) und 14.1.5 (36), wo aber ohne Weiteres ein o ergänzt werden könnte, in fam.14.2.2 (23) sowie 14.1.1 (4) und (5). Andererseits handelt es sich bei fam. 14.1.5 (42) trotz der einleitenden (sekundären) Interjektion per fortunas miseras nostras um keinen Ausrufe-, sondern einen Wunschsatz. Weitergehende Betrachtungen zu evtl. illokutionären Eigenschaften von Ausrufesätzen sind kaum möglich, da es im Analysekorpus nur wenige eindeutige Beispiele dafür gibt. Fam. 14.4.3 (17) ist darüber hinaus ein Sonderfall, insofern zwei mit $o$ eingeleitete Ausrufe zu einer Illokution zusammengefasst werden können, weil es sich im Grunde nur um die stilistische Variation einer einzigen Aussage handelt.

(Direkte) Fragesätze ${ }^{1097}$ sind meist durch Fragepartikeln oder -pronomina wie -ne bzw. quid gekennzeichnet. Gelegentlich werden sie nur durch eine interrogative Satzmelodie signalisiert, die in schriftlichen Texten aus der Wortstellung oder dem Kontext sowie evtl. weiteren sprachlichen Auffälligkeiten (wie dem Verbmodus) erschlossen werden kann und i. d. R. (in modernen Texteditionen) durch ein Fragezeichen kenntlich gemacht wird, wie z. B. in fam. 14.4.3 (20): sine te igitur sim? Manchmal bilden mehrere Fragen zusammen auch eine Einheit, sei es additiv, wie z. B. in fam. 14.4.5 (40): nunc miser quando tuas iam litteras accipiam? quis ad me perferet?, oder disjunktiv, indem zwei Alternativen zur Wahl gestellt werden, wie z. B. in fam. 14.4.3 (18): quid nunc? rogem te ut venias [...]? non rogem? Komplizierter gestaltet sich außerdem eine Äußerung wie fam. 14.1.1 (6), bei der die Antwort quasi schon in die Frage integriert ist. Handlungssemantisch gehören beide zusammen und bilden nur einen Sprechakt, der zudem indirekt formuliert ist, da er eher als (expressiver) Ausruf denn als Frage zu verstehen ist, wie es im Übrigen genauso auf viele andere der zitierten Beispiele zutrifft. Dabei kann die Expressivität durch die Aneinanderreihung oder Splittung von Fragen oder auch durch die bloße Wiederholung der Fragepartikel (wie z. B. in fam. 14.1 .5 (35) und 14.4.3 (27)) erhöht werden.

${ }^{1097}$ Zu den indirekten Fragesätzen vgl. a. das Kap. „Subjekt(sätz)e und Objekt(sätz)e“ ab S. 264. 
Fazit:

Aufgrund der Satzart bzw. der entsprechenden Partikeln und Wendungen lässt sich nur bedingt auf den Illokutionsstatus einer Äußerung schließen.

Aufzählungen ${ }^{1098}$

\section{Wortgruppen}

Den einzelnen Elementen einer Aufzählung kommt kein eigener Illokutionsstatus zu, wenn sie in irgendeiner Weise eine verbundene Einheit bilden:

\begin{tabular}{|c|c|c|}
\hline \multicolumn{3}{|c|}{ Personennamen (+ Pronomina) } \\
\hline fam. 14.5.1 (2): & $\begin{array}{l}\text { Si tu et Tullia, lux nostra, valetis, ego et } \\
\text { suavissimus Cicero valemus. }\end{array}$ & $\begin{array}{l}\text { - } \quad \text { tu et Tullia } \\
\text { - ego et suavissimus Ci- } \\
\text { cero }\end{array}$ \\
\hline fam. 14.5.2 (21): & $\begin{array}{l}\text { De hereditate Preciana, [...] - sed hoc } \\
\text { velim cures, si auctio ante meum adven- } \\
\text { tum fiet, ut Pomponius aut, si is minus } \\
\text { poterit, Camillus nostrum negotium curet }\end{array}$ & $\begin{array}{l}\text { - Pomponius aut Camil- } \\
\quad \text { lus }\end{array}$ \\
\hline fam. $14.2(1):$ & $\begin{array}{l}\text { Tullius s. } d \text {. Terentiae suae et Tulliollae et } \\
\text { Ciceroni suis }\end{array}$ & $\begin{array}{l}\text { - Terentiae suae et Tul- } \\
\text { liollae et Ciceroni suis }\end{array}$ \\
\hline fam. 14.2.1 (7): & $\begin{array}{l}\text { ad te vero et ad nostram Tulliolam non } \\
\text { queo sine plurimis lacrimis scribere. }\end{array}$ & $\begin{array}{l}\text { - ad te vero et ad nos- } \\
\text { tram Tulliolam }\end{array}$ \\
\hline fam. 14.9 (2): & $\begin{array}{l}\text { Ad ceteras meas miserias accessit dolor } \\
\text { et de Dolabellae valetudine et de Tulliae. }\end{array}$ & $\begin{array}{l}\text { - et de Dolabellae vale- } \\
\text { tudine et de Tulliae }\end{array}$ \\
\hline fam. 14.17 (5): & $\begin{array}{l}\text { ego autem quo modo sim affectus, ex } \\
\text { Lepta et Trebatio poteris cognoscere. }\end{array}$ & - ex Lepta et Trebatio \\
\hline fam. 14.14.2 (11): & $\begin{array}{l}\text { his de rebus velim cum Pomponio, cum } \\
\text { Camillo, cum quibus vobis videbitur, } \\
\text { consideretis }\end{array}$ & $\begin{array}{l}\text { - cum Pomponio, cum } \\
\text { Camillo, cum quibus } \\
\text { vobis videbitur }\end{array}$ \\
\hline \multicolumn{3}{|c|}{ (Weitere) Substantive und Pronomina } \\
\hline fam. 14.2.4 (36): & $\begin{array}{l}\text { Ego ad quos scribam nescio, nisi ad eos } \\
\text { qui ad me scribunt aut ad eos de quibus } \\
\text { ad me vos aliquid scribitis. }\end{array}$ & - ad eos aut ad eos \\
\hline fam. $14.18 .1(2):$ & $\begin{array}{l}\text {... id non solum meum consilium est sed } \\
\text { etiam vestrum. }\end{array}$ & $\begin{array}{l}\text { non solum meum con- } \\
\text { silium sed etiam } \\
\text { vestrum. }\end{array}$ \\
\hline fam. 14.2.2 (22): & $\begin{array}{l}\text { mea lux, meum desiderium, unde omnes } \\
\text { opem petere solebant }\end{array}$ & $\begin{array}{l}\text { - mea lux, meum deside- } \\
\text { rium }\end{array}$ \\
\hline fam. 14.1.1 (2): & $\begin{array}{l}\text { Et litteris multorum et sermone omnium } \\
\text { perfertur ad me incredibilem tuam virtu- } \\
\text { tem et fortitudinem esse teque nec animi } \\
\text { neque corporis laboribus defatigari. }\end{array}$ & $\begin{array}{l}\text { - et litteris multorum et } \\
\text { sermone omnium } \\
\text { - tuam virtutem et forti- } \\
\text { tudinem }\end{array}$ \\
\hline
\end{tabular}

${ }^{1098}$ Vgl. a. SCHMITT 2000, 102ff. (zur Illokutionsidentifikation von „Aufzählungen“). 


\begin{tabular}{|c|c|c|}
\hline & & - nec animi neque corpo- \\
\hline fam. 14.1.1 (4): & $\begin{array}{l}\text { te ista virtute, fide, probitate, humanitate } \\
\text { in tantas aerumnas propter me incidisse }\end{array}$ & $\begin{array}{l}\text { - ista virtute, fide, probi- } \\
\text { tate, humanitate }\end{array}$ \\
\hline fam. 14.1.4 (28): & $\begin{array}{l}\text { Pisonis humanitas, virtus, amor in omnis } \\
\text { nos tantus est ut nihil supra possit. }\end{array}$ & $\begin{array}{l}\text { - Pisonis humanitas, vir- } \\
\text { tus, amor }\end{array}$ \\
\hline fam. 14.4.3 (19): & $\begin{array}{l}\text { mulierem aegram, et corpore et animo } \\
\text { confectam }\end{array}$ & $\begin{array}{l}\text { - et corpore et animo } \\
\text { confectam }\end{array}$ \\
\hline fam. 14.4.3 (28): & $\begin{array}{l}\text { iste vero sit in sinu semper et complexu } \\
\text { meo. }\end{array}$ & $\begin{array}{l}\text { - in sinu et complexu } \\
\text { meo }\end{array}$ \\
\hline fam. 14.7.1 (2): & $\begin{array}{l}\text { Omnis molestias et sollicitudines [...] de- } \\
\text { posui et eieci. }\end{array}$ & $\begin{array}{l}\text { - omnis molestias et sol- } \\
\text { licitudines }\end{array}$ \\
\hline fam. 14.3.2 (10): & $\begin{array}{l}\text { nam mi ante oculos dies noctesque versa- } \\
\text { tur squalor vester et maeror et infirmitas } \\
\text { valetudinis tuae. }\end{array}$ & $\begin{array}{l}\text { - dies noctesque } \\
\text { squalor vester et mae- } \\
\text { ror et infirmitas valetu- } \\
\text { dinis tuae }\end{array}$ \\
\hline fam. 14.18.2 (12): & $\begin{array}{l}\text { domus ut propugnacula et prae }\langle\text { si }\rangle \text { dium } \\
\text { habeat Philotimo dicetis. }\end{array}$ & $\begin{array}{l}\text { propugnacula et prae- } \\
\langle\text { si }\rangle \text { dium }\end{array}$ \\
\hline fam. 14.4.2 (12): & $\begin{array}{l}\text { qui periculum fortunarum et capitis sui } \\
\text { prae mea salute neglexit neque legis im- } \\
\text { probissimae poena deductus est quo } \\
\text { minus hospiti et amicitiae ius officiumque } \\
\text { praestaret. }\end{array}$ & $\begin{array}{l}\text { - } \quad \text { periculum fortunarum } \\
\text { et capitis sui } \\
\text { - hospiti et amicitiae ius } \\
\text { officiumque }\end{array}$ \\
\hline fam. 14.2 .3 (33): & $\begin{array}{l}\text { nam mihi ante oculos dies noctesque ver- } \\
\text { saris ... }\end{array}$ & - dies noctesque \\
\hline fam. 14.2.2 (21): & $\begin{array}{l}\text { hem, [...] te nunc, mea Terentia, sic vexa- } \\
\text { ri, sic iacere in lacrimis et sordibus }\end{array}$ & - in lacrimis et sordibus \\
\hline fam. 14.20 (7): & $\begin{array}{l}\text { item cetera quae sunt ad victum et ad va- } \\
\text { letudinem necessaria }\end{array}$ & $\begin{array}{l}\text { - ad victum et ad valetu- } \\
\text { dinem }\end{array}$ \\
\hline Adjektive & & \\
\hline fam. 14.2 .3 (27): & $\begin{array}{l}\text { illud doleo, quae impensa facienda est, in } \\
\text { eius partem te miseram et despoliatam } \\
\text { venire. }\end{array}$ & $\begin{array}{l}\text { - miseram et despolia- } \\
\text { tam }\end{array}$ \\
\hline fam. 14.5.2 (27): & $\begin{array}{l}\text { vos, mea suavissima et optatissima Te- } \\
\text { rentia, si nos amatis, curate ut valeatis. }\end{array}$ & $\begin{array}{l}\text { - suavissima et optatissi- } \\
\text { ma }\end{array}$ \\
\hline fam. 14.3.1 (7): & $\begin{array}{l}\text { hoc miserius, turpius, indignius nobis nihil } \\
\text { fuit. }\end{array}$ & $\begin{array}{l}\text { miserius, turpius, indig- } \\
\text { nius }\end{array}$ \\
\hline fam. 14.2.2 (16): & $\begin{array}{l}\text { A te quidem omnia fieri fortissime et } \\
\text { amantissime video, nec miror }\end{array}$ & $\begin{array}{l}\text { - fortissime et amantissi- } \\
\text { me }\end{array}$ \\
\hline fam. 14.5.1 (4): & $\begin{array}{l}\text { cum sane adversis ventis usi essemus tar- } \\
\text { deque et incommode navigassemus. }\end{array}$ & - tarde et incommode \\
\hline
\end{tabular}




\begin{tabular}{|c|c|c|}
\hline fam. 14.7.1 (7): & $\begin{array}{l}\text { cui quidem tu deo, quem ad modum so- } \\
\text { les, pie et caste satis facies ... }\end{array}$ & - pie et caste \\
\hline \multicolumn{3}{|l|}{ Verben } \\
\hline fam. 14.2.2 (21): & $\begin{array}{l}\text { hem, [...] te nunc, mea Terentia, sic vexa- } \\
\text { ri, sic iacere in lacrimis et sordibus }\end{array}$ & - sic vexari, sic iacere \\
\hline fam. 14.3.1 (6): & $\begin{array}{l}\text { meum fuit officium vel legatione vitare } \\
\text { periculum vel diligentia et copiis resistere } \\
\text { vel cadere fortiter }\end{array}$ & $\begin{array}{l}\text { - vel vitare vel resistere } \\
\text { vel cadere }\end{array}$ \\
\hline fam. $14.8(4):$ & $\begin{array}{l}\text { nam mihi et scriptum et nuntiatum est te } \\
\text { in febrim subito incidisse. }\end{array}$ & $\begin{array}{l}\text { - et scriptum et nuntia- } \\
\text { tum est }\end{array}$ \\
\hline fam. $14.16(6):$ & $\begin{array}{l}\text { quamquam alia sunt quae magis cure- } \\
\text { mus magisque doleamus }\end{array}$ & $\begin{array}{l}\text { - magis curemus magis- } \\
\text { que doleamus }\end{array}$ \\
\hline \multicolumn{3}{|l|}{ Sonstiges } \\
\hline fam. $14.20(2):$ & $\begin{array}{l}\text { In Tusculanum nos venturos putamus aut } \\
\text { Nonis aut postridie. }\end{array}$ & - aut Nonis aut postridie \\
\hline
\end{tabular}

Abbildung 38: Aufzählungen von Wortgruppen ohne eigenen Illokutionsstatus

Die Einzelelemente der Aufzählungen können Teile einer übergeordneten Gesamtheit darstellen, z. B. „Familie(nmitglieder)“ in fam. 14.2 (1), 14.2.1 (7) und 14.5.1 (2), oder es werden sich ergänzende, bedeutungsähnliche oder -gleiche Begriffe aneinandergereiht, wie z. B. bei nec animi neque corporis laboribus in fam. 14.1.1 (2) bzw. sic vexari, sic iacere in fam. 14.2.2 (21) und miserius, turpius, indignius in fam. 14.3.1 (7). Auch eine Aneinanderreihung von Beispielen kann dazu zählen, wie z. B. cum Pomponio, cum Camillo, cum quibus vobis videbitur in fam. 14.14.2 (11).

Es gibt allerdings Fälle, in denen die Abgrenzung einer separaten Illokution angebracht erscheint. In fam. 14.3.2 werden bspw. zwei verschiedene Gefühle miteinander verbunden: qua re cum dolore conficiar, tum etiam pudore. Diese gehen mit zwei verschiedenen (expressiven) Untermustern einher und sollten deshalb voneinander getrennt werden, nämlich dolor: JAMMERN = (8) und pudor: SICH ENTSCHULDIGEN = (9). In fam. 14.11 bekundet Cicero zunächst einmal die Absicht, seinen Sohn zu Cäsar zu schicken: Nobis erat in animo Ciceronem ad Caesarem mittere $=(5)$. In einem Nachtrag, der durch die exponierte Wortstellung und durch (redundantes) cum eo auch auf der Äußerungsebene deutlich vom Vorangehenden abgegrenzt wird, ergänzt er diese Information durch eine weitere, nämlich dass er $\mathrm{Cn}$. Sallustius mitschicken werde: et cum eo Cn. Sallustium. = (6).

Fazit:

Aufzählungen von Wortgruppen können einen eigenen Illokutionsstatus haben. 
Teilsätze

Für die Aneinanderreihung von Teilsätzen ${ }^{1099}$ gilt im Prinzip das Gleiche wie für Wortgruppen. In folgenden Fällen sind z. B. zwei Nebensätze quasi zu einer (inhaltlichen und illokutionären) Einheit verschmolzen:

\begin{tabular}{|lll|} 
fam. 14.2.4 (35): & $\begin{array}{l}\text {... quare, ut id quod speras et quod agis } \\
\text { consequamur, servi valetudini. }\end{array}$ & $\begin{array}{l}\text { quod speras et quod } \\
\text { agis }\end{array}$ \\
fam.14.8(7): & $\begin{array}{l}\text { item posthac, si quid opus erit, si quid } \\
\text { acciderit novi, facies ut sciam. }\end{array}$ & $\begin{array}{l}\text { si quid opus erit, si quid } \\
\text { acciderit novi }\end{array}$ \\
fam. 14.9 (3): & $\begin{array}{l}\text { omnino de omnibus rebus nec quid con- } \\
\text { sili capiam nec quid faciam scio. }\end{array}$ & $\begin{array}{l}\text { nec quid consili capiam } \\
\text { nec quid faciam }\end{array}$ \\
\hline
\end{tabular}

Abbildung 39: Aufzählungen von Nebensätzen ohne eigenen Illokutionsstatus

Bei Hauptsätzen passiert dies seltener, wenn man nicht jede (sowohl asyndetische als auch syndetische) Aufeinanderfolge als Aufzählung auffassen möchte. ${ }^{1100}$ Man kann nämlich bspw. bereits bei einer Satzfolge wie viximus, floruimus in fam. 14.4 .5 (43) die Frage stellen, ob es sich um eine (asyndetisch-enumerative) Satzreihe oder um zwei getrennte Hauptsätze handelt. Tatsächlich besteht eine enge Verbindung zwischen den Sätzen, was normalerweise in den Texteditionen durch die Interpunktion auch so kenntlich gemacht wird. ${ }^{1101}$ Andere Sätze sind schwieriger einzuordnen, wie z. B. Volumnia debuit in te officiosior esse quam fuit et id ipsum quod fecit potuit diligentius facere et cautius. (fam. 14.16 (5)). Man könnte von zwei Illokutionen ausgehen: 1 . „Volumnia hätte mehr für dich (= Terentia) tun können.“ 2. „Was sie getan hat, hätte sie besser tun müssen. "Die Sätze sind aber m. E. so stark aufeinander bezogen, dass ich von einer Illokution ausgehe: „Volumnia hätte sich entgegenkommender verhalten müssen." Diese Version deckt sich mit der Textgestaltung in den gängigen Ausgaben. Man kann also von einer Satzreihe sprechen, weniger indes von einer wirklichen Aufzählung. Letzteres gilt erst recht für die meisten anderen aufeinanderfolgenden Hauptsätze, bei denen man weder von Satzreihen und noch viel weniger von Aufzählungen sprechen kann und die i. d. R. folgerichtig durch Punkt oder Semikolon voneinander abgegrenzt werden. Bei syntaktischer Verflechtung, wie z. B. in fam. 14.3.3 (20), wo der Hauptsatz aus zwei Prädikaten (perspicio und praedicant) mit jeweils zugehörigem Subjekt (ego bzw. omnes) besteht, die sich aber auf dasselbe Objekt (Pisonem nostrum mirifico esse studio in nos et officio) beziehen, kann man hingegen sicher davon ausgehen, dass nur ein Satz und oft auch (wie hier) nur eine Illokution vorliegt.

Es gibt verschiedene Arten, sprachliche Elemente syndetisch-enumerativ miteinander zu verknüpfen. Sind nicht nur Satzteile, sondern ganze (Teil-)Sätze betroffen, signalisieren die Konnektoren dabei oft (aber bei Weitem nicht immer) eine neue Illokution. Den einzelnen Elementen einer disjunktiven Aufzählung mit aut (oder vel) kommt bspw. normalerweise kein eigener Illokutionsstatus zu, weil die verknüpften Einheiten einander ausschließen und so per

\footnotetext{
1099 Der Übergang von einer bloßen Aneinanderreihung von Prädikaten zu einer von Teilsätzen ist fließend. So könnte man bspw. im Falle von fam. 14.16 (6) theoretisch ein zweites Relativpronomen ergänzen und dadurch zwei Attributsätze erhalten: quae magis curemus und quae magis doleamus.

1100 Vgl. das Kap. „Adverbiale Bestimmungen und Adverbialsätze“ ab S. 267, in dem auch Hauptsätze behandelt werden, die verschiedenartige adverbiale Beziehungen herstellen.

${ }^{1101}$ Vgl. a. S. 251.
} 
se keine eigenständigen Informationen bzw. Illokutionen darstellen können. ${ }^{1102}$ Es gibt ohnehin nur wenige Fälle, in denen aut tatsächlich einen (annähernd) vollständigen (Teil-)Satz einleitet, wie z. B. in fam. 14.4.1 (4), wo die Konjunktion, oder fam. 14.18.1 (3), wo das Prädikat ergänzt werden muss. Etwas komplizierter ist der Fall bei fam. 14.16 (3) / (4), wo aut ... aut tatsächlich zwei Illokutionen voneinander trennt, was aber letztlich v. a. durch die komplexe Schachtelstruktur bedingt ist. ${ }^{1103}$

Dagegen finden sich zahlreiche Beispiele, in denen durch adversative Konnexion eine neue Illokution indiziert wird:

\begin{tabular}{|c|c|}
\hline sed (rursus) & \\
\hline fam. 14.1.3 (23): & sed adhuc Plancius me retinet \\
\hline fam. 14.2.2 (15): & sed Crassum tamen metuo. \\
\hline fam. 14.2.2 (17): & sed maereo casum eius modi ut ... \\
\hline fam. $14.2 .3(35):$ & sed video in te esse omnia. quare ... \\
\hline fam. 14.2.4 (38): & sed velim quam saepissime litteras mittatis, praesertim si ... \\
\hline fam. 14.5.1 (18): & sed quoniam subeunda fortuna est \\
\hline fam. $14.5 .2(21):$ & De hereditate Preciana, $[. .$.$] - sed hoc velim cures ...$ \\
\hline fam. $14.18 .1(4):$ & sed rursus illud me movet, quod video ... \\
\hline autem & \\
\hline fam. 14.4.4 (35): & est autem in officio adhuc Orpheus \\
\hline fam. $14.17(5):$ & $\begin{array}{l}\text { ego autem quo modo sim affectus, ex Lepta et Trebatio poteris cognos- } \\
\text { cere. }\end{array}$ \\
\hline fam. 14.18.2 (14): & maxime autem date operam ut valeatis, si ... \\
\hline vero und verum & \\
\hline fam. 14.2.1 (7): & $\begin{array}{l}\text { ad te vero et ad nostram Tulliolam non queo sine plurimis lacrimis scri- } \\
\text { bere. }\end{array}$ \\
\hline fam. $14.2 .3(25):$ & ... ego vero tum denique mihi videbor restitutus si ... \\
\hline fam. $14.2 .3(26):$ & verum haec non sunt in nostra manu \\
\hline fam. 14.4.1 (4): & tum vero, cum aut scribo ad vos aut vestras lego, conficior lacrimis ... \\
\hline fam. 14.4 .3 (28): & iste [= Ciceros Sohn] vero sit in sinu semper et complexu meo. \\
\hline
\end{tabular}

Abbildung 40: Illokutionsmarkierung durch adversative Konnexion

Es gibt aber auch einige Gegenbeispiele, in denen ein adversativer Konnektor keine eigenständige Illokution einleitet, wie besonders sed, z. B. in fam. 14.3 .1 (5) und 14.19 (5). Oft liegt dann

\footnotetext{
1102 Es gibt auch disjunktive Aufzählungen, die nicht durch einen Konnektor miteinander verbunden sind, wie z. B. die Alternativfrage(n) in fam. 14.4.3 (18): ... rogem te ut venias [...]? non rogem? Ein gewisses Problem stellt fam. 14.4.1 (6) / (7) dar, wo zwei hypothetische Alternativen einander gegenübergestellt werden, die mit verschiedenen (expressiven) Untermustern verbunden sind, nämlich HOFFNUNG ÄUSSERN in (6) und ANGST ÄUSSERN in (7), weshalb in diesem Fall doch von zwei getrennten Illokutionen auszugehen ist.

${ }^{1103}$ Vgl. S. $244 f$.
} 
ein quasi-konditionales Verhältnis vor („,Ich hätte es getan, wenn mich nicht vieles davon abhalten hätte."), welches i. d. R. einen eigenen Illokutionsstatus ausschließt ${ }^{1104}$, oder es wird ein sehr unmittelbarer Gegensatz (,sondern“) bezeichnet.

Zu erwähnen sind noch einige Verwendungsweisen der Partikel quidem, die ebenfalls adversativ bzw. in Korrelation mit adversativen Konnektoren wie sed gebraucht werden kann, z. B. in fam. 14.2.2 (16) / (17), 14.5.2 (21) / (22) und fam. 14.1.3 (18) / (19). In anderen Fällen hat sie einen eher bekräftigenden oder einschränkenden Charakter (,jedenfalls“, „wenigstens“), wie z. B. in fam. 14.1.4 (30) und 14.4.2 (14) sowie 14.14.1 (9). ${ }^{1105}$

Am stärksten vertreten ist die additive Konnexion ${ }^{1106}$ :

\section{et}

fam. 14.2.1 (10): et nisi tam timidi fuissemus, praestitissem.

fam. 14.2.3 (32): et valetudinem istam infirmam, si me amas, noli vexare.

fam. 14.20 (5): $\quad$ et, ut arbitror, diutius ibi commorabimur

-que

fam. 14.2.1 (9): idque praestare debui

fam.14.2.2 (13): gratiasque egi, ut debui

fam. 14.2.2 (23): idque fieri mea culpa

fam. 14.5 .1 (10): diligentissimeque a te perscripta sunt omnia,

fam. 14.5.1 (11): idque mihi gratissimum fuit.

atque

fam. 14.4.5 (47): atque ego, qui te confirmo, ipse me non possum.

nec

fam. 14.2.1 (5): nec enim habeo quid scribam

fam. 14.2.1 (6): nec hoc tempore quicquam difficilius facio.

neque

fam. 14.5.1 (12):

neque sum admiratus hanc epistulam quam Acastus attulit brevem fuisse.

item

fam. 14.20 (7): $\quad$ item cetera quae sunt ad victum et ad valetudinem necessaria

\footnotetext{
${ }^{1104}$ Vgl. das Kap. „Konditionale Beziehungen“ ab S. 272.

1105 Häufig wird quidem allerdings weniger adversativ i. e. S. gebraucht, sondern hat vielmehr eine versichernde Bedeutung. Vgl. KüHNER UND STEGMANN 1966, 802f. (§ 145), wo zur Verwendungsweise von quidem u. a. auch angemerkt wird: „Oft stellt es den betonten Begriff nachdrücklich einem vorhergehenden oder nachfolgenden Worte entgegen, so daß es adversative (= aber, allerdings) oder konzessive (= zwar [...]) Bedeutung annimmt. Oft, besonders in Verbindung mit Konjunktionen und Relativen [...] hat es eine begründende, ergänzende und weiterführende Kraft (= nämlich, und zwar). Alle diese verschiedenen Bedeutungen liegen aber an sich nicht in dem Worte, das immer hervorhebende Kraft behält, sondern ergeben sich jedesmal aus dem Zusammenhange." Vgl. außerdem MüLlER 1997, 67ff. und (ausführlicher) SOLODOw 1978. Grundsätzlich wird quidem von Cicero im Vergleich zu anderen Autoren besonders häufig gebraucht: VgI. KüHNER UND STEGMANN 1966, 803 (§ 145).

1106 Die Partikel etiam kann ebenfalls der additiven Verknüpfung dienen, wie z. B. in fam. 14.14.1 (6) und (10), allerdings nicht der von ganzen (Teil-)Sätzen.
} 


\begin{tabular}{|c|c|}
\hline fam. 14.8 (7): & item posthac, si quid opus erit, si quid acciderit novi, facies ut sciam. \\
\hline $\begin{array}{l}\text { praeterea } \\
\text { fam. 14.4.4 (36): }\end{array}$ & praeterea magno opere nemo [erg. in officio est] \\
\hline $\begin{array}{l}\text { primum } \\
\text { fam. } 14.4 .4(34) \text { : } \\
\text { fam. } 14.7 .3(14) \text { : }\end{array}$ & $\begin{array}{l}\text { primum tuis [= Terentias Sklaven] ita promissum est, te facturam esse ... } \\
\text { tu primum valetudinem tuam velim cures }\end{array}$ \\
\hline $\begin{array}{l}\text { tum } \\
\text { fam. 14.2.3 (25): } \\
\text { fam. 14.4.1 (4): }\end{array}$ & $\begin{array}{l}\text {... ego vero tum denique mihi videbor restitutus si illa nobis erit restituta. } \\
\text { tum vero, cum aut scribo ad vos aut vestras lego, conficior lacrimis ... }\end{array}$ \\
\hline $\begin{array}{l}\text { deinde } \\
\text { fam. 14.7.2 (10): } \\
\text { fam. 14.7.3 (15): }\end{array}$ & $\begin{array}{l}\text { deinde conscribam ad nostros familiaris multas epistulas, quibus ... } \\
\text { deinde, si tibi videbitur, villis iis utere quae ... }\end{array}$ \\
\hline $\begin{array}{l}\text { omnino } \\
\text { fam. } 14.1 .6(46) \text { : } \\
\text { fam. } 14.9(3) \text { : }\end{array}$ & $\begin{array}{l}\text { mihi omnino iam brevis exspectatio est. } \\
\text { omnino de omnibus rebus nec quid consili capiam nec quid faciam scio. }\end{array}$ \\
\hline
\end{tabular}

Abbildung 41: Illokutionsmarkierung durch additive Konnexion

Wenngleich die zugrunde liegende Datenbasis nur recht schmal ist, spricht einiges dafür, dass additive Konjunktionen i. d. R. deutlich demarkativ wirken, sofern sie nicht nur Satzteile, sondern (Teil-)Sätze miteinander verknüpfen. Ein besonders augenfälliges Beispiel ist fam. 14.12, wo durch et drei aufeinanderfolgende Illokutionen voneinander abgegrenzt sind, die drei verschiedene Gründe benennen, warum Terentia Cicero besser nicht entgegenreisen sollte (wobei zu der zweiten ein est zu ergänzen ist): et longum est iter (7) - et non tutum (8) - et non video quid prodesse possis si veneris. (9) Ausnahmen, bei denen trotz eines additiven Anschlusses keine eigene Illokution angenommen wird, wie in den auf S. 260 beschriebenen Fällen, sind recht selten. ${ }^{1107}$ Dagegen scheint die illokutionsmarkierende Funktion von tum nur vergleichsweise schwach ausgeprägt zu sein: Es wird häufig parallel zu einem mit cum (oder si) eingeleiteten Temporalsatz konstruiert, der nicht immer nachgestellt ist (wie bei den Beispielen in Abbildung 41), sondern auch vorangestellt sein kann, wie z. B. in fam. 14.3.4 (29). Manchmal verknüpfen cum und tum zwei Aussagen auch rein enumerativ, wie z. B. in fam. 14.4.1 (3) / (4). In diesem Fall werden zwei (illokutionär zu trennende) Gründe für Ciceros Schreibfaulheit genannt. ${ }^{1108}$ Die demarkative Wirkung von tum verstärkt sich durch eine Verbindung mit vero oder denique. Temporaladverbien wie primum, tum, deinde wirken explizit strukturierend. Tum denique hat ebenso wie omnino einen zusammenfassenden Charakter. Ähnlich verhält es sich mit einer Wendung wie ad summam, z. B. in fam. 14.14.2 (12), und anderen sekundären Illokutionen wie (quod) reliquum est oder auch tantum scribo und unum hoc scito..$^{1109}$

\footnotetext{
${ }^{1107}$ Zu fam. 14.2.3 (35) vgl. a. S. 227. Vgl. außerdem S. 219 zu fam. 14.2 .2 (16) und S. 190 zu 14.5 .1 (4).

${ }^{1108}$ Vgl. a. fam. 14.3.2 (8) / (9), wo keine (Teil-)Sätze, sondern zwei Substantive durch die beiden Konjunktionen verbunden werden.

${ }^{1109}$ Vgl. das Kap. „Sekundäre Illokutionen“ ab S. 275.
} 
Fazit:

Aufzählungen von Teilsätzen können einen eigenen Illokutionsstatus haben.

Subjekt(sätz)e und Objekt(sätz)e

Eine Proposition besteht aus Referenz und Prädikation, die untrennbar miteinander verbunden sind, also keine eigenständigen Illokutionen darstellen können. Für die Beurteilung des Illokutionsstatus spielt es dabei keine Rolle, ob die Referenz durch ein (ggf. in ein Prädikat integriertes) einfaches Subjekt oder einen Subjektsatz dargestellt wird und ob das (ggf. auch negierte) Prädikat allein oder in Verbindung mit einem oder mehreren (Genitiv-, Dativ-, Akkusativ-, Ablativ-, Präpositional-)Objekten bzw. entsprechenden Erweiterungen wie Infinitivkonstruktionen (einschl. $A c l$ ), faktischen quod- und indirekten Fragesätzen die Prädikation bildet. ${ }^{1110}$ So kann das „Akkusativobjekt" zu videre u. a. in folgender Form auftreten:

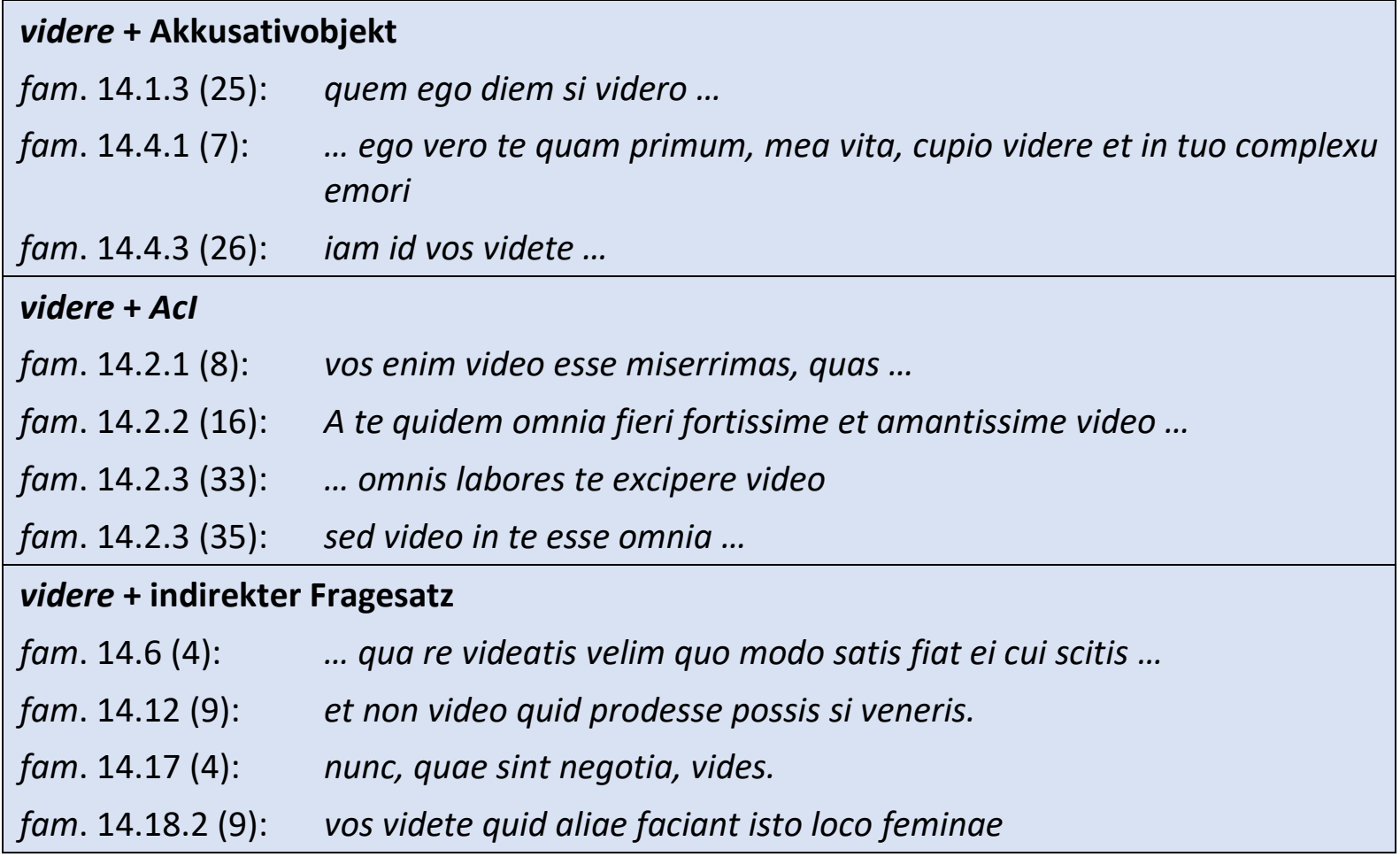

Abbildung 42: Objekte und Objektsätze in Abhängigkeit von, videre'

Die übrigen verba sentiendi und die verba dicendi werden in ähnlicher Weise wie videre verwendet. ${ }^{1111}$ Zu letzteren gehören $u$. a. auch die Verben des Meinens und Wissens, mit denen ebenso wie mit verschiedenen anderen Ausdrücken eine bestimmte propositionale Einstellung ${ }^{1112}$ ausgedrückt werden kann:

1110 Zur Illokutionsidentifikation von „Inhaltsbeziehungen“ vgl. a. SCHMITT 2000, $74 f$.

1111 Genannt seien hier nur audire, wie z. B. in nam ego eo nomine sum Dyrrachi hoc tempore ut quam celerrime quid agatur audiam (fam. 14.3.4 (27)), cognoscere, wie z. B. in cognovi enim [...] ad arma rem spectare (fam. 14.5.1 (15)), intellegere, wie z. B. in res quanta sit intellego (fam. 14.1.2 (12)), bzw. dicere, wie z. B. in Sicca dixerat se mecum fore ... (fam. 14.4.6 (54)), und scribere, wie z. B. in Quid fieri placeret scripsi ad Pomponium (fam. 14.10 (2)).

1112 Vgl. a. S. 31. 


\begin{tabular}{|c|c|}
\hline \multicolumn{2}{|c|}{ epistemische Einstellung } \\
\hline \multicolumn{2}{|c|}{ Verben des Meinens und Wissens } \\
\hline fam. 14.2.1 (4): & cui puto rescribi oportere \\
\hline fam. $14.2 .4(36):$ & Ego ad quos scribam nescio ... \\
\hline fam. 14.9 (3): & omnino de omnibus rebus nec quid consili capiam nec quid faciam scio. \\
\hline fam. 14.13 (2): & ... quae sit istius vis hoc tempore et quae concitatio multitudinis ignoro. \\
\hline fam. $14.20(2):$ & In Tusculanum nos venturos putamus aut Nonis aut postridie. \\
\hline \multicolumn{2}{|c|}{ unpersönliche Ausdrücke } \\
\hline fam. $14.18 .2(8):$ & mihi plane non satis constat adhuc utrum sit melius. \\
\hline \multicolumn{2}{|c|}{ motivationale Einstellung } \\
\hline \multicolumn{2}{|c|}{ Modalverben (wollen, sollen, müssen, dürfen) } \\
\hline fam. 14.2.1 (8): & ... quas ego beatissimas semper esse volui \\
\hline fam. 14.2.1 (9): & idque praestare debui \\
\hline fam. $14.5 .1(14):$ & qui quidem quam primum ad vos venire cupimus \\
\hline \multicolumn{2}{|c|}{ unpersönliche Ausdrücke } \\
\hline fam. 14.3.1 (6): & $\begin{array}{l}\text { meum fuit officium vel legatione vitare periculum vel diligentia et copiis } \\
\text { resistere vel cadere fortiter. }\end{array}$ \\
\hline fam. 14.3.5 (31): & si perficitis quod agitis, me ad vos venire oportet \\
\hline fam. 14.5.1 (17): & ut mihi, cum venero, dissimulare non liceat quid sentiam. \\
\hline fam. $14.10(2):$ & Quid fieri placeret scripsi ad Pomponium \\
\hline fam. $14.10(5):$ & apertius scribi, quoniam ad illum scripseram, necesse non fuit \\
\hline fam. $14.11(5):$ & Nobis erat in animo Ciceronem ad Caesarem mittere \\
\hline
\end{tabular}

Abbildung 43: Möglichkeiten zum Ausdruck einer propositionalen Einstellung

Es gibt noch zahlreiche weitere Möglichkeiten zum Ausdruck der Sprechereinstellung. So kann ein $\mathbf{N c l}$ mit videri ebenfalls eine epistemische Modalität vermitteln, wie z. B. in fam. 14.2.3 (25): ego vero tum denique mihi videbor restitutus si ..., 14.4 .3 (24): unum hoc scito: si te habebo, non mihi videbor plane perisse. ${ }^{1113}$ und 14.7.1. (6): statim ita sum levatus ut mihi deus aliquis medicinam fecisse videatur. Das Gerundivum sowie Modus (Konjunktiv) und Tempus (Futur) können hingegen eine motivationale Einstellung ausdrücken, wie z. B. in fam. 14.14.1 (8): si enim [erg. feminae Romae] non sunt, videndum est ut honeste vos esse possitis. bzw. 14.5.2 (25): sin tu iam Roma profecta eris, tamen curabis ut hoc ita fiat. ${ }^{1114}$

Nicht nur in Trägersätzen eines Subjekt- oder Objektsatzes kann ein Sprecher seine Einstellung zum Inhalt einer Äußerung deutlich machen. Das Gerundivum vermittelt bspw. auch unabhängig davon eine motivationale Einstellung, wie z. B. in fam. 14.5 .1 (18): quoniam subeunda fortuna est. ${ }^{1115}$ Eine epistemische Einstellung ist auch Adverbien wie fortasse und certe eigen, wie z. B. in fam. 14.20 (4): plures enim fortasse nobiscum erunt und 14.22 (4): qui [= tabellarii]

\footnotetext{
${ }^{1113}$ Man beachte den Kontrast zwischen dem Gewissheit vermittelnden scito und dem Ungewissheit ausdrückenden videbor.

${ }^{1114}$ Vgl. a. das Kap. „Besonderheiten des Lateinischen“ ab S. 278.

1115 Vgl. a. S. 278.
} 
si venerint, fortasse erimus certiores quid nobis faciendum sit bzw. 14.4 .1 (5): quod utinam minus vitae cupidi fuissemus! certe nihil aut non multum in vita mali vidissemus. und 14.4.3 (26): sed certe, quoquo modo se res habebit, illius misellae et matrimonio et famae serviendum est. Hinzu kommen Einschübe ${ }^{1116}$ wie ut arbitror (epistemische Modalität), z. B. in fam. 14.20 (5), bzw. ut debui (motivationale Modalität), z. B. in fam. 14.2 .2 (13). ${ }^{1117}$

Mit Verben wie sperare und metuere oder timere wird ähnlich wie mit putare die Gewissheit einer Aussage eingeschränkt, diese zugleich aber auch emotional und evaluativ eingefärbt, insofern der auf die Zukunft bezogene Inhalt positiv oder negativ bewertet wird ${ }^{1118}$, z. B. in fam. 14.5.2 (26) und 14.7.2 (8) bzw. 14.12 (3), 14.14.1 (6) sowie 14.2.3 (34). Weitere evaluativ oder emotiv verwendete Verben sind $u$. a. (ad)mirari (wie in fam. 14.5 .1 (12)), maerere (wie in fam. 14.2.2 (17)) und dolere (wie in fam. 14.2.3 (27)). Hier sind ebenfalls alternative Wendungen möglich, z. B. unpersönliche Ausdrücke wie me movet (in fam. 14.18 .1 (4)) und me pudet (in fam. 14.3.2 (9)) oder ein Nachtrag wie nec miror (in fam. 14.2.2 (16)).

Normalerweise ist - wie in den bis hierhin angeführten Beispielen - mit dem Ausdruck einer propositionalen Einstellung keine eigene Illokution verbunden, da er unmittelbar mit der betreffenden Aussage verbunden ist. Man kann putamus in fam. 14.20 (2) nicht einfach weglassen, ohne dass sich der Sinn der Äußerung stark verändert. Hingegen sollte in fam. 14.4.4 (30) / (31) quod metuo als eigenständige Illokution aus dem übrigen Satz herausgelöst werden: Cicero drückt einerseits (epistemisch) Ungewissheit (nescio) über Terentias aktuelle Vermögenssituation aus $(=(30)$ ), andererseits (emotiv) seine Befürchtung, dass sie tatsächlich finanziell am Ende sein könnte $(=(31)) .{ }^{1119}$ Dieser Fall ist indes etwas speziell, weil zwei propositionale Einstellungen miteinander konkurrieren. Aus einem anderen Grund fällt auch fam. 14.4.3 (21) - (23) aus der Reihe. Die Konditionalsätze in (21) und (22) benennen zwei möglichen Situationen, aus denen jeweils eine bestimmte Handlungsoption (BITTE) abgeleitet wird. Davon abzugrenzen ist der Einschub ut ego metuo (= (23)), mit dem Cicero seine ANGST vor dem Eintreten der zweiten Situation ÄUSSERT. Allerdings ist eine solche Auflösung insofern problematisch, als im Gegensatz dazu die korrelierende positive Bewertung durch spes in (21) kaum von der zugehörigen Illokution zu separieren ist. Die Einschübe quod metuo bzw. ut ego metuo sind nichtsdestotrotz anders zu bewerten als bspw. ut arbitror in fam. 14.20 (5). Außerdem besteht ein Unterschied zur Verwendung des Verbs metuere z. B. in fam. 14.14.1 (6), wo

\footnotetext{
1116 ,Einschub` ist hier kein Synonym für ,Parenthese', sondern meint einfach nur ein in die lineare Satzstruktur eingeschobenes Äußerungselement.

1117 Vgl. a. das Kap. „Appositionen und Parenthesen“ ab S. 274.

${ }_{1118}$ Zu bemerken ist allerdings, dass es auch ein paar (seltene) Fälle gibt, in denen sperare eher negativ konnotiert ist, wie z. B. in VERG. Aen. 4.419: hunc ego si potui tantum sperare dolorem, et perferre, soror, potero. Vgl. a. AMM. 14.7.5, HIST. AUG. Maximin. 23.1 und FLOR. epit. 1.36. Bei Cicero hingegen geht sperare, soweit ich dies überblicken kann, immer mit einer positiven Evaluation einher. In fam. 14 wird das Verb (ebenso wie das Substantiv spes) jedenfalls nur in Verbindung mit erwünschten Inhalten verwendet. An anderen Stellen sind zwar negative Inhalte damit verknüpft, die Cicero aber gleichwohl (positiv) „erhofft“, wie z. B. in Cıc. de orat. 3.13.51: Verum, si placet, quoniam haec satis spero vobis quidem certe maioribus molesta et putida videri, ad reliqua aliquanto odiosiora pergamus.; oder sperare wird in einem entsprechenden Zusammenhang negiert, wie z. B. in CIC. S. Rosc. 10: sin a vobis, id quod non spero, deserar, tamen animo non deficiam et id quod suscepi, quoad potero perferam. (Beispiele nach GEORGES 2013, s. v. ,spero').

1119 Vgl. a. SCHMITT 2000, 84ff. zur Illokutionsidentifikation von „autoaktiven Satzadverbialien“ wie ,leider' und ,glücklicherweise'.
} 
zwar ebenfalls zugleich (epistemische) Ungewissheit und (emotive) Angst ausgedrückt werden, sich beides aber auf einen einzigen Ausdruck (etiam illud metuo) konzentriert, in dem sie untrennbar miteinander verbunden sind.

Im Übrigen sind außerdem Fälle denkbar, in denen Objektsatz und zugehöriger Trägersatz zwei verschiedene (handlungsfunktional bedeutsame) Informationen vermitteln und damit illokutionär eigenständig sind. Wäre bspw. nicht Terentia selbst Subjekt des indirekten Fragesatzes, könnte man fam. 14.2.2 (18) zwei Informationen entnehmen: 1., dass jemand zur Tabula Valeria verschleppt wurde und 2., dass P. Valerius (darüber) einen Brief an Cicero geschrieben hat. Die Hauptinformation würde man dann wahrscheinlich eher bei Punkt 1 vermuten, aber je nachdem, welches Verhältnis Terentia zum Schreiber hat, könnte auch Punkt 2 sehr wichtig für sie sein, sodass ggf. die Annahme von zwei eigenständigen Illokutionen gerechtfertigt wäre. Da Terentia als von dem geschilderten Ereignis Betroffene notwendigerweise bereits Kenntnis von ebendiesem hat, ist aber nur Punkt 2 für sie von Bedeutung. ${ }^{1120}$ Umgekehrt liegt der Fall bei fam. 14.10 (2). Terentia erfährt hier: 1., dass sie von Pomponius Näheres über Ciceros Wünsche erfahren kann, und 2., dass Cicero Pomponius einen Brief geschrieben hat. Obgleich schwer zu entscheiden ist, was Terentia bereits bekannt ist und was nicht, kann man wohl davon ausgehen, dass hier v. a. die erste Information für sie von Belang ist. ${ }^{1121}$

Fazit:

Subjekt(satz) und Objekt(satz) haben i. d. R. keinen eigenen Illokutionsstatus.

Adverbiale Bestimmungen und Adverbialsätze ${ }^{1122}$

Temporale Beziehungen

Temporale Bestimmungen und Temporalsätze haben meistens lediglich eine informationsspezifizierende Funktion wie z. B. hoc tempore in fam. 14.2.1 (6), semper in fam. 14.2.1 (8), nunc in fam. 14.2.2 (21), tum denique in fam. 14.2.3 (25), dies noctesque in fam. 14.2.3 (33), quam saepissime in fam. 14.2.4 (38), iam in fam. 14.5.1 (13) und quam primum in fam. 14.5.1 (14) bzw. cum venero in fam. 14.5.1 (17). Manchmal handelt es sich aber auch um informationstragende Bestandteile einer Äußerung, wie z. B. bei Prid. Id. Oct. Athenas in fam. 14.5 .1 (3), ante meum adventum in fam. 14.5.2 (21), circiter Id. Nov. in fam. 14.5.2 (26), aut Nonis aut postridie in fam. 14.20 (2) und diutius in fam. 14.20 (5) bzw. cum [...] venerimus in fam. 14.5.2

\footnotetext{
${ }^{1120}$ Vgl. a. Kap. 2.1.3.

1121 Ähnliche Überlegungen kann man auch in anderen Fällen anstellen. So kann in einer Äußerung mit videre je nach Informationswert der Akt des Sehens, das gesehene Objekt bzw. die gesehene Handlung oder beides gleichzeitig im Fokus stehen. Das Verb scire kann ebenfalls bei besonderer Betonung eine eigene Aussagekraft entfalten, wenn z. B. einerseits eine bestimmte Information an und für sich übermittelt, aber außerdem noch hervorgehoben werden soll, dass man sich seiner Sache wirklich ganz sicher ist. Im Analysekorpus findet sich leider kein passendes Beispiel. In fam. 14.19 (3) wird zwar die Gewissheit des Sprechers mit certo scio stark betont, der Inhalt der Äußerung stellt aber keine eigenständige Information für den Adressaten dar. Vgl. a. SCHMITT 2000,75 und (zu präsuppositionalen Äußerungen) ebd., $93 \mathrm{ff}$.

1122 In dieser Arbeit werden als Adverbialsätze sowohl die entsprechenden Neben- als auch Hauptsätze erfasst, da eine Unterscheidung in handlungsfunktionaler Hinsicht grundsätzlich keinen Sinn macht, obgleich teilweise durchaus differierende Tendenzen zu beobachten sind: Vgl. z. B. das Kap. „Unabhängigkeit des Illokutionsstatus von der grammatischen Einheit ,Satz“" ab S. 243 sowie S. 254. Vgl. a. Kap. 1.3.2.1. Zur Illokutionsidentifikation von „Adverbien und Adverbialien“ vgl. außerdem ebd., $81 \mathrm{ff}$.
} 
(23) und in eam simul atque conscendi in fam. 14.7.2 (9). Nur selten stellen sie hingegen eine eigenständige Information dar, wie es z. B. bei dem Nachtrag uno et vice $\langle n\rangle$ simo die in fam. 14.5.1 (6) der Fall ist. ${ }^{1123}$ Zu nennen wären evtl. noch die Zeitangaben im Postskriptum, die in der vorliegenden Arbeit aber nicht als eigenständige Illokutionen betrachtet werden, da sie eine untrennbare konventionelle Einheit mit der jeweiligen Ortsangabe bilden. ${ }^{1124}$

Dass bei einigen Adverbialsätzen und Partizipialkonstruktionen nicht genau zu bestimmen ist, ob sie eher temporal oder konditional aufzufassen sind, spielt für die Bewertung des Illokutionsstatus keine Rolle. Was Letztere betrifft, ist die Art der Beziehung zum zugehörigen Satz(teil) ja ohnehin nicht immer genau zu klären. Und selbst das p. c. de nave exeuntibus in fam. 14.5.1 (5), das offensichtlich ein temporales Verhältnis (mit Bezug auf nobis) bezeichnet, ist insofern mehrdeutig, als es zugleich eine lokale Angabe ist. ${ }^{1125}$

Fazit:

Temporale Bestimmungen und Temporalsätze haben i. d. R. keinen eigenen Illokutionsstatus.

Lokale Beziehungen

Für lokale Bestimmungen und Lokalsätze gilt weitgehend das Gleiche wie für die temporalen Bestimmungen und Temporalsätze. Eine informationsspezifizierende Funktion haben z. B. longius in fam. 14.2.4 (37), quam longissime in fam. 14.5.1 (20), Roma in fam. 14.5.2 (25), in Tusculanum in fam. 14.20 (2), ibi in fam. 14.20 (3) und (5) sowie in balineo in fam. 14.20 (6). Informationstragend sind z. B. a Vestae ad Tabulam Valeriam in fam. 14.2.2 (18), Athenas in fam. 14.5.1 (3), in Italia in fam. 14.5.2 (26) sowie (noch stärker) die lokalen Adverbialien bzw. Lokalsätze in per Macedoniam Cyzicum petebamus. (fam. 14.4 .3 (16)) und ego volebam loco magis deserto esse in Epiro, quo neque Piso veniret nec milites (fam. 14.1.3 (22)). Als freien Lokalsatz (i. w. S.) mit eigenem Illokutionsstatus kann man unde omnes opem petere solebant in fam. 14.2.2 (22) ansehen. ${ }^{1126}$

Fazit:

Lokale Bestimmungen und Lokalsätze haben i. d. R. keinen eigenen Illokutionsstatus.

Modale Beziehungen

Fälle von illokutionärer Eigenständigkeit, wie z. B. sane strenue in fam. 14.5 .1 (7) oder ut ego metuo in fam. 14.4.3 (23), sind selten. ${ }^{1127}$ Meist dienen modale Adverbialbestimmungen ebenfalls lediglich der Spezifizierung einer Illokution, wie z. B. sic in fam. 14.2.2 (21), ita in fam. 14.2.4 (37) und 14.5.2 (25), tam in fam. 14.2.1 (10), plurimum in fam. 14.2.2 (11), valde in fam. 14.5.2 (22) und circiter in fam. 14.5.2 (26); oder sie sind zum Verständnis der jeweiligen Äußerung unbedingt notwendig, wie z. B. difficilius in fam. 14.2.1 (6), fortissime et amantissime in fam. 14.2.2 (16), non sine plurimis lacrimis in fam. 14.2.1 (7), maximo cum fletu in fam. 14.2.2

\footnotetext{
${ }^{1123}$ Vgl. a. das Kap. „Appositionen und Parenthesen“ ab S. 274.

${ }^{1124}$ Vgl. a. das Kap. „Kontextuelle Indikatoren“ ab S. 279.

1125 Vgl. a. Kap. 2.1.2.

${ }^{1126}$ Vgl. a. das Kap. „Attribute und Attributsätze“ ab S. 273.

${ }^{1127}$ Vgl. a. das Kap. „Subjekt(sätz)e und Objekt(sätz)e“ ab S. 264 (zum Ausdruck von propositionalen Einstellungen).
} 
(20) und nobiscum in fam. 14.20 (4). Kommunikativ tragend sind außerdem komparativische Wendungen wie bspw. magis iam rem quam litteras in fam. 14.3 .5 (35), vehementius tua miseria quam mea in fam. 14.4.6 (56) und fortiores quam quemquam virum in fam. 14.7.2 (11). Entsprechendes gilt für Komparativsätze, wie z. B. ut potui in fam. 14.2 .2 (12), ut debui in fam. 14.2.2 (13) und ut arbitror in fam. 14.20 (5) sowie quam (longissime) poteris in fam. 14.5.1 (20). Weitere Beispiele finden sich u. a. in fam. 14.4.1 (2): quam possum, fam. 14.7.1 (7): quem ad modum soles, fam. 14.11 (4): atque eius pietas ac dignitas postulabat, fam. 14.12 (4): quantum potes und fam. 14.16 (5): quam fuit sowie 14.16 (7): ut ii voluerunt.

Fazit:

Modale Bestimmungen und Modalsätze haben i. d. R. keinen eigenen Illokutionsstatus.

Kausale Beziehungen

Viele kausale Bestimmungen bzw. Kausalsätze sind illokutionär eigenständig, zahlreiche andere hingegen nicht:

\begin{tabular}{|c|c|}
\hline adverbiale Bestin & $\begin{array}{l}\text { kutionsstatus } \\
\text { Imungen }\end{array}$ \\
\hline fam. 14.2.2 (11): & Pisonem nostrum merito eius amo plurimum. \\
\hline fam. 14.2.2 (23): & idque fieri mea culpa \\
\hline fam. 14.6 (5): & $\begin{array}{l}\text { quod nostra [erg. Tullia] tibi gratias agit, id ego non miror, te mereri ut } \\
\text { ea tibi merito tuo gratias agere possit. }\end{array}$ \\
\hline Partizipialkonstru & ktionen \\
\hline fam. $14.12(3):$ & $\begin{array}{l}\text { sed perturbati dolore animi magnisque }\langle\text { meorum }\rangle \text { iniuriis metuo ne id } \\
\text { consili ceperimus quod ... }\end{array}$ \\
\hline fam. $14.13(3):$ & si [erg. Dolabella] metuendus iratus est, quiesces \\
\hline Nebensätze & \\
\hline fam. 14.1.2 (11): & $\begin{array}{l}\text { nunc, quoniam sperare nos amici iubent, dabo operam, ne mea valetu- } \\
\text { do tuo labori desit. }\end{array}$ \\
\hline fam. 14.1.4 (32): & $\begin{array}{l}\text { sed vos, cum praesertim tam pauci sitis, volui esse quam coniunctissi- } \\
\text { mos. }\end{array}$ \\
\hline fam. 14.2.4 (37): & longius, quoniam ita vobis placet, non discedam \\
\hline fam. 14.3.1 (5): & $\begin{array}{l}\text { ego autem hoc miserior sum quam tu, quae es miserrima, quod ipsa } \\
\text { calamitas communis est utriusque nostrum, sed culpa mea propria est. }\end{array}$ \\
\hline fam. $14.10(5):$ & apertius scribi, quoniam ad illum scripseram, necesse non fuit \\
\hline Hauptsätze & \\
\hline fam. 14.2.3 (35): & $\begin{array}{l}\text { sed video in te esse omnia. quare, ut id quod speras et quod agis conse- } \\
\text { quamur, servi valetudini. }\end{array}$ \\
\hline fam. 14.5.1 (15): & $\begin{array}{l}\text { etsi in quam rem publicam veni }\langle a\rangle \text { mus intellego. cognovi enim [...] ad } \\
\text { arma rem spectare }\end{array}$ \\
\hline fam. 14.5.2 (22): & quae quidem mihi magno dolori est (valde enim illum amavi) \\
\hline fam. 14.19 (3): & $\begin{array}{l}\text { de qua nihil est quod ad te plura scribam; tibi enim aeque magnae curae } \\
\text { esse certo scio. }\end{array}$ \\
\hline
\end{tabular}




\begin{tabular}{|c|c|}
\hline \multicolumn{2}{|c|}{ mit eigenem Illokutionsstatus } \\
\hline \multicolumn{2}{|l|}{ Nebensätze } \\
\hline fam. 14.4.6 (49): & quod valetudine oculorum impediebatur \\
\hline fam. $14.5 .1(18):$ & quoniam subeunda fortuna est \\
\hline fam. 14.15 (4): & quia de illius adventu nihil audiebamus \\
\hline \multicolumn{2}{|l|}{ Hauptsätze $^{1128}$} \\
\hline fam. 14.2.1 (5): & nec enim habeo quid scribam \\
\hline fam. 14.2.1 (6): & nec hoc tempore quicquam difficilius facio. \\
\hline fam. 14.2.1 (8): & vos enim video esse miserrimas, quas ... \\
\hline fam. 14.2.2 (18): & nam ad me $P$. Valerius [...] scripsit, [...] quem ad modum ... \\
\hline fam. 14.2.3 (33): & nam mihi ante oculos dies noctesque versaris ... \\
\hline fam. 14.3.4 (24): & $\begin{array}{l}\text { ea re ad te statim Aristocritum misi ut ad me continuo initia rerum et } \\
\text { rationem totius negoti posses scribere }\end{array}$ \\
\hline fam. 14.3 .4 (27): & $\begin{array}{l}\text { nam ego eo nomine sum Dyrrachi hoc tempore ut quam celerrime quid } \\
\text { agatur audiam }\end{array}$ \\
\hline fam. 14.5.1 (13): & iam enim me ipsum exspectas, sive nos ipsos \\
\hline fam. 14.12 (4): & Qua re, quantum potes, adiuva \\
\hline fam. 14.20 (4): & plures enim fortasse nobiscum erunt \\
\hline fam. $14.20(5):$ & et, ut arbitror, diutius ibi commorabimur \\
\hline
\end{tabular}

Abbildung 44: Kausale Bestimmungen und Kausalsätze mit eigenem und ohne eigenen Illokutionsstatus

Zu ergänzen sind noch einige Verwendungsweisen der Partikel quidem, die z. B. in fam. 14.5.1 (14) und 14.7.1 (7) kausal verwendet wird. Dies gilt auch für den Nachtrag („,und zwar“) in fam. 14.3.3 (22). ${ }^{1129}$

Die Beispiele in der Übersicht bestätigen die bereits ausgeführte These, dass Parataxe oft mit einem eigenen Illokutionsstatus einhergeht. Im vorliegenden Zusammenhang betrifft dies die durch nam, enim oder quare und ea re eingeleiteten Sätze, wobei eine Konjunktion teilweise auf zwei aufeinanderfolgende Illokutionen zu beziehen ist. ${ }^{1130} \mathrm{Es}$ gibt aber auch uneindeutige Fälle und Ausnahmen, wo ein (meist durch enim signalisierter) kausaler Hauptsatz so eng mit dem vorangehenden Satz verbunden ist, dass ihm kein eigener Illokutionsstatus zugesprochen werden kann, wie z. B. in fam. 14.5 .2 (22) und 14.19 (3). Etwas ungewöhnlich stellt sich insbesondere fam. 14.5.1 (15) dar, wo der Kausalsatz einem Konzessivsatz untergeordnet ist.

\footnotetext{
${ }^{1128}$ Einigen Hauptsätzen - fam. 14.2.3 (35) sowie fam. 14.3.4 (24) und (27) - ist ein Finalsatz untergeordnet, zu dem sie in enger und in gewisser Weise ebenfalls kausaler Beziehung stehen. Entscheidend für die Einordnung ist hier aber die i. e. S. kausale (begründende) Beziehung zum vorangehenden Satz.

1129 Vgl. a. N. 1105.

1130 Zur schwierigen Abgrenzung von (Quasi-)Synonymen wie nam und enim vgl. z. B. DENIZOT UND SPEVAK 2017b, 9: „nam is a connector that marks the relationship between two elements that are actually expressed, while enim is an interactional particle that refers to an extra-textual element and involves interaction between the speaker and the addressee." Vgl. a. KROON 1989 und KROON 1995.
} 
Von den subordinierenden Konjunktionen zeigt quoniam recht zuverlässig ein auch in illokutionärer Hinsicht enges Verhältnis zum übergeordneten Satz an. Allerdings gibt es hier ebenfalls eine Ausnahme, nämlich fam. 14.5.1 (18), die jedoch in erster Linie dadurch begründet ist, dass der übergeordnete Satz (als Wiederholung von fam. 14.5.1 (14)) ohne eigenen Illokutionsstatus bleibt. ${ }^{1131}$ Die anderen Konjunktionen sind in dieser Hinsicht unspezifischer. Oft finden sich aber zusätzliche Indikatoren, die darauf schließen lassen, dass der betreffende Satz keinen eigenen Illokutionsstatus hat, wie z. B. praesertim in Verbindung mit cum in fam. 14.1.4 (32) oder hoc miserior in Verbindung mit quod in fam. 14.3.1 (5). Zu erwarten wäre eine engere Verbindung eigentlich auch bei einer Konjunktion wie propterea quod, die jedoch nur in fam. 14.4.1 (3) begegnet, wo zwei illokutionär eigenständige Gründe für Ciceros seltene Schreiben aufgezählt werden. ${ }^{1132}$ Ein Sonderfall liegt im Übrigen bei fam. 14.5 .1 (4) vor, wo zwei Kausalsätze so eng aufeinander bezogen sind, dass sie eine gemeinsame Illokution bilden, die aber illokutionär eigenständig in Bezug auf den übergeordneten Hauptsatz ist. Bei Participia coniuncta wie iratus in fam. 14.13 (3) wird die fehlende illokutionäre Eigenständigkeit bereits durch die grammatische Konstruktion und die damit zusammenhängende enge Verbundenheit mit dem (hier zu ergänzenden) Bezugswort bzw. der Sprechhandlung insgesamt nahegelegt.

Fazit:

Kausale Bestimmungen und Kausalsätze können einen eigenen Illokutionsstatus haben.

Finale Beziehungen

Finale Bestimmungen und Finalsätze sind illokutionär untrennbar mit dem Rest des Satzes bzw. mit dem übergeordneten Satz verbunden. Dies gilt unabhängig von der jeweiligen grammatischen Konstruktion, wobei die meisten Finalsätze mit ut oder ne, einige hingegen mit quo eingeleitet werden, wie z. B. in fam. 14.5 .2 (25), 14.1 .2 (11) bzw. 14.7.2 (11). ${ }^{1133}$ Häufig wird die Konjunktion aber auch weggelassen, z. B. in Verbindung mit velim wie in fam. 14.2.4 (38). Manchmal wiederum muss der übergeordnete Satz (durch cura o. Ä.) ergänzt werden, wie z. B. in fam. 14.20 (3) und 14.20 (6). In der noch stärker rudimentären Äußerung fam. 14.20 (7) findet sich zusätzlich eine präpositionale finale Bestimmung: ad victum et ad valetudinem necessaria. Der finale Charakter von ad kann in Verbindung mit einem Gerundivum weiter verstärkt werden, wie z. B. in fam. 14.4.1 (6): ad aliquam alicuius commodi aliquando reciperandi spem.

Fazit:

Finale Bestimmungen und Finalsätze haben i. d. R. keinen eigenen Illokutionsstatus.

Konsekutive Beziehungen

Konsekutivsätze stellen die Folge einer (grammatisch) übergeordneten Handlung dar, der für sich ein eigenständiger Informationswert zukommen kann, wie z. B. im Fall von fam. 14.5.1

\footnotetext{
1131 Vgl. Kap. 2.1.2.

1132 Vgl. das Kap. „Aufzählungen“ ab S. 257.

1133 Schwieriger ist der Illokutionsstatus der Finalsätze in einem verschränkten Satz wie sed quoniam subeunda fortuna est, eo citius dabimus operam ut veniamus, quo facilius de tota re deliberemus. (fam. 14.5.1 (18) / (19)) zu bestimmen. Vgl. Kap. 2.1.2 und das Kap. „Unabhängigkeit des Illokutionsstatus von der grammatischen Einheit ,Satz“" ab S. 243.
} 
(17). Die beiden Konsekutivsätze in fam. 14.18.1 (7) bilden zwar miteinander eine illokutionäre Einheit, sind aber ebenfalls unabhängig vom übergeordneten Satz. Manchmal ist ein Konsekutivsatz jedoch nicht von ihm zu trennen. Eine enge Verbindung wird dabei häufig durch korrespondierende Partikeln und Wendungen wie eius modi, sic oder tantus im übergeordneten Satz verdeutlicht, z. B. in fam. 14.1.4 (28), 14.2.2 (17) und 14.4.1 (4).

Fazit:

Konsekutivsätze können einen eigenen Illokutionsstatus haben.

Konzessive Beziehungen

Im Analysekorpus finden sich sowohl Beispiele für illokutionär eigenständige Konzessivsätze als auch für Konzessivsätze ohne eigenen Illokutionswert. Ein Beispiel für erstere ist fam. 14.3.5 (35). In fam. 14.16 (6) hängt vom Konzessivsatz noch ein (zweiteiliger) Attributsatz ab, in fam. 14.3.4 (25) und (26) jeweils ein Finalsatz, wobei in fam. 14.3.4 (26) die einleitende Konjunktion aus (25) zu ergänzen ist. In fam. 14.5.1 (15) ist mit dem Konzessivsatz ein (kausaler) Hauptsatz illokutionär eng verknüpft. ${ }^{1134}$ Eine illokutionäre Verbundenheit von konzessiven Adverbialien mit dem übergeordneten Satz dagegen kann durch eine korrelierende Partikel, wie z. B. tamen in fam. 14.16 (3) / (4) ${ }^{1135}$, durch eine Wortwiederholung, wie z. B. von ferre (ferenda-feramus) in fam. 14.4.5 (46), oder durch die Art der grammatischen Konstruktion, z. B. von Adjektiven / Partizipien wie miseram et despoliatam in fam. $14.2 .3(27)^{1136}$, hergestellt werden. In fam. 14.4.3 (19) sind (konzessiv gebrauchtes) Adjektiv und Partizip allerdings quasi illokutionär eigenständig und lediglich abhängig von der (auf te in (18) bezogenen) appositiven Anrede mulierem: (mulierem) aegram, et corpore et animo confectam.

Fazit:

Konzessive Bestimmungen und Konzessivsätze können einen eigenen Illokutionsstatus haben.

Konditionale Beziehungen

Konditionalsätze sind grammatisch und inhaltlich üblicherweise strikt auf den übergeordneten Satz bezogen und verbinden sich mit ihm entsprechend auch illokutionär zu einer Einheit. Dies gilt weitgehend unabhängig von der einleitenden Konjunktion, d. h. sowohl bei Einleitung mit si, wie z. B. in fam. 14.2.4 (38), 14.4.1 (7) und 14.5.2 (21), als auch mit quod si, wie z. B. in fam. 14.2.3 (28) und 14.4.1 (6), und $\sin$, wie z. B. in fam. 14.2.3 (29), 14.4.3 (22) und 14.5.2 (25), sowie nisi, wie z. B. in fam. 14.2.1 (10). Floskelhafte Wendungen wie si me amas in fam. 14.2.3 (32) und si di adiuvabunt in fam. 14.5.2 (26) bilden dabei keine Ausnahme, zumal sie ohnehin keinen eigenen Informationswert haben. ${ }^{1137}$ Ein Sonderfall ist fam. 14.2.1 (3). Die detaillierte Sprechaktanalyse legt nahe, dem Konditionalsatz innerhalb des Satzgefüges Noli putare me ad

\footnotetext{
${ }^{1134}$ Vgl. Kap. 2.1.2.

1135 Die Partikel tamen wird häufig auch mit Bezug auf einen vorangehenden Satz verwendet, der nicht explizit konzessiv ist, wie z. B. in fam. 14.2.2 (15): sed Crassum tamen metuo. Meist liegt in solchen Fällen keine sehr enge (illokutionäre) Verbindung vor. Entsprechend finden sich dann zusätzlich oft trennende (demarkative) Indikatoren wie sed, et oder ein betont vorangestelltes Personalpronomen im Nominativ. Vgl. a. fam. 14.7.2 (12) und 14.3.3 (16).

${ }^{1136} \mathrm{Vgl.} \mathrm{Kap.} \mathrm{2.1.3.}$

1137 Vgl. a. das Kap. „Kontextuelle Indikatoren“ ab S. 279.
} 
quemquam longiores epistulas scribere, nisi si quis ad me plura scripsit, cui puto rescribi oportere. einen eigenen Illokutionswert zuzugestehen. ${ }^{1138}$ Ob dies generell für Sätze gilt, die mit nisi si eingeleitet werden, kann aufgrund der geringen Zahl an Beispielen im Analysekorpus nicht beurteilt werden. ${ }^{1139}$

Fazit:

Konditionalsätze haben i. d. R. keinen eigenen Illokutionsstatus.

Attribute und Attributsätze ${ }^{1140}$

Einfache Attribute bilden normalerweise eine illokutionäre Einheit mit ihrem Bezugswort. Sie wirken entweder spezifizierend, wie z. B. mea suavissima et optatissima (Terentia) in fam. 14.5.2 (27), nostram (Tulliolam) in fam. 14.2.1 (7), hanc (epistulam) in fam. 14.5 .1 (12), (me) ipsum und (nos) ipsos in fam. 14.5.1 (13) sowie (periculum) fortunarum et capitis sui in fam. 14.4.2 (12); oder sie sind restringierend, wie z. B. adversis (ventis) in fam. 14.5 .1 (4), (de hereditate) Preciana, meum (adventum) und nostrum (negotium) in fam. 14.5 .2 (21) sowie (commodo) valetudinis tuae in fam. 14.5 .1 (20). ${ }^{1141}$ Participia coniuncta wie (de familia) liberata in fam. 14.4.4 (33) sind ähnlich zu beurteilen. Bei prädikativer Verwendung in Verbindung mit esse haben Partizipien und Adjektive (als Teil des Prädikats) im Übrigen erst recht keinen eigenen Illokutionsstatus, wie z. B. (fore) observantem in fam. 14.4.6 (53) bzw. gratissimum (fuit) in fam. 14.5 .1 (11). ${ }^{1142}$ Anders sieht es hingegen mit dem Prädikativum salvi in fam. 14.5.2 (24) aus, das als eigene Illokution vom Rest des in (23) eingebetteten Temporalsatzes (cum venerimus) abgetrennt werden sollte. ${ }^{1143}$

Bei den Attributsätzen kann man in vergleichbarer Weise zwischen spezifizierenden oder explizierenden Attributsätzen, wie z. B. (vos,) quas ego beatissimas semper esse volui in fam. 14.2.1 (8) und (tu, ) quae es miserrima in fam. 14.3.1 (5), sowie restringierenden Attributsätzen, wie z. B. (ad eos) qui ad me scribunt und (ad eos) de quibus ad me vos aliquid scribitis. in fam. 14.2.4 (36), (hanc epistulam) quam Acastus attulit in fam. 14.5 .1 (12) und (cetera) quae sunt ad victum et ad valetudinem necessaria. in fam. 14.20 (7), unterscheiden. Diesen beiden Arten von Attributsätzen kommt kein eigener Illokutionsstatus zu. Es gibt aber auch illokutionär eigenständige freie Attributsätze, wie z. B. fam. 14.2.3 (24), 14.2.3 (31), 14.5.1 (14) und 14.5.2 (22). Der Relativsatz unde omnes opem petere solebant in fam. 14.2 .2 (22) kann evtl.

\footnotetext{
${ }^{1138}$ Vgl. Kap. 2.1.3.

${ }^{1139}$ Vgl. a. den Gebrauch von nisi als Präposition in der Bedeutung ,außer', z. B. in fam. 14.2.4 (36).

1140 Vgl. a. SCHMITT 2000, 75ff. bzw. ebd., 67ff. In dieser Arbeit werden alle (Neben-)Sätze, die auf ein Wort oder eine Wortgruppe bezogen sind, zu dem sie eine bestimmte Aussage treffen, als Attributsätze bezeichnet. Meistens handelt es sich dabei zugleich um Relativsätze. Relativpronomina können aber auch in anderer Funktion verwendet werden, z. B. zur Einleitung von Subjekt- und Objektsätzen.

1141 Gelegentlich wird das Bezugswort eines Attributs ausgelassen und muss (aus dem vorangehenden Text oder dem allgemeinen Kontext) ergänzt werden, wie z. B. homines (o. Ä.) in fam. 14.2.3 (24), litterae in fam. 14.5.1 (9) oder navem in fam. 14.7.2 (9). In einigen Fällen kann von einer Substantivierung ausgegangen werden, wie z. B. auch bei totum in fam. 14.13 (5) oder inimici in fam. 14.3.4 (29). Zuweilen ist die Grenze zwischen i. e. S. adjektivischem und substantivischem Gebrauch fließend, wie z. B. bei inimici sunt multi, invidi paene omnes. (fam. 14.3.2 (12)). Für die illokutionäre Bewertung ist dies alles aber unerheblich.

1142 Manchmal ist nicht ganz klar, ob ein Partizip attributiv oder prädikativ aufzufassen ist, wie z B. bei $O$ me perditum, o me adflictum! (fam. 14.4.3 (17)), wo beide Partizipien entweder als attributiv mit Bezug auf me oder als prädikativ (Prädikatsnomen) mit Bezug auf einen ausgelassenen Infinitiv esse interpretiert werden können. ${ }^{1143} \mathrm{VgI}$. Kap. 2.1.2.
} 
ebenfalls dazu gezählt werden, wenngleich er eine i. w. S. lokale Bedeutung hat und zudem der Anrede mea lux, meum desiderium untergeordnet ist. Manchmal ist nicht leicht zu entscheiden, ob tatsächlich ein freier Attributsatz vorliegt, wie z. B. auch bei cui puto rescribi oportere in fam. 14.2.1 (4). ${ }^{1144}$ Solche und ähnliche Schwierigkeiten bereiten v. a. Attributsätze, die grammatisch direkt in das Satzgefüge eingebunden sind, während ein relativer Satzanschluss, bei dem das betreffende Relativpronomen eine deutlich demarkative Funktion erfüllt, ein guter Indikator für eine illokutionäre Eigenständigkeit ist.

Fazit:

Einfache Attribute haben i. d. R. keinen eigenen Illokutionsstatus. Attributsätze können einen eigenen Illokutionsstatus haben.

Extrapositionen ${ }^{1145}$

Appositionen und Parenthesen

Das Durchbrechen der Satzsstruktur scheint auf den ersten Blick ein sehr deutlicher Hinweis auf die illokutionäre Eigenständigkeit des jeweiligen Elementes zu sein. ${ }^{1146}$ Dies trifft bspw. auf viele Appositionen auch zu. So hat eine Apposition, die sich auf eine dritte Person bezieht, häufig tatsächlich eine eigene handlungslogische Funktion, welche sich von der des übrigen Satzes unterscheidet, wie z. B. fam. 14.2.2 (19): homo officiosus oder fam. 14.4 .2 (11): virum optimum und fam. 14.4.6 (50): hominem fidelem. Anreden dienen dagegen meist lediglich der expressiven Einfärbung eines Sprechaktes, wie z. B. mea Terentia in fam. 14.2 .2 (21), mea lux, meum desiderium in fam. 14.2.2 (21), mea vita in fam. 14.2.3 (30) und 14.4.1 (7), lux nostra in fam. 14.5.1 (2), mea suavissima et optatissima Terentia in fam. 14.5 .2 (27) und mea desideria in fam. 14.2.4 (39). Mit anderen Appositionen (i. w. S.) wird nur ein bestimmter Sachverhalt genauer spezifiziert oder expliziert, wie z. B. mit praesertim si quid est firmius quod speremus in fam. 14.2.4 (38) und sive nos ipsos in fam. 14.5.1 (13)..$^{1147}$

Eine exponierte Position am Satzende geht also nicht unbedingt mit einem eigenen Illokutionswert einher, wie dies bei anderen Nachträgen ebenfalls zu erkennen ist, z. B. bei nec miror in fam. 14.2.2 (16) oder auch nisi ad eos qui ad me scribunt aut ad eos de quibus ad me vos aliquid scribitis in fam. 14.2.4 (36). ${ }^{1148}$ In einigen Fällen wiederum findet eine deutliche Abgrenzung statt, wie z. B. bei uno et vice $\langle n\rangle$ simo die (fam. 14.5 .1 (6)), sane strenue (fam.

\footnotetext{
1144 Vgl. Kap. 2.1.3.

1145 Thema dieses Teilkapitels sind Äußerungselemente, welche die lineare Satzstruktur durchbrechen. Diese können vorangestellt (Linksdislokation), nachgetragen (Rechtsdislokation) oder in den Satz eingeschoben sein. Man kann dabei u. a. Appositionen und Parenthesen unterscheiden. Unter Appositionen versteht man i. d. R. Beifügungen zu einem Satz bzw. Satzelement, welche - im Unterschied zu Parenthesen - grammatisch angeglichen sind. Manchmal zählen dazu auch Nachträge, die z. B. mit „das heißt“, „besonders“ o. Ä. angeschlossen werden. Die Grenzen zu anderen Arten von Voran-, Zwischen- und Nachstellungen, die in einer eher losen Beziehung zum Bezugssatz stehen, sind nicht immer klar zu ziehen. Für die Illokutionsidentifikation ist dies aber im Allgemeinen nicht von Bedeutung. Vgl. a. SCHMITT 2000, 75ff., ebd., 92f. und ebd., 158ff. Zur Linksdislokation (vor Cicero) vgl. außerdem HALLA-AHO 2018.

${ }^{1146}$ Vgl. a. das Kap. „Illokutionsdemarkation durch exponierte Wortstellung“ ab S. 245.

${ }^{1147}$ Um eine erklärende Apposition handelt es sich auch bei hoc est de area in fam. 14.2.3 (25). Ihr kommt allerdings bereits deshalb kein eigener Illokutionsstatus zu, da sie Bestandteil einer (lediglich zitierenden) ausführlichen Themenangabe ist. Vgl. das Kap. „Zitate“ ab S. 276. Vgl. außerdem den (eher glossematischen) Nachtrag id est Apollini et Aesculapio in fam. 14.7.1 (7).

1148 Vgl. Kap. 2.1.3.
} 
14.5.1 (7)), serius quam oportuit (fam. 14.10 (3)) und auch nisi si quis ad me plura scripsit (fam. 14.2.1 (3)). ${ }^{1149}$ Das gilt ebenso für Einschübe ${ }^{1150}$ wie id quod ego maximo cum fletu legi (fam. 14.2.2 (20)) und die kurzen Komparativsätze ut ego metuo (fam. 14.4 .3 (23)) und quod metuo (fam. 14.4.4 (31) $)^{1151}$, wohingegen ut arbitror in fam. 14.20 (5), ut potui in fam. 14.2.2 (12) und ut debui in fam. 14.2.2 (13) ebenso wie das vorangestellte obsecro te in fam. 14.2.3 (30) nicht als illokutionär eigenständig angesehen werden können. ${ }^{1152}$ Nicht einmal einer vom übrigen Satz vollständig losgelösten Parenthese muss ein eigener Illokutionswert zukommen, wie das Beispiel valde enim illum amavi in fam. 14.5 .2 (22) zeigt.

Fazit:

Appositionen und Parenthesen sowie ähnliche die lineare Satzstruktur durchbrechende Dislokationen können einen eigenen Illokutionsstatus haben.

Sekundäre lllokutionen

Prinzipiell ohne eigenen Illokutionsstatus sind sekundäre Illokutionen ${ }^{1153}$ :

\begin{tabular}{|c|c|c|}
\hline \\
\hline \multicolumn{3}{|l|}{$\begin{array}{l}\text { Textgliederung } \\
\text { fam. 14.1.5 (40): }\end{array}$} \\
\hline fam. 14.4 .3 (21): & $\begin{array}{l}\text { opinor, sic agam: si est spes nostri } \\
\text { reditus, eam confirmes et rem adiu- } \\
\text { ves }\end{array}$ & - opinor, sic agam \\
\hline fam. 14.4 .3 (24): & $\begin{array}{l}\text { unum hoc scito: si te habebo, non } \\
\text { mihi videbor plane perisse. }\end{array}$ & - unum hoc scito \\
\hline fam. 14.4 .5 (42): & $\begin{array}{l}\text { Quod reliquum est, sustenta te, } \\
\text { mea Terentia, ut potes honestissi- } \\
\text { me. }\end{array}$ & - quod reliquum est \\
\hline fam. 14.14 .1 (7): & $\begin{array}{l}\text { reliquum est, quod ipsae optime } \\
\text { considerabitis, vestri similes femi- } \\
\text { nae sintne Romae. }\end{array}$ & - reliquum est, quod \\
\hline fam. 14.14.2 (12): & ad summam animo forti sitis. & - ad summam \\
\hline fam. 14.18.1 (3): & $\begin{array}{l}\text { Mihi veniunt in mentem haec: } \\
\text { Romae vos esse tuto posse per } \\
\text { Dolabellam... }\end{array}$ & - mihi veniunt in mentem haec \\
\hline
\end{tabular}

${ }^{1149}$ Vgl. Kap. 2.1.2 bzw. 2.1.3.

1150 Vgl. N. 1116.

${ }^{1151}$ Dagegen ist der Einschub id quod mihi molestissimum est in fam. 14.7.1 (3) eng mit der Äußerung, in die er eingebettet ist, verbunden und bestimmt die Handlungsfunktion (SICH ENTSCHULDIGEN) wesentlich mit, sodass ihr kein eigener Illokutionsstatus zukommt.

${ }^{1152}$ Vgl. a. die Kap. „Subjekt(sätz)e und Objekt(sätz)e“ ab S. 264 (zu propositionalen Einstellungen) und „Modale Beziehungen“ ab S. 268.

${ }^{1153}$ Vgl. das Kap. „Primäre und sekundäre Illokutionen“ ab S. 57. Die unter „Textgliederung“ erfassten Illokutionen entsprechen den dort angeführten „Textillokutionen“, während es sich beim „Verweis auf vorangehende Kommunikation“ um „quellenreportierende Illokutionen“ handelt, die aber zugleich „,bekanntheitsreportierend“ sind, sich dabei allerdings nicht auf den vorliegenden Brief, sondern frühere Briefe beziehen. 


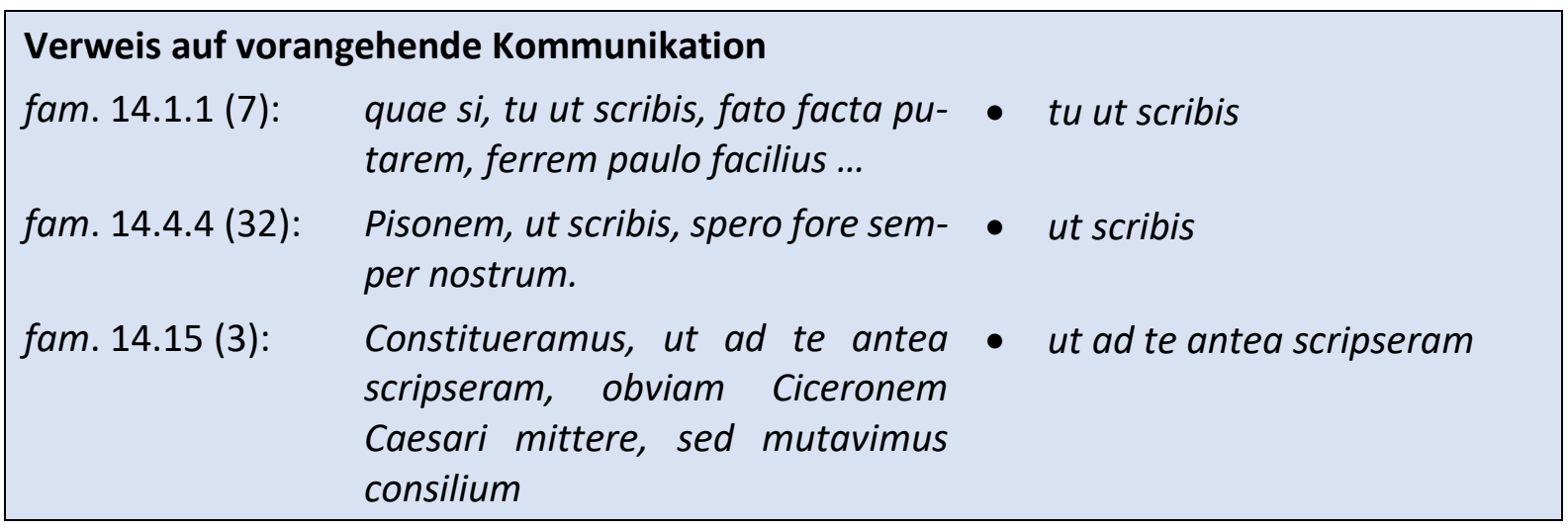

Abbildung 45: Sekundäre Illokutionen ohne eigenen Illokutionsstatus

Mit textgliedernden Wendungen wird ein neuer Gedanke angekündigt, wie z. B. mit mihi veniunt in mentem haec, bzw. ein Gedankengang zum Abschluss gebracht, indem er zusammengefasst oder die Aufmerksamkeit auf eine besonders wichtige Aussage gelenkt wird, wie z. B. mit opinor, sic agam; tantum scribo; (quod) reliquum est und ad summam. Der Textgliederung dienen im Übrigen auch Themenangaben, die teilweise mit sekundären Illokutionen kombiniert werden, wie z. B. in fam. 14.15 (3). ${ }^{1154}$ Diese werden ebenfalls einer Äußerung normalerweise vorangestellt. Bei Verweisen auf die vorangegangene Kommunikation handelt es sich hingegen meistens um Einschübe. ${ }^{1155}$

Fazit:

Sekundäre Illokutionen haben keinen eigenen Illokutionsstatus.

Zitate

Cicero greift oft Äußerungen Terentias, manchmal auch seine eigenen auf, um darauf bezugnehmend auf einen bestimmten Sachverhalt einzugehen. Da es sich hierbei ja um keine neuen Informationen handelt, kommt ihnen kein eigener Illokutionsstatus zu:

\section{Bezugnahme auf Äußerungen Terentias}

fam. 14.1.5 (35): Quod ad me, mea Terentia, scribis te vicum vendituram: quid, obsecro te, [...] quid futurum est?

fam. 14.2.2 (14): in novis tribunis pl. intellego spem te habere: id erit firmum, si Pompei voluntas erit

fam. 14.2.3 (25): Quod de domo scribis, hoc est de area: ego vero tum denique mihi videbor restitutus si illa nobis erit restituta.

fam. 14.3.3 (15): Ut tuto sim quod laboras:

id mihi nunc facillimum est, quem etiam inimici volunt vivere in tantis miseriis.

fam. 14.3.5 (30): Quod scribis te, si velim, ad me venturam: ego vero, cum sciam magnam partem istius oneris abs te sustineri, te istic esse volo.

1154 Vgl. die Kap. „Illokutionsdemarkation durch exponierte Wortstellung“ (ab S. 245) und „Zitate“ (ab S. 276).

1155 Zur Redewiedergabe in Ciceros Briefen vgl. a. GARCEA 2001. 


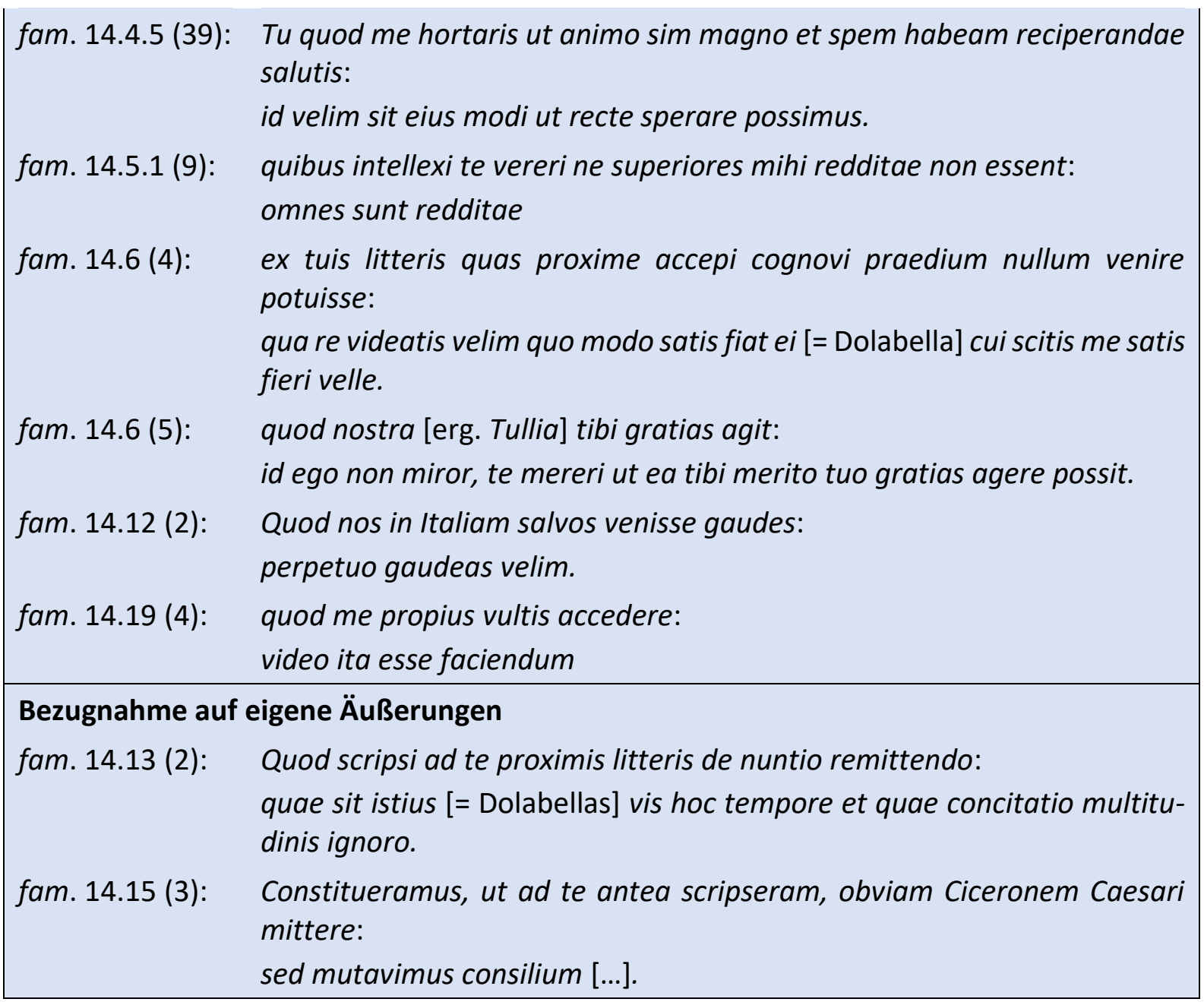

Abbildung 46: Bezugnahme auf vorangehende Äußerungen (von Briefadressat oder -autor)

In einigen Fällen verweist Cicero nur allgemein auf das Thema, das in einem früheren Brief (oder Gespräch) besprochen wurde, wie z. B. bei quod de domo scribis, hoc est de area in fam. 14.2.3 (25) oder quod scripsi ad te proximis litteris de nuntio remittendo in fam. 14.13 (2); in anderen bezieht er sich direkt auf eine konkrete Aussage, wie z. B. bei in novis tribunis pl. intellego spem te habere in fam. 14.2.2 (14) und tu quod me hortaris ut animo sim magno et spem habeam reciperandae salutis in fam. 14.4 .5 (39). Nur bei letzteren kann man von (indirekten und paraphrasierenden) Zitaten i. e. S. sprechen, während es sich bei ersteren lediglich um kurze Themenangaben (in enger Verbindung mit einer sekundären Illokution wie quod scribis) handelt. ${ }^{1156}$

Typisch für solche Bezugnahmen ist die Einleitungspartikel quod, die manchmal sogar (abgesehen vom weiteren Kontext) der einzige Hinweis darauf ist, dass Cicero sich auf eine vorangehende Äußerung bezieht, wie z. B. bei quod nostra tibi gratias agit in fam. 14.6 (5). Sie kann durch andere Indikatoren ergänzt oder ganz ersetzt werden. So wird bisweilen direkt auf die betreffenden Briefe referiert, wie z. B. in fam. 14.6 (4) mit ex tuis litteris, in fam. 14.13 (2) mit proximis litteris und in fam. 14.5.1 (9) mit quibus, das an tuas litteras in 14.5 .1 (8) anschließt;

${ }^{1156}$ Vgl. das Kap. „Sekundäre Illokutionen“ ab S. 275. 
oder es wird ein entsprechendes Verb verwendet, welches den intertextuellen Zusammenhang explizit (scripsi, scripseram, scribis) oder mehr oder weniger implizit (intellego, intellexi, cognovi bzw. hortaris, vultis, gaudes) verdeutlicht. ${ }^{1157}$

Nach einer ausführlicheren Themenangabe wird der Beginn der eigentlichen Illokution oft durch korrelierendes id, wie z. B. in fam. 14.2.2 (14), fam. 14.3.3 (15), fam. 14.4.5 (39) und fam. $14.6(5)^{1158}$, demarkative Konnektoren, wie z. B. vero in fam. 14.2 .3 (25) und fam. 14.3 .5 (30), sed in fam. 14.15 (3) bzw. qua re in fam. 14.6 (4), oder andere Indikatoren signalisiert.

Fazit:

Bezugnahmen auf vorangehende Äußerungen (von Briefadressat oder -autor) haben keinen eigenen Illokutionsstatus.

Besonderheiten des Lateinischen

Die Sprechaktanalyse von fam. 14 zeigt, dass sich die Vorgehensweise zur Illokutionsidentifikation, wie sie in Kap. 1.3.2 dargelegt wurde, ohne größere Probleme auf das Lateinische übertragen lässt.

Sprachliche Elemente im Ablativ und sprachspezifische Varianten anderer Kasus werden gemäß ihrer Funktion eingeordnet. So sind Objekte und Prädikatsnomina (zu esse) i. d. R. - im Unterschied zu einem Prädikativum wie salvi in fam. 14.5.2 (24) - illokutionär nicht eigenständig. ${ }^{1159}$ Als Beispiele seien das Ablativobjekt adversis ventis (usi essemus) in fam. 14.5 .1 (4) und der finale Dativ (mihi) magno dolori (est) in fam. 14.5.2 (22) genannt. Das Gleiche gilt für Präpositionalobjekte, wie z. B. a te in fam. 14.2.2 (16) und 14.5.1 (10) sowie de tota re in fam. 14.5.1 (19). Handelt es sich um Adverbialien, sind sie jeweils entsprechend einzuordnen, d. h., in den meisten Fällen kommt ihnen kein eigener Illokutionsstatus zu, z. B. kausalen, modalen, lokalen und temporalen Bestimmungen wie merito (eius) in fam. 14.2.2 (11), cum litteris in fam. 14.5.1 (5) und sine plurimis lacrimis in fam. 14.2.1 (7), Roma in fam. 14.5 .2 (25) bzw. aut Nonis aut postridie in fam. 14.20 (2). Manchmal treten sie aber doch illokutionär eigenständig auf, wie es z. B. der Fall ist beim (elliptischen) Nachtrag uno et vice〈n〉simo die in fam. 14.5.1 (6). ${ }^{1160}$

In morphologischer oder syntaktischer Hinsicht besondere Verbformen sind ebenfalls gemäß ihrer Verwendungsweise zu beurteilen. Deponentien, wie z. B. arbitror in fam. 14.20 (5) und cohortatus sum in fam. 14.2.2 (12), werden genauso wie andere Verben auch behandelt. Das Gerundivum ist v. a. im Hinblick auf seine modalitätsspezifizierende (motivationale) Funktion zu berücksichtigen, und zwar sowohl in Verbindung mit esse, wie z. B. in fam. 14.5 .1 (18):

\footnotetext{
1157 Von einem eigenen Illokutionswert könnte man nur dann sprechen, wenn man bspw. davon ausgeht, dass Cicero besonders hervorheben will, dass er eine Äußerung tatsächlich verstanden hat. In diesem Fall läge ein assertiver Sprechakt vor. Vgl. a. N. 899.

1158 Bei den betreffenden Zitaten handelt es sich also im Grunde um Attributsätze zu id.

${ }^{1159}$ Vgl. die Kap. „Subjekt(sätz)e und Objekt(sätz)e“ ab S. 264 und „Attribute und Attributsätze“ ab S. 273.

1160 Vgl. Kap. 2.1.2 sowie die Kap. "Illokutionsdemarkation durch exponierte Wortstellung" (ab S. 245), „Adverbiale Bestimmungen und Adverbialsätze“ (ab S. 267) und „Appositionen und Parenthesen“ (ab S. 274).
} 
subeunda (fortuna) est, als auch ohne esse, wie z. B. in fam. 14.14.1 (5): (homo amens) diripiendam (urbem daturus est). ${ }^{1161}$ Exklamative Infinitive und Akkusative signalisieren Ausrufesätze, stellen also (zusammen mit ihren unmittelbar verbundenen Komponenten) oft einen eigenständigen Sprechakt dar, wie z. B. in fam. 14.2.2 (23) und fam. 14.1.1 (3). ${ }^{1162}$ Acl und $\mathbf{~ N c l}$ sind wie Objekt- bzw. Subjektsätze zu bewerten, haben demnach i. d. R. keinen eigenen Illokutionsstatus. ${ }^{1163}$

Participia coniuncta können prädikativ oder attributiv gebraucht werden, wie z. B. (semper spero tui fore) observantem in fam. 14.4.6 (53) bzw. (de familia) liberata in fam. 14.4.4 (33), was bedeutet, dass innen kein eigener Illokutionsstatus zukommt. ${ }^{1164}$ Oft haben sie eine (auch illokutionär) den Adverbialsätzen vergleichbare Funktion, wie z. B. de nave exeuntibus in fam. 14.5.1 (5). ${ }^{1165}$ Das wird wahrscheinlich auf den $\boldsymbol{a b l}$. abs. weitgehend übertragbar sein. Allerdings finden sich im Analysekorpus keine Beispiele zur Verifikation. Zu vermuten ist, dass ein $a b l$. abs. eher als ein p. c. einen eigenständigen Sprechakt bilden kann. Allerdings geht der Grad der grammatischen Verankerung in der Satzstruktur ja nicht unbedingt mit einer stärkeren oder schwächeren semantischen und pragmatischen Verbindung einher.

\section{Kontextuelle Indikatoren}

Wenngleich sie manchmal durchaus hilfreich bei der handlungsfunktionalen Einordnung einer Äußerung sein können, gibt es keinen allgemeingültigen festen Zusammenhang von bestimmten grammatischen Strukturen und dem Illokutionsstatus einer Äußerung: „Die wichtigste Einsicht, die die bisherigen Betrachtungen zutage gefördert haben, ist die, dass Illokutionen grammatisch kaum zu fixieren sind: Ein Nebensatz, sei es ein Relativ-, ein Verhältnis- oder Inhaltssatz, kann illokutionär sein oder auch nicht, ebenso ein Adverbial, ein Attribut oder eine wie auch immer geartete Präsupposition. Die Kriterien zur Illokutionsidentifikation müssen [...] pragmatischer Natur sein." 1166

Am Ende entscheidet v. a. der (intra-, inter- und transtextuelle) Kontext. Ein wichtiger Indikator ist u. a. die auf den antiken Briefkonventionen beruhende Ritualität oder Formelhaftigkeit. Deshalb werden bspw. das Postskript mit Angabe von Ort und Zeit der Briefabfassung, wie z. B. D. a. d. III Non. Oct. Thessalonica. in fam. 14.2.4 (40), Athenis a. d. XV 〈II Kal. Nov. in fam. 14.5.2 (29) und Kal. Oct. de Ven〈u〉sino in fam. 14.20 (9), sowie Wohlergehensformeln, wie z. B. Valete, mea desideria, valete. in fam. 14.2.4 (39), Si tu et Tullia, lux nostra, valetis, ego et suavissimus Cicero valemus. in fam. 14.5 .1 (2) und vos, mea suavissima et optatissima Terentia, si nos amatis, curate ut valeatis. in fam. 14.5.2 (27), nur als jeweils eine Illokution gewertet, obwohl man ansonsten möglicherweise auch von mehreren Illokutionen ausgehen könnte. So haben die beiden üblichen Bestandteile des Postskripts oft im Prinzip einen mehr oder weniger gleich großen Informationswert für den Briefempfänger. Die eben zitierten Wohlergehensformeln sind allerdings bereits aus anderen Gründen als illokutionäre Einheiten

\footnotetext{
${ }^{1161}$ Vgl. das Kap. „Subjekt(sätz)e und Objekt(sätz)e“ ab S. 264 (zum Ausdruck von propositionalen Einstellungen). 1162 Vgl. das Kap. „Satzarten: Aufforderungs-, Wunsch-, Ausrufe- und Fragesätze“ (ab S. 254).

1163 Vgl. das Kap. „Subjekt(sätz)e und Objekt(sätz)e“ (ab S. 264).

1164 Vgl. das Kap. „Attribute und Attributsätze“ (ab S. 273).

${ }^{1165}$ Vgl. a. die Kap. „Adverbiale Bestimmungen und Adverbialsätze“ (ab S. 267) und „Attribute und Attributsätze“ (ab S. 273). 1166 SCHMITT 2000, 105.
} 
anzusehen, da bspw. Konditionalsätze, Anreden, eng verbundene Aufzählungen und Wiederholungen zur expressiven Verstärkung keinen eigenen Illokutionswert besitzen. Die Formelhaftigkeit ergibt sich darüber hinaus aus der Textposition (Briefbeginn bzw. -schluss). Ähnliche Formulierungen an anderer Stelle werden evtl. anders bewertet. ${ }^{1167}$ Textsortenwissen spielt also eine bedeutende Rolle bei der Beurteilung des Illokutionsstatus.

\subsection{Illokutionsklassifikation}

\section{Grundlegende Probleme}

Bei der Zuweisung einer Illokution zu einer Sprechaktoberklasse und noch viel mehr zu einem bestimmten Untermuster ergeben sich verschiedene Probleme, die zum größten Teil bereits angesprochen wurden:

Die zur Verfügung stehenden textuellen (inhaltlich-grammatischen) Indikatoren sind häufig uneindeutig, v. a., wenn man in Betracht zieht, dass einige Sprechakte eher indirekt ausgedrückt werden, also ein Widerspruch zwischen diesen Indikatoren und der (vermutlichen) tatsächlichen Illokution besteht. Oft ist deshalb eine Interpretation aufgrund des Kontextes notwendig, um zu entscheiden, ob die entsprechenden Handlungsbedingungen erfüllt sind. Deren Ergebnisse stehen allerdings gerade bei einer historischen Analyse wie der vorliegenden dennoch immer unter einem gewissen Vorbehalt. Ferner ist eine grundsätzliche Multifunktionalität zu berücksichtigen, wonach im Grunde jeder Sprechakt mit Adressatenbezug einen informativen bzw. assertiven, einen auffordernden bzw. direktiven und einen emotional-wertenden bzw. expressiven Anteil enthält. Hinzu kommt evtl. noch eine kommissive oder deklarative Komponente. ${ }^{1168}$

Die Schwierigkeit besteht nun darin, zu bestimmen, was die tatsächlich dominierende Illokution ist, im Einklang mit oder unabhängig vom direkt ausgedrückten Sprechakt und möglichen weiteren (bewusst oder unbewusst eingesetzten) Rede- bzw. Handlungsprinzipien. Dabei ist u. a. abzuwägen, welcher Stellenwert emotionalen, rhetorischen und Höflichkeitsaspekten beigemessen werden soll, welche ebenfalls die genaue Art der Formulierung einer Äußerung mit beeinflussen. ${ }^{1169}$ Indirekte Sprechakte als Mittel, einen möglichen FTA abzumildern, wie inn v. a. viele Direktiva und einige Expressiva (z. B. des Typs KLAGEN) darstellen ${ }^{1170}$, sind im Lateinischen allerdings relativ selten; sie werden meist weniger aus Gründen der Höflichkeit verwendet als zur Vermeidung von Redundanz und aus anderen mehr situativen als sozialen Gründen. Zur Abschwächung werden eher andere (explizite) Mittel genutzt. ${ }^{1171}$ Dieser Befund mag auch darin begründet sein, dass wir für unsere Beurteilung naturgemäß nur auf

\footnotetext{
1167 Vgl. z. B. Kap. 2.1.3. zu fam. 14.2.3 (32) und (35), wo der Unterschied allerdings nur die Klassifikation und nicht die Identifikation betrifft, insofern in beiden Fällen jeweils nur von einer Illokution ausgegangen wird, welche aber nicht als konventioneller WOHLERGEHENSWUNSCH eingeordnet wird, sondern als ANWEISUNG. In (35) tritt dabei noch ein eng verbundener (kausaler) Hauptsatz hinzu.

${ }^{1168}$ Vgl. S. 167.

1169 Vgl. a. WEIGAND 2003, 27

1170 Andere Expressiva (z. B. SICH ENTSCHULDIGEN) und einige Kommissiva sind ebenfalls gesichtsbedrohend, allerdings für den Sprecher und nicht den Adressaten, weshalb in diesen Fällen nicht von Höflichkeit gesprochen werden kann. Vgl. a. WüEST 2011, 44 (s. N. 346).

1171 Vgl. RISSELADA 1993, 90ff. (,implicitness, indirectness, and politeness“), bes. ebd., 92. Vgl. a. ROESCH 2004, 152. Zu den verschiedenen Graden von Direktheit bzw. Indirektheit sprachlicher Äußerungen vgl. außerdem S. 166 und das Kap. "Indirekte Sprechakte“ ab S. 20.
} 
schriftsprachliche Äußerungen zurückgreifen können. Auf die situationsbedingte Notwendigkeit (und auch Möglichkeit) einer stärkeren Explizierung in der Briefkorrespondenz wurde bereits eingegangen. ${ }^{1172}$ Überhaupt sind die Besonderheiten dieser Art von Kommunikation immer mit zu berücksichtigen.

\section{Assertiva}

\section{Charakteristika im Überblick}

In vereinfachender Perspektive kann die assertive Handlungsfunktion quasi als Standardfunktion betrachtet werden, die im Grunde meistens dann vorliegt, wenn nichts auf eine andere Illokution hinweist. Dennoch lassen sich einige Merkmale erkennen, die für viele Assertiva charakteristisch sind, obschon sie zum größten Teil nicht exklusiv auf diese Sprechhandlungskategorie beschränkt sind:

\begin{tabular}{|c|c|}
\hline \multicolumn{2}{|l|}{ Allgemeine Semantik } \\
\hline propositionale Einstellung & $\begin{array}{l}\text { epistemisch: } \\
\text { - } \text { (certo) scio } \\
\text { - nescio } \\
\text { - ignoro } \\
\text { - in mentem non venit } \\
\text { - non constat } \\
\text { - } \text { certiores erimus } \\
\text { - } \text { dicitur } \\
\text { - } \text { puto, putamus } \\
\text { - ut arbitror } \\
\text { - } \text { fortasse }\end{array}$ \\
\hline Affirmation & $\begin{array}{l}\text { bei den Konfirmativa (ZUSTIMMEN): } \\
\text { - ita }\end{array}$ \\
\hline Negation & $\begin{array}{l}\text { regelmäßig bei den Detraktiva (ABSTREITEN): } \\
\text { - noli putare } \\
\text { nihil }\end{array}$ \\
\hline \multirow[t]{3}{*}{ Lexik insgesamt } & $\begin{array}{l}\text { präzise und kompakte (Einzel-)Informationen } \\
\text { (im Unterschied bspw. zur teilweise anzutreffenden Vag- } \\
\text { heit bei den Expressiva) }\end{array}$ \\
\hline & $\begin{array}{l}\text { Metadirektiva }{ }^{1173} \text { : } \\
\text { noli putare } \\
\text { Anmerkung: Die für Assertiva ebenfalls typische Wendung scito fin- } \\
\text { det sich nur in fam. } 14.4 .3 \text { (24), also einem expressiven Sprechakt des } \\
\text { Typs HOFFNUNG ÄUSSERN: unum hoc scito: si te habebo... }\end{array}$ \\
\hline & $\begin{array}{l}\text { (epistemische) Verben und verbale Wendungen zum } \\
\text { Ausdruck von (Un-)Gewissheit (s. propositionale Einstellung): } \\
\text { (non) constare, (ne)scire, certiorem esse, in mentem (non) } \\
\text { venire, ignorare, arbitrari, putare, dicitur }\end{array}$ \\
\hline
\end{tabular}

1172 Vgl. Kap. 1.2.1.3. Vgl. a. S. 133.

1173 Vgl. N. 959. 







\begin{tabular}{|c|c|}
\hline & 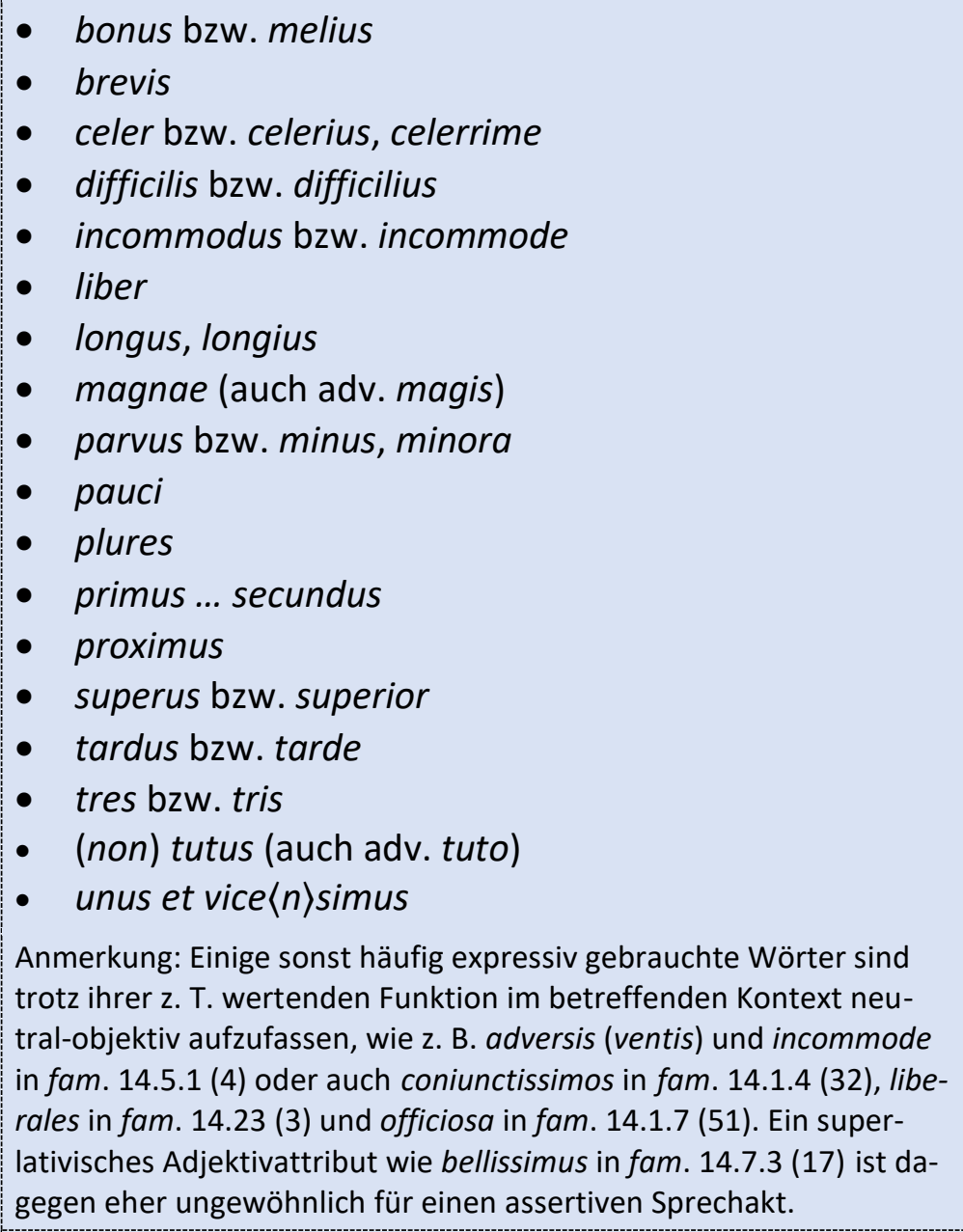 \\
\hline & $\begin{array}{l}\text { Possessivpronomina hauptsächlich in obligatorisch-re- } \\
\text { stringierender (und nicht affektiver) Verwendungsweise } \\
\text { Anmerkungen: } \\
\text { - } \quad \text { Eine Ausnahme bildet Tullia nostra in fam. } 14.11 \text { (3), wobei zu } \\
\text { bemerken ist, dass dies die übliche Bezeichnung Ciceros für seine } \\
\text { Tochter darstellt. } \\
\text { - } \\
\text { Die eigentlich fakultativen Personalpronomina der 1. Person fin- } \\
\text { den sich häufiger, z. B. in fam. 14.1.4 (32), 14.2.4 (36), 14.4.1 (2), } \\
\text { 14.18.1 (6), 14.22 (3), 14.24 (3) und (4). }\end{array}$ \\
\hline \multicolumn{2}{|l|}{ Morphosyntax } \\
\hline Komparation & $\begin{array}{l}\text { vornehmlich Positive und Komparative (vgl. o. bzw. u.: sach- } \\
\text { lich beschreibende und bewertende Adjektive sowie modale Bestim- } \\
\text { mungen und Adverbialsätze) } \\
\text { Anmerkungen: } \\
\text { Zur (nicht explizit-vergleichenden) Abstufung werden statt des } \\
\text { Komparativs auch bestimmte Adverbien benutzt, wie z. B. satis } \\
\text { (satis liberales). } \\
\text { Manchmal findet sich auch der Superlativ (in neutral-beschrei- } \\
\text { bender bzw. vergleichender Verwendungsweise), wie z. B. proxi- } \\
\text { ma und celerrime. Ungewöhnlich für einen assertiven Sprechakt } \\
\text { sind jedoch die Elative coniunctissimos in fam. 14.1.4 (32) und } \\
\text { bellissimus in 14.7.3 (17). }\end{array}$ \\
\hline
\end{tabular}




\begin{tabular}{|c|c|}
\hline Person & $\begin{array}{l}\text { je nach Art des Sprechaktes v. a. 1. und 3. Person } \\
\text { Anmerkung: Nur in wenigen Ausnahmefällen wird auch die 2. Person } \\
\text { verwendet, wie z. B. in fam. 14.2.1 (2) und 14.5.1 (13). }\end{array}$ \\
\hline Modus & $\begin{array}{l}\text { Indikativ } \\
\text { Anmerkungen: } \\
\text { - Der Konjunktiv findet sich häufiger bei Modusanpassung in be- } \\
\text { - } \quad \text { } \text { Zur Wendung noli putare vgl. o.: Metadirektiva. }\end{array}$ \\
\hline Tempus & $\begin{array}{l}\text { Futur in zukunftsbezogenen Sprechakten des Untermus- } \\
\text { ters PROGNOSTIZIEREN, sonst meist Präsens und v. a. } \\
\text { Perfekt, seltener auch Imperfekt und Plusquamperfekt }\end{array}$ \\
\hline \multicolumn{2}{|l|}{ Syntax } \\
\hline Satzlänge & $\begin{array}{l}\text { viele kürzere Sätze, u. a. auch Teile von Aufzählungen und } \\
\text { (andere) Ellipsen } \\
\text { Anmerkung: Neben Erweiterungen in Form von Infinitiv- und Partizi- } \\
\text { pialkonstruktionen (Acl: fam. } 14.1 .5 \text { (34), } 14.3 .3 \text { (19), } 14.8 \text { (4), } 14.15 \\
\text { (3) bzw. p. c.: fam. } 14.5 .1 \text { (5)) finden sich aber durchaus in einigen } \\
\text { Fällen auch längere Satzreihen und Satzgefüge (fam. } 14.3 .4 \text { (28), } \\
14.15 \text { (3), } 14.19 \text { (3) bzw. fam. } 14.2 .4(36), 14.7 .1(5), 14.13 \text { (2) und } \\
14.16 \text { (4)). }\end{array}$ \\
\hline Satzart & $\begin{array}{l}\text { Aussagesätze } \\
\text { Anmerkungen: } \\
\text { - In fam. } 14.2 .1 \text { (2) findet sich ein seltenes Beispiel für einen (me- } \\
\text { tadirektiv eingeleiteten) Aufforderungssatz. } \\
\text { - Auch Nebensätze als eigenständige Illokution sind möglich, wie } \\
\text { z. B. fam. } 14.2 .1 \text { (4): cui puto rescribi oportere. }\end{array}$ \\
\hline Objektsätze & $\begin{array}{l}\text { indirekte Fragesätze und Acl: } \\
\text { - fam. } 14.1 .5 \text { (34): et me a te certiorem factum esse } \\
\text { scripsi. } \\
\text { fam. } 14.2 .1 \text { (5): nec enim habeo quid scribam } \\
\text { te in febrim subito incidisse. } \\
\text { - fam. } 14.20 \text { (2): In Tusculanum nos venturos putamus } \\
\text { aut Nonis aut postridie. } \\
\text { fam. } 14.22 \text { (4): qui si venerint, fortasse erimus certio- } \\
\text { res quid nobis faciendum sit }\end{array}$ \\
\hline $\begin{array}{l}\text { adverbiale Bestimmungen und } \\
\text { Adverbialsätze }\end{array}$ & 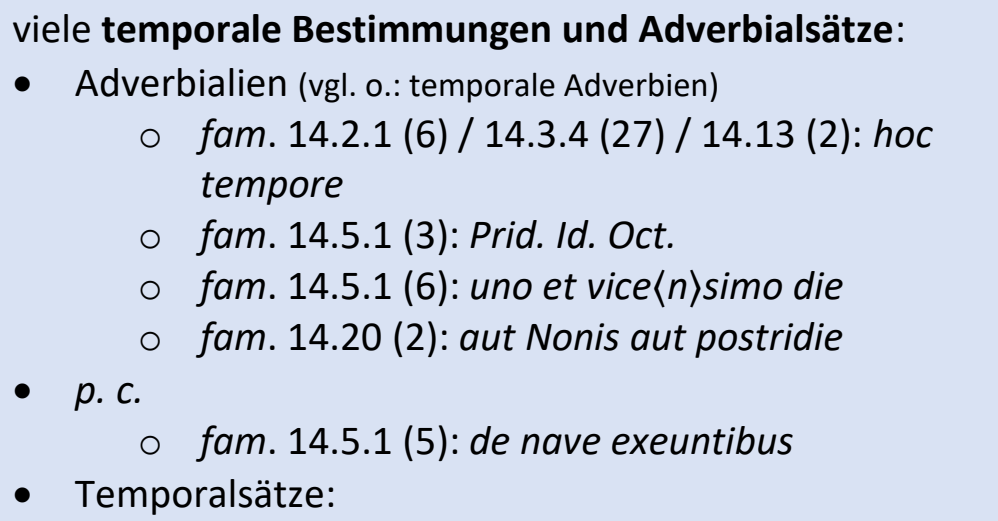 \\
\hline
\end{tabular}




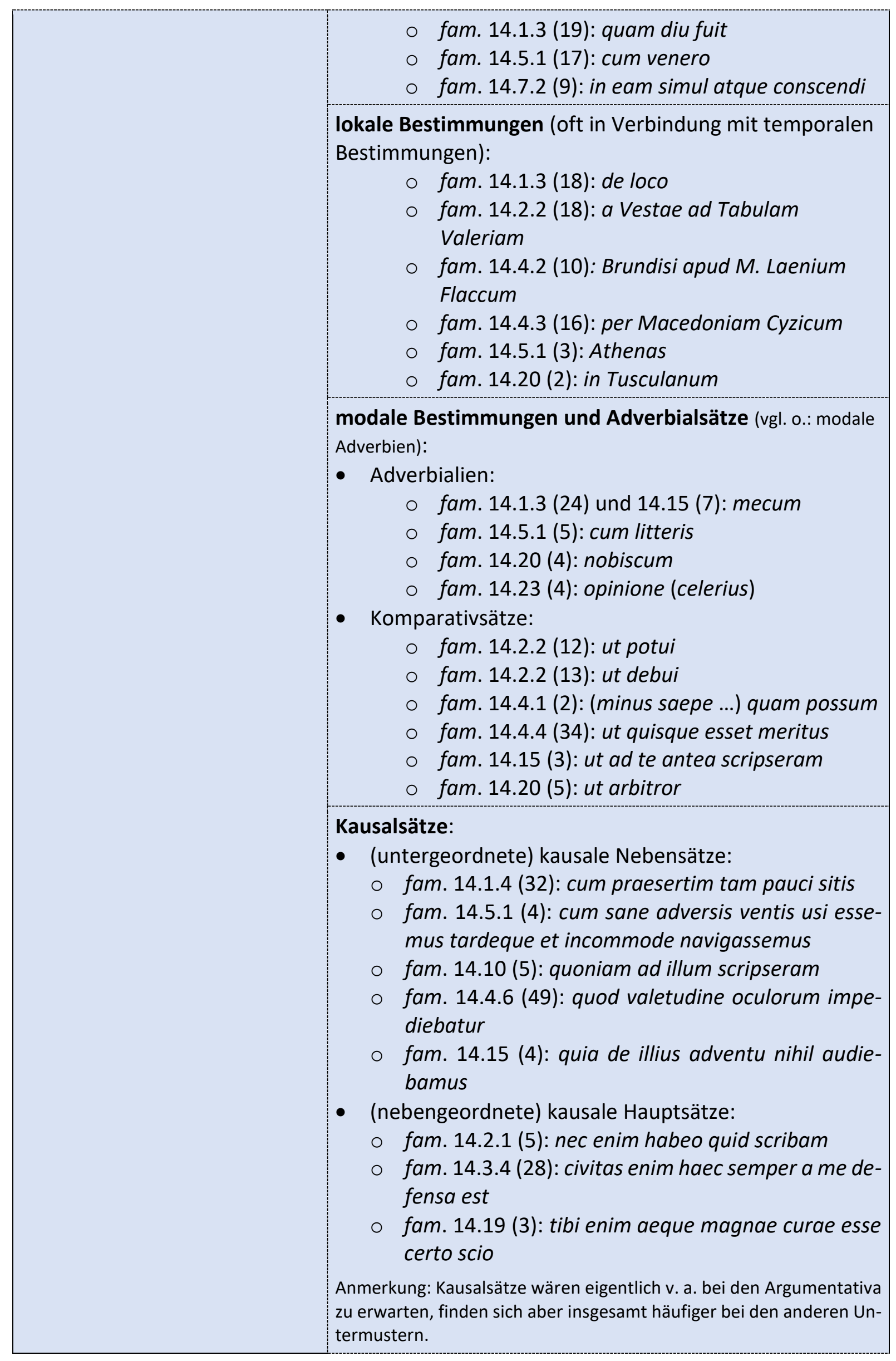




\begin{tabular}{|c|c|}
\hline & $\begin{array}{l}\text { Konditionalsätze: } \\
\text { - } \text { fam. } 14.2 .1 \text { (3): nisi si quis ad me plura scripsit } \\
\text { - } \text { fam. } 14.2 .3 \text { (31): si modo volunt } \\
\text { - } \text { fam. } 14.4 .4 \text { (37): si res a nobis abisset } \\
\text { - } \text { fam. } 14.4 .4 \text { (37): si obtinere potuissent } \\
\text { - } \text { fam. } 14.4 .4 \text { (37): sin ad nos pertinerent } \\
\text { - } \text { fam. } 14.4 .5 \text { (41): si esset licitum per nautas } \\
\text { - fam. } 14.17 \text { (3): si quid haberem } \\
\text { - } \text { fam. } 14.22 \text { (4): qui si venerint }\end{array}$ \\
\hline & 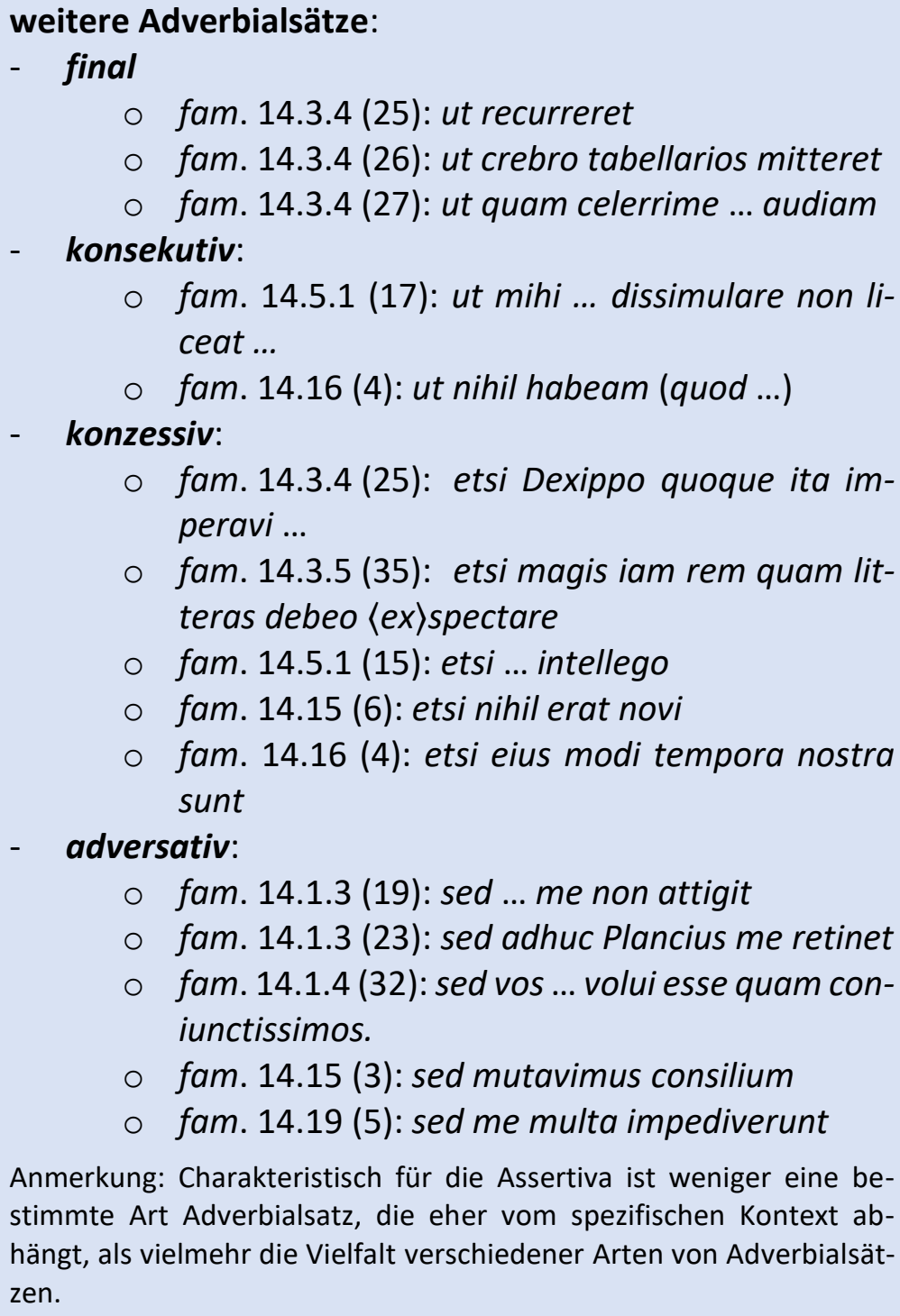 \\
\hline Attribute und Attributsätze & $\begin{array}{l}\text { spezifizierende und v. a. restringierende Attribute und At- } \\
\text { tributsätze zur genaueren Beschreibung bzw. Identifizie- } \\
\text { rung (vgl. o.: allgemeine Lexik - Adjektive): } \\
\text { - Attribute: } \\
\quad \text { o fam. } 14.4 .6 \text { (49): (valetudine) oculorum } \\
\circ \text { fam. } 14.5 .1 \text { (4): adversis (ventis) } \\
\circ \text { fam. } 14.5 .1 \text { (16): (ex) multorum amicorum (lit- } \\
\text { teris) }\end{array}$ \\
\hline
\end{tabular}




\begin{tabular}{|c|c|}
\hline & 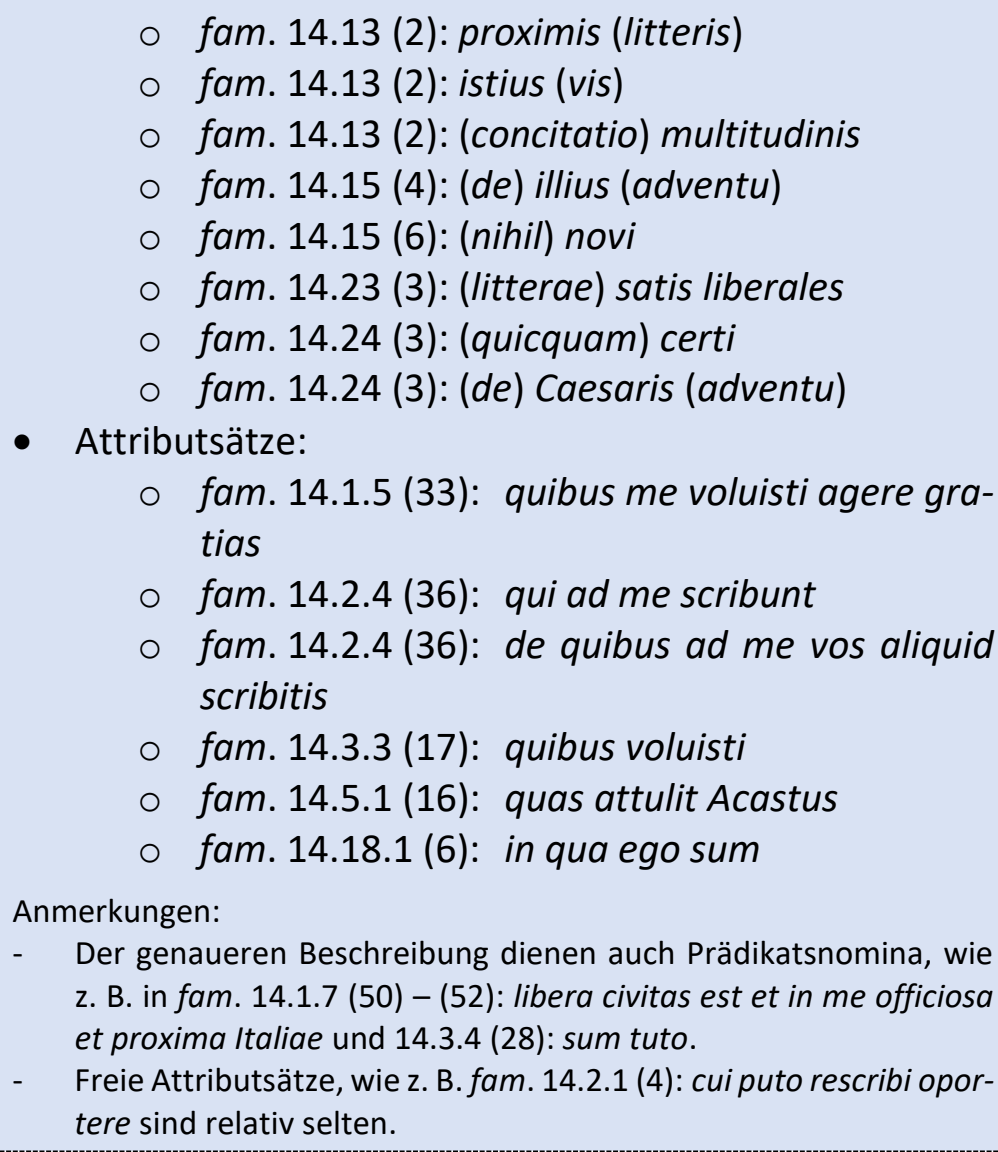 \\
\hline \multirow[t]{2}{*}{ Extrapositionen } & $\begin{array}{l}\text { erläuternde Nachträge: } \\
\text { - fam. } 14.2 .1 \text { (3): nisi si quis ad me plura scripsit } \\
\text { - fam. } 14.5 .1 \text { (13): sive nos ipsos } \\
\text { eos de quibus ad me vos aliquid scribitis } \\
\text { Anmerkung: Fam. } 14.2 .1 \text { (3) stellt sogar eine eigenständige Illokution } \\
\text { dar. }\end{array}$ \\
\hline & $\begin{array}{l}\text { (vorangestellte) Zitate als Bezugspunkt für Konfirmativa } \\
\text { und Assentiva (s. (Inter-)Textualität) }\end{array}$ \\
\hline \multicolumn{2}{|l|}{ (Inter-)Textualität } \\
\hline Konnexion & $\begin{array}{l}\text { kausale Konnexion bei den Argumentativa (vgl. o.: Kausal- } \\
\text { sätze): } \\
\text { - cum } \\
\text { - enim }\end{array}$ \\
\hline $\begin{array}{l}\text { Referenz auf vorangehende } \\
\text { Kommunikation }\end{array}$ & $\begin{array}{l}\text { grundsätzlich bei den reaktiven und re-initiativen Sprech- } \\
\text { akten (Konfirmativa, Assentiva, Detraktiva und Argumen- } \\
\text { tativa) } \\
\text { Anmerkungen: } \\
\text { - In fam. } 14 \text { ist die Referenz auf die vorangehende Kommunikation } \\
\text { oft aus dem Kontext zu erschließen, nur relativ selten finden sich } \\
\text { (bei den Konfirmativa und Assentiva) Beispiele für eine direkte } \\
\text { Bezugnahme. }\end{array}$ \\
\hline
\end{tabular}


Eine Referenz auf die vorangehende Kommunikation ist gelegentlich auch bei anderen (assertiven) Sprechakttypen anzutreffen, wie z. B. beim Untermuster BENACHRICHTIGEN in fam. $14.15(3)$.

Abbildung 47: Charakteristika assertiver Sprechakte

Assertive Sprechakte dienen dazu, über Sachverhalte verschiedenster Art zu informieren. ${ }^{1174}$ Dabei kann der Sprecher seine epistemische Einstellung bzw. einen besonders hohen oder niedrigen Grad an (Un-)Gewissheit hinsichtlich des Wahrheitsgehaltes einer Aussage explizit durch bestimmte Adverbien wie certo oder fortasse und Verben oder verbale Wendungen wie (non) constare, (ne)scire, certiores esse, in mentem (non) venire, ignorare, arbitrari, putare oder dicitur signalisieren. ${ }^{1175}$ Eine motivationale Einstellung begegnet zwar ebenfalls gelegentlich, wie z. B. in fam. 14.2.2 (13): ut debui oder 14.5.1 (18): subeunda fortuna est, kann aber nicht als charakteristisch für die Assertiva erachtet werden. ${ }^{1176}$ Außer den gerade genannten Verben enthalten auch einige Verben des Wahrnehmens wie intellegere, cognoscere oder videre eine epistemische Komponente (erkennen $\approx$ wissen). Daneben sind in den Assertiva häufiger Verben des Kommunizierens wie nuntiare und insbesondere scribere anzutreffen.

Bei nuntiare und anderen SB-Verben wie v. a. certiorem facere läge eine explizit performative Verwendungsweise nahe; sie werden in fam. 14 aber nur in berichtender bzw. ankündigender Funktion gebraucht, wie z. B. in fam. 14.8 (4): mihi et scriptum et nuntiatum est ..., sowie in vielen kommissiven Sprechakten (faciam te certiorem). ${ }^{1177}$ Die Wendung scito, mit der "metadirektiv“ eigentlich ein assertiver Sprechakt bzw. (perlokutionär) dessen Ziel („du sollst wissen, dass ...") signalisiert wird, begegnet interessanterweise lediglich in Zusammenhang mit einem expressiven Sprechakt (HOFFNUNG ÄUSSERN): unum hoc scito: si te habebo, non mihi videbor plane perisse. (fam. 14.4.3 (24)). Zu den (negierten) Metadirektiva zählt aber auch die Wendung noli putare, die in Zusammenhang mit dem Untermuster ABSTREITEN in fam. 14.2.1 (2) gebraucht wird. 1178

Ansonsten werden Prädikatsverben meist in der 1. oder 3. Person und fast ausschließlich im Indikativ verwendet, abgesehen von den Nebensätzen mit Modusanpassung im Konjunktiv. ${ }^{1179}$ Was das Tempus betrifft, sind die Assertiva nicht festgelegt. Am häufigsten vertreten sind Präsens und Perfekt, manchmal begegnen aber auch das Imperfekt und das Plusquamperfekt, bei einem zukunftsbezogenen Untermuster wie PROGNOSTIZIEREN regelmäßig zudem das Futur.

\footnotetext{
${ }^{1174}$ Vgl. das Kap. „Sprechaktkategorien und Klassifikationskriterien“ ab S. 24.

1175 Vgl. a. PINKSTER 2015, 309. Vgl. außerdem KÜHNER UND STEGMANN 1966, 795ff. (§ 143ff.: Modalitätsadverbien zum Ausdruck von „Gewißheit, Versicherung, Bekräftigung, Beteuerung, Bejahung“ bzw. „Ungewißheit“).

1176 Vgl. a. die Gerundivkonstruktion quid nobis faciendum sit in den indirekten Fragesätzen in fam. 14.3.5 (33) und 14.22 (4) sowie oportere in 14.2.1 (4).

1177 Zu den Kommissiva vgl. das betreffende Kap. ab S. 318. Vgl. a. erimus certiores in fam. 14.22 (4). Vgl. außerdem MUÑOz MARTín 1991, 340ff. zu „fórmulas declarativas“ in Ciceros Briefen, wie z. B. illud te scire volo und hoc te intellegere volo. Sie nennt u. a. auch den (metadirektiven) Imperativ scito. Vgl. N. 959.

${ }^{1178}$ Vgl. Kap. 2.1.3.

1179 Vorstellbar wäre evtl. auch die rein assertive Verwendung eines hypothetischen Konjunktivs. Meistens sind solche Äußerungen aber expressiv konnotiert, wie z. B. fam. 14.1.2 (10) und 14.2.1 (10). Vgl. a. PINKSTER 2015, 310 zum Konjunktiv als Mittel der Abmilderung von Assertiva, z. B. in Cic. Brut. 25: Hoc vero sine ulla dubitatione confirmaverim.
} 
Charakteristisch für assertive Sprechakte sind Aussagesätze. ${ }^{1180}$ Ein Aufforderungssatz wie in fam. 14.2.1 (2) bildet die große Ausnahme. Häufiger sind illokutionär eigenständige Nebensätze wie z. B. in fam. 14.2.1 (4), 14.3.5 (35), 14.4.6 (49), 14.5.1 (4), 14.5.1 (18), 14.15 (4) und (6) oder 14.24 (5), wobei von diesen z. T. noch weitere Nebensätze abhängig sind, wie z. B. in fam. 14.2.3 (31), 14.3.4 (25) und (26) oder 14.5.1 (17).

Während bspw. bei den Expressiva oft eher das große Ganze im Blick steht und die Details einem alles bestimmenden Gefühl untergeordnet sind, woraus sich teilweise eine mehr oder minder ausgeprägte Vagheit ergibt, tendieren die Assertiva zur Darstellung präziser und kompakter Einzelinformationen, was sich in häufig recht kurzen Äußerungseinheiten niederschlägt, die z. B. nur aus nüchtern und knapp formulierten Kurzsätzen wie accepi tuas litteras (fam. 14.5.1 (8)), einzelnen Bestandteilen von Aufzählungen (wie fam. 14.1.7 (50)ff.) und (anderen) Ellipsen (wie v. a. die Postskripta) bestehen. Daneben finden sich aber durchaus auch längere Äußerungen, die z. B. um Infinitiv- und Partizipialkonstruktionen (Acl: fam. 14.1 .5 (34), 14.3.3 (19), 14.8 (4), 14.15 (3) bzw. p. c.: fam. 14.5.1 (5)) sowie (mit sive oder nisi eingeleitete) erläuternde oder intertextuell bezugnehmende Extrapositionen (bzw. Zitate) erweitert sind. Darüber hinaus gibt es einige Fälle längerer Satzreihen (fam. 14.3.4 (28), 14.15 (3), 14.19 (3)) und Satzgefüge (z. B. fam. 14.2.4 (36), 14.7.1 (5), 14.13 (2), 14.16 (4)).

Dabei begegnen häufiger sowohl indirekte Fragesätze, welche (ebenso wie der $A c l$ ) meist mit den erwähnten Verben des Wissens, Wahrnehmens und Kommunizierens eingeleitet werden, als auch verschiedene Arten von Adverbialsätzen (wie Komparativ-, Konditional-, Final-, Konsekutiv-, Konzessiv- und Adversativsätze). Was Letztere betrifft, ist weniger eine bestimmte Art Adverbialsatz für die Assertiva kennzeichnend, welche eher vom spezifischen Kontext abhängt, als vielmehr deren Vielfalt. Selbst für einzelne Untermuster lassen sich nur eingeschränkt allgemeinere Aussagen treffen. So wären Kausalsätze eigentlich v. a. bei den Argumentativa zu erwarten. Tatsächlich werden aber nur zwei argumentative Sprechakte kausal (mit cum bzw. enim) angeschlossen. Dies hängt wohl u. a. damit zusammen, dass viele Begründungen in fam. 14 nicht re-initiativ, sondern präsentativ und noch dazu nicht einmal auf die Assertiva beschränkt sind, sondern sich auch bei den Direktiva, Kommissiva und Expressiva finden. Am ehesten können Temporalsätze als typisch gelten. Sie ermöglichen genauso wie die zahlreichen nicht satzwertigen temporalen, lokalen und modalen Bestimmungen eine genauere Beschreibung, wobei es sich meist (auch außerhalb der Postskripta) um Reiseinformationen handelt.

Spezifizierende und insbesondere restringierende Attribute (Adjektive, Pronomina, Substantive) und Attributsätze liefern ebenfalls wesentliche, zum Verständnis oft sogar unbedingt erforderliche Angaben. Rein schmückende affektive Attribute wie das Possessivpronomen nostra (fam. 14.11 (3): Tullia nostra) und das Adjektiv bellissimus (fam. 14.7 .3 (17): Cicero bellissimus) sind für sich genommen eher ungewöhnlich, müssen jedoch vor dem Hintergrund betrachtet werden, dass es sich (v. a. bei Tullia nostra) um nahezu „standardisierte" Bezeichnungen für die eigenen Kinder handelt. ${ }^{1181}$

\footnotetext{
1180 Zum Zusammenhang von Aussagesätzen und assertiver Funktion vgl. a. PINKSTER 2015, $308 \mathrm{ff}$.

${ }^{1181}$ Alternativ wäre evtl. eine Separierung als zusätzlicher (expressiver) Sprechakt denkbar.
} 
Im Übrigen zeichnen sich die Assertiva i. A. durch eine objektiv-neutrale Ausdrucksweise aus. So dienen Adverbien, (attributiv, prädikativ und adverbial gebrauchte) Adjektive, Numeralia und Pronomina in erster Linie einer sachlichen Beschreibung und Bewertung. Dazu gehören u. a. Vergleiche, weshalb neben dem einfachen Positiv häufiger auch Komparative begegnen, wohingegen der Superlativ selten ist, obwohl ja grundsätzlich durchaus ein rein beschreibendvergleichender Gebrauch vorstellbar ist, wie z. B. proxima (Italiae) in fam. 14.1 .7 (52) zeigt. Die Elative coniunctissimos (fam. 14.1.4 (32)) und v. a. bellissimus (fam. 14.7 .3 (17)) sind dagegen eher untypisch. ${ }^{1182}$ Dies gilt ähnlich auch für andere Verstärkungen, z. B. mit magnus (fam. 14.19 (3): magnae curae) oder tam (fam. 14.1.4 (32): tam pauci), die in den Assertiva eigentlich nicht notwendig und sonst eher kennzeichnend für die Direktiva und Expressiva sind.

Absolut neutrale, rein sachlich-informierende Aussagen sind zwar ohnehin kaum möglich, einige assertive Äußerungen erscheinen allerdings deutlicher subjektiv eingefärbt, sodass die Entscheidung, ob noch ein assertiver oder bereits ein expressiver oder anderer Sprechakttyp vorliegt, gar nicht so leicht ist. ${ }^{1183}$ Manchmal besteht der entscheidende Unterschied im personalen Bezug: Da es sich beim Subjekt nicht um den Sprecher selbst handelt, gehört z. B. Cicero bellissimus tibi salutem plurimam dicit. (fam. 14.7.3 (17)) zum assertiven Untermuster HINWEISEN und nicht zum expressiven Untermuster GUNST ERWEISEN. ${ }^{1184}$ Wenn es sich nicht auf die Vergangenheit beziehen würde, wäre sed vos, cum praesertim tam pauci sitis, volui esse quam coniunctissimos. (fam. 14.1.4 (32)) den Direktiva zuzuordnen. Auch die Abgrenzungen innerhalb der Assertiva sind z. T. nicht eindeutig. Zwischen Sprechhandlungen der Untermuster PROGNOSTIZIEREN und ANKÜNDIGEN bspw. lässt sich auf der Sprachoberfläche oft kein Unterschied erkennen. Der Interpret muss dann aufgrund anderer (kontextueller) Kriterien entscheiden, ob die vermittelte Aussage nur als möglich (PROGNOSTIZIEREN) oder als ziemlich sicher (ANKÜNDIGEN) betrachtet wird. ${ }^{1185}$ Die in diesem Kapitel genannten sprachlichen Indikatoren können also bei der Zuordnung zu einem bestimmten Sprechakttyp durchaus hilfreich sein, sind aber allein meistens nicht ausreichend.

Assertiva (i. e. S.)

Zu den Assertiva i. e. S. ${ }^{1186}$ gehören in fam. 14 folgende Äußerungen:

\section{BEHAUPTEN}

fam. 14.2.3 (31): qui possunt si modo volunt

\section{FESTSTELLEN}

fam. 14.2.3 (26): verum haec non sunt in nostra manu

fam. 14.4.4 (35): est autem in officio adhuc Orpheus

\footnotetext{
1182 Auch (quam) celerrime in fam. 14.3.4 (27) dient lediglich der sachlichen Beschreibung, während ähnliche Wendungen (wie quam primum) v. a. bei den Direktiva eine verstärkende Funktion haben.

${ }^{1183} \mathrm{Vgl}$. die Beispiele zu den einzelnen assertiven Untergruppen in den folgenden Abschnitten.

1184 Ähnliches gilt für Quintus pater et filius et Rufus vobis s. d. (fam. 14.14 .2 (16)), das aber bereits aufgrund seiner Position im Text nicht dem deklarativen Untermuster BRIEF ERÖFFNEN zugeordnet werden kann. Vgl. N. 1194.

1185 Eine Ähnlichkeit besteht außerdem zum kommissiven Untermuster ABSICHT BEKUNDEN. VgI. das Kap. zu den „Assertiva (i. e. S.)“ ab S. 290 sowie das Kap. zu den „Kommissiva“ ab S. 318.

${ }^{1186}$ Vgl. das Kap. „Assertiva“ ab S. 35.
} 


\begin{tabular}{|c|c|}
\hline $\begin{array}{l}\text { fam. 14.4.4 (36): } \\
\text { fam. 14.4.4 (38): } \\
\text { fam. 14.5.1 (18): }\end{array}$ & $\begin{array}{l}\text { praeterea magno opere nemo } \\
\text { sed haec minora sunt. } \\
\text { quoniam subeunda fortuna est }\end{array}$ \\
\hline \multicolumn{2}{|c|}{ PROGNOSTIZIEREN } \\
\hline fam. 14.1.4 (30): & gloriae [erg. ea Pisoni] quidem video fore. \\
\hline fam. 14.1.6 (46): & mihi omnino iam brevis exspectatio est. \\
\hline fam. 14.3.5 (33): & $\begin{array}{l}\text { ex primis aut summum secundis litteris tuis constituere poterimus quid } \\
\text { nobis faciendum sit. }\end{array}$ \\
\hline fam. 14.3 .5 (35): & etsi magis iam rem quam litteras debeo $\langle$ ex $\rangle$ spectare. \\
\hline fam. 14.5.1 (15): & $\begin{array}{l}\text { etsi in quam rem publicam veni }\langle a\rangle \text { mus intellego. cognovi enim [...] ad } \\
\text { arma rem spectare }\end{array}$ \\
\hline fam. 14.5.1 (17): & ut mihi, cum venero, dissimulare non liceat quid sentiam. \\
\hline fam. $14.13(4):$ & tamen ab illo [= Dolabella] fortasse nascetur \\
\hline fam. $14.19(7):$ & sed a Pomponio exspecto litteras \\
\hline fam. $14.20(2):$ & In Tusculanum nos venturos putamus aut Nonis aut postridie. \\
\hline fam. 14.20 (4): & plures enim fortasse nobiscum erunt \\
\hline fam. 14.20 (5): & et, ut arbitror, diutius ibi commorabimur \\
\hline fam. 14.22 (3): & Nos cottidie tabellarios nostros exspectamus \\
\hline fam. $14.22(4):$ & $\begin{array}{l}\text { qui [= tabellarii] si venerint, fortasse erimus certiores quid nobis } \\
\text { faciendum sit }\end{array}$ \\
\hline fam. 14.23 (4): & et ipse opinione celerius venturus esse dicitur \\
\hline \multicolumn{2}{|l|}{ VERMUTEN } \\
\hline fam. 14.5.1 (13): & iam enim me ipsum exspectas, sive nos ipsos \\
\hline fam. $14.24(5):$ & [de litteris] quas Philotimus habere dicitur \\
\hline
\end{tabular}

Abbildung 48: Assertive Assertiva

Mit der BEHAUPTUNG in fam. 14.2.3 (31) weist Cicero seine Frau, die sich dessen möglicherweise nicht so deutlich bewusst ist, darauf hin, dass die Freunde sie in ihrer schwierigen finanziellen Situation seiner Meinung nach ohne Weiteres unterstützen könnten. ${ }^{1187}$

Bei den Sprechakten des Typs FESTSTELLEN ist zumindest in dem betreffenden Moment für Terentia auf den ersten Blick offensichtlich, dass die Aussage Ciceros zutrifft, sei es, weil sie quasi Augenzeugin ist wie bei fam. 14.4.4 (35) und (36), sei es, weil es sich um allgemeine Lebensweisheiten handelt wie bei fam. 14.5.1 (18) oder die Äußerung anderweitig (zunächst) kaum in Zweifel gezogen werden kann wie bei fam. 14.2 .3 (26) und 14.4.4 (38). ${ }^{1188}$ In fam. 14.2.3 (26) und 14.5.1 (18) sind dabei auch Anklänge an das kommissive Untermuster ABSICHT BEKUNDEN zu erkennen (,Ich beabsichtige, nichts weiter zu unternehmen“ bzw. „Ich habe die Absicht, mich meinem Schicksal zu stellen. "), in fam. 14.2.3 (26) zusätzlich auch an das direktive Untermuster ANWEISEN (,Du brauchst nichts weiter zu unternehmen. “) und das expressive Untermuster ANGST ÄUSSERN. ${ }^{1189}$

\footnotetext{
${ }^{1187}$ Vgl. Kap. 2.1.3.

1188 Vgl. RoLf 1983, $144 f$.

${ }^{1189} \mathrm{VgI}$. Kap. 2.1.2 und Kap. 2.1.3.
} 
Das Untermuster VERMUTEN in fam. 14.5.1 (13) bestimmt sich in erster Linie aus dem Kontext, der gegen die sonst evtl. näher liegende Annahme des Untermusters BEHAUPTEN spricht. Die Sprachoberfläche lässt nämlich nicht erkennen, dass Ciceros Erklärung für die Kürze von Terentias Briefen nur „schwache Gründe“ zugrunde liegen und durchaus auch andere Ursachen vorstellbar sind. ${ }^{1190}$ In fam. 14.24 (5) stützt sich Ciceros Vermutung dagegen explizit auf die Aussage anderer (dicitur).

Dies trifft auch auf fam. 14.23 (4) zu, wo sich die Handlung allerdings auf die Zukunft bezieht, weshalb es dem Untermuster PROGNOSTIZIEREN zuzuweisen ist, welches ein mögliches künftiges Geschehen zum Gegenstand hat, für dessen Eintreten - im Gegensatz zu PROPHEZEIEN - rationale Gründe sprechen. ${ }^{1191}$ Insofern kann auch fam. 14.1.4 (30) dazu gezählt werden, obwohl diese Äußerung spekulativer wirkt als die übrigen und eine Zuordnung zum expressiven Untermuster HOFFNUNG ÄUSSERN ebenso denkbar erscheint. Cicero ist jedoch überzeugt davon, dass Piso den verdienten Ruhm erhalten wird, den er mithin PROGNOSTIZIERT.

Der Zukunftsbezug wird nicht nur durch das Futur (poterimus, nascetur, erunt, erimus certiores, commorabimur bzw. fore, venturos und venturus esse) hergestellt, sondern außerdem durch das (im Unterschied zu fam. 14.5 .1 (13) nicht auf den Adressaten, sondern den Sprecher bezogene) Verb exspectare (exspecto, exspectamus) bzw. die Wendung (brevis) exspectatio est. ${ }^{1192}$ Manchmal ergibt er sich mehr aus dem Gesamtzusammenhang, wie in fam. 14.5.1 (15) und (17), wobei im ersten Fall auch die Wendung ad arma rem spectare, im zweiten das Futur II im untergeordneten Temporalsatz (cum venero) einen deutlichen Hinweis liefern. Die Gerundivkonstruktion quid nobis faciendum sit in den indirekten Fragesätzen in fam. 14.3.5 (33) und fam. 14.22 (4) ist ebenfalls zukunftsbezogen.

Kennzeichnend für das Untermuster PROGNOSTIZIEREN ist zudem der Ausdruck von Ungewissheit, z. B. durch das Adverb fortasse oder Verben wie putare (putamus) und arbitrari (ut arbitror) sowie auch posse (poterimus). Damit ist der wesentliche Unterschied zum transmissiven Untermuster ANKÜNDIGEN benannt, das man sonst bspw. bei fam. 14.20 (2), (4) und (5) annehmen könnte, wo es sich immerhin um Sachverhalte handelt, von deren Eintreffen Cicero mit ziemlich großer Sicherheit ausgeht. Gegen die Annahme des kommissiven Untermusters ABSICHT BEKUNDEN spricht, dass in diesem Zusammenhang nicht von einer „Selbstverpflichtung" gesprochen werden kann. Die Sprechereinstellung ist epistemisch und nicht motivational. Nicht ganz klar ist im Übrigen auch die Einordnung von fam. 14.5 .1 (15) und (17), wo die (nicht explizit formulierte) Ungewissheit zugleich mit Angst verbunden ist, welche jedoch nicht im Zentrum der Sprechakte steht. ${ }^{1193}$

\footnotetext{
1190 Vgl. Kap. 2.1.2.

1191 Vgl. Rolf 1983, 130ff., bes. ebd., 157ff.

1192 Das Verb exspectare begegnet auch häufiger bei anderen zukunftsbezogenen Sprechakten, wie z. B. den Expressiva des Typs HOFFNUNG und ANGST ÄUSSERN. Vgl. dazu die Kap. zu den „Expressiva mit Sprecherpräferenz“ (ab S. 355) und zu den „Expressiva mit Sprecheraversion“ (ab S. 368). In fam. 14.1.6 (46) finden sich im Übrigen Anklänge an diese beiden Untermuster. Durch expressive Elemente wie das Adverb omnino oder das Adjektiv brevis wird eine solche Zuordnung auf den ersten Blick sogar gestützt. M. E. legt der Kontext aber nahe, dass nicht das Entladen von Gefühlen im Vordergrund steht, sondern dass es sich um eine weitgehend neutrale Informationshandlung handelt.

${ }^{1193} \mathrm{Vgl}$. Kap. 2.1.2.
} 
Transmissiva

Die Briefe in fam. 14 wurden in besonderen, meist schwierigen Lebenssituationen Ciceros verfasst, in denen Terentia erwarten konnte, über alle Neuigkeiten auf dem Laufenden gehalten zu werden. Dementsprechend sind die Transmissiva in fam. 14 die am stärksten repräsentierte Gruppe von Assertiva (i. w. S.):

\begin{tabular}{|c|c|}
\hline \multicolumn{2}{|c|}{ BENACHRICHTIGEN } \\
\hline fam. $14.11(3):$ & Tullia nostra venit ad me prid. Id. Iun. \\
\hline fam. 14.15 (3): & $\begin{array}{l}\text { Constitueramus, ut ad te antea scripseram, obviam Ciceronem Caesari } \\
\text { mittere; sed mutavimus consilium }\end{array}$ \\
\hline fam. 14.15 (7): & Tulliam adhuc mecum teneo. \\
\hline fam. 14.23 (3): & Redditae mihi tandem sunt a Caesare litterae satis liberales \\
\hline \multicolumn{2}{|l|}{ HINWEISEN } \\
\hline fam. 14.1 .3 (18): & de loco, nunc quidem iam abiit pestilentia \\
\hline fam. 14.1.3 (19): & sed quam diu fuit me non attigit \\
\hline fam. $14.1 .3(20):$ & Plancius [...] me cupit esse secum et adhuc [erg. me] retinet. \\
\hline fam. $14.1 .3(23):$ & sed adhuc Plancius me retinet \\
\hline fam. 14.1.3 (24): & sperat posse fieri ut mecum in Italiam decedat. \\
\hline fam. 14.1 .5 (33): & quibus me voluisti agere gratias egi \\
\hline fam. 14.1 .5 (34): & et me a te certiorem factum esse scripsi. \\
\hline fam. 14.1.7 (49): & Dyrrachium veni \\
\hline fam. 14.1.7 (50): & quod et libera civitas est \\
\hline fam. 14.1.7 (51): & et in me officiosa \\
\hline fam. 14.1.7 (52): & et proxima Italiae \\
\hline fam. 14.2.2 (12): & eum, ut potui, per litteras cohortatus sum \\
\hline fam. 14.2.2 (13): & gratiasque egi, ut debui. \\
\hline fam. 14.2.2 (18): & $\begin{array}{l}\text { nam ad me P. Valerius, [...] scripsit, [...] quem ad modum a Vestae ad } \\
\text { Tabulam Valeriam ducta esses. }\end{array}$ \\
\hline fam. 14.3.3 (17): & amicis quibus voluisti egi gratias \\
\hline fam. 14.3.3 (18): & et eas litteras Dexippo dedi \\
\hline fam. 14.3.3 (19): & meque de eorum officio scripsi a te certiorem esse factum. \\
\hline fam. $14.3 .4(25):$ & etsi Dexippo quoque ita imperavi statim ut recurreret \\
\hline fam. 14.3.4 (26): & et ad fratrem misi ut crebro tabellarios mitteret. \\
\hline fam. 14.3.4 (27): & $\begin{array}{l}\text { nam ego eo nomine sum Dyrrachi hoc tempore ut quam celerrime quid } \\
\text { agatur audiam }\end{array}$ \\
\hline fam. $14.3 .4(28):$ & et sum tuto; civitas enim haec semper a me defensa est. \\
\hline fam. 14.4.2 (10): & Nos Brundisi apud M. Laenium Flaccum dies XIII fuimus \\
\hline fam. 14.4.3 (15): & Brundisio profecti sumus a. d. II Kal. Mai. \\
\hline fam. 14.4 .3 (16): & per Macedoniam Cyzicum petebamus. \\
\hline fam. 14.4.5 (41): & $\begin{array}{l}\text { quas ego exspectassem Brundisi si esset licitum per nautas, qui tempes- } \\
\text { tatem praetermittere noluerunt. }\end{array}$ \\
\hline
\end{tabular}




\begin{tabular}{|c|c|}
\hline fam. 14.4.6 (48): & Clodium Philetaerum [...] remisi. \\
\hline fam. 14.4.6 (49): & quod valetudine oculorum impediebatur \\
\hline fam. 14.5.1 (3): & Prid. Id. Oct. Athenas venimus \\
\hline fam. 14.5.1 (4): & $\begin{array}{l}\text { cum sane adversis ventis usi essemus tardeque et incommode navigas- } \\
\text { semus. }\end{array}$ \\
\hline fam. 14.5.1 (5): & de nave exeuntibus nobis Acastus cum litteris praesto fuit \\
\hline fam. 14.7.1 (2): & Omnis molestias et sollicitudines [...] deposui et eieci. \\
\hline fam. 14.7.1 (5): & 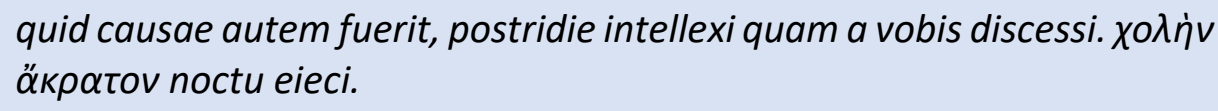 \\
\hline fam. 14.7.3 (17): & Cicero bellissimus tibi salutem plurimam dicit. \\
\hline fam. 14.8 (4): & nam mihi et scriptum et nuntiatum est te in febrim subito incidisse. \\
\hline fam. $14.10(2):$ & Quid fieri placeret scripsi ad Pomponium, \\
\hline fam. $14.10(5):$ & apertius scribi, quoniam ad illum scripseram, necesse non fuit. \\
\hline fam. 14.12 (5): & quid autem possis mihi in mentem non venit. \\
\hline fam. $14.13(2):$ & $\begin{array}{l}\text { Quod scripsi ad te proximis litteris de nuntio remittendo, quae sit istius } \\
\text { vis hoc tempore et quae concitatio multitudinis ignoro. }\end{array}$ \\
\hline fam. 14.14.2 (16): & Quintus pater et filius et Rufus vobis s. $d$. \\
\hline fam. 14.15 (4): & quia de illius adventu nihil audiebamus. \\
\hline fam. 14.15 (6): & etsi nihil erat novi \\
\hline fam. 14.16 (4): & $\begin{array}{l}\text { Etsi eius modi tempora nostra sunt ut nihil habeam quod [aut ... aut } \\
\text { ipse] ad te scribam [...], tamen nescio quo modo [et ... et] scribo ad vos } \\
\text { cum habeo qui ferat. }\end{array}$ \\
\hline fam. $14.18 .1(6):$ & $\begin{array}{l}\text { haec autem regio in qua ego sum nostrorum est cum oppidorum tum } \\
\text { etiam praediorum }\end{array}$ \\
\hline fam. 14.18.2 (8): & mihi plane non satis constat adhuc utrum sit melius. \\
\hline fam. 14.19 (3): & $\begin{array}{l}\text { de qua nihil est quod ad te plura scribam; tibi enim aeque magnae curae } \\
\text { esse certo scio. }\end{array}$ \\
\hline fam. 14.24 (3): & $\begin{array}{l}\text { Nos neque de Caesaris adventu [neque...] quicquam adhuc certi habe- } \\
\text { mus. }\end{array}$ \\
\hline fam. 14.24 (4): & Nos [neque ...] neque de litteris [...] quicquam adhuc certi habemus. \\
\hline \multicolumn{2}{|l|}{ MITTEILEN } \\
\hline fam. $14.2 .4(36):$ & $\begin{array}{l}\text { Ego ad quos scribam nescio, nisi ad eos qui ad me scribunt aut ad eos } \\
\text { de quibus ad me vos aliquid scribitis. }\end{array}$ \\
\hline 14.5.1 (6): & uno et vice $\langle n\rangle$ simo die \\
\hline fam. 14.5 .1 (16): & ex multorum amicorum litteris, quas attulit Acastus \\
\hline m. 14.7.2 (9): & in eam simul atque conscendi, haec scripsi. \\
\hline
\end{tabular}

Abbildung 49: Assertive Transmissiva

Es geht in den Transmissiva häufig um Ciceros genauen Reiseverlauf, seine Reisebegleiter und -gastgeber, seine Sicherheit und sein (gesundheitliches) Wohlbefinden und um die Briefe, die 
er geschrieben und erhalten hat oder eben (noch) nicht sowie deren Beförderung. Gelegentlich richtet er Terentia Grüße von anderen aus. ${ }^{1194}$ Manchmal betrifft der Inhalt der Schreiben eine mögliche Unterstützung durch Terentia, wobei Cicero sie meist für Details an Dritte verweist. ${ }^{1195}$ Auf der anderen Seite zeigt er auch Interesse an Terentias Situation, teilt ihr mit, dass er von ihren Schicksalsschlägen wie der Verschleppung zur Tabula Valeria oder einem plötzlichen Fieberanfall erfahren habe ${ }^{1196}$, und versucht, ihr mit hilfreichen Informationen zur Seite zu stehen, z. B. (während des Bürgerkrieges) hinsichtlich eines geeigneten Zufluchtsortes außerhalb von Rom. Ein wichtiges Thema sind außerdem die gemeinsamen Kinder, über deren aktuellen Aufenthaltsort Cicero bspw. Auskunft gibt.

Mit Abstand am häufigsten vertreten ist das Untermuster HINWEISEN, das quasi als Paradebeispiel für eine assertive Sprechhandlung gelten kann. Die Abgrenzung zu den Untermustern MITTEILEN und BENACHRICHTIGEN liegt im Prinzip lediglich im Wichtigkeitsgrad der Information (wichtig vs. interessant bzw. notwendig) begründet, den zu beurteilen nicht immer ganz leicht und aufgrund unzureichenden Hintergrundwissens oft recht subjektiv ist. Man kann aber wohl davon ausgehen, dass u. a. die genaue Anzahl der Tage, die Acastus für den Brieftransport benötigt hat (fam. 14.5.1 (6)), für Terentia zwar durchaus bemerkenswert, aber nicht sonderlich bedeutsam ist - ganz im Gegensatz zu der Nachricht, der lang erwartete Brief Cäsars sei endlich eingetroffen, welcher Cicero auf seine vollständige Rehabilitierung nach der Schlacht bei Pharsalus hoffen lässt (fam. 14.23 (3)).

Ein mittlerer Wichtigkeitsgrad und damit das Untermuster HINWEISEN ist im Übrigen auch bei den Angaben von Ort und / oder Datum der Briefabfassung im Postskriptum anzunehmen, die Terentia ebenfalls eine wichtige Orientierung über Ciceros Reiseverlauf geben ${ }^{1197}$ :

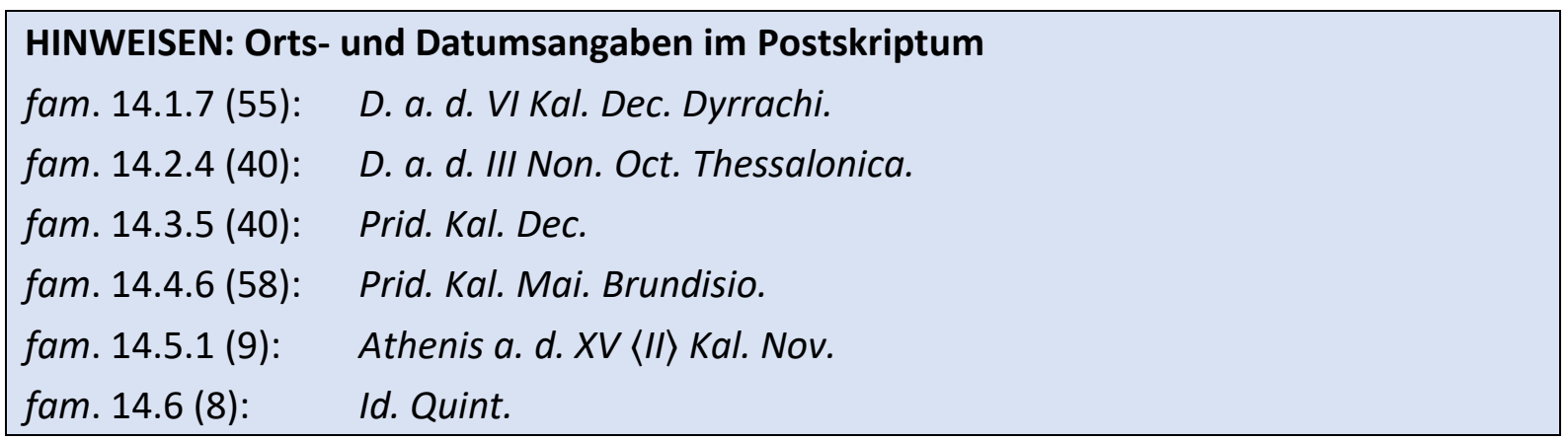

${ }^{1194}$ Fam. 14.14.2 (16) und 14.7.3 (17) ähneln Sprechakten des Typs BRIEF ERÖFFNEN bzw. GUNST ERWEISEN. Im ersten Fall ist die Zuordnung zu den Assertiva jedoch ziemlich eindeutig: Quintus und sein Sohn sowie Rufus sind nicht Absender des Schreibens, und die Äußerung steht nicht am Briefanfang, sodass das deklarative Untermuster BRIEF ERÖFFFNEN in keine Weise in Frage kommt. Der zweite Fall ist etwas schwieriger einzuordnen. Allerdings kann Ciceros Sohn, auch wenn er sich gerade bei seinem Vater aufhält, nicht als Absender des Briefes angesehen werden, und die Äußerung ist somit trotz starker Anklänge an das Untermuster GUNST ERWEISEN anders zu bewerten. Vgl. a. das Kap. „Begrüßungsformeln: deklaratives BRIEF ERÖFFNEN vs. expressives GUNST ERWEISEN“ ab S. 346.

${ }^{1195}$ Fam. 14.10 (2) hat auch eine direktive Komponente, die allerdings erst in 14.10 (4) als dominant zu erachten ist, während in (2) die Information im Zentrum steht, dass Cicero einen Brief an Pomponius geschrieben habe. Vgl. a. das Kap. „Direktiva mit Sprecherpräferenz" ab S. 313.

1196 In beiden Illokutionen (fam. 14.2.2 (18) und 14.8 (4)) finden sich leichte Anklänge an das expressive Untermuster BEDAUERN BEKUNDEN. Vornehmlich geht es Cicero aber darum, seine Frau davon in Kenntnis setzen, dass er von den betreffenden Sachverhalten erfahren habe. Fam. 14.8 (4) begründet dabei auch den vorangehenden WOHLERGEHENSWUNSCH in 14.8 (3).

1197 Vgl. S. 182. 


\begin{tabular}{|c|c|}
\hline fam. 14.7.3 (19): & D. VII Id. Iun. \\
\hline fam. 14.8 (10): & D. III Non. Iun. \\
\hline fam. 14.10 (9): & VII Id. Quint. \\
\hline fam. 14.11 (10): & XVII Kal. Quint. \\
\hline fam. 14.12 (11): & D. prid. Non. Nov. Brundisio. \\
\hline fam. 14.13 (8): & VI Id. Quint. \\
\hline fam. 14.14.2 (18): & VIIII Kal. Febr. Minturnis. \\
\hline fam. 14.15 (10): & XII Kal. Quint. \\
\hline fam. 14.16 (10): & Prid. Non. Ian. \\
\hline fam. 14.18.2 (15): & VIIII Kal. Form〈i $\rangle$ s \\
\hline fam. 14.20 (9): & Kal. Oct. de Ven $\langle u\rangle$ sino. \\
\hline fam. 14.22 (8): & Kal. Sept. \\
\hline fam. 14.23 (9): & D. prid. Id. Sext. \\
\hline fam. 14.24 (9): & III Id. Sext. \\
\hline
\end{tabular}

Abbildung 50: Assertive Transmissiva: Orts- und Datumsangaben in den Postskripta

In vielen Transmissiva schwingt eine mehr oder weniger deutliche expressive Note mit, z. B. Freude bzw. Dankbarkeit oder Bewunderung ${ }^{1198}$ in fam. 14.1 .7 (51), 14.1 .3 (20) und (23), 14.5.1 (6) 1199 und $14.11(3)^{1200}$, Traurigkeit bzw. Bedauern in fam. 14.2.2 (18) und $14.8(4)^{1201}$, Ärger in fam. 14.5.1 (4), Angst und Sorge in fam. 14.13 (2), 14.18 .2 (8) und $14.19(3)^{1202}$. Auch in fam. 14.2.3 (26) und fam. 14.12 (5) sind - neben einer direktiven Komponente ${ }^{1203}$ - Anklänge an Gefühle wie Traurigkeit oder Unzufriedenheit bzw. Angst zu erkennen. In all diesen Fällen überwiegt aber m. E. die Assertivität, weshalb ich nicht von indirekten (expressiven oder direktiven) Sprechakten ausgehe.

Konfirmativa und Assentiva

In fam. 14 lassen sich nur wenige Äußerungen sicher als reaktive Assertiva bestimmen, da in den meisten Fällen unklar bleiben muss, inwieweit sich Cicero tatsächlich auf eine entsprechende Kommunikation im Vorfeld bezieht. ${ }^{1204}$ Als Beispiele für reaktiv-akzeptative Assertiva können aber mit einiger Wahrscheinlichkeit folgende Sprechakte aus der Gruppe der Konfirmativa bzw. Assentiva gelten:

\footnotetext{
1198 Vgl. a. N. 1194 zu Ähnlichkeiten von fam. 14.14.2 (16) und 14.7.3 (17) mit Sprechakten des Typs BRIEF ERÖFFNEN bzW. GUNST ERWEISEN.

1199 In fam. 14.5.1 (6) wird Ciceros Bewunderung für Acastus, die er dann in 14.5 .1 (7) klarer äußert, bereits angedeutet.

1200 Mit fam. 14.11 (3) beruhigt Cicero zugleich seine Frau, die sich sonst Sorgen um den Verbleib ihrer Tochter machen könnte. Dies gilt im Übrigen auch für fam. 14.15 (7).

1201 Vgl. N. 1196.

1202 Der erste Teil von fam. 14.19 (3) (de qua nihil est quod ad te plura scribam) weist auch eine gewisse Nähe zum kommissiven Untermuster ABSICHT BEKUNDEN auf.

1203 So ERBITTET Cicero mit seinen Äußerungen bis zu einem gewissen Grad RAT. Im Falle von fam. 14.12 (5) könnte man evtl. auch von einer KOOPERATIONSFRAGE ausgehen oder sogar von einer BITTE: Cicero BITTET seine Frau, sich selbst zu überlegen, wie sie ihm helfen könnte, und dann ggf. entsprechend aktiv zu werden. Vgl. a. N. 1195.

${ }^{1204}$ Vgl. a. PINKSTER 2015, 368ff. („Responses“), bes. ebd., 371ff. und ebd., 376.
} 


\begin{tabular}{|c|c|}
\hline \multicolumn{2}{|l|}{ BESTÄTIGEN } \\
\hline fam. 14.3.1 (2): & Accepi ab Aristocrito tris epistulas \\
\hline fam. 14.5.1 (8): & accepi tuas litteras \\
\hline fam. 14.5.1 (9): & $\begin{array}{l}\text { [quibus intellexi te vereri ne superiores mihi redditae non essent.] } \\
\text { omnes sunt redditae }\end{array}$ \\
\hline \multicolumn{2}{|l|}{ ZUGEBEN } \\
\hline fam. 14.2.1 (3): & nisi si quis ad me plura scripsit \\
\hline fam. 14.4.1 (2): & Ego minus saepe do ad vos litteras quam possum \\
\hline \multicolumn{2}{|l|}{ ZUSTIMMEN } \\
\hline fam. $14.19(4):$ & [quod me propius vultis accedere,] video ita esse faciendum \\
\hline
\end{tabular}

Abbildung 51: Reaktiv-akzeptative Assertiva: Konfirmativa und Assentiva

In fam. 14.5.1 (9) und 14.19 (4) zitiert Cicero die Äußerungen Terentias, auf welche er referiert, während in den anderen Sprechakten eine solche Bezugnahme nur vermutet werden kann. So ist davon auszugehen, dass Terentia generell eine BESTÄTIGUNG über den Erhalt ihrer Briefe erwartet, wie er sie nicht nur in fam. 14.5.1 (9), sondern eben auch in 14.3.1 (2) und 14.5.1 (8) gibt $^{1205}$; und sie wird sich sicherlich auch schon öfter darüber beschwert haben, dass Cicero $\mathrm{ihr}$ - im Gegensatz zu anderen - nur selten und zu kurze Briefe schreibt, was er in der Folge manchmal - wie in fam. 14.2.1 (3) und 14.4.1 (2) - notgedrungen ZUGEBEN (und BEGRÜNDEN) muss. ${ }^{1206}$ Fam. 14.2.1 (10) und 14.3.1 (6) lassen ebenfalls Anklänge an das Untermuster ZUGEBEN erkennen, insofern Cicero mit ihnen indirekt ZUGIBT, feige gewesen zu sein und seine Pflichten gegenüber Familie bzw. Staat nicht erfüllt zu haben. Dominant ist in beiden Fällen jedoch die expressive Handlungsfunktion (FLUCHEN bzw. SICH ENTSCHULDIGEN). ${ }^{1207}$

Das Untermuster ZUSTIMMEN gehört ebenfalls zu den akzeptativen Assertiva, bei denen der ausgedrückte Inhalt positiv bewertet wird. Im Unterschied zu den Konfirmativa BESTÄTIGEN und ZUGEBEN, mit denen „Sp2 Sp1 zu überzeugen [versucht], daß er von der Wahrheit der durch Sp1 ausgedrückten Proposition überzeugt ist “1208, ist Sp2 beim assentiven Untermuster ZUSTIMMEN „dagegen lediglich bestrebt, Sp1 davon in Kenntnis zu setzen, daß er (Sp2) im schwachen Sinne glaubt, daß die Proposition wahr ist. "1209 In fam. 14.19 (4) STIMMT Cicero seiner Frau ZU, dass er ihr entgegenreisen sollte, BEGRÜNDET allerdings im Folgenden, warum

\footnotetext{
1205 Die Konfirmativa sind insofern leicht expressiv gefärbt, als Cicero damit auch emotional beruhigend auf Terentia einwirkt. Es werden allerdings keine Gefühle des Sprechers ausgedrückt, wie dies für die Expressiva kennzeichnend ist, auch wenn Cicero Freude über die Briefe seiner Frau empfinden mag. Zu fam. 14.5.1 (8) und (9) vgl. a. Kap. 2.1.2.

${ }^{1206}$ Zu fam. 14.2.1 (3) vgl. a. Kap. 2.1.3. Zu den Sprechakten des Typs BEGRÜNDEN vgl. den Abschnitt zu den „Argumentativa“ ab S. 298.

1207 Vgl. die Kap. zu den „Expressiva mit beidseitiger Aversion“ (ab S. 361) und den „Expressiva mit Sprecheraversion“ (ab S. 368).

1208 KoHL UND KRANZ 1992, 10. Vgl. Kap. 2.1.2, wo auch auf die generelle Unangemessenheit der Annahme eines Untermusters BEJAHEN im Lateinischen eingegangen wird, und Kap. 2.1.3.

${ }^{1209}$ Ebd., 10. Vgl. a. RoLf 1983, 181: „H bringt mit einem assentiven Kommunikationsversuch auf eine zuvor von $S$ thematisierte Proposition $p$ hin zum Ausdruck, daß er $(H)$ (ebenfalls) glaubt ${ }_{\alpha}$, daß p. ZUSTIMMEN und BEIPFLICHTEN unterscheiden sich hinsichtlich der ,Qualität' der Gründe, die H für sein Handeln hat. Als charakteristische Handlungsbedingung für ZUSTIMMEN ist anzusehen, daß H gute Gründe dafür hat, zu glauben $\alpha$, daß p; hingegen gilt als charakteristische Handlungsbedingung für BEIPFLICHTEN, daß H keine Gründe (Anhaltspunkte) hat, zu glauben ${ }_{\alpha}$, daß nicht-p [...]. “ Zum tiefgestellten $\alpha$ vgl. N. 1628.
} 
ihm dies bislang nicht möglich (gewesen) sei. ${ }^{1210}$ Mit fam. 14.16 (5) dagegen STIMMT Cicero zwar einer Klage Terentias über Volumnia ZU; es dominiert jedoch das expressive Untermuster BEDAUERN BEKUNDEN. ${ }^{1211}$

Als charakteristisch für die akzeptativen Assertiva kann lediglich die gelegentliche explizite Referenz auf die vorangehende Kommunikation angesehen werden. Eine affirmative Partikel wie ita findet sich in den zitierten Beispielen nur in fam. 14.19 (4). ${ }^{1212}$ Ob die notwendigen Handlungsbedingungen erfüllt sind, ist also in erster Linie auf der Grundlage eines entsprechenden Hintergrundwissens zu entscheiden.

\section{Detraktiva}

Lediglich zwei Illokutionen in fam. 14 können relativ zuverlässig den reaktiv-rejektiven Assertiva zugeordnet werden ${ }^{1213}$ :

\begin{tabular}{|ll|}
\hline ABSTREITEN & \\
fam. 14.1.4 (31): & de Quinto fratre, nihil ego te accusavi \\
fam. 14.2.1 (2): & $\quad$ Noli putare me ad quemquam longiores epistulas scribere
\end{tabular}

Abbildung 52: Reaktiv-rejektive Assertiva: Detraktiva

Mit fam. 14.1.4 (31) reagiert Cicero ganz offensichtlich auf einen vorangehenden opponierenden Sprechakt seiner Frau, in dem sie ihm unterstellt hat, ihr Vorwürfe hinsichtlich ihres Verhaltens gegenüber Quintus gemacht zu haben. ${ }^{1214}$ Er STREITET die Behauptung Terentias AB, unterstreicht dabei die Vehemenz seiner Äußerung durch das pointierte ego und die Verwendung von nihil. Der kommunikative Zusammenhang in fam. 14.2.1 (2), aus dem sich die Reaktivität des Sprechaktes ableitet, muss stärker aus dem weiteren Kontext rekonstruiert werden. ${ }^{1215}$ Obwohl die Äußerung explizit eine (verneinte) Aufforderung darstellt, handelt es sich um einen assertiven Sprechakt, mit dem Cicero augenscheinlich einen Vorwurf seiner Frau ABSTREITET, er habe anderen längere Briefe als ihr geschrieben. ${ }^{1216}$ Die Wendung noli putare zählt zu den auf den perlokutionären Akt zielenden Metadirektiva: „Du sollst nicht glauben, dass ..."1217

\section{Argumentativa}

Das einzige (potenziell) re-initiative Untermuster, das sich trotz der fehlenden Briefe Terentias in fam. 14 feststellen lässt, ist der insistent-argumentative Typ BEGRÜNDEN:

\section{BEGRÜNDEN}

fam. 14.1.4 (32): sed vos, cum praesertim tam pauci sitis, volui esse quam coniunctissimos.

fam.14.2.1 (4): cui puto rescribi oportere.

fam. 14.2.1 (5): nec enim habeo quid scribam

fam. 14.2.1 (6): nec hoc tempore quicquam difficilius facio.

\footnotetext{
1210 Vgl. den Abschnitt zu den „Argumentativa“ ab S. 298.

${ }^{1211}$ Vgl. das Kap. zu den „Expressiva mit beidseitiger Aversion“ (ab S. 361).

1212 Vgl. a. PINKSTER 2015, 309 zu Bestätigungspartikeln wie certe und profecto.

${ }^{1213}$ Vgl. a. ebd., 368ff. („Responses“), bes. ebd., 375f. und ebd., 377. Vgl. außerdem FerRI 2012.

1214 Vgl. a. den Abschnitt „Argumentativa“ ab S. 298 zu fam. 14.1.4 (32).

$1215 \mathrm{Vgl}$. Kap. 2.1.3.

1216 Vgl. Kap. 2.1.3.

${ }^{1217}$ Vgl. Kap. 2.1.3, bes. N. 959. Zu noli vgl. a. N. 1232.
} 


\begin{tabular}{|c|c|}
\hline fam. 14.4.4 (34): & primum tuis ita promissum est, te facturam esse ut quisque esset meritus \\
\hline fam. 14.4.4 (37): & $\begin{array}{l}\text { ceterorum servorum ea causa est ut, si res a nobis abisset, liberti nostri } \\
\text { essent, si obtinere potuissent; sin ad nos pertinerent, servirent, praeter- } \\
\text { quam oppido pauci. }\end{array}$ \\
\hline fam. $14.6(2):$ & Nec saepe est cui litteras demus \\
\hline fam. $14.6(3):$ & nec rem habemus ullam quam scribere velimus. \\
\hline fam. 14.12 (7): & et longum est iter \\
\hline fam. 14.12 (8): & et non tutum \\
\hline fam. 14.12 (9): & et non video quid prodesse possis si veneris \\
\hline fam. 14.17 (3): & $\begin{array}{l}\text { Si quid haberem quod ad te scriberem, facerem id et pluribus verbis et } \\
\text { saepius. }\end{array}$ \\
\hline fam. 14.19 (5): & et iam ante fecissem, sed me multa impediverunt \\
\hline fam. 14.19 (6): & quae ne nunc quidem expedita sunt \\
\hline
\end{tabular}

Abbildung 53: Re-initiativ-insistente Assertiva: Argumentativa

Dabei wird angenommen, dass Terentia Cicero gegenüber etwas behauptet oder vorgeschlagen hat, was dieser zunächst negiert bzw. ablehnt. Darauf folgt (insistent) eine argumentative Erläuterung bzw. BEGRÜNDUNG.

Häufig geht es, wie in fam. 14.2.1, 14.6 und 14.17, um Ciceros Schreibfaulheit, die er damit rechtfertigt, dass es nichts zu schreiben gebe (nec enim habeo quid scribam - nec rem habemus ullam quam scribere velimus - Si quid haberem quod ad te scriberem, facerem id ...) oder dass ihm kein Bote zur Verfügung stehe (Nec saepe est cui litteras demus). Außerdem verweist er (in fam. 14.2.1 (6)) auf seine schlechte psychische Verfassung (nec hoc tempore quicquam difficilius facio), wobei im Unterschied zu fam. 14.4.1 (3) und (4), die dem Untermuster JAMMERN zuzuordnen sind, tatsächlich eine weitgehend objektive Begründung im Vordergrund steht und nicht das Abreagieren negativer Gefühle. ${ }^{1218}$ Längere Briefe schreibe er im Übrigen nur ausnahmsweise in wenigen wichtigen Fällen (cui puto rescribi oportere)..$^{1219}$

Während in den genannten drei Schreiben eine Klage Terentias über zu seltene und zu kurze Briefe ihres Ehemannes nur (mit sehr großer Wahrscheinlichkeit) vermutet werden kann, ergibt sich die Reaktivität in den anderen Beispielen deutlicher aus dem Text: In fam. 14.1.4 (31) weist Cicero zunächst zurück, dass er Terentia in irgendeiner Weise Vorwürfe hinsichtlich ihres Verhaltens gegenüber Quintus gemacht habe ${ }^{1220}$, und BEGRÜNDET seinen offensichtlich zuvor geäußerten Wunsch, sie mögen (während der so schwierigen Zeit seines Exils) enger aneinander rücken (sed vos volui esse quam coniunctissimos), in 14.1.4 (32) damit, dass sie nur so wenige seien (cum praesertim tam pauci sitis). In fam. 14.4.4 reagiert er auf Terentias Sorge wegen einer möglichen Freilassung ihrer Sklaven, die er in 14.4.4 (33) zunächst generell für

\footnotetext{
${ }^{1218}$ Vgl. das Kap. „Expressiva mit Sprecheraversion“ ab S. 368. Vgl. a. den Abschnitt „Transmissiva“ ab S. 293 zu fam. 14.16 (4) und außerdem zu fam. 14.10 (5), wo Cicero noch einen anderen Grund dafür nennt, dass er sich gegenüber Terentia so kurz fasse, dass er nämlich bereits alles ausführlich an Pomponius geschrieben habe, bei dem seine Frau sich nach den Details erkundigen könne. Hiermit reagiert er jedoch nicht auf eine Äußerung Terentias, sondern es handelt sich um einen präsentativen Sprechakt (HINWEISEN).

${ }^{1219} \mathrm{Zu}$ fam. 14.2.1 (4) bis (6) vgl. a. Kap. 2.1.3.

${ }^{1220}$ Vgl. den Abschnitt „Detraktiva“ ab S. 298.
} 
unbegründet erklärt ${ }^{1221}$, was er dann in fam. 14.4 .4 (34) und (37) genauer erläutert. Ähnlich äußert er in fam. 14.12 (6) erst allgemein seine Ablehnung gegenüber einem Angebot seiner Frau, zu ihm zu kommen ${ }^{1222}$, und führt dann in 14.12 (7) bis (9) verschiedene Gründe an, weshalb dies nicht sinnvoll sei. In fam. 14.19 antwortet Cicero auf die Bitte Terentias, ihr entgegen zu reisen, indem er ihr in 14.19 (4) zunächst grundsätzlich zustimmt ${ }^{1223}$, dann in 14.19 (5) und (6) aber (wenn auch recht vage) BEGRÜNDET, warum dies bislang nicht möglich (gewesen) sei. ${ }^{1224}$

Oft ergibt sich die Argumentativität lediglich aus dem Kontext. Verschiedene Gründe können durch nec oder et syndetisch aneinandergereiht oder auch relativisch miteinander verbunden sein. In fam. 14.4.4 (34) wird eine Aufzählung mit primum begonnen, jedoch nur implizit, d. $h$. ohne folgendes tum o. Ä., fortgesetzt. Der Zusammenhang erhellt sich vielmehr aus dem Gegensatz tuis (erg. servis) vs. ceterorum (servorum) bzw. (liberti) nostri. In fam. 14.19 (5) wird die BEGRÜNDUNG mit sed eingeleitet, in 14.19 (6) auch mit ne ... quidem verdeutlicht. Von den kausalen Konnektoren i. e. S. finden sich in den hier angeführten Beispielen nur enim in fam. 14.2.1 (5) und cum (praesertim) in fam. 14.1.4 (32).

\section{Direktiva}

\section{Aufforderungshandlungen}

\section{Charakteristika im Überblick}

Wenngleich die antiken Rechtsverhältnisse von denen in unserer modernen Gesellschaft abweichen und dem pater familias im alten Rom eine weitgehende juristische Befehlsgewalt zustand, sollen Aufforderungshandlungen unter engen Familienmitgliedern im privaten Bereich dennoch als nicht-bindend betrachtet werden. ${ }^{1225}$ Solche Aufforderungshandlungen (ohne Fragehandlungen) weisen i. A. folgende Charakteristika auf ${ }^{1226}$ :

\footnotetext{
${ }^{1221}$ Dabei ist fam. 14.4.4 (33) seinerseits als Fortsetzung von 14.4.4 (32) zu sehen. Die sekundäre Illokution ut scribis legt nahe, dass Cicero auf bestimmte Aussagen in einem früheren Brief Terentias Bezug nimmt, wobei er sich zunächst zu ihrem Schwiegersohn Piso äußert und dann - mit expliziter, herausgestellter Themenbenennung - übergeht zu Ratschlägen im Umgang mit den Freigelassenen, um die Terentia in ihrem Schreiben augenscheinlich gebeten hat. Vgl. a. das Kap. „Weitere Expressiva mit beidseitiger Präferenz“ ab S. 349.

1222 Vgl. das Kap. „Direktiva mit beidseitiger Präferenz“ ab S. 311.

${ }^{1223}$ Vgl. den Abschnitt „Konfirmativa und Assentiva“ ab S. 296.

${ }^{1224}$ Möglicherweise könnte man fam. 14.19 (5) auch aufsplitten in zwei Illokutionen: eine, die (indirekt) Ablehnung ausdrückt (et iam ante fecissem), und eine, welche die Begründung dafür liefert (sed me multa impediverunt).

${ }^{1225}$ Vgl. S. 180. Dagegen kann man Aufforderungen eines Herrn an seine Sklaven, die Teil der familia i. w. S. sind, als bindend betrachten. Vgl. a. die von CABRILLANA 2016, 186ff. und UNCETA GómEZ 2014a, 29ff. angeführten Beispiele für „orders" bzw. „ordres“.

${ }^{1226}$ VgI. RISSELADA 1993, 78ff. („The expression of directive illocutionary force“: „,semantic properties“, ", sentence types in directives“, „lexical properties“) und ebd., 97ff. („grammatical expressions of directivity“) sowie ebd., 107ff. („imperative directives“), ebd., 165ff. („declarative directives“), ebd., 187ff. („interrogative directives“) bzw. ebd., 233ff. („directives expressed by lexical means“). Vgl. a. GARCEA 2005, 117ff. zu den sprachlichen Mitteln, mit denen Cicero in den Exilbriefen Direktivität vermittelt, sowie HALL 2009, 42ff. (mit Bezug auf fam. 13.42) und ebd., 204f. zu „requests“ (unter den Aspekten der „affiliative politeness“ und der „politeness of respect“).
} 


\begin{tabular}{|c|c|}
\hline \multicolumn{2}{|l|}{ Allgemeine Semantik } \\
\hline propositionale Einstellung & $\begin{array}{l}\text { motivational: } \\
\text { - Imperativ } \\
\text { - } \text { Indikativ Futur } \\
\text { - Gerundivum } \\
\text { volitive Verben wie nolle (noli) und velle (volo, velim) } \\
\text { hnmerkung: Bei den Direktiva mit Adressatenpräferenz findet sich } \\
\text { Untermudem eine evaluative Komponente, und zwar nicht nur beim }\end{array}$ \\
\hline Negation & $\begin{array}{l}\text { indirekte ANWEISUNG zur Unterlassung einer Handlung: } \\
\text { nihil est quod (+ Konjunktiv) }\end{array}$ \\
\hline \multirow[t]{4}{*}{ Lexik insgesamt } & $\begin{array}{l}\text { Metadirektiva }{ }^{1227} \text { : } \\
\text { - } \quad \text { curabis (ut fiat) } \\
\text { - fac (venias / extrudas) bzw. facies (ut sciam) }\end{array}$ \\
\hline & $\begin{array}{l}\text { Bittformeln: } \\
\text { - } \quad \text { obsecro te } \\
\text { - velim } \\
\text { - } \quad \text { si me amas } \\
\text { - } \quad \text { si tibi videbitur }\end{array}$ \\
\hline & $\begin{array}{l}\text { abschwächende motivationale und epistemische Verben } \\
\text { bzw. verbale Wendungen: } \\
\text { - posse (poteris uti, poteris cognoscere, ut posses scribe- } \\
\text { re) } \\
\text { - putare (puto, quod putabis) } \\
\text { videri (si tibi videbitur) }\end{array}$ \\
\hline & $\begin{array}{l}\text { Verben des (Nicht-)Handelns zur Bezeichnung der erwar- } \\
\text { teten Reaktion auf eine Aufforderung (v. a. bei den Direk- } \\
\text { tiva mit Sprecherpräferenz des Typs BITTEN): } \\
\text { - dicere (dicetis, dic), extrudere (fac extrudas), facere } \\
\text { (facies), instituere (velim instituatis), (re)mittere (mit- } \\
\text { tas, velim remittas / mittatis), perferre (litteras perfe- } \\
\text { rendas cures velim), (per)scribere (posses scribere, ve- } \\
\text { lim perscribas, scribite), prodire (velim prodeas), venire } \\
\text { (fac venias) } \\
\text { esse (vos istic esse volo), quiescere (quiesces), sinere } \\
\text { (sine sustinere) } \\
\text { Anmerkung: Einige der Verben können nur kontextbezogen und / } \\
\text { oder in einem (sehr) weiten Sinne als Verben des (praktischen) Han- } \\
\text { delns bezeichnet werden. Dies gilt auch bzw. noch mehr für Verben } \\
\text { wie z. B. adiuvare, confirmare, uti sowie (valetudini) servire und (va- } \\
\text { letudinem) vexare. }\end{array}$ \\
\hline
\end{tabular}

1227 Vgl. N. 959. Vgl. a. PINKSTER 2015, 349 und ebd., 351ff. Er nennt zudem velim und noli als Metadirektiva. 


\begin{tabular}{|c|c|}
\hline & $\begin{array}{l}\text { Verben des (Be-)Denkens und Urteilens zur Bezeichnung } \\
\text { der erwarteten Reaktion auf eine Aufforderung (v. a. bei } \\
\text { den Direktiva mit Adressatenpräferenz des Typs RATEN): } \\
\text { - cognoscere (poteris cognoscere) } \\
\text { - considerare (considerabitis, considerandum puto, } \\
\text { velim consideretis) } \\
\text { - consilium esse (vestrum consilium est) } \\
\text { - videre (videndum est, videte) }\end{array}$ \\
\hline & $\begin{array}{l}\text { verstärkende Adjektive und Adverbien: } \\
\text { - continuo } \\
\text { - } \text { cottidie } \\
\text { - } \text { etiam (atque etiam) } \\
\text { - } \text { optime } \\
\text { - saepissime } \\
\text { - } \text { statim } \\
\text { tamen }\end{array}$ \\
\hline & $\begin{array}{l}\text { abschwächende Adverbien: } \\
\text { - modo }\end{array}$ \\
\hline & $\begin{array}{l}\text { wertende Adjektive und Adverbien (bei Direktiva mit } \\
\text { Adressatenpräferenz des Typs RATEN): } \\
\text { - bene } \\
\text { - honeste } \\
\text { tuto }\end{array}$ \\
\hline & $\begin{array}{l}\text { verabsolutierende Pronomina bzw. Pronominaladjektive } \\
\text { zur Verstärkung von Sprechakten: } \\
\text { - } \text { omnis } \\
\text { - } \text { totus } \\
\text { - } \text { ceterus } \\
\text { - nullus } \\
\text { nihil }\end{array}$ \\
\hline & $\begin{array}{l}\text { häufige (affektive und intensivierende) Verwendung der } \\
\text { Personalpronomina der 2. Person, insbesondere auch im } \\
\text { Nominativ: } \\
\text { - tu und (noch öfter) vos } \\
\text { Anmerkung: Neben den verschiedenen Formen der Personalprono- } \\
\text { mina finden sich auch (in den Anreden: s. Extrapositionen) die Pos- } \\
\text { sessivpronomina mea bzw. meae sowie ipsae. }\end{array}$ \\
\hline besondere Stilmittel & $\begin{array}{l}\text { Erhöhung des Dringlichkeitsgrades der Aufforderungen } \\
\text { z. B. durch: } \\
\text { - Alliterationen }\end{array}$ \\
\hline
\end{tabular}




\begin{tabular}{|c|c|}
\hline & $\begin{array}{l}\text { - Anaphern und andere Wiederholungen (Wörter, Satz- } \\
\text { teile und Teilsätze) } \\
\text { - Asyndeta und Polysyndeta } \\
\text { Anmerkung: Die Stilmittel treten oft kombiniert auf, wie z. B. in fam. } \\
\text { 14.14.2 (11): cum Pomponio, cum Camillo, cum quibus vobis videbitur } \\
\text { und fam. } 14.20 \text { (7): ad victum et ad valetudinem. }\end{array}$ \\
\hline \multicolumn{2}{|l|}{ Morphosyntax } \\
\hline Wortbildung & $\begin{array}{l}\text { evaluativ-emotives Diminutiv (mit Bezug auf Tullia) zur } \\
\text { Intensivierung der Sprechakte: } \\
\text { - misellae } \\
\text { - Tulliola }\end{array}$ \\
\hline Komparation & $\begin{array}{l}\text { häufig verstärkende Superlative: } \\
\text { - } \text { carissimae } \\
\text { - } \text { diligentissime } \\
\text { - } \text { minime } \\
\text { - } \text { miserrimis } \\
\text { - } \text { (quam) primum } \\
\text { - } \text { (quame } \\
\text { (quam) saepissime }\end{array}$ \\
\hline Person & $\begin{array}{l}\text { 2. Person } \\
\text { Anmerkung: In einigen Fällen wird auch die 1. oder 3. Person verwen- } \\
\text { det, z. B. beim Gerundivum, bei volitiven Verben oder auch, wenn die } \\
\text { Aufforderung als Acl von einem Trägersatz (bspw. mit einem epistemi- } \\
\text { schen Verb wie putare) abhängig ist. Vgl. z. B. fam. } 14.18 .1 \text { (2): } \\
\text { considerandum vobis puto und fam. } 14.3 .5 \text { (30): te istic esse volo. } \\
\text { Manchmal wird das Prädikat aber auch ganz ausgelassen wie bei den } \\
\text { Finalsätzen in fam. } 14.20 \text {. }\end{array}$ \\
\hline Modus & $\begin{array}{l}\text { Imperativ und Konjunktiv, aber auch Indikativ } \\
\text { Anmerkung: Der Indikativ findet sich v. a. in Verbindung mit volitiven } \\
\text { Verben wie velle und allgemein bei Prädikaten im Futur. Vgl. aber } \\
\text { auch vides in fam. } 14.17 \text { (4). }\end{array}$ \\
\hline Tempus & $\begin{array}{l}\text { Präsens und Futur } \\
\text { Anmerkung: Andere Tempora finden sich nur in wenigen speziellen } \\
\text { Fällen, wie z. B., bedingt durch die consecutio temporum, das Imper- } \\
\text { fekt in fam. 14.3.4 (24). }\end{array}$ \\
\hline \multicolumn{2}{|l|}{ Syntax } \\
\hline Satzart & $\begin{array}{l}\text { Aufforderungssätze und Aussagesätze } \\
\text { Anmerkung: Aussagesätze finden sich in Verbindung mit volitiven } \\
\text { Verben wie velle und allgemein bei Prädikaten im Futur (vgl. Modus). }\end{array}$ \\
\hline Aufzählungen & $\begin{array}{l}\text { disjunktive Aufzählungen von (Handlungs-)Alternativen: } \\
\text { - fam. } 14.5 .2 \text { (21): Pomponius aut Camillus } \\
\text { - fam. 14.18.1 (2): Romaene sitis an mecum an aliquo } \\
\text { tuto loco }\end{array}$ \\
\hline
\end{tabular}




\begin{tabular}{|c|c|}
\hline & $\begin{array}{l}\text { additive (syndetische und asyndetische) Aufzählungen } \\
\text { von Satzteilen und Teilsätzen mit verstärkender Wirkung: } \\
\text { - } \text { fam. } 14.3 .4 \text { (24): initia rerum et rationem totius negoti } \\
\text { - } \text { fam. } 14.14 .2 \text { (11): cum Pomponio, cum Camillo, cum } \\
\text { - } \text { quibus vobis videbitur } \\
\text { - fam. } 14.17 \text { (5): ex Lepta et Trebatio } \\
\text { - } \text { fam. } 14.18 .2 \text { (11): vobiscum et cum amicis } \\
\text { - } \text { fam. } 14.20 \text { (7): ad victum et ad valetudinem } \\
\text { - fam. } 14.21 \text { (4): res tempusque } \\
\text { - fam. } 14.4 .3 \text { (21): eam [spem] confirmes et rem adiuves } \\
\text { - fam. } 14.21 \text { (4): provideas atque administres } \\
\text { - fam. } 14.1 .6 \text { (45): quid agatur et vos quid agatis. } \\
\text { - fam. } 14.2 .3 \text { (35): quod speras et quod agis } \\
\text { - fam. } 14.8 \text { (7): si quid opus erit, si quid acciderit novi, } \\
\text { - fam. } 14.14 .2 \text { (15): et vos quid agatis et quid istic agatur }\end{array}$ \\
\hline Objektsätze & $\begin{array}{l}\text { indirekte Fragesätze (v. a. bei den Direktiva mit Adressa- } \\
\text { tenpräferenz des Typs RATEN): } \\
\text { - fam. } 14.14 .1 \text { (7): vestri similes feminae sintne Romae. } \\
\text { - fam. 14.18.1 (2): quid faciatis. Romaene sitis an mecum } \\
\text { an aliquo tuto loco. } \\
\text { - fam. } 14.18 .2 \text { (9): quid aliae faciant isto loco feminae } \\
\text { Anmerkung: Indirekte Fragesätze finden sich auch, wenngleich selte- } \\
\text { ner, bei den anderen Sprechakttypen, wie z. B. in fam. 14.13: totum } \\
\text { iudicabis quale sit (ANWEISEN) bzw. fam. 14.1.6 (45): quid agatur et } \\
\text { vos quid agatis und 14.17 (4): quae sint negotia (BITEN). }\end{array}$ \\
\hline \multirow[t]{2}{*}{$\begin{array}{l}\text { adverbiale Bestimmungen und } \\
\text { Adverbialsätze }\end{array}$} & $\begin{array}{l}\text { finale Bestimmungen und Finalsätze (zur inhaltlichen } \\
\text { Spezifizierung und Verstärkung): } \\
\text { - } \text { fam. } 14.20 \text { (7): ad victum et ad valetudinem necessaria } \\
\text { - } \text { fam. } 14.1 .6 \text { (45): ut sciam } \\
\text { - } \text { fam. } 14.2 .3 \text { (35): ut id consequamur } \\
\text { tionem totius negoti posses scribere } \\
\text { - } \text { fam. } 14.5 .2 \text { (21): ut Pomponius aut Camillus nostrum } \\
\text { negotium curet } \\
\text { - fam. } 14.5 .2 \text { (25): ut hoc ita fiat } \\
\text { - fam. } 14.14 .1 \text { (8): ut honeste vos esse possitis } \\
\text { fam. } 14.18 .2 \text { (12): ut propugnacula et prae(si)dium } \\
\text { - } \text { fam. } 14.18 .2 \text { (13): ut cottidie aliquas a vobis litteras } \\
\text { accipiam } \\
\text { - fam. } 14.20 \text { (3): ibi ut sint omnia parata } \\
\text { fam. } 14.20 \text { (6): ut sit }\end{array}$ \\
\hline & $\begin{array}{l}\text { Konditionalsätze (zur genaueren Anleitung und Verstär- } \\
\text { kung, besonders bei den Direktiva mit Sprecherpräferenz } \\
\text { des Typs BITTEN): }\end{array}$ \\
\hline
\end{tabular}




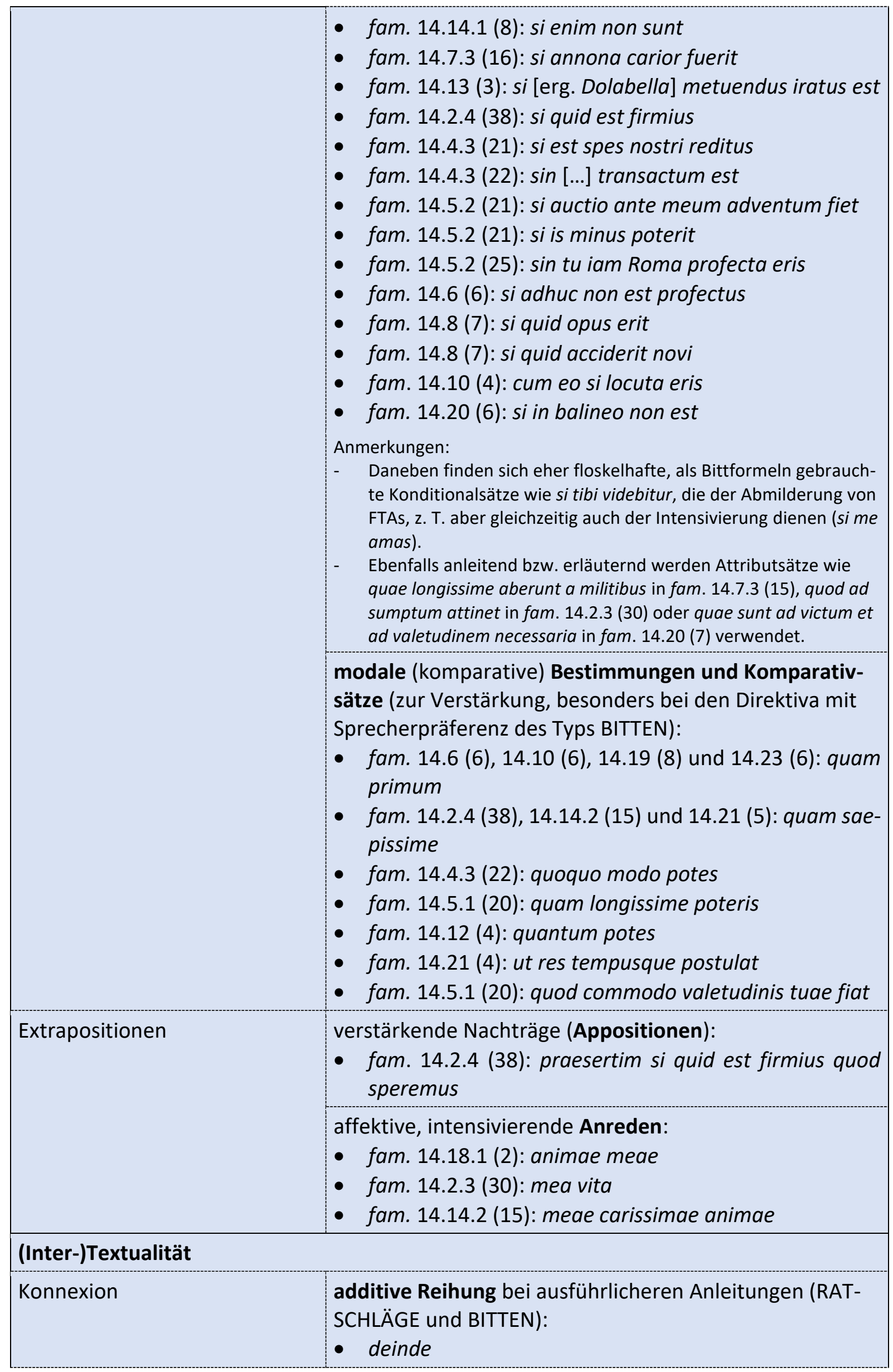




\begin{tabular}{|c|c|}
\hline & $\begin{array}{l}\text { - reliquum est } \\
\text { - item }\end{array}$ \\
\hline & $\begin{array}{l}\text { kausaler Anschluss an eine vorangehende Begründung, } \\
\text { auf der die Aufforderung beruht ( } \rightarrow \text { Abmilderung des } \\
\text { FTAs): } \\
\text { - fam. 14.2.3 (35): quare, ut id quod speras et quod agis } \\
\text { consequamur, servi valetudini. } \\
\text { fam. 14.3.4 (24): ea re ad te statim Aristocritum misi } \\
\text { ut ad me continuo initia rerum et rationem totius ne- } \\
\text { goti posses scribere } \\
\text { - fam. } 14.12 \text { (4): qua re, quantum potes, adiuva } \\
\text { fam. } 14.14 .1 \text { (8): si [erg. vestri similes feminae Romae] } \\
\text { enim non sunt, videndum est ut honeste vos esse } \\
\text { possitis. } \\
\text { Anmerkungen: } \\
\text { In fam. } 14.3 .4 \text { (24) stellt ea re einen kausalen Bezug sowohl zum } \\
\text { vorangehenden Satz als auch zum nachfolgenden Finalsatz her. } \\
\text { Manchmal folgt die Begründung einer Aufforderung auch nach } \\
\text { und wird dann mit nam eingeleitet, wie z. B. in fam. 14.2.3 (32) / } \\
\text { (33). }\end{array}$ \\
\hline $\begin{array}{l}\text { Referenz auf vorangehende } \\
\text { Kommunikation }\end{array}$ & $\begin{array}{l}\text { erwartbar v. a. bei den Direktiva mit Adressatenpräferenz } \\
\text { (RATEN), z. T. auch bei den Direktiva mit beidseitiger Prä- } \\
\text { ferenz (ANWEISEN) } \\
\text { Anmerkung: Der Bezug erfolgt in fam. } 14 \text { nicht explizit, sondern ist } \\
\text { aus dem Kontext zu erschließen. Lediglich in fam. } 14.3 .5(30) \text {, also im } \\
\text { Zusammenhang mit einer BITTE, wird eine Äußerung Terentias zitiert: } \\
\text { Quod scribis te, si velim, ad me venturam, ego vero ... }\end{array}$ \\
\hline
\end{tabular}

Abbildung 54: Charakteristika direktiver Sprechakte: (nicht-bindende) Aufforderungshandlungen

Kennzeichnend für direktive Aufforderungshandlungen ist eine motivationale Einstellung, die auf verschiedene Weise zum Ausdruck gebracht werden kann, ohne dass mit einer bestimmten Art der Formulierung schon eindeutig auf den Dringlichkeitsgrad geschlossen werden könnte. ${ }^{1228}$ Typisch sind Aufforderungssätze im Imperativ und Konjunktiv („imperative directives“). ${ }^{1229}$ Außerdem begegnen häufiger Aussagesätze im Indikativ, meistens im Futur, seltener in Form der gerundivischen coniugatio periphrastica („declarative directives“). ${ }^{1230}$ Die Direktivität einer Äußerung kann auch - meistens in Aussage-, sehr viel seltener in Imperativ-

1228 So unterscheiden sich im Lateinischen Imperativ und Konjunktiv nicht im Grad der Höflichkeit. Ein bloßer Imperativ wird nicht als so rüde empfunden wie bspw. im Englischen: Vgl. z. B. DICKEY 2016, 206f. und DICKEY 2012b, 318 bzw. RISSELADA 1993, 138, ebd., 155 und ebd., 163. Vgl. dagegen ROESCH 2004, 145, die den Imperativ als „mode très agressif“ bezeichnet, und MUÑOz MARTín 1991, 350, die andere Formulierungen (z. B. im Konjunktiv und Indikativ Futur) für „más corteses“ hält. Nach PINKSTER 2015, 351 N. 78 wird auch in antiken Quellen der Imperativ als „more binding“ empfunden.

${ }^{1229}$ Vgl. RISSELADA 1993, 107ff.

1230 Vgl. ebd., 165ff. PINKSTER 2015, 311f. betrachtet Äußerungen mit „,, prescriptive’ future tense expressions“ als indirekte Direktiva. Der direkte Sprechakt sei assertiv. Er meint allerdings auch, dass „the use of the future [...] can be explained on the basis of the semantic value of that tense." In ebd., 314 geht er außerdem auf das direktiv gebrauchte unpersönliche Passiv (in Verbindung mit recte und utiliter) ein. Dieses spielt in fam. 14 aber ebenso 
und (noch seltener bzw. in fam. 14 gar nicht) in Fragesätzen - durch verschiedene lexikalische Mittel vermittelt werden („lexical directives“). ${ }^{1231}$ Vorherrschend sind dabei Modalausdrücke, insbesondere volitive Verben wie velle, manchmal im Indikativ (wie in fam. 14.3.5 (30): te istic esse volo), v. a. aber als konjunktivische Bittformel velim. Nolle tritt nur als Teil des negierten Imperativs auf, wie z. B. in fam. 14.2.3 (32): noli vexare. Bei noli putare in fam. 14.2.1 (2) handelt es sich dabei noch nicht einmal um eine direktive, sondern um eine metadirektive assertive Sprechhandlung. ${ }^{1232}$ Sogenannte „non-modal evaluating expressions“ spielen kaum eine Rolle. Cicero verwendet in fam. 14 zwar z. B. cupere, aber nicht direktiv, sondern nur expressiv und kommissiv. ${ }^{1233}$ Die Wendung nihil est quod ${ }^{1234}$ findet sich hingegen auch im Zusammenhang mit einer Aufforderungshandlung.

Im Lateinischen existieren zahlreiche Verben, bei denen grundsätzlich eine (explizit) performative Verwendungsweise denkbar ist. ${ }^{1235}$ Viele werden als konventionelle Bittformel $\boldsymbol{n}^{1236}$ gebraucht, wie z. B. quaeso, rogo und peto, welche aber in fam. 14 nicht vorkommen, sowie

wenig eine Rolle wie der jussive Infinitiv, den Pinkster als weitere Möglichkeit zum Ausdruck eines direktiven Sprechaktes nennt (ebd., 358).

1231 Risselada unterscheidet „speech act expressions“, „modal expressions“ und „non-modal evaluating expressions", bemerkt dazu aber, dass diese Kategorien sich überschneiden und die Unterscheidung eher aus analytischen Gründen erfolgt. Dies gilt v. a. für die „modal expressions“ wie velle, nolle, malle, debere, posse, potin est?, oportet, opus est, necesse est auf der einen sowie die "non-modal evaluating expressions" wie erit tibi curae, mea/tua (magni) interest, tua refert, placet, censeo ut und mihi valde gratum erit auf der anderen Seite. Vgl. z. B. RISSELADA 1993, 239: „In fact, ,modal expressions' [...] and ,evaluating expressions' [...] are notions that do not necessarily exclude each other, because for instance expressing that one wants some state of affairs to be realized constitutes, in fact, an evaluation in terms of desirability. Nevertheless, the distinction is useful in so far that modal expressions often constitute, in other languages as well as in Latin, conventionalized expressions of directivity and therefore deserve a separate treatment." Vgl. a. ebd., 322f. Zu den "speech act expressions" vgl. ebd., 242ff., z. B. ebd., 242: „Speech act expressions are lexical expressions that explicitly refer to the speech act function of the utterance to which they belong. They do so by either explicitly naming the speech act that is being performed in terms of the speaker's illocutionary intentions [= performative Verben] or by specifying the perlocutionary effect that the utterance is intended to have on the addressee [= Metadirektiva]."

1232 Vgl. ebd., 279ff. Vgl. a. BOLKESTEIN 1980. In fam. 14 wird lediglich velim häufiger verwendet, vielfach mit abhängigem Finalsatz (häufig mit Ellipse von ut). Zu volo und velim vgl. a. Risselada 281ff. Zu noli vgl. ebd., $296 \mathrm{ff}$. Vgl. a. PINKSTER 2015, 352.

${ }^{1233}$ Nämlich in fam. 14.5.1 (14) bzw. 14.4 .1 (7). Vgl. die Kap. zu den „Kommissiva“ (ab S. 319) bzw. „Expressiva“ (ab S. 326). VgI. a. RISSELADA 1993, 324f.

1234 Vgl. RISSELADA 1993, 325f. Vgl. a. das Kap. „Direktiva mit beidseitiger Präferenz“ ab S. 311.

1235 Vgl. z. B. ebd., 82f. und ebd., 249 bzw. RISSELADA 1989, 372. Risselada unterscheidet dabei folgende Gruppen von Direktiva: „order" (imperare, iubere, mandare, flagitare, exigere, postulare, poscere), „request" (rogare, quaesere, petere, contendere), „supplication“ (precari, supplicare, obsecrare, obtestari, orare), „advice“ (hortari und adhortari, monere und admonere, praecipere, suadere), „invitation“ (invitare, vocare) und „permission“ (permittere, licet, sinere). Tatsächlich werden die genannten Verben aber relativ selten, in fam. 14 nahezu überhaupt nicht bzw. nur als „illocutionary parenthetical“ (obsecro te: vgl. N. 1237), performativ verwendet. Vgl. a. RISSELADA 1993, 248 sowie ebd., 250ff. zu den Gründen für „the uneven distribution of the use of performatives over the various types of directives". Sie führt u. a. die unterschiedliche Notwendigkeit zur Explizitheit der Äußerungen, Höflichkeitsaspekte, den Wunsch nach stärkerer Betonung und die Möglichkeit zu Ergänzungen (Modifizierung, Rechtfertigung, Kontexteinbindung) an.

${ }^{1236}$ Im Lateinischen gibt es nicht nur ein bestimmtes Wort für ,bitte', sondern es werden verschiedene Ausdrücke benutzt, besonders häufig velim, rogo, peto und quaeso: Vgl. z. B. DICKEY 2012b, 327. Zu einigen selteneren Wendungen vgl. a. DICKEY 2012a, 732 N. 4. Vgl. außerdem DICKEY 2016, 207ff.; PINKSTER 2015, 353ff. und HOFMANN 1978, 125ff. Zur Konventionalität bzw. zur historischen Entwicklung der Bittformeln vgl. a. RISSELADA 1993, 95; MOLINELLI 2016 sowie GHEZZI UND MOLINELLI 2014a. 
die Wendung obsecro te, die meist als (parenthetische) Extraposition ${ }^{1237}$ begegnet, wie $\mathrm{z}$. B. in fam. 14.2.3 (30). Als Gegenstück zu den Bittformeln, zu denen auch das bereits erwähnte velim und Wendungen wie si me amas und si tibi videbitur gehören, können Metadirektiva betrachtet werden, wie z. B. cura(bis) und fac(ies), die bei stärkeren Aufforderungen (ANWEISUNGEN und BITTEN) genutzt werden. ${ }^{1238}$

Die Aufforderungsfunktion wird i. d. R. explizit (in Form von primären Sprechakten) signalisiert. Indirekte Sprechakte sind relativ selten, wenn man nicht alle „lexical directives“ oder gar alle Aussagesätze dazu zählen möchte. ${ }^{1239}$ Die wenigen tatsächlich festzustellenden indirekten Sprechakte dienen darüber hinaus eher selten der Abmilderung von FTAs. Diese erfolgt auf andere Weise ${ }^{1240}$ : Besonders bei den Direktiva mit Adressatenpräferenz kann mit den (durch Verwendung des Futurs z. T. noch weiter abgeschwächten) Verben videri und posse sowie mit der Darstellung verschiedener Handlungsalternativen (z. B. durch disjunktive Aufzählungen) die Entscheidungsfreiheit des Adressaten betont werden. Ungewissheit ausdrückende (epistemische) Verben wie putare und Adverbien wie modo verringern ebenfalls eine potenzielle Gesichtsbedrohung. ${ }^{1241}$

Das Wohlwollen des Adressaten wird allgemein dadurch befördert, dass mit verschiedenen Mitteln emotionale Nähe hergestellt wird, z. B. durch (individualisierende) affektive Anreden und Verwendung von Personal- und Possessivpronomina der 2. Person, manchmal auch - zur Herstellung eines Gemeinschaftsgefühls - der 1. Person Plural. ${ }^{1242}$ Die Akzeptanz kann durch eine Begründung erhöht werden, an die eine Aufforderung, z. B. - wie in fam. 14.2.3 (35) -

\footnotetext{
${ }^{1237}$ Risselada spricht in diesem Zusammenhang von „illocutionary parentheticals“, welche sie folgendermaßen definiert: „,...] illocutionary parentheticals can be characterized as expressions that are semantically closely connected with the sentence they ,belong' to, but stand outside the sentence construction proper." (RISSELADA 1989, 369). Dabei ist die Verwendung von obsecro nicht auf die Direktiva beschränkt, sondern dient auch der Intensivierung anderer (adressatenorientierter) Sprechakte: Vgl. ebd., 375f. Vgl. a. UNCETA GóMEZ 2009a, 250ff. und MüLLER 1997, 100f. (zu obsecro te in der römischen Komödie). Vgl. außerdem das Kap. „Expressiva mit Sprecheraversion" ab S. 368 zu obsecro te in fam. 14.1.5 (35).

1238 Vgl. a. RISSELADA 1993, 327. Zum verstärkenden Charakter von fac vgl. außerdem Garcea 2005, 118 N. 81.

1239 Vgl. z. B. RISSELADA 1993, 67ff. und ebd., 86ff. sowie ebd., 238. Vgl. außerdem PINKSTER 2015, 311ff., der grundsätzlich alle direktiv aufzufassenden Deklarativsätze zunächst einmal als indirekte Direktiva klassifiziert, also auch Aussagesätze im Indikativ Futur, mit gerundivischer coniugatio periphrastica, mit deontischen Verben sowie unpersönlichem Passiv. Zu den Aussagesätzen im Indikativ Futur vgl. aber auch ebd., 311f. bzw. N. 1230. Er nennt des Weiteren noch folgende drei Fälle: „A first type is where the declarative sentence contains an expression that is typical of directive utterances, such as opsecro [...]." (ebd., 311), wie z. B. in PLAUT. Mil. 1406: Oiei, satis sum verberatus, opsecro. Ein zweiter Typ sei "typical of military language“, wie z. B. TRAG. inc. 34: Itis, paratis arma quam primum, viri.: „The directive interpretation of these declarative sentences is usually based on the presence of second person verb forms [...].“ (ebd., 311). Ein dritter Typ finde sich z. B. in didaktischen Werken, in denen das Präsens die älteren (futurischen) Imperative auf -to ersetze, wie z. B. in VARRO rust. 2.2.15: In nutricatu, cum parere coeperunt, inigunt in stabula... (ebd., 313).

1240 Vgl. S. 280. Vgl. a. CABRILLANA 2016, 208ff.

1241 Vgl. z. B. WhITE 2010, 122; GARCEA 2005, 129 und ROESCH 2004, 146 (s. N. 1244). Zur Abmilderung von Bitten durch „verbi di stato mentale“ (wie credo) vgl. a. GARCEA 2002, 215f. Zu modo vgl. z. B. RISSELADA 1993, 86. VgI. a. PINKSTER 2015, 355.

1242 Vgl. z. B. WÜEST 2011, 219f. zu Anreden als „kooperationssichernden Akten“; ROESCH 2004, 147 zu affektiven Ausdrücken; GARCEA 2002, 215f. zu „fatismi“ (z. B. pluralis sociativus, dativus ethicus) im Sinne positiver Höflichkeit zur Förderung der „solidarietà“und HoFMANN 1978, 135ff. („Sprachliche Mittel im Dienste der captatio benevolentiae“) sowie auch ebd., 144ff. („Euphemismus und verwandte Erscheinungen“). Zu tu vgl. außerdem PINKSTER 2015, 353.
} 
mit qua re, anknüpft oder die ihr, z. B. - wie in fam. 14.2.3 (33) - eingeleitet mit nam, nachfolgt. ${ }^{1243}$ Konditionalsätze dienen (besonders bei den Direktiva mit Sprecherpräferenz des Typs BITTEN) meist der genaueren Anleitung und Verstärkung, können aber auch abschwächend sein, wie die eben zitierte Wendung si tibi videbitur in fam. 14.7 .3 (15). ${ }^{1244}$ Ein floskelhafter Einschub wie si me amas in fam. 14.2.3 (32) dagegen verstärkt eher den Druck auf den Adressaten. Dies gilt so ähnlich auch für weitere Bittformeln und andere sprachliche Mittel, mit denen Affektivität und Akzeptanz einer Äußerung gesteigert werden: Einerseits wird ein FTA abgeschwächt, andererseits die Eindringlichkeit einer Aufforderung erhöht. ${ }^{1245}$

Weitere Möglichkeiten zur Verstärkung sind zusätzliche Gerundiva, modale (komparative) Bestimmungen und Komparativsätze (besonders bei den Direktiva mit Sprecherpräferenz des Typs BITTEN), wie z. B. quoquo modo potes in fam. $14.4 .3(22)^{1246}$, und v. a. finale Bestimmungen und Finalsätze, außerdem viele additive (syndetische und asyndetische) Aufzählungen von Satzteilen und Teilsätzen (bei ausführlicheren Anleitungen in RATSCHLÄGEN und BITTEN) sowie Nachträge, die z. B. mit praesertim eingeleitet werden. Darüber hinaus können u. a. Alliterationen, Asyndeta, Polysyndeta, Anaphern und andere Wiederholungen, Superlative und verschiedene Arten von Adjektiven und Adverbien eine Aufforderung intensivieren, wobei die sprachlich-stilistischen Mittel oft miteinander kombiniert werden. ${ }^{1247}$

\section{Direktiva mit Adressatenpräferenz}

Mit Ausnahme von fam. 14.17 (5) stammen die folgenden Beispiele aus Briefen, die im Jahr 49 v. Chr. zu Beginn des Bürgerkriegs entstanden sind. Es geht darum, ob Terentia in Rom bleiben soll oder nicht. Da diese Frage vornehmlich ihr eigenes Wohl (und das Tullias) betrifft, ist von einer Dominanz der Adressatenpräferenz auszugehen, wobei die Interessen von Eheleuten häufig nicht klar voneinander zu trennen sind und in den vorliegenden Fällen im Hintergrund oft gemeinsame Belange eine Rolle spielen, wie z. B. in Bezug auf den Schutz der ehelichen Güter, die in Rom zurückgelassen werden müssen:

\begin{tabular}{|ll|}
\hline RATEN & \\
fam. 14.7.3 (15): & $\begin{array}{l}\text { deinde, si tibi videbitur, villis iis utere quae longissime aberunt a militi- } \\
\text { bus. }\end{array}$ \\
fam. 14.7.3 (16): & $\begin{array}{l}\text { fundo Arpinati bene poteris uti cum familia urbana si annona carior } \\
\text { fuerit. }\end{array}$ \\
fam. 14.14.1 (3): & Vestrum iam consilium est, non solum meum, quid sit vobis faciendum. \\
fam. 14.14.1 (7): & $\begin{array}{l}\text { reliquum est, quod ipsae optime considerabitis, vestrimiles feminae } \\
\text { sintne Romae. }\end{array}$ \\
fam. 14.14.1 (8): & si enim non sunt, videndum est ut honeste vos esse possitis.
\end{tabular}

\footnotetext{
1243 Vgl. RisSELADA 1993, 327 und ebd., 250ff. sowie Muñoz MARTín 1991, 350. Vgl. a. RoESCH 2004, 145.

${ }^{1244}$ Vgl. ebd., 146: „Pour modérer l'impact d'une demande, un [...] procédé consiste à introduire des restrictions, en même temps qu'on formule la demande, pour souligner que c'est la décision de l'autre qui prévaudra et que l'affaire repose entre ses mains; cela permet de minimiser le FTA. De façon générale, les subordonnées conditionnelles permettent de relativiser la demande." Vgl. a. ebd., 152.

${ }^{1245}$ Vgl. S. 226 (einschl. N. 1034). Vgl. a. RISSELADA 1993, 254f. Zu den Unterschieden in der Verwendung verschiedener Bittformeln i. E. vgl. DICKEY 2012b, 318ff. und DICKEY 2012a. Vgl. außerdem ROESCH 2004, $145 f$.

${ }^{1246}$ Vgl. dagegen ebd., 146, die hierin „restrictions“ und damit Abschwächungen eines FTAs sieht.

1247 Die Analyse der sprachlich-stilistischen Mittel findet hier und in den übrigen Kapiteln zur Illokutionsklassifikation im Wesentlichen nur auf der Ebene der Einzeläußerungen statt.
} 


\begin{tabular}{|c|c|}
\hline ر & bitur, consideretis \\
\hline fam. & $\begin{array}{l}\text { ego autem quo modo sim affectus, ex Lepta et Trebatio poteris cognos- } \\
\text { cere. }\end{array}$ \\
\hline fam. & $\begin{array}{l}\text { Considerandum vobis etiam atque etiam, animae meae, diligenter puto } \\
\text { quid faciatis. Romaene sitis an mecum an aliquo tuto loco. id non solum } \\
\text { meum consilium est sed etiam vestrum. }\end{array}$ \\
\hline fam. 1 & vos videte quid aliae faciant isto loco feminae \\
\hline fam. & $\begin{array}{l}\text { id velim diligenter etiam atque etiam vobiscum et cum amicis conside- } \\
\text { retis. }\end{array}$ \\
\hline
\end{tabular}

Abbildung 55: Aufforderungshandlungen mit Adressatenpräferenz

Die Direktiva mit Adressatenpräferenz sind in fam. 14 lediglich durch das Untermuster RATEN $^{1248}$ vertreten. Es geht in den zitierten Beispielen um eher zwischenmenschliche und nicht um technische Angelegenheiten, abgesehen evtl. von fam. 14.7.3 (16), wo die Lebensmittelversorgung thematisiert wird, sodass man dort möglicherweise auch das Untermuster TIPP GEBEN in Erwägung ziehen könnte. Allerdings handelt es sich m. E. um ein praktisches Problem, das "schwieriger und komplizierter als bei einem TIP“1249 ist. Von EMPFEHLUNGEN, die eher auf allgemeinen Geschmacksurteilen beruhen und nicht wirklich nachvollziehbar zu begründen sind, kann man hingegen in keinem Fall sprechen. Im Übrigen sind Bewertungen aber prinzipiell mit allen Arten von RATSCHLÄGEN verbunden. So enthalten auch Direktiva des Typs RATEN häufiger wertende Adjektive und Adverbien, wie z. B. bene und honeste.

Bei Aufforderungen mit Adressatenpräferenz wird es sich meist um reaktive Sprechakte in Folge entsprechender Bitten (RAT ERBITTEN) handeln. Sie beziehen sich in fam. 14 sehr oft auf (dem praktischen Handeln vorangehende) Prozesse des (Be-)Denkens und Urteilens (cognoscere, considerare, consilium esse, iudicare, videre) und sind demgemäß häufiger verbunden mit indirekten Fragesätzen.

Im Allgemeinen sind sie milder formuliert als Aufforderungen mit beidseitiger Präferenz (ANWEISEN) und Sprecherpräferenz (BITTEN). ${ }^{1250}$ Sie werden z. B. abgeschwächt und eher indirekt formuliert, indem die vorgeschlagenen Handlungsweisen lediglich als Möglichkeit dargestellt werden (bene poteris uti, poteris cognoscere) ${ }^{1251}$, die nur unter bestimmten Voraussetzungen überhaupt in Betracht zu ziehen sind (si enim non sunt, si annona carior fuerit) und auch anderweitig begründet werden (quae longissime aberunt a militibus). Bisweilen schlägt Cicero mehrere Alternativen (Romaene sitis an mecum an aliquo tuto loco) vor. ${ }^{1252}$ Zudem betont er in einigen Fällen, dass die Entscheidung in Terentias eigenem Ermessen (si tibi videbitur, cum quibus vobis videbitur bzw. vestrum iam consilium est, non solum meum und id non solum

\footnotetext{
1248 Vgl. S. 225. Vgl. a. die Unterscheidung von „advice“ und „suggestion“ nach dem Verbindlichkeitsgrad einer (adressatenpräferierten) Aufforderung in RISSELADA 1993, 48. Vgl. außerdem die Beispiele (aus Plautus) in CABRILLANA 2016, $187 f$.

1249 HINDELANG 1978, 416.

1250 Vgl. a. WHITE 2010, 118ff. („The sensivity of advice“).

${ }^{1251}$ Vgl. a. die in fam. 14.15 (5) formulierte BITTE (s. das Kap. „Direktiva mit Sprecherpräferenz“ ab S. 313). Im Unterschied dazu liegt der Handlungsvollzug in fam. 14.17 (5) vorwiegend im Interesse Terentias, die sicherlich stets über Ciceros Verfassung im Bilde sein möchte.

1252 Vgl. a. PINKSTER 2015, 339ff. zu „Multiple questions“.
} 
meum consilium est sed etiam vestrum) ${ }^{1253}$ liege und äußert seine eigene Meinung nur sehr vorsichtig (puto).

Es werden sowohl der Imperativ (utere, videte) verwendet als auch der Konjunktiv mit velim (velim consideretis), der Indikativ Futur (poteris uti, poteris cognoscere, considerabitis) und das Gerundivum (videndum est, considerandum vobis puto). ${ }^{1254}$ Die Aufforderungshandlung wird direkt intensiviert, u. a. durch modal-evaluative Adverbialien, die z. T. (superlativisch oder iterativ) weiter verstärkt werden, wie z. B. diligenter (considerare), optime (considerare) und etiam atque etiam (considerare), oder - mit ähnlichen Mitteln - indirekt, also z. B. mit Superlativen (longissime) und Wiederholungen bzw. Anaphern. Manchmal treten noch weitere Stilmittel (Alliteration, Asyndeton, Chiasmus, Parallelismus u. a.) unterstützend hinzu, wie z. B. bei vobiscum et cum amicis und (noch deutlicher) cum Pomponio, cum Camillo, cum quibus vobis videbitur. Zugleich intensivierend und abschwächend wirken affektive Anreden wie animae meae.

\section{Direktiva mit beidseitiger Präferenz}

Eine beidseitige Präferenz ist anzunehmen, wenn es bspw. um die gemeinsamen Kinder, das gemeinsame Heim ${ }^{1255}$ oder überhaupt ein gemeinsam verfolgtes Ziel geht: Thema in fam. 14.13 ist die bevorstehende Scheidung Tullias von Dolabella. Fam. 14.18 bezieht sich auf Schutzmaßnahmen für das Haus in Rom. Fam. 14.2 betrifft das (finanzielle und gesundheitliche) Wohlergehen Terentias, das in engem Zusammenhang mit der Rückberufung Ciceros aus seinem Exil steht, an der letztlich beide Eheleute ein großes Interesse haben ${ }^{1256}$ :

\begin{tabular}{|c|c|}
\hline \\
\hline \multicolumn{2}{|l|}{$\begin{array}{l}\text { ANWEISEN } \\
\text { fam. 14.2.3 (30): }\end{array}$} \\
\hline fam. 14.2 .3 (32): & et valetudinem istam infirmam, si me amas, noli vexare. \\
\hline fam. $14.2 .3(35):$ & $\begin{array}{l}\text { sed video in te esse omnia. quare, ut id quod speras et quod agis } \\
\text { consequamur, servi valetudini. }\end{array}$ \\
\hline fam. $14.4 .3(26):$ & $\begin{array}{l}\text { iam id vos videte; mihi deest consilium. sed certe, quoquo modo se res } \\
\text { habebit, illius misellae et matrimonio et famae serviendum est. }\end{array}$ \\
\hline fam. 14.6 (4): & $\begin{array}{l}\text { ex tuis litteris quas proxime accepi cognovi praedium nullum venire } \\
\text { potuisse. qua re videatis velim quo modo satis fiat ei cui scitis me satis } \\
\text { fieri velle. }\end{array}$ \\
\hline fam. $14.12(6):$ & in viam quod te des hoc tempore nihil est. \\
\hline fam. $14.13(3):$ & si [erg. Dolabella] metuendus iratus est, quiesces. \\
\hline fam. 14.13 (5): & totum iudicabis quale sit \\
\hline fam. $14.13(6):$ & et quod in miserrimis rebus minime miserum putabis id facies \\
\hline
\end{tabular}

\footnotetext{
${ }^{1253}$ Wendungen wie vestrum iam consilium est, non solum meum in fam. 14.14 .1 (3) und id non solum meum consilium est sed etiam vestrum. in fam. 14.18.1 (2) wirken allerdings nur eingeschränkt abschwächend, sondern drücken mehr noch Abwehr bzw. Ratlosigkeit aus.

1254 Zur Modalität in Abhängigkeit von der speziellen Art einer Aufforderung vgl. a. CABRILLANA 2016, 204ff. Sie bezieht sich dabei auf Plautus, weshalb ihre Ergebnisse nur sehr bedingt auf fam. 14 übertragen werden können. 1255 Hier wird von einem gemeinsamen Interesse ausgegangen, unabhängig davon, wem eine bestimmte Immobilie rechtlich tatsächlich gehört.

${ }^{1256}$ Warum die Illokutionen in fam. 14.2 nicht als (expressive) WOHLERGEHENSWÜNSCHE betrachtet werden, wurde bereits erläutert: Vgl. Kap. 2.1.3.
} 
fam. 14.18.2 (12): domus ut propugnacula et prae〈si〉dium habeat Philotimo dicetis.

Abbildung 56: Aufforderungshandlungen mit beidseitiger Pröferenz

In den genannten Beispielen, bei denen Terentia ihren Mann zumindest in einigen Fällen (wie in fam. 14.13) zuvor gefragt haben wird, wie sie am besten vorgehen soll, sind keine größeren Diskussionen zwischen Sprecher und Adressat notwendig. Cicero äußert also nicht nur einen VORSCHLAG, sondern WEIST Terentia direkt AN, sich auf eine bestimmte Art und Weise zu verhalten bzw. eine bestimmte Handlung auszuführen. ${ }^{1257}$

Insgesamt scheinen die ANWEISUNGEN deutlicher und zielgerichteter formuliert zu sein als die RATSCHLÄGE: Bevorzugte Form sind der Imperativ (noli vexare, servi, sine, videte) und der Indikativ Futur (quiesces, iudicabis, facies, dicetis). ${ }^{1258}$ Außerdem werden das Gerundivum (serviendum est) und der Konjunktiv (videatis velim) in direktiver Funktion verwendet. Eher indirekt wird eine Aufforderung durch nihil est quod (+ Konjunktiv) zum Ausdruck gebracht. ${ }^{1259}$

Lediglich fam. 14.13 (6) wird ein wenig dadurch abgemildert, dass Cicero die Entscheidung über die genaue Verfahrensweise Terentia überlässt: quod in miserrimis rebus minime miserum putabis. Gleichzeitig wird allerdings durch Superlative, Wiederholung und Alliteration der Ernst der Lage betont. In anderen Sprechakten wird der Druck auf Terentia u. a. durch eine Anrede (mea vita), Bittformeln (obsecro te ${ }^{1260}$, si me amas) sowie Begründungen (video in te esse omnia, mihi deest consilium) und (modale) Spezifizierungen (quoquo modo se res habebit, illius misellae et matrimonio et famae serviendum est ${ }^{1261}$ erhöht. Dies gilt ebenso für den durch zwei Attributsätze verstärkten Finalsatz ut id quod speras et quod agis consequamur in fam. 14.2.3 (35), mit dem das gemeinsame Ziel genau fokussiert, zugleich allerdings auch (abschwächend) das Eigeninteresse Terentias an der Handlung hervorgehoben wird. Der zusätzlichen Intensivierung der Sprechakte dienen neben den bereits genannten Superlativen, Alliterationen und Wortwiederholungen (vgl. a. quod ... quod) noch weitere, oft miteinander verbundene sprachlich-stilistische Mittel, wie z. B. Hendiadyoin (propugnacula et prae〈si〉-

\footnotetext{
${ }^{1257}$ Vgl. a. RISSELADA 1993, 48 und (mit Beispielen aus Plautus) CABRILLANA 2016, 187f. zum direktiven Sprechakttyp „proposal”, „,in which there usually is benefit for both speaker and addressee“.

1258 Vgl. a. RISSELADA 1993, 112 zur quantitativen Verteilung der Imperativform auf verschiedene Untertypen der Direktiva. Vgl. außerdem CABRILLANA 2016, 204ff. (s. N. 1254).

1259 Vgl. RISSELADA 1993, 325f., z. B. ebd., 325: „[...] the expression nihil est quod , there is no reason' can be used both in (reassuring) advice (,you need not' [...]) and in an order (,you shouldn't [...]); which of the two is at stake in a particular case depends on whether or not the content is primarily in the interest of the addressee. "In fam. 14 findet sich die Wendung in einer Aufforderung mit beidseitiger Präferenz, nämlich 14.12 (6). Dabei besteht im Übrigen eine gewisse Nähe zum assertiven Untermuster WIDERSPRECHEN; die direktive Handlungsfunktion ist jedoch dominant. Ähnlich zu werten ist die Äußerung de familia liberata, nihil est quod te moveat. (fam. 14.4.4 (33)), die allerdings dem expressiven Untermuster WOHLERGEHEN WÜNSCHEN zuzuordnen ist, da die geforderte „Handlung“ im Unterschied zu fam. 14.12 (6) vom Adressaten kaum zu beeinflussen ist: Vgl. das Kap, „Weitere Expressiva mit beidseitiger Präferenz".

1260 RISSELADA 1989, 376 bemerkt allgemein zur Verwendung solcher „illocutionary parentheticals“, dass sie v. a. in stark gesichtsbedrohenden Sprechakten verwendet würden, zu denen sie „requests“ und „pleas“ zählt. In fam. 14 werden hingegen neben BITTEN auch Direktiva mit beidseitiger Präferenz wie ANWEISUNGEN anscheinend als besonders gesichtsbedrohend betrachtet.

1261 Insbesondere diese Spezifizierung in fam. 14.4 .3 (26) signalisiert eine starke Expressivität der Äußerung, insofern Cicero große ANGST um seine Tochter ÄUSSERT. Sie ist im vorliegenden Zusammenhang jedoch nicht dominant und dient lediglich der Verstärkung der Aufforderung an Terentia, sich um Tullia zu kümmern.
} 
dium), Periphrase (ei cui scitis me satis fieri velle), Polysyndeton (et matrimonio et famae) sowie verabsolutierende Ausdrücke (omnia, totum, nullum, nihil) ${ }^{1262}$ oder auch ein evaluativemotives Diminutiv wie misellae.

Direktiva mit Sprecherpräferenz

Direktiva begegnen am häufigsten als Aufforderungshandlungen mit Sprecherpräferenz in Form des Untermusters BITTEN. ${ }^{1263}$ Auch hier finden sich Fälle, in denen ungewiss bleibt, inwieweit nicht evtl. doch eher von einer beidseitigen Präferenz ausgegangen werden sollte, wie z. B. bei fam. $14.5 .1(20)^{1264}$ :

\begin{tabular}{|c|c|}
\hline \multicolumn{2}{|l|}{ BITTE } \\
\hline fam. 14.1.6 (45): & [et] ad me tabellarios mittas ut sciam quid agatur et vos quid agatis. \\
\hline am. 14.1.6 (47): & Tulliolae et Ciceroni salutem dic. \\
\hline $.2 .4(38):$ & $\begin{array}{l}\text { sed velim quam saepissime litteras mittatis, praesertim si quid est fir- } \\
\text { mius quod speremus. }\end{array}$ \\
\hline Im. & $\begin{array}{l}\text { ea re ad te statim Aristocritum misi ut ad me continuo initia rerum et } \\
\text { rationem totius negoti posses scribere }\end{array}$ \\
\hline m. 14.3 .5 (30): & $\begin{array}{l}\text { Quod scribis te, si velim, ad me venturam, ego vero, cum sciam magnam } \\
\text { partem istius oneris abs te sustineri, te istic esse volo. }\end{array}$ \\
\hline m. 14.3 .5 (34): & tu modo ad me velim omnia diligentissime perscribas \\
\hline$a m$. & $\begin{array}{l}\text { opinor, sic agam: si est spes nostri reditus, eam confirmes et rem adiu- } \\
\text { ves }\end{array}$ \\
\hline m. 14.4 .3 & sin [...] transactum est, quoquo modo potes, ad me fac venias. \\
\hline am. & $\begin{array}{l}\text { n, quod commodo valetudinis tuae fiat, quam longissime poteris } \\
\text { nobis prodeas. }\end{array}$ \\
\hline 1): & $\begin{array}{l}\text { De hereditate Preciana [...] - sed hoc velim cures, si auctio ante meum } \\
\text { adventum fiet, ut Pomponius aut, si is minus poterit, Camillus nostrum } \\
\text { negotium curet }\end{array}$ \\
\hline fam. 14.5.2 (25): & sin tu iam Roma profecta eris, tamen curabis ut hoc ita fiat. \\
\hline fam. 14.6 (6): & Pollicem, si adhuc non est profectus, quam primum fac extrudas. \\
\hline fam. 1 & $\begin{array}{l}\text { cui quidem tu deo, quem ad modum soles, pie et caste satis facies [id } \\
\text { est Apollini et Aesculapio]. }\end{array}$ \\
\hline fam. 14.8 (7): & item posthac, si quid opus erit, si quid acciderit novi, facies ut sciam. \\
\hline am. 12 & si locuta eris, intelleges quid fieri velim. \\
\hline fam. 14.10 & de ea re et de ceteris rebus quam primum velim nobis litteras mittas. \\
\hline am. $14.12(4$ & qua re, quantum $p$ \\
\hline fam. 14.14.2 (15): & $\begin{array}{l}\text { simae animae, quam saepissime ad me scribite et vos } \\
\text { uid istic agatur. }\end{array}$ \\
\hline fam. 14.15 & $\begin{array}{l}\text { de ceteris rebus [...] (tamen) quid velimus et quid hoc tempore putemus } \\
\text { opus esse ex Sicca poteris cognoscere. }\end{array}$ \\
\hline
\end{tabular}

$1262 \mathrm{Vgl}$. a. ORLANDINI 1995, 39ff. (zu omnis und totus).

${ }^{1263}$ Vgl. N. 863. Vgl. a. RISSELADA 1993, 48 und (mit Beispielen aus Plautus) CABRILLANA 2016, 187f. zu den direktiven Sprechakttypen "request" und "supplication“.

$1264 \mathrm{Vgl}$. Kap. 2.1.2. 


\begin{tabular}{|ll|}
\hline fam. 14.17 (4): & nunc, quae sint negotia, vides. \\
fam. 14.18.2 (13): & $\begin{array}{l}\text { et velim tabellarios instituatis certos ut cottidie aliquas a vobis litteras } \\
\text { accipiam. }\end{array}$ \\
fam. $14.19(8):$ & $\begin{array}{l}\text { [sed a Pomponio exspecto litteras,] quas ad me quam primum perferen- } \\
\text { das cures velim. }\end{array}$ \\
fam. $14.20(3):$ & ibi ut sint omnia parata \\
fam. $14.20(6):$ & labrum si in balineo non est, ut sit \\
fam. $14.20(7):$ & item cetera quae sunt ad victum et ad valetudinem necessaria \\
fam. $14.21(4):$ & quod opus erit, ut res tempusque postulat, provideas atque administres \\
fam. $14.21(5):$ & [et] ad me de omnibus rebus quam saepissime litteras mittas \\
fam. $14.23(6):$ & tabellarios mihi velim quam primum remittas
\end{tabular}

Abbildung 57: Aufforderungshandlungen mit Sprecherpräferenz

Die BITTEN in fam. 14 beziehen sich (im Unterschied zu den RATSCHLÄGEN) meist direkt auf ein erwartetes aktives Handeln bzw. das Unterlassen einer Handlung durch den Adressaten. Am weitesten verbreitet ist in solchen Sprechakten der Gebrauch von velim in Verbindung mit dem Konjunktiv (z. B. velim cures, velim instituatis, velim remittas bzw. mittas / mittatis, velim perscribas, velim prodeas). Bisweilen steht auch der bloße Konjunktiv ohne übergeordneten Hauptsatz (adiuves, administres, confirmes, mittas, provideas), z. T. eingeleitet mit ut (ut sint, ut sit). Im Extremfall fehlt sogar das Prädikat (item cetera). Häufiger anzutreffen ist außerdem der Imperativ (adiuva, dic, scribite), gelegentlich (bei den Metadirektiva) ebenfalls mit abhängigem Konjunktiv (fac extrudas, fac venias). ${ }^{1265}$ Außerdem wird manchmal das Futur verwendet (curabis, facies, intelleges, poteris cognoscere ${ }^{1266}$ ), einmal auch das Präsens (vides), wobei der direktive Sprechakt meist, insbesondere bei Verben des Wahrnehmens wie intellegere, cognoscere und videre, als eher indirekt aufzufassen ist. Die Direktivität ergibt sich z. B. in fam. 14.15 (5) v. a. aus der Wortsemantik von posse, im Übrigen auch aus der Verwendung eines volitiven Verbs wie velle (quid fieri velim, quid velimus) oder ähnlichen Wendungen (quid putemus opus esse, quae sint negotia) in den untergeordneten indirekten Fragesätzen. In fam. 14.3.5 (30) wird das Modalverb velle dagegen direkt direktiv gebraucht. ${ }^{1267}$ Noch indirekter hinwiederum ist die BITTE in fam. 14.3.4 (24) formuliert, wo der direkte Sprechakt (ebenfalls) eher assertiv ist (HINWEISEN). In Anbetracht von zahlreichen intensivierenden Faktoren, z. B. verstärkenden Adjektiven und Adverbien wie statim, continuo und totius, sowie des Finalsatzes (mit dem abschwächenden, aber dennoch - wie in fam. 14.15 (5) - eine Aufforderung ausdrückenden Modalverb posse), ist der direktive Charakter von fam. 14.3.4 (24) allerdings dennoch sehr deutlich, sodass die Äußerung auch nur bedingt höflicher als eine direkte BITTE

\footnotetext{
1265 Vgl. N. 1258.

1266 Vgl. N. 1251 bzw. fam. 14.17 (5), wo das Interesse am Handlungsvollzug im Unterschied zu fam. 14.15 (5) nicht beim Sprecher, sondern eher bei Terentia zu verorten ist.

${ }^{1267} \mathrm{Vgl}$. a. fam. 14.1.4 (32): sed vos, cum praesertim tam pauci sitis, volui esse quam coniunctissimos. Die Äußerung bezieht sich allerdings auf die Vergangenheit, wenngleich anzunehmen ist, dass Cicero damit seinen Wunsch wiederholt und sie durchaus direktiv aufzufassen ist. Auch eine unpersönliche Wendung wie (mihi) placet könnte direktiv verwendet werden, wird in fam. 14 allerdings nur indirekt-berichtend gebraucht, wie z. B. in fam. 14.10 (2): Quid fieri placeret scripsi ad Pomponium.
} 
ist. Der Grund für diese Art der Formulierung liegt eher darin, dass Cicero so die mit der BITTE verbundenen Umstände leichter in die Äußerung einbinden kann.

Direktiva ohne eine Bittformel wie velim klingen oft besonders rüde. Insgesamt werden BITTEN in fam. 14 anscheinend ähnlich wie ANWEISUNGEN im Unterschied zu RATSCHLÄGEN nur recht selten abgemildert, wie z. B. in fam. 14.3.5 (34) durch modo. Eines der wenigen weiteren Beispiele ist fam. 14.7.1 (7), wo der Komparativsatz quem ad modum soles hervorhebt, dass von Terentia nichts Besonderes verlangt werde und sie nur das tun solle, was ohnehin ihrem üblichen Verhalten entspreche. ${ }^{1268}$ Zu nennen ist außerdem fam. 14.5 .1 (20), also ein Fall, bei dem auch ein gewisses Interesse Terentias an der betreffenden Handlung unterstellt werden kann: Cicero signalisiert mit quod commodo valetudinis tuae fiat Rücksichtnahme auf die Gesundheit seiner Frau und schränkt die BITTE dadurch ein. Auf der anderen Seite verstärkt er sie aber zugleich mit dem Komparativsatz quam longissime poteris. Andere Äußerungen werden ebenfalls durch modale (komparativische) Wendungen und Komparativsätze, wie z. B. quoquo modo potes, quantum potes und ut res tempusque postulat, intensiviert.

Häufiger noch begegnen Konditionalsätze, welche die Handlungsbedingungen bzw. -alternativen genauer erläutern und eher einen anleitenden Charakter haben, wie z. B. si quid est firmius, si est spes nostri reditus, sin transactum est ${ }^{1269}$, si auctio ante meum adventum fiet, si is minus poterit, si adhuc non est profectus, si quid opus erit, si quid acciderit novi, cum eo si locuta eris, si in balineo non est. Eine disjunktive Aufzählung wie Pomponius aut Camillus in fam. 14.5.2 (21) dient ebenfalls lediglich der genaueren Erläuterung (von Handlungsalternativen). Extrem verstärkend wirkt der Konditionalsatz in fam. 14.5.2 (25), wo Cicero seine BITTE sogar in dem Fall aufrechterhält, dass Terentia Rom bereits verlassen haben sollte (tamen curabis). ${ }^{1270}$

Generell fordernd, in fam. 14.20 sogar ziemlich unhöflich wirken die meisten Finalsätze (z. B. ut sint, ut sit, aber auch ut hoc ita fiat). ${ }^{1271}$ Ähnlich zu bewerten ist ein zusätzliches Gerundivum wie perferendas oder ein Adjektiv wie necessaria. Außerdem kann mit Attributsätzen wie quod opus erit, verabsolutierenden Ausdrücken wie totus, omnis und ceterus, aber auch z. B. cottidie und continuo, mit Superlativen und semantisch vergleichbaren Wendungen wie quam longissime, quam saepissime, quam primum und diligentissime sowie mit praesertim eingeleiteten Nachträgen die Dringlichkeit einer BITTE intensiviert werden.

\footnotetext{
1268 Möglich wäre evtl. auch eine Zuordnung von fam. 14.7.1 (7) zum assertiven Untermuster PROPHEZEIEN, wenn man unterstellt, dass Cicero kein besonderes eigenes Interesse daran hat, (symbolisch) den Göttern für seine Genesung zu danken, und nur eine voraussichtliche Handlung Terentias vorwegnimmt. Einen wirklich informativen Charakter hat die Aussage allerdings nicht. Alternativ könnte man eher noch einen expressiven Sprechakt wie BEGRÜSSEN annehmen, der jedoch normalerweise auf eine vergangene Handlung bezogen ist. 1269 Der Konditionalsatz sin transactum est kann auf fam. 14.4 .3 (22) und (23) bezogen werden. Im ersten Fall gibt er lediglich (objektiv) die Handlungsbedingung für die Aufforderung an, im zweiten liefert er die Grundlage für einen expressiven Akt des Typs ANGST ÄUSSERN, wie er mit ut ego metuo expliziert wird. Eine ähnliche Aufsplittung ist für fam. 14.4.3 (21) nicht möglich, wo Cicero nur sehr implizit auch eine gewisse HOFFNUNG ÄUSSERT.

${ }^{1270} \mathrm{Vgl}$. Kap. 2.1.2.

${ }^{1271}$ Vgl. a. Kap. 2.1 .1 (zu fam. 14.20 (3) und 14.20 (6)). Hinzu kommen die (teilweise von velim oder fac abhängigen) finalen Konjunktivkonstruktionen.
} 
Hinzu kommen Wiederholungen und Aufzählungen, z. B. von Prädikaten (eam confirmes et rem adiuves, provideas atque administres) und Teilsätzen (quid agatur et vos quid agatis; et vos quid agatis et quid istic agatur; quid velimus et quid hoc tempore putemus opus esse; si quid opus erit, si quid acciderit novi), sowie weitere besondere sprachlich-stilistische Mittel, z. B. Alliterationen (ad victum et ad valetudinem), die teilweise miteinander kombiniert werden. Eine affektive Anrede wie meae carissimae animae dient zugleich als captatio benevolentiae und als Mittel, um den Druck auf den Adressaten zu erhöhen. Eine höhere Emotionalität und allgemein eine Verstärkung der Sprechakte wird zudem durch ein (auf die Tochter bezogenes) Diminutiv wie Tulliola sowie emotive und evaluative (z. T. adverbial gebrauchte) Adjektive wie magnus, pie et caste und Substantive wie onus erreicht.

Fragehandlungen

Charakteristika im Überblick

In fam. 14 gibt es nur sehr wenige direktive Fragehandlungen. Im Folgenden können deshalb nur einige grundlegende Eigenschaften benannt werden, die zudem weitgehend hypothetischer Natur bleiben müssen:

\begin{tabular}{|c|c|}
\hline \multicolumn{2}{|l|}{ Allgemeine Semantik } \\
\hline propositionale Einstellung & $\begin{array}{l}\text { motivational (Erwartung bzw. Forderung einer Antwort) } \\
\text { und epistemisch (Ausdruck von Ungewissheit) }\end{array}$ \\
\hline \multirow[t]{2}{*}{ Lexik insgesamt } & $\begin{array}{l}\text { je nach Art der Frage eher sachlich-nüchtern oder expres- } \\
\text { siv-wertend }\end{array}$ \\
\hline & $\begin{array}{l}\text { Anmerkung: Sachlichkeit ist z. B. bei reinen Informationsfragen (IN- } \\
\text { FORMATION ERBITTEN) erwartbar, eine größere Expressivität bei } \\
\text { stark partnerbezogenen Fragen (wie ANTEILNEHMENDEN FRAGEN). }\end{array}$ \\
\hline \multicolumn{2}{|l|}{ Morphosyntax } \\
\hline \multirow[t]{2}{*}{ Modus } & Indikativ und Konjunktiv \\
\hline & $\begin{array}{l}\text { Anmerkung: Auch der Imperativ (in Verbindung mit einem indirekten } \\
\text { Fragesatz) bzw. Metadirektiva sind denkbar. }\end{array}$ \\
\hline \multirow[t]{2}{*}{ Tempus } & Präsens und Futur \\
\hline & $\begin{array}{l}\text { Anmerkung: In bestimmten Zusammenhängen sind auch andere } \\
\text { Tempora (wie das Perfekt) möglich, z. B. bei partnerzentrierten Fra- } \\
\text { gen (vgl. fam. 14.4.4 (30): quid egeris) oder dem Untermuster INFOR- } \\
\text { MATION ERBITTEN. }\end{array}$ \\
\hline \multicolumn{2}{|l|}{ Syntax } \\
\hline Satzart & $\begin{array}{l}\text { Fragesätze } \\
\text { Anmerkung: Auch Aufforderungs- und Aussagesätze mit indirektem } \\
\text { Fragesatz sind denkbar. }\end{array}$ \\
\hline
\end{tabular}

Abbildung 58: Charakteristika direktiver Sprechakte: Fragehandlungen 
Die verschiedenen Typen von Fragehandlungen unterscheiden sich z. T. erheblich voneinander. Es sind, abgesehen von der epistemisch-motivationalen Sprechereinstellung, kaum Gemeinsamkeiten zu erkennen. Selbst der Fragesatz ${ }^{1272}$ als deutlichstes Charakteristikum ist keine notwendige Voraussetzung für das Vorliegen einer Fragehandlung. Alternativ sind bspw. Aufforderungs- und Aussagesätze mit indirektem Fragesatz denkbar, die mit Metadirektiva wie dic bzw. explizit performativen Verben wie quaerere oder (inter)rogare eingeleitet werden. ${ }^{1273}$ Indirekte Fragesätze können außerdem auch unabhängig davon (indirekte) Fragehandlungen darstellen. Hinzu kommt, dass zahlreiche, in fam. 14 sogar die meisten Fragesätze indirekte Expressiva sind. ${ }^{1274}$ Aber selbst einige tatsächlich als Fragehandlungen zu kategorisierende Äußerungen sind mehr oder weniger stark expressiv gefärbt. Deshalb verwundert es nicht, dass Fragehandlungen bisweilen nicht als eigene Sprechakt(unter-)kategorie gewertet werden. ${ }^{1275}$

Problemzentrierte initiale Fragehandlungen: KOOPERATIONSFRAGEN

Lediglich zwei Fragesätze bzw. Fragesatzsequenzen in fam. 14 können als direktive Fragehandlungen i. e. S. betrachtet werden:

\section{KOOPERATIONSFRAGE STELLEN}

fam. 14.4.3 (18): quid nunc? rogem te ut venias [...]? non rogem?

fam. 14.4.3 (25): sed quid Tulliola mea fiet?

Abbildung 59: Problemzentrierte initiale Fragehandlungen: KOOPERATIONSFRAGEN

Für Sprechakte des Typs KOOPERATIONSFRAGE STELLEN gilt: „Es handelt sich [...] um Fragen, die ein gemeinsames praktisches Problem von Sprecher und Hörer [oder genauer: Adressat] betreffen. [...] Wie bei den PROBLEMATISIERUNGSFRAGEN setzt Sp1 auch bei den KOOPERATIONSFRAGEN nicht voraus, daß Sp2 die Lösung bereits kennt. Stellt Sp1 in einer Planungssituation eine Frage des Typs Was sollen wir jetzt tun?, so befragt er Sp2 nicht als Experten, sondern als gleichberechtigten Partner, der bei der Problemlösung seine Vorstellungen und Präferenzen einbringen kann. Sp1 zielt mit seiner Frage also auf einen Lösungsvorschlag ab, der in einer längeren Planungsinteraktion akzeptiert, modifiziert oder verworfen werden kann. “1276

Im ersten Beispiel (fam. 14.4.3 (18)) geht es um den Konflikt Ciceros hinsichtlich der Frage, ob Terentia ihm in sein Exil folgen solle oder nicht. Nach einer allgemeinen Bekundung seiner Ratlosigkeit stellt Cicero zwei mögliche Alternativen dar. ${ }^{1277}$ Der jeweils damit verbundene Nachteil wird einmal (konzessiv) innerhalb einer Anrede in Form eines Attributs und eines p. c.s innerhalb des Satzes (fam. 14.4 .3 (19): mulierem aegram, et corpore et animo confectam), einmal in Form eines darauf folgenden eigenständigen Fragesatzes (fam. 14.4.3 (20): sine te igitur sim?) zum Ausdruck gebracht, der (konsekutiv) die sich aus der zweiten

\footnotetext{
1272 Vgl. a. PINKSTER 2015, 315ff. zu „Interrogative sentences“ (im Zusammenhang mit „Sentence type and illocutionary force").

${ }^{1273}$ Vgl. z. B. RISSELADA 1993, 246 und RISSELADA 1989, 370 zum metadirektiven Ausdruck dic (mihi) zur Einleitung von Fragen. Sie nennt außerdem noch (mihi) responde und fac me certiorem.

${ }^{1274}$ Vgl. PINKSTER 2015, 342ff. zu "Interrogative sentences with an indirect illocutionary force“.

1275 Vgl. S. 27.

1276 HINDELANG 1981, 218.

1277 Vgl. a. PINKSTER 2015, 346 (zu „Elliptical interrogative sentences“ mit quid).
} 
Handlungsmöglichkeit ergebende Folge zu bedenken gibt. Im ersten Fall ist die Äußerung dem expressiven Untermuster SORGE BEKUNDEN zuzuordnen, im zweiten Fall dem Untermuster ANGST ÄUSSERN. ${ }^{1278}$ Obwohl fam. 14.4 .3 (19) und (20) nicht direkt zur Fragehandlung gehören, erscheint fam. 14.4.3 (18) durch die Dreiteiligkeit und die Wiederholung von rogem auch für sich genommen sehr expressiv. Es handelt sich nichtsdestotrotz um eine wirkliche Frage, auf die Cicero zunächst eine Antwort von Terentia zu erwarten scheint, wenngleich er im Folgenden selbst eine (vorläufige) Entscheidung trifft: opinor, sic agam: si est spes nostri reditus, eam confirmes et rem adiuves; sin, ut ego metuo, transactum est, quoquo modo potes, ad me fac venias. Er ergänzt allerdings: unum hoc scito: si te habebo, non mihi videbor plane perisse. Ganz sicher ist er sich also nicht. Da es letztlich genauso um das Schicksal Terentias geht, die am Ende selbst wissen muss, ob sie in der Lage und willens ist, die Strapazen der Reise auf sich zu nehmen, liegt ein gemeinsames Problem und somit eine KOOPERATIONSFRAGE und keine RATFRAGE vor. ${ }^{1279}$

Bei dem zweiten Beispiel könnte man möglicherweise das Untermuster ANTEILNEHMENDE FRAGE STELLEN in Erwägung ziehen. ${ }^{1280}$ Obwohl Tullia in der Begrüßungs- und der abschlieBenden Wohlergehensformel (zumindest formell) auch Adressatin des Briefes ist, wird sie allerdings nicht direkt angesprochen. Neben dem Ausdruck von Anteilnahme finden sich Anklänge an das Untermuster SORGE BEKUNDEN bzw. ANGST ÄUSSERN. Im Unterschied zu der etwas später folgenden Frage quid? Cicero meus quid aget? legt der Textzusammenhang jedoch nahe, dass Cicero eine - kontextuell und durch die Bezeichnung der Tochter als Tulliola mea (Diminutiv mit Possessivpronomen) expressiv eingefärbte - KOOPERATIONSFRAGE STELLT, auf die tatsächlich eine Antwort gegeben werden soll. Cicero muss gemeinsam mit Terentia klären, wie im Interesse Tullias am besten zu verfahren sei. Schließlich überlässt Cicero die Entscheidung seiner Frau: iam id vos videte; mihi deest consilium, weist aber darauf hin: quoquo modo se res habebit, illius misellae et matrimonio et famae serviendum est. ${ }^{1281}$

Partnerzentrierte initiale Fragehandlungen: ANTEILNEHMENDE FRAGEN

Neben den beiden KOOPERATIONSFRAGEN kann außerdem noch folgende Äußerung als Fragehandlung in Erwartung einer Antwort des Adressaten gelten:

\section{ANTEILNEHMENDE FRAGE STELLEN}

fam. 14.4.4 (30): Tu quid egeris nescio, utrum aliquid teneas an [...] plane sis spoliata.

Abbildung 60: Partnerzentrierte initiale Fragehandlungen: ANTEILNEHMENDE FRAGE

Auf der sprachlichen Oberfläche wird ein assertiver Sprechakt signalisiert, mit dem Cicero auf seine Unkenntnis der aktuellen Situation Terentias hinweist. Ähnlich wie in fam. 14.4.3 (18) folgt auf eine eher allgemeine Frage (quid egeris) eine speziellere (zweiteilige) Alternativfrage (utrum ... an). Indirekt ist damit die Bitte verbunden, ihn aufzuklären. Obwohl Cicero durchaus

\footnotetext{
1278 Vgl. die Kap. zu den „Expressiva mit beidseitiger Aversion“ (ab S. 361) bzw. den „Expressiva mit Sprecheraversion“ (ab S. 368).

1279 Zum Untermuster RATFRAGEN bzw. RAT ERBITTEN vgI. HINDELANG 1981, $217 f$.

${ }^{1280}$ Vgl. den folgenden Abschnitt „Partnerzentrierte initiale Fragehandlungen“.

${ }^{1281}$ Mit matrimonio servire bezieht sich Cicero wohl auf die noch nicht vollständig ausgezahlte Mitgift, mit famae servire darauf, dass Tullia als Ehefrau Terentia nicht ohne Weiteres auf einer so großen Reise hätte begleiten können: Vgl. z. B. Shackleton Bailey in CICERO 1977, 285f. und Tyrrell / Purser in CICERO 1904 - 1933, I 364 bzw. TREGGIARI 2007, 58ff. und ebd., 185.
} 
auch an der Information an sich Interesse haben wird, geht es $\mathrm{m}$. E. aber mehr noch darum, Terentia zu ermöglichen, ihre durch eine prekäre Lage verursachte schlechte Verfassung ausführlicher zu beschreiben, und zwar in dem Wissen, dass ihr Mann großen Anteil daran nimmt.

Somit handelt es sich weniger um eine reine AUSKUNFTSFRAGE ${ }^{1282}$ als um einen Sprechakt des Untermusters ANTEILNEHMENDE FRAGE STELLEN, das folgendermaßen charakterisiert ist: „Im Zentrum der ANTEILNEHMENDEN FRAGEN stehen Äußerungen, mit denen Sp1 nach Gefühlen, Empfindungen und Bewertungen von Sp2 fragt. Es wird dabei unterstellt, daß sich Sp1 aus Liebe, Freundschaft oder solidarischer Anteilnahme für das Befinden von Sp2 interessiert und ihm durch eine entsprechende Frage mitteilen will, daß ihm der Adressat nicht gleichgültig ist. Der Fragende gibt Sp2 damit die Möglichkeit, seine Gefühle, Empfindungen, Einschätzungen und Bewertungen zu formulieren und sich so bei Sp1 auszusprechen. Charakteristisch für solche Fragen ist, daß - im Gegensatz zu AUSKUNFTSFRAGEN - niemand anders als der Adressat selbst die Frage überhaupt beantworten kann. “1283 Letzteres gilt hier allerdings nur eingeschränkt, zumindest was die reine Sachebene betrifft.

Wie bei den meisten ANTEILNEHMENDEN FRAGEN besteht eine Nähe zu den Expressiva, in diesem Fall auch indiziert durch die expressive Lexik (plane spoliata): Cicero BEKUNDET mit seiner Frage SORGE um das Wohlergehen Terentias. ${ }^{1284}$ Insgesamt dominiert jedoch das Untermuster ANTEILNEHMENDE FRAGE STELLEN, sowohl gegenüber expressiven als auch assertiven und anderen direktiven Sprechaktmustern.

Kommissiva

Charakteristika im Überblick

Kommissive Sprechhandlungen sind wie die Direktiva in erster Linie durch ihre motivationale Einstellung geprägt, unterscheiden sich aber in anderer Hinsicht mehr oder weniger deutlich von diesen, bedingt v. a. dadurch, dass nicht der Adressat, sondern der Sprecher selbst zu einer Handlung aufgefordert ist:

\begin{tabular}{|c|c|}
\hline \multicolumn{2}{|l|}{ Allgemeine Semantik } \\
\hline propositionale Einstellung & $\begin{array}{l}\text { motivational: } \\
\text { - } \quad \text { Indikativ Futur } \\
\text { - } \quad \text { volitiver) Konjunktiv Präsens: feramus } \\
\text { cupere, in animo esse, operam dare }\end{array}$ \\
\hline \multirow[t]{2}{*}{ Lexik insgesamt } & $\begin{array}{l}\text { oft eher sachliche Lexik, v. a. bei den Kommissiva mit Spre- } \\
\text { cherpräferenz des Typs ABSICHT BEKUNDEN }\end{array}$ \\
\hline & $\begin{array}{l}\text { z. T. recht expressive Lexik, v. a. bei den Kommissiva des Typs } \\
\text { VORSATZ BEKUNDEN und (weniger deutlich) des Typs VER- } \\
\text { SPRECHEN }\end{array}$ \\
\hline
\end{tabular}

\footnotetext{
1282 Vgl. HINDELANG 1981, 217.

${ }^{1283} \mathrm{Vgl}$. ebd., $219 f$.

${ }^{1284} \mathrm{Vgl}$. a. den Einschub quod metuo (fam. 14.4.4 (31)), der diese Sorge explizit zum Ausdruck bringt.
} 


\begin{tabular}{|c|c|}
\hline & $\begin{array}{l}\text { Verben des (Nicht-)Handelns: } \\
\text { - } \quad \text { allgemein: agere, facere, curare } \\
\text { - Fortbewegung (v. a. bei den Kommissiva mit Sprecherprä- } \\
\text { ferenz des Typs ABSICHT BEKUNDEN): se conferre, ire, } \\
\text { venire, (non) discedere } \\
\text { - Willensbekundung (v. a. bei den Kommissiva mit Sprecher- } \\
\text { präferenz des Typs VORSATZ BEKUNDEN): operam dare, } \\
\text { (non) deficere } \\
\text { - Kommunikation (v. a. bei den Kommissiva mit Adressaten- } \\
\text { präferenz des Typs VERSPRECHEN): certiorem facere, } \\
\text { (con)scribere } \\
\text { Anmerkungen: } \\
\text { - Zu den Verben des Handelns zählt außerdem das ebenfalls in den } \\
\text { Kommissiva verwendete Verb mittere. } \\
\text { - Teilweise finden sich auch Verben aus anderen Bereichen, wie z. B. } \\
\text { deliberare in fam. } 14.5 .1 \text { (19), welches in diesem Fall aber ähnlich zu } \\
\text { verstehen ist wie bspw. agere in fam. } 14.5 .2 \text { (23). } \\
\text { Das Gegenteil von Fortbewegung (esse) wird in fam. } 14.1 .3 \text { (22) als } \\
\text { Ziel verfolgt. }\end{array}$ \\
\hline & $\begin{array}{l}\text { verstärkende Adjektive und Adverbien (oft komparativisch } \\
\text { oder superlativisch bzw. in superlativischer Bedeutung): } \\
\text { - (eo) citius } \\
\text { - diligentissime } \\
\text { - } \quad \text { (quo) facilius } \\
\text { - } \text { magis } \\
\text { - } \text { multas } \\
\text { - omnia } \\
\text { - } \quad \text { (quam) primum } \\
\text { - } \text { reliqua } \\
\text { - } \text { statim } \\
\text { - } \text { tamen } \\
\text { - tota } \\
\text { Anmerkungen: } \\
\text { - Die verstärkende Wirkung von tamen ergibt sich aus der Opposition } \\
\text { zu vorher genannten erschwerenden Bedingungen (,Trotz alledem } \\
\text { werde ich dennoch ..."): Vgl. die Konzessivsätze in fam. 14.4.5 (46) } \\
\text { und } 14.16 \text { (6). } \\
\text { - Komparative finden sich auch sonst zur Intensivierung der Sprechakte } \\
\text { (vgl. gratius in fam. } 14.4 .5 \text { (46)). }\end{array}$ \\
\hline & $\begin{array}{l}\text { Pronomina der 2. Person, v. a. bei den Kommissiva mit Adres- } \\
\text { satenpräferenz des Typs VERSPRECHEN zur Verstärkung des } \\
\text { Partnerbezugs: tuo, }(a d) \text { te, vobis, vos } \\
\text { Anmerkung: Manchmal wird der Partnerbezug durch eine kontrastierende } \\
\text { Verwendung von Pronomina der } 1 \text {. Person verstärkt. }\end{array}$ \\
\hline besondere Stilmittel & $\begin{array}{l}\text { Wortwiederholungen zur Intensivierung der Sprechakte, oft } \\
\text { in Verbindung mit weiteren Stilmitteln: }\end{array}$ \\
\hline
\end{tabular}




\begin{tabular}{|c|c|}
\hline & $\begin{array}{l}\text { - fam. } 14.4 .5 \text { (46): quamquam ferenda non sunt, feramus. } \\
\text { (Paradoxon) } \\
\text { - fam. } 14.16 \text { (6): quamquam alia sunt quae magis curemus } \\
\text { magisque doleamus (Hendiadyoin) } \\
\text { - fam. } 14.1 .3 \text { (22): quo neque Piso veniret nec milites (Poly- } \\
\text { syndeton) }\end{array}$ \\
\hline \multicolumn{2}{|l|}{ Morphosyntax } \\
\hline Person & $\begin{array}{l}\text { 1. Person } \\
\text { Anmerkung: V. a. bei Kommissiva mit Adressatenpräferenz des Typs VER- } \\
\text { SPRECHEN findet sich in den Nebensätzen häufiger auch die 2. Person } \\
\text { bzw. eine entsprechende unpersönliche Wendung (mit Bezug auf einen } \\
\text { vom Adressaten geäußerten Wunsch). }\end{array}$ \\
\hline Modus & $\begin{array}{l}\text { Indikativ } \\
\text { Anmerkung: In einigen Fällen (fam. } 14.4 .5(46) \text { und } 14.16(6)) \text { findet sich } \\
\text { auch ein volitiver Konjunktiv. }\end{array}$ \\
\hline Tempus & $\begin{array}{l}\text { Futur } \\
\text { Anmerkungen: Bei volitiv-evaluativen Verben wie cupere wird das Präsens } \\
\text { benutzt. Man beachte jedoch die Brieftempora in fam. 14.1.3 (22) und } \\
\text { 14.11 (5). Vgl. außerdem den (Konjunktiv) Präsens in fam. 14.4.5 (46) und } \\
\text { 14.16 (6). Im Übrigen begegnet das Futur auch in vielen Nebensätzen. }\end{array}$ \\
\hline \multicolumn{2}{|l|}{ Syntax } \\
\hline Satzart & Aussagesätze \\
\hline Objekt- und Attributsätze & $\begin{array}{l}\text { indirekte Fragesätze und Attributsätze zur (genaueren bzw. } \\
\text { spezifizierenden) Bezeichnung des Inhalts eines VERSPRE- } \\
\text { CHENS: } \\
\text { fam. } 14.23 \text { (5): cui utrum obviam procedam an hic eum } \\
\text { exspectem } \\
\text { - fam. } 14.3 .3 \text { (16): quae praecipis } \\
\text { - fam. } 14.7 .2 \text { (10): quibus te et Tulliolam nostram diligentis- } \\
\text { sime commendabo }\end{array}$ \\
\hline $\begin{array}{l}\text { adverbiale Bestimmungen } \\
\text { und Adverbialsätze }\end{array}$ & $\begin{array}{l}\text { zeitliche und v. a. Iokale Bestimmungen bzw. Adverbialsätze } \\
\text { im Zusammenhang mit den Reisen Ciceros: } \\
\text { - } \text { ad vos } \\
\text { - } \text { alio } \\
\text { - citius } \\
\text { - in Epirum / Epiro } \\
\text { - loco (deserto) } \\
\text { - longius } \\
\text { - obviam } \\
\text { - quam primum } \\
\text { - Lokalsatz: quo neque Piso veniret nec milites } \\
\text { Anmerkung: Vgl. u. (Konditional- und Temporalsätze). }\end{array}$ \\
\hline
\end{tabular}




\begin{tabular}{|c|c|}
\hline & $\begin{array}{l}\text { Finalsätze } \\
\text { zur genaueren Bezeichnung des Inhalts einer Willensbe- } \\
\text { kundung: ne mea valetudo tuo labori desit (fam. } 14.1 .2 \\
\text { (11)) } \\
\text { zur Verstärkung einer Willensbekundung: ne omnia mea } \\
\text { culpa cecidisse videantur (fam. } 14.3 .2 \text { (14)) }\end{array}$ \\
\hline & $\begin{array}{l}\text { Konditional- und Temporalsätze zur Benennung der Voraus- } \\
\text { setzungen, unter denen eine Verpflichtung gelten soll: } \\
\text { - fam. } 14.1 .7 \text { (53): si offendet me loci celebritas } \\
\text { - fam. } 14.3 .2 \text { (14): quam diu vos eritis in spe } \\
\text { - fam. } 14.3 .4 \text { (29): cum inimici nostri venire dicentur [tum ...] } 14.4 .5 \text { (46): si hoc fuit liberis nostris gratius } \\
\text { - fam. } 14.5 .2 \text { (23): cum salvi venerimus } \\
\text { - fam. } 14.11 \text { (7): si profectus erit } \\
\text { - fam. } 14.23 \text { (5): cum constituero } \\
\text { - } \text { fi quid erit certi }\end{array}$ \\
\hline & $\begin{array}{l}\text { Kausalsätze zur Bezugnahme auf einen zuvor geäußerten } \\
\text { Wunsch bei den Kommissiva mit Adressatenpräferenz des Typs } \\
\text { VERSPRECHEN oder zur allgemeinen Verstärkung einer Wil- } \\
\text { lensbekundung: } \\
\text { - fam. 14.2.4 (37): quoniam ita vobis placet } \\
\text { - fam. 14.1.2 (11): quoniam sperare nos amici iubent } \\
\text { Anmerkung: Auch andere Nebensätze enthalten manchmal eine kausale } \\
\text { Komponente, wie z. B. quam diu vos eritis in spe in fam. } 14.3 .2 \text { (14). }\end{array}$ \\
\hline \multicolumn{2}{|l|}{ (Inter-)Textualität } \\
\hline $\begin{array}{l}\text { Referenz auf vorangehen- } \\
\text { de Kommunikation }\end{array}$ & $\begin{array}{l}\text { Voraussetzung für Kommissiva mit Adressatenpräferenz des } \\
\text { Typs VERSPRECHEN (vgl. Kausalsätze) } \\
\text { Anmerkung: Manchmal erschließt der Sprecher (aufgrund seiner Perso- } \\
\text { nenkenntnis und / oder seines allgemeinen Weltwissens) den Wunsch des } \\
\text { Adressaten, ohne dass dieser einen solchen vorher explizit geäußert hat. }\end{array}$ \\
\hline
\end{tabular}

Abbildung 61: Charakteristika kommissiver Sprechakte

Vorrangiges Mittel zum Ausdruck der motivationalen Einstellung sind Aussagesätze im Indikativ Futur. Daneben finden sich gelegentlich volitiv-evaluative Verben bzw. verbale Wendungen wie velle, cupere, operam dare und in animo esse, die auch im Präsens (cupimus) gebraucht werden können. In seltenen Fällen begegnet zudem ein volitiver Konjunktiv (feramus). ${ }^{1285} \mathrm{Im}$ Unterschied zu den Direktiva wird nicht der Adressat zu etwas aufgefordert, sondern der Sprecher verpflichtet sich selbst zu einer Handlung. Entsprechend steht das Prädikat gewöhnlich nicht in der 2., sondern in der 1. Person, wobei die z. T. uneindeutige Verwendung des Plurals im Lateinischen (bspw. als pluralis modestiae) eine klare Zuordnung manchmal erschwert. Bei den Kommissiva mit Adressatenpräferenz steht zugleich der Briefpartner verstärkt im Fokus. Dies macht sich bspw. durch die relativ häufige Verwendung von Pronomina sowie gelegent-

${ }^{1285}$ Vgl. aber die Anmerkung in Abbildung 61 zu den Brieftempora in fam. 14.1.3 (22) und 14.11 (5). 
lich (in Nebensätzen) Prädikaten in der 2. Person (oder entsprechenden unpersönlichen Wendungen) bemerkbar. Der Sprecher bezieht sich in solchen Nebensätzen, z. B. Kausal- oder Attributsätzen (quoniam ita vobis placet bzw. quae praecipis), oft auf einen zuvor geäußerten Wunsch des Adressaten und begründet damit seine Selbstverpflichtung. Manchmal wird zugleich auf den Inhalt des VERSPRECHENS verwiesen, der im Übrigen auch mit anderen Attribut-, mit indirekten Frage- und Finalsätzen bezeichnet, manchmal aus einem Konditionalsatz (wie si profectus erit oder si quid erit certi) oder aus einer vorangehenden Äußerung (wie bei fam. 14.1.7 (54) und 14.22 (5)) erschlossen werden kann.

Typisch für Sprechakte des Typs VORSATZ BEKUNDEN in fam. 14 sind Verben, die eine Willensbekundung verdeutlichen, wie z. B. operam dare und (non) deficere, während sich in VERSPRECHEN viele Verben finden, die sich auf den Kommunikationsprozess beziehen, wie $z$. B. (con)scribere und besonders certiorem facere. Letztere sind v. a. durch die Kommunikationsart und -situation bedingt, also die Korrespondenz per Brief über eine größere örtliche und zeitliche Distanz hinweg. Entsprechendes gilt für die Dominanz von Verben der Fortbewegung bei Sprechhandlungen des Untermusters ABSICHT BEKUNDEN, wie z. B. se conferre, ire und venire, die - ebenso wie einige zeitliche und $v$. a. lokale Bestimmungen - vor dem Hintergrund der Reisen Ciceros zu sehen sind, auf denen er sich befindet, wenn er Briefe an Terentia schreibt. Hinzu kommen allgemeine Handlungsverben wie agere und facere. Hingegen finden sich keine explizit performativen Verben (wie promittere oder polliceri). ${ }^{1286}$

Da es sich bei kommissiven Sprechakten nicht um FTAs für den Adressaten handelt, sind keine speziellen Höflichkeitsfloskeln oder andere Mittel zur Abschwächung notwendig. Vielmehr könnte der Sprecher eher Maßnahmen ergreifen, um sein eigenes Gesicht zu wahren, wofür sich in den zitierten Beispielen allerdings kaum Anhaltspunkte ergeben. ${ }^{1287}$ Abmildernd sind aber z. B. Konditional- und Temporalsätze, die meist objektiv die Voraussetzungen nennen, unter denen eine Verpflichtung gelten soll, und damit einschränkend wirken. Ansonsten entsprechen höchstens noch der Verzicht auf eine zu große „Selbsterniedrigung" und eine in großen Teilen eher nüchterne Lexik einer solchen Strategie der Gesichtswahrung. Es gibt jedoch andererseits Fälle von stärker emotional gefärbten Sprechakten, die dieser zuwiderlaufen, besonders beim Typ VORSATZ BEKUNDEN, z. T. auch bei VERSPRECHEN. ${ }^{1288}$

Die in den Kommissiva zum Ausdruck gebrachte Willensbekundung wird mit verschiedenen sprachlichen Mitteln intensiviert. Dazu gehören neben verstärkenden Adjektiven und Adverbien, die oft eine superlativische Bedeutung haben bzw. superlativisch oder komparativisch gebraucht werden, auch Finalsätze wie ne omnia mea culpa cecidisse videantur in fam 14.3.2 (14) sowie Kausalsätze und andere Nebensätze (wie z. B. quo modo placuisse scribis amicis in fam. 14.1.3 (17) und quam diu vos eritis in spe in fam. 14.3.2 (14)), die implizit eine Begründung beinhalten.

\footnotetext{
1286 Vgl. a. HALL 2009, 38ff. (zu „Pledges of support“ in fam. 13.41) und ebd., 199 („Pledges and promises“). Er nennt folgende Verben, mit denen ein Versprechen zum Ausdruck gebracht werden könne: adfirmare, confirmare, polliceri, profiteri, promittere, spondere.

1287 Vgl. N. 346 bzw. WÜEST 2011, 44.

1288 Bisweilen sind Anklänge an bestimmte Expressiva zu erkennen, wie z. B. HOFFNUNG ÄUSSERN in fam. 14.2 (37); die kommissive Handlungsfunktion ist aber immer eindeutig dominant. Vgl. dazu z. B. Kap. 2.1.3.
} 
Kommissiva mit Sprecherpräferenz

In den folgenden Äußerungen BEKUNDET Cicero die ABSICHT ${ }^{1289}$ bzw. den VORSATZ, eine bestimmte Handlung zu vollziehen, die nicht unmittelbar im Interesse Terentias liegt, über die sie aber dennoch in Kenntnis gesetzt werden soll, unabhängig davon, ob sie selbst davon betroffen ist (wie z. B. in fam. 14.5) ) $^{1290}$ oder eher nicht (wie z. B. in fam. 14.1.3 (22), 14.1.7 (53) und 14.3.4 (29)):

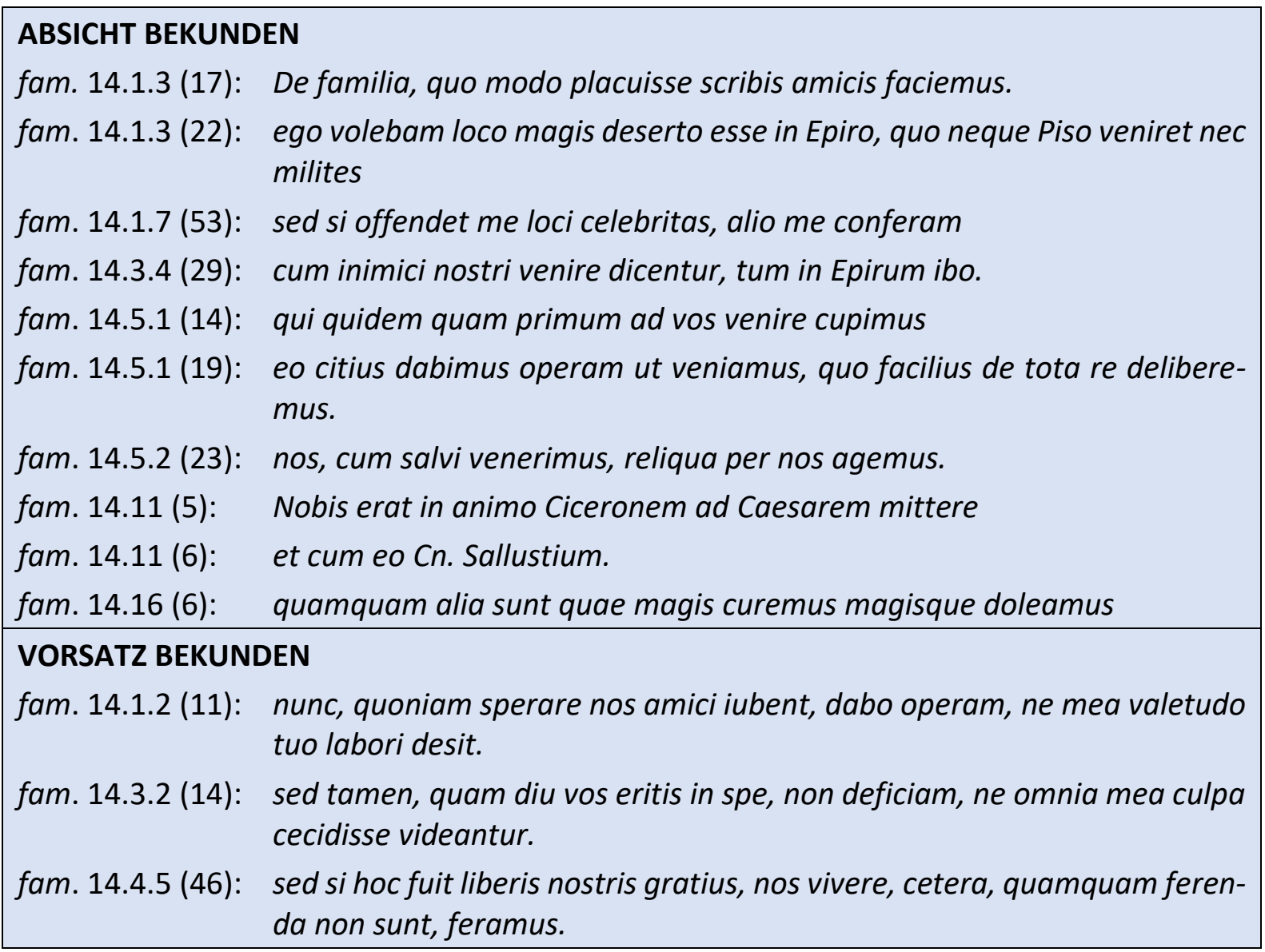

Abbildung 62: Kommissiva mit Sprecherpräferenz

Wichtig ist dabei im Gegensatz z. B. zu den assertiven Sprechhandlungstypen PROGNOSTIZIEREN und ANKÜNDIGEN - wie bei allen Kommissiva - nicht die (zukunftsbezogene) Information an sich, sondern v. a. die Willensbekundung Ciceros. ${ }^{1291}$ Der Unterschied zu den Assertiva ist also durch die motivationale Einstellung begründet. ${ }^{1292}$ Außerdem sind die sprachlich-grammatischen Ausdrucksmöglichkeiten (z. B. fast ausschließliche Verwendung der 1. Person) stärker eingeschränkt.

Fam. 14.5.1 (19) ist etwas speziell, insofern die kommissive Handlungsfunktion durch (quo facilius) de tota re deliberemus repräsentiert wird („Ich beabsichtige, mit dir über die ganze Angelegenheit zu beraten. ") und nicht durch das übergeordnete Satzgefüge eo citius dabimus

\footnotetext{
${ }^{1289}$ Vgl. S. 195 bzw. GRAFFe 1990, $116 f$.

1290 Vgl. Kap. 2.1.2.

${ }^{1291}$ Vgl. a. HALL 2009, 46f. (mit Bezug auf fam. 4.11) und ebd., 203f. zu „Assertions of goodwill“ bzw. benevolentia, studium und voluntas.

1292 Vgl. a. das Kap. zu den „Assertiva“ (ab S. 281).
} 
operam ut veniamus, welches lediglich die stilistische Variation eines bereits zuvor formulierten Sprechaktes darstellt. ${ }^{1293}$

Bei vielen kommissiven Sprechhandlungen ist die (überwiegende) Sprecherpräferenz in erster Linie aufgrund des Kontextes zu bestimmen, insbesondere z. B. in fam. 14.1.2 (11), 14.3.2 (14), 14.5 (14) / (19) / (23) und 14.16 (6). ${ }^{1294}$ Mit quam diu vos eritis in spe und tuo labori sowie durch die Verwendung der 1. Person Plural wird zwar möglicherweise deutlich, dass auch ein gewisses Interesse aufseiten Terentias anzunehmen ist, am Ende steht aber v. a. Ciceros eigenes Schicksal im Zentrum. Dies gilt ebenso für die Fälle, in denen (ebenfalls) die Freunde oder die Kinder erwähnt werden, nach deren Wunsch Cicero handeln will, wie in fam. 14.1.3 (17) bzw. 14.4.5 (46).

Bei den Kommissiva in fam. 14.1.2 (11), 14.3.2 (14) und 14.4.5 (46) tritt im Übrigen noch ein weiterer Aspekt hinzu: Terentia wird nicht nur über Ciceros Vorhaben informiert, sondern soll außerdem als eine Art „Kontrollinstanz“ fungieren. ${ }^{1295}$ Es geht dabei um „eine auf längere Dauer und Kontinuität angelegte Handlung "1296. Solche Sprechhandlungen gehören nicht zum neutralen Sprechakttyp ABSICHT BEKUNDEN, sondern zum Untermuster VORSATZ BEKUN$D E N$, das (in den hier zitierten Beispielen) zudem durch eine insgesamt stärkere Emotionalität gekennzeichnet ist.

Kommissiva mit Adressatenpräferenz

Zumindest oberflächlich stehen bei den Kommissiva des Typs VERSPRECHEN die Interessen des Adressaten im Mittelpunkt. ${ }^{1297}$ Es geht also um die Erfüllung von Terentias Wünschen, welche sie im Vorfeld bereits explizit kundgetan hat oder die Cicero auf Basis eingehender Kenntnisse über seine Ehefrau erschließt oder vermutet:

\section{VERSPRECHEN}

fam. 14.1.7 (54): ad te scribam

fam. 14.2.4 (37): longius, quoniam ita vobis placet, non discedam

fam. 14.3 .3 (16): ego tamen faciam quae praecipis

\footnotetext{
1293 Vgl. S. 197.

${ }^{1294}$ Vgl. Kap. 2.1.2. Fam. 14.16 (6) enthält auch eine direktive Komponente (BITTEN); m. E. überwiegt aber die kommissive Handlungsfunktion. Unabhängig davon ist die Zuordnung insofern problematisch, als die zugrunde liegende Handlung nur eingeschränkt von Cicero beeinflussbar ist, was im Übrigen in ähnlicher Weise für die drei Beispiele des Untermusters VORSATZ BEKUNDEN gilt. VgI. a. N. 1295.

${ }^{1295}$ Vgl. KOHL UND KRANZ 1992, 21: „Der Unterschied zwischen den beiden Sprechakten ABSICHT BEKUNDEN und VORSATZ BEKUNDEN besteht darin, daß sich Sp1 im Falle von VORSATZ BEKUNDEN sich selbst gegenüber verpflichten will und Sp2 eine ,Kontrollinstanz' darstellen soll, während bei ABSICHT BEKUNDEN lediglich eine Festlegung auf zukünftiges Verhalten intendiert ist.“ Vgl. a. GRAFFE 1990, 128: „In der subjektiven Einschätzung von H weiß Sp1, daß er H zwar prinzipiell, jedoch nicht ohne ,innere Schwierigkeiten ' vollziehen kann. Die Kompetenzbedingung ist in diesem Sinne eingeschränkt.“ und ebd., 129: „Sp1 will sich gegenüber Sp2 verpflichtend auf die von ihm in Aussicht genommene Handlung festlegen, um sich selbst in seiner eigenen Steuerungsfähigkeit bezüglich von $\mathrm{H}$ zusätzlich zu unterstützen. Der Vollzug von ,Erinnerungshandlungen' durch Sp2 ist (mit gemischten Gefühlen auf seiten von Sp1) zur Unterstützung dieser Steuerungsfähigkeit erwünscht.“

1296 Ebd., 128.

1297 Vgl. a. WÜEST 2011, 38, der meint, „dass ein Versprechen häufig kein rein altruistischer Akt ist. Wer etwas verspricht, hat häufig wieder etwas gutzumachen (,Ich verspreche, das nie mehr zu tun') oder hofft, etwas Anderes im Gegenzug zu erhalten (,Gib mir von deinem Teller. Ich gebe dir dann von meinem Teller')." Zu den Handlungsbedingungen von VERSPRECHEN vgl. S. 228 bzw. GRAFFE 1990, $189 f$.
} 


\begin{tabular}{|ll} 
fam. $14.7 .2(10):$ & deinde conscribam ad nostros familiaris multas epistulas, quibus te et \\
& Tulliolam nostram diligentissime commendabo. \\
fam. $14.11(7):$ & si profectus erit, faciam te certiorem. \\
fam. $14.22(5):$ & faciemusque te statim certiorem \\
fam. $14.23(5):$ & $\begin{array}{l}\text { cui utrum obviam procedam an hic eum exspectem cum constituero, fa- } \\
\text { ciam te certiorem }\end{array}$ \\
fam. $14.24(6):$ & si quid erit certi, faciam te statim certiorem.
\end{tabular}

Abbildung 63: Kommissiva mit Adressatenpräferenz

In fam. 14.2.4 (37) und fam. 14.3.3 (16) erhellt sich die Adressatenpräferenz deutlich aus dem Nebensatz, in fam. 14.7.2 (10) legt dieser eine solche Präferenz zumindest nahe. Im Übrigen ergibt sich das Interesse Terentias aus ihrem generellen Bedürfnis, über alle wichtigen Angelegenheiten ihres Mannes auf dem Laufenden gehalten zu werden.

Expressiva

Charakteristika im Überblick

Von allen Sprechaktoberklassen sind die Expressiva in fam. 14 mit Abstand am stärksten vertreten. ${ }^{1298}$ Sie zeichnen sich i. A. durch folgende Eigenschaften aus:

\begin{tabular}{|c|c|}
\hline \multicolumn{2}{|l|}{ Allgemeine Semantik } \\
\hline \multirow[t]{2}{*}{ propositionale Einstellung } & emotiv und evaluativ \\
\hline & $\begin{array}{l}\text { Anmerkung: Bei zukunftsbezogenen Sprechakten wie WOHLERGE- } \\
\text { HEN WÜNSCHEN, HOFFNUNG ÄUSSERN, SORGE BEKUNDEN und } \\
\text { ANGST ÄUSSERN wird auch eine epistemische Einstellung vermittelt, } \\
\text { insofern der Ausdruck von Ungewissheit kennzeichnend für sie ist. }\end{array}$ \\
\hline \multirow[t]{2}{*}{ Negation } & $\begin{array}{l}\text { Negationen an sich positiver Inhalte zur negativen Evalu- } \\
\text { ation bzw. an sich negativer Inhalte zur positiven Evalua- } \\
\text { tion }\end{array}$ \\
\hline & $\begin{array}{l}\text { Anmerkungen: } \\
\text { - Vgl. u.: evaluative Verben } \\
\text { Verstärkend wirkt eine doppelte Verneinung (Litotes) wie non } \\
\text { sine lacrimis. }\end{array}$ \\
\hline \multirow[t]{3}{*}{ Lexik insgesamt } & $\begin{array}{l}\text { Expressivität durch individuelle Abwandlung von rituel- } \\
\text { len Formeln (z. B. der Begrüßungs- und Verabschiedungs- } \\
\text { formel) }\end{array}$ \\
\hline & $\begin{array}{l}\text { Abundanz zur Intensivierung der Sprechakte: } \\
\text { überflüssige bzw. nicht unbedingt erforderliche Infor- } \\
\text { mationen, wie z. B. der Temporalsatz cum velitis in } \\
\text { fam. } 14.14 .1(6) \\
\text { Wiederholungen (vgl. u.: besondere Stilmittel) }\end{array}$ \\
\hline & $\begin{array}{l}\text { Vagheit bzw. Auslassen von Informationen als emotiona- } \\
\text { lisierendes Mittel, z. B. bei Sprechakten des Typs ANGST } \\
\text { ÄUSSERN: } \\
\text { - unkonkrete Äußerungen in Verbindung mit seman- } \\
\text { tisch (emotiv und evaluativ) eher neutralen Verben, }\end{array}$ \\
\hline
\end{tabular}

${ }^{1298}$ Vgl. a. Kap. 2.2.1.3. 


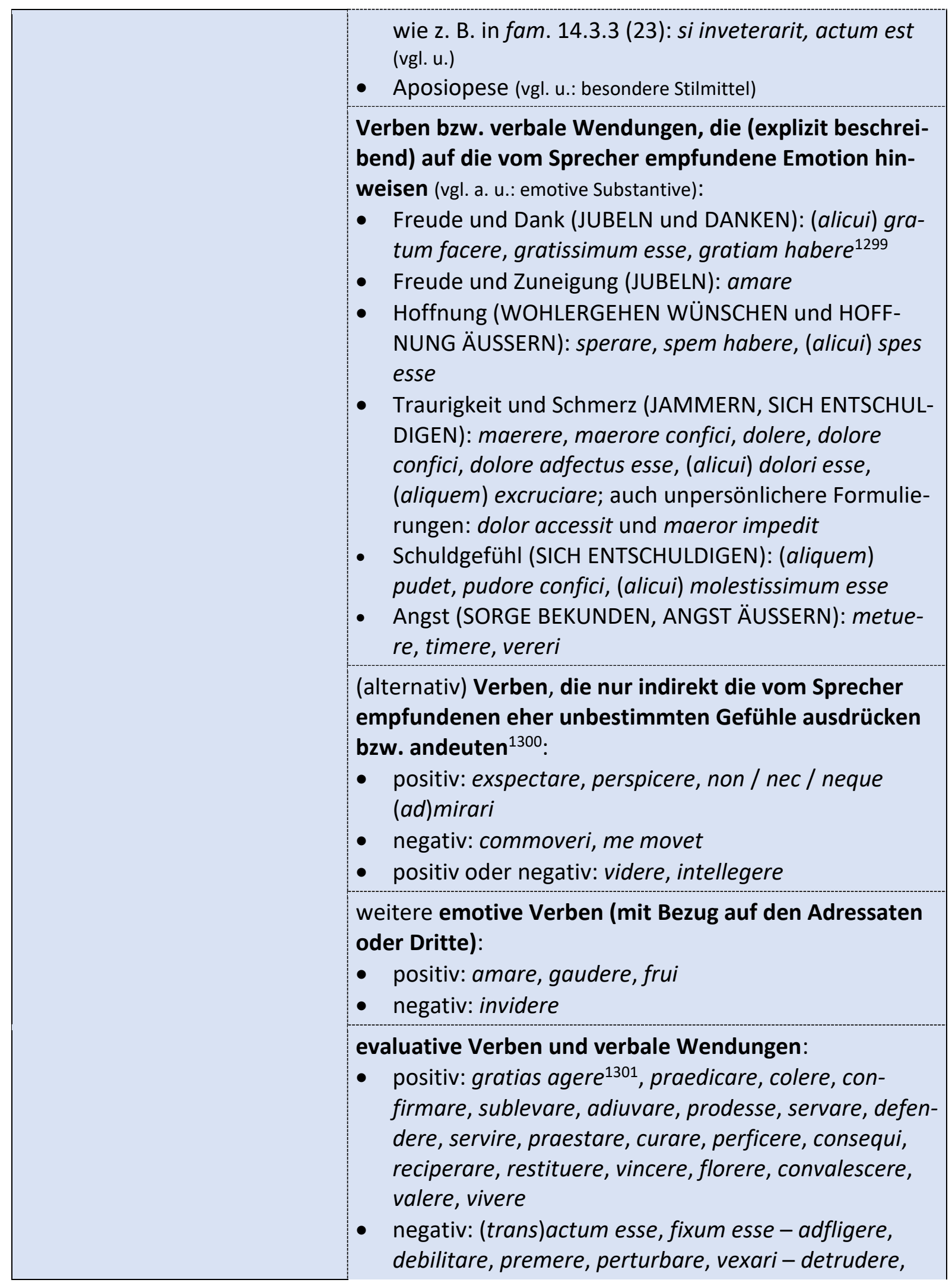

1299 Vgl. N. 1301.

1300 Vgl. S. 365.

${ }^{1301}$ Die Wendung gratias agere wird nicht emotiv i. e. S. gebraucht. Sie kann aber performativ verwendet werden, wofür sich in fam. 14 allerdings kein Beispiel findet. Dagegen bringen gratiam habere und gratissimum esse dem Adressaten gegenüber ein Gefühl von Dankbarkeit zum Ausdruck. Letzteres gilt auch, wenngleich nicht ganz so deutlich, für gratum facere. 


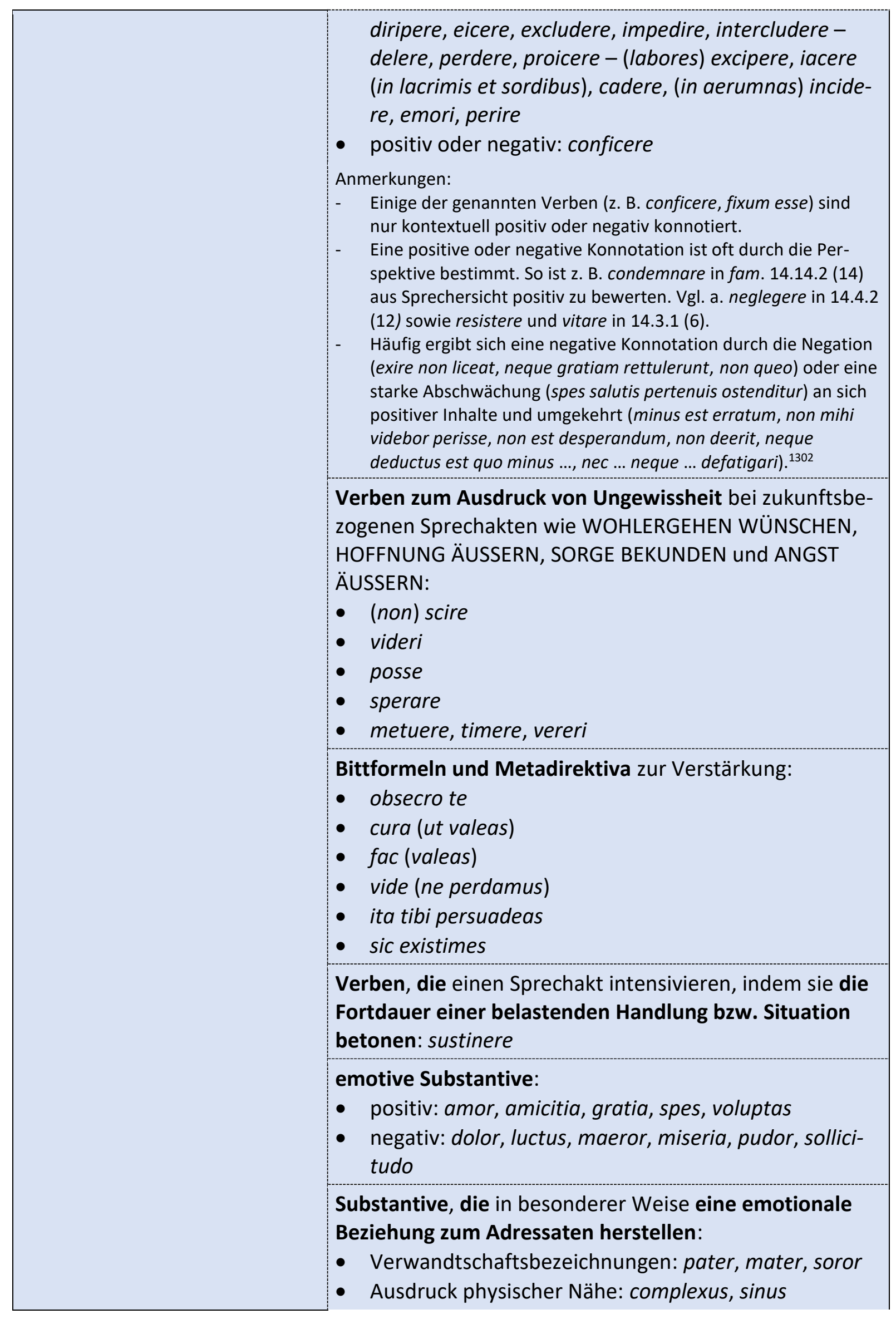

${ }^{1302}$ Vgl. a. fam. 14.4 .5 (47): atque ego, qui te confirmo, ipse me non possum. 
Anmerkung: Die genannten Ausdrücke können sich auch auf enge Familienangehörige wie den Sohn beziehen (vgl. fam. 14.4.3 (28)).

(weitere) evaluative Substantive:

- positiv: commodum, fructus, salus, valetudo, anima, caput, ornamenta, meritum, dignitas, probitas, pietas, virtus, fortitudo, officium, studium, diligentia, fides, humanitas, hospitium, adiumentum, ops

- negativ: malum, calamitas, aerumna, labores, sordes, squalor, lacrimae, fletus, infirmitas, fames, periculum,

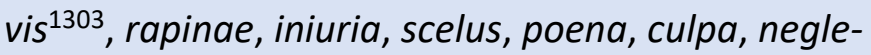
gentia, peccatum, vitium

Substantive, die (bei zukunftsbezogenen Sprechakten wie WOHLERGEHEN WÜNSCHEN, HOFFNUNG bzW. ANGST ÄUSSERN, SORGE BEKUNDEN) ein Gefühl der Ungewissheit oder sogar des Ausgeliefertseins ausdrücken:

- fortuna

- $\operatorname{deus}(d i)$

- spes

\section{Substantive mit verstärkender Wirkung:}

- vis (vis lacrimarum) $)^{1304}$

Personal- und Possessivpronomina bzw. verwandte Pronomina (z. B. ipse) zur Herstellung einer emotionalen Beziehung:

- mit Bezug auf den Sprecher, bes. bei abreagierenden Sprechakten und zur Kontrastierung

- mit Bezug auf den Adressaten, z. B. Possessivpronomina in Anreden: mea Terentia (vgl. u.: Extrapositionen)

- mit Bezug auf nahestehende Dritte: nostra Tulliola, Cicero meus, Pisonem nostrum

Indefinitpronomina zum Ausdruck von Ungewissheit: (ali)quis, aliquid, aliqui / -qua / -quod (vgl. u.: Wortbildung)

\section{Pronomina zur Intensivierung von Sprechakten:}

- verabsolutierende Pronomina bzw. Pronominaladjektive: quisquam, uterque, nullus, nihil

- Pronomina, mit denen die Fortdauer einer belastenden Handlung bzw. Situation betont wird: idem (fam. 14.1.5 (37): si nos premet eadem fortuna)

emotive Adjektive und Adverbien (einschließlich adjektivisch bzw. adverbial gebrauchter Partizipien):

- positiv: beatus bzw. beatissimus, gratus / gratissimus, perbenevolus, amantissime

${ }^{1303}$ Hier ist vis i. S. v. physischer Gewalt gegenüber Menschen gemeint.

${ }^{1304}$ Hier spezifiziert vis lediglich die Menge und Heftigkeit der Tränen. 
- negativ: miser / miserior / miserius, aeger, molestus bzw. molestissimus, timidus, invidus, inimicus

evaluative Adjektive und Adverbien (einschließlich adjektivisch bzw. adverbial gebrauchter Partizipien):

- positiv: bonus / melior / optimus / bene, recte, bellissime, commode / commodissime, tuto, salvus, caute bzw. cautius, fortis / fortior / fortiter / fortissime, strenue, studiosus, diligenter / diligentius / diligentissime, officiosus / officiosior / officiosissimus, observans, fidelis, modeste, castissime, carus bzw. carius, suavis bzw. suavissimus - facilius, celeriter

- negativ: acerbus bzw. acerbissimus, turpis bzw. turpior / turpius, indignus bzw. indignior / indignius, perditus, despoliatus, stultus, improbus bzw. improbissimus, amens - magnus, sero bzw. serius

Anmerkungen:

- $\quad$ Der positive oder negative Wert einiger Adjektive bzw. Adverbien (wie z. B. magnus und sero) ergibt sich in erster Linie aus dem Kontext. Vgl. a. quantus in fam. 14.1.2 (12): res quanta sit intellego.

- $\quad$ Er kann außerdem durch Negation ins Gegenteil verkehrt werden, wie z. B. in fam. 14.12 (3): non facile explicare possimus.

- Vgl. o.: Negation

verstärkende (bzw. abschwächende) Adjektive und Adverbien zur Intensivierung von Sprechakten:

- quantitativ:

- valde, plane, omnino

- magnus / maxime, vehemens bzw. vehementius

- multus / plures bzw. plura / plurimum

- (quasi) verabsolutierend: omnis / omnia, ceterus bzw. ceteri, reliquus / reliqui

○ abschwächend: mediocris, tantum, paulo, satis

- komparativisch-steigernd:

○ etiam

○ ita, sic, tam

○ talis

- tantus

- longe (longe alia in fortuna)

- supra (nihil supra)

- modal:

○ die Einzigartigkeit hervorhebend: singularis, mirificus, incredibilis - proprius (vgl. a. die Possessivpronomina und Pronomina wie ipse: s. o.)

- Gewissheit ausdrückend: firmus, certe, sane

- abschwächend: nescio quo modo

- temporal: 


\begin{tabular}{|c|c|}
\hline & $\begin{array}{l}\text { o brevi tempore, statim, (cum) primum } \\
\text { O konklusiv: tum denique } \\
\circ \text { kontinuativ: perpetuo, semper (vgl. a. die Ad- } \\
\text { verbiale dies noctesque) vs. nec umquam } \\
\text { konzessiv: tamen } \\
\text { Anmerkung: Die hier genannten Gruppen überschneiden sich teilwei- } \\
\text { se. So ist tantus zugleich quantifizierend und komparativisch, semper } \\
\text { ebenso temporal wie verabsolutierend. }\end{array}$ \\
\hline & $\begin{array}{l}\text { (primäre und sekundäre) Interjektionen und ähnliche } \\
\text { Wendungen / Phraseologismen: } \\
\text { - Ausdruck von Traurigkeit und Schmerz: } 0 \text {, hem } \\
\text { - Ausdruck von Ungewissheit (und Schmerz): per } \\
\text { fortunas miseras nostras, di faxint, si di adiuvabunt }\end{array}$ \\
\hline besondere Stilmittel & 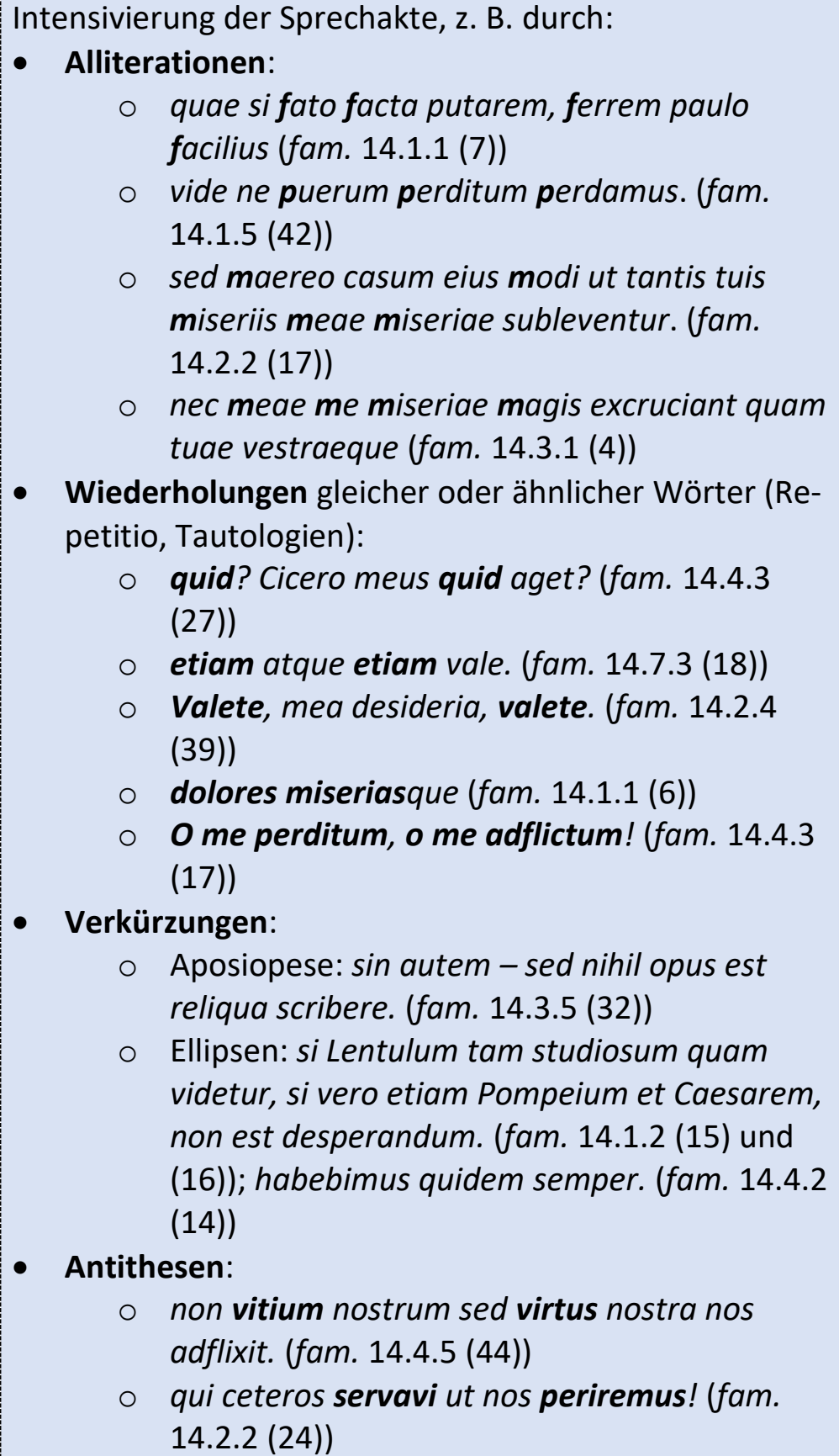 \\
\hline
\end{tabular}


- qui ab iis me amari putabam qui invidebant (fam. 14.1 .1 (8))

- eicere nos magnum fuit, excludere facile est. (fam. 14.3.2 (13))

- vos enim video esse miserrimas, quas ego beatissimas semper esse volui. (fam. 14.2.1 (8))

- Vergleiche:

- Tulliolam, quae nobis nostra vita dulcior est (fam. 14.7.1 (4))

- sic existimes, me vehementius tua miseria quam mea commoveri. (fam. 14.4 .6 (56))

- [intellego] quantoque fuerit facilius manere domi quam redire (fam. 14.1.2 (13))

- ... ut longe alia in fortuna esset atque eius pietas ac dignitas postulabat. (fam. 14.11 (4))

- Hyperbeln:

- ita tibi persuadeas, mihi te carius nihil esse nec umquam fuisse. (fam. 14.3.5 (37))

- cohortarer vos quo animo fortiores essetis nisi vos fortiores cognossem quam quemquam virum. (fam. 14.7.2 (11))

- Pisonis humanitas, virtus, amor in omnis nos tantus est ut nihil supra possit. (fam. 14.1.4 (28))

- Klimax:

- inimici sunt multi, invidi paene omnes. (fam. 14.3.2 (12))

- hoc miserius, turpius, indignius nobis nihil fuit. (fam. 14.3.1 (7))

- Asyndeta:

- te ista virtute, fide, probitate, humanitate in tantas aerumnas propter me incidisse (fam. 14.1.1 (4))

- Polysyndeta:

- meum fuit officium vel legatione vitare periculum vel diligentia et copiis resistere vel cadere fortiter. (fam. 14.3.1 (6))

- nam mi ante oculos dies noctesque versatur squalor vester et maeror et infirmitas valetudinis tuae. (fam. 14.3.2 (10))

Anmerkung: Oft werden verschiedene Stilmittel miteinander verbunden, z. B. Asyndeton, Hyperbel und Klimax in fam. 14.3.1 (7) und fam. 14.1.4 (28), Ellipse, Repetitio (Anapher) und Klimax in fam. 14.1.2 (15), Hyperbel und Vergleich in fam. 14.3 .5 (37) und 14.7.2 (11), Alliteration und Vergleich in fam. 14.3.1 (4), Alliteration und Repetitio in fam. 14.1.5 (42). 


\begin{tabular}{|c|c|}
\hline & $\begin{array}{l}\text { fast nur bei WOHLERGEHENSWÜNSCHEN, z. B. } \\
\text { in Formeln wie vale(te) und cura ut valeas, } \\
\text { aber auch in anderen Äußerungen, wie z. B. } \\
\text { sustenta te, mea Terentia, ut potes honestissi- } \\
\text { me. (fam. 14.4.5 (42)) } \\
\text { Anmerkungen: } \\
\text { Der Konjunktiv findet sich auch in metadirektiver Verwendung } \\
\text { (ita tibi persuadeas, sic existimes) und im Übrigen regulär (kon- } \\
\text { junktionsbedingt) in vielen Nebensätzen. } \\
\text { In seltenen Fällen kann auch ein imperativischer Aufforderungs- } \\
\text { satz dominant expressiv sein, wie z. B. fam. 14.1.5 (42). } \\
\text { Ebenfalls selten sind Gerundiva wie non desperandum est und } \\
\text { etiam illud verendum est. }\end{array}$ \\
\hline Tempus & $\begin{array}{l}\text { - Futur oft bei zukunftsbezogenen Sprechakten des } \\
\text { Typs GUTEN WUNSCH ÄUSSERN, HOFFNUNG ÄUS- } \\
\text { SERN, SORGE BEKUNDEN und ANGST ÄUSSERN } \\
\text { sonst meist Gegenwarts- und Vergangenheitstempo- } \\
\text { ra, z. B. } \\
\text { O Präsens bei Hinweisen auf die (eigene) Emo- } \\
\text { tion (spero, metuo, maereo, ...) } \\
\text { O Perfekt oft bei Expressiva des Typs FLUCHEN } \\
\text { Anmerkung: Ein Zukunftsbezug kann auch anderweitig vermittelt } \\
\text { werden, z. B. durch bestimmte Adverbien wie perpetuo, Verben wie } \\
\text { sperare, metuere oder auch posse und Wendungen wie oportet und } \\
\text { opus est sowie durch Gerundiva, den Imperativ oder einen futuri- } \\
\text { schen Konjunktiv. }\end{array}$ \\
\hline \multicolumn{2}{|l|}{ Syntax } \\
\hline Satzart & $\begin{array}{l}\text { - meist Aussagesätze } \\
\text { len aversiven Expressiva: } \\
\text { oxklamativer Infinitiv (JAMMERN und SICH } \\
\text { ENTSCHULDIGEN): } \\
\text { - Tulliolamque nostram, ex quo patre tan- } \\
\text { tas voluptates capiebat, ex eo tantos } \\
\text { percipere luctus! (fam. } 14.1 .1 \text { (5)) } \\
\text { te ista virtute, fide, probitate, huma- } \\
\text { nitate in tantas aerumnas propter me } \\
\text { incidisse (fam. 14.1.1 (4)) } \\
\text { hem, [...] te nunc, mea Terentia, sic } \\
\text { vexari, sic iacere in lacrimis et sordibus, } \\
\text { idque fieri mea culpa (fam. 14.2.2 (21) } \\
\text { und (23)) } \\
\text { exklamativer Akkusativ (JAMMERN): } \\
\text { me miserum (fam. 14.1.1 (3) und } \\
\text { 14.1.5 (36)) } \\
\text { O me perditum, o me adflictum! (fam. } \\
14.4 .3 \text { (17)) }\end{array}$ \\
\hline
\end{tabular}


- Wunschsätze meist bei Expressiva mit Sprecherpräferenz (HOFFNUNG ÄUSSERN) oder mit beidseitiger Präferenz (WOHLERGEHEN WÜNSCHEN):

○ mit utinam:

- utinam ea res ei voluptati sit! (fam. 14.1.4 (29))

- huic utinam aliquando gratiam referre possimus! (fam. 14.4.2 (13))

- aber auch JAMMERN: quod utinam minus vitae cupidi fuissemus! (fam. 14.4.1(5))

○ mit velim:

- Tu quod me hortaris ut animo sim magno et spem habeam reciperandae salutis, id velim sit eius modi ut recte sperare possimus. (fam. 14.4 .5 (39))

- Quod nos in Italiam salvos venisse gaudes, perpetuo gaudeas velim. (fam. $14.12(2))$

- Valetudinem tuam velim cures diligentissime. (fam. 14.8 (3))

- tu velim tuam et Tulliae valetudinem cures. (fam. 14.9 (4))

○ ohne einleitende Konjunktion:

- ad summam animo forti sitis. (fam. 14.14.2 (12))

- iste vero sit in sinu semper et complexu meo. (fam. 14.4.3 (28))

- di faxint, ut tali genero mihi praesenti tecum simul et cum liberis nostris frui liceat! (fam. 14.3.3 (21))

- Fragesätze, v. a. zum Ausdruck von Ungewissheit bei aversiven Expressiva wie ANGST ÄUSSERN und (seltener) SORGE BEKUNDEN:

- sin eadem nos fortuna premet, etiamne reliquias tuas miseras proicies? (fam. 14.2.3 (29))

- Quod ad me, mea Terentia, scribis te vicum vendituram, quid, obsecro te, [...] quid futurum est? (fam. 14.1.5 (35))

- et si nos premet eadem fortuna, quid puero misero fiet? (fam. 14.1.5 (37))

- aber auch JAMMERN: nam quid ego de Cicerone dicam? qui cum primum sapere coepit, acerbissimos dolores miseriasque percepit. (fam. 14.1.1 (6)) 


\begin{tabular}{|c|c|}
\hline & $\begin{array}{l}\text { Viele (v. a. rituelle) WOHLERGEHENSWÜNSCHE haben die Form } \\
\text { eines Aufforderungssatzes im Imperativ, obwohl es sich eigent- } \\
\text { lich um Wunschsätze handelt.1305 } \\
\text { - Auch indirekte Fragesätze können dem Ausdruck von Ungewiss- } \\
\text { heit dienen, wie z. B. fam. } 14.9 \text { (3): omnino de omnibus rebus nec } \\
\text { quid consili capiam nec quid faciam scio. }\end{array}$ \\
\hline \multirow[t]{2}{*}{$\begin{array}{l}\text { adverbiale Bestimmungen und } \\
\text { Adverbialsätze }\end{array}$} & $\begin{array}{l}\text { Konditionalsätze zum Ausdruck von Ungewissheit durch } \\
\text { Benennung von Eventualitäten: } \\
\text { positiv (HOFFNUNG ÄUSSERN): } \\
\text { si Lentulum tam studiosum quam videtur, si vero } \\
\text { etiam Pompeium et Caesarem, non est } \\
\text { si erunt in officio amici, pecunia non deerit (fam. } \\
\text { 14.1.5 (40)) } \\
\text { quod si conficitur negotium, omnia consequemur } \\
\text { (fam. 14.2.3 (28)) } \\
\text { nos, si di adiuvabunt, circiter Id. Nov. in Italia spe- } \\
\text { ramus fore. (fam. 14.5.2 (26)) } \\
\text { negativ (ANGST ÄUSSERN): } \\
\text { et si nos premet eadem fortuna, quid puero misero } \\
\text { fiet? (fam. } 14.1 .5 \text { (37)) } \\
\text { si non erunt, tu efficere tua pecunia non poteris. } \\
\text { (fam. } 14.1 .5 \text { (41)) } \\
\text { si haec mala fixa sunt, ego vero te quam primum, } \\
\text { mea vita, cupio videre et in tuo complexu emori } \\
\text { (fam. 14.4.1 (7)) } \\
\text { den für einen expressiven Sprechakt mit beidseitiger Präferenz wie } \\
\text { ar Dolabellam eamque rem posse nobis adiumento esse si quae vis } \\
\text { aut si quae rapinae fieri coeperint (fam. 14.18.1 (3)). }\end{array}$ \\
\hline & $\begin{array}{l}\text { adverbiale Bestimmungen und Adverbialsätze zur Inten- } \\
\text { sivierung und / oder Emotionalisierung von Sprechakten: } \\
\text { temporal: } \\
\text { o dies noctesque - semper, ... (vgl. o.: allgemeine Lexik - } \\
\text { verstärkende Adjektive und Adverbien) } \\
\text { modal: } \\
\text { Adverbialien: non sine plurimis lacrimis, maximo } \\
\text { cum fletu, in lacrimis et sordibus (iacere), diligen- } \\
\text { tia (resistere) - diligenter, fortissime et amantissi- } \\
\text { me, sane strenue, ... (vgl. o.: allgemeine Lexik) } \\
\text { Komparativsätze (WOHLERGEHEN WÜNSCHEN): } \\
\text { ut potes honestissime, quod potes (vgl. o.: besondere } \\
\text { Stilmittel - Vergleiche) } \\
\text { kausal: } \\
\text { propter me, mea culpa, merito tuo, merito eius }\end{array}$ \\
\hline
\end{tabular}

${ }^{1305}$ Vgl. die mit velim eingeleiteten Wunsch- bzw. Aufforderungssätze. Vgl. a. N. 1337. 


\begin{tabular}{|c|c|}
\hline & $\begin{array}{l}\text { - konzessiv und adversativ (bei aversiven Expressiva): } \\
\text { o konzessiv: (te) ista virtute, fide, probitate, humani- } \\
\text { tate (in tantas aerumnas incidisse) } \\
\text { adversativ: } \\
\text { - sed Crassum tamen metuo. (fam. 14.2.2 } \\
\text { (15)) } \\
\text { quae si, tu ut scribis, fato facta putarem, } \\
\text { ferrem paulo facilius; sed omnia sunt mea } \\
\text { culpa commissa (fam. 14.1.1 (7)) } \\
\text { - sed rursus illud me movet, quod video } \\
\text { omnis bonos abesse Roma (fam. 14.18.1 } \\
\text { (4)) } \\
\text { - konditional (WOHLERGEHEN WüNSCHEN): } \\
\text { o vos, mea suavissima et optatissima Terentia, si } \\
\text { nos amatis, curate ut valeatis. (fam. 14.5.2 (27)) } \\
\text { maxime autem date operam ut valeatis, si nos } \\
\text { vultis valere. (fam. } 14.18 .2 \text { (14)) }\end{array}$ \\
\hline Attribute & $\begin{array}{l}\text { Attribute und Attributsätze zur emotionalen Einfärbung } \\
\text { und Intensivierung von Sprechakten: } \\
\text { - Attribute: satis magnum (fructum) et vestrae pietatis } \\
\text { et meae, (animo) forti, (valetudinem) infirmam, (spes) } \\
\text { salutis pertenuis, (fortunas) miseras, acerbissimos (do- } \\
\text { lores miseriasque) - suavissima et optatissima (Teren- } \\
\text { tia), fidissima atque optima (uxor), (mulierem) aegram } \\
\text { - optimae, suavissimae (sorori), carissima (filiola), sua- } \\
\text { vissimae (filiae), suavissimis (liberis), suavissimus (Cice- } \\
\text { ro), (puerum) perditum, (puero) misero - (homo) offi- } \\
\text { ciosus / officiosissimus, (hominem) fidelem, (homo) } \\
\text { amens, aut stultorum (amicorum) aut improborum (vgl. } \\
\text { o.: allgemeine Lexik - emotive und evaluative Adjektive und Ad- } \\
\text { verbien) } \\
\text { - Attributsatz: qui invidebant } \\
\text { Anmerkung: Adjektive (und Substantive) können auch in prädikativer } \\
\text { Verwendung eine entsprechende Wirkung entfalten. Vgl. z. B. beatissi- } \\
\text { mi in fam. } 14.1 .2 \text { (10), salvi in 14.5.2 (24), timidi in 14.2.1 (10) sowie } \\
\text { inimici und invidi in 14.3.2 (12). }\end{array}$ \\
\hline Extrapositionen & $\begin{array}{l}\text { affektive Anreden und andere Appositionen: } \\
\text { mit Bezug auf den / die Adressaten (Terentia und Tul- } \\
\text { suavissima et optatissima Terentia, fidissima atque } \\
\text { optima uxor, mea vita, mea desideria, duabus animis } \\
\text { suis, lux nostra } \\
\text { mit Bezug auf Dritte (oft bei JUBELN): homo officiosus, } \\
\text { homo officiosissimus, hominem fidelem, virum opti- } \\
\text { mum }\end{array}$ \\
\hline
\end{tabular}


Parenthesen und andere (emotive und evaluative) Einschübe bzw. Nachträge:

- valde enim illum amavi (fam. 14.5 .2 (22))

- nec miror (fam. 14.2.2 (16))

- sane strenue (fam. $14.5 .1(7))$

(Inter-)Textualität

Referenz auf vorangehende Kommunikation
- i. A. vorauszusetzen bei sympathisierenden Sprechakten wie DANKEN, (etwas) BEGRÜSSEN, KOMPLIMENT MACHEN SOWie BEDAUERN BEKUNDEN und SICH ENTSCHULDIGEN

- eher nicht gegeben bei den (sprecherfokussierten) abreagierenden Sprechakten

Abbildung 64: Charakteristika expressiver Sprechakte

Mit expressiven Sprechakten drückt der Sprecher Gefühle aus, die er tatsächlich empfindet oder die von ihm aufgrund gesellschaftlicher Konventionen erwartet werden. ${ }^{1306}$ Letzteres trifft v. a. auf Sprechakttypen wie DANKEN und SICH ENTSCHULDIGEN zu. ${ }^{1307}$ I. A. sind die betreffenden (sympathisierenden) Sprechakte - im Unterschied zu den (sprecherfokussierten) abreagierenden Sprechakten, in denen spontane Gefühle zum Ausdruck gebracht werden ${ }^{1308}$ - reaktiv, d. h., sie referieren auf die vorangehende Kommunikation oder direkt auf eine vorangehende Handlung des Adressaten bzw. einen sich darauf beziehenden Bericht Dritter. ${ }^{1309}$

1306 Während bei den Direktiva v. a. die „redressive politeness“ wichtig ist, spielt bei den Expressiva in fam. 14 die „affiliative politeness“ (zur Herstellung von Verbundenheit und Nähe) eine besondere Rolle. Vgl. das Kap. „Höflichkeit“ (ab S. 69). Vgl. außerdem N. 1308. Wie in unserer heutigen konnte man auch in der römischen Gesellschaft nicht von der Authentizität der zum Ausdruck gebrachten Gefühle ausgehen, obwohl Aufrichtigkeit und Integrität im Prinzip wertgeschätzt wurden: Vgl. z. B. DICKEY 2016, 204. Dabei schließt eine Beachtung der Höflichkeitskonventionen echte Gefühle nicht aus, und zwar i. A. umso mehr, je individueller die Ausformulierung eines Sprechaktes gestaltet wird. Eine Nicht-Beachtung kann einen Affront darstellen und damit äußerst emotionalisierend wirken. Vgl. a. ORTNER 2014b, 272: „Höflichkeit und Unhöflichkeit bilden [...] ein Kontinuum mit vielen Abstufungen und Übergangsformen. Unhöflichkeit ist kein markiertes, sekundäres Phänomen, sondern in manchen Kommunikationssituationen [...] durchaus normal [...]. Allerdings sind nicht alle unhöflichen Strategien und Täuschungen emotiv und umgekehrt nicht alle negativen emotionalen Argumente unhöflich [...]. " Vgl. im Übrigen das Kap. „Besonderheiten der Expressiva“ ab S. 28.

1307 Weitere Beispiele für Sprechakttypen, mit denen soziale Gefühle vermittelt werden, sind KOMPLIMENT MACHEN und (etwas) BEGRÜSSEN ( $\rightarrow$ Lobemotionen) sowie Expressiva des Typs BEDAUERN BEKUNDEN, v. a. der Untertyp KONDOLIEREN ( $\rightarrow$ Empathieemotionen). Vgl. MARTEN-CLEEF 1991, $275 \mathrm{ff.}$

1308 Durch die Rücksichtnahme auf die Gefühle des Adressaten mittels den Höflichkeitskonventionen entsprechender sympathisierender Sprechakte zeigt der Sprecher Wertschätzung, wodurch ebenso wie durch den Ausdruck eigener Gefühle und die damit verbundene Signalisierung von Vertrauen und Vertrautheit eine intensive emotionale Nähe hergestellt werden kann. Eine strikte Abgrenzung zwischen sozialen und spontanen Gefühlen ist kaum möglich. Vgl. a. N. 1314.

${ }^{1309}$ Eine solche intertextuelle Bezugnahme ist auch bei opponierenden Sprechakten anzunehmen, welche in fam. 14 aber nicht begegnen. Mit ,direkt' ist im vorliegenden Zusammenhang im Übrigen gemeint, dass in der vorangehenden Kommunikation (noch) kein Bezug auf die Handlung des Adressaten genommen wurde, von welcher der Sprecher entweder durch persönliche Anschauung vor der räumlichen Trennung, welche die aktuelle Briefkommunikation notwendig macht, oder auf irgendeinem anderen Wege (wie einem Bericht Dritter) erfahren hat. 
Als Grundemotionen können Freude, Traurigkeit, Ärger und Angst zählen. ${ }^{1310}$ Über Anzahl und Art weiterer Emotionen herrscht in der Forschung, in erster Linie der Emotionspsychologie, keine Einigkeit. Von den öfter angeführten Emotionen sind für die vorliegende Arbeit nur Zuneigung und Scham wirklich relevant. ${ }^{1311}$ Zu ergänzen sind außerdem Hoffnung ${ }^{1312}$ als positive Korrelation zu Angst und Dankbarkeit als Variante von Freude. Hinzu kommen (sekundäre) Gefühle wie Zufriedenheit, Bewunderung und Stolz, die man ebenfalls als Unterkategorien von Freude (bzw. Zuneigung) betrachten kann, sowie Mitleid und Schuld als spezielle Erscheinungsformen von Traurigkeit (bzw. Ärger und Scham).

Für die genannten Emotionen existieren zahlreiche verschiedene Begriffe, die man nach unterschiedlichen Kriterien differenzieren kann ${ }^{1313}$, die teilweise aber auch (quasi) synonym gebraucht werden (z. B. Zuneigung und Sympathie, Angst und Furcht). So kann man Gefühle wie Freude und Ärger nach ihrem Intensitätsgrad auf einer Skala anordnen: Zufriedenheit Freude - Begeisterung - Ekstase, Missmut - Ärger - Wut - Zorn. ${ }^{1314}$ Häufig werden Gefühle nach ihrer Valenz (positiv: Freude, Hoffnung, Zuneigung - negativ: Traurigkeit, Angst, Abneigung) unterschieden. Möglich ist außerdem eine Differenzierung danach, wer Betroffener und wer Urheber eines emotionsauslösenden Sachverhaltes ist, also Sprecher (Sp), Adressat (Ad), eine dritte Person $\left(P_{3}\right)$ oder eine nicht-personale Quelle (O). Bei von Ungewissheit geprägten erwartungsorientierten Gefühlen wie Hoffnung, Angst und Sorge ${ }^{1315}$ bleibt der Verursacher meist eher unbestimmt (N). Eine weitere Unterscheidung kann danach erfolgen, ob ein Gefühl ereignis-, handlungs- oder objektfundiert ist, wobei die Abgrenzung nicht immer eindeutig ist, wie z. B. im Falle von KOMPLIMENTEN, mit denen Freude und Zuneigung bekundet werden, die im Grunde zwar objektfundiert sind und sich auf bestimmte Eigenschaften des Adressaten (z. B. Hilfsbereitschaft) beziehen können, welche sich jedoch wiederum in bestimmten

\footnotetext{
${ }^{1310}$ Vgl. ORTNER 2014b, 24. Als ,Grundemotionen' gelten in dieser Arbeit die das jeweilige Untermuster gem. den Definitionen in MARTEN-CLeEF 1991 bestimmenden Gefühle. ,Sekundäremotionen' stellen spezielle Nuancen oder zusätzlich vermittelte Emotionen dar. Vgl. a. ebd., 59ff. Vgl. außerdem ORTNER 2014b, 22f. zu ,Basisemotionen', die oft als kulturell universelle Gefühle gelten. Bei beiden finden sich z. T. abweichende Definitionen und Begrifflichkeiten.

${ }^{1311}$ Vgl. ebd., 22ff. Häufig genannte grundlegende Emotionen sind danach u. a. noch Verachtung, Abscheu und Überraschung.

1312 Vgl. a. KAZANTZIDIS UND SPATHARAS 2018b, 3ff. zur Frage, ob Hoffnung lediglich als „(controllable) state of mind“ oder tatsächlich als Emotion i. e. S. betrachtet werden sollte. Vgl. außerdem ebd., 10ff. zum Bedeutungsspektrum von lat. spes (vs. metus).

${ }^{1313}$ So kann man Emotionen bspw. nach Auslöser, Dauer und Manifestation weiter differenzieren. Vgl. z. B. ORTNER 2014b, 347. Vgl. a. ebd., 184ff. (zu „Kategorien der Systematisierung“ von Emotionen wie u. a. Unmittelbarkeit, Explizitheit, Intensität und Involviertheit) sowie ARNDT UND JANNEY 1987, 330: „Three emotive dimensions of speech have been isolated and given considerable attention in clinical and social psychology: (1) the confidence dimension, or control dimension [...], which is inferred from cues of assertiveness/nonassertiveness or self-confidence/insecurity; (2) the positive-negative dimension, or evaluative dimension, which is inferred from cues of positive/negative value-ladenness; and (3) the involvement dimension, or intensity dimension, which is inferred from cues of emotional or interpersonal involvement/uninvolvement. " Vgl. außerdem N. 1314.

1314 Vgl. a. ORTNER 2014b, 23f. zur Dimensionierung von Emotionen und zu diskreten Emotionskategorien. Vgl. außerdem die detaillierteren Ausführungen zu den einzelnen expressiven Untermustern in den folgenden Teilkapiteln.

${ }^{1315}$ Vgl. a. MARTEN-CLEEF 1991, 63. Im Gegensatz zu den Zuordnungen in der dort abgebildeten Tabelle wird Sorge hier als Variante des Gefühls Angst und nicht des Gefühls Traurigkeit eingeordnet. Auch sonst finden sich gelegentlich Abweichungen.
} 
Handlungen (z. B. Unterstützung anderer in einer schwierigen Situation) äußern, also auch handlungsorientiert sind. ${ }^{1316}$

Ordnet man die Emotionen den in fam. 14 vertretenen expressiven Untermustern zu, ergibt sich damit insgesamt folgendes Bild:

\begin{tabular}{|c|c|c|c|c|c|c|c|c|}
\hline & $\begin{array}{l}\text { Grund- } \\
\text { emotion }\end{array}$ & $\begin{array}{l}\text { Sekundär- } \\
\text { emotionen }\end{array}$ & $\begin{array}{l}\text { Betroffe- } \\
\text { ner }\end{array}$ & $\begin{array}{l}\text { Urhe- } \\
\text { ber }\end{array}$ & $\begin{array}{l}\text { ereignis- } \\
\text { fundiert }\end{array}$ & $\begin{array}{l}\text { handlungs- } \\
\text { fundiert }\end{array}$ & $\begin{array}{l}\text { objekt- } \\
\text { fundiert }\end{array}$ & Weiteres \\
\hline \multicolumn{9}{|c|}{ positive Emotionen: beidseitige Präferenz } \\
\hline DANKEN & Freude & Dankbarkeit & $\mathrm{Sp}$ & $\mathrm{Ad}$ & & v & & $\begin{array}{l}\text { soziale } \\
\text { Emotion }\end{array}$ \\
\hline BEGRÜSSEN & Freude & $\begin{array}{l}\text { Zufrieden- } \\
\text { heit }\end{array}$ & Sp & $\mathrm{Ad}$ & & $\mathrm{v}$ & & $\begin{array}{l}\text { (soziale) Lob- } \\
\text { emotion }\end{array}$ \\
\hline $\begin{array}{l}\text { KOMPLIMENT } \\
\text { MACHEN }\end{array}$ & Freude & $\begin{array}{l}\text { Bewunde- } \\
\text { rung }\end{array}$ & $\mathrm{P}_{3}$ oder $\mathrm{O}$ & $\mathrm{Ad}$ & & $(\sqrt{ })$ & v & $\begin{array}{l}\text { (soziale) Lob- } \\
\text { emotion }\end{array}$ \\
\hline $\begin{array}{l}\text { GUNST ER- } \\
\text { WEISEN }\end{array}$ & Freude & Zuneigung & $\mathrm{Sp}$ & $\mathrm{Ad}$ & & & v & $\begin{array}{l}\text { (soziale } \\
\text { Emotion) }\end{array}$ \\
\hline $\begin{array}{l}\text { WOHLERGE- } \\
\text { HEN WÜN- } \\
\text { SCHEN }\end{array}$ & Hoffnung & & $\mathrm{Ad}$ & $\mathrm{N}$ & $\mathrm{v}$ & $(\mathrm{V})$ & & $\begin{array}{l}\text { (soziale und) } \\
\text { erwartungs- } \\
\text { orientierte } \\
\text { Emotion }\end{array}$ \\
\hline \multicolumn{9}{|c|}{ positive Emotionen: Sprecherpröferenz } \\
\hline FROHLOCKEN & Freude & Stolz & Sp oder $\mathrm{P}_{3}$ & $\mathrm{Sp}$ & & $v$ & & $\begin{array}{l}\text { (Selbstlob- } \\
\text { emotion) }\end{array}$ \\
\hline JUBELN & Freude & $\begin{array}{l}\text { Dankbar- } \\
\text { keit, Zunei- } \\
\text { gung, Wert- } \\
\text { schätzung }\end{array}$ & Sp oder $\mathrm{P}_{3}$ & $\begin{array}{l}\mathrm{P}_{3} \\
\text { oder O }\end{array}$ & $\mathrm{v}$ & $v$ & & \\
\hline $\begin{array}{l}\text { HOFFNUNG } \\
\text { ÄUSSERN }\end{array}$ & Hoffnung & & Sp oder $\mathrm{P}_{3}$ & $\mathrm{~N}$ & $\mathrm{~V}$ & $(\sqrt{ })$ & & $\begin{array}{l}\text { erwartungs- } \\
\text { orientierte } \\
\text { Emotion }\end{array}$ \\
\hline \multicolumn{9}{|c|}{ negative Emotionen: beidseitige Aversion } \\
\hline $\begin{array}{l}\text { BEDAUERN } \\
\text { BEKUNDEN }\end{array}$ & $\begin{array}{l}\text { Traurig- } \\
\text { keit }\end{array}$ & $\begin{array}{l}\text { Mitleid, } \\
\text { Mitgefühl }\end{array}$ & $\mathrm{Ad}$ & $\begin{array}{l}\mathrm{P}_{3} \\
\text { oder O }\end{array}$ & $\mathrm{v}$ & v & & $\begin{array}{l}\text { (soziale } \\
\text { Emotion) }\end{array}$ \\
\hline $\begin{array}{l}\text { SORGE BE- } \\
\text { KUNDEN }\end{array}$ & Angst & Sorge & $\mathrm{Ad}$ & $\mathrm{N}$ & $\mathrm{v}$ & ( $v)$ & & $\begin{array}{l}\text { (soziale und) } \\
\text { erwartungs- } \\
\text { orientierte } \\
\text { Emotion }\end{array}$ \\
\hline $\begin{array}{l}\text { SICH ENT- } \\
\text { SCHULDIGEN }\end{array}$ & $\begin{array}{l}\text { Traurig- } \\
\text { keit }\end{array}$ & $\begin{array}{l}\text { Schuld, } \\
\text { Scham, Är- } \\
\text { ger }\end{array}$ & Ad & $S p$ & & v & & $\begin{array}{l}\text { soziale } \\
\text { Selbstvor- } \\
\text { wurfsemo- } \\
\text { tion }\end{array}$ \\
\hline \multicolumn{9}{|c|}{ negative Emotionen: Sprecheraversion } \\
\hline JAMMERN & $\begin{array}{l}\text { Traurig- } \\
\text { keit }\end{array}$ & Leid & Sp oder $\mathrm{P}_{3}$ & $\begin{array}{l}\mathrm{Sp}, \mathrm{P}_{3} \\
\text { oder O }\end{array}$ & $\mathrm{v}$ & & & \\
\hline FLUCHEN & Ärger & $\begin{array}{l}\text { Empörung, } \\
\text { Abneigung }\end{array}$ & Sp oder $\mathrm{P}_{3}$ & $\begin{array}{l}\mathrm{Sp}, \mathrm{P}_{3} \\
\text { oder O }\end{array}$ & $\mathrm{v}$ & $v$ & & $\begin{array}{l}\text { (Selbst-)Vor- } \\
\text { wurfsemo- } \\
\text { tion }\end{array}$ \\
\hline
\end{tabular}

1316 KOMPLIMENTE können sich aber z. B. auch auf den Reichtum und die Besitztümer des Adressaten beziehen. Vgl. das Kap. „Weitere Expressiva mit beidseitiger Präferenz“ (ab S. 349). 


\begin{tabular}{|l|l|l|l|l|l|l|l|l|}
\hline $\begin{array}{l}\text { ANGST ÄUS- } \\
\text { SERN }\end{array}$ & Angst & Sp oder $P_{3}$ & $N$ & $V$ & $(V)$ & $\begin{array}{l}\text { erwartungs- } \\
\text { orientierte } \\
\text { Emotion }\end{array}$ \\
\hline
\end{tabular}

Abbildung 65: Expressive Untermuster und Emotionsdifferenzierung

Die Identifizierung von Expressiva wird mehr noch als die von Sprechakten der anderen Oberklassen durch die prinzipiell immer gegebene Multifunktionalität erschwert, da alle Äußerungen mehr oder weniger emotiv sind. ${ }^{1317}$ Von einem expressiven Sprechakt kann jedoch nur gesprochen werden, wenn der Gefühlsausdruck gegenüber anderen Handlungsfunktionen dominant ist. Das Problem stellt sich insbesondere bei der Abgrenzung von vielen assertiven Sprechakten. ${ }^{1318}$ Werden Emotionen z. B. lediglich (objektiv) beschrieben, überwiegt oft die Informationsfunktion. Andererseits kann eine scheinbar neutrale, sehr vage gehaltene Äußerung (kontextuell bedingt) hochemotional sein und als vorrangiges Ziel den Ausdruck starker Gefühle verfolgen. Im Übrigen enthalten die Expressiva in fam. 14 grundsätzlich eine assertive Komponente, insofern Cicero dem Informationsbedürfnis seiner Frau nachkommt, die i. A. großes Interesse an seinem Seelen- und Gefühlszustand haben wird. ${ }^{1319}$ Aber auch zu den Kommissiva und Direktiva bestehen z. T. starke Verbindungen. So erinnert die volitive Wendung te quam primum cupio videre in fam. 14.4.1 (7) an ein kommissives Untermuster wie ABSICHT BEKUNDEN. ${ }^{1320}$ Die ziemlich häufig begegnenden Fragesätze weisen auf den ersten Blick eigentlich auf Fragehandlungen hin. ${ }^{1321}$ Ein Imperativsatz wie in fam. 14.1 .5 (42) signalisiert zunächst einmal eine direktive Aufforderungshandlung. Viele Expressiva enthalten tatsächlich eine direktive (persuasive) Komponente, insofern sie emotional auf Terentia einwirken und mehr oder weniger subtilen Einfluss auf ihre Handlungsweise ausüben. Bei Sprechakten, in denen die direktive Handlungsfunktion überwiegt, steht eine (direkte) Einwirkung auf den Adressaten dagegen im Vordergrund. Aufforderungen werden durch Emotionalisierung verstärkt.

Es ist also nicht immer einfach zu beurteilen, ob in einer Äußerung der Gefühlsausdruck dominiert. Ebenfalls schwierig gestaltet sich häufig die genaue Zuordnung zu einem spezifischen Gefühlszustand bzw. Untermuster. Oft ist der Kontext entscheidend, und dabei gerät man leicht in Gefahr, sich zu sehr von alltagspsychologischen Vorstellungen beeinflussen zu lassen. ${ }^{1322}$ Als Linguist ist man deshalb eigentlich umso mehr gehalten, sprachliche Indikatoren zu beachten. Es geht schließlich nicht um eine psychologische Analyse, sondern darum, die Emotionen zu erfassen, die auf der sprachlichen Oberfläche signalisiert werden. ${ }^{1323}$ Allerdings gibt es keine 1:1-Entsprechung bzw. kaum eindeutige Indikatoren, sodass man eben doch vielfach auf außersprachliche Faktoren zurückgreifen muss.

\footnotetext{
${ }^{1317}$ Vgl. z. B. EICHINGER 2014, 41: „Vielleicht ist Emotionslosigkeit von Texten eine Fiktion, die einen normalen Grad an Emotionalität als Normalnull geschriebener Prosa markiert. Damit wäre Emotionalität etwas wie Stil, ohne das ein Text eigentlich nicht gedacht werden kann.“ Vgl. a. das Kap. „Besonderheiten der Expressiva“ ab S. 28. 1318 Vgl. a. AdAMzIK 1984, 180ff., die die Auffassung vertritt, dass es sich bei Searles Expressiva eigentlich um Repräsentativa bzw. Assertiva handelt.

${ }^{1319}$ Vgl. die Einleitung zum Kap. „Weitere Expressiva mit beidseitiger Präferenz" (ab S. 349).

1320 Vgl. das Kap. zu den „Expressiva mit Sprecheraversion“ (ab S. 368).

${ }^{1321}$ Vgl. die Kap. zu den „Fragehandlungen“ (ab S. 316) und zu den „Expressiva mit Sprecheraversion“ (ab S. 368).

1322 Vgl. z. B. ORTNER 2014b, 156.

${ }^{1323}$ Vgl. z. B. ebd., 46.
} 
Marten-Cleef hat für das Deutsche folgende für die Expressiva typische Äußerungsformen festgemacht ${ }^{1324}$, die prinzipiell auch im Lateinischen anzutreffen sind:

- performativer Gefühlsausdruck: explizit performative Äußerung bzw. Routineformel

- Empfindungsausdruck: Interjektionen und einfache Ausrufe

- Hinweis auf die Emotion: „(explizit) sagen, wie man sich fühlt“

- Hinweis auf die Reaktion: „sagen, wie man auf ein Faktum reagiert“

- Hinweis auf die Evaluation: „sagen, wie man etwas / jemanden bewertet“

- Hinweis auf die Fakten: „sagen, was der Fall ist“.

Beispiele für Sprechakte, in denen Gefühle explizit performativ ausgedrückt werden, finden sich in fam. 14 nicht; sie wären aber grundsätzlich denkbar bei sympathisierenden Sprechakten wie DANKSAGUNGEN (gratias agere) und ENTSCHULDIGUNGEN (se excusare). ${ }^{1325}$ Zu den Empfindungsausdrücken, die selten allein einen bestimmten Gefühlszustand signalisieren, sondern meist mit anderen Äußerungsformen verbunden werden, gehören Interjektionen wie hem und $o$, mit denen Cicero in Sprechakten des Typs SICH ENTSCHULDIGEN bzw. JAMMERN Traurigkeit und Schmerz ausdrückt. ${ }^{1326}$ Beides kann außerdem durch Hinweise auf die Emotion, mit denen der Sprecher sagt, wie er sich fühlt, vermittelt werden, z. B. durch Verben bzw. verbale Wendungen wie maerere, maerore confici, dolere oder dolore adfectus esse. ${ }^{1327}$ Eine weitere Möglichkeit besteht darin, die dadurch ausgelöste Reaktion zu beschreiben ${ }^{1328}, \mathrm{z}$. B. durch Äußerungen wie non queo sine plurimis lacrimis scribere (fam. 14.2.1 (7)) oder non queo reliqua scribere, tanta vis lacrimarum est (fam. 14.1 .5 (38)). ${ }^{1329}$

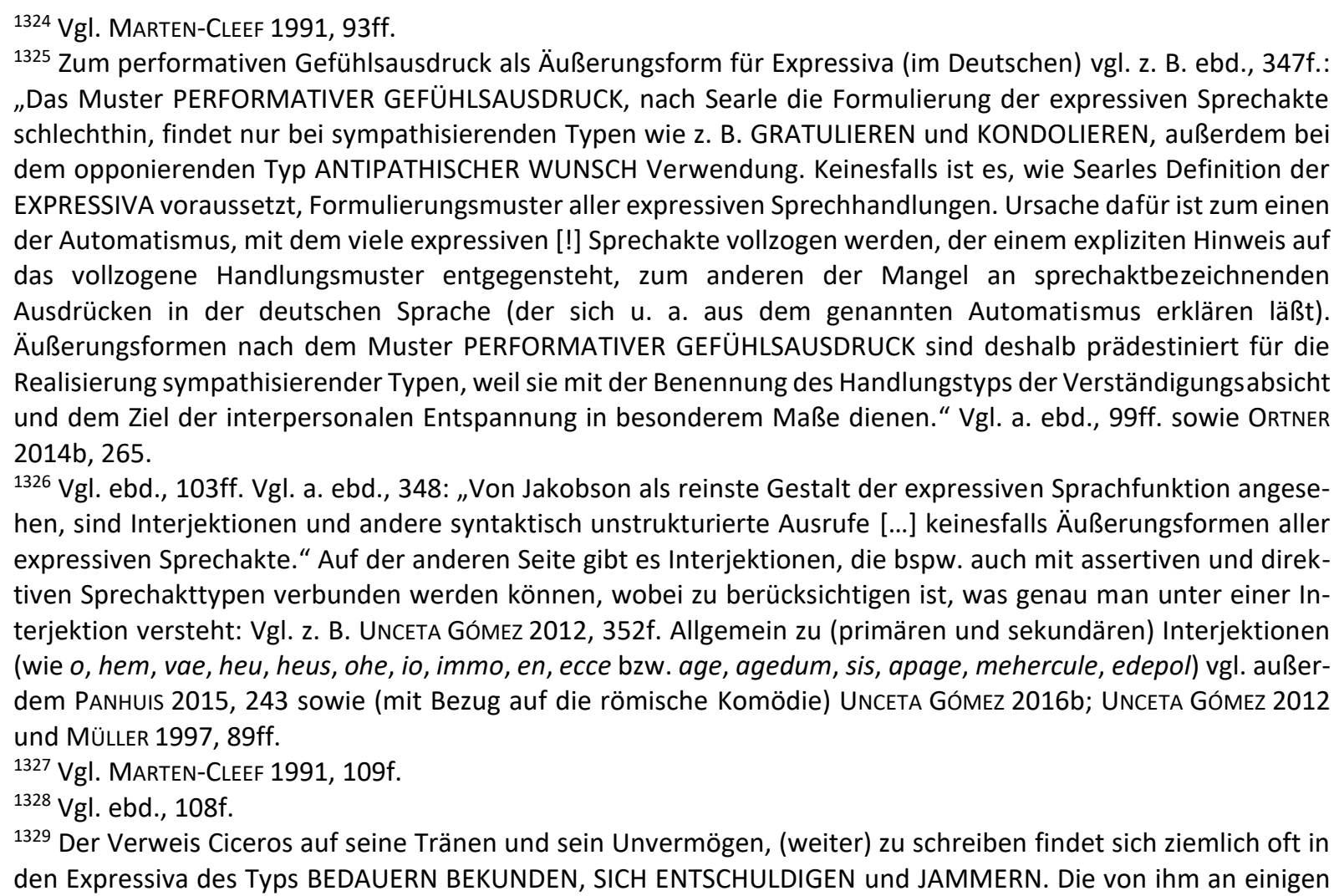


Hinweise auf die Evaluation können ebenfalls mit bestimmten Emotionen bzw. Untermustern verbunden sein ${ }^{1330}$, wenngleich die Zuordnung i. A. schwieriger ist, wie z. B. ein Vergleich von fam. 14.4.5 (44) und (45) zeigt. Beiden Äußerungen liegt eine positive Bewertung des Verhaltens Ciceros (non vitium, sed virtus - peccatum nullum, cum ornamentis) zugrunde, aus dem sich negative Folgen für ihn ergeben haben. Im ersten Fall steht der Ärger darüber im Vordergrund, im zweiten die Traurigkeit, weshalb die Äußerungen zwei verschiedenen Untermustern (FLUCHEN bzw. JAMMERN) zugeordnet werden. Hinweise auf die Fakten sind für sich allein genommen noch unspezifischer. ${ }^{1331}$ Bei der Einordnung, z. B. von fam. 14.1.1 (5), können aber bestimmte sprachliche Charakteristika wie ein exklamativer Infinitiv und eine emotive Lexik, verstärkt durch weitere sprachlich-stilistische Mittel, hilfreich sein. ${ }^{1332}$

Abgesehen von den performativen Ausdrücken sind die von Marten-Cleef angeführten Äußerungsformen selten eindeutig hinsichtlich bestimmter Emotionen und noch seltener hinsichtlich eines bestimmten Untermusters. So ist bei Sprechakten des Typs JAMMERN und SICH ENTSCHULDIGEN die beherrschende Emotion Traurigkeit, und sie wird z. T. auch in ganz ähnlicher Weise sprachlich zum Ausdruck gebracht. Selbst eine scheinbar sehr spezifische Emotion wie Schuldgefühl signalisiert nicht unbedingt einen Sprechakt des Typs SICH ENTSCHULDIGEN, wie fam. 14.3.1 (5) beweist, also ein Sprechakt des Typs JAMMERN.

Entscheidend für die Zuordnung einer Äußerung zu den Expressiva ist letztlich eine emotive und evaluative Einstellung, die durch verschiedene sprachliche Mittel vermittelt werden kann. Neben den bereits erwähnten Interjektionen und vergleichbaren Wendungen (per fortunas miseras nostras) ${ }^{1333}$ sowie den Verben bzw. verbalen Wendungen, welche mehr oder weniger deutlich (explizit beschreibend) auf die vom Sprecher empfundene Emotion hinweisen, gehören dazu noch weitere (z. B. auf den Adressaten oder dritte Personen bezogene) emotive Verben, Substantive und Adjektive, wobei Letztere oft in Form von Attributen oder in Attributsätzen begegnen. ${ }^{1334}$ Eine emotionale Beziehung zum Adressaten kann darüber hinaus hergestellt werden durch den Ausdruck physischer Nähe und den Gebrauch von Verwandtschaftsbezeichnungen ${ }^{1335}$, durch Diminutiva sowie Personal- und Possessivpronomina bzw. entsprechende andere Pronomina (ipse). Possessivpronomina werden bspw. in affektiven Anreden verwendet, können sich aber ebenso wie die anderen sprachlichen Mittel außerdem auf (nahestehende) dritte Personen beziehen, wie z. B. den Schwiegersohn (Pisonem nostrum), den Sohn (Cicero meus) oder die Tochter (Tulliola nostra).

Stellen (fam. 14.4.1 (5), 14.4.5 (45)) angedeutete Todessehnsucht kann ebenfalls als Reaktion auf seine (unglückliche) Situation betrachtet werden. Fam. 14.1 .5 (39) referiert dagegen auf eine mögliche Reaktion des Adressaten: neque te in eundem fletum adducam.

1330 Vgl. MARTEN-CLEef 1991, $114 \mathrm{ff}$.

${ }^{1331}$ Vgl. ebd., $112 \mathrm{ff}$.

1332 Vgl. das Kap. zu den „Expressiva mit Sprecheraversion“ (ab S. 368).

1333 Vgl. S. 342.

1334 Vgl. ORTNER 2014b, 200ff. und ebd., 347. Zur Klassifikation von Adjektiven vgl. a. WüEST 2011, 213. Danach kann man objektive Adjektive (verheiratet, weiß, leuchtend) und subjektive Adjektive unterscheiden. Letztere werden weiter differenziert in affektive (tragisch, traurig, merkwürdig) und evaluative, welche wiederum unterteilt werden können in axiologische (gut schlecht, schön hässlich) und nicht-axiologische (groß $\sim$ klein, schwer $\sim$ leicht).

1335 Vgl. HALL 2009, 56ff. („The commemoration of family ties and mutual services“). 
Expressiva sind häufig durch eine unkonventionelle Syntax gekennzeichnet. Die Satzstruktur wird nicht nur durch Anreden und andere Appositionen, sondern auch sonst öfter durch Extrapositionen wie z. B. Parenthesen durchbrochen. Neben einer abweichenden (affektiven) Wortstellung finden sich gelegentlich zudem verkürzte und unvollständige Sätze (Ellipsen, Aposiopese). ${ }^{1336}$ Eine sehr spezifische Möglichkeit zur Formulierung von expressiven Sprechakten sind exklamative Akkusative und Infinitive, oft in Verbindung mit Empfindungsausdrücken bzw. Interjektionen (bei den aversiven Untermustern JAMMERN und SICH ENTSCHULDIGEN), und (meist durch utinam oder velim eingeleitete) Wunschsätze. ${ }^{1337}$ Der Konjunktiv Präsens ist dabei hauptsächlich in den Expressiva mit Sprecherpräferenz (HOFFNUNG ÄUSSERN) oder mit beidseitiger Präferenz (WOHLERGEHEN WÜNSCHEN) anzutreffen. Der Konjunktiv Plusquamperfekt (Irrealis) begegnet dagegen - und dies auch außerhalb von Wunschsätzen, d. h. in einigen Aussagesätzen (Konditionalsatzgefügen) - eher, wenngleich nicht ausschließlich, in aversiven Expressiva. Der Imperativ findet sich fast nur in WOHLERGEHENSWÜNSCHEN, z. B. in Formeln wie vale(te) und cura ut valeas sowie ähnlichen Äußerungen wie z. B. sustenta te, mea Terentia, ut potes honestissime. (fam. 14.4 .5 (42)). ${ }^{1338}$ Fragesätze werden in fam. 14 nur recht selten in direktiven Fragehandlungen, sondern (als rhetorische Fragen) häufiger in stark expressiven Sprechakten des Typs ANGST ÄUSSERN (und SORGE BEKUNDEN) verwendet. ${ }^{1339}$ Manchmal stehen sie im Konjunktiv, meist aber im Indikativ Futur. Im Übrigen ist der Indikativ der Standardmodus in Aussagesätzen, welche bei den Expressiva insgesamt überwiegen, obschon mit ihnen i. A. keine so große Emotionalität erzielt wird wie mit den anderen Satzarten.

Bewertungen, welche direkt auf die mit dem Sprechakt ausgedrückte Emotion referieren oder schlicht die allgemeine Expressivität erhöhen, können sich auf den Sprecher, den Adressaten, dritte Personen oder bestimmte Sachverhalte beziehen. ${ }^{1340}$ Sie stehen jedoch - im Unterschied bspw. zu den Bewertungen nach Zillig - nie im Vordergrund, nicht einmal bei den (Selbst-)Vorwurfs- und Lobemotionen, bei denen es nicht um eine Evaluation per se geht, sondern vielmehr um die damit verbundenen Gefühle, wie z. B. Scham, Traurigkeit, Freude oder Bewunderung. Positive und negative Bewertungen werden mit bestimmten (evaluativen) Ver-

\footnotetext{
1336 Vgl. ORTNER 2014b, 248ff.

1337 Vgl. PINKSTER 2015, 361ff. zu Wunschsätzen (einschl. exklamativen Akkusativen und Infinitiven), z. B. ebd., 361: „Exclamatory sentences have an exclamatory illocutionary force, to express the speaker's or writer's disbelief, surprise, relief, indignation, misery, or disgust about a certain state of affairs. "Zu Wunschsätzen mit utinam vgl. ebd., 359f. Zur Nähe solcher Expressiva zu anderen Sprechaktklassen, insbesondere den Direktiva vgl. RISSELADA 1993, 41: „The boundaries of this speech act type [= Expressiva] are not very strict. On the one hand, a gradual transition into the assertive speech act type is formed by exclamations. [...] More interesting, however, [...] is the gradual transition from expressives into directives (and third person directives) via wishes. “ Vgl. a. N. 1096 sowie N. 1318.

1338 Vgl. N. 1305.

1339 Vgl. a. PINKSTER 2015, 361ff. zur Unterscheidung von Ausrufe- und Fragesätzen. Vgl. außerdem ebd., 343f. zu rhetorischen Fragen als Assertiva sowie ebd., 310 zu Aussagesätzen als rhetorischen Fragen.

1340 Vgl. MARTEN-CLEEF 1991, 116ff. zur Unterscheidung von Sprecher-, Adressaten- und Objektbewertung. Vgl. a. ADAMZIK 1984, 252ff. zur ähnlichen Differenzierung von Selbstbewertungen, Partnerbewertungen und extradyadischen Bewertungen.
} 
ben bzw. verbalen Wendungen, Substantiven, Adjektiven und Adverbien zum Ausdruck gebracht. Mittels Negation können an sich positive Inhalte negativ bewertet werden und umgekehrt. $^{1341}$

In erwartungsorientierten Sprechakten (WOHLERGEHEN WÜNSCHEN, HOFFNUNG ÄUSSERN, SORGE BEKUNDEN und ANGST ÄUSSERN) spielt neben der (für Expressiva spezifischen) emotiven und evaluativen die epistemische Einstellung eine Rolle, insofern mit ihnen - ähnlich wie z. B. mit Assertiva des Typs PROGNOSTIZIEREN - zukunftsbezogene Ungewissheit vermittelt wird. Während bei den Expressiva ansonsten eher Gegenwarts- und Vergangenheitstempora vorherrschen, ist bei solchen Sprechakten häufiger das Futur anzutreffen. Ein Zukunftsbezug kann aber auch auf andere Weise hergestellt werden, z. B. durch einen futurischen Konjunktiv, den Imperativ, das Gerundivum, verbale Ausdrücke wie oportet und opus est oder bestimmte Adverbien wie perpetuo. Den Verben sperare, metuere, timere und vereri, welche als Hinweise auf die (eigene) Emotion immer im Präsens (1. Person) stehen ${ }^{1342}$, sowie dem Modalverb posse ist ein solcher ebenfalls inhärent. Sie drücken zudem - ebenso wie (non) scire und videri - (positive oder negative) Erwartungen an die Zukunft bzw. Ungewissheit aus, wie sie im Übrigen auch mit (oft futurischen) Fragesätzen und Konditionalsätzen, Substantiven wie spes sowie durch Indefinitpronomina und Adverbien mit dem Präfix ali- vermittelt wird. Substantive wie fortuna und deus (di), z. B. in Interjektionen bzw. Phraseologismen wie per fortunas miseras nostras, di faxint und si di adiuvabunt, betonen darüber hinaus das Gefühl des Ausgeliefertseins. Außerdem kann durch eine allgemeine Vagheit bzw. das Auslassen von Informationen (Aposiopese) Ungewissheit oder sogar Verzweiflung zum Ausdruck gebracht werden.

Im Übrigen sind expressive Sprechakte aber eher durch Abundanz gekennzeichnet. Je direkter, expliziter und ausgeprägter eine emotive und evaluative Einstellung zu erkennen gegeben wird, je stärker die sprachliche Formulierung von einer neutralen oder konventionalisierten Ausdrucksweise abweicht, wie sie z. B. in sachbezogenen Assertiva bzw. rituellen (Wohlergehens-)Formeln üblich ist, umso intensiver wirken die Expressiva und umso leichter sind sie als solche zu erkennen.

Mit zusätzlich zu den bereits genannten lexikalischen und (morpho-)syntaktischen Variationen eingesetzten verstärkenden (und abschwächenden) sprachlichen Mitteln können die zum Ausdruck gebrachten Emotionen in ihrer Intensität noch weiter nuanciert werden, z. B. durch Bittformeln (obsecro te) und Metadirektiva ${ }^{1343}$, Verben und Pronomina, mit denen die Fortdauer einer belastenden Handlung bzw. Situation betont wird, sowie durch verabsolutierende Pronomina bzw. Pronominaladjektive und weitere intensivierende Adjektive, Adverbien ${ }^{1344}$ und Substantive. Adjektive können zudem (ggf. auch bei adverbialer Verwendung) durch das Präfix per- sowie Steigerung verstärkt werden, wobei Komparative v. a. in Verbindung mit Vergleichen und Superlative als Hyperbeln begegnen. Weitere besondere Stilmittel, die in

\footnotetext{
${ }^{1341} \mathrm{Vgl}$. a. die Einteilung der Expressiva nach Präferenz vs. Aversion (aufseiten von Sprecher und Adressat) in MARTEN-CLEEF 1991.

$1342 \mathrm{Vgl}$. ORTNER 2014b, 347.

${ }^{1343}$ Vgl. das Kap. zu den „Direktiva“ ab S. 300. Zu Metadirektiva in nicht-direktiven Sprechakten vgl. außerdem RISSELADA 1993, 258ff. Zu ihnen können auch sic existimes (fam. 14.4.6 (56)) und tibi persuadeas (fam. 14.3.5 (37)) gerechnet werden. Vgl. HALL 2009, 209f. (zu velim persuadeas / existimes).

${ }^{1344} \mathrm{Vgl}$. a. ebd., 200f. zu „Intensifying adjectives and adverbs“.
} 
fam. 14 zur Intensivierung der Sprechakte verwendet werden, sind z. B. Alliterationen, Wortwiederholungen, Antithesen, Asyndeta und Polysyndeta. Hinzu kommen (temporale, modale, kausale, konzessive, adversative, konditionale) adverbiale Bestimmungen und Adverbialsätze. Alle erwähnten sprachlichen Mittel können auf die verschiedenste Art und Weise miteinander kombiniert werden und sich so in ihrer Wirkung verstärken.

Expressiva mit beidseitiger Präferenz

Grußformeln

Die i. A. stark ritualisierten Grußformeln am Anfang und Ende der Briefe sollten selbst in ihrer konventionellen "Grundform" als Zeichen der Höflichkeit und Mittel der Kooperationssicherung bei einer handlungssemantischen Analyse nicht unbeachtet bleiben. Je stärker Cicero sie individuell abwandelt, desto authentischer wirken sie und desto mehr dominiert die expressive gegenüber der deklarativen Handlungsfunktion. ${ }^{1345}$ Im Folgenden wird eine Übersicht über die verschiedenen Varianten sowohl der Begrüßungs- als auch der Verabschiedungsformeln in fam. 14 gegeben, um so die Unterschiede zu verdeutlichen.

Begrüßungsformeln: deklaratives BRIEF ERÖFFNEN vs, expressives GUNST ERWEISEN

Im Gegensatz zu den Verabschiedungsformeln sind die Begrüßungsformeln offenbar quasi obligatorisch und fehlen in keinem der 24 Briefe in fam. 14:

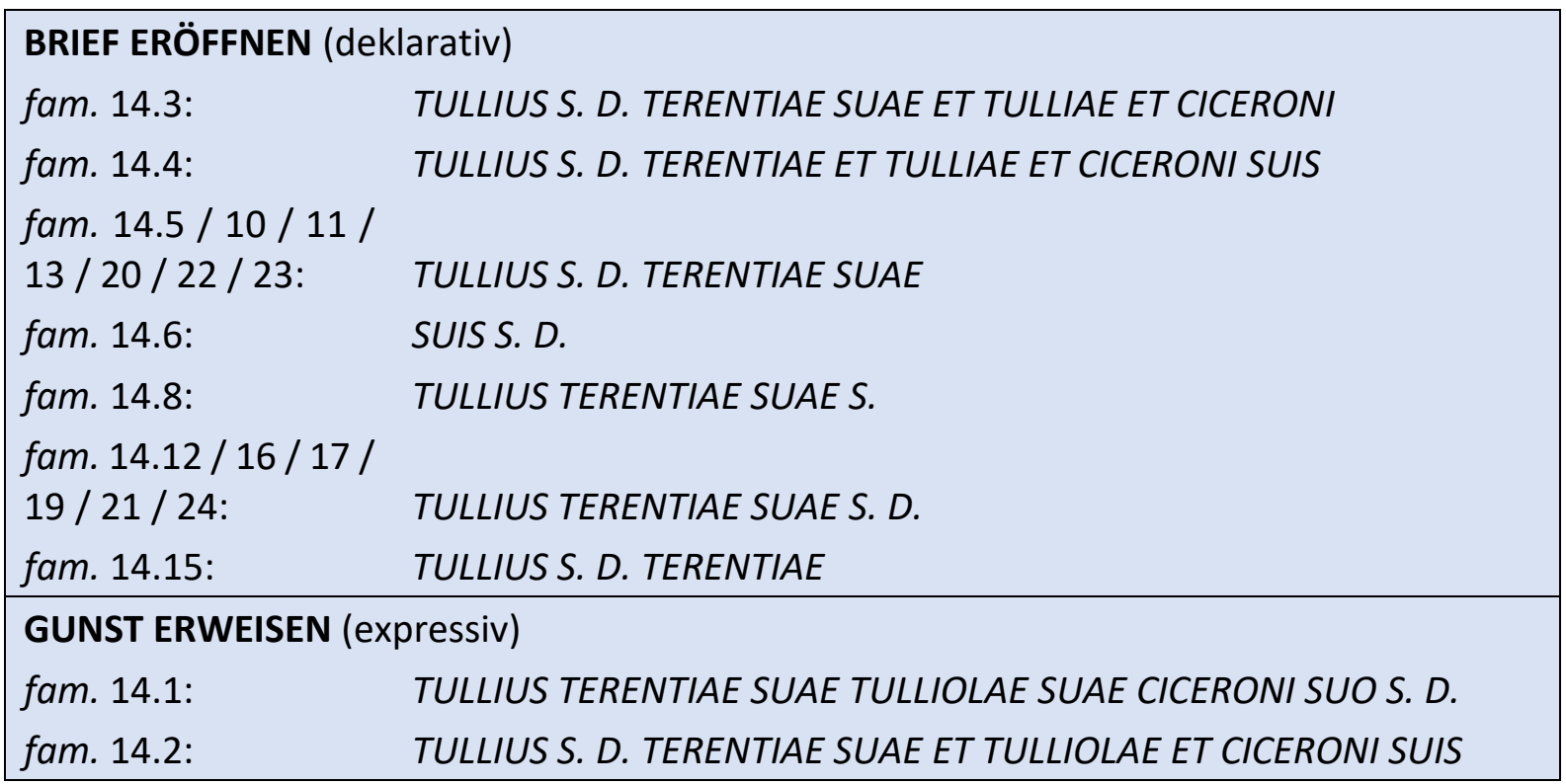

${ }^{1345}$ Zur Personalisierung und der damit einhergehenden stärkeren Expressivität der Grußformeln vgl. z. B. CORBINELLI 2008, 107f. und GARCEA 2002, 216. Vgl. a. (mit Bezug auf das Deutsche) WüEST 2011, 219. Nach Terkourafis Modell seien gerade die häufig gebrauchten rituellen Formeln (unabhängig vom eigentlichen Wortlaut) ein Zeichen der Höflichkeit. Vgl. z. B. Dickey 2016, 202f. (zu Terkourafi): „Many situations in which interpersonal interaction occurs are common and frequently repeated; in these situations there is an expected sequence of formulaic politeness, and people who deviate from the expected formulae, even in a direction that might seem to an outside observer more polite than the expected formulae, may be perceived as behaving impolitely. " Hingegen mache nach Watts erst ihre individuelle Gestaltung die Höflichkeit einer Äußerung aus. Vgl. z. B. ebd., 203: „On the other hand Watts [...] has proposed a view of politeness that, while in some respects very similar to Terkourafi's, is in one important feature its opposite: for Watts only that which is not usual (i.e., Terkourafi's marked politeness) should be termed, polite'. What is normal and expected in a particular context should, he argues, be termed ,politic behaviour' and distinguished from especially noticeable courtesy, or ,polite' behaviour. “ Vgl. a. das Kap. „Höflichkeit“ ab S. 69. Vgl. außerdem CORDIER 1995, 25ff. und KERBRAT-ORECCHIONI 1990, $220 \mathrm{ff}$. 


\begin{tabular}{|ll|}
\hline fam. 14.7 und 14.9: & TULLIUS TERENTIAE SUAE S. P. \\
fam. 14.14: & TULLIUS TERENTIAE ET PATER TULLIAE, DUABUS ANIMIS SUIS, ET \\
& CICERO MATRI OPTIMAE, SUAVISSIMAE SORORI S. P. D. \\
fam. 14.18: & TULLIUS TERENTIAE SUAE ET PATER SUAVISSIMAE FILIAE, CICERO \\
& MATRI ET SORORIS. D. P.
\end{tabular}

Abbildung 66: Begrüßungsformeln (deklaratives BRIEF ERÖFFNEN vs. expressives GUNST ERWEISEN)

Alle Begrüßungsformeln haben eine assertive Funktion, insofern Briefabsender (Tullius bzw. Cicero, z. T. unter Einschluss seines Sohnes) und -adressat (Terentia, z. T. unter Einschluss ihrer Kinder) genau identifiziert werden. ${ }^{1346}$ Diese ist allerdings weitgehend zu vernachlässigen, weil die Information Terentia bereits mit der Übergabe des Schreibens durch einen ihrer Boten bekannt sein dürfte. ${ }^{1347}$ Da die Formeln ausnahmslos direkt am Beginn eines jeden Schreibens stehen, sind sie ein eindeutiges Signal dafür, dass der Brief genau an dieser Stelle beginnt. Mit innen wird also deklarativ der BRIEF ERÖFFNET. ${ }^{1348}$ Zugleich sind sie immer auch expressiv. ${ }^{1349}$ Die Expressivität kann sich darauf beschränken, dass dem Adressaten schlicht Respekt gezollt wird, indem die Höflichkeitsregeln beachtet werden, die ein Auslassen der Formel nicht zulassen. Sie kann aber auch darüber hinausgehen, wenn Cicero mit einer individuellen Abwandlung seiner Frau (und seinen Kindern) gegenüber Zuneigung zeigt und ihr (bzw. ihnen) seine GUNST ERWEIST. ${ }^{1350}$ Bei einer rein stereotypen (eher emotionslosen) Begrüßungsformel soll also ein deklarativer Sprechakt BRIEF ERÖFFNEN angenommen werden; wird jedoch ein besonderes (emotionales) Verhältnis zum Adressaten zum Ausdruck gebracht, ist sie dem Untermuster GUNST ERWEISEN zuzuordnen.

Im Unterschied zu anderen Adressaten kann man das Possessivpronomen in den Begrüßungsformeln in fam. 14 als konventionell betrachten. Es fehlt lediglich in fam. 14.15, einem insgesamt recht nüchternen Brief, bei dem zu überlegen wäre, inwieweit die Auslassung nicht evtl. als unhöflich zu betrachten ist. In fam. 14.6, einem kurzen, aber dennoch recht liebenswürdigen Brief, ersetzt das Possessivpronomen hingegen sogar den bzw. die Namen. Die Grenze zu einem dominant expressiven Sprechakt scheint erst bei einer weiteren Abwandlung überschritten, wozu bereits der Zusatz p. (plurimam) und die Anrede der Tochter mit dem zärtlichen Diminutiv Tulliola(e) zählen können. Eindeutig expressiv sind die Formeln in fam. 14.14

\footnotetext{
${ }^{1346}$ Vgl. a. das Kap. zu den „Transmissiva“ (ab S. 293), in dem auf die ähnlichen Formulierungen in fam. 14.14.2 (16) und 14.7.3 (17) eingegangen wird. Vgl. außerdem RüHL 2019, 20 (mit Verweis auf DICKEY 2002, 36f.), die auf die Abstraktion der Kommunikationsrollen / -funktionen von Sender und Empfänger durch die Verwendung der 3. statt der 1. und 2. Person (wie im Deutschen) aufmerksam macht.

${ }^{1347}$ Vgl. aber auch ROESCH 2004, 143f.: „Dans la correspondance, il y a évidemment l'en-tête des lettres et la fameuse formule salutem (plurimam) dat, indispensable puisque c'est elle qui livre l'identité de l'auteur du courrier." Absender und Adressat waren i. d. R. allerdings bereits durch die entsprechende Aufschrift auf der Briefrolle und / oder Bekanntgabe des Boten bekannt. Vgl. a. ConRING 2001, 6.

${ }^{1348}$ Vgl. N. 850. Vgl. a. BERGER 2017a und BERGER 2016 (zu den Strategien der Gesprächseröffnung in der römischen Komödie).

${ }^{1349}$ Zu einer evtl. auch vorhandenen kommissiven, direktiven und metakommunikativen Komponente vgl. S. 177. 1350 Vgl. ROESCH 2004, 144: „Elle [d. h. die Begrüßungsformel] permet aussi d'engager le dialogue en douceur. “ Sie verweist auch auf KERBRAT-ORECCHIONI 1990, 221f. Zu den Handlungsbedingungen von GUNST ERWEISEN und den Unterschieden zu verwandten Sprechaktuntermustern wie WILLKOMMEN HEISSEN und KOMPLIMENT MACHEN vgl. S. 214.
} 
und 14.18, welche nicht nur um die Verwandtschaftsbezeichnungen (pater, mater, soror) ergänzt sind, sondern v. a. auch durch superlativische Attribute wie optimae und suavissimae oder gar eine affektive Apposition wie duabus animis suis.

Verabschiedungsformeln: deklaratives BRIEF BEENDEN vs. expressives WOHLERGEHEN WÜNSCHEN

In fam. 14.6, 14.18 und 14.19 findet sich zwar eine Wohlergehensformel am Ende des Briefes, der übliche Abschiedsgruß vale(te) fehlt allerdings. In den übrigen Briefen in fam. 14 erscheint er in verschiedenen Varianten:

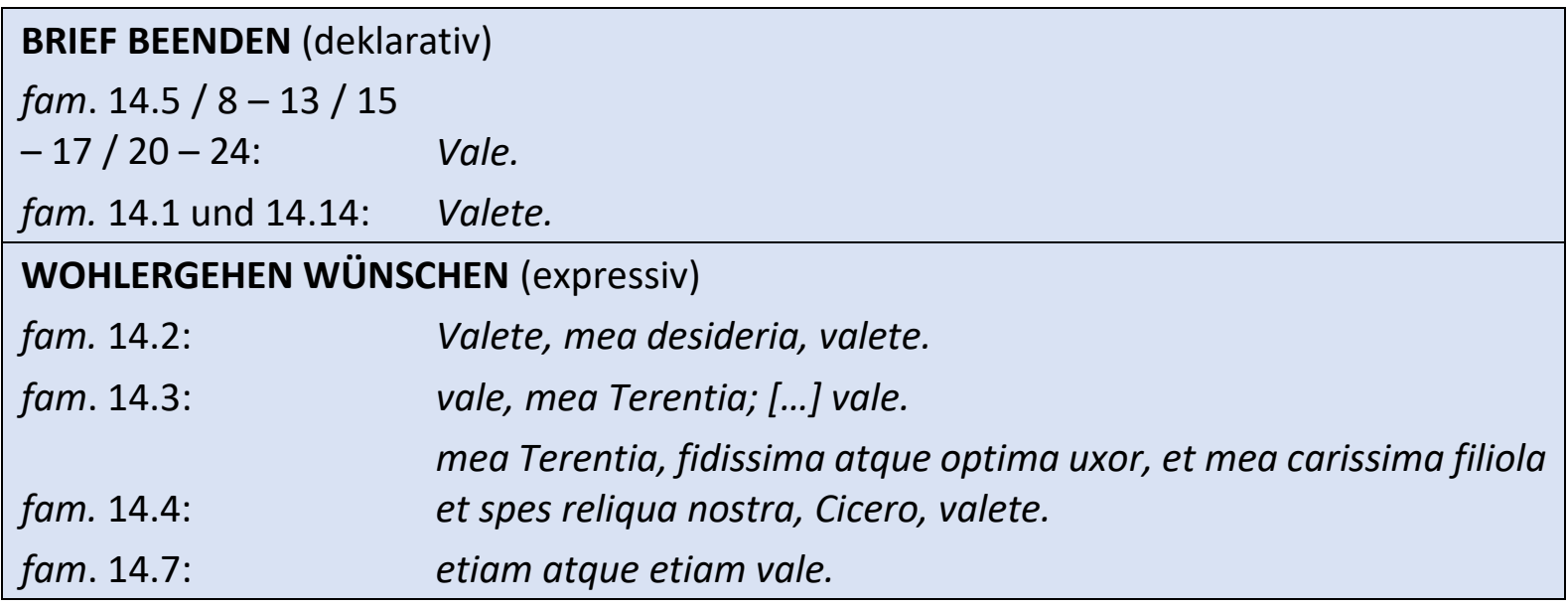

Abbildung 67: Verabschiedungsformeln (deklaratives BRIEF BEENDEN vs. expressives WOHLERGEHEN WÜNSCHEN)

Meist folgt auf die Verabschiedungsformel noch ein Postskriptum, das gelegentlich (wie in fam. 14.1) sogar über die Angabe von Ort und Zeit der Briefabfassung hinausgeht. Dennoch wird auch mit ihr der Schluss eines Briefes oder zumindest des Hauptteils signalisiert, und sie kann als konventionelles Mittel betrachtet werden, deklarativ einen BRIEF zu BEENDEN.

Daraus, dass Cicero in einigen Briefen, die im Übrigen nicht generell durch mangelnde Expressivität gekennzeichnet sind, gar keine Verabschiedungsformel verwendet, kann ein gewisser expressiver Wert an sich abgeleitet werden, der darin besteht, Terentia WOHLERGEHEN zu WÜNSCHEN. ${ }^{1351}$ In ihrer Grundform vale(te) erscheint dieser jedoch sehr begrenzt. Ungleich höher ist er in fam. 14.2 - 4 und 14.7. ${ }^{1352}$ Durch Wiederholung (valete ... valete, vale ... vale sowie auch etiam atque etiam vale), affektive Anreden (mea desideria, mea Terentia bzw. mea Terentia et mea carissima filiola et spes reliqua nostra) und weitere Appositionen (fidissima atque optima uxor, Cicero) mit z. T. äußerst emotiver Lexik (in Verbindung mit weiteren in-

\footnotetext{
1351 Vgl. a. KeRBRAT-ORECCHIONI 1990, 144: „Ces formules permettent de conclure en douceur. Elles montrent le souci de la santé du correspondant et l'affection qu'on lui porte et c'est pour cela qu'elles sont récurrentes. Ainsi, on ne s'étonnera pas que vale en soit venu à servir de formule finale de congé, permettant de clore l'échange sur une note optimiste qui compense le moment à risque qu'est la fin de l'échange par lettre." Vgl. außerdem MARTEN-CLEEF 1991, 91f. zur Abgrenzung von Wünschen und Expressiva, z. B. ebd., 92: „Ein WUNSCH ist keine expressive Sprechhandlung, wenn in ihm ein Wunsch oder eine Absicht ausgedrückt werden. In einer Taxonomie expressiver Sprechhandlungen werden nur solche WÜNSCHE berücksichtigt, deren psychische Basis ein Gefühl wie Hoffnung oder Woh/wollen ist." Vgl. a. N. 1096, 1337 und 1354.

1352 In fam. 14.3 ist die Verabschiedungsformel unterbrochen durch die Äußerung quam ego videre videor itaque debilitor lacrimis, welche eine eigene (expressive) Illokution darstellt.
} 
tensivierenden sprachlichen Mitteln wie dem Diminutiv und Superlativ) wird das Vorherrschen der expressiven Handlungsfunktion sehr deutlich. ${ }^{1353}$ Gerade in diesen Fällen ist außerdem zu erkennen, wie wenig die Abschiedsformel dem durch den Imperativ signalisierten direkten, also direktiven Sprechakt entspricht, dessen Dominanz außerdem durch Anwendung des Absurditätskriteriums ausgeschlossen werden kann: Einer Aufforderung wie „Lebe wohl!“ oder „Bleib gesund!“ wird der Adressat kaum Folge leisten können, da er nur eingeschränkt Kontrolle darüber hat. ${ }^{1354}$

Weitere Expressiva mit beidseitiger Präferenz

Die Untermuster GUNST ERWEISEN und v. a. WOHLERGEHEN WÜNSCHEN begegnen auch außerhalb der Grußformeln. Hinzu kommen noch weitere Sprechakttypen mit beidseitiger Präferenz, denen Handlungen bzw. Sachverhalte zugrunde liegen, von denen Terentia und / oder Cicero positiv betroffen sind:

\begin{tabular}{|c|c|}
\hline $\begin{array}{l}\text { DANKEN } \\
\text { fam. } 14.5 .1(11) \text { : } \\
\text { fam. } 14.8(6) \text { : }\end{array}$ & $\begin{array}{l}\text { idque mihi gratissimum fuit. } \\
\text { fecisti mihi gratum. }\end{array}$ \\
\hline \multicolumn{2}{|l|}{ BEGRÜSSEN } \\
\hline fam. 14.1.1 (2): & $\begin{array}{l}\text { Et litteris multorum et sermone omnium perfertur ad me incredibilem } \\
\text { tuam virtutem et fortitudinem esse teque nec animi neque corporis } \\
\text { laboribus defatigari. }\end{array}$ \\
\hline fam. 14.2.2 (16): & A te quidem omnia fieri fortissime et amantissime video, nec miror \\
\hline fam. $14.5 .1(10):$ & diligentissimeque a te perscripta sunt omnia \\
\hline fam. 14.5.1 (12): & $\begin{array}{l}\text { neque sum admiratus hanc epistulam quam Acastus attulit brevem } \\
\text { fuisse. }\end{array}$ \\
\hline fam. $14.8(5):$ & quod celeriter me fecisti de Caesaris litteris certiorem \\
\hline \multicolumn{2}{|c|}{ KOMPLIMENT MACHEN } \\
\hline fam. $14.2 .2(22):$ & mea lux, meum desiderium, unde omnes opem petere solebant \\
\hline fam. 14.6 (5): & $\begin{array}{l}\text { quod nostra }[=\text { Tullia] tibi gratias agit, id ego non miror, te mereri ut } \\
\text { ea tibi merito tuo gratias agere possit. }\end{array}$ \\
\hline fam. 14.7.2 (11): & $\begin{array}{l}\text { cohortarer vos quo animo fortiores essetis nisi vos fortiores cognos- } \\
\text { sem quam quemquam virum. }\end{array}$ \\
\hline \multicolumn{2}{|l|}{ GUNST ERWEISEN } \\
\hline fam. 14.3 .5 (37): & et ita tibi persuadeas, mihi te carius nihil esse nec umquam fuisse. \\
\hline
\end{tabular}

${ }^{1353}$ Vgl. a. MARTEN-CLEef 1991, 164 zur Unterscheidung von rituellen (Abschieds-)Grüßen und „echten“ Wohlergehenswünschen. Nur auf Letztere könne man mit „Danke.“ antworten. M. E. sind die Übergänge aber fließend. Im Deutschen kann man auf einen Abschiedsgruß wie „Leb wohl!“ oder „Mach's gut!“ (im Unterschied zu „Tschüs!“) sehr wohl mit „Danke.“ antworten, muss es allerdings nicht. Vgl. N. 864 und 865. Vgl. außerdem RISSELADA 1993, 118 zu einem Fall von „non-final occurrence of vale“, zu dem sie meint, er zeige, dass „vale can also be used in a more literal way in wishes of well-being“.

${ }^{1354} \mathrm{Vgl}$. ebd., 117ff. („the imperative in non-directive speech acts“), z. B. ebd., 117: „In addition to these various directive uses, the imperative mood is also used in a restricted number of other speech acts. A first group consists of wishes and maledictions. These speech acts are not directive, because the action involved is usually not controllable or not fully controllable. The content of wishes and maledictions often involves some sort of evaluative expression, such as bene [...], male [...], or malus [...]. “ und ebd., 118: „A number of imperative wishes have turned into conventional expressions of greeting and farewell, like e.g. vale and salve (,be healthy'). "Vgl. a. N. 1096. 


\begin{tabular}{|c|c|}
\hline \multicolumn{2}{|c|}{ WOHLERGEHEN WÜNSCHEN } \\
\hline \multicolumn{2}{|c|}{ Wohlergehensformeln am Briefanfang } \\
\hline fam. 14.5.1 (2): & Si tu et Tullia, lux nostra, valetis, ego et suavissimus Cicero valemus. \\
\hline fam. $14.8(2):$ & Si vales, bene est; ego valeo. \\
\hline \multicolumn{2}{|l|}{ fam. $14.11(2) / 16$} \\
\hline \multicolumn{2}{|l|}{$(2) / 17(2) / 21(2)-$} \\
\hline $24(2):$ & S. v. b.; e.v. \\
\hline fam. 14.14.1 (2): & Si vos valetis, nos valemus. \\
\hline fam. 14.15 (2): & Si vales, bene est. \\
\hline \multicolumn{2}{|c|}{ zusätzliche Wohlergehensformeln am Briefanfang } \\
\hline fam. 14.8 (3): & Valetudinem tuam velim cures diligentissime. \\
\hline fam. 14.21 (3): & Da operam ut convalescas \\
\hline \multicolumn{2}{|c|}{ Wohlergehensformeln am Briefende } \\
\hline fam. 14.1.6 (44): & fac valeas \\
\hline \multicolumn{2}{|l|}{ fam. $14.3 .5(36) /$} \\
\hline \multicolumn{2}{|l|}{$14.6(7) / 14.8(8) /$} \\
\hline $14.16(8):$ & cura ut valeas \\
\hline \multirow[t]{2}{*}{ fam. 14.4.6 (55): } & cura, quod potes, ut valeas \\
\hline & $\begin{array}{l}\text { vos, mea suavissima et optatissima Terentia, si nos amatis, curate ut } \\
\text { valeatis. }\end{array}$ \\
\hline fam. 14.7.3 (14): & tu primum valetudinem tuam velim cures \\
\hline fam. 14.9 (4): & tu velim tuam et Tulliae valetudinem cures. \\
\hline \multicolumn{2}{|l|}{ fam. 14.10 (7) / 11} \\
\hline \multicolumn{2}{|l|}{$(8) / 15(8) / 22(6) /$} \\
\hline 23 (7): & valetudinem tuam cura diligenter. \\
\hline fam. 14.17 (6): & tu fac ut tuam et Tulliae valetudinem cures. \\
\hline fam. 14.18.2 (14): & maxime autem date operam ut valeatis, si nos vultis valere. \\
\hline fam. 14.19 (9): & Da operam ut valeas. \\
\hline fam. 14.24 (7): & valetudinem tuam fac ut cures. \\
\hline \multicolumn{2}{|c|}{ weitere WOHLERGEHENSWÜNSCHE } \\
\hline fam. 14.4.4 (33): & de familia liberata, nihil est quod te moveat. \\
\hline fam. 14.4.5 (42): & Quod reliquum est, sustenta te, mea Terentia, ut potes honestissime. \\
\hline fam. 14.4.6 (53): & quem [= Pescennius] semper spero tui fore observantem \\
\hline fam. 14.7.2 (12): & $\begin{array}{l}\text { et tamen eius modi spero negotia esse ut [...] vos istic commodissime } \\
\text { sperem esse }\end{array}$ \\
\hline fam. 14.14.1 (4): & $\begin{array}{l}\text { si ille Romam modeste venturus est, recte in praesentia domi esse } \\
\text { potestis }\end{array}$ \\
\hline fam. $14.14 .1(9):$ & $\begin{array}{l}\text { quo modo quidem nunc se res habet, modo ut haec nobis loca tenere } \\
\text { liceat, bellissime vel mecum vel in nostris praediis esse poteritis. }\end{array}$ \\
\hline fam. 14.14.1 (12): & ad summam animo forti sitis. \\
\hline
\end{tabular}




$\begin{array}{|ll|}\text { fam. 14.18.1 (3): } & \begin{array}{l}\text { Mihi veniunt in mentem haec: } \text { Romae vos esse tuto posse per Dolabel- } \\ \text { lam eamque rem posse nobis adiumento esse si quae vis aut si quae } \\ \text { rapinae fieri coeperint }\end{array} \\ \text { fam. 14.18.1 (7): } & \begin{array}{l}\text { ut et multum esse mecum et, cum aberitis, commode et in nostris [erg. } \\ \text { praediis] esse possitis. }\end{array}\end{array}$

Abbildung 68: Expressiva mit beidseitiger Präferenz

Wie bereits bei der Analyse der Direktiva und Kommissiva deutlich geworden sein sollte, ist eine trennscharfe Unterscheidung der Interessen Ciceros von denen seiner Frau kaum möglich. ${ }^{1355}$ Unter Expressiva mit (nach Marten-Cleef) beidseitiger Präferenz werden hier Sprechakte verstanden, bei denen v. a. oder nur Terentia betroffen ist; bei Expressiva mit Sprecherpräferenz steht dagegen Cicero (oder eine dritte Person) im Zentrum. Bei ersteren liegt eine deutliche, aber nicht unbedingt ausschließliche Adressatenpräferenz vor, während unter Expressiva mit Sprecherpräferenz solche Sprechakte gefasst werden sollen, in denen die Sprecherpräferenz überwiegt, außerdem aber auch solche mit beidseitiger Präferenz, in denen Cicero sich als Teil einer ehelichen bzw. familiären Einheit betrachtet.

Demnach gehören Sprechakte zum Untermuster HOFFNUNG ÄUSSERN, wenn sie sich auf das Wohlergehen Ciceros beziehen; geht es jedoch um Terentia, liegt ein WOHLERGEHENSWUNSCH vor. Kennzeichnend für beide Untermuster sind der Zukunftsbezug, der Ausdruck von Ungewissheit und eine positive Bewertung der betreffenden Inhalte. Alle drei Aspekte werden durch das Verb sperare vermittelt. Auch mit posse, das die Möglichkeit des Eintreffens einer erwünschten Handlung oder Situation fokussiert und besonders oft bei WOHLERGEHENSWÜNSCHEN begegnet, und mit Konditionalsätzen (oft im Futur), die manchmal negative, meist aber positive Eventualitäten beschreiben und v. a. beim Untermuster HOFFNUNG ÄUSSERN anzutreffen sind, wird ein Zukunftsbezug hergestellt. Eine positive Bewertung wird $u$. a. durch evaluative Adjektive und Adverbien ausgedrückt, bei WOHLERGEHENSWÜNSCHEN z. B. durch (animo) forti und (tui) observantem bzw. bellissime, commode, commodissime, honestissime, recte und tuto. Verstärkend wirken u. a. der Superlativ, verabsolutierende Ausdrücke wie nihil und Adverbien wie semper und multum.

Mit seinen WOHLERGEHENSWÜNSCHEN drückt Cicero die Hoffnung aus, Terentias Sicherheit möge gewährleistet sein (tuto / recte esse), sie möge ihre Zeit komfortabel (commode / commodissime / bellissime esse) und möglichst in seiner Gesellschaft (mecum esse) verbringen ${ }^{1356}$ sowie von anderen unterstützt (adiumento esse) und geachtet (tui observantem esse) werden. Was fam. 14.18.1 (3) angeht, wird hier davon ausgegangen, dass Cicero mit seiner Äußerung v. a. die Sicherheit und das Wohlergehen seiner Frau im Blick hat, obgleich die Sorge um seinen Besitz, der bei evtl. Plünderungen in Gefahr sein könnte, ebenfalls eine Rolle spielen wird. ${ }^{1357}$

\footnotetext{
1355 Dabei wurde u. a. auch auf die besondere Problematik des Plurals (pluralis modestiae) im Lateinischen verwiesen.

1356 Man kann wohl annehmen, dass Cicero den Wunsch nach gemeinsamer Zeit mit seiner Frau teilt; in fam. 14.18.1 (7) liegt der Fokus aber auf Terentia, während er in anderen Fällen, die dem Untermuster HOFFNUNG ÄUSSERN zugeordnet werden (vgl. das Kap. „Expressiva mit Sprecherpräferenz“ ab S. 355), stärker auf Cicero ausgerichtet ist.

1357 Denkbar wäre evtl. auch die Separierung einer eigenen Illokution (eamque rem posse nobis adiumento esse si quae vis aut si quae rapinae fieri coeperint) oder sogar zweier zusätzlicher Illokutionen, insofern vis sich eher auf Terentia, rapinae auf das Eigentum bezieht, wobei Ersteres lediglich eine Spezifizierung des ersten Teils der
} 
Andere WOHLERGEHENSWÜNSCHE betreffen ganz allgemein die Gesundheit und das Wohlbefinden Terentias. Cicero versucht, sie in schwierigen Situationen zu beruhigen, wie in fam. 14.4.4 (33): nihil est quod te moveat, und ihr Mut zuzusprechen und Zuversicht zu vermitteln, wie in fam. 14.4.5 (42): sustenta te und 14.14 .1 (12): animo forti sitis. ${ }^{1358}$ Bei weiteren Sprechakten dieser Art handelt es sich meist um mehr oder weniger rituelle Formeln, die konventioneller Bestandteil der Einleitungs- bzw. Schlusssequenz eines Briefes sind. Insofern haben sie oft auch einen deklarativen Charakter, zumindest wenn sie nicht allzu weit in den Binnentext hineingezogen sind und tatsächlich ganz am Anfang bzw. Ende stehen. ${ }^{1359}$ In den Fällen, in denen die Verabschiedungsformel fehlt, wäre zu überlegen, ob dann nicht sogar der deklarative Charakter dominiert. Im Übrigen spricht aber einiges dafür, dass es sich um vorrangig expressive Sprechakte handelt. Während Begrüßungs- und (eingeschränkt) Verabschiedungsformel quasi obligatorisch sind, ergibt sich die Expressivität der in diesem Teilkapitel thematisierten Wohlergehensformeln, welche häufiger auch mal ausgelassen werden, schon aus ihrer Verwendung an sich. Deutlicher noch wird sie, je stärker die Formeln individuell abgewandelt werden. ${ }^{1360}$

In 11 von 24 Briefen findet sich am Briefanfang eine Variante der rituellen Formel si vales, bene est; ego valeo. Der direkte Sprechakt ist, insbesondere im zweiten Teil (ego valeo), assertiv; die expressive Funktion dominiert aber aus den bereits erläuterten Gründen eindeutig und wird zudem durch das evaluative bene befördert. ${ }^{1361}$ In sieben Fällen ist die Formel (mit Ellipse von est bzw. e.) abgekürzt. In fam. 14.15 (2) wird der zweite Teil weggelassen, in fam. 14.14.1 (2) der Plural (vos - nos) verwendet. Stark expressiv gefärbt ist die Formel in fam. 14.5.1 (2), wo sie ebenfalls im Plural steht, allerdings mit Aufsplittung der Subjekte (tu et Tullia - ego et Cicero) und v. a. mit affektiven Ergänzungen in Form der Apposition lux nostra und des superlativischen Attributs suavissimus. Manchmal tritt ergänzend eine weitere Wohlergehensformel hinzu, wie in fam. 14.8 (3): Valetudinem tuam velim cures diligentissime. und 14.21 (3): Da operam ut convalescas. Beide sind ähnlich formuliert wie die Wohlergehensformeln am Schluss eines Briefes, gehören dabei zu den etwas individueller gestalteten WOHLERGEHENSWÜNSCHEN, insofern velim cures durch den Superlativ diligentissime verstärkt bzw. das übliche valere durch (anlassbezogenes) convalescere ersetzt wird. ${ }^{1362}$

\footnotetext{
Äußerung (Romae vos esse tuto posse per Dolabellam) darstellen würde. Da eine klare und überzeugende Trennung nicht möglich scheint, soll darauf an dieser Stelle ganz verzichtet werden.

${ }^{1358}$ Die Grenze zu ähnlichen direktiven Sprechakten (wie z. B. fam. 14.2.3 (32): et valetudinem istam infirmam, si me amas, noli vexare. und 14.2.3 (35): sed video in te esse omnia. quare, ut id quod speras et quod agis consequamur, servi valetudini.) ist dabei nicht immer klar zu ziehen. Vgl. das Kap. zu den „Direktiva mit beidseitiger Präferenz" (ab S. 311). Vgl. außerdem fam. 14.2.3 (34): timeo ut sustineas, wo das expressive Untermuster ANGST ÄUSSERN dominiert. Was fam. 14.4.4 (33) betrifft, sind zudem Anklänge an das assertive Untermuster WIDERSPRECHEN zu erkennen. Vgl. darüber hinaus WAGNER 2001, 194 zum illokutiven Typ BERUHIGEN.

${ }^{1359}$ Vgl. a. N. 1353 bzw. RISSELADA 1993, 118.

1360 Vgl. a. VALETTE-CAGNAC 2017 zur (nicht unerheblichen) Bedeutung und Funktion des Themas Gesundheit in Ciceros Briefen, sowohl in den konventionellen Wohlergehensformeln als auch in anderen Äußerungen.

${ }^{1361} \mathrm{VgI}$. S. 352. Vgl. außerdem das Kap. „Verabschiedungsformeln: deklaratives BRIEF BEENDEN vs. expressives WOHLERGEHEN WÜNSCHEN“.

1362 Vgl. a. MARTEN-CLEEF 1991, 163 zu GENESUNGSWÜNSCHEN, welche sie als WOHLERGEHENSWÜNSCHE einordnet, die aber eine starke Nähe zu GELINGENSWÜNSCHEN aufweisen.
} 
Am Briefende, wo Wohlergehensformeln noch häufiger anzutreffen sind als zu Beginn, vierzehnmal zusätzlich zur Verabschiedungsformel vale(te), dreimal sogar als Ersatz, werden ebenfalls der Konjunktiv (fam. 14.9 (4) und 14.7.3 (14): velim cures) oder der Imperativ gebraucht. Bevorzugtes Verb ist dabei curare, das manchmal mit Akkusativobjekt (valetudinem tuam cura), meistens jedoch metadirektiv mit Finalsatz (cura ut valeas bzw. curate ut valeatis) verwendet wird. Auch bei da(te) operam (fam. 14.18 .2 (14): date operam ut valeatis bzw. 14.19 (9): Da operam ut valeas.) und fac handelt es sich um Metadirektiva, wobei fac meist in Verbindung mit curare (fac ut valetudinem cures), aber auch direkt mit valere (fac valeas) begegnet. ${ }^{1363}$

Die Wohlergehensformeln werden nicht nur mit den genannten Metadirektiva intensiviert, sondern auch durch die Ausweitung des WOHLERGEHENSWUNSCHES auf Tullia, durch exponiertes tu am Satzanfang, durch (z. T. superlativische) Adverbialien wie diligenter und maxime und Appositionen mit (superlativischen) Attributen wie mea suavissima et optatissima Terentia. Außerdem finden sich Erweiterungen in Form von kurzen Nebensätzen wie quod potes, si nos amatis oder si nos vultis valere, wobei das dritte Beispiel gewisse Anklänge an die konventionelle Wohlergehensformel am Briefanfang (si valetis ...) erkennen lässt. Manchmal sind mit den Wohlergehensformeln am Briefende sogar noch Nachträge mit eigener Handlungsfunktion verbunden, wie bei fam. 14.1.6 (44), 14.3.5 (37) und 14.4.6 (55).

Bei fam. 14.3.5 (37) handelt es sich um einen (sprachlichen) GUNSTERWEIS. ${ }^{1364}$ Die Expressivität ist hier sogar noch höher als bei den Begrüßungsformeln in fam. 14.14 und 14.18. Es mag eine gewisse Konventionalisierung vorliegen; diese ist ihr $\mathrm{m}$. E. aber in keiner Weise abträglich, und man kann dennoch von einer sehr emotionalen Liebeserklärung an Terentia sprechen. ${ }^{1365}$ Die Intensität der Äußerung ergibt sich in erster Linie aus der zweiteiligen Hyperbel, verstärkt durch den metadirektiven Ausdruck ita tibi persuadeas. ${ }^{1366}$ Zentral ist das affektive Adjektiv carius. ${ }^{1367}$

Im Unterschied zum GUNSTERWEIS betreffen die KOMPLIMENTE nicht die Person Terentias als Ganzes, sondern besondere Eigenschaften wie ihre Tapferkeit (fam. 14.7.2 (11)) und ihre

\footnotetext{
${ }^{1363}$ Vgl. a. RISSELADA 1993, 272f. Zur (nicht dominanten) Direktivität der WOHLERGEHENSWÜNSCHE vgl. S. 349. In fam. 14.2.3 (32) und (35), die in dieser Arbeit dem direktiven Sprechaktuntermuster ANWEISEN zugeordnet werden, ist diese dagegen $\mathrm{m}$. E. eher gegeben, da der Fokus stärker darauf liegt, dass Terentia aktiv etwas für ihre Gesundheit tun bzw. gesundheitsschädliche Handlungen unterlassen soll: Vgl. Kap. 2.1.3 und das Kap. „Direktiva mit beidseitiger Präferenz" (ab S. 311).

1364 Vgl. S. 214 sowie das Kap. „Begrüßungsformeln: deklaratives BRIEF ERÖFFNEN vs. expressives GUNST ERWEISEN“ (ab S. 346).

1365 Vgl. a. HALL 2009, 206f. („Assertions of affection and esteem“). Er nennt folgende Möglichkeiten zum Ausdruck von Wertschätzung im Lateinischen: $a m o(r)$, te habeo carum, diligo, te pluris / plurimi facio. Vgl. außerdem (mit Bezug auf fam. 13.41) ebd., 35f. („Expressions of thanks and appreciation“).

${ }^{1366}$ Vgl. a. ebd., 209f. (zu tibi persuadeas velim) und RISSELADA 1993, 263 (zu tibi persuade).

${ }^{1367}$ Vgl. a. fam. 14.7.1 (4): Tulliolam, quae nobis nostra vita dulcior est. Die Äußerung enthält starke Anklänge an das Untermuster GUNST ERWEISEN, bezieht sich aber nicht auf den Adressaten, also Terentia, sondern die Tochter Tullia und ist im Gesamtkontext dem Untermuster JAMMERN zuzuordnen: Vgl. das Kap. zu den „Expressiva mit Sprecheraversion“ (ab S. 368).
} 
Hilfsbereitschaft (fam. 14.2.2 (22)). ${ }^{1368}$ Fam. 14.6 (5) bezieht sich auf die Unterstützung Tullias nach ihrer Scheidung von Dolabella, zielt also ebenfalls auf Terentias Hilfsbereitschaft. Ist Cicero selbst der Begünstigte, liegt das Untermuster BEGRÜSSEN vor. ${ }^{1369}$ Wie bei KOMPLIMENTEN geht die Würdigung der positiven Eigenschaften Terentias mit einem Gefühl der Sympathie einher, das aber bei Sprechakten des Typs BEGRÜSSEN dominiert wird von Freude, die von eher verhaltener Zufriedenheit oder Akzeptanz bis hin zu ekstatischer Begeisterung reichen kann. ${ }^{1370}$ So drückt Cicero in fam. 14.5.1 (12) lediglich ein gewisses Verständnis für die Kürze eines Briefes seiner Frau aus ${ }^{1371}$ und gibt in fam. 14.8 (5) eine eher neutrale Bewertung ihres Handelns (schnelle Weitergabe einer Nachricht Cäsars) ab, während er sich in fam. 14.5.1 (10) ausgesprochen positiv über ihre Sorgfalt beim Briefeschreiben äußert. ${ }^{1372}$ Noch deutlicher zum Ausdruck gebracht wird seine Freude in fam. 14.1.1 (2) und 14.2.2 (16), wo er Terentias unermüdlichen Einsatz für ihn und ihre Tapferkeit und Tüchtigkeit rühmt.

Die sprachlichen Mittel zur Intensivierung ähneln sich bei den beiden Untermustern KOMPLIMENT MACHEN und BEGRÜSSEN. Je mehr Cicero involviert ist, umso stärker ist die Expressivität, weshalb sie tendenziell bei letzterem etwas größer zu sein scheint. Sie äußert sich in der Verwendung von Superlativen (fortissime et amantissime) und Hyperbeln (nisi vos fortiores cognossem quam quemquam virum, allumfassende Pronomina wie omnis: omnium, omnia, omnes) sowie anderen intensivierenden Ausdrücken (incredibilem, nec animi neque corporis laboribus defatigari, celeriter). ${ }^{1373}$ Mit vielen der genannten Adjektive und Adverbien sind ebenso wie mit einigen Substantiven (virtus, fortitudo) und Verben (non miror bzw. nec miror, neque sum admiratus) positive Bewertungen verbunden, manche eher objektiv (z. B. celeriter $)^{1374}$, andere sehr emotional (z. B. amantissime). Hinzu kommt ein starker Partnerbezug (Pronomina der 2. Person: tibi, te, a te, tuam, tuo, vos und affektive Anreden: mea lux, meum desiderium ${ }^{1375}$ ). Abgesehen davon, dass Cicero bemerkt, er staune nicht über solch vorbildliches Verhalten bzw. er habe von seiner Frau nichts anderes erwartet, bringt er seine Gefühle (wie Freude und Stolz) nicht explizit zum Ausdruck, sondern sie sind aus der Art seiner Darstellung der Handlungen bzw. des Charakters seiner Frau zu erschließen. ${ }^{1376}$ In einigen Äußerungen (wie dem mittels eines Irrealis formulierten KOMPLIMENT in fam. 14.7.2 (11)) ist die Indirektheit besonders stark ausgeprägt.

\footnotetext{
1368 Zu den Handlungsbedingungen des Untermusters KOMPLIMENT MACHEN vgl. S. 221. VgI. a. S. 214 . Vgl. außerdem UNCETA Gómez 2019b (mit Bezug auf Plautus); LATEINER 2013, 327ff. (mit Bezug auf Petron und Apuleius): „Compliments (laudes)“; LóPEZ LóPEZ 2012 (mit Bezug auf die römische Komödie und Tragödie) sowie HALL 2009, 49ff. (mit Bezug auf fam. 4.11): „Polite wit and compliments“.

1369 Vgl. S. 192 bzw. MARTEN-CLeEf 1991, 129 und ebd., 180.

${ }^{1370}$ Vgl. N. 910.

1371 Vgl. N. 910.

1372 Vgl. S. 193 und 214.

${ }^{1373}$ Vgl. HALL 2009, 200ff. („Intensifying adjectives and adverbs“).

${ }^{1374} \mathrm{Vgl}$. a. brevem in fam. 14.5.1 (12), das aber eher negativ konnotiert ist.

1375 Die Anrede kann allerdings auch auf die in fam. 14.2.2 (21) ausgedrückte ENTSCHULDIGUNG bezogen werden.

${ }^{1376}$ Vgl. a. ebd., 199f. bzw. (zu fam. 13.41) ebd., 41f. Als Möglichkeiten zum Ausdruck von Freude im Lateinischen werden u. a. folgende Verben genannt: laetari, gaudere, magnam voluptatem capere, laetitiam capere.
} 
Grundsätzlich besteht eine große Nähe zwischen den Untermustern BEGRÜSSEN und DANKEN. ${ }^{1377}$ Ist eine Handlung des Adressaten dem Sprecher willkommen (gratus), wird er zugleich Freude und Dank empfinden. ${ }^{1378}$ Beide Gefühle schwingen sowohl beim BEGRÜSSEN als auch beim DANKEN mit, wobei jeweils das eine oder das andere überwiegt. Häufig sind beide Sprechakttypen auch miteinander verbunden, wie z. B. fam. 14.5 .1 (10) und (11) sowie 14.8 (5) und (6). ${ }^{1379}$ Dabei ergibt sich aus ersterem (assertiv) der Grund des Danks. Voraussetzung zur Ausübung des Sprechakts DANKEN sind performative Verben oder ähnliche Wendungen zum expliziten Ausdruck von Dankesgefühlen wie gratum facere oder gratum esse ${ }^{1380}$, meist mit Bezug auf den Adressaten (mihi). Der Dankesausdruck kann durch Verwendung des Superlativs (gratissimum) intensiviert werden. ${ }^{1381}$

\section{Expressiva mit Sprecherpräferenz}

Cicero äußert sich Terentia gegenüber nie opponierend; bei den Expressiva mit Sprecherpräferenz in fam. 14 handelt es sich ausschließlich um abreagierende Sprechakte, mit denen Cicero seine (positiven) Gefühle entlädt. Terentia ist dafür weder verantwortlich noch unmittelbar davon betroffen. Dennoch sind solche Sprechakte durchaus nicht völlig unabhängig vom Adressaten. ${ }^{1382}$ Sie wirken auch auf Terentia emotional ein, haben zudem eine recht stark ausgeprägte assertive und direktive (persuasive) Komponente. Cicero kommt dem Informationsbedürfnis seiner Frau nach, die i. A. großes Interesse an seinem Seelen- und Gefühlszustand haben wird, und er übt mehr oder weniger subtilen Einfluss auf ihre Handlungsweise aus, indem er sie an seinen Gefühlen (wie z. B. Freude), Wünschen und Hoffnungen teilhaben lässt:

\begin{tabular}{|ll|}
\hline FROHLOCKEN & \\
fam. 14.4.5 (43): & viximus, floruimus \\
\hline JUBELN & \\
fam. 14.1.3 (21): & homo officiosissimus [= Plancius] \\
fam. 14.1.4 (28): & $\begin{array}{l}\text { Pisonis humanitas, virtus, amor in omnis nos tantus est ut nihil supra } \\
\text { possit. }\end{array}$ \\
fam. 14.2.2 (11): & Pisonem nostrum merito eius amo plurimum. \\
fam. 14.2.2 (19): & homo officiosus [= P. Valerius] \\
\hline
\end{tabular}

1377 Vgl. a. MARTEN-CLEEF 1991, 202ff. Vgl. dagegen ROESCH 2004, 149, die keine Unterscheidung zwischen diesen beiden Sprechakttypen bzw. Gefühlen macht: „Le remerciement peut aussi simplement consister en l'affirmation de la joie de celui qui écrit face à un service rendu (il en découle logiquement qu'exprimer cette joie, c'est remercier). Par exemple en [fam.] 3, 9, 3, Cicéron remercie Appius Pulcher de lui avoir envoyé un ouvrage: mehercule tuis incredibiliter studiis erga me muneribusque delector [...]." Nach den in dieser Arbeit angewendeten Kriterien würde es sich bei dem Beispiel um einen Sprechakt des BEGRÜSSENS handeln. Vgl. a. UNCETA GÓMEZ 2010 zum Danken als Sequenz, die verschiedene Sprechakte (wie DANKEN, VERSPRECHEN, BEGRÜSSEN usw.) umfasst. 1378 Vgl. a. N. 909 (zur Verwandtschaft zwischen den Untermustern GRATULIEREN und DANKEN).

1379 Die Trennung der zwei Illokutionen (5) und (6) in fam. 14.8 erfolgt dadurch, dass der Objektsatz einmal als (5) für sich gewertet wird, zugleich aber als (obligatorisches) Akkusativobjekt zu (6) ergänzt wird.

${ }^{1380}$ Vgl. MARTEN-CLEef 1991, 208. Zum Lateinischen vgl. a. (mit Bezug auf fam. 13.41) HALL 2009, 35f. („Expressions of thanks and appreciation“) und ebd., 198 („Expressions of thanks“). Neben gratum est und hoc mihi gratius facere nihil potes nennt er noch gratias ago und verschiedene Varianten dieser Ausdrücke. Vgl. außerdem ROESCH 2004, 149 und FERRI 2012, 134.

1381 Vgl. ROESCH 2004, 152 zum „moyen de superlatifs“, wobei allerdings zu beachten ist, dass sie dabei auch Sprechakte im Blick hat, die eigentlich unter das Untermuster BEGRÜSSEN fallen. Vgl. a. N. 1377.

1382 Vgl. MARTEN-CLEEF 1991, 244ff., z. B. ebd., 244: „Aufgrund der fehlenden oder geringen Mitteilungsabsicht gelten abreagierende EXPRESSIVA in gewisser Hinsicht als ,defekte' illokutionäre Akte." 


\begin{tabular}{|c|c|}
\hline fam. 14.3.3 (20): & $\begin{array}{l}\text { Pisonem nostrum mirifico esse studio in nos et officio et ego perspicio } \\
\text { et omnes praedicant. }\end{array}$ \\
\hline am. 14.4.2 (11): & virum optimum [= M. Laenius Flaccus] \\
\hline fam. 14.4.2 (12): & $\begin{array}{l}\text { qui periculum fortunarum et capitis sui prae mea salute neglexit neque } \\
\text { legis improbissimae poena deductus est quo minus hospiti et amicitiae } \\
\text { ius officiumque praestaret. }\end{array}$ \\
\hline fam. 14.4.2 (14): & habebimus [d. h. gratiam] quidem semper. \\
\hline fam. 14.4.6 (50): & hominem fidelem \\
\hline fam. 14.4.6 (51): & SaI \langle\rangle$\rangle$ ustius officio vincit omnes. \\
\hline fam. 14.4.6 (52): & Pescennius est perbenevolus nobis \\
\hline fam. 14.5.1 (7): & sane strenue \\
\hline fam. 14.7.1 (6): & statim ita sum levatus ut mihi deus aliquis medicinam fecisse videatur. \\
\hline fam. 14.14.2 (13): & Labienus rem meliorem fecit \\
\hline fam. 14.14.2 (14): & et sceleris conde \\
\hline
\end{tabular}

\section{HOFFNUNG ÄUSSERN}

fam. 14.1.2 (14): $\quad$ sed tamen, si omnis tribunos pl. habemus [...], non est desperandum. fam. 14.1.2 (15): $\quad$ si Lentulum tam studiosum quam videtur [...], non est desperandum. fam. 14.1.2 (16): $\quad$ si vero etiam Pompeium et Caesarem, non est desperandum.

fam. 14.1.3 (25): quem ego diem [d. h. den Tag der Rückkehr nach Italien] si videro [...], satis magnum mihi fructum videbor percepisse et vestrae pietatis et meae.

fam. 14.1.3 (26): $\quad$ si in vestrum complexum venero [...], satis magnum mihi fructum videbor percepisse et vestrae pietatis et meae.

fam. 14.1.3 (27): $\quad$ si et vos et me ipsum reciperaro, satis magnum mihi fructum videbor percepisse et vestrae pietatis et meae.

fam. 14.1.4 (29): $\quad$ utinam ea res ei [= Piso] voluptati sit!

fam. 14.1.5 (40): $\quad$ tantum scribo: si erunt in officio amici, pecunia non deerit

fam. 14.1.5 (43): cui si aliquid erit ne egeat, mediocri virtute opus est et mediocri fortuna ut cetera consequatur.

fam. 14.2.2 (14): in novis tribunis pl. intellego spem te habere. id erit firmum, si Pompei voluntas erit

fam. 14.2.3 (25): Quod de domo scribis, hoc est de area, ego vero tum denique mihi videbor restitutus si illa nobis erit restituta.

fam. 14.2.3 (28): quod si conficitur negotium, omnia consequemur

fam. 14.3.3 (21): di faxint, ut tali genero mihi praesenti tecum simul et cum liberis nostris frui liceat!

fam. 14.3.3 (22): $\quad$ nunc spes reliqua est in novis tribunis pl. et in primis quidem diebus.

fam. 14.3.5 (31): $\quad$ si perficitis quod agitis, me ad vos venire oportet

fam. 14.4.1 (6): $\quad$ quod si nos ad aliquam alicuius commodi aliquando reciperandi spem fortuna reservavit, minus est erratum a nobis

fam. 14.4.2 (13): huic [= M. Laenius Flaccus] utinam aliquando gratiam referre possimus! 


\begin{tabular}{|c|c|}
\hline fam. 14.4.3 (24): & unum hoc scito: si te habebo, non mihi videbor plane perisse. \\
\hline fam. 14.4.3 (28): & iste [= Ciceros Sohn] vero sit in sinu semper et complexu meo. \\
\hline fam. 14.4.4 (32): & Pisonem, ut scribis, spero fore semper nostrum. \\
\hline fam. 14.4.5 (39): & $\begin{array}{l}\text { Tu quod me hortaris ut animo sim magno et spem habeam reciperan- } \\
\text { dae salutis, id velim sit eius modi ut recte sperare possimus. }\end{array}$ \\
\hline fam. 14.5.2 (24): & [cum] salvi [venerimus] \\
\hline fam. 14.5.2 (26): & nos, si di adiuvabunt, circiter Id. Nov. in Italia speramus fore. \\
\hline fam. 14.7.2 (8): & Navem spero nos valde bonam habere. \\
\hline fam. 14.7.2 (13): & $\begin{array}{l}\text { et tamen eius modi spero negotia esse ut sperem [...] me aliquando cum } \\
\text { similibus nostri rem publicam defensuros. }\end{array}$ \\
\hline fam. 14.12 (2): & Quod nos in Italiam salvos venisse gaudes, perpetuo gaudeas velim. \\
\hline fam. 14.16 (3): & $\begin{array}{l}\text { Etsi eius modi tempora nostra sunt ut nihil habeam quod [aut] a te } \\
\text { litterarum exspectem [...], tamen nescio quo modo [et ipse] vestras } \\
\text { litteras exspecto [et ...]. }\end{array}$ \\
\hline
\end{tabular}

Abbildung 69: Expressiva mit Sprecherpräferenz

In fam. 14 findet sich kaum ein überzeugendes Beispiel für das Untermuster FROHLOCKEN, dessen Handlungsbedingungen wie folgt lauten:

„B1: Sp1 hat eine Handlung $\mathrm{H}$ vollzogen und damit einen Sachverhalt S herbeigeführt. (Bei Dialogsituation gilt zusätzlich: Sp1 nimmt an, daß Sp2 Kenntnis von H und S hat.)

B2: Sp1 bewertet $\mathrm{H}$ bzw. S positiv für sich selbst.

B3: Sp1 freut sich über H bzw. S. “1383

Am ehesten kann man fam. 14.4.5 (43) dazu zählen. Cicero drückt damit Freude über sein vergangenes glückliches Leben aus: viximus, floruimus. ${ }^{1384}$ Dass er dies v. a. durch seine eigenen Leistungen begründet sieht, macht $u$. a. die folgende Äußerung fam. 14.4 .5 (44) deutlich. Dort erkennt man ebenfalls Anklänge an das Untermuster FROHLOCKEN, insofern er Stolz auf seine Leistungen in der Vergangenheit (virtus nostra) bzw. Freude darüber ausdrückt. Zugleich entladen sich damit aber auch Ärger und Traurigkeit, weil ihn ebendiese ins Unglück gestürzt hätten (nos adflixit), was die Lage für ihn noch schlimmer macht, als wenn er sich selbst die Schuld daran geben könnte. Fam. 14.4.5 (44) ist daher eher dem Untermuster FLUCHEN oder JAMMERN zuzuordnen. ${ }^{1385}$

Dass das Untermuster FROHLOCKEN so wenig vertreten ist, kann kaum verwundern angesichts der Tatsache, dass die Briefe in fam. 14 in eher ernsten, angespannten Situationen entstanden sind, in denen es kaum einen (aktuellen) Anlass zur Freude über das eigene Handeln gab. Hingegen hatte Cicero des Öfteren Anlass zur Freude über das Handeln anderer Menschen, die ihm in seiner Not beigestanden haben, wobei sein Schwiegersohn Piso besonders herausragt. Entsprechend finden sich zahlreiche Beispiele für das Untermuster JUBELN ${ }^{1386}$, bei

\footnotetext{
1383 MARTEN-CLEef 1991, 248.

1384 Durch den Plural wird zwar die ganze Familie eingeschlossen, dennoch erscheint die Äußerung stark selbstbezogen.

1385 Vgl. das Kap. „Expressiva mit Sprecheraversion“ (ab S. 368).

${ }^{1386} \mathrm{Vgl}$. ebd., $253 \mathrm{ff}$.
} 
dem sich Freude (oder auch Bewunderung) und Dankbarkeit oft verbinden, also nicht wie bei den adressatenorientierten Untermustern BEGRÜSSEN und DANKEN getrennt werden.

Eine „nicht-personale Quelle“ kann ebenfalls für eine Verbesserung der Situation Ciceros verantwortlich sein, wie z. B. deus aliquis in fam. 14.7.1 (6). Diese Äußerung macht aber zugleich deutlich, dass nicht immer leicht zu entscheiden ist, ob tatsächlich bereits von (indirekten) Expressiva gesprochen werden sollte oder nicht doch die Assertivität überwiegt. In diesem Fall ergibt sich die Dominanz des expressiven Sprechakts v. a. aus dem hyperbolischen Vergleich (ut mihi deus aliquis medicinam fecisse videatur), bei dem zweiteiligen Attributsatz in fam. 14.4.2 (12), mit dem Cicero seine positive Einschätzung von M. Laenius Flaccus begründet, aus dem Gebrauch „existenzieller“, z. T. superlativischer Begriffe. Damit hebt Cicero (ähnlich wie bei den adressatenbezogenen Untermustern BEGRÜSSEN und KOMPLIMENT MACHEN) hervor, dass jener selbst unter schwersten Bedingungen (periculum fortunarum et capitis sui neglexit neque legis improbissimae poena deductus est quo minus ...) grundlegende menschliche Werte (hospiti et amicitiae ius officiumque) zum Wohle Ciceros (prae mea salute) aufrechterhalten habe. Besonders schwach erscheinen die Indikatoren in fam. 14.14.2 (13) und (14), wo Cicero ohnehin nur mittelbar (als Bürger Roms) betroffen ist. ${ }^{1387}$ Hier könnte man möglicherweise tatsächlich von einer Dominanz der Assertivität ausgehen, wenngleich recht starke expressive bzw. evaluative Ausdrücke (meliorem, sceleris, condemnat) verwendet werden, wie sie charakteristisch sind für JUBELN: In Sprechakten dieses Typs finden sich allgemein Adjektive und Adverbien, mit denen die betreffenden Personen (fidelem, officiosus, officiosissimus, optimum, perbenevolus) bzw. deren Eigenschaften (mirifico) und Handlungen (sane strenue) bewertet werden, Hyperbeln (in omnis nos tantus est ut nihil supra possit, et ego perspicio et omnes praedicant) sowie weitere intensivierende und evaluative, oft auch superlativische und verabsolutierende Ausdrücke. Gerühmt werden Werte und Tugenden wie amor, humanitas, officium, studium und virtus oder ganz allgemein die Verdienste (meritum) eines bestimmten Menschen. Die Zuneigung wird durch affektive Possessivpronomina (nostrum) oder sogar ganz explizit durch amo bekundet, das in fam. 14.2 .2 (11) durch plurimum noch weiter verstärkt wird. In fam. 14.4 .2 (14) drückt Cicero mit habebimus quidem semper seine immerwährende Dankbarkeit gegenüber M. Laenius Flaccus aus, ebenfalls explizit, obschon gratiam aus der vorangehenden Äußerung ergänzt werden muss: huic utinam aliquando gratiam referre possimus!

Dieser Ausrufesatz selbst wiederum ist dem Untermuster HOFFNUNG ÄUSSERN ${ }^{1388}$ zuzuordnen, mit dem ein guter Wunsch nicht in Bezug auf das Wohl des Adressaten, also Terentias, sondern auf das eigene, also Ciceros, oder das dritter Personen geäußert wird, $d$. h. das seiner Kinder und seines Schwiegersohns oder anderer ihm nahestehender Personen, wie eben z. B. M. Laenius Flaccus. ${ }^{1389}$ Die für das Untermuster typischen konjunktivischen Wunschsätze können nicht nur mit utinam, wie z. B. auch in fam. 14.1.4 (29), sondern ebenso mit velim, wie

1387 Vgl. a. MARTEN-CLEEF 1991, 255: „Der Sprecher kann von der Situation unmittelbar positiv betroffen sein, aber auch nur mittelbar, wenn er lediglich Beobachter eines positiv bewerteten Ereignisses ist. Im letzteren Fall gibt es allerdings Faktoren, die eine Verbindung oder ,Einheit' zwischen ihm und dem Sachverhalt bzw. dem davon unmittelbar betroffenen Sp3 schaffen."

1388 Vgl. S. 198 bzw. ebd., $260 f f$.

1389 Vgl. ebd., 262, wo zum Untermuster HOFFNUNG ÄUSSERN bemerkt wird: „Wie bei JUBELN ist zu ergänzen, daß der Sprecher vom zukünftigen Sachverhalt nicht nur unmittelbar betroffen sein kann, sondern auch nur 
z. B. in fam. 14.12 (2), oder entsprechenden floskelhaften Wendungen wie di faxint eingeleitet werden, wie z. B. in fam. 14.3.3 (21); manchmal steht der Konjunktiv auch für sich allein, wie z. B. in fam. $14.4 .3(28) .{ }^{1390}$

Ähnlich wie di faxint wird si di adiuvabunt in fam. 14.5.2 (26) gebraucht. Allerdings stehen die Verben dort im Indikativ. Prägend ist das Futur (fore, adiuvabunt) in Verbindung mit speramus (im Präsens). Der Indikativ Futur findet sich genauso noch in vielen anderen Sprechakten des Untermusters HOFFNUNG ÄUSSERN (videbor, deerit, erit firmum, consequemur), z. T. auch als (elliptischer) Infinitiv (fore, defensuros) und in vielen Konditionalsätzen (Futur I: si habebo / erunt in officio / voluntas erit, Futur II: si videro / venero / reciperaro / coeperint / erit restituta). ${ }^{1391}$ Manchmal steht in solchen Fällen das Präsens, wie z. B. in fam. 14.1.5 (43) und 14.3.5 (31), wo aber quasi als Ersatz futurische Wendungen wie oportet und opus est verwendet werden. Mit innen ist ebenso wie mit dem Gerundivum (z. B. non est desperandum in fam. 14.1.2 (14) bis (16)) zugleich eine gewisse Direktivität verbunden, welche aber nicht als dominant erachtet werden kann, da die Handlungsvoraussetzungen (zumindest im Fall von fam. 14.1.2 (14) bis (16) und 14.1.5 (43)) kaum von der betroffenen Person zu kontrollieren sind, wie es für direktive Sprechakte die Voraussetzung ist. Es handelt sich vielmehr um Wünsche und nicht um Aufforderungen. Dass sie in gewisser Hinsicht eng verwandt miteinander sind, zeigt u. a. der Gebrauch von velim in beiden Äußerungsformen. ${ }^{1392}$

In den exklamativen Wunschsätzen wird die Expressivität von Sprechakten des Untermusters HOFFNUNG ÄUSSERN sehr direkt ausgedrückt, in vielen anderen Äußerungen, die nicht nur häufig eine mehr oder weniger deutlich ausgeprägte Nähe zu den Direktiva aufweisen, sondern auch zu einigen Kommissiva und v. a. Assertiva, hingegen eher indirekt. Bei fam. 14.5.2 (26) kann man z. B. starke Anklänge an die Untermuster ANKÜNDIGEN und PROGNOSTIZIEREN erkennen. Explizit performative Ausdrücke sind nicht üblich. SB-Verben wie sperare und entsprechende Wendungen (spem habere, spes est) werden lediglich emotionsbeschreibend verwendet. ${ }^{1393}$ Entscheidend für die Einordnung ist neben dem Zukunftsbezug, der durch das Futur, das Gerundivum sowie bestimmte Adverbien (perpetuo) und Verben (exspectare, sperare, oportet, opus est) vermittelt wird, aber eben genauso für viele andere Sprechaktmuster (wie z. B. PROGNOSTIZIEREN, ANKÜNDIGEN, VERSPRECHEN) typisch ist, außerdem ein damit und

mittelbar, und zwar dann, wenn es um das zukünftige Schicksal von Sp3 geht. Die für jedes Gefühlserlebnis notwendige Selbstbetroffenheit ergibt sich auch hier aus einem Bindungsgefühl von Sp1 gegenüber Sp3 aufgrund irgendeiner gemeinsamen Gruppenzugehörigkeit oder (im Falle eines Mißgeschicks von Sp3) aufgrund bestehender Antipathien."

1390 Vgl. a. MESA SANZ 1998.

${ }^{1391}$ Ein Sonderfall ist fam. 14.5.2 (24), wo die Illokution auf der Sprachoberfläche im Prinzip lediglich durch das Prädikativum salvi repräsentiert wird, zu dem aber venerimus, also ein Prädikat im Futur II, zu ergänzen ist.

1392 Vgl. RISSELADA 1993, 94: „,[...] in view of its very frequent use in requests in Cicero's letters [...] [velim] appears to have been a conventional request expression. [...] Unlike potin ut, however, velim is also occasionally used in other speech acts, cf. the wish [...]." Vgl. a. ebd., 117ff. (zu Wünschen im Imperativ) und ebd., 282ff. (zu Wünschen mit volo). Zur Abgrenzung von Wünschen und Expressiva vgl. außerdem MARTEN-CLEEF 1991, 91f. bzw. N. 1351. Vgl. außerdem N. 1096, 1337 und 1354.

${ }^{1393}$ Vgl. ebd., 264. Dies würde ähnlich auch für Verben wie velle, cupere, desiderare und optare gelten, welche in fam. 14 allerdings (abgesehen von velim) nicht in Verbindung mit dem Untermuster HOFFNUNG ÄUSSERN verwendet werden. Vgl. a. MESA SANZ 1998. Vgl. außerdem N. 1392. 
mit einem Gefühl des Ausgeliefertseins verbundener Ausdruck von Ungewissheit. V. a. Substantive wie fortuna und deus (di) betonen die Schicksalhaftigkeit der erhofften Ereignisse, die von den Betroffenen nur wenig zu beeinflussen sind und von vielen Eventualitäten abhängen, welche z. B. in Konditionalsätzen benannt werden. Hinzu kommen u. a. weitere Substantive wie spes, Verben wie sperare, videri (im Futur) und z. T. auch posse ${ }^{1394}$, Wendungen wie nescio quo modo und Adverbien bzw. Pronomina mit ali- (aliquando, aliquis, aliquid, aliqui, ...). ${ }^{1395}$ Ein besonders anschauliches Beispiel stellt fam. 14.4.1 (6) dar: quod si nos ad aliquam alicuius commodi aliquando reciperandi spem fortuna reservavit, minus est erratum a nobis.

Kennzeichnend für das Untermuster HOFFNUNG ÄUSSERN ist des Weiteren (im Unterschied z. B. zu ANGST ÄUSSERN) die positive Bewertung des erhofften Sachverhalts, welche u. a. durch evaluative und emotiv-affektive Ausdrücke wie bonam (navem), tali (genero), voluptas, spes, recte sperare, non desperare, non perire, minus erratum esse, gaudere, frui, magnum fructum percipere et vestrae pietatis et meae, in vestrum complexum venire, in sinu et complexo meo esse verdeutlicht wird. ${ }^{1396}$ Sie können noch weiter intensiviert und damit verstärkt oder auch abgeschwächt werden, z. B. durch semper, perpetuo, plane, valde, tam, etiam, tamen, omnis / omnia, nihil, firmus bzw. satis, tantum, mediocris.

Den Begriffen, mit denen der Inhalt der Wünsche bezeichnet wird, ist eine positive Bewertung häufig bereits inhärent. Manchmal ist er aus dem weiteren Kontext zu erschließen, meist jedoch dem Text explizit zu entnehmen, oft auch den Konditionalsätzen, insofern diese positive (also erwünschte) Handlungsbedingungen beschreiben. Es geht dabei ähnlich wie beim Untermuster WOHLERGEHEN WÜNSCHEN v. a. um Hilfe und Unterstützung (spem esse / habere in aliquo, aliquem habere, nostrum esse, studiosum esse, in officio esse, adiuvare, alicuius voluntatem esse, ...), Sicherheit und Komfort (navem bonam habere, salvum venire), die Rückkehr nach Italien (in Italia esse, in Italiam venire, quem ego diem si videro) und das Zusammensein mit nahestehenden Personen wie seiner Frau Terentia, den Kindern und seinem Schwiegersohn Piso (tali genero mihi praesenti tecum simul et cum liberis nostris frui, in sinu semper et complexu meo esse, in vestrum complexu venire, ad vos venire, te habere $)^{1397}$ sowie den brieflichen Kontakt mit innen (vestras litteras exspectare). Cicero ist es wichtig, dass andere Menschen (Piso, M. Laenius Flaccus) die gebührende Anerkennung und Dank erhalten (eam rem ei voluptati esse, huic gratiam referre), so wie er diese auch für sich in Anspruch nimmt und deshalb auf die Wiederherstellung seiner Reputation hofft. Dies macht er z. B. (unter Einschluss Terentias) in fam. 14.1.3 (27) deutlich: si et vos et me ipsum reciperaro, satis magnum mihi fructum videbor percepisse et vestrae pietatis et meae. ${ }^{1398}$ Der Begriff reciperare findet sich auch in Zusammenhang mit allgemeinen Begriffen wie salus und commodum. Ähnlich wird das Verb restituere verwendet, welches sich in fam. 14.2.2 (25) auf Ciceros Haus bzw. Grundstück (domus, area) auf dem Palatin bezieht, also auf seine finanzielle Situation, die für ihn eng mit seiner persönlichen Rehabilitation verknüpft ist. Dies gilt ähnlich für die Wendung

\footnotetext{
1394 Vgl. S. 351.

1395 Vgl. a. ORLANDINI 1995, 19ff. (zu aliquis).

1396 Vgl. a. MARTEN-CLEEF 1991, 265 zu den Ausdrucksmöglichkeiten für das Untermuster HOFFNUNG ÄUSSERN, zu denen u. a. der Hinweis auf die Emotion oder eine Evaluation (Objekt- oder Sprecherbewertung) gehört. 1397 Vgl. N. 1356.

${ }^{1398}$ Hier wie auch z. B. in fam. 14.2.3 (25) und (28) werden Cicero und Terentia (teilweise unter Einschluss der Kinder) als Einheit betrachtet. Vgl. S. 351.
} 
omnia bzw. cetera consequi, die Cicero in fam. 14.2.2 (28) im Hinblick auf seine eigenen Finanzen, in fam. 14.1 .5 (43) auf die seines Sohnes benutzt, dessen Lebensglück in den Augen Ciceros v. a. von dessen gesicherten Vermögensverhältnissen (pecunia, aliquid esse, ne egeat) abhängt. Für Cicero haben also Geld und Besitz einen großen Stellenwert, besonders da sie Voraussetzung für Ansehen und Ruhm sind, die er sich durch seinen Einsatz für das Staatswohl erworben hat und weiterhin erwerben will (aliquando cum similibus nostri rem publicam defendere).

\section{Expressiva mit beidseitiger Aversion}

Durch Expressiva mit beidseitiger Aversion gibt Cicero seiner Frau gegenüber zu erkennen, dass er Traurigkeit (BEDAUERN BEKUNDEN und SICH ENTSCHULDIGEN) oder Angst (SORGE BEKUNDEN) angesichts eines Sachverhalts empfindet, von dem Terentia in irgendeiner Weise negativ betroffen ist bzw. war oder sein wird. Oft geht mit ihnen zudem Ärger über sich selbst (SICH ENTSCHULDIGEN) oder über andere (BEDAUERN BEKUNDEN) einher:

\begin{tabular}{|c|c|}
\hline \multicolumn{2}{|c|}{ BEDAUERN BEKUNDEN } \\
\hline fam. $14.2 .2(20):$ & id quod ego maximo cum fletu legi \\
\hline fam. 14.16 (5): & $\begin{array}{l}\text { Volumnia debuit in te officiosior esse quam fuit et id ipsum quod fecit } \\
\text { potuit diligentius facere et cautius. }\end{array}$ \\
\hline \multicolumn{2}{|l|}{ SORGE BEKUNDEN } \\
\hline fam. 14.1.5 (39): & neque te in eundem fletum adducam. \\
\hline fam. 14.4.3 (19): & $\begin{array}{l}\text { [rogem te ut venias,] mulierem aegram, et corpore et animo confec- } \\
\text { tam[?] }\end{array}$ \\
\hline fam. 14.4.4 (31): & [nescio, utrum ... an,] quod metuo, [plane sis spoliata.] \\
\hline fam. 14.14.1 (5): & $\begin{array}{l}\text { sin homo amens diripiendam urbem daturus est, vereor ut Dolabella } \\
\text { ipse satis nobis prodesse possit. }\end{array}$ \\
\hline fam. 14.14.1 (6): & $\begin{array}{l}\text { etiam illud metuo, ne iam intercludamur, ut, cum velitis, exire non } \\
\text { liceat. }\end{array}$ \\
\hline fam. 14.14.1 (10): & etiam illud verendum est, ne brevi tempore fames in urbe sit. \\
\hline fam. 14.18.1 (4): & sed rursus illud me movet, quod video omnis bonos abesse Roma \\
\hline fam. 14.18.1 (5): & et eos mulieres suas secum habere. \\
\hline fam. 14.18.2 (10): & [Vos videte quid ...] et ne, cum velitis, exire non liceat. \\
\hline \multicolumn{2}{|c|}{ SICH ENTSCHULDIGEN } \\
\hline fam. 14.1.1 (4): & $\begin{array}{l}\text { te ista virtute, fide, probitate, humanitate in tantas aerumnas propter } \\
\text { me incidisse }\end{array}$ \\
\hline fam. 14.1.1 (7): & $\begin{array}{l}\text { quae si, tu ut scribis, fato facta putarem, ferrem paulo facilius; sed } \\
\text { omnia sunt mea culpa commissa }\end{array}$ \\
\hline fam. 14.2.1 (7): & $\begin{array}{l}\text { ad te vero et ad nostram Tulliolam non queo sine plurimis lacrimis } \\
\text { scribere. }\end{array}$ \\
\hline fam. 14.2.1 (8): & vos enim video esse miserrimas, quas ego beatissimas semper esse volui \\
\hline fam. 14.2.1 (9): & idque praestare debui \\
\hline fam. 14.2.2 (17): & $\begin{array}{l}\text { sed maereo casum eius modi ut tantis tuis miseriis meae miseriae suble- } \\
\text { ventur. }\end{array}$ \\
\hline
\end{tabular}




\begin{tabular}{|c|c|}
\hline fam. 14.2.2 (21): & $\begin{array}{l}\text { hem, [...] te nunc, mea Terentia, sic vexari, sic iacere in lacrimis et sordi- } \\
\text { bus }\end{array}$ \\
\hline fam. $14.2 .2(23):$ & idque fieri mea culpa \\
\hline fam. 14.2 .3 (27): & $\begin{array}{l}\text { illud doleo, quae impensa facienda est, in eius partem te miseram et } \\
\text { despoliatam venire. }\end{array}$ \\
\hline fam. 14.2 .3 (33): & $\begin{array}{l}\text { nam mihi ante oculos dies noctesque versaris. omnis labores te excipere } \\
\text { video }\end{array}$ \\
\hline fam. 14.3.1 (4): & nec meae me miseriae magis excruciant quam tuae vestraeque. \\
\hline fam. 14.3.1 (6): & $\begin{array}{l}\text { meum fuit officium vel legatione vitare periculum vel diligentia et copiis } \\
\text { resistere vel cadere fortiter. }\end{array}$ \\
\hline fam. 14.3.2 (9): & $\begin{array}{l}\text { [tum etiam] pudore [erg. conficior]. pudet enim me uxori [mae] } \\
\text { optimae, suavissimis liberis virtutem et diligentiam non praestitisse. }\end{array}$ \\
\hline fam. 14.3.2 (10): & $\begin{array}{l}\text { nam mi ante oculos dies noctesque versatur squalor vester et maeror et } \\
\text { infirmitas valetudinis tuae. }\end{array}$ \\
\hline fam. 14.3.5 (39): & quam ego videre videor itaque debilitor lacrimis. \\
\hline fam. 14.4.6 (56): & et sic existimes, me vehementius tua miseria quam mea commoveri. \\
\hline fam. 14.7.1 (3): & quibus [et] te miserrimam habui, id quod mihi molestissimum est \\
\hline
\end{tabular}

Abbildung 70: Expressiva mit beidseitiger Aversion

BEKUNDET jemand BEDAUERN über einen Sachverhalt, von dem der Adressat negativ betroffen ist, stellt dies normalerweise die (mehr oder weniger unmittelbare) Antwort dar auf einen Akt des JAMMERNS oder FLUCHENS, wie z. B. in fam. 14.16 (5), wo davon ausgegangen werden kann, dass Terentia Cicero zuvor ihr Leid wegen der Probleme mit Volumnia geklagt hat, oder auf eine Information, die man von Dritten erhalten hat, wie z. B in fam. 14.2.2 (20), wo Cicero bemerkt, er habe von P. Valerius über die Verschleppung seiner Frau zur Tabula Valeria erfahren. ${ }^{1399}$

In fam. 14.2.2 (20) referiert Cicero auf seine Reaktion auf die schlimme Nachricht, welche ihn zu heftigen Tränen gerührt habe. Mit (durch superlativisches magnus verstärkter) emotiver

${ }^{1399}$ Vgl. Kap. 2.1.3. Vgl. a. MARTEN-CLEEF 1991, 270. 
Lexik (maximo cum fletu) wird deutlich seine eigene Betroffenheit angesichts des Vorfalls vermittelt. ${ }^{1400}$ In fam. 14.16 (5) drückt Cicero sein Bedauern hingegen durch eine negative Beurteilung des geschilderten Sachverhalts bzw. von dessen Urheber aus ${ }^{1401}$, und zwar mittels adverbial gebrauchter evaluativer Adjektive im Komparativ. Das Verhalten Volumnias wird durch die perfektische Verwendung der Modalverben debere und posse in Beziehung gesetzt zu dem Verhalten, das eigentlich angemessen gewesen wäre. Der Vergleich wird z. T. explizit formuliert (debuit officiosior esse quam fuit), z. T. nur elliptisch (potuit diligentius et cautius facere, erg. quam fecit). Cicero gibt Terentia also recht mit ihrer Kritik. In erster Linie geht es ihm aber vielmehr darum, ihr sein Mitgefühl zu signalisieren. Der direkte Sprechakt ist demnach zwar eher assertiv, die (indirekt formulierte) expressive Handlungsfunktion jedoch dominant.

Verantwortlich für Terentias Unzufriedenheit ist in fam. 14.16 (5) Volumnia, für den in fam. 14.2.2 (20) geschilderten Vorfall - ungeachtet dessen, dass Cicero die (mittelbare) Schuld bei sich selbst sieht - eine Gruppe von nicht genauer benannten dritten Personen. ${ }^{1402}$ Damit unterscheidet BEDAUERN BEKUNDEN sich vom Untermuster SICH ENTSCHULDIGEN ${ }^{1403}$, wo der Sprecher schuld an der bedauernswerten Situation des Adressaten ist. Die Schuld kann zwar auch nur indirekt bestehen, wenn er z. B. als Vormund oder Besitzer für die Handlungen eines Dritten haftbar zu machen ist. ${ }^{1404}$ Dies trifft aber auf fam. 14.2.2 (20) so nicht zu. ${ }^{1405}$

Der Akt des SICH ENTSCHULDIGENS i. e. S. ist zu unterscheiden von umfassenderen Entschuldigungssequenzen, die zusätzlich oft (assertive) Begründungen bzw. Rechtfertigungen und weitere Arten von Sprechakten beinhalten. ${ }^{1406}$ Auch in anderer Hinsicht ist der Begriff , sich

\footnotetext{
1400 Nach MARTEN-CLeEF 1991, 274 ist ein HINWEIS AUF DIE REAKTION allerdings eher unüblich: „Wahrscheinlich aufgrund der Tatsache, daß der Sprecher nur den Status eines Beobachters besitzt, werden Äußerungsformen nach dem thematischen HINWEIS AUF DIE REAKTION zur Formulierung von BEDAUERN BEKUNDEN nur selten verwendet. Ein weiterer nicht unwesentlicher Grund ist der, daß der Sprecher mit Sprechakten des Typs BEDAUERN BEKUNDEN häufig versucht, den Adressaten aufzumuntern oder zu trösten. Solche Effekte sind aber schwerlich zu erzielen, wenn der Sprecher seine eigene emotionale Reaktion thematisiert, da dies eher zur Festigung der negativen Emotion des Adressaten beiträgt. “ Vgl. a. ebd., 272f. zu weiteren Äußerungsformen des Untermusters BEDAUERN BEKUNDEN, wie z. B. HINWEISEN AUF DIE EMOTION und EMPFINDUNGSAUSDRÜCKEN. HINWEISE AUF DIE FAKTEN seien unüblich: „Der Grund liegt vermutlich darin, daß durch sprachliche Mittel dieser Art (auch in Begleitung eines EMPFINDUNGSAUSDRUCKS) die Negativbewertung sowie das eigene Gefühlserlebnis dem Adressaten nicht deutlich genug zu erkennen gegeben werden können." (ebd., 273). Ein PERFORMATIVER GEFÜHLSAUSDRUCK sei (im Deutschen) nicht möglich, schon allein deshalb, weil es keine entsprechenden SB-Verben gebe.

1401 Vgl. ebd., 273f. (zu HINWEISEN AUF DIE EVALUATION). Vgl. a. ebd., 270 zum Unterschied zu einer Negativbewertung: Bei BEDAUERN BEKUNDEN „ist nicht das Ausdrücken der negativen Bewertung, sondern das Ausdrücken der emotionalen Aversion [beabsichtigt]. “

1402 Vgl. Kap. 2.1.3.

${ }^{1403}$ Vgl. S. 216. Zu Entschuldigungen (bzw. umfassenderen Entschuldigungssequenzen) in der römischen Komödie vgl. a. UnCETA Gómez 2014b und KRUSCHWITZ UND CLEARY-VENABLES 2013.

1404 Vgl. MARTEN-CLEEF 1991, 291.

${ }^{1405}$ Hier wie auch bei vielen anderen Sprechakten in den Exilbriefen ist schwer zu entscheiden, wie hoch der Grad an Verantwortlichkeit von Cicero tatsächlich einzuschätzen ist.

${ }^{1406}$ Vgl. Kap. 2.2.1.2. Zum sehr stark differierenden Umfang von Entschuldigungen vgl. a. KRUSCHWITZ UND CLEARYVENABLES 2013, 57: „It is not difficult to find examples of apologies in ancient literature (and, in fact, beyond literature in inscriptional and epistolary evidence). Examples cover instances as diverse as full-blown defence speeches (apologiae) or just mere aside remarks in speeches of all sorts, dramas, epics, and novels. Even the peculiar genre of recusatio belongs in this category."
} 
entschuldigen' missverständlich. In dieser Arbeit wird er (nach Marten-Cleef) im Sinne von „um Verzeihung bitten“ gebraucht. ${ }^{1407}$

In fam. 14 existieren keine Beispiele zur explizit performativen Vollziehung eines Sprechakts des Typs SICH ENTSCHULDIGEN mit Verben bzw. verbalen Wendungen wie se excusare oder se excusatum velle. Ebenso wenig werden metadirektive Ausdrücke wie ignosce oder velim ignoscas verwendet. ${ }^{1408}$ Im Unterschied zum DANKEN können jedoch andere, häufig miteinander kombinierte (indirektere) Äußerungsformen ebenfalls als Möglichkeiten zum Ausdruck einer Entschuldigung gelten. ${ }^{1409}$

Zentral für eine Bitte um Entschuldigung ist ein Schuldbewusstsein bzw. -anerkenntnis, wie es z. B. direkt durch propter me und mea culpa (fieri, commissum esse) oder eher indirekt durch Wendungen wie te miserrimam habui sowie non praestitisse, debui, meum fuit officium expliziert wird. Insbesondere bei letzteren schwingt meist auch Ärger über das eigene Fehlverhalten mit. Außerdem besteht eine gewisse Nähe zum assertiven Untermuster ZUGEBEN, welches allerdings einen vorangehenden Vorwurf des Adressaten voraussetzt.

Aus dem Schuldbewusstsein resultieren ein Schuldgefühl bzw. Reue und Bedauern, welche u. a. durch Ausdrücke wie doleo, maereo, me pudet oder pudore conficior und mihi molest(issim)um est vermittelt werden können ${ }^{1410}$, sowie eine allgemeine Gefühlsaufwallung, welche durch Formulierungen wie me excrucia(n)t (tuae miseriae) und (tua miseria) commoveor oder

\footnotetext{
${ }^{1407}$ Vgl. z. B. MARTEN-CLEEF 1991, 288f. zum Unterschied zwischen aktiver Entschuldigung (Vergebung) und passiver Entschuldigung (Bitte um Entschuldigung) sowie zwischen (Bitte um) Entschuldigung, Verzeihung und Rechtfertigung. Sie selbst gebraucht den Begriff SICH ENTSCHULDIGEN am ehesten im Sinne von „um Verzeihung bitten“ oder „sich schuldig bekennen“. Vgl. a. Moussy 2005 zum Wortfeld ,Vergebung' (ignosco, venia) im Lateinischen.

${ }^{1408}$ Vgl. aber z. B. fam. 13.75 .1 (velim ignoscas). Vgl. a. die Ablehnung einer Bitte in SEN. benef. 5.22 (ignosce; non mehercules scivi hoc te desiderare [...]; rogo, ne me ingratum existimes). Zu expliziten Entschuldigungen in der römischen Komödie vgl. außerdem UnCETA Gómez 2014b, 77ff., wo als Beispiele PlaUt. Amph. 923f., PLAUt. Poen. 1410ff., Ter. Haut. 1066f., Ter. Haut. 1049f. sowie PlaUt. Most. 1168f. und Ter. Eun. 852f. genannt werden. In den modernen Sprachen gibt es nur relativ wenige Variationsmöglichkeiten für solche expliziten und insgesamt stark konventionalisierten Formulierungen (wie engl. ,sorry', franz. ,désolé(e)', it. ,mi dispiace', span. ,lo siento'): Vgl. z. B. ebd., 77. Vgl. a. MARTEN-CLeEF 1991, 295 zur insgesamt (ähnlich wie bei DANKEN) „geringen Zahl der Formulierungsmöglichkeiten“ im Deutschen. Für das frühe Latein gilt dies aber nur eingeschränkt: Vgl. z. B. UNCETA GÓMEZ 2014b, 76.

${ }^{1409}$ Vgl. z. B. UNCETA GÓMEZ 2014b, 77 und ebd., 90f. In ebd., 77ff. („Disculpas explícitas“: vgl. N. 1408) und ebd., 79ff. („Disculpas implícitas“) werden verschiedene sprachliche Mittel genannt und mit Beispielen (aus der römischen Komödie) veranschaulicht. Die Art ihrer Verwendung hänge von verschiedenen Faktoren ab: „En su selección intervienen factores como el grado de violación y la importancia de la ofensa, pero también criterios sociolingüísticos como la distancia social de los interlocutores, o su jerarquía relativa [...], que puede estar agravada, en el caso de la comedia, por la amenaza de un castigo físico, especialmente para los esclavos o los antagonistas, factores todos ellos que correlacionan con el grado de elaboración y el carácter intensivo de este acto de habla." (ebd., 91). Vgl. a. Kap. 2.2.1.2.

1410 Zur Frage, inwieweit man im Zusammenhang mit Entschuldigungen im alten Rom tatsächlich von einem schlechten Gewissen und einem echten Schuldgefühl sprechen kann, vgl. UNCETA GómEZ 2014b, 73ff. (mit Bezug u. a. auf KONSTAN 2011 und FULKERSON 2013). Er kommt zu dem Schluss: „,...] aunque no sea conveniente establecer una equivalencia completa entre los conceptos antiguo y moderno de ,perdón', la comedia romana presenta un buen número de situaciones en las que se reconocen solicitudes de disculpa e indulgencia, por lo que no parece recomendable llegar al extremo de negar la existencia del perdón en la Antigüedad.“ Vgl. a. WILHELMHOOIJBERGH 1954. Vgl. außerdem N. 1306.
} 
Interjektionen wie hem ausgedrückt wird. Mit debilitor lacrimis oder non queo sine lacrimis scribere beschreibt Cicero, wie sich seine Traurigkeit gelegentlich in Tränen Bahn bricht. ${ }^{1411}$

Sogar ein Verb wie videre kann im Kontext oft Mitgefühl anzeigen. Wenn Cicero z. B. schreibt: vos video esse miserrimas, omnis labores te excipere video oder mihi ante oculos dies noctesque versaris, will er damit sagen, dass er seine Schuld ständig vor Augen habe, was wiederum großen Schmerz seinerseits impliziert, der manchmal auch zugleich direkt mit ausgedrückt wird, wie z. B. in fam. 14.3.5 (39): quam ego videre videor itaque debilitor lacrimis. ${ }^{1412}$ Zudem geht mit solchen und anderen Äußerungen in Verbindung mit einem Schuldbekenntnis oder dem Ausdruck des Bedauerns häufig eine Veranschaulichung der unglücklichen Situation Terentias einher.

Ihre Lage und ihre Gefühle werden mit emotiv-evaluativen Begriffen z. T. sehr expressiv beschrieben, z. B. mit Substantiven wie squalor, maeror und v. a. miseria(e) bzw. mit Adjektiven wie miser(rim) a und despoliata und mit verbalen Wendungen - z. T. in Form von exklamativen Infinitiven - wie in aerumnas incidisse, sic vexari, sic iacere in lacrimis et sordibus, labores excipere. Eher selten wird deutlicher, worin Terentias Unglück konkret besteht, also z. B. im verloren gegangenen (sozialen) Ansehen sowie den gesundheitlichen und finanziellen Belastungen (vgl. z. B. fam. 14.2.3 (27): quae impensa facienda est). ${ }^{1413}$

Die Intensität einer Entschuldigung kann u. a. durch den Verweis auf Terentias ohnehin schon schwache Gesundheit (infirmitas valetudinis) erhöht werden. Die Schuld Ciceros wird außerdem durch die Kontrastierung der aktuellen leidvollen Situation mit dem, was Terentia verdient und was Cicero ihr eigentlich gewünscht hätte, als besonders schwerwiegend dargestellt, z. T. in Form direkter Antithesen, wie z. B. in fam. 14.1.1 (4): tantae aerumnae $\leftrightarrow$ virtus, fides, probitas, humanitas bzw. fam. 14.2.1 (8): miserrimae $\leftrightarrow$ beatissimae. Ciceros Zuneigung zu seiner Frau, die er $u$. a. durch Anreden wie mea Terentia und häufige Verwendung von Pronomina der 2. Peron (te, tua, tuae, vos, vester) bekundet, und die Tugenden Terentias stehen zudem im Gegensatz zu Ciceros Verhalten, dessen Verantwortung durch die häufige Verwendung von Pronomina der 1. Person (me, mihi, mea), unterstrichen wird: Er hätte eigentlich Umsicht (diligentia) walten, Tüchtigkeit und Tapferkeit (virtus, fortiter cadere) zeigen, der Gefahr entgegentreten und sie abwehren (resistere, vitare periculum) müssen. Deshalb weist er auch die Äußerung Terentias in fam. 14.1.1 (7) zurück, mit der sie ihn von jeder Schuld freisprechen will. ${ }^{1414}$ Cicero stellt darüber hinaus mehrfach sein Leid direkt (vergleichend) dem seiner Frau gegenüber, wie in fam. 14.4.6 (56): me vehementius tua miseria quam

\footnotetext{
1411 HINWEISE AUF DIE EMOTION („,es tut mir leid“) sind (im Deutschen) neben dem performativen Vollzug die üblichste und häufigste Form der ENTSCHULDIGUNG: Vgl. z. B. MARTEN-CleEf 1991, 295. Vgl. a. ebd., 272f. zum Ausdruck von Bedauern im Zusammenhang mit dem Untermuster BEDAUERN BEKUNDEN. Dagegen seien HINWEISE AUF DIE REAKTION nach ebd., 299 nicht üblich; m. E. kann damit aber (indirekt) durchaus Bedauern vermittelt werden.

1412 Cicero drückt hier zum einen Mitleid mit Terentia aus, zum anderen aber auch Sehnsucht nach ihr bzw. Schmerz darüber, dass sie nicht bei ihm ist.

${ }^{1413}$ Vgl. Prost 2015, 12ff., bes. ebd., 14f. (zu den materiellen und sozialen Konsequenzen seines Exils für die ganze Familie und Ciceros daraus resultierenden Schulgefühlen). Vgl. a. BuONOPANE 2016, z. B. ebd., 52.

${ }^{1414}$ Bemerkenswert ist der Irrealis im ersten Teil der Äußerung (quae si, tu ut scribis, fato facta putarem, ferrem paulo facilius), der implizit einen Wunsch enthält, im Gesamtkontext aber nur den kontrastierenden Ausgangspunkt bildet für Ciceros Selbstbeschuldigung. Im Unterschied bspw. zum Untermuster HOFFNUNG ÄUSSERN ist
} 
mea commoveri), 14.3.1 (4): meae me miseriae magis excruciant quam tuae vestraeque sowie 14.2.2 (17): tuis miseriis meae miseriae subleventur. Generell verstärkend wirken neben solchen Antithesen und Vergleichen zudem Hyperbeln, Superlative (beatissimas, miserri$\mathrm{mam} / \mathrm{s}$, molestissimum, optimae) und ähnliche (verabsolutierende) Ausdrücke wie omnis sowie auch tantus, dies noctesque und weitere Stilmittel, wie z. B. Alliterationen (fam. 14.1.1 (7): fato facta ... ferrem ... facilius, culpa commissa; 14.2 .2 (17): tantis tuis, maereo ... modi ... miseriis meae miseriae; 14.3 .1 (4): meae me miseriae magis; 14.4 .6 (56): me ... miseria ... mea; 14.7.1 (3): miserrimam ... mihi molestissimum), Asyndeta (fam. 14.1.1 (4) und 14.2.2 (21)) und Polysyndeta (fam 14.3.1 (6): vel ... vel ... vel; 14.3 .2 (10): et ... et).

Sprechakte des Untermusters SORGE BEKUNDEN sind im Unterschied zu BEDAUERN BEKUNDEN und SICH ENTSCHULDIGEN auf die (ungewisse) Zukunft bezogen. ${ }^{1415}$ Mit ihnen sollen nicht wie mit den Assertiva PROGNOSTIZIEREN und PROPHEZEIEN Informationen, sondern Gefühle übermittelt werden. Es geht nicht um positive Sachverhalte wie bei den Expressiva GUTEN WUNSCH ÄUSSERN bzW. WOHLERGEHEN WÜNSCHEN und HOFFNUNG ÄUSSERN. Außerdem ist nicht wie bei ANGST ÄUSSERN Cicero oder eine dritte Person, sondern Terentia betroffen, also der Adressat der Äußerung. ${ }^{1416}$

Im Allgemeinen ist zudem der Sprecher nicht verantwortlich für das zukünftige Leid des Adressaten. Eine Äußerung wie neque te in eundem fletum adducam. (fam. 14.1.5 (39)) ist deshalb nur bedingt dem Untermuster SORGE BEKUNDEN zuzuordnen: Cicero hat Angst, dass Terentia in Tränen ausbrechen könnte, wenn er die Zukunft ihres gemeinsamen Sohnes weiterhin thematisiert. Er wäre somit zwar der unmittelbare Urheber, die eigentliche Ursache für die Traurigkeit Terentias hingegen ist das ungewisse Schicksal des Kindes. Deshalb handelt es sich $\mathrm{m}$. E. nicht um einen Sprechakt des Typs SICH ENTSCHULDIGEN. Ebenso wenig entspricht er einem kommissiven Untermuster wie VERSPRECHEN, obgleich Cicero mit ihm ja seine Absicht bekundet, Terentia nicht zum Weinen bringen zu wollen. Im Vordergrund steht seine Sorge um Terentia, also der Ausdruck eines Gefühls, wie er für einen expressiven Sprechakt charakteristisch ist. Ähnliches gilt für die anderen Sprechakte des Typs SORGE BEKUNDEN in den Exilbriefen, also fam. 14.4.3 (19) und 14.4.4 (31), wobei die Verantwortlichkeit bei 14.4 .3 (19) noch am deutlichsten gegeben ist.

In einigen Äußerungen wird der Zukunftsbezug durch das Futur (adducam) hergestellt, der den Gerundiva (verendum est, diripiendam) und Verben des Fürchtens (metuere, vereri) per se innewohnt. Letztere drücken zugleich Ungewissheit aus, welche im Übrigen oft aus dem (engeren oder weiteren) Kontext zu erschließen ist, wie z. B. in fam. 14.4.4 (31). Die Äußerung

die Aussage nicht auf die Zukunft bezogen. Möglich wäre aber evtl. die Separierung eines Sprechaktes des Typs JAMMERN.

${ }^{1415}$ Allerdings ist auch bei den anderen Untermustern ein Zukunftsbezug denkbar. Manchmal ENTSCHULDIGT man SICH bspw. bereits im Voraus. Inwieweit man dann aber tatsächlich noch von SICH ENTSCHULDIGEN reden kann, wäre zu diskutieren. Zur Entschuldigung „como movimiento precautorio de un acto de habla que puede no ser bienvenido“ vgl. a. UNCETA GÓMEZ 2014b, 76.

${ }^{1416}$ Vgl. MARTEN-CLEEF 1991, 282 und ebd., 284. Vgl. a. ebd., 283 zum Unterschied zu den Direktiva, von denen sich SORGE BEKUNDEN u. a. dadurch unterscheide, dass der Adressat keinen oder zumindest kaum Einfluss auf die kommenden Geschehnisse habe. 
bezieht sich auf eine bereits bestehende Situation, ist aber insofern zukunftsbezogen und ungewiss, als deren Beschaffenheit Cicero noch nicht bekannt ist. ${ }^{1417}$ Sie ist typisch für die Briefkommunikation.

Zentral für Sprechakte des Typs SORGE BEKUNDEN ist der Ausdruck von Angst bzw. Sorge, der explizit durch Verben des Fürchtens formuliert werden kann, ansonsten eher nur impliziert ist. ${ }^{1418}$ Eine Wendung wie me movet drückt z. B. zunächst nur innere Bewegtheit aus, durch den Verweis auf die während des Bürgerkriegs (49 v. Chr.) aktuell unsichere Lage in Rom wird jedoch deutlich, dass es sich dabei konkret um Sorge handelt. ${ }^{1419}$ Cicero beschreibt in fam. 14.18.1 (4) und (5) die allgemein ungünstigen Bedingungen (omnis bonos abesse, mulieres secum habere). In fam. 14.14.1 (5) bezieht er sich spezieller auf ihre persönliche Situation und bezweifelt, dass Dolabella ausreichenden Schutz gewährleisten könne. Aus alledem lassen sich leicht die unangenehmen Folgen ableiten, die an anderer Stelle teilweise aber deutlicher benannt werden, nämlich die Gefahr von Plünderungen (sin homo amens diripiendam urbem daturus est), Nahrungsmittelknappheit und Hunger (fames) sowie die Einschränkung der Bewegungsfreiheit (ne intercludamur, ne exire non liceat). ${ }^{1420}$ In den Exilbriefen geht es um Terentias gefährdete Vermögensverhältnisse (fam. 14.4.4 (31)) sowie ihre Gesundheit und ihr Wohlergehen (neque te in eundem fletum adducam, mulierem aegram, et corpore et animo confectam).

In fam. 14.4.3 (19) drückt Cicero seine Sorge um Terentia eher indirekt aus. Der Einschub ist konzessiv aufzufassen in Bezug auf die KOOPERATIONSFRAGE, in die er eingebettet ist, und impliziert die Sorge, dass Terentias Gesundheit durch eine Reise zu ihrem Mann noch weiter belastet werden könnte. ${ }^{1421}$ Ein deutlich indirekter Sprechakt liegt auch bei fam. 14.18.2 (10) vor. Der direkte Sprechakt ist direktiv (RATEN); es dominiert jedoch die expressive Handlungsfunktion, die sich aus dem Kontext ableiten lässt: Ähnlich wie in fam. 14.14.1 (6) geht es um die Angst, Terentia könnte in Rom eingeschlossen werden.

Die negative Bewertung der befürchteten Ereignisse ergibt sich meist schon aus den betreffenden Sachverhalten an sich und ist auch den Verben des Fürchtens inhärent, wird aber teilweise noch weiter expliziert, z. B. durch evaluative Adjektive wie aegram und amens. ${ }^{1422} \mathrm{Im}$ plizit (negativ) wertend sind außerdem Verben wie conficere (confectam), diripere (diripiendam) und (aus dem Kontext zu ergänzen) spoliare (spoliata).

\footnotetext{
1417 Insofern noch Hoffnung besteht, dass es Terentia gut geht, wird in fam. 14.4.4 (30) zugleich ein WOHLERGEHENSWUNSCH formuliert, der aber nur sehr schwach ausgeprägt ist und nicht eigens durch einen Zusatz zum Ausdruck gebracht wird wie die SORGE durch quod metuo in fam. 14.4.4 (31).

1418 Vgl. MARTEN-CLEef 1991, 286 zU HINWEISEN AUF DIE EMOTION als Äußerungsform zum Ausdruck eines Sprechaktes des Typs SORGE BEKUNDEN. Hingegen würden PERFORMATIVE GEFÜHLSAUSDRÜCKE sowie EMPFINDUNGSAUSDRÜCKE „,in Ermangelung entsprechender sprachlicher Ausdrücke" nicht verwendet.

1419 Vgl. ebd., 286 bzw. ebd., 287 zu HINWEISEN AUF DIE FAKTEN, die (da antizipiert) nicht, und HINWEISEN AUF DIE REAKTION, die nur eingeschränkt zum Ausdruck eines Sprechaktes des Typs SORGE BEKUNDEN verwendet würden.

${ }^{1420} \mathrm{Vgl}$. a. den weiteren Kontext, z. B. fam. 14.18.1 (3): si quae vis aut si quae rapinae fieri coeperint.

${ }^{1421} \mathrm{Vgl}$. S. 366.

1422 Vgl. ebd., 286 zu HINWEISEN AUF DIE EVALUATION zum Ausdruck eines Sprechaktes des Typs SORGE BEKUNDEN.
} 
Der Ausdruck von Sorge kann intensiviert werden durch Adverbien wie etiam, satis oder (aus dem Kontext zu ergänzen) plane und adverbiale Wendungen wie brevi tempore, verabsolutierende Ausdrücke wie omnis und polysyndetische Wendungen wie et corpore et animo. Verstärkend wirkt zudem ein an sich redundanter Temporalsatz wie cum velitis, der die Bedrohungslage hinsichtlich der möglichen Abgeschnittenheit Roms drastisch vor Augen führt. Eine ähnliche Wirkung kann die kontrastierende Verwendung von positiven Ausdrücken (bonos) entfalten. Mit einem Pronomen wie idem (eundem fletum) verweist Cicero auf sein eigenes Leid und die Gefahr, dass Terentia dies wohl mit inm werde teilen müssen.

\section{Expressiva mit Sprecheraversion}

Expressiven Sprechakten mit Sprecheraversion liegen negative Sachverhalte zugrunde, von denen der Sprecher, also Cicero, oder ihm nahestehende dritte Personen wie z. B. seine Kinder betroffen sind. Opponierende Sprechakte, bei denen Terentia dafür verantwortlich gemacht würde, finden sich in fam. 14 nicht, wenn man davon absieht, dass Cicero in fam. 14.1.4 (31) offensichtlich einen Vorwurf Terentias ABSTREITET, er hätte sie in Bezug auf ihre Beziehung zu Quintus kritisiert (de Quinto fratre, nihil ego te accusavi). ${ }^{1423}$ Dagegen finden sich zahlreiche abreagierende Sprechakte, mit denen Cicero Gefühlen wie Traurigkeit (JAMMERN), Ärger (FLUCHEN) oder Angst (ANGST ÄUSSERN) Luft macht:

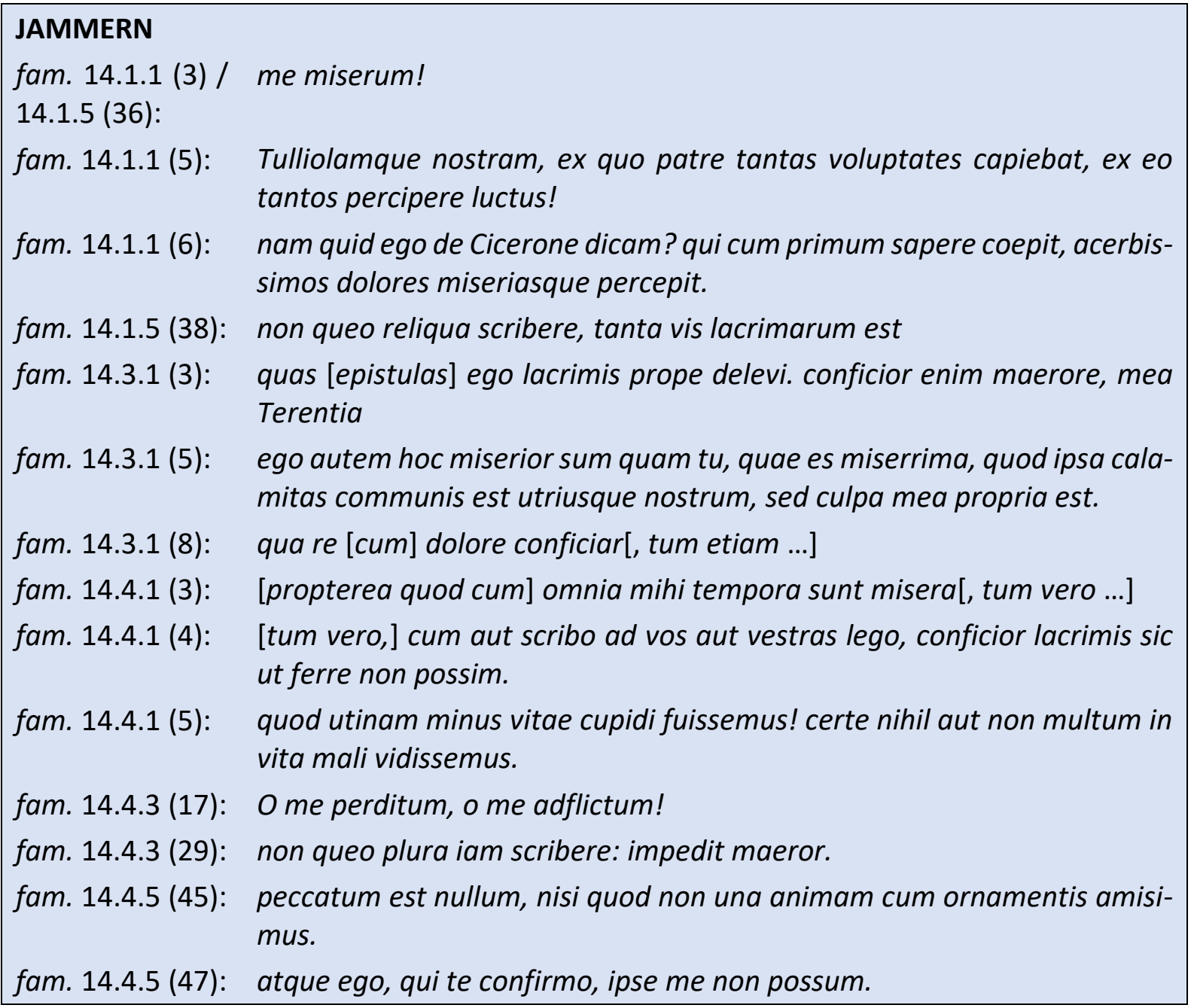

${ }^{1423}$ Vgl. a. ROESCH 2004, 148f. zu „plaintes“. Sie nennt als Beispiel fam. 7.18.2 (an Trebatius). 


\begin{tabular}{|c|c|}
\hline fam. 14.5.2 (22): & quae quidem mihi magno dolori est (valde enim illum amavi) \\
\hline fam. 14.7.1 (4): & $\begin{array}{l}\text { Quibus [molestiis et sollicitudinibus] [et te] miserrimam habui[ id quod } \\
\text { mihi molestissimum est, et] Tulliolam, quae nobis nostra vita dulcior est }\end{array}$ \\
\hline fam. 14.9 (2): & $\begin{array}{l}\text { Ad ceteras meas miserias accessit dolor et de Dolabellae valetudine et de } \\
\text { Tulliae. }\end{array}$ \\
\hline fam. 14.11 (4): & $\begin{array}{l}\text { cuius summa virtute et singulari humanitate graviore etiam sum dolore } \\
\text { adfectus nostra factum esse neglegentia ut longe alia in fortuna esset } \\
\text { atque eius pietas ac dignitas postulabat. }\end{array}$ \\
\hline fam. 14.19 (2): & In maximis meis doloribus excruciat me valetudo Tulliae nostrae \\
\hline \multicolumn{2}{|l|}{ FLUCHEN } \\
\hline fam. 14.1.1 (8): & qui ab iis me amari putabam qui invidebant \\
\hline fam. 14.1.2 (9): & eos non sequebar qui petebant. \\
\hline fam. 14.1.2 (10): & $\begin{array}{l}\text { quod si nostris consiliis usi essemus neque apud nos tantum valuisset ser- } \\
\text { mo aut stultorum amicorum aut improborum, beatissimi viveremus. }\end{array}$ \\
\hline fam. 14.1.2 (13): & [intellego] quantoque fuerit facilius manere domi quam redire. \\
\hline fam. 14.2.1 (10): & et nisi tam timidi fuissemus, praestitissem. \\
\hline fam. $14.2 .2(24):$ & qui ceteros servavi ut nos periremus! \\
\hline fam. 14.3.1 (7): & hoc miserius, turpius, indignius nobis nihil fuit. \\
\hline fam. 14.3.2 (12): & inimici sunt multi, invidi paene omnes. \\
\hline fam. 14.3.2 (13): & eicere nos magnum fuit, excludere facile est. \\
\hline fam. 14.3.3 (15): & $\begin{array}{l}\text { Ut tuto sim quod laboras, id mihi nunc facillimum est, quem etiam inimici } \\
\text { volunt vivere in tantis miseriis. }\end{array}$ \\
\hline fam. 14.4.1 (8): & $\begin{array}{l}\text { quoniam neque di, quos tu castissime coluisti, [... nobis gratiam rettule- } \\
\text { runt]. }\end{array}$ \\
\hline fam. 14.4.1 (9): & $\begin{array}{l}\text { [quoniam neque ...] neque homines, quibus ego semper servivi, nobis gra- } \\
\text { tiam rettulerunt. }\end{array}$ \\
\hline fam. 14.4.5 (44): & non vitium nostrum sed virtus nostra nos adflixit. \\
\hline fam. $14.4 .5(54):$ & Sicca dixerat se mecum fore sed Brundisio discessit \\
\hline fam. 14.10 (3): & serius quam oportuit \\
\hline fam. 14.16 (7): & $\begin{array}{l}\text { quae me ita conficiunt ut ii voluerunt qui me de mea sententia detruse- } \\
\text { runt. }\end{array}$ \\
\hline \multicolumn{2}{|l|}{ ANGST ÄUSSERN } \\
\hline fam. 14.1.2 (12): & res quanta sit intellego \\
\hline fam. 14.1.5 (35): & $\begin{array}{l}\text { Quod ad me, mea Terentia, scribis te vicum vendituram, quid, obsecro te, } \\
\text { [...] quid futurum est? }\end{array}$ \\
\hline fam. 14.1.5 (37): & et si nos premet eadem fortuna, quid puero misero fiet? \\
\hline fam. 14.1 .5 (41): & si non erunt, tu efficere tua pecunia non poteris. \\
\hline fam. $14.1 .5(42):$ & per fortunas miseras nostras, vide ne puerum perditum perdamus. \\
\hline fam. 14.2.2 (15): & sed Crassum tamen metuo. \\
\hline fam. 14.2.3 (29): & sin eadem nos fortuna premet, etiamne reliquias tuas miseras proicies? \\
\hline fam. 14.2 .3 (34): & timeo ut sustineas \\
\hline
\end{tabular}




\begin{tabular}{|c|c|}
\hline fam. 14.3.2 (11): & spes autem salutis pertenuis ostenditur. \\
\hline fam. 14.3.3 (23): & nam, si inveterarit, actum est. \\
\hline fam. 14.3.5 (32): & sin autem - sed nihil opus est reliqua scribere. \\
\hline fam. 14.4.1 (7): & $\begin{array}{l}\text { si haec mala fixa sunt, ego vero te quam primum, mea vita, cupio videre } \\
\text { et in tuo complexu emori }\end{array}$ \\
\hline fam. 14.4.3 (20): & sine te igitur sim? \\
\hline fam. 14.4 .3 (23): & {$[\sin$,$] ut ego metuo, [transactum est [. .]$.} \\
\hline fam. 14.4.3 (27): & quid? Cicero meus quid aget? \\
\hline fam. 14.4 .5 (40): & $\begin{array}{l}\text { nunc miser quando tuas iam litteras accipiam? quis ad me perferet? } \\
\text { [quas ego exspectassem Brundisi si esset licitum per nautas] }\end{array}$ \\
\hline fam. 14.9 (3): & omnino de omnibus rebus nec quid consili capiam nec quid faciam scio. \\
\hline fam. 14.12 (3): & $\begin{array}{l}\text { sed perturbati dolore animi magnisque 〈meorum〉 iniuriis metuo ne id } \\
\text { consili ceperimus quod non facile explicare possimus. }\end{array}$ \\
\hline
\end{tabular}

Abbildung 71: Expressiva mit Sprecheraversion

Der exklamative Akkusativ (o) me miserum kann als prototypische Äußerungsform für die Expressiva des Typs JAMMERN gelten. In fam. 14.4.3 (17) wird alternativ (und mit noch stärkerer Wirkung) $O$ me perditum, o me adflictum! verwendet. ${ }^{1424}$ Exklamative Infinitive sowie Ausrufesätze (wie z. B. der mit utinam eingeleitete Irrealis in fam. 14.4.1 (5)) und Fragesätze (wie z. B. die rhetorische Frage in fam. 14.1.1 (6)) sind ebenfalls besonders geeignete Satzformen zum Ausdruck tiefer Traurigkeit.

Solche Sprechakte verweisen mit Nachdruck auf die schlimme Situation Ciceros bzw. seines Sohnes, an anderer Stelle auch die seiner Tochter (und ihres Mannes): Sie werden mit Adjektiven bzw. adjektivisch gebrauchten Partizipien wie miser(a), perditus und adflictus charakterisiert. Manchmal beziehen sich diese oder ähnliche Adjektive auch auf die Umstände (tempora misera) oder die durch die unglückliche Lage ausgelösten Gefühle (acerbissimos dolores), zu deren Bezeichnung (neben dolor) entsprechende Substantive wie miseriae, malum, calamitas, luctus sowie die Quasi-Negation alia fortuna (atque ...) verwendet werden.

Oft bleibt Cicero im Allgemeinen, nur manchmal konkretisiert er die Gründe seines Kummers, verursacht z. B. durch den Tod seines Freundes Precius, den (schlechten) Gesundheitszustand (valetudo) seines Schwiegersohnes Dolabella, v. a. aber seiner Tochter Tullia oder einfach nur sein schlechtes Gewissen, weil er jemanden aufgrund seiner eigenen schlechten Verfassung beunruhigt haben könnte (miserrimam habui). ${ }^{1425}$ Häufigster Anlass zum JAMMERN ist die für ihn selbst und seine Angehörigen unerträgliche Situation während des Exils, die u. a. mit dem Verlust seiner Würde und seines Ansehens (ornamenta) einhergeht, wie er in fam. 14.4.5 (45)

\footnotetext{
1424 Die Zuordnung von me miserum zum Untermuster JAMMERN ist nicht ganz eindeutig, zumindest in fam. 14.1.1 (3), wo die folgenden Äußerungen sich sowohl auf das Schicksal von Ciceros Kindern als auch das seiner Frau beziehen, sodass er zugleich JAMMERT und SICH ENTSCHULDIGT. Der Fokus liegt aber auf seiner eigenen unglücklichen Situation, welche bis zu einem gewissen Grad ja auch immer die seiner ganzen Familie miteinschließt. Fam. 14.1.5 (36) referiert hingegen in erster Linie auf die Zukunft des Sohnes. Vgl. a. MARTEN-CLEEF 1991, 329 zum EMPFINDUNGSAUSDRUCK als Äußerungsform zum Ausdruck des Sprechakttyps JAMMERN.

${ }^{1425}$ Bei fam. 14.7.1 (4) ist die Gefühlslage Ciceros nicht so klar zu erkennen: Ist er traurig darüber, seiner Tochter Sorge bereitet zu haben, oder eher ärgerlich über sich selbst? M. E. überwiegt die Traurigkeit, die besser in Einklang zu bringen ist mit den Zärtlichkeitsbekundungen (Tulliolam, quae nobis nostra vita dulcior est).
} 
darlegt. ${ }^{1426}$ Dort behauptet er sogar, er hätte lieber sein Leben (anima) verloren. Todessehnsucht wird ähnlich (ebenfalls eher indirekt) in fam. 14.4.1 (5) angedeutet. ${ }^{1427}$ Neben einer solch drastischen möglichen Folge seiner Verzweiflung erwähnt er immer wieder die tatsächlich dadurch verursachten Tränen (lacrimae), die es ihm unmöglich machen würden, Briefe zu schreiben oder auch nur zu lesen (cum aut scribo ad vos aut vestras lego, conficior lacrimis sic ut ferre non possim; non queo reliqua scribere; quas ego lacrimis prope delevi). ${ }^{1428}$

In vielen Fällen macht Cicero seine traurigen Gefühle durch Wendungen wie conficior maerore bzw. dolore, sum dolore adfectus, mihi dolori est, accessit dolor, impedit maeror oder me excruciat explizit. ${ }^{1429}$ Eher indirekt werden sie durch eine Äußerung wie atque ego, qui te confirmo, ipse me non possum (fam. 14.4 .5 (47)) zum Ausdruck gebracht, mit der er v. a. das (neben dem individuellen Abreagieren) wesentliche Ziel von Sprechakten des Typs JAMMERN verdeutlicht: Der Sprecher will Mitleid erwecken und getröstet werden. ${ }^{1430}$

Die Intensität des JAMMERNS und das Mitgefühl des Adressaten kann u. a. durch dessen persönliche Ansprache (mea Terentia), durch die Verwendung von Hyperbeln bzw. Superlativen (acerbissimos, miserrima/m, maximis, summa) und verabsolutierenden Ausdrücken wie nihil, nullum und omnia ${ }^{1431}$ sowie anderweitig verstärkenden Adjektiven und Adverbien, wie z. B. singulari (humanitate), graviore (dolore), magno (dolori), tanta (vis), tantas (voluptates), tantos (luctus), propria (culpa) bzw. longe (alia in fortuna), valde (amavi), (cum) primum sowie sic und certe, erhöht werden. Geht es um sein eigenes Leid, fokussiert Cicero dieses u. a. durch die häufige Verwendung entsprechender Pronomina der 1. Person (me, mihi, ipse). Verstärkend wirken außerdem die Wiederholung gleicher oder ähnlicher Ausdrücke (dolores miseriasque, o me perditum, o me adflictum), Antithesen (tantas voluptates capere $\leftrightarrow$ tantos percipere luctus; communis utriusque nostrum $\leftrightarrow$ mea propria; ego, qui te confirmo $\leftrightarrow$ ipse me non possum) und andere besondere Stilmittel wie Parallelismus und Chiasmus, Polysyndeta und Alliterationen oder Konsekutivsätze wie ut ferre non possim und generell eine besonders expressive Lexik (z. B. auch Substantive wie vis und Verben wie amittere, conficere und delere).

Cicero vergleicht seine Situation während des Exils mit der Terentias und hält sich dabei selbst für untröstlicher (qui te confirmo, ipse me non possum) und unglücklicher (hoc miserior sum quam tu, quae es miserrima) als sie, v. a. da er verantwortlich für ihr Leid sei (quod ipsa calamitas communis est utriusque nostrum, sed culpa mea propria est). ${ }^{1432}$ Das Bewusstsein der

\footnotetext{
${ }^{1426}$ Vgl. MARTEN-CLeEF 1991, 328, die als „Anlässe von JAMMERN [...] persönlich erlittene Verluste oder die Verluste nahestehender Personen an materiellen Gütern, physischer Unversehrtheit oder sozialem Ansehen“ nennt. ${ }^{1427} \mathrm{Vgl}$. a. fam. 14.4 .1 (7): si haec mala fixa sunt, ego vero te quam primum, mea vita, cupio videre et in tuo complexu emori bzw. die Ausführungen weiter unten zum Untermuster ANGST ÄUSSERN.

1428 Vgl. ebd., 330 zu HINWEISEN AUF DIE REAKTION.

${ }^{1429}$ Vgl. ebd., 329f. zu HINWEISEN AUF DIE EMOTION. Ein PERFORMATIVER GEFÜHLSAUSDRUCK sei hingegen aufgrund der „fehlenden Mitteilungsabsicht“ (ebd., 329) unüblich.

${ }^{1430}$ Vgl. ebd., 327: „Mögliche Handlungsziele von JAMMERN in Dialogsituationen können darin bestehen, in Sp2 Mitleid zu wecken oder Trost einzuholen."

${ }^{1431}$ An einigen (allzu emphatischen) Stellen werden die Äußerungen (wieder) abgeschwächt, z. B. in fam. 14.4.1 (5) und 14.3.1 (3): (nihil aut) non multum bzw. prope (delevi).

${ }^{1432}$ Es handelt sich hier trotz einer gewissen Ähnlichkeit nicht um das Untermuster SICH ENTSCHULDIGEN, was auch die Anwendung des Absurditätskriteriums erweist: Man kann sich kaum dafür entschuldigen, dass es einem selbst schlechter geht als dem anderen.
} 
eigenen Schuld erhöht ebenso in anderen Zusammenhängen seine Betrübnis und Niedergeschlagenheit, z. B. in fam. 14.11 (4) (nostra factum esse neglegentia), wo es um das Schicksal seiner Tochter und nicht sein eigenes geht. ${ }^{1433}$

Besonders groß wirkt das Unglück, wenn es kontrastiert wird mit der (unschuldigen) Jugend der Betroffenen, z. B. von Ciceros Sohn (cum primum sapere coepit), oder deren einzigartigen Tugenden. So lassen Tullias summa virtus, singularis humanitas, pietas ac dignitas ihr Schicksal gänzlich unverdient erscheinen. Dass seine Tochter ihm besonders am Herzen liegt, macht er nicht nur durch den Gebrauch des Possessivpronomens nostra und das Diminutiv Tulliola deutlich, sondern v. a. durch den äußerst affektiven Vergleich quae nobis nostra vita dulcior est. ${ }^{1434}$ Zudem hebt er hervor, wie viel Lebensglück und Freude er ihr zu verdanken habe (ex quo patre tantas voluptates capiebat). Aber auch seine Verbundenheit zu anderen Personen drückt Cicero z. T. sehr explizit aus, z. B. in Bezug auf Precius (valde enim illum amavi), und intensiviert damit seine Äußerungen. Je näher jemandem eine Person steht, umso stärker wird nämlich die Bestürzung im Unglücksfall ausfallen.

Manchmal ist nicht genau zu entscheiden, ob Cicero angesichts eines negativen Sachverhalts eher Traurigkeit verspürt und JAMMERT oder ob der Ärger überwiegt und damit das Untermuster FLUCHEN vorliegt, wobei der Ärger von leichtem Missmut bis zu heftiger Wut reichen kann. ${ }^{1435}$ Einigen Äußerungen ist sogar Angst zu entnehmen, wie z. B. fam. 14.1.2 (13) und 14.3.2 (13), die seine gegenwärtige Lage betreffen, welche wahrscheinlich weiterhin andauern wird. Diese Uneindeutigkeit ist v. a. dadurch bedingt, dass Cicero in den betreffenden Sprechakten seine Gefühle nicht explizit benennt. ${ }^{1436}$ Ärger ist anscheinend ein Gefühl, das (aufgrund kultureller Gepflogenheiten und Höflichkeitskonventionen) nicht so deutlich gezeigt wird, v. a., wenn er sich gegen andere richtet und es sich bei dem Leidtragenden um den Sprecher selbst handelt. ${ }^{1437}$ Letzteres ist eigentlich bei allen Sprechakten des Typs FLUCHEN in fam. 14 der Fall, abgesehen evtl. von 14.4.1 (8), wo Cicero seine Frau (im Unterschied zu den anderen

\footnotetext{
${ }^{1433}$ Da nicht Terentia betroffen ist, liegt hier ebenfalls keine ENTSCHULDIGUNG vor.

1434 Würde der Vergleich Terentia gelten, läge das Untermuster GUNST ERWEISEN vor.

1435 Vgl. a. N. 1425 zu fam. 14.7.1 (4). Vgl. außerdem fam. 14.16 (5), wo der Ärger aber eher aufseiten Terentias zu verorten ist und Cicero nur Anteil nimmt, ohne selbst direkt betroffen zu sein. Zu den verschiedenen Nuancen, die das Gefühl Ärger umfassen kann, vgl. MARTEN-CleEf 1991, 333f. Zu Ärger und Wut im alten Rom vgl. z. B. IURESCIA 2019, 146ff. („Emozione e conflittualità“) und HARRIS 2004.

${ }^{1436}$ Auch conficere, das z. B. im Zusammenhang mit dem Untermuster JAMMERN in Bezug auf ein bestimmtes Gefühl konkretisiert wird (conficior maerore / dolore), begegnet (in fam. 14.16 (7)) nur in unspezifischer Verwendung. Vgl. a. MARTEN-CLEEF 1991, 334f. zum PERFORMATIVEN GEFÜHLSAUSDRUCK, EMPFINDUNGSAUSDRUCK und HINWEIS AUF DIE EMOTION als Äußerungsformen des Untermusters FLUCHEN. Ersterer sei unüblich: „Ursache hierfür dürften [...] die i. a. hohe emotionale Erregung des Sprechers, aber auch die fehlende Mitteilungsabsicht sein." (ebd., 334).

${ }^{1437}$ Vgl. a. IURESCIA 2019, 151ff. zu den rhetorischen Vorschriften Ciceros, nach denen (echte) ira von einem guten Redner zu vermeiden sei. Mangelnde Kontrolle der eigenen Emotionen und Beleidigungen anderer waren in den Augen der römischen Elite kennzeichnend für Personen der unteren Gesellschaftsschichten und entsprachen nicht dem Bild, das sie von sich vermitteln wollte: Vgl. ebd., 163 und ebd., 183. Iurescia behandelt in ihrer Untersuchung das Thema Streit. Relevant im vorliegenden Zusammenhang ist dies insofern, als dafür ebenso wie für Sprechakte des Typs FLUCHEN Gefühle wie Ärger bzw. Wut charakteristisch sind, die sich in fam. 14 zwar nicht gegen Terentia, aber gegen Dritte richten.
} 
Äußerungen) ganz direkt miteinbezieht, und macht sich u. a. deutlich bemerkbar im häufigen Gebrauch von Verbformen und Pronomina der 1. Person. ${ }^{1438}$

Die Briefsituation erleichtert es, heftige Gefühlsaufwallungen einzudämmen. Der Ärger wird eher indirekt vermittelt und muss aus der Darstellung der betreffenden Sachverhalte erschlossen werden. ${ }^{1439}$ Die meisten Äußerungen stehen dabei im Zusammenhang mit Ciceros Exilsituation. Besonders schmerzlich für ihn ist der Undank (neque di neque homines nobis gratiam rettulerunt) derjenigen, für die er sich doch, unterstützt von seiner Frau, die ihren religiösen Pflichten eifrig nachgekommen sei (castissime coluisti), unter Beweis seiner virtus immer so sehr eingesetzt (semper servivi), ja die er sogar gerettet habe (ceteros servavi). ${ }^{140} \mathrm{Er}$ habe es nicht für möglich gehalten, statt auf Anerkennung und Wohlgesonnenheit auf Missgunst und Feindseligkeit zu stoßen (ab iis me amari putabam qui invidebant; inimici sunt multi, invidi paene omnes.). ${ }^{1441}$ Er selbst habe sich nichts zuschulden kommen lassen (non vitium nostrum sed virtus nostra nos adflixit.) ${ }^{1442}$, macht sich aber dennoch Vorwürfe, zu feige gewesen zu sein (nisi tam timidi fuissemus ... ${ }^{1443}$ und nicht das getan zu haben, was er eigentlich für richtig gehalten habe (quod si nostris consiliis usi essemus ...), sondern stattdessen auf die Falschen, die entweder nur töricht oder gar niederträchtig gewesen seien, gehört (apud nos tantum valuisset sermo aut stultorum amicorum aut improborum) und deshalb Chancen, die sich ihm boten, ausgeschlagen (eos non sequebar qui petebant) zu haben. All dies habe ihn ins Unglück gestürzt (nos periremus; virtus nostra nos adflixit) und in eine unnötig prekäre und völlig verzweifelte Situation gebracht (vivere in tantis miseriis), wie sie gar nicht schlimmer und unwürdiger sein könnte (hoc miserius, turpius, indignius nobis nihil fuit). Es wäre einfacher für ihn gewesen, in Rom zu bleiben, als jetzt für seine Rehabilitierung kämpfen zu müssen (quantoque fuerit facilius manere domi quam redire; eicere nos magnum fuit, excludere facile est.). In fam. 14.16 (7) beklagt Cicero ebenfalls, er habe sich von anderen negativ beeinflussen lassen, was ihm sehr zusetze (me ita conficiunt ut ...). In anderen Fällen ist der Anlass seines Ärgers eher geringfügig: In fam. 14.10 (3) kritisiert er sich dafür, dass er Pomponius so spät geschrieben habe. In fam. 14.4.5 (54) äußert er Unmut darüber, dass ihn Sicca entgegen seiner Zusage frühzeitig verlassen habe.

\footnotetext{
1438 Dabei schließt Cicero allerdings teilweise seine ganze Familie mit ein. Vgl. im Übrigen MARTEN-CLEEF 1991, 333 zum Untermuster FLUCHEN: „Entweder ist der Sprecher selbst unmittelbar betroffen, oder er hält sich für betroffen, weil Personen, denen er persönlich (zumindest in bestimmten Aspekten) nahe steht, Schaden genommen haben."

${ }^{1439}$ Vgl. ebd., 335ff. zu HINWEISEN AUF DIE FAKTEN bzw. EVALUATION und REAKTION als Äußerungsformen des Untermusters FLUCHEN. Vgl. a. ebd., 333 zu den möglichen Anlässen für Sprechakte des Typs FLUCHEN.

${ }^{1440}$ Bis zu einem gewissen Grad schwingt in fam. 14.4.1 (8) auch BEDAUERN mit, insofern Terentia die Erfüllung ihrer religiösen Pflichten nicht gedankt werde; aber $\mathrm{m}$. E. steht auch hier Cicero im Fokus.

1441 Vgl. a. PROST 2015, 8 zur (fluktuierenden) Unterscheidung Ciceros von amici, inimici und „envieux / malveillants" bzw. invidi / improbi während seines Exils.

$1442 \mathrm{Vgl}$. a. fam. 14.4.5 (45): peccatum est nullum, nisi quod non una animam cum ornamentis amisimus. Der erste Teil der Äußerung enthält ebenfalls Anklänge an das Untermuster FLUCHEN, stellt aber im Grunde nur die Wiederholung der vorherigen Äußerung (fam. 14.4 .5 (44): non vitium nostrum sed virtus nostra nos adflixit.) dar. Im zweiten (dominanten) Teil überwiegt das Untermuster JAMMERN. Vgl. das Kap. zu den „Expressiva mit beidseitiger Aversion".

${ }^{1443}$ Vgl. a. fam. 14.4.1 (5): quod utinam minus vitae cupidi fuissemus! certe nihil aut non multum in vita mali vidissemus.
} 
Das letzte Beispiel muss vor dem Hintergrund betrachtet werden, dass Cicero unmittelbar zuvor in fam. 14.4.5 (51) - (53) die anderen Sklaven im Gegensatz zu Sicca sehr positiv beurteilt hat, was nahe legt, dass es sich bei fam. 14.4 .5 (54) nicht nur um eine rein assertive Information handelt. ${ }^{1444}$ Auch fam. 14.1.2 (9) kann nur angemessen im Gesamtkontext beurteilt werden. ${ }^{1445}$ Die meisten anderen Äußerungen sind weniger neutral formuliert, sodass sich die negative Bewertung der zugrunde liegenden Sachverhalte leichter erschließt. Ciceros Situation wird durch Substantive wie miseriae und (komparativische) Adjektive wie miserius, turpius, indignius beschrieben. ${ }^{1446}$ Die dafür Verantwortlichen werden mit Adjektiven wie stulti, invidi, inimici, improbi oder einem Attributsatz wie qui invidebant charakterisiert. Sich selbst bezeichnet er als timidus (bzw. timidi). ${ }^{1447}$ Negativ konnotiert sind außerdem Verben wie perire, adfligere, conficere oder auch eicere, excludere und detrudere bzw. negierte verbale Wendungen wie neque gratiam rettulerunt. Der negative Wert von Adjektiven wie magnum (fuit) und facile (fuerit bzw. est) oder (komparativischen) Adverbien wie serius ${ }^{1448}$ ergibt sich allerdings ebenfalls mehr aus dem Kontext.

Noch weiter intensiviert werden können die Aussagen mit den üblichen Mitteln: Hyperbeln bzw. Superlativen (beatissimi, facillimum, castissime) und verabsolutierenden Ausdrücken wie nihil, omnes und ceteros ${ }^{1449}$ sowie weiteren verstärkenden Adverbien (semper, ita, tam, tantum) und Adjektiven (tantus ${ }^{1450}$, multi). Außerordentlich viel Bitterkeit schwingt in von Ironie bzw. Galgenhumor gezeichneten Äußerungen wie qui ceteros servavi ut nos periremus! und Ut tuto sim quod laboras, id mihi nunc facillimum est, quem etiam inimici volunt vivere in tantis miseriis. mit.

Auffällig sind zudem die vielen, z. T. sehr emotionalen (expliziten und impliziten) Vergleiche, wie z. B. die (asyndetische) Klimax hoc miserius, turpius, indignius nobis nihil fuit. ${ }^{1451}$ Oft handelt es sich um Antithesen, wie sie auch sonst in den Sprechakten des Typs FLUCHEN dominieren und deren kontrastierende Wirkung teilweise von weiteren Stilmitteln (wie Alliteration, Asyndese, Parallelismus) unterstützt wird. ${ }^{1452}$ Damit kann z. B. ein Gegensatz konstruiert werden zwischen der tatsächlichen Situation und einer (nicht mehr) möglichen, erwünschten, wie in fam. 14.10 (3): serius quam oportuit und fam. 14.1.2 (13): quantoque fuerit facilius manere

\footnotetext{
${ }^{1444}$ Vgl. das Kap. „Expressiva mit Sprecherpräferenz“ zum Untermuster JUBELN.

1445 So erwähnt Cicero öfter seine schlechten Ratgeber, auf die er im Gegensatz zu denen, qui petebant, besser nicht gehört hätte.

1446 Die Äußerung ist zugleich ein Schuldanerkenntnis und bezieht sich letztlich auf die schlimme Situation der ganzen Familie, weshalb nicht nur Anklänge an die Untermuster FLUCHEN und JAMMERN festzustellen sind, sondern auch an das Untermuster SICH ENTSCHULDIGEN.

${ }^{1447}$ Zugleich enthält fam. 14.2.1 (10) eine Rechtfertigung, weshalb er seine Familie nicht besser geschützt habe. Es sind Anklänge an die Untermuster ZUGEBEN und SICH ENTSCHULDIGEN („Es tut mir leid, dass ich so feige gewesen bin. ") zu erkennen.

1448 Cicero gibt mit seiner Äußerung zu, dass er zu langsam oder nachlässig bzw. faul gewesen sei, womit er offenbar selbst unzufrieden ist.

1449 Teilweise werden die Äußerungen aber zugleich wieder abgeschwächt, z. B. mit paene (paene omnes).

${ }^{1450} \mathrm{Vgl}$. quantus in fam. 14.1.22 (13). Vgl. a. PINKSTER 2015, 336f. (zu quantus in Fragen).

${ }^{1451} \mathrm{Vgl}$. a. fam. 14.16 (7): quae me ita conficiunt ut ii voluerunt qui me de mea sententia detruserunt.

1452 V. a. Alliterationen sind häufig anzutreffen, entfalten dabei eine unterschiedlich starke Wirkung. Einige besonders anschauliche Beispiele sind fam. 14.4 .5 (44): non vitium nostrum sed virtus nostra nos adflixit. sowie 14.4.1 (8) und (9), wo durch die Alliteration die darüber hinaus noch mit einem Parallelismus verbundene Antithese stärker fokussiert wird (castissime coluisti $\leftrightarrow$ semper servivi).
} 
domi quam redire. Neben dem Indikativ Perfekt wird dazu gerne der Irrealis im Konjunktiv Imperfekt oder Plusquamperfekt genutzt, wie in fam. 14.1.2 (10): quod si nostris consiliis usi essemus neque apud nos tantum valuisset sermo aut stultorum amicorum aut improborum, beatissimi viveremus. und 14.2.1 (10): nisi tam timidi fuissemus, praestitissem. Möglich ist außerdem eine adversative Gegenüberstellung mit sed, wie in fam. 14.4 .5 (54): Sicca dixerat se mecum fore, sed Brundisio discessit.

In fam. 14.3.2 (13) wird die aktuell für Ciceros Feinde eher leichte mit der vorherigen eher schwierigen Lage kontrastiert: eicere nos magnum fuit, excludere facile est. In fam. 14.4 .5 (44) wird Ciceros virtus als Kontrapunkt zum erlittenen Unglück (adflixit) und zu einem möglichen Verschulden (vitium) hervorgehoben, das ihm ja in keiner Weise vorzuwerfen sei. Cicero setzt zudem häufiger seinen (vergangenen) Verdiensten und der ihm dafür gebührenden Anerkennung das folgende Elend, die Missgunst und den Undank der anderen entgegen, wie in fam. 14.1.1 (8): amare $\leftrightarrow$ invidere, 14.2.2 (24): servare $\leftrightarrow$ perire, 14.4.1 (8) und (9): castissime colere bzw. semper servire $\leftrightarrow$ gratiam non referre.

Sprechakte des Typs ANGST ÄUSSERN beziehen sich auf eine ungewisse und unheilvolle Zukunft. ${ }^{1453}$ Der Zukunftsbezug wird oft durch das Futur hergestellt, manchmal auch durch den Imperativ (fam. 14.1.5 (42)) oder einen futurischen Konjunktiv (fam. 14.4.3 (20)). Teilweise ergibt er sich aufgrund einer länger (also auch zukünftig) andauernden Handlung, deren noch nicht bekanntem Ausgang bzw. noch nicht bekannten Folgen (fam. 14.1.2 (12), 14.3.2 (11), 14.3.3 (23), 14.4.1 (7)) oder anderweitig aus dem Kontext (fam. 14.3 .5 (32)). ${ }^{1454}$ Die Ungewissheit wird bisweilen durch direkte Berufung auf die verhängnisvolle Macht des Schicksals (fortuna) hervorgehoben (fam. 14.1.5 (42), 14.1.5 (37), 14.2.3 (29)), v. a. aber durch den Gebrauch von Fragesätzen (fam. 14.1.5 (35), 14.1.5 (37), 14.2.3 (29), 14.4.3 (20), 14.4.3 (27), 14.4.5 (40)). Ein bspw. mit negiertem scio eingeleiteter indirekter Fragesatz wie in fam. 14.9 (3) ist ebenfalls möglich. Die negative Bewertung der befürchteten Sachverhalte oder des Betroffenen bzw. seines Schicksals ${ }^{1455}$ wird z. B. durch Adjektive wie miser und malus (substantiviert: malum bzw. mala) und Verben wie premere, perdere (auch als Partizip: perditum) und proicere angezeigt. ${ }^{1456}$ Oft erfolgt sie mittels Negation (z. B. durch non, nec, ne, sine) oder starker Abschwächung an sich positiver Inhalte. ${ }^{1457}$ Durch pertenuis wird bspw. eine Äußerung wie spes autem salutis pertenuis ostenditur. (fam. 14.3.2 (11)), die eigentlich Hoffnung zum Ausdruck bringt, in ihr Gegenteil verkehrt.

\footnotetext{
${ }^{1453}$ Damit „,handelt es sich [bei Sprechakten des Typs ANGST ÄUSSERN] gewissermaßen um die negative Entsprechung zum Handlungsmuster HOFFNUNG ÄUSSERN.“ (MARTEN-CLeEF 1991, 338). Von Sprechakten des Typs SORGE BEKUNDEN unterscheiden sie sich dadurch, dass der Betroffene nicht der Adressat ist, sondern der Sprecher oder eine dritte, ihm nahestehende Person. Außerdem kann der Sprecher selbst Urheber des Unglücks sein. Im Gegensatz zu den assertiven Untermustern PROGNOSTIZIEREN und PROPHEZEIEN ist die Sprechereinstellung emotiv bzw. evaluativ und nicht epistemisch. Vgl. a. ebd., 338, die u. a. meint, bei ANGST ÄUSSERN werde die „Faktizität des Eintretens der zukünftigen Situation“ vorausgesetzt. Der Sprecher muss aber m. E. nicht unbedingt davon überzeugt sein, dass ein negatives Ereignis eintritt, um Angst davor zu haben.

${ }^{1454}$ Auch ein Verb wie cupere (fam. 14.4.1 (7)) ist meist zukunftsbezogen.

${ }^{1455} \mathrm{Vgl}$. ebd., 341f. zum HINWEIS AUF DIE EVALUATION als Äußerungsform des Untermusters ANGST ÄUSSERN. ${ }^{1456}$ Vgl. a. S. 376.

${ }^{1457} \mathrm{Vgl}$. fam. 14.1 .5 (41), 14.1.5 (42), 14.3.5 (32), 14.4 .3 (20), 14.9 (3) und 14.12 (3). Vgl. a. fam. 14.2 .3 (34): timeo ut sustineas.
} 
Verben wie metuere und timere kombinieren die drei eben genannten Aspekte, d. h., sie sind i. d. R. auf eine Zukunft gerichtet, die als bedrohlich und schicksalhaft wahrgenommen wird. Mit ihnen wird in den Expressiva des Typs ANGST ÄUSSERN im Unterschied z. B. zum FLUCHEN die empfundene Emotion häufiger tatsächlich explizit benannt (fam. 14.2.2 (15), 14.2.3 (34), 14.4.3 (23) und 14.12 (3)). ${ }^{1458}$ In anderen Äußerungen erschließt sich das Gefühl der Angst hingegen eher aus dem Zusammenspiel grammatischer, inhaltlicher und kontextueller Faktoren. ${ }^{1459}$ Es kann dabei von leichter Beunruhigung bis hin zu Panik reichen. ${ }^{1460}$ So befürchtet Cicero in fam. 14.4.5 (40) lediglich, Briefe seiner Frau nicht oder erst sehr spät zu erhalten, während es in 14.4.3 (20) um ein persönliches Wiedersehen geht. In fam. 14.2.3 (29), 14.3.3 (23), 14.3.5 (32) und 14.4.3 (23) bricht sich sogar richtiggehend Verzweiflung Bahn, die sich in fam. 14.4.1 (7) zu einer veritablen Todessehnsucht steigert.

Die Exilbriefe betreffen nicht nur Ciceros eigene Zukunft, $d$. h. die Rückkehr nach Rom und seine Rehabilitierung (fam. 14.1.2 (12), 14.2.2 (15), 14.2.3 (34), 14.3.2 (11), 14.3 .3 (23), 14.3.5 (32), 14.4.1 (7), 14.4.3 (20), 14.4.3 (23), 14.4.5 (40)), sondern auch die seines Sohnes, welche v. a. von der finanziellen Situation der Familie abhängt (fam. 14.1.5 (35), 14.1 .5 (37), 14.1 .5 (41), 14.1.5 (42), 14.2.3 (29), 14.4.3 (27)). Fam. 14.9 (3) und 14.12 (3) hinwiederum thematisieren Ciceros schwierige Positionierung gegenüber Cäsar nach der Schlacht bei Pharsalus. ${ }^{1461}$

Ziel der Äußerungen sind neben der Emotionsentladung das Erwecken von Mitleid und eine daraus resultierende psychologische und praktische Unterstützung. ${ }^{1462}$ Zu diesem Zweck können sie mit verschiedenen, Mitteln weiter verstärkt werden, z. B. durch Bittformeln wie obsecro te $e^{1463}$, Anreden wie mea Terentia oder (noch intensiver) mea vita, (sekundäre) Interjektionen wie per fortunas miseras nostras ${ }^{1464}$ und allgemein eine partner- und sprecherbezogene emotive Lexik (vgl. z. B. cupio ... in tuo complexu emori bzw. perturbati dolore animi magnisque 〈meorum〉 iniuriis). Eine große Anzahl von Personal- und Possessivpronomina, die

${ }^{1458}$ Vgl. MARTEN-CLEEF 1991, 341 zUm HINWEIS AUF DIE EMOTION als Äußerungsform des Untermusters ANGST ÄUSSERN. Denkbar wären auch EMPFINDUNGSAUSDRÜCKE - für die sich in fam. 14 jedoch kein Beispiel findet. Ein PERFORMATIVER GEFÜHLSAUSDRUCK sei dagegen (aufgrund fehlender SB-Ausdrücke) nicht möglich.

1459 Eine bedeutende Rolle spielen dabei v. a. die HINWEISE AUF DIE (negative) EVALUATION (vgl. N. 1455). Ein HINWEIS AUF DIE FAKTEN i. e. S. ist bei Sprechakten des Typs ANGST ÄUSSERN nicht möglich, da es ja um noch nicht gesicherte (zukünftige) Sachverhalte geht. HINWEISE AUF DIE REAKTION sind dagegen i. A. (im Deutschen) weit verbreitet, begegnen in fam. 14 allerdings nur in Form eines Hinweises auf potenzielle suizidale Absichten Ciceros (fam. 14.4.1 (7)). Vgl. ebd., 341f.

1460 Vgl. ebd., 339f. zur Bandbreite der vom Begriff ,Angst' umfassten Gefühle (wie Beunruhigung, Bangigkeit, Feigheit, Entsetzen, Panik, Verzweiflung).

1461 Vgl. a. ebd., 339: „Akte des ANGST ÄUSSERNs werden in Situationen vollzogen, deren Folgen Sp1 als bedrohlich für sein persönliches physisches oder psychisches Wohlergehen bewertet." und ebd., 340, wo Existenzangst (körperliche Unversehrtheit, Bedrohung des Selbstkonzepts), Leistungsangst (Selbstwertbedrohungen bei Leistungsanforderungen) und soziale Angst (Selbstwertbedrohungen in öffentlichen Situationen) unterschieden werden. In fam. 14 geht es demnach um Existenzangst.

1462 Vgl. ebd., 338: „Sprechhandlungen nach dem Muster ANGST ÄUSSERN werden vollzogen, um dem aktuell erlebten Angstgefühl Luft zu machen; die Aussprache dient als ,Ventil' des unangenehmen Erregungszustandes. Erfolgen Sprechakte des Typs ANGST ÄUSSERN in einer Dialogsituation, bestehen potentielle Handlungsziele darin, daß Sp2 veranlaßt werden soll, Sp1 zu trösten, ihm Mut zuzusprechen oder Mitleid mit Sp1 zu empfinden." Vgl. a. S. 355.

${ }^{1463}$ Bittformeln sind normalerweise Bestandteil direktiver Sprechakte, können zur Intensivierung aber auch in anderen (expressiven) Sprechakttypen eingesetzt werden. Vgl. N. 1237.

${ }^{1464} \mathrm{Im}$ Unterschied zu anderen Interjektionen wird damit keine Emotion i. e. S. ausgedrückt, sodass man nicht von einem EMPFINDUNGSAUSDRUCK sprechen kann. Vgl. N. 1458. 
auch auf eine leidtragende dritte Person (Cicero meus) bezogen sein können, erhöht ebenfalls die Affektivität und damit die Zugkraft der Sprechakte. Sie werden des Weiteren intensiviert durch Adjektive wie magnus, superlativische und verabsolutierende Ausdrücke (quam primum bzw. nihil, omnis, reliquus; vgl. a. pertenuis), Wiederholungen (z. B. quid in fam. 14.1.5 (35) und 14.4.3 (27) bzw. nec quid in fam. 14.9 (3) und perdere in fam. 14.1 .5 (42): perditum perdamus) sowie Alliterationen (z. B. in fam. 14.1.5 (35), 14.1 .5 (42) und 14.12 (3)) und andere Stilmittel, die oft zudem miteinander kombiniert werden, wie z. B. in fam. 14.9 (3): omnino de omnibus rebus nec quid consili capiam nec quid faciam scio., wo das Adverb omnino, verabsolutierendes omnis, Wiederholungen, Alliterationen und Parallelismus einander in ihrer Wirkung ergänzen.

Pronomina wie idem (fam. 14.1 .5 (37): si nos premet eadem fortuna; 14.2 .3 (29): sin eadem nos fortuna premet) und Verben wie sustinere (fam. 14.2.3 (34): timeo ut sustineas) weisen ebenso wie der Konditionalsatz si haec mala fixa sunt (fam. 14.4.1 (7)) auf die Fortdauer einer belastenden Handlung bzw. Situation hin. ${ }^{1465} \mathrm{Im}$ Übrigen sind Konditionalsätze wie auch die häufig damit verbundenen Kontrastierungen (tamen, sed, autem, vero), mit denen gelegentliche Ansätze von Hoffnung im Keim erstickt werden, überhaupt charakteristisch für viele Sprechakte des Typs ANGST ÄUSSERN und in vielen Fällen ebenfalls intensivierend. Mit ihnen werden u. a. negative Handlungsvoraussetzungen in den Raum gestellt, welche die Grundlage bilden für die gedankliche Vorwegnahme befürchteter künftiger Ereignisse, wie z. B. in fam. 14.1.5 (41): si non erunt, ... und fam. 14.4 .1 (7): si haec mala fixa sunt, ... ${ }^{1466}$ Oft bleibt dabei allerdings unklar, was konkret befürchtet wird, wie z. B. in fam. 14.3.3 (23): nam, si inveterarit, actum est. und 14.1.5 (37): et si nos premet eadem fortuna, quid puero misero fiet ? ${ }^{1467}$ Eben dadurch erscheint das künftige Schicksal umso angsteinflößender. Auf die Spitze getrieben wird dies mit einer Aposiopese wie sin autem - sed nihil opus est reliqua scribere. (fam. 14.3.5 (32)), welche ein besonders markantes Mittel zum Ausdruck heftiger Emotionen darstellt.

Eine solche Vagheit zeichnet auch viele andere Sprechakte des Typs ANGST ÄUSSERN aus, wie z. B. fam. 14.1.2 (12): res quanta sit intellego. Das Verb intellegere ist eigentlich neutral, aufgrund des Kontextes jedoch expressiv aufgeladen und nähert sich dadurch der Bedeutung eines Verbes wie metuere an. Ähnliches lässt sich beim Adjektiv quantus (bzw. quanta) feststellen, das im vorliegenden Zusammenhang auf die beträchtliche Größe der zu bewältigenden Schwierigkeiten verweist. Daraus ergibt sich, dass kein assertiver Sprechakt vorliegt. ${ }^{1468}$ Bei anderen Äußerungen, deren sprachliche Oberfläche zunächst eine andere Sprechaktoberklasse anzuzeigen scheint, wird die Dominanz des expressiven Untermusters ANGST ÄUSSERN deutlicher durch eine expressive bzw. (negativ) evaluative Lexik indiziert, wie z. B. bei einigen Fragesätzen, die eine Nähe zum direktiven Untermuster ANTEILNEHMENDE FRAGE STELLEN aufweisen, oder beim Imperativsatz per fortunas miseras nostras, vide ne puerum perditum

\footnotetext{
1465 Vgl. a. fam. $14.3 .3(23)$.

${ }^{1466}$ Vgl. a. fam. 14.1.5 (35), wo dies in anderer Form geschieht: Quod ad me, mea Terentia, scribis te vicum vendituram, quid, obsecro te, [...] quid futurum est?

${ }^{1467}$ Vgl. a. die ähnlichen Äußerungen in fam. 14.1 .5 (35) bzw. 14.4.3 (23).

${ }^{1468} \mathrm{Vgl}$. dagegen die ähnlichen Äußerungen in fam. 14.5.1 (15) und (17), in denen aber die assertive Handlungsfunktion überwiegt. Vgl. dazu auch Kap. 2.1.2.
} 
perdamus. (fam. 14.1 .5 (42)), der eigentlich eine direktive Aufforderungshandlung indiziert $^{1469}$, sowie auch bei fam. 14.4.1 (7): si haec mala fixa sunt, ego vero te quam primum, mea vita, cupio videre et in tuo complexu emori, wo sich Anklänge an ein kommissives Untermuster wie ABSICHT BEKUNDEN finden.

\subsubsection{Teiltexthandlungen: Sequenzierung und Hierarchisierung}

Bereits bei der Analyse der Einzelhandlungen in Kap. 2.2.1.1 wurden teilweise übergreifende intra- und intertextuelle Aspekte berücksichtigt, da eine isolierte Betrachtung nicht sinnvoll und oft kaum möglich ist. Im Folgenden werden einige grundlegende Phänomene und Muster, die sich daraus und aus den exemplarischen Analysen in Kap. 2.1 ergeben haben, anhand von ausgewählten Beispielen noch einmal illustriert und zusammengefasst.

\subsection{Abgrenzung von Teiltext(handlung)en}

In einigen Fällen wird in fam. 14.2, 14.5 und 14.20 zu Beginn eines Teiltextes das neue Thema explizit benannt, sei es in Form einer ablativischen Präpositionalwendung mit de wie de hereditate Preciana in fam. 14.5.2 (21), sei es durch einen mit quod eingeleiteten Nebensatz wie quod ad sumptum attinet in fam. 14.2.3 (30) ${ }^{1470}$ oder quod de domo scribis, hoc est de area in fam. 14.2.3 (25). Manchmal nimmt Cicero dabei (indirekt zitierend) eine vorangehende Äußerung seiner Frau auf. In fam. 14.2.2 (14) geschieht dies in Form eines normalen Aussagesatzes (ohne besondere Einleitung): in novis tribunis pl. intellego spem te habere. Der Beginn der eigentlichen Illokution wird hier mit dem unmittelbar darauffolgenden Pronomen id signalisiert.

In fam. 14.2.3 (27) leitet das pointiert an den Anfang gesetzte Demonstrativpronomen illud, in fam. 14.5.2 (22) das Relativpronomen quae einen neuen Teiltext bzw. Exkurs ohne zusätzliche Themenangabe ein. Auch sonst weist eine fokussierte Spitzenposition oft auf einen Themenwechsel hin, in fam. 14.2.2 (11) z. B. zu Ciceros Schwiegersohn (Pisonem nostrum). Häufiger anzutreffen ist ein durch exponierte Personalpronomina (ego / nos vs. tu / vos) bzw. entsprechende Ersatzformen (relativer Anschluss qui in fam. 14.5 .1 (14) $\approx$ ego ipse sive nos ipsi) indizierter Perspektivwechsel von Cicero zu Terentia und umgekehrt, bisweilen in steter Aufeinanderfolge wie am Ende von fam. 14.5. Im Übrigen zeigt ein Personen- bzw. Themenwechsel auch unabhängig von der Wortstellung i. d. R. einen neuen Teiltext an. Dies gilt für quod ad sumptum attinet in fam. 14.2.3 (30) ebenso wie z. B. für fam. 14.5.1 (5), wo Acastus als neue Person eingeführt wird, dessen Leistung beim Brieftransport Thema eines kleinen Exkurses ist. Zugleich liefert er in seiner Funktion als Briefbote (cum litteris) aber auch den Ausgangspunkt für den folgenden Teiltext, dessen Thema die an Cicero übergebenen Briefe Terentias (accepi tuas litteras) darstellen.

\footnotetext{
${ }^{1469} \mathrm{Vgl}$. dagegen z. B. fam. 14.4.3 (26) und 14.16 (6), wo ebenfalls Angst mitschwingt, letztlich aber die direktive bzw. kommissive Handlungsfunktion dominiert. Vgl. a. N. 1463 zur Bittformel obsecro te in fam. 14.1.5 (35). 1470 Die Wendung quod ad sumptum attinet zeigt innerhalb von fam. 14.2 [E2] den Übergang (von impensa) zu einem neuen inhaltlichen Teilaspekt (sumptus) an.
} 
Oft wird ein Teiltext außerdem durch bestimmte (abgrenzende) Konnektoren eingeleitet. ${ }^{1471}$ Demarkativ wirken v. a. die mit den genannten Personalpronomina und Relativpronomina verbundenen Adverbien quidem und vero: a te quidem, ego vero, ad te vero bzw. qui quidem, quae quidem. Dagegen grenzt die Konjunktion sed (wie in fam. 14.2.2 (15) und 14.2.2 (17)) eher Einzelillokutionen als größere zusammenhängende Einheiten voneinander ab. Lediglich in fam. 14.5.1 (18) markiert sie zugleich den Beginn eines Teiltextes, in 14.5.2 (21) zumindest den Beginn der eigentlichen Illokution am Anfang eines Teiltextes. Einen zusammenfassenden Charakter hat sie in fam. 14.2.3 (35) sowie auch 14.2.4 (38), signalisiert in diesen Fällen also mehr das Ende eines Teiltextes. Ähnliches gilt für verum in fam. 14.2.3 (26). In fam. 14.2.3 (32) und 14.2.1 (5) hinwiederum stehen eigentlich verbindende Konjunktionen wie et bzw. nec (enim) am Anfang eines neuen Teiltextes. Dabei ist zu beachten, dass von der Einzelillokution bis hin zum Gesamttext verschiedene Ebenen zu unterscheiden sind und derselbe Konnektor auf der einen Ebene abgrenzend, auf der anderen verbindend (weiterführend) wirken kann. ${ }^{1472}$ Letztlich haben die Konnektoren meist weniger eine direkt demarkative Wirkung hinsichtlich der Abgrenzung von Teiltexten, sondern sie sind v. a. relevant zur Beurteilung der grammatischen Textgliederung, können aber auch Hinweise auf die Art der Beziehung zwischen den verschiedenen Handlungsebenen und innerhalb dieser geben. ${ }^{1473}$

Ein Teiltext wird nicht nur intertextuell durch die Abgrenzung von anderen Teiltexten bestimmt, sondern v. a. durch intratextuelle Verbindungen bzw. Kohärenz, wobei auch dies teilweise ebenenübergreifend (im Hinblick auf den Gesamttext oder nur auf einzelne Teilebenen) geschieht. ${ }^{1474}$ So wird z. B. in fam. 14.20 [B] durch Personalpronomina (nos, nobiscum) und Verben (putamus, commorabimur) in der 1. Person ein durchgehender Bezug auf Cicero (und seine Begleiter) hergestellt. Die Adverbialien in balineo und ibi verweisen zurück auf das Tusculanum in fam. 14.20 (2). In fam. 14.5 [C] wird mit dem Relativpronomen quibus und den Adjektiven superiores und omnes / omnia auf die Briefe Terentias bzw. deren Inhalt, in fam. 14.2 [B2] und 14.2 [D] mit den Personalpronomina ( $a / a d)$ te und vos, dem Relativpronomen quas, dem Possessivpronomen tuis und den (teilweise den Eigennamen einschließenden) Anreden mea Terentia, mea lux und meum desiderium auf Terentia (und z. T. auch Tullia) referiert. Verben ebenso wie Pronomina mit Bezug auf Terentia stehen in der 2. Person (ducta esses). Außerdem wirkt das Genus der Possessiv- und Relativpronomina sowie der Adjektive (z. B. miserrimas, beatissimas) kohäsiv. Die gilt im Übrigen auch für Demonstrativpronomina (wie eum mit Bezug auf Piso in fam. 14.2.2 (12)). ${ }^{1475}$ Die Rekurrenz anderer morphologischer

\footnotetext{
1471 Dabei bleiben einleitende Themenbenennungen, wie sie am Anfang dieses Teilkapitels besprochen wurden, unberücksichtigt, d. h., der Beginn der eigentlichen Illokution ist entscheidend. So ist ego vero in fam. 14.2.3 (25) quod de domo scribis, hoc est de area vorgeschaltet. Zur Kombination von Themen oder "fronted constituents" und (eigentlich unnötigen) Konnektoren mit "forward-linking"- oder Kontrast-Funktion vgl. a. SomERS 1994, 155ff. 1472 Deshalb ergeben sich an dieser Stelle viele Überschneidungen zu Kap. 2.2.1.1.1 (,Illokutionsidentifikation“). $1473 \mathrm{Vgl}$. das folgende Teilkapitel 2.2.1.2.2 („Funktionale Beziehungen“). Vgl. a. Baños Baños 2009, 367ff. zu den (diskursiven) Konnektoren im Lateinischen.

1474 Zur Abgrenzung von Teiltexten im Lateinischen vgl. a. SOMERS 1994 und SCHERER 1975, 104ff. („Textanfang“) sowie zur Textkohärenz ebd., 106ff. („Verbundene Sätze“). Vgl. im Übrigen das Kap. „Abgrenzungs- und Gliederungskriterien" ab S. 60.

1475 Der Numerus ist dagegen weniger aussagekräftig, da Cicero z. B. von sich selbst sowohl im Singular als auch im Plural spricht.
} 
Merkmale (wie z. B. der Superlative in fam. 14.2) und syntaktischer Muster (wie z. B. der Konditionalsätze in 14.5 [E], der Komparativsätze ut potui und ut debui in fam. 14.2 [B3] oder der Finalsätze ut sint bzw. ut sit in fam. 14.20 [B]) sowie einzelner Wörter (wie z. B. sustinere und consequi in fam. 14.2) kann - neben Koreferenz (und Konnexion) - ebenfalls kohärenzstiftend sein. ${ }^{1476}$

Die Teiltexte in Ciceros Briefen werden meist von semantisch (z. T. auch etymologisch) zusammengehörigen Wörtern eines Sachfeldes beherrscht, wobei vielfältige Querverbindungen bestehen. ${ }^{1477}$ So knüpft de nave exeuntibus in fam. 14.5 [C] an navigassemus in 14.5 [B] an, bildet an dieser Stelle allerdings lediglich den Ausgangspunkt für den Übergang zu einem neuen Thema. In [B] steht die Schiffsreise im Mittelpunkt, in [C] dagegen eine Bestätigung über den Empfang von Terentias Briefen. Damit sind zugleich zwei der häufigsten Themen in Ciceros Briefen angesprochen, die charakteristisch sind für die Brieferöffnungs- und Briefbeendigungsphase: Reisen (bisheriger Reiseverlauf bzw. voraussichtliche Reisepläne) und Briefe (Briefempfang, Brieftransport, Schreiben von Briefen, Bitten um Briefe, ...). Damit verbunden ist eine dem jeweiligen Sachfeld entsprechende spezifische Lexik (tarde / eo citius / quam primum / quam longissime, navigare / venire / prodire ... bzw. epistula / litterae, (re-, per-) scribere / accipere / reddere / afferre ...). Ebenfalls ein typisches Briefthema ist die Gesundheit von Empfänger und Schreiber, das aber durchaus situationsspezifisch ausgeprägt sein und über konventionelle Floskeln hinausgehen kann. So litt Terentia tatsächlich häufig unter schwerwiegenderen Gesundheitsproblemen. Bei den Exilbriefen kommt hinzu, dass von ihrer gesundheitlichen (und finanziellen) Lage viel für Cicero abhing. Einige Teiltexte sind demgemäß thematisch und lexikalisch stark von ihrem Leid geprägt (miseriae / labores, vexari / iacere in lacrimis et sordibus ...). In anderen Teiltexten rückt stärker Ciceros eigenes Schicksal in den Vordergrund: Ein beherrschendes Thema von fam. 14.1 bis 14.4 ist seine Rehabilitation (restituere / consequi / conficere, negotium ...). Ein spezielleres Thema stellen auch die Erbschaft des Precius und Terentias diesbezügliche Verpflichtungen in fam. 14.5 [E] dar (hereditas Preciana / auctio / nostrum negotium, agere / curare ...).

Inhaltliche und funktionale Kriterien liefern i. d. R. zuverlässigere und letztlich die entscheidenderen Anhaltspunkte bei der Abgrenzung bzw. Zusammenfassung von Teiltexten als grammatische Aspekte. Dennoch gibt es Fälle, in denen auch damit kein überzeugender Zusammenhang zwischen sequenziell aufeinanderfolgenden Einzelillokutionen hergestellt werden kann, sodass eigentlich mehrere sehr kurze Teiltexte voneinander unterschieden werden müssten. Dies wird in der vorliegenden Arbeit aus praktischen Erwägungen (z. B. im Sinne einer größeren Übersichtlichkeit) möglichst vermieden. Außerdem wird römischen Konventionen zur Briefstrukturierung Vorrang vor anderen Kriterien eingeräumt, weshalb bspw. Präskript und Wohlergehensformel am Briefanfang und Wohlergehensformel und Postskript (mit Angabe von Ort und Zeit der Briefabfassung) am Briefende grundsätzlich als jeweils ein Teiltext

\footnotetext{
${ }^{1476}$ Zu erwähnen sind außerdem Anaphern und andere besondere Stilmittel, die auf der Wiederholung von bestimmten (phonologischen, morphologischen oder syntaktischen) Elementen beruhen, die an anderer Stelle bereits ausführlicher thematisiert wurden, wenngleich eher nur auf der Ebene der Einzelillokutionen. ${ }^{1477}$ Vgl. das folgende Teilkapitel 2.2.1.2.2 („Funktionale Beziehungen“).
} 
gelten. ${ }^{1478}$ Insgesamt erweisen sich Ciceros Briefe jedoch auch unabhängig davon - sogar in emotional sehr beanspruchenden Situationen - als ausgesprochen durchstrukturiert. ${ }^{1479}$

\subsection{Funktionale Beziehungen}

Handlungseinheiten auf der gleichen Hierarchieebene stehen in einem Verhältnis der funktionalen Nebenordnung: Informationen aus den Teiltexten der Brieferöffnungsphase werden z. B. häufig in den Teiltexten der Briefschlussphase ergänzt. So geht es in fam. 14.2 [B] um die Briefe, die Cicero bereits geschrieben hat (SICH ENTSCHULDIGEN), in [F] um die Briefe, die er noch schreiben will (MITTEILEN) bzw. die Terentia ihm schreiben soll (BITTEN). In fam. 14.5 [B] beschreibt Cicero seinen bisherigen, in [F] seinen künftigen Reiseverlauf (HINWEISEN vs. HOFFNUNG ÄUSSERN). ${ }^{1480}$ Ähnliches ist auch im zentralen Teil des Briefkorpus zu beobachten: In fam. 14.2 [E] wird die in [D] geschilderte Gegenwart (SICH ENTSCHULDIGEN für das aktuelle Leid Terentias) um einen Ausblick in die Zukunft (HOFFNUNG und ANGST ÄUSSERN im Hinblick auf das gemeinsame Schicksal) erweitert. Um die Art der Beziehung zwischen den Teiltexten genauer zu bestimmen, wären exakt definierte Termini notwendig. In Kap. 1.3.4.2 werden als Möglichkeiten funktionaler Nebenordnung - neben Wiederholungen, die sich in fam. 14.2, 14.5 und 14.20 ohnehin nicht in reiner Form finden ${ }^{1481}$ - Fortsetzungen, Ergänzungen und Nachträge angeführt. Insbesondere die beiden zuletzt genannten Begriffe sind aber zunächst einmal weitgehend synonym, weshalb in dieser Arbeit auf eine weitergehende Analyse nebenordnender Beziehungen verzichtet wird, zumal auch der Zusammenhang von thematischer und funktionaler Beziehung differenzierter herausgearbeitet werden müsste.

Handlungseinheiten auf verschiedenen Hierarchieebenen stehen in einem Verhältnis der Unter- bzw. Überordnung zueinander. Manchmal muss eine virtuelle Zwischenebene, die eine Verbindung zwischen mehreren einander nebengeordneten Einheiten herstellt, (re)konstruiert werden, wie z. B. Ebene 3 in fam. 14.2 [B1], die den Überbau bildet für (2) bis (5). In fam. 14.5 [D] wird Ebene 3 dagegen tatsächlich durch eine eigene Illokution (15) dargestellt, welche den folgenden Illokutionen (16) bis (20) übergeordnet ist.

Wird eine argumentative Gesprächs- bzw. Schreibstrategie verfolgt ${ }^{1482}$, kann dies in der Form „x, weil y“ geschehen, d. h., eine Äußerung wird nachfolgend begründet: Cicero erklärt bspw. in fam. 14.5.1 (13) sein in (12) geäußertes Verständnis für die Kürze der Briefe Terentias (BEGRÜSSEN) mit seiner Vermutung, dass sie ihn ja bald persönlich zu sehen erwarte (VERMUTEN), in fam. 14.5.1 (19) seinen in (14) geäußerten Willen, möglichst bald nach Rom zu reisen (ABSICHT BEKUNDEN), mit seiner Absicht, sich möglichst schnell mit seiner Frau beraten zu können (ABSICHT BEKUNDEN), und in fam. 14.2.3 (31) seine in (30) geäußerte BITTE an Terentia, sich von anderen finanziell unterstützen zu lassen, mit der BEHAUPTUNG, dass diese dazu ohne Weiteres in der Lage seien.

\footnotetext{
${ }^{1478}$ Vgl. a. Kap. 2.1.3.2.3 (ab S. 237) zu fam. 14.2 [F] und Kap. 2.1.2.3.2 (ab S. 202) zu 14.5 [D].

1479 Vgl. S. 243.

${ }^{1480}$ Auch die Postskripta, die dem Wortsinne nach ja Nachträge sind, handlungsfunktional aber ebenso als Ergänzungen gelten können, liefern zusätzliche Informationen zum Reiseverlauf. Vgl. bes. fam. 14.1.7.

${ }^{1481}$ Selbst im Falle der Einzelillokutionen fam. 14.5.1 (14) und (19) sind die Handlungsfunktionen trotz Vorliegens des gleichen Untermusters (ABSICHT BEKUNDEN) nicht identisch, insofern der handlungsfunktionale Schwerpunkt verschoben ist. Vgl. Kap. 2.1.2.

${ }^{1482}$ Subjektive Begründungen spielen in fam. 14.2, 14.5 und 14.20 keine Rolle.
} 
In anderen Fällen wird der umgekehrte Blickwinkel eingenommen, d. h., aus einer vorangehenden Äußerung wird eine bestimmte Schlussfolgerung gezogen, also „weil x, (deshalb) y”: Die in fam. 14.5 .1 (7) geäußerte Bewunderung für Acastus (JUBELN) ergibt sich aus der MITTEILUNG in (6) über die Anzahl der von ihm für den Brieftransport benötigten Tage, das in fam. 14.5.1 (11) geäußerte Gefühl der Dankbarkeit gegenüber Terentia (DANKEN) aus dem Lob ihrer Schreibkünste (BEGRÜSSEN) in (10) und Ciceros in fam. 14.5.1 (17) geäußerte Erwartung, nach seiner Rückkehr nach Rom politisch in jedem Fall Position beziehen zu müssen (PROGNOSTIZIEREN), aus der Vorhersage eines bevorstehenden Krieges (PROGNOSTIZIEREN) in (15).

Manchmal entstehen richtiggehende Argumentationszirkel: Ein Grund wird genannt, aus dem sich eine bestimmte Folgehandlung ableitet, welche wiederum begründet wird. So informiert Cicero Terentia bspw. in fam. 14.20 (2) über seine voraussichtliche Ankunftszeit auf dem Tusculanum (PROGNOSTIZIEREN) und BITTET sie (deshalb) in (3), alles Notwendige vorzubereiten, was er in (4) und (5) damit begründet (PROGNOSTIZIEREN), dass er wahrscheinlich nicht allein kommen und mit seinen Begleitern länger auf dem Landgut verweilen werde, worauf in (6) und (7) wiederum weitere (spezifizierte) BITTEN folgen.

Hier wird auch die Problematik besonders deutlich, die sich daraus ergibt, dass der linearsequenziellen Abfolge Vorrang vor der logischen Hierarchie eingeräumt wird. Das Hauptziel Ciceros wird in den Aufforderungen formuliert, die damit handlungslogisch übergeordnet sind. Dies entspricht der sequenziellen Abfolge „x, weil y“. Bei „weil x, (deshalb) y“ verkehrt sich allerdings das Verhältnis: Die handlungslogisch eigentlich untergeordnete Begründung wird als hierarchisch übergeordnet, die handlungslogisch übergeordnete Aufforderung als untergeordnet betrachtet.

Begründungen können die Akzeptanz einer Äußerung beim Adressaten erhöhen. In fam. 14.20 soll z. B. die Bereitschaft Terentias gefördert werden, Ciceros Bitten nachzukommen. Spezifizierungen bzw. Präzisierungen dienen dagegen der Verständlichkeit. So nennt Cicero in fam. 14.20 (6) und (7) Details, die verdeutlichen, was er mit omnia in (3) meint, nämlich die Bereitstellung einer Badewanne sowie weitere Vorkehrungen für das Wohlbefinden der Gäste; und während Cicero in fam. 14.5.1 (5) allgemein darauf HINWEIST, dass Acastus inn nach seiner Schiffslandung mit einigen Briefen (cum litteris) empfangen habe, präzisiert er diese Information in (8), indem er BESTÄTIGT, dass sich darunter auch der Brief seiner Frau (tuas litteras) befunden habe. Einige Äußerungen sind zugleich begründend und spezifizierend. Mit fam. 14.2.1 (7) begründet Cicero z. B., warum es ihm gerade so schwerfalle, Briefe zu verfassen, und erklärt zugleich, worin sein besonderes Problem beim Schreiben an die Familie bestehe: ad te vero et ad nostram Tulliolam non queo sine plurimis lacrimis scribere.

Manchmal werden Äußerungen nicht um zusätzliche Einzelheiten ergänzt, sondern im Gegenteil werden bereits genannte Details wieder zurückgenommen bzw. relativiert oder eingeschränkt. In fam. 14.2.1 (3) nimmt Cicero bspw. seine Aussage in (2), er habe niemandem längere Briefe geschrieben (ABSTREITEN), wieder zurück, indem er ZUGIBT, dass es Ausnahmen gebe. In fam. 14.2.2 (23) gibt Cicero sich die Schuld an Terentias Unglück, relativiert in (24) seine ENTSCHULDIGUNG jedoch dadurch, dass diese ja im Grunde nur darin bestehe, dass er andere gerettet habe (FLUCHEN). In fam. 14.2.3 (26) schränkt er seine in (25) GEÄUSSERTE 
HOFFNUNG auf Rückerstattung seines ehemaligen Eigentums durch die FESTSTELLUNG ein, dies liege nicht in ihrer Hand. Relativierungen können eine abmildernde Funktion haben: In fam. 14.2.3 (27) ENTSCHULDIGT SICH Cicero z. B. für die hohen Ausgaben, die Terentia seinetwegen entstünden, mildert seine Aussage in (28) aber dadurch ab, dass er die HOFFNUNG auf Wiedererhalt ihrer Güter ÄUSSERT. Allerdings wird sie unmittelbar darauf wieder verstärkt, indem er in (29) seine ANGST vor einem weiterhin ungünstigen Schicksal ÄUSSERT. Ebenfalls einen verstärkenden und zugleich auch einen spezifizierenden und zusammenfassenden Charakter hat die BITTE in fam. 14.5.2 (25), mit der Cicero seine BITTE in (21) wiederholt und dabei ergänzt, Terentia solle sich selbst dann um die Erbschaftssache Precius kümmern, wenn sie bereits aus Rom aufgebrochen sei.

Sprachliche Erklärungen sind im Unterschied zu inhaltlichen Erläuterungen seltener, wobei die Abgrenzung zwischen beiden nicht immer ganz klar ist. Beispiele finden sich in fam. 14.2.3 (25): de domo ... hoc est de area und 14.5.1 (13): me ipsum ... sive nos ipsos. ${ }^{1483}$ Sie bilden keine eigenen Illokutionen, was gelegentlich aber auch für inhaltliche Präzisierungen gilt, wie z. B. praesertim si quid est firmius quod speremus in fam. 14.2.4 (38), und im Übrigen auch für Mittel der Beziehungsgestaltung wie z. B. Anreden oder Bittformeln ${ }^{1484}$, die Teil der spekulativen (sekundären) Hierarchie sind, also dazu dienen, das Anliegen des Sprechers durch Wohlgesonnenheit des Adressaten (indirekt) zu unterstützen.

Die spekulative Hierarchie durchzieht den ganzen Text ${ }^{1485}$, und die entsprechenden Handlungseinheiten nehmen oft einen sehr breiten Raum ein, da Briefkonventionen bzw. Höflichkeitsrituale allgemein in Rom einen hohen Stellenwert hatten. Die konventionell geprägten Brieferöffnungs- und Briefbeendigungssequenzen sind teilweise umfassender als die Passagen, die das eigentliche Anliegen des Autors betreffen. ${ }^{1486}$ Das Wohlwollen Terentias wird dabei sowohl durch Assertiva (z. B. BESTÄTIGUNG des Briefempfangs wie in fam. 14.5.1 (8) bzw. [C] insgesamt) als auch durch Kommissiva (z. B. VERSPRECHEN, sie auf dem Laufenden zu halten, wie in fam. 14.24 (6): si quid erit certi, faciam te statim certiorem. $)^{1487}$ und insbesondere durch sympathisierende Expressiva befördert. Zu Letzteren gehören z. B. Lob und Dank für Terentias Briefe (wie in fam. 14.2.2 (22): KOMPLIMENT MACHEN und 14.5.1 (10): BEGRÜSSEN bzw. 14.5.1 (11): DANKEN), Entschuldigungen für die Kürze der eigenen Briefe (wie in fam. 14.2 [B]) und - außerhalb der eher konventionellen Briefbestandteile i. e. S. - Mitleidsbekundungen (wie in fam. 14.2.2 (20): BEDAUERN BEKUNDEN). Zu erwähnen sind außerdem die Gruß- und Wohlergehensformeln am Briefbeginn und -schluss. ${ }^{1488}$ Bei einigen WOHLERGEHENSWÜNSCHEN (im eigentlichen Briefkorpus) handelt es sich manchmal aber durchaus um weit mehr als einfache Höflichkeitsfloskeln, wie z. B. bei den ANWEISUNGEN in fam. 14.2.3 (32) und (35), die in engem Zusammenhang mit Ciceros Streben nach Rehabilitation stehen,

\footnotetext{
${ }^{1483} \mathrm{Vgl}$. a. die textkritisch unsichere Erläuterung id est Apollini et Aesculapio in fam. 14.7 .1 (7).

1484 Vgl. das Kap. „Direktiva“ ab S. 300. Vgl. a. HofmAnn 1978, $125 \mathrm{ff}$. („Die Rolle des Partners in der Äußerung des persönlichen Gedankens").

1485 Vgl. a. HALL 2009, 11.

1486 Vgl. a. S. 415.

${ }^{1487}$ Vgl. das Kap. „Kommissiva mit Adressatenpräferenz“ ab S. 325.

1488 Vgl. a. WÜEST 2011, $217 \mathrm{ff}$.
} 
welches als übergeordnetes (latentes) Handlungsziel der Exilbriefe Ciceros gelten kann, selbst wenn es i. E. nicht dominant ist.

Wie für die Abgrenzung von Teiltexten können Konnektoren auch für die Analyse der funktionalen und hierarchischen Beziehungen zwischen den Handlungseinheiten gewisse Hinweise liefern. Dies gilt indes weniger im Hinblick auf eine mögliche Unter- oder Nebenordnung, sondern mehr für die Art der Funktion. Zwar signalisiert z. B. item in fam. 14.20 (7) tatsächlich eine funktionale Nebenordnung, aber kausale Konnektoren wie das grammatisch nebenordnende Adverb enim (z. B. in fam. 14.5.1 (13) und 14.20 (4)) bzw. die unterordnende Konjunktion cum (z. B. in fam. 14.5.1 (4)) geben keinen Aufschluss über die Hierarchieverhältnisse. Sie weisen allerdings beide auf eine begründende Funktion hin, ebenso wie im Übrigen häufig konsekutive und finale Konnektoren, wohingegen konzessive, modale sowie attributive Konnektoren eher in Verbindung mit Erklärungen gebraucht werden. Meistens erschließen sich die funktionalen Beziehungen jedoch unabhängig von einer expliziten Konnexion.

\subsection{Typische Sprechaktsequenzen in fam. 14 Intra- und intertextuelle Sequenzen}

Die Handlungseinheiten eines Briefes stehen untereinander in vielfältigen Beziehungen, wobei sie auf den verschiedenen Handlungsebenen jeweils unterschiedliche Funktionen erfüllen können. Außerdem sind sie Teil eines über den jeweiligen Text hinausgehenden Diskurses, der aber aufgrund der unzureichenden Quellenlage nur teilweise rekonstruiert werden kann. ${ }^{1489}$ Dennoch lassen sich einige typische intra- und intertextuelle Sequenzen identifizieren. Insbesondere direkt am Briefbeginn und -schluss sowie in den Übergangspassagen zum Briefkorpus i. e. S. finden sich häufig wiederkehrende Muster. ${ }^{1490}$ Insofern haben diese immer auch eine deklarative Funktion, unabhängig von der Dominanz anderer Handlungsfunktionen auf den untergeordneten Ebenen.

\section{Assertive Sequenzen}

Assertive Sequenzen betreffen oft den Reisverlauf Ciceros, wobei davon auszugehen ist, dass Cicero damit einem Wunsch Terentias nachkommt, unabhängig davon, ob sie diesen zuvor explizit (in Form einer INFORMATIONSBITTE) geäußert hat. Reiseinformationen geben den zeitlich-räumlichen Bezugsrahmen eines Briefes vor ${ }^{1491}$ und sind deshalb eigentlich ein typisches Thema der Eröffnungs- und Beendigungsphase, können sich aber grundsätzlich über den ganzen Brief verteilen. Zumindest in fam. 14 ist es in der Tat so, dass sie sich unmittelbar am Briefanfang oder -schluss meist auf Einzelillokutionen beschränken, die nicht einmal unbedingt dominant assertiv sind (wie fam. 14.20 (2)) ) $^{1492}$, sondern auch expressiv (wie fam. 14.5.2 (26): HOFFNUNG ÄUSSERN) oder kommissiv (wie fam. 14.2.4 (34): VERSPRECHEN) sein können. Lediglich fam. 14.5 [B] besteht aus zwei (assertiven) Illokutionen. Längere Sequenzen finden sich eher weiter im Inneren des Briefkorpus, wie z. B. fam. 14.1.3 (20) - (24), 14.3.4 (27) - (29) und 14.4.2/3 (10) - (16) sowie der Nachtrag im Postskript zu fam. 14.1 (14.1.7 (49) -

\footnotetext{
${ }^{1489} \mathrm{Vgl}$. a. die Versuche zur Rekonstruktion der Briefe Terentias in RICHLIN 2013.

${ }^{1490}$ Vgl. das Kap. „Aufbau römischer Briefe“ ab S. 124 sowie z. B. GIORGIO 2015, 87ff. und (zu Plautus und Terenz) BERGER 2017a, BERGER 2017b und BERGER 2016.

1491 Vgl. a. GIORGIO 2015, $94 \mathrm{f}$.

${ }^{1492}$ Assertiv sind außerdem die Angaben von Ort und Zeit der Briefabfassung in den Postskripta.
} 
(52)). Vorherrschend sind transmissive HINWEISE zum bisherigen Reiseverlauf, gelegentlich (wie in fam. 14.1.3 (20) - (24) und 14.3.4 (27) - (29)) kombiniert mit kommissiven Sprechakten des Typs ABSICHT BEKUNDEN mit Bezug auf den voraussichtlichen weiteren Reiseverlauf. ${ }^{1493}$ In fam. 14.1.3 (20) - (24) und 14.4.2/3 (10) - (16) sind außerdem expressive Exkurse eingeschoben, in denen Cicero seine Freude über die Gastfreundschaft seiner Gastgeber äußert (JUBELN). In fam. 14.4.2/3 wird er noch um einen guten Wunsch für den Gastgeber (HOFFNUNG ÄUSSERN) ergänzt. Insgesamt ergibt sich folgendes Muster:

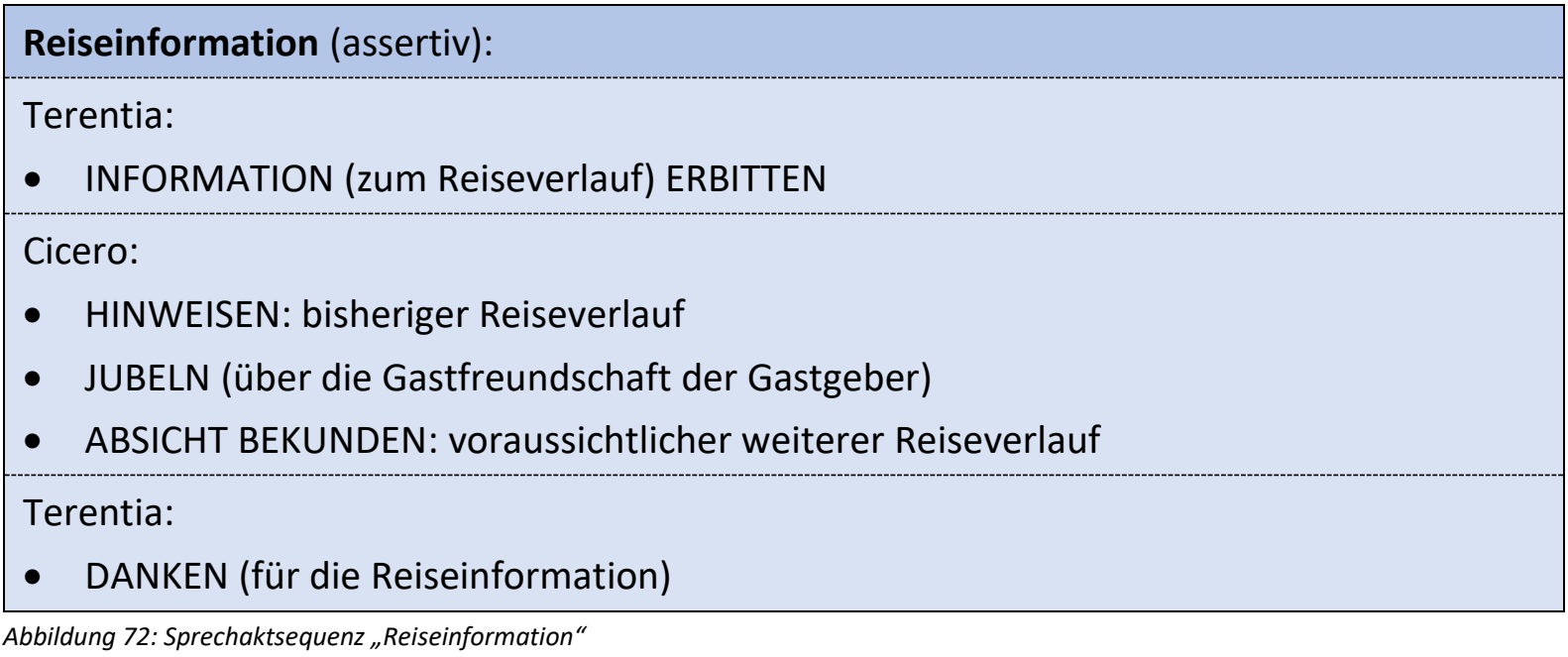

Ebenfalls assertiv geprägt sind Empfangsbestätigungen wie in fam. 14. 5 [C], mit denen Cicero seine Frau - ihrem (vermutlichen) Wunsch entsprechend - über den Erhalt ihrer Briefe informiert und sich zugleich bedankt. ${ }^{1494}$ Charakteristisch sind somit konfirmative Sprechakte des Typs BESTÄTIGEN in Verbindung mit expressiven Sprechakten des Typs BEGRÜSSEN und DANKEN, welche im Übrigen auch sonst (wie in fam. 14.8 (5) und (6)) i. d. R. gemeinsam auftreten. ${ }^{1495}$ Eine Empfangsbestätigung sieht üblicherweise also wie folgt aus:

Empfangsbestätigung (assertiv):

Terentia:

- INFORMATION (über den Erhalt ihrer Briefe) ERBITTEN

Cicero:

- BESTÄTIGEN (des Briefempfangs)

- BEGRÜSSEN (z. B. der Schreibkünste Terentias)

- DANKEN (z. B. für den schön geschriebenen Brief)

Terentia:

- DANKEN (für die Empfangsbestätigung)

Abbildung 73: Sprechaktsequenz „Empfangsbestätigung"

${ }^{1493}$ Auch assertive Sprechakte des Typs PROGNOSTIZIEREN (wie fam. 14.20 (2)) und expressive Sprechakte des Typs HOFFNUNG ÄUSSERN (wie fam. 14.5.2 (26)) können auf den weiteren Reiseverlauf verweisen.

${ }^{1494}$ Eine Empfangsbestätigung dient zudem der Einordnung in den Konversationsdiskurs. Vgl. a. GIORGIO 2015, $92 f$.

1495 Vgl. a. ebd., $91 \mathrm{f}$. 
Ein intertextueller Bezug ist auch bei anderen reaktiven und den re-initiativen Assertiva prinzipiell gegeben. Oft treten sie in Kombination miteinander auf: So ist die ZUSTIMMUNG zu einem Vorschlag Terentias in fam. 14.19 (4) ebenso wie das ABSTREITEN eines Vorwurfs in 14.1.4 (31) jeweils mit einer (einfachen bzw. doppelten) BEGRÜNDUNG verbunden; und auf den Akt des ABSTREITENS in fam. 14.2.1 (2) folgen Akte des ZUGEBENS und BEGRÜNDENS in (3) bis (6). Die Sequenz in fam. 14.2.1 (2) - (6) ist allerdings nicht dominant assertiv, sondern der erste Teil einer umfassenden expressiven Entschuldigungssequenz. ${ }^{1496}$ Auch in fam. 14.4.1 (2) - (4) setzt eine längere Entschuldigung mit einem Akt des ZUGEBENS (des eigenen Fehlverhaltens) ein, auf den eine zweiteilige Begründung folgt, bei der jedoch das expressive Untermuster JAMMERN gegenüber dem assertiven BEGRÜNDEN dominiert.

\section{Expressive Sequenzen}

Überhaupt sind die Grenzen zwischen assertiven BEGRÜNDUNGEN (des eigenen Fehlverhaltens) und expressiven Akten wie JAMMERN (über das eigene Unglück bzw. die eigene Schuld) und FLUCHEN (über das eigene Fehlverhalten) in Entschuldigungen fließend. ${ }^{1497}$ In fam. 14.2 [B] schließt bspw. an den assertiv geprägten ersten Teil [B1] der expressive zweite Teil [B2] an, welcher aus Sprechakten des Typs SICH ENTSCHULDIGEN und FLUCHEN besteht, die aber ebenso eine (assertiv) begründende Komponente enthalten. Zugleich geht Cicero von einer Entschuldigung dafür, seiner Frau keine längeren Briefe zu schreiben, über zu einer allgemeinen Entschuldigung für das Unglück der Familie während seiner Verbannung, wie sie auch sonst (z. B. in fam. 14.1.1 (3) - (10), 14.2.2/3 (16) - (24), 14.3.1 (3) - (10)) in den Exilbriefen häufiger anzutreffen ist.

Oft sind Entschuldigungen noch mit weiteren, v. a. expressiven Sprechakten verbunden, die abmildernd oder verstärkend wirken können, indem bspw. (wie in fam. 14.2.3 (28): HOFFNUNG ÄUSSERN) eine Änderung der prekären Situation des Adressaten in Aussicht gestellt oder (wie in fam. 14.2.3 (29): SORGE BEKUNDEN) genau das Gegenteil heraufbeschworen wird. Zentral für eine Entschuldigung sind allerdings Sprechakte des Typs SICH ENTSCHULDIGEN, mit denen Cicero seine Schuld eingesteht, Bedauern über seine Verfehlung und Mitleid mit dem Adressaten bekundet, wenngleich sie keine unbedingte Voraussetzung sind: In fam. 14.6.1 (2) und (3) besteht die Entschuldigung z. B. lediglich aus einer zweiteiligen BEGRÜNDUNG, in fam. 14.4.1 (2) - (4) nur aus Akten des ZUGEBENS und JAMMERNS.

Als Abschluss einer Entschuldigung wäre ein kommissiver Sprechakt des Typs VERSPRECHEN denkbar, z. B. die Versicherung, in Zukunft häufiger und ausführlicher zu schreiben. VERSPRECHEN wie faciam te certiorem begegnen in fam. 14. jedoch nur unabhängig von Entschuldigungen und v. a. am Schluss einiger Briefe. Entschuldigungssequenzen finden sich dagegen bevorzugt, wenn auch nicht ausschließlich am Briefanfang. Mit ihnen reagiert Cicero auf tatsächliche oder zu erwartende Vorwürfe Terentias (z. B. in Form einer KLAGE). Eine mögliche

\footnotetext{
${ }^{1496}$ Vgl. a. GIORGIO 2015, 95ff. Vgl. außerdem MARTEN-CLEEF 1991, 289. Entschuldigungen können im Übrigen auch als Einzelillokutionen auftreten (wie fam. 14.3.5 (39)).

${ }^{1497}$ Vgl. z. B. fam. 14.2.2/3 (23) und (24).
} 
Reaktion besteht darin, die Entschuldigung anzunehmen oder zurückzuweisen. ${ }^{1498}$ Daraus lässt sich folgendes Grundmuster ableiten ${ }^{1499}$ :

\section{Entschuldigung (expressiv):}

Terentia:

- KLAGEN (über Fehlverhalten Ciceros)

Cicero:

- ZUGEBEN (des eigenen Fehlverhaltens: Schuldeingeständnis)

- BEGRÜNDEN (des eigenen Fehlverhaltens)

- FLUCHEN (über das eigene Fehlverhalten)

- JAMMERN (über die eigene Schuld bzw. das eigene Unglück: Selbstmitleid)

- SICH ENTSCHULDIGEN (für das eigene Fehlverhalten: Bedauern und Mitleid mit dem Adressaten)

- (Besserung) VERSPRECHEN

Terentia:

- Annahme oder Zurückweisung der Entschuldigung (BEGRÜSSEN, DANKEN, ZUSTIMMEN, BEIPFLICHTEN, BESTREITEN, ANZWEIFELN, ...)

Abbildung 74: Sprechaktsequenz „Entschuldigung"

In anderen Fällen antwortet Cicero offenbar auf Äußerungen, in denen Terentia Kummer über eine unangenehme Situation zum Ausdruck gebracht hat, für die nicht er verantwortlich ist (JAMMERN, FLUCHEN). Dem wiederum ist evtl. eine ANTEILNEHMENDE FRAGE Ciceros vorangegangen wie - verbunden mit einem nachfolgenden Sprechakt des Typs SORGE BEKUNDEN - in fam. 14.4.4 (30). Eine typische Reaktion darauf wäre das BEKUNDEN von BEDAUERN wie in fam. 14.16 (5), wo sich Terentia wohl im Vorfeld über das Verhalten Volumnias beschwert hat. ${ }^{1500}$ In fam. 14.4.4 (33)ff. versucht Cicero hingegen seine Frau zu beruhigen, nachdem sie vorher wahrscheinlich RAT von ihm ERBETEN und möglicherweise auch ANGST GEÄUSSERT hat, indem er ihr deutlich macht, dass sie sich nicht zu sorgen brauche (WOHLERGEHEN WÜNSCHEN), und dies im Folgenden BEGRÜNDET und i. E. noch weiter erläutert (FESTSTELLEN). Im Übrigen finden sich in fam. 14 oft längere expressive Sequenzen abreagierender Expressiva (vorwiegend mit Sprecheraversion). Ein häufiges Muster ist dabei die Kontrastierung von

\footnotetext{
1498 Vgl. MARTEN-CLEEF 1991, $292 \mathrm{f}$.

1499 Vgl. a. UNCETA GÓMEZ 2014b, 88ff. zu Entschuldigungen als „macroacto de habla“. Vgl. außerdem KRUSCHWITZ UND CLEARY-VENABLES 2013 zu verschiedenen Entschuldigungsstrategien, die mehr oder weniger effektiv sein können: „Even without any theoretical framework it becomes obvious, of course, that apologies, as face-restoring strategy, can be designed in manifold ways. Some strategies will be more effective in securing the recipient's forgiveness, whereas others have been proven to be less successful. Thomas Holtgraves has measured the effectiveness of different types, ranging from mere justification (low effectiveness) to a full-blown apology (high effectiveness) [...]." (ebd., 56 mit Bezug auf Holtgraves 1989).

1500 Zugleich signalisiert Cicero in fam. 14.16 (5) (assertive) ZUSTIMMUNG („Du hast recht.“), die aber nicht dominant ist. Ein Akt des BEDAUERNS ist im Übrigen auch möglich als Reaktion auf eine Nachricht durch andere (wie in fam. 14.2.2 (20)). Vgl. das Kap. zu den „Expressiva mit beidseitiger Aversion“ ab S. 361.
} 
Sprechakten des Typs ANGST ÄUSSERN und HOFFNUNG ÄUSSERN, zuweilen kombiniert mit den Untermustern JAMMERN und FLUCHEN. ${ }^{1501}$

\section{Direktive Sequenzen}

Direktive Sequenzen ${ }^{1502}$ sind oft recht kurz, v. a. was sprecherpräferierte BITTEN betrifft, die vielfach für sich allein stehen und ggf. innerhalb der Illokution selbst intensiviert werden, z. B. durch Bittformeln und eng verbundene Kausalsätze. ${ }^{1503}$ Eine zusätzliche Abmilderung ist bei konventionellen BITTEN um einen Antwortbrief oder Ausrichten von Grüßen an andere (wie in fam. 14.1.6 (47)) im Grunde kaum notwendig. Manchmal werden BITTEN aber durchaus (abmildernd oder verstärkend) um weitere Sprechakte erweitert, z. B. durch begründende Assertiva des Typs PROGNOSTIZIEREN wie in fam. $14.20^{1504}$ oder Expressiva des Typs HOFFNUNG und ANGST ÄUSSERN wie in fam. 14.3.5 (30)ff. Darüber hinaus stehen die BITTEN in Zusammenhang mit der übergreifenden spekulativen Hierarchie.

Im Unterschied zu den initiativen BITTEN handelt es sich bei Ratschlägen i. d. R. um Reaktionen auf eine RATBITTE des Adressaten, wobei aber in beiden Fällen eine Antwort zu erwarten ist, mit der der Adressat z. B. der BITTE entspricht oder sie ablehnt bzw. für den erhaltenen Rat DANKT. Die Ratschläge in fam. 14 bestehen dabei oft nicht nur aus einem direktiven Akt des RATENS, sondern werden bisweilen mit Blick auf die zu erwartende (positive oder negative) Zukunft mit expressiven Sprechakten des Typs WOHLERGEHEN WÜNSCHEN oder SORGE BEKUNDEN sowie auch mit erläuternden Assertiva (HINWEISEN) verbunden. ${ }^{1505}$ Eine typische Sprechaktsequenz entspricht demnach in etwa folgendem Muster:

\section{Ratschlag (direktiv)}

Terentia:

- RAT ERBITTEN

Cicero:

- RATEN

- HINWEISEN (auf für die Entscheidung des Adressaten wichtige Umstände)

- WOHLERGEHEN WÜNSCHEN vs. SORGE BEKUNDEN (mit Bezug auf mögliche Vor-bzw. Nachteile der verschiedenen Optionen)

Terentia:

- DANKEN (für den Ratschlag)

Abbildung 75: Sprechaktsequenz „Ratschlag“

Eine ähnliche Konstellation ist bei Direktiva mit gemeinsamer Problemlage zu erkennen. Dabei ist ein gegenseitiger Austausch notwendig, um sich einer Problemlösung zu nähern. Am Anfang kann ein Sprechakt in Art einer KOOPERATIONSFRAGE stehen, wie sie Cicero bspw. in fam. 14.4.3 (18) und 14.4.3 (25) an Terentia richtet. Darauf folgt evtl. eine ANWEISUNG, wie

\footnotetext{
${ }^{1501}$ Vgl. z. B. fam. 14.1 .2 (12)ff., 14.1.5 (35)ff. oder 14.3.2 (11)ff.

1502 Vgl. a. RISSELADA 1993, 49ff. zu „Directives in interactional structure“.

1503 Dabei sind auch doppelte BITTEN möglich wie in fam. 14.20 (6) / (7) und 14.21 (4) / (5).

${ }^{1504}$ Assertiva des Typs BEGRÜNDEN sind aufgrund der Initiativität von BITTEN i. d. R. nicht möglich.

${ }^{1505}$ Vgl. z. B. fam. 14.18.1 (2)ff. Vgl. a. Kap. 2.2.1.3.4.
} 
sie im zweiten Fall (in fam. 14.4.3 (26)) Cicero selbst vorwegnimmt, während sie sonst normalerweise vom Adressaten zu erwarten ist. Hinzu kommen ggf. erklärende oder begründende Assertiva, z. B. des Typs BEHAUPTEN (wie in fam. 14.2.3 (31)) ) $^{1506}$ oder PROGNOSTIZIEREN (wie in fam. 14.14.13 (4)), oder Expressiva, z. B. des Typs SICH ENTSCHULDIGEN und ANGST ÄUSSERN (wie in fam. 14.2.3 (33) bzw. (34)). Die ANWEISUNG in fam. 14.12 (6) ist insofern ein Sonderfall, als sie einen FTA in Form einer Ablehnung des Angebotes von Terentia beinhaltet, zu ihrem Mann zu reisen, der von Cicero aber immerhin mit drei BEGRÜNDUNGEN (in fam. $14.12(7)-(9))$ abgemildert wird. ${ }^{1507}$

\subsubsection{Gesamttexthandlungen: Bestimmung der Textfunktionen \\ 2.2.1.3.1 Indikatoren der Textfunktion}

Bei Ciceros Schreiben an seine Frau handelt es sich um Familienbriefe, die i. A. durch Multifunktionalität gekennzeichnet sind. ${ }^{1508}$ Dennoch lässt sich in den meisten Briefen mehr oder weniger deutlich die Dominanz einer Handlungsfunktion erkennen, welche den Text als Ganzes bestimmt und damit als übergeordnete Textfunktion gelten kann. Wenngleich sie sich nicht ohne Weiteres aus den Funktionen der Einzel- und Teilhandlungen erschließt, können diese durchaus einen Anhaltspunkt liefern. Allerdings müssen andere Aspekte ebenfalls berücksichtigt werden, die ggf. sogar den Ausschlag geben. ${ }^{1509}$

Die insgesamt 412 Illokutionen in fam. 14 sind folgendermaßen auf die fünf Sprechaktoberklassen verteilt:

\begin{tabular}{|l|l|l|}
\hline Sprechaktoberklasse & Anzahl & Prozent \\
\hline Assertiva & 119 & $29 \%$ \\
\hline Direktiva & 51 & $12 \%$ \\
\hline Kommissiva & 21 & $5 \%$ \\
\hline Expressiva & 186 & $45 \%$ \\
\hline Deklarativa & 35 & $9 \%$ \\
\hline
\end{tabular}

Abbildung 76: Distribution der Einzelillokutionen in fam. 14 im Hinblick auf die fünf Sprechaktoberklassen

Es fällt sofort eine starke Überrepräsentanz der Expressiva auf, die $45 \%$ aller Illokutionen ausmachen. ${ }^{1510}$ Diese lässt sich v. a. auf die vier Exilbriefe - die (mit Abstand) längsten Schreiben

\footnotetext{
1506 In fam. 14.6 (4) ergibt sich die Begründung der ANWEISUNG aus dem vorgeschalteten Zitat einer Äußerung Terentias.

1507 Somit weist fam. 14.12 (6) Nähe zu einem assertiven Untermuster wie WIDERSPRECHEN auf. Um einen FTA handelt es sich insofern, als dem Adressaten ja mehr oder weniger direkt vorgeworfen wird, im Unrecht zu sein. Zu den (höflichen und unhöflichen) Möglichkeiten einer Ablehnung vgl. FerRI 2012.

1508 Vgl. das Kap. „Multifunktionale Briefe“ ab S. 116. Zu den Exilbriefen vgl. a. NDIAYE 2010, 192.

${ }^{1509} \mathrm{Vgl.} \mathrm{Kap.} \mathrm{1.3.5.}$

1510 Vgl. dagegen SCHMITT 2000, 122 zur Überrepräsentation der Assertiva (im Deutschen und Englischen) im Vergleich zu den anderen Sprechaktklassen Searles: „Zumindest, wenn man diese Klasse [d. h. die Repräsentativa bzw. Assertiva] in einer weiten Fassung versteht [...], so muss die weit überwiegende Mehrheit aller empirischen Illokutionen hier eingeordnet werden Gesicherte Zahlen sind hierfür nicht verfügbar, nach Schätzungen liegt ihr Anteil jedoch bei etwa 85-90 \%." Der hohe Anteil der Expressiva in fam. 14 hängt sicherlich auch mit einer recht weiten Auffassung dieser Sprechaktklasse (und einer recht engen Auffassung der Assertiva) in der vorliegenden Arbeit zusammen.
} 
der Briefsammlung ${ }^{1511}$ - zurückführen. Sie sind auch in der Tat als Kontaktbriefe zu klassifizieren, obgleich den Expressiva (sowohl auf der Ebene der Einzelillokutionen als auch der Teiltexte $)^{1512}$ im Vergleich zu den anderen Sprechaktkategorien meist ein geringerer Stellenwert zukommt, weil sie häufig als Bestandteil konventioneller Briefrituale eher eine Rolle innerhalb der spekulativen als der logisch-funktionalen Hierarchie spielen. Der Konventionalitätsgrad der Expressiva ist gleichwohl i. E. (z. B. bei guten Wünschen für die Gesundheit) immer zu überprüfen, um ihre Bedeutung für die Textfunktion besser einschätzen zu können. Dies gilt ebenso für die anderen Sprechaktklassen, die bisweilen ebenfalls stark konventionell geprägt sind. ${ }^{1513}$ Deklarativa bzw. Briefbeginn und -schluss insgesamt dienen z. B. konventionell der Brieferöffnung und -beendigung. Sogar ein Brief als Ganzes kann durchaus deklarativ im Blick auf größere Handlungseinheiten sein, wie z. B. Widmungsbriefe zur Eröffnung einer Briefsammlung. ${ }^{1514}$ Bei der Bestimmung der Textfunktion sind sie aber generell zu vernachlässigen. Direktiva und Kommissiva kommt dagegen i. A. ein sehr hoher funktionaler Wert innerhalb eines Briefes zu, sodass oft schon bei einer relativ geringen Anzahl solcher Sprechakte von einem Aufforderungs- oder Obligationsbrief ausgegangen werden kann. Des Weiteren sind die einzelnen Untermuster innerhalb einer Sprechaktoberklasse z. T. unterschiedlich zu bewerten. So sind Transmissiva des Typs BENACHRICHTIGEN bedeutsamer für die Textfunktion als HINWEISE und MITTEILUNGEN. Nicht zu vernachlässigen sind im Übrigen weitergehende Zusammenhänge wie z. B. der soziokulturelle Hintergrund der Briefe.

\subsection{Kontaktbriefe}

Alle vier Exilbriefe (fam. 14.1 - 14.4) können eindeutig als Kontaktbriefe gelten, auch wenn andere Handlungsfunktionen ebenfalls eine mehr oder minder bedeutsame Rolle spielen. Die Expressivität geht weit über die üblichen Konventionen hinaus. Der Anteil der expressiven Sprechakte liegt mit ca. 56 bis 65 \% klar über dem Durchschnitt. Am höchsten ist er in fam. 14.4, dem chronologisch ersten Brief, der zu Beginn des Exils entstanden ist, als Cicero sich noch in die neue Situation einfinden musste und offenbar in einer besonders desaströsen emotionalen Verfassung war. ${ }^{1515}$ Diese spiegelt sich darin, dass 29 von 37 Expressiva abreagierende Sprechakte sind: $7 \times$ JAMMERN, $5 \times$ ANGST ÄUSSERN, 4 x FLUCHEN, aber auch $6 \times$ HOFFNUNG ÄUSSERN und $6 \times$ JUBELN (über die Loyalität von Freunden und Sklaven) sowie 1 $x$ FROHLOCKEN (angesichts einer glücklicheren Vergangenheit). Der zweite Exilbrief fam. 14.2

\footnotetext{
${ }^{1511}$ Außer den Exilbriefen sind nur noch fam. 14.5, 14.7, 14.14 und 14.18 etwas länger und umfassen mehrere Teiltexthandlungen.

1512 Die Teiltexthandlungen in fam. 14 werden hier nicht i. E. statistisch ausgewertet, da lediglich fam. 14.2, 14.5 und 14.20 in dieser Hinsicht genauer analysiert wurden. Dabei ergibt sich im Übrigen ebenfalls eine klare Dominanz der Expressiva, gefolgt von den (gleichstark) vertretenen Assertiva und Direktiva und am Ende den Kommissiva: Wenn man von den jeweils zwei deklarativen Teiltexten am Briefanfang und -schluss absieht, besteht fam. 14.2 aus vier expressiven Teiltexten und einem multifunktionalen (teilweise ebenfalls expressiven) Teiltext, fam. 14.5 aus zwei assertiven Teiltexten, einem direktiven, einem kommissiven und einem expressiven Teiltext, fam. 14.20 aus einem direktiven Teiltext.

${ }^{1513}$ So sind z. B. assertive Empfangsbestätigungen, direktive BITTEN um einen Antwortbrief oder kommissive VERSPRECHEN, Terentia auf dem Laufenden zu halten, für die Textfunktionsbestimmung oft nicht so bedeutsam. Vgl. a. das Kap. „Typische Sprechaktsequenzen in fam. 14“ ab S. 384.

${ }^{1514}$ Vgl. das Kap. „Brieftypen und Brieffunktionen“ ab S. 110.

${ }^{1515}$ Dem entspricht auch, dass der Anteil der Expressiva im letzten Exilbrief fam. 14.3 am niedrigsten ist.
} 
ist dagegen stärker adressatenbezogen. 14 von 23 Expressiva sind den sympathisierenden Expressiva zuzuordnen: 8 x SICH ENTSCHULDIGEN, 1 x BEDAUERN BEKUNDEN, 1 x SORGE BEKUNDEN, $1 \times$ BEGRÜSSEN, $1 \times$ GUNST ERWEISEN, $1 \times$ KOMPLIMENT MACHEN, $1 \times$ WOHLERGEHEN WÜNSCHEN. Insbesondere Entschuldigungen (als Einzel- und Teilhandlungen) prägen den Brief, haben aber letztlich nur eine eher konventionelle und mittelbare Funktion innerhalb der spekulativen Hierarchie. Sie sind dem Wunsch Ciceros nach Rückkehr und Rehabilitation untergeordnet. Zentral für den Brief ist das Schwanken zwischen ANGST und HOFFNUNG ÄUSSERN im Hinblick auf die gegenwärtige Exilsituation. Obwohl fam. 14.2 insgesamt weniger verzweifelt wirkt als fam. 14.4, geht es auch darin also vornehmlich um das Abreagieren von Gefühlen.

Die Assertiva sind mit 21 bis $30 \%$ durchschnittlich bis leicht unterdurchschnittlich vertreten, was ein wenig überrascht, da es ja zumindest am Anfang und am Ende der Exilzeit einen großen Informationsbedarf (z. B. zum bisherigen und künftigen Reiseverlauf und zu den neuesten Entwicklungen bzgl. einer möglichen Rehabilitation Ciceros) gab. Am höchsten liegt der Anteil noch in fam. 14.2, was sich v. a. auf die ausführlichen Rechtfertigungsversuche Ciceros in diesem Brief zurückführen lässt. Ausgerechnet in fam. 14.4 und 14.3 liegt ihr Anteil aber am niedrigsten, d. h., in entscheidenden Situationen überwiegt offensichtlich der Drang, seine Emotionen zu entladen, gegenüber dem Wunsch nach Informationsaustausch.

Immerhin stellt Cicero in fam. 14.4 zwei KOOPERATIONSFRAGEN, die sein Informationsbedürfnis verdeutlichen; und in einigen (eigentlich recht konventionellen) BITTEN in den anderen drei Exilbriefen formuliert Cicero den Wunsch, seine Frau möge ihn per Brief über alles auf dem Laufenden halten. ${ }^{1516} \mathrm{Im}$ Übrigen ist die Direktivität in den Exilbriefen aber recht schwach ausgeprägt. ${ }^{1517}$ Es finden sich lediglich noch eine (konventionelle) BITTE um das Ausrichten von Grüßen an seine Kinder in fam. 14.1 und ein paar (über das Konventionelle hinausgehende) BITTEN zur praktischen bzw. moralischen Unterstützung Ciceros in fam. 14.3 und 14.4 sowie (v. a. in fam. 14.2) einige ANWEISUNGEN, darunter auch Äußerungen, die den üblichen WOHLERGEHENSWÜNSCHEN ähneln, denen jedoch eine größere Bedeutung zukommt, insofern Terentia v. a. deshalb auf ihre Gesundheit achten solle, um sich mit voller Kraft für Cicero einsetzen zu können. Hinzu kommt eine (expressiv gefärbte) ANTEILNEHMENDE FRAGE in fam. 14.4.

Einen noch geringeren Stellenwert haben die Kommissiva, obwohl sie in fam. 14.3 (mit knapp $8 \%$ ) und v. a. 14.1 (mit über $9 \%$ ) deutlich stärker repräsentiert sind als im Durchschnitt. In fam. 14.2 und 14.4 sind sie dagegen nur durch jeweils eine Illokution vertreten. In allen vier Briefen sind sie kaum von Bedeutung für die Textfunktion, sondern sie stehen in den meisten Fällen vielmehr in engem Zusammenhang mit den Reiseinformationen (z. B. ABSICHT BEKUNDEN in Bezug auf den künftigen Reiseverlauf) oder Ciceros emotionaler Verfassung (VORSATZ

\footnotetext{
${ }^{1516}$ Vgl. a. N. 1518 zu den Kommissiva im Zusammenhang mit dem Informationsaustausch während Ciceros Exilzeit.

${ }^{1517}$ Der Anteil der Direktiva an sämtlichen Illokutionen der Exilbriefe beträgt zwischen ca. 4 \% (fam. 14.1) und knapp $11 \%$ (fam. 14.4).
} 
BEKUNDEN, sich „zusammenzureißen“), weisen also eine gewisse Nähe zu den Assertiva bzw. Expressiva auf. ${ }^{1518}$

Abgesehen von den Exilbriefen können drei weitere, ziemlich kurze Briefe als Kontaktbriefe bezeichnet werden, da die Expressiva über konventionelle Phrasen hinausgehen bzw. die anderen Sprechaktklassen unterrepräsentiert und / oder von geringer textfunktionaler Bedeutung sind: In fam. 14.9 äußert Cicero Sorge um seine Tochter und seinen Schwiegersohn, die beide erkrankt sind (JAMMERN), was für ihn eine zusätzliche Belastung darstellt angesichts vieler anderer Probleme, denen er ratlos gegenübersteht (ANGST ÄUSSERN). ${ }^{1519}$ In fam. 14.16 halten sich sympathisierende und abreagierende Expressiva ebenfalls in etwa die Waage. Hinzu tritt eine kommissive ABSICHTSBEKUNDUNG, die aber an dieser Stelle dem Gefühlsausdruck untergeordnet ist: Nachdem Cicero Terentia sein BEDAUERN wegen Volumnias unangemessenem Verhalten BEKUNDET hat, macht er seinem Ärger über andere Dinge Luft (FLUCHEN), die ihn letztlich mehr beschäftigen und sein Handeln erfordern (ABSICHT BEKUNDEN). In fam. 14.8 dominieren hingegen die sympathisierenden Expressiva: Zum einen geht es um einen Fieberanfall Terentias, auf den Cicero HINWEIST, wodurch die (konventionellen) WOHLERGEHENSWÜNSCHE (v. a. (3)) authentischer wirken. Noch mehr Gewicht kommt in dem Schreiben aber wohl dem Dank an Terentia dafür zu, dass sie ihn über einen Brief Cäsars informiert habe (BEGRÜSSEN und DANKEN). ${ }^{1520}$ Eng damit verbunden ist die (weitgehend konventionelle) BITTE, ihn weiterhin auf dem Laufenden zu halten.

\subsection{Informationsbriefe}

In den Informationsbriefen fam. 14.24 und 14.22 besteht die Information im Grunde darin, es gebe keine neuen Nachrichten. ${ }^{1521}$ In fam. 14.24 wird immerhin klar, dass Cicero auf Cäsars Kommen bzw. einen Brief von ihm referiert ( 2 x HINWEISEN), und die Vermutung geäußert, dieser Brief befinde sich gerade in den Händen von Philotimus (VERMUTEN), während in fam. 14.22 der thematische Bezug unklar bleibt und Cicero lediglich auf eine baldige Klärung der Situation verweist, sobald die Briefboten eingetroffen seien ( 2 x PROGNOSTIZIEREN). In beiden Fällen VERSPRICHT Cicero seiner Frau, sie weiter auf dem Laufenden zu halten.

Sowohl in fam. 14.11 als auch 14.15 stehen die gemeinsamen Kinder Ciceros und Terentias im Fokus. Cicero setzt seine Frau darüber in Kenntnis, dass Tullia bei ihm angekommen sei bzw. immer noch verweile und dass er den Sohn Cäsar entgegenschicken wollte, dann aber seine Meinung geändert habe. In Anbetracht der großen sozialen Bedeutung familiärer Bindungen

\footnotetext{
1518 Ein VERSPRECHEN, Terentia zu schreiben, wie in fam. 14.1.7 (54) steht dabei ebenfalls im Zusammenhang mit dem Informationsaustausch während des Exils. Im Übrigen geht es auch in fam. 14.1.3 (17), wo Cicero seine ABSICHT BEKUNDET, einigen Freunden zu schreiben, um den Austausch von Briefen.

${ }^{1519}$ Vor diesem Hintergrund kommt auch dem WOHLERGEHENSWUNSCH am Briefende, der Tullia miteinschließt, eine besondere Bedeutung zu.

1520 Im vorliegenden Kontext kommt den beiden Illokutionen ein höherer Stellenwert zu als den üblichen Empfangsbestätigungen von Briefen.

1521 Vgl. a. SCHRÖDER 2018, 88f. („The letter as token of esteem“) und SCHRÖDER 2007, 149f. zu (weitgehend) inhaltsleeren Briefen, die möglicherweise nur aus Wertschätzung des Adressaten oder auch wegen eines sich anbietenden Briefboten geschrieben wurden. Danach würde es sich eher um Kontaktbriefe handeln, während nach meiner Interpretation die Informationsfunktion überwiegt. M. E. wirkt die Kontaktfunktion nur unterschwellig, ähnlich wie die Persuasivität in einigen anderen Briefen. In ebd., 149f. wird außerdem darauf hingewiesen, dass solche Briefe evtl. nur eine „Beigabe zu einer wichtigen mündlichen Nachricht“ waren. Vgl. a. Kap. 1.2.1.3.
} 
(auch oder vielmehr gerade in der Antike) müssen nicht nur fam. 14.11 (3) sowie 14.15 (3) und (7) eher als BENACHRICHTIGUNGEN denn als bloße HINWEISE eingestuft werden, sondern beide Briefe können insgesamt als Informationsbriefe gelten. Andere Illokutionen in den Briefen sind im (engeren oder weiteren) Zusammenhang mit der übergeordneten Informationsfunktion zu sehen, und zwar der die Meinungsänderung bzgl. des Sohnes begründende HINWEIS in fam. 14.15 (4) ebenso wie die (informative) ABSICHTSBEKUNDUNG mit Bezug auf dessen möglichen Wechsel des Aufenthaltsortes in fam. 14.11 (5) bzw. sein VERSPRECHEN in fam. 14.11 (7), Terentia über Neuigkeiten zu informieren, sowie der expressive Exkurs (JAMMERN) in fam. 14.11 (4), in dem Cicero sein schlechtes Gewissen gegenüber Tullia zum Ausdruck bringt. Der Stellenwert der mit einem HINWEIS verbundenen BITTE, sich bei Sicca über Ciceros anderweitige Wünsche zu erkundigen (und diesen zu entsprechen), bzw. die direktive Komponente in fam. 14.15 ist allerdings nur schwer einzuschätzen, d. h., die Dominanz der Informationsfunktion nicht so eindeutig.

Ein ähnliches Problem ergibt sich bei der Einordnung von fam. 14.19. Das Schreiben enthält eine recht konkrete BITTE um die Weiterleitung eines Briefes von Pomponius, den Cicero z. Z. erwarte (PROGNOSTIZIEREN), die aber ebenso wenig dominant erscheint wie die expressive Passage am Briefanfang, in der Cicero seine Sorge um Tullia bekundet (JAMMERN und HINWEISEN). Im Zentrum steht vielmehr Ciceros (assertive) Erklärung, warum er Terentia (noch) nicht entgegenreise könne ( 1 x ZUSTIMMEN, 2 x BEGRÜNDEN).

Bei der Analyse der Textfunktion von fam. 14.23 hingegen ist zwar die (weitgehend konventionelle) direktive BITTE um baldige Rücksendung der Boten vor dem Hintergrund der überragenden Neuigkeit zu vernachlässigen, Cicero habe endlich den lang erwarteten Brief Cäsars erhalten (BENACHRICHTIGEN) und erwarte inn bald persönlich (PROGNOSTIZIEREN). Das kommissive VERSPRECHEN, Terentia Bescheid zu geben, sobald er wisse, ob er Cäsar entgegenreisen oder ihn vor Ort erwarten werde, geht in seiner Konkretheit über das sonst übliche VERSPRECHEN, sie auf dem Laufenden zu halten, allerdings hinaus. Dennoch überwiegt insgesamt die Informationsfunktion.

Im Unterschied dazu ist das Verhältnis zwischen Information und Obligation in fam. 14.5 ausgewogener, weshalb das Schreiben bei der Analyse in Kap. 2.1.2 als (multifunktionaler) Obligations- und Informationsbrief eingeordnet wurde: Zum einen bekundet Cicero seinen unbedingten Willen, so bald wie möglich nach Italien zurückzukehren, zum anderen ist es ihm wichtig, Terentia über seine Reisepläne (Rückreise aus Kilikien) zu informieren. Die direktiven und expressiven Handlungseinheiten sind demgegenüber von untergeordneter (oft recht konventioneller) Bedeutung im Hinblick auf die Textfunktion(en) und dienen vielfach nur zu deren (funktionaler) Unterstützung.

\subsection{Aufforderungsbriefe}

Am stärksten vertreten in fam. 14 sind mit insgesamt zehn Schreiben - gegenüber jeweils sieben Kontakt- und Informationsbriefen - die Aufforderungsbriefe.

Vier von ihnen stellen sprecherpräferierte Bitten dar, darunter auch der in Kap. 2.1.1 bereits ausführlich analysierte Brief fam. 14.20, bei dem sich die Dominanz der direktiven gegenüber der assertiven Funktion nicht quantitativ, sondern aus ihrer funktional höheren Gewichtung ergibt. Im Zentrum steht der mit drei BITTEN zum Ausdruck gebrachte Wunsch Ciceros, bei 
seiner Ankunft auf dem Tusculanum möge alles Notwendige vorbereitet sein. Die Assertiva (3 $x$ PROGNOSTIZIEREN) liefern lediglich die entsprechende Begründung. In fam. 14.17, 14.21 und 14.10 sind die Bitten dagegen sehr viel allgemeiner gehalten: Cicero BITTET Terentia, sich um alles Erforderliche bzw. um das kümmern, was er Pomponius mitgeteilt habe. Fam. 14.21 und 14.10 sind um die BITTE ergänzt, ihn darüber (und über alles andere) per Brief zu informieren, während sich in fam. 14.17 ein davon unabhängiger RAT findet, Terentia solle sich an Trebatius wenden, wenn sie mehr über seine (psychische) Verfassung erfahren wolle. Die drei zusätzlichen (nicht-direktiven ) Illokutionen in fam. 14.10 stehen dagegen in engem Zusammenhang mit der zentralen BITTE um Unterstützung: Cicero verweist auf den Brief, den er Pomponius geschrieben habe und der alle weiteren Erklärungen überflüssig mache (HINWEISEN), und bedauert in einer expressiven Nebenbemerkung, ihm erst so spät geschrieben zu haben (FLUCHEN).

Bei fam. 14.6, 14.12 und 14.13 handelt es sich um Anweisungen mit beidseitiger Präferenz. In fam. 14.6 geht es um die Zahlung des noch ausstehenden Teils der Mitgift Tullias an Dolabella, um die sich Terentia kümmern solle (ANWEISEN), verbunden mit einer (indirekten) Würdigung ihres Einsatzes für die gemeinsame Tochter (KOMPLIMENT MACHEN). ${ }^{1522}$ Die übrigen (von Konventionalität geprägten) Illokutionen wie die BITTE um Rücksendung des Briefboten Pollex und die BEGRÜNDUNGEN für Ciceros Schreibfaulheit sind im Hinblick auf die Textfunktion zu vernachlässigen. In fam. 14.12 WEIST Cicero seine Frau AN, besser nicht zu ihm zu kommen. ${ }^{1523}$ Die Aufforderung wird durch drei Assertiva BEGRÜNDET, die dem übergeordneten Ziel also untergeordnet sind. Mit ihr korreliert die BITTE, Terentia solle (vor Ort) tun, was in ihrer Macht stehe. Was genau sie tun könnte, das wisse er allerdings nicht, wie er zugeben muss (HINWEISEN). Beiden Direktiva liegen die Bemerkungen Ciceros vom Briefanfang zugrunde, mit denen er HOFFNUNG und ANGST ÄUSSERT hinsichtlich dessen, was ihn nun nach seiner Rückkehr nach Italien erwarten werde. Fam. 14.13 betrifft abermals den Schwiegersohn Dolabella, stammt jedoch aus der Zeit nach der Scheidung von Tullia, als unklar ist, wie viel Gefahr für sie und ihre Eltern von ihm ausgehen könnte. Hier ist die Dominanz des direktiven Untermuster ANWEISEN mit 3 von 7 Illokutionen sehr deutlich: Cicero WEIST seine Frau bezüglich ihres Verhaltens gegenüber Dolabella AN. Auch der HINWEIS in (2) und die PROGNOSE in (4) referieren darauf.

Die drei während des Bürgerkrieges zwischen Cäsar und Pompejus entstandenen Briefe fam. 14.14, 14.18 und (weniger deutlich) 14.7 verfolgen das vorrangige Ziel, Terentia angesichts der schwierigen Situation in Rom in der Frage ihres Aufenthaltsortes (adressatenpräferierte) Ratschläge zu erteilen: Soll sie in Rom bleiben, Cicero nachreisen oder sich an einen anderen sichereren Ort begeben ${ }^{1524}$

\footnotetext{
1522 Vgl. GUglielmi 2013, 282 N. 3; Shackleton Bailey in CICERO 1977, 500 und Tyrrell / Purser in CICERO 1904 - 1933, IV 279.

${ }^{1523}$ Möglicherweise könnte man auch von einer BITTE mit dominanter Sprecherpräferenz ausgehen. Die folgende BEGRÜNDUNG (bes. (7) und (8)) zeigt allerdings, dass Cicero bei der Ablehnung von Terentias Angebot, zu ihm zu kommen, durchaus auch ihre Interessen im Blick hat.

${ }^{1524}$ Guglielmi stellt eher den informativen Charakter von fam. 14.18 und 14.14 in den Vordergrund, insofern beide Briefe die Grundlagen für die anstehende Entscheidung Terentias liefern würden. VgI. z. B. GUGLIELMI 2013, 229 (zu fam. 14.18): „In conclusione, [...] si può dire che il carattere generale è piuttosto informativo, in quanto
} 
Fam. 14.18 und 14.14 sind an zwei aufeinanderfolgenden Tagen (22. bzw. 23.01.49 v. Chr.) entstanden und ähneln sich (z. T. bis hin zu einzelnen Formulierungen) sehr stark. ${ }^{1525}$ Cicero WEIST Terentia darauf HIN, dass er im Grunde ratlos sei. ${ }^{1526} \mathrm{Er}$ empfiehlt ihr, die Lage ganz genau zu überdenken und sich dabei auch mit anderen auszutauschen (RATEN). Am Ende müsse sie aber selbst entscheiden, was augenblicklich das Beste für sie sei (RATEN). Dabei solle sie insbesondere darauf achten, was die anderen Frauen machten (RATEN). Er teilt ihr mit, die Gegend, in der er sich gegenwärtig aufhalte, sei in ihrer Hand (HINWEISEN). Im Übrigen wägt Cicero das Für und Wider der bestehenden Optionen v. a. in Form expressiver Sprechakte des Typs WOHLERGEHEN WÜNSCHEN bzw. SORGE BEKUNDEN gegeneinander ab. ${ }^{1527}$ In fam. 14.14 drückt er in diesem Zusammenhang auch seine Freude über die Unterstützung durch Labienus und Piso aus (JUBELN). ${ }^{1528}$ Fam. 14.18 ist zudem um eine ANWEISUNG zu notwendigen Schutzmaßnahmen für das Haus ergänzt. Sowohl in fam. 14.18 als auch 14.14 findet sich jeweils eine BITTE um häufige Briefe, die aufgrund ihrer Eindringlichkeit (cottidie, quam saepissime) über die üblichen Floskeln hinausgeht. ${ }^{1529}$ An anderer Stelle sind sonst eher konventionelle Formeln, wie z. B. die expressiven Grußformeln (GUNST ERWEISEN), die (zusätzlichen) WOHLERGEHENSWÜNSCHE und sogar der HINWEIS auf den Gruß von Quintus und Rufus, ebenfalls emotional mehr oder weniger stark aufgeladen bzw. sie verstärken durch ihre Präsenz an sich die Emotionalität der beiden Briefe, bestimmen allerdings nicht die Textfunktion, sondern dienen nur mittelbar ihrer Stützung. ${ }^{1530}$

Fam. 14.7 ist ein paar Monate später als 14.18 und 14.14 (am 07.06.49 v. Chr.) geschrieben worden. Zwischenzeitlich hat Terentia (zusammen mit Tullia) Cicero in Formiae und Cumae getroffen. ${ }^{1531}$ Cicero RÄT ihr (erneut), sich ggf. auf eines der Landgüter mit weitem Abstand

lo scopo non è lo sfogo emotivo ma la comunicazione di notizie e la presentazione di alternative sulla base delle quali le destinatarie devono operare una scelta razionale [...].“

1525 Vgl. z. B. GUGLIELMI 2013, 232; RICHLIN 2013, 103 und GUNDERSON 2007, 22.

1526 Überhaupt sind die Ratschläge Ciceros nur bedingt hilfreich. Zu den möglichen Gründen, weshalb Cicero keinen eindeutigeren Rat erteilt, vgl. z. B. JÄGER 1986, 255f.: „Cicero erleichtert Terentia und Tullia die Entscheidung nicht gerade, denn aus seinen ,Ratschlägen“ ist weder eine unmittelbare Aufforderung, Rom zu verlassen, noch dort zu bleiben, herauszulesen. [...] Zum Schluß bittet er darum, ihm möglichst oft zu schreiben, damit auch er über alles informiert sei. Dies macht Ciceros Zögern und Unentschlossenheit in der Frage, ob Tullia, Terentia und auch Atticus die Stadt verlassen sollten, verständlicher: Er fürchtet, zuverlässige Informationsquellen zu verlieren, zumal die meisten Senatoren und Magistraten Rom schon verlassen hatten. “

${ }^{1527}$ Vgl. a. GUGLIELMI 2013, 233 (zu fam. 14.14): „, [...] ora egli, esprimendo paura per la sorte di Tullia e di Terenzia, intende probabilmente fare pressione sulle due donne affinché prendano una decisione." sowie JäGER 1986, 284. ${ }^{1528}$ Vgl. ebd., 255, der zu fam. 14.14 bemerkt, dass Cicero in diesem Brief „die bissige Deutlichkeit [vermeidet], mit der er gegenüber Atticus [in Att. 7.13] Caesar und Pompeius kritisiert hatte. Der einzige Nachhall dieser Äußerungen ist die Bemerkung am Ende des Briefes (§ 2), wo er den Abfall von Labienus und Piso ebenfalls mit Genugtuung erwähnt."

${ }^{1529}$ Vgl. N. 1526.

1530 Vgl. Guglielmi 2013, 229 (zu fam. 14.18) und ebd., 233 (zu fam. 14.14). Sie hält fam. 14.14 für insgesamt weniger nüchtern und reflektiert als 14.18: „,...] nonostante gli argomenti siano molto simili a quelli dell'epistola scritta il giorno prima e il tono complessivo sia ancora certamente affettuoso, non si riscontra più il tono sobrio e riflessivo della lettera precedente [...].“ (ebd., 233). Vgl. a. JÄGER 1986, 255 (zu fam. 14.14): „In dem am selben Tag [wie Att. 7.13] verfaßten Brief an die Familie findet man zwar immer noch den Ton verbundener Herzlichkeit, aber nicht mehr die nüchterne, ruhige und überlegene Art sprachlicher Äußerung wie im Brief am Vortag." Die Intensität der direktiven RATSCHLÄGE ist dagegen umgekehrt in fam. 14.18 stärker: Vgl. a. S. 404.

1531 Vgl. dazu Treggiari 2007, 104ff. Vgl. a. GUGLIELMI 2013, 270 N. 3 bzw. Tyrrell / Purser in CICERO 1904 - 1933, IV 262 und Shackleton Bailey in CICERO 1977, $495 \mathrm{f}$. 
zum Militär zurückzuziehen. Bei einem Anstieg der Lebensmittelpreise sei das Arpinatum empfehlenswert. ${ }^{1532}$ Er VERSPRICHT, Briefe an Freunde zu schreiben, damit diese sich für ihren Schutz einsetzen. Mit dem KOMPLIMENT für ihre außerordentliche Tapferkeit wird jedoch ebenso wie mit dem WOHLERGEHENSWUNSCH in (12), durch den er seine Hoffnung äußert, bei ihnen möge alles in Ordnung sein bzw. bleiben, implizit große Sorge um Frau und Tochter zum Ausdruck gebracht. Cicero ÄUSSERT außerdem die HOFFNUNG, bald persönlich zur Verteidigung des Staates beitragen zu können. Damit verlagert er den Fokus weg von Terentia hin zu sich selbst, wie dies auch in (8) und (9), welche auf die Schiffsreise mit dem gemeinsamen Sohn referieren, und v. a. im ersten Teil des Briefes $((2)-(7))$ zu beobachten ist, der darüber hinaus in keinem Zusammenhang mit dem Bürgerkrieg steht. Cicero teilt seiner Frau darin mit, er habe die Krankheit, durch welche er bei seinem letzten Treffen mit Terentia und Tullia geplagt worden sei, mittlerweile überstanden und kenne auch die Ursache (HINWEISEN). Er drückt einerseits Bedauern aus (SICH ENTSCHULDIGEN, JAMMERN) für die Unannehmlichkeiten, die er Terentia und Tullia bereitet habe, andererseits Freude über seine Genesung (JUBELN) und BITTET Terentia darum, den Göttern dafür zu danken. ${ }^{1533}$ Möglicherweise dient das Ansprechen anderer Themen in fam. 14.7 der Ablenkung. Fam. 14.18 und 14.14 sind sehr viel stärker auf ein Thema fokussiert. Zudem fällt auf, dass in fam. 14.7 weniger aversive Sprechakte (wie SORGE BEKUNDEN) verwendet werden, vielleicht um Terentia nicht zusätzlich zu beunruhigen. ${ }^{1534}$ Die Emotionalität ist nichtsdestotrotz auch hier sehr hoch und wird durch expressiv verstärkte oder zusätzliche (an sich konventionelle) Wendungen gesteigert, wie z. B. die Grußformeln (GUNST ERWEISEN und WOHLERGEHEN WÜNSCHEN), einen zusätzlichen WOHLERGEHENSWUNSCH (in (14)) und den (affektiven) HINWEIS auf einen Gruß des Sohnes.

\subsubsection{Beziehungs- und Identitätskonstitution: Das Verhältnis zwischen Cicero und Terentia}

\subsubsection{Historischer Hintergrund}

Cicero wird Terentia in erster Linie aufgrund ihrer Wohlhabenheit und ihres gesellschaftlichen Einflusses geheiratet haben, sie ihn hingegen wegen seiner im Hinblick auf die berufliche und politische Zukunft vielversprechenden Anlagen und Fähigkeiten. Es ist demnach also kaum von einer Liebesheirat auszugehen. ${ }^{1535}$ Nichtsdestotrotz scheinen beide über einen langen Zeitraum eine gute Ehe geführt zu haben. ${ }^{1536}$ Darauf lassen nicht nur die Briefe Ciceros an seine Frau, sondern auch an andere Adressaten wie insbesondere Atticus schließen. ${ }^{1537}$ Erst ab ca.

\footnotetext{
1532 Vgl. fam. 14.14.1 (10).

1533 JÄGER 1986, 257 hält diese Bitte, mit der Cicero „für Terentias Frömmigkeit Verständnis zeigt“, für einen „Vertrauensbeweis".

${ }^{1534}$ Dass Cicero auch in fam. 14.18 (und 14.14) anscheinend viel daran gelegen ist, Terentia nicht zu beunruhigen, erhellt sich aus einem Vergleich mit dem am selben Tag wie fam. 14.18 geschriebenen sehr viel emotionaleren Brief an Atticus (Att. 7.12): Vgl. z. B. ebd., 252f. sowie ebd., 284. Vgl. a. N. 1530.

1535 Vgl. z. B. TREGGIARI 2007, 32.

1536 Vgl. z. B. ERMETE 2003, 197; GreBe 2003, 129 und CLAASSEN 1996, 224. Zur Beziehung zwischen Cicero und Terentia insgesamt vgl. z. B. ebd., 174ff. („Das eheliche Verhältnis“) bzw. ebd., 203ff. („Terentias Bild in Ciceros Briefen") und CLAASSEN 1996, $214 f$.

${ }^{1537}$ Vgl. die umfassenden Analysen der Cicero-Briefe im Hinblick auf das Verhältnis zu Terentia in GUGLIELMI 2013.
} 
47 v. Chr. kam es wohl zu einer zunehmenden Entfremdung zwischen den beiden. ${ }^{1538}$ Manche Forscher gehen auch von einem plötzlichen Bruch der Beziehung aus. ${ }^{1539}$ Ende 47 oder Anfang 46 v. Chr. erfolgte jedenfalls nach etwa 30 Jahren die Scheidung.

Über die genaue(n) Ursache(n) der Trennung kann man nur spekulieren. ${ }^{1540}$ Oft werden - im Anschluss an einige Passagen in den Atticusbriefen wie Att. 11.16.5 und 11.24.3 sowie die Darstellung Plutarchs - Unstimmigkeiten in Geldangelegenheiten angeführt. ${ }^{1541}$ Es geht dabei v. a. um die Erstellung eines Testamentes und die angebliche Unterschlagung größerer Geldsummen durch Terentia. Die Vorwürfe reichten manchmal so weit, dass ihr eine generelle Weigerung, Cicero (weiterhin) finanziell zu unterstützen, und eine Gefährdung der Zukunft der gemeinsamen Kinder unterstellt wurden. ${ }^{1542}$ Dabei sind die Hintergründe nicht ganz klar: Inwieweit waren die Verdächtigungen gegen Terentia tatsächlich begründet? Welche Rolle spielte Philotimus, der wenig vertrauenswürdige Vermögensverwalter Terentias? Ermete hält die Auseinandersetzungen ohnehin mehr für Symptome eines bereits zerrütteten Vertrauensverhältnisses zwischen den Eheleuten und nicht für die eigentliche Ursache der Scheidung. ${ }^{1543}$ Ebenso wenig stellen politische Meinungsverschiedenheiten, wonach Terentia bspw. ihrem Mann im Bürgerkrieg seine zögerliche Haltung oder seine Positionierung für die falsche Seite vorgeworfen habe, eine überzeugende Erklärung dar. ${ }^{1544}$

Somit wären die Gründe also vornehmlich im Persönlichen zu suchen. In der Tat wurde Terentia (z. B. von Plutarch) neben einer finanziellen auch eine persönliche Vernachlässigung ihres Mannes und ihrer Kinder vorgeworfen. ${ }^{1545}$ Sie soll Cicero bspw. zwischen November 48 und September 47 v. Chr., obwohl er sich fast ein Jahr in Brundisium aufgehalten hat, nicht ein einziges Mal dort besucht und sich ihm gegenüber nach seiner Rückkehr im Oktober $47 \mathrm{v}$. Chr. ziemlich abweisend verhalten haben. ${ }^{1546}$ Sie habe überhaupt einen schwierigen Charakter gehabt und nicht dem traditionellen Ideal einer römischen Frau entsprochen, sei egoistisch und übermäßig ehrgeizig gewesen und habe eigenmächtige Entscheidungen getroffen, wie bspw.

1538 Vgl. z. B. ERMETE 2003, 185ff. („Beginnende Entfremdung“) und CLAASSEN 1996. Einige, v. a. ältere Wissenschaftler wie Schmidt und Drumann sehen schon etwas früher Anzeichen für ein abgekühltes Verhältnis zwischen den Eheleuten: Vgl. ERMETE 2003, 185f. bzw. SCHMidt 1898, 181 (zu fam. 14.6) und Drumann 1929, 6, 608f. sowie N. 1539 und 1560. Vgl. aber auch LeHMANN 2015, 92f., der mit Verweis auf die fehlende Erwähnung Terentias in Att. 4.2.7 (amamur a fratre et a filia) auf Unstimmigkeiten bereits im Jahr 57 v. Chr. aufmerksam macht, die er als Vorzeichen für die sehr viele Jahre später erfolgende Scheidung interpretiert, welche m. E. aber, sofern man solche darin überhaupt erkennen will, nicht überbewertet werden sollten.

1539 Vgl. z. B. JÄGER 1986, 287: „Kurz nach ihrem Eintreffen in Brindisi [im Jahr 47 v. Chr.] hat Tullia ihrem Vater vielleicht Genaueres von zu Hause erzählt, was ihn dann schockierte und ihn von Terentia endgültig distanzieren mußte." SCHMIDT 1898, 181 erkennt einen deutlichen Bruch bereits 48 v. Chr. (in fam. 14.6). Vgl. a. GREBE 2003, 144 N. 63. Vgl. außerdem N. 1538 und 1560.

1540 Vgl. z. B. GUGLIELMI 2013, 365f. (,Le cause del divorzio di Cicerone e Terenzia“); TREgGIARI 2007, 128ff.; ERMETE 2003, 188ff. („Die Scheidung“) und JÄGER 1986, 286ff. („Gründe für das Scheitern der Ehe mit Terentia“).

1541 Vgl. z. B. Lehmann 2015, 93; Treggiari 2007, 129f.; Grebe 2003, 129; ERMETe 2003, 191f. und CLAASSEN 1996, 224.

1542 Vgl. z. B. SCHMIDT 1898, $184 \mathrm{f}$.

1543 ERMETE 2003, 192.

${ }^{1544}$ Vgl. ERMETE 2003, 192f. und TREGGIARI 2007, 130.

${ }^{1545}$ Vgl. z. B. SCHMIDT 1898, 184f. Vgl. außerdem ERMETE 2003, 193f. zur angeblichen Eifersucht Terentias auf Tullia, die im Widerspruch zur Darstellung des Verhältnisses zwischen Mutter und Tochter in der Korrespondenz Ciceros stehe.

${ }^{1546}$ Vgl. z. B. ebd., 189 und TREGGIARI 2007, 129. 
beim Arrangement der Ehe Tullias mit dem von ihrem Mann nicht eben favorisierten Dolabella oder während Ciceros Exil, als sie ihn in Rom vertreten und dadurch bis zu einem gewissen Grad den männlichen Part in der Beziehung übernommen hat bzw. übernehmen musste. ${ }^{1547}$ Claassen meint sogar, man müsse die Trennung Ciceros von Terentia als einen Versuch sehen, aus einer daraus resultierenden dysfunktionalen Familienstruktur auszubrechen und seiner „Empfindung eines Kontrollverlustes“ entgegenzuwirken. ${ }^{1548}$ Dem widerspricht Ermete: Cicero habe Terentia kaum „an einem Ideal gemessen [...], welches in der späten Republik bereits einem Wandel unterlegen war" ${ }^{\prime 1549}$, sondern habe ihr unabhängiges aktives Handeln i. A. vielmehr geschätzt und befördert. ${ }^{1550}$ Auch von anderen wird Terentias Verhalten z. B. während des Exils für vorbildlich erachtet. Es sei schon allein aufgrund der besonderen Umstände gerechtfertigt gewesen. ${ }^{1551}$ Cicero habe dagegen ein eher jämmerliches Bild abgegeben. ${ }^{1552}$ Einige sehen überdies in seinem Egozentrismus ${ }^{1553}$ und seiner psychischen Instabilität bzw. seiner Erschütterung wegen der politischen Umwälzungen durch den Bürgerkrieg den Hauptgrund für die Trennung. ${ }^{1554}$ Dass Cicero - wie Terentia nach Plutarch behauptet haben soll seine Frau verlassen hat, weil er sich in die junge Publilia verliebt habe, die er kurz nach der Scheidung geheiratet hat, kann hingegen ausgeschlossen werden. ${ }^{1555}$ Laut Att. 12.11 war er noch Ende 46 v. Chr. auf der Suche nach einer passenden zweiten Ehefrau. Zudem waren möglicherweise eher die Vermögensverhältnisse Publilias (als ein „Johannistrieb“) ausschlaggebend für seine Wahl. ${ }^{1556}$

${ }^{1547}$ Zu Tullias Eheschließung mit Dolabella vgl. z. B. ERMETE 2003, 221ff. Zu Terentias Rolle während des Exils vgl. a. Kap. 2.1.3.3, bes. N. 1066.

1548 CLAASSEN 1996. Vgl. a. ERMETE 2003, 195 Vgl. außerdem Gunderson 2007, 45: „In dealing with Terentia Cicero either recognizes himself as impotent and effeminate or he writes letters that are unrecognizable as communication, letters that can only drone endlessly, ,Fare well.',"

1549 ERMETE 2003, 195. Allerdings hält Cicero an anderer Stelle (De re publica) durchaus das traditionelle Ideal einer römischen Ehefrau hoch. GREBE 2003, 142 erklärt diesen Widerspruch mit den besonderen Umständen der Exilzeit und mit dem Unterschied zwischen öffentlicher und privater Meinung Ciceros.

1550 Vgl. z. B. ERMETE 2003, 196: „Terentias Verantwortungsübernahme während der Abwesenheit ihres Mannes, die Claassen als Ursache betrachtet, die wesentlich zu Ciceros Empfindung eines Kontrollverlustes beigetragen haben soll, wird sowohl in zeitgenössischen Quellen als Idealverhalten beschrieben als auch von Cicero an Terentia gelobt und explizit gefordert."

${ }^{1551}$ Vgl. z. B. Grebe 2003, 134: „There were occasions - such as a spouse's exile, assumption of the government of a province, military service - when married couples were separated from each other in ancient Rome. These occasions gave the wife the opportunity to move from the domestic female sphere into the public male sphere, for city wives and peasant women needed to care for their families and to look after the interests of their husbands." Vgl. a. ebd., 127 und ebd., 145; BuONOPANE 2016, 52; GuglielMI 2013, 356 sowie S. 400 und Kap. 2.1.3.3, bes. N. 1066.

1552 Vgl. z. B. SCHMIDT 1898, 174f., der u. a. auf Drumanns Darstellung hinweist: „Drumann schildert Terentia als eine Heroine, neben der Cicero eine klägliche Rolle spielt: [...].“ (ebd., 174). Vgl. Drumann 1929, 6, 604ff. Vgl. a. ERMETE 2003, 196.

1553 CLAASSEN 1996, 224 bemerkt z. B., dass das Verhältnis zwischen Cicero und Terentia großen Belastungen ausgesetzt war, „caused by the egocentrism of a husband and father, the fluctuations of whose political career influenced the fortunes of his family to a considerable degree."

1554 Vgl. z. B. JÄGER 1986, $288 f$.

1555 Vgl. SCHMIDT 1898, $184 \mathrm{f}$.

1556 Dies soll zumindest nach Plutarch die Meinung Tiros gewesen sein. Im Übrigen hat Cicero sich bereits nach kurzer Zeit wieder von Publilia scheiden lassen: Vgl. ERMETE 2003, 189 und TREGGIARI 2007, 134f. Vgl. außerdem SCHMIDT 1898, 185. 
Letztlich lassen sich keine wirklich überzeugenden konkreten Gründe für die Scheidung Ciceros von Terentia finden, obgleich bereits in der Antike alle möglichen Vermutungen angestellt wurden. ${ }^{1557}$ Es wird auf jeden Fall keine einfache Entscheidung für Cicero gewesen sein. Die Scheidung nach einer so langen Ehe, aus der zudem zwei Kinder hervorgegangen sind, war mit einem deutlichen Gesichtsverlust verbunden. ${ }^{1558}$ Außerdem stellte die notwendige Rückzahlung von Terentias Mitgift eine große Belastung für ihn dar. Besonders ihr (von ihm als solcher empfundene) Verrat hat ihn offenbar tief getroffen. Kurz: Cicero hatte schwer an den finanziellen und emotionalen Folgen der Scheidung zu tragen, wie u. a. auch Att. 12.22.1 belegt: De Terentia, quod mihi omne onus imponis, non cognosco tuam in me indulgentiam. ista enim sunt ipsa vulnera quae non possum tractare sine maximo gemitu. ${ }^{1559}$

\subsubsection{Die Briefe Ciceros an Terentia als Spiegel ihrer Ehe \\ 2.2.2.2.1 Bisherige Forschung}

Ciceros Briefe an seine Frau werden im Hinblick auf ihre gemeinsame Beziehung unterschiedlich interpretiert, wobei jedoch kaum je in Zweifel gezogen wird, dass sie eine negative Entwicklung anzeigen. Einige erkennen ab fam. 14.6 oder 14.11 einen abrupten Wechsel im Ton, während andere meinen, dieser ändere sich nur allmählich. Hingewiesen wird zudem auf die nachlassende Sorgfalt bei der sprachlichen Ausarbeitung und eine zunehmende Inhaltsleere. Augenfällig ist auf jeden Fall, dass die Briefe immer kürzer werden. ${ }^{1560}$

\footnotetext{
1557 Vgl. GUGLIELMI 2013, 366: „In ogni caso, la discussione sulle probabili cause del divorzio di Cicerone da Terenzia, che inizia dall'antichità e arriva ai giorni nostri, indica che molto probabilmente i coniugi non avevano addotto alcuna motivazione precisa per la separazione [...]. “ Vgl. a. JÄGER 1986, 288: „Man sieht, daß eine einseitig-subjektive Schuldzuweisung dem Problem nicht gerecht wird. Ebenfalls für falsch halte ich die akribiehafte Suche nach dem eigentlichen Grund der Ehescheidung, der aus keiner der bekannten Quellen eindeutig herauszulesen ist."

1558 VgI. z. B. TREGGIARI 2007, 129: „To divorce a wife of long standing who had given a man children was regarded as disgraceful. Antonius, in reply to Cicero's invectives against him in 44, among other things, charged Cicero with having cast out the wife with whom he had grown old; Dio makes the Antonian Fufius Calenus (cos. 47) focus on the fact that she was the mother of his two children."

${ }^{1559}$ Guglielmi unterscheidet zwei Gruppen von Briefen aus der Zeit nach der Scheidung, in denen deutlich werde, wie sehr Cicero diese (emotional und finanziell) mitgenommen hat: „Nei due gruppi così individuati, si osserva che i contesti in cui Terenzia compare è notevolmente diverso: nel primo i riferimenti sono essenzialmente all'imbarazzo provocato dal recente divorzio, anche nel ricordo del comportamento tenuto dalla donna negli ultimi tempi del matrimonio [...], mentre nel secondo Cicerone menziona l'ex moglie solamente in relazione a questioni di carattere pratico che la riguardano, cioè il testamento e soprattutto la restituzione della dote. Per quanto riguarda il linguaggio utilizzato dal mittente in questi riferimenti, si è osservato che le connotazioni emotive non sono frequenti, ma, qualora presenti, vanno principalmente nel senso dell'espressione del disagio causatogli sia dal tradimento subito da Terenzia (nel primo gruppo di epistole) sia dalla necessità di trovare il denaro necessario a restituirle la dote, o del fastidio per le ingerenze di lei nella redazione del testamento dell'ex marito (nel secondo gruppo di epistole).“ (Guglielmi 2013, 353). Vgl. a. GreBE 2003, 144 N. 63: „The epistles written to Atticus in March 45 reflect Cicero's anger and hostility towards his divorced wife (12.16.2; 12.23.3;12.24.1)." und (zur Belastung durch die Notwendigkeit der Rückerstattung der Mitgift Terentias) ebd., 129 sowie Treggiari 129.

1560 VgI. z. B. CLAASSEN 1996, 216: „As the years went on, the letters to Terentia became briefer and briefer, degenerating to mere notes, their contents more formal, and their tone perhaps more cool [...]. Critics ascribe such brevity to cooling relations [...].“ Zur (scheinbaren) Inhaltsleere der späteren Briefe vgl. a. GUNDERSON 2007, 24, zur sprachlichen Ausgestaltung und zum veränderten Ton der Briefe GUGLIELMI 2013, 359f. und GREBE 2003, 144 N. 63. SCHMIDT 1898, 180 sieht dabei einen Bruch ab fam. 14.6, JÄGER 1986, 287 hingegen erst ab fam. 14.11. GUGLIELMI 2013, 358 hinwiederum spricht von einem allmählichen Wandel des Tons. Vgl. a. N. 1538 und 1539.
} 
Bei alldem muss jedoch bedacht werden, dass fam. 14 zwar bis in die Zeit kurz vor der Scheidung reicht, insgesamt aber nur einen recht kurzen Ausschnitt (29.04.58 bis 01.10.47 v. Chr.) aus der langjährigen Beziehung repräsentiert. Zudem spiegeln die Briefe lediglich die Sichtweise Ciceros selbst wider, ohne dass diese durch den entgegengesetzten Blickwinkel Terentias ergänzt und ggf. korrigiert würde. ${ }^{1561}$ Darüber hinaus stellt sich angesichts der nahezu plakativ in Szene gesetzten Abwärtsspirale der Beziehung die Frage, wie weitreichend der Einfluss der Herausgeber auf die konkrete Ausgestaltung der Briefsammlung war. ${ }^{1562}$ Aussagen können am Ende nur über das im Text angelegte und weniger über das tatsächliche Verhältnis zwischen Cicero und Terentia getroffen werden. Allerdings sind selbst vor diesem Hintergrund keine einfachen und eindeutigen Bewertungen möglich. Die speziellen Gegebenheiten der einzelnen Briefe müssen jeweils berücksichtigt werden.

So sind fam. 14.1 bis 14.4 stark beeinflusst von den besonderen Umständen des Exils. Cicero befand sich in einer desolaten emotionalen Verfassung und war in vielerlei Hinsicht abhängig von anderen, insbesondere auch von Terentia, die ihn psychisch, praktisch und finanziell unterstützte, indem sie ihm Trost spendete, ihn mit Informationen über die Lage vor Ort in Rom versorgte und sich v. a. für seine Rehabilitierung starkmachte. ${ }^{1563}$ Dies schlägt sich sprachlich und inhaltlich in seinen Briefen nieder. Trotz einer insgesamt großen Selbstbezogenheit werden sie bspw. von Grebe als Ausdruck einer tiefen Liebe gedeutet. ${ }^{1564}$ Cicero bekunde seine Gefühle in einer für diese frühe literarische Epoche recht ungewöhnlichen Weise, wie es sonst - gegenüber einer Geliebten und nicht der eigenen Ehefrau! - typisch für die römische Liebeselegie sei. ${ }^{1565}$ Mit zärtlichen Anreden wie mea lux, meum desiderium äußert er Zuneigung und Sehnsucht. Ähnliche affektive Ausdrücke benutzt er allerdings ebenso in Bezug auf seine Kinder. Es fehlt die erotische Komponente. ${ }^{1566}$ Vielmehr gleicht das Verhältnis zwischen Cicero und Terentia in verschiedener Hinsicht eher der Freundschaft zu Atticus, ist geprägt von Sympathie, Respekt und Vertrauen. Die Grenzen zwischen Liebes- und Freundschaftsbeziehung

\footnotetext{
1561 Vgl. z. B. CLAASSEN 1996, 225.

1562 Vgl. z. B. PROST 2015, 10 zu den Exilbriefen als „un ensemble sélectif unifié par une intention éditoriale marquée“. Zur letztlich dann doch nicht ganz kontinuierlichen Abwärtsentwicklung der Beziehung vgl. z. B. S. 421.

1563 Vgl. z. B. GreBe 2003, 127 und ebd., 135ff. sowie N. 1551. Zu den Briefen Terentias als Form moralischer Unterstützung vgl. außerdem RICHLIN 2013, 113 und TREGGIARI 2007, 61. Zur Abhängigkeit Ciceros auch von anderen Personen vgl. z. B. JEPPESEN-WIGELSWORTH 2013, 362.

${ }^{1564}$ Vgl. GREBE 2003, 130ff. („The Celebration of Deep Marital Love“). Guglielmi geht trotz einer starken Rhetorisierung (mit Rückgriff auf Elemente der römischen Liebeselegie und Topoi der miseratio) ebenfalls von der Authentizität der Gefühle Ciceros aus: Vgl. z. B. GUGLIELMI 2013, 168f. und ebd., 356. Umgekehrt sei im Übrigen auch das Handeln Terentias von Liebe angetrieben gewesen, meint GREBE 2003, 140. Vgl. außerdem GUGLIELMI 2013, 363f. („L'aspetto sentimentale nel rapporto matrimoniale romano“).

${ }^{1565}$ Vgl. GREBE 2003, 130. Es gibt nur wenige Berichte über eheliche Liebe in (früh)römischer Zeit und diese stammen zudem noch meist aus zweiter Hand, wie z. B. Lukans Beschreibung der Abschiedsszene zwischen Cornelia und Pompejus vor der Schlacht von Pharsalus (LUCAN. 5.725-815) und eine Passage in Plutarchs Biografie des Tiberius Gracchus (PLUT. Tib. Gracch. 1.2-4), dessen Frau Cornelia nach seinem um ihretwillen erlittenen Tod alle Heiratsanträge ausschlug. In ebd., 131 wird außerdem auf die Tradition der Epithalamien und die fiktiven Heroides Ovids hingewiesen. Andere Zeugnisse betreffen Liebesbeziehungen aus späterer Zeit, wie z. B. die von Sueton erwähnten Briefe von Augustus an Livia (SUET. Claud. 4) oder Plinius' Hinweise auf Arria und Fannia (PLIN. epist. 3.16 bzw. 7.19), die ihren Männern aus Liebe ins Exil gefolgt seien.

${ }^{1566}$ Vgl. z. B. Prost 2015, 10f. Vgl. a. S. 190 und 221 bzw. N. 891 und 1003.
} 
verwischen. ${ }^{1567}$ Ehen in Rom waren i. A. Zweckbündnisse. Ein partnerschaftliches Verhältnis zwischen den Eheleuten war zwar durchaus üblich, die Beziehung von Cicero und Terentia ging aber zumindest zeitweise deutlich darüber hinaus. ${ }^{1568}$ Die Extremsituation während des Exils führte z. B. dazu, dass sie inniger war als in der Zeit davor und danach. ${ }^{1569}$ Obwohl den späteren Briefen keine ganz so intensive Emotionalität eigen ist, zeugen aber auch diese zumeist von gegenseitiger Achtung, Rücksichtnahme und Interesse am anderen. ${ }^{1570}$ Für die z. T. größere Sachlichkeit und die Kürze sind verschiedene Erklärungen denkbar, wie z. B. die Absicht, Terentia nicht unnötig zu beunruhigen, die fehlende Notwendigkeit ausführlicher Darlegungen wegen eines bald bevorstehenden persönlichen Aufeinandertreffens oder schlicht die Eile beim Schreiben auf einer nur kurzen Zwischenstation während einer längeren Reise. ${ }^{1571}$

In einigen Fällen legt jedoch ein Vergleich mit den Briefen an Atticus, die manchmal am selben Tag geschrieben wurden, nahe, dass wohl doch mehr dahinter steckt. ${ }^{1572}$ Somit kann man zwar von den Eigenheiten sowohl der Exilbriefe als auch der späteren Briefe nicht automatisch auf einen kontinuierlichen Niedergang der Beziehung schließen; gewisse Tendenzen sind aber nicht zu übersehen und finden letztlich ja ihre Bestätigung in der Scheidung, die kurz auf den

1567 Vgl. z. B. GREBE 2003, 139: „During Cicero's exile, the boundaries between love and friendship, spouse and friend, became blurred. Ideal marriage and true friendship have much in common: mutual love or liking, care for the other, altruism, reliability, interpersonal confidence, reciprocity, sharing of experience, frankness, intimacy, each partner desiring the best for the other. Ideal marriage and true friendship withstand disputes and are longlasting, and are valued as indicators of the perfect relationship. " Vgl. a. ebd., 143. Vgl. außerdem JEPPESEN-WIGELSWORTH 2013, bes. ebd., 359 und ebd., 363f. sowie RICHLIN 2013, 112, die auf die (charakterlichen) Gemeinsamkeiten von Terentia und Atticus hinweist. Insgesamt scheint Ciceros Beziehung zu Terentia zwar sehr innig, die zu Atticus aber noch enger gewesen zu sein: VgI. z. B. JEPPESEN-WIGELSWORTH 2013, 352; ALBRECHT 2003, 68f. Und JÄGER 1986, 228f.

1568 Vgl. z. B. JEPPESEN-WIGELSWORTH 2013, 351 und ebd., 363f. Als weitere Beispiele partnerschaftlicher Beziehungen nennt sie Cornelia und P. Sestius, Postumia und Ser. Sulpicius, Eppuleia und T. Ampius sowie Valeria Paulla und ihren Mann.

${ }^{1569}$ Darauf deuten die Atticusbriefe hin, die Hinweise auf die Beziehung zwischen Cicero und Terentia auch in der Zeit, die von fam. 14 nicht abgedeckt wird, liefern: Vgl. z. B. BAILLEUX 1933, 66f. sowie GUGLIELMI 2013,95 (über die Zeit vor dem Exil) bzw. ebd., 189 (über die Zeit unmittelbar nach dem Exil).

1570 Vgl. z. B. GReBe 2003, 144 und CLAASSEN 1996, 216 (mit Bezug auf die späteren Briefe).

1571 Vgl. z. B. ebd., 216: „Critics ascribe such brevity [wie in den späteren Briefen Ciceros an Terentia] to cooling relations, but secure conjugal affection can take short note-writing. Politics and family concerns may have dictated their brevity. In Fam. 14.16 the husband explained that he wrote whenever a messenger was available, whether he had any news or not. In many letters the frequent formulaic abbreviation for the already formulaic Si tu vales, ego quoque valeo [...] may appear abrupt, but can be read in the context of hasty but comfortable intercourse of a relaxed kind, with affection taken for granted. [...] There may, however, be another reason for brevity in the notes to his wife: emotional strain occasioned by their daughter Tullia's changing fortunes and indifferent health. “ Vgl. a. SCHRÖDER 2018, 88 zu Fällen, „in which potential couriers announce their departure (and thus generate the opportunity to send letters along), but do so only at very short notice. [...] In such cases, the recipient would have been aware that the author had seized the opportunity to write something quickly and could assume that the letter would otherwise have been lengthier." Vgl. außerdem Kap. 2.2.1.3.4 zu den (RATENDEN) Briefen an Terentia kurz nach Ausbruch des Bürgerkrieges, deren Sachlichkeit wohl gerade durch die Sorge um seine Frau bedingt ist.

1572 Vgl. z. B. GUNDERSON 2007, 24f.: „Many of these letters [d. h. die späteren Briefe Ciceros an Terentia] are written on the same day as a letter to Atticus that is by no means brief. Cicero is not so pressed for time in general that he cannot write at all." Dagegen CLAASSEN 1996, 216: „It should be noted that most of the letters to Atticus written at this time (late 49 to mid 47) were not much longer [als die an Terentia], and were equally guarded in tone." Vgl. a. Kap. 2.1.2.4 zu möglichen Gründen für eine unterschiedliche Gestaltung der Briefe an Terentia und an Atticus. Dort (S. 209) wird u. a. darauf verwiesen, dass es bestimmte Themen gab, für die Terentia nicht der geeignete Gesprächspartner war. Vgl. außerdem S. 410. 
letzten Brief fam. 14.20 folgt, dessen unterkühlter Ton ziemlich offensichtlich ist - obgleich sogar hier noch einiges für ein weiterhin bestehendes Vertrauensverhältnis zwischen den Eheleuten spricht. ${ }^{1573}$

\subsection{Handlungsfunktionale Interpretation}

\section{Einzelhandlungen}

\section{Assertiva}

Der Gebrauch von Assertiva scheint - zumindest verglichen mit den anderen Sprechaktklassen - zunächst nur wenig über das Verhältnis zwischen Cicero und Terentia auszusagen. Tatsächlich gibt es aber einige Aspekte, die für eine Beurteilung durchaus aufschlussreich sein können.

Bei den reaktiven und re-initiativen Assertiva ist mit der Bezugnahme auf Äußerungen Terentias $^{1574}$ automatisch eine direkte Orientierung auf den Adressaten hin vorhanden. Dadurch, dass Cicero auf seine Frau eingeht, zeigt er ihr gegenüber Respekt. Dabei spielt die Beachtung von Höflichkeitskonventionen, mit denen Cicero Rücksichtnahme auf die Gefühle Terentias beweist, im Positiven, wie z. B. bei einer BESTÄTIGUNG des Empfangs ihrer Briefe, wie auch v. a. im Negativen, z. B. bei Ablehnungen, eine große Rolle. So STIMMT Cicero in fam. 14.19 dem Vorschlag Terentias, ihr entgegen zu reisen, zunächst einmal grundsätzlich ZU, weist ihn dann im Folgenden aber indirekt ab und BEGRÜNDET seine Entscheidung. In fam. 14.12 schlägt Cicero umgekehrt (in Form einer ANWEISUNG) ein Angebot Terentias aus, ihm entgegen zu reisen. Auch hier dienen BEGRÜNDUNGEN der Abschwächung des FTAs. Ein ähnliches Muster ist bei vielen Entschuldigungen zu erkennen, welche die Reaktion auf einen vorangehenden Vorwurf Terentias darstellen: Zuerst STREITET Cicero ihn AB, GIBT ihn dann evtl. doch ZU und BEGRÜNDET schließlich sein Verhalten, um so den Ärger seiner Frau abzudämpfen. Die Detraktiva, Konfirmativa und Argumentativa sind hier Bestandteil expressiver Sequenzen, was ihren starken Partnerbezug sowie allgemein die oft zu bemerkende Nähe der Assertiva zu den Expressiva verdeutlicht.

Die präsentativen Assertiva sind dagegen stärker sprecherbezogen, was u. a. durch die gelegentliche Referenz auf eigene Äußerungen aus früheren Briefen unterstrichen wird ${ }^{1575}$, haben aber ebenfalls einen klar erkennbaren Partnerbezug. Mit den Transmissiva (v. a. HINWEISEN und BENACHRICHTIGEN) und Assertiva i. e. S. (v. a. PROGNOSTIZIEREN) etwa befriedigt Cicero das Informationsbedürfnis seiner Frau und demonstriert zudem in weiten Bereichen Vertrauen. Reiseinformationen sind z. B. situativ bedingt ein wichtiger Bestandteil seiner Briefe. Dazu gehören u. a. auch die Datums- und Ortsangaben im Postskript, welche er im Unterschied zu anderen Adressaten in fast allen Briefen dazu setzt. ${ }^{1576}$

Selbst unter widrigen Umständen kommt Cicero seinen „ehelichen Auskunftspflichten“ nach, z. B. in fam. 14.5, als sein ganzes Denken und Handeln auf seine Rückkehr nach Italien ausgerichtet sind ${ }^{1577}$; und bis zuletzt erfüllt er sie wenigstens rudimentär. In fam. 14.20 übergeht er

\footnotetext{
${ }^{1573}$ Vgl. Kap. 2.1.1.4.

${ }^{1574}$ Vgl. fam. 14.5 .1 (9) und 14.19 (4), wo die Äußerungen Terentias explizit zitiert werden, was allerdings bei den Expressiva viel häufiger der Fall ist.

$1575 \mathrm{Vgl}$. fam. 14.13 (2) und 14.15 (3).

${ }^{1576} \mathrm{VgI}$. WHITE 2010, 76: „Half of the letters to Tiro and 80 percent of those to Terentia include a dateline, showing [...] that Cicero was more scrupulous about epistolary format with them than with anyone else."

${ }^{1577}$ Vgl. Kap. 2.1.2.
} 
zwar anscheinend einige wichtige Informationen, übermittelt aber doch immerhin das Wesentliche und zeigt gegenüber Terentia in ihrer Rolle als Hausherrin Achtung und Vertrauen. ${ }^{1578}$ Auffällig ist jedoch, dass die Zahl reaktiver und re-initiativer Sprechakte am Ende der Briefsammlung geringer wird. Am häufigsten begegnen sie in den Exilbriefen, allerdings wohl v. a. durch deren Länge bedingt. Ab Anfang 47 v. Chr. sind keine reaktiven oder re-initiativen Sprechakte mehr feststellbar. Begründungen wie in fam. 14.20 erfolgen präsentativ mit Sprechakten des Typs PROGNOSTIZIEREN, wobei aber schon die letzte re-initiative BEGRÜNDUNG in fam. 14.17 nicht als besonders höflich zu bezeichnen ist.

\section{Direktiva}

\section{Aufforderungshandlungen}

Je nach Situation und Interessenlage werden Aufforderungen mehr oder weniger höflich formuliert, abgemildert oder verstärkt, manchmal auch beides zugleich.

Bei sprecherpräferierten BITTEN kann die Abschwächung eines FTAs darauf hindeuten, dass der Sprecher auf die Unterstützung des Adressaten angewiesen ist und diesen milde stimmen will, aber ebenso darauf, dass der Sprecher große Sympathie für den Adressaten empfindet und deshalb besondere Rücksicht auf seine Gefühle nimmt. Letzteres könnte bspw. der Fall sein bei den BITTEN aus dem Jahr 49 v. Chr., die in einer Situation entstanden sind, in der sich Cicero große Sorgen um Terentia machte, wie z. B. die Anrede meae carissimae animae in fam. 14.14.2 (15) nahelegt. Allerdings sind die verwendeten sprachlichen Mittel zur Abmilderung insgesamt zu spärlich und damit kaum ausreichend für eine weitergehende Interpretation. Dies gilt auch für den Rest der Briefsammlung: Cicero schwächt seine BITTEN nur äußerst selten intraillokutionär ab. Lediglich die Bittformel velim in Verbindung mit dem Konjunktiv ist häufiger anzutreffen, hat aber im Vergleich zu alternativen Formulierungen kaum eine wirklich abmildernde Wirkung. Befindet sich Cicero in einer schwierigen Notlage und ist von Terentia abhängig, wie z. B. während des Exils, verstärkt Cicero seine BITTEN (z. B. mit Superlativen und verabsolutierenden Ausdrücken) vielmehr sogar und erhöht damit deren Dringlichkeitsgrad. Sowohl die Verstärkung als auch die weitgehend fehlende Abmilderung der BITTEN in dieser Zeit könnte man damit erklären, dass Cicero zu sehr auf sich selbst fokussiert ist. Dies trifft jedoch nur auf der Ebene der Einzelillokutionen so deutlich zu. In den Briefen finden sich an anderer Stelle ja durchaus adressatenbezogene Sprechakte und Wendungen, die große Zuneigung erkennen lassen. Ähnliches gilt für viele der späteren Briefe, wenngleich nicht ganz so deutlich, d. h., die Aufforderungen werden häufig verstärkt, was aber angesichts einer im Vergleich zur Exilzeit veränderten Situation meist eher auf eine Überlegenheit Ciceros deuten würde, der keinen Anlass mehr sieht, auf Terentias psychische Verfassung achtgeben zu müssen; und andererseits gibt es hier ebenfalls zusätzliche Sprechakte, welche die BITTEN weniger rüde erscheinen lassen, z. B. Kommissiva des Typs VERSPRECHEN oder sympathisierende Expressiva, die freilich am Ende selten über die konventionellen WOHLERGEHENSWÜNSCHE hinausgehen. Abgesehen davon, muss das Interesse, das ein Sprecher mit seiner BITTE verfolgt, nicht im Widerspruch zu Mitgefühl mit dem Adressaten stehen, wenn es sich nämlich gerade auf dessen Wohl richtet. In fam. 14.18.2 (13) BITTET Cicero bspw. Terentia eindringlich darum, ihn über ihr Schicksal auf dem Laufenden zu halten, und drückt damit große Angst um seine 
Frau aus, wodurch die Äußerung zugleich über eine eher unbedeutende konventionelle BITTE um Briefe hinausgeht.

Die ANWEISUNGEN aus der Exilzeit (fam. 14.4 und v. a. 14.2) wirken mit Wendungen wie obsecro te, mea vita oder si me amas und video in te esse omnia noch dringlicher als die BITTEN in fam. 14, wohingegen sie in den späteren Briefen nicht so stark intensiviert werden. Abschwächungen sind auf intraillokutionärer Ebene ebenfalls generell kaum anzutreffen, sondern werden auf die Teiltext- bzW. Gesamttextebene ausgelagert. ANWEISUNGEN werden bspw. durch expressive KOMPLIMENTE und (konventionelle) WOHLERGEHENSWÜNSCHE abgemildert oder, wie im Fall von fam. 14.12 (6), mit drei assertiven BEGRÜNDUNGEN der in Form einer ANWEISUNG geäußerten Ablehnung eines Angebotes Terentias. ${ }^{1579}$ Die (chronologisch letzten) ANWEISUNGEN in fam. 14.13 werden dagegen nicht einmal auf den übergeordneten Handlungsebenen abgeschwächt und stehen darüber hinaus (im Unterschied zu den Imperativen der Exilzeit und den späteren Konjunktiven) in einem sehr fordernd wirkenden Futur. Die relative Härte der ANWEISUNGEN ist ein wenig überraschend. Vielleicht sah Cicero keine Notwendigkeit zur Abschwächung der Aufforderungen, da mit ihnen ja übereinstimmende Interessen verfolgt wurden, er also nicht die Wohlgesonnenheit Terentias eigens befördern musste. Dass beide Eheleute in einem ständigen Austausch standen, wird z. B. in fam. 14.6 (4) deutlich, wo Cicero explizit Bezug auf eine Äußerung Terentias nimmt, die Teil eines Prozesses zur Erreichung eines gemeinsamen Zieles ist, das in diesem Fall in der Zahlung der Mitgift Tullias an Dolabella besteht. Obwohl bei ANWEISUNGEN im Prinzip eine symmetrische Situation vorliegt, scheint Cicero den superioren Part einzunehmen. Dies mag allerdings v. a. dem Ernst der Lage geschuldet sein.

In einer überlegenen Position befindet sich Cicero prinzipiell eigentlich erst recht, wenn er seiner in Rom zurückgebliebenen Frau (auf ihre Bitte hin) RÄT, wie sie sich angesichts der bedrohlichen Situation zu Beginn des Bürgerkriegs am besten verhalten sollte. Ciceros Äußerungen deuten aber tatsächlich mehr noch als bei den ANWEISUNGEN auf eine gleichberechtigte Partnerschaft hin. Insgesamt sind die (adressatenpräferierten) RATSCHLÄGE milder und weniger zielgerichtet formuliert als die ANWEISUNGEN und BITTEN in fam. 14. Teilweise äußert er sich ziemlich indirekt. Er betont mehrfach, die Entscheidung über ihr weiteres Vorgehen liege letztlich bei Terentia selbst, gibt nur ein paar Dinge zu bedenken und stellt verschiedene Alternativen in den Raum, ohne sie damit direkt in eine bestimmte Richtung zu lenken. Dies liegt möglicherweise darin begründet, dass die Sorge um Terentia im Widerstreit steht zur Verfolgung eigener Interessen wie dem Schutz seines Eigentums und dem Erhalt seiner Informationsquellen in Rom, was aber im Text nicht so deutlich gesagt wird. ${ }^{1580}$ Ähnliches gilt für die Verstärkungen, mit denen Cicero offenbar große Angst um seine Familie zum Ausdruck bringt, die also nicht erfolgen, weil Cicero selbst sich in einer Notlage befindet und dringend auf Hilfe angewiesen wäre, was aber nicht bedeutet, dass nicht auch hier eigene Interessen mit im Hintergrund stehen. Verstärkungen finden sich v. a. in fam. 14.18, als die Situation noch neu und die Familie emotional besonders aufgewühlt war, lassen allerdings in ihrer Intensität in den

\footnotetext{
1579 Vgl. das Kap. zu den „Assertiva“ ab S.402.

${ }^{1580}$ Vgl. z. B. fam. 14.18.2 (12) bzw. das Kap. zu den „Aufforderungshandlungen“ ab S. 300 insgesamt. 
beiden folgenden Briefen (fam. 14.14 und 14.7) immer weiter nach, während Abschwächungen umgekehrt zunehmen. ${ }^{1581}$

Die Unterschiede bei den ANWEISUNGEN und BITTEN können z. T. ebenfalls aus den zur Zeit der Briefabfassung jeweils gegebenen Umständen und Erforderlichkeiten, der entsprechenden emotionalen Verfassung Ciceros und den damit verbundenen Dominanzverhältnissen erklärt werden, müssen also nicht mit einer grundsätzlich veränderten Beziehung zwischen Cicero und Terentia zusammenhängen. Die ANWEISUNGEN während der Exilzeit sind z. B. besonders emotiv aufgrund der Verzweiflung Ciceros angesichts des nicht nur ihn, sondern die ganze Familie betreffenden Unglücks. Bei den stärker sachbezogenen ANWEISUNGEN in den späteren Briefen geht es um z. T. zwar sehr ernste, aber nicht ganz so existenzielle Angelegenheiten, bei denen Cicero seine Gefühle besser unter Kontrolle hat. Die vielen Verstärkungen und kaum bzw. gar nicht vorhandenen Abmilderungen der BITTEN sind in den Exilbriefen ebenfalls Ciceros desaströser Lage, in fam. 14.5 möglicherweise seinem Misstrauen gegenüber Philotimus (und nicht seiner Ehefrau), in den letzten Briefen evtl. Eile und Stress geschuldet. ${ }^{1582}$ Darüber hinaus ist zu bemerken, dass Cicero seine Aufforderungen an andere Adressaten nicht unbedingt „netter" formuliert ${ }^{1583}$ und außerdem zumindest die grundlegenden Höflichkeitsregeln bis zuletzt beachtet, wenngleich trotzdem bemerkenswert ist, dass die Sprechakte des Typs ANWEISEN und BITTEN in fam. 14.13 bzw. 14.20 einen eklatanten Mangel an beziehungsgestalterischen Elementen (auch auf den übergeordneten Ebenen) erkennen lassen. Sprechakte des Typs RATEN, die sich im Wesentlichen auf die erste Hälfte des Jahres 49 v. Chr. konzentrieren, finden sich in dieser späten Phase der Korrespondenz nicht. Auffällig ist in fam. 14 zudem die klare Überrepräsentanz des Untermusters BITTEN im Vergleich sowohl zu ANWEISEN als auch zu RATEN, was als Beleg für den recht stark ausgeprägten Egozentrismus Ciceros gesehen werden könnte.

\section{Fragehandlungen}

Fragehandlungen sind lediglich im ersten Exilbrief fam. 14.4 anzutreffen, weshalb deren Analyse und Interpretation keinen Aufschluss über eine evtl. Entwicklung des Verhältnisses zwischen Cicero und Terentia geben kann, sondern nur ein Schlaglicht wirft auf eine Ausnahmesituation am Anfang des Exils, die sich im Folgenden so nicht wiederholt. Mit den zwei problemzentrierten KOOPERATIONSFRAGEN will Cicero - ähnlich wie bei den ANWEISUNGEN ein gemeinsames Vorgehen mit Terentia in einer Angelegenheit abstimmen, die sie beide, in fam. 14.4.3 (25) außerdem ihre Tochter Tullia betrifft. Sie enthalten mehrere emotionale Komponenten, welche die Angst Ciceros um sich und seine Frau bzw. seine Tochter vermitteln. Damit verstärkt sich der Eindruck einer ehelichen Gemeinschaft in einer Lage, in der beide Partner aufeinander angewiesen sind. Sehr deutlich wird die Anteilnahme Ciceros am Schicksal seiner Frau naturgemäß zudem in der ANTEILNEHMENDEN FRAGE in fam. 14.4.4 (30). Nicht klar zu entscheiden ist, inwieweit er dabei auch die finanzielle Zukunft seiner Kinder und seine

\footnotetext{
${ }^{1581}$ Nach GUGLIELMI 2013, 229 bzw. ebd., 233 und JÄGER 1986, 255 ist die Expressivität dagegen umgekehrt in fam. 14.14 stärker als in 14.18, was man damit begründen kann, dass Cicero seine ohnehin aufgewühlte Ehefrau nicht noch mehr beunruhigen wollte: VgI. N. 1530.

1582 Allerdings ist es kaum wahrscheinlich, dass Cicero sich ab einem bestimmten Zeitpunkt im Unterschied zu vorher ständig in solchen Ausnahmesituationen befand.

${ }^{1583}$ Vgl. Kap. 2.1.1.4.
} 
eigene im Blick hat. Die sprachliche Oberfläche wenigstens signalisiert aber in allen drei Fällen Sorge um Terentia bzw. Tullia und Zuneigung für beide.

Kommissiva

In den Exilbriefen (fam. 14.1 und 14.3) verwendet Cicero Kommissiva des Typs ABSICHT BEKUNDEN, um Terentia über einen evtl. Wechsel seines Aufenthaltsortes oder auch andere (nicht näher bezeichnete) beabsichtigte Handlungen in Kenntnis zu setzen. In fam. 14.11 geht es um seine Pläne für den gemeinsamen Sohn. Die Kommissiva in fam. 14.5 belegen, dass Cicero seine Informationspflichten gegenüber Terentia sogar in Stresssituationen erfüllt. Sie deuten darüber hinaus - trotz der zugrunde liegenden Sprecherpräferenz - auf ein Bedürfnis nach Kooperation mit seiner Ehefrau hin, insofern Cicero es offensichtlich für wichtig erachtet, sich mit Terentia über seine Angelegenheiten zu beratschlagen. ${ }^{1584}$ Fam. 14.16 (6) hinterlässt dagegen einen zwiespältigen Eindruck. Möglicherweise versucht Cicero, seine Frau, der er ja immerhin zuvor sein BEDAUERN über das unangemessene Verhalten Volumnias BEKUNDET hat, zu beruhigen, indem er die Bedeutsamkeit des Vorgefallenen relativiert. Mehr noch wird jedoch der Anschein erweckt, Cicero werte die Sorgen Terentias ab und nehme sie nicht wirklich ernst.

Während Kommissiva des Typs ABSICHT BEKUNDEN ziemlich nüchtern wirken, sind solche des Typs VORSATZ BEKUNDEN (in fam. 14.1, 14.3 und 14.4) emotionaler und weniger selbstbezogen. Sie zeugen von dem zwischen den Eheleuten bestehenden Vertrauensverhältnis während des Exils. Cicero will aus Liebe zu Familie und Freunden sein widriges Schicksal ertragen und nicht aufhören zu kämpfen. Damit weisen sie im Prinzip eine z. T. große Nähe zu den adressatenpräferierten Kommissiva des Typs VERSPRECHEN auf.

Die VERSPRECHEN in fam. 14 beziehen sich allerdings meist auf eher unbedeutende Handlungen. Am häufigsten anzutreffen ist die Wendung faciam bzw. faciemus te certiorem, und zwar ausschließlich in den späteren Briefen. In fam. 14.1.7 (54) verpflichtet sich Cicero mit der alternativen Formulierung ad te scribam dazu, seine Frau pflichtgemäß auf dem Laufenden zu halten. In fam. 14.3.3 (16) bezieht sich Ciceros VERSPRECHEN auf eine unbestimmte Handlung; in fam. 14.2.4 (37) VERSPRICHT er dagegen konkreter, sich nicht in eine noch weiter entfernte Region zu begeben. Obwohl Cicero in all diesen Fällen einer (nicht immer unbedingt direkt ausgesprochenen) Bitte Terentias nachkommt, steht letztlich doch eher er selbst im Fokus. Eine Ausnahme bildet das VERSPRECHEN in fam. 14.7.2 (10), das am deutlichsten Empathie für Terentia erkennen lässt. Cicero kündigt an, Empfehlungsbriefe für Terentia und Tullia schreiben zu wollen, eine Maßnahme also, die tatsächlich v. a. im Interesse seiner Frau und nicht seinem eigenem liegt.

Insgesamt betrachtet sind die Exilbriefe ( $58 \mathrm{v}$. Chr.) demnach stark selbstfokussiert. Die informativen ABSICHTSBEKUNDUNGEN und die VERSPRECHEN belegen zugleich Ciceros Pflichtbewusstsein und unterstreichen seine Abhängigkeit von Terentia. Die VORSATZBEKUNDUNGEN lassen auch Zuneigung zu seiner Frau erkennen. Die ABSICHTSBEKUNDUNGEN in fam. 14.5 (50 v. Chr.) sind trotz des Eigeninteresses Ciceros von einem Gemeinschaftsgefühl der beiden Eheleute getragen. Das VERSPRECHEN in fam. 14.7 (49 v. Chr.) steht im Einklang mit dem Befund

${ }^{1584} \mathrm{Vgl.} \mathrm{Kap.} \mathrm{2.1.2.4.}$ 
einer im Vergleich zu den Briefen aus anderen Lebensphasen stärkeren Adressatenorientierung und Empathie. Die Kommissiva in den späteren Briefen (48 und v. a. 47 v. Chr.) dagegen erfüllen im Prinzip nur noch die grundlegendsten Erwartungen an einen Ehepartner, indem Terentia z. B. über den voraussichtlichen Verbleib ihres Sohnes in Kenntnis gesetzt wird. Meist wird sie - vielleicht aus Zeitmangel - mit hinhaltenden Floskeln vertröstet, in fam. 14.16 sogar mit ihren Bedürfnissen hintangestellt.

\section{Expressiva}

\section{Sympathisierende, opponierende und abreagierende Expressiva}

In fam. 14 gibt es keine opponierenden Expressiva, was auf ein insgesamt harmonisches Verhältnis zwischen Cicero und Terentia hindeutet. Es finden sich lediglich (neutrale) Zurückweisungen von Vorschlägen Terentias in Form assertiver bzw. direktiver Sprechakte. ${ }^{1585}$ Außerdem reagiert Cicero in fam. 14.1.4 offenbar auf einen Vorwurf Terentias, den er zunächst ABSTREITET, um seine Frau dann mit einer Erklärung bzw. BEGRÜNDUNG zu besänftigen. Kleinere Missstimmungen - welche Cicero sofort aus der Welt zu schaffen bemüht war - scheint es also durchaus gegeben zu haben, zumindest aufseiten Terentias. ${ }^{1586}$

Ciceros Antipathien richten sich eher gegen Dritte. Er drückt bspw. mehrfach Ärger über andere Personen aus (FLUCHEN). Damit entlädt er ebenso wie mit anderen abreagierenden Expressiva seine Gefühle und teilt sie zugleich seiner Frau mit. Solche Expressiva führen nicht wie die opponierenden Expressiva - zu einer Distanzierung, sondern tragen vielmehr zu einer Annäherung der beiden Eheleute bei. Ciceros Äußerungen beweisen sein Vertrauen in Terentia. Er kann davon ausgehen, dass sie wissen möchte, wie er sich fühlt, ob er bspw. fröhlich oder traurig ist und welche Hoffnungen und Ängste ihn bewegen (assertive Komponente). So kann sie seine Freude teilen bzw. ihm Trost spenden, ihm Mut machen usw. (direktive Komponente).

Terentias Interesse ergibt sich deutlich aus einigen ihrer Äußerungen, welche Cicero z. B. in fam. 14.4.5 (39): Tu quod me hortaris ut animo sim magno et spem habeam reciperandae salutis: ... und 14.3.3 (15): Ut tuto sim quod laboras: ... aufgreift. ${ }^{1587}$ Dabei handelt es sich um sympathisierende Expressiva, wie sie Terentia umgekehrt auch von Cicero erwarten kann. Durch den Ausdruck empathischen Mitempfindens stellt er direkter als mit den abreagierenden Expressiva eine intensive (positive) Beziehung zu ihr her.

Konventionalität und Individualisierung

Je stärker Cicero von den konventionellen Formeln abweicht, umso größere Wirkkraft entfalten seine Äußerungen, obgleich diesen ihre Aufrichtigkeit auch sonst nicht grundsätzlich abgesprochen werden kann. ${ }^{1588}$ Bei den Gruß- und Wohlergehensformeln wird bspw. zwischen den Untermustern BRIEF ERÖFFNEN bzw. BEENDEN und GUNST ERWEISEN bzW. WOHLERGEHEN WÜNSCHEN unterschieden, wobei man bei letzteren noch weiter danach differenzieren

\footnotetext{
1585 Vgl. die entsprechenden Kapitel zu den „Assertiva“ ab S. 402 und den „Direktiva“ ab S. 403. Vgl. a. WüEST 2011, 44 zu Kritik, Vorwürfen oder Beleidigungen als FTAs.

1586 Vgl. das Kap. zu den „Assertiva“ ab S. 402.

${ }^{1587} \mathrm{Vgl}$. a. fam. 14.2.3 (14) und 14.12 (2).

1588 Vgl. das Kap. „Expressiva mit beidseitiger Präferenz“ ab S. 346.
} 
kann, ob es sich nur um die Abwandlung einer gängigen Formel handelt oder einen (weitgehend) davon unabhängigen WOHLERGEHENSWUNSCH, mit dem Cicero z. B. seine Hoffnung auf Sicherheit und allgemeines Wohlbefinden seiner Frau bekundet. Solche speziellen WOHLERGEHENSWÜNSCHE lassen ganz besonders auf ein inniges Verhältnis zwischen Cicero und Terentia schließen. Die Verwendung von Gruß- und Wohlergehensformeln vermittelt aber selbst in ihrer Grundform in jedem Fall ein Mindestmaß an Achtung gegenüber der Ehefrau. ${ }^{1589}$ Darüber hinaus sollte man die besondere Bedeutung des Themas Gesundheit im Falle der an schwerem Rheuma leidenden Terentia berücksichtigen und die in fam. 14 verwendeten rituellen formulae valetudinis erst recht nicht automatisch bloß als leere Floskeln betrachten. ${ }^{1590}$ Die angeschlagene Gesundheit Terentias mag zudem eine Erklärung dafür sein, dass die Wohlergehensformeln (am Briefende) im Vergleich zu den Briefen an andere Adressaten überproportional oft und in einzelnen Briefen häufig sogar mehrfach verwendet und in verschiedener Form variiert werden. ${ }^{1591}$ Möglicherweise sieht Cicero in der Dopplung und individuellen Abwandlung auch einen einfachen Weg, Mitgefühl und Sympathie auszudrücken, ohne allzu viel Mühe zu investieren, wie es bei weniger stabilen Beziehungen zu anderen, außerhalb der engeren Familie stehenden Personen notwendig wäre. ${ }^{1592}$

\section{Das in fam. 14 entworfene Bild von Cicero und Terentia}

Mit den gerade genannten und weiteren sympathisierenden Expressiva mit beidseitiger Präferenz entwirft Cicero das Bild einer von ihm zärtlich geliebten Frau (GUNST ERWEISEN), die sich - im Kleinen wie im Großen - für ihn und andere eifrig sowie mit großer Tapferkeit einsetzt (BEGRÜSSEN und DANKEN bzw. KOMPLIMENT MACHEN) und für die er sich in jeder Hinsicht alles Gute erhofft (WOHLERGEHEN WÜNSCHEN). ${ }^{1593}$ Er selbst zeigt sich als aufmerksamer und mitfühlender Ehemann, der SORGE um seine Frau und BEDAUERN über das BEKUNDET, was man ihr angetan hat, $\mathrm{SICH}$ für seine eigenen Versäumnisse und Verfehlungen ENTSCHULDIGT und auch sonst in jeder Weise auf seine Frau eingeht. ${ }^{1594}$

Dieser Eindruck relativiert sich bei genauerer Betrachtung allerdings ein wenig. Darauf, dass Cicero das in fam. 14.16 (5) BEKUNDETE BEDAUERN durch seine ABSICHTSBEKUNDUNG in 14.16 (6) quasi entwertet, wurde bereits eingegangen. ${ }^{1595}$ Was die ENTSCHULDIGUNGEN betrifft, ist zu bemerken, dass Cicero z. B. in den Exilbriefen sein eigenes Versagen zwar eingesteht, seine Feigheit und Gutgläubigkeit beklagt und verständnisvolle Äußerungen Terentias,

\footnotetext{
1589 Vgl. WHITE 2010, 73.

1590 Vgl. z. B. CLAASSEN 1996, 221. Andererseits war Terentia ja nicht ständig krank; am Ende ist sie sogar bemerkenswert alt geworden. Vgl. a. WHITE 2010, 74.

1591 Vgl. White 2010, 74f. Er weist u. a. auch darauf hin, dass der ebenfalls oft kränkliche Tiro eine weitere Ausnahme bildet.

1592 Vgl. ebd., 75. Vgl. a. (zur üblichen Wohlergehensformel am Briefanfang) CLAASSEN 1996, 216 (s. N. 1571).

${ }^{1593} \mathrm{Vgl}$. a. die an anderer Stelle gebrauchten affektiven Anreden wie mea lux, meum desiderium in fam. 14.2.2 (22). Die Expressiva des Typs DANKEN beziehen sich wie auch einige des Typs BEGRÜSSEN z. T. auf eher unwesentliche Gefälligkeiten und Dienste Terentias wie z. B. ihre Schreibfertigkeiten: Vgl. das Kap. „Expressiva mit beidseitiger Präferenz" ab S. 346.

1594 Zur epistolographischen Selbstdarstellung allgemein vgl. z. B. LUDOLPH 1997, 30ff., der (mit Bezug auf Goffmans Face-Konzept und Bühlers Sprachfunktionen) zwischen expliziter Selbstdarstellung (Ausdrucksfunktion) und impliziter Selbstdarstellung (Darstellungs- und Appellfunktion) unterscheidet, und SCHRÖDER 2007, 154 (zum Topos „Brief als Spiegel der Seele“). Zur linguistischen Analyse der (individuellen und sozialen) Identitätskonstruktion in (mündlichen) Texten vgl. z. B. VAN DE MIEROOP 2017.

1595 Vgl. S. 406.
} 
die ihn zu verteidigen sucht, zurückweist. ${ }^{1596}$ Am Ende gibt er die tatsächliche Schuld jedoch anderen Personen, die ihn und seine Familie aus Torheit oder gar aus Missgunst und Niedertracht ins Unglück gestürzt hätten, obwohl ihm doch Dank und Anerkennung für seine großartigen Leistungen in der Vergangenheit zugestanden hätten (FLUCHEN). Außerdem schildert Cicero einerseits das Leid, welches Terentia seinetwegen zu tragen habe, in sehr lebhaften Farben und vermittelt durchaus glaubhaft aufrichtiges Mitleid mit ihr, andererseits verschwimmen die Grenzen zum Selbstmitleid, wie dies ähnlich in einigen Sprechakten des Typs BEDAUERN und SORGE BEKUNDEN, JAMMERN und ANGST ÄUSSERN zu beobachten ist, mit denen Cicero Kummer bzw. (un)gewisse Befürchtungen hinsichtlich des Schicksals anderer Personen äußert, zugleich aber sein daher rührendes eigenes Leid bzw. seine Ängste hervorhebt. Diese häufig zu bemerkende Selbstfokussierung muss dabei nicht im Widerspruch zur Authentizität der Gefühle Ciceros stehen, von der man gerade in Bezug auf die Kinder sicherlich ausgehen kann.

Bei den meisten Expressiva mit Sprecheraversion ist ebenso wie bei denen mit Sprecherpräferenz Cicero selbst der von dem zugrunde liegenden Sachverhalt Betroffene. Als uneigennützig sind nur wenige Äußerungen zu bewerten, die v. a. seine Kinder betreffen, z. B. der in fam. 14.1.5 (43) geäußerte Wunsch nach einer guten Zukunft für seinen Sohn (HOFFNUNG ÄUSSERN) und die damit kontrastierenden ANGSTÄUSSERUNGEN im selben Brief. Fam. 14.4.2 (13) bezieht sich dagegen zwar ebenfalls auf das Wohl eines Dritten (M. Laenius Flaccus), ist allerdings begründet in den Cicero erwiesenen Diensten. Das Untermuster JUBELN findet sogar ausschließlich Verwendung in Bezug auf Personen, die in irgendeiner Weise in Ciceros Sinne und zu seinem Vorteil gehandelt haben. ${ }^{1597}$ Selbstlose Freude ist kaum anzutreffen, v. a. nicht in Form eigenständiger Sprechakte. Ein Beispiel ist evtl. fam. 14.6 (5), wo Cicero Freude über Terentias Einsatz für Tullia zum Ausdruck bringt, wobei die Freude v. a. im Hinblick auf seine Tochter selbstlos ist, wohingegen das KOMPLIMENT für Terentia auch als Teil der spekulativen Hierarchie des Briefes gesehen werden muss. Der Sprechakt gehört zu den Expressiva mit beidseitiger Präferenz, bei denen ebenfalls meistens Cicero der - in diesem Fall von Terentias Handlungen - (positiv) Betroffene ist. ${ }^{1598}$

Die abreagierenden Expressiva überwiegen mit 97 Illokutionen leicht gegenüber den sympathisierenden mit 89. Diese Überrepräsentanz ist allerdings zu schwach ausgeprägt, um daraus weitergehende Schlüsse wie etwa eine evidente Selbstbezogenheit Ciceros ableiten zu können. Etwas augenfälliger ist die Verteilung von positiven und aversiven Sprechakten in beiden Gruppen. Bei den sympathisierenden Expressiva liegt das Verhältnis, bedingt v. a. durch die Vielzahl konventioneller WOHLERGEHENSWÜNSCHE, bei 61 zu $28^{1599}$, bei den abreagierenden beträgt es 43 zu 54. Dabei ist noch zu berücksichtigen, dass z. T. nur eingeschränkt eine Sprecherpräferenz i. e. S. vorliegt. Dies könnte man so deuten, dass Cicero darum bemüht ist,

\footnotetext{
1596 Vgl. fam. 14.1.1 (7). Vgl. a. Prost 2015, 13 zu den Pflichten eines pater familias: Seine Aufgabe war es v. a., für das Wohl seiner Angehörigen zu sorgen.

${ }^{1597}$ Dies gilt z. B. auch für die Bewunderung der Leistung von Acastus in fam. 14.5.1 (7), da Cicero ja von einem schnellen Brieftransport profitiert. Nicht ausgeschlossen ist dabei, dass weitere Personen einen Vorteil vom betreffenden Sachverhalt haben, wie z. B. in fam. 14.3.3 (20).

${ }^{1598}$ So sind z. B. auf Dritte bezogene KOMPLIMENTE seltener als Expressiva des Typs BEGRÜSSEN.

${ }^{1599}$ Von den 61 sympathisierenden Expressiva mit beidseitiger Präferenz entfallen 44 auf WOHLERGEHENSWÜN$\mathrm{SCHE}$, von denen lediglich 9 nicht konventionell geprägt sind.
} 
positiv auf Terentia einzuwirken, sich selbst in schwierigen Lebensphasen wie dem Exil hingegen nur mit Mühe aufrechthalten kann, was er ja selbst in fam. 14.4 .5 (47) eingesteht: atque ego, qui te confirmo, ipse me non possum.

Der Egozentrismus Ciceros, der sich im Übrigen in den meisten Schreiben auch in der Überzahl von Ich- bzw. Wir-Aussagen gegenüber Du- bzw. Ihr-Aussagen spiegelt ${ }^{1600}$, schließt selbstverständlich nicht aus, dass er seiner Frau wirkliche Zuneigung entgegenbringt, sich über ihre Tugenden freut, den Wunsch hegt, ihr möge es gut gehen usw. Wie weit Cicero darüber hinaus (bewusst oder unbewusst) eine bestimmte Strategie verfolgt, lässt sich nicht abschließend beurteilen; es ist aber kaum zu leugnen, dass in den Briefen eine subtile Beeinflussung Terentias stattfindet. ${ }^{1601}$ Die Darstellung in fam. 14 weicht z. B. auffällig ab von der in Briefen an andere Adressaten, begründet evtl. in einem gewissen Schamgefühl gegenüber Dritten. ${ }^{1602}$ In fam. 14.1 - 14.4 wird Cicero bspw. als liebevoll, sensibel, v. a. aber bedauernswert und hilflos geschildert, Terentia auf der anderen Seite als zwar auch beklagenswerte, v. a. jedoch bewunderungswürdige, selbstlose und starke Frau. Cicero ist demnach nicht nur auf Unterstützung angewiesen, sondern hat sie auch verdient, während Terentia ohne Weiteres in der Lage und moralisch quasi dazu verpflichtet ist, ihm diese zu leisten. ${ }^{1603}$ Gegenüber anderen Adressaten wird hingegen Terentia als diejenige herausgestellt, welche der Hilfe bedarf. Zudem finden sich keine so deutlichen Liebesbekundungen. Hier wie dort ist Cicero also darauf bedacht, seine Frau und sich selbst in einem bestimmten Licht erscheinen lassen.

\section{Entwicklung der Beziehung}

Alle vier Exilbriefe (fam. 14.1 - 14.4) wirken - ähnlich wie die Briefe an Quintus und anders als die oft stärker reflektierenden Briefe an Atticus aus dieser Zeit (58 v. Chr.) - äußerst emotional. ${ }^{1604}$ Dies lässt auf eine große Intimität zwischen den Eheleuten schließen, evtl. aber auch darauf, dass Terentia für einige Themen nicht der richtige Ansprechpartner war, es also durchaus Unterschiede zwischen ehelicher Partnerschaft und Freundschaft gab. ${ }^{1605}$ Cicero scheint

\footnotetext{
1600 Vgl. die umfassenden Analysen von JäGER 1986. Vgl. außerdem die Beispielanalysen in Kap. 2.1. Dabei sind natürlich auch die anderen Sprechaktklassen miteinzubeziehen.

${ }^{1601}$ Direkter erfolgt die persuasive Einwirkung in Äußerungen wie fam. 14.2.3 (32), die entsprechend als direktive ANWEISUNG klassifiziert wird, obwohl die Formulierung auf den ersten Blick mehr einem WOHLERGEHENSWUNSCH ähnelt. Dagegen ist die persuasive Komponente in Äußerungen, die tatsächlich dem expressiven Untermuster WOHLERGEHEN WÜNSCHEN zugeordnet werden, nicht so dominant, aber durchaus vorhanden.

1602 Vgl. z. B. GuglielMI 2013, 169 (mit Bezug auf die Exilbriefe). Vgl. a. JePPESEN-WIGELSWORTH 2013, 357ff., die analysiert hat, in welcher Weise Terentia in Ciceros Briefen und Reden in Erscheinung tritt. Dabei stellt sie $u$. a. fest, dass Terentia in einem eher öffentlichen Rahmen - als rhetorisches Mittel - mit Bezeichnungen wie misera, raptata oder exanimata, aber auch fidissima coniunx bzw. uxor versehen wird.

1603 Vgl. a. GUGLIELMI 2013, 169 zur persuasiven Ausgestaltung der Exilbriefe: „Il fatto che Cicerone applichi questi procedimenti di carattere persuasivo anche nelle lettere alla moglie vuol dire che egli la ritiene senz'altro in grado di agire in suo favore, proprio allo stesso modo di Attico e di Quinto: è l'oratore stesso che loda la donna per il suo impegno e per la sua forza d'animo, dimostrandole tutta la propria stima e la propria fiducia. "Vgl. außerdem HUTCHINSON 1998, 47f. (bzw. N. 1075) sowie PROST 2015, 20f., der darlegt, es sei Cicero trotz der Sehnsucht nach Wiedervereinigung mit seiner Familie ganz recht gewesen, dass Terentia und andere Angehörige in Rom blieben, weil sie sich dort besser für seine Rehabilitierung einsetzen konnten. Vgl. außerdem WHITE 2010, 76 zur Funktion Terentias als Nachrichtenübermittlerin.

1604 Vgl. z. B. JÄGER 1986, 112 und GUGLIELMI 2013, 168f. sowie - mit teilweise etwas anderer Einschätzung (eines Briefes an Quintus) - HUTCHINSON 1998, 47.

1605 Vgl. a. S. 209 (zu fam. 14.5).
} 
auf jeden Fall ein großes Bedürfnis nach Nähe gehabt zu haben, wie der hohe Anteil an Expressiva in den recht ausführlichen Briefen an seine Frau belegt. Er liegt bei ca. 58,5\% aller Sprechakte (113 / 193) und damit um 13,5 \% höher als im Durchschnitt aller Briefe. Mit 78 zu 35 Illokutionen ( $\approx 69 \%$ ) überwiegen eindeutig die abreagierenden gegenüber den sympathisierenden Expressiva (einschließlich der konventionellen Formeln!), wohingegen das Verhältnis in der Briefsammlung insgesamt mit 97 zu $89(\approx 52 \%)$ recht ausgewogen ist. Die Exilbriefe erfüllen also in erster Linie eine kathartische Funktion und dienen Cicero dazu, sich seiner v. a. aversiven ( 45 / $78 \approx 58 \%$ ) - übermächtigen Gefühle zu entladen.

Die starke Selbstfokussierung schlägt sich außerdem in einer Vielzahl von Ich-Aussagen nieder. ${ }^{1606}$ Dennoch erscheint Cicero insgesamt eher passiv, Terentia trotz relativ weniger expliziter Du-Aussagen und mehrerer unpersönlicher Aussagen, in denen sie $u$. a. als bedauernswertes Opfer dargestellt wird, als aktiverer Part. ${ }^{1607}$ Mit sympathisierenden Expressiva, in denen er große Zuneigung (GUNST ERWEISEN, KOMPLIMENT MACHEN, BEGRÜSSEN) und Empathie zum Ausdruck bringt, sucht Cicero sie in seinem Sinne zu beeinflussen, um Trost und anderweitige Unterstützung zu finden. Dabei überwiegen ebenfalls aversive Sprechakte (20 / 35 $\approx 57 \%$ ), bedingt v. a. durch die große Zahl von ENTSCHULDIGUNGEN, mit denen Cicero, ebenso wie mit vielen Expressiva des Typs BEDAUERN und SORGE BEKUNDEN, immer wieder die Grenze tangiert zum selbstmitleidigen JAMMERN, sodass sogar hier eine starke Selbstbezogenheit erkennbar wird.

Überhaupt bleibt oft unklar, wie weit Ciceros Sorge und seine guten Wünsche auf Terentias oder nicht doch eher auf sein eigenes Wohl gerichtet sind. Schließlich ist die finanzielle und gesundheitliche Situation seiner Frau entscheidend für die so inbrünstig erhoffte Rückkehr nach Rom und seine Rehabilitation. Dies zeigt sich auch in Äußerungen wie fam. 14.2.3 (29) und (34) sowie 14.1.5 (35), wo tatsächlich von einer Dominanz der eigenen Interessen ausgegangen wird (ANGST ÄUSSERN), wobei Cicero aber teilweise wohl außerdem die Zukunft des gemeinsamen Sohnes im Auge hat. Hier und in einigen anderen (abreagierenden) Expressiva sind die Kinder Betroffene des jeweiligen Sachverhalts, meistens steht jedoch Cicero selbst im Blickpunkt. Nur selten (wie z. B. in fam. 14.4.1 (8) und (9)) sieht er sich und Terentia als eine Einheit.

Ciceros Brief kurz vor der Rückkehr aus Kilikien ( 50 v. Chr.) ist zwar ebenfalls stark selbstfokussiert, was sich in einer sehr hohen Anzahl von Ich-Aussagen spiegelt ${ }^{1608}$, wirkt allerdings nüchterner als die Exilbriefe. Die Expressiva spielen mit 9 von insgesamt 29 Illokutionen ( $~ 31 \%$ ) eine weitaus geringere Rolle. Abreagierende und sympathisierende Expressiva, die in einem

\footnotetext{
${ }^{1606}$ Vgl. a. CLAASSEN 1999, 27f. (zu Ciceros Exilbriefen allgemein): „Although he frequently acknowledges receipt of letters, the impression is of a drawn-out monologue, not conversation. Cicero is the ,exiled $\mathrm{I}^{\prime}$, the centre of a dislocated universe where the hub is out of the kilter. His correspondents exist only as sounding boards for his misery. [...] Pure solipsism is reflected by the predominance of first person verbs and pronouns. Verbs in the second person, implying the other half of ,sermo absentis', the addressees of his many letters from exile, are important only in their subjective relation to the exile. On occasion he employs third person narrative to portray the villainy of those who had brought him down. The letters, written almost as a journal at the height of his troubles, reflect Cicero's daily fluctuations of hope, despair, misery and grief. [...] the banished man is wrapped in a self-imposed cocoon of misery."
}

1607 Vgl. Kap. 2.1.3.

${ }^{1608}$ Vgl. Kap. 2.1.2. 
recht ausgewogenen Verhältnis ( 4 zu $5 \approx 44,5 \%$ bzw. 55,5 \%) zueinander stehen, thematisieren keine existenziellen Probleme, vermitteln aber gleichwohl Zuneigung und Vertrautheit. Darüber hinaus wird mit ihnen die Wohlgesonnenheit Terentias befördert und damit bspw. ihre Bereitschaft, sich um die Erbschaftssache Precius zu kümmern. Cicero freut sich über den schnellen Brieftransport durch Acastus (JUBELN), hofft, schnell und wohlbehalten in Italien einzutreffen (HOFFNUNG ÄUSSERN), und verleiht seiner (selbstlosen) Trauer über den Tod von Precius Ausdruck (JAMMERN). Er rühmt die Schreibkünste seiner Frau (BEGRÜSSEN und DANKEN), geht aber anscheinend geflissentlich über eine leichte Verstimmtheit Terentias wegen seiner Schreibfaulheit hinweg. Brieferöffnung und -beendigung beschränken sich auf die konventionellen (deklarativen) Grußformeln, sind allerdings um jeweils einen zusätzlichen WOHLERGEHENSWUNSCH erweitert. Insbesondere fam. 14.5.2 (27) ist von hoher Affektivität geprägt.

Die drei Briefe vom Anfang des Bürgerkrieges (49 v. Chr.), besonders fam. 14.18 und 14.14, also die beiden ersten, sind von allen Schreiben der Briefsammlung fam. 14 mit Abstand am stärksten adressatenorientiert bzw. am wenigsten selbstfokussiert. Im Vordergrund steht die Sorge Ciceros um Terentia (und Tullia), obschon auch eher egoistische Motive wie der Schutz seines Eigentums stellenweise nicht auszuschließen sind. Diesen Befund bestätigt - neben der Analyse der Ich- / Wir-Aussagen im Vergleich zu den Du- / Ihr-Aussagen - die Distribution der Sprechakte bzw. der einzelnen Untermuster. ${ }^{1609} 21$ von 27 Expressiva, also fast $78 \%$ sind sympathisierend, nur 6 abreagierend, und selbst diese konzentrieren sich vielfach nicht auf Cicero allein, sondern schließen z. B. die Tochter (fam. 14.7.1 (4)), den Sohn (fam. 14.7.2 (8)), die ganze Familie oder sogar den gesamten Staat (fam. 14.14.2 (13) und (14) sowie 14.7.2 (13)) mit ein. Mit den sympathisierenden Expressiva versucht Cicero, Terentia seines Beistands und Mitgefühls zu versichern und ihr v. a. Mut zu machen: Cicero verwendet - in fam. 14.18 und 14.14 sogar extrem - affektive Begrüßungsformeln (GUNST ERWEISEN) und lobt Terentias Tapferkeit (KOMPLIMENT MACHEN). Auffällig sind die vielen - zusätzlich zu den rituellen Wohlergehensformeln verwendeten - nicht-konventionellen WOHLERGEHENSWÜNSCHE: 6 von insgesamt 9 dieser Illokutionen sind Bestandteil der drei Briefe aus dem Jahr 49 v. Chr. Mit ihnen äußert er seine Hoffnung, es möge Frau und Tochter gut gehen. Das Untermuster SORGE BEKUNDEN, das in fam. 14 gleichfalls insgesamt nur 9-mal anzutreffen ist, findet sich allein 6-mal in fam. 14.18 und 14.14. Mit 27 von 52 Illokutionen (52 \%) sind die Expressiva zwar nicht so stark wie in den Exilbriefen vertreten, liegen aber dennoch recht deutlich über dem Gesamtdurchschnitt.

Die späteren Briefe aus den Jahren 48 und 47 v. Chr. stellen ungeachtet ihrer durchgehenden Kürze keine homogene Gruppe dar und müssten für eine genauere Interpretation detaillierter und differenzierter unter die Lupe genommen werden, als dies der folgende kurze Überblick leisten kann. Was sofort ins Auge fällt, ist aber zumindest, dass der Anteil der Expressiva mit 37 von 138 Illokutionen ( $\approx 27 \%$ ) drastisch unter dem Durchschnitt liegt, im Vergleich des Jahres 48 v. Chr. (12 / $40 \approx 30 \%)$ zum Jahr 47 v. Chr. (25 / $98 \approx 25,5 \%)$ sogar noch weiter sinkt.

\footnotetext{
${ }^{1609}$ Vgl. z. B. JÄGER 1986, 252f. (zu fam. 14.18): „Wie sehr der Ton dieses Briefes von Mitgefühl und Einfühlungsvermögen bestimmt ist, erkennt man auch daran, daß Cicero nur selten von sich spricht. Seine Überlegungen sind überwiegend adressatenorientiert durch die zahlreichen Wir- und Ihr-Aussagen."
} 
Hinzu kommt, dass sie hauptsächlich durch konventionelle WOHLERGEHENSWÜNSCHE repräsentiert werden, die allein 23 Illokutionen ( $\approx 62 \%$ ) ausmachen. Dadurch relativiert sich auch der Eindruck eines auf den ersten Blick erheblich höheren Anteils von sympathisierenden Expressiva (28) im Vergleich zu den abreagierenden Expressiva (9). ${ }^{1610}$

Nichtsdestotrotz gibt es einzelne (Kontakt-)Briefe, in denen die Expressiva dominieren, wenngleich die Äußerungen oft recht allgemein gehalten sind und (auf der Sprachoberfläche) nur selten dezidiert über die reine Konventionalität hinausgehen, was ihrer Emotionalität allerdings nicht unbedingt abträglich sein muss. In fam. 14.9 wird z. B. die Begrüßungsformel nur leicht variiert, kann aber dennoch als expressiv bewertet werden (GUNST ERWEISEN). Der WOHLERGEHENSWUNSCH ist ebenso recht konventionell gestaltet, gewinnt jedoch vor dem Hintergrund der Krankheit Tullias und Dolabellas, über die Cicero aufrichtig betrübt zu sein scheint (JAMMERN), aktuelle Bedeutung. Die Vagheit der ANGSTÄUSSERUNG macht die Ratlosigkeit Ciceros deutlich. Vereinzelte Expressiva finden sich außerdem in einigen Informations- und Aufforderungsbriefen. Teilweise sind sie sogar sehr eindringlich und emotiv formuliert, wie z. B. die Sprechakte des Typs JAMMERN in fam. 14.19 (2) und 14.11 (4), die sich (ebenfalls) auf den Gesundheitszustand von Ciceros geliebter Tochter Tullia beziehen.

Abgesehen von den konventionellen Wohlergehensformeln und dem recht belanglosen FLUCHEN in fam. 14.10 ist fam. 14.11 (4) im Übrigen auch der letzte expressive Sprechakt in fam. 14. Dies würde der These entsprechen, wonach sich der Ton zwischen Cicero und Terentia erst im Anschluss an fam. 14.11 (14.06.47 v. Chr.) auffallend ändert. ${ }^{1611}$ Zu bedenken ist dabei allerdings, dass sich die Äußerung auf Tullia und nicht Terentia bezieht. Die letzten expressiven Sprechakte mit Bezug auf Terentia (BEGRÜSSEN und DANKEN) finden sich im Kontaktbrief fam. 14.8 (02.06.47 v. Chr.), also vier Monate vor dem letzten Brief fam. 14.20 (01.10.47), in dem Cicero im Prinzip gar nicht mehr (expressiv) auf seine Frau eingeht und sogar die in den unmittelbar vorangehenden Schreiben so häufig anzutreffenden zusätzlichen konventionellen Wohlergehensformeln fehlen. ${ }^{1612}$

\footnotetext{
${ }^{1610}$ Zu den Wohlergehensformeln in den letzten Briefen Ciceros an Terentia vgl. a. GUNDERSON 2007, 26f.: „In the place of the potentially explosive complaints that Cicero might level against his wife, we read [in fam. 14.8] instead the wish, the admonition, and the command: ,Take care!' And if she does not take care (cura ut valeas), then it is good-bye (vale). This same reading can be used with more or less the whole mass of letters from 48 and 47. The valetudo that Terentia was asked to look after in 49 becomes the mantra of this period. [...] As goes Terentia's health, so goes the marriage. There is nothing left to talk about other than this two-fold health even as the manifest talk is only of a simple body health. “Speziell zur Formel „s. v. b.; e. v." vgl. außerdem WHITE 2010, 73, der die These in ADAMS 1978, Cicero würde damit bewusst Distanz zu Terentia schaffen, zurückweist: „Cicero would not have allowed himself if he were delivering an overt rebuff. Here as elsewhere, the formula is best seen as a warrant of epistolary propriety. Although much of its communicative value had leached away by Cicero's time, it always carried the sanction of formal correctness. [...] And in the letters to Terentia? Perhaps it was a tic. Two-thirds of the seventeen letters in which Cicero uses the formula are addressed to her, and the less he found to say her, the more often he resorted to it. [...] The problem with Cicero's letters from his wife's vantage point might have been that they communicated little more than civility. The epistolary proprieties would have sounded not so much brusque as hollow. "Zu unterschiedlichen Auffassungen über die Verwendung der Formel in Abhängigkeit vom Adressaten bzw. dem zu ihm bestehenden Grad an Vertrautheit vgl. darüber hinaus GUGLIELMI 2013, 210 N. 2.
}

${ }^{1611}$ Vgl. Kap. 2.2.2.2.1 (S. 399).

${ }^{1612} \mathrm{Vgl}$. Kap. 2.1.1. 
Aus der Analyse der Expressiva lässt sich also keine durchgehende Abwärtsentwicklung ableiten, gewisse Tendenzen sind jedoch unübersehbar: Die innigste Verbindung zwischen Cicero und Terentia kommt in den drei Briefen vom Beginn des Bürgerkrieges (49 v. Chr.) zum Ausdruck. Sie sind eindeutig am stärksten adressatenorientiert. Die einige Jahre früher geschriebenen Exilbriefe (58 v. Chr.) sind sichtlich emotiver, aber stark egozentrisch ausgerichtet. Der vor der Rückkehr aus Kilikien (50 v. Chr.) entstandene Brief fam. 14.5 ist ebenfalls sehr selbstfokussiert, darüber hinaus allerdings nüchterner, enthält indes trotzdem deutliche affektive Elemente, die auf großes Vertrauen und Zuneigung deuten, wie es auch in vielen späteren Briefen (48 / 47 v. Chr.) zunächst noch öfter anklingt. Ab spätestens Anfang oder Mitte Juni 47 v. Chr. scheint sich das Verhältnis dann tatsächlich abzukühlen. Mit fam. 14.20 ist der endgültige Tiefpunkt erreicht.

\section{Teiltexthandlungen}

Die Art, wie ein Autor seinen Text aufbaut, wirft insoweit Licht auf sein Verhältnis zum Adressaten, als das Bemühen um Klarheit eine gewisse Zugewandtheit und Rücksichtnahme aufzeigt. ${ }^{1613}$ Wichtig ist eine deutlich fassbare hierarchische Grundstruktur der Handlungseinheiten, die zwar durchaus assoziativ aneinandergereiht werden können; ein kaum nachvollziehbarer unmotivierter Wechsel sollte aber vermieden werden. An diese Vorgaben hält sich Cicero im Prinzip in sämtlichen Briefen an seine Frau, sogar in den emotionalen Exilbriefen (wie z. B. fam. 14.2). Dabei kann im Übrigen auch die Länge der Briefe relevant sein, weil damit i. A. ein entsprechender Komplexitätsgrad einhergeht. Bei einem ausführlicheren Schreiben besteht bspw. eher die Gefahr, dass es unübersichtlich und damit unverständlich wird. Diese kann durch die passende und nicht übermäßige Verwendung stützender Sprechakte und intraillokutionärer Wendungen verringert werden.

Cicero versucht in der Tat oft, die Verständlichkeit seiner Äußerungen durch präzisierende und (v. a. in den längeren Briefen) relativierende Spezifizierungen zu erhöhen. Dem widerspricht eine gelegentliche bewusste Unklarheit nicht, wenn eine solche nur für Außenstehende gegeben ist, wie z. B. in fam. 14.13 (3) und 14.14.1 (4), wo Cicero den Namen von Dolabella bzw. Cäsar auslässt. Sie kann vielmehr als Zeichen der Vertrautheit gelten. ${ }^{1614}$ Neben inhaltlichen und sprachlichen Erläuterungen sind außerdem Begründungen zur Steigerung der Akzeptanz häufig. Selbst in fam. 14.20 finden sich trotz des knappen Raums klärende bzw. argumentative Erweiterungen. Der brüske Ton dieses Briefes wird so allerdings kaum abgemildert. Auch die informelle Umgangssprache, wie sie in allen Briefen in fam. 14 vorherrscht, trägt kaum zu einer positiven Grundstimmung bei. Dies liegt v. a. am weitgehenden Mangel an (weiteren) beziehungsgestalterischen Elementen im Sinne einer captatio benevolentiae. Cicero verwendet z. B. keine (affektiven) Anreden und keine Bittformeln, sondern lediglich die üblichen Grußformeln.

Allgemein lässt sich sagen, dass eine individuell abgewandelte Äußerung deutlicher ein inniges Verhältnis der Korrespondenten anzeigt als rein konventionelle Formeln, auch wenn sie quantitativ stärker vertreten sind, wie z. B. die gerade in den späteren Briefen oft anzutreffenden

\footnotetext{
1613 Natürlich nehmen auch die rhetorische Vorbildung und Gewandtheit des Autors Einfluss auf die Darstellung. 1614 Daneben können Sicherheitsaspekte eine Rolle spielen.
} 
zusätzlichen Wohlergehensformeln. ${ }^{1615}$ Ähnliches gilt für größere Handlungseinheiten. Höflichkeitsrituale sind im alten Rom offenbar äußerst bedeutsam, was sich in fam. 14 darin niederschlägt, dass konventionelle Sequenzen wie Empfangsbestätigungen und Entschuldigungen für das Ausbleiben oder den begrenzten Umfang von Briefen oft breiteren Raum einnehmen als die Darlegung des eigentlichen Anliegens. ${ }^{1616}$ Allein schon die Beachtung der Konventionen beweist eine gewissen Achtung vor Terentia. Die im Vergleich zu anderen, Cicero weniger nahe stehenden Adressaten individuellere Formulierung z. B. von Entschuldigungen ist Zeichen einer generell größeren Intimität. ${ }^{1617}$ Diese erhöht sich noch, je weiter die Äußerungen über die üblichen Konventionen hinausgehen. So finden sich in den Exilbriefen auch sehr persönliche Entschuldigungen für das (mittelbar) durch Cicero verursachte Unglück seiner Familie, das für ihn noch unerträglicher sei als sein eigenes. Cicero wird von einem schlechten Gewissen gedrückt, weil er seine Aufgabe als pater familias nicht erfüllt habe. ${ }^{1618}$ Dies wiegt umso schwerer, als seine Empfindungen gegenüber Frau und Kindern anscheinend über ein reines Pflichtgefühl hinausgehen. Mehrfach bringt er seine Zuneigung und Liebe zum Ausdruck, indem er bspw. deren Tugenden rühmt, welche ihr gegenwärtiges Leid umso schlimmer machten.

Cicero bemüht sich in all seinen Briefen an Terentia um Verständlichkeit, Akzeptanz und Wohlgesonnenheit. Keiner der 24 Briefe kann als wirklich unhöflich gelten. Damit vermittelt Cicero eine grundlegende und durchgehende Wertschätzung gegenüber Terentia. Zugleich liegen solchen Handlungsstrategien aber meist noch weitergehende Absichten zugrunde. Aufrichtige Sympathie und Empathie sind kaum klar abzugrenzen von persuasiven Verfahren zur Erreichung egoistischer Ziele. ${ }^{1619}$ Die Exilbriefe lassen bspw. sehr positive Gefühle für Terentia und großes Vertrauen in seine Ehefrau erkennen, ebenso aber eine starke Abhängigkeit von ihr, was alles die sprachliche, inhaltliche und funktionale Ausgestaltung der Briefe beeinflusst. $\mathrm{Ci}$ cero schwächt seine Äußerungen z. B. mit relativierenden Sprechakten ab oder verstärkt sie mit Spezifizierungen, um ihren Einsatz in seiner Sache zu befördern. Er erklärt präzise, was er meint und will, um sicherzustellen, dass Dinge genau nach seinen Vorstellungen geregelt werden.

Wenn man die Briefsammlung fam. 14 als Ganzes in den Blick nimmt, ist auf der Teiltextebene eine kontinuierliche Abwärtsentwicklung der Beziehung von Cicero und Terentia nicht eindeutig auszumachen. Lediglich eine eingeschränkte sekundäre Hierarchie, d. h. die Vernachlässigung beziehungsgestalterischer Elemente, liefert evtl. gewisse Anhaltspunkte für eine Verschlechterung der Beziehung. So wird in fam. 14.20 nur ein Mindestmaß an Höflichkeitsregeln beachtet, wobei aber auch hier der Einfluss bestimmter situativer Faktoren nicht außer Betracht bleiben sollte, die nicht unbedingt mit der Person Terentias bzw. Ciceros Verhältnis zu ihr verknüpft sind. Die Kürze allein ist jedenfalls nicht auschlaggebend, wie z. B. der sehr überschaubare Kontaktbrief fam. 14.9 zeigt.

\footnotetext{
${ }^{1615}$ Vgl. das Kap. zu den „Einzelhandlungen“ ab S. 402.

1616 Zum i. A. stärkeren Fokus auf der positiven Höflichkeit in Rom, dem allerdings die sprachliche Gestaltung vieler Direktiva zuwiderläuft, vgl. z. B. DICKEY 2016, 209 und DICKEY 2012b, 321. Vgl. a. S. 383.

1617 Vgl. ROESCH 2004, 151.

1618 Vgl. N. 1596 bzw. Prost 2015, 13.

${ }^{1619}$ Vgl. a. N. 1603.
} 


\section{Gesamttexthandlungen}

Betrachtet man die drei in Kap. 2.1 analysierten Briefe fam. 14.2, 14.5 und 14.20, die aus drei unterschiedlichen Lebensphasen Ciceros stammen, scheint auf den ersten Blick eine bestimmte Entwicklung erkennbar: Am Anfang steht ein Kontaktbrief, der auf eine starke gefühlsmäßige Bindung zwischen den Eheleuten deutet, gefolgt von einem Informations- und Obligationsbrief, welcher zwischen Erfüllung der Informationspflichten gegenüber Terentia und selbstfokussierter Kommissivität schwankt, abgelöst wiederum vom Aufforderungsbrief am Ende der Briefsammlung, der mit seinen nüchternen Befehlen nahezu gefühllos wirkt. Ein Überblick über alle 24 Briefe zeigt jedoch, dass kein durchgehendes Muster erkennbar ist:

\begin{tabular}{|c|c|c|}
\hline Brief-Nr. & Entstehungszeit & Art des Briefes \\
\hline fam. 14.4 & 29.04 .58 v. Chr. & Kontaktbrief \\
\hline fam. 14.2 & 05.10 .58 v. Chr. & Kontaktbrief \\
\hline fam. 14.1 & 25.11.58 v. Chr. & Kontaktbrief \\
\hline fam. 14.3 & 29.11.58 v. Chr. & Kontaktbrief \\
\hline fam. 14.5 & 16.10.50 v. Chr. & Informations- und Obligationsbrief \\
\hline fam. 14.18 & 22.01.49 v. Chr. & Aufforderungsbrief \\
\hline fam. 14.14 & 23.01.49 v. Chr. & Aufforderungsbrief \\
\hline fam. 14.7 & 07.06.49 v. Chr. & Aufforderungsbrief \\
\hline fam. 14.6 & 15.07 .48 v. Chr. & Aufforderungsbrief \\
\hline fam. 14.12 & 04.11 .48 v. Chr. & Aufforderungsbrief \\
\hline fam. 14.19 & 27.11.48 v. Chr. & Informationsbrief \\
\hline fam. 14.9 & 17.12.48 v. Chr. & Kontaktbrief \\
\hline fam. 14.17 & 23.12. (oder 19.12.) 48 v. Chr. & Aufforderungsbrief \\
\hline fam. 14.16 & 04.01 .47 v. Chr. & Kontaktbrief \\
\hline fam. 14.8 & 02.06.47 v. Chr. & Kontaktbrief \\
\hline fam. 14.21 & 03.06.47 v. Chr. & Aufforderungsbrief \\
\hline fam. 14.11 & 14.06.47 v. Chr. & Informationsbrief \\
\hline fam. 14.15 & 19.06.47 v. Chr. & Informationsbrief \\
\hline fam. 14.10 & 09.07.47 v. Chr. & Aufforderungsbrief \\
\hline fam. 14.13 & 10.07.47 v. Chr. & Aufforderungsbrief \\
\hline fam. 14.24 & 11.08.47 v. Chr. & Informationsbrief \\
\hline fam. 14.23 & 12.08.47 v. Chr. & Informationsbrief \\
\hline fam. 14.22 & 01.09.47 v. Chr. & Informationsbrief \\
\hline fam. 14.20 & 01.10.47 v. Chr. & Aufforderungsbrief \\
\hline
\end{tabular}


Auffällig sind eher die stellenweise erkennbaren Kumulationen, wie z. B. die Aufeinanderfolge von vier Kontaktbriefen (fam. 14.1 - 14.4) im Jahr 58 v. Chr. bzw. von drei RATENDEN Aufforderungsbriefen (fam. 14.18, 14.14 und 14.7) 49 v. Chr. oder drei Informationsbriefen (fam. 14.24, 14.23 und 14.22) im August und September 47 v. Chr. Zum Teil handelt es sich quasi um Doppelungen, wie bei den Exilbriefen und den Briefen vom Beginn des Bürgerkriegs (bes. fam. 14.14 und 14.18), die der Dringlichkeit der Lage und evtl. Bedenken hinsichtlich der Zuverlässigkeit des Brieftransportes geschuldet sein werden. Manchmal stellen sie eine sich aus dem Handlungsablauf ergebende Reihung dar, wie die Informationsbriefe, mit denen Cicero zunächst das baldige Eintreffen Cäsars bzw. eines Briefes von ihm ankündigt (fam. 14.24), dann vom Erhalt des Briefes berichtet (fam. 14.23) und schließlich seine Ungewissheit angesichts des anstehenden persönlichen Zusammentreffens ausdrückt (fam. 14.22). ${ }^{1620}$

Eine Häufung einzelner Briefarten zu einem gewissen Zeitpunkt lässt sich demnach in erster Linie aus den situativen Erfordernissen erklären. Im Exil stand das Abreagieren von Gefühlen und das Aufrechterhalten des Kontakts mit Terentia ( $\rightarrow$ Kontaktfunktion) im Vordergrund. ${ }^{1621}$ Zu Beginn des Bürgerkrieges bestand ein erhöhter Bedarf an Ratschlägen für die in Rom zurückgebliebene Ehefrau ( $\rightarrow$ Aufforderungsfunktion). Nach der Niederlage von Pompejus bangte Cicero zunächst in Erwartung einer Reaktion Cäsars um sein künftiges Schicksal und musste dann überlegen, wie er weiter vorgehen sollte. In dieser Situation war es unabdingbar, Terentia ständig auf dem Laufenden zu halten ( $\rightarrow$ Informationsfunktion). Hier wie auch in anderen späteren Briefen erweist sich im Übrigen, dass von Inhaltsleere keine Rede sein kann, sondern durchaus wichtige Informationen übermittelt werden, wie dies in einer funktionierenden Ehe zu erwarten ist. ${ }^{1622}$

Eine Entwicklung in eine bestimmte Richtung ist kaum erkennbar. Noch am 2. Juni 47 v. Chr. schreibt Cicero einen (kurzen) Kontaktbrief an seine Frau, in den letzten vier Monaten der erhaltenen Korrespondenz allerdings nicht mehr. Insbesondere bei den Informations- und Aufforderungsbriefen findet ein steter Wechsel statt. Die leichte Schwerpunktverschiebung bei den Aufforderungsbriefen von sprecherpräferierten RATSCHLÄGEN hin zu ANWEISUNGEN mit beidseitiger Präferenz und sprecherpräferierten BITTEN ist zwar bemerkenswert: Den RATSCHLÄGEN liegt ein eher ausgewogenes Hierarchieverhältnis zugrunde, insofern Terentia Rat sucht und Cicero bemüht ist, ihn ihr zu geben, die Entscheidung aber letztlich ihr selbst überlässt, während in den folgenden Aufforderungsbriefen das Pendel wieder mehr zu Cicero hin ausschlägt. Eine eindeutige Tendenz bei der Abfolge von ANWEISUNGEN und BITTEN ist aber nicht erkennbar. Daraus lässt sich schwerlich eine insgesamt zunehmende Selbstfokussierung ableiten. Dazu ist noch die grundsätzliche Multifunktionalität der Familienbriefe zu bedenken, d. h., neben der (die Briefart) bestimmenden dominanten Textfunktion werden die Briefe auch von anderen Handlungsfunktionen beeinflusst, die auf den verschiedenen Handlungsebenen in vielfältigen Beziehungen zueinander stehen. Hinweise auf eine zunehmende Verschlechterung des Verhältnisses zwischen Cicero und Terentia sind jedenfalls nur teilweise ableitbar.

\footnotetext{
${ }^{1620} \mathrm{Vgl}$. a. fam. 14.11 und 14.15 (mit Informationen zum Aufenthaltsort der gemeinsamen Kinder).

1621 Hinzu kommt die persuasive Komponente.

1622 Vgl. dagegen S. 399 bzw. N. 1560.
} 


\section{Schlussbetrachtungen}

\section{Probleme und NutZen eINER handLUngSFUnKTIONALEN ANALYSE}

\section{Analyseverfahren allgemein}

Eine handlungsfunktionale Analyse in der Form, wie sie in dieser Arbeit anhand von fam. 14 exemplarisch vorgeführt wurde, bedeutet einen erheblichen Aufwand und ist wohl nur für eng begrenzte Textkorpora im Detail zu leisten. Dennoch kann sich dieser lohnen, da durch eine genaue Untersuchung der funktionalen Handlungsebenen bis hin zu den kleinsten Einheiten einschließlich ihrer strukturellen Verflechtungen Präzision sowie ein reflektiertes und methodisches Vorgehen forciert werden. Dadurch wird die Gefahr verringert, bedeutende (pragmatische) Aspekte der Interpretation zu übersehen, und eine sehr weitreichende Texterfassung ermöglicht.

Genauigkeit und Umfassendheit bedeuten allerdings nicht Eindeutigkeit. Trotz aller Bemühungen, die Briefe auf der Grundlage sachlich nachvollziehbarer Kriterien pragmatisch zu erfassen, bleibt die Interpretation letztlich immer subjektiv. Dabei zeigen sich auch die Schwierigkeiten einer historischen Analyse, bei der dem Interpreten mehr noch als bei einer gegenwarts-, insbesondere muttersprachlichen Analyse neben der perfekten Sprachbeherrschung außerdem oft Kenntnisse über den genauen situativen Kontext fehlen, die gerade bei einer handlungsfunktionalen Untersuchung eigentlich unabdingbar sind. So ist nur schwer zu beurteilen, welchen Informationswert eine Äußerung für Terentia tatsächlich hat. Ist eine Information neu und erhält die Äußerung deshalb einen eigenen Illokutionsstatus? Wenn ja, wie wichtig ist die Information für sie? Handelt es sich bei einem assertiven Sprechakt bspw. um eine BENACHRICHTIGUNG oder lediglich einen HINWEIS oder gar nur eine MITTEILUNG? Ist Cicero sich über den Inhalt seiner Äußerung recht sicher oder stellt er nur eine Vermutung an (z. B. FESTSTELLEN vs. VERMUTEN)? Häufig bleibt außerdem unklar, inwieweit eine Äußerung mehr den Adressaten oder den Sprecher betrifft. Zielt ein expressiver Sprechakt in erster Linie auf Terentia oder Cicero (z. B. WOHLERGEHEN WÜNSCHEN vs. HOFFNUNG ÄUSSERN oder SORGE BEKUNDEN vs. ANGST ÄUSSERN)? Besteht bei einem kommissiven Sprechakt oder einer direktiven Aufforderungshandlung eine beidseitige, eine Adressaten- oder Sprecherpräferenz (z. B. VERSPRECHEN vs. VORSATZ BEKUNDEN bzW. ANWEISEN vs. RATEN und BITTEN)? Liegt bei einer problemzentrierten Fragehandlung eine einseitige oder eine gemeinsame Problemlage vor (z. B. RAT ERBITTEN vs. KOOPERATIONSFRAGE STELLEN)? Zusätzlich sind die Besonderheiten der Briefkommunikation (Phasenverzug) sowie die Überlieferungslage (fehlende Briefe Terentias) zu berücksichtigen, u. a. bei der Beurteilung der Frage, ob Cicero auf eine vorangehende Äußerung Terentias reagiert und damit ein reaktiver Sprechakt vorliegt oder nicht (z. B. BEGRÜNDEN vs. HINWEISEN).

Obwohl die Untermuster im Prinzip ziemlich genau definiert sind, ist aufgrund dieser und anderer Schwierigkeiten eine konkrete Zuordnung manchmal nicht leicht und nur unter Vorbehalt möglich. Zwar existieren einige (antike) Quellen, wie z. B. Briefe von Cicero an andere Adressaten und weitere zeitgenössische und spätere historische Zeugnisse, die bei der Klärung helfen können, hauptsächlich ist man jedoch auf den Text selbst angewiesen. Die sprachliche Oberfläche liefert allerdings meist keine eindeutigen Hinweise, kann also bei der Bestimmung 
der Handlungsfunktionen - wie im Übrigen auch bei der Identifikation der Handlungseinheiten sowie ihrer Sequenzierung und Hierarchisierung - lediglich unterstützend wirken.

Wenngleich durchaus die Dominanz einiger sprachlicher Charakteristika in einzelnen Sprechaktoberklassen zu bemerken ist und einzelne Untermuster bzw. Gruppen von Untermustern oft recht spezifische Merkmale aufweisen, sind solche Sprachmittel selten ausschließlich auf eine Sprechaktkategorie beschränkt. Und selbst wenn dies im Einzelfall für fam. 14 so zutreffen sollte, kann dies für andere Texte anders aussehen. Sprachliche Mittel zur Verstärkung von Sprechakten (wie Superlative und verabsolutierende Ausdrücke) sind ohnehin kaum mit einer bestimmten Sprechaktklasse verbunden, am wenigsten vielleicht noch mit den Assertiva. Affirmativpartikeln sind durchaus typisch für akzeptative, Negationen für rejektive Assertiva, begegnen aber ebenso bei anderen Untermustern und in weiteren Sprechaktkategorien. Eine expressive Lexik ist naturgemäß charakteristisch für die Expressiva, kann nichtsdestotrotz auch in anderen Sprechakten gebraucht werden, in denen eine andere Handlungsfunktion dominant ist, wie z. B. den Kommissiva des Typs VORSATZ BEKUNDEN oder einigen Direktiva. Das Futur ist kennzeichnend für Sprechakte des Typs ANKÜNDIGEN, die so von den übrigen Transmissiva unterschieden werden können, verbindet sie aber zugleich mit anderen Assertiva wie denen des Typs PROGNOSTIZIEREN sowie außerdem mit Sprechakten anderer Oberklassen, wie z. B. den Kommissiva. Selbst die Satzarten, die bei einigen Sprachwissenschaftlern als grundlegendes Unterscheidungskriterium für die Sprechaktoberklassen gelten, liefern keine zuverlässigen Anhaltspunkte. Exklamative Infinitive und Akkusative finden sich bspw. hauptsächlich bei den Expressiva und Imperativsätze bei den Direktiva. Gleichwohl sind einige Imperativsätze expressiv aufzufassen. Fragesätze trifft man in fam. 14 sogar häufiger bei den Expressiva (SORGE BEKUNDEN, ANGST ÄUSSERN) an als bei den eigentlichen Fragehandlungen. Aussagesätze sind in allen Sprechaktoberklassen vertreten.

Besteht ein Widerspruch zwischen sprachlicher Oberfläche und Handlungsfunktion, spricht man von indirekten Sprechakten. Für deren Analyse müsste genau definiert werden, welche sprachlichen Merkmale i. E. zu welcher Sprechaktklasse gehören. Dies scheint aber nicht einmal im Hinblick auf die Satzarten in überzeugender Weise umsetzbar sein. Eindeutige Bestimmungen sind $m$. E. kaum möglich, sondern man wird nur gewisse Tendenzen innerhalb eines Kontinuums erfassen können. Bei der handlungsfunktionalen Interpretation von fam. 14 spielen indirekte Sprechakte allerdings ohnehin kaum eine Rolle. Eine Abmilderung von Aufforderungen erfolgt bspw. auf anderem Wege, nämlich $u$. a. durch Begründungen und weitere Sprechakte, welche die Wohlgesonnenheit Terentias i. w. S. befördern. Es ist zwar durchaus wichtig zu untersuchen, ob Cicero sich in seinen Briefen eher explizit oder implizit äußert, ob z. B. in einer auf den ersten Blick recht sachlich wirkenden Feststellung nicht doch Gefühle wie Freude oder Ärger mitschwingen. Aufschlussreich kann zudem die Frage sein, inwieweit Ciceros Äußerungen den üblichen zu erwartenden Formulierungen entsprechen oder davon abweichen. Solche Aspekte werden aber nur bedingt vom Konzept der Indirektheit erfasst, dessen Sinnhaftigkeit auch angesichts vieler weiterer Schwierigkeiten in der Tat zu diskutieren wäre. 
Ein grundlegendes Problem stellt die Multifunktionalität von Sprechakten dar. Bei einigen Äußerungen ist relativ offensichtlich, welche Funktion dominiert, in anderen muss diese weitgehend aus dem Kontext erschlossen werden, z. B. bei expressiven Sprechakten, die recht nüchtern und sachlich formuliert sind und damit eher den Assertiva gleichen. Ein ähnliches Bild ergibt sich auf den anderen Handlungsebenen, z. B. auf der Teiltextebene, wobei sich Sequenzierung und Hierarchisierung der Handlungseinheiten umso schwieriger gestalten, je komplexer der Text ist und je engmaschiger die Strukturierung ausfällt. Was die Ebene der Gesamttexthandlungen betrifft, ist ja gerade bei den prinzipiell multifunktionalen Familienbriefen eigentlich nie von nur einer Textfunktion auszugehen; jedes Schreiben erfüllt normalerweise mehrere Funktionen. Dennoch ist in fam. 14 meistens relativ klar eine Funktion als dominant zu erkennen, sodass die einzelnen Briefe jeweils als Informations-, Aufforderungsoder Kontaktbrief kategorisiert werden können. Nur in einem Fall (fam. 14.5) erscheint eine endgültige Festlegung nicht sinnvoll, da Informations- und Obligationsfunktion ungefähr gleich zu gewichten sind.

Trotz aller Probleme und Einschränkungen haben sich die in dieser Arbeit angewandten Analyseverfahren bewährt. Insbesondere die Klassifizierungen der Münsteraner Schule haben sich als sehr gewinnbringend herausgestellt. Sie basieren zwar auf introspektiv gewonnenen (fingierten) mündlichen Äußerungen der deutschen Sprache und sind somit nicht 1:1 übertragbar auf Ciceros Briefe. Authentische Äußerungen der Schriftsprache sind i. A. komplexer und passen nicht immer so glatt in die theoretisch abgeleiteten Schemata. Dazu kommen die Eigenheiten der römischen Kultur, denen bspw. die Unterscheidung von Aufforderungshandlungen nach ihrem Verbindlichkeitsgrad (bindend vs. nicht-bindend) nur bedingt gerecht wird, aber auch sprachliche Spezifika, wodurch z. B. das assertive Untermuster BEJAHEN entbehrlich wird. Die Ausdifferenzierung der Sprechaktoberklassen Searles liefert dennoch eine gute Ausgangsbasis für eine weitergehende Interpretation. Durch die Zusammenstellung gleicher, ähnlicher und kontrastierender Sprechaktmuster ergeben sich ausgesprochen interessante Einsichten, sowohl was das Sprechaktinventar im Lateinischen allgemein betrifft als auch Besonderheiten der Kommunikation in Rom i. E., z. B. hinsichtlich der sprachlichen Ausgestaltung von Entschuldigungen, die i. d. R. aus mehreren Sprechakten (z. B. ABSTREITEN - ZUGEBEN BEGRÜNDEN - FLUCHEN - JAMMERN - SICH ENTSCHULDIGEN - VERSPRECHEN) bestehen, welche sich in verschiedener Weise ergänzen. V. a. aber haben sich die Unterscheidung der Expressiva in sympathisierende, opponierende und abreagierende Sprechakte sowie nach Präferenz und Aversion und die entsprechenden Einteilungen der anderen Oberklassen nach Adressaten- bzw. Sprecherorientierung als ausgesprochen nützlich bei der Analyse der Beziehungs- und Identitätskonstitution im Hinblick auf Cicero und Terentia erwiesen. Dies gilt im Übrigen mehr oder weniger auch für die darüber hinausgehenden Untersuchungen auf den Ebenen der Teil- und Gesamttexthandlungen.

\section{Beitrag zur philologischen Textinterpretation von fam. 14}

Ciceros Briefe sind im Laufe der Jahrhunderte bereits bis ins kleinste Detail umfassend interpretiert worden, sodass keine aufsehenerregenden neuen Erkenntnisse mehr zu erwarten sind. Dies gilt auch für fam. 14, obwohl die Schreiben an Terentia meist nicht ganz so stark im Fokus standen, da sie inhaltlich nur wenig spektakulär erschienen. Eine handlungsfunktionale 
Analyse kann immerhin dazu beitragen, einzelne Thesen zu stützen oder zu widerlegen. Denn die vorliegenden Deutungen ergeben ein recht buntes Bild sich teilweise widersprechender Aussagen.

Eine kontinuierliche Abwärtsentwicklung der Beziehung von Cicero und Terentia lässt sich z. B. nicht bestätigen. Nur zum Ende hin ist eine negative Tendenz erkennbar. Die Exilbriefe aus dem Jahr 58 v. Chr. (fam. 14.1 - 14.4) sind zwar am emotionalsten, und Cicero formuliert in ihnen am klarsten seine Zuneigung zu Terentia, sie sind jedoch zugleich - wie die meisten anderen Briefe - sehr selbstfokussiert. Der darauffolgende Brief (fam. 14.5), den Cicero kurz vor seiner Rückkehr aus Kilikien im Jahr 50 v. Chr. verfasst hat, ist recht nüchtern, enthält aber auch einige affektive Elemente. Die drei Briefe vom Anfang des Bürgerkrieges aus dem Jahr 49 v. Chr. (fam. 14.18, 14.14 und 14.7) sind wiederum emotionaler, v. a. jedoch von allen Briefen mit Abstand am stärksten adressatenorientiert. In ihnen kommt am deutlichsten eine innige Verbundenheit Ciceros mit seiner Frau zum Ausdruck, um die er sich augenscheinlich sehr große Sorgen macht. Die späteren Briefe aus den Jahren 48 und $47 \mathrm{v}$. Chr. sind dagegen wenig emotiv, insbesondere die Schreiben im Anschluss an fam. 14.8. (02.06.47 v. Chr.). Seine besondere Sympathie äußert Cicero im Folgenden nur noch gegenüber Tullia (und Dolabella), nach fam. 14.11 (14.06.47 v. Chr.) nicht einmal mehr das. In fam. 14.20 schließlich verzichtet er gänzlich auf eine emotive Beziehungsgestaltung.

Die Vernachlässigung der sekundären Hierarchie ist wohl der deutlichste Hinweis auf eine Abkühlung des Verhältnisses der Eheleute. Gleichwohl wahrt Cicero bis zum Schluss die Höflichkeitskonventionen, verwendet z. B. zumindest die üblichen Grußformeln, begründet seine Aufforderungen und erfüllt allgemein seine Informationspflichten. Wenn sich auch keine so affektiven Zuneigungsbekundungen mehr finden, verhält er sich doch immer respektvoll gegenüber seiner Frau. Er vertraut (offensichtlich zu Recht) auf ihre Zuverlässigkeit. Am Ende stimmt er sich allerdings mit ihr nicht mehr so explizit über ein gemeinsames Vorgehen ab wie in den früheren Briefen, in denen eine stärkere Kooperation festzustellen ist, z. B. in Gestalt von KOOPERATIONSFRAGEN und ANWEISUNGEN. Die Interaktivität scheint überhaupt nachzulassen, wie u. a. der zuletzt nur spärliche bzw. gar nicht mehr vorhandene Gebrauch reaktiver und re-initiativer Assertiva belegt.

Es entsteht also insgesamt durchaus der Eindruck einer funktionierenden und weitgehend harmonischen Ehe, die selbst unter schwierigen Bedingungen Bestand hat. Nur selten sind kleinere Missstimmungen festzustellen. Was jedoch auffällt, ist ein fast durchgehender starker Egozentrismus Ciceros. Wie weit dieser reicht, in welchem Ausmaß auch die auf den ersten Blick mehr adressatenorientierten Äußerungen (z. B. die sympathisierenden Expressiva) von einer übergeordneten egoistischen Strategie überlagert werden, lässt sich allein aufgrund des vorliegenden Textes kaum wirklich beurteilen. Dies gilt ebenso für Erklärungen der Überschwänglichkeit der Exilbriefe oder der unterkühlten Prägnanz einiger späterer Briefe aus den jeweiligen situativen Gegebenheiten (z. B. emotionale Extremsituation bzw. Zeitmangel), die man wiederum u. a. mit Verweis auf Briefe Ciceros an andere Adressaten teilweise zu entkräften versucht hat.

Die historische Wahrheit über das Verhältnis zwischen Cicero und Terentia lässt sich so oder so nur in sehr begrenztem Rahmen ermitteln, da zu wenig Quellenmaterial (z. B. Verlust der 
Briefe Terentias und weiterer Briefe Ciceros, kaum Texte anderer Autoren) vorliegt und das vorhandene in vielfacher Hinsicht hinterfragt werden muss, u. a. was den möglichen Einfluss der Herausgeber und weitere Unwägbarkeiten der Überlieferungsgeschichte betrifft. Dies gilt erst recht, wenn man der Analyse nur die 24 Briefe aus fam. 14 zugrunde legt, ohne dass sie durch ergänzende Texte möglicherweise korrigiert würde. In dieser Arbeit geht es aber auch gar nicht um eine historische, sondern um eine handlungsfunktionale Interpretation, die sich vornehmlich daran ausrichtet, was im Text selbst angelegt ist. Dabei sollten allerdings - wie bei allen Quellentexten - die potenziellen Wirkungs- und Selbstdarstellungsabsichten des Verfassers berücksichtigt werden. ${ }^{1623}$ Nicht zuletzt muss sich jeder Interpret außerdem seiner eigenen Voreingenommenheiten bewusst bleiben, aus der die subjektive Konstruktion jedweder Interpretation resultiert.

\section{MÖGLICHKEITEN WEITERfüHRENDER ARBEITEN}

Die Briefsammlung fam. 14 hat sich als gut geeignete Grundlage für eine erste Erprobung des hier gewählten Ansatzes zur handlungsfunktionalen Analyse lateinischer Texte erwiesen. Die Aussagekraft der damit erzielten Ergebnisse ist jedoch begrenzt und eine Ausweitung des Analysekorpus dringend notwendig. Dazu bieten sich zunächst einmal die Briefe Ciceros an, in denen er Themen aus fam. 14 aufgreift bzw. Terentia in irgendeiner Weise erwähnt. Durch die Einbeziehung weiterer Briefe von ihm und anderen Autoren könnte die Themen- bzw. Funktionsvielfalt des Untersuchungsmaterials noch mehr erhöht werden. Interessant wären v. a. Briefe, zu denen die Referenzschreiben der Adressaten existieren, mit denen sich z. B. die Reaktivität von Sprechakten besser belegen ließe. Intertextuelle Bezüge ergeben sich allerdings auch zu anderen Briefen.

Eine solche Erweiterung des Analysekorpus ermöglicht es, die Unterschiede in der handlungsfunktionalen Gestaltung zwischen Briefen verschiedener Autoren an verschiedene Adressaten zu verschiedenen Themen und mit verschiedenen Handlungszielen herausarbeiten. Vorstellbar wäre bspw. die Untersuchung einzelner Brieftypen wie z. B. Empfehlungsschreiben (als Variante der Aufforderungsbriefe), der Vergleich von privaten Familienbriefen mit eher offiziellen Schreiben, von Briefen an die Ehefrau mit Schreiben an andere Familienangehörige oder Freunde in derselben oder einer vergleichbaren Situation. So könnte man fam. 14.1-14.4 mit Att. 3, ad Q. fr. 1.3 und 1.4 sowie fam. 5.4, darüber hinaus außerdem mit Ov. Pont. und trist. kontrastieren. Eine Gegenüberstellung von Ciceros Briefen an Terentia und Briefen anderer Männer an ihre Frauen bzw. Geliebten sowie umgekehrt (z. B. PLIN. epist. 6.4, 6.7 und 7.5 oder Ov. epist.) wäre ebenfalls aufschlussreich. Die literarischen bzw. poetischen Briefe von Plinius und Ovid, v. a. die Heroides stellen dabei gewiss eine besondere Herausforderung dar.

Die Analysemethode sollte des Weiteren bei anderen Kommunikationsformen und Textsorten zur Anwendung kommen, um ein möglichst umfassendes Bild der Art und Weise sprachlichen

\footnotetext{
${ }^{1623}$ Vgl. a. HUTCHINSON 1993, 442: „Das Verhältnis der römischen Literatur zur ,historischen Wirklichkeit' ist vielfach diskutiert worden. Mit diesen [d. h. Ciceros] Briefen stehen wir, so scheint es, der geschichtlichen Realität besonders nahe; gerade hier aber zeigt sich, daß Literatur selten oder nie als reiner, unmittelbarer Ausdruck selbst subjektiver Realität gelten kann. Auch wenn der verbannte Cicero eine zutiefst bewegende Beschreibung seiner Gefühle gibt [...], so darf man doch das Überredungsziel sowie den Reichtum rhetorischer Erfindung und die Kunst der Disposition nicht übersehen - freilich ohne darüber zynisch zu werden."
} 
Handelns in der römischen Antike zu erhalten. ${ }^{1624}$ Hier liegt z. B. eine Untersuchung der Dialoge in den Komödien v. a. von Plautus nahe, bei denen aber ebenfalls die Eigenheiten fiktiver Texte bedacht werden müssen. ${ }^{1625}$ Letztlich kann man im Prinzip lateinische Texte aller Art handlungsfunktional zu analysieren versuchen. Bei komplexeren Texten wie philosophischen Traktaten wird man jedoch voraussichtlich schnell an die Grenzen dessen geraten, was unter vertretbarem Aufwand zu bewältigen ist.

Im Hinblick auf einen möglichen philologischen Erkenntnisgewinn wäre es wohl ratsam, ein Analysekorpus zu wählen, das nicht (wie fam. 14) bereits nahezu ausinterpretiert ist. Dennoch erscheint auch eine Analyse solcher Texte berechtigt, selbst wenn sie die bestehenden Interpretationen einfach nur bestätigt oder lediglich um fein nuancierte Facetten ergänzt. Es besteht nämlich immer die Chance, durch eine veränderte Perspektive neue Einsichten zu gewinnen. ${ }^{1626}$ Auf jeden Fall wird sie den Blick schärfen für das Funktionieren der lateinischen Sprache. In diesem Zusammenhang ist zudem eine didaktische Aufbereitung denkbar. Die allgemeine und spezifische Sprachkompetenz von Schülern würde sehr davon profitieren, wenn diese sich z. B. damit auseinandersetzten, wie man jemandem im Lateinischen dankt, wie man sich entschuldigt, wie man einem Menschen sagt, dass man ihn gernhat, dass man sich freut oder traurig ist usw. Im Übrigen trägt die Untersuchung jedes Textes dazu bei, das angewandte Analyseverfahren zu verfeinern. Was dies betrifft, wäre sogar eine noch genauere Analyse von fam. 14 erforderlich. Allgemein sollten u. a. folgende Punkte noch weiter untersucht bzw. verbessert werden:

Hinsichtlich der Illokutionsidentifikation müsste z. B. noch deutlicher herausgearbeitet werden, inwieweit einzelne Sprachelemente lediglich Wiederholungen ohne eigenen Informations- und Handlungswert darstellen und deshalb nicht als eigenständige Illokutionen zu werten sind. Bei der Anwendung auf ein größeres Textkorpus könnten sich einige der ermittelten Indikatoren zur Illokutionsdemarkation als weniger oder gar nicht relevant erweisen.

Obwohl sie eng miteinander verflochten sind, sollten inhaltliche und funktionale Aspekte v. a. bei der Sequenzierung und Hierarchisierung von Handlungseinheiten exakter voneinander geschieden werden, als es in dieser Arbeit möglich war, wo die Abgrenzung von thematischer Ebene und Handlungsebene oft unscharf bleiben musste. Was insbesondere die Teiltext- und Gesamttexthandlungen betrifft, wurden ohnehin nur fam. 14.2, 14.5 und 14.20 etwas genauer unter die Lupe genommen. Eine eingehendere Untersuchung der übrigen Briefe in fam. 14 steht also noch aus. Man könnte dabei u. a. die Briefsorten weiter unterteilen und z. B. BITTENDE, ANWEISENDE und RATENDE Aufforderungsbriefe voneinander unterscheiden. Dafür bieten sich die Ausdifferenzierungen der Sprechaktoberklassen Searles durch die Münsteraner Schule als Ausgangspunkt an.

\footnotetext{
${ }^{1624}$ Angesichts des recht umfangreichen, insgesamt jedoch begrenzten und mithin vergleichsweise übersichtlichen lateinischen Literaturerbes wäre durchaus der Versuch überlegenswert, das Sprechaktinventar im Lateinischen in seiner Gesamtheit bzw. innerhalb einer bestimmten Sprachepoche (z. B. 1. Jh. v. Chr.) zu erfassen.

1625 Dazu ist zu bemerken, dass zu einzelnen Sprechakttypen schon einige Untersuchungen (v. a. unter dem Gesichtspunkt der Höflichkeit) vorliegen: Vgl. z. B. BARRIOS-LECH 2016 und die zahlreichen Arbeiten von Unceta Gómez. Auch zu anderen Autoren und Textgattungen gibt es bereits entsprechende Studien. Vgl. Kap. 1.1.3.3. ${ }^{1626}$ Vgl. a. DICKEY 2016, 197f. und ebd., 217 (zu Ciceros Briefen als Gegenstand von Höflichkeitsstudien): Sie meint, gerade solche Texte seien besonders geeignet, eine (neue) Methode auf ihre Tauglichkeit hin zu überprüfen.
} 
Diese haben sich überhaupt als gut geeignet für die Klassifikation der illokutionären Untermuster auch lateinischer Texte erwiesen, müssten an einigen Stellen aber erweitert und angepasst werden. Es fehlt z. B. eine Einteilung der Deklarativa in durch Handlungsbedingungen klar definierte Untermuster, zu denen u. a. GESPRÄCH bzw. BRIEF ERÖFFNEN und BEENDEN gehören würden. Bei den abreagierenden Expressiva könnte weiter danach differenziert werden, ob der Sprecher selbst oder eine dritte Person von einem Sachverhalt betroffen ist. Natürlich ist zu berücksichtigen, dass die Typologisierungen der Münsteraner Schule das Resultat eines bestimmten Arbeitsverfahrens und Abänderungen deshalb nicht so ohne Weiteres möglich sind. Aufgrund der spezifischen Erfordernisse des Lateinischen wäre aber ohnehin zu überlegen, inwieweit die Entwicklung einer eigenen Klassifikation sinnvoll ist, wie sie bislang lediglich in Ansätzen (für die Direktiva) vorliegt. Die Erfahrungen bei der Analyse von fam. 14 lassen immerhin den Schluss zu, dass vieles grundsätzlich übernommen werden könnte. ${ }^{1627}$

Ein spezielles Thema stellen die indirekten Sprechakte dar. Sollte es gelingen, zu einem tragfähigen Konzept zu kommen, wären genauere Analysen und damit Aussagen zur konkreten Ausgestaltung und Funktionsweise sowie ggf. zur unterschiedlichen Bedeutsamkeit in Abhängigkeit vom zugrunde liegenden (Teil-)Text möglich. Da sie im Lateinischen offenbar seltener oder zumindest zu anderen Zwecken als in modernen Sprachen verwendet werden, bieten sich zudem komparativische Studien an, um herauszuarbeiten, inwieweit dies sprach- und kulturspezifisch oder nicht vielmehr eher medial bedingt ist, also durch die Schriftform der lateinischen Texte. Im direkten Gespräch von Angesicht zu Angesicht bestehen ja andere pragmatische Erfordernisse als bei einer nur mittelbaren Kommunikation.

Überhaupt müssen bei einer Beurteilung von Sprechakten immer viele verschiedene Faktoren miteinbezogen werden, die Einfluss auf die jeweilige sprachliche Formulierung nehmen können. Man könnte unter diesem Gesichtspunkt bspw. untersuchen, wie sich Entschuldigungen in verschiedenen Kulturen und Epochen handlungsfunktional i. E. unterscheiden, oder - vor dem Hintergrund der großen Bedeutung positiver Höflichkeit bei den Römern - Umfang und Ausgestaltung beziehungsgestalterischer Elemente in lateinischen Texten und Texten anderer Sprachen vergleichen. Die bereits vorliegenden recht umfangreichen pragmatischen Arbeiten zur Höflichkeit im alten Rom liefern sicherlich eine gute Basis für solche kontrastiven Studien, müssten aber z. T. noch stärker im Hinblick auf eine handlungsfunktionale Analyse i. e. S. spezifiziert werden. Intralinguale diachrone Untersuchungen mit einer Ausweitung auch auf das

\footnotetext{
${ }^{1627}$ Es müsste auch überprüft werden, inwieweit eine lexikographische Vorgehensweise nach dem Vorbild der Münsteraner Schule möglich ist. Die antiken Glossare wären dabei indes nur teilweise hilfreich. Zur antiken (lateinischen) Lexikographie vgI. z. B. SPLETT 1990 und die (z. T. allerdings veralteten) Übersichtsartikel in den einschlägigen Sachlexika. Vgl. a. EgELHAAF-GAISER 2000, 487f. zum spezifischen Charakter antiker Glossare bzw. Onomastika, die kaum allgemeine Aussagen zum lateinischen Wortschatz zulassen. Erfolgversprechender erscheint - sobald dieser vollständig vorliegt - ein Rückgriff auf den TLL mit seinem Anspruch auf (moderne) Wissenschaftlichkeit, Exaktheit, Vollständigkeit und genaue Erfassung des Kotextes: Vgl. https://thesaurus.badw.de/das-projekt.html (zuletzt geprüft am 12.11.2020). Durch Feststellung aller SB-Ausdrücke könnten die im Lateinischen realisierbaren Sprechhandlungen erfasst werden. Nicht immer wird man allerdings entscheiden können, ob einem SB-Ausdruck tatsächlich ein reales Sprechhandlungsmuster im Lateinischen zugrunde lag. Zudem ist strittig, inwiefern das Vorliegen eines SB-Ausdruckes für die Existenz einer Sprechhandlung zwingende Voraussetzung ist: Vgl. N. 98.
} 
nicht-klassische Latein eröffnen zusätzliche Perspektiven und tragen ebenfalls zu einer Erweiterung des Fundus handlungsfunktionaler Analysen bei.

Insgesamt kann so in Ergänzung zu anderen, z. B. syntaktischen und semantischen Sprachanalysen die Grundlage geschaffen werden für ein besseres Verständnis von Sprache bzw. sprachlichen Äußerungen in ihren Handlungszusammenhängen, und zwar sowohl, was speziell die lateinische Sprache betrifft, als auch in Bezug auf vergangene (tote) Sprachen überhaupt und darüber hinaus - durch eine Differenzierung universeller und sprach- bzw. kulturspezifischer Phänomene - auf einer übergreifenden allgemeinsprachlichen Ebene. 
Anhang 1 - Überblick über die Einzelillokutionen aller Briefe in fam. 14

\begin{tabular}{|c|c|c|c|c|c|}
\hline $\begin{array}{l}\text { Nr. } \\
\text { Brief }\end{array}$ & $\S$ & $\begin{array}{l}\text { Nr. } \\
\text { III. }\end{array}$ & Text & Oberklasse & Untermuster \\
\hline 14.1 & & $(1)$ & $\begin{array}{l}\text { TULLIUS TERENTIAE SUAE TULLIOLAE SUAE CICE- } \\
\text { RONI SUO S. D. }\end{array}$ & expressiv & GUNST ERWEISEN \\
\hline 14.1 & 1 & (2) & $\begin{array}{l}\text { Et litteris multorum et sermone omnium perfertur } \\
\text { ad me incredibilem tuam virtutem et fortitudinem } \\
\text { esse teque nec animi neque corporis laboribus de- } \\
\text { fatigari. }\end{array}$ & expressiv & BEGRÜSSEN \\
\hline 14.1 & 1 & (3) & me miserum! & expressiv & JAMMERN \\
\hline 14.1 & 1 & (4) & $\begin{array}{l}\text { te ista virtute, fide, probitate, humanitate in tan- } \\
\text { tas aerumnas propter me incidisse, }\end{array}$ & expressiv & $\begin{array}{l}\text { SICH ENTSCHULDI- } \\
\text { GEN }\end{array}$ \\
\hline 14.1 & 1 & (5) & $\begin{array}{l}\text { Tulliolamque nostram, ex quo patre tantas volup- } \\
\text { tates capiebat, ex eo tantos percipere luctus! }\end{array}$ & expressiv & JAMMERN \\
\hline 14.1 & 1 & (6) & $\begin{array}{l}\text { nam quid ego de Cicerone dicam? qui cum pri- } \\
\text { mum sapere coepit, acerbissimos dolores mise- } \\
\text { riasque percepit. }\end{array}$ & expressiv & JAMMERN \\
\hline 14.1 & 1 & (7) & $\begin{array}{l}\text { quae si, tu ut scribis, fato facta putarem, ferrem } \\
\text { paulo facilius; sed omnia sunt mea culpa commis- } \\
\text { sa, }\end{array}$ & expressiv & $\begin{array}{l}\text { SICH ENTSCHULDI- } \\
\text { GEN }\end{array}$ \\
\hline 14.1 & 1 & (8) & qui ab iis me amari putabam qui invidebant, & expressiv & FLUCHEN \\
\hline 14.1 & 1 & (9) & eos non sequebar qui petebant. & expressiv & FLUCHEN \\
\hline 14.1 & 2 & (10) & $\begin{array}{l}\text { quod si nostris consiliis usi essemus neque apud } \\
\text { nos tantum valuisset sermo aut stultorum amico- } \\
\text { rum aut improborum, beatissimi viveremus. }\end{array}$ & expressiv & FLUCHEN \\
\hline 14.1 & 2 & (11) & $\begin{array}{l}\text { nunc, quoniam sperare nos amici iubent, dabo } \\
\text { operam, ne mea valetudo tuo labori desit. }\end{array}$ & kommissiv & VORSATZ BEKUNDEN \\
\hline 14.1 & 2 & $(12)$ & res quanta sit intellego & expressiv & ANGST ÄUSSERN \\
\hline 14.1 & 2 & (13) & $\begin{array}{l}\text { quantoque fuerit facilius manere domi quam red- } \\
\text { ire. }\end{array}$ & expressiv & FLUCHEN \\
\hline 14.1 & 2 & (14) & $\begin{array}{l}\text { sed tamen, si omnis tribunos pl. habemus [...], } \\
\text { non est desperandum. }\end{array}$ & expressiv & HOFFNUNG ÄUSSERN \\
\hline 14.1 & 2 & (15) & $\begin{array}{l}\text { [...], si Lentulum tam studiosum quam videtur [...], } \\
\text { non est desperandum. }\end{array}$ & expressiv & HOFFNUNG ÄUSSERN \\
\hline 14.1 & 2 & (16) & $\begin{array}{l}\text { [...], si vero etiam Pompeium et Caesarem, non } \\
\text { est desperandum. }\end{array}$ & expressiv & HOFFNUNG ÄUSSERN \\
\hline 14.1 & 3 & (17) & $\begin{array}{l}\text { De familia, quo modo placuisse scribis amicis fa- } \\
\text { ciemus. }\end{array}$ & kommissiv & ABSICHT BEKUNDEN \\
\hline 14.1 & 3 & $(18)$ & de loco, nunc quidem iam abiit pestilentia, & assertiv & HINWEISEN \\
\hline 14.1 & 3 & $(19)$ & sed quam diu fuit me non attigit & assertiv & HINWEISEN \\
\hline 14.1 & 3 & (20) & $\begin{array}{l}\text { Plancius [...] me cupit esse secum et adhuc [erg. } \\
\text { me] retinet. }\end{array}$ & assertiv & HINWEISEN \\
\hline 14.1 & 3 & $(21)$ & {$[\ldots]$, homo officiosissimus, $[\ldots]$} & expressiv & JUBELN \\
\hline 14.1 & 3 & $(22)$ & $\begin{array}{l}\text { ego volebam loco magis deserto esse in Epiro, } \\
\text { quo neque Piso veniret nec milites, }\end{array}$ & kommissiv & ABSICHT BEKUNDEN \\
\hline 14.1 & 3 & $(23)$ & sed adhuc Plancius me retinet; & assertiv & HINWEISEN \\
\hline 14.1 & 3 & (24) & sperat posse fieri ut mecum in Italiam decedat. & assertiv & HINWEISEN \\
\hline
\end{tabular}




\begin{tabular}{|c|c|c|c|c|c|}
\hline 14.1 & 3 & $(25)$ & $\begin{array}{l}\text { quem ego diem si videro }[. . .] \text {, satis magnum mihi } \\
\text { fructum videbor percepisse et vestrae pietatis et } \\
\text { meae. }\end{array}$ & expressiv & HOFFNUNG ÄUSSERN \\
\hline 14.1 & 3 & $(26)$ & $\begin{array}{l}{[. . .] \text { et si in vestrum complexum venero }[. . .] \text {, satis }} \\
\text { magnum mihi fructum videbor percepisse et ves- } \\
\text { trae pietatis et meae. }\end{array}$ & expressiv & HOFFNUNG ÄUSSERN \\
\hline 14.1 & 3 & $(27)$ & $\begin{array}{l}{[\ldots] \text { ac si et vos et me ipsum reciperaro, satis }} \\
\text { magnum mihi fructum videbor percepisse et ves- } \\
\text { trae pietatis et meae. }\end{array}$ & expressiv & HOFFNUNG ÄUSSERN \\
\hline 14.1 & 4 & $(28)$ & $\begin{array}{l}\text { Pisonis humanitas, virtus, amor in omnis nos tan- } \\
\text { tus est ut nihil supra possit. }\end{array}$ & expressiv & JUBELN \\
\hline 14.1 & 4 & $(29)$ & utinam ea res ei voluptati sit! & expressiv & HOFFNUNG ÄUSSERN \\
\hline 14.1 & 4 & $(30)$ & gloriae quidem video fore. & assertiv & PROGNOSTIZIEREN \\
\hline 14.1 & 4 & $(31)$ & de Quinto fratre, nihil ego te accusavi, & assertiv & ABSTREITEN \\
\hline 14.1 & 4 & $(32)$ & $\begin{array}{l}\text { sed vos, cum praesertim tam pauci sitis, volui es- } \\
\text { se quam coniunctissimos. }\end{array}$ & assertiv & BEGRÜNDEN \\
\hline 14.1 & 5 & $(33)$ & quibus me voluisti agere gratias egi & assertiv & HINWEISEN \\
\hline 14.1 & 5 & (34) & et me a te certiorem factum esse scripsi. & assertiv & HINWEISEN \\
\hline 14.1 & 5 & $(35)$ & $\begin{array}{l}\text { Quod ad me, mea Terentia, scribis te vicum vendi- } \\
\text { turam, quid, obsecro te, [...] quid futurum est? }\end{array}$ & expressiv & ANGST ÄUSSERN \\
\hline 14.1 & 5 & $(36)$ & (me miserum!) & expressiv & JAMMERN \\
\hline 14.1 & 5 & $(37)$ & $\begin{array}{l}\text { et si nos premet eadem fortuna, quid puero mise- } \\
\text { ro fiet? }\end{array}$ & expressiv & ANGST ÄUSSERN \\
\hline 14.1 & 5 & $(38)$ & $\begin{array}{l}\text { non queo reliqua scribere, tanta vis lacrimarum } \\
\text { est; }\end{array}$ & expressiv & JAMMERN \\
\hline 14.1 & 5 & $(39)$ & neque te in eundem fletum adducam. & expressiv & SORGE BEKUNDEN \\
\hline 14.1 & 5 & $(40)$ & $\begin{array}{l}\text { tantum scribo: si erunt in officio amici, pecunia } \\
\text { non deerit; }\end{array}$ & expressiv & HOFFNUNG ÄUSSERN \\
\hline 14.1 & 5 & $(41)$ & si non erunt, tu efficere tua pecunia non poteris. & expressiv & ANGST ÄUSSERN \\
\hline 14.1 & 5 & $(42)$ & $\begin{array}{l}\text { per fortunas miseras nostras, vide ne puerum per- } \\
\text { ditum perdamus. }\end{array}$ & expressiv & ANGST ÄUSSERN \\
\hline 14.1 & 5 & $(43)$ & $\begin{array}{l}\text { cui si aliquid erit ne egeat, mediocri virtute opus } \\
\text { est et mediocri fortuna ut cetera consequatur. }\end{array}$ & expressiv & HOFFNUNG ÄUSSERN \\
\hline 14.1 & 6 & $(44)$ & Fac valeas & expressiv & $\begin{array}{l}\text { WOHLERGEHEN } \\
\text { WÜNSCHEN }\end{array}$ \\
\hline 14.1 & 6 & $(45)$ & $\begin{array}{l}\text { et ad me tabellarios mittas ut sciam quid agatur } \\
\text { et vos quid agatis. }\end{array}$ & direktiv & BITTEN \\
\hline 14.1 & 6 & $(46)$ & mihi omnino iam brevis exspectatio est. & assertiv & PROGNOSTIZIEREN \\
\hline 14.1 & 6 & $(47)$ & Tulliolae et Ciceroni salutem dic. & direktiv & BITTEN \\
\hline 14.1 & 6 & $(48)$ & valete. & deklarativ & BRIEF BEENDEN \\
\hline 14.1 & 7 & $(49)$ & Dyrrachium veni, & assertiv & HINWEISEN \\
\hline 14.1 & 7 & $(50)$ & quod et libera civitas est & assertiv & HINWEISEN \\
\hline 14.1 & 7 & $(51)$ & et in me officiosa & assertiv & HINWEISEN \\
\hline 14.1 & 7 & $(52)$ & et proxima Italiae & assertiv & HINWEISEN \\
\hline 14.1 & 7 & $(53)$ & $\begin{array}{l}\text { sed si offendet me loci celebritas, alio me confe- } \\
\text { ram, }\end{array}$ & kommissiv & ABSICHT BEKUNDEN \\
\hline
\end{tabular}




\begin{tabular}{|c|c|c|c|c|c|}
\hline 14.1 & 7 & $(54)$ & ad te scribam. & kommissiv & VERSPRECHEN \\
\hline 14.1 & 7 & $(55)$ & D. a. d. VI Kal. Dec. Dyrrachi. & assertiv & HINWEISEN \\
\hline 14.2 & & (1) & $\begin{array}{l}\text { TULLIUS S. D. TERENTIAE SUAE ET TULLIOLAE ET } \\
\text { CICERONI SUIS }\end{array}$ & expressiv & GUNST ERWEISEN \\
\hline 14.2 & 1 & (2) & $\begin{array}{l}\text { Noli putare me ad quemquam longiores epistulas } \\
\text { scribere, }\end{array}$ & assertiv & ABSTREITEN \\
\hline 14.2 & 1 & (3) & nisi si quis ad me plura scripsit, & assertiv & ZUGEBEN \\
\hline 14.2 & 1 & (4) & cui puto rescribi oportere. & assertiv & BEGRÜNDEN \\
\hline 14.2 & 1 & (5) & nec enim habeo quid scribam & assertiv & BEGRÜNDEN \\
\hline 14.2 & 1 & (6) & nec hoc tempore quicquam difficilius facio. & assertiv & BEGRÜNDEN \\
\hline 14.2 & 1 & (7) & $\begin{array}{l}\text { ad te vero et ad nostram Tulliolam non queo sine } \\
\text { plurimis lacrimis scribere. }\end{array}$ & expressiv & $\begin{array}{l}\text { SICH ENTSCHULDI- } \\
\text { GEN }\end{array}$ \\
\hline 14.2 & 1 & (8) & $\begin{array}{l}\text { vos enim video esse miserrimas, quas ego beatis- } \\
\text { simas semper esse volui }\end{array}$ & expressiv & $\begin{array}{l}\text { SICH ENTSCHULDI- } \\
\text { GEN }\end{array}$ \\
\hline 14.2 & 1 & (9) & idque praestare debui, & expressiv & $\begin{array}{l}\text { SICH ENTSCHULDI- } \\
\text { GEN }\end{array}$ \\
\hline 14.2 & 1 & $(10)$ & et, nisi tam timidi fuissemus, praestitissem. & expressiv & FLUCHEN \\
\hline 14.2 & 2 & $(11)$ & Pisonem nostrum merito eius amo plurimum. & expressiv & JUBELN \\
\hline 14.2 & 2 & $(12)$ & eum, ut potui, per litteras cohortatus sum & assertiv & HINWEISEN \\
\hline 14.2 & 2 & (13) & gratiasque egi, ut debui. & assertiv & HINWEISEN \\
\hline 14.2 & 2 & (14) & $\begin{array}{l}\text { in novis tribunis pl. intellego spem te habere. id } \\
\text { erit firmum, si Pompei voluntas erit; }\end{array}$ & expressiv & HOFFNUNG ÄUSSERN \\
\hline 14.2 & 2 & $(15)$ & sed Crassum tamen metuo. & expressiv & ANGST ÄUSSERN \\
\hline 14.2 & 2 & $(16)$ & $\begin{array}{l}\text { A te quidem omnia fieri fortissime et amantissime } \\
\text { video, nec miror, }\end{array}$ & expressiv & BEGRÜSSEN \\
\hline 14.2 & 2 & $(17)$ & $\begin{array}{l}\text { sed maereo casum eius modi ut tantis tuis miseri- } \\
\text { is meae miseriae subleventur. }\end{array}$ & expressiv & $\begin{array}{l}\text { SICH ENTSCHULDI- } \\
\text { GEN }\end{array}$ \\
\hline 14.2 & 2 & $(18)$ & $\begin{array}{l}\text { nam ad me } P \text {. Valerius }[\ldots] \text { scripsit, }[. . .] \text { quem ad } \\
\text { modum a Vestae ad Tabulam Valeriam ducta es- } \\
\text { ses. }\end{array}$ & assertiv & HINWEISEN \\
\hline 14.2 & 2 & (19) & {$[\ldots]$, homo officiosus, $[\ldots]$} & expressiv & JUBELN \\
\hline 14.2 & 2 & $(20)$ & {$[\ldots]$ id quod ego maximo cum fletu legi, $[\ldots]$} & expressiv & $\begin{array}{l}\text { BEDAUERN BEKUN- } \\
\text { DEN }\end{array}$ \\
\hline 14.2 & 2 & $(21)$ & $\begin{array}{l}\text { hem, }[. . .] \text { te nunc, mea Terentia, sic vexari, sic } \\
\text { iacere in lacrimis et sordibus, }\end{array}$ & expressiv & $\begin{array}{l}\text { SICH ENTSCHULDI- } \\
\text { GEN }\end{array}$ \\
\hline 14.2 & 2 & $(22)$ & $\begin{array}{l}\text { [...] mea lux, meum desiderium, unde omnes } \\
\text { opem petere solebant, }\end{array}$ & expressiv & $\begin{array}{l}\text { KOMPLIMENT MA- } \\
\text { CHEN }\end{array}$ \\
\hline 14.2 & 2 & $(23)$ & idque fieri mea culpa, & expressiv & $\begin{array}{l}\text { SICH ENTSCHULDI- } \\
\text { GEN }\end{array}$ \\
\hline 14.2 & 3 & $(24)$ & qui ceteros servavi ut nos periremus! & expressiv & FLUCHEN \\
\hline 14.2 & 3 & (25) & $\begin{array}{l}\text { Quod de domo scribis, hoc est de area, ego vero } \\
\text { tum denique mihi videbor restitutus si illa nobis } \\
\text { erit restituta. }\end{array}$ & expressiv & HOFFNUNG ÄUSSERN \\
\hline 14.2 & 3 & $(26)$ & verum haec non sunt in nostra manu; & assertiv & FESTSTELLEN \\
\hline 14.2 & 3 & $(27)$ & $\begin{array}{l}\text { illud doleo, quae impensa facienda est, in eius } \\
\text { partem te miseram et despoliatam venire. }\end{array}$ & expressiv & $\begin{array}{l}\text { SICH ENTSCHULDI- } \\
\text { GEN }\end{array}$ \\
\hline
\end{tabular}




\begin{tabular}{|c|c|c|c|c|c|}
\hline 14.2 & 3 & $(28)$ & quod si conficitur negotium, omnia consequemur; & expressiv & HOFFNUNG ÄUSSERN \\
\hline 14.2 & 3 & $(29)$ & $\begin{array}{l}\text { sin eadem nos fortuna premet, etiamne reliquias } \\
\text { tuas miseras proicies? }\end{array}$ & expressiv & ANGST ÄUSSERN \\
\hline 14.2 & 3 & $(30)$ & $\begin{array}{l}\text { obsecro te, mea vita, quod ad sumptum attinet, } \\
\text { sine alios [...] sustinere; }\end{array}$ & direktiv & ANWEISEN \\
\hline 14.2 & 3 & $(31)$ & {$[\ldots]$, qui possunt si modo volunt, $[\ldots]$} & assertiv & BEHAUPTEN \\
\hline 14.2 & 3 & $(32)$ & $\begin{array}{l}\text { et valetudinem istam infirmam, si me amas, noli } \\
\text { vexare. }\end{array}$ & direktiv & ANWEISEN \\
\hline 14.2 & 3 & $(33)$ & $\begin{array}{l}\text { nam mihi ante oculos dies noctesque versaris. } \\
\text { omnis labores te excipere video; }\end{array}$ & expressiv & $\begin{array}{l}\text { SICH ENTSCHULDI- } \\
\text { GEN }\end{array}$ \\
\hline 14.2 & 3 & $(34)$ & timeo ut sustineas, & expressiv & ANGST ÄUSSERN \\
\hline 14.2 & 3 & $(35)$ & $\begin{array}{l}\text { sed video in te esse omnia. quare, ut id quod spe- } \\
\text { ras et quod agis consequamur, servi valetudini. }\end{array}$ & direktiv & ANWEISEN \\
\hline 14.2 & 4 & $(36)$ & $\begin{array}{l}\text { Ego ad quos scribam nescio, nisi ad eos qui ad me } \\
\text { scribunt aut ad eos de quibus ad me vos aliquid } \\
\text { scribitis. }\end{array}$ & assertiv & MITTEILEN \\
\hline 14.2 & 4 & $(37)$ & longius, quoniam ita vobis placet, non discedam; & kommissiv & VERSPRECHEN \\
\hline 14.2 & 4 & $(38)$ & $\begin{array}{l}\text { sed velim quam saepissime litteras mittatis, prae- } \\
\text { sertim si quid est firmius quod speremus. }\end{array}$ & direktiv & BITTEN \\
\hline 14.2 & 4 & $(39)$ & Valete, mea desideria, valete. & expressiv & $\begin{array}{l}\text { WOHLERGEHEN } \\
\text { WÜNSCHEN }\end{array}$ \\
\hline 14.2 & 4 & $(40)$ & D. a. d. III Non. Oct. Thessalonica. & assertiv & HINWEISEN \\
\hline 14.3 & & $(1)$ & $\begin{array}{l}\text { TULLIUS S. D. TERENTIAE SUAE ET TULLIAE ET CI- } \\
\text { CERONI }\end{array}$ & deklarativ & BRIEF ERÖFFNEN \\
\hline 14.3 & 1 & $(2)$ & Accepi ab Aristocrito tris epistulas, & assertiv & BESTÄTIGEN \\
\hline 14.3 & 1 & $(3)$ & $\begin{array}{l}\text { quas ego lacrimis prope delevi. conficior enim } \\
\text { maerore, mea Terentia, }\end{array}$ & expressiv & JAMMERN \\
\hline 14.3 & 1 & (4) & $\begin{array}{l}\text { nec meae me miseriae magis excruciant quam } \\
\text { tuae vestraeque. }\end{array}$ & expressiv & $\begin{array}{l}\text { SICH ENTSCHULDI- } \\
\text { GEN }\end{array}$ \\
\hline 14.3 & 1 & $(5)$ & $\begin{array}{l}\text { ego autem hoc miserior sum quam tu, quae es } \\
\text { miserrima, quod ipsa calamitas communis est } \\
\text { utriusque nostrum, sed culpa mea propria est. }\end{array}$ & expressiv & JAMMERN \\
\hline 14.3 & 1 & $(6)$ & $\begin{array}{l}\text { meum fuit officium vel legatione vitare periculum } \\
\text { vel diligentia et copiis resistere vel cadere fortiter. }\end{array}$ & expressiv & $\begin{array}{l}\text { SICH ENTSCHULDI- } \\
\text { GEN }\end{array}$ \\
\hline 14.3 & 1 & $(7)$ & hoc miserius, turpius, indignius nobis nihil fuit. & expressiv & FLUCHEN \\
\hline 14.3 & 2 & $(8)$ & qua re cum dolore conficiar, & expressiv & JAMMERN \\
\hline 14.3 & 2 & (9) & $\begin{array}{l}\text { tum etiam pudore. pudet enim me uxori [mae] } \\
\text { optimae, suavissimis liberis virtutem et diligen- } \\
\text { tiam non praestitisse. }\end{array}$ & expressiv & $\begin{array}{l}\text { SICH ENTSCHULDI- } \\
\text { GEN }\end{array}$ \\
\hline 14.3 & 2 & $(10)$ & $\begin{array}{l}\text { nam mi ante oculos dies noctesque versatur } \\
\text { squalor vester et maeror et infirmitas valetudinis } \\
\text { tuae. }\end{array}$ & expressiv & $\begin{array}{l}\text { SICH ENTSCHULDI- } \\
\text { GEN }\end{array}$ \\
\hline 14.3 & 2 & $(11)$ & spes autem salutis pertenuis ostenditur. & expressiv & ANGST ÄUSSERN \\
\hline 14.3 & 2 & $(12)$ & inimici sunt multi, invidi paene omnes. & expressiv & FLUCHEN \\
\hline 14.3 & 2 & $(13)$ & eicere nos magnum fuit, excludere facile est. & expressiv & FLUCHEN \\
\hline 14.3 & 2 & $(14)$ & $\begin{array}{l}\text { sed tamen, quam diu vos eritis in spe, non defi- } \\
\text { ciam, ne omnia mea culpa cecidisse videantur. }\end{array}$ & kommissiv & VORSATZ BEKUNDEN \\
\hline
\end{tabular}




\begin{tabular}{|c|c|c|c|c|c|}
\hline 14.3 & 3 & $(15)$ & $\begin{array}{l}\text { Ut tuto sim quod laboras, id mihi nunc facillimum } \\
\text { est, quem etiam inimici volunt vivere in tantis mi- } \\
\text { seriis. }\end{array}$ & expressiv & FLUCHEN \\
\hline 14.3 & 3 & $(16)$ & ego tamen faciam quae praecipis. & kommissiv & VERSPRECHEN \\
\hline 14.3 & 3 & $(17)$ & amicis quibus voluisti egi gratias & assertiv & HINWEISEN \\
\hline 14.3 & 3 & $(18)$ & et eas litteras Dexippo dedi & assertiv & HINWEISEN \\
\hline 14.3 & 3 & (19) & $\begin{array}{l}\text { meque de eorum officio scripsi a te certiorem es- } \\
\text { se factum. }\end{array}$ & assertiv & HINWEISEN \\
\hline 14.3 & 3 & (20) & $\begin{array}{l}\text { Pisonem nostrum mirifico esse studio in nos et of- } \\
\text { ficio et ego perspicio et omnes praedicant. }\end{array}$ & expressiv & JUBELN \\
\hline 14.3 & 3 & $(21)$ & $\begin{array}{l}\text { di faxint, ut tali genero mihi praesenti tecum si- } \\
\text { mul et cum liberis nostris frui liceat! }\end{array}$ & expressiv & HOFFNUNG ÄUSSERN \\
\hline 14.3 & 3 & $(22)$ & $\begin{array}{l}\text { nunc spes reliqua est in novis tribunis pl. et in pri- } \\
\text { mis quidem diebus. }\end{array}$ & expressiv & HOFFNUNG ÄUSSERN \\
\hline 14.3 & 3 & $(23)$ & nam, si inveterarit, actum est. & expressiv & ANGST ÄUSSERN \\
\hline 14.3 & 4 & $(24)$ & $\begin{array}{l}\text { ea re ad te statim Aristocritum misi ut ad me con- } \\
\text { tinuo initia rerum et rationem totius negoti pos- } \\
\text { ses scribere; }\end{array}$ & direktiv & BITTEN \\
\hline 14.3 & 4 & $(25)$ & $\begin{array}{l}\text { etsi Dexippo quoque ita imperavi statim ut recur- } \\
\text { reret, }\end{array}$ & assertiv & HINWEISEN \\
\hline 14.3 & 4 & (26) & et ad fratrem misi ut crebro tabellarios mitteret. & assertiv & HINWEISEN \\
\hline 14.3 & 4 & $(27)$ & $\begin{array}{l}\text { nam ego eo nomine sum Dyrrachi hoc tempore ut } \\
\text { quam celerrime quid agatur audiam, }\end{array}$ & assertiv & HINWEISEN \\
\hline 14.3 & 4 & $(28)$ & $\begin{array}{l}\text { et sum tuto; civitas enim haec semper a me de- } \\
\text { fensa est. }\end{array}$ & assertiv & HINWEISEN \\
\hline 14.3 & 4 & (29) & $\begin{array}{l}\text { cum inimici nostri venire dicentur, tum in Epirum } \\
\text { ibo. }\end{array}$ & kommissiv & ABSICHT BEKUNDEN \\
\hline 14.3 & 5 & (30) & $\begin{array}{l}\text { Quod scribis te, si velim, ad me venturam, ego ve- } \\
\text { ro, cum sciam magnam partem istius oneris abs } \\
\text { te sustineri, te istic esse volo. }\end{array}$ & direktiv & BITTEN \\
\hline 14.3 & 5 & $(31)$ & si perficitis quod agitis, me ad vos venire oportet; & expressiv & HOFFNUNG ÄUSSERN \\
\hline 14.3 & 5 & $(32)$ & sin autem - sed nihil opus est reliqua scribere. & expressiv & ANGST ÄUSSERN \\
\hline 14.3 & 5 & $(33)$ & $\begin{array}{l}\text { ex primis aut summum secundis litteris tuis con- } \\
\text { stituere poterimus quid nobis faciendum sit. }\end{array}$ & assertiv & PROGNOSTIZIEREN \\
\hline 14.3 & 5 & $(34)$ & $\begin{array}{l}\text { tu modo ad me velim omnia diligentissime per- } \\
\text { scribas; }\end{array}$ & direktiv & BITTEN \\
\hline 14.3 & 5 & $(35)$ & $\begin{array}{l}\text { etsi magis iam rem quam litteras debeo }\langle\text { ex }\rangle \text { spec- } \\
\text { tare. }\end{array}$ & assertiv & PROGNOSTIZIEREN \\
\hline 14.3 & 5 & $(36)$ & Cura ut valeas & expressiv & $\begin{array}{l}\text { WOHLERGEHEN } \\
\text { WÜNSCHEN }\end{array}$ \\
\hline 14.3 & 5 & (37) & $\begin{array}{l}\text { et ita tibi persuadeas, mihi te carius nihil esse nec } \\
\text { umquam fuisse. }\end{array}$ & expressiv & GUNST ERWEISEN \\
\hline 14.3 & 5 & (38) & vale, mea Terentia [...]. vale. & expressiv & $\begin{array}{l}\text { WOHLERGEHEN } \\
\text { WÜNSCHEN }\end{array}$ \\
\hline 14.3 & 5 & (39) & $\begin{array}{l}\text { [...]; quam ego videre videor itaque debilitor lacri- } \\
\text { mis. }\end{array}$ & expressiv & $\begin{array}{l}\text { SICH ENTSCHULDI- } \\
\text { GEN }\end{array}$ \\
\hline 14.3 & 5 & $(40)$ & Prid. Kal. Dec. & assertiv & HINWEISEN \\
\hline
\end{tabular}




\begin{tabular}{|c|c|c|c|c|c|}
\hline 14.4 & & (1) & $\begin{array}{l}\text { TULLIUS S. D. TERENTIAE ET TULLIAE ET CICERONI } \\
\text { SUIS }\end{array}$ & deklarativ & BRIEF ERÖFFNEN \\
\hline 14.4 & 1 & $(2)$ & Ego minus saepe do ad vos litteras quam possum & assertiv & ZUGEBEN \\
\hline 14.4 & 1 & (3) & $\begin{array}{l}\text { propterea quod cum omnia mihi tempora sunt } \\
\text { misera, }\end{array}$ & expressiv & JAMMERN \\
\hline 14.4 & 1 & (4) & $\begin{array}{l}\text { tum vero, cum aut scribo ad vos aut vestras lego, } \\
\text { conficior lacrimis sic ut ferre non possim. }\end{array}$ & expressiv & JAMMERN \\
\hline 14.4 & 1 & (5) & $\begin{array}{l}\text { quod utinam minus vitae cupidi fuissemus! certe } \\
\text { nihil aut non multum in vita mali vidissemus. }\end{array}$ & expressiv & JAMMERN \\
\hline 14.4 & 1 & (6) & $\begin{array}{l}\text { quod si nos ad aliquam alicuius commodi aliquan- } \\
\text { do reciperandi spem fortuna reservavit, minus est } \\
\text { erratum a nobis; }\end{array}$ & expressiv & HOFFNUNG ÄUSSERN \\
\hline 14.4 & 1 & (7) & $\begin{array}{l}\text { si haec mala fixa sunt, ego vero te quam primum, } \\
\text { mea vita, cupio videre et in tuo complexu emori, }\end{array}$ & expressiv & ANGST ÄUSSERN \\
\hline 14.4 & 1 & (8) & $\begin{array}{l}\text { quoniam neque di, quos tu castissime coluisti, }[. . .] \\
\text { nobis gratiam rettulerunt. }\end{array}$ & expressiv & FLUCHEN \\
\hline 14.4 & 1 & (9) & $\begin{array}{l}\text { [quoniam neque ...] neque homines, quibus ego } \\
\text { semper servivi, nobis gratiam rettulerunt. }\end{array}$ & expressiv & FLUCHEN \\
\hline 14.4 & 2 & $(10)$ & $\begin{array}{l}\text { Nos Brundisi apud M. Laenium Flaccum dies XIII } \\
\text { fuimus, }\end{array}$ & assertiv & HINWEISEN \\
\hline 14.4 & 2 & $(11)$ & virum optimum, & expressiv & JUBELN \\
\hline 14.4 & 2 & $(12)$ & $\begin{array}{l}\text { qui periculum fortunarum et capitis sui prae mea } \\
\text { salute neglexit neque legis improbissimae poena } \\
\text { deductus est quo minus hospiti et amicitiae ius } \\
\text { officiumque praestaret. }\end{array}$ & expressiv & JUBELN \\
\hline 14.4 & 2 & $(13)$ & huic utinam aliquando gratiam referre possimus! & expressiv & HOFFNUNG ÄUSSERN \\
\hline 14.4 & 2 & $(14)$ & habebimus quidem semper. & expressiv & JUBELN \\
\hline 14.4 & 3 & $(15)$ & Brundisio profecti sumus a. d. II Kal. Mai. & assertiv & HINWEISEN \\
\hline 14.4 & 3 & $(16)$ & per Macedoniam Cyzicum petebamus. & assertiv & HINWEISEN \\
\hline 14.4 & 3 & $(17)$ & O me perditum, o me adflictum! & expressiv & JAMMERN \\
\hline 14.4 & 3 & $(18)$ & quid nunc? rogem te ut venias $[. .$.$] ? non rogem?$ & direktiv & $\begin{array}{l}\text { KOOPERATIONSFRA- } \\
\text { GE STELLEN }\end{array}$ \\
\hline 14.4 & 3 & $(19)$ & $\begin{array}{l}{[. . .], \text { mulierem aegram, et corpore et animo con- }} \\
\text { fectam }\end{array}$ & expressiv & SORGE BEKUNDEN \\
\hline 14.4 & 3 & $(20)$ & sine te igitur sim? & expressiv & ANGST ÄUSSERN \\
\hline 14.4 & 3 & $(21)$ & $\begin{array}{l}\text { opinor, sic agam: si est spes nostri reditus, eam } \\
\text { confirmes et rem adiuves; }\end{array}$ & direktiv & BITTEN \\
\hline 14.4 & 3 & $(22)$ & $\begin{array}{l}\text { sin [...] transactum est, quoquo modo potes, ad } \\
\text { me fac venias. }\end{array}$ & direktiv & BITTEN \\
\hline 14.4 & 3 & $(23)$ & {$[$ sin, ] ut ego metuo, [transactum est] } & expressiv & ANGST ÄUSSERN \\
\hline 14.4 & 3 & $(24)$ & $\begin{array}{l}\text { unum hoc scito: si te habebo, non mihi videbor } \\
\text { plane perisse. }\end{array}$ & expressiv & HOFFNUNG ÄUSSERN \\
\hline 14.4 & 3 & $(25)$ & sed quid Tulliola mea fiet? & direktiv & $\begin{array}{l}\text { KOOPERATIONSFRA- } \\
\text { GE STELLEN }\end{array}$ \\
\hline 14.4 & 3 & $(26)$ & $\begin{array}{l}\text { iam id vos videte; mihi deest consilium. sed certe, } \\
\text { quoquo modo se res habebit, illius misellae et } \\
\text { matrimonio et famae serviendum est. }\end{array}$ & direktiv & ANWEISEN \\
\hline
\end{tabular}




\begin{tabular}{|c|c|c|c|c|c|}
\hline 14.4 & 3 & $(27)$ & quid? Cicero meus quid aget? & expressiv & ANGST ÄUSSERN \\
\hline 14.4 & 3 & $(28)$ & iste vero sit in sinu semper et complexu meo. & expressiv & HOFFNUNG ÄUSSERN \\
\hline 14.4 & 3 & (29) & non queo plura iam scribere impedit maeror. & expressiv & JAMMERN \\
\hline 14.4 & 4 & $(30)$ & $\begin{array}{l}\text { Tu quid egeris nescio, utrum aliquid teneas an [...] } \\
\text { plane sis spoliata. }\end{array}$ & direktiv & $\begin{array}{l}\text { ANTEILNEHMENDE } \\
\text { FRAGE STELLEN }\end{array}$ \\
\hline 14.4 & 4 & $(31)$ & {$[\ldots]$, quod metuo, $[\ldots]$} & expressiv & SORGE BEKUNDEN \\
\hline 14.4 & 4 & (32) & Pisonem, ut scribis, spero fore semper nostrum. & expressiv & HOFFNUNG ÄUSSERN \\
\hline 14.4 & 4 & $(33)$ & de familia liberata, nihil est quod te moveat. & expressiv & $\begin{array}{l}\text { WOHLERGEHEN } \\
\text { WÜNSCHEN }\end{array}$ \\
\hline 14.4 & 4 & (34) & $\begin{array}{l}\text { primum tuis ita promissum est, te facturam esse } \\
\text { ut quisque esset meritus; }\end{array}$ & assertiv & BEGRÜNDEN \\
\hline 14.4 & 4 & $(35)$ & est autem in officio adhuc Orpheus, & assertiv & FESTSTELLEN \\
\hline 14.4 & 4 & $(36)$ & praeterea magno opere nemo. & assertiv & FESTSTELLEN \\
\hline 14.4 & 4 & $(37)$ & $\begin{array}{l}\text { ceterorum servorum ea causa est ut, si res a no- } \\
\text { bis abisset, liberti nostri essent, si obtinere potuis- } \\
\text { sent; sin ad nos pertinerent, servirent, praeter- } \\
\text { quam oppido pauci. }\end{array}$ & assertiv & BEGRÜNDEN \\
\hline 14.4 & 4 & $(38)$ & sed haec minora sunt. & assertiv & FESTSTELLEN \\
\hline 14.4 & 5 & $(39)$ & $\begin{array}{l}\text { Tu quod me hortaris ut animo sim magno et } \\
\text { spem habeam reciperandae salutis, id velim sit } \\
\text { eius modi ut recte sperare possimus. }\end{array}$ & expressiv & HOFFNUNG ÄUSSERN \\
\hline 14.4 & 5 & $(40)$ & $\begin{array}{l}\text { nunc miser quando tuas iam litteras accipiam? } \\
\text { quis ad me perferet? quas ego exspectassem } \\
\text { Brundisi si esset licitum per nautas, }\end{array}$ & expressiv & ANGST ÄUSSERN \\
\hline 14.4 & 5 & $(41)$ & qui tempestatem praetermittere noluerunt. & assertiv & HINWEISEN \\
\hline 14.4 & 5 & $(42)$ & $\begin{array}{l}\text { Quod reliquum est, sustenta te, mea Terentia, ut } \\
\text { potes honestissime. }\end{array}$ & expressiv & $\begin{array}{l}\text { WOHLERGEHEN } \\
\text { WÜNSCHEN }\end{array}$ \\
\hline 14.4 & 5 & $(43)$ & viximus, floruimus; & expressiv & FROHLOCKEN \\
\hline 14.4 & 5 & $(44)$ & non vitium nostrum sed virtus nostra nos adflixit. & expressiv & FLUCHEN \\
\hline 14.4 & 5 & $(45)$ & $\begin{array}{l}\text { peccatum est nullum, nisi quod non una animam } \\
\text { cum ornamentis amisimus. }\end{array}$ & expressiv & JAMMERN \\
\hline 14.4 & 5 & $(46)$ & $\begin{array}{l}\text { sed si hoc fuit liberis nostris gratius, nos vivere, } \\
\text { cetera, quamquam ferenda non sunt, feramus. }\end{array}$ & kommissiv & VORSATZ BEKUNDEN \\
\hline 14.4 & 5 & $(47)$ & atque ego, qui te confirmo, ipse me non possum. & expressiv & JAMMERN \\
\hline 14.4 & 6 & $(48)$ & Clodium Philetaerum [...] remisi. & assertiv & HINWEISEN \\
\hline 14.4 & 6 & $(49)$ & {$[\ldots]$, quod valetudine oculorum impediebatur, $[\ldots]$} & assertiv & HINWEISEN \\
\hline 14.4 & 6 & $(50)$ & {$[\ldots]$, hominem fidelem, $[\ldots]$} & expressiv & JUBELN \\
\hline 14.4 & 6 & $(51)$ & 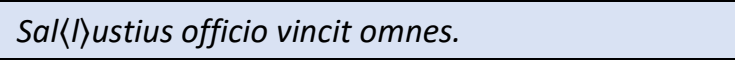 & expressiv & JUBELN \\
\hline 14.4 & 6 & $(52)$ & Pescennius est perbenevolus nobis; & expressiv & JUBELN \\
\hline 14.4 & 6 & $(53)$ & quem semper spero tui fore observantem. & expressiv & $\begin{array}{l}\text { WOHLERGEHEN } \\
\text { WÜNSCHEN }\end{array}$ \\
\hline 14.4 & 6 & $(54)$ & $\begin{array}{l}\text { Sicca dixerat se mecum fore sed Brundisio disces- } \\
\text { sit. }\end{array}$ & expressiv & FLUCHEN \\
\hline 14.4 & 6 & $(55)$ & Cura, quod potes, ut valeas & expressiv & $\begin{array}{l}\text { WOHLERGEHEN } \\
\text { WÜNSCHEN }\end{array}$ \\
\hline
\end{tabular}




\begin{tabular}{|c|c|c|c|c|c|}
\hline 14.4 & 6 & $(56)$ & $\begin{array}{l}\text { et sic existimes, me vehementius tua miseria } \\
\text { quam mea commoveri. }\end{array}$ & expressiv & $\begin{array}{l}\text { SICH ENTSCHULDI- } \\
\text { GEN }\end{array}$ \\
\hline 14.4 & 6 & $(57)$ & $\begin{array}{l}\text { mea Terentia, fidissima atque optima uxor, et } \\
\text { mea carissima filiola et spes reliqua nostra, Cice- } \\
\text { ro, valete. }\end{array}$ & expressiv & $\begin{array}{l}\text { WOHLERGEHEN } \\
\text { WÜNSCHEN }\end{array}$ \\
\hline 14.4 & 6 & $(58)$ & Prid. Kal. Mai. Brundisio. & assertiv & HINWEISEN \\
\hline 14.5 & & $(1)$ & TULLIUS S. D. TERENTIAE SUAE & deklarativ & BRIEF ERÖFFNEN \\
\hline 14.5 & 1 & $(2)$ & $\begin{array}{l}\text { Si tu et Tullia, lux nostra, valetis, ego et suavissi- } \\
\text { mus Cicero valemus. }\end{array}$ & expressiv & $\begin{array}{l}\text { WOHLERGEHEN } \\
\text { WÜNSCHEN }\end{array}$ \\
\hline 14.5 & 1 & (3) & Prid. Id. Oct. Athenas venimus, & assertiv & HINWEISEN \\
\hline 14.5 & 1 & (4) & $\begin{array}{l}\text { cum sane adversis ventis usi essemus tardeque et } \\
\text { incommode navigassemus. }\end{array}$ & assertiv & HINWEISEN \\
\hline 14.5 & 1 & (5) & $\begin{array}{l}\text { de nave exeuntibus nobis Acastus cum litteris } \\
\text { praesto fuit }\end{array}$ & assertiv & HINWEISEN \\
\hline 14.5 & 1 & (6) & uno et vice $\langle n\rangle$ simo die & assertiv & MITTEILEN \\
\hline 14.5 & 1 & (7) & sane strenue. & expressiv & JUBELN \\
\hline 14.5 & 1 & $(8)$ & accepi tuas litteras, & assertiv & BESTÄTIGEN \\
\hline 14.5 & 1 & (9) & $\begin{array}{l}\text { quibus intellexi te vereri ne superiores mihi reddi- } \\
\text { tae non essent. omnes sunt redditae }\end{array}$ & assertiv & BESTÄTIGEN \\
\hline 14.5 & 1 & $(10)$ & diligentissimeque a te perscripta sunt omnia, & expressiv & BEGRÜSSEN \\
\hline 14.5 & 1 & $(11)$ & idque mihi gratissimum fuit. & expressiv & DANKEN \\
\hline 14.5 & 1 & $(12)$ & $\begin{array}{l}\text { neque sum admiratus hanc epistulam quam } \\
\text { Acastus attulit brevem fuisse. }\end{array}$ & expressiv & BEGRÜSSEN \\
\hline 14.5 & 1 & $(13)$ & iam enim me ipsum exspectas, sive nos ipsos, & assertiv & VERMUTEN \\
\hline 14.5 & 1 & $(14)$ & qui quidem quam primum ad vos venire cupimus, & kommissiv & ABSICHT BEKUNDEN \\
\hline 14.5 & 1 & $(15)$ & $\begin{array}{l}\text { etsi in quam rem publicam veni }\langle a\rangle \text { mus intellego. } \\
\text { cognovi enim [...] ad arma rem spectare, }\end{array}$ & assertiv & PROGNOSTIZIEREN \\
\hline 14.5 & 1 & $(16)$ & $\begin{array}{l}{[. . .] \text { ex multorum amicorum litteris, quas attulit }} \\
\text { Acastus, }[. . .]\end{array}$ & assertiv & MITTEILEN \\
\hline 14.5 & 1 & $(17)$ & $\begin{array}{l}\text { ut mihi, cum venero, dissimulare non liceat quid } \\
\text { sentiam. }\end{array}$ & assertiv & PROGNOSTIZIEREN \\
\hline 14.5 & 1 & $(18)$ & sed quoniam subeunda fortuna est, & assertiv & FESTSTELLEN \\
\hline 14.5 & 1 & (19) & $\begin{array}{l}\text { eo citius dabimus operam ut veniamus, quo } \\
\text { facilius de tota re deliberemus. }\end{array}$ & kommissiv & ABSICHT BEKUNDEN \\
\hline 14.5 & 1 & $(20)$ & $\begin{array}{l}\text { tu velim, quod commodo valetudinis tuae fiat, } \\
\text { quam longissime poteris obviam nobis prodeas. }\end{array}$ & direktiv & BITTEN \\
\hline 14.5 & 2 & $(21)$ & $\begin{array}{l}\text { De hereditate Preciana, [...] - sed hoc velim cures, } \\
\text { si auctio ante meum adventum fiet, ut Pompo- } \\
\text { nius aut, si is minus poterit, Camillus nostrum ne- } \\
\text { gotium curet; }\end{array}$ & direktiv & BITTEN \\
\hline 14.5 & 2 & $(22)$ & $\begin{array}{l}\text { [...] quae quidem mihi magno dolori est (valde } \\
\text { enim illum amavi) [...] }\end{array}$ & expressiv & JAMMERN \\
\hline 14.5 & 2 & $(23)$ & nos, cum [...] venerimus, reliqua per nos agemus. & kommissiv & ABSICHT BEKUNDEN \\
\hline 14.5 & 2 & $(24)$ & {$[\ldots]$ salvi $[\ldots]$} & expressiv & HOFFNUNG ÄUSSERN \\
\hline 14.5 & 2 & (25) & $\begin{array}{l}\text { sin tu iam Roma profecta eris, tamen curabis ut } \\
\text { hoc ita fiat. }\end{array}$ & direktiv & BITTEN \\
\hline
\end{tabular}




\begin{tabular}{|c|c|c|c|c|c|}
\hline 14.5 & 2 & $(26)$ & $\begin{array}{l}\text { nos, si di adiuvabunt, circiter Id. Nov. in Italia spe- } \\
\text { ramus fore. }\end{array}$ & expressiv & HOFFNUNG ÄUSSERN \\
\hline 14.5 & 2 & $(27)$ & $\begin{array}{l}\text { vos, mea suavissima et optatissima Terentia, si } \\
\text { nos amatis, curate ut valeatis. }\end{array}$ & expressiv & $\begin{array}{l}\text { WOHLERGEHEN } \\
\text { WÜNSCHEN }\end{array}$ \\
\hline 14.5 & 2 & $(28)$ & Vale. & deklarativ & BRIEF BEENDEN \\
\hline 14.5 & 2 & (29) & Athenis a. d. XV $\langle I I\rangle$ Kal. Nov. & assertiv & HINWEISEN \\
\hline 14.6 & & $(1)$ & SUIS S. D. & deklarativ & BRIEF ERÖFFNEN \\
\hline 14.6 & & $(2)$ & Nec saepe est cui litteras demus & assertiv & BEGRÜNDEN \\
\hline 14.6 & & (3) & nec rem habemus ullam quam scribere velimus. & assertiv & BEGRÜNDEN \\
\hline 14.6 & & (4) & $\begin{array}{l}\text { ex tuis litteris quas proxime accepi cognovi prae- } \\
\text { dium nullum venire potuisse. qua re videatis ve- } \\
\text { lim quo modo satis fiat ei cui scitis me satis fieri } \\
\text { velle. }\end{array}$ & direktiv & ANWEISEN \\
\hline 14.6 & & $(5)$ & $\begin{array}{l}\text { quod nostra tibi gratias agit, id ego non miror, te } \\
\text { mereri ut ea tibi merito tuo gratias agere possit. }\end{array}$ & expressiv & $\begin{array}{l}\text { KOMPLIMENT MA- } \\
\text { CHEN }\end{array}$ \\
\hline 14.6 & & $(6)$ & $\begin{array}{l}\text { Pollicem, si adhuc non est profectus, quam pri- } \\
\text { mum fac extrudas. }\end{array}$ & direktiv & BITTEN \\
\hline 14.6 & & (7) & Cura ut valeas. & expressiv & $\begin{array}{l}\text { WOHLERGEHEN } \\
\text { WÜNSCHEN }\end{array}$ \\
\hline 14.6 & & (8) & Id. Quint. & assertiv & HINWEISEN \\
\hline 14.7 & & (1) & TULLIUS TERENTIAE SUAE S. P. & expressiv & GUNST ERWEISEN \\
\hline 14.7 & 1 & $(2)$ & $\begin{array}{l}\text { Omnis molestias et sollicitudines [...] deposui et } \\
\text { eieci. }\end{array}$ & assertiv & HINWEISEN \\
\hline 14.7 & 1 & (3) & $\begin{array}{l}\text { quibus et te miserrimam habui, id quod mihi mo- } \\
\text { lestissimum est, }\end{array}$ & expressiv & $\begin{array}{l}\text { SICH ENTSCHULDI- } \\
\text { GEN }\end{array}$ \\
\hline 14.7 & 1 & (4) & et Tulliolam, quae nobis nostra vita dulcior est, & expressiv & JAMMERN \\
\hline 14.7 & 1 & (5) & 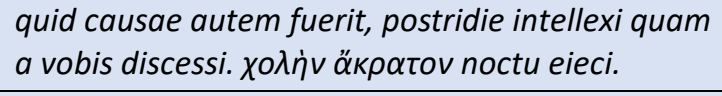 & assertiv & HINWEISEN \\
\hline 14.7 & 1 & (6) & $\begin{array}{l}\text { statim ita sum levatus ut mihi deus aliquis medici- } \\
\text { nam fecisse videatur. }\end{array}$ & expressiv & JUBELN \\
\hline 14.7 & 1 & (7) & $\begin{array}{l}\text { cui quidem tu deo, quem ad modum soles, pie et } \\
\text { caste satis facies [id est Apollini et Aesculapio]. }\end{array}$ & direktiv & BITTEN \\
\hline 14.7 & 2 & (8) & Navem spero nos valde bonam habere. & expressiv & HOFFNUNG ÄUSSERN \\
\hline 14.7 & 2 & (9) & in eam simul atque conscendi, haec scripsi. & assertiv & MITTEILEN \\
\hline 14.7 & 2 & $(10)$ & $\begin{array}{l}\text { deinde conscribam ad nostros familiaris multas } \\
\text { epistulas, quibus te et Tulliolam nostram dili- } \\
\text { gentissime commendabo. }\end{array}$ & kommissiv & VERSPRECHEN \\
\hline 14.7 & 2 & $(11)$ & $\begin{array}{l}\text { cohortarer vos quo animo fortiores essetis nisi } \\
\text { vos fortiores cognossem quam quemquam virum. }\end{array}$ & expressiv & $\begin{array}{l}\text { KOMPLIMENT MA- } \\
\text { CHEN }\end{array}$ \\
\hline 14.7 & 2 & $(12)$ & $\begin{array}{l}\text { et tamen eius modi spero negotia esse ut et vos } \\
\text { istic commodissime sperem esse }\end{array}$ & expressiv & $\begin{array}{l}\text { WOHLERGEHEN } \\
\text { WÜNSCHEN }\end{array}$ \\
\hline 14.7 & 2 & $(13)$ & $\begin{array}{l}\text { et me aliquando cum similibus nostri rem publi- } \\
\text { cam defensuros. }\end{array}$ & expressiv & HOFFNUNG ÄUSSERN \\
\hline 14.7 & 3 & (14) & tu primum valetudinem tuam velim cures; & expressiv & $\begin{array}{l}\text { WOHLERGEHEN } \\
\text { WÜNSCHEN }\end{array}$ \\
\hline 14.7 & 3 & $(15)$ & $\begin{array}{l}\text { deinde, si tibi videbitur, villis iis utere quae longis- } \\
\text { sime aberunt a militibus. }\end{array}$ & direktiv & RATEN \\
\hline
\end{tabular}




\begin{tabular}{|c|c|c|c|c|c|}
\hline 14.7 & 3 & $(16)$ & $\begin{array}{l}\text { fundo Arpinati bene poteris uti cum familia urba- } \\
\text { na si annona carior fuerit. }\end{array}$ & direktiv & RATEN \\
\hline 14.7 & 3 & $(17)$ & Cicero bellissimus tibi salutem plurimam dicit. & assertiv & HINWEISEN \\
\hline 14.7 & 3 & $(18)$ & etiam atque etiam vale. & expressiv & $\begin{array}{l}\text { WOHLERGEHEN } \\
\text { WÜNSCHEN }\end{array}$ \\
\hline 14.7 & 3 & (19) & D. VII Id. Iun. & assertiv & HINWEISEN \\
\hline 14.8 & & $(1)$ & TULLIUS TERENTIAE SUAE S. & deklarativ & BRIEF ERÖFFNEN \\
\hline 14.8 & & $(2)$ & Si vales, bene est; ego valeo. & expressiv & $\begin{array}{l}\text { WOHLERGEHEN } \\
\text { WÜNSCHEN }\end{array}$ \\
\hline 14.8 & & (3) & Valetudinem tuam velim cures diligentissime. & expressiv & $\begin{array}{l}\text { WOHLERGEHEN } \\
\text { WÜNSCHEN }\end{array}$ \\
\hline 14.8 & & (4) & $\begin{array}{l}\text { nam mihi et scriptum et nuntiatum est te in fe- } \\
\text { brim subito incidisse. }\end{array}$ & assertiv & HINWEISEN \\
\hline 14.8 & & $(5)$ & $\begin{array}{l}\text { quod celeriter me fecisti de Caesaris litteris certio- } \\
\text { rem, }\end{array}$ & expressiv & BEGRÜSSEN \\
\hline 14.8 & & $(6)$ & fecisti mihi gratum. & expressiv & DANKEN \\
\hline 14.8 & & (7) & $\begin{array}{l}\text { item posthac, si quid opus erit, si quid acciderit } \\
\text { novi, facies ut sciam. }\end{array}$ & direktiv & BITTEN \\
\hline 14.8 & & (8) & cura ut valeas. & expressiv & $\begin{array}{l}\text { WOHLERGEHEN } \\
\text { WÜNSCHEN }\end{array}$ \\
\hline 14.8 & & (9) & Vale. & deklarativ & BRIEF BEENDEN \\
\hline 14.8 & & $(10)$ & D. III Non. Iun. & assertiv & HINWEISEN \\
\hline 14.9 & & (1) & TULLIUS TERENTIAE SUAE S. P. & expressiv & GUNST ERWEISEN \\
\hline 14.9 & & $(2)$ & $\begin{array}{l}\text { Ad ceteras meas miserias accessit dolor et de Do- } \\
\text { labellae valetudine et de Tulliae. }\end{array}$ & expressiv & JAMMERN \\
\hline 14.9 & & (3) & $\begin{array}{l}\text { omnino de omnibus rebus nec quid consili capiam } \\
\text { nec quid faciam scio. }\end{array}$ & expressiv & ANGST ÄUSSERN \\
\hline 14.9 & & (4) & tu velim tuam et Tulliae valetudinem cures. & expressiv & $\begin{array}{l}\text { WOHLERGEHEN } \\
\text { WÜNSCHEN }\end{array}$ \\
\hline 14.9 & & (5) & Vale. & deklarativ & BRIEF BEENDEN \\
\hline 14.10 & & $(1)$ & TULLIUS S. D. TERENTIAE SUAE & deklarativ & BRIEF ERÖFFNEN \\
\hline 14.10 & & $(2)$ & Quid fieri placeret scripsi ad Pomponium, & assertiv & HINWEISEN \\
\hline 14.10 & & (3) & serius quam oportuit. & expressiv & FLUCHEN \\
\hline 14.10 & & (4) & cum eo si locuta eris, intelleges quid fieri velim. & direktiv & BITTEN \\
\hline 14.10 & & $(5)$ & $\begin{array}{l}\text { apertius scribi, quoniam ad illum scripseram, ne- } \\
\text { cesse non fuit. }\end{array}$ & assertiv & HINWEISEN \\
\hline 14.10 & & (6) & $\begin{array}{l}\text { de ea re et de ceteris rebus quam primum velim } \\
\text { nobis litteras mittas. }\end{array}$ & direktiv & BITTEN \\
\hline 14.10 & & (7) & valetudinem tuam cura diligenter. & expressiv & $\begin{array}{l}\text { WOHLERGEHEN } \\
\text { WÜNSCHEN }\end{array}$ \\
\hline 14.10 & & $(8)$ & Vale. & deklarativ & BRIEF BEENDEN \\
\hline 14.10 & & (9) & VII Id. Quint. & assertiv & HINWEISEN \\
\hline 14.11 & & $(1)$ & TULLIUS S. D. TERENTIAE SUAE & deklarativ & BRIEF ERÖFFNEN \\
\hline 14.11 & & $(2)$ & S. v. b.; e. v. & expressiv & $\begin{array}{l}\text { WOHLERGEHEN } \\
\text { WÜNSCHEN }\end{array}$ \\
\hline 14.11 & & (3) & Tullia nostra venit ad me prid. Id. Iun. & assertiv & BENACHRICHTIGEN \\
\hline
\end{tabular}




\begin{tabular}{|c|c|c|c|c|c|}
\hline 14.11 & & $(4)$ & $\begin{array}{l}\text { cuius summa virtute et singulari humanitate gra- } \\
\text { viore etiam sum dolore adfectus nostra factum } \\
\text { esse neglegentia ut longe alia in fortuna esset at- } \\
\text { que eius pietas ac dignitas postulabat. }\end{array}$ & expressiv & JAMMERN \\
\hline 14.11 & & $(5)$ & $\begin{array}{l}\text { Nobis erat in animo Ciceronem ad Caesarem mit- } \\
\text { tere }\end{array}$ & kommissiv & ABSICHT BEKUNDEN \\
\hline 14.11 & & $(6)$ & et cum eo Cn. Sallustium. & kommissiv & ABSICHT BEKUNDEN \\
\hline 14.11 & & (7) & si profectus erit, faciam te certiorem. & kommissiv & VERSPRECHEN \\
\hline 14.11 & & $(8)$ & valetudinem tuam cura diligenter. & expressiv & $\begin{array}{l}\text { WOHLERGEHEN } \\
\text { WÜNSCHEN }\end{array}$ \\
\hline 14.11 & & (9) & Vale. & deklarativ & BRIEF BEENDEN \\
\hline 14.11 & & $(10)$ & XVII Kal. Quint. & assertiv & HINWEISEN \\
\hline 14.12 & & $(1)$ & TULLIUS TERENTIAE SUAE S. D. & deklarativ & BRIEF ERÖFFNEN \\
\hline 14.12 & & $(2)$ & $\begin{array}{l}\text { Quod nos in Italiam salvos venisse gaudes, perpe- } \\
\text { tuo gaudeas velim. }\end{array}$ & expressiv & HOFFNUNG ÄUSSERN \\
\hline 14.12 & & (3) & $\begin{array}{l}\text { sed perturbati dolore animi magnisque }\langle\text { meorum }\rangle \\
\text { iniuriis metuo ne id consili ceperimus quod non } \\
\text { facile explicare possimus. }\end{array}$ & expressiv & ANGST ÄUSSERN \\
\hline 14.12 & & $(4)$ & Qua re, quantum potes, adiuva; & direktiv & BITTEN \\
\hline 14.12 & & (5) & quid autem possis mihi in mentem non venit. & assertiv & HINWEISEN \\
\hline 14.12 & & (6) & in viam quod te des hoc tempore nihil est. & direktiv & ANWEISEN \\
\hline 14.12 & & (7) & et longum est iter & assertiv & BEGRÜNDEN \\
\hline 14.12 & & $(8)$ & et non tutum; & assertiv & BEGRÜNDEN \\
\hline 14.12 & & (9) & et non video quid prodesse possis si veneris. & assertiv & BEGRÜNDEN \\
\hline 14.12 & & $(10)$ & Vale. & deklarativ & BRIEF BEENDEN \\
\hline 14.12 & & $(11)$ & D. prid. Non. Nov. Brundisio. & assertiv & HINWEISEN \\
\hline 14.13 & & $(1)$ & TULLIUS S. D. TERENTIAE SUAE & deklarativ & BRIEF ERÖFFNEN \\
\hline 14.13 & & $(2)$ & $\begin{array}{l}\text { Quod scripsi ad te proximis litteris de nuntio re- } \\
\text { mittendo, quae sit istius vis hoc tempore et quae } \\
\text { concitatio multitudinis ignoro. }\end{array}$ & assertiv & HINWEISEN \\
\hline 14.13 & & (3) & si metuendus iratus est, quiesces. & direktiv & ANWEISEN \\
\hline 14.13 & & $(4)$ & tamen ab illo fortasse nascetur. & assertiv & PROGNOSTIZIEREN \\
\hline 14.13 & & $(5)$ & totum iudicabis quale sit, & direktiv & ANWEISEN \\
\hline 14.13 & & $(6)$ & $\begin{array}{l}\text { et quod in miserrimis rebus minime miserum pu- } \\
\text { tabis id facies. }\end{array}$ & direktiv & ANWEISEN \\
\hline 14.13 & & $(7)$ & Vale. & deklarativ & BRIEF BEENDEN \\
\hline 14.13 & & $(8)$ & VI Id. Quint. & assertiv & HINWEISEN \\
\hline 14.14 & & $(1)$ & $\begin{array}{l}\text { TULLIUS TERENTIAE ET PATER TULLIAE, DUABUS } \\
\text { ANIMIS SUIS, ET CICERO MATRI OPTIMAE, SUA- } \\
\text { VISSIMAE SORORI S. P. D. }\end{array}$ & expressiv & GUNST ERWEISEN \\
\hline 14.14 & 1 & $(2)$ & Si vos valetis, nos valemus. & expressiv & $\begin{array}{l}\text { WOHLERGEHEN } \\
\text { WÜNSCHEN }\end{array}$ \\
\hline 14.14 & 1 & $(3)$ & $\begin{array}{l}\text { Vestrum iam consilium est, non solum meum, } \\
\text { quid sit vobis faciendum. }\end{array}$ & direktiv & RATEN \\
\hline 14.14 & 1 & $(4)$ & $\begin{array}{l}\text { si ille Romam modeste venturus est, recte in prae- } \\
\text { sentia domi esse potestis; }\end{array}$ & expressiv & $\begin{array}{l}\text { WOHLERGEHEN } \\
\text { WÜNSCHEN }\end{array}$ \\
\hline
\end{tabular}




\begin{tabular}{|c|c|c|c|c|c|}
\hline 14.14 & 1 & (5) & $\begin{array}{l}\text { sin homo amens diripiendam urbem daturus est, } \\
\text { vereor ut Dolabella ipse satis nobis prodesse pos- } \\
\text { sit. }\end{array}$ & expressiv & SORGE BEKUNDEN \\
\hline 14.14 & 1 & (6) & $\begin{array}{l}\text { etiam illud metuo, ne iam intercludamur, ut, cum } \\
\text { velitis, exire non liceat. }\end{array}$ & expressiv & SORGE BEKUNDEN \\
\hline 14.14 & 1 & (7) & $\begin{array}{l}\text { reliquum est, quod ipsae optime considerabitis, } \\
\text { vestri similes feminae sintne Romae. }\end{array}$ & direktiv & RATEN \\
\hline 14.14 & 1 & (8) & $\begin{array}{l}\text { si enim non sunt, videndum est ut honeste vos es- } \\
\text { se possitis. }\end{array}$ & direktiv & RATEN \\
\hline 14.14 & 1 & (9) & $\begin{array}{l}\text { quo modo quidem nunc se res habet, modo ut } \\
\text { haec nobis loca tenere liceat, bellissime vel me- } \\
\text { cum vel in nostris praediis esse poteritis. }\end{array}$ & expressiv & $\begin{array}{l}\text { WOHLERGEHEN } \\
\text { WÜNSCHEN }\end{array}$ \\
\hline 14.14 & 1 & (10) & $\begin{array}{l}\text { etiam illud verendum est, ne brevi tempore fames } \\
\text { in urbe sit. }\end{array}$ & expressiv & SORGE BEKUNDEN \\
\hline 14.14 & 2 & (11) & $\begin{array}{l}\text { his de rebus velim cum Pomponio, cum Camillo, } \\
\text { cum quibus vobis videbitur, consideretis, }\end{array}$ & direktiv & RATEN \\
\hline 14.14 & 2 & (12) & ad summam animo forti sitis. & expressiv & $\begin{array}{l}\text { WOHLERGEHEN } \\
\text { WÜNSCHEN }\end{array}$ \\
\hline 14.14 & 2 & (13) & Labienus rem meliorem fecit; & expressiv & JUBELN \\
\hline 14.14 & 2 & (14) & $\begin{array}{l}\text { adiuvat etiam Piso, quod ab urbe discedit et sce- } \\
\text { leris condemnat generum suum. }\end{array}$ & expressiv & JUBELN \\
\hline 14.14 & 2 & (15) & $\begin{array}{l}\text { Vos, meae carissimae animae, quam saepissime } \\
\text { ad me scribite et vos quid agatis et quid istic aga- } \\
\text { tur. }\end{array}$ & direktiv & BITTEN \\
\hline 14.14 & 2 & (16) & Quintus pater et filius et Rufus vobis s. $d$. & assertiv & HINWEISEN \\
\hline 14.14 & 2 & (17) & Valete. & deklarativ & BRIEF BEENDEN \\
\hline 14.14 & 2 & (18) & VIIII Kal. Febr. Minturnis. & assertiv & HINWEISEN \\
\hline 14.15 & & (1) & TULLIUS S. D. TERENTIAE & deklarativ & BRIEF ERÖFFNEN \\
\hline 14.15 & & (2) & Si vales, bene est. & expressiv & $\begin{array}{l}\text { WOHLERGEHEN } \\
\text { WÜNSCHEN }\end{array}$ \\
\hline 14.15 & & (3) & $\begin{array}{l}\text { Constitueramus, ut ad te antea scripseram, ob- } \\
\text { viam Ciceronem Caesari mittere; sed mutavimus } \\
\text { consilium }\end{array}$ & assertiv & BENACHRICHTIGEN \\
\hline 14.15 & & (4) & quia de illius adventu nihil audiebamus. & assertiv & HINWEISEN \\
\hline 14.15 & & (5) & $\begin{array}{l}\text { de ceteris rebus [...] (tamen) quid velimus et quid } \\
\text { hoc tempore putemus opus esse ex Sicca poteris } \\
\text { cognoscere. }\end{array}$ & direktiv & BITTEN \\
\hline 14.15 & & (6) & {$[\ldots]$, etsi nihil erat novi, $[\ldots]$} & assertiv & HINWEISEN \\
\hline 14.15 & & (7) & Tulliam adhuc mecum teneo. & assertiv & BENACHRICHTIGEN \\
\hline 14.15 & & (8) & valetudinem tuam cura diligenter. & expressiv & $\begin{array}{l}\text { WOHLERGEHEN } \\
\text { WÜNSCHEN }\end{array}$ \\
\hline 14.15 & & (9) & Vale. & deklarativ & BRIEF BEENDEN \\
\hline 14.15 & & (10) & XII Kal. Quint. & assertiv & HINWEISEN \\
\hline 14.16 & & (1) & TULLIUS TERENTIAE SUAE S. D. & deklarativ & BRIEF ERÖFFNEN \\
\hline 14.16 & & (2) & S. v. b.; e.v. & expressiv & $\begin{array}{l}\text { WOHLERGEHEN } \\
\text { WÜNSCHEN }\end{array}$ \\
\hline
\end{tabular}




\begin{tabular}{|c|c|c|c|c|c|}
\hline 14.16 & & (3) & $\begin{array}{l}\text { Etsi eius modi tempora nostra sunt ut nihil habe- } \\
\text { am quod [aut] a te litterarum exspectem [...], ta- } \\
\text { men nescio quo modo [et ipse] vestras litteras ex- } \\
\text { specto [et ...]. }\end{array}$ & expressiv & HOFFNUNG ÄUSSERN \\
\hline 14.16 & & (4) & $\begin{array}{l}\text { Etsi eius modi tempora nostra sunt ut nihil habe- } \\
\text { am quod [aut ... aut ipse] ad te scribam [...], ta- } \\
\text { men nescio quo modo [et ... et] scribo ad vos cum } \\
\text { habeo qui ferat. }\end{array}$ & assertiv & HINWEISEN \\
\hline 14.16 & & (5) & $\begin{array}{l}\text { Volumnia debuit in te officiosior esse quam fuit et } \\
\text { id ipsum quod fecit potuit diligentius facere et } \\
\text { cautius. }\end{array}$ & expressiv & $\begin{array}{l}\text { BEDAUERN BEKUN- } \\
\text { DEN }\end{array}$ \\
\hline 14.16 & & (6) & $\begin{array}{l}\text { quamquam alia sunt quae magis curemus magis- } \\
\text { que doleamus; }\end{array}$ & kommissiv & ABSICHT BEKUNDEN \\
\hline 14.16 & & (7) & $\begin{array}{l}\text { quae me ita conficiunt ut ii voluerunt qui me de } \\
\text { mea sententia detruserunt. }\end{array}$ & expressiv & FLUCHEN \\
\hline 14.16 & & (8) & cura ut valeas. & expressiv & $\begin{array}{l}\text { WOHLERGEHEN } \\
\text { WÜNSCHEN }\end{array}$ \\
\hline 14.16 & & (9) & Vale. & deklarativ & BRIEF BEENDEN \\
\hline 14.16 & & (10) & Prid. Non. Ian. & assertiv & HINWEISEN \\
\hline 14.17 & & (1) & TULLIUS TERENTIAE SUAE S. D. & deklarativ & BRIEF ERÖFFNEN \\
\hline 14.17 & & $(2)$ & S. v. b.; e. v. & expressiv & $\begin{array}{l}\text { WOHLERGEHEN } \\
\text { WÜNSCHEN }\end{array}$ \\
\hline 14.17 & & (3) & $\begin{array}{l}\text { Si quid haberem quod ad te scriberem, facerem id } \\
\text { et pluribus verbis et saepius. }\end{array}$ & assertiv & BEGRÜNDEN \\
\hline 14.17 & & (4) & nunc, quae sint negotia, vides. & direktiv & BITTEN \\
\hline 14.17 & & $(5)$ & $\begin{array}{l}\text { ego autem quo modo sim affectus, ex Lepta et } \\
\text { Trebatio poteris cognoscere. }\end{array}$ & direktiv & RATEN \\
\hline 14.17 & & (6) & tu fac ut tuam et Tulliae valetudinem cures. & expressiv & $\begin{array}{l}\text { WOHLERGEHEN } \\
\text { WÜNSCHEN }\end{array}$ \\
\hline 14.17 & & (7) & Vale. & deklarativ & BRIEF BEENDEN \\
\hline 14.18 & & (1) & $\begin{array}{l}\text { TULLIUS TERENTIAE SUAE ET PATER SUAVISSI- } \\
\text { MAE FILIAE, CICERO MATRI ET SORORI S. D. P. }\end{array}$ & expressiv & GUNST ERWEISEN \\
\hline 14.18 & 1 & $(2)$ & $\begin{array}{l}\text { Considerandum vobis etiam atque etiam, animae } \\
\text { meae, diligenter puto quid faciatis. Romaene sitis } \\
\text { an mecum an aliquo tuto loco. id non solum me- } \\
\text { um consilium est sed etiam vestrum. }\end{array}$ & direktiv & RATEN \\
\hline 14.18 & 1 & (3) & $\begin{array}{l}\text { Mihi veniunt in mentem haec: Romae vos esse tu- } \\
\text { to posse per Dolabellam eamque rem posse nobis } \\
\text { adiumento esse si quae vis aut si quae rapinae } \\
\text { fieri coeperint; }\end{array}$ & expressiv & $\begin{array}{l}\text { WOHLERGEHEN } \\
\text { WÜNSCHEN }\end{array}$ \\
\hline 14.18 & 1 & (4) & $\begin{array}{l}\text { sed rursus illud me movet, quod video omnis bo- } \\
\text { nos abesse Roma }\end{array}$ & expressiv & SORGE BEKUNDEN \\
\hline 14.18 & 1 & $(5)$ & et eos mulieres suas secum habere. & expressiv & SORGE BEKUNDEN \\
\hline 14.18 & 1 & (6) & $\begin{array}{l}\text { haec autem regio in qua ego sum nostrorum est } \\
\text { cum oppidorum tum etiam praediorum, }\end{array}$ & assertiv & HINWEISEN \\
\hline 14.18 & 1 & (7) & $\begin{array}{l}\text { ut et multum esse mecum et, cum aberitis, com- } \\
\text { mode et in nostris esse possitis. }\end{array}$ & expressiv & $\begin{array}{l}\text { WOHLERGEHEN } \\
\text { WÜNSCHEN }\end{array}$ \\
\hline 14.18 & 2 & (8) & $\begin{array}{l}\text { mihi plane non satis constat adhuc utrum sit me- } \\
\text { lius. }\end{array}$ & assertiv & HINWEISEN \\
\hline
\end{tabular}




\begin{tabular}{|c|c|c|c|c|c|}
\hline 14.18 & 2 & (9) & vos videte quid aliae faciant isto loco feminae & direktiv & RATEN \\
\hline 14.18 & 2 & (10) & et ne, cum velitis, exire non liceat. & expressiv & SORGE BEKUNDEN \\
\hline 14.18 & 2 & $(11)$ & $\begin{array}{l}\text { id velim diligenter etiam atque etiam vobiscum et } \\
\text { cum amicis consideretis. }\end{array}$ & direktiv & RATEN \\
\hline 14.18 & 2 & $(12)$ & $\begin{array}{l}\text { domus ut propugnacula et prae }\langle\text { si }\rangle \text { dium habeat } \\
\text { Philotimo dicetis. }\end{array}$ & direktiv & ANWEISEN \\
\hline 14.18 & 2 & (13) & $\begin{array}{l}\text { et velim tabellarios instituatis certos ut cottidie } \\
\text { aliquas a vobis litteras accipiam. }\end{array}$ & direktiv & BITTEN \\
\hline 14.18 & 2 & (14) & $\begin{array}{l}\text { maxime autem date operam ut valeatis, si nos } \\
\text { vultis valere. }\end{array}$ & expressiv & $\begin{array}{l}\text { WOHLERGEHEN } \\
\text { WÜNSCHEN }\end{array}$ \\
\hline 14.18 & 2 & (15) & VIIII Kal. Form $\langle i\rangle s$ & assertiv & HINWEISEN \\
\hline 14.19 & & $(1)$ & TULLIUS TERENTIAE SUAE S. D. & deklarativ & BRIEF ERÖFFNEN \\
\hline 14.19 & & $(2)$ & $\begin{array}{l}\text { In maximis meis doloribus excruciat me valetudo } \\
\text { Tulliae nostrae, }\end{array}$ & expressiv & JAMMERN \\
\hline 14.19 & & (3) & $\begin{array}{l}\text { de qua nihil est quod ad te plura scribam; tibi } \\
\text { enim aeque magnae curae esse certo scio. }\end{array}$ & assertiv & HINWEISEN \\
\hline 14.19 & & (4) & $\begin{array}{l}\text { quod me propius vultis accedere, video ita esse } \\
\text { faciendum }\end{array}$ & assertiv & ZUSTIMMEN \\
\hline 14.19 & & $(5)$ & et iam ante fecissem, sed me multa impediverunt, & assertiv & BEGRÜNDEN \\
\hline 14.19 & & (6) & quae ne nunc quidem expedita sunt. & assertiv & BEGRÜNDEN \\
\hline 14.19 & & (7) & sed a Pomponio exspecto litteras, & assertiv & PROGNOSTIZIEREN \\
\hline 14.19 & & (8) & $\begin{array}{l}\text { quas ad me quam primum perferendas cures } \\
\text { velim. }\end{array}$ & direktiv & BITTEN \\
\hline 14.19 & & (9) & Da operam ut valeas. & expressiv & $\begin{array}{l}\text { WOHLERGEHEN } \\
\text { WÜNSCHEN }\end{array}$ \\
\hline 14.20 & & $(1)$ & TULLIUS S. D. TERENTIAE SUAE & deklarativ & BRIEF ERÖFFNEN \\
\hline 14.20 & & $(2)$ & $\begin{array}{l}\text { In Tusculanum nos venturos putamus aut Nonis } \\
\text { aut postridie. }\end{array}$ & assertiv & PROGNOSTIZIEREN \\
\hline 14.20 & & (3) & ibi ut sint omnia parata. & direktiv & BITTEN \\
\hline 14.20 & & (4) & plures enim fortasse nobiscum erunt & assertiv & PROGNOSTIZIEREN \\
\hline 14.20 & & (5) & et, ut arbitror, diutius ibi commorabimur. & assertiv & PROGNOSTIZIEREN \\
\hline 14.20 & & (6) & labrum si in balineo non est, ut sit; & direktiv & BITTEN \\
\hline 14.20 & & (7) & $\begin{array}{l}\text { item cetera quae sunt ad victum et ad valetudi- } \\
\text { nem necessaria. }\end{array}$ & direktiv & BITTEN \\
\hline 14.20 & & (8) & Vale. & deklarativ & BRIEF BEENDEN \\
\hline 14.20 & & (9) & Kal. Oct. de Ven $\langle u\rangle$ sino. & assertiv & HINWEISEN \\
\hline 14.21 & & (1) & TULLIUS TERENTIAE SUAE S. D. & deklarativ & BRIEF ERÖFFNEN \\
\hline 14.21 & & $(2)$ & S. v. b.; e. v. & expressiv & $\begin{array}{l}\text { WOHLERGEHEN } \\
\text { WÜNSCHEN }\end{array}$ \\
\hline 14.21 & & (3) & Da operam ut convalescas; & expressiv & $\begin{array}{l}\text { WOHLERGEHEN } \\
\text { WÜNSCHEN }\end{array}$ \\
\hline 14.21 & & (4) & $\begin{array}{l}\text { quod opus erit, ut res tempusque postulat, provi- } \\
\text { deas atque administres, }\end{array}$ & direktiv & BITTEN \\
\hline 14.21 & & (5) & $\begin{array}{l}\text { et ad me de omnibus rebus quam saepissime lit- } \\
\text { teras mittas. }\end{array}$ & direktiv & BITTEN \\
\hline 14.21 & & (6) & Vale. & deklarativ & BRIEF BEENDEN \\
\hline
\end{tabular}




\begin{tabular}{|c|c|c|c|c|}
\hline 14.22 & (1) & TULLIUS S. D. TERENTIAE SUAE & deklarativ & BRIEF ERÖFFNEN \\
\hline 14.22 & $(2)$ & S. v. b.; e. v. & expressiv & $\begin{array}{l}\text { WOHLERGEHEN } \\
\text { WÜNSCHEN }\end{array}$ \\
\hline 14.22 & (3) & Nos cottidie tabellarios nostros exspectamus; & assertiv & PROGNOSTIZIEREN \\
\hline 14.22 & (4) & $\begin{array}{l}\text { qui si venerint, fortasse erimus certiores quid no- } \\
\text { bis faciendum sit }\end{array}$ & assertiv & PROGNOSTIZIEREN \\
\hline 14.22 & (5) & faciemusque te statim certiorem. & kommissiv & VERSPRECHEN \\
\hline 14.22 & (6) & valetudinem tuam cura diligenter. & expressiv & $\begin{array}{l}\text { WOHLERGEHEN } \\
\text { WÜNSCHEN }\end{array}$ \\
\hline 14.22 & (7) & Vale. & deklarativ & BRIEF BEENDEN \\
\hline 14.22 & (8) & Kal. Sept. & assertiv & HINWEISEN \\
\hline 14.23 & (1) & TULLIUS S. D. TERENTIAE SUAE & deklarativ & BRIEF ERÖFFNEN \\
\hline 14.23 & $(2)$ & S. v. b. e.; e.v. & expressiv & $\begin{array}{l}\text { WOHLERGEHEN } \\
\text { WÜNSCHEN }\end{array}$ \\
\hline 14.23 & (3) & $\begin{array}{l}\text { Redditae mihi tandem sunt a Caesare litterae sa- } \\
\text { tis liberales }\end{array}$ & assertiv & BENACHRICHTIGEN \\
\hline 14.23 & $(4)$ & et ipse opinione celerius venturus esse dicitur; & assertiv & PROGNOSTIZIEREN \\
\hline 14.23 & (5) & $\begin{array}{l}\text { cui utrum obviam procedam an hic eum exspec- } \\
\text { tem cum constituero, faciam te certiorem. }\end{array}$ & kommissiv & VERSPRECHEN \\
\hline 14.23 & (6) & tabellarios mihi velim quam primum remittas. & direktiv & BITTEN \\
\hline 14.23 & (7) & valetudinem tuam cura diligenter. & expressiv & $\begin{array}{l}\text { WOHLERGEHEN } \\
\text { WÜNSCHEN }\end{array}$ \\
\hline 14.23 & (8) & Vale. & deklarativ & BRIEF BEENDEN \\
\hline 14.23 & (9) & D. prid. Id. Sext. & assertiv & HINWEISEN \\
\hline 14.24 & (1) & TULLIUS TERENTIAE SUAE S. D. & deklarativ & BRIEF ERÖFFNEN \\
\hline 14.24 & $(2)$ & S. v. b.; e. v. & expressiv & $\begin{array}{l}\text { WOHLERGEHEN } \\
\text { WÜNSCHEN }\end{array}$ \\
\hline 14.24 & (3) & $\begin{array}{l}\text { Nos neque de Caesaris adventu [neque ...] quic- } \\
\text { quam adhuc certi habemus. }\end{array}$ & assertiv & HINWEISEN \\
\hline 14.24 & (4) & $\begin{array}{l}\text { Nos [neque ...] neque de litteris [...] quicquam ad- } \\
\text { huc certi habemus. }\end{array}$ & assertiv & HINWEISEN \\
\hline 14.24 & (5) & [...] quas Philotimus habere dicitur [...] & assertiv & VERMUTEN \\
\hline 14.24 & (6) & si quid erit certi, faciam te statim certiorem. & kommissiv & VERSPRECHEN \\
\hline 14.24 & (7) & valetudinem tuam fac ut cures. & expressiv & $\begin{array}{l}\text { WOHLERGEHEN } \\
\text { WÜNSCHEN }\end{array}$ \\
\hline 14.24 & (8) & Vale. & deklarativ & BRIEF BEENDEN \\
\hline 14.24 & (9) & III Id. Sext. & assertiv & HINWEISEN \\
\hline
\end{tabular}

Abbildung 78: Überblick über die Einzelillokutionen aller Briefe in fam. 14 


\section{Anhang 2 - Definitionen der Sprechaktuntermuster (gem. Münstera- ner Schule)}

ABSICHT BEKUNDEN

„B1: Sp1 glaubt, Sp2 habe am Vollzug der angekündigten Handlung H kein unmittelbares eigenes Interesse.

B2: Sp1 glaubt, Sp2 werde sich auf den Vollzug von $\mathrm{H}$ nicht verlassen. $\mathrm{B} 3: \mathrm{H}$ ist nicht gegen die unmittelbaren eigenen Interessen von $\mathrm{Sp} 2$ gerichtet.

B4: $H$ ist eine zukünftige Handlung von Sp1, für deren Vollzug Sp1 unmittelbar selbst verantwortlich ist.

B5: $\mathrm{H}$ ist keine auf Dauer und Kontinuität angelegte Handlung, deren Vollzug Sp1 subjektiv Schwierigkeiten bereitet.

B6: Sp1 ist nicht gegenüber $\mathrm{Sp} 2$ verpflichtet, $\mathrm{H}$ zu tun.

B7: Sp2 ist bezüglich $\mathrm{H}$ gegenüber Sp1 gleichgeordnet, er hat keine Sanktionsgewalt. Der Vollzug von $\mathrm{H}$ kann jedoch abhängig sein von einer Erlaubnis durch Sp3, die (i) bereits vorliegt oder (ii) noch von Sp1 einzuholen ist.

B8: Sp1 will Sp2 über die von ihm in Aussicht genommenen Handlungen ,informieren', ihm eine ,Orientierung' bezüglich seines eigenen, zukünftigen Verhaltens geben.KGRAFFE 1990, 116f.)

ABSTREITEN

Detraktiva allgemein: „Für Realisierungen dieser Handlungsmuster ist kennzeichnend: daß von $\mathrm{H}$ gilt, er habe hinsichtlich der zuvor von $\mathrm{S}$ thematisierten Proposition p ein bestimmtes Wissen, und zwar, daß nicht-p." (ROLF 1983, 195)

ABSTREITEN speziell: „H gilt in epistemischer Hinsicht als notwendigerweise kompetent bezüglich $p$ und trägt die Rolle eines auf eine Unterstellung Antwortenden." (ebd., 196)

$\begin{array}{ll}\text { ANGST ÄUSSERN } & \text { "B1: Sp1 antizipiert einen Sachverhalt S, von dem er betroffen ist. (Bei } \\ & \text { Dialogsituation gilt zusätzlich: Sp1 nimmt an, daß Sp2 Kenntnis von S hat.) } \\ & \text { B2: Sp1 bewertet S negativ für sich selbst. } \\ & \text { B3: Sp1 hat Angst vor S.“ (MARTEN-CLEEF 1991, 338) }\end{array}$

ANTEILNEHMENDE FRAGE STELLEN
„Im Zentrum der ANTEILNEHMENDEN FRAGEN stehen Äußerungen, mit denen $\mathrm{Sp}_{1}$ nach Gefühlen, Empfindungen und Bewertungen von $\mathrm{Sp}_{2}$ fragt. Es wird dabei unterstellt, daß sich $\mathrm{Sp}_{1}$ aus Liebe, Freundschaft oder solidarischer Anteilnahme für das Befinden von $\mathrm{Sp}_{2}$ interessiert und inm durch eine entsprechende Frage mitteilen will, daß inm der Adressat nicht gleichgültig ist. Der Fragende gibt $\mathrm{Sp}_{2}$ damit die Möglichkeit, seine Gefühle, Empfindungen Einschätzungen und Bewertungen zu formulieren und sich so bei $\mathrm{Sp}_{1}$ auszusprechen. Charakteristisch für solche Fragen ist, daß - im Gegensatz zu AUSKUNFTSFRAGEN - niemand anders als der Adressat selbst die Frage überhaupt beantworten kann." (HINDELANG 1981, 219f.)

ANWEISEN
$\mathrm{B} 1$ : $\mathrm{Sp}_{1}$ und $\mathrm{Sp}_{2}$ kooperieren zur Erreichung eines Zielzustandes $\mathrm{p}$.

$\mathrm{B} 2: \mathrm{Sp}_{1}$ und $\mathrm{Sp}_{2}$ sind beide gleich stark an der Erreichung von $\mathrm{p}$ interessiert. B3: $\mathrm{Sp}_{1}$ und $\mathrm{Sp}_{2}$ sind gleichberechtigte Partner.

$\mathrm{B} 4: \mathrm{Sp}_{1}$ und $\mathrm{Sp}_{2}$ sind sich über den zur Erreichung von $\mathrm{p}$ notwendigen Lösungsweg einig. $p$ kann nur durch die Ausführung einer komplexen Handlungssequenz HS erreicht werden. 
B5: X-en ist Teil von HS oder steht in direktem Zusammenhang mit der Erreichung von p." (HINDELANG 1978, 450)

BEDAUERN BEKUNDEN

„B1: Sp1 beobachtet einen gegenwärtigen Sachverhalt S, von dem Sp2 betroffen ist.

B2: Sp1 bewertet $\mathrm{S}$ negativ für $\mathrm{Sp2}$ und negativ im Rückbezug auf sich selbst.

B3: Sp1 empfindet angesichts von S Mitleid mit Sp2.“(MARTEN-CLEef 1991, 269)

BEGRÜNDEN Argumentativa allgemein: „Während [...] mit einer refutativen Informationshandlung zum Ausdruck gebracht wird, daß nicht-p hergeleitet ist, besteht das mit einer argumentativen Informationshandlung konventionellerweise verfolgte Ziel darin, daß deren Adressat glaubt: $p$ ist hergeleitet." (ROLF 1983, 202)

BEGRÜNDEN speziell: „S hat Anhaltspunkte (Gründe) für die Überzeugung, daß p; es ist jedoch nicht sicher, daß diese Gründe hinreichend sind für diese Überzeugung." (ebd., 203)

BEGRÜSSEN S. WILLKOMMEN HEISSEN

BEHAUPTEN

Assertiva (i. e. S.) allgemein: „Mit einer assertiven Informationshandlung [...] gibt $\mathrm{S}$ zu verstehen, daß die Herleitung der Proposition $\mathrm{p}$ möglich ist [...]. Das mit einer solchen Informationshandlung verfolgte Ziel ist dementsprechend, daß $\mathrm{H}$ (im starken Sinne) glaubt, daß die Herleitung von $\mathrm{p}$ möglich ist [...]." (ebd., 97)

BEHAUPTEN speziell: „Es ist möglich, daß $\mathrm{H}$ die Herleitung von $\mathrm{p}$ für unwahr hält." (ebd., 163)

BENACHRICHTIGEN Transmissiva allgemein: „S [bringt] mit einer eine Handlung dieser Art realisierenden Äußerung zum Ausdruck, daß er um das tatsächliche Bestehen des durch $p$ bezeichneten Sachverhalts weiß. Dementsprechend soll auch $\mathrm{H}$ registrieren, daß p." (ebd., 164)

BENACHRICHTIGEN speziell: „Es ist für $\mathrm{H}$ notwendig, zu wissen, daß p.“ (ebd., 175)

BESTÄTIGEN Konfirmativa allgemein: „H [bringt] mit einer konfirmativen Informationshandlung bezüglich einer zuvor (etwa im Rahmen einer Mitteilung, einer Frage oder auch einer Beschuldigung) thematisierten Proposition $p$ zum Ausdruck, daß er weiß bzw. davon überzeugt ist, daß p den Tatsachen entspricht. $\mathrm{H}$ erweist sich in bezug auf $\mathrm{p}$ als in epistemischer Hinsicht kompetent." (ebd., 176)

BESTÄTIGEN speziell: „,H ist in epistemischer Hinsicht (kontingenterweise) kompetent im Hinblick auf p." (ebd., 178)

BITTEN (symmetrisch) „Eine Aufforderung AUF zum X-en ist eine SYMMETRISCHE BITTE, wenn gilt:

$\mathrm{B} 1: \mathrm{Sp}_{1}$ hat ein direktes und persönliches Interesse daran, daß Sp2 Xt.

$\mathrm{B} 2$ : $\mathrm{Sp}_{2}$ hat kein direktes oder persönliches Interesse an der Ausführung von $\mathrm{X}$ oder dem entsprechenden Handlungsergebnis.

B3: $\mathrm{Sp}_{2}$ ist nicht verpflichtet zu X-en. $\mathrm{Sp}_{1}$ verfügt nicht über die Sanktionsmöglichkeiten, durch die er AUF Nachdruck verleihen könnte.

B4: Aufgrund der Rollen- und Statusbeziehung zwischen $\mathrm{Sp}_{1}$ und $\mathrm{Sp}_{2}$ wäre es denkbar, daß sich auch $\mathrm{Sp}_{2}$ in einer analogen Situation mit einer Aufforderung zum X-en an $\mathrm{Sp}_{1}$ gewandt hätte." (HINDELANG 1978, 504) 
FESTSTELLEN (KONSTATIEREN)

Assertiva (i. e. S.) allgemein: „Mit einer assertiven Informationshandlung [...] gibt $S$ zu verstehen, daß die Herleitung der Proposition $\mathrm{p}$ möglich ist [...]. Das mit einer solchen Informationshandlung verfolgte Ziel ist dementsprechend, daß $\mathrm{H}$ (im starken Sinne) glaubt, daß die Herleitung von $\mathrm{p}$ möglich ist [...]." (RoLf 1983, 97)

FESTSTELLEN speziell: „Obwohl (auch) H registriert hat, daß $p$, ist nicht ausgeschlossen, daß $\mathrm{H}$ die Herleitung (Geltung) von $\mathrm{p}$ (irgendwann) in Zweifel zieht." (ebd., 163)

FLUCHEN „B1: Sp1 ist von einem Sachverhalt S betroffen. Die Verantwortlichkeit für $S$ liegt bei Sp1, Sp3 oder der nicht-personalen Quelle Q. (Bei Dialogsituation gilt zusätzlich: Sp1 nimmt an, daß Sp2 Kenntnis von S hat.)

B2: Sp1 bewertet $S$ negativ für sich selbst.

B3: Sp1 ist ärgerlich über S." (MARTEN-CLeEF 1991, 332)

\begin{tabular}{ll}
\hline FROHLOCKEN & „B1: Sp1 hat eine Handlung H vollzogen und damit einen Sachverhalt S \\
& herbeigeführt. (Bei Dialogsituation gilt zusätzlich: Sp1 nimmt an, daß Sp2 \\
& Kenntnis von $\mathrm{H}$ und S hat.) \\
& B2: Sp1 bewertet $\mathrm{H}$ bzw. S positiv für sich selbst. \\
& B3: Sp1 freut sich über H bzw. S.“ (ebd., 248) \\
\hline (SPRACHLICHE) & „B1: Sp1 beobachtet Sp2 und glaubt sich durch dessen Anblick positiv be- \\
GUNST ERWEISEN & troffen. \\
& B2: Sp1 bewertet Sp2 als Person positiv. \\
& B3: Sp1 empfindet Sympathie für Sp2.“ (ebd., 195f.)
\end{tabular}

GUTEN WUNSCH ÄUS- „B1: Der Sprecher Sp1 antizipiert einen zukünftigen Sachverhalt S, von SERN dem der Adressat Sp2 betroffen ist. Sp1 ist nicht, Sp2 ist nicht bzw. nicht allein verantwortlich für das (So-)Eintreten von $\mathrm{S}$.

B2: Sp1 bewertet S positiv für Sp2 und positiv im Rückbezug auf sich selbst. B3: Sp1 erhofft S." (ebd., 167)

Es werden (auf eine zukünftige Handlung des Adressaten bezogene) ,GELINGENSWÜNSCHE' und (ereignisbezogene), WOHLERGEHENSWÜNSCHE' unterschieden.

HINWEISEN

Transmissiva allgemein: „S [bringt] mit einer eine Handlung dieser Art realisierenden Äußerung zum Ausdruck, daß er um das tatsächliche Bestehen des durch $\mathrm{p}$ bezeichneten Sachverhalts weiß. Dementsprechend soll auch H registrieren, daß p." (Rolf 1983, 164)

HINWEISEN speziell: „S ist zur Weitergabe von $p$ nicht verpflichtet; zu wissen, daß p, könnte für $\mathrm{H}$ wichtig sein.“ (ebd., 175)

HOFFNUNG ÄUSSERN „B1: Der Sprecher Sp1 antizipiert einen künftigen Sachverhalt S, von dem er selbst betroffen ist. $\mathrm{Sp} 1$ ist nicht bzw. nicht allein verantwortlich für das (So-)Eintreten von $\mathrm{S}$.

B2: Sp1 bewertet $S$ positiv für sich selbst.

B3: Sp1 erhofft S." (MARTEN-CleEF 1991, 261) 

S liegt bei Sp1, Sp3 oder der nicht-personalen Quelle Q. (Bei Dialogsituation gilt zusätzlich: Sp1 nimmt an, daß Sp2 Kenntnis von S hat.)

B2: $S p 1$ bewertet $S$ negativ für sich selbst.

B3: Sp1 ist traurig über S." (MARTEN-CLEEF 1991, 327f.)

\begin{tabular}{l} 
JUBELN \\
KOMPLIMENT MA- \\
CHEN \\
\hline KOOPERATIONSFRAGE \\
STELLEN
\end{tabular}

„B1: Sp1 nimmt eine Handlung $\mathrm{H}$ wahr, für die Sp3 verantwortlich ist, oder einen Sachverhalt $S$, dessen Ursache eine nicht-personale Quelle $Q$ ist. (Bei Dialogsituation gilt zusätzlich: Sp1 nimmt an, daß Sp2 Kenntnis von H oder $S$ hat.)

B2: Sp1 bewertet $\mathrm{H}$ bzw. S positiv im Rückbezug auf sich selbst.

B3: Sp1 freut sich über S oder H. “ (ebd., 255)

„B1: Der Sprecher Sp1 beobachtet einen gegenwärtigen oder vergangenen Sachverhalt $\mathrm{S}$, für den der Adressat $\mathrm{Sp2}$ verantwortlich ist und/oder von dem Sp2 betroffen ist.

B2: Sp1 bewertet S positiv für Sp2 und positiv im Rückbezug auf sich selbst. (Anders ausgedrückt: $S$ entspricht einem Wunsch von Sp1 und nach seiner Einschätzung auch dem Wunsch von Sp2).

B3: Sp1 empfindet angesichts von S Sympathie für Sp2.“ (ebd., 129f.)

KOOPERATIONSFRAGE „Es handelt sich bei dieser Gruppe um Fragen, die ein gemeinsames praktisches Problem von Sprecher und Hörer betreffen. [...] Wie bei den PROBLEMATISIERUNGSFRAGEN [mit einem gemeinsamen theoretischen Problem] setzt $\mathrm{Sp}_{1}$ auch bei den KOOPERATIONSFRAGEN nicht voraus, daß $\mathrm{Sp}_{2}$ die Lösung bereits kennt. Stellt $\mathrm{Sp}_{1}$ in einer Planungssituation eine Frage des Typs Was sollen wir jetzt tun?, so befragt er $\mathrm{Sp}_{2}$ nicht als Experten, sondern als gleichberechtigten Partner, der bei der Problemlösung seine Vorstellungen und Präferenzen einbringen kann. $\mathrm{Sp}_{1}$ zielt mit seiner Frage also auf einen Lösungsvorschlag ab, der in einer längeren Planungsinteraktion akzeptiert, modifiziert oder verworfen werden kann. Bei einer initialen Fragehandlung [...] wird der Adressat der Frage dazu aufgefordert, die Planungssituation mit einem ersten Lösungsvorschlag zu eröffnen." (HINDELANG 1981, 218f.)

MITTEILEN Transmissiva allgemein: „S [bringt] mit einer eine Handlung dieser Art realisierenden Äußerung zum Ausdruck, daß er um das tatsächliche Bestehen des durch $p$ bezeichneten Sachverhalts weiß. Dementsprechend soll auch $\mathrm{H}$ registrieren, daß p." (ROLF 1983, 164)

MITTEILEN speziell: „S ist zur Weitergabe von $\mathrm{p}$ nicht verpflichtet; zu wissen, daß p, könnte für H interessant sein." (ebd., 175)

PROGNOSTIZIEREN Assertiva (i. e. S.) allgemein: „Mit einer assertiven Informationshandlung [...] gibt $\mathrm{S}$ zu verstehen, daß die Herleitung der Proposition $\mathrm{p}$ möglich ist [...]. Das mit einer solchen Informationshandlung verfolgte Ziel ist dementsprechend, daß $\mathrm{H}$ (im starken Sinne) glaubt, daß die Herleitung von $\mathrm{p}$ möglich ist [...]." (ebd., 97)

PROGNOSTIZIEREN speziell: „p bezieht sich auf einen künftigen Sachverhalt." (ebd., 163) 
B3: $\mathrm{Sp}_{1}$ glaubt, daß X-en die beste Lösung für T darstellt bzw. daß X-en ein optimaler Beitrag zur Bewältigung von $T$ ist.

B4: Es bleibt $\mathrm{Sp}_{2}$ überlassen ob er AUF berücksichtigt oder nicht." (HINDELANG 1978, 413)

SICH ENTSCHULDIGEN „B1: Sp1 ist verantwortlich für eine Handlung $\mathrm{H}$ oder eine Unterlassung $\mathrm{U}$, von der bzw. deren Folgen Sp2 betroffen ist.

B2: Sp1 bewertet $\mathrm{H}$ bzw. U negativ für Sp2 und negativ im Rückbezug auf sich selbst.

B3: Sp1 bedauert H bzw. U.“ (MARTEN-CleEF 1991, 290)

SORGE BEKUNDEN

„B1: Sp1 antizipiert eine zukünftigen Sachverhalt S, von dem Sp2 betroffen ist. Sp1 ist nicht, Sp2 ist nicht bzw. nicht allein für das (So-)Eintreten von S verantwortlich.

B2: $S p 1$ bewertet $S$ negativ für $S p 2$ und negativ im Rückbezug auf sich selbst.

B3: Sp1 hat Sorge um Sp2 wegen S." (ebd., 283)

VERMUTEN (KONJIZIE- Assertiva (i. e. S.) allgemein: „Mit einer assertiven Informationshandlung REN)

[...] gibt $S$ zu verstehen, daß die Herleitung der Proposition $p$ möglich ist

[...]. Das mit einer solchen Informationshandlung verfolgte Ziel ist dementsprechend, daß $\mathrm{H}$ (im starken Sinne) glaubt, daß die Herleitung von $\mathrm{p}$ möglich ist [...]." (RoLf 1983, 97)

VERMUTEN i. e. S.: „S hat für die Geltung von p nur schwache Gründe.“ (ebd., 163)

„B1: Sp2 hat durch eine Initialsprechhandlung vom Typ ,symmetrische BITTE' seine Interessen am Vollzug von $\mathrm{H}$ durch Sp1 zu erkennen gegeben. B2: Demzufolge weiß Sp1, daß Sp2 den Vollzug von $\mathrm{H}$ durch ihn gegenüber dem Nicht-Vollzug präferiert.

B3: Sp1 glaubt, daß er in der Lage ist, $\mathrm{H}$ zu vollziehen.

B4: Sp1 ist nicht im Rahmen gesetzlicher bzw. institutioneller Vorschriften oder Vereinbarungen verpflichtet, $\mathrm{H}$ ohnehin zu tun.

B5: Sp1 und Sp2 sind gleichberechtigte Partner hinsichtlich der Entscheidung, die Handlungsverpflichtung einzugehen.

B6: Sp1 glaubt, Sp2 habe die Absicht, sich auf den Vollzug H durch Sp1 zu verlassen.

B7: H kann demzufolge die Voraussetzung zum Vollzug von H', die Sp2 vollziehen will, darstellen.

B8: Sp1 verpflichtet sich beim Vollzug von VERSPRECHEN gegenüber $\mathrm{Sp2}$, H zu tun." (Graffe 1990, 189f.)

VORSATZ BEKUNDEN „B1: Sp1 glaubt, Sp2 habe am Vollzug der angekündigten Handlung H kein unmittelbares eigenes Interesse.

B2: Sp1 glaubt nicht, daß Sp2 sich auf den Vollzug von $\mathrm{H}$ verlassen wird.

B3: $\mathrm{H}$ ist nicht gegen die unmittelbaren Interessen von $\mathrm{Sp} 2$ gerichtet.

B4: $\mathrm{H}$ ist eine zukünftige Handlung von Sp1, für deren Vollzug er unmittelbar selbst verantwortlich ist.

B5: $\mathrm{H}$ ist eine auf längere Dauer und Kontinuität angelegte Handlung.

B6: In der subjektiven Einschätzung von $\mathrm{H}$ weiß Sp1, daß er $\mathrm{H}$ zwar prinzipiell, jedoch nicht ohne, innere Schwierigkeiten'vollziehen kann. Die Kompetenzbedingung ist in diesem Sinne eingeschränkt.

B7: Sp1 ist nicht gegenüber Sp2 verpflichtet, $\mathrm{H}$ zu tun. Er kann jedoch gegenüber Dritten verpflichtet sein oder sich verpflichtet fühlen, $\mathrm{H}$ zu tun. 
B8: Sp1 will sich gegenüber Sp2 verpflichtend auf die von ihm in Aussicht genommene Handlung festlegen, um sich selbst in seiner eigenen Steuerungsfähigkeit bezüglich von $\mathrm{H}$ zusätzlich zu unterstützen. Der Vollzug von ,Erinnerungshandlungen' durch Sp2 ist (mit gemischten Gefühlen auf seiten von Sp1) zur Unterstützung dieser Steuerungsfähigkeit erwünscht." (GRAFFE 1990, 128f.)

WILLKOMMEN HEIS- „B1: Es geht eine Handlung $\mathrm{H}$ voraus, für die Sp2 verantwortlich und von SEN der Sp1 betroffen ist.

B2: Sp1 bewertet $\mathrm{H}$ bzw. die Folgen von $\mathrm{H}$ positiv für sich selbst.

B3: Sp1 freut sich über H.“ (MARTEN-CleEF 1991, 177)

Es werden die Untertypen ,jd. WILLKOMMEN HEISSEN` und ,etw. BEGRÜSSEN' unterschieden.

WOHLERGEHEN WÜN- S. GUTEN WUNSCH ÄUSSERN SCHEN

ZUGEBEN

Konfirmativa allgemein: „, $\mathrm{H}$ [bringt] mit einer konfirmativen Informationshandlung bezüglich einer zuvor (etwa im Rahmen einer Mitteilung, einer Frage oder auch einer Beschuldigung) thematisierten Proposition $\mathrm{p}$ zum Ausdruck, daß er weiß bzw. davon überzeugt ist, daß p den Tatsachen entspricht. H erweist sich in bezug auf $p$ als in epistemischer Hinsicht kompetent." (ROLF 1983, 176)

ZUGEBEN speziell: „H ist in epistemischer Hinsicht notwendigerweise kompetent bezüglich $\mathrm{p}$ und trägt die Rolle eines auf eine Unterstellung Antwortenden." (ebd., 178)

ZUSTIMMEN Assentiva allgemein: „H bringt mit einem assentiven Kommunikationsversuch auf eine zuvor von $\mathrm{S}$ thematisierte Proposition $\mathrm{p}$ hin zum Ausdruck, daß er (H) (ebenfalls) glaubt ${ }_{\alpha}{ }^{1628}$, daß p.“ (ebd., 181)

ZUSTIMMEN speziell: „,H hat gute Gründe, zu glauben ${ }_{\alpha}$, daß p.“ (ebd., 182)

1628 Bei dem tiefgestellten $\alpha$ handelt es sich um einen „Index, der kennzeichnet, daß eine so charakterisierte epistemische Modalität nicht als ,Glauben (im starken Sinn)‘ gelesen werden soll“ (RoLf 1983, 215). 


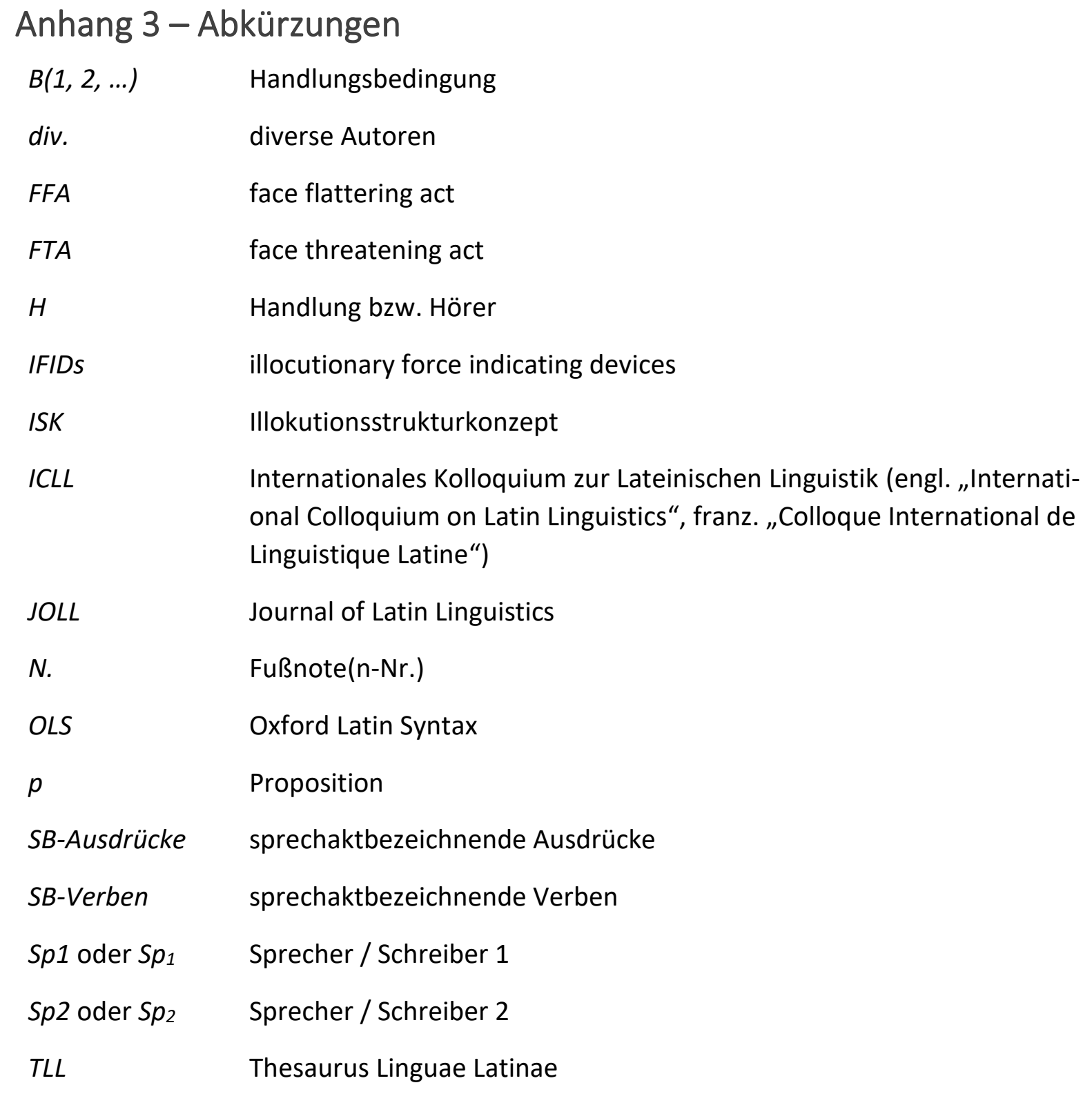




\section{Literaturverzeichnis}

\section{Textausgaben, ÜBersetzungen und Kommentare}

Marcus Tullius CICERO (1904 - 1933): The correspondence of M. Tullius Cicero. Arranged according to its chronological order, with a revision of the text, a commentary, and introductory essays. 6 Bde. Hg. v. R. Y. Tyrrell und L. C. Purser. 2. Aufl. (Bd. II - VI) bzw. 3. Aufl. (Bd. I). Dublin, London.

Marcus Tullius CiCERo (1927): Letters to his friends. (Loeb Classical Library.) 3 Bde. Hg. v. W. G. Williams. London.

Marcus Tullius Cicero (1952): M. Tvlli Ciceronis Epistvlae. (Oxford Classical Texts.) Hg. v. L. C. Purser. Nachdr. d. 1. Aufl. 1901. Oxford.

Marcus Tullius CICERo (1958 - 1982): M. Tulli Ciceronis Epistulae. (Oxford Classical Texts.) 3 Bde. Hg. v. W. S. Watt und D. R. Shackleton Bailey. Oxford.

Marcus Tullius CiCERo (1977): Cicero. Epistulae ad familiares. (Cambridge classical texts and commentaries.) 2 Bde. Hg. v. D. R. Shackleton Bailey. Cambridge u. a.

Marcus Tullius CICERO (1987): M. Tulli Ciceronis Epistulae ad Atticum. (Bibliotheca scriptorum Graecorum et Romanorum Teubneriana.) 2 Bde. Hg. v. D. R. Shackleton Bailey. Stuttgart.

Marcus Tullius CICERo (1988): M. Tulli Ciceronis Epistulae ad familiares. (Bibliotheca scriptorum Graecorum et Romanorum Teubneriana.) Hg. v. D. R. Shackleton Bailey. Stuttgart.

Marcus Tullius CiCERo (1996): Lettere dall'esilio. Dalle Epistulae ad Atticum, ad familiares, ad Quintum fratrem. Introduzione, testo, traduzione, commento. (II nuovo melograno.) Hg. v. R. Degl'Innocenti Pierini. Florenz.

Marcus Tullius CiCERo (2001): Letters to friends. (Loeb Classical Library.) Hg. v. D. R. Shackleton Bailey. Cambridge / MA.

Marcus Tullius Cicero (2002): Correspondance. (Collection des universités de France.) Hg. v. J. Beaujeu, L. A. Constans und J. Bayet. 2. Aufl. Paris.

Marcus Tullius CICERo (2004): An seine Freunde. Lateinisch-deutsch. (Sammlung Tusculum.) Hg. v. H. Kasten. 6. Aufl. Düsseldorf, Zürich.

Marcus Tullius CICERo (2007): Lettere ai familiari. (BUR Classici greci e latini.) Hg. v. A. Cavarzere. Mailand.

Div. (1964): Rhetores Latini minores. Ex codicibus maximam partem primum adhibitis. Hg. v. K. F. Halm. Frankfurt a. M.

Div. (2003): Greek and Latin letters. An anthology with translation. (Cambridge Greek and Latin classics.) Hg. v. M. B. Trapp. Cambridge.

Marcus Fabius QUINTILIANus (2011): Quintilians Grammatik ('Inst. orat.' 1,4-8). Text, Übersetzung und Kommentar Hg. v. W. Ax. Berlin, Boston.

Erasmus von RotTerdam (1971): Opera omnia desiderii Erasmi. Ordinis primi tomus secundus Hg. v. J. C. Margolin und P. Mesnard. Amsterdam.

\section{FORSCHUNGSLITERATUR}

ADAM, J.-M. (1998): Les genres du discours épistolaire. De la rhétorique à l'analyse pragmatique des pratiques discursives. In: La lettre entre réel et fiction. Hg. v. J. Siess. Paris. 3753. 
AdAMS, J. N. (1978): Conventions of naming in Cicero. In: The Classical Quarterly 28 (1), 145166.

AdAMS, J. N. (1984): Female speech in Latin comedy. In: Antichthon. Journal of the Australasian Society for Classical Studies 18, 43-77.

AdAMS, J. N. (2013): Social variation and the Latin language. Cambridge.

ADAMZIK, K. (1984): Sprachliches Handeln und sozialer Kontakt. Zur Integration der Kategorie 'Beziehungsaspekt' in eine sprechakttheoretische Beschreibung des Deutschen. Tübingen.

AdAMZIK, K. (2004): Textlinguistik. Eine einführende Darstellung. Berlin.

ADAMZIK, K. (2008): Textsorten und ihre Beschreibung. In: Textlinguistik. 15 Einführungen. Hg. v. N. Janich. Tübingen. 145-175.

ADAMZIK, K. (2016): Textlinguistik. Grundlagen, Kontroversen, Perspektiven. 2., völlig neu bearb., aktual. und erw. Neuauflage. Berlin, Boston.

AdAMzIK, K. (2018a): Textlinguistik. In: Handbuch Pragmatik. Hg. v. F. Liedtke und A. Tuchen. Stuttgart. 53-64.

AdAMzIK, K. (2018b): Was ist ein Text? In: Handbuch Text und Gespräch. Hg. v. K. Birkner und N. Janich. Berlin. 26-51.

Airenti, G.; Cruciani, M.; Plebe, A. (Hgg.) (2017): Context in communication. A cognitive view. O. 0 .

AirentI, G.; Plebe, A. (2017): Editorial: Context in communication. A cognitive view. In: Context in communication. A cognitive view. Hg. v. G. Airenti, M. Cruciani und A. Plebe. O. 0. 6-8.

AlBERTINI, T. (1994): Elegantia. In: Historisches Wörterbuch der Rhetorik. Bie - Eul. Hg. v. G. Ueding. Tübingen. 991-1004.

AlBRECHT, M. von (2003): Cicero's style. A synopsis. Followed by selected analytic studies. Leiden.

ALLEN JR., W. (1957 - 1959): Private and confidential. Cicero's correspondence. In: Lectures in the Humanities (Chapel Hill) 14 - 15, 57-78.

AlLEN JR., W. (1960): Cicero's last letter to Terentia (fam. 14.20). In: Studies in honor of Berthold Louis Ullman. Presented to him on the occasion of his seventy-fifth birthday. Hg. v. L. B. Lawler. Sant Louis. 58-60.

ALtMAN, J. G. (1982): Epistolarity. Approaches to a form. Columbus.

Antón, B. (1996): La epistolografia Romana. Cicerón, Seneca y Plinio. In: Helmántica. Revista de Filología Clásica y Hebrea 47 (142 - 143), 105-148.

ARCHER, D. (2010): Speech acts. In: Historical pragmatics. Hg. v. A. H. Jucker, I. Taavitsainen und W. Bublitz. Berlin. 379-417.

ARCHER, D. (2017): Politeness. In: The Routledge handbook of pragmatics. Hg. v. A. Barron, Y. Gu und G. Steen. Abingdon, New York. 384-398.

ARNDT, H.; JANNEY, R. W. (1987): InterGrammar. Toward an integrative model of verbal, prosodic, and kinesic choices in speech. Berlin, New York.

ARTMANN, P. (1996): Tätertexte. Eine linguistische Analyse der Textsorten 'Erpresserbrief' und 'Drohbrief'. München.

ARWEILER, A. H. (2010): What is a literary speech act? Quintilian, John Searle, and the notion of 'constatives'. In: Acting with words. Communication, rhetorical performance and performative acts in Latin literature. Hg. v. T. Fuhrer und D. Nelis. Heidelberg. 199-242. 
Asmuth, B. (1992): Angemessenheit. In: Historisches Wörterbuch der Rhetorik. A - Bib. Hg. v. G. Ueding. Tübingen. 579-604.

AsMuth, B. (2003): Perspicuitas. In: Historisches Wörterbuch der Rhetorik. Must - Pop. Hg. v. G. Ueding. Tübingen. 814-874.

Austin, J. L. (1956 - 1957): A plea for excuses. The presidential address. In: Proceedings of the Aristotelian Society N. S. 57, 1-30.

Austin, J. L. (1971): Performative-constative. In: The philosophy of language. Hg. v. J. R. Searle. London. 13-22.

Austin, J. L. (2002): Zur Theorie der Sprechakte (= How to do things with words). Hg. von E. von Savigny. 2. Aufl. Stuttgart.

AUSTIN, J. L. (2009): How to do things with words. The William James lectures delivered at Harvard University in 1955. Hg. von J. O. Urmson und M. Sbisà. 2. Aufl. Oxford u. a.

Ax, W. (1992): Aristoteles (384-322). In: Sprachphilosophie. Ein internationales Handbuch zeitgenössischer Forschung. Hg. v. M. Dascal, D. Gerhardus u. a. Berlin u. a. 244-259.

Ax, W. (2006a): Sprachwissenschaft. Griechisch-römische Antike. In: Text und Stil. Studien zur antiken Literatur und deren Rezeption. Hg. v. W. Ax und C. Schwarz. Stuttgart. 227-243.

Ax, W. (2006b): Textlinguistische Ansätze in der antiken Grammatik. In: Text und Stil. Studien zur antiken Literatur und deren Rezeption. Hg. v. W. Ax und C. Schwarz. Stuttgart. 214226.

BACH, K.; HARNISH, R. M. (1979): Linguistic communication and speech acts. Cambridge / MA u. a.

BAILLEUX, R. (1933): Les sentiments familiaux de Cicéron d' après le vocabulaire de les lettres. In: Revue des Études Latines 11, 66-68.

BALDI, P.; CUZzolIN, P. (2009 - 2011): New perspectives on historical Latin syntax. 4 Bde. Berlin, New York.

BAllmeR, T. T; BRENNENSTUHL, W. (1981): Speech act classification. A study in the lexical analysis of English speech activity verbs. Berlin u. a.

BAMmANN, D. (2015): A treebank-based study on Latin word order. In: Latin linguistics in the early 21st century. Acts of the 16th International Colloquium on Latin Linguistics. Uppsala, June 6th - 11th, 2011. Hg. v. G. V. M. Haverling. Uppsala. 338-350.

BAÑos BAÑos, J. M. (Hg.) (2009): Sintaxis del latín clásico. Madrid.

BARRIOS-LECH, P. (2016): Linguistic interaction in Roman comedy. Cambridge.

BARRON, A. (2017): Variational pragmatics. In: The Routledge handbook of pragmatics. Hg. v. A. Barron, Y. Gu und G. Steen. Abingdon, New York. 91-104.

BARron, A.; Gu, Y.; SteEN, G. (2017): Pragmatics broadly viewed. Introduction. In: The Routledge handbook of pragmatics. Hg. v. A. Barron, Y. Gu und G. Steen. Abingdon, New York. 1-3.

BAUM, R. (2009): Vulgärsprache. In: Historisches Wörterbuch der Rhetorik. St - Z. Hg. v. G. Ueding. Tübingen. 1245-1255.

BEARD, M. (2002): Ciceronian correspondences. Making a book out of letters. In: Classics in progress. Essays on ancient Greece and Rome. Hg. v. T. P. Wiseman. Oxford, New York. 103-144.

Beaugrande, R. de; Dressler, W. U. (1981): Einführung in die Textlinguistik. Tübingen. 
BECKER, E. (1972): De syntaxi interrogationum obliquarum apud priscos sriptores Latinos. In: Studien auf dem Gebiete des archaischen Lateins. Hg. v. W. Studemund. Hildesheim. 113314.

BEHRENDT, A. (2013): Mit Zitaten kommunizieren. Untersuchungen zur Zitierweise in der Korrespondenz des Marcus Tullius Cicero. Rahden / Westf.

BELKE, H. (1973): Literarische Gebrauchsformen. Düsseldorf.

BeLKE, H. (1986): Gebrauchstexte. In: Literaturwissenschaft. Hg. v. H. L. Arnold und V. Sinemus. 8. Aufl. München. 320-341.

Bendel LARCHER, S. (2015): Linguistische Diskursanalyse. Ein Lehr- und Arbeitsbuch. Tübingen.

BERGER, Ł. (2015): (Meta)discursive uses of Latin HEUS. In: Studia Romanica Posnaniensia 42 (5), 3-22.

Berger, Ł. (2016): Escenas de bienvenida en las comedias de Plauto. In: Scripta Classica 13, 65-84.

BERGER, Ł. (2017a): Bendecir para saludar en Plauto. Redistribución de la función pragmática. In: Emerita. Revista de Lingüística y Filología Clásica 85 (2), 261-287.

BERGER, Ł. (2017b): Estrategias de la cortesía positiva en la apertura dialógica en Plauto y Terencio. In: Revista de Estudios Latinos (17), 11-35.

BERNARD, J.-E. (2004): Vie Sociale et norme épistolaire. Les lettres de Cicéron et la 'brevitas'. In: Euphrosyne. Revista de Filología Clásica 32, 141-156.

BERNARD, J.-E. (2006): Art et tradition épistolaires dans la correspondance de Cicéron. In: Actes du IVe Colloque International 'L'épistolaire antique et ses prolongements européens'. Université François-Rabelais, Tours, 1 - 2 - 3 décembre 2004. Hg. v. P. Laurence und F. Guillaumont. Louvain. 67-79.

Bernard, J.-E. (2008): Le langage de l'amicitia' dans les lettres de Cicéron à Appius Claudius. In: La société des amis à Rome et dans la littérature médiévale et humaniste. Hg. v. P. Galand. Turnhout. 95-112.

BeRNARD, J.-E. (2010): 'Non sic oportet?' (Fam. 16, 18, 1). Les paradoxes de la correspondance des 'Tullii Cicerones' avec Tiron. In: 'Stylus'. La parole dans ses formes. Mélanges en I'honneur du professeur Jacqueline Dangel. Hg. v. M. Baratin, C. Levy u. a. Paris. 415-431.

Bernard, J.-E. (2013): La sociabilité épistolaire chez Cicéron. Paris.

BeRnARDI PERINI, G. (1985): Alle origini della lettera familiare. In: La lettera familiare. Hg. v. G. Folena. Padua. 17-24.

Bernaus, O. (2004): Els 'Sermones ad populum' de Sant Agustí. Noves perspectives. In: Ciència, didàctica i funció social dels estudis clàssics. Actes del XIV Simposi de la Secció Catalana de la S.E.E.C. Vic, 26 - 28 de setembre del 2002. Hg. v. B. Usobiaga und P. J. Quetglas. Barcelona. 145-155.

BERTUCCELLI PAPI, M. (2000): Is a diachronic speech act theory possible? In: Journal of Historical Pragmatics 1 (1), 57-66.

BeYeR, K.; Cherubim, D. (1973): Linguistik und alte Sprachen. Eine Polemik? In: Gymnasium. Zeitschrift für Kultur der Antike und humanistische Bildung 80, 251-279.

BICKMANN, J. (1998): Kommunikation gegen den Tod. Studien zur paulinischen Briefpragmatik am Beispiel des Ersten Thessalonicherbriefes. Würzburg. 
BINDER, V. (2007): Cicero, Marcus Tullius. In: Der Neue Pauly. Supplemente 1. Bd. 2: Geschichte der antiken Texte. Autoren- und Werklexikon. Hg. v. M. Landfester. Unter Mitarb. v. B. Egger. Stuttgart. 148-175.

BIRKNER, K.; JANICH, N. (Hgg.) (2018): Handbuch Text und Gespräch. Berlin.

BIVILLE, F. (2003): Échos de voix romaines dans la correspondance de Cicéron. Réflexions sur l'oralité. In: Colloquia absentium. Studi sulla comunicazione epistolare in Cicerone. Hg. v. A. Garcea. Turin. 13-45.

BIVILLE, F. (2006): The qualification of personal names by possessive adjectives in Cicero's letters. In: What's in a name? The significance of proper names in classical Latin literature. International conference held at the University of Wales, Gregynog, Powys, in July 2002. Hg. v. J. Booth, R. Maltby und F. Biville. Swansea. 1-12.

BIVILLE, F. (2014): Lettres de soldats romains. In: La lettre gréco-latine, un genre littéraire. Hg. v. J. Schneider. Lyon. 81-100.

BLACK, D. A. (1995): The discourse structure of Philippians. A study in textlinguistics. In: Novum Testamentum. An International Quarterly for New Testament and Related Studies 37 (1), 16-49.

BLÄNSDORF, J. (2007): Textlinguistische Beobachtungen zu einigen nicht-vulgärsprachlichen Reden in Petrons Satyrica. In: Studien zu Petron und seiner Rezeption. Hg. v. L. Castagna und E. Lefèvre. Unter Mitarb. v. C. Riboldi. Berlin. 105-122.

BLÄNSDORF, J. (2015): Die Methoden der Textlinguistik und ihre Anwendung auf die lateinische Literatur. In: Vorträge und Aufsätze zur lateinischen Literatur der Antike und des Mittelalters (von J. Blänsdorf). Frankfurt a. M. 51-67.

BLUM-KULKA, S.; HOUSE, J.; KASPER, G. (Hgg.) (1989): Cross-cultural pragmatics. Requests and apologies. Norwood / NJ.

BODELOT, C. (1987): L' interrogation indirecte en latin. Syntaxe - valeur illocutoire -formes. Louvain.

BODELOT, C. (1990): Termes introducteurs et modes dans l'interrogation indirecte en latin de Plaute à Juvénal. Avignon.

BOLKESTEIN, M. A. (1976a): Acl and ut-clauses with verba dicendi in Latin. In: Glotta. Zeitschrift für griechische und lateinische Sprache 54, 263-291.

BOLKESTEIN, M. A. (1976b): The relation between form and meaning of Latin subordinate clauses governed by verba dicendi. In: Mnemosyne. A Journal of Classical Studies 29, 155-175 und 268-300.

BolKESTEIN, M. A. (1977): De herkenbaarheid van illocutieve functies in het Latijn. In: Apophoreta voor A. D. Leeman. Hg. v. F. Ahlheid, E. Vester und J. J. L. Smolenaars. Amsterdam. 59-72.

BOLKeSTEIN, M. A. (1980): Problems in the description of modal verbs. An investigation of Latin. Assen.

BOLKESTEIN, M. A. (1994): Participant tracking in Latin discourse. In: Linguistic studies on Latin. Selected papers from the 6th International Colloquium on Latin Linguistics. Budapest, 23 27 March 1991. Hg. v. J. Herman. Amsterdam, Philadelphia. 283-302.

BOLKESTEIN, M. A. (1995): Questions about questions. In: De Vsv. Études de syntaxe latine offertes en hommage à Marius Lavency. Hg. v. D. Longrée. Louvain. 59-70. 
BOLKESTEIN, M. A. (1998a): Between brackets: (some properties of) parenthetical clauses in Latin. An investigation of the language of Cicero's letters. In: Latin in use. Amsterdam studies in the pragmatics of Latin. Hg. v. R. Risselada. Amsterdam. 1-17.

BOLKESTEIN, M. A. (1998b): What to do with topic and focus? Evaluating pragmatic information. In: Functional grammar and verbal interaction. Hg. v. M. A. Bolkestein und M. Hannay. Amsterdam. 193-214.

BOLKESTEIN, M. A. (2001): Discourse organization and anaphora in Latin. In: Textual parameters in older languages. Hg. v. S. C. Herring, P. van Reenen und L. Schøsler. Amsterdam, Philadelphia. 107-138.

BOLKESTEIN, M. A. (Hg.) (2002): Theory and description in Latin linguistics. Selected papers from the XIth International Colloquium on Latin Linguistics. Amsterdam, June 24 - 29, 2001. Amsterdam.

BoRk, H. S. (2018): A rough guide to insult in Plautus. Dissertation. University of California. Los Angeles.

BRANDT, M.; KOCH, W. u. a. (1983): Der Einfluß der kommunikativen Strategie auf die Textstruktur. Dargestellt am Beispiel des Geschäftsbriefes. In: Sprache und Pragmatik. Lunder Symposium 1982. Hg. v. I. Rosengren. Stockholm. 105-135.

BRANDT, M.; ROSENGREN, I. (1992): Zur Illokutionsstruktur von Texten. In: Zeitschrift für Literaturwissenschaft und Linguistik 22 (86), 9-51.

BRENNAN, T. C. (2012): Perceptions of women's power in the late republic. Terentia, Fulvia, and the generation of $63 B C E$. In: A companion to women in the ancient world. Hg. v. S. L. James und S. Dillon. Malden / MA. 354-366.

BringmanN, K.; Clauss, M. (2014): Cicero. Darmstadt.

BRINKER, K. (1983): Textfunktionen. Ansätze zu ihrer Beschreibung. In: Zeitschrift für Germanistische Linguistik 11, 127-148.

BRINKER, K. (1994): Zum Zusammenhang von Textfunktion und thematischer Einstellung am Beispiel eines Zeitungskommentars. In: Überredung in der Presse. Texte, Strategien, AnaIysen. Hg. v. M. Moilanen und L. Tiittula. Berlin. 35-44.

BRINKER, K. (Hg.) (2000 - 2001a): Text- und Gesprächslinguistik. Ein internationales Handbuch zeitgenössischer Forschung. 2 Bde. Berlin, New York.

BRINKER, K. (2000 - 2001b): Textfunktionale Analyse. In: Text- und Gesprächslinguistik. Ein internationales Handbuch zeitgenössischer Forschung. 2 Bde. Hg. v. K. Brinker. Berlin, New York. 175-186.

BRINKER, K. (2000 - 2001c): Textstrukturanalyse. In: Text- und Gesprächslinguistik. Ein internationales Handbuch zeitgenössischer Forschung. 2 Bde. Hg. v. K. Brinker. Berlin, New York. 164-175.

BRINKER, K. (2002): Textsortenbeschreibung auf handlungstheoretischer Grundlage (am Beispiel von Erpresserbriefen). In: Texte - Diskurse - Interaktionsrollen. Analysen zur Kommunikation im öffentlichen Raum. Hg. v. K. Adamzik. Tübingen. 41-59.

BRINKER, K. (2006): Ursprung und Entwicklung der Textlinguistik. In: Handbücher zur Sprachund Kommunikationswissenschaft $=$ Handbooks of linguistics and communication science = Manuels de linguistique et des sciences de communication. Hg. v. S. Auroux, H. E. Wiegand und G. Ungeheuer. Berlin. 2540-2550. 
BRINKER, K.; CöLFEN, H.; PAPPERT, S. (2014): Linguistische Textanalyse. Eine Einführung in Grundbegriffe und Methoden. 8., neu bearb. und erw. Aufl. Berlin.

BRINTON, L. (2010): Discourse markers. In: Historical pragmatics. Hg. v. A. H. Jucker, I. Taavitsainen und W. Bublitz. Berlin. 285-314.

BRookINS, T. A. (2010): A politeness analysis of Catullus' polymetric poems. Can Leech's GSP cross the ancient-modern divide? In: Journal of Pragmatics 42 (5), 1283-1295.

Brown, P. (2017): Politeness and impoliteness. In: The Oxford handbook of pragmatics. Hg. v. Y. Huang. Oxford. 383-399.

Brown, P.; LeVInson, S. C. (2006): Politeness. Some universals in language usage. In: The discourse reader. Hg. v. A. Jaworski und N. Coupland. 2. Aufl. London, New York. 311-323.

BüCHNER, K. (1962): Cicero. Wiesbaden.

BüHLER, K. (1918): Kritische Musterung der neuen Theorien des Satzes. In: Indogermanisches Jahrbuch 6, 1-20.

BÜHLER, K. (1999): Sprachtheorie. Die Darstellungsfunktion der Sprache. 3. Aufl. (ungek. Neudr. der Ausg. 1934). Stuttgart.

Buonopane, A. (2016): Terenzia, una matrona 'in domo et in re publica agens'. In: Matronae in domo et in re publica agentes. Spazi e occasioni dell'azione femminile nel mondo romano tra tarda repubblica e primo impero. Hg. v. F. Cenerini und F. Rohr. Triest. 51-64.

BurCKHARDT, L. (2003): 'Zu Hause geht alles, wie wir wünschen ...'. Privates und Politisches in den Briefen Ciceros. In: Klio. Beiträge zur Alten Geschichte 85, 94-113.

BüRGEL, P. (1976): Der Privatbrief. Entwurf eines heuristischen Modells. In: Deutsche Vierteljahrsschrift für Literaturwissenschaft und Geistesgeschichte 50 (1 - 2), 281-297.

BURKARD, T.; SCHAUER, M. (2012): Lehrbuch der lateinischen Syntax und Semantik. Begründet von Hermann Menge. 5., durchges. u. verb. Aufl. Darmstadt.

BURKHARDT, A. (1986): Soziale Akte, Sprechakte und Textillokutionen. A. Reinachs Rechtsphilosophie und die moderne Linguistik. Tübingen.

BUSCH-LAUER, I.-A. (2008): Funktionale Varietäten und Stil. In: Rhetorik und Stilistik. Ein internationales Handbuch historischer und systematischer Forschung. Hg. v. U. Fix, A. Gardt und J. Knape. Berlin, New York. 1722-1738.

BUSSE, D. (2013): Linguistische Diskurssemantik. Rückschau und Erläuterungen nach 30 Jahren. In: Linguistische Diskursanalyse. Neue Perspektiven. Hg. v. D. Busse und W. Teubert. Wiesbaden. 31-53.

BUSSE, D. (2015): Sprachverstehen und Textinterpretation. Grundzüge einer verstehenstheoretisch reflektierten interpretativen Semantik. Wiesbaden.

CABrillana, C. (2016): Directives in Latin comedy. Pragmatics, dramatic role and social status. In: Journal of Latin Linguistics 15 (2), 179-214.

CABrillanA, C. (2017): Constituent order in directives with stative verbs in Latin. In: Pragmatic approaches to Latin and Ancient Greek. Hg. v. C. Denizot und O. Spevak. Amsterdam, Philadelphia. 113-135.

CAFFI, C.; JANNEY, R. W. (1994): Involvement in language. Amsterdam u. a.

CAIN, A. (2009): The letters of Jerome. Asceticism, biblical exegesis, and the construction of Christian authority in late antiquity. Oxford, New York.

CALBOLI, G. (1972): La linguistica moderna e il latino. I casi. Bologna. 
CALBOLI MonteFusCo, L. (1988): Exordium - narratio - epilogus. Studi sulla teoria retorica greca e romana delle parti del discorso. Bologna.

CALENDRILLO, L. T. (2009): Medieval rhetoric. In: Encyclopedia of rhetoric and composition. Communication from ancient times to the information age. Hg. v. T. Enos. New York, London. 429-438.

CampbelL, B. G. (2001): Performing and processing The Aeneid. New York.

CARCOPINO, J. (1947): Les secrets de la correspondance de Cicéron. Paris.

CARneY, T. F. (1964): The words 'sodes' and 'quaeso' in Terentian usage. In: Acta Classica. Proceedings of the Classical Association of South Africa 7 (1), 57-63.

CAtrambone, M. (2016): Off-record politeness in Sophocles. The patterned dialogues of female characters. In: Journal of Politeness Research 12 (2), 173-195.

CAVARzere, A. (1998): Caro amico ti scrivo. 'Privato' e 'pubblico' nella letteratura epistolare di Roma. In: Alla lettera. Teorie e pratiche epistolari dai Greci al Novecento. Hg. v. A. Chemello. Mailand. 11-31.

CHANIOTIS, A.; DUCREY, P. (Hgg.) (2013): Unveiling emotions II. Emotions in Greece and Rome. Texts, images, material culture. Stuttgart.

CHERUBIM, D. (1980): Zum Programm einer historischen Sprachpragmatik. In: Ansätze zu einer pragmatischen Sprachgeschichte. Zürcher Kolloquium 1978. Hg. v. H. Sitta. Tübingen. 323.

CHESSA, A. (1999): Aspetti di espressività nell'epistolario ciceroniano. In: Annali della Facoltà di Lettere e Filosofia dell'Università di Cagliari N. S. 17, 205-253.

Citroni MARChETtI, S. (2000): Amicizia e potere nelle lettere di Cicerone e nelle elegie ovidiane dall'esilio. Florenz.

ClAASSEN, J.-M. (1992): Cicero's banishment. Tempora et mores. In: Acta Classica. Proceedings of the Classical Association of South Africa 35, 19-47.

CLAASSEN, J.-M. (1996): Documents of a crumbling marriage. The case of Cicero and Terentia. In: Phoenix. The Journal of the Classical Association of Canada 50, 208-232.

CLAASSEN, J.-M. (1999): Displaced persons. The literature of exile from Cicero to Boethius. London.

CONRING, B. (2001): Hieronymus als Briefschreiber. Ein Beitrag zur spätantiken Epistolographie. Tübingen.

ContI, S.; Proverbio, G. (1990): Latein und Textlinguistik. In: Der Altsprachliche Unterricht 33 (3), 76.

CoRBInelLI, S. (2008): Amicorum colloquia absentium. La scrittura epistolare a Roma tra comunicazione quotidiana e genere letterario. Neapel.

CORDIER, P. (1995): La lettre et l'amicitia. In: Paroles romaines. Hg. v. F. Dupont. Nancy. 25-34.

CORREA, S. (2010): 'Scribo me ita dolere ut [...] a mente non deserar'. Escritura y estrategias retórico-pragmáticas de autofiguración en Att., III, 15. In: Nova Tellus. Revista Semestral del Centro de Estudios Clásicos 28 (2), 181-206.

CORREA, S. (2011): Autofiguración epistolar y construcción del destinatario en la correspondencia ciceroniana del exilio. La imagen de Terencia en Fam. 14, 1 - 4. In: Argos. Revista de la Asociación Argentina de Estudios Clásicos 34 (2), 1-21. 
CORREA, S. (2013): 'Omnis peregrinatio (...) obscura et sordida est'. Estrategias de autofiguración de un nouus homo en Epistulae ad Atticum y Epistulae ad Familiares de M. T. Cicerón. Bahía Blanca.

COȘERIU, E. (1994): Textlinguistik. Eine Einführung. Hg. von J. Albrecht. 3., überarb. und erw. Aufl. Tübingen, Basel.

CotTon, H. M. (1984): Greek and Latin epistolary formulae. Some light on Cicero's letter writing. In: American Journal of Philology 105, 409-425.

CTIBOR, M. (2017): Pragmatic functions of the Latin vocative. In: Pragmatic approaches to Latin and Ancient Greek. Hg. v. C. Denizot und O. Spevak. Amsterdam, Philadelphia. 45-62.

CUGUSI, P. (1983): Evoluzione e forme dell' epistolografia latina nella tarda repubblica e nei primi due secoli dell'impero. Con cenni sull' epistolografia preciceroniana. Rom.

CugusI, P. (1989 - 1991): L'epistolografia. Modelli e tipologie. In: Lo spazio letterario di Roma antica. Bd. 2: La circolazione del testo. Hg. v. G. Cavallo, P. Fedeli und A. Giardina. Rom. 379-419.

CUGUSI, P. (1998): L'epistola ciceroniana. Strumento di comunicazione quotidiana e modello letterario. In: Ciceroniana On Line 10, 163-189.

Degl'INNOCENTI PIERINI, R. (1998a): Ovidio esule e le epistole ciceroniane dell'esilio. In: Ciceroniana On Line 10, 93-106.

Degl'INNOCENTI PIERINI, R. (1998b): 'Ubi non sis qui fueris, non esse cur velis vivere'. A proposito di una citazione in Cicerone, fam. 7, 3, 4. In: Rivista di Filologia e di Istruzione Classica 126 (1), 47-54.

DeIßMANN, G. A. (1895): Bibelstudien. Beiträge, zumeist aus den Papyri und Inschriften, zur Geschichte der Sprache, des Schrifttums und der Religion des hellenistischen Judentums und des Urchristentums. Marburg.

Deißmann, G. A. (1908): Licht vom Osten. Das Neue Testament und die neuentdeckten Texte der hellenistisch-römischen Welt. Tübingen.

DÉNIAUX, È. (1993): Clientèles et pouvoir à l'époque de Cicéron. Rom.

Denizot, C.; SpeVak, O. (Hgg.) (2017a): Pragmatic approaches to Latin and Ancient Greek. Amsterdam, Philadelphia.

Denizot, C.; SPEVAK, O. (2017b): Pragmatics in Latin and Ancient Greek. An introduction. In: Pragmatic approaches to Latin and Ancient Greek. Hg. v. C. Denizot und O. Spevak. Amsterdam, Philadelphia. 1-13.

DERRIDA, J. (1987): The post card. From Socrates to Freud and beyond. Chicago.

DEVINE, A. M.; STEPHENS, L. D. (2006): Latin word order. Structured meaning and information. Oxford, New York.

DICKEY, E. (2002): Latin forms of address. From Plautus to Apuleius. Oxford, New York.

DICKEY, E. (2012a): How to say 'please' in classical Latin. In: The Classical Quarterly 62 (2), 731-748.

DICKEY, E. (2012b): The rules of politeness and Latin request formulae. In: Laws and rules in Indo-European. Hg. v. P. Probert und A. Willi. Oxford. 313-328.

DICKEY, E. (2016): Politeness in ancient Rome. Can it help us evaluate modern politeness theories? In: Journal of Politeness Research 12 (2), 197-220.

DiCKeY, E.; CHAHOUd, A. (Hgg.) (2010): Colloquial and literary Latin. Cambridge, New York. 
DIEGRITZ, T.; FüRST, C. (1999): Empirische Sprechhandlungsforschung. Ansätze zur Analyse und Typisierung authentischer Äußerungen. Erlangen.

DIMTER, M. (1981): Textklassenkonzepte heutiger Alltagssprache. Kommunikationssituation, Textfunktion und Textinhalt als Kategorien alltagssprachlicher Textklassifikation. Tübingen.

DIxon, S. (1984): Family finances. Tullia and Terentia. In: Antichthon. Journal of the Australasian Society for Classical Studies 18, 78-101.

DотY, W. G. (1969): The classification of epistolary literature. In: The Catholic Biblical Quarterly 31 (2), 183-199.

DRECOLL, C. (2006): Nachrichten in der römischen Kaiserzeit. Untersuchungen zu den Nachrichteninhalten in Briefen. Freiburg.

DRUMANN, W. (1929): Geschichte Roms in seinem Uebergange von der republikanischen zur monarchischen Verfassung, oder Pompejus, Caesar, Cicero und ihre Zeitgenossen. Nach Geschlechtern und mit genealogischen Tabellen. Hg. von P. Groebe. 2. Aufl. Leipzig.

DUBREUIL, P. (2013): Le marché aux injures à Rome. Injures et insultes dans la littérature latine. Paris.

Ebbeler, J. V. (2010): Letters. In: The Oxford handbook of Roman studies. Hg. v. A. Barchiesi und W. Scheidel. Oxford. 464-476.

EDMUNDS, L. (2008): Deixis in ancient Greek and Latin literature. Historical introduction and state of the question. In: Philologia Antiqua. An International Journal of Classics 1, 67-98.

EgelHAAF-GAISER, U. (2000): Kulträume im römischen Alltag. Das Isisbuch des Apuleius und der Ort von Religion im kaiserzeitlichen Rom. Stuttgart.

EHRHARDT, C. (2018): Höflichkeit. In: Handbuch Pragmatik. Hg. v. F. Liedtke und A. Tuchen. Stuttgart. 282-192.

Ehrhardt, C.; HeRInger, H. J. (2011): Pragmatik. Paderborn.

EICHINGER, L. M. (2014): Emotionen zeigen. Ihre Darstellung im Text und ihre Präsenz im Stil. In: Emotionalität im Text. Hg. v. L. Vaňková. Tübingen. 35-54.

ERMERT, K. (1979): Briefsorten. Untersuchungen zu Theorie und Empirie der Textklassifikation. Tübingen.

ERMETE, K. (2003): Terentia und Tullia - Frauen der senatorischen Oberschicht. Frankfurt a. M., Wien u. a.

ERnstberger, R. (1956): Studien zur Selbstdarstellung Ciceros in seinen Briefen. Dissertation. Universität Heidelberg.

ESCANDELL-VIDAL, V. (1996): Towards a cognitive approach to politeness. In: Language Sciences $18(3-4), 629-650$.

FABER, P.; LEÓN-ARAÚZ, P. (2017): Specialized knowledge representation and the parameterization of context. In: Context in communication. A cognitive view. Hg. v. G. Airenti, M. Cruciani und A. Plebe. O. O. 9-28.

FEDRIANI, C. (2017): Quapropter, quaeso? 'Why, for pity's sake?'. Questions and the pragmatic functions of 'quaeso', 'obsecro', and 'amabo' in Plautus. In: Pragmatic approaches to Latin and Ancient Greek. Hg. v. C. Denizot und O. Spevak. Amsterdam, Philadelphia. 83-109.

FedrianI, C.; MolineluI, P. (2013): 'Ut ita dicam' and cognates. A pragmatic account. In: Journal of Latin Linguistics 12 (1), 71-99. 
FEKADU, S. (2009): Variation. In: Historisches Wörterbuch der Rhetorik. St - Z. Hg. v. G. Ueding. Tübingen. 1006-1012.

FERNÁNDEZ LÓPEZ, M. C. (1994): Sidonio Apolinar, humanista de la antigüedad tardía. Su correspondencia. Murcia.

FERRI, R. (2008): Politeness in Latin comedy. Some preliminary thoughts. In: Materiali e Discussioni per l'Analisi dei Testi Classici 61, 15-28.

FERRI, R. (2012): How to say no in Latin. Negative turns, politeness and pragmatic variation. In: Variation and change in Greek and Latin. Hg. v. M. Leiwo. Helsinki. 115-137.

FERRI, R. (2014): Witness and lawyer in the Roman courts. Linguistic strategies of evasiveness and intimidation in Roman trial debates. In: Incontri Triestini di Filologia Classica 12 (2012 / 2013), 57-99.

FISH, S. E. (1980): Is there a text in this class? Cambridge / MA u. a.

FIX, U. (2008): Text und Textlinguistik. In: Textlinguistik. 15 Einführungen. Hg. v. N. Janich. Tübingen. 15-34.

FIX, U. (2014): Aktuelle Tendenzen des Textsortenwandels. Thesenpapier. In: Musterwandel Sortenwandel. Aktuelle Tendenzen der diachronen Text(sorten)linguistik. Hg. v. S. Hauser, U. Kleinberger und K. S. Roth. Bern. 15-48.

FöGEN, T. (2001): Spracheinstellungen und Sprachnormbewußtsein bei Cicero. In: Glotta. Zeitschrift für griechische und lateinische Sprache 75, 1-33.

FRANKE, W. (1983): Insistieren. Eine linguistische Analyse. Göppingen.

Frurt, M.; Moussy, C. (Hgg.) (2002): Les modalités en Latin. Colloque du Centre Alfred Ernout. Université de Paris IV, 3, 4 et 5 juin 1998. Paris.

FuHRER, T.; Nelis, D. (Hgg.) (2010): Acting with words. Communication, rhetorical performance and performative acts in Latin literature. Heidelberg.

FuHRMANN, M. (2011): Cicero und die römische Republik. Eine Biographie. Unter Mitarb. v. G. Burde. 5., durchges. und bibliogr. erw. Aufl. Mannheim.

FULKERSON, L. (2013): No regrets. Remorse in classical antiquity. Oxford.

FÜRST, A. (1996): Streit unter Freunden. Stuttgart, Leipzig.

GALASSO, L. (1987): Modelli tragici e ricodificazione elegiaca. Appunti sulla poesia ovidiana dell'esilio. In: Materiali e Discussioni per l'Analisi dei Testi Classici 18, 83-99.

GANSEL, C. (2011): Textsortenlinguistik. Göttingen u. a.

GANSEL, C.; JÜRGENS, F. (2008): Textgrammatische Ansätze. In: Textlinguistik. 15 Einführungen. Hg. v. N. Janich. Tübingen. 55-83.

GANSEL, C.; JÜRgENS, F. (2009): Textlinguistik und Textgrammatik. Eine Einführung. 3., unv. Aufl., Neuausg. d. 2., überarb. u. erg. Aufl. von 2007. Stuttgart.

GARCEA, A. (2001): Représentation et reproduction du discours dans la correspondance de Cicéron. In: Lalies. Actes des Sessions de Linguistique et de Littérature 22, 187-202.

GARCEA, A. (2002): Dialogo ed emozioni nell'epistolario ciceroniano. In: Sul dialogo. Contesti e forme di interazione verbale. Hg. v. C. Bazzanella. Mailand. 209-220.

GARCEA, A. (2004): Le langage des émotions dans les lettres d'exil de Cicéron. In: Actes du Ille Colloque International 'L'épistolaire antique et ses prolongements européens'. Université François Rabelais, Tours, 25 - 27 septembre 2002. Hg. v. L. Nadjo. Louvain, Paris. 153-167.

GarceA, A. (2005): Cicerone in esilio. I'epistolario e le passioni. Hildesheim u. a. 
GARCíA, C. C. (1974): La epístola como género literario de la antigüedad a la edad media latina. In: Estudios Clásicos 18 (73), 427-442.

GARDT, A. (1993): Sprachreflexion in Barock und Frühaufklärung. Berlin, New York.

GARDT, A. (2007): Linguistisches Interpretieren. Konstruktivistische Theorie und realistische Praxis. In: Linguistische Hermeneutik. Theorie und Praxis des Verstehens und Interpretierens. Hg. v. F. Hermanns und W. Holly. Tübingen. 263-280.

Gavollle, É.; Guillaumont, F. (Hgg.) (2017a): Conseiller, diriger par lettre. Tours.

Gavollle, É.; Guillaumont, F. (2017b): Introduction. In: Conseiller, diriger par lettre. Hg. v. É. Gavoille und F. Guillaumont. Tours. 13-49.

GavollLe, L. (2004): Lettre et sermo. In: Actes du Ille Colloque International 'L'épistolaire antique et ses prolongements européens'. Université François Rabelais, Tours, 25 - 27 septembre 2002. Hg. v. L. Nadjo. Louvain, Paris. 33-52.

Gelzer, M. (2014): Cicero. Ein biographischer Versuch. 2. Aufl. Stuttgart.

GEORGES, K. E. (2013): Der neue Georges. Ausführliches Lateinisch-Deutsches Handwörterbuch. Auf der Grundlage der 8., verb. und verm. Aufl. von Heinrich Georges, Hannover und Leipzig 1912, neu bearb. Darmstadt.

GHEZZI, C. (2014): The development of discourse and pragmatic markers. In: Discourse and pragmatic markers from Latin to the Romance languages. Hg. v. C. Ghezzi und P. Molinelli. Oxford. 10-26.

GHEZZI, C. (2016): Marcatori interazionali di cortesia dal latino alle lingue romanze. Nomi e verbi tra morfosintassi e contesto discorsivo. In: Actes du XXVIle Congrès International de Linguistique et de Philologie Romanes. Section 2: Linguistique Latine / Linguistique Romane. Nancy, 15 - 20 juillet 2013. Hg. v. M. Fruyt, G. V. M. Haverling und R. Sornicola. Nancy. 49-61. | URL: http://www.diacronia.ro/indexing/details/V2115/pdf (zuletzt geprüft am 12.11.2020).

GHEZZI, C.; MOLINELLI, P. (2014a): Deverbal pragmatic markers from Latin to Italian (Lat. QUAESO and It. prego). The cyclic nature of functional developments. In: Discourse and pragmatic markers from Latin to the Romance languages. Hg. v. C. Ghezzi und P. Molinelli. Oxford. 61-85.

GHEZZI, C.; Molinelul, P. (Hgg.) (2014b): Discourse and pragmatic markers from Latin to the Romance languages. Oxford.

GhezZI, C.; MolineluI, P. (2015): Segnali allocutivi di richiamo. Percorsi pragmatici e sviluppi diacronici tra latino e italiano. In: Cuadernos de Filología Italiana 22, 21-47.

GhezzI, C.; MolineluI, P. (2016): Politeness markers from Latin to Italian. Periphery, discourse structure and cyclicity. In: Journal of Historical Pragmatics 17 (2), 307-337.

GIBSON, B.; ReES, R. (2013): Introduction. Pliny the Younger in Late Antiquity. In: Arethusa 46 (2), 141-165.

GIBSON, R. K. (2012): On the nature of ancient letter collections. In: Journal of Roman Studies 102, 56-78.

GIBSON, R. K. (2013): Letters in autobiography. The generic mobility of the ancient letter collection. In: Generic interfaces in Latin literature. Encounters, interactions and transformations. Hg. v. T. Papangelis, S. J. Harrison und S. Frangoulidis. Berlin. 387-416. 
GIBSON, R. K.; MORRISON, A. D. (2007): Introduction. What is a letter? In: Ancient letters. Classical and late antique epistolography. Hg. v. R. Morello und A. D. Morrison. Oxford, New York. 1-16.

Giebel, M. (2013): Marcus Tullius Cicero. Überarb. Neuausg. Reinbek bei Hamburg.

GILBERT, M. A. (2001): Emotional Messages. In: Argumentation. An International Journal on Reasoning 15 (3), 239-250.

Giondano, P. (1989): La deissi personale nella comunicazione drammatica. Analisi del Miles gloriosus di Plauto. In: Lingua e Stile 24, 409-433.

GIORGIO, J.-P. de (2008a): 'Je t'ai vu tout entier dans la lettre'. 'Humanitas', 'Portrait d'âme' et persuasion dans la correspondance de Cicéron. In: Actes du Ve Colloque International 'L'épistolaire antique et ses prolongements européens'. Université François Rabelais, Tours, 6-7-8 septembre 2006. Hg. v. P. Laurence und F. Guillaumont. Louvain. 101-114.

GIORGIO, J.-P. de (2008b): Savoir commencer une lettre et savoir la finir. Étude des interactions dans les séquences d'ouverture et de clôture des lettres de Cicéron. In: Commencer et finir. Début et fin dans les littératures grecque, latine et néolatine. $2 \mathrm{Bde}$. $\mathrm{Hg}$. v. B. Bureau und C. Nicolas. Lyon. 347-360.

GIORGIO, J.-P. de (2015): L'écriture de soi à Rome. Autour de la correspondance de Cicéron. Brüssel.

GLÜCKLICH, H.-J. (1976): Lineares Dekodieren, Textlinguistik und typisch lateinische Satzelemente. In: Der Altsprachliche Unterricht 19 (5), 5-36.

GLÜCKLICH, H.-J.; NICKEL, R.; PETERSEN, P. (1980): Interpretatio. Neue Lateinische Textgrammatik. Freiburg.

GRAFFE, J. (1990): Sich festlegen und verpflichten. Die Untertypen kommissiver Sprechakte und ihre sprachlichen Realisierungsformen. Münster, New York.

GraSMück, E. L. (1978): Exilium. Untersuchungen zur Verbannung in der Antike. Paderborn u. a.

GreBE, S. (2003): Marriage and exile. Cicero's letters to Terentia. In: Helios. Journal Devoted to Critical and Methodological Studies of Classical Culture, Literature and Society 30 (2), 127-146.

Griswold, C. L.; KonstAN, D. (Hgg.) (2012): Ancient forgiveness. Cambridge.

Grolimund, C. (1995): Die Briefe der Stadt Basel im 15. Jahrhundert. Ein textlinguistischer Beitrag zur historischen Stadtsprache Basels. Tübingen.

Gross, S. (2006): Lese-Zeichen. Kognition, Medium und Materialität im Leseprozeß. Sonderausg. Darmstadt.

GROßE, E. U. (1976): Text und Kommunikation. Eine linguistische Einführung in die Funktionen der Texte. Stuttgart.

GuglieLmi, M. (2013): Cicerone e Terenzia. Un ritratto di coppia nell'epistolario ciceroniano. Dissertation. Università degli Studi di Padova. Padua. | URL:

http://paduaresearch.cab.unipd.it/6064/1/guglielmi_marta_tesi.pdf (zuletzt geprüft am 12.11.2020).

GÜLICH, E.; HEGER, K.; RAIBLE, W. (1979): Linguistische Textanalyse. Überlegungen zur Gliederung von Texten. 2., durchges. u. erg. Aufl. Hamburg.

Gunderson, E. (2007): S. V. B. E.; E. V. In: Classical Antiquity 26 (1), 1-48. 
HALL, J. (1996): Cicero Fam. 5. 8 and Fam. 15. 5 in the light of modern politeness theory. In: Antichthon. Journal of the Australasian Society for Classical Studies 30, 19-33.

HALL, J. (1998): The deference-greeting in Roman society. In: Maia. Rivista di Letterature Classiche 50, 413-426.

HALL, J. (2005a): Cicero Fam. 16.21. Roman politeness, and the socialization of Marcus Cicero the Younger. In: Roman crossings. Theory and practice in the Roman Republic. Hg. v. K. Welch und T. W. Hillard. Swansea. 263-282.

HALL, J. (2005b): Politeness and formality in Cicero's Letter to Matius (Fam. 11.27). In: Museum Helveticum 62 (4), 193-213.

HALL, J. (2009): Politeness and politics in Cicero's letters. Oxford, New York.

Halla-Aho, H. (2009): The non-literacy Latin letters. A study of their syntax and pragmatics. Helsinki.

HALLA-AHO, H. (2010): Requesting in a letter. Context, syntax and the choice between complements in the letters of Cicero and Pliny the Younger. In: Transactions of the Philological Society 108 (3), 232-247.

Halla-AHO, H. (2018): Left-dislocation in republican Latin. Boston.

HAPP, H. (1967): Die lateinische Umgangssprache und die Kunstsprache des Plautus. In: Glotta. Zeitschrift für griechische und lateinische Sprache 45, 60-104.

HAPP, H. (1976): Grundfragen einer Dependenz-Grammatik des Lateinischen. Göttingen.

HARRAS, G. (2004): Handlungssprache und Sprechhandlung. Eine Einführung in die theoretischen Grundlagen. 2. Aufl. Berlin.

HARRIS, W. V. (2004): Restraining rage. The ideology of anger control in classical antiquity. Cambridge / MA.

HARRIS, W. V. (Hg.) (2018): Pain and pleasure in classical times. Leiden, Boston.

Harrison, S. J.; Frangoulidis, S.; PAPANGelis, T. (Hgg.) (2018): Intratextuality and Latin literature. Berlin, Boston.

HARTUNG, W. (1983): Briefstrategien und Briefstrukturen oder: Warum schreibt man Briefe? In: Sprache und Pragmatik. Lunder Symposium 1982. Hg. v. I. Rosengren. Stockholm. 215228.

HARTUNG, W. (2000 - 2001): Kommunikationsorientierte und handlungstheoretisch ausgerichtete Ansätze. In: Text- und Gesprächslinguistik. Ein internationales Handbuch zeitgenössischer Forschung. 2 Bde. Hg. v. K. Brinker. Berlin, New York. 83-96.

HAUSENDORF, H.; KESSELHEIM, W. (2008): Textlinguistik fürs Examen. Göttingen.

HeBERLEIN, F. (2001): Lateinische Grammatik und Lateinische Linguistik. Zur Neuausgabe von 'Menges Repetitorium'. In: Gymnasium. Zeitschrift für Kultur der Antike und humanistische Bildung 108 (2), 149-155.

Heinemann, M. (2000 - 2001a): Textsorten des Alltags. In: Text- und Gesprächslinguistik. Ein internationales Handbuch zeitgenössischer Forschung. 2 Bde. Hg. v. K. Brinker. Berlin, New York. 604-614.

HeInEMANN, W. (2000 - 2001b): Aspekte der Textsortendifferenzierung. In: Text- und Gesprächslinguistik. Ein internationales Handbuch zeitgenössischer Forschung. 2 Bde. Hg. v. K. Brinker. Berlin, New York. 523-546. 
Heinemann, W. (2000 - 2001c): Textsorte - Textmuster - Texttyp. In: Text- und Gesprächslinguistik. Ein internationales Handbuch zeitgenössischer Forschung. 2 Bde. Hg. v. K. Brinker. Berlin, New York. 507-523.

Heinemann, W. (2008): Textpragmatische und kommunikative Ansätze. In: Textlinguistik. 15 Einführungen. Hg. v. N. Janich. Tübingen. 113-143.

Heinemann, W.; Heinemann, M. (2002): Grundlagen der Textlinguistik. Interaktion - Text - Diskurs. Berlin.

Heinemann, W.; ViehWeger, D. (1991): Textlinguistik. Eine Einführung. Tübingen.

HELFRICH, H. (2003): Kulturelle Aspekte der Sprachproduktion. In: Sprachproduktion. Hg. v. T. Herrmann und J. Grabowski. Göttingen u. a. 393-428.

Hellegouarc'H, J. (1972): Le vocabulaire latin des relations et des partis politiques sous la République. 2., überarb. u. korr. Aufl. Paris.

HENNE, H. (1975): Sprachpragmatik. Nachschrift einer Vorlesung. Tübingen.

HERINGER, H. J. (2015): Linguistische Texttheorie. Eine Einführung. Tübingen.

HeRRING, S. C.; VAN ReEnen, P.; SCHøSLER, L. (2001a): On textual parameters and older Languages. In: Textual parameters in older Languages. Hg. v. S. C. Herring, P. van Reenen und L. Schøsler. Amsterdam, Philadelphia. 1-31.

HeRring, S. C.; VAN ReEnen, P.; SChøSLeR, L. (Hgg.) (2001b): Textual parameters in older Languages. Amsterdam, Philadelphia.

Hindelang, G. (1978): Auffordern. Die Untertypen des Aufforderns und ihre sprachlichen Realisierungsformen. Göppingen.

HINDELANG, G. (1981): Zur Klassifikation der Fragehandlungen. In: Sprache. Verstehen und Handeln. Hg. v. G. Hindelang und W. Zillig. Tübingen. 215-225.

HINDELANG, G. (2010): Einführung in die Sprechakttheorie. Sprechakte, Äußerungsformen, Sprechaktsequenzen. 5., neu bearb. und erw. Aufl. Berlin u. a.

HINDELANG, G.; YANG, Y. S. (2014): Sprechakttheoretische Dialoganalyse. In: Pragmatiktheorien. Analysen im Vergleich. Hg. v. S. Staffeldt und J. Hagemann. Tübingen. 149-181.

HoFf, F. (1979): Le système linguistique de l'interrogation en latin classique. Dissertation. Université de Strasbourg II. Straßburg.

Hofmann, M. E. (1983): Conversation openings in the comedies of Plautus. In: Latin linguistics and linguistic theory. Hg. v. H. Pinkster. Amsterdam. 217-226.

HOFFMANN, R. (2010): Latin word order revisited. Information structure of topic and focus. In: Latin linguistics today. Akten des 15. Internationalen Kolloquiums zur Lateinischen Linguistik. Innsbruck, 4.- 9. April 2009. Hg. v. P. Anreiter und M. Kienpointner. Innsbruck. 267279.

HofFMANN, R. (2018): Lateinische Linguistik. Morphosyntax und Syntax in einzelsprachlicher und typologischer Perspektive. Hamburg.

HofMANN, J. B. (1978): Lateinische Umgangssprache. 4. Aufl. Heidelberg.

HÖHN, W. (1979): Zur Anwendung textlinguistischer Verfahren im Lateinunterricht der Sekundarstufe II. In: Handbuch für den Lateinunterricht. Hg. v. W. Höhn. Frankfurt a. M. 133150.

HoLODYNSKI, M. (2006): Emotionen - Entwicklung und Regulation. Unter Mitarb. v. W. Friedlmeier. Mit 16 Tabellen. Berlin, Heidelberg. 
HoltgRAVES, T. (1989): The form and function of remedial moves. Reported use, psychological reality and perceived effectiveness. In: Journal of Language and Social Psychology 8, 1-16.

Hoppmann, M. (2008): Pragmatische Aspekte der Kommunikation. Höflichkeit und Ritualisierung. In: Rhetorik und Stilistik. Ein internationales Handbuch historischer und systematischer Forschung. Hg. v. U. Fix, A. Gardt und J. Knape. Berlin, New York. 826-836.

HuANG, Y. (2014): Pragmatics. 2. Aufl. Oxford.

HÜLSER, K. (1992): Stoische Sprachphilosophie. In: Sprachphilosophie. Ein internationales Handbuch zeitgenössischer Forschung. Hg. v. M. Dascal, D. Gerhardus u. a. Berlin u. a. 1734.

Hummel, P. (2008): Mala dicta. Essai sur la malédiction et la calomnie dans l'antiquité classique. Paris.

HutCHINSON, G. O. (1993): Ciceros Briefe als Literatur. Ad Att. 1,16. In: Hermes. Zeitschrift für Klassische Philologie 121 (4), 441-451.

HUtCHINSON, G. O. (1998): Cicero's correspondence. A literary study. Oxford.

ISENBERG, H. (1978): Probleme der Texttypologie. Variation und Determination von Texttypen. In: Wissenschaftliche Zeitschrift der pädagogischen Hochschule Leipzig 27, 565-579.

IURESCIA, F. (2019): 'Credo iam ut solet iurgabit'. Pragmatica della lite a Roma. Göttingen.

JACOBS, A.; JUCKER, A. H. (1995): The historical perspective in pragmatics. In: Historical pragmatics. Pragmatic developments in the history of English. Hg. v. A. H. Jucker. Amsterdam, Philadelphia. 3-33.

JÄGER, W. (1986): Briefanalysen. Zum Zusammenhang von Realitätserfahrung und Sprache in Briefen Ciceros. Frankfurt a. M. u. a.

JAHR, S. (2000): Emotionen und Emotionsstrukturen in Sachtexten. Ein interdisziplinärer Ansatz zur qualitativen und quantitativen Beschreibung der Emotionalität von Texten. Berlin.

JAKOBSON, R. (1979): Linguistik und Poetik. In: Roman Jakobson. Poetik. Ausgewählte Aufsätze 1921 - 1971. Hg. v. E. Holenstein und T. Schelbert. Frankfurt a. M. 83-121.

Jeppesen-Wigelsworth, A. (2013): 'Amici' and 'coniuges' in Cicero's letters. Atticus and Terentia. In: Latomus. Revue d'Études Latines 72 (2), 350-364.

JONES, F. (1992): Subject, topic, given and salient. Sentence-beginnings in Latin. In: Proceedings of the Cambridge Philological Society 37, 81-105.

JoNG, J. R. de (1998): Deictic and (pseudo)anaphoric functions of the pronoun 'iste'. In: Latin in use. Amsterdam studies in the pragmatics of Latin. Hg. v. R. Risselada. Amsterdam. 1935.

JONGE, C. C. de (2007): From Demetrius to Dik. Ancient and modern views on Greek and Latin word order. In: The language of literature. Linguistic approaches to classical texts. Hg. v. R. J. Allan und M. Buijs. Leiden, Boston. 211-231.

JUCKER, A. H. (2012): Pragmatics in the history of linguistic thought. In: The Cambridge handbook of pragmatics. Hg. v. K. Allan und K. M. Jaszczolt. Cambridge. 495-512.

JUCKER, A. H. (2017): Pragmatics and language change. Historical pragmatics. In: The Oxford handbook of pragmatics. Hg. v. Y. Huang. Oxford. 550-566.

JUCKER, A. H. (2018): Historische Pragmatik. In: Handbuch Pragmatik. Hg. v. F. Liedtke und A. Tuchen. Stuttgart. 132-139. 
JUCKER, A. H.; LANDERT, D. (2017): Variation and change. Historical pragmatics. In: The Routledge handbook of pragmatics. Hg. v. A. Barron, Y. Gu und G. Steen. Abingdon, New York. 79-90.

JUCKER, A. H.; TAAVITSAINEN, I. (2008): Speech acts now and then. Towards a pragmatic history of English. In: Speech acts in the history of English. Hg. v. A. H. Jucker. Amsterdam. 1-23.

JUCKER, A. H.; TAAVITSAINEN, I. (2010): Trends and developments in historical pragmatics. In: Historical pragmatics. Hg. v. A. H. Jucker, I. Taavitsainen und W. Bublitz. Berlin. 3-30.

KÁDÁR, D. Z. (2016): Postscript. In: Journal of Politeness Research 12 (2), 291-294.

KALLENDORF, C. (1994): Brevitas. In: Historisches Wörterbuch der Rhetorik. Bie - Eul. Hg. v. G. Ueding. Tübingen. 53-60.

KALVERKÄMPER, H. (2000 - 2001): Vorläufer der Textlinguistik. Die Rhetorik. In: Text- und Gesprächslinguistik. Ein internationales Handbuch zeitgenössischer Forschung. 2 Bde. Hg. v. K. Brinker. Berlin, New York. 1-17.

KASPER, G. (2007): Politeness. In: Handbook of Pragmatics Online. | URL: https://benjamins.com/online/hop/articles/pol1 (zuletzt geprüft am 12.11.2020).

KASTER, R. A. (2005): Emotion, restraint, and community in ancient Rome. Oxford, New York. KAZANTZIDIS, G.; SPATHARAS, D. (Hgg.) (2018a): Hope in ancient literature, history, and art. Ancient Emotions I. Berlin, Boston.

KAZANTZIDIS, G.; SPATHARAS, D. (2018b): Introductory. 'Hope', elpis, spes: Affective and non-affective expectancy. In: Hope in ancient literature, history, and art. Ancient Emotions I. Hg. v. G. Kazantzidis und D. Spatharas. Berlin, Boston. 1-32.

KeIP, M.; DoepNer, T. (2014): Interaktive Fachdidaktik Latein. 3., durchges. Aufl. Göttingen. KeRBRAT-ORECCHIONI, C. (1990): Les interactions verbales. Bd. 1. Paris.

KeRBRAT-ORECCHIONI, C. (1992): Les interactions verbales. Bd. 2. Paris.

KeRBRAT-ORECCHIONI, C. (1994): Les interactions verbales. Bd. 3. Paris.

KeRBRAT-ORECCHIONI, C. (1998): L'interaction épistolaire. In: La lettre entre réel et fiction. Hg. v. J. Siess. Paris. 15-36.

KIENPOINTNER, M. (1998): Speech act sequences in Latin prose. Questions and answers. In: Actes du Colloque 'Oratio soluta - Oratio numerosa'. Les mécanismes linguistiques de cohésion et de rupture dans la prose Latine. Actes des huitièmes 'Rencontres Scientifiques de Luxembourg'. Hg. v. C.-M. Ternes. Unter Mitarb. v. D. Longrée. Luxemburg. 65-86.

KIENPOINTNER, M. (2010): Latein-Deutsch kontrastiv. Vom Phonem zum Text. Tübingen.

KIESENDAHL, J. (2011): Status und Kommunikation. Ein Vergleich von Sprechhandlungen in universitären E-Mails und Sprechstundengesprächen. Berlin.

KISS, S. (2001): Principes d'organisation textuelles dans les 'Lettres' de Cicéron. In: De lingua Latina nouae quaestiones. Actes du X Colloque International de Linguistique Latine. ParisSèvres, 19 - 23 avril 1999. Hg. v. C. Moussy. Louvain, Paris. 385-391.

KISSINE, M. (2009): Illocutionary forces and what is said. In: Mind \& Language 24 (1), 122-138.

KISSINE, M. (2012): Sentences, utterances, and speech acts. In: The Cambridge handbook of pragmatics. Hg. v. K. Allan und K. M. Jaszczolt. Cambridge. 169-190.

KLAUCK, H.-J. (1998): Die antike Briefliteratur und das Neue Testament. Ein Lehr- und Arbeitsbuch. Paderborn. 
KLEINE, W. (2002): Zwischen Furcht und Hoffnung. Eine textlinguistische Untersuchung des Briefes 2 Kor 1 - 9 zur wechselseitigen Bedeutsamkeit der Beziehung von Apostel und Gemeinde. Berlin.

KOCH, P.; OesterreicheR, W. (2008): Mündlichkeit und Schriftlichkeit von Texten. In: Textlinguistik. 15 Einführungen. Hg. v. N. Janich. Tübingen. 199-215.

KOCH, W.; ROSENGREN, I.; SCHONEBOHM, M. (1981): Ein pragmatisch orientiertes Textanalyseprogramm. In: Sprache und Pragmatik. Lunder Symposium 1980. Hg. v. I. Rosengren. Lund. 155-203.

KocHOVSKA, S. (2013): Expressing congratulations in Latin. The case of Cicero's correspondence (= Sveikinimy raiška lotyny kalboje: Cicerono laiškai). In: Literatūra 55 (3), 27.

KOHL, M.; KRANZ, B. (1992): Untermuster globaler Typen illokutionärer Akte. Zur Untergliederung von Sprechaktklassen und ihrer Beschreibung. In: Sprechakttheorie. Hg. v. P.-P. König und $\mathrm{H}$. Wiegers. Münster. 1-44.

KONSTAN, D. (1997): Friendship in the classical world. Cambridge.

KONSTAN, D. (2011): Before forgiveness. The origins of a moral idea. Cambridge.

KOSCHMIEDER, E. (1945): Zur Bestimmung der Funktionen grammatischer Kategorien. In: Abhandlungen der Bayrischen Akademie der Wissenschaften. Phil.-hist. Abt. N. F. (25), 5-64.

KoskenNiemi, H. (1954): Cicero über die Briefarten (genera epistularum). In: Arctos. Acta Philologica Fennica (1), 97.

KoskenNIEMI, H. (1956): Studien zur Idee und Phraseologie des griechischen Briefes bis 400 n. Chr. Helsinki.

КотSCHI, T. (1996): Textkonstitutionsstruktur und Informationsstruktur. In: Ebenen der Textstruktur. Sprachliche und kommunikative Prinzipien. Hg. v. W. Motsch. Tübingen. 241271.

KRÄMER, S. (2008a): Medien, Boten, Spuren. Wenig mehr als ein Literaturbericht. In: Was ist ein Medium? Hg. v. S. Münker und A. Roesler. Frankfurt a. M. 65-90.

KRÄMER, S. (2008b): Medium, Bote, Übertragung. Kleine Metaphysik der Medialität. Frankfurt a. M.

KRAtochVILOVA, I. (2014): Zum Emotionspotential der Kommunikationsform Privatbrief. Am Beispiel der Korrespondenz Lichnowsky - Hofmannsthal. In: Emotionalität im Text. Hg. v. L. Vaňková. Tübingen. 473-480.

KRIEG-Holz, U.; BüLoW, L. (2015): Linguistische Stil- und Textanalyse. Eine Einführung. Tübingen.

KROON, C. (1989): Causal connectors in Latin. The discourse function of 'nam', 'enim', 'igitur' and 'ergo'. In: Cahiers de l'Institut de Linguistique de Louvain 15 (1 - 4), 231-243.

KROON, C. (1994): Discourse connectives and discourse type. The case of Latin 'at'. In: Linguistic studies on Latin. Selected papers from the 6th International Colloquium on Latin Linguistics. Budapest, 23 - 27 March 1991. Hg. v. J. Herman. Amsterdam, Philadelphia. 303319.

KRoON, C. (1995): Discourse particles in Latin. A study of 'nam', 'enim', 'autem', 'vero' and 'at'. Amsterdam. 
KROON, C. (2007): Latin linguistics between grammar and discourse. Units of analysis, levels of analysis. In: Pragmatische Kategorien. Form, Funktion und Diachronie. Akten der Arbeitstagung der Indogermanischen Gesellschaft vom 24. bis 26. September 2007 in Marburg. Hg. v. E. Rieken und P. Widmer. Wiesbaden. 143-158.

KROON, C. (2017): Textual deixis and the 'anchoring' use of the Latin pronoun 'hic'. In: Mnemosyne. A Journal of Classical Studies 70 (4), 585-612.

KRUSCHWITZ, P. (2012): How to avoid profanity in Latin. An exploratory study. In: Materiali e Discussioni per l'Analisi dei Testi Classici 68, 9-38.

KruschWitz, P.; Cleary-Venables, A. (2013): How to apologise in Latin. A case study. In: Form und Bedeutung im lateinischen Drama = Form and meaning in Latin drama. Hg. v. T. J. Moore und W. Polleichtner. Trier. 53-86.

KRYLOVÁ, B. (2006): Consensus suggested and demanded. The use and role of 'enim' and 'ergo' in conflict management. In: Graecolatina Pragensia 20, 95-107.

KRYLOVÁ, B. (2007): Zur Diachronie der lateinischen Diskurspartikeln. Methodologische Überlegungen. In: Pragmatische Kategorien. Form, Funktion und Diachronie. Akten der Arbeitstagung der Indogermanischen Gesellschaft vom 24. bis 26. September 2007 in Marburg. Hg. v. E. Rieken und P. Widmer. Wiesbaden. 159-172.

Kunlmann, P. A. (2014a): Römische Briefliteratur. Plinius und Cicero. Lehrerband zur Reihe classica. Göttingen.

Kunlmann, P. A. (2014b): Römische Briefliteratur. Plinius und Cicero. Göttingen.

KÜHNER, R. (1879): Ausführliche Grammatik der lateinischen Sprache. Zweiter Teil: Satzlehre. Zweiter Band. Hannover.

KÜHNER, R.; StEGMANN, C. (1966): Ausführliche Grammatik der lateinischen Sprache. Zweiter Teil: Satzlehre. Erster Band. Hannover.

Kunkel-RAzum, K.; EISENBerg, P. (Hgg.) (2009): Grammatik. Der Duden. 8., überarb. Aufl. Mannheim.

KUßE, H. (2012): Kulturwissenschaftliche Linguistik. Eine Einführung. Göttingen.

LACOURSE MUNTEANU, D. (Hg.) (2011a): Emotion, genre and gender in classical antiquity. London.

LACOURSE MUNTEANU, D. (2011b): Introduction. Emotion in literature: genre and gender. In: Emotion, genre and gender in classical antiquity. Hg. v. D. LaCourse Munteanu. London. 113.

LAIRD, A. (1999): Powers of expression, expressions of power. Speech presentation and Latin literature. Oxford u. a.

LAKOFF, R. T. (1968): Abstract syntax and Latin complementation. Cambridge.

LANDFESTER, M. (2008): Rhetorische und stilistische Praxis der römischen Antike. In: Rhetorik und Stilistik. Ein internationales Handbuch historischer und systematischer Forschung. Hg. v. U. Fix, A. Gardt und J. Knape. Berlin, New York. 307-326.

LANDFESTER, M.; KUHN, B. (2006): Einführung in die Stilistik der griechischen und lateinischen Literatursprachen. Sonderausg. Darmstadt.

LANGEHEINE, V. (1983a): Bemerkungen zur Briefforschung. In: Sprache und Pragmatik. Lunder Symposium 1982. Hg. v. I. Rosengren. Stockholm. 299-316.

LANGEHEINE, V. (1983b): Textpragmatische Analyse schriftlicher Kommunikation am Beispiel des Briefes. In: Schriftsprachlichkeit. Hg. v. S. Grosse. Düsseldorf. 190-211. 
LANHAM, C. D. (1975): Salutatio formulas in Latin letters to 1200. Syntax, style, and theory. München.

LATACZ, J. (1974): Klassische Philologie und moderne Linguistik. In: Gymnasium. Zeitschrift für Kultur der Antike und humanistische Bildung 81, 67-89.

LATEINER, D. (2013): Gendered and gendering insults and compliments in the Latin novels. In: Eugesta. Revue sur le Genre dans I'Antiquité 3, 303-351.

LAUSBERG, H. (2008): Handbuch der literarischen Rhetorik. Eine Grundlegung der Literaturwissenschaft. 4. Aufl. Stuttgart.

LEECH, G. N. (1983): Principles of pragmatics. London.

LEECH, G. N. (2014): The pragmatics of politeness. Oxford.

LEHMANN, Y. (2015): Historiographie et autobiographie dans la correspondance de Cicéron des années 58-56. In: Revue des Études Latines 91, 84-95.

LEIDL, C. (2012): Urbanitas. In: Historisches Wörterbuch der Rhetorik. Nachträge A - Z. Hg. v. G. Ueding. Berlin u. a. 1344-1364.

LeJeUne, P. (1975): Le pacte autobiographique. Paris.

LeTESSIER, P. (1999): La 'salutatio' chez Plaute. Adaptation Iudique d'un rituel social. In: Lalies. Actes des Sessions de Linguistique et de Littérature 20, 151-163.

LeVInSON, S. C. (2011): Pragmatics. 21. Aufl. Cambridge.

LEVINSON, S. C. (2017): Speech acts. In: The Oxford handbook of pragmatics. Hg. v. Y. Huang. Oxford. 199-216.

LI CAUSI, P. (2008): Strategie per un ritorno. II 'gioco' della persuasione e la rappresentazione dell'esilio nelle 'Epistulae ad Marcellum' di Cicerone. In: Clementia Caesaris. Modelli etici, parenesi e retorica dell'esilio. Hg. v. G. Picone. Palermo. 105-127.

LIEDTKE, F. (1998): Grammatik der Illokution. Über Sprechhandlungen und ihre Realisierungsformen im Deutschen. Tübingen.

LIEDTKE, F. (2018): Sprechakttheorie. In: Handbuch Pragmatik. Hg. v. F. Liedtke und A. Tuchen. Stuttgart. 29-40.

LILA, S. (1965): Terms of abuse in Roman comedy. Helsinki.

LÖFFLER, H. (2016): Germanistische Soziolinguistik. 5., neu bearb. Aufl. Berlin.

LÖFSTEDT, L. (1966): Les expressions du commandement et de la défense en latin et leur survie dans les langues romanes. Helsinki.

LÓPEZ LÓPEZ, M. (2012): El preludio de la risa o el llanto (I). Expresiones de halago y requiebro en los tragediógrafos y comediógrafos fragmentarios latinos. In: Estudios sobre teatro romano. El mundo de los sentimientos y su expresión. Hg. v. R. L. Gregoris. Saragossa. 243276.

LÖTSCHER, A. (1987): Text und Thema. Studien zur thematischen Konstituenz von Texten. Berlin.

LÖTSCHER, A. (2008): Textsemantische Ansätze. In: Textlinguistik. 15 Einführungen. Hg. v. N. Janich. Tübingen. 85-111.

LOWERY, Z.; FORSYTH, F. (2016): Cicero. New York.

LUDOLPH, M. (1997): Epistolographie und Selbstdarstellung. Tübingen.

LUPPOLD, S. (2015): Textrhetorik und rhetorische Textanalyse. Berlin. 
MAAS, U.; WUNDERLICH, D. (1974): Pragmatik und sprachliches Handeln. Mit einer Kritik am Funkkolleg 'Sprache'. 3., korr. und erg. Aufl. Frankfurt a. M.

MAKRI-TSILIPAKOU, M. (2001): Congratulations and bravo! In: Linguistic politeness across boundaries. The case of Greek and Turkish. Hg. v. A. Bayraktaroğlu und M. Sifianou. Amsterdam. 137-176.

Malherbe, A. J. (1988): Ancient epistolary theorists. Atlanta / GA.

MamoojeE, A.-H. (2001): Naming relatives and intimates in Cicero's correspondence. In: Cahiers des Études Anciennes 38, 5-15.

Manuwald, G. (2009): Briefe und Briefliteratur in der (griechisch-römischen) Antike. In: Der Altsprachliche Unterricht 52 (5), 2-13.

MARTEN-CLEEF, S. (1991): Gefühle ausdrücken. Die expressiven Sprechakte. Göppingen.

MARTíneZ-INSUA, A. E. (2010): 'I desire to have some tyme to consider of it'. A pragmaphilological approach to refusals and refutations in Modern-English trials. In: Discourses in interaction. Hg. v. S.-K. Tanskanen. Amsterdam. 173-194.

MCCUTCHEON, R. W. (2016): A revisionist history of Cicero's letters. In: Mouseion. Journal of the Classical Association of Canada 13, 35-63.

Meibauer, J. (2008): Pragmatik. Eine Einführung. Unveränd. Nachdr. d. 2., verb. Aufl. 2001. Tübingen.

MENCACCI, F. (2016): Praeter consuetudinem. (Im)politeness e stili comunicativi a Roma. In: Studi e Saggi Linguistici 54 (2), 91-115.

MenNa, P. (1955): Aspetti sintattici e lessicali di carattere intimo e familiare nelle lettere ciceroniane. Nola.

MeSA SANZ, J. F. (1998): El deseo y el subjuntivo. Análisis de los actos de habla y el valor 'optativo' en lengua latina. Alicante.

MILLER, A. B. (1914): Roman etiquette of the late Republic as revealed by the correspondence of Cicero. Lancaster, PA.

MolineLLI, P. (2010): From verbs to interactional discourse markers. The pragmaticalization of Latin 'rogo', 'quaeso'. In: Journal of Latin Linguistics 11 (1), 181-192.

MolinelLI, P. (2015): Plural pronouns and social deixis in Latin. A pragmatic development. In: Studi e Saggi Linguistici 53 (2), 65-88.

Molinelu, P. (2016): Cicli di pragmaticalizzazione tra latino e lingue romanze. La formazione di marcatori interazionali. In: Actes du XXVIle Congrès International de Linguistique et de Philologie Romanes. Section 2: Linguistique Latine / Linguistique Romane. Nancy, 15 - 20 juillet 2013. Hg. v. M. Fruyt, G. V. M. Haverling und R. Sornicola. Nancy. 151-162.

MolineLLI, P. (2018): Sociocultural and linguistic constraints in address choice from Latin to Italian. In: Positioning the self and others. Linguistic perspectives. Hg. v. K. Beeching, C. Ghezzi und P. Molinelli. Amsterdam, Philadelphia. 51-79.

MonserRat RoIG, C. (2004): Algunes consideracions sobre la pragmàtica i els textos llatins. In: Ciència, didàctica i funció social dels estudis clàssics. Actes del XIV Simposi de la Secció Catalana de la S.E.E.C. Vic, 26 - 28 de setembre del 2002. Hg. v. B. Usobiaga und P. J. Quetglas. Barcelona. 287-295.

MonserRat RoIG, C. (2013a): Los vocativos despectivos en Plauto. Análisis de los insultos en la reacción interaccional. In: Anuari de Filología. Antiqua et Mediaevalia 3, 79-96. 
MonserRat RoIG, C. (2013b): Los vocativos plautinos en la impostura de las identidades. In: Myrtia. Revista de Filología Clásica 28, 85-103.

MonserRat RoIG, C. (2015a): Insultarse en Roma y en Madrid. Los vocativos despectivos en Plauto y en Alonso de Santos. In: Miscellanea Latina. Hg. v. M. T. Muñoz García de Iturrospe und L. Carrasco Reija. Madrid. 703-710.

MonserRat RoIG, C. (2015b): Otras perspectivas para el análisis lingüístico de Plauto. Los vocativos insultantes en la reacción conversacional. In: Minerva. Revista de Filología Clásica. (28), 133-161.

Monsuez, R. (1953): Le style épistolaire de Cicéron et la langue de la conversation. In: Pallas. Revue d'Etudes Antiques 1, 97-120.

MontAgU, A. (1967): The anatomy of swearing. New York.

MoRello, R. (2013): Writer and addressee in Cicero's letters. In: The Cambridge companion to Cicero. Hg. v. C. E. W. Steel. Cambridge. 196-214.

MoRRIS, E. P. (1889): On the sentence-question in Plautus and Terence. First Paper. In: The American Journal of Philology 10 (4), 397.

MoRRIS, E. P. (1890a): On the sentence-question in Plautus and Terence. Concluding Paper. In: The American Journal of Philology 11 (2), 145.

MorRIS, E. P. (1890b): On the sentence-question in Plautus and Terence. Second Paper. In: The American Journal of Philology 11 (1), 16.

MorRIS, E. P. (1897a): The subjunctive in independent sentences in Plautus I. In: The American Journal of Philology 18 (2), 133.

MORRIS, E. P. (1897b): The subjunctive in independent sentences in Plautus II. In: The American Journal of Philology 18 (3), 275.

MorRIS, E. P. (1897c): The subjunctive in independent sentences in Plautus III. In: The American Journal of Philology 18 (4), 383.

MotSCH, W. (1987): Zur Illokutionsstruktur von Feststellungstexten. In: Zeitschrift für Phonetik, Sprachwissenschaft und Kommunikationsforschung 40, 45-67.

MотSCH, W. (1996): Ebenen der Textstruktur. Begründung eines Forschungsprogramms. In: Ebenen der Textstruktur. Sprachliche und kommunikative Prinzipien. Hg. v. W. Motsch. Tübingen. 3-33.

MotsCH, W.; PASCH, R. (1987): Illokutive Handlungen. In: Satz, Text, sprachliche Handlung. Hg. v. W. Motsch. Berlin. 11-79.

MotsCh, W.; ViehWEGER, D. (1981): Sprachhandlung, Satz und Text. In: Sprache und Pragmatik. Lunder Symposium 1980. Hg. v. I. Rosengren. Lund. 125-153.

Moussy, C. (2005): Champ lexical et polysémie. L'expression du pardon en latin. In: Journal of Latin Linguistics 9 (1), 359-370.

MüLLER, G. M. (2018): Einleitung. In: Zwischen Alltagskommunikation und literarischer Identitätsbildung. Studien zur lateinischen Epistolographie in Spätantike und Frühmittelalter. Hg. v. G. M. Müller. Stuttgart. 7-42.

MüLLER, R. (1997): Sprechen und Sprache. Dialoglinguistische Studien zu Terenz. Heidelberg.

MuÑoz MARTín, M. N. (1985): Teoría epistolar y concepción de la carta en Roma. Granada.

MuÑoz MARTín, M. N. (1991): El sector central del cuerpo epistolar en Cicerón. In: Florentia lliberritana. Revista de Estudios de Antigüedad Clásica 2, 339-355. 
MUÑOz MARTín, M. N. (1994): Estructura de la carta en Cicerón. Madrid.

MUSTAKALLIO, K. (2013): Grief and mourning in Roman context. In: Unveiling emotions II. Emotions in Greece and Rome. Texts, images, material culture. Hg. v. A. Chaniotis und P. Ducrey. Stuttgart. 237-250.

NARDUCCI, E. (Hg.) (2004): Cicerone e i suoi interpreti. Studi sull'opera e la fortuna. Pisa.

NARDUCCI, E. (2012): Cicero. Eine Einführung. Stuttgart.

NDIAYE, É. (2010): Les souffrances de l'exil dans la correspondance de Cicéron. In: Les écritures de la douleur dans l'épistolaire. De l'antiquité à nos jours. Hg. v. P. Laurence und F. Guillaumont. Tours. 189-208.

Nevala, M. (2010): Politeness. In: Historical pragmatics. Hg. v. A. H. Jucker, I. Taavitsainen und W. Bublitz. Berlin. 419-450.

NiCHOLSON, J. (1994): The delivery and confidentiality of Cicero's letters. In: The Classical Journal 90 (1), 33-63.

NICHOLSON, J. (1998): The survival of Cicero's letters. In: Studies in Latin literature and Roman history IX. Hg. v. C. Deroux. Brüssel. 63-105.

NICKEL, R. (2014): Interpretieren heißt Verknüpfen. In: Der Altsprachliche Unterricht 57 (5), 27.

NICKISCH, R. M. (1991): Brief. Stuttgart.

NIEHR, T. (2014): Einführung in die linguistische Diskursanalyse. Darmstadt.

NúÑEZ Romero-BALMAS, S. (1991a): Hacia una tipología de los actos de habla directiva en latín. In: Florentia Iliberritana. Revista de Estudios de Antigüedad Clásica 2, 357-375.

NúÑEz Romero-BALMAS, S. (1991b): Semántica de la modalidad en latín. Granada.

NúÑEZ ROMERO-BALMAS, S. (1995): Materiales para una sociología de la lengua latina. Terencio y los modificadores de imperativo. In: Florentia lliberritana. Revista de Estudios de Antigüedad Clásica (6), 347-366.

NüNNING, V.; NüNNING, A. (Hgg.) (2010): Methoden der literatur- und kulturwissenschaftlichen Textanalyse. Ansätze - Grundlagen - Modellanalysen. Unter Mitarb. v. I. Bauder-Begerow. Stuttgart.

OLIENSIS, E. (1998): Horace and the rhetoric of authority. Cambridge.

ONIGA, R.; SCHIFANO, N. (2014): Latin. A linguistic introduction. Oxford.

ORLANDINI, A. M. (1980): 'Unius figurae crudelis eventus'. Or on rhetorical questions. In: Papers on grammar. Bd. 1. Hg. v. G. Calboli und P. Cuzzolin. Bologna. 103-140.

ORLANDINI, A. M. (1995): II riferimento del nome. Un'analisi semantico-pragmatica del nome latino. Bologna.

ORLANDINI, A. M.; PocCETTI, P. (2007): Semantisch-pragmatische Beziehungen zwischen koordinierenden adversativen Strukturen im Lateinischen und in den Sprachen Altitaliens. In: Pragmatische Kategorien. Form, Funktion und Diachronie. Akten der Arbeitstagung der Indogermanischen Gesellschaft vom 24. bis 26. September 2007 in Marburg. Hg. v. E. Rieken und P. Widmer. Wiesbaden. 205-219.

OrlandinI, A. M.; PoccetTI, P. (2008): Pour une pragmatique du début et de la fin. Stratégies de I' organisation textuelle et argumentative. In: Commencer et finir. Début et fin dans les littératures grecque, latine et néolatine. 2 Bde. Hg. v. B. Bureau und C. Nicolas. Lyon. 237252. 
ORLANDINI, A. M.; PocCETTI, P. (2010): Stratégies discursives de non-interpellation et échecs de l'interpellation dans des dialogues latin. In: L'interpellation. Prédication, récurrences discursives et variation. Hg. v. F. Torterat. Poitiers.

ORTAK, N. (2004): Persuasion. Zur textlinguistischen Beschreibung eines dialogischen Strategiemusters. Tübingen.

ORTNER, H. (1992): Nachdenken über die Funktionen der Sprache. In: Zeitschrift für Germanistische Linguistik 20, 271-297.

ORTNER, H. (2014a): Automatisierte Sentimentanalyse und emotionslinguistische Textanalyse im Vergleich. In: Emotionalität im Text. Hg. v. L. Vaňková. Tübingen. 67-84.

ORTNER, H. (2014b): Text und Emotion. Theorie, Methode und Anwendungsbeispiele emotionslinguistischer Textanalyse. Tübingen.

OVERBECK, F. (1882): Über die Anfänge der patristischen Literatur. In: Historische Zeitschrift 48 (1), 417-472.

Palander-Collin, M. (2010): Correspondence. In: Historical pragmatics. Hg. v. A. H. Jucker, I. Taavitsainen und W. Bublitz. Berlin. 651-677.

PANHUIS, D. G. J. (1982): The communicative perspective in the sentence. A study of Latin word order. Amsterdam, Philadelphia.

PANHUIS, D. G. J. (2015): Lateinische Grammatik. Berlin.

PASCH, R. (1987): Illokutionsstrukturtypen und Typen der Verknüpfung von Inhalten illokutiver Handlungen. In: Satz, Text, sprachliche Handlung. Hg. v. W. Motsch. Berlin. 119-161.

PASETTI, L. (2015): L'arte di ingiuriare. Stilistica e retorica dell'insulto in Apuleio. In: Lexis. Poetica, Retorica e Comunicazione nella Tradizione Classica 33, 363-399.

PAVlenKo, A. (2005): Emotions and multilingualism. Cambridge.

PENNACINI, A. (1985): Situazione e struttura dell'epistola familiare nella teoria classica. In: Quaderni di Retorica e Poetica. Rivista Semestrale di Retorica e Poetica del Circolo Filologico Linguistico Padovano 1, 11-15.

PETER, H. W. G. (1965): Der Brief in der römischen Literatur. Hildesheim.

PINA Polo, F. (2010): Rom, das bin ich. Marcus Tullius Cicero, ein Leben. Stuttgart.

PINKSTER, H. (1988): Lateinische Syntax und Semantik. Rev. u. erw. Fassung d. niederländ. Orig.-Ausg. Tübingen.

PINKSTER, H. (1996): Linguistique latine et pragmatique. In: Les Études Classiques 64 (3), 245260.

PINKSTER, H. (2015): The Oxford Latin syntax. The simple clause. Oxford.

Pizzolato, L. F. (1993): L'idea di amicizia nel mondo antico classico e cristiano. Turin.

PLETT, H. F. (2001): Einführung in die rhetorische Textanalyse. 9., aktual. und erw. Aufl. Hamburg.

POCCETTI, P. (2010): Greeting and farewell expressions as evidence for colloquial language. Between literary and epigraphical texts. In: Colloquial and literary Latin. Hg. v. E. Dickey und A. Chahoud. Cambridge, New York. 100-126.

PolENZ, P. von (2008): Deutsche Satzsemantik. Grundbegriffe des Zwischen-den-Zeilen-Lesens. Mit einem Vorwort von W. Holly. 3., unv. Auflage. Berlin, Boston.

PöRINGS, R.; SCHMITZ, U. (Hgg.) (2003): Sprache und Sprachwissenschaft. Eine kognitiv orientierte Einführung. 2., überarb. und aktual. Aufl. Tübingen. 
PowelL, J. G. F. (2013): Cicero's style. In: The Cambridge companion to Cicero. Hg. v. C. E. W. Steel. Cambridge. 41-72.

PRASALSKI, D. (2010): Bühler als Vorläufer der Sprechakttheorie. In: Acta Universitatis Lodziensis. Folia Germanica. 6, 15-23.

PRESCH, G. (1981): Zur begründung einer historischen pragmalinguistik. In: Institutionen, Konflikte, Sprache. Arbeiten zur linguistischen Pragmatik. Hg. v. J. Klein und G. Presch. Tübingen. 206-238.

Prost, F. (2015): Amor et amicitia dans la correspondance d'exil de Cicéron. In: Vita Latina 191, 7-35.

Quetglas, P. J. (1997): Aplicaciones de la pragmática al estudio del latín. Los discursos de Cicerón. In: Anuari de Filología. Studia Graeca et Latina 20, 53-65.

Quetglas, P. J. (2005): La pragmática latina. In: Actas del XI Congreso Español de Estudios Clásicos. Hg. v. A. Alvar Ezquerra. Madrid. 569-588.

RABE, H. (1909): Aus Rhetoren-Handschriften. Griechische Briefsteller. In: Rheinische Museum für Philologie 64, 284-309.

RANDALL, D. (2018): The concept of conversation. From Cicero's 'sermo' to the Grand Siècle's conversation. Edinburgh.

RAWSON, E. (2001): Cicero. A portrait. Nachdr. Bristol.

REINHARDT, T. (2010): Syntactic colloquialism in Lucretius. In: Colloquial and literary Latin. Hg. v. E. Dickey und A. Chahoud. Cambridge, New York. 203-228.

REISIGL, M. (1999): Sekundäre Interjektionen. Eine diskursanalytische Annäherung. Frankfurt a. M.

REISIGL, M. (2018): Kritische Diskursanalyse. In: Handbuch Pragmatik. Hg. v. F. Liedtke und A. Tuchen. Stuttgart. 163-174.

RICHLIN, A. E. (2013): The fragments of Terentia. In: Roman literature, gender and reception. Domina illustris. Essays in honour of Judith Peller Hallett. Hg. v. D. Lateiner, B. K. Gold und J. Perkins. New York. 93-118.

RICOTTILLI, L. (1982): Tra filologia e semiotica. Ripristino e interpretazione di una formula allocutiva (quid tu? quid uos?). In: Materiali e Discussioni per l'Analisi dei Testi Classici 9, 107151.

RICOTTILLI, L. (2009): Appunti sulla pragmatica della comunicazione e della letteratura latina. In: Studi Italiani di Filologia Classica 1, 121-170.

RICOTTILLI, L. (2010): Teatro latino e pragmatica della comunicazione. In: Dionysus ex Machina 1, 360-379.

RIDEALGH, K. (2016): Introduction. In: Journal of Politeness Research 12 (2).

RINAS, K. (2015): Zum linguistischen Status des Absatzes. In: Text und Stil im Wandel. Neue Perspektiven der Textlinguistik und Stilistik. Hg. v. H. Bergerová, G. Schuppener und P. Szatmári. Ústí nad Labem, Wien. 139-157.

RISSELADA, R. (1989): Latin illocutionary parentheticals. In: Cahiers de I'Institut de Linguistique de Louvain 15 (1 - 4), 367-378.

RISSELADA, R. (1993): Imperatives and other directive expressions in Latin. A study in the pragmatics of a dead language. Amsterdam.

RISSELADA, R. (2004): Actes de langage et rapports sociaux. Les directifs dans Plaute. In: Registros lingüísticos en las lenguas clásicas. Hg. v. A. López Eire. Salamanca. 269-290. 
ROESCH, S. (2002a): Les stratégies de clôture du dialogue dans les comédies de Plaute. In: Theory and description in Latin linguistics. Selected papers from the XIth International Colloquium on Latin Linguistics. Amsterdam, June 24 - 29, 2001. Hg. v. M. A. Bolkestein. Amsterdam. 317-332.

ROESCH, S. (2002b): L'interaction auteur / destinataire dans la correspondance de Cicéron. In: Actes du lle Colloque International 'Le genre épistolaire antique et ses prolongements européens'. Université François-Rabelais, Tours, 28 - 30 septembre 2000. Hg. v. L. Nadjo und É. Gavoille. Louvain, Paris. 89-112.

ROESCH, S. (2004): La politesse dans la correspondance de Cicéron. In: Actes du Ille Colloque International 'L'épistolaire antique et ses prolongements européens'. Université François Rabelais, Tours, 25 - 27 septembre 2002. Hg. v. L. Nadjo. Louvain, Paris. 139-152.

ROESCH, S. (2005): L'échec des clôtures du dialogue dans les comédies de Plaute. In: Journal of Latin Linguistics 9 (2), 921-932.

ROESCH, S. (2008): Les débuts des dialogues dans la comédie et la tragédie latines. In: Commencer et finir. Début et fin dans les littératures grecque, latine et néolatine. 2 Bde. Hg. v. B. Bureau und C. Nicolas. Lyon. 207-222.

ROESCH, S. (2010): Interpellation et enjeux de pouvoir dans les comédies et tragédies latines. In: L'interpellation. Prédication, récurrences discursives et variation. Hg. v. F. Torterat. Poitiers.

ROLF, E. (1983): Sprachliche Informationshandlungen. Göppingen.

RoLF, E. (1993): Die Funktionen der Gebrauchstextsorten. Berlin u. a.

RoLf, E. (1997): Illokutionäre Kräfte. Grundbegriffe der Illokutionslogik. Opladen.

RoLF, E. (2000 - 2001): Textuelle Grundfunktionen. In: Text- und Gesprächslinguistik. Ein internationales Handbuch zeitgenössischer Forschung. 2 Bde. Hg. v. K. Brinker. Berlin, New York. 422-435.

Rolf, E. (2003): Klaus Brinkers 'Linguistische Textanalyse'. Vorschläge zur 6., durchgesehenen und verbesserten Auflage. In: Schriftliche und mündliche Kommunikation. Begriffe - Methoden - Analysen. Festschrift zum 65. Geburtstag von Klaus Brinker. Hg. v. J. Hagemann und S. F. Sager. Tübingen. 199-206.

Rolf, E. (2006): Die Rezeption und Weiterentwicklung der Sprechakttheorie in der Sprachwissenschaft. In: Handbücher zur Sprach- und Kommunikationswissenschaft = Handbooks of linguistics and communication science $=$ Manuels de linguistique et des sciences de communication. Hg. v. S. Auroux, H. E. Wiegand und G. Ungeheuer. Berlin. 2520-2539.

RoLf, E. (2013): Inferentielle Pragmatik. Zur Theorie der Sprecher-Bedeutung. Berlin.

ROLLINGER, C. (2014): Amicitia sanctissime colenda. Freundschaft und soziale Netzwerke in der Späten Republik. Heidelberg.

RolLINGER, C. (2015): Bilingualität, Codewechsel und Zitate im Briefverkehr Ciceros und der spätrepublikanischen Oberschicht. In: Gymnasium. Zeitschrift für Kultur der Antike und humanistische Bildung 122 (2), 133-154.

RosÉN, H. (2009): Coherence, sentence modification, and sentence-part-modification. The contribution of particles. In: New perspectives on historical Latin syntax. Hg. v. P. Baldi und P. Cuzzolin. Berlin, New York. 317-441.

ROSEngRen, I. (1979a): Die Sprachhandlung als Mittel zum Zweck. Typen und Funktionen. In: Sprache und Pragmatik. Lunder Symposium 1978. Hg. v. I. Rosengren. Lund. 188-213. 
Rosengren, I. (Hg.) (1979b): Sprache und Pragmatik. Lunder Symposium 1978. Lund.

RoSENGREN, I. (Hg.) (1981): Sprache und Pragmatik. Lunder Symposium 1980. Lund.

ROSENGREN, I. (Hg.) (1983): Sprache und Pragmatik. Lunder Symposium 1982. Stockholm.

ROSENGREN, I. (1987): Hierarchisierung und Sequenzierung von Illokutionen. Zwei interdependente Strukturierungsprinzipien bei der Textproduktion. In: Zeitschrift für Phonetik, Sprachwissenschaft und Kommunikationsforschung 40 (1), 28-44.

ROSENMEYer, P. A. (2001): Ancient epistolary fictions. The letter in Greek literature. Cambridge, New York.

RüHL, M. (2009): 'Sed quid ago? paene orationem in epistulam inclusi'. Das Selbstzitat in Ciceros Briefen. In: Fremde Rede - eigene Rede. Zitieren und verwandte Strategien in antiker Prosa. Hg. v. U. Tischer und A. Binternagel. Bern, Frankfurt a. M.

RüHL, M. (2019): Ciceros Korrespondenz als Medium literarischen und gesellschaftlichen Handelns. Leiden.

RüTTEN, T. (2011): How to do things with texts. Patterns of instruction in religious discourse 1350 - 1700. Frankfurt a. M. u. a.

SAGER, J. C. (1994): Language engineering and translation. Consequences of automation. Amsterdam.

SAlLABERGER, W. (1999): 'Wenn du mein Bruder bist...'. Interaktion und Textgestaltung in altbabylonischen Alltagsbriefen. Groningen.

SANDIG, B. (1978): Stilistik. Sprachpragmatische Grundlegung der Stilbeschreibung. Berlin, New York.

SANDIG, B. (2006): Textstilistik des Deutschen. 2., völlig neu bearb. und erw. Aufl. Berlin.

SARRI, A. (2017): Material aspects of letter writing in the Graeco-Roman world. C. 500 BC - c. $A D$ 300. Berlin, Boston.

SBISÀ, M. (1995): Speech act theory. In: Handbook of pragmatics. Manual. Hg. v. J. Verschueren, J.-O. Östman und J. Blommaert. Amsterdam, Philadelphia. 495-506.

SCHENKEVELD, D. M. (1984): Studies in the history of ancient linguistics, II. Stoic and peripatetic kinds of speech act and the distinction of grammatical moods. In: Mnemosyne. A Journal of Classical Studies 37, 291-353.

SCHERER, A. (1975): Handbuch der lateinischen Syntax. Heidelberg.

SCHIEWE, J. (2009): Satz - Text - Diskurs. Überlegungen zum Status und zu den Aufgaben der Textlinguistik. In: Kalbotyra. Germanų Ir Romanų Studijos 60 (3), 94-103.

SCHIRREN, T. (2009a): Kriterien der Textgestaltung (virtutes elocutionis: latinitas, perspicuitas, ornatus, aptum). In: Rhetorik und Stilistik. Ein internationales Handbuch historischer und systematischer Forschung. Hg. v. U. Fix, A. Gardt und J. Knape. Berlin, New York. 14171424.

SCHIRREN, T. (2009b): Niveau der Textgestaltung (Dreistillehre/genera dicendi). In: Rhetorik und Stilistik. Ein internationales Handbuch historischer und systematischer Forschung. Hg. v. U. Fix, A. Gardt und J. Knape. Berlin, New York. 1425-1444.

SCHIRREN, T. (2009c): Topik im Rahmen der klassischen Rhetorik. In: Rhetorik und Stilistik. Ein internationales Handbuch historischer und systematischer Forschung. Hg. v. U. Fix, A. Gardt und J. Knape. Berlin, New York. 1444-1459. 
SCHIRREN, T. (2010): 'Quam efficax est animi sermonisque grauitas'. Dicta als Marker symbolischer Interaktion. In: Acting with words. Communication, rhetorical performance and performative acts in Latin literature. Hg. v. T. Fuhrer und D. Nelis. Heidelberg. 79-100.

SCHLIEBEN-LANGE, B. (1976): Für eine historische Analyse von Sprechakten. In: Sprachtheorie und Pragmatik. Hg. v. H. Weber und H. Weydt. Tübingen. 113-119.

SChlieben-LANGE, B. (1979): Linguistische Pragmatik. 2., überarb. Aufl. Stuttgart.

SCHLIEBEN-LANGE, B. (1983): Traditionen des Sprechens. Elemente einer pragmatischen Sprachgeschichtsschreibung. Stuttgart.

SCHLIEBEN-LANGE, B.; WEYDT, H. u. a. (1979): Streitgespräch zur Historizität von Sprechakten. In: Linguistische Berichte 60, 65-78.

SCHLUND, K. (2014): On form and function of politeness formulae. In: Journal of Politeness Research 10 (2), 271-296.

SCHMIDT, O. E. (1898): Cicero und Terentia. In: Neue Jahrbücher für das klassische Altertum, Geschichte und deutsche Literatur 1, 174-185.

SCHMITT, H. (2000): Zur Illokutionsanalyse monologischer Texte. Ein Konzept mit Beispielen aus dem Deutschen und Englischen. Frankfurt a. M.

SCHNeIDER, J. G. (2018): Medialität. In: Handbuch Pragmatik. Hg. v. F. Liedtke und A. Tuchen. Stuttgart. 272-281.

SCHNEIDER, W. C. (1998): Vom Handeln der Römer. Kommunikation und Interaktion der politischen Führungsschicht vor Ausbruch des Bürgerkriegs im Briefwechsel mit Cicero. Hildesheim.

SCHRICKX, J. (2017): Polar questions in Latin with and without the enclitic particle '-ne'. In: Pragmatic approaches to Latin and Ancient Greek. Hg. v. C. Denizot und O. Spevak. Amsterdam, Philadelphia. 235-255.

SCHRIJVERS, P. H. (1993): 'Amicus liber et dulcis'. Horace moraliste. In: Horace. L'œuvre et les imitations. Un siècle d'interprétation. Hg. v. W. Ludwig. Vandoeuvres / Genf. 41-94.

SCHRÖDER, B.-J. (2004 - 2005): Ciceros Briefe als Briefe. In: Acta Classica Universitatis Scientiarum Debreceniensis 40 - 41, 193-214.

SCHRÖDER, B.-J. (2007): Bildung und Briefe im 6. Jahrhundert. Studien zum Mailänder Diakon Magnus Felix Ennodius. Berlin, New York.

SCHRÖDER, B.-J. (2009): Brief als multifunktionales Medium. Beispiele aus Ciceros Briefen. In: Der Altsprachliche Unterricht 52 (5), 14-26.

SCHRÖDER, B.-J. (2018): Couriers and conventions in Cicero's epistolary network. In: Letters and communities. Studies in the socio-political dimensions of ancient epistolography. Hg. v. P. Ceccarelli, L. Doering und T. Fogen. Oxford, New York. 81-100.

SCHRÖDER, T. (2003): Die Handlungsstruktur von Texten. Ein integrativer Beitrag zur Texttheorie. Tübingen.

SCHRÖTER, J. (2011): Offenheit. Die Geschichte eines Kommunikationsideals seit dem 18. Jahrhundert. Berlin, Boston.

SCHULleR, W. (2013): Cicero. München.

SCHULLER, W. (2018): Cicero. 100 Seiten. Ditzingen.

SCHulz Von Thun, F. (2010): Miteinander reden 1. Störungen und Klärungen: Allgemeine Psychologie der Kommunikation. 48. Aufl. Reinbek bei Hamburg. 
SCHURICHT, R. (1994): Cicero an Appius (Cic. fam. III). Umgangsformen in einer politischen Freundschaft. Trier.

SChWARZ-FrIESEL, M. (2013): Sprache und Emotion. 2., aktual. und erw. Aufl. Tübingen.

SChwarz-Friesel, M.; Consten, M. (2014): Einführung in die Textlinguistik. Darmstadt.

SCHWEIZER, H. (Hg.) (1995): Computerunterstützte Textinterpretation. Die Josefsgeschichte beschrieben und interpretiert im Dreischritt: Syntax - Semantik - Pragmatik. 3 Bde. Tübingen.

SCHWITALLA, J. (2018): Was ist ein Gespräch? In: Handbuch Text und Gespräch. Hg. v. K. Birkner und N. Janich. Berlin. 80-103.

SCHWITTER, R. (2018): Gebrauchstext oder Literatur? Methodenkritische Überlegungen zur literarischen Stellung des Privatbriefs in der Spätantike. In: Zwischen Alltagskommunikation und literarischer Identitätsbildung. Studien zur lateinischen Epistolographie in Spätantike und Frühmittelalter. Hg. v. G. M. Müller. Stuttgart. 85-106.

ScIOR, V. (2018): Hinkmar von Reims und sein Bote Egilo von Sens oder: Wer spricht? Substitution und Verkörperung durch Boten in der brieflichen Kommunikation. In: Zwischen Alltagskommunikation und literarischer Identitätsbildung. Studien zur lateinischen Epistolographie in Spätantike und Frühmittelalter. Hg. v. G. M. Müller. Stuttgart. 367-380.

SEARLE, J. R. (1969): Speech acts. An essay in the philosophy of language. Cambridge, New York.

SEARLE, J. R. (1971): What is a speech act? In: The philosophy of language. Hg. v. J. R. Searle. London. 39-53.

SEARLE, J. R. (1975): Indirect speech acts. In: Speech acts. Hg. v. P. Cole und J. L. Morgan. New York, London. 59-82.

SEARLE, J. R. (1976): A taxonomy of illocutionary acts. In: Language in Society 5 (1), 1-23.

SEARLE, J. R. (1979): Expression and meaning. Studies in the theory of speech acts. Cambridge.

SeARLE, J. R. (1980): Eine Klassifikation der Illokutionsakte. In: Sprechakttheorie. Ein Reader. Hg. v. P. Kußmaul. Wiesbaden. 82-108.

SeArle, J. R. (1999): Intentionality. An essay in the philosophy of mind. Nachdr. Cambridge.

SeARLE, J. R.; VANDERVEKEN, D. (1985): Foundations of illocutionary logic. Cambridge.

SEEL, O. (1967): Cicero. Wort, Staat, Welt. 3. Aufl. Stuttgart.

SERBAT, G. (Hg.) (1994-2003): Grammaire fondamentale du latin. Louvain.

Shackleton Bailey, D. R. (1971): Cicero. London.

SHARROCK, A. R.; MoRALES, H. (Hgg.) (2000): Intratextuality. Greek and Roman textual relations. Oxford u. a.

SÖKELAND, W. (1980): Indirektheit von Sprechhandlungen. Eine linguistische Untersuchung. Tübingen.

Solodow, J. B. (1978): The Latin particle 'quidem'. New York.

SOMERS, M. H. (1994): Theme and topic. The relation between discourse and constituent fronting in Latin. In: Linguistic studies on Latin. Selected papers from the 6th International Colloquium on Latin Linguistics. Budapest, 23 - 27 March 1991. Hg. v. J. Herman. Amsterdam, Philadelphia. 151-163.

SPEVAK, O. (2010): Constituent order in classical Latin prose. Amsterdam, Philadelphia. 
SPEYER, A. (2003): Kommunikationsstrukturen in Senecas Dramen. Eine pragmatisch-linguistische Analyse mit statistischer Auswertung als Grundlage neuer Ansätze zur Interpretation. Göttingen.

SPITZMÜLlER, J.; WARNKE, I. H. O. (2011): Diskurslinguistik. Eine Einführung in Theorien und Methoden der transtextuellen Sprachanalyse. Berlin, Boston.

SPLETT, J. (1990): Lateinische und alt- bzw. mittelhochdeutsche Lexikographie. In: Welt der Information. Wissen und Wissensvermittlung in Geschichte und Gegenwart. Hg. v. H.-A. Koch. Stuttgart. 39-48.

STAFFELDT, S. (2009): Einführung in die Sprechakttheorie. Ein Leitfaden für den akademischen Unterricht. 2. Aufl. Tübingen.

StAFFELDT, S. (2014): Sprechakttheoretisch analysieren. In: Pragmatiktheorien. Analysen im Vergleich. Hg. v. S. Staffeldt und J. Hagemann. Tübingen. 105-148.

STEEL, C. E. W. (2005): Reading Cicero. Genre and performance in late republican Rome. London.

STEIN, S. (2018): Oralität und Literalität. In: Handbuch Text und Gespräch. Hg. v. K. Birkner und N. Janich. Berlin. 3-25.

STEPHENS, L. D. (1985): Indirect questions in old Latin. Syntactic and pragmatic factors conditioning modal shift. In: Illinois Classical Studies 10 (2), 195-214.

STETTER, C. (1991): Text und Textur. Hat die Sprechakttheorie eine historische Dimension? In: Diachrone Semantik und Pragmatik. Untersuchungen zur Erklärung und Beschreibung des Sprachwandels. Hg. v. D. Busse. Tübingen. 67-81.

STOWERS, S. K. (1986): Letter writing in Greco-Roman antiquity. Philadelphia.

STOWERS, S. K. (1988): Social typification and the classification of ancient letters. In: The social world of formative Christianity and Judaism. Essays in tribute to Howard Clark Kee. Hg. v. J. Neusner. Philadelphia. 78-90.

STRAWSON, P. F. (1971): Intention and convention in speech acts. In: The philosophy of language. Hg. v. J. R. Searle. London. 23-38.

StUTTERHEIM, C. v.; KLEIN, W. (2008): Mündliche Textproduktion. Informationsorganisation in Texten. In: Textlinguistik. 15 Einführungen. Hg. v. N. Janich. Tübingen. 217-235.

STYKA, J. (2017): The stylistic category of clarity ( $\sigma \alpha \varphi \dot{v} v \varepsilon \iota \alpha$, explanatio, perspicuitas, claritas) in the eyes of Greek and Roman writers. In: Classica Cracoviensia 20, 119-139.

SUÁREZ MARTínEZ, P. M. (2012): Catégories grammaticales, systèmes grammaticaux et autres questions de linguistique latine. Mit einem Vorwort von J. L. Moralejo. Hildesheim.

SYKUTRIS, J. (1931): Epistolographie. In: Paulys Realencyclopädie der classischen Altertumswissenschaft. Supplemente 5. Hg. v. A. F. Pauly und G. Wissowa. Stuttgart. 185-220.

SZWED, I. (2014): Zum Ausdruck von Intentionen in deutschen und polnischen Geschäftsbriefen aus kontrastiver Sicht. Eine textlinguistische Untersuchung. Frankfurt a. M.

Terkourafi, M. (2012): Politeness and pragmatics. In: The Cambridge handbook of pragmatics. Hg. v. K. Allan und K. M. Jaszczolt. Cambridge. 617-637.

THRAEDE, K. (1970): Grundzüge griechisch-römischer Brieftopik. München.

THRAEDE, K. (1980): Zwischen Gebrauchstext und Poesie. Zur Spannweite der antiken Gattung 'Brief'. In: Acta Colloquii Didactici Classici octavi. Amstelodami, DD. 8 - 11 m. apr. A.D. 1980. Hg. v. J. Veremans und F. Decreus. Gent. 179-218. 
TÖCHTERLE, K. (1980): Textwissenschaftliche Aspekte der unterrichtlichen Behandlung von Plinius ep. X 96 und 97. In: Acta Colloquii Didactici Classici octavi. Amstelodami, DD. 8 - 11 m. apr. A.D. 1980. Hg. v. J. Veremans und F. Decreus. Gent. 108-116.

TÖCHTERLE, K. (1985): Ovids 'Weltalter'. Eine textlinguistische Interpretation. In: Der Altsprachliche Unterricht 28 (1), 4-15.

TORREgo SAlCEDo, E. (2013): 'lubeo saluere'. Una forma de saludo con directivo léxico. In: Otium cum dignitate. Estudios en homenaje al profesor J. J. Iso Echegoyen. Hg. v. J. A. Beltrán Cebollada, A. Encuentra Ortega u. a. Saragossa. 173-184.

TORREgo SAlCEDO, E. (2017): Res gestae divi Augusti. Word order and pragmatics of the Latin original. In: Pragmatic approaches to Latin and Ancient Greek. Hg. v. C. Denizot und O. Spevak. Amsterdam, Philadelphia. 159-179.

TOURATIER, C. (1994): Syntaxe latine. Louvain.

TOURATIER, C. (2013): Lateinische Grammatik. Linguistische Einführung in die lateinische Sprache. Darmstadt.

TRAPP, M. B. (2006): Biography in letters. Biography and letters. In: The limits of ancient biography. Hg. v. B. McGing und J. Mossman. Swansea. 335-350.

TRAUGOTT, E. C. (2004): Historical pragmatics. In: The handbook of pragmatics. Hg. v. L. R. Horn. Malden / MA u. a. 538-561.

TREgGiARI, S. (2007): Terentia, Tullia and Publilia. The woman of Cicero's family. London, New York.

TRISOGLIO, F. (1984): La quotidianità dei rapporti sociali in Cicerone epistolografo. In: Civiltà Classica e Cristiana 5, 95-143.

TRISOGLIO, F. (1985): La lettera ciceroniana come specchio di umanità. Turin.

TuCHEN, A. (2018): Methodologie der Pragmatik. In: Handbuch Pragmatik. Hg. v. F. Liedtke und A. Tuchen. Stuttgart. 13-25.

TYRRELL, R. Y. (1966): Cicero in his letters. Nachdr. London.

ULKAN, M. (1992): Zur Klassifikation von Sprechakten. Eine grundlagentheoretische Fallstudie. Tübingen.

UNCETA GÓMEZ, L. (2008): Incidencia de factores pragmáticos en la evolución semántica del verbo 'rogare'. In: Autour du lexique latin. Communications faites lors du XIIle Colloque International de Linguistique Latine. Bruxelles, 4 au 9 avril 2005. Hg. v. G. Viré. Brüssel. 244-255.

UNCETA GÓMEZ, L. (2009a): Elementos parentéticos en la organización discursiva de la oratoria de Cicerón. In: Pectora mulcet. Estudios de retórica y oratoria latinas. Hg. v. T. Arcos Pereira, J. Fernández López und F. Moya del Baño. Logroño. 247-258.

UNCETA GÓMEZ, L. (2009b): La petición verbal en latín. Estudio léxico, semántico y pragmático. Madrid.

UNCETA GÓMEZ, L. (2010): La expresión del agradecimiento en la comedia Latina. In: Latin linguistics today. Akten des 15. Internationalen Kolloquiums zur Lateinischen Linguistik. Innsbruck, 4.- 9. April 2009. Hg. v. P. Anreiter und M. Kienpointner. Innsbruck. 625-639.

UNCETA GÓMEZ, L. (2012): Cuando los sentimientos irrumpen. Valores expresivos de las interjecciones primarias en las comedias de Plauto. In: Estudios sobre teatro romano. EI mundo de los sentimientos y su expresión. Hg. v. R. L. Gregoris. Saragossa. 347-395. 
UNCETA GÓMEZ, L. (2014a): La politesse linguistique en latin. Bilan d'une étude en cours. | URL: https://www.academia.edu/8582067/_La_politesse_linguistique_en_latin_Bilan_d_une_ \%C3\%A9tude_en_cours_(zuletzt geprüft am 12.11.2020).

UNCETA GÓMEZ, L. (2014b): Pedir perdón en latín. El acto de habla de la disculpa en las obras de Plauto y Terencio. In: Emerita. Revista de Lingüística y Filología Clásica 82 (1), 69-97.

UNCETA GÓMEZ, L. (2016a): Congratulations in Latin comedy. Types and functions. In: Journal of Politeness Research 12 (2), 180.

UNCETA GÓMEZ, L. (2016b): Cuando los sentimientos irrumpen (2). Análisis de las interjecciones secundarias en las comedias de Plauto. In: Semántica latina y románica. Unidades de significado conceptual y procedimental. Hg. v. B. García-Hernández und M. Azucena Penas Ibáñez. Bern. 213-241.

UNCETA GÓMEZ, L. (2017a): Cuando las emociones irrumpen. Análisis comparativo del empleo de las interjecciones en las comedias de Terencio y las tragedias de Séneca. In:

Onomázein. Revista de Lingüística, Filología y Traducción 38, 107-146.

UNCETA GÓMEZ, L. (2017b): Estrategias de cortesía lingüística en Querolus. In: Latomus. Revue d'Études Latines 76, 140-161.

UNCETA GÓMEZ, L. (2018): Gli studi sulla (s)cortesia linguistica in latino. Possibilità di analisi e proposte per il futuro. In: Studi e Saggi Linguistici 56 (2), 9-37.

UNCETA GÓMEZ, L. (2019a): Conceptualizations of linguistic politeness in Latin. The emic perspective. In: Journal of Historical Pragmatics 20 (2), 286-312.

UNCETA GÓMEZ, L. (2019b): I complimenti e il loro contributo all'espressione della cortesia linguistica nelle commedie di Plauto. In: Dionysus ex Machina 10, 283-311.

URÍA, J. (2007): The semantics and pragmatics of Ciceronian invective. In: Cicero on the attack. Invective and subversion in the orations and beyond. Hg. v. J. Booth. Swansea. 4770.

Vairel-Carron, H. (1975): Exclamation, ordre et défense. Analyse de deux systèmes syntaxiques en latin. Paris.

VAIREL-CARRON, H. (1981): Les énoncés prohibitifs au subjonctif. In: Revue de Philologie, de Littérature et d'Histoire Anciennes 55, 249-272.

VAlETte-CAGNAC, E. (2017): 'Cura ut valeas'. Santé et épistolarité dans la correspondance de Cicéron. In: Dossier. Soigner par les lettres: La bibliothérapie des Anciens. Paris und Athen 21-56. | URL: http://books.openedition.org/editionsehess/4634 (zuletzt geprüft am 12.11.2020).

VALLBRACHT, S. (2019): Die normative Kraft des Decorum. Tübingen.

VAN DE MIEROOP, D. (2017): Identity and membership. In: The Routledge handbook of pragmatics. Hg. v. A. Barron, Y. Gut und G. Steen. Abingdon, New York. 184-196.

VAŇKovÁ, L. (2014): Einleitend. Emotionalität im Text. In: Emotionalität im Text. Hg. v. L. Vaňková. Tübingen. 11-18.

VATER, H. (2001): Einführung in die Textlinguistik. Struktur und Verstehen von Texten. 3., überarb. Aufl. München.

VERSCHUEREN, J. (1995): The pragmatic perspective. In: Handbook of pragmatics. Manual. Hg. v. J. Verschueren, J.-O. Östman und J. Blommaert. Amsterdam, Philadelphia. 1-19.

VieHWEGER, D. (1983): Dieter Viehweger zu Wolfdietrich Hartung. In: Sprache und Pragmatik. Lunder Symposium 1982. Hg. v. I. Rosengren. Stockholm. 229-231. 
WAGNER, A. (1995): Die Sprechaktklassifikation nach Searle in historischer Sprechaktanalyse. In: Aspekte der Sprachbeschreibung. Akten des 29. Linguistischen Kolloquiums. Aarhus 1994. Hg. v. P. Bærentzen. Tübingen. 269-272.

WAGNER, A. (1997): Sprechakte und Sprechaktanalyse im Alten Testament. Untersuchungen im biblischen Hebräisch an der Nahtstelle zwischen Handlungsebene und Grammatik. Berlin, New York.

WAGNER, K. R. (2001): Pragmatik der deutschen Sprache. Frankfurt a. M., New York.

WARNKE, I. H. O. (2008): Text und Diskurslinguistik. In: Textlinguistik. 15 Einführungen. Hg. v. N. Janich. Tübingen. 35-52.

WARNKE, I. H. O.; SPITZMÜlleR, J. (Hgg.) (2008): Methoden der Diskurslinguistik. Sprachwissenschaftliche Zugänge zur transtextuellen Ebene. Berlin u. a.

WATT, W. S. (1963): Heus. In: Glotta. Zeitschrift für griechische und lateinische Sprache 41, 138-143.

WatZlaWick, P.; Beavin, J. H.; Jackson, D. D. (2011): Menschliche Kommunikation. Formen, Störungen, Paradoxien. 12., unveränd. Aufl. Bern.

WEEKE, B. (2011): Die Textstrategie als Grundkategorie linguistischer Textanalyse. | URL: http://biecoll.ub.uni-bielefeld.de/index.php/nlk/article/view/343 (zuletzt geprüft am 12.11.2020).

WeIGAND, E. (2003): Sprache als Dialog. Sprechakttaxonomie und kommunikative Grammatik. Tübingen.

WEIL, H. (1844): De l'ordre des mots dans les langues anciennes comparées aux langues modernes. Question de grammaire générale. Paris.

WENDLAND, P. (1907): Die hellenistisch-römische Kultur in ihren Beziehungen zu Judentum und Christentum. Tübingen.

WENSKUS, O. (2001): Wie schreibt man einer Dame? Zum Problem der Sprachwahl in der römischen Epistolographie. In: Wiener Studien. Zeitschrift für Klassische Philologie, Patristik und lateinische Tradition 114, 215-232.

WERNER, C. (2016): Wie man mit Worten Dinge erschafft. Die sprachliche Konstruktion fiktiver Gegenstände. Göttingen.

WHITE, P. (2010): Cicero in letters. Epistolary relations of the late republic. New York.

WIERZBICKA, A. (2003): Cross-cultural pragmatics. The semantics of human interaction. 2. Aufl. (mit einem neuen Vorwort). Berlin, Boston.

WILCOX, A. (2005): Sympathetic rivals: Consolation in Cicero's letters. In: American Journal of Philology 126 (2), 237-255.

WILCOX, A. (2012): The gift of correspondence in classical Rome. Friendship in Cicero's Ad familiares and Seneca's Moral epistles. Madison.

Wilhelm-Hooljbergh, A. E. (1954): Peccatum. Sin and guilt in ancient Rome. Groningen.

WILLIAMS, C. A. (2012): Reading Roman friendship. Cambridge.

WISTRAND, M. (1979): Cicero imperator. Studies in Cicero's correspondence 51-47 B.C. Göteborg.

WitTGensteIN, L. (2001): Philosophische Untersuchungen. Kritisch-genetische Edition. Frankfurt a. M. 
WÜEST, J. (2002): Teiltextsorten und Sprechakthierarchie in Gerichtsurteilen. In: Texte - Diskurse - Interaktionsrollen. Analysen zur Kommunikation im öffentlichen Raum. Hg. v. K. Adamzik. Tübingen. 171-190.

WÜEST, J. (2011): Was Texte zusammenhält. Zu einer Pragmatik des Textverstehens. Tübingen.

WuLF, D. (2018): Fokus-Hintergrund-Gliederung. In: Handbuch Pragmatik. Hg. v. F. Liedtke und A. Tuchen. Stuttgart. 214-222.

WüLFING-VON MARTITZ, P. (1993): Textlinguistics applied to the Metamorphoses of Ovid. In: Sprachen und Schriften des antiken Mittelmeerraums. Festschrift für Jürgen Untermann zum 65. Geburtstag. Hg. v. F. Heidermanns, H. Rix und E. Seebold. Innsbruck. 473-481.

WULfRAM, H. (2008): Das römische Versepistelbuch. Eine Gattungsanalyse. Berlin.

WUNDERLICH, D. (1970): Die Rolle der Pragmatik in der Linguistik. In: Der Deutschunterricht. Beitrage zu seiner Praxis und wissenschaftlichen Grundlegung. 22 (4), 5-41.

WUNDERLICH, D. (1976): Studien zur Sprechakttheorie. Frankfurt a. M.

ZAEFFERER, D. (2001): Deconstructing a classical classification. A typological look at Searle's concept of illocution type. In: Revue Internationale de Philosophie 216 (2), 209-225.

ZeLzER, M. (1997): Die Briefliteratur. In: Neues Handbuch der Literaturwissenschaft. 4: Spätantike. Hg. v. L. J. Engels, H. Hofmann und K. von See. Wiesbaden. 321-354.

ZHAO, J. (2011): Kulturspezifik, Inter- und Transkulturalität von Textsorten. In: Textsorten, Handlungsmuster, Oberflächen. Linguistische Typologien der Kommunikation. Hg. v.

S. Habscheid. Berlin. 123-143.

ZILLIG, W. (1992): Bewerten. Sprechakttypen der bewertenden Rede. Tübingen.

ZimmermanN, B.; RenKaKOS, A. (Hgg.) (2014): Die Literatur der klassischen und hellenistischen Zeit. München. 